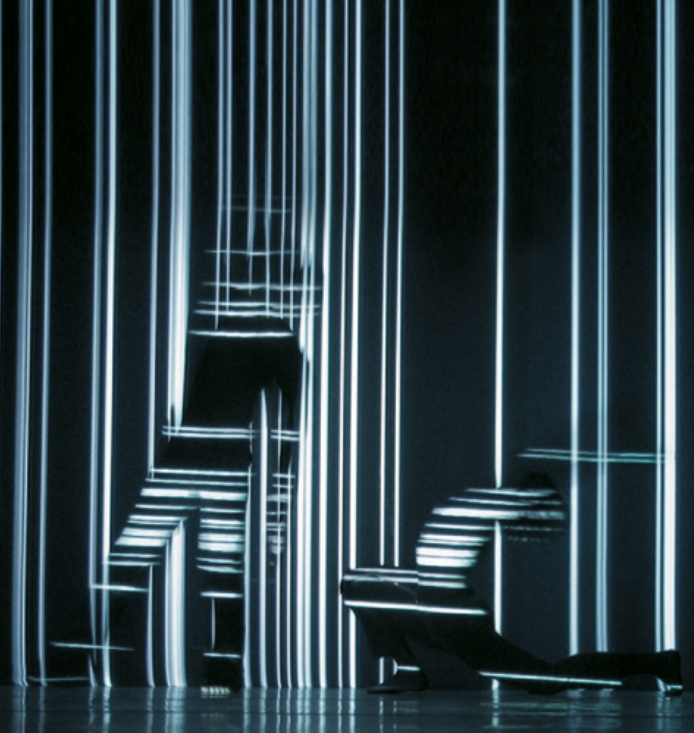

Henri Schoenmakers, Stefan Bläske, Kay Kirchmann, Jens Ruchatz (Hg.)

\title{
Theater und Medien Theatre and the Media
}

Grundlagen - Analysen - Perspektiven Eine Bestandsaufnahme

[transcript] Kultur-und Medientheorie 
Henri Schoenmakers, Stefan Bläske, Kay Kirchmann, Jens Ruchatz (Hg.) Theater und Medien/Theatre and the Media 

Henri Schoenmakers, Stefan Bläske, Kay Kirchmann, Jens Ruchatz (Hg.)

Theater und Medien/Theatre and the Media.

Grundlagen - Analysen - Perspektiven.

Eine Bestandsaufnahme

[transcript] 
Gedruckt mit Unterstützung der Gesellschaft für Theaterwissenschaft e.V., der Dr. German Schweiger-Spende an der Friedrich-Alexander-Universität Erlangen-Nürnberg sowie des Instituts für Theater- und Medienwissenschaft Erlangen-Nürnberg.

\author{
Bibliografische Information der Deutschen Nationalbibliothek \\ Die Deutsche Nationalbibliothek verzeichnet diese Publikation \\ in der Deutschen Nationalbibliografie; detaillierte \\ bibliografische Daten sind im Internet über \\ http://dnb.d-nb.de abrufbar.
}

(C) 2008 transcript Verlag, Bielefeld

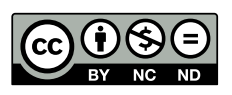

This work is licensed under a Creative Commons Attribution-NonCommercial-NoDerivatives 3.0 License.

Umschlaggestaltung: Kordula Röckenhaus, Bielefeld Umschlagabbildung: Foto aus APPARITION von Klaus Obermaier mit dem Ars Electronica Futurelab, feat. Desireé Kongerød und Matthew Smith,

Quelle: www.exile.at, (C) Klaus Obermaier

Lektorat: Henri Schoenmakers, Stefan Bläske, Kay Kirchmann, Jens Ruchatz Satz: Stefan Bläske, Heike Dörr Druck: Majuskel Medienproduktion GmbH, Wetzlar ISBN 978-3-8376-1064-2

Gedruckt auf alterungsbeständigem Papier mit chlorfrei gebleichtem Zellstoff.

Besuchen Sie uns im Internet: http://www.transcript-verlag.de

Bitte fordern Sie unser Gesamtverzeichnis und andere Broschüren an unter: info@transcript-verlag.de 


\section{INHALT}

$\begin{array}{ll}\text { Vorwort } & 11\end{array}$

Einleitung: Theater und (andere) Medien. Themen und Positionen

\section{Teil 1: Theatralität, Medialität, Intermedialität}

Definierbar ist nur, was keine Geschichte hat.

Über Fortschritte der Medien und Wandlungen von Theater

ANDREAS KOTTE

Vom Körper zum Bild. Ein Streifzug durch die Theatergeschichte als Mediengeschichte in sieben kurzen Kapiteln

ULRIKE HASS

Transmissionen - Vorüberlegungen zu

einer Mediengeschichte des Theaters

MEIKE WAGNER

Theatralität als mediales Dispositiv. Zur Emergenz von Modellen theatraler Performanz aus medienhistorischer Perspektive

SABINE FRIEDRICH/KIRSTEN KRAMER

Un/Sichtbarkeit: Blindheit und Schrift. Peter Turrinis »Alpenglühen« und William Forsythes »Human Writes«

GABRIELE BRANDSTETTER

Tanz der Figuren - zur Darstellung von Bewegung

in den Bildern des Hans von Marées

ISA WORTELKAMP

Zeit des Theaters/Zeit der Fotografie.

Intermediale Verschränkungen

JENS RUCHATZ

Intermedialität als Bedingung von Theater:

methodische Überlegungen

KATI RÖTTGER

Multi-, Trans- und Intermedialität: drei unterschiedliche

Perspektiven auf die Beziehungen zwischen den Medien 
The Use of Audio-visual Media in Italian Futurist Theatre

Das intermediale Jahrhundert: die Saison 1922/23

KLEMENS GRUBER

Medium, Theater und Film bei Beckett

FRANZISKA SICK

Bilder, die das Auge berührt - Zum Verhältnis von Film und Körperkunst bei Matthew Barney

JÖRG VON BRINCKEN

Lars von Trier und Volker Lösch erkunden ihr Medium in "Dogville« ANNETTE BÜHLER-DIETRICH

Seriendramaturgien als Performance?

Konvergente Entwicklungen im Theater und in der populären

Fernsehserie seit den 1960er Jahren

ANDREAS ENGLHART

Theatersoap und Talkshow-Oper: Über Theater im Fernsehformat und Fernsehen als theatrales Ereignis

BIANCA MiCHAELS

\section{Teil 2: Theater in (anderen) Medien}

An Early Film Adaptation of Sophocles' »Oedipus the King «:

Cinema, Theatre, Photography

PANTELIS MICHELAKIS

Reading Classical Drama on Film

EDWIN HEES

Stage Door - Über den kinematographischen Blick

auf den Bühneneingang

STEFANIE DIEKMANN

Der Bühnentod im Film

THOMAS KLEIN

Geschlossene Anstalt: Schauspielschüler im deutschen Film

HANS-FRIEDRICH BORMANN

Die Öffentlichkeit der Oper - Alexander Kluges Thematisierung der Oper in seinem Film »Die Macht der Gefühle« (1983)

Die Theatralität der Gesellschaft gespiegelt in der Theatralität des Filmischen. >Umbrüche ‘ im rumänischen zeitgenössischen Kurzfilm 
Von der >Hörbühne< zum Hybridmedium. Theater und Hörfunk

PETER SEIBERT

Poetische Sichtbarmachung:

Be- und Er-Schreibungen in Tanzkritiken des 19. Jahrhunderts

CHRISTINA THURNER

\section{Teil 3: Medialität \& Medien im Theater}

Schau-Spiel-Technik und Medien als Repräsentationstechnologien

ANJA KLÖCK

Schauspiel durch Medien. Die verdeckte Funktion

der Techne bei Konstantin Stanislawski und Alexander Moissi

WOLF-DIETER ERNST

Kaleidoscopic Encounters.

The Actor, Character and Spectator in Intermedial Performances

LIESBETH GROOT NIBBELINK

Media-bodies.

Choreographierte Körper als Wissensmedium bei William Forsythe

SABINE HUSCHKA

Zur Medialität des Performativen im zeitgenössischen Tanz/Theater

SABINE SÖRGEL

Die Promiskuität der Musik -

Über intermediale Verfremdungsstrategien in der

zeitgenössischen Inszenierung von Oper

ROBERT SOLLICH

Simultaneität - Immaterialität - Performativität.

Aspekte der Integration elektronischer und live-elektronischer

Medien im zeitgenössischen Musik-Theater

REGINE ELZENHEIMER

Die Unruhe hinter der Uhr zu lesen suchen.

Vom Umgang mit den Neuen Medien in der Opernarbeit

JOHANNA DOMBOIS

Durchquerungen.

Brechts Lehrstück als Medien- und Theaterexperiment

PATRICK PRIMAVESI

Armes Theater oder Medienspektakel?

LUTZ ELLRICH

Living in a Box - Zur Medialität räumlicher Anordnungen 
Montage der kulturellen Attraktionen.

Frank Castorfs medienästhetische Theaterpraxis der 80er Jahre

ERHARD ERTEL

Zur Intermedialität des Tieres. The Baa-Lamb's Holiday

401

JÖRG WIESEL

Mediating Phèdre

JOHAN CALLENS

Towards a Rich Theatre: Where Does the Wooster Group Take Technology? Where Does Technology Take Theatre Performance?

SERAP ERINCIN

Filmic Photogénie in the Theatre

SIGRID MERX

-Literaturtheater< mit der Videokamera?

Zu Stefan Puchers Inszenierung von Shakespeares »Othello« am Hamburger Schauspielhaus

HAJO KURZENBERGER

Medial real oder:

Die Ökonomie der Präsenz als Präsenz der Ökonomie

KATHARINA PEWNY

(Un-)Glauben. Das Spiel mit der Illusion

NIKOLAUS MÜLLER-SCHÖLL

Spielräume zwischen Medienkunst und Virtueller Realität

SUSANNE VILL

Theater in der Ambivalenz zum Technischen -

Anthropologische Dimensionen von Internet Performances

JULIA GLESNER

\section{Teil 4: Theatrale Praktiken in der Mediengesellschaft}

Kriegspropaganda multimedial.

Spektakel, Variété und Kino im Ersten Weltkrieg

EVA KRIVANEC

Medialität des Terrors.

Theater und Fernsehen im Umgang mit dem 11. September 2001

MATTHIAS WARSTAT

Medienpädagogik und Theaterpädagogik an der Schule.

Über das (Nicht-)Verhältnis zweier fremder Schwestern 
In echt oder getrickst? Drittklässler über die Unterschiede zwischen Theater, Film und Fernsehen

INA GOMBERT

The Intermedial Theatron: A Paradigm Shift

in Education and Performance in the Public Sphere?

FREDA CHAPPLE

www.theatertheorie.net

ANTON REY/THOMAS GRÜEBLER

Coming Soon to a Cinema/Television/Website/Video Game/ Theatre Near You...: Theatre, Intellectual Property Rights, and the Control of American Culture

KIMON KERAMIDAS

\section{Teil 5: Vom Nutzen und Nachteil des Medienbegriffs für} das Theater und die Theaterwissenschaft

Podiumsdiskussion

MIT CHRISTOPHER BALME, UlRiKe HASS, ChIEL KATTENBElt, ANDREAS KOTTE UND IRINA RAJEWSKY, EINGELEITET UND MODERIERT VON KAY KIRCHMANN

\section{Anhang}

Register 



\section{VORWORT}

Dieser Band versammelt eine Auswahl der Beiträge des VIII. internationalen Kongresses der Gesellschaft für Theaterwissenschaft e.V., der unter dem Titel »Theater $\&$ Medien / Theatre \& the Media« vom 12. bis 15. Oktober 2006 vom Institut für Theater- und Medienwissenschaft in Erlangen ausgerichtet wurde.

Für die Unterstützung der Konferenz danken wir der Deutschen Forschungsgemeinschaft, der Hochschulleitung der Friedrich-Alexander-Universität ErlangenNürnberg und der Luise Prell-Stiftung an der Universität Erlangen-Nürnberg, dem städtischen Kulturamt und dem Theater Erlangen.

Für die finanzielle Unterstützung zur Erstellung dieser Publikation möchten wir der Gesellschaft für Theaterwissenschaft e.V. sowie an der Friedrich-Alexander-Universität Erlangen-Nürnberg der Dr. German Schweiger-Spende, der Hochschulleitung und dem Institut für Theater- und Medienwissenschaft ganz herzlich danken.

Ein besonderer Dank gilt Ingrid Rauh für ihre immer kompetente und zuverlässige Hilfe bei allen Fragen der Verwaltung und Organisation sowohl für den Kongress als auch für diesen Band.

Schließlich sollen die vielen Kolleginnen und Kollegen nicht unerwähnt bleiben, die auf dem Kongress die Funktion eines Chairs übernommen und bei der Vorbereitung dieser Veröffentlichung eine wichtige Rolle gespielt haben, indem sie uns bei der zu treffenden Auswahl der Beiträge beratend unterstützt haben. Wir danken Christopher Balme, Johan Callens, Freda Chapple, Lutz Ellrich, Klemens Gruber, Ulrike Haß, Günther Heeg, Stefan Hulfeld, Chiel Kattenbelt, Friedemann Kreuder, Hajo Kurzenberger, Jean-Marc Larrue, Andy Lavender, Eckart Liebau, Platon Mavromoustakos, Petra Maria Meyer, Robin Nelson, Irina Rajewsky, Kati Röttger, Helmar Schramm, Peter Seibert, Gerald Siegmund, Susanne Vill und Birgit Wiens.

Die Herausgeber 



\section{Einleitung: Theater und (andere) Medien. THEMEN UND POSITIONEN}

HENRI SCHOENMAKERS/STEFAN BLÄSKE/

KAY KIRCHMANN/JENS RUCHATZ

\section{Theater und Medien}

Die Frage, ob das Theater oder gar konkrete Theateraufführungen als Medien bezeichnet werden sollten, wird in kulturwissenschaftlichen Diskursen unterschiedlich beantwortet.

Positionen, die Medien als vor allem technische Agenturen und Apparate begreifen, die beispielsweise Kommunikation zwischen Personen ermöglichen, welche nicht am gleichen Ort und/oder zur gleichen Zeit anwesend sind, würden die Frage mit >Nein $<$ beantworten - denn Theater und Performance setzten schließlich Jahrhunderte lang voraus, dass sich Performer/-innen und Zuschauer/-innen zur gleichen Zeit im gleichen Raum befinden. In dem umfangreichen Inventar von Medien als »Ausweitungen des Menschen«, das Marshall McLuhan in Understanding Media vorgelegt hat, findet das Theater keinen Platz. Die Unterscheidung von unmittelbarer theatraler und technisierter medialer Kommunikation ist aber nicht zuletzt von der Theaterwissenschaft forciert worden, um die Spezifik des Theaters zu pointieren.

Positionen, die nicht mit einem primär technisch verfassten Medienbegriff operieren, sondern Medien vorrangig über ihre Funktion oder Leistung bestimmen, könnten (wenn sie dies nicht schon getan haben) die Frage mit $>\mathrm{Ja}<$ beantworten, etwa wenn ein >Medium< allgemein als Mitte und Mittleres, als Vermittlung und Vermittler aufgefasst wird. Gleiches gilt, wenn man von Medien als Boten und Spuren (z.B. Krämer; Mersch), als Bedingung von Formbildung (Luhmann), als Wahrnehmungsanordnungen, als Dispositive (Baudry; Hickethier; Paech; u.a.) oder als Kulturtechniken (z.B. Krämer/Bredekamp; Siegert) spricht.

»Medien machen lesbar, hörbar, sichtbar, wahrnehmbar, all das aber mit der Tendenz, sich selbst und ihre konstitutive Beteiligung an diesen Sinnlichkeiten zu löschen und also gleichsam unwahrnehmbar, an-ästhetisch zu werden«, heißt es im Kursbuch Medienkultur. »Medien sind nicht auf Präsentationsformen wie Theater und Film, nicht auf Techniken [...], nicht auf Symboliken [...] reduzierbar und doch in all dem virulent « (Pias u.a.: 10). Solch fundamentale und umfassende Medienbegriffe, wie sie in wissenschaftlichen Diskursen immer häufiger anzutreffen sind, lassen eine größer werdende Diskrepanz zu einem Alltagsverständnis von $>$ Medium $<$ entstehen, das im deutschen und englischen Sprachraum vor allem mit (sowohl analogen als auch digitalen) technischen audiovisuellen Medien assoziiert wird.

Die Unklarheiten über die Begriffe >Medium < und >Medien $<$ und die damit einhergehende Vielfalt von Medientheorien lässt sich auch dadurch illustrieren, dass 
in Inventarisierungen mancher grundlegenden Veröffentlichung über Medientheorie oder -geschichte das Theater völlig fehlt (zum Beispiel Leonhard u.a.; Leschke; Devereux; Kümmel u.a.), während ihm in anderen Aufmerksamkeit gewidmet wird. Faulstich konzipiert das Theater beispielsweise als »Primärmedium« oder »Menschmedium«, Hörisch würdigt das Theater der antiken Polis als frühes Massenmedium, und Schanzes Handbuch der Mediengeschichte stellt die »Mediengeschichte des Theaters « gleichrangig neben die des Buchdrucks oder des Fernsehens.

Im deutschen Sprachraum sind sich, so hat u.a. das sogenannte >Hellerauer Gespräch< (Leeker) deutlich gemacht, auch führende Theaterwissenschaftler/-innen nicht einig in der Frage, ob Theater ein Medium ist oder als Medium verstanden werden sollte.

Die hier nur kurz skizzierte Problematik verdeutlicht, dass eine einfache, allgemeine oder gar gemeinsame Antwort nicht erwartet werden kann. Medienbegriffe werden eben in ganz unterschiedlichen gesellschaftlichen und wissenschaftstheoretischen Diskursen und damit unter grundlegend verschiedenen epistemologischen Paradigmen benutzt. Wenn man Problembeschreibung, -analyse und -lösung als wichtige Aufgaben von Wissenschaft betrachtet, ist eine einheitliche Antwort auch weniger wichtig als eine Reflexion darüber, was man gewinnen (oder verlieren) kann, wenn man Theater in bestimmten theoretisch-analytischen Diskursen als Medium betrachtet oder nicht.

Daraus resultiert dann beispielsweise die Frage, wie sich Phänomene, die als $>$ Theater oder >Performance $<$ bezeichnet werden, zu anderen Phänomenen verhalten, die traditionell mit einem der Medienbegriffe etikettiert sind oder derart verstanden werden könnten. Oder die Frage, was die Konsequenzen für das Selbstverständnis und für die Merkmale von theatralen Aktivitäten und deren Funktionen in der Gesellschaft sein können.

Neben der Polyphonie in den theoretischen Diskursen gibt es auch die praktische Frage der Situierung der Theaterwissenschaft im institutionellen, hochschulpolitischen Umfeld. Da an medienwissenschaftlichen Instituten kaum je spezielle Lehre im Theaterbereich angeboten wird, scheint es - selbst wenn man Theater als Medium begreifen mag - weiterhin sinnvoll, Institute, an denen Theater und (andere) Medien studiert werden, als Institut für Theater- und Medienwissenschaft zu titulieren, wie es etwa in Erlangen-Nürnberg oder - als Institut für Theater-, Film- und Medienwissenschaft - in Frankfurt a. M. und Wien der Fall ist. Angesichts der beschriebenen Breite medienwissenschaftlicher Begriffe und Forschungen könnte sonst an Instituten, die >Theater < nicht in ihrer Namensgebung erwähnen, das Risiko einer Marginalisierung der Theaterwissenschaft bestehen, die gerade im deutschen Sprachraum auf eine vergleichsweise lange Tradition zurückblicken kann.

Diese wissenschaftspolitischen Anmerkungen zur Theaterwissenschaft in einer $>$ Medienwelt< vorausgeschickt, konzentriert sich der Band jedoch auf eine Bestandsaufnahme der wissenschaftstheoretischen Auseinandersetzungen mit den vorwiegend (inter-)medialen und ästhetischen Beziehungen zwischen Theater und (anderen) Medien. 


\section{Themen dieses Bandes}

In vorwiegend deutsch-, z.T. englischsprachigen Aufsätzen beschäftigen sich internationale Wissenschaftler/-innen der Theater-, Tanz-, Literatur- und Medienwissenschaften sowie Theaterpraktiker/-innen und Pädagogen aus unterschiedlichen Perspektiven mit den Begriffen >Theater $>$ Theatralität $<$ und >Medialität $<$. In der Erforschung der mannigfachen Beziehungen zwischen Theater und (anderen) Medien findet insbesondere die Analysekategorie der >Intermedialität< Anwendung, sowie verwandte Konzepte wie >Trans- und Intramedialität< oder Nuancierungen wie >Medienwechsel<, >Medienkombination< oder >intermediale Bezüge< (vgl. Rajewsky). Das Theater wird dabei zunächst in Differenz zu einem bestimmten Medium gesetzt, um sodann die jeweiligen Bezüge auszuloten.

In diesem Band wird Theater zumeist im Sinne einer heuristischen Strategie von Medien unterschieden. Der Begriff >Medium< wird - wie aufgrund der kurzen Problemskizze zu erwarten - von den verschiedenen Autor/-innen, wie die jeweiligen Kontexte klarmachen, sowohl in der engen Bedeutung der technischen audiovisuellen Medien als auch im breiten Sinne, ganz allgemein etwa als technisches Mittel oder als >Mittleres< und >Dazwischen<, benutzt. Ziel der gesammelten Aufsätze ist die vergleichende Analyse von theatralen Darstellungsformen und den (u.a. audiovisuellen) Medien, sowie die Analyse der Verhältnisse zwischen Theater und (u.a. technischen) Mitteln/Medien allgemein. Eine Begrenzung der Thematik besteht darin, dass bei allen Vergleichen Theater (bzw. Performance oder Dramentext) den Bezugspunkt der Analysen bildet.

Der Band ist in fünf Teile gegliedert:

Teil 1: Theatralität, Medialität, Intermedialität

Teil 2: Theater in (anderen) Medien

Teil 3: Medialität \& Medien im Theater

Teil 4: Theatrale Praktiken in der Mediengesellschaft

Teil 5: Vom Nutzen und Nachteil des Medienbegriffs für das Theater und die Theaterwissenschaft.

Die Einteilung der ersten vier Themenkomplexe basiert auf der ausführlichen Beschreibung, die die Herausgeber dieses Bandes als Einladung und Bestimmung der Themenfelder für den VIII. internationalen Kongress der Gesellschaft für Theaterwissenschaft e.V. 2006 in Erlangen zum Thema »Theater \& Medien / Theatre \& the Media « verfasst hatten. ${ }^{1}$ Dieser Text, der den vortragenden Wissenschaftler/-innen als Inspirationsquelle, punching ball oder sparring partner gedient hat und dem auch Gedanken dieser Einführung entnommen sind, hatte zum Ziel, diejenigen Gebiete und Perspektiven zu kartographieren, in denen sich die Theaterwissenschaft mit Fragen und Problemen der Beziehungen zwischen Theater und (anderen) Medien konfrontiert sieht. Damit kann dieser Text auch als Folie dienen, um festzustellen, welche Gebiete von den Wissenschaftler/-innen auf dem Kongress und in diesem Band exploriert und welche noch wenig oder gar nicht entdeckt und erforscht worden sind.

1 Theater und Medien - Exposé zum Thema und zu den Sektionen (13 Seiten). Siehe: http://www.theater-medien.de/kongress/pdf/TK06_expose.pdf (01.08.2008). 
Natürlich lassen sich nicht alle Beiträge konsequent in das aufgestellte Raster einordnen, am wenigsten in die monodirektionale Trennung »Theater in (anderen) Medien« und »(andere) Medien im Theater «. Denn genauso, wie insbesondere im 20. Jahrhundert Künstler/-innen die Gattungs-, Kunst- und Mediengrenzen überschritten, erweitert und niedergerissen haben, so bewegen sich - diese künstlerische Praxis reflektierend - freilich auch die Autor/-innen dieses Bandes gerade zwischen und über die Grenzen hinweg in diesem weiten Feld der gegenseitigen Beeinflussung von Theater und Medien. Um den Leser/-innen eine Struktur und Übersicht über die breit gestreuten Themen der 53 Beiträge zu bieten, wurde im Aufbau des Bandes dennoch zu diesem Schubladensystem gegriffen. Auch sind, soweit es sinnvoll schien, die vier Themenkomplexe noch einmal in detailliertere Rubriken (z.B. Tanz/Musiktheater/Theater) unterteilt.

Im Folgenden werden alle Aufsätze in der Reihenfolge ihres Abdrucks kurz charakterisiert und der thematischen Struktur entsprechend eingebettet. Zusammen mit dem Register sollten diese Charakterisierungen den Leser/-innen eine Hilfe bieten, ihren Weg durch diesen Band zu finden und sich in den »Liaisons dangereuses « von Theater und Medien nicht zu verlieren.

\section{Teil 1: Theatralität, Medialität, Intermedialität}

Im ersten Teil dieses Bandes sind diejenigen Beiträge aufgenommen, die sich mit den Grundlagen, Definitionen, Konzepten und Aufgaben der wissenschaftlichen Beschäftigung mit Theater in seinen Beziehungen zu (anderen) Medien auseinandersetzen - also mit jenen grundsätzlichen Fragen, die eingangs skizziert worden sind.

Ebenfalls in diesem Teil aufgenommen sind Beiträge zur Intermedialität und medienvergleichende Fallstudien. Je nachdem, welchem Intermedialitätsbegriff man folgt, beinhalten freilich alle Aufsätze dieses Bandes intermediale Aspekte. In diesem 1. Teil sind insbesondere jene Analysen aufgenommen, bei denen nicht eine $(s)$ der beteiligten Künste oder Medien, sondern gerade die wechselseitigen Beeinflussungen im Zentrum stehen.

Da sich die Plenarvortragenden der »Theater \& Medien«-Konferenz (Gabriele Brandstetter, Klemens Gruber, Ulrike Haß und Andreas Kotte) sämtlich mit grundlegend theoretischen wie intermedial fallanalytischen Fragen beschäftigt haben, sind sie in diesem Teil aufgenommen.

Andreas Kotte plädiert in seinem Beitrag dafür, Beziehungen zwischen Theater und Medien zu erforschen, wehrt sich dabei allerdings gegen eine Vereinnahmung des Theaters durch einen zu weiten, »theoretisch eingesetzten« Medienbegriff, der sowohl die Geschichtlichkeit der Begriffe und Phänomene außer Acht lässt als auch die Differenzen zwischen Theater und Medien als unwesentlich einzustufen scheint. Ulrike Haß erlebt auf ihrem Streifzug durch die Theatergeschichte eine medientheoretische Perspektive, die an einer Interrelation von Medien interessiert und durch das Phänomen der Remediatisierung geprägt ist, als Vorteil für die Theaterwissenschaft. In historischen Exkursen zum (antiken) Zusammenhang von Schrift und Bild sowie dem Dispositiv der Renaissance legt Haß eine Entwicklung »vom Körper zum Bild « und eine daraus entstehende Dichotomie offen. Auch Meike Wagner sieht einen Mehrwert darin, wenn Theater- als Mediengeschichte 
und >Medium< dabei als >contested concept< gedacht wird. Als Methodologie für eine mediale Theatergeschichtsschreibung und Möglichkeit, dem Theaterbegriff kritisch neu zu begegnen, schlägt sie die Mediologie von Régis Debray vor. Aus mediengeschichtlicher Perspektive bestimmen Sabine Friedrich und Kirsten Kramer Theatralität als mediales Dispositiv, »das nur durch das Zusammenspiel verschiedener materieller und technisch vermittelter Praktiken und Interaktionsformen beschreibbar ist und aufgrund der Appropriation unterschiedlichster audiovisueller >Fremdmedien< zugleich immer schon ein komplexes intermediales Gefüge darstellt « - was sie am historischen Beispiel eines auto sacramental von Calderón de la Barca illustrieren.

Die >alten Medien< Schrift, Gedächtnis und Körper werden von Gabriele Brandstetter in den Blick genommen. Dabei stellt sie das Nicht-Sehen des »Alpenglühens « in Peter Turrinis gleichnamigem Drama neben die sichtbar werdende Schrift in William Forsythes Choreo-Graphie HUMAN WRITES (2005). Da die Struktur von Medien im Übertragen und Übersetzen, im Transformieren liege, sei Medium und Medialität »immer schon von der Bewegung her zu denken«. Die Beziehungen zwischen »Wahrnehmung der Bewegung « und »Bewegtheit der Wahrnehmung « reflektiert Isa Wortelkamp aus Anlass einer tänzerischen Umsetzung des HESPERIDENTRIPTYCHONS von Hans von Marées im Jahr 1999, wofür sie sowohl die Unterscheidung von Merleau-Ponty zwischen Bild- und Körper-Sehen, als auch die von Max Imdahl zwischen einem sehenden und einem wiedererkennenden Sehen heranzieht.

Der mit Lessing »fruchtbare Augenblick « dient Jens Ruchatz als Ausgangspunkt für grundlegende Überlegungen zum Verhältnis von Photographie und Theater. Anhand seiner Untersuchungen von Theaterphotographien und staged photography argumentiert er, dass >Intermedialität< nicht Medien voraussetzt, sondern erst Medien erzeugt. Ausgehend von grundlegenden Überlegungen (u.a. ob Körper und Theater Medien sind) entwickelt Kati Röttger die These, dass sich die Trennung von Theater und Medien nicht aufrecht erhalten lässt, wenn man die Dynamik der medialen Transformationen in den Blick nimmt, »die in und zwischen Medien stattfinden «. Theater definiert sie als per se intermediales Geschehen, indem sie mittels des Begriffs der Verkörperung und veranschaulicht an Sasha Waltz' DIDO \& AENEAS (2005) - die Konzepte Medialität und Performativität zusammenschließt. Ebenfalls aus einer theoretischen Perspektive definiert Chiel Kattenbelt die Begriffe Multi-, Trans- und Intermedialität als drei unterschiedliche Perspektiven, aus denen Medienphänomene analysiert werden können, und unterstreicht die Bedeutung der wechselseitigen Verhältnisse von Materialität, Medialität und ästhetischen Konventionen für die Dynamik trans- und intermedialer Prozesse.

Günter Berghaus zeichnet die Entwicklung der Nutzung (damals) neuer Medien und Technologien im Italienischen Futurismus von 1909 bis in die dreißiger Jahre anhand der Arbeiten von Filippo Tommaso Marinetti nach und hebt insbesondere das völlig neue Verständnis von der Medialität des Theaters hervor, das sich u.a. anhand des THEATRE OF THE SKIES (1932) illustrieren lässt. (Inter-)Mediale Inszenierungen in Russland und Frankreich der Saison 1922/23 nimmt Klemens Gruber ins Visier. In einem spannungsreichen Bogen von Meyerholds GRossMÜTIGER HAHNREI über die LAUTSPRECHERTRIBÜNEN von Gustav Klucis und Within THE QUOTA der Ballets Suédois bis hin zu Dziga Vertovs KINOPRAVDA NR. 16 beleuchtet er die »wechselseitige Erhellung der medialen Verfasstheit « und die Bedeutung der Avantgarden für das »intermediale Jahrhundert «. Arbeiten von Samuel Beckett aus den sechziger und siebziger Jahren jenes Jahrhunderts (u.a. 
Film, Spiel, Das letzte Band) dienen Franziska Sick dazu, Prozesse von Medienreflexivität und intermediale Strukturanalogien zu untersuchen, wobei sie zu dem Schluss kommt, dass Beckett Medien »nicht nur in ihrer medialen Dinglichkeit, sondern ebenso sehr in Spielstrukturen und Anordnungsbeziehungen « offen legt.

Dem Verhältnis von Film und körperbasierter Performancekunst spürt Jörg von Brincken in Matthew Barneys Arbeiten THE CREMASTER CyCLE (1996-2002), DRAWING RESTRAINT (2005) und HoIST (2006) nach. Dabei nutzt er u.a. Deleuzes Vorstellung einer >haptischen Dimension des Blicks<, um eine »korporelle Präsenzdimension« nicht des Films, sondern des Filmerlebens zu beschreiben.

Die Frage nach einer »körperlichen Wahrnehmung « von Film und Theater ist auch Teil des Aufsatzes von Annette Bühler-Dietrich, die Lars von Triers Film DogviLle (2003) und die gleichnamige Theaterinszenierung von Volker Lösch (2005) in medien- und wirkungsästhetischer Hinsicht einander gegenüberstellt und in von Triers Film das »Spiel mit den Zeichen«, in Löschs Inszenierung »die Evidenz des Körpers « am Werk sieht.

Weitere medienvergleichende Analysen, diesmal von Fernsehen und Theater, bieten Andreas Englhart und Bianca Michaels. Dabei analysiert Bianca Michaels das Phänomen der Formatübernahme aus dem Fernseh- in den Theaterbereich anhand von Theatersoaps (u.a. FRIEDRICHSTRASSE, 2005) und Talkshow-Opern (u.a. Denis Cleveland, 1996), basierend auf den Fernsehformaten der Talkshows und der Soap Series. Andreas Englhart erkennt in aktuellen TV-Serien (z.B. DESPERATE Housewives, SoPranos oder SiX FEet Under) Merkmale der (Neo-)Avantgarde wie eine >avantgardistische< Dramaturgie und Bildästhetik, die - zusammen mit Formen der Intertextualität und inhaltliche Grenzüberschreitungen - Gründe seien, derartige Serien nicht länger als »Unterschichtenfernsehen« zu betrachten.

\section{Teil 2: Theater in (anderen) Medien}

Dieser Themenkomplex umfasst etwa den Wechsel von Stoffen aus Drama und Theater in andere Medien, z.B. Dramen- und Literaturverfilmungen; die Thematisierung von Theater in (fiktionalen) Welten in anderen Medien und Kunstwerken, z.B. in den sogenannten >Theaterfilmen<; die Übernahme von (Darstellungs-)Konventionen aus dem Theater in anderen Medien, worunter hier z.B. >Theatralität im Film< verstanden wird; und schließlich die diskursive Thematisierung von Theater in anderen Medien, z.B. in der Berichterstattung über Theater.

Ein Medienwechsel, der ebenfalls in diesem Teil verhandelt werden und eine wichtige Rolle in der Theaterwissenschaft spielen müsste, ist die Dokumentation von Theateraufführungen in statischen wie bewegten Bildern. Mit der Theaterphotographie beschäftigt sich der Beitrag von Jens Ruchatz in Teil 1 dieses Bandes. Mit der bewegten Aufzeichnung von Theateraufführungen indes hat sich von den knapp hundert Vortragenden des Kongresses erstaunlicher Weise niemand auseinandergesetzt, dabei sind gerade Theateraufzeichnungen für Fernsehsender, Theater und Archive wesentliche Quellen theaterwissenschaftlicher Forschung und wichtiges Arbeitsmaterial für Inszenierungsanalysen - ihre Nutzung jedoch ist mit erheblichen theoretischen Problemen verbunden, zu denen weitere Reflexionen durchaus wünschenswert wären. 
Dramen-Verfilmung: Anders als zu erwarten beschäftigten sich wenige (Theater-) Wissenschaftler/-innen mit dem Phänomen der Dramen- und Literaturverfilmungen. Die einzigen (englischsprachigen) Aufsätze in diesem Bereich behandeln Verfilmungen antiker griechischer Tragödien. Pantelis Michelakis zieht u.a. eine frühe Filmfassung von KÖNIG OEDIPUS (1912) heran, um zu zeigen, dass sich bereits die frühen Formen der Medientransformation in ästhetischer Hinsicht unabhängig von Theaterkonventionen ausprägten. Edwin Hees wählte für seinen Beitrag die MEDEAAdaptionen von Pier Paolo Pasolini (1970) und Lars von Trier (1988) sowie die ElECTRA-Adaptionen von Michael Cacoyannis (1961) und Miklós Jancsó (1975) als Beispiele für einen immer weitergeführten Prozess von »cultural transmission«.

Theater und Theatralität im Film: >Theaterfilme< im Sinne einer motivischen Behandlung von Theater im (meist fiktionalen) Spielfilm werden gleich in mehreren Beiträgen behandelt: Beginnend mit dem Film STAGE Door (1937) und stets die >Stage Door<, den Übergang zum Bühnenraum im Blick, untersucht Stefanie Diekmann Vorstellungen von Theater in einer Reihe von Filmen (von ALL ABOUT Eve bis QuAND LA MER MONTE), die einen Blick auf jene Aspekte des Theaters ermöglichen, die >normale< Theaterbesucher nicht zu sehen bekommen: auf das, was hinter der Bühne passiert. Thomas Klein interessiert sich für die Grenzgänge zwischen Bühne und Leben im Film und blickt dabei dem »Bühnentod« ins Auge: Das Motiv, das sich in Filmen von Ernst Lubitsch, Peter Greenaway, Baz Luhrmann u.v.a. finden lässt, treibe das Verhältnis von »Ernst und Spiel« in Theaterfilmen auf die Spitze. Für seine genauere Betrachtung von MARQUISE (Vera Belmont, 1997) und M. ButTERFly (David Cronenberg, 1993) nutzt Klein die Theater- und Filmform sowie den Theater-Rahmen (nach Erwin Goffman) als Analysekategorien. Hans Friedrich Bormann lotet das Verhältnis von >Authentizität< und Selbst-Darstellung anhand zweier selbst- und medienreflexiver Filme über den Werdegang (angehender) Schauspielschüler/-innen aus. Dabei zeige sich, dass hinsichtlich der Frage nach der Selbstdarstellung eine Unterscheidung zwischen dem Spielfilm KLEINE HaIE (Sönke Wortmann, 1992) und dem Dokumentarfilm DIE SPIELwÜTIGEN (Andres Veiel, 2004) irrelevant werde, »weil der Film bereits als Medium eine genuine Beziehung zum Imaginären unterhält «.

»Des Kinematografen oft zitierte >dokumentarische Authentizität ««sei, so wird Alexander Kluge im Beitrag von Christoph Ernst zitiert, »nichts anderes als die hohe Stilisierung der Oper«. Anhand des Films DIE MACHT DER GEFÜHLE (1983) zeigt Ernst, wie Kluge die Spannung zwischen Form und Funktion der Oper im Gegensatz zu Adorno nicht als ästhetisches, sondern als mediales Problem verhandelt. Mithin ziele Kluges Praxis - wenn man seine Filmästhetik eines »dritten Bildes « mitdenkt - nicht auf die Integration der Medien Film und Oper, sondern vielmehr auf eine stete Mitrepräsentation der Mediendifferenz.

Alexandra Vlad beschreibt die Inszenierung theatraler Konventionen im zeitgenössischen rumänischen Kurzfilm, die als Stilmittel eingesetzt wird, um die Ästhetik rumänischer Filmproduktion der kommunistischen Ära zu persiflieren und gesellschaftskritisch eine »Kultur des Spektakels « zu spiegeln.

Der Vollständigkeit halber sei erwähnt, dass auch der Beitrag von Annette Bühler-Dietrich (siehe 1. Teil) in den Passagen über von Triers DogVILLE Theatralität im Film behandelt, der Beitrag von Andreas Englhart über Seriendramaturgien (ebenfalls 1. Teil) Theatralität im Fernsehen. 
Theater im Hörfunk: Peter Seibert erkundet das noch relativ unerforschte Terrain von »Theater und Hörfunk« und dokumentiert die Entwicklung von Hörfunkformaten, bei denen Theater als Referenzmedium konstitutiv ist, ab den 1920er Jahren. Dabei skizziert er, wie sich das Hörspiel von einem von Konventionen und Repertoire des Theaters dominierten Genre zu einem eigenständigen ästhetischen Medium entwickelt hat, wobei allerdings das >alte Format< vom »Theater im Rundfunk « nie völlig verschwunden ist.

Diskursive Thematisierung des Theaters: In der Radio- oder Fernsehberichterstattung über Theater (die vorwiegend in bestimmten Kultur-Kanälen und -Zeitfenstern oder bei »Theater-Skandalen« stattfindet) sowie in Theaterbesprechungen und Kritiken im Medium der Schrift wird (ein Bild von) Theater einerseits über die jeweilige Aufführung mit ihren begrenzten Zuschauerzahlen hinaus in die Gesellschaft transportiert, andererseits werden - so kann man erwarten - inhaltliche und ästhetische Normen verhandelt, gebildet oder geändert und damit Erwartungen, Präferenzen, Kulturproduktion und -partizipation beeinflusst. Auch dieses Problemgebiet der fremdmedialen Diskurse über Theater erfährt in theaterwissenschaftlichen Forschungen - und damit auch in diesem Band - nur wenig Aufmerksamkeit.

Hinsichtlich der Printmedien zeichnet Christina Thurner nach, wie in Tanzkritiken im 19. Jahrhundert ein Starkult um Ballerinas populär wird, wie einzelne Tänzerinnen als Idealwesen dargestellt und »zu Göttinnen hochgeschrieben« wurden. Diese Art des Schreibens, diese Wahrnehmung von Tanz/Tänzerinnen habe in der Folgezeit zwar nachgelassen, jedoch sei auch im 21. Jahrhundert, so Thurner, der Gestus der Mythisierung noch nicht ganz aus dem Genre der Tanzkritik verschwunden.

\section{Teil 3: Medialität \& Medien im Theater}

Prinzipiell wäre in diesem Themenbereich eine ähnliche Reihe von Medienwechseln denkbar wie im 2. Teil, nur eben in umgekehrter Richtung, schließlich gibt es zahlreiche Prozesse der Übersetzung, der Transposition eines Stoffes aus diversen Medien ins Theater, zum Beispiel Romane, Filme etc. als Vorlagen für TheaterInszenierungen.

Eine Besonderheit des Theaters wird allerdings darin gesehen, dass es andere Medien nicht nur repräsentieren, sondern auch in ihrer Materialität präsentieren könne. Und so reflektiert die Mehrheit der Beiträge des 3. Teiles vor allem die Nutzung von technischen audiovisuellen Medien im Theater sowie die dramaturgischen Merkmale, Probleme und Konsequenzen der Beziehungen zwischen Theater und (anderen) Medien im Sinne von Mediennutzung und -kombination. Weitere Inszenierungsanalysen gelten dem Phänomen der intermedialen und intertextuellen Bezüge.

Weniger Beachtung findet die motivische und diskursive Thematisierung von (anderen) Medien im Theater, sowie die Konventionsübernahme aus (anderen) Medien, die z.T. im ersten Teil dieses Bandes angesprochen wurde (etwa im Beitrag von Bianca Michaels in Bezug auf das Fernsehen).

Es ist kein Zufall, dass theaterwissenschaftliche Forschungen häufig zunächst mit rein beschreibenden Analysen und Dokumentationen versuchen, die transitorischen theatralen Events für die Zukunft zu bewahren und so ein externes Gedächtnis der 
Wahrnehmung theatraler Ereignisse zu bilden, die nur relativ wenige Zuschauer live gesehen haben können. Solche Analysen und Dokumentationen bilden einen wesentlichen Aspekt des 3. Teils dieses Bandes.

Die Aufsätze, die Medien(techniken) im Theater und/oder damit einhergehende Aspekte der Medialität des Theaters behandeln, sind soweit als möglich nach (traditionellen) theatralen Disziplinen - Musiktheater, Tanz, Theater/Performance geordnet. Dem vorangestellt sind drei Beiträge, die sich aus verschiedenen Perspektiven mit dem zentralen >Medium $<$ und Zeichenträger des Theaters beschäftigen, dem Schauspieler/Körper und seinen Darstellung(stechnik)en.

Schauspieler/Körper: Anja Klöck bietet einen historischen Blick in das Denken, das hinter den schauspieltheoretischen Schriften seit der frühen Neuzeit steckt und veranschaulicht, wie dieses Denken durch Diskurse und Abbildungen über das Innere der Menschen, die zum Beispiel in Anatomiebüchern zu finden sind, kontextualisiert werden sollte. Wolf-Dieter Ernst untersucht konkrete Schauspieltheorien und stellt die Funktion der >Techne < bei Konstantin Stanislawski und Alexander Moissi dar. Davon ausgehend unterscheidet er zwischen dramaturgischem und rhetorischem Einsatz von Medien in aktuellen Inszenierungen und behandelt dann am Beispiel von Stanislawski > visuelle Energie< als rhetorische Technik. Liesbeth Groot Nibbelink analysiert die Beziehungen zwischen den live-Schauspielern, den Videobildern der Schauspieler und den Zuschauern und befragt dabei die Nützlichkeit der Begriffe >character $<$ und >persona $<$ anhand der Aufführung der Theatergruppe Space THE Place Where We BelOng (2005).

Tanz: Bereits in Teil 1 dieses Bandes wurde im Beitrag von Gabriele Brandstetter u.a. William Forsythes HUMAN WRITES diskutiert. Sabine Huschka setzt sich ebenfalls mit dieser »Performance-Installation « auseinander und zeigt, wie sich Forsythes Interesse an Neuen Medien und Technologien primär auf »die technologisch durch die Medien eröffneten Modulationsformen körperlicher Bewegung « richtet, »die Sichtbarkeiten und aufmerkende Wahrnehmungen des Körpers-in-Bewegung erzeugen«. Neben jener »Art der Bewegungszeichnung « reflektiert Huschka die Modi der Bewegungsaufzeichnung in den Arbeiten von Forsythe und Peter Weltz.

Sabine Sörgel beschreibt u.a., wie die Zuschauer in Bewegung versetzt werden, wenn Wanda Golonka die Poesie und (Sehnsuchts-)Motivik von Sarah Kanes GIER und 4.48 PSYCHOSIS in kreativen Raumanordnungen auf die Bühne bringt.

Mit der Wahrnehmung von Bewegung hatte sich im 1. Teil bereits Isa Wortelkamp in Hinblick auf eine Bildbeschreibung von Max Imdahl beschäftigt, die »einer choreographischen Anweisung gleichkommt«. An Tanzbeschreibungen aus dem 19. Jahrhundert und deren leitmotivischer Ballerinen-Verehrung erinnerte Christina Thurner im 2. Teil. Und Susanne Vill, die am Ende des 3. Teils »Spielräume zwischen Medienkunst und Virtueller Realität « in zeitgenössischen Performances auslotet, greift dafür stellenweise ebenfalls auf Tanz- und Musiktheater-Produktionen zurück.

Musiktheater: Intermediale Verfremdungsstrategien in der zeitgenössischen Inszenierung der Oper sind das Thema von Robert Sollich, der sich bei seiner Analyse von EUGEN ONEGIN (Peter Konwitschny, 1995) mit den »klassischen« Medien des Theaters, mit Körper, Klang und Stimme auseinandersetzt. Regine Elzenheimer hingegen diskutiert die neueren technischen Medien und verfolgt deren Einsatz im modernen Musiktheater von Bernd Alois Zimmermanns Die SoldATEN (1965) 
über Luigi Nonos Prometeo (1984) bis hin zu Jörg Mainkas VoYeUR (2004). Johanna Dombois berichtet aus ihrer eigenen Theaterpraxis und reflektiert die Arbeit an der Oper FIDELIO, 21. JAHRHUNDERT (2001-04), die mit neuesten Medien wie Echtzeit-Computer-Graphik, immersiver Virtual Reality Technology und Passiv-Stereoprojektion inszeniert wurde.

Theater/Performance: Patrick Primavesi setzt sich mit der Theorie und Praxis von Brechts Lehrstücken der 1920er Jahre, vor allem seinem OzEANFLUG und dem BADENER LEHRSTÜCK VOM EINVERSTÄNDNIS, auseinander, um »die Herausforderung des Theaters durch diese frühen Medienexperimente « zu verstehen. Dafür schlägt er auch einen Bogen zum zeitgenössischen Theater und behandelt die Aufführungen von Chris Kondek (HIER IST DER APPARAT, 2006; BADENER LEHRSTÜCK, 2007), die - im Sinne Brechts - als Übung für die Beteiligten gestaltet wurden.

Lutz Ellrich beschreibt die »Krise der Repräsentation im Theater « anhand von zwei extremen Reaktionen und ihrem Spannungsfeld: dem Theater, das sich »von medialen Beimengungen reinigt « am Beispiel von Jerzy Grotowski, und dem Theater, das die Medien »exzessiv integriert « am Beispiel von Frank Castorf.

Castorfs in Kritiken als > Totaltheater< bezeichnete Inszenierung DER IDIOT (2003) analysiert Annemarie Matzke als räumliche Anordnung »zwischen Panoptikum und Peepshow «. Dabei erkennt sie in den Bühnenbildentwürfen von Bert Neumann eine Thematisierung des Verhältnisses von Wohn-Architektur und Medien und im zeitgenössischen Theater eine auffällige Tendenz, »Bungalows, Boxen oder Container auf die Bühne « zu stellen. Sowohl der Container als »Idee der Bühne als Black Box « als auch der Einsatz von Film- und Videoprojektionen könne die Wahrnehmung des Raumes im Theater ändern und auf diese Weise die Frage nach der »Medialität der räumlichen Anordnung selbst« aufwerfen.

Dass der erste Fernseher auf der Bühne in einer Castorf-Inszenierung (VOLKSFEIND, 1988) das Medium als Gefängnis, das »Eingesperrtsein in einen Kasten sinnlich erlebbar « machte, zeigt Erhard Ertel. Unter Berücksichtigung von Castorfs Biographie und Theaterverständnis gibt Ertel einen Überblick über dessen noch weitgehend videotechnikfreie und dennoch »medienästhetische« Theaterpraxis der 1980er Jahre. In einem Exkurs zur Rockmusik wird hinsichtlich Castorfs prägendem Musikeinsatz argumentiert, dass »die einmontierten Songs keine Zitate, keine eigenständig dramaturgisch gesetzten Bedeutungsebenen, [sondern] komplexe kulturelle Gesten [sind], mit denen szenisch agiert wird «.

Einmontierte Musik- und Toneinspielungen bilden einen wichtigen Untersuchungsgegenstand von Jörg Wiesel, der sich mit der Münchner Theaterinszenierung DAS FEST DES LAMMS (2003) und deren Bezügen zum Dramentext von Leonore Carrington (1940) sowie einer Musiktheateraufführung (FEST DES LAMMS, 1999) auf Basis von Elfriede Jelineks Libretto auseinandersetzt. Intertextuelle und intermediale Bezüge, insbesondere zum leitmotivisch zitierten Godard-Film LE MÉPRIS (1963), finden dabei häufig allein über die auditive Ebene statt.

Sowohl für ihre reichen intermedialen Bezüge als auch eine intensive Nutzung technischer Medien sind die Performances der New Yorker Wooster Group bekannt, denen sich zwei englischsprachige Aufsätze widmen: Johan Callens analysiert die Aufführung To YoU, THE BIRDIE (2001) und deren intermediale und intertextuelle Bezüge zu Racines PHÈDRE. Er fokussiert dabei sowohl die Nutzung technologischer Mittel als auch die Art und Weise, in der eine genderorientierte Interpretation gestaltet worden ist. Die Aufführungen POOR THEATRE (2003) and HAMLET (2005) der Wooster Group diskutiert Serap Erincin vor allem im Hinblick darauf, wie 
Intermedialität (im Sinne von Mediennutzung bzw. -kombination) und Intertextualität (im Sinne von intertextuellen Bezügen) während der Proben und der Aufführung gestaltet wird. Interviews mit Mitgliedern der Wooster Group verdeutlichen, wie (inter-)aktiv und verwoben die Beziehungen zwischen Technik, Techniker/-innen und Performer/-innen während der Proben und Aufführungen sind.

Sigrid Merx plädiert dafür, das filmische Konzept der >Photogénie< aus der französischen Filmtheorie der 1920er Jahre für die Analyse des Einsatzes von neuen Medien in Theateraufführungen fruchtbar zu machen, und illustriert dies anhand der Theaterarbeit (u.a. anhand des PROUST-ZYKLUS, 2003/05) des flämischen Theatermachers Guy Cassiers, der erzählerische Ausdruckmittel mit >live<-Kameras und Videoprojektionen erweitert. Unterschiedliche Formen möglicher Nutzungen von Kamera und Videoscreen behandelt Hajo Kurzenberger am Beispiel von Stefan Puchers OTHELLO-Inszenierung (2004). Dabei katalogisiert er verschiedene Funktionen und Perspektiven, die AV-Bilder im Theater einnehmen können. So dienen Bühneneinblendungen etwa einer »visualisierten Psyche« von Figuren, »einer visuell beschleunigten Dramaturgie« oder auch der Erzeugung des Eindrucks von »Authentizität « - die freilich, so Kurzenberger, »dank wackelnder Handkamera « nichts anderes sei als »ein Darstellungstrick «.

Die komplexen Beziehungen zwischen Theater, Medien, Realität und >medialisierter Realität< lotet Katharina Pewny anhand der Aufführungen SABENATION (Rimini Protokoll, 2004) und Perform Performing (Jochen Roller, 2005) aus. Garniert mit Gedanken zu grundlegenden Problemen der Performativität bzw. des >Performens< illustriert sie, wie Medienrepräsentationen weniger als »Beglaubigungssiegel « für Realitäten denn vielmehr > welterzeugend < fungieren. Nikolaus Müller-Schöll entwickelt mit Blick auf die Inszenierungen CARGO SOFIA ZOLLVEREIN (Rimini Protokoll, 2006) und MY NECK IS THINNER THAN A HAIR: ENGINES (Walid Raad, 2005) die These, dass das »angebliche >Wirklichkeitstheater< [...] auf dem Wege seiner Suche nach dem Realen die unauflösbare Ambivalenz des Glaubens an die Illusion wiederentdeckt « habe.

Susanne Vill setzt sich mit den neuesten technologischen Entwicklungen in den Medien, die die virtuellen Bühnenraumgestaltungsmöglichkeiten bereichert haben, auseinander und behandelt dazu interaktive Formen von Installationen, Environments, virtuellen Realitäten und Immersionsräumen, die Mediatisierung des Körpers, telematisches Theater und interaktives Theater in Cyberspace. Sie geht auch auf die Arbeit von Klaus Obermaier ein und kompensiert damit die Tatsache, dass sich der Plenarvortrag von Obermaier auf dem »Theater \& Medien«-Kongress aufgrund der vielen Video-Beispiele aus seiner innovativen Arbeit leider nicht im Schriftmedium dieser Publikation umsetzen ließ.

Internet Performance: Julia Glesner analysiert Internet Performances (u.a. HAMNET, 1993 und das CASSANDRA PROJECT, 1996) und deren Entwicklung in den letzten Jahren und stellt diese in einen Zusammenhang mit grundlegenden Fragen über die anthropologische Dimension (Plessner) von Theater, um zu ergründen, ob Internet Performances potentiell eine ähnliche Funktion erfüllen können wie das (traditionelle) Theater.

Für die Herausgeber stellte sich die Frage, ob das Phänomen der Internet Performances besser im 2. Teil, Theater in (anderen) Medien, oder doch im 3. Teil, (andere) Medien im Theater, aufgehoben sei. Zwar fehlen bei Internet Performances gemeinhin als wesentlich betrachtete Kennzeichen des Theaters wie liveness und die leibliche Ko-Präsenz von Produzenten und Rezipienten. Die Frage ist, ob 
es sich dabei eventuell um Merkmale handeln könnte, die - wie viele andere einst als notwendig betrachtete (z.B. die Notwendigkeit einer Konfliktstruktur, einer kausalen und chronologischen Narration im Drama/Theater oder von Als-ob-Handlungen) - auf dem Scheiterhaufen der als letztlich nur akzidentiell erkannten Merkmale landen werden. Ob das der Fall sein wird, ist sowohl von gesellschaftlichen Aushandlungen als auch von diskursiven Verläufen abhängig. Vorläufig gehen wir davon aus, dass - je nach Perspektive - Internet Performances eine Erweiterung des Begriffs > Theater< oder >Performance< bringen könnten und haben diesen Beitrag darum am Ende des 3. Teils platziert. Es wird spannend zu beobachten sein, welche Demarkationslinien und -verschiebungen sich bei fortschreitender technischer Entwicklung zwischen Theater und (anderen) Medien herausbilden.

\section{Teil 4: Theatrale Praktiken in der Mediengesellschaft}

Der vierte Themenkomplex bezieht sich auf die Funktionen der theatralen Praktiken und Medien in einer Gesellschaft, die zunehmend als eine mediatisierte beschrieben wird. Dabei handelt es sich sowohl um die Beziehungen zu anderen Systemen wie Politik, Ökonomie, Bildung, Religion usw., als auch um einen Vergleich der theatralen Praktiken und Medien in gesellschaftlicher Hinsicht: Welche Funktionen werden von welchen Medien und für welche Nutzer-/Teilnehmer-/ZuschauerGruppen übernommen? Damit wäre etwa auch eine vergleichende Analyse impliziert, die die Wirkungen und Funktionen, die Produzenten auszulösen und zu erfüllen beabsichtigen, mit den tatsächlichen Erfahrungen der Rezipienten konfrontiert. Eine Historisierung solcher Fragen bedeutet, dass die Konsequenzen der Einführung von (historisch gesehen) je neuen Medien wie Film, Fernsehen und digitalen Medien für das Theater reflektiert werden sollten: Welche neuen Medien oder Events übernehmen welche (Teil-)Funktionen der >alten<?

Die Verbindungen von Theater und Medien mit anderen gesellschaftlichen Systemen, wie z.B. der Politik, die Fragen nach der Kulturpartizipation - insbesondere die vergleichende Analyse der Kulturpartizipation bei Theater und (anderen) Medien - sowie die gesamte Rezeptionsforschung sind auf dem Kongress und in diesem Band unterbelichtet geblieben, was durchaus als repräsentativ für die aktuellen Forschungsinteressen von Theater- und Medienwissenschaftlern gesehen werden muss.

Teilaspekte der Thematiken immerhin werden in Aufsätzen in anderen Kapiteln dieses Bandes angesprochen, zum Beispiel die Übernahme von Konventionen im Theater aus der Fernsehpraxis (im Aufsatz von Bianca Michaels über Theatersoap und Talkshow-Oper in Teil 1); die Übernahme von dramaturgischen Merkmalen und Funktionen aus dem Theater im Fernsehen (im Aufsatz von Andreas Englhart ebenfalls in Teil 1); oder die Beziehung zwischen Theater und Hörspiel, die Peter Seibert (in Teil 2) ausgelotet hat und die u.a. klar macht, inwieweit etwa die Adaptionspraxis der Radioübertragungen auch zu Selektion und Kanonisierung der Dramatik beigetragen hat.

Selten nur werden die Beziehungen zur Welt außerhalb des Theaters oder der Medien ins Zentrum der Forschungsarbeiten gerückt. Immerhin drei Bereichen wird in diesem Band Aufmerksamkeit gewidmet: 
Gesellschaftliche Funktionen von Theater und Medien: Eine vergleichende Analyse, wie Theater, Film und andere theatrale Formen wie Varietés, Cabarets, Revuen und »Sensationsstücke « auf die Ereignisse des Ersten Weltkrieges reagiert und welche Funktionen sie dabei erfüllt haben, präsentiert Eva Krivanec. Vor diesem Hintergrund untersucht sie die Frage, inwieweit sich die Theateravantgarden der 1920er Jahren ästhetisch durch propagandistische Großprojekte wie die sogenannten »Kriegsausstellungen « und allgemein die experimentierfreudige Kriegsunterhaltungskunst inspirieren ließen. Matthias Warstat analysiert, wie amerikanische Theater - sowohl kommerzielle Mainstreamtheater als auch politische Performancekunst - im Vergleich zum Fernsehen auf die Anschläge des 11. September 2001 reagiert haben, und problematisiert dabei den Anspruch der Theater, auf angebliche Traumatisierungen in der Gesellschaft therapeutisch zu reagieren.

Bildung, Theater und Medien: Mit ganz unterschiedlichen Aspekten der Bildung beschäftigen sich vier Beiträge.

Leopold Klepacki blickt auf die Bedeutung der Theater- und Medienpädagogik im Schulsystem sowie das Selbstverständnis beider Disziplinen und kommt zu dem Schluss, dass ein »sinnvolles methodisch-inhaltliches Verhältnis« nur möglich sei, »wenn die Medienpädagogik das ästhetische Element von Medien zum zentralen Ausgangspunkt macht und das Darstellende Spiel anerkennt, dass mediale Erfahrungen ebenfalls sinnlich-leibliche Primärerfahrungen sind «.

Die Frage, welches Bild Kinder von Theater, Film und Fernsehen haben, wird von Ina Gombert auf Basis einer empirischen Forschung diskutiert. Anhand einer Befragung von Drittklässler/-innen gelangt sie zu dem Befund, dass Kinder (Kino-) Filme vor allem als Illusionsmedien wahrnähmen, während der Reiz des Theaters in der Wechselwirkung zwischen »echt « und »getrickst « bestehe.

Freda Chapple stellt ein Pilotprojekt vor, das die Bedeutung der digitalen Technologie für Theaterpraxis und Bildung im Kontext britischer Bildungspolitik erforscht. Nicht nur auf der Produktionsseite, sondern auch im Kontakt mit dem Publikum finde durch die Verfügbarkeit digitaler Medien eine grundlegende Veränderung der Rolle statt, die das Theater im Bildungswesen erfülle oder erfüllen könne.

Einen besseren Transfer der Kenntnisse aus der Theaterwissenschaft in die Praxis - oder genauer: zu angehenden Praktiker/-innen wie den Studierenden an Theaterhochschulen - ist das Anliegen von Anton Rey und Thomas Grüebler, die dafür einen Webauftritt entwickelt haben (www.theatertheorie.net), über den sich Studierende (inter)aktiv mit wichtigen epistemischen Erkenntnissen der Theaterwissenschaft vertraut machen können, mit Theorien, die - so die optimistische Annahme - auch grundlegende Auswirkungen auf die Praxis haben könnten.

Recht: Die Verbindung zum juristischen System wählt Kimon Keramidas, um die Frage des Copyrights anzusprechen: In einer Zeit, in der Medientechnologien das Kopieren und Reproduzieren von audiovisuellen (Kunst-)Werken stark vereinfacht hat, wird das Urheberschutzrecht zu einem zentralen - technischen wie juristischen Problem. Keramidas reflektiert, welche Konsequenzen es für das Persönlichkeitsrecht hätte, würde man Theater im juristischen Sinne als Medium betrachten. 


\section{Teil 5: Vom Nutzen und Nachteil des Medienbegriffs für das Theater und die Theaterwissenschaft}

Den Abschluss des Buches bildet eine von Kay Kirchmann moderierte Podiumsdiskussion mit Christopher Balme, Ulrike Haß, Chiel Kattenbelt, Andreas Kotte und Irina Rajewsky, in der versucht wird, wesentliche Fragen, die der »Theater \& Medien«-Tagung zugrunde lagen, zu beantworten. Dabei wurden folgende vom Moderator vorgestellte Thesen diskutiert:

1. Es gibt keinen Medienbegriff oder »Welchen Medienbegriff hättens' denn gern?

2. Medienvergleiche wie Einzelmedienontologien sind diskursive Strategien, keine epistemologischen Operationen.

3. Die Relationierung >des< Theaters $\mathrm{zu}>$ den $<$ Medien ist eine historisch variierende Diskursstrategie, die kulturpolitischen Interessenslagen und -konjunkturen unterliegt.

4. Auch die Frage nach der Integrationsfähigkeit >der< Medien in den Gegenstandsbereich der Theaterwissenschaft unterliegt institutions- und hochschulpolitischen Konjunkturen.

\section{Schluss}

Aus dem Überblick über die von den Autor/-innen gewählten Themen der Beiträge ergibt sich ein Eindruck, welche Forschungsinteressen in der Theaterwissenschaft für unterschiedliche Problembereiche im Feld von »Theater und Medien « aktuell dominieren. Zugleich wird deutlich - zumal wenn man die Beschreibung der Problemgebiete für die Konferenz »Theater \& Medien« als Kontrastfolie heranzieht (vgl. Fußnote 1) -, welche Themengebiete kaum erforscht und unterbelichtet geblieben sind. Dabei zeichnen sich interessante Perspektiven für neue Forschungsbereiche ab.

Wie zu erwarten war, beschäftigen sich die meisten Beiträge mit (anderen) Medien im Theater (Teil 3). Dabei sind vorwiegend Inszenierungen des letzten Jahrzehnts als Analyse-Objekt gewählt worden, woraus sich ein aufschlussreicher Überblick über aktuelle Entwicklungen in der Theaterpraxis ergibt. Diese Entwicklungen in der künstlerischen Praxis zwingen - obschon bereits in den ersten Jahrzehnten des 20. Jahrhunderts durchaus vergleichbare Entwicklungen stattgefunden haben Praktiker/-innen und Wissenschaftler/-innen (wieder) dazu, das Selbstverständnis des Phänomens Theater grundlegend zu reflektieren. Die Faszination für die aktuellen Entwicklungen und die damit zusammenhängenden Fragen über das Selbstverständnis des Theaters spiegeln sich auch in dem Interesse für Grundlagenprobleme und medienvergleichende Analysen (Teil 1).

Für den Bereich »Theater in (anderen) Medien« (Teil 2) wurde anders als erwartet nur wenig über das Phänomen der Dramenverfilmung geschrieben, und nahezu gar nichts über das Problem der Aufzeichnung von Theater, während sich die Thematisierung von Theater im Spielfilm eines großen Interesses erfreuen konnte. Die Analyse von Diskursen über Theater in anderen Medien (Print, Fernsehen und Internet) fiel völlig aus dem Fokus des Interesses. Ähnliches gilt für das Thema »Theatrale Praktiken in der Mediengesellschaft« (Teil 4). Dort hat allein der Bereich 
der Bildung größere Aufmerksamkeit bekommen, sehr geringe hingegen andere gesellschaftliche Themen wie Produktion, Rezeption und die Voraussetzungen, unter denen Theater und Medien produziert werden, Funktionen von Theater im Vergleich zu anderen Medien usw.

Im Allgemeinen kann konstatiert werden, dass sich die meisten Wissenschaftler/-innen (evidenterweise) mit dem zentralen Objekt der Theaterwissenschaft, der Inszenierung bzw. Aufführung (im Sinne dessen, was Zuschauer/-innen präsentiert wird), beschäftigt haben. Je weiter man sich von diesem Zentrum wegbewegt, desto weniger Forschungen liegen vor. Ähnliches gilt für die historische Dimension. Obwohl einige Aufsätze zeigen, dass auch in früheren Jahrhunderten Probleme der Beziehung zwischen Theater und (anderen) Medien mit spannenden Ergebnissen zu untersuchen sind, beschäftigen sich die meisten Wissenschaftler/-innen mit der zeitgenössischen Theaterpraxis. Dies freilich muss nicht bedeuten, dass die Beziehungen zwischen Theater und (anderen) Medien speziell als Problem unserer Zeit wahrgenommen werden. Es könnte auch daran liegen, dass Theaterwissenschaftler/-innen derzeit ohnehin vorwiegend das zeitgenössische Theater in den Blick nehmen - und vielleicht aus gutem Grund, denn nur zeitgenössisches Theater kann als Theater rezipiert werden. Alle früheren Formen sind per definitionem nicht mehr als Theater, sondern nur noch in ihren Repräsentationen und Spuren in anderen Medien zu erforschen. Auch darum spielt das Verhältnis von Theater und Medien solch eine wesentliche Rolle und wird immer weiter virulente Fragen für theaterwissenschaftliche Forschungen aufwerfen.

\section{Literatur}

Baudry, Jean Louis (1994): »Das Dispositiv: Metapsychologische Betrachtungen des Realitätseindrucks«. In: Psyche. Zeitschrift für Psychoanalyse und ihre Anwendungen. Hg. von Margarete Mitscherlich: 48. Jahrg., Heft 11, S. 1047-1074.

Devereux, Eoin (2003): Understanding the Media. London, Thousand Oaks, New Dehli: Sage Publications.

Faulstich, Werner (2004): Medienwissenschaft. Paderborn: Fink.

Hickethier, Knut (1995): »Dispositiv Fernsehen. Skizze eines Modells«. In: montage/AV. 4. Jg. Heft 1, S. 63-84.

Hörisch, Jochen (2001): Der Sinn und die Sinne. Eine Geschichte der Medien. Frankfurt/M.: Eichborn.

Krämer, Sybille (2008): Medium, Bote, Übertragung. Kleine Metaphysik der Medialität. Frankfurt/M.: Suhrkamp.

Krämer, Sybille/Horst Bredekamp (2003): »Kultur, Technik, Kulturtechnik«. In: Dies. (Hg.): Bild, Schrift, Zahl. München: Fink, S. 11-22.

Kümmel, Albert/Leander Scholz/Eckhard Schumacher (Hg.) (2004): Einführung in die Geschichte der Medien. Stuttgart: Fink.

Leeker, Martina (2001): Maschinen, Medien, Performances. Theater an der Schnittstelle zu digitalen Welten. Berlin: Alexander.

Leonhard, Joachim-Felix/Hans-Werner Ludwig/Dietrich Schwarze/Erich Straßner (Hg.) (1999-2001): Medienwissenschaft: Ein Handbuch zur Entwicklung der Medien und Kommunikationsformen. Berlin: De Gruyter.

Leschke, Rainer (2003): Einführung in die Medientheorie. München: Fink.

Luhmann, Niklas (1996): Die Realität der Massenmedien. Opladen: Westdeutscher Verlag. 
Luhmann, Niklas (1998): Die Gesellschaft der Gesellschaft. Frankfurt/M.: Suhrkamp.

McLuhan, Marshall (1994 [1964]): Die magischen Kanäle. Understanding Media. Dresden: Verlag der Kunst.

Mersch, Dieter (2006): Medientheorien zur Einführung. Hamburg: Junius.

Paech, Joachim (1997): »Überlegungen zum Dispositiv als Theorie medialer Topik«. In: Medienwissenschaft, Heft 4, Marburg, S.400-420.

Pias, Claus/Joseph Vogl/Lorenz Engell/Oliver Fahle/Britta Neitzel (Hg.) (1999): Kursbuch Medienkultur. Die maßgeblichen Theorien von Brecht bis Baudrillard. Stuttgart: DVA.

Rajewsky, Irina O. (2002): Intermedialität. Tübingen \& Basel: Francke.

Schanze, Helmut (Hg.) (2001): Handbuch der Mediengeschichte. Stuttgart: Kröner. Siegert, Bernhard/Tobias Nanz (Hg.) (2006): EX MACHINA. Beiträge zur Geschichte der Kulturtechniken. Weimar: VDG. 


\section{TEIL 1}

Theatralität, MEdialitäT, INTERMEDIALITÄT 



\title{
Definierbar ist NUR, WAS KeINe Geschichte hat. ÜBER FORTSCHRITTE DER MEDIEN UND WANDLUNGEN VON THEATER
}

\author{
ANDREAS KOTTE
}

Nach Friedrich Nietzsche entziehen sich »alle Begriffe, in denen sich ein ganzer Prozess « zusammenfasst, der Definition, »definirbar [sic] ist nur Das, was keine Geschichte hat « (316). ${ }^{1}$ Geschichte wird als Prozess des tatsächlichen Gewordenseins verstanden. Audiovisuelle Medien wie Theater, mit dem sie einige Eigenschaften teilen, besitzen solche Geschichte. Deshalb berührt das grundsätzliche Definitionsproblem, das hier in einem Prolog, fünf Akten und einem Epilog anzusprechen ist, die Theater- und die Medienwissenschaft in ähnlichem Maße.

\section{Prolog}

Bezeichnungen wie Medien bzw. Theater fassen ganze Prozesse zusammen, das gilt sogar für die einzelnen Theaterformen und einzelnen Medienprodukte. Sollte Nietzsche in seiner Streitschrift Zur Genealogie der Moral Recht haben damit, dass sich die Begriffe dann der Definition entziehen, weil nur definierbar ist, was keine Geschichte hat, dann reihen sich alle unsere Definitionen in einen Totentanz ein. Denn jeder szenische oder mediale Vorgang bleibt, wenn er sich tatsächlich ereignet, fern eines geschichtslosen Prinzips oder Wertes oder theoretischen Terminus' - die nur ihre Begriffsgeschichten besitzen. Vorgänge hingegen schleppen den Rucksack ihres Gewordenseins mit sich. Die Probe ist in der Aufführung, das Setting im Bild enthalten. - Empfiehlt uns Nietzsche nun, deshalb alle Manuskripte mit Definitionen auf dem Marktplatz der Eitelkeiten öffentlich auszustellen und anschließend zu verbrennen? Nein, wir wissen seit Michail Bulgakow: »Manuskripte brennen nicht $\ll .{ }^{2}$ Die Botschaft ist eine andere. Unsere Definitionen erfassen je einzelne Aspekte der Phänomengruppen Theater beziehungsweise Medien. Sie beleuchten wie Spots nur je einen Teil einer opaken Kugel, die der Gegenstand, das heißt die Blackbox unserer jeweiligen Wissenschaft ist. Es sind analysierende Blicke, die auf die Kugel gerichtet werden. Kein Spot vermag die Kugel ganz zu erfassen, deshalb muss es viele geben. Unter einem solchen Leitgedanken entgeht man der Tragikomik von Auseinandersetzungen um Alleinvertretungsansprüche. In

1 Nietzsche exemplifiziert dies am Beispiel der Strafe, indem er deren Prozeduren [Vorgänge] als etwas »Älteres, Früheres« beschreibt, das dann zum Strafen benutzt wird. Den Prozeduren wird ein Sinn oder vielmehr eine »Synthesis von >Sinnen « beigelegt. Die entstehende Einheit $>$ Strafe< ist undefinierbar, was für die Fälle [Phänomene] im Einzelnen nicht gilt.

2 In seinem Roman DER MEISTER UND MARGARITA. 
diesem Sinne endet der Prolog mit der These: Theater und Medien sind in einzelnen ihrer Aspekte definierbar.

\section{Akt: Und wie wir's dann so herrlich weit gebracht.}

Über die Entwicklung der Medien vom Niederen zum Höheren ist unendlich viel geschrieben worden, weil ihr Siegeszug die wohl gewaltigste produktive Umwälzung im kriegerischen 20. Jahrhundert darstellte. Befand sich das Kunstwerk Drama schon seit Gutenberg im Zeitalter seiner technischen Reproduzierbarkeit, so entstand durch das Aufkommen der Fotografie, des Films, des Fernsehens, des Videobandes, der DVD und des Internets doch eine bis anhin ungekannte Dynamik, die den Globus auf Weltdorfgröße schrumpfen ließ. Die meisten Filme und Serien werden für das ganze Dorf produziert. Deshalb darf im Mainstream auch nichts vorkommen, was vielleicht den Absatz auf den Malediven oder in Nepal schmälern könnte. Eine breite Akzeptanz gilt als Wert bei der Identitätsfindung der audiovisuellen Medien. Telenovelas gibt es nun auch fürs Handy, jene im Fernsehen sind dafür aber viel zu kompliziert, zu differenziert, die Geschichten werden entschlackt und die Konturen für den kleinen Bildschirm geschärft. Bollywood erreicht mehr als 3 Mrd. Menschen, Hollywood bleibt zurück (Folath: 130). - Es ist atemberaubend, der Digitalisierung zuzuschauen. Wie lange ist es her, da konnte eine Festplatte grandiose $25 \mathrm{MB}$ aufnehmen? Dann, als 1987 der Begriff Internet entsteht, sind sage und schreibe schon 27.000 Computer vernetzt, heute sprechen wir von einer Milliarde (Mingels: 18). ${ }^{3}$ Es gibt einen medialen Fortschritt, und für Medien ist er das Nonplusultra. Gerade berauschen wir uns an einer ganzen Million Pixel, da bietet die Kodak V610 6,1 Millionen Pixel, allein das Display hat schon 230.000 Pixel, der Zoombereich reicht mit zwei Objektiven von 38 bis zu sagenhaften $380 \mathrm{~mm}$, 10-faches Zoom, dreifach war schon toll, Anti-Blur-Technologie reduziert nun Verwacklungen, auch noch Video-Aufnahmen in VGA-Auflösung sind möglich. ${ }^{4}$ Die sicher unwiderlegbare These dieses Aktes heißt: Medien entwickeln sich vom Niederen zum Höheren.

\section{Akt: Drum schonet mir... Prospekte nicht und nicht Maschinen.}

Wie steht es nun aber mit dem Fortschritt im Theater? Theater, das ist keine Erfolgsgeschichte, eher eine Krise ohne Ende. Nur selten in seiner Vielgestaltigkeit akzeptiert, immer wieder in mehreren seiner Formen verboten, angefeindet, beschnitten oder reformiert. Den Agierenden wurde wegen fehlender Sesshaftigkeit Sozialprestige entzogen, Theater wurde über Jahrhunderte - anders als die bildende Kunst und die Musik - vom ästhetischen Diskurs ausgeschlossen, schließlich wurde es normiert und auf eine eingeschränkte Bildungsfunktion festgelegt. Als der Film aufkam, initiierte man ästhetische Debatten, ob er denn das Theater verdränge. Während der breiten Einführung des Fernsehens prognostizierte man für die Theaterform »subventioniertes Stadttheater« ein Debakel.

3 In den Jahren 1996: 55, 2000: 250, 2003: 600 und 2005: 900 Millionen.

4 Angaben aus der Werbung für diese Kamera. 
Wenn überhaupt irgendein Fortschritt, dann muss man diesen in den technologienahen Rahmenbedingungen suchen.

Es ist keine Frage, dass das tiefer in den Hang eingegrabene Theatron in Form eines Koilon in Theatern wie Epidaurus einen Fortschritt darstellte gegenüber der rektilinearen Anordnung der Sitzreihen in Thorikos. Viel mehr Zuschauende konnten unter ähnlich guten Sichtverhältnissen die Vorstellung verfolgen. Es ist keine Frage, dass die Winkelrahmenbühne Serlios mehr Verwandlung zuließ als die (allerdings später fertig gestellte!) Architekturbühne des Teatro Olimpico in Vicenza, aber klar übertroffen wurde von der Wandelbarkeit der Kulissenbühne im Teatro Farnese in Parma. Und Joseph Furttenbach gereicht es sicher nicht zum Ruhme, dass er, Kulissen verachtend, für den Binderhof in Ulm noch an den Telarien festhielt. Drehscheiben und Versenkpodien besitzen ebenso ihre Fortschrittsgeschichte wie Scheinwerfer, Zerhacker, Kameras und die Film- und Videoprojektionsapparate. In Christoph Schlingensiefs KUNST UND GEMÜSE agiert Frau Angela Jansen, die seit dem 6. Dezember 1998 vollständig bewegungsunfähig im Bett liegen muss, weil sie an ALS leidet. Mit ihren Augen animiert sie über eine Laserkamera einen Computer und schreibt Texte, die alle Zuschauer lesen können. Dies miterlebend zweifelt wohl niemand mehr am Medienfortschritt im Theater. Frau Jansen sagt von sich, es fehle ihr nichts, sie könne sich nur nicht bewegen. Die erschütternde Wirkung bei den Zuschauern, medial vermittelt, tritt allerdings nur durch die stumme Präsenz der Akteurin ein. - Und was die Bühnen und ihre Ausstattung betrifft, muss man in Rechnung stellen, dass parallel $\mathrm{zu}$ den enormen Fortschritten schon immer die einfache Podiumsbühne existiert hat, ein Indiz dafür, dass der gesamte Bühnenzauber eine unglaubliche Bereicherung für Theater darstellte, Theater nichtsdestotrotz auch ohne ihn auskommt.

Theaterwissenschaft kann den Begriff Medium sinnvoll verwenden in einer Mediengeschichte von Theater (Kotte: 263f). Am Anfang steht eine Beziehung zwischen Menschen zu gleicher Zeit am gleichen Ort, eine Situation. Die Menschen bewegen sich unterschiedlich, wodurch Gruppen von Agierenden und $\mathrm{Zu}$ schauenden sowie Vorgänge zwischen diesen Gruppen entstehen. Um die Vorgänge zu verstärken, werden Dinge in den Vorgang eingebracht, zum Beispiel der Stab des Rhapsoden. Der Stab kann nicht nur als Wanderstab Fortbewegung andeuten, sodass der Rhapsode gleichsam durch den Mythos schreitet, oder horizontal gehalten etwa eine Wellenbewegung verdeutlichen, er kann auch auf den Boden gestoßen einen Autoritätsanspruch ausdrücken usw. Er ist ein dingliches Attribut des Handelns, etwas Eingeschobenes, zwischen Agierende und Zuschauende, das den Vorgang unterstützt, ihn einprägsamer macht, nachhaltiger. Dieses Dazwischengeschobene und Unterstützende kann man, wenn man möchte, ein >Medium< nennen. Dazu gehört die gesamte Theatertechnik vom Flugkran über den Vorhang bis zur Drehbühne samt der Rahmenbedingung Theaterbau. Eine Mediengeschichte der Theaterformen reflektiert eine technologische Erfolgsgeschichte. These dieses Aktes: Es braucht eine Mediengeschichte von Theater.

Nachsatz: Eine Ruine ohne Dach, sogar ohne Bühnenbretter - das war das Nationaltheater in Kabul, Afghanistan, gezeigt in der TAGESSCHAU vom 8. Januar 2002. ${ }^{5}$ Auf den verbliebenen Eisenträgern der Drehbühne balancierten Darsteller, und zwar nicht in Kostümen, in ihrer Alltagskleidung, mit Fackeln in den Händen. Gespielt wurde eine sehr alte Geschichte, ursprünglich ein Epos, gezeigt vor Männern und Frauen, vor Frauen ohne Burka. - Solche Momente legen den Kern dessen bloß, was Theater ist, woher es kommt und was es vermag. Die Entwicklungen

5 Gemeint ist die Schweizer TAGeSSCHAU von SF DRS, hier: SF 1, 19.30 Uhr. 
sind das Marginale, die das Bleibende bestätigen. Es braucht eine Mediengeschichte von Theater. Aber, Erweiterung der These: Theater als sinnlicher Vorgang unterscheidet sich von seiner Mediengeschichte.

\section{Akt: Die Zeiten der Vergangenheit sind uns ein Buch mit sieben Siegeln.}

Wie wandelt sich Theater? Eruptiv, vulkanistisch, wie Goethe sagen würde, oder »am farbigen Abglanz haben wir das Leben« $(162)^{6}$-, eher neptunistisch? Was wissen wir davon wirklich? Tragen die Modelle unserer Theatergeschichten zur Aufhellung des Problems bei? Fast ausnahmslos variieren diese Modelle das Konzept von Pietro Napoli-Signorellis erster Universaltheatergeschichte von 1777 (vgl. Hulfeld: 185-208). Ein Blick in deren Inhaltsverzeichnis genügt, um festzustellen, dass wir seine Periodisierung übernehmen und uns auf einen Beginn von Theater in Griechenland einigen. Auch deshalb gibt es keine theaterwissenschaftlichen Großforschungsprojekte zum Beispiel zum ägyptischen Theater sechshundert Jahre vor Troja, wovon uns mit dem Ramesseum-Papyrus sogar ein kompletter Text überliefert ist (vgl. Sethe). Unsere kulturelle Prägung durch die Darwinsche Entwicklungslehre und die Zivilisationstheorie von Norbert Elias ist so stark, dass gar nie die Frage aufkommt, ob nicht vielleicht bestimmte Beziehungen, darunter die spezifische zwischen Agierenden und Schauenden, sich vielleicht nicht im Sinne irgendeines Fortschritts entwickeln, sondern nur in ihren Formen wandeln. Ich bin versucht, dies mehr und mehr anzunehmen: Theater entwickelt sich nicht, es wandelt sich nur. Während Entwicklung Etappen auf dem Wege zur Perfektion kennt, bedeutet Wandlung, dass anderes, mit den jeweiligen Zeitumständen korrespondierendes, aber nicht unbedingt >besseres $<$ Theater entsteht.

Außerhalb der Mediengeschichte von Theater und der Institutionsgeschichte von Theater, die ebenfalls noch zu schreiben ist, unterliegt Theater wegen seiner Körpergebundenheit keinem Entwicklungszwang vom Niederen zum Höheren. Das unbefragte Fortschrittskonzept verlangte allerdings, dass zum Beispiel für die Benennung von >Theaterähnlichem< vor der Entstehung des >eigentlichen< Theaters in Griechenland Begriffe wie Ur- oder Prätheater eingeführt wurden. Damit die Höchstleistungen des griechischen Theaters, die im römischen Reich versickern, noch eindrucksvoller wie ein Fels aus der Brandung ragen, schuf das Fortschrittskonzept auch das so genannte Theatervakuum zwischen 530 und 930. Man brauchte einen Neuansatz nach mehrhundertjähriger Pause, eine >zweite Geburt des Theaters< vor den nächsten >Gipfelleistungen< des elisabethanischen Theaters und jenen der jeweiligen Gegenwart.

Wenn man einräumt, dass nur wenige Nachrichten für die dunklen Jahrhunderte des so genannten Theatervakuums überkommen sind, darf man auch einmal konstatieren, wie viel Energie in die Aufrechterhaltung der Vakuum-Version gesteckt worden ist und wie wenig in alternative Lesarten. Dass Theater auf Konzilien und Synoden der Pausenzeit weiterhin verboten wurde, führte nicht zu der Schlussfolgerung, es müsse noch, vielleicht gewandelt, existieren, und wer diese Folgerung dennoch zog und dabei dann übertrieb, wie Hermann Reich, wurde wegen Übertreibung gebannt (vgl. Reich). Nach älteren Herodesspielen, von Johann Drumbl in seiner Dissertation erwähnt, wurde nicht weiter gefahndet, die depositio,

6 Es ist die letzte Zeile der ersten Szene »Anmutige Gegend«. 
adoratio, elevatio crucis wurde nicht als Theater untersucht, weil die Schulbildung, auf die Suche nach einem kohärenten, richtigen und umfassenden Theaterbegriff fixiert, dies verhinderte (Drumbl: 118, 120, 137, 204).

Selbst die Varianten der so genannten zweiten Geburt von Theater, auf die man sich verständigte, wurden nie systematisch verglichen. Waren es nun der Ostertropus im 10. oder die Entstehung des weltlichen Spiels zwischen dem 12. und 14. Jahrhundert (Simon: 38$)^{7}$, war es das Fastnachtsspiel oder war es die berufsmäßige Schauspielkunst im 15. Jahrhundert, die den vermeintlichen Neubeginn von Theater markieren? Schon der Wettbewerb um die Palme der zweiten Geburt legt die Vermutung nahe, dass sich hier Konstrukte historischen Diskurses befehden. Eine Abkehr hiervon unter dem Gesichtspunkt, es gibt keinen kohärenten Theaterbegriff, sondern nur Definitionen für Aspekte von Theater, würde eine zumindest partielle Neuausrichtung der Schwerpunkte im Forschungsnetz verlangen. Die Theatergeschichte ist weit, sehr weit davon entfernt, aufgeschrieben worden zu sein. Statt sie wirklich zu erforschen nun die unzulänglichen Texte nur unter dem Motto »Theater ist ein Medium« neu zusammenzufassen, um sie einem Fortschrittskonzept anzupassen, das wäre eine veritable Forschungssatire.

Deutlich wird also der Fortschritt der Medien und dass sie an diesen gebunden sind. Auch ein Fortschritt von mindestens dreitausend Jahren Bühnenbau und Bühnentechnik, Dekoration, verwendeten dinglichen Attributen des Spiels, Räumen und Technologien steht außer Zweifel. Existiert aber eine Höherentwicklung der Beziehung zwischen Agierenden und Schauenden, die man früher als selbstverständlich erachtete? Eine Meyerholdsche Biomechanik, reflektiert und beschrieben in den 1920er Jahren - haben wir je gefragt, ob nicht einige Truppen der Commedia dell'arte solche Techniken nutzten? Rhythmisierung, Nachahmung des Maschinellen bis zur physischen Erschöpfung, stark überhöhtes, kunsthaftes Spiel? Haben wir das Phänomen vielleicht zu eng an seine erstmalige intensive schriftliche Erörterung gekoppelt? Oder nehmen wir die Differenziertheit heutigen Schauspiels, in Diderotscher Schauspieltheorie beschrieben. War sie wirklich erst nach ihrer aufgeklärten Reflexion physisch und psychisch möglich oder vielleicht schon zu spätantiken Zeiten, als man in den Diskursen vorrangig das Verhältnis von Schauspielkunst und Rhetorik reflektierte? In Frank Castorfs MEISTER UND MARGARITA oder DER IDIOT werden Innenräume mittels Video zu Außenräumen und umgekehrt. Ein grandioses Spiel mit mehreren Medien. Spätestens seit Christoph Schlingensiefs CHANCE 2000 wird immer wieder auf Gesichter auf Leinwänden eingeschlagen. ${ }^{8}$ Neue Spielobjekte und Spielräume werden erkundet. Aber ändert dies etwas daran, dass die Spieler präzise sein müssen, so präzise wie Joseph Felix von Kurz-Bernardon oder Johann Nestroy, dass sie die Doppeltheit von Rolle und eigenem Leib variantenreich ausspielen und genau überlegen müssen, wann sie als Privatperson hervortreten? Die Möglichkeiten des Körpers, der Sprechweise, des Spiels, der Bildung von Situationen sind über die Jahrhunderte ähnlich geblieben, in unterschiedlichen Theaterformen unterschiedlich intensiv und variiert genutzt. Die These lautet daher: Theater entwickelt sich nicht, es wandelt sich nur.

7 Deutschsprachig um 1370.

8 ChanCE 2000 - WAHLKAMPFZIRKuS '98, Regie: Christoph Schlingensief, Zirkuszelt des Zirkus Sperlich im Garten des Prater, Prenzlauer Berg, Berlin, Premiere: Freitag, 13.03.1998, Vorstellung 04.04.1998. 


\section{Akt: Zwar sind sie an das Beste nicht gewöhnt, allein sie haben schrecklich viel-gesehen.}

Ohne Frage ist unser aller Wahrnehmung vornehmlich medial geprägt. Theater positioniert sich täglich in medialer Umwelt, reagiert auf zwei Erwartungshaltungen: Dopplung und Störung. Dopplung meint, man möchte zwar das Ereignis Theater genießen, aber doch möglichst nah den Sehgewohnheiten von LINDENSTRAßE und GUTE ZEITEN, SCHLECHTE ZEITEN oder Spielfilmen und Talkshows bleiben. Störung meint, das Ereignis Theater soll die mediale Prägung der Wahrnehmung zumindest kurzzeitig aufbrechen, was als anregend und genussvoll empfunden wird. Theater versucht sich allabendlich an diesem Spagat. Am besten werden aber meist Erwartungshaltungen erfüllt, wenn die Theaterform selbst schon Signale aussendet. Im Familienprogramm auf der Freilichtbühne wird kaum Störung erwartet, im Kellertheater mit vierzig Plätzen wird ein zweiter Förster aus Falkenau eher Unmut erzeugen. ${ }^{9}$ Die Dopplung, die Vertiefung der medial geprägten Wahrnehmungsweise, wird am besten deutlich, wenn man an die Übernahme des »Movischen « im Theater denkt. Bei Ohnsorg in Hamburg, aber auch in einzelnen Produktionen der Stadttheater, zum Beispiel in Musicals, wird reaktiviert, was vor kurzem Nikolaus von Festenberg in einem Artikel über die Kunstsprache des »Movismus « formulierte. Er stellte die Frage, ob der Strom immer neuer FernsehMovies nicht einfach nur den ewig gleichen Film zeige.

»Eine Betrogene sagt zum Fremdgänger [...]: >Seit wann geht das?< Er: Guckt dumm. Sie: >Ist es ernst? Er (in die Ferne blickend): >Ich glaube, ja.< Sie: >Warum gerade jetzt?< Er: $>$ Ich weiß es ja auch nicht. $<$ Sie: >Was soll werden? $<$ Er: >Gib mir Zeit. $<$ Dann sieht man den Mann mit einem Koffer das Haus verlassen. Movie-Manns Habe passt immer in einen Koffer. Draußen regnet es gern, der Himmel heult. Dass nur die Musik weint, reicht ja nicht. Doppelt, dreifach, vierfach - Movisch ist auf Redundanz gebaut. Movisch? Kommt von >Movie<. Wir alle verstehen Movisch, die Sprache des Fernsehfilms, denn wir sind abgerichtet. Unsere Spracherzieher heißen Rosamunde Pilcher und Inga Lindström. Der Landarzt spricht es uns vor, der Förster aus Falkenau lässt es aus seinem Mund rauschen: >Der Wald war schon vor uns Menschen da.< [...] Kompliziertes, Uneindeutiges, wissenschaftliche Vorbildung Erforderndes - für Movisten kein Problem. [...] >Du musst an dich glauben<, >Du musst es einfach nur wollen $<$. Und die Gretchenfrage aus den meisten Doktorspielen, Movisch in seiner ganzen Reinheit: >Wird er/sie/es durchkommen?<>Im Moment können wir nicht mehr tun.< [...] Movisch [...] braucht nicht übersetzt zu werden, denn es ist längst fest verankert im Zuschauerhirn. Auf dem Ölfilm der Musik gleiten die Stereotypen in den Zuschauer hinein und zwingen ihm sanft ihre Präsenz auf. Movisch hat ein triviales Geheimnis: Es verweist auf keine andere Welt, es verweist nur auf sich selbst. Die Wahrheit dieser Kunstsprache besteht in der dauernden Wiederholung (Festenberg: 140-141).

Und das im Fernsehen wie im Theater. Deshalb hier die vorgezogene These des vierten Aktes: Entweder stützt Theater die medial geprägte Wahrnehmung oder es stört sie.

9 Serie Forsthaus FALKENAU des Senders ZDF. 
Ohne Frage erreichen Medien viele Menschen, Theater erreicht nur einige wenige. Dass dieser quantitative Aspekt aber nichts über die Wichtigkeit von Theater oder Medien aussagt, lässt sich am Fall Beltrametti erläutern. Dezember 2001. Der Skifahrer Silvano Beltrametti ist in der Schweiz etwa so populär wie in Deutschland der Torwart Oliver Kahn. Beltrametti stürzt in Val-d'Isère. Der Sturz führt zu einer Querschnittslähmung. Ein Dokumentarfilm über die Rehabilitationsbemühungen wird gedreht und im Dezember 2002 ausgestrahlt. Er regt eine Theaterproduktion an, Premiere März 2004. Die ersten Medien-Kommentare zum Sturz gelten den Komplexen Gefahr, Leistung, Heldentum und Mythos. O-Ton Trainer: »so hart das tönt... Der Sport geht weiter«(Geisser: 43). Dann drängt Beltrametti mit Statements selbst in die Massenmedien. Das Filmteam stärkt und schafft unter dem Titel MiT KLEINEN SIEGEN ZURÜCK INS LEBEN einen Mythos und die Theatermacher der Gruppe 400asa befragen schließlich genau diese Mythenbildung. Sie spielen in B. EIN STÜCK ÜBER SPORT UND BEHINDERUNG vermeintlich den Dokumentarfilm nach, amüsant-bissig, unter Einsatz von Kasperle-Figuren, Musik und Videoprojektionen. Sie konterkarieren die Dokumentarvariante des Movischen, die Heroisierung. Der Film erzielt mit klassischer Steigerung seinen emotionalen Höhepunkt in der Szene, in der man Beltrametti an den Ort des Unfalls zurückkehren lässt, an den Ort, mit dem er sich nun aussöhnt. Tragödie und Katharsis, oder wie es die Filmankündigung formuliert: »Ein bewegender Film, der trotz allem Mut macht «. Im Theater entsteht durch Distanz eine exemplarische Erörterung des Verhältnisses von zeitgenössischem Film und Theater. Gerade weil dieser Sport-Film mit seiner Dauerpräsenz von Optimismus jede Frage nach dem Sinn moderner Rekordjagden meidet und weil das Theater nicht rührt, werden die Differenzen von Medium und Theater so deutlich: Eine Theaterproduktion im Sinne des Films fände kaum einen einzigen Besucher. Ein Film im Sinne des Theaterstücks wäre nicht gesendet worden. Theater realisiert hier eine kritisch-tätige Draufsicht auf Mediales, ganz nach dem Theaterbegriff von Novalis: »Das Theater ist die thätige Reflexion der Menschen über sich selbst « (836). - Der Nachricht vom Unfall war das größte und das kürzeste Echo beschieden. Der Dokumentarfilm mit fünf Wiederholungen wurde sehr breit - knapp zwei Millionen Zuschauer - und generell zustimmend rezipiert, während die Theaterproduktion nur von 1.010 Personen gesehen wurde, aber wohl die intensivste Auseinandersetzung hervorrief (Graffenried: 8, 23, 56, 58, 96). ${ }^{10}$ Insofern besitzen Medien und Theater deutlich unterschiedliche Funktionen in der Gesellschaft, denen die Bezeichnungsebene auch angemessen Rechnung tragen sollte.

Dies geschieht nicht, wenn an die Wirklichkeit, statt konkret, subjektiv und sinnlich, ausgesprochen abstrakt herangegangen wird, wie z.B. mit der Auffassung: »Menschliche Lebewesen als soziale und kulturelle Wesen sind [...] selbst $>$ mediale Ereignisse«« (Kracht: 196). ${ }^{11}$ Wenn der Mensch mediales Ereignis wird, dann braucht es keine Theaterwissenschaft mehr, höchstens noch - wenn überhaupt - eine Medienwissenschaft als Lebenswissenschaft. Und wenn Theater, wie

10 Ausführlich zum Gesamtkomplex siehe Ariane von Graffenried Der Fall Beltramettis in Film und Theater und B. EIN STÜCK ÜBER SPORT UND BEHINDERUNG von 400asa, Regie: Samuel Schwarz, Fabriktheater Rote Fabrik, Zürich, Premiere am 17.03.2004. 883 Besucher in der Schweiz, 127 in Österreich. Ausgangspunkt ist der Sturz Silvano Beltramettis am 08.12.2001 in Val-d'Isère. Der Dokumentarfilm von Martin Masafret, Elmar Deflorin und Peter Staub wurde vom Schweizer Fernsehen am 12.12.2002 erstmals ausgestrahlt.

11 Der Autor nimmt Bezug auf Jochen Hörisch (2001). 
in Grundwissen Medien, als das vierzehnte von siebzehn aufgeführten »Einzelmedien « erscheint, gleich nach Plakat, Schallplatte und Telefon, dann wird nicht mehr geforscht, sondern nur noch zusammengefasst (Uka: 327). Auf das >mediale Ereignis< Mensch oder auf Theater als so genanntes »Menschmedium « (Faulstich: 23) könnten Theaterwissenschaftler ebenso abstrakt antworten, und sich unter der Prämisse »Die Welt ist eine Bühne« ganz nebenbei der Gegenstände der Medienwissenschaft bemächtigen. Das Ergebnis wäre Zusammenfassung statt Forschung, heilloser Dilettantismus. Die Gegenstandsbereiche beider Wissenschaften sind hochgradig komplex. Auch aus solchen rein forschungspraktischen Gründen wäre es wenig sinnvoll, Theater zum Medium machen zu wollen, anstatt dass Theaterund Medienwissenschaftler ihre Disziplinen ausgestalten und zusammenarbeiten, beispielsweise auf den Gebieten der Dramaturgie, Aufführungsanalyse und Intermedialität, gerade weil es auch in der Medienwissenschaft nicht nur um Technologie geht.

\section{Akt: Die Masse könnt ihr nur durch Masse zwingen, ein jeder sucht sich endlich selbst was aus.}

Der Theaterdirektor im Vorspiel zu Goethes FAUST meint damit klar die Angebotsvielfalt innerhalb einer Vorstellung. Der Satz lässt sich aber sehr gut auf das kulturelle Angebot einer Freizeitgesellschaft ausdehnen. Massenhafte Medienverwendung neben einzelnen Theater- und anderen Besuchen, ein Nebeneinander von Freizeitangeboten. Ausschließlich besondere Qualitäten und Funktionen von Theater entscheiden darüber, ob die Zuschauenden kommen oder ausbleiben, ob sie $i h r$ Theater finden oder der erwähnte Spagat eben misslingt. - Ins Düsseldorfer Schauspielhaus strömt gewiss nicht die Masse, und wenn die, die sich das ausgesucht haben, in der MACBETH-Inszenierung von Jürgen Gosch sieben nackte Schauspieler ihre psychophysischen Grenzen ausloten sehen, mit armem Theater konfrontiert werden, dann zeigt sich wie bei 400asa, dass zuweilen Theater nicht mehrheitsfähig ist. Viel Blut, kein Fortschritt, da hält die Technologie den Atem an. »Andererseits«, wie Hermann Pitt schreibt,

»großes Schauspieler-Theater mit stillen, ja poetischen Momenten zwischendurch. Und einem siebenköpfigen Männerensemble, das mit den hier im Brechtschen Sinn ganz offen ausgestellten Theatermitteln und bei vollem Saallicht eine geradezu atemberaubende Bühnenpräsenz erreicht, die keinem mit noch so viel Hightech vollgestopften HollywoodStreifen je gelingt «.

Die Zuschauenden haben die Möglichkeit, den Saal zu verlassen, wenn sie nicht mehr ertragen, was ihnen hier direkter als im Fernsehen erscheint. »Ekeltheater « hin oder her. Nicht nur Klaus Wowereit ${ }^{12}$ hat es gefallen: »Der Regisseur hat uns an die Grenzen geführt, und die schauspielerische Leistung ist genial, soviel Körperlichkeit nicht nur im eigentlichen körperlichen Sinne, sondern auch sehr viel Emotion mitgezeigt. Das ist schon einmalig « (Plenio/Lange). Eben, einmalig. So nicht reproduzierbar, nicht zu speichern. Für die einen ist das kein Theater mehr, sie lassen die Saaltüren klappen. Für andere ist das endlich einmal Theater, weil ihr

12 Klaus Wowereit, regierender Bürgermeister von Berlin. 
Theaterbegriff ein anderer ist. Vielleicht verstehen selbst wir Wissenschaftlerinnen und Wissenschaftler nach solchen Erlebnissen besser, warum es viele Theater- und Medienbegriffe geben muss - weil eindeutig nur definiert werden kann, was keine Geschichte besitzt. Einerseits erfordert das professionelle Arbeiten auf der Bezeichnungsebene viel Gelassenheit, weil die Theaterphänomene in den Theaterformen und die Medienphänomene in den Medienarten und -formaten sich sowieso nicht um wissenschaftliche Bezeichnungsprobleme scheren, sondern munter fortexistieren. Andererseits sind wir beruflich aufgefordert, Vorschläge für den allgemeinen Sprachgebrauch zu unterbreiten. Erinnert sei an das postdramatische Theater, das ohne solchen Vorschlag vielleicht noch immer namenlos wäre. Diese gesellschaftliche Verantwortung ist es, die die Diskussion über das Verhältnis von Theater und Medien anregt. Einige, einem bestimmten Diskursumfeld verpflichtet, halten Theater für ein Medium, andere nicht. Wie damit umgehen? Sicher ist jeweils die Abstraktionshöhe des Diskussionsgegenstandes zu bestimmen. Auf der Bezeichnungsebene, die immer nur einzelne Aspekte der Phänomene zu erfassen vermag, kann es vorkommen, dass ein bestimmter Theaterbegriff einmal ein bestimmtes Medium subsumiert. Zum Beispiel kann der Aspekt Interaktion, für einige Theaterbegriffe zentral, auf das Internet ausgedehnt werden. Oder einer der Medienbegriffe erklärt Theater zum Medium, weil er auf Institutionalisierungsvergleiche aus ist. Man kann einen Stuhl eine Zeit lang als Tisch betrachten, denn er hat eine Ablagefläche und er hat vier Beine. Man erhält als Ergebnis den Tischaspekt dieses Stuhles, einen Aspekt unter vielen. Und niemand wird es beanstanden, wenn ein Tisch einmal als Stuhl angesehen wird, denn man kann darauf sitzen, was den Stuhlaspekt des Tisches ausmacht. Betrachtet man nun Theater als ein Medium, erkennt man einen medialen Aspekt von Theater, beispielsweise den technischen. Und sieht man audiovisuelle Medien als Theater an, begreift man einen Theateraspekt dieser Medien, beispielsweise den dramaturgischen. Solche begründeten Ausschweifungen können nützlich und lehrreich sein. Ausschließlich die Behauptung, der Tisch sei tatsächlich ein Stuhl (oder umgekehrt) beeinträchtigt dann die Kommunikation mit den Laien, die von anderen Erfahrungen ausgehen.

Beim Übergang von szenischen in mediale Vorgänge werden Phänomene durch medientechnische Apparate wie eine Kamera in Daten, in Informationen umgewandelt. Die Umwandlung hinterlässt Spuren. Wird auch Theater nur als eine solche Informationsvermittlung betrachtet, als Medium, dann werden sinnliche Beziehungen zwischen Agierenden und Schauenden, auch Angst und Scham und Macht, mit Technologien und Apparaturen gleichgeschaltet beziehungsweise gleich bewertet, ohne dass der Gegenstand, das Phänomen es zwingend erforderte oder daraus irgendein Erkenntnisgewinn resultierte. Die Aufhebung der Differenzen zwischen Menschen, Mitteln und Technologien wiegt innerhalb einer - vielleicht altmodischen? (Schechner: 96) ${ }^{13}$ - humanistischen Wissenschaftsauffassung erkenntnistheoretisch schwer. Besser: »Contradictio est regula veri, non contradictio falsi« (Hegel: 533). »Der Widerspruch ist die Regel für das Wahre, der Nichtwiderspruch für das Falsche«. Die Affinitäten zwischen Theater und Medien sind das unwidersprochen empirisch Gegebene. Sie werden gern und oft und gut beschrieben. Die Differenzen zwischen Theater und Medien schwinden dabei mit steigender Abstraktionshöhe des Diskurses dahin. Da nun m. E. Forschung weniger durch Affinitäten generiert wird als durch Differenzen, muss ich persönlich, der ich forschend von den Phänomenen starte und nicht von der Diskursebene, es für

13 »Humanism is a very arrogant, anthropocentric, expansionist, and high-energy ideo$\log \mathrm{y}$. 
sinnvoller erachten, Theater nicht als ein Medium zu bezeichnen. Denn Theater ist nach wie vor nicht reproduzierbar, nicht speicherbar, arg begrenzt wirksam, zuwielen nicht mehrheitsfähig, fortschrittsresistent, und vor allem nicht in Informationen beziehungsweise Daten wandelbar.

Kurz, es ist atavistisch, ein Relikt aus der Zeit der Handarbeit, weil es doch nicht ohne die gleichzeitige Anwesenheit von Akteuren und Schauenden auskommen kann. Heutige Übergänge und Hybridformen, auch Performances und FrankCastorf-Inszenierungen, beweisen nur, dass das Problem der Handarbeit ins Bewusstsein gerückt ist und dass man herrlich damit spielen kann. Die erfreuliche Vielfalt der Theaterbegriffe führt zu folgender These für den 5. Akt: Die unterschiedlichen Existenz- und Funktionsweisen von Theater und Medien rechtfertigen die unterschiedlichen Bezeichnungen.

\section{Epilog}

Theater- und Medienwissenschaft treffen sich u.a. bei der Verwendung von Begriffen wie Intermedialität, Theatralität oder Performativität. Diese bezeichnen Prozesshaftes, sind aber - wie wohl alle Begriffe, die auf -ität enden - theoretische Begriffe des Diskurses. Insofern besitzen sie, jenseits der eigenen Begriffsgeschichte, keine Geschichte und können nach Nietzsche daher grundsätzlich etwas besser definiert werden. Zwar gibt es für Intermedialität - ähnlich Theater und Medien - fast so viele Bestimmungen wie damit befasste Forscherinnen und Forscher, aber eine wichtige Größe entfällt: Während die Laien, die Nicht-Wissenschaftlerinnen und Nicht-Wissenschaftler, angeregt durch ihnen bekannte Theaterformen und Medienformate, durchaus je einen eigenen Theater- und Medienbegriff ausbilden, was man durch Umfragen belegen könnte, unterlassen sie das für abstraktere Begriffe des theoretischen Diskurses.

Versteht man unter Intermedialität etwa die Realisierung der ästhetischen Konventionen und/oder Seh- und Hörgewohnheiten (Balme: 154) eines Mediums 1 in einem Medium 2, so kann man unter anderem im Fernsehen fotografische Techniken oder theaterdramaturgische Mittel im Film DogVILLE untersuchen. Man kann zu diesem Zweck nun Theater unter die Medien aufnehmen oder nicht. Tut man es, werden, unter dem Zwang eines theoretisch eingesetzten Begriffes, die genannten Unterschiede zwischen Theater und Medien als unwesentlich eingestuft und der künstliche Begriff reguliert deduktiv weiteres Denken. Tut man es nicht, werden bestimmte Beziehungen zwischen Medien erforscht, und man stellt spezifische Bezüge zu Theater her. Auch dies funktioniert reibungslos unter dem Begriff Intermedialität.

Aus der Sicht der Preisfrage der Gesellschaft für Theaterwissenschaft »Ist Theater (k)ein Medium? « gilt vorliegender Text klar als ein Minderheitsvotum. Bei vierzehn Voten wird Theater sieben Mal als ein Medium bezeichnet, vier der Nachwuchswissenschaftlerinnen und -wissenschaftler legen sich nicht fest und nur drei Mal ist Theater kein Medium. Der Sinn des Abdrucks eines Minderheitsvotums könnte vielleicht dennoch aufscheinen, wenn man in Rechnung stellt, dass hier eine rhetorische Figur exemplifiziert wird. Statt auf der Bezeichnungsebene zu sagen: Das ist richtig und das ist falsch, wäre generell die Formulierung zu bevorzugen, man halte das und das für sinnvoller als das andere, Komma, weil ... 


\section{Literatur}

Balme, Christopher (1999): Einführung in die Theaterwissenschaft. Berlin: Schmidt.

Drumbl, Johann (1969): Der Begriff des Theaters und der Ursprung des liturgischen Spiels (Diss.). Wien: Privatdruck.

Simon, Eckehard (2003): Die Anfänge des weltlichen deutschen Schauspiels 13701530. Tübingen: Niemeyer.

Faulstich, Werner (2002): Einführung in die Medienwissenschaft. München: Fink.

Festenberg, Nikolaus von (2006): »Du willst es doch auch«. In: Der Spiegel, Nr. 22, S. 140-41.

Folath, Erich (2006): »Big Bang Bollywood «. In: Der Spiegel, Nr. 23, S. 130-139.

Geisser, Remo (2001): »Vom Schicksal eingeholt«. In: Neue Zürcher Zeitung, Nr. 287, 10.12.2001, S. 43.

Goethe, Johann Wolfgang (1961): »Faust. Der Tragödie zweiter Teil«. In: Goethes Werke, hg. v. Ernst Beutler. Zürich: Artemis.

Graffenried, Ariane von (2005): Der Fall Beltramettis in Film und Theater (Lizentiatsarbeit). Bern: Institut für Theaterwissenschaft.

Hegel, Georg Wilhelm Friedrich (1986): »Habilitationsthesen«. In: Werke. Jenaer Schriften 1801-07, Bd. 2, hg. v. Eva Moldauer/Karl Markus Michel. Frankfurt/M.: Suhrkamp.

Hörisch, Jochen (2001): Der Sinn und die Sinne. Eine Geschichte der Medien. Frankfurt/M.: Eichborn.

Hulfeld, Stefan (2007): Theatergeschichtsschreibung als kulturelle Praxis. Wie Wissen über Theater entsteht. Materialien des ITW Bern 8. Zürich: Chronos.

Kotte, Andreas (2005): Theaterwissenschaft. Eine Einführung. Köln: Böhlau.

Kracht, Günter (2003): »Medien/Medium«. In: Gerd Koch/Marianne Streisand (Hg.): Wörterbuch der Theaterpädagogik. Berlin: Schibri.

Mingels, Guido (2005): »Die Revolution, die keine war«. In: Tages-Anzeiger. Das Magazin, Nr. 41, S. 18-29.

Napoli-Signorelli, Pietro (1777): Storia critica de' teatri antichi e moderni (Libri III). Napoli: Orsino.

Nietzsche, Friedrich (1988): »Zur Genealogie der Moral«. In: Sämtliche Werke. Kritische Studienausgabe in 15 Bänden, Bd. 5, hg. v. Giorgio Colli/Mazzino Montanari. München: dtv.

Novalis (1999): »Das philosophisch-theoretische Werk«. In: Werke, Tagebücher und Briefe Friedrich von Hardenbergs, Bd. 2, hg. v. Hans-Joachim Mähl/ Richard Samuel. Darmstadt: Wissenschaftliche Buchgesellschaft.

Pitt, Hermann (2006): »Macbeth. Düsseldorfer Schauspielhaus«. In: Herner Feuilleton, http://www.herner-netz.de/Macbeth-121005/macbeth-121005.html (25.04.2006).

Plenio, Jörg/Ralf Lange (2006): »Theatertreffen 2006: Eröffnung ohne Ekel - >Macbeth««. In: rbbonline, http://www.rbb-online.de/_/stilbruch/beitrag_jsp/key=43 25462/print=yes.html (11.05.2006).

Reich, Hermann (1903): Der Mimus. Berlin: Weidmann.

Schechner, Richard (1982): The End of Humanism. Writings on Performance. New York: Performing Arts Journal Publications.

Sethe, Kurt (1964): Untersuchungen zur Geschichte und Altertumskunde Aegyptens, Bd. 10, Hildesheim: Olm (Nachdruck der Ausgabe Leipzig 1928).

Uka, Walter (1995): »Theater«. In: Werner Faulstich (Hg.): Grundwissen Medien. München: Fink, S. 303-332. 



\title{
VOM KÖRPER ZUM BILD. EIN STREIFZUG DURCH DIE THEATERGESCHICHTE ALS MEDIENGESCHICHTE IN SIEBEN KURZEN KAPITELN
}

\author{
ULRIKE HASS
}

\section{Medialität und Intermedialität des Theaters (zur Einleitung)}

Gegenwärtige Entgrenzungen und Transformationen einzelner Fächer sowie die Neuabsteckung von claims - Kunstwissenschaft tritt als Bildwissenschaft auf, Bildwissenschaft tritt mit einem gewichtigen Anteil als Kulturanthropologie oder als Wissenschaft der visuellen Kultur auf, Filmwissenschaft transformiert sich zu Medienwissenschaft - haben ihr Hauptmotiv in den bildmedialen Veränderungen der Gegenwart. Somit wird die mediale Evolution mit ihrer jüngsten, durch die Einführung der digitalen Technologien ins Bewusstsein getretenen Wendung als bildmediale Entwicklung akzentuiert - obwohl dies nicht zwingend wäre, denn die Digitaltechniken modellieren Akustik und Audiovisualität in keinem geringeren Maß. Eine solche Akzentuierung kann daher kaum anders denn als Folge der neuzeitlichen Privilegierung des Sehens aufgefasst werden: Die bildmediale Orientierung verstärkt eine auf den Sehsinn zentrierte Tradition. Dies ist der Anknüpfungspunkt für die vielfach erhobene Kritik an einer relativen Vernachlässigung der akustischen Medien, der Stimme, der oral/auditiven Dimension sowie der Audiovisualität im engeren Sinn ihrer Geschichte einer wechselseitigen Verschränkung als auch ihrer geräuschhaften Koppelung von Bild und Ton im Video (vgl. Spielmann: 66; Kolesch/Krämer).

Wenn nun das Verhältnis von Theater und Medien zur Debatte steht - wozu setzen wir uns dann ins Verhältnis? Zu Veränderungen von Gestalt und Struktur der Medienentwicklung? Zu medientheoretischen Auseinandersetzungen? Zu Gegenständen der Medienwissenschaft bzw. zur Frage, welche Gegenstände Theaterund Medienwissenschaft teilen?

In meinem Beitrag möchte ich zweierlei aufweisen: Zum einen, inwiefern Theaterwissenschaft unter eine medientheoretische Perspektive geraten ist - und zwar zu ihrem Vorteil. Zum anderen, inwiefern der Gegenstand des Theaters in seiner Geschichte entscheidenden Anteil an der Herausbildung einer auf den Sehsinn zentrierten Tradition hat - und zwar, bis in die Gegenwart hinein, zum Nachteil des Theaters.

Zum ersten Punkt möchte ich mich im Rahmen dieser theoretischen Einleitung kurz halten. Zweifellos wurde die Entwicklung einer spezifisch medienwissenschaftlichen Perspektive ausgelöst durch das Phänomen der technischen Reproduzierbarkeit akustischer und visueller Artefakte im frühen 20. Jahrhundert. Dieser Sachverhalt hat zu der Entstehung einer Aufmerksamkeit für größere Verschiebungen im Gefüge der Medien beigetragen, die von der analytischen Erschließung 
der jeweils gegenwärtigen medialen Entwicklung ausgeht und motiviert wird. Von dieser Ausgangslage her ist die medienwissenschaftliche Perspektive durch zweierlei Besonderheiten geprägt:

Erstens ist sie zutiefst an einer Interrelation von Medien interessiert, weil in der Entstehungsphase eines neuen Mediums nur die Diskussion des intermedialen Settings dazu verhilft, Aufschluss über die in dieser Phase eingeleiteten Strukturveränderungen zu gewinnen. Zweitens ist sie aufgrund des Zwangs, das neue Medium nur im Horizont allgemeinerer Medienentwicklung spezifizieren zu können, durch das Phänomen der Remediatisierung geprägt. Die Analyse elektronischer Bildlichkeit etwa verlangt, den Standort der Bildkultur unter medialen Bedingungen tendenziell insgesamt zu erfassen. Sie verlangt die Auseinandersetzung mit strukturellen Formen des Bildes in der Geschichte bildhafter Repräsentation. Theater, Malerei, Fotografie, Film und Installation nehmen sowohl künstlerisch als auch in Form der theoretischen Reflexion diese Auseinandersetzung auf, indem sie und dies ist das Kennzeichen der Remediatisierung, die als Doppelstrategie erscheint - als Medien auf Medien Bezug nehmen. Anders herum gesagt: Ihre Auseinandersetzung ist zwangsläufig davon geprägt, die je spezifische, eigene Medialität selbst zu thematisieren (vgl. Bolter/Grusin: zur »Doppelstrategie « insbes. 3336). Dieses im Phänomen der Remediatisierung angezeigte Paradox verdankt sich der Beschaffenheit des Medialen selbst, das eher als Umgebung, Voraussetzung oder Bedingung wirkt, während das Medium im Singular eigentlich ein Unding ist. Selbst wenn wir von einem Bildmedium oder, sagen wir, vom Spiegel oder der Geste als einem Medium sprechen, ist in der Verwendung des Begriffs >Medium< schon der interrelative Bezug zu anderen Medien enthalten. Diese Beschaffenheit des Medialen als Umgebung, Voraussetzung oder Bedingung bedeutet desweiteren, nicht länger von einem instrumentalen Bezug zwischen Benutzern und Medien ausgehen zu können.

Für das Subjekt bedeutet diese Beschaffenheit des Medialen, sich unter den Aspekten der Interrelation und Remediatisierung gleichsam selbst zu begreifen: In seinem Anteil an und in einer medialen Umgebung, als Teil des Mediums, das es anwendet unter Anerkennung seiner Bedingungen. Und das heißt, dass in einem Medium zu sein notwendig ausschließt, es jemals restlos zu beherrschen.

Der Hinweis auf das Phänomen der Remediatisierung muss an dieser Stelle genügen, um anzudeuten, warum es möglich ist, von einer konstitutiven Medialität von Theater zu sprechen, während die Frage, ob Theater ein Medium sei, insofern obsolet ist, als es keinen Ort gibt, von dem aus sie sich stellen ließe. Theater kann, für sich genommen, gar nicht danach fragen, ob es ein Medium sei, sondern es muss - so wie es auch die Geschichte dieser Fragestellung ausweist - gefragt werden. Als Befragtes wird es seiner Medialität und seiner intermedialen Bedingungen eingedenk, experimentiert mit ihnen um und erforscht sie. Es setzt sich in Beziehung zu einer medialen Umgebung, indem es ihr antwortet. Dabei geht es jedoch um Relationalität und nicht um einen Status. Theater ist ein Ort der Verhandlung, es besteht wesentlich in der Ausstellung seiner Ortlosigkeit vor Ort. Es wird daher in der Auseinandersetzung mit seinen medialen Bedingungen nicht einfach zu einem Medium, sondern es versucht, als ein solches $\mathrm{zu}$ antworten und sich $\mathrm{zu}$ reflektieren. Außerhalb dieser Prozesse ist es nicht.

Medienwissenschaft geht von der Interrelation der Medien aus, weshalb sie sich auch nicht auf bestimmte Gegenstände beruft oder bestimmte andere ausschließt. Sie besteht wesentlich in einer theoretischen Perspektivierung (Glanz und Elend sind in solche Ungegenständlichkeitsbeschreibung mit eingeschlossen), die 
von der Theaterwissenschaft aufgegriffen wird, insofern sich Geschichte und Gegenwart des Theaters in einer Mediengesellschaft ohne diese Perspektivierung nicht mehr begreifen und darstellen lassen.

\section{Erinnerung an den (antiken) Zusammenhang von Schrift und Bild}

Die Geschichte des westeuropäischen Theaters ist tief mit der okzidentalen Entscheidung für eine Versichtbarung der Welt im Namen oder im Begriff des Bildes verbunden. In den Umbrüchen der Renaissance vollzieht sie einen markanten Bruch mit einer anderen, tiefer liegenden Traditionslinie, in der die Sichtbarmachung und -werdung an die Relation von Schrift und Bild geknüpft war.

Diese Relation, die hinsichtlich ihrer Wirkung auch als Einschreibung und Einbildung tituliert werden kann, war in der griechischen Antike noch als Erfahrungshorizont zugänglich und umkämpft. Zahllos sind die Verschränkungen zwischen »Anschaulichkeit « (enargeia) und Sprache. Sie bilden das Hauptfeld der Auseinandersetzung, in der es Platon um die Ablehnung der sprachlichen Mimesis durch die Tragödiendichter geht. Um jedoch deren Abbildlichkeit zu verurteilen, spricht Platon im entscheidenden zehnten Buch der POLITEIA über weite Teile nur vom Maler, der lediglich >Abbilder von Abbildern< erzeuge. Interessant in diesem $\mathrm{Zu}$ sammenhang ist, dass das griechische Wort für >Malerei<zo-graphia bzw. >Maler zo-graphos in dem Wort für Schreiben oder Schrift wurzelt: graphia, während für Dichtung bzw. Dichter in der POLITEIA stets das Wort mimesis bzw. mimetes verwendet wird, ein Wort, für das sich im Deutschen die unscharfen Begriffe der $>$ Nachahmung< (Schleiermacher) bzw. der >Nachbildung< oder des >Nachbildners< eingebürgert haben.

Doch nicht nur bei Platon, auch in der aristotelischen Rehabilitierung der Mimesis wird der Begriff eikon für >Bild< oder > Vergleich< vor allem im Zusammenhang mit der Erörterung der anschaulichen sprachlichen Darstellung verwendet (und in der Theorie der Metapher/Rhetorik diskutiert). Von besonderem Interesse ist dabei, dass die Anschaulichkeit des Bildes (eikon) zwar die überragende Leitvorstellung für die dichterische Mimesis bildet, als solche jedoch keine gesonderte theoretische Aufmerksamkeit erfährt. Diese gilt bei Aristoteles vielmehr den Verfahren oder der Wirkung als Übertragung, während die Anschaulichkeit des Bildes das stillschweigend Vorausgesetzte zu sein scheint.

Bei Aristoteles ist des Weiteren von Interesse, dass seine Diskussion von $>\mathrm{Na}-$ tur $<$ physis und $>$ Kunst $</$ techne in Bezug darauf, dass sie beide hervorbringende, verwirklichende Kräfte aufweisen, große Ähnlichkeit zwischen Natur und Kunst feststellt. Sie sind einander nicht im Verhältnis einer objektiven Gegebenheit und einer subjektiven, künstlerischen Bearbeitung entgegengesetzt, sondern strukturgleich in Bezug auf ihre energetische Potenz.

Wie diese knappen Anmerkungen vielleicht andeuten, stellen sich die Verhältnisse zwischen Schrift und Bild in der antiken Diskussion außerordentlich verzweigt und einander überlappend dar. ${ }^{1}$ Beide erscheinen eingebettet in eine Sphäre des Hervorbringens. Beide zeigen. Zwar gibt es unterschiedliche Arten des Zeigens, aber sie erscheinen füreinander durchlässig, stehen sich nahe und erscheinen keinesfalls isoliert voneinander.

1 Ausführlicher dazu Haß 2008. 
Vor diesem Hintergrund wird der Einsatz des neuzeitlichen Umbruchs, in dem Anschaulichkeit und Bildlichkeit ausschließlich dem Bild zugeordnet werden, während Schrift, Text, Dichtung ausschließlich dazu da sind, zu sagen und zu bezeichnen, in seiner Tragweite leichter zu ermessen. »Die tiefe Zusammengehörigkeit der Sprache und der Welt wird dadurch aufgelöst «, wie Foucault in seinem Portrait der prosaischen Neuzeit festhält. Er fährt fort:

»Der Primat der Schrift wird aufgehoben, und damit verschwindet jene uniforme Schicht, in der sich unendlich das Gesehene und das Gelesene, das Sichtbare und das Aussagbare kreuzten. Die Sache und die Wörter werden sich trennen. Das Auge wird zum Sehen und nur zum Sehen bestimmt sein; das Ohr lediglich zu Hören. Der Diskurs wird zwar zur Aufgabe haben zu sagen, was ist, aber er wird nichts anderes mehr sein, als was er sagt« (1974: 75f).

Das gewaltsame Auseinanderreißen von Text, Schrift und Bildlichkeit, von Sagbarem und Sichtbarem, zieht eine ganze Phalanx von weiteren Umdeutungen, Vereinseitigungen und Binarismen nach sich - vor allem solche, die das Verhältnis des Körpers zu seiner Umgebung neuartig ordnen: Die Natur wird mit einer vermeintlich objektiv vorliegenden, äußeren Wirklichkeit identifiziert und im Umkehrschluss dazu der menschliche Körper als physische Entität aufgefasst. Der Natur wird eine Darstellung durch ökonomische Verwertung auferlegt, die Körper werden einer Darstellung durch die Programmatik der abbildenden Ähnlichkeit zugeführt. Die Entfaltung des gesamten Unterfangens, die Welt im Bild und als Bild zu behaupten, wird von jenen problematischen Relektüren der Antike begleitet, mit denen sich die Renaissance als Erfinderin einer neuen, prosaischen Welt strahlend ins Werk setzte.

\section{Das Dispositiv der Renaissance}

Der Einsatz der Renaissance verdankt sich in paradigmatischer und operativer Hinsicht entscheidend dem System der Zentralperspektive. In Bezug auf deren Stellenwert und Status wäre viel gewonnen, wenn sie nicht länger unter dem Kürzel transportiert würde, sie sei ein Instrument oder Mittel, um dreidimensionale Körper auf einer zweidimensionalen Fläche abbilden zu können. ${ }^{2}$ Demgegenüber ist es sinnvoll, die Zentralperspektive als ein System, ein Dispositiv oder auch als ein Denken zu charakterisieren, das auf eine völlig neuartige Konzeption des Horizonts hinausläuft. Während in früheren Zeiten der Horizont entweder als Umgebung gedacht wurde, die den menschlichen Körper multidirektional umgibt und sich mit ihm austauscht (Antike) oder, wie im langen christlich geprägten Mittelalter, oben in der Höhe über den Köpfen angenommen wurde, geht es in der Folge der Zentralperspektive um einen Horizont, der als Linie auf einer Bildfläche in Augenhöhe dem Betrachter gegenüber behauptet wird. Die Bezeichnung der »Augenhöhe« kein Begriff, eher eine Schimäre - erhält schon in der Konstruktionsbeschreibung zur Perspektive bei Leon Battista Alberti einen systematischen Stellenwert. Sie

2 Die Dimension resultiert aus einer wesentlichen Operation der Zentralperspektive: Zum Vorgang der Umkehrung zweiergegenläufig gerichteter Vektoren und ihrer Verschmelzung in einer Dimension vgl. die Diskussion des ersten Experiments zur Perspektive von Brunelleschi (Haß 2005: 81-109). 
verdankt sich einer willkürlichen Empfehlung, die bei Alberti nicht weiter begründet oder diskutiert wird: Der Horizont, an dem alle Linien zusammenlaufen, wird in Augenhöhe des fiktiven Betrachters fixiert.

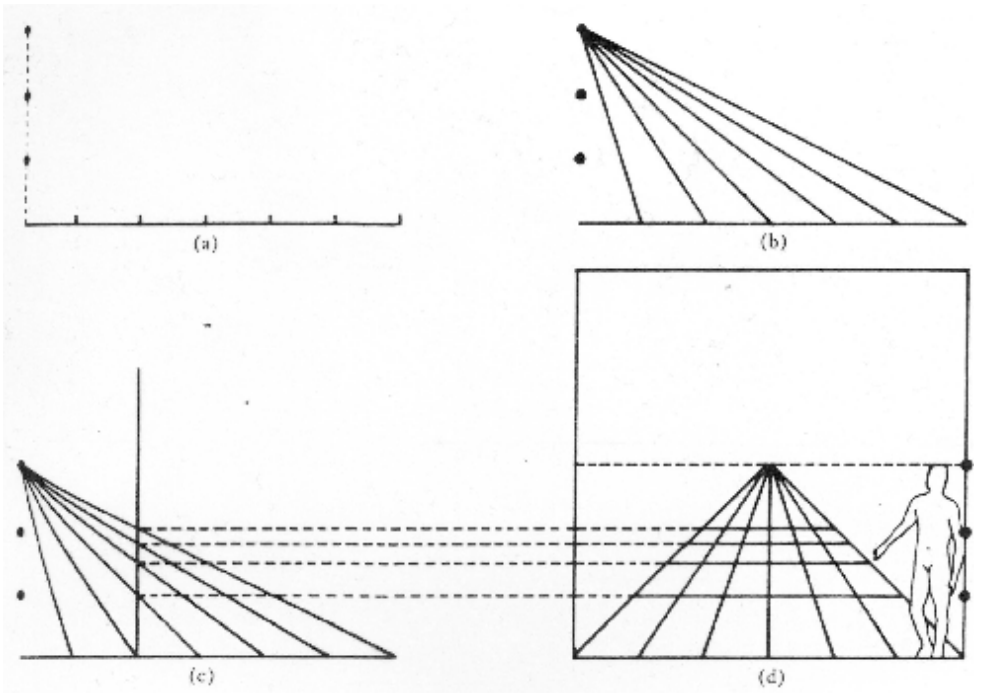

Abbildung 1: Samuel Edgerton: Albertis Konstruktion der perspektivischen Darstellung.

Der fiktive Bezugspunkt der >Augenhöhe des Betrachters < tritt in dieser schematischen Darstellung der Ausführungen Albertis durch Samuel Edgerton schon in der ersten Phase der Konstruktion hinzu. Über der in gleichmäßige Abschnitte geteilten Grundlinie »lege ich dann einen einzelnen Punkt fest «, schreibt Alberti. Dieser Punkt wird in der zweiten Phase der Konstruktion zu jenem Bezugspunkt, von dem aus die Linien zu den Markierungen auf der Grundlinie gezogen werden. »Dann lege ich fest, wie groß der Abstand zwischen dem Auge des Betrachters und dem Bild sein soll«, erläutert Alberti seinen nächsten Vorgang der Einrichtung einer bestimmten, willkürlich festgelegten Distanz. Die vorausgesetzte Augenhöhe kehrt als Höhe der Horizontlinie in der bildlichen Darstellung wieder. Alberti empfiehlt abschließend, die im Bild dargestellten Personen nicht über diese Horizontlinie hinaus ragen zu lassen.

Unter dem Label der >Augenhöhe< geht es bei Alberti um die Erreichbarkeit des Horizonts, um seine Familiarisierung und seine Beherrschbarkeit. Das entscheidende Mittel dazu ist nicht so sehr eine mehr oder minder konsequent perspektivisch durchgeführte Bildkonstruktion, sondern eine Anordnung des Sehens, die das Sehen selbst in den Blick nimmt. Diese Anordnung wird mit dem Begriff der Zentralperspektive als Dispositiv bezeichnet. 


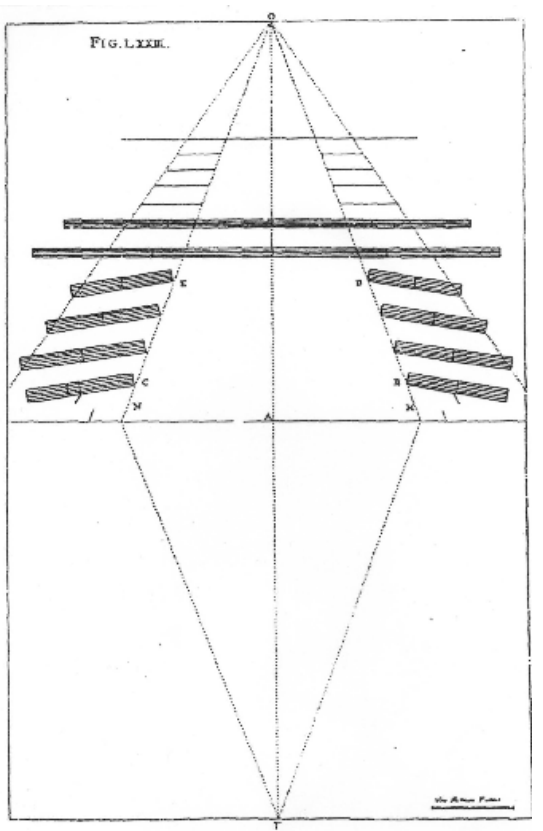

Ausgehend vom Theaterraum wird das Dispositiv von Andrea Pozzo erstmals um 1700 in seinem systematischen $\mathrm{Zu}$ sammenhang vollständig erfasst und in ein Schema überführt. Dieses abstrakte Schema - eingedenk dessen, dass ein Schema umso weniger aussagt und sich immer mehr versiegelt, je rudimentärer es sich zeichnen oder transportieren lässt - wird zum Bestandteil der Ausbildung von Bühnenbildnern. In ihm sind auf das Konsequenteste verdichtet: Die Teilung von Darstellung und Zuschauern, die entlang einer Linie in der Mitte erfolgt und sie einander gegenüber konfrontativ anordnet. Diese Linie wird vom Darstellungsraum aus als Linie der Projektion definiert, auf die hin sich der Bildeindruck der Szene entwirft und berechnet. Pozzo selbst tituliert sie als »tabula $\ll /$ Einschreibefläche.

Abbildung 2: Andrea Pozzo, Bd. I, Fig. 73 (1700).

Vom Zuschauerraum aus ergibt sich auf dieser Linie das szenische Bild in illusionärer Geschlossenheit zu sehen. Die beiden, zwischen Fluchtpunkt und Sichtpunkt (oder Augenpunkt) maximal geöffneten Dreiecke erlauben den Zuschauern größtmögliche Einsicht in die Szene und zwingen andererseits alles, was im optisch erschlossenen Bühnenraum zur Darstellung herangezogen wird, im Bild zu erscheinen. Dieses Dispositiv bildet die wichtigste Ursache dafür, dass die Körper der Darsteller fortan damit hadern, in völliger Sichtbarkeit den Augen der Zuschauer preisgegeben zu sein. Von hier aus datieren ein einseitiger Voyeurismus des $\mathrm{Zu}$ schauerblicks und eine unaufhebbare Scham, die sich an das einseitige Gesehenwerden des Schauspielers knüpft und nach besonderen Strategien ihrer Durchbrechung oder des Schutzes verlangt. Unter der Voraussetzung, mit der in diesem Dispositiv Sehen und Gesehenwerden miteinander verschränkt sind, müssen die Körper in diesem Darstellungsraum zum Bild werden. Sie können mit ihrem Bild absichtsvoll verschmelzen ${ }^{3}$ oder es spielerisch unterlaufen ${ }^{4}$, aber sie können nicht vor seine Setzung zurück.

3 Wie z.B. Isabelle Huppert als Merteuil in Bob Wilsons Inszenierung von Heiner Müllers QUARTETT. Odéon Paris, Herbst 2006.

4 Wie z.B. häufig in Inszenierungen von Jürgen Gosch zu beobachten ist, zuvörderst in seiner Inszenierung von Shakespeares MACBETH. Schauspielhaus Düsseldorf, Herbst 2005. 


\section{Körper der Darstellung, Körper der Zuschauer}

Um die Abstraktion, die mit diagrammatischen Darstellungen gegeben ist, etwas zu mildern, zitiere ich im Folgenden eine etwas längere, diskursive Beschreibung dieses Dispositivs von Joachim Paech. Er beschreibt den kinematographischen Raum, der denselben dispositiven Bedingungen gehorcht wie das neuzeitliche Theater.

»Das Kino als Raum ist die Bedingung dafür, dass die Projektion von Kinofilmen auf eine Leinwand sichtbar wird; wie die >camera obscura< muss er innen dunkel sein, damit das einfallende gebündelte Licht im Innern ein Bild projizieren kann; im Prinzip gehorcht diese Anordnung noch der neuzeitlichen Perspektivkonstruktion. Der Kinoraum ist auch ökonomisch, als Versammlungsraum, von Bedeutung, denn er muss groß genug sein, um ausreichend vielen Besuchern zugleich Zutritt zu gewähren, die als Massenpublikum die relativ hohen Kosten der Filmproduktion amortisieren müssen; daher ist das Kino von vornherein auch mit dem urbanen Lebensraum der Großstadt als einem weiteren Paradigma der Moderne verbunden.

Der Raum des Kinos ist geordnet. An beiden Stirnseiten ist er zu weiteren Räumen geöffnet, zur Wirklichkeit des sozialen Lebensraumes auf der einen und zum ästhetischen Raum der Filmprojektion auf der anderen. Insofern ist das Kino ein Zwischenraum zwischen zwei Wirklichkeiten, einer sozialen und einer ästhetischen. Es verwundert daher nicht, dass das Kino selbst in der Wahrnehmung von Zuschauern [...] kaum Erwähnung findet, denn [der Kinoraum] hat einen bruchlosen Übergang in den ästhetischen Raum der Filmprojektion zu gewährleisten« (Paech: 28).

Der Kinoraum fixiert den Betrachter in räumlicher Distanz der Leinwand gegenüber. Diese Distanz selbst ist Bedingung für den effet de réalité in der Wahrnehmung des Zuschauers, für seine imaginäre Teilnahme, für sein Kleben an der Pseudo-Natur der gefilmten Szene. »Als ob ich zwei Körper zugleich hätte«, sagt Roland Barthes (292) zur Situation beim Verlassen des Kinos: Im Ausgang des Transitoriums Kino muss der schattenhafte, phantasmagorisch identifizierte Doppelgängerkörper weichen - oft nur zögernd und widerwillig und erst, wenn im Saal das Licht angeht.

Paechs Beschreibung des Kino-Lichtspieltheaterraums impliziert den Theaterraum, der entscheidenden Anteil an der Herausbildung dieser Anordnung des Sehens hat. Diese Anordnung bezieht ihren Mehrwert aus der Regelung einer Distanz (in dieser Distanz arbeitet der ehemals unerreichbare Horizont), die in einer Phantasmagorie von Nähe kulminiert. Die Darstellung durch Ähnlichkeit evoluiert ihre Formensprache permanent, um unter veränderten Bedingungen immer wieder dasselbe zu leisten: Die imaginäre Überwindung des faux terrain zwischen dem physischen Raum der Zuschauer und dem fiktiven Raum der Darstellung.

Mit faux terrain bezeichnet die französische Kinotheorie die Schwelle, an der diese beiden >Räume< aneinander geheftet werden. Diese Schwelle entspricht dem Un-Ort einer unräumlichen Bezugnahme, der zugleich an das angrenzt, was außerhalb seiner liegt und in ihn nicht eingeht und nicht eingehen kann. Die medialen Eigenschaften dieser dispositiven Anordnung bedingen die Aufführung notwendig als einen fragilen Ausschnitt. 


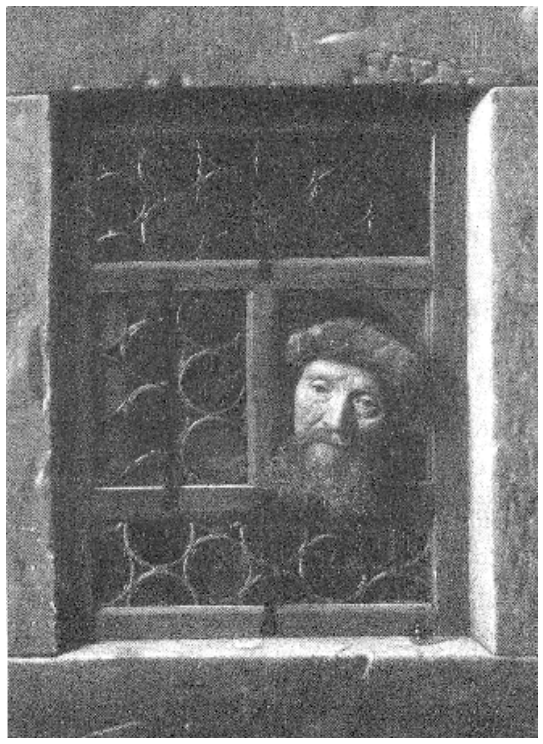

Das faux terrain besteht aus einem $\mathrm{Zu}-$ gleich von Hier und Anderswo. Es findet seinen Nachhall im Doppelgängerkörper des Zuschauers, von dem im Zitat von Roland Barthes die Rede war. Darstellungen im Rahmen dieser dispositiven Anordnung des Sehens finden, so Samuel Weber in seinen Reflexionen zur Theatralität, auf einem Resonanzboden statt, der jeden Versuch, eine abschließende Handlung durchzuführen, immer wieder in Frage stellt. Darstellungen im Rahmen dieser dispositiven Anordnung sind grundsätzlich Schwellenbilder und teilen mit dem Gespenst dessen Spektralität bzw. Theatralität.

Abbildung 3: Samuel van Hoogstraeten: MANN IM FENSTER, 1653.

Schwellenraum, faux terrain, zur Zeit der Einrichtung und Realisierung des besprochenen Dispositivs. Ununterscheidbar sind bei diesem Bild: Innen oder außen, zur Rede anhebend oder verstummend, Sprechen oder Schweigen, das Zugleich von Hier und Anderswo.

\section{Vom Körper zum Bild und die Entstehung einer Dichotomie}

Das abendländische Theater hat in seiner Entwicklung einen unersetzbaren Anteil am besprochenen Dispositiv zur Sichtbarmachung und Wahrnehmung, indem es die Leistungen der bildenden Kunst um die systematische Einbeziehung der dritten Dimension gleichsam ergänzt. Das transportable, flächige Bild/tableau handelt mit der Möglichkeit, die Richtungen > vorne und hinten< sowie >rechts und links< durch seine, dem Betrachter selbständig entgegentretende Darstellung zu transformieren nämlich in die einfachen, eindimensionalen Oppositionen: Gegenüber und seitenverkehrt. Bild und Betrachter teilen jedoch weiterhin dieselben, im Betrachterraum nicht umkehrbare Richtungen >oben und unten<. Die Transformation dieser Richtungen, die unmittelbar mit der Schwerkraft des Betrachterkörpers spielen, vollbringt das Theater - und zwar in seiner neuzeitlich vielleicht stärksten Phase, auf die immer wieder zurückzukommen ist, dem Barock.

Im Barocktheater vollzieht sich eine Bewegung, in der alles und jedes zur Darstellung gerinnt. Himmel und Hölle sind die bevorzugten Themen, die bühnentechnisch durch eine Vervielfachung der Tiefe, die Einführung von Böden unter und über der Bühne sowie eine perfektionierte Wandelbarkeit der Schiebekulissen realisiert werden und damit eine vollständige Entrealisierung des Raumes sowie eine umfassende Entlokalisierung der Betrachterposition bewirken. Barocktheater ist pure Realisierung des Schwellenraums, pures faux terrain. Von hier aus datiert eine doppelte Perspektive, unter der die Körper im Darstellungsraum in Erscheinung treten. 
Zum einen erfahren die Körper eine Konturierung im Bild, ihre Abgeschlossenheit und Reduktion auf die Kontur als einer äußeren Linie, mit der sie sich gegen den Hintergrund verschließen und abgrenzen und innerhalb derer sie sich als Subjekt selbst permanent aktualisieren müssen. Die bildhafte Konturierung des Körpers verschließt sich dabei gegen jenen anderen Körper, der in kein Bild eingehen kann, wird ihm zur Qual.

Zum anderen erfahren die Körper den Verlust dessen, was »den gesamten Realraum, alle Platzierungen, in die der Betrachter gesperrt ist, als noch illusorischer denunziert « (vgl. Foucault 2002: 45) den Verlust ihrer Lokalisierbarkeit >im eigenen Fleisch . Wenn dieser Verlust im Bild thematisiert wird, tritt er als Theatralität einer besonderen Konturlosigkeit der Körper auf. Diese wäre als eine Geschichte der Ausgesetztheit und der Überflüssigkeit von Körpern brut et nu zu analysieren.

Diese doppelte Perspektivierung der Körper im barocken Darstellungsraum wird in der unfassbaren Gleichzeitigkeit von Nicolas Poussin und Peter Paul Rubens auf den Punkt gebracht. Bei Poussin triumphieren die Geschlossenheit der Linie, die Einheit der Körperbilder und die Geschlossenheit ihrer Bildhintergründe, die atmosphärische Dichte ihrer Umgebungen, Schönheit, Luxus, die edlen Himmel.

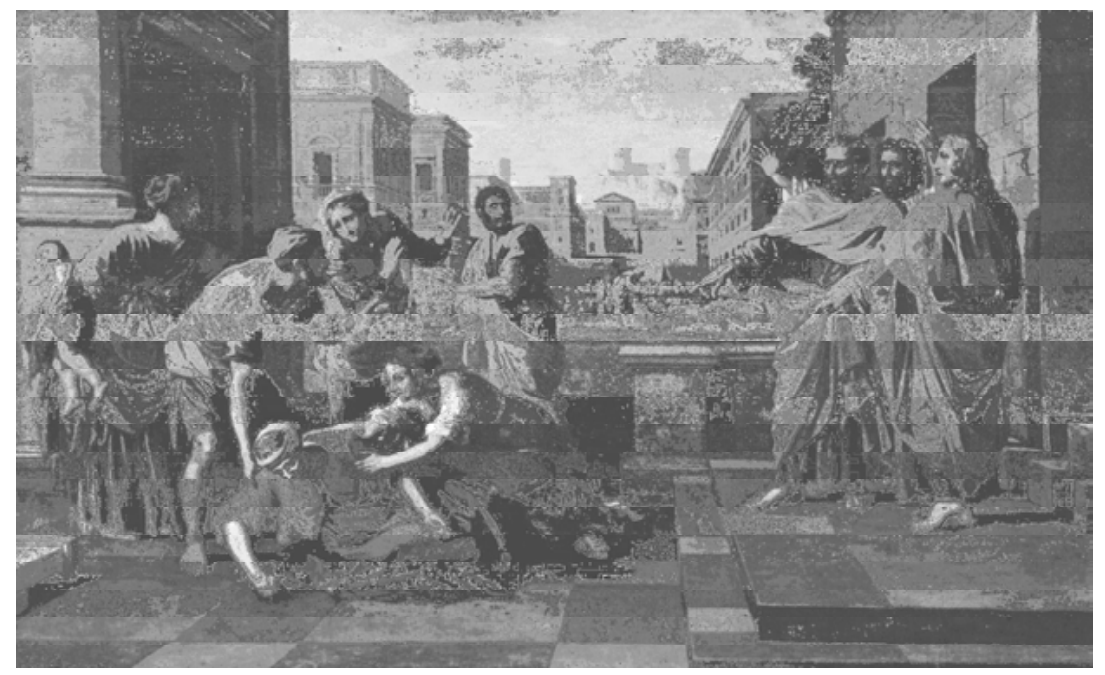

Abbildung 4: Nicolas Poussin: DER TOD DER SAPHIRA (1655). Das Bild zitiert im Hintergrund den stereotypen Bühnenaufbau für eine tragische Szene mit einem >Spielsteg im Bildvordergrund. Innerhalb ihrer Konturen leisten die dargestellten Körper jeweils ein Maximum an bedeutendem gestischen Ausdruck.

Bei Rubens hingegen gibt es die ausgestellte Nacktheit der Körper, ihre Ausgesetztheit, mittelalt und schwer, wild, fremd, konturlos und ohne soziale Färbung, den fleischlichen Exzess, das schwere Fleisch, stürzend, das Geschlecht häufig im Zentrum des Bildes präsentierend. Die Welt ist ein Loch. Folgend ein Detail aus 
HÖLLENSTURZ DER VERDAMMTEN, dem Sturz aus dem Himmel auf eine Erde oder etwas, das darunter ist und niemanden mehr trägt. ${ }^{5}$

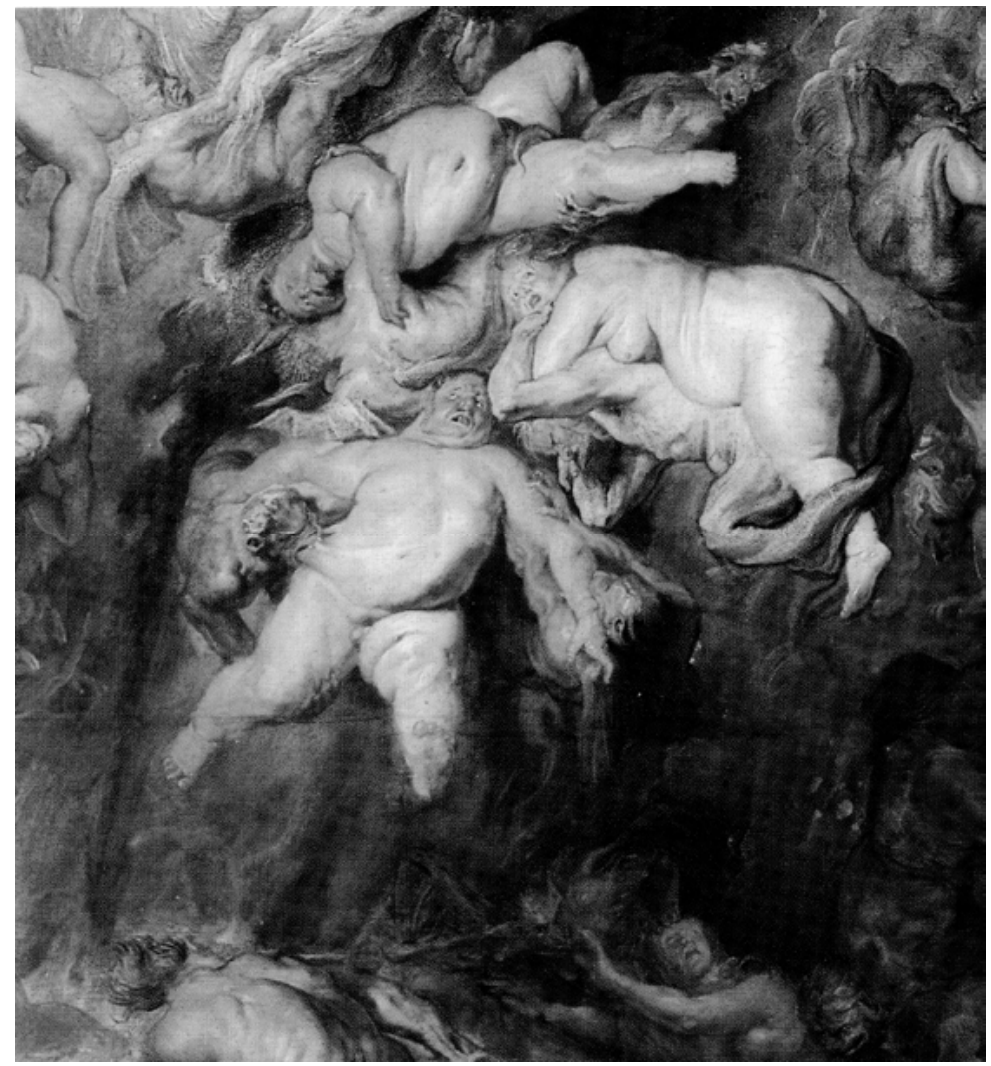

Abbildung 5: Rubens, Detail aus dem Zentrum des Bildes HöLLENSTURZ DER VERDAMMTEN (um 1620). Die Theatralität ist den dargestellten Körpern nicht zitathaft angeheftet, sondern wird als eine ihnen innewohnende ausgestellt.

Die doppelte Perspektive, unter der die Körper ins Bild geraten, führt zu einer Dichotomie: Sistierte Bewegung in der körperbildlichen Kontur oder der Körper selbst als äußerste Grenze einer umfassenderen Bewegung, die in ihm als geronnene Bewegung erscheint. Es sind, sieht man genauer hin, zwei verschiedene Formen, die Körperbewegung zu arretieren, die mit diesem Schritt vom Körper zum Bild einhergehen.

Ich kann die These, die ich in Bezug auf diese Dichotomie verfolge, hier nur andeuten. Aber mir scheint - und dazu diente die Erwähnung des älteren Zusammenhangs von Schrift und Bild - dass sich in dieser Dichotomie eine doppelte Isolation des Bildes niederschlägt. Zum einen seine Isolation in der neuzeitlichen Anordnung des Sehens, die das Bild zur Ausstellung seiner manifesten Sichtbarkeit

5 Ein Bild übrigens, dem Elfriede Jelinek mehrfach Bildbeschreibungen gewidmet hat und das gleichsam zu ihren paradigmatischen Bildern zu rechnen ist. 
drängt, zur Lesbarkeit seiner Konturen und zur Behauptung ihrer Abgeschlossenheit. Zum zweiten spielt jedoch in diesem Umbruch auch die ältere Isolation des Bildes und seine Entlassung aus dem Schrift/Bild-Zusammenhang eine Rolle. In dieser älteren Traditionslinie realisierte sich der Körper bzw. die Körperbewegung (des Schreibenden) stets in der Funktion eines mitanwesenden Dritten. Weit entfernt vom Gebot eines Selbstausdrucks, diente dieser Körper als Medium einer Versichtbarung (der Schrift) und verwies in dieser Funktion auf die anhaltende Schwierigkeit, den Körper in der Repräsentation überhaupt zu verorten. Der Körper ist nicht ausstellbar. Er verliert gegen seine bildhafte Repräsentation, verschwindend brut et nu, als sterblicher Rest.

Es ist klar, dass diese beiden Isolationsformen des Bildes sich nicht hermetisch gegeneinander verhalten. Aus den Überschneidungen, Überlappungen, wechselseitigen Verdrängungen und Verstellungen ihrer Dichotomie generieren wir bis heute die gesamte Bandbreite der bildhaften Erscheinungen des Körpers. Es scheint mir darüber hinaus klar, dass das Theater, das prinzipiell an eine singuläre raumzeitliche Lokalisierung gebunden bleibt und damit in der Art des Partizip Präsenz stets an das gebunden bleibt, was es als Bühne nie allein besitzen kann, eher mit der Bildproblematik der verlassenen Körper korrespondiert - eher also mit dem aufgekündigten Schrift/Bild-Zusammenhang, von dem aus es seine spezifische Szenographie je neu zu gewinnen trachtet.

\section{Jelineks BABEL: Verdinglichtes Sehen}

Heute werden Phänomene unter dem Siegel des Betrachters, des Sehens und der Wahrnehmung platziert, die längst dabei sind, den Schauplatz der Bilder, der Fähigkeit zum Bild überhaupt zu verlassen. Dies geschieht in großem Maßstab, für den insbesondere die Formveränderungen in den heutigen Überwachungsgesellschaften und der Kriegsführung heranzuziehen sind. Die erreichte Kommutation von Bild/Medien, Gewalt und Pornographie ist Gegenstand des Theatertextes BABEL von Elfriede Jelinek. Der Irakkrieg im Frühjahr 2003 zeitigte einen endlosen Nachkrieg, endlose Ströme von Fotos, zusammenbrechende Server. Die Folterfotos von Abu Ghraib gingen ebenso um die Welt wie die Bilder der vier gelynchten USAmerikaner, von denen zwei an der Brücke von Falludscha aufgehängt wurden. Im Zusammenhang mit Fotohandys und Digitalkameras im Zubehör von Soldaten oder Special Forces in Zivil ist dieser Krieg die Berichterstattung über ihn. Ein verdinglichtes Sehen folgt diesen Berichten. Es steht zu dem Betrachteten in einer Relation der Erfahrung ohne Vermögen dazu: Es nimmt auf, aber es spricht nicht vom Betrachteten und gleich einem Kameraauge, das auch keine Erfahrung von dem hat, was es aufnimmt.

»Ich öffne Ihnen jetzt die Augen«, heißt es im dritten Monolog von BABEL. Ein Schnitt durchs Auge wird angekündigt und mit dem Messer im Text durchgeführt wie in Buñuels Un CHIEN ANDALOU. Dort gilt er, wenn man das Szenario betrachtet, in der er auftaucht, einem bestimmten Auge mit einem bestimmten Blick. Es ist der Blick einer Frau, die offenkundig nicht auf den vorausgegangenen Blick des Mannes reagiert, obwohl sie von der Montagefolge in eine beredte Beziehung zueinander gesetzt werden: Zunächst die Großaufnahme eines männlichen Gesichts, das den Mond betrachtet - ein heller Fleck im dunklen Himmel, der in der folgenden Einstellung durch das helle, von dunklen Haaren umrahmte Gesicht der Frau 
abgelöst wird. Doch die Mondschau des Mannes führt nicht zu einem Kontakt mit dem begehrten Objekt: Der Blick der Frau ist eher nach innen gerichtet und kündet, träumerisch zerstreut, von eigener Schaulust, von einem anderen Sehen. ${ }^{6}$ Mit dem Schnitt durch dieses Auge wird das Sehen des Anderen getroffen und meint hier, im Gestus der Kritik, die Negation der Möglichkeit von Wahrnehmung und Beziehung.

Jelinek benutzt diese berühmte Bilderfindung Buñuels, um das verdinglichte Sehen zu charakterisieren:

»Ein Eisberg, scharf wie eine Rasierklinge, hat Ihr titanisch dahingleitendes Augenschiff einfach der Länge nach aufgeschnitten, und jetzt ist alles Eis, ja; auch drinnen. Alles Eis. Kälte. [...] Schauen Sie sich diese Fotos an! Sie finden es unmoralisch wie Sex vor der Ehe, daß dieses Foto gemacht worden ist und uns an die Netzhaut geworfen wird, als wäre sie ein leerer Fetzen, der alles aufnimmt und alles gleichzeitig durchläßt? Das Auge, eh schon selber zerfetzt vom Schnitt vorhin?«(138f)

Ein Portrait des verdinglichten Sehens, neutral und ohne die Erfahrung des Sehens - wie das Auge der Kamera (was auch der entscheidende Punkt der Verknüpfung im Film und mit dem Film von Buñuel ist).

Auf der anderen Seite entspricht diesem Sehen ohne Erfahrung ein Bild ohne Blick. Der Blick bezeichnet im Vorgang des Sichtbarmachens die Bildintention. Im Fall eines Fotos zum Beispiel den Moment des Auslösens. Dieser Moment des Auslösens kann beschrieben werden als Motor von etwas zwischen Wunsch und Zwang, dem zwingenden Wunsch zur Darstellung. Mit den Wort >Motor $<$, >Wunsch $<$ und >Zwang< ist die Ebene des Unbewussten annonciert. Etwas, das vorbewusst ist und kein Bild hat, zwingt zum Übersprung in die Geste des Auslösens, in das Erzwingen der Darstellung. Dazwischen ist ein Riss, der selbst undarstellbar bleibt, aus dem das kreative >Sehen-als< jedoch hervorgeht. Diese in sich gespaltene, von einer essentiellen Abwesenheit durchzogene Bildintention kann im Fall eines Fotos als die Arbeit des Blicks bezeichnet werden.

Im Fall der Folterbilder aus Abu Ghraib, deren intendiertes Bild die Gruppierung der Folternden um ihre Opfer vorsieht, handelt es sich indessen um eine Arbeit des Blicks ohne Entsprechung im visuellen Feld, um ein In-Werk-Setzen des Blicks, um seine Verwirklichung anstelle einer Betrachtung. Es handelt sich um eine Vernichtung des Blicks, den die Arbeit der Folter ohne Rest zu realisieren trachtet.

Der Folterer sieht und hört sich nicht als Subjekt, er vermag sich nicht in einem Raum der Übertragung wahrzunehmen. Seine Beziehung zum Raum der Referenzhaltigkeit ist gerissen. Den Opfern werden die Augen verbunden oder Kapuzen übergestülpt. Der Abbruch jeder möglichen Blickbeziehung ist wesentlich für die Folter, deren Arbeit durch den Blick des Anderen gefährdet ist.

Jelinek: »Die Lynndie und Sabrina und Mega-Megan, die sind ganz bei sich, wenn sie so was machen! Das Ereignis der Organentnahme. Also das Organ fällt. Das haben Sie kapiert? Gut. Der Totenschein wurde ausgestellt« (151). In dieser Szene der absolut ausgesetzten Referenzhaltigkeit treten hinzugezogene optische Aufzeichnungsgeräte - Kamera, Video, Handy - an die Stelle von Augenzeugen. Sie übernehmen dank ihrer technischen Neutralität die Stelle der nichtexistenten

6 In Bezug auf diese Sequenz des Films von Buñuel folge ich hier den Ausführungen von Regine Prange (351). 
Augenzeugen. Wer auch immer hier sein Handy in die Höhe hält, ist Beteiligter, Täter im Zustand der Nicht-Trennung von sich selbst. Die Distanz der Wahrnehmung ist unterschritten. Das Szenario der Folter ist weder Darstellung noch Aufführung, sondern Realisierung eines Blicks ohne »Selbst«-Struktur und Aufnahme dieses Blicks durch ein, auf eine tödliche Verletzung reduziertes menschliches Wesen.

Die technische Neutralität der Apparate ist der einzige Punkt, der diese Szene der Beteiligten im Zustand ihrer ausschließlichen Beteiligung noch mit etwas verbindet, weil dieses technische Supplement gleichzeitig einen Speicher bietet. Im Vorgang und als Teil der Folter entstehen latente Bilder für den Gebrauch der Beteiligten.

Anscheinend per Zufall - doch da in diesem Zusammenhang nicht von Zufällen auszugehen ist, eher deswegen, weil die restlose Auslöschung des Blicks nie vollständig gelingt ${ }^{7}$ - gerät dieses technisch simulierte Bild einer Augenzeugenschaft in die Hände von medialen Multiplikatoren. Jetzt wird eine mediale Maschinerie angeworfen, über die sich das Verhältnis von blickhafter Intention und Augenzeugenschaft - dieses im Moment der Aufnahme nicht existente Verhältnis vermeintlich restituiert. Über die Behauptung, dieses über die digitalen Vertriebswege laufende Bild sei ein Bild im herkömmlichen Sinn z.B. eines Fotos, wird der Zusammenhang von Blickobjekt und Augenzeugenschaft restituiert oder auch reterritorialisiert (wenn dieser Begriff auf die Architektur des Netzes überhaupt noch anzuwenden ist).

Der fatale Zirkelschluss, dass wir es bei einem Bild im Zustand seiner NichtIdentität per medialer Rahmung plötzlich mit einem Bild zu tun haben wollen, das wir mit Bildidentität ausstatten, also mit einem solchen Bild verwechseln, von dem wir denken, dass es die Beziehungen zwischen Darstellung und Betrachter ordnet dieser fatale Zirkelschluss ist allein der medialen Kontextualisierung geschuldet. Ein metaphorischer Effekt der medialen Zirkulation, die als solche keine Territorien und Abwesenheiten kennt und von daher gezwungen ist, sich in einem der analogen Welt zugehörigen Muster zu präsentieren. Ein Vorgang der Hybridisierung.

»Niemand bekommt durch dieses Foto eine Ahnung. Niemand bekommt durch ein Foto diese Ahnung. [...] Dies alles ist darauf ausgerichtet, daß Sie wie ein Kompaß immer dorthin zeigen, wo gerade die Post abgeht an diejenigen, die längst keine Post mehr erwarten. Es wird ihnen alles persönlich mitgeteilt. Sie brauchen keine Botenstoffe. Sie sollen sie bekommen, ihre Ahnung. Ihre Ahnung von keiner Wirklichkeit«(Jelinek: 141).

\section{Zum Nachteil des Theaters}

Es ist nun wirklich fatal, wenn das Theater derart weit entfernt von einem Begreifen des Einsatzes der neuen Medien arbeitet, wie in den hier beiläufig gefundenen Beispielen. Theater geht mit der Gewalt der Schändung, der Folter, des Krieges um und hat so wenig Bewusstsein von sich, dass es sich nicht scheut, die aus dem hybriden Verteiler des Netzes resultierende optische Post als Bilder aufzufassen, die sich visuell zitieren lassen. Doch deren Bildstatus ist, wie im Fall der Folterbilder aus Abu Ghraib, unterschritten. Ihr visuelles Zitat im Theaterraum, der mit dem traditionellen Bildraum verschwistert ist, ist unmöglich, weil sich im Bildraum des Theaters die ruinöse Energie dieser Hybriden nicht mehr lesen lässt.

7 Reste eines anderen, ehemaligen Blicks arbeiten z.B. im pornographischen Setting, das bekannte Bilder zitiert. 

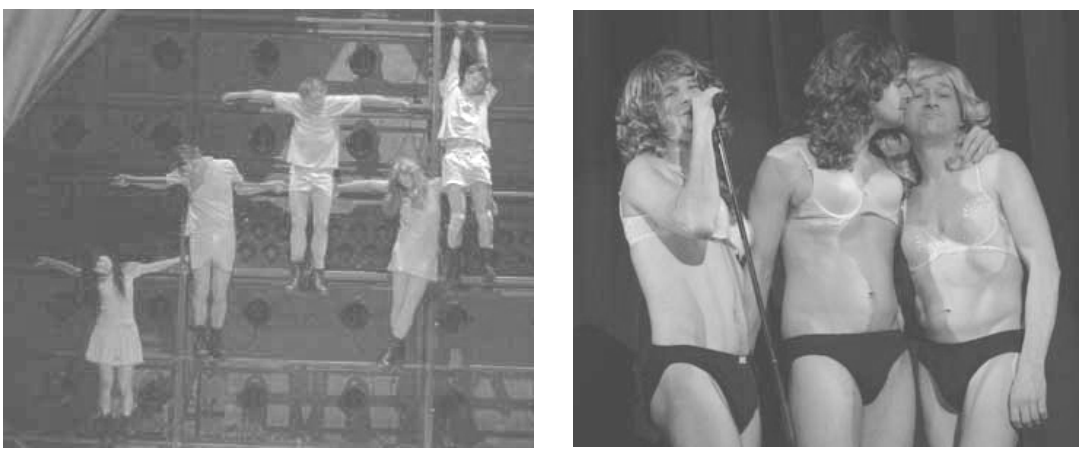

Abbildungen 6 und 7: Szenen aus der Uraufführung von Elfriede Jelineks BABEL durch Nicolas Stemann am Burgtheater Wien, Frühjahr 2004.

Der Zusammenbruch der Relation von Bildbetrachter und Bildobjekt zeitigt nicht nur die gigantischen Bildfriedhöfe auf den Festplatten und im Netz, sondern auch Texte wie BABEL, den ich als Untersagung nicht nur im Sinne des Einspruchs, sondern auch des Verstummens lese.

\section{Literatur}

Barthes, Roland (1976): »Beim Verlassen des Kinos«. In: Filmkritik, Nr. 235, S. 290-293.

Bolter, Jay David/Richard Grusin (1999): Remediation: Understanding New Media. Cambridge (Mass.): MIT Press.

Foucault, Michel (1974): Die Ordnung der Dinge. Eine Archäologie der Humanwissenschaften. Frankfurt/M.: Suhrkamp.

Foucault, Michel (2002): »Andere Räume«. In: Karlheinz Barck u.a. (Hg.): Aisthesis. Wahrnehmung heute oder Perspektiven einer anderen Ästhetik, Leipzig: Reclam, S. 34-46.

Haß, Ulrike (2005): Das Drama des Sehens. Auge, Blick und Bühnenform. München: Fink, S. 81-109.

Haß, Ulrike (2008, in Druck): »Schrift, Bild und Theater. Entwurf einer Fragestellung «. In: Kati Röttger/Alexander Jackob (Hg.): Theater und Bild. Inszenierungen des Sehens. Bielefeld: transcript.

Jelinek, Elfriede (2004): »Babel«. In: Dies.: Bambiland. Reinbek bei Hamburg: Rowohlt.

Kolesch, Doris/Sybille Krämer (Hg.) (2006): Stimme. Frankfurt/M.: Suhrkamp.

Paech, Joachim (2002): »Rodin, Rilke und der kinematographische Raum«. In:

Ders.: Der Bewegung einer Linie folgen... Schriften zum Film. Berlin: Vorwerk 8, S. 24-41.

Prange, Regine (2006): »Bunuel - Dali - Magritte: Die surrealistische Montage in

Film und Malerei«. In: Klaus Krüger/Thomas Hensel/Tanja Michalsky (Hg.):

Das bewegte Bild. Film und Kunst, München: Fink, S. 337-372.

Spielmann, Yvonne (2006): Video. Das reflexive Medium. Frankfurt/M.: Suhrkamp. 


\title{
TRANSMISSIONEN - VORÜBERLEGUNGEN ZU EINER MEDIENGESCHICHTE DES THEATERS
}

\author{
MEIKE WAGNER
}

Medientheorie ist nur ein flüchtiger Gast in der Theaterwissenschaft und konnte sich bislang nicht wirklich als Denkwerkzeug in unserer Disziplin etablieren. Die Aussage scheint von den zahlreichen Tagungen, wissenschaftlichen Arbeitsgruppen und Sammelbänden zum Thema >Theater und Medien< deutlich widerlegt, und dennoch möchte ich mit dem folgenden Beitrag einige Topoi dieses Diskursfeldes kritisch darstellen und auf den blinden Fleck einer medialen Methodologie für die Theaterwissenschaft hinweisen. Es gibt eine Anzahl überzeugender Einzelstudien, die sich Medientheorie nutzbar gemacht haben, Konzepte für Theater als performatives Ereignis erarbeitet haben und sich auf die jeweils aktuelle Wahrnehmungssituation im Theater beziehen. Der Bereich der Theatergeschichte und Kulturgeschichte des Theaters bleibt jedoch medial deutlich unterbelichtet. Daher möchte ich an dieser Stelle Régis Debrays >Mediologie< vorstellen, die meines Erachtens das Potential hat, in eine Methodologie für mediale Theatergeschichtsschreibung überführt zu werden.

Gehäuse, Wechselstrom, Glotzaugen - diese zugegebenermaßen polemisch überzeichneten Begriffe stehen für die gröbsten Missverständnisse im Hinblick auf Medien, Medialität, Intermedialität. Und dennoch sind die medialen Mythen, die mit diesen Schlagworten zusammengefasst werden, auch in der Theaterwissenschaft höchst wirksam und entzünden Debatten um das Für und Wider medientheoretischer Forschung. Für eine Diskussion um den Stellenwert von medialen Konzepten in der Theaterwissenschaft ist es nicht hilfreich, wenn sich die Debatte auf die Kernfrage zuspitzt, ob nun Theater ein Medium sei oder nicht. Die Beantwortung dieser Frage scheint mit einem Bekenntnis verbunden zu sein: Stehe ich nun auf der Seite des Theaters, oder auf der Seite der Medien? In dieser Gretchenfrage klingt unschön eine Reminiszenz an theatrale Legitimierungsdiskurse und heraufbeschworene Medienkonkurrenz an: Theater im Rückzugsgefecht gegen populäre Bildmedien. Auf der anderen Seite hat der Fragende ein berechtigtes Interesse an grundsätzlicher Klärung. Was bedeutet es denn, wenn ich Theater als Medium bezeichne? Oder - welche methodischen Konsequenzen müssen gezogen werden aus der Ablehnung des Medienbegriffs für die darstellenden Künste?

Schwierig gestaltet sich die Sache in der Argumentation dadurch, dass der Medienbegriff einen höchst divergenten Gebrauch findet, um nicht zu sagen: die Begrifflichkeit ist schwammig. Es soll hier behauptet werden, dass doch genau aus dieser medialen Grauzone eine fruchtbare Methodologie entwickelt werden kann. Denkt man das Medium als $>$ contested concept $<-$ als einen Begriff, der sich widerstreitende Bedeutungen innehat und konzeptualisiert werden muss, wie es Marvin Carlson (1) im Rückgriff auf W.B. Gallie für >Performance< vorschlägt, dann eröffnet die begriffliche Unschärfe Analyse-Perspektiven. Ob als >contested concept $<$ oder als $>$ travelling concept $<$ im Sinne Mieke Bals (7-25) verstanden, das 
$>$ Medium < verlangt eine historische und situative Positionierung: Verwendet man >Medium< als Konzept, dann muss einem bewusst sein, welche Funktion dieses Konzept in der eigenen Terminologie ausweist und in welcher Rahmung seine Verwendung operationalisiert wird. Stefan Hoffmann stellt in seiner Begriffsgeschichte des Mediums fest, dass das Medium oszilliert zwischen einem begrifflichen und einem metaphorischen Gebrauch. Und es ist genau diese schwankende Reise, die das Überleben des Begriffes in neuen Denkzusammenhängen über die Zeit sicherte.

Unsere heutige Vorstellung von Medium ist stark von der Vermittlungs-Apparatur geprägt. Die Bilder der technischen Medien wirken in realiter und in der Übertragung als allgemeine Idee vom Medium. Zwei Bedeutungsstränge lassen sich dabei ausmachen. Zum einen das >diaphane Medium< des aisthetischen Wahrnehmungskonzeptes, das als transparentes Trägersubstrat vom Objekt aus auf das Auge wirkt und die Objektschau erst ermöglicht. Zum anderen das $>$ Refraktionsmedium< der Physik, das sich gegen den Lichtstrahl stellt und ihn bricht. Beide Medien erzeugen Sichtbarkeiten - das eine durch Vermittlung, das andere durch Trennung. Der Vermittlungsaspekt findet sich in der Vorstellung von der technischen Apparatur als Transportkanal für Botschaften, der Trennungsaspekt lagert sich an die Medienmaschine an: die mediale Apparatur schneidet ab und aus, verändert und manipuliert. Während nun dieses mediale Technicum in Opposition zu solchen Theatererscheinungen wie energetische Wirkung, körperliche Unmittelbarkeit gesetzt wird, ist es kaum noch vorstellbar, dass bis zum 19. Jahrhundert gerade diese theatralen Wirkungen in medialen Begriffen gedacht worden wären: nämlich als mediales Fluidum, das Raum füllend und Körper füllend sinnliche Wirkung zwischen Subjekten, oder Subjekt und Objekt erzeugt.

Mediales Fluidum oder Darstellungsmaschine - die Theaterkunst ist von medialen Aspekten besetzt und durchdrungen. Sie zu bergen bedarf methodischer Perspektivierungen und ist letztlich ein >Vermittlungsproblem<. Der Scientific Community können sie genau dann nicht wirklich vermittelt werden, wenn die medialen Mythen von Gehäuse, Wechselstrom und Glotzaugen den Diskurs bestimmen.

Gehäuse. Hier wäre vor allem der Apparate-Begriff zu problematisieren. Technophobie, Verdrängung des Technischen färben das Reden über Theater und Medien negativ ein. Wegweisend könnte hier die Ersetzung des Apparates durch den Apparatus im Sinne der Apparatus-Theorie ${ }^{1}$ sein, damit gewinnt man eine Aufweitung des technisch verstandenen Apparates um den Aspekt der Medienpraxis und der Subjektkonstitution durch mediale Apparat-Anordnungen. Ihre Fokussierung auf das Kino hat zunächst eine Anwendung der Apparatus-Theorie auf Theater verstellt. Die Umformulierung dieser Theorie auf das Theater hin hat es mir ermöglicht, bestimmte Aspekte der Medialität von Theater zu benennen (Wagner: insbes. 103-110). Allerdings gäbe es hier noch ein Desiderat an weiteren Analysen und einer weiteren Verknüpfung mit theaterwissenschaftlicher Methodologie. Meine eigene Konsequenz im Hinblick auf die >Technophobie< des >Gehäuse-Diskurses< war es zunächst, den Begriff >Medium < in Bezug auf Theater gar nicht mehr anzuwenden, sondern anstelle dessen von >Medialität< zu sprechen - um dann im Gegenzug etwa Video-Bilder, Projektionsmaschinen, Monitore als >Medienapparate< zu bezeichnen.

Wechselstrom. Dieses Schlagwort steht für den Themenkomplex der Bindekräfte zwischen Bühne und Zuschauerraum. Gerade hier wird der Medienbegriff ausmanövriert im Verweis auf Energieströme, auf Live und Recorded, auf direkte,

1 Zur Apparatus-Theorie siehe etwa Jean-Louis Baudry (36-43) und Jean-Louis Comolli (121-142). 
unmittelbare Wahrnehmungs-Steuerung des Theaters, auf entgrenzte Sinnlichkeit, die gerade das Theater im Gegensatz zu technischen Medien herstellen kann/können soll. Aus dieser dichotomischen Setzung scheint es jedoch zwei Auswege zu geben: Zum einen die phänomenologische Perspektive, die den Wechselstrom als Wahrnehmungsereignis betrachtet und damit gerade an einen Begriff von Medialität anschließbar macht. Aufschluss geben hier etwa die Schriften von Maurice Merleau-Ponty in der medientheoretischen Lesart von Georg Christoph Tholen (siehe etwa 1995 und 1999). Zum anderen können relationelle Forschungsperspektiven wie etwa aus der neueren Intermedialitäts-Theorie, die nicht mehr nur auf inhaltliche Übersetzungsvorgängen von einem Medium in ein anderes fokussiert ist, Gegensätze aushebeln und sich gerade auf die Prozesse beziehen, die zwischen Medien und ihren Nutzern, Betrachtern, Teilnehmern ablaufen. ${ }^{2}$

Glotzaugen. Der Sehvorgang im Theater darf grundsätzlich nicht mit >glotzen< beschrieben werden. Im Theater wird geschaut, rezipiert, kontemplativ erschaut. Das hat sich schon Peter Handke als Provokation in PuBLIKUMSBESCHIMPFUNG zunutze gemacht: »Ihr Glotzaugen!« schleudern seine Schauspieler dem Publikum entgegen. Glotzen ist eine niedrige Form des ungenierten Starrens, des hypnotischen und hypnotisierten Blicks. Verursacht durch effektheischende Augen-Attraktion. Glotzen ist absolut, lässt keine Reflexion zu, ist dem Rausch verwandt, lässt einen nicht los. Eine gefährliche Sache also, die bestenfalls beim Dauerkonsum von $>$ Medien-Medien< passieren darf. Mit diesem Schlagwort ist also die Scheidung von Hochkultur und niederem Medien-Entertainment benannt. Eine Zwei-Klassen-Kultur, die sich an ihren Wahrnehmungsdispositiven trennt.

Doch ein zweiter Aspekt erscheint durch die Glotzaugen. Er betrifft die melancholische Verabschiedung der $>$ Wirklichkeit< durch eine angenommene >zunehmende Medialisierung< der Welt. Damit einher geht die Vorstellung einer negativen Beeinflussung des Bildungsstandes - es wird nicht mehr gelesen, sondern nur noch Fernsehen geglotzt - und die Annahme einer Verschlechterung der Allgemeinkörperverfassung; dicke Kinder, die vor dem Computer ihre Mobilität schrumpfen und sich mit arthritischem SMS-Daumen ins Netz verflüchtigen. Genauso verzerrt erscheinen die euphorischen Verklärungen einer medialen Teleologie, Proklamation von direkten Medien-Körper-Verschaltungen mit ungeheuerlichem Perzeptionspotential.

\section{Mediale Methode?}

Nach wie vor fehlen überzeugende und grundlegende Darstellungen methodischer Konsequenzen aus dem theaterwissenschaftlichen Umgang mit dem Medienbegriff. Die Theaterwissenschaft hat kein mediales Methodenspektrum. Zahlreiche Fallstudien definieren sich ihre eigenen Medienkonzeptionen und kommen damit zunächst einmal zu interessanten Ergebnissen. Was fehlt ist eine medientheoretische Methode, die sich in aller Selbstverständlichkeit einordnete in das aufgefächerte Instrumentarium der Theaterwissenschaft wie etwa Semiotik, Dramentheorie oder Performance Analysis. In einigen Feldern wurde bisher theatertheoretisch Fundiertes geleistet: Intermedialität - hier sei vor allem Petra Maria Meyer zu nennen -, Mediale Sehvorgänge - in der Arbeit von Ulrike Haß - und Bildtheorie, vor allem in der Forschungsarbeit von Kati Röttger, die Theater als >Bildmaschine< analysiert.

2 Siehe etwa Petra Maria Meyer und Freda Chapple/Chiel Kattenbelt. 
Alle drei gehen letztlich von einer medialen Wahrnehmungssituation im Theater aus und bewegen sich auf einer erkenntnistheoretischen Ebene. Die Verhandlung von körperlicher Wahrnehmung wird dabei zunehmend über den Weg der Phänomenologie gekreuzt. Ich selbst bin in meiner eigenen Forschung soweit gegangen, das phänomenologische Theater->Medien<-Dispositiv als Produktionsmatrix von Körperlichkeit zu definieren. Basis dieser Überlegungen war ein Konzept von Medialität, das auf eine phänomenologisch auf Merleau-Ponty bezogene Medientheorie fußt, die von einem körperlichen Wahrnehmungsvorgang als Wechselspiel zwischen Wahrnehmen und Wahrgenommen werden ausgeht und so den Betrachter, den Theater-Zuschauer als betroffenen, nicht nur als Bedeutung generierenden Körper fokussiert. Wenn man möchte, dann kann man hier fast konzeptionelle Spuren eines medialen Fluidums ausmachen, das in den historischen MedienKonzepten von Paracelsus bis zur Äther-Theorie Objekte und wahrnehmende Subjekte gleichermaßen umgibt und ausfüllt.

Doch alle bisher aufgezeigten medientheoretischen Perspektiven verbleiben letztlich in der performativen Situation, ziehen ihre Schlüsse aus dem aktualisierten Mediendispositiv der sich ereignenden Theater-Performance und einer angenommenen medialen Wahrnehmungs-Situation. Eine medienhistorisch ausgerichtete kulturwissenschaftliche Sichtweise bleibt ein Desiderat. Christopher Balme hat 1999 in Hellerau das Desiderat einer »relationellen Mediengeschichte des Theaters « formuliert. Er bestimmt als Ausgangspunkt einer solchen Geschichtsschreibung »die Frage, wie sich das Theater zu anderen Medien verhält« (Leeker: 407). Genau hier gilt es einzusetzen und weiterzudenken. Zum einen könnte man die mediale Perspektive auf eine kulturwissenschaftliche ausweiten, zum anderen liegt der Reiz einer >Mediengeschichte des Theaters < im Erkenntnisgewinn für die heutige mediale Umbruchsituation. Die historische Distanz schärft den Blick auf die kulturtheoretische Funktion des zeitgenössischen Mediums Theater. Worin liegt nun der Mehrwert einer >Mediengeschichte des Theaters $<$ ? Ich werde im Folgenden versuchen, dies darzulegen, indem ich eine kulturwissenschaftliche Medientheorie vorstelle, die seit Mitte der 1990er Jahre in Frankreich an Einfluss gewinnt: Régis Debrays methodische Perspektive der $>$ Mediologie $<$.

\section{Material und Organ}

Régis Debray formuliert das Anliegen seiner Mediologie ${ }^{3}$ als Ausweitung der Analyse medialer Übertragungsprozesse durch Fokussierung auf den >übermittelnden Menschen $<$. Er unterscheidet dabei Kommunikation als technischen Übertragungsakt von der Übermittlung, die eine Information in der Zeit und nicht im Raum transportiert:

»Unter dem Begriff der Übermittlung [Transmission] werden wir alles zusammenfassen, was mit der Dynamik des kollektiven Gedächtnisses zu tun hat, und unter dem Begriff Kommunikation das Zirkulieren der Botschaften zu einem gegebenen Zeitpunkt. Oder um den Gegensatz noch zu verstärken - wir werden sagen, dass Kommunizieren darin besteht, eine Information im Raum innerhalb ein und derselben räumlich-zeitlichen Sphäre $z u$

3 Vgl. Debray 1999. Die folgenden Zitate stammen ausnahmslos aus der deutschen Ausgabe, Debray 2003. 
transportieren, und Übermitteln darin, eine Information in der Zeit zwischen unterschiedlichen räumlich-zeitlichen Sphären zu transportieren« (Debray: 11).

Anstelle von >Übermittlung< verwendet Debray in der französischen Ausgabe den Begriff >Transmission<, der im Deutschen wunderbarerweise den Aspekt der mechanischen Kraftübertragung des >Transmissions-Riemens « in sich trägt und auch eine materielle Durchlässigkeit für Strahlung bezeichnet, während im Französischen vor allem der Akt des Übergebens von etwas an jemanden damit benannt ist. In diesem Doppelsinn verkreuzt sich die Frage nach den Transportwegen des kulturellen Gedächtnisses und den damit verbundenen Diskursen mit einer deutlichen Hinwendung zur Frage nach der Funktionalität von Technik. Debray nimmt hier eine kulturanthropologische Position ein und bezieht sich auf die Schriften von Leroi-Gourhan, der eine Auflösung der Opposition von menschlichem Subjekt und technischem Objekt vorantreibt durch seine Thesen zur Ko-Evolution von Werkzeug, Sprache und Körper. Der Mensch wird zum technifizierten Wesen durch die operationale Freisetzung seiner Hand im aufrechten Gang und setzt damit den Beginn einer Wechselbeziehung von technischem Objekt und menschlicher Handlung.

Entsprechend übernimmt Debray den Gedanken, das Technische auf seinen etymologischen Ursprung zurückzuführen: technê als Einwirkung des Menschen auf die Dinge; und stellt demgegenüber den Begriff praxis als Einwirkung des Menschen auf den Menschen. Damit erfährt die Technik und in diesem Sinne auch der technische Medienapparat eine Entdämonisierung und wird eingeführt in den zirkulären Kreislauf vermittelnder Einwirkungen. Obgleich die medialen Apparaturen eine wichtige Rolle in den Übermittlungsvorgängen spielen, propagiert Debray einen erweiterten Medienbegriff und weist dem Medium eine Position in einem kulturellen Beförderungsdispositiv zu:

»Das Medium ist weder eine Sache noch eine zählbare Kategorie von Objekten, die von weitem und mit bloßem Auge mit einer Etikette versehen werden könnten. Es ist ein Platz und eine Funktion in einem Beförderungsdispositiv. Noch einmal: Es ist nie gegeben, man muss ein Konzept von Fall zu Fall, je nach Situation, erarbeiten« (Debray: 149).

Von Fall zu Fall zu erarbeiten ist also das Medium - deutlich wird auch hier die Nähe zum contested concept, wie zu Beginn konstatiert.

Das Medium hat eine zweiflügelige Struktur - eine Körperlichkeit und eine Materialität. Es handelt sich zum einen um das Werkzeug, die organisierte Materialität $(\mathrm{OM})$, zum anderen um die persönliche oder kollektive Geste, die materialisierte Organisation (MO). Debray bezeichnet etwa das Einschreiben bestimmter Zeichen auf einen Träger als Organisation von Material - ein Vorgang, der wiederum eine Speicherapparatur erzeugt. Darum herum materialisiert sich die Organisation eines soziokulturellen Dispositivs - Institutionen, Verwaltung oder Körperschaft (Debray: 150).

Dieses Medium entfaltet sich in und durch ein Milieu, das einem ökologischen Biotop gleich Voraussetzungen und Lebensraum für bestimmte Entwicklungen schafft - in unserem Fall befördert und begründet das mediologische Milieu neue technische Entwicklung, die wiederum in Wechselwirkung zum Milieu stehen. Es gibt also keine lineare Kausalität zwischen Milieu und Medium, sondern eine zirkuläre systemische Ordnung. Die technische Innovation entsteht nicht ex nihilo, sondern ist »selbst das Produkt eines sozialen Milieus und kommt mit Imaginärem 
und Mythen beladen auf uns. Ob eine Erfindung Erfolg hat oder nicht, ob sie sich umsetzen lässt oder nicht hängt umgekehrt davon ab, ob es gelingt, sie einem kulturellen Milieu aufzupfropfen « (Debray: 113).

Mediengeschichtlich ordnet Debray bestimmte Übermittlungskonfigurationen in Mediensphären. Das Suffix »-sphäre« bezeichnet den Charakter des Einhüllenden - eine Mediensphäre wirkt also als kulturelle Matrix einer gesellschaftlichen Phase, in der bestimmte Medienkonfigurationen dominant wirken als »Dispositive, die in der Lage sind, die Wahrnehmung, die Erkenntnis und die Fortbewegung, also unsere Zeit- und Raumpraktiken zu verändern « (Debray: 105).

Das Medium, realisiert in einer Mediensphäre, die in und durch ein bestimmtes Milieu befördert und transformiert wird, ist die Voraussetzung für symbolische Übermittlungsvorgänge. Das kulturelle Gedächtnis ${ }^{4}$ wird generiert durch die Übermittlung von kulturellen Symbolen. Das Medium fungiert solchermaßen als Stütze dieser Symbole, als Matrix des kulturellen Gedächtnisses.

\section{Eine Mediologie des Theaters?}

Wie nun lassen sich diese mediale Konfiguration und ihre Methode auf das Theater übertragen?

Im Zentrum der Mediologie steht der Begriff des kulturellen Gedächtnisses. Das kulturelle Gedächtnis hat als Topos auch in der Theaterwissenschaft vor einigen Jahren von sich reden gemacht. So etwa auch als Thema der IFTR-Konferenz in Amsterdam im Jahr 2002: Theatre and Cultural Memory. Theater als Ort der Geschichte, Theater als Erinnerungsraum. Erwähnt seien hier etwa die Studien von Freddie Rokem (2000), in Deutschland von Gerald Siegmund (1996), Friedemann Kreuder (2001) oder Peter Marx (2003). Vorwiegend gestalten sich diese Theaterstudien als Analysen theatraler Gedächtnis-Ästhetik und Marx (13, Anm. 4) stellt zu recht fest: »Eine Beschreibung von Theater als Medium der Transmission kulturellen Wissens steht noch aus. « Er selbst begegnet diesem Desiderat mit dem Versuch eines kultursemiotischen Modells von Theater, seine semiotischen Kategorisierungen von Theater-Aufführungen beziehen sich letztlich jedoch wiederum auf das Konzept eines Theaters als kulturellen Textes und lassen die mediale Praxis außen vor. Die Frage nach dem >Medium der Transmission< bleibt letztlich offen.

Dreh- und Angelpunkt ist hier die Begrifflichkeit eines kulturellen Gedächtnisses und ihrer Reichweite - ob es sich um einen engen Begriff handelt, der eine Gedächtniskultur mit ihren Gedächtnisästhetiken anhand von »Kunstwerken« und »Inszenierungen « umschreibt - also im Rahmen des Werkes bleibt - oder um einen weiten Begriff, der auf eine Beschreibung von kulturpoetischen symbolischen Verfahren zielt, d.h. die Kultur als zirkuläre symbolische Selbstschöpfung fasst. Régis Debray schreibt seine Mediologie in den zweiten Begriff ein, dies wird deutlich, wenn er den Begriff der >Geschichte< von >Geschichten erzählen< ableitet (184), zum anderen konstatiert, der Mediologe möge »von der Geschichte der Ideen zur Geschichte ihrer Vermittler und Träger übergehen « (140). Debray bestimmt Kultur von ihren Übermittlungen her und nicht von eigentlichen Erinnerungs-Fällen oder geschichtlichen Fakten. Régis Debray unternimmt in diesem Zusammenhang zwei

4 Der Begriff des kulturellen Gedächtnisses wurde in Deutschland durch Jan und Aleida Assmann bekannt, den diese im Rückgriff auf Aby Warburg und Maurice Halbwachs entwickelten als Kontinuierung kollektiv geteilten Wissens in der kommunikativen Aufeinanderbezogenheit von Gedächtnis, Kultur und Gruppe. Vgl. Assmann. 
für eine Theatergeschichte wichtige Abgrenzungen. Er begründet, warum der Mediologe kein Semiologe und auch kein Soziologe sei. Die Semiotik versuche, eine kulturelle Praxis innerhalb eines Zeichens (etwa im Sinne einer Aktualisierung) zu verorten, was aber dem Mediologen nicht genügt, wie Debray am Beispiel der Filmkunst erläutert. Ein Mediologe betrachtet das Kino-Dispositiv im umfassenden Sinne und berücksichtigt alle Faktoren - technische, kulturelle, soziale, politische die das Transmissions-Ereignis »Kino « bestimmen. Die mediale Ästhetik ist nicht im (Bild)Werk, sondern in den Bedingungen des Blicks zu finden:

»Ein Mediologe wird eher an den Blick als an das Bild denken. Das quid des Filmbildes war von seinem quomodo nicht zu trennen, und sein eigentümlicher Charme nicht von der ganzen trivialen, aber reichlich überdeterminierten Art, wie sie sich auf unserer Netzhaut einprägt« (Debray: 169f).

Der Soziologie wirft Debray vor, Objekte und technische Variablen als Teil von sozialen und kulturellen Praktiken zu vernachlässigen. Die Soziologie suggeriere, so Debray, eine Gesellschaft von Subjekten ohne Objekte und andererseits eine Gesellschaft von Utensilien ohne Benutzer. So liegt auch hier im Zentrum der Kritik die fehlende Reflexion der Beziehung von technê und praxis, die als mediale Praxis kulturelle Relevanz erreicht.

Folgte man Debray hier, so könnte die Mediologie im Zusammenhang mit der kulturpoetischen Funktion von Theater gestellt und genutzt werden, um Theater außerhalb des hochkulturellen Rahmens und der Ästhetik der Aufführung zu bestimmen. Theater als mediale Praxis, Theater zwischen Wahrnehmungsdispositiv und kultureller Performance.

Nicht unproblematisch für unsere Disziplin erscheint jedoch Debrays Kunstbegriff. Er stellt leicht ironisierend fest, dass nichts

»weniger mediologisch [ist] [...] als die Vorstellung einer ewigen Kunst, die in der Tiefe des Menschen schlummert, in allen Kulturen latent vorhanden ist und von Zeit zu Zeit hier und da, mit sich selbst identisch zutage tritt« (80f).

Mit dieser Kritik an einer idealistischen Ästhetik verpflichteten Kunst-Vorstellung kann man zunächst problemlos mitgehen. Schwieriger wird es jedoch, wenn die mediologische Perspektive die Kunst in ihren Übermittlungsvorgängen definiert und dabei ihre spezifisch ästhetische Positionierung aus den Augen verliert. So konstatiert Debray (81):

»Das Auftauchen des Kunstbegriffs ist fest mit einer mediologischen Übermittlungskonfiguration verbunden, die gleichzeitig - und gleichwertig - aus einem Ensemble von Repräsentationen und einem Ensemble von Institutionen besteht. Einem System, in dem Wörter und Orte einander ablösen. Man produziert keine Kunst, ohne Werkzeuge der Kodifizierung (also autonome kritische Wissensinhalte, Handbücher, Abhandlungen, Geschichte, Künstlerbiografien) und der Kapitalisierung (also autonome Aufbewahrungsorte, Sammlungen und Museen) zu produzieren.«

Grundsätzlich ist auch diesen Annahmen zuzustimmen, jedoch scheint die Kunst hier anderen Symbolisierungsprozessen gleich geordnet. Das künstlerische Werk wird quasi in den Übermittlungs-Zusammenhang aufgelöst, es kann nicht mehr in 
seiner ästhetischen Funktion bestimmt werden. Das erscheint im Zusammenhang mit der Theatergeschichte schwer vorstellbar, da somit der kritisch ästhetische Fokalpunkt - die Aufführung in all ihren verschiedenen kulturellen Ausprägungen sein Differenzkriterium verlöre. Es müsste sich in Einzelstudien erweisen, ob die Mediologie für Analysen des Theaters taugt und ob es gar möglich wäre, doch eine spezifische ästhetische Funktion in der medialen Übermittlungskonfiguration Theater zu verorten. ${ }^{5}$

Spannend erscheint es jedoch allemal, mithilfe der Mediologie dem Theaterbegriff kritisch neu zu begegnen und ihn darauf hin abzuklopfen, inwiefern er immer noch vom Erbe der idealistischen Ästhetik geprägt und in der Folge davon als Hochkultur symbolisiert ist - seien es nun die postdramatische Idee von Theater oder performative Konzepte der Avantgarde. Es könnte zu irritierend neuen Erkenntnissen führen, wenn man einmal das Verhältnis von Zentrum und Peripherie wie es Debray für eine mediologische Pragmatik vorschlägt (197f) - in Bezug auf Theater umkehren würde: Das Theater nicht als Mittelpunkt der anvisierten Kulturepoche betrachten und von seinen Werken ausgehend ein Bild der historischen Theaterpraxis zeichnen, sondern ein spezifisches Beziehungsgeflecht von technê und praxis herausarbeiten und das Theater als Medium in der betreffenden Übermittlungskonfiguration situieren. Mit diesem methodischen Zugriff ließe sich in der Tat eine >Mediengeschichte des Theaters< schreiben.

\section{Literatur}

Assmann, Jan (1992): Das kulturelle Gedächtnis. München: Beck.

Bal, Mieke (2000): »Introduction. Travelling Concepts and Cultural Analysis«. In: Goggin Joyce/Sonja Neef (Hg.): Travelling Concepts 1. Text, Subjectivity, Hybridity. Amsterdam: ASCA, S. 7-25.

Baudry, Jean-Louis (1993): »Ideologische Effekte erzeugt vom Basisapparat«. Übersetzt von Gloria Custance und Siegfried Zielinski. In: Eikon. Zeitschrift für Photographie \& Medienkunst, Heft 5 [Original: »Effets idéologiques produits par l'appareil de base«, Paris 1970], S. 36-43.

Carlson, Marvin (1996): Performance. A Critical Introduction. London: Routledge.

Chapple, Freda/Chiel Kattenbelt (Hg.) (2006): Intermediality in Theatre and Performance. Amsterdam: Rodopi.

Comolli, Jean-Louis (1980): »Machines of the Visible.« In: Teresa de Lauretis/ Stephen Heath (Hg.): The Cinematic Apparatus. Basingstoke, London u.a.: Macmillan, S. 121-142.

Debray, Régis (1999): Introduction à la médiologie. Paris: Presses Universitaires de France.

Debray, Régis (2003): Einführung in die Mediologie. Bern u. a.: Haupt.

Handke, Peter (1966): Publikumsbeschimpfung und andere Sprechstücke. Frankfurt/M.: Suhrkamp.

Haß, Ulrike (2005): Das Drama des Sehens. Auge, Blick und Bühnenform. München: Fink (Zugl. Berlin, Univ. Habil.-Schrift 1999).

Hoffmann, Stefan (2002): Geschichte des Medienbegriffs. Hamburg: Meiner.

5 Die ästhetische Performanz des Theaters ermöglicht etwa eine Selbstreflexion des medialen Dispositivs mit den Mitteln des Überschusses und der Verfehlung. Vgl. Wagner. 
Kreuder, Friedemann (2002): Formen des Erinnerns im Theater Klaus Michael Grübers. Berlin: Alexander (Zugl. FU Berlin, Univ. Diss. 2001).

Leeker, Martina (Hg.) (2001): Maschinen, Medien und Performance. Berlin: Alexander.

Leroi-Gourhan, André (1985): Hand und Wort. Die Evolution von Technik, Sprache und Kunst. Frankfurt/M.: Suhrkamp [Frz.: Le geste et la parole. 2 Bde. Paris: Albin Michel, 1964].

Marx, Peter (2003): Theater und kulturelle Erinnerung. Tübingen u. Basel: Francke (Zugl. Mainz, Univ. Diss. 2001).

Meyer, Petra-Maria (2001): Intermedialität des Theaters. Entwurf zu einer Semiotik der Überraschung. Düsseldorf: Parerga (Zugl. Mainz, Univ. Habil.-Schrift, 2000).

Rokem, Freddie (2000): Performing History. Theatrical Representations of the Past in Contemporary Theatre. Iowa City: University of Iowa Press.

Röttger, Kati (2004): Fremdheit und Spektakel. Theater als Medium des Sehens. Mainz, Univ. Habil.-Schrift.

Siegmund, Gerald (1996): Theater als Gedächtnis. Semiotische und psychoanalytische Untersuchungen zur Funktion des Dramas. Tübingen: Narr (Zugl. Frankfurt/M., Univ. Diss. 1994).

Tholen, Georg Christoph (1995): »Der Verlust (in) der Wahrnehmung. Zur Topographie des Imaginären.«In: Texte. Psychoanalyse, Ästhetik, Kulturkritik, Heft 3, S. 46-75.

Tholen, Georg Christoph (1999): »Überschneidungen. Konturen einer Theorie der Medialität.«In: Sigrid Schade/Ders. (Hg.): Konfigurationen. Zwischen Kunst und Medien. München: Fink, S. 15-34.

Wagner, Meike (2003): Nähte am Puppenkörper. Der mediale Blick und die Körperentwürfe des Theaters. Bielefeld: transcript. 



\title{
Theatralität als MEdiales Dispositiv. ZUR EMERGENZ VON MODELLEN THEATRALER Performanz aus medienhistorischer Perspektive
}

\author{
SABINE FRIEDRICH/KIRSTEN KRAMER
}

Zielsetzung der folgenden Ausführungen ist es, die Entstehung neuer, historisch je spezifischer Konzepte von Theatralität aus einer mediengeschichtlichen Perspektive zu beschreiben. In einem ersten Schritt soll zunächst das Verhältnis von Theatralität und Medialität aus einer systematischen Perspektive untersucht werden, um in einem zweiten Schritt am Beispiel eines auto sacramentral von Calderón de la Barca exemplarisch zu analysieren, auf welche Weise durch die szenographische Raumorganisation und den Einsatz medialer Visualisierungsmodelle konkurrierende Typen theatraler Performanz begründet werden, die sich als Ausdruck eines historischen $>$ Medienwettstreits $<$ deuten lassen, der auf differente Theatralitätskonzepte verweist. ${ }^{1}$

\section{I.}

Im Zuge des so genannten >performative turn ${ }^{2}$ ist in den vergangenen Jahren das Konzept der Theatralität zu einer Leitkategorie der aktuellen Kulturwissenschaften avanciert. Vor dem Hintergrund der inflationären Verwendung des Begriffs >Theatralität< scheint es angeraten, einige terminologische Überlegungen voranzustellen. Diese Vorüberlegungen nehmen ihren Ausgang von den zwei Grundbestimmungen des Begriffs von Theatralität. In der jüngeren Forschung besteht weitgehend Konsens darüber, dass > Theatralität< in einem engeren, spezifisch ästhetischen Sinn eine fest umrissene Kunstform bezeichnet; demgegenüber wird Theatralität in einem weiteren Sinne als ein umfassenderes Kultur erzeugendes Prinzip gefasst und bezeichnet ein Modell von Wirklichkeitserfahrung bzw. ein Verhaltensdispositiv, das nicht nur der Kunst, sondern auch anderen Bereichen der Kultur zugrunde liegt und

1 Der erste, systematische Teil des Aufsatzes nimmt Überlegungen auf, welche die Verfasserinnen in dem Einleitungsaufsatz des von ihnen herausgegebenen Sammelbandes La teatralidad desde una perspectiva histórica de los medios, der 2008 im Verlag Reichenberger erscheinen wird, formuliert haben. Der zweite Teil, der sich mit Calderóns auto sacramental beschäftigt, fasst die Analyse von Kirsten Kramer zusammen, die in dem Aufsatz La medialidad de la >performance<teatral en los autos sacramentales de Calderón in dem genannten Sammelband publiziert wird.

2 Zum Begriff des >performative turn $<$ vgl. Fischer-Lichte 1998 sowie Fischer-Lichte/ Wulf. 
in engem Zusammenhang mit sozialen Praktiken wie höfischen Festen, Spielen, Prozessionen, Krönungen, Zeremonien, Ritualen etc. steht. ${ }^{3}$

Die kulturwissenschaftliche Ausweitung des Begriffs Theatralität erscheint allerdings nur dann sinnvoll, wenn sie eine konkrete Beziehung zwischen spezifischen Praktiken des Theaters im engeren Sinn und theatralen Prozessen außerhalb des Theaters postuliert und damit die historisch sich wandelnden Erscheinungsformen des Theaters weiterhin als zentralen Bezugspunkt für die Auseinandersetzung mit kulturellen Phänomenen von Theatralität bestimmt. Nur unter Berücksichtigung der konkreten Theatersituation und der sie kennzeichnenden Merkmale lässt sich beschreiben, ob und inwiefern Affinitäten und Differenzen zwischen theatralen Praktiken einerseits und sozialen oder kulturellen Interaktionsformen andererseits bestehen.

Die konkreten Erscheinungsformen und historischen Funktionen von Theatralität werden daher im Folgenden ausgehend vom Zusammenspiel von vier zentralen Aspekten untersucht, die vor allem von Erika Fischer-Lichte erarbeitet wurden. ${ }^{4}$ Bei den vier Kategorien handelt es sich um: Inszenierung, Körperlichkeit, Wahrnehmung und Performanz. Auf der Grundlage dieser vier Kategorien, deren Relationierungen zueinander zu präzisieren sind, geht es sodann um eine Klärung des Zusammenhangs zwischen Theatralität und Medialität aus historischer und systematischer Perspektive. Dabei ist zum einen zu berücksichtigen, dass das Theater aufgrund der Verwendung unterschiedlichster Bühnentechniken und audiovisueller Medien von jeher eine eigene >Mediengeschichte $<$ aufweist und zum anderen aufgrund seiner spezifischen Verfasstheit als integraler Bestandteil der (insbesondere von McLuhan beschriebenen) medienhistorischen Epochen der Oralkultur, der literalen Manuskriptkultur, der Buchdruckkultur wie auch des Zeitalters der elektronischen Medien fungiert. ${ }^{5}$

Zunächst stellt sich jedoch aus theoretischer Perspektive die Frage, wie die mediale Vermittlung bzw. Fundierung des Theatralen überhaupt zu erfassen ist. Was ist eigentlich das Mediale in der theatralen Aufführung? Die Stimme und der Körper der Schauspieler? Der Bühnenraum? Die Interaktion zwischen Bühne und Zuschauerraum oder aber eine Kombination all dieser Elemente? Es ist dabei keineswegs von einem ahistorischen Medienbegriff auszugehen. Theatrale Medialität ist ein höchst komplexes Gefüge, das aus mehreren Teilaspekten besteht, die in historisch je unterschiedlichen Relationierungen auftreten.

Für eine Bestimmung der theatralen Medialität ist eine kurze Klärung der Begriffe Medium und Medialität erforderlich. Grundsätzlich gilt: Ausgehend von einer kulturanthropologischen Perspektive können Medien als prothetische Extensionen oder Exteriorisierungen natürlicher Körperfunktionen verstanden werden (entsprechend der bekannten Definition McLuhans, der die materielle Dimension von Mediensystemen hervorhebt). ${ }^{6}$ Diese anthropologische Bestimmung, welche die Gefahr eines deterministischen Medienverständnisses in sich birgt, ist grundsätzlich durch eine kulturpragmatische Betrachtungsweise zu ergänzen, die in neu-

3 Vgl. zu Voraussetzungen und Implikationen der kulturwissenschaftlichen Ausweitung des Theatralitätsbegriffs stellvertretend für zahlreiche neuere Forschungsarbeiten Fischer-Lichte 2004.

4 Vgl. zu den vier Aspekten, die in verschiedenen Arbeiten Fischer-Lichtes beschrieben werden, exemplarisch Fischer-Lichte 2001.

5 Vgl. dazu Kotte (251-270). Das skizzierte Phasenmodell wird insbesondere in diversen Arbeiten McLuhans entwickelt; vgl. paradigmatisch McLuhan 2001 sowie 2002.

6 So der klassische Ansatz McLuhans (2001). 
eren Forschungsarbeiten vertreten wird, welche die Emergenz und die Funktionsweise der Medien in Relation zu verschiedenen Diskursen und sozialen Praktiken innerhalb spezifischer kultureller Felder untersuchen. Gemäß diesem kulturpragmatischen Ansatz situieren sich Medien also innerhalb eines kulturellen Feldes, das durch den Austausch und die konstitutive Interaktion konkurrierender und konfligierender Diskurse und Praktiken gekennzeichnet ist, die das Verhältnis des Medienbenutzers zur Umwelt bestimmen. ${ }^{7}$

Besonders aufschlussreich für die von uns verfolgte Fragestellung sind vor allem die Ausführungen von Sybille Krämer, die das Medium in Abgrenzung zur Funktionsweise von den technischen Instrumenten und den Zeichen bestimmt. ${ }^{8}$ Krämer betont ebenfalls den konstitutiven Körperbezug wie auch die Materialität des Mediums und unterscheidet den Mediengebrauch ausdrücklich von Formen einer rein symbolischen Kommunikation. Sie geht dabei zunächst von der Unterscheidung zwischen Werkzeug einerseits und Medium oder technischer Apparatur andererseits aus. Das Werkzeug dient zur bloßen Leistungssteigerung natürlicher Funktionen des menschlichen Sinnesapparates. Dies bedeutet keinen qualitativen Wandel des Weltbezugs des Benutzers, sondern das Werkzeug steigert lediglich die Fähigkeiten, die auch ohne Gebrauch des Mediums vorhanden sind. Der Apparat bzw. das Medium hingegen ist für Krämer ein Instrument, mit dem wir künstliche Welten erzeugen können, die neue Erfahrungen und neue soziale und kulturelle Interaktionsformen eröffnen. Impliziert ist darin, dass Medien stets einen Überschuss an Bedeutung, einen signifikanten Mehrwert produzieren, der sich der Kontrolle der Benutzer entzieht. Kraft ihrer Materialität verhalten sich Medien wie Symptome, die eine Spur darstellen, durch die sie mehr sagen, als ihr Benutzer intendiert.

Aus Krämers Ansatz lässt sich folgende Schlussfolgerung ziehen: Der kulturelle >Mehrwert< des Mediums beruht darauf, dass sich im Gebrauch materieller und technischer Medien ein signifikanter Bruch mit bestehenden Wahrnehmungs- und Kommunikationskonventionen vollzieht. Erst vor dem Hintergrund eines solchen Bruches kann Neues entstehen, können sich neue Formen symbolischer Interaktion und Kommunikation herausbilden und im Zuge historischer Transformationsprozesse etablieren/stabilisieren.

Darüber hinaus erscheint es sinnvoll, bei der Klärung des Verhältnisses zwischen Theatralität und Medialität die genannten Teilaspekte Inszenierung, Körperlichkeit, Wahrnehmung und Performanz zueinander in Relation zu setzten. Dies betrifft insbesondere die Unterscheidung der Konzepte von Theatralität und Performanz. Legt man einen sehr weiten Begriff von Performanz zugrunde, dann umfasst Performanz unterschiedlichste künstlerische Praktiken, soziale Handlungen oder kulturelle >Darstellungen $<$, denen ein >Veranstaltungs $<-$ oder Präsentationscharakter sowie der Bezug zum Körper zuzuschreiben ist. ${ }^{9}$

Es erscheint sinnvoller, zunächst die Frage nach der Bestimmung eines theatralen Performanzbegriffs zu stellen, der der Besonderheit konkreter Theatersituationen Rechnung trägt und es damit erlaubt, theatrale Performanz von anderen, ebenfalls historisch zu differenzierenden Formen kultureller Performanz abzugrenzen. Diese Differenzierung ist insbesondere für die im folgenden als historischer Schwerpunkt gewählte Untersuchung frühneuzeitlicher Theatralität in Spanien von

7 Vgl. zum kulturpragmatischen Medienbegriff paradigmatisch Crary.

8 Vgl. hierzu wie auch zu der in Krämers Ansatz implizierten Kritik an McLuhans Position Krämer 2000.

9 Vgl. hierzu paradigmatisch Fiebach. 
Bedeutung, da gerade in dieser Epoche die unterschiedlichen Theaterformen als Bestandteil einer umfassenden barocken Festkultur figurieren und in je besondere Beziehung zu kulturellen, politischen oder religiösen Festen und Zeremonien treten. $^{10}$

Da es sich nach dem von Fischer-Lichte entwickelten Modell bei der theatralen Performanz um einen von vier konstitutiven Teilaspekten von Theatralität handelt, lässt sich der Begriff nur relational, d.h. in Abgrenzung von den übrigen drei Aspekten präzisieren. Grundsätzlich ist Theatralität ausgehend von einer grundlegenden Aufführungssituation zu beschreiben, die den fundierenden Rahmen bildet: Figuren spielen auf einer Bühne, während ihnen Zuschauer dabei zusehen. Hieraus lassen sich die ersten drei bereits genannten Aspekte ableiten.

Erstens die Gestaltung des Bühnenraums durch die Organisation der Bühne bzw. der verschiedenen Teilbühnen, durch die Verwendung von Kulissenmalerei, Aufbauten und Bühnentechnik sowie den Einsatz von Lichteffekten und Musik. Diese Verfahren betreffen vor allem den Aspekt der Inszenierung, die Produktionsseite der theatralen Aufführung, die zugleich ein Bewusstsein des Inszenierens voraussetzt und in dieser Hinsicht vom sozialen Ritual abzugrenzen ist, dem ein solches Bewusstsein nicht notwendig zugrunde liegt.

Zweitens das Spiel der Figuren auf der Bühne, das als eine bestimmte Organisation von Körperbewegungen und sprachlichen Äußerungen zu beschreiben ist. Die Stimme und der Körper des Schauspielers fungieren nicht nur deshalb als materielle Medien, weil die Sprache im Theater (in der Terminologie Krämers) immer schon als »verkörperte Sprache« in Erscheinung tritt (Krämer 1998), sondern vor allem, weil die Stimme gegenüber der reinen Zeichenhaftigkeit der Sprache einen Überschuss an Sinn produzieren kann. Der Aspekt des Körpers der Schauspieler betrifft ebenfalls die Produktionsseite der Aufführung. Historisch zu differenzieren ist dabei vor allem zwischen der dominanten Verkörperung einer Rolle - und damit zugleich dem Verweischarakter des Körpers - einerseits und der Dominanz der physischen Präsenz des Körpers andererseits. ${ }^{11}$

Drittens die Relation zwischen Bühne und Zuschauerraum, die sich auf die jeweiligen Grenzziehungen zwischen beiden Räumen und die daraus resultierenden unterschiedlichen Wahrnehmungs- und Rezeptionsmodi bezieht. Diese Relation betrifft den Aspekt der Wahrnehmung und schließt damit die Rezeptionsseite ein. Auf dieser Ebene lassen sich ebenfalls historische Differenzierungen (bspw. zwischen mittelalterlichen und frühneuzeitlichen Theaterpraktiken) vornehmen, die sich auf die Grenzziehungen zwischen beiden Räumen, die mögliche Differenz zwischen der Kontinuität bzw. der Trennung von Zuschauerraum und Bühnenraum beziehen; ebenso sind hier konkrete historische Formen der Wahrnehmungsorganisation zu berücksichtigen.

Die spezifische theatrale Performanz ergibt sich nun aus den unterschiedlichen Formen der Interaktion der genannten drei Aspekte. Bezogen auf die Teilaspekte der >Inszenierung<, der >Körperlichkeit $<$ und der >Wahrnehmung < lässt sich das Konzept theatraler Performanz folglich als Oberbegriff fassen, der die übrigen Kategorien einbegreift. Jede historisch konkrete Aktualisierung theatraler Performanz ist erst über das besondere Zusammenwirken der Bühnengestaltung, des

10 Vgl. zum Zusammenhang von Theatralität und barocker Festkultur in Spanien u.a. Díez Borque 1986 und 2002.

11 Vgl. zu den unterschiedlichen Modi der Körperpräsenz u.a. Fischer-Lichte/Horn/Warstat. 
Spiels der Akteure und der zugrunde gelegten Wahrnehmungsformen von ebenfalls historisch konkreten Formen kultureller Performanz abzugrenzen.

Hinsichtlich der Medialität der Theatersituation ist zugleich festzuhalten, dass jeder der genannten drei Aspekte unterschiedliche Materialisierungen erfährt. Zur physischen oder materiellen Dimension des Bühnenraums gehören z.B. die Bühnentechnik, Wahrnehmungs- und Beleuchtungsapparaturen, Bilder sowie die Bühnenform. Das Spiel der Figuren ist an die Materialität der Stimme und der Körperbewegungen gebunden. Die Relation zwischen Bühne und Zuschauer resultiert aus unterschiedlichen Materialisierungen. Bei den materiellen Bühnenformen wird häufig auf bildmediale Formen der Raumorganisation zurückgegriffen, wie z.B. im Falle der Perspektivbühne oder der Guckkastenbühne, zwei Bühnenformen, deren Herausbildung charakteristisch für die Entstehung frühneuzeitlicher Theatralität ist, insofern sie zur Ausdifferenzierung eines modernen Blickdispositivs beitragen, das wesentlich auf dem Prinzip der »Frontalität« beruht (Haß: bes. 27-121). Die mediale/intermediale Fundierung der Wahrnehmungssituation (des Zuschauers) leitet sich zudem aus den unterschiedlichen Verfahren visueller oder bildlicher Repräsentation im Theater her, wobei Spielraum und Bildraum entweder getrennt erscheinen können, so dass sich der Effekt einer Autonomisierung der Bildebene einstellt, oder aber in ein Konvergenzverhältnis treten, welches bedingt, dass die Bildfigurationen unmittelbar aus der Bewegung der Akteure hervorgehen und sich als »Extensionen des Körpers « präsentieren (Balme 2003). Wichtig ist hierbei zudem die Bühnenform, wie z.B. die Simultanbühne, die Guckkastenbühne, die fahrbare carro-Bühne der autos sacramentales oder die corral-Bühne.

Diese materiellen Gegebenheiten sowie die hieraus resultierenden medialen Praktiken fügen sich zu einem komplexen medialen Dispositiv, ${ }^{12}$ das jede theatrale Performanz zuallererst ermöglicht. Theatrale Medialität kann somit als relationales Gefüge verstanden werden, wobei sich je nach historischem und kulturellem Kontext unterschiedliche Relationierungen der Teilaspekte ergeben.

Am Beispiel der Grenzziehungen zwischen Bühnen- und Zuschauerraum wird dies unmittelbar sinnfällig. In mittelalterlichen Theateraufführungen (und vielfach bei der Aufführung kultureller Feste oder Zeremonien) besteht der Spielraum aus einem für Protagonisten und Publikum gemeinsam konstituierten Raum, so dass der Beginn der Spielsituation erst durch ein abweichendes Verhältnis zwischen Schauspielern und Publikum durchgesetzt werden muss, wie etwa Hans Ulrich Gumbrecht beschreibt. Demgegenüber wird im neuzeitlichen Theater die Trennung zwischen den verschiedenen Wirklichkeitsbereichen vor allem durch die Verwendung des Vorhangs oder die Präsenz von Rahmenaufbauten des Bühnenraums markiert (Gumbrecht 1992).

Aus mediengeschichtlicher Perspektive lässt sich Theatralität demzufolge als mediales Dispositiv bestimmen, das nur durch das Zusammenspiel verschiedener materieller und technisch vermittelter Praktiken und Interaktionsformen beschreibbar ist und aufgrund der Appropriation unterschiedlichster audiovisueller $>$ Fremdmedien< zugleich immer schon ein komplexes intermediales Gefüge darstellt. ${ }^{13}$ Dieses Verständnis der Medialität des Theatralen kann aus unserer Sicht dazu bei-

12 Vgl. zu Begriff und Konzept des >Dispositivs« Baudry; zur Bedeutung des Begriffs innerhalb der medientheoretischen Debatte vgl. Winkler. Mit Bezug auf das Theater wird der Begriff auch von Kay Kirchmann verwendet; vgl. Kirchmann.

13 Zur konstitutiven intermedialen Verfasstheit des Theaters, die sich etwa im Zusammenspiel von >Rahmenmedialität<, >Binnenmedialität< und >thematisierter Medialität< dokumentiert, vgl. Balme (2004). 
tragen, in unterschiedlicher Hinsicht neue Zugangsweisen zu historischen Theaterpraktiken zu eröffnen.

Zudem tritt die hier skizzierte Bestimmung von Theatralität als mediales Dispositiv in Differenz zu bestimmten Ansätzen in der Forschung, die ebenfalls die Materialität theatraler Aufführungssituationen betonen. Denn zum einen betrifft die Materialität des Theatralen nicht einzelne Elemente einer gegebenen Aufführungssituation, die isoliert auftreten, sondern muss im Gegenteil die konstitutive Interferenz der jeweiligen Wahrnehmungssituation, Bühnenraumgestaltung und des Spiels der Akteure erfassen. Zum anderen ist auch die in neueren Forschungsarbeiten anzutreffende kategoriale Unterscheidung zwischen der >nicht-mediatisierten $<$ Aufführung (Theateraufführung) und >mediatisierten< Aufführungsformen (Video-Vorführungen) zu relativieren. So ist zwar unstrittig, dass sich die theatrale Aufführung im Unterschied etwa zu einer Fernseh- oder Videoaufzeichnung durch die raumzeitliche Nähe oder Kontiguität von Akteuren und Zuschauern sowie durch die Einmaligkeit der Inszenierung auszeichnet (Fischer-Lichte 2004: 22-24). Begreift man Theatralität jedoch im skizzierten Sinne als ein komplexes medial-intermediales Dispositiv, so lässt sich auch und gerade die für die Theatersituation postulierte »leibliche Ko-Präsenz von Akteuren und Zuschauern « (Fischer-Lichte 2004: 11) nicht mehr im Zeichen authentischer >Unmittelbarkeit< und Präsenz begreifen. Vielmehr setzt jede theatrale Situation eine komplexe - materielle, technische, >mediale $<$ - Vermittlung zwischen Publikum und Schauspieler voraus, die sich von jeher im beschriebenen Sinne dem Zusammenspiel der Verfahren der Inszenierung, der Aktualisierung der Körperlichkeit wie auch den besonderen szenographischen Formen der Organisation der Sinneswahrnehmung verdankt.

Schließlich ist noch eine letzte Implikation der medienhistorischen Konzeptualisierung des Phänomens der Theatralität zu benennen. Wenngleich sich jede theatrale Aufführung über den Einsatz medialer Praktiken realisiert, bestehen erhebliche Abstufungen im Hinblick auf den jeweiligen Manifestationsgrad, die $>$ Sichtbarkeit< der Medialität. Dabei kann unterschieden werden zwischen den Polen der $>$ Medienvergessenheit< (der Begriff leitet sich aus Heideggers Konzept der >Seinsvergessenheit $<$ her), der $>$ Medienaktualisierung $<$ und der $>$ Medienreflexivität $<$. Tritt die mediale Vermittlung überwiegend gegenüber der Repräsentation der dargestellten Bühnenwelt in den Hintergrund, so lässt sich diese Konstellation als Ausdruck einer >Medienvergessenheit< begreifen. Bei der >Medienaktualisierung < ist die mediale Vermittlung demgegenüber für den Zuschauer sehr präsent, und verdankt sich etwa besonders spektakulären (Bühnen-)Effekten. Im Falle der >Medienreflexivität< schließlich thematisiert sich das Medium selbst, indem es seine Funktionsweise etwa durch Verdoppelungsstrukturen oder Spiegelungseffekte - ostentativ ausstellt und den eigenen Einsatz gleichsam zu einem eigenwertigen Gegenstand des Bühnengeschehens erhebt.

\section{II.}

Die komplexen mediengeschichtlichen Bedingungen und Voraussetzungen, die der Emergenz und Herausbildung konkreter historischer Theatralitätskonzepte zugrunde liegen, treten nun auch in der Entstehung des spanischen Fronleichnamsspiels zutage und lassen sich exemplarisch an Calderóns spätem auto sacramental EL VIÁTICO CORDERO aus dem Jahr 1655 aufweisen. 
Wie bereits die Anspielung auf das Lamm (»cordero«) und das viaticum im Titel zu erkennen gibt, setzt das auto den Auszug der Juden aus Ägypten unter der Führung Moses' sowie die Befreiung der Israeliten aus der ägyptischen Knechtschaft in Szene. Der Handlungsablauf realisiert damit jene übergreifende allegorische Struktur, welche die autos sacramentales insgesamt kennzeichnet und das dramatische Spielgeschehen innerhalb eines zeichenhaften Verweiszusammenhangs situiert, ${ }^{14}$ der in EL VIÁTICO CORDERO die alttestamentarischen Ereignisse als Präfigurationen der Passion Christi sowie des christlichen Erlösungswerks ausweist und in die Glorifizierung der Eucharistie münden lässt. Zugleich stellt die biblische Geschichte des Auszugs der Juden aus Ägypten einen zentralen >Typos< für die opulente Prozession der Fronleichnamszeremonie dar, bei der die geweihte Hostie in der kunstvoll gestalteten Monstranz aus der Kirche in die Welt und wieder zurück in die Kirche getragen wird, so dass bereits die Handlung des auto auf seine Einbindung in das kultische Festgeschehen des kirchlichen Feiertages verweist. ${ }^{15}$

In Calderóns späten autos sacramentales leiten sich die spezifischen Ausprägungsformen theatraler Performanz indes nicht allein aus der Aufführungssituation, sondern vor allem aus der materiellen Verteilung der Spielräume und den szenographischen Verfahren der Raumorganisation her, welche durch die besondere Form der fahrbaren carro-Bühne ermöglicht werden, die aus einer horizontalen Hauptbühne und mehreren Teilbühnen besteht. Im Folgenden ist zu zeigen, dass diese für die carro-Bühne und das auto sacramental charakteristische Raumgestaltung, die Aufteilung des Spielgeschehens auf unterschiedliche materielle Spielflächen, mit dem Rekurs auf divergierende mediale Inszenierungsformen einhergeht, die in EL VIÁTICO CORDERO in den Entwurf dreier konkurrierender Typen theatraler Performanz mündet. Bei diesen handelt es sich 1. um das Rollenspiel der Idolatrie, 2. die Epiphanie des Heiligen im Rückbezug auf die barocke Emblematik und 3. die Visualisierung des Göttlichen mittels des bildtechnischen Verfahrens der Zentralperspektive. Die Konfrontation dieser Formen theatraler Performanz beruht insbesondere auf einer Differenzierung divergierender Wahrnehmungskonfigurationen, welche dem auto sacramental als Ganzem eine eminent medienreflexive Dimension verleiht.

Erstens: Im zweiten Teil des auto initiiert die Idolatrie ein eigenes theatrales Spiel, in dem sie eine Doppelrolle verkörpert: sie stellt nun nicht mehr nur die mit ihrem Namen bezeichnete allegorische Figur, sondern zugleich die alttestamentarische Frauengestalt Cozbi dar, die das Erwählte Volk vom rechten Weg abzubringen sucht (Calderón de la Barca: 1174-1175). ${ }^{16}$ Dabei wird sie von zahlreichen Götzen-

14 Die Betonung der allegorischen Grundstruktur, der theologischen Fundierung und der darin begründeten didaktischen Wirkabsichten der autos sacramentales kennzeichnet nicht nur die ältere Forschungstradition, sondern kehrt auch in neueren, kultur- und diskurshistorisch geprägten Deutungsansätzen wieder; vgl. hierzu paradigmatisch Küpper. Nach Hugo Friedrich ist es insbesondere die theologische Dimension der autos sacramentales, die diesen aus der Sicht des modernen Publikums den Charakter der Fremdheit oder Alterität verleiht; vgl. Friedrich.

15 Zur dramaturgischen Gestaltung der Fronleichnamsprozession und zu historischen Auslegungen des Prozessionsgeschehens, bei denen die im Alten Testament geschilderte Befreiung aus der Knechtschaft in Ägypten als >typologische< Präfiguration der Befreiung aus der Knechtschaft des Teufels fungiert, vgl. paradigmatisch Poppenberg (262-263).

16 Da die Textausgabe des Viático CORDERO keine Versnummerierung enthält, wird hier und im Folgenden auf die Seitenzahlen der zitierten Edition verwiesen. 
dienern begleitet, die sich zum Klang von Musikinstrumenten zu einem pompösen Festzug formieren. Formal handelt es sich um ein 〉Spiel-im-Spiel<, bei dem die Idolatrie, der der Dämon Baal assistiert, als Spielleiterin fungiert und an dessen Schluss die Figur des Ungläubigen Zambrí den sinnlichen Verführungen der weiblichen Gestalt erliegt, den falschen Göttern ein Opfer darbringt und aus diesem Grund vom Gläubigen Finés getötet wird.

Dieses >Spiel-im-Spiel< ist ganz offenkundig durch den thematischen Rekurs auf konventionelle Komödienschemata gekennzeichnet, die insbesondere im Verkleidungsspiel der Idolatrie und der von ihr verkörperten Doppelrolle zutage treten. Bedeutsamer für den vorliegenden Zusammenhang ist indes vor allem die szenographische Raumorganisation, die aus der Lokalisierung des Spielgeschehens auf der Bühne hervorgeht. Wie erwähnt, besteht die carro-Bühne aus einer rechteckigen Hauptbühne, dem horizontalen tablado, sowie zunächst zwei, später vier an den Seiten bzw. hinter der Bühne befindlichen Wagen (carros), auf denen sich bis zu 18 Meter hohe, vielfach zweistöckige Aufbauten befinden, welche weitere Standund Spielflächen bereit stellen (vgl. Abbildungen 1 und 2). Während die Hauptbühne meist frei von Dekorationen und Requisiten bleibt, weisen die Wagen eindrucksvoll gestaltete Kulissen und Bildelemente auf; darüber hinaus sind sie oft mit mechanischen oder technischen Apparaturen (wie Seilzügen, Flugkränen o.ä.) ausgestattet, deren Einsatz nicht nur der Erzeugung zahlreicher spektakulärer und >magischer< Bühneneffekte, sondern auch dem Öffnen und Schließen von Teilen der carros dient, wodurch oberhalb der Hauptbühne weitere Teilbühnen entstehen, die als zusätzliche Spielflächen für die Akteure fungieren. ${ }^{17}$

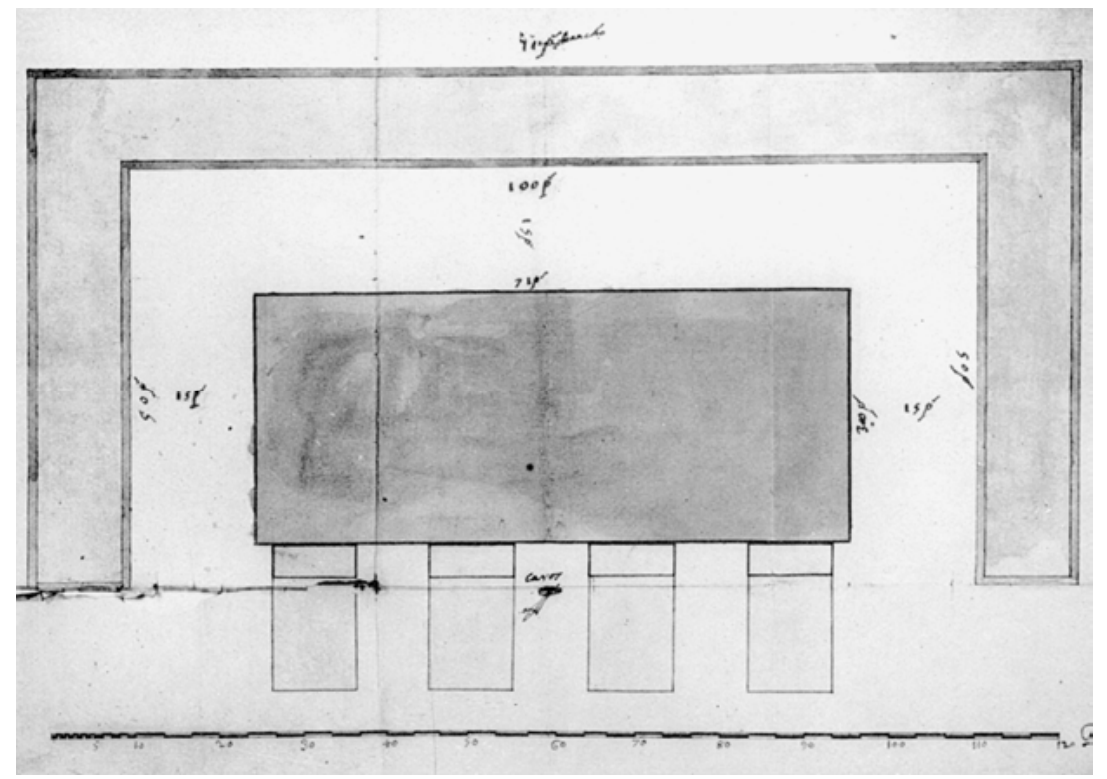

Abbildung 1: Carro-Bühne mit tablado und carros (1665) (aus: Shergold 1967: o.S.).

17 Vgl. zu Entstehung, Aufbau und Ausstattung der carro-Bühne paradigmatisch Shergold (1967: 452-504), Shergold (1970) und Tietz. 


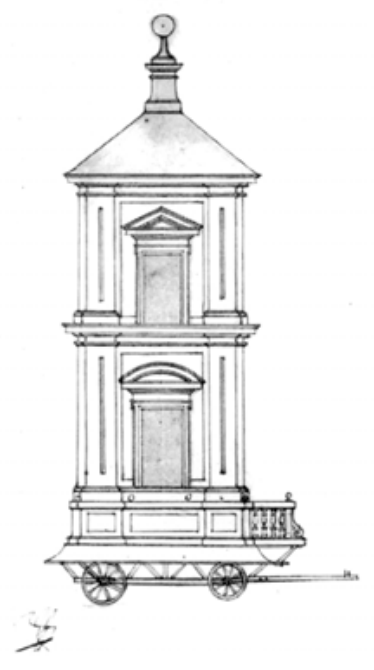

Abbildung 2: Zweistöckiger carro (aus: Shergold 1967: o.S.).

Auffallend ist nun, dass die gesamte Verführungshandlung der Idolatrie ausschließlich auf dem leeren tablado, der Hauptbühne, stattfindet und die Spielflächen der carros nicht mit einbezieht. Mit dieser deutlichen räumlichen Begrenzung des Handlungsgeschehens geht zugleich der vollständige Verzicht auf bühnentechnische Spezialeffekte einher, da die Aktion vornehmlich durch den Tanz und Gesang der beteiligten Figuren bestimmt wird. In der Gestaltung des Bühnenraums knüpft das >Spiel-im-Spiel< damit an die kargere Ausstattung der corral-Bühne an, bei der es sich innerhalb des spanischen Barocktheaters um die einfachste Bühnenform handelt, insofern sie zwar die Aufteilung des Bühnenraums in eine Hauptbühne und weitere Spielflächen vorsieht, jedoch eher begrenzte technische Effekte ermöglicht, weshalb sie ab der Mitte des Jahrhunderts zunehmend von der aufwendiger gestalteten Palastbühne und der in ihr verwendeten perfekteren Bühnenmaschinerie verdrängt wird. ${ }^{18}$

Darüber hinaus ist hinsichtlich der besonderen Form der Relationierung und Interaktion von Bühnenraum und Zuschauerraum festzustellen, dass das Spiel auf dem tablado in mehrfacher Hinsicht an das kultische Festtagsgeschehen anschließt, das im Raum des Publikums außerhalb der Bühne statthat. Zum einen gemahnt der festliche Aufzug der Idolatrie und ihres Gefolges an die Prozession des Fronleichnamstages, die sich in ihrer dramaturgischen Gestaltung maßgeblich an militärischen Triumph- und Heerzügen orientiert und daher auch ihrerseits auf jenen Bereich des Weltlichen verweist, für den der im Stück in Szene gesetzte Festumzug der profanen weiblichen Figur einsteht; zum anderen wird die Idolatrie explizit als eine »lebendige Statue (»viva estatua «) bezeichnet (Calderón de la Barca: 1176) und erinnert in dieser Erscheinung an jene aus menschlichen Körpern formierten >lebenden Bilderく, die vielfach im Zuge der Prozession gezeigt und szenisch ausge-

18 Vgl. zu den szenographischen Darstellungsmöglichkeiten der corral-Bühne Shergold (1967: 177-235), Allen sowie Ruano de la Haza (bes. 129-155, 223-269). 
staltet werden. ${ }^{19}$ Der Tag, an dem sich der Auszug aus Ägypten vollzieht und das diabolische >Spiel-im-Spiel< aufgeführt wird, entspricht schließlich dem »Passionstag « (»día de pasión «; Calderón de la Barca: 1172) und weist damit einen engen Bezug zum kirchlichen Feiertag auf, an dem das reale Prozessionsgeschehen stattfindet.

Es lässt sich daher vorläufig folgern, dass das Spiel der Idolatrie zwar unverkennbar an zeitgenössische Theaterformen und deren Inszenierungsverfahren anknüpft, zugleich jedoch eine signifikante Relativierung des fundierenden situationalen Rahmens vornimmt, der den modernen Erscheinungsformen des Theaterdispositivs zugrunde liegt. Folgt man der erwähnten, von Gumbrecht und anderen hervorgehobenen Unterscheidung des mittelalterlichen vom frühneuzeitlichen Theater, so ist ersteres durch die Herstellung eines Raums gekennzeichnet, der von Akteuren und Zuschauern gemeinsam konstituiert wird und dessen Etablierung zur Folge hat, dass sich die Spielwirklichkeit erst durchzusetzen vermag, wenn das Verhalten der Akteure sichtlich von ihrem Alltagsverhalten abweicht. Das frühneuzeitliche Theater setzt demgegenüber eine Grenzziehung zwischen Bühnenraum und $\mathrm{Zu}$ schauerraum, die räumliche Trennung der Bereiche des Spiels und des Publikums voraus, die das theatrale Geschehen aus dem festlichen oder kultischen Zusammenhang heraushebt und es so als Inszenierung erfahrbar macht. ${ }^{20}$ Wenn die von der Idolatrie initiierte Aktion ostentativ die Affinität zwischen dem theatralen Spiel und der Prozession betont, die das kultische Geschehen des Fronleichnamsfestes prägt, so knüpft die Handlung indirekt an religiöse mittelalterliche Aufführungsformen an, in denen die theatrale Performanz als integraler Bestandteil einer umfassenderen kulturellen oder rituellen Performanz erscheint. Sie führt in dieser Hinsicht bruchlos das Vorspiel, die loa, des auto fort, das insbesondere in seiner temporalen Deixis einen unmittelbaren Bezug zum Nunc des Fronleichnamstag herstellt (Calderón de la Barca: 1155) und damit ebenfalls die theatrale Grenze zwischen Bühnenwelt und Zuschauerwirklichkeit punktuell durchlässig erscheinen lässt. Die Handlung der dämonischen Figur stellt folglich ein anachronistisches Theatralitätsmodell zur Schau, das nicht nur durch den weitgehenden Verzicht auf den Einsatz zeitgemäßer bühnentechnischer Effekte gekennzeichnet ist, sondern zudem die partielle Aufhebung der Trennung der Räume des Spiels und des Publikums suggeriert und mit dieser doppelten Relativierung der spezifisch frühneuzeitlichen Wahrnehmungsund Rezeptionsbedingungen einen Typus theatraler und medialer Performanz ausstellt, der den besonderen Gegebenheiten und Erfordernissen der Aufführungssituation im modernen Barocktheater nurmehr bedingt Genüge zu leisten vermag.

Zweitens: Aus mediengeschichtlicher Sicht komplexer erweist sich der zweite Typus theatraler Performanz, der unterschiedliche Formen der Visualisierung des Göttli-

19 Zur Anlehnung der Fronleichnamsprozession an die weltlichen Triumphzüge sowie zur Verwendung >lebender Bilder vgl. besonders Poppenberg (261-265) sowie de Bustos.

20 Vgl. zu dieser Bestimmung des frühneuzeitlichen Theaters Gumbrecht (1992) sowie Cruciani (bes. 47-72), der eine historische Entwicklung vom »spazio delle rappresentazioni«, der in höfische oder religiöse Festzusammenhänge eingebettet ist, zum eigenständigen und institutionalisierten »spazio del teatro« postuliert. - Gumbrecht setzt darüber hinaus die Etablierung der Grenze zwischen Bühnenraum und Zuschauerraum in einen engen kulturhistorischen Bezug zur Entwicklung spezifisch frühneuzeitlich-moderner Modelle von Fiktionalität; vgl. hierzu paradigmatisch Gumbrecht (1990: 175221). 
chen betrifft, in denen sich eine »Epiphanie« des Heiligen ausdrückt, welche bewusst die Möglichkeiten szenographischer Raumgestaltung ausschöpft, die durch die historische carro-Bühne eröffnet werden. Grundsätzlich beruht die Visualisierung des Heiligen in den autos sacramentales auf einer spezifischen Aufteilung des Bühnenraums, die vorsieht, dass Figuren oder Szenen, die mit dem Göttlichen assoziiert werden, auf den erhöhten Spielflächen der carros in Erscheinung treten. Im VIÁTICO CORDERO wird diese Form der Raumverteilung insbesondere am Schluss des Stückes in den mechanisch-technisch unterstützten apariencias, den epiphanischen Erscheinungen des »Passionskindes« (»Niño de Pasión«) und des »Kindes mit Hostie und Kelch« (»Niño con la Ostia y el Caliz«) deutlich, die als Verkörperungen der Realpräsenz Christi und des Sakraments der Eucharistie die Apotheose des Heiligen in Szene setzen (Calderón de la Barca: 1177).

Vergleichbare Visualisierungen des Heiligen treten im auto jedoch bereits $\mathrm{zu}$ einem früheren Zeitpunkt zutage: besonders eindrucksvoll erscheint vor allem jene Szene, in der die Figur Moses auf der erhöhten Spielfläche eines carro auftritt, um sich dort mit anderen Figuren zu einem Standbild zu formieren. Im Zentrum des Bildes befindet sich der kniende Moses, der einen Baum in Form des Kreuzes hält und von den Figuren des Ungläubigen Zambrí und des Gläubigen Finés flankiert wird (Calderón de la Barca: 1170). ${ }^{21}$ Gerade mit diesem dreiteiligen Aufbau verweist die Figuration ganz offenkundig auf die barocke Bildpraxis der Emblematik $;^{22}$ in den emblematischen Darstellungen figuriert ein bildliches Element, die imago oder pictura, als Mittelstück und wird von den oberhalb und unterhalb des Bildes angebrachten Schriftelementen der inscriptio und subscriptio gerahmt, die der Offenlegung und näheren Explikation des verborgenen abstrakten Sinngehalts dienen, der der bildlichen Repräsentation zugrunde liegt. ${ }^{23}$ Innerhalb des spanischen Barocktheaters findet die historische Bildpraxis insbesondere im Hoftheater Verwendung, auf dessen Bühnenvorhängen vielfach emblematische Darstellungen zu sehen sind; wie in der Forschung verschiedentlich gezeigt wurde, dienen diese nicht allein der Dekoration der Bühne, sondern fungieren gleichsam als paradigmatisches Strukturmodell für die Rahmung des theatralen Aufführungszusammenhangs als Ganzen, insofern die im Emblem angelegte Verbindung von pictura und erklärender subscriptio ihre exakte Entsprechung in der Kombination von Bühnenvorhang und dramatischem Handlungsgeschehen findet, dem ebenfalls die Funktion der auslegenden Explikation des verborgenen allegorischen Bedeutungsgehalts der Bildfiguration zukommt. ${ }^{24}$

Im VIÁTICO CORDERO wird dagegen die gesamte emblematische Bildkonfiguration in die Handlungswirklichkeit selbst integriert; das aus den Körpern einzelner Figuren zusammengesetzte Bild verbindet sich im Spielgeschehen mit den in der

21 Vgl. zur Lokalisierung des Standbildes und der Figuren auf der Bühne Shergold (1967: 456-57).

22 Der historische Bezug, der zwischen dem Standbild und barocken Bilddarstellungen besteht, wird auch von Shergold (1967: 456-57) hervorgehoben, der allerdings aus der Anlehnung des auto an zeitgenössische Bildpraktiken keine Rückschlüsse auf deren spezifische Funktionalisierung innerhalb des Mediendispositivs des Theaters zieht, sondern sich auf die Bestimmung des allegorischen religiösen Sinns beschränkt.

$23 \mathrm{Zu}$ Erscheinungsformen und Funktionen der barocken Emblematik vgl. paradigmatisch Henkel/Schöne, Moog-Grünewald sowie (mit Bezug auf den Kontext der spanischen Kultur der Frühen Neuzeit) Egido (13-49).

24 Vgl. hierzu paradigmatisch die ausführliche und differenzierte Beschreibung der Erscheinungsformen und Funktionen der Emblematik innerhalb des Hoftheaters Calderóns in Neumeister (209-256). 
Rede anderer Figuren geleisteten Kommentaren, die das Standbild als Präfiguration der biblischen Kreuzigungsszene deuten (vgl. Calderón de la Barca: 1170). Der Modus der Visualisierung zielt mithin auf eine epiphanische Vergegenwärtigung des Heiligen, welche auf der Aufhebung der physischen Bewegung der Akteure im Raum und ihrer Formierung zu einer körperhaften Bildkonfiguration beruht. ${ }^{25}$ Leitet sich deren besonderer medialer Status einerseits aus einer spezifischen, dem Theaterdispositiv inhärenten $>$ Verkörperungspraxis $<$ her, so ist andererseits festzustellen, dass das in Szene gesetzte Bild expressis verbis auf eine vorgängig etablierte Bedeutung, eine allegorische Sinnstruktur zurückbezogen wird, welche vollständig im religiösen Schriftsinn der Bibel aufgeht und dem theatralen Geschehen wesensgemäß äußerlich bleibt. Es hat daher zunächst den Anschein, dass der bildmediale Verkörperungs- und Visualisierungsmodus - mit Sybille Krämer gesprochen - keineswegs einen >Überschuss $<$ oder >Mehrwert< gegenüber dem vorausgesetzten zeichenhaften theologischen Verweiszusammenhang zu entwickeln vermag, sondern lediglich als dessen nachträgliche Bestätigung und Bekräftigung fungiert.

Gleichwohl erschöpft sich bereits dieses Modell theatraler Performanz keineswegs in der bloßen Bestätigung des vorgängigen allegorischen Sinnzusammenhangs des auto sacramental: Dies verdeutlicht vor allem die besondere Wahrnehmungssituation, welche die Szene kennzeichnet und sich unmittelbar aus den materiellen Inszenierungsmöglichkeiten der carro-Bühne ableitet. So korreliert die räumliche Lokalisierung des Spielgeschehens mit der binnentheatralen Aufteilung des Bühnenraums in einen Aktionsraum und einen Zuschauerraum und bringt damit eine Raumverteilung zur Anschauung, welche mit Ausnahme des skizzierten >Spiels im Spiel< der Handlungswirklichkeit des gesamten auto zugrunde liegt, in dem die aufwendig gestalteten carros den Raum des theatralen Spiels präsentieren, während der leere tablado als Raum der Wahrnehmung und Beobachtung fungiert. Diese räumliche Konfiguration erfährt im Rahmen der emblematischen Visualisierung des Heiligen eine signifikante Komplexitätssteigerung. So teilt sich bereits die Gruppe der auf dem carro um Moses versammelten Personen in Figuren, die aktiv am Spiel teilhaben und sich zum beschriebenen Standbild formieren, und reine Beobachterfiguren, die das Geschehen lediglich betrachten und divergierenden Deutungsperspektiven unterziehen (vgl. Calderón de la Barca: 1170). Dieser Gruppe stehen wiederum die aus der Handlung ausgeschlossenen und auf dem unteren tablado situierten Figuren Baal und Idolatrie gegenüber, die auch räumlich in Distanz zum Spielgeschehen treten und in ihren Kommentaren die emblematische Bildfiguration zum Gegenstand einer weiteren Interpretation erheben, die der betonten Unwissenheit der Kommentatoren zum Trotz - die eigentliche Offenlegung des allegorisch-christlichen Sinngehalts der bildmedialen Verkörperung beinhaltet (Calderón de la Barca: 1170).

Es bleibt daher festzuhalten, dass der Modus der emblematischen Visualisierung durch eine signifikante Ambivalenz gekennzeichnet ist: Einerseits dienen die Bildfigurationen einer epiphanischen Vergegenwärtigung des Heiligen, die sich auf die Ebene des Dargestellten bezieht und den übergreifenden allegorischen Sinnbezug zu bestätigen scheint, der dem gesamten auto sacramental zugrunde liegt. Andererseits legt es sowohl die Einbettung des emblematisch Repräsentierten in

25 Das emblematische Standbild der Kreuzigungsszene bringt demnach die punktuelle Konvergenz eines auf der Bühne eröffneten >Bildraums< mit dem körperhaft konstituierten >Aktionsraum< der Schauspieler zur Anschauung, der die bildliche Figuration in der Tat - gemäß der eingangs vorgestellten Terminologie Christopher Balmes - als eine buchstäbliche »Extension des Körpers« präsentiert; vgl. Balme (2003). 
eine konkrete Blicksituation als auch die Anbindung an divergierende Betrachterperspektiven nahe, den auf der Bühne inszenierten Visualisierungsmodus als Zurschaustellung der Wahrnehmungssituation des realen Zuschauers vor der Bühne zu deuten. Insbesondere die Trennung des erhöhten Spielbereichs der carros vom leeren Raum des tablado, der durchgängig als ein Raum der Beobachtung fungiert, lässt sich als Wiederholung und ostentative Sichtbarmachung jener Grenze begreifen, die für das zeitgenössische Publikum zwischen dem theatralen Raum des Spiels als Ganzem und dem Zuschauerraum besteht. Die Epiphanie des Heiligen inszeniert folglich eben jenen situationalen Rahmen, der maßgeblich die Emergenz des frühneuzeitlichen Theaters kennzeichnet und dieses von seinen mittelalterlichen Vorformen abgrenzt.

Drittens: Im auto ist nun noch ein dritter Typus theatraler Performanz zu beobachten, der sich ebenfalls auf die Visualisierung des Göttlichen bezieht. Es handelt sich um die Darstellung des Mahls auf dem zweitem carro, das im Rahmen des dramatischen Spiels das Abendmahl präfiguriert und mit dieser theatralen Verkörperung der Eucharistie den eigentlichen thematischen Kern des auto in Szene setzt. Ebenso wie die emblematische Figuration zeichnet sich auch diese Szene durch eine komplexe Verschränkung von Wahrnehmungssituationen aus, die auf der binnentheatralen Unterscheidung eines Raums des Spiels und eines Raums der Beobachtung beruht und sich als Verdoppelung und Sichtbarmachung jener Blickkonfiguration deuten lässt, die die Rezeption des auto durch den realen zeitgenössischen $\mathrm{Zu}$ schauer kennzeichnet, der der Bühne und dem Handlungsgeschehen frontal gegenübergestellt ist. ${ }^{26}$

Die spezifische Blicksituation, die dem theatralen Spiel auf dem zweiten carro zugrundeliegt, wird von Calderón selbst in den memorias de apariencia, den ausführlichen Anweisungen an die zeitgenössischen Bühneningenieure, expressis verbis mit dem Begriff der »Perspektive « (»perspectiba «) umschrieben. ${ }^{27}$ Der Terminus bezieht sich auf das moderne bildtechnische Verfahren der Zentral- oder Linearperspektive, das insbesondere im zeitgenössischen Palasttheater eingesetzt wird und dort dem Aufbau eines dreidimensionalen Bühnenraums dient, dessen Gestaltung sich an den Wahrnehmungskapazitäten des Zuschauers orientiert und maßgeblich auf dessen Augenpunkt ausgerichtet ist. ${ }^{28}$ In den memorias de apariencia wird diese (zentral-)perspektivische Gestaltung des Bühnenraums auf den Blickpunkt eines auf dem carro selbst situierten Betrachters bezogen, dessen Position im auto von einer beteiligten Figur eingenommen wird. Unter Berücksichtigung der in der Szene vorgenommenen Verdoppelung der Wahrnehmungskonfiguration liegt es jedoch nahe, die perspektivische Raumkonstruktion zugleich auf die Rezeptionssituation des realen Zuschauers und die dieser zugrunde liegende räumliche Grenzzie-

26 Das Prinzip der >Frontalität<, das die Rezeptionssituation des realen Zuschauers prägt, wird im auto auch selbst thematisch, wie dies paradigmatisch eine Bemerkung der Figur María verdeutlicht, die die Frage stellt, ob zum (Abend-)Mahl nicht auch Nachbarn »von gegenüber « (»de enfrente«) eingeladen werden könnten, und mit dieser lokaldeiktischen Angabe exakt die Position des realen Publikums benennt, das sich gegenüber dem zweiten carro befindet; vgl. Calderón de la Barca: 1164.

27 Vgl. hierzu die in Shergold/Varey (192) abgedruckten Instruktionen Calderóns, die sich auf die konkrete Gestaltung des Bühnenraums und die Ausstattung der carros im Rahmen der Aufführung des VIÁTICO CORDERO beziehen.

28 Vgl. zur perspektivischen Konstruktion der Palastbühne paradigmatisch Shergold (1967: 264-297). 
hung zwischen den Bereichen der handelnden Akteure und des Publikums zu beziehen. Dies bestätigt ein von der Figur Moses formulierter Kommentar, der eine Phänomenologie sinnlicher Wahrnehmungsformen skizziert, welche auf der kategorialen Unterscheidung des Hörsinns und des Sehsinns beruht und beiden Sinnen explizit eine materielle Grenze zuordnet, die im jeweiligen Akt der Perzeption überschritten wird. Wenn Moses das Hören dabei als Überwindung einer »Wand « (»pared «), das Sehen hingegen als Blick durch ein »Fenster« (»ventana $)$ beschreibt (Calderón de la Barca: 1164), so greift er mit dieser Bestimmung des Augensinns auf jenes Bild zurück, das seit Leon Battista Albertis Traktat Della pittura als zentrale Metapher fungiert, die das nach den geometrischen Gesetzen der Zentralperspektive konstruierte Bild expliziert. ${ }^{29}$ Insofern die gesamte Szene auf den realen Zuschauer des Spielgeschehens Bezug nimmt, weist Moses’ Kommentar damit die Grenze, die im Theater zwischen Bühnen- und Zuschauerraum besteht, als unmittelbaren Ausdruck und Korrelat des spezifisch frühneuzeitlich-modernen Blickdispositivs der Linearperspektive aus und nähert zudem die carro-Bühne des auto sacramental jener komplexen Bühnenform des höfischen Theaters an, bei der sich dem Betrachter das dargestellte Bühnengeschehen im dreidimensionalen Raum präsentiert.

Die hier zutage tretende Parallele zwischen dem Blickdispositiv der Zentralperspektive und jener Wahrnehmungskonstellation, die das frühneuzeitliche Theater kennzeichnet, wird insbesondere durch die loa des auto bestätigt, die in eindrucksvoller Form sämtliche technischen und medialen Verfahrensweisen offen legt, welche der Konstruktion des modernen Bühnen- und Perzeptionsraums zugrunde liegen. In dieser loa tritt die mit Lineal, Karte und Kompass ausgestattete allegorische Figur der Geographie in Erscheinung, die berichtet, wie sie Punkte und Linien auf Papier einträgt und eine Sonnenuhr konstruiert, die als reale Kartonrequisite von Anfang an auf der Bühne zu sehen ist (Calderón de la Barca: 1154, 1156). Die übrigen Figuren, die als Verkörperungen der Stunden auftreten, halten Bänder in den Händen, die mit jeder Markierung der Uhr verbunden sind, und verlängern damit die auf der Sonnenuhr eingezeichneten Linien in den empirischen Raum des Spielgeschehens. Die physische Raumbewegung der Körper, mittels derer die Linien auf die Spielfläche der Bühne übertragen werden, mündet damit in die Erstellung eben jener geometralen >Gitter-< oder >Rasterkonstruktion<, die zum einen das materielle Gerüst für die Herstellung des zentralperspektivisch konstruierten Bildes darstellt und zum anderen dem Projektionsprinzip moderner geographischer Gradnetzkarten entspricht. ${ }^{30}$ Mit dem Rekurs auf diese mathematische >Gitterkonstruktion<, die allererst die mediale Übertragung und Speicherung optischer Informationsdaten ermöglicht und sich in der loa des auto zudem mit der körpergebundenen Inszenierung zeitgenössischer kryptographischer Schriftpraktiken verbindet (Calderón de la Barca: 1158), ${ }^{31}$ stellt die Konstruktion des Bühnenraums ostentativ jenes spezifisch

29 Zum Vergleich des Bildes mit einem Fenster, vgl. Alberti (79); zur Funktion, die der Metapher des Fensters im Rahmen der technischen Erklärung des Verfahrens der Linealperspektive bei Alberti zukommt, vgl. Panofsky sowie Haß (bes. 27-41).

30 Die physische Bewegung der Körper der Akteure konstituiert in der Tat eine geographisch exakte Weltkarte, auf der die gesamte damals bekannte Welt verzeichnet ist; vgl. Calderón de la Barca (1154-1158).

31 Die kryptographischen Schriftpraktiken, die geheime Botschaften produzieren, deren Verschlüsselung auf der Veränderung der Zuordnungsregeln von Buchstaben beruht, treten in der loa insbesondere in den Positionsveränderungen der Figuren zutage, die jeweils einen Buchstaben verkörpern und erst bei Aufstellung in richtiger Reihenfolge 
moderne Visualisierungsmodell aus, das in der Frühen Neuzeit gleichermaßen im Bereich der empirischen Wissenschaften, der Bildkünste wie auch des Theaters eine neuartige geometrale Ordnung des Sichtbaren generiert. ${ }^{32}$ Das auto gewinnt folglich ein eminent medienreflexives Potential, insofern es die für die Emergenz frühneuzeitlicher Theatralität konstitutiven Wahrnehmungsbedingungen nicht nur umsetzt, sondern zugleich auf deren medienhistorische Entstehungsbedingungen befragt und zurückführt.

Es bleibt festzuhalten, dass die Visualisierung des Göttlichen auf den erhöhten Spielflächen der carros im Zeichen konkurrierender Modelle theatraler Performanz und Medialität steht. So ist hinsichtlich der emblematischen Figurationen hervorzuheben, dass zwar bereits in ihnen jene komplexe Wahrnehmungssituation gedoppelt wird, die einerseits aus den besonderen szenographischen Inszenierungsmöglichkeiten der carro-Bühne erwächst, andererseits aber für die Entstehung des frühneuzeitlichen Theaters insgesamt konstitutiv ist. Zugleich drückt sich in ihnen jedoch eine Epiphanie oder Apotheose des Heiligen aus, die insbesondere die Ebene des Dargestellten, den theologischen Sinngehalt des auto betrifft. Ein anderes Bild ergibt sich für die zweite Form der Visualisierung, die auf das bildtechnische Verfahren der Zentralperspektive rekurriert: hier bezieht sich die theatrale Performanz vor allem auf die Ebene der Darstellung selbst, die Art und Weise der Erzeugung von Sichtbarkeit, welche gegenüber dem Gesehenen die Oberhand gewinnt und sich partiell gegenüber dem bloß dargestellten Heiligen verselbständigt, das nunmehr als Bestandteil einer visuellen Repräsentation erscheint, welche eine spezifisch frühneuzeitliche Betrachterordnung generiert. Die Übernahme des modernen Blickregimes der Zentralperspektive gibt damit insgesamt zu erkennen, dass es sich nicht mehr primär um die Epiphanie des Heiligen selbst, sondern um die Apotheose seiner Visualisierung und Theatralisierung handelt; es ist nicht das dargestellte Heilige, sondern der Modus seiner medialen Darstellung, der nun in das Zentrum der theatralen Performanz rückt.

Abschließend lässt sich daher ein doppeltes Fazit ziehen: So ist erstens festzustellen, dass die unterschiedlichen Modi theatraler Performanz mit verschiedenen medialen Techniken korrelieren, denen sich zugleich divergierende Manifestationsgrade von Medialität zuordnen lassen: Während das von der Idolatrie inszenierte Rollenspiel auf technische Effekte weitgehend verzichtet und damit gewissermaßen eine medienhistorische $>$ Nullstufe< markiert, die sich als Ausdruck einer affichierten >Medienvergessenheit< deuten lässt, entspricht der emblematische Visualisierungsmodus, der das Dargestellte mit den Modalitäten seiner Wahrnehmbarkeit konfrontiert, jener Erscheinungsform, die als >Medienaktualisierung $<$ zu beschreiben ist. Der am zentralperspektivischen Blickdispositiv ausgerichtete dritte Performanztyp rückt hingegen gleichermaßen die Inszenierungstechniken wie auch die

einen lesbaren christlichen Glaubenssatz formieren. Zum medienhistorischen Zusammenhang, der in der Frühen Neuzeit zwischen dem Wahrnehmungsdispositiv der Zentralperspektive und den Verfahrensformen der Kryptographie besteht, vgl. paradigmatisch Kittler (48-75). - Vgl. zur Bedeutung der Gitter- oder Rasterkonstruktion im Rahmen der zunehmenden Formalisierung, Mathematisierung und Verwissenschaftlichung der Zentralperspektive Kemp.

32 Zur kulturhistorischen Bedeutung von Vermessungs- und Repräsentationsverfahren, die der praktischen Geometrie entstammen und zur Entstehung eines für die Frühe Neuzeit spezifischen (>diagrammatischen $<$ ) Modus der Sichtbarkeit und Evidenz beitragen, vgl. paradigmatisch Schäffner 1997 sowie 2001. 
Interaktion von Bühne und Zuschauerraum in ostentativer Form in den Entstehungskontext zeitgenössischer Medientechniken ein und lässt sich daher dem Modell einer gesteigerten $>$ Medienreflexivität $<$ zuordnen.

Zweitens: Diese Abfolge medialer Performanztypen erlaubt eine vorsichtige Neuperspektivierung der kulturgeschichtlichen Funktion und Bedeutung des auto sacramental: insbesondere die Konfrontation des einfachen >medienvergessenen< Performanztyps, des Rollenspiels der dämonischen Macht der Idolatrie, mit den komplexeren Formen theatraler Performanz, die sich auf die Visualisierung des Heiligen und Göttlichen beziehen, lässt sich als Ausdruck jenes Antagonismus von Christus und Satan deuten, der thematisch im Zentrum der autos sacramentales steht. Im vorliegenden Stück präsentiert sich die topische Rivalität zwischen Teufel und Gott jedoch nicht als ein dramatischer oder poetischer Konflikt, der - gemäß der unlängst formulierten These des Hispanisten Gerhard Poppenberg - im Zeichen einer >poetischen Theodizee< oder einer >säkularisierten Eucharistie< steht, ${ }^{33}$ sondern wird als gleichermaßen theatrale und mediale Agonalität in Szene gesetzt, im Rahmen derer die Theatralisierung des Göttlichen ostentativ ihre mediale Überlegenheit gegenüber der Performanz des Teufels bekundet. Die theologische Dimension des auto sacramental manifestiert sich folglich nicht primär im zeichenhaften allegorischen Verweisungszusammenhang, sondern tritt insbesondere in den unterschiedlichen Modi der theatralen Medialisierung zutage. In letzter Konsequenz präsentieren sich diese konkurrierenden Vermittlungsmodi in Form eines historischen >Medienwettstreits<, der auf divergierende kulturgeschichtliche Theatralitätskonzepte verweist, in denen sich paradoxerweise gleichermaßen die Modernität des auto sacramental wie auch seine irreduzible Fremdheit und Alterität dokumentiert.

\section{Literatur}

Alberti, Leon Battista (1877 [1435/36]): Della Pittura Libri Tre (Drei Bücher über die Malerei). Hg. v. Hubert Janitschek. Wien: Wilhelm Braumüller (Quellenschriften für Kunstgeschichte und Kunsttechnik des Mittelalters und der Renaissance XI), S. 50-163.

Allen, John J. (1989): »Estado presente de los estudios de la escenografía en los corrales de comedias«. In: Aurora Egido (Hg.): La escenografía del teatro barrocco. Salamanca: UIMP, S. 13-24.

Balme, Christopher (2003): »Stages of Vision: Bild, Körper und Medium im Theater«. In: Christopher Balme/Erika Fischer-Lichte/Stephan Grätzel (Hg.): Theater als Paradigma der Moderne? Positionen zwischen historischer Avantgarde und Medienzeitalter. Tübingen und Basel: Francke, S. 49-68.

Balme, Christopher (2004): »Theater zwischen den Medien: Perspektiven theaterwissenschaftlicher Intermedialitätsforschung «. In: Christopher Balme/Markus Moninger (Hg.): Crossing Media. Theater - Film - Photographie - Neue Medien. München: epdium, S. 13-31.

Baudry, Jean-Louis (1975): »Le dispositif: approches métapsychologiques de l'impression de réalité «. In: Communications 23, S. 56-72.

Calderón de la Barca, Don Pedro (1952 [1655]): »El viático cordero«. In: Ders: Obras completas, Bd. 3: Autos sacramentales, hg. v. Angel Valbuena Prat. Madrid: Aguilar, S. 1153-1178.

33 Vgl. hierzu Poppenberg (bes. 11-26). 
Crary, Jonathan (1999): Techniques of the Observer. On Vision and Modernity in the Nineteenth Century (9th ed.). Cambridge u.a.: MIT Press.

Cruciani, Fabrizio (1992): Lo spazio del teatro. Roma: Laterza.

de Bustos, Eugenio (1988): »Das auto sacramental Calderóns und sein Zusammenhang mit dem Fronleichnamsfest «. In: Angel San Miguel (Hg.): Calderón. Fremdheit und Nähe eines spanischen Barockdramatikers. Akten des internationalen Kongresses anläßlich der Bamberger Calderón-Tage 1987. Frankfurt/M.: Vervuert, S. 115-145.

Díez Borque, José María (1986): »Relaciones de teatro y fiesta en el Barroco español «. In: José María Díez Borque (Hg.): Teatro y fiesta en el Barroco. España e Iberoamérica. Barcelona: Serbal, S. 11-40.

Díez Borque, José María (2002): Los espectáculos del teatro y de la fiesta en el Siglo de Oro español. Madrid: Ediciones del Labirinto.

Egido, Aurora (2004): De la mano de Artemia. Estudios sobre literatura, emblemática, mnemotécnia y arte en el siglo de oro. Palma de Mallorca: Olañeta.

Fiebach, Joachim (2002): »Performance«. In: Karlheinz Barck u.a. (Hg.): Ästhetische Grundbegriffe. Historisches Wörterbuch in sieben Bänden, Bd. 4. Stuttgart und Weimar: Metzler, S. 740-758.

Fischer-Lichte, Erika (1998): »Auf dem Wege zu einer performativen Kultur«. In: Erika Fischer-Lichte/Doris Kolesch (Hg.): Kulturen des Performativen $[=\mathrm{Pa}$ ragrana 7/1]. Berlin: Akademie-Verlag, S. 13-29.

Fischer-Lichte, Erika (2001): Ästhetische Erfahrung. Das Semiotische und das Performative. Tübingen/Basel: Francke.

Fischer-Lichte, Erika (2004): »Einleitung: Theatralität als kulturelles Modell«. In: Erika Fischer-Lichte/Christian Horn/Sandra Umathum/Matthias Warstat (Hg.) (2004): Theatralität als Modell in den Kulturwissenschaften. Tübingen/Basel: Francke, S. 7-26.

Fischer-Lichte, Erika/Christoph Wulf (Hg.) (2001): Theorien des Performativen. Berlin: Akademie Verlag.

Fischer-Lichte, Erika/Christian Horn/Matthias Warstat (Hg.) (2001): Verkörperung. Tübingen und Basel: Francke.

Friedrich, Hugo (1972 [1955]): »Der fremde Calderón«. In: Ders.: Romanische Literaturen, Bd. 2. Frankfurt/M.: Klostermann, S. 119-161.

Gumbrecht, Hans Ulrich (1990): Eine Geschichte der spanischen Literatur, 2 Bde. Frankfurt/M.: Suhrkamp.

Gumbrecht, Hans Ulrich (1992): »Für eine Erfindung des mittelalterlichen Theaters aus der Perspektive der frühen Neuzeit «. In: Johannes Janota (Hg.): Festschrift Walter Haug und Burghart Wachinger, Bd. 2, Tübingen: Niemeyer, S. 827-848.

Haß, Ulrike (2005): Das Drama des Sehens. Auge, Blick und Bühnenform. München: Fink.

Henkel, Arthur/Albrecht Schöne (Hg.) (1996): Emblemata. Handbuch zur Sinnbildkunst des XVI. und XVII. Jahrhunderts (2. Aufl.). Stuttgart: J.B. Metzler.

Kemp, Martin (1984): »Geometrical Perspective from Brunelleschi to Desargues: A Pictorial Means or an Intellectual End? «In: Proceedings of the British Academy, 70, S. 89-132.

Kirchmann, Kay (2002): »Vom erhellenden zum gestaltenden Licht. Die LichtOntologie im Theater der Moderne«. In: Lorenz Engell/Joseph Vog1/Bernhard Siegert (Hg.): Licht und Leitung. Weimar: Verlag der Bauhaus-Universität Weimar, S. 139-154.

Kittler, Friedrich (2002): Optische Medien. Berliner Vorlesung 1999. Berlin: Merve. 
Kotte, Andreas (2005): Theaterwissenschaft. Eine Einführung. Köln: Böhlau UTB.

Krämer, Sybille (1998): »Sprache - Stimme - Schrift: Sieben Thesen über Performativität als Medialität«. In: Erika Fischer-Lichte/Doris Kolesch (Hg.): Kulturen des Performativen [= Paragrana 7/1]. Berlin: Akademie-Verlag, S. 33-57.

Krämer, Sybille (2000): »Das Medium als Spur und als Apparat «. In: Dies. (Hg.): Medien - Computer - Realität (2. Aufl.). Frankfurt/M.: Suhrkamp, S. 73-94.

Küpper, Joachim (1990): Diskurs-Renovatio bei Lope de Vega und Calderón. Untersuchungen zum spanischen Barockdrama. Mit einer Skizze zur Evolution der Diskurse in Mittelalter, Renaissance und Manierismus. Tübingen: Narr.

McLuhan, Marshall (2001): Understanding Media. The Extensions of Man. Cambridge/London: MIT Press.

McLuhan, Marshall (2002): The Gutenberg Galaxy. The Making of Typographic Man. Toronto: Toronto UP.

Moog-Grünewald, Maria (2000): »Zwischen Kontingenz und Ordo. Das Emblem in Renaissance und Barock «. In: Joachim Küpper/Friedrich Wolfzettel (Hg.): Diskurse des Barock. Dezentrierte oder rezentrierte Welt?. München: Fink, S. 187-216.

Neumeister, Sebastian (1978): Mythos und Repräsentation. Die mythologischen Festspiele Caderóns. München: Fink.

Panofsky, Erwin (1974 [1927]): »Die Perspektive als >symbolische Form««. In: Ders.: Aufsätze zu Grundfragen der Kunstwissenschaft (2. Aufl.). Berlin: Hessling, S. 99-167.

Poppenberg, Gerhard (2003): Psyche und Allegorie. Studien zum spanischen auto sacramental von den Anfängen bis zu Calderón. München: Fink.

Ruano de la Haza, José María (2000): La puesta en escena en los teatros comerciales del Siglo de Oro. Madrid: Castalia.

Schäffner, Wolfgang (1997): »Operationale Topographie - Repräsentationsräume in den Niederlanden um 1600«. In: Hans-Jörg Rheinberger (Hg.): Räume des Wissens - Repräsentation, Codierung, Spur. Berlin: Akademie-Verlag, S. 63-90.

Schäffner, Wolfgang (2001): »Telemathische Repräsentation im 16. und 17. Jahrhundert«. In: Erika Fischer-Lichte (Hg.): Theatralität und die Krisen der Repräsentation. Stuttgart: Metzler, S. 411-428.

Shergold, Norman D./John E. Varey (1961): Los autos sacramentales en Madrid en la época de Calderón. Madrid: Ed. de Historia, Geografía y Arte.

Shergold, Norman D. (1967): A History of the Spanish Stage. Oxford: Clarendon Press.

Shergold, Norman D. (1970): »El gran teatro del mundo y sus problemas escenográficas «. In: Hans Flasche (Hg.): Hacía Calderón. Coloquio anglogermano, Exeter 1969. Berlin: de Gruyter, S. 77-84.

Tietz, Manfred (1988): »Theater und Bühne im Siglo de Oro«. In: Angel San Miguel (Hg.): Calderón. Fremdheit und Nähe eines spanischen Barockdramatikers. Akten des internationalen Kongresses anläßlich der Bamberger Calderón-Tage 1987. Frankfurt/M.: Vervuert, S. 35-59.

Winkler, Hartmut (1992): Der filmische Raum und seine Zuschauer. Apparatus Semantik - Ideologie. Heidelberg: Winter. 


\title{
UN/SICHTBARKEIT: BLINDHEIT UND SCHRIFT. PETER TURRINIS »ALPENGLÜHEN《 UND WILLIAM FORSYTHES »HUMAN WRITES«
}

\author{
GABRIELE BRANDSTETTER
}

Die Konsultation von Handbüchern zu Medienwissenschaft und Medientheorien führen rasch zu jenem Diktum, mit dem Dieter Mersch einen Band über Medien der Künste als eine Theorie des Darstellens eröffnet: »Medientheorie bezeichnet ein noch ungedecktes Programm « (2003: 9) ${ }^{1}$ und: $»$ Dem Begriff $>$ Medium< eignet ein ubiquitärer Gebrauch « (10). ${ }^{2}$

Je nach theoretischem Ansatz wird der Begriff Medium auf technische Medien im engeren Sinn bezogen (wie Druck, Telegraphie, Photographie, Video und Computer), auf Funktionen ausgerichtet, etwa in der Unterscheidung von SpeicherMedien (Schrift, Tonband, digitale Speicher) und Darstellungsmedien; auf symbolische Prozesse ausgeweitet (etwa Sprache, Geld, Kommunikation) oder auf massen-mediale Prozesse, ihre materiellen Träger, ihre ökonomischen Strukturen und technischen Entwicklungen bezogen (wie etwa Presse, Radio, TV, Internet). Am Anfang also steht, im Blick auf eine Theaterwissenschaft als Medien-Wissenschaft, die Gretchenfrage: Wie hältst du's mit dem Medien-Begriff? Ich will im Folgenden vom Wortsinn des Begriffs Medium ausgehen: Medium, die Mitte. Jener Raum inmitten, der Einsicht gibt: für den Zeugen; für diejenigen, die vermitteln. Diese Mitte, Medium, ist nicht mittig, sie ist nicht zentriert. Damit ist vielmehr ein ZeitRaum-Intervall bezeichnet, das - in eine Zwischenzone gestellt - intermittiert und schwankt (vgl. Mersch: 10). Medium und Medialität: Im Feld von Übertragung und Übersetzung beruht die Struktur von Medien in diesem Transformieren: in einem Prozess des »Differenzen machens « (vgl. Seel 2000). So gesehen sind - in der Unruhe der Übertragung ${ }^{3}$ - Medium und Medialität immer schon von der Bewegung her zu denken. Bewegung ist Bestandteil der Performativität von Medien. Bewegung bestimmt aber auch und noch vor der Performanz der jeweiligen Medien und Medienprozesse das Mediale selbst: in der Differenz-Bewegung, im Zwischenraum, im Intervall der Übertragung.

Theater und Medien? Mein Interesse richtet sich hier nicht auf die so genannten Neuen Medien und ihren Einsatz im Theater. Vielmehr erscheint es mir im Kontext von Theater und Tanz wichtig, die Medialität jener alten Medien zu reflektieren, die Schlüsselthemen der Medialitätsdebatte markieren und damit auch theatertheoretisch relevant sind: Schrift (vgl. Greber 2002 sowie Arns 2004), Gedächtnis und

1 Vgl. das Kapitel »Schnittstelle Medien« bei Kotte 2005: 252f.

2 Merschs These lautet im Folgenden: »Das Ästhetische und vor allem die Artistik der Künste« gelte als »der Prüfstein der spezifischen Reichweite und Leistungsfähigkeit von Medien « (14).

3 Zur »Unruhe« des Bildes in Bewegung, vgl. Brandstetter 2008. 
Körper. Medien kommt die Eigenart zu, im »Erscheinen « zu verschwinden, so Dieter Mersch über die Negativität medialer Prozesse (vgl. Mersch: 16). Im Prozess der Übertragung ist ein Zeigen impliziert, das die Sichtbarkeit und die Unsichtbarkeit eben dieser Transmission betrifft. Hier, so meine ich, ist der Ort des Theaters. Statt weiterer vorläufiger Begriffs-Reflexionen versuche ich deshalb zunächst einen Schritt medias in res.

Ich will meine Überlegungen von zwei Beispielen herleiten: von einem Beispiel, das aus dem Theater stammt mit dem Akzent auf der Medialität von Sprache und Stimme, und mit einem zweiten Beispiel aus der Choreographie mit dem Akzent auf Schrift.

\section{Blindheit und Vor-Augen-Stellen: Peter Turrinis ALPENGLÜHEN}

Man stelle sich vor: »Alpenglühen«! Nimmt man dieses Natur-Schauspiel als ästhetisches Ereignis, so hätte man es - gemäß den kunsttheoretischen Kategorien des 18. und 19. Jahrhunderts - mit einer Erscheinungsweise des Erhabenen zu tun. Wobei man sich streiten könnte, ob und in wiefern die spezifische Zeitlichkeit dieses Naturtheaters und Lichtspektakels das Sublime erhöht bzw. überhöht. Der Ästhetik des Erhabenen zufolge - von Burke, Kant bis zu Lyotard (vgl. Lyotard; Pries sowie Stäheli) - wäre dieses Phänomen, »Alpenglühen«, im Medium von Bild und Kunst nicht darstellbar, auch und schon gar nicht im Guck-Kasten der Theaterbühne.

Alpenglühen als Bild dennoch dargestellt, als Gemälde, als Hochglanz-Prospekt von Postkarten und von Phototapeten herleuchtend, signalisiert demgegenüber den Inbegriff von Kitsch. In diesem Format ist der Titel eines Theaterstücks von Peter Turrini (1993) gehalten. »Alpenglühen« wird zur Chiffre für die medialen Inszenierungsstrategien eines billigen Austro-Alpin-Tourismus. Wenn dem Touristen die Welt der Berge als authentisches Erlebnis verkauft wird, so kommt es auf die Inszenierung dieses Erlebnisses, auf die Wiederholbarkeit, auf die Performance des Natur-Spektakels an. Turrinis Dreipersonen-Stück macht daraus eine Farce: ein alter Mann, ein ehemaliger und erfolgloser Theaterdirektor auf einer Hütte in den Alpen betätigt sich als Stimmen-Imitator in einer Thomas Bernhardschen Manier. In einem auf die Minute abgestimmten Zeitplan des Bergführers ahmt er für die ahnungslos begeisterten, Lieder singenden Touristen die Tierstimmen der Region nach: den Kuckuck und den balzenden Auerhahn, Dohlengeschrei und Gemsenruf. Natur-Theater als Branche der Konsumwelt, als Fremdenverkehrs-Regie, Alpenglühen inbegriffen: »Ich bin ein Imitator. Ich imitiere die Stimmen von toten Tieren. Im Auftrag des Fremdenverkehrsverbandes « (Turrini: 48). So gesehen ist Turrinis Stück eine Satire auf das Verhältnis von Natur, Kunst und Warenästhetik als Mediensimulation. Unter einem anderen Gesichtspunkt - und auf diesen kommt es mir hier an - ist Turrinis ALPENGLÜHEN ein Stück über das Verhältnis von Theater und Medialität. Die Hauptfigur, ein 72jähriger einsam in einer Berghütte lebender Mann, ist blind. Seine Erzählungen über die Geschichte seiner Erblindung widersprechen sich: Einmal ist es ein Unfall, weil er aus Liebe am inneren Idealbild einer Frau festhielt (Turrini: 43); einmal ist es Neugierde - ein Medien-Unfall, weil er zu lange in die Life-Performance eines Atombombentests geblickt habe (Turrini: 45). - Es ist eine Blendung aus der Gewalt, die zugleich die Gewalt der Blendung bezeugen soll: 
»Die vollständige Erblindung kam eines Morgens, ich war völlig ausgeschlafen, doch um mich war Nacht, und es dauerte eine Ewigkeit, vielleicht eine ganze Minute, bis ich begriff, daß diese Nacht für alle anderen Menschen schon der Tag war, nur nicht für mich « (Turrini: 45).

Seine Verbindung zur Welt ist ein junger, tölpelhafter Mann, der ihn mit dem Lebensnotwendigen versorgt und der ihm über die Vorkommnisse in der Welt Auskunft zu geben hat - mit der von dem alten Mann vorgeschriebenen und immer gleichen Formel: »Alle Menschen sind glücklich und leben in Frieden. Freudig gehen sie ihren Beschäftigungen nach « (Turrini: 46). Es ist die Kurzformel von warenförmigen Mediennachrichten. Diesem starren Illusionsbild steht andererseits ein seltsamer Medienkontakt zu den Ereignissen in der Welt gegenüber: die Berichte im Radio, die der Blinde in die Innenwelt seiner Vorstellung transportiert. ${ }^{4}$ Dieser Übertragungsprozess einer inneren Bebilderung des Unsichtbaren folgt einer eigentümlichen Dynamik der Ent-Bildlichung und Ent-Visualisierung:

»1956 gab es das erste batteriebetriebene Radio [...] Zu jeder Nachricht stellte ich mir das Ereignis selbst vor, ich machte mir mein Bild davon [...] Obwohl ich seit vierzig Jahren in diesem Haus lebe und es seitdem noch kein einziges Mal verlassen habe, bin ich durchaus kein Verweigerer der Welt gewesen. Im Gegenteil, ich nahm alles auf, was sie mir, einem Blinden, zu bieten hatte (Turrini: 45).

Er erzählt eine Chronik der Weltereignisse: Fidel Castro in Havanna, der Bau der Berliner Mauer, Bombenterror in Südtirol,

»und der Autosalon in Genf wurde glanzvoll eröffnet, und ich wollte mir die neuesten Modelle vorstellen, [er schreit] ... aber ich konnte nicht, denn ich war noch in Saigon, ich sah noch die vietnamesischen Kinder und färbte gerade ihre Brandwunden ein, da brach der nächste Krieg aus, der Jom-Kippur-Krieg, und noch einer und noch einer. Ich kam einfach nicht mehr nach mit der Herstellung meiner Bilder, mit meinen Vorstellungen. Zuerst verlor ich [...] die Farbe [...], ich sah alles nur noch schwarz-weiß, und seit einigen Jahren sehe ich nichts mehr. Ich, ein Blinder, sehe nichts mehr. Ich höre die Nachrichten, aber sie bedeuten mir nichts. Ich kann mir die deutsche Wiedervereinigung nicht mehr vorstellen « (Turrini: 45).

Die Radio-Verknüpfung zu den Ereignissen der Weltgeschichte bleibt abstrakt. Unsichtbarkeit der sprachlich-medial übertragenen Vorgänge und Imaginationen, die Vorstellungsbilder (phantasmata) der Einbildungskraft geraten in ein wachsendes Missverhältnis. Mit der Analogie der Bilder, die der Blinde sprachlich produziert, zu einer allmählich verblassenden Chronik der Wochenschau ist ein prinzipielles Thema von Medialität angesprochen: Der Zusammenhang von Speicher und Übertragungsmedien, von Gedächtnis und Aktualisierung qua Einbildungskraft. Denn: nicht nur Farbe und Licht verlöschen; zuletzt auch die inneren Bilder: »Ich, ein Blinder, sehe nichts mehr.« Das Verlöschen der Vorstellungskraft fällt ineins mit einer medialen Anästhesie. Der Ausfall der Bilder bezeichnet eine doppelte Blind-

4 Auch hier zeigt sich der Medien-Farce-Charakter des Stücks: Das Radio- bzw. das Hörspiel war lange Zeit nach 1945 das Medium für Kriegsblinde (Preis der Kriegsblinden für beste Hörspiele). 
heit: den Verlust der Sichtbarkeit der physisch präsenten Welt; und dann jener Unsichtbarkeit des Abwesenden, die durch die Medien - die Radio-Übertragung markiert ist. In diese Blind-Stelle trägt sich eine Geschichte der Gewalt ein; eine Chronik des Krieges und der technischen Macht - eben jene Geschichte, deren Technologien etlichen Medientheorien zufolge (etwa bei Paul Virilio 1993 sowie Friedrich Kittler 1986) den Siegeszug neuer Medien begünstigen: Funk, Technik und Telegraphie, Fernsehen und elektronische Übertragungsmedien.

Der Blinde, seine doppelte Blindheit, zeigt sich als ein Medien-Effekt. Die Blindheit ohne innere Bilder (»blindness without insight $~^{5}$ ) ist ein Blackout des Nicht-Vorstellbaren, der reportierbaren und unsichtbaren Welt. Gewalt-Geschichte inmitten des Empfangsfelds des Mediums. Dies alles aber stellt sich als ein »coup de théâtre « heraus; mehr noch: »Der Blinde « ist die Figuration, die Allegorie des Theaters selbst. Da, wo die Bilder versagen, da, wo die Kluft zwischen Sprachmedien und Visualisierung die Vorstellungskraft lähmt und die innere Bildproduktion zum Erliegen bringt, in diesem »dark room « entfaltet sich das Theater, das die Bilder anders zum Erscheinen bringt. Der Blinde, ein Theatermacher, dessen Imitationskunst die Grenze zwischen Natur und Kunst, zwischen Schauspielerei und der (Vor-)Täuschung selbst noch der Blindheit und ihrer Authentizität beständig verwischt - dieser Blinde steht für das Grundprinzip des Theaters: eine Bühne, die Abwesendes, Un/Sichtbares und Unsichtbarkeit selbst sichtbar macht. Der Blinde, der Theatermacher, figuriert als Allegorie dieser doppelten und widersprüchlichen Verknüpfung von Sehen bzw. Sichtbarkeit des Unsichtbaren und einer Unsichtbarkeit des Sehens selbst. Es ist die Sprache, die da einspringt, wo Abwesendes sichtbar werden soll; die Sprache, immerhin nach Meinung einiger Medientheoretiker das älteste Medium, die das Vor-Augen-Stellen des Nicht-Sichtbaren übernimmt. ${ }^{6}$ Der alten rhetorischen Tradition zufolge ist es die Hypotypose (vgl. Campe 1997), das bildgebende Verfahren des Vor-Augen-Stellens durch Wort und Stimme, das Umgebung, Welt, Vorgänge sichtbar macht, wie ein lebendes Bild, wie ein Film (so würden wir heute sagen). Quintilian definierte die Hypotypose als eine »in Worten so geprägte Gestaltung von Vorgängen (»proposita quadam forma rerum ita expressis verbis «), daß man eher glaubte, sie zu sehen als zu hören. ${ }^{7}$ Der Blinde, als Meister der Hypotypose, des Vor-Augen-Stellens von Geschichte(n) und der erhabenen Ereignisse der Natur (Alpenglühen!), tritt in eben dieser archaischen Rolle des Mediators von Unsichtbarem und des Darstellens von Undarstellbarem auf: als Repräsentant des Theatermachens schlechthin - freilich als verzerrte Pose. Seine Kunst des Vor-Augen-Stellens ist ein Hybrid aus dem Theater und aus den Medien der neuen Zeit, denn seine Kunst der Hypotypose setzt bis zuletzt und noch mit der Balkonszene aus ROMEO UND JULIA - als Stimmverführung ein. ${ }^{8}$ Und sie versagt zuletzt doch angesichts der Undarstellbarkeit von Unglück, von Gewalt und Terror. Das Theater - ein lichtloser, leerer Raum - wird erst durch die Kraft, die enargeia einer Kunst des Vor-Augen-Stellens zu einem Ereignis-Raum, in dem Sichtbarkeit allererst hergestellt wird: ein »Alpenglühen« ... metaphorisch gesprochen. Das Theater - seine Medialität - beruht darauf, die eigenen Verfahren der Sichtbarmachung (des Vor-Augen-Stellens) selbst noch vorzuführen und damit

5 ... um mit dem abgewandelten Titel von Paul de Man 1971 zu sprechen; vgl. auch: Derrida 1997.

$6 \mathrm{Zu} »$ Prosopopöie« vgl. Menke 2000.

$7 \mathrm{Zu} »$ Vor-Augen-Stellen« vgl. Quintilian 1965.

8 Vgl. die Schlussszene, die »Kulmination« des »Alpenglühens« in der Sonnenaufgangsbeschwörung aus ROMEO UND JULIA (Turrini: 50). 
sich selbst, als Theater mit seinen eigenen Darstellungsbedingungen, zu thematisieren. Turrinis ALPENGLÜHEN reflektiert und präsentiert diese Verfasstheit des Theaters: die Verfahren der Übertragung und ebenso ihr Versagen.

Die Frage nach der Medialität des Theaters umfasst immer schon unterschiedliche Medien und ihre Differenz, je nach Maßgabe der historischen, technologischen, theaterästhetischen Entwicklung - und diese Medialität konstituiert sich als grundlegendes (Sich-)Zeigen: als das visuelle, akustische und körperliche Vor-AugenStellen in der Differenz von An- und Abwesenheit, von Sichtbarkeit und Unsichtbarkeit. Das Übertragungsgeschehen ist >treulos<, verräterisch. Umberto Eco hat in seinem Buch über das Übersetzen: »Quasi dasselbe - mit anderen Worten « (Eco 2006) die Medialität, die Handlung des Übertragens unter dem Aspekt des Verhandelns betrachtet: auf der Suche nach einer Wahrheit, die nie nur auf einer Seite liegen könne. Translation als Negotiation und als Frage der Loyalität, der Treue! In diesem Prozess liegt das mediale Potential, das »Nicht-Gesagte « zu zeigen und sich zeigen zu lassen und im Prozess des Sichtbarwerdens jene Erinnerungen heraufzubeschwören, die das »Noch-nicht-Gesehene « sichtbar machen. Die Hypotypose kann die Erinnerung, die sie als Gestus realisiert, in diesem Prozess des Vor-Augen-Stellens erst hervorbringen. Medienhistorisch gesprochen (mit Niklas Luhmann 1995 und Vilém Flusser 1993) sind es die Effekte von »Anthropo-Techniken « (Sprache, Schrift und Körper), die die allgemeine Schaubühnensituation als ein »Monstre«, als Zeigen des Vor-Augen-Stellens ermöglichen.

Ich möchte diese Fragen des Sichtbar-Werdens in meinem zweiten Beispiel von der Schrift her, d.h. von Choreographie als Schriftbewegung noch einmal anders beleuchten.

\section{Schrift/Choreographie - Schreib-Bewegung: William Forsythes HUMAN WRITES}

William Forsythe hat in einer langen Serie von Stücken, die in unterschiedlicher Weise Medien implizieren und reflektieren, die Medialität von Choreographie zum Thema gemacht. In der Wissenschaft sind diese Arbeiten - auch und gerade unter Mediengesichtspunkten - ausführlich analysiert worden (vgl. Evert 2003 sowie Sulcas 1999). Während die Arbeit mit digitalen Medien und ihrer Speicherfunktion in erster Linie als analytisches Instrument eingesetzt wird - besonders als Reservoir für improvisatorische Aufgaben, wie z.B. in SELF MEANT TO GOVERN oder in der mit dem Zentralinstitut für Kunst und Medien in Karlsruhe produzierten CD-Rom Improvisation Technologies (Forsythe 1999) - konzipiert Forsythe in seinen Choreographien seit den späten Neunziger Jahren ein anderes Modell von Medialität. Er interessiert sich für eine ganz spezifische theatrale Konstellation - nämlich jene von Darstellen bzw. Aufführen als Sich-Zeigen (>monstrare $<$ ) und als das Zeigen von Betrachten, Beobachten. Forsythe arbeitet an und mit jener Schwelle, die üblicherweise räumlich markiert ist, zwischen Zuschauerraum und Bühnenraum, zwischen Saal und Rampe oder Podesten als Bewegungsfläche. Forsythe macht eben diese Konstellation zum Thema von Choreographie oder besser, von choreographischen Um-Schreibungen (wenn wir davon ausgehen, dass Choreographie bedeutet: Raum-Be-Schreibung in und als Bewegung). In KAMMER/KAMMER (Frankfurt/Main 2000, vgl. Siegmund 2006: 313ff) beispielsweise verläuft ganz traditionell die Linie der Spaltung zwischen Bühne und Zuschauerraum. Durch die unregel- 
mäßig in den Zuschauerraum gehängten Screens wird diese Demarkationslinie jedoch verschoben: Die Schirme zeigen die Life-Übertragung von Aktionen, die auf der Bühne in verschachtelten Räumen ablaufen; Räume, die teilweise einsehbar, zumeist aber für den Zuschauer nicht sichtbar sind. Sichtbarkeit und Unsichtbarkeit der Körper in den Kuben übersetzen sich in ein Bild-»Monstre «, das die Räume überspringt und sie mobil werden lässt. Der Effekt der Video-Übertragung - das Offenlegen, Präsentmachen eines Verborgenen - zersetzt sich im Blickraum des Betrachters wieder. Dieser befindet sich in einer beständigen Spaltung seines Blicks - zwischen den Bildern auf dem Bildschirm und dem Fokus auf das Bühnengeschehen. Übertragung, als eine »Performance als Absence« (mit den Worten von Heidi Gilpin") bezieht sich nicht nur auf die Un/Sichtbarkeit von Bewegung auf der Bühne und in der Grauzone (vgl. Brandstetter 2004) von Intervallen zwischen Tänzer-Performern und Betrachter. Sie reflektiert zugleich den Rahmen dieser medialen Inszenierung: die Möglichkeit des Theaters, die Bedingungen eines »Monstre«, nämlich das Zeigen zu zeigen - nicht in erster Linie im Sinn von deuten und hinweisen, d.h. im Sinn von deixis, sondern von »Erscheinen-lassen « (vgl. Seel 2000).

»Je traduis« - ich übersetze. Diese Formel ist programmatisch als SchriftRahmen in einer Art Lettern-Serie um die Bühne von KAMMER/KAMMER gesetzt. Übersetzung, als Form der Reflexion von Medialität, spielt in William Forsythes Choreographien eine immer wichtigere Rolle. In ALIE/NA(C)TION war das Thema die Fremdheit, die Andersheit, die von den Tänzern aus Film-Bildern, die für den Zuschauer uneinsehbar waren, in »Action «, in corporeality übertragen wurden. Zehn Jahre später, in Clouds AFTER CRANACH - dem Mittelteil von THREE ATMOSPHERIC STUDIES - geht es um den humanitären, den körperpolitischen Akt des Übersetzens und um die katastrophischen Folgen der Fehl-Lenkungen von Übertragung: bis zum Schrei, bis zur Unartikuliertheit, die sich medialer Übertragung entzieht und sich ihr widersetzt. Zu diesen Stücken wäre viel zu sagen - gerade über jene Seiten, in denen Forsythe Übertragung und Verstärkungsmöglichkeiten von Medien (über Bild und Mikrophon) in eine politische Kritik treibt, indem er mediale Desartikulationen zum Thema choreographischer Reflexion macht (etwa im dritten Teil von THREE ATMOSPHERIC STUDIES, vgl. Brandstetter 2005).

Ich möchte zuletzt das Augenmerk auf jene Arbeiten Forsythes legen, in denen er die Grenze zwischen Bühne und Zuschauerraum, zwischen Tänzern und Zuschauern verschiebt, ja aufhebt. Das Grundprinzip scheint einfach und im Blick auf die Geschichte der »Performance Art «nicht absolut neu: Tänzer und Zuschauer teilen sich einen Raum, bewegen sich in ein- und demselben Raum. Anders ausgedrückt: indem sich der Zuschauer ebenso wie der Tänzer auf dem ausgelegten Tanzboden bewegt - wie auch immer er sich bewegt, geht, steht, sitzt, »nicht bewegt « - wird er, der Zuschauer, zu einem Teil der Choreographie. In dieser Weise ist Forsythe bereits in seinem Stuick ENDLESS HouSE (Frankfurt/Main 1999) verfahren. Im zweiten Teil löst er die klassische, hierarchische Seh-Ordnung des Theaters auf. Der Betrachter ist eingeladen, sich zwischen den Tänzern auf dem Spielfeld zu bewegen, sich seinen Sicht-Platz zu suchen. Und er ist konfrontiert mit der Erfahrung, dass Sichtbarkeit im Sinn von Übersicht und Übersichtlichkeit nur partiell, fragmentiert und ausschnitthaft - im Vorübergehen - zu haben ist. Um den Preis der Unsichtbarkeit, der Abwesenheit und Unzugänglichkeit jener Vorgänge, die nicht im Blickfeld zu halten sind, die quasi »im Rücken« geschehen und die

9 Vgl. Gilpin 1994: 55 sowie grundlegend zum Thema »Abwesenheit« und Medialität: Siegmund 2006. 
den Zuschauer mit seiner bewegungs- und standpunkts-inhärenten Blindheit konfrontieren. Bewegung (des Zuschauers) als Des-Orientierung, als Verlust des Ordnungsrahmens, ist damit ein kontingentes Element dieser Choreographie: als ein Gehen, als eine Raum-Beschreibung, die eine kritische Auseinandersetzung mit der Politik des Sehens herausfordert. Es ist zugleich eine kritische Auseinandersetzung mit Tanz als einer Politik des Körpers: kritisch dann nämlich, wenn Tanz - als eine Kunst, Schritte zu setzen - die Gesetze seiner eigenen Körpernormierung nicht reflektiert. Choreo-graphie im Sinne von Forsythe ist demgegenüber die Reflexion von Körper-Bewegung in und durch die Art und Weise, den Raum zu (be-)schreiben und ihn zu be-schreiten. »Choreographie verstehe ich als Organisation. Es geht mir nicht darum, Bewegungen zu schaffen und zu zeigen. Mich interessiert die Wahrnehmung und das Verständnis von Wahrnehmung «, so William Forsythe (2005). Das Medium ist so gesehen: Schrift! Wobei sich hier sofort die »Falltür der Skription « (wie Roland Barthes dies genannt hat, vgl. Barthes 2002) auftut. Ohne auf die verzweigte theoretische Debatte zum Thema Schrift hier näher einzugehen: Eine Differenz ist immer schon im Spiel - die Differenz von Schreiben (als Bewegung) und Geschriebenem. Was verschwindet in der »Falltür der Skription? im Niedergeschriebenen? «(Barthes: 9) - um nochmals mit Roland Barthes zu sprechen: Der Körper, die Bewegung (des Schreibens) fügt sich in die hierarchischen Strukturen der Schrift und überführt sie in Zeichen: Körper - Schreib-Bewegung beugt sich der »Subordination « (Barthes: 11), die eine Tanz-Grammatik vor-schreibt. Choreographie im Konzept William Forsythes schreibt diese subordinative Vorschrift um. Indem sie die Abwesenheit des Körpers in der Schrift reflektiert und sichtbar macht, rückübersetzt und in Positionswechseln der Bewegung weiter überträgt. In diesem Sinn wäre und ist William Forsythes zusammen mit dem Juristen Kendall Thomas entworfene Choreographie HUMAN WRITES (Uraufführung 2005 in Zürich, Deutsche Erstaufführung zur Eröffnung des Festspielhauses in Hellerau im September 2006) eine Reflexion über die Medialität von Schrift; genauer, so sagt es der Titel: HuMAN WRITES, ist es eine Reflexion über das Schreiben als menschliche Handlung.

»Schreiben ist immer auch Bewegung. Ich verstehe meine choreographische Praxis als räumliches Schreiben. Die Tänzer sollen mit ihrer Bewegung Spuren hinterlassen. In HUMAN WriteS müssen sie gut sein, um, soweit das geht, mit den Hindernissen fertig zu werden und um zumindest einige Buchstaben reproduzieren zu können« (Forsythe 2005).

Und zugleich, so sagt es der Titel ebenfalls, in homophoner Bedeutung von »Human Rights «, Menschenrechte, geht es um Schrift als Verfassungstext als einen zentralen Gesetzestext, nämlich die Allgemeine Erklärung der Menschenrechte und ihre Geschichte. Es ist eine Geschichte der Übersetzungen, der Verfehlungen, Verletzungen dieses körperpolitischen Grundrecht-Textes. Die »Performance-Installation « (so der Untertitel) dauert drei Stunden. Die strukturelle Anordnung ebenso wie das Konzept unterliegen klaren Regeln (ich will sie hier kurz und unter Auslassung vieler Details skizzieren):

Der Raum, der Festsaal in Hellerau ${ }^{10}$, ist in vier Reihen mit 40 Tischen ausgestattet, die mit weißem Papier bedeckt sind: einzelne Sätze aus der Menschenrechts-

10 Ich habe die Aufführung in Hellerau im September 2006 gesehen und berufe mich auf diese Performance. 
Erklärung (deren gesamter Text im Foyer gedruckt ausgehängt ist) sind in unterschiedlichen Sprachen auf dem Papier der Tische vor-geschrieben. Die Tänzer haben die Aufgabe, diese Schrift/Zeichen nachzuschreiben, wobei die Regel lautet:

»Das Schreiben muss mit einer gleichzeitigen Behinderung dessen [des Schreibens, G.B.] einhergehen. Kein Strich oder Buchstabe darf direkt [Hervorhebung G.B.] entstehen [...] Jedwede Markierung, die zu der Entstehung eines Buchstabens beiträgt, muss aus einer physischen Einschränkung, einer Belastung oder einem Widerstand entstehen« (Programmheft, Hellerau, 15. September 2006).

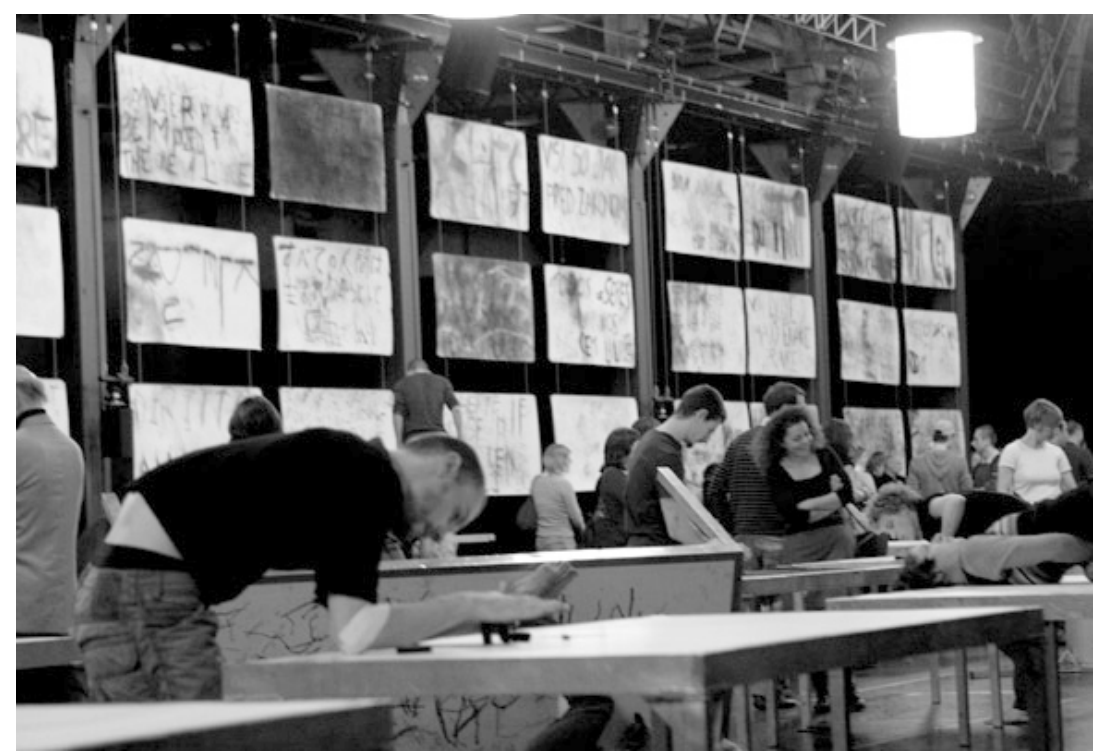

Abbildung 1: HUMAN WRITES. Foto: (C) Frank Sygusch.

Die Regel der Indirektheit - eines über Hindernisse der Körperbewegung im Übersetzungsakt vermittelten Schreibens - lenkt die Aufmerksamkeit auf die Medialität, auf die Mitte zwischen der Schrift und jenem Schreibakt, der üblicherweise automatisch bzw. automatisiert als Performanz einer Körpertechnik funktioniert; auf jene Mitte also, in der - dezentriert - Widerstände und Behinderungen der reibungslosen Bewegung des Schreibens selbst auftreten, dieses punktieren und verzerren. An einem der Tische ist William Forsythe der Schreibende: die Hände fixiert auf dem Rücken, mit einer Körperhälfte weit und halb liegend auf die Papierfläche gebeugt, versucht er mit sechs dicken Kohlestiften, die er im Mund »hält«, einzelne Striche der auf dem Blatt vorgegebenen Buchstaben nachzuzeichnen - unendlich mühsam, langsam, mit dem Kopf und ruckenden Gesamtbewegungen des Körpers agierend - verrenkt in den Gelenken bis zum Äußersten, ist diese Schreibbewegung ein Zittern, ein Stottern.

Das Schreib-Stück mit Kohle und Speichel verwischt den Gesetzestext, Gesicht und Körper schwarz: gezeichnet vom unablässigen Versuch, die klare Schrift klar zu schreiben, ein Akt der Grenzüberschreitung unter äußerster Belastung des Körpers. 
An einem anderen Tisch befindet sich der Tänzer unter der Schreibfläche. Mit Hilfe von körperlichen, »zeigenden « Richtungsanweisungen (rechts, links, nach oben, nach unten), die ein $\mathrm{Zu}-$ schauer ihm körperlich vermittelt, versucht er in Irrläufen einer blinden Handbewegung, die, verdreht, die Richtung sensorisch auszusteuern hat, die Linien der Buchstaben nachzuzeichnen - langsam, zögernd, äußerst konzentriert ... Diese Schreibungen sind in ihrer Behinderung so fern jeder »eloquentia « und »Schule des geläufigen Schreibens «, so fern von Perfektion kalligraphischer Bewegung - es sind äußerste Herausforderungen an die physische und mentale Koordination. Mehr und in einem tieferen Engagement sind die Zuschauer hier involviert als in früheren Stücken Willliam Forsythes.

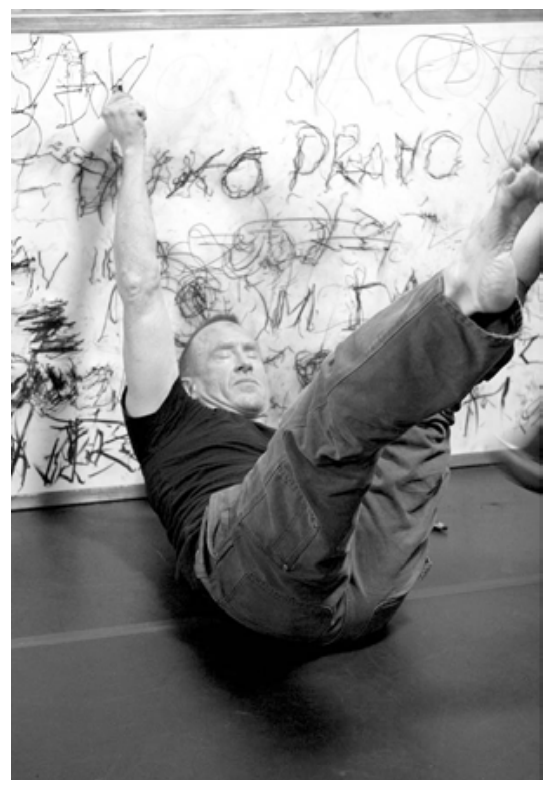

Abbildung 2: William Forsythe in HUMAN WRITES. Foto: (C) Frank Sygusch.

Im Programmheft des Abends wird das Konzept erläutert: dass nämlich die Performer das Publikum um Hilfe bitten, aktiv an dieser Arbeit, an diesem Projekt »Human Writes/Rights « mitzuwirken, um ein gemeinsames »Nachdenken « über die Rolle der Kunst in der Erstellung einer »Kultur der Menschenrechte « zu bewirken. Anders als in ENDLESS HOUSE oder in den Installationen von Forsythe wie etwa Bouncy Castle oder You Made Me A Monster ist der Betrachter nicht nur dadurch in die Choreographie einbezogen, dass er sich selbst inmitten der Szene und der Aktion bewegt, dass er die Choreographie also mitbestimmt und deren Ausschnitt und Sichtbarkeit mit jedem Schritt, mit jener Perspektiv-Entscheidung in Blick-Bewegung und blinden Stellen, Raum-Öffnungen und Grauzonen der Wahrnehmung produziert. Darüber hinaus ist hier jedoch jeder Zuschauer zur MitSchreibung, zur Inter-Aktion aufgefordert: Ob pures Flanieren, Beobachten, Gehen, Bleiben, oder deutliches Sich-Einlassen auf die unsichere, riskante, mühsame körperliche Vermittlungsarbeit im Schreibprozess: Dies wird für jeden zu einer ethischen Entscheidung. Choreographie: die Körper-Schreibung, der Prozess einer Nachschrift des Gesetzes, geschieht in Um-Wegen; vermittelt über eine Kette von Gesten. Diese Verschiebung der Schrift im gemeinschaftlichen, interkorporalen Schreibgeschehen bringt, wenn man so möchte, eine choreographische »différance « zu tage. Die Störung der direkten Übertragung lenkt die Aufmerksamkeit nicht in erster Linie auf die Schrift als Text, sondern auf die Spatien in ihrer Schreibung: auf das Zögern, die Verlangsamung, die Unentschiedenheit des korporalen Akts und die Lücken, die Zwischenräume. Medialität des Schreibakts wird in einer Praxis der Entstellung, der Unvollständigkeit und der Verfälschung reflektiert. Es ist die Un/Sichtbarkeit der Gewalt in der Schrift des Gesetzes, auch und gerade dann, wenn dieser Text die »Gewaltfreiheit« des Körpers zu garantieren verspricht, die in den Distorsionen dieses Schreibakts sichtbar werden. 


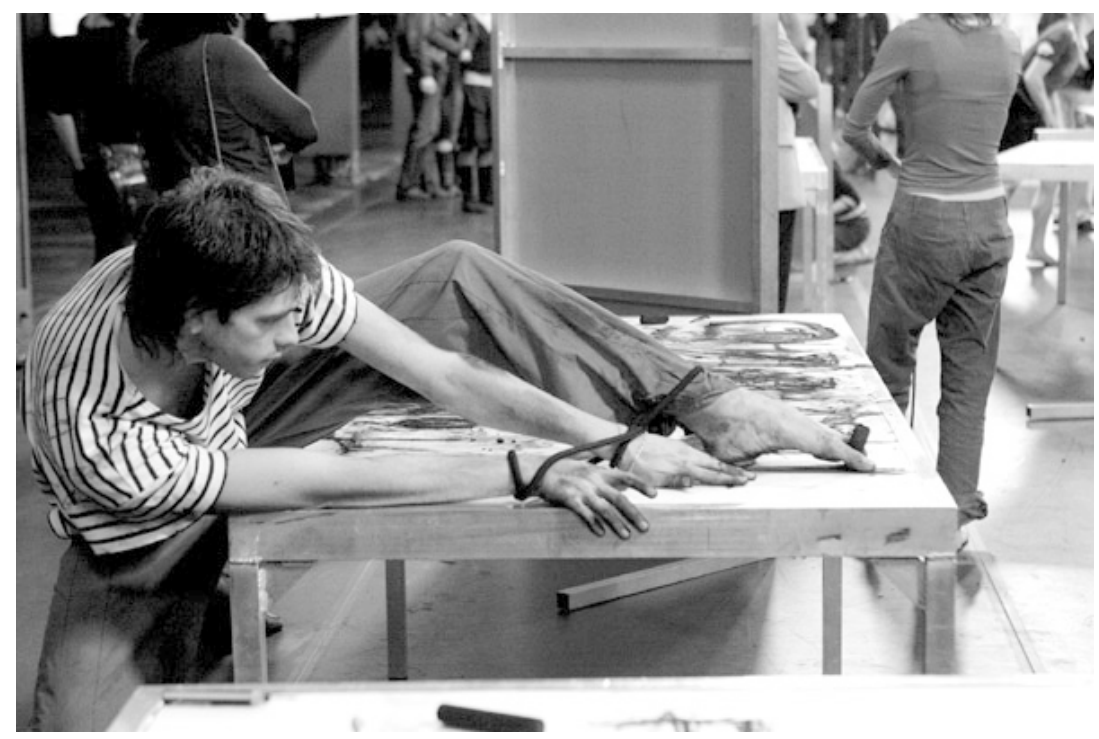

Abbildung 3: HUMAN WRITES. Foto: (C) Frank Sygusch.

Im Verlaufe der Performance nehmen die Mühseligkeiten, die Peinlichkeiten, die Vergeblichkeit, die Gewaltsamkeit gegen den Körper als Werkzeug des Gesetzestextes immer mehr zu - und zugleich verdichten sich im Raum die Zonen der Unordnung. In der Ballung der Zuschauer und Akteure in wechselnden Raum-Flecken, Stellen der Leere, der Verlassenheit, steigern sich heftige und hämmernde Schreibaktionen: Einer der Performer trägt den Tisch mit dem Blatt der Schrift umgekehrt, schräg gekippt auf die Schultern gelehnt, wie Christus das Kreuz. ${ }^{11}$ In einer anderen Zone versuchen vier Performerinnen, mit Stricken aneinander gefesselt, indem sie sich gegenseitig mitreißen oder sich Widerstand bieten, Kohlestücke auf die senkrecht gekippten Tischflächen hinter ihrem Rücken zu zeichnen: eine extrem heftige, affektintensive Szene, die in der Gefesseltheit durch Seile an die LaokoonGruppe erinnert, oder an Allegorien eines vielteiligen politischen Körpers.

Der Zuschauer ist nicht mehr »Publikum«, sondern - wie auch immer er sich wenden mag - Mit-Schreiber dieser choreographischen Installation. Er ist CoWriter, Übermittler der Schreibung in Impuls und De-tour. Er ist eingeschlossen, wohin auch immer er sich wendet, zugleich auch wieder ausgeschlossen in diesen unablässig sich verschiebenden Intervallen und Körper-Verbünden: inmitten der Ver-Fassung der Schrift. Die Medialität von Choreographie - im strengen Sinn des Begriffs - zeigt sich an den Rändern dieses Prozesses. Nicht als »Schrift «, als Niederschrift also im Sinne von Roland Barthes ${ }^{12}$, sondern in der Bewegung der Schreibung. Wobei sowohl Zuschauer als auch Performer im Verlauf des Abends an einem Schreibprozess beteiligt sind, der in der körperlichen Aktion etwas zeigt und etwas bezeugt, was der Gesetzestext verbirgt: In Übertragungen wird sichtbar, dass und wie in der Re-écriture der Text degeneriert. »Human Rights«, das ist jener Text, der explizit und als wiederholter politischer Akt sagt: »habeas corpus «.

11 Die Entstehung von »Bildern«, Zuschreibungen von ikonischem und politischem Gedächtnis gehören mit zum Prozess dieser kommunikativen Aktion.

12 »Das Schreiben ist nicht das Geschriebene« (Barthes: 13). 
HuMAN WRITES, ein Schreibstück, das einen Akt der Transgression zeigt und spürbar werden lässt. Das Stück lotet die Grenze zwischen Schrift und Körper, zwischen Gesetz und Bewegung des Re-Writing aus und reflektiert in dieser Zone das, was sich der Medialisierung entzieht: die Un-Übersetzbarkeit von Schmerz und jenen Akten von körperlicher Gewalt, die das Versagen, die Schändung, die »inhibition« von »Human Rights/Writes « ausmachen: der Verlust jenes unantastbaren Körper-Rechts, der erstmals in der Habeas-Corpus-Akte (in England/London 1679) niedergelegt wurde; der Schutzbrief, der Körper, Leib und Leben und individuelle Freiheit der Bewegung vor dem Übergriff der Staatsgewalt schützt. Keine Haft ohne richterliche Überprüfung und Anordnung; ein Freiheitsrecht, das - bis 1948 - bis zur Declaration of Human Rights einen langen Weg hatte. Auf die Widersprüche dieses Grund-Gesetzes der neuzeitlichen Körperpolitik hat - nach Foucault - Giorgio Agamben aufmerksam gemacht. Die zentrale Bedeutung des Körpers in »Menschenrechten « und »Biopolitik ${ }^{13}$ : »Corpus ist ein doppelgesichtiges Wesen, das sowohl Träger der Unterwerfung unter die souveräne Macht als auch [Träger] der individuellen Freiheit ist « (Agamben: 133). Diese Widersprüche sind laut Agamben in modernen Staaten nicht geschwunden - »in jedem modernen Staat gibt es [den Punkt], an dem die Entscheidung über das Leben zur Entscheidung über den Tod, und die Biopolitik zur Thanatopolitik wird « (Agamben: 130).

Vor der Erkenntnis, dass »die Menschheit weiterhin von der Unmenschlichkeit erfüllt ist « (William Forsythe zitiert hier im Programmheft Jean-François Lyotard), ist HumAN WriTES der Versuch, Choreographie im Wort-Sinn des Schreibens, der (Raum-)Beschreibung als Körper-Akt(e) an jener Grenze einzusetzen, über jene Grenzen zu treiben, die Kunst als politische Handlung wirksam werden lassen. Wenn Human Rights/Menschenrechte als Recht auf körperliche Unversehrtheit und Freiheit Bestandteil politischer Verfassungen sein soll und damit wirksam, so ist dieses »Verfassen« des Gesetzes-Textes immer ein Nachschreiben, ein körperlich antizipierendes Erinnern dieser humanen Verfasstheit, wie Heiner Müller diesen Bezug zu Geschichts-»Schreibung « fasste. Dieses Verfassen ist ein gemeinschaftlicher Akt, der im Schreiben selbst korpo-real werden lassen müsste, was der Gesetzestext, als Nieder- und Vor-Schrift, ausschließt: Die implizite, die strukturelle Gewalt des Gesetzes selbst. Choreographie in diesem Schreibprozess der »Human Writes/Rights « arbeitet dann und so gesehen am Schreiben und Edieren als einem permanenten Prozess dieser Schrift. Wieder und wieder: Nachdenklich und betroffen macht dabei - inmitten der Performance-Installation von William Forsythes Gesetzes-Schrift-Text -, dass zuletzt, in der großen Un-Ordnung und Um-Setzung dieser Vorschrift der Human Rights vom Text des Gesetzes kaum ein Satz, kaum ein Wort lesbar bleibt. In einem eher vordergründigen Sinn mag man Forsythes Choreographie HuMAN WrITES (wie auch sein Stück THREE ATMOSPHERIC STUDIES) als kritische Reflexion von Medienpolitik in Zeiten des Terrorismus und der globalen westlichen Medienmacht betrachten. Als Choreo-graphie hingegen inszeniert HUMAN WRITES den Einspruch von Kunst gegen die politische, ökonomische, juristische und medien-bestimmte Verfügbarkeit des Körpers. Forsythe bezeichnet in diesem Prozess und immer neu die Grenze, an der die diskursive, die kommunikative Funktion der Schrift - als Speicher- und als Darstellungsmedium - umspringt, und er markiert genau hier den Einspruch der Kunst gegen die Verfügbarkeit dieses Mediums. Kunst klagt demgegenüber die Unverfügbarkeit des Körpers und seiner Bewegung ein. Die Bewegung: der Schreibakt des Choreographierens, wäre dann eine Form des Sichtbarmachens einer Politik des Medialen:

13 Vgl. Agamben 2002, insbes. Kap. 2, $135 f f$ - zur Habeas-Corpus-Akte: 131ff. 
im Übertragungsgeschehen als einem ästhetischen, als politischen Akt, in der differenziellen Bewegung des Schreibens und des Löschens. Man könne - so sagte William Forsythe im Gespräch nach der Aufführung von HUMAN WRITES in Hellerau: »gut schreiben... for bad reasons«; man könne aber auch »»schlecht< schreiben for good reasons «.

\section{Literatur}

Agamben, Giorgio (2002): Homo Sacer. Die Souveränität der Macht und das nackte Leben. Übers. v. Hubert Thüring. Frankfurt/M.: Suhrkamp.

Arns, Inke (Hg.) (2004): Kinetographien. Bielefeld: Aisthesis.

Barthes, Roland (2002): »Die Falltür der Skription«. In: Ders.: Die Körnung der Stimme, Interviews 1962-1980. Aus dem franz. v. Agnés Bucaille-Euler, Birgit Spielmann, Gerhard Mahlberg. Frankfurt/M.: Suhrkamp, S. 9-13.

Brandstetter, Gabriele (2004): »Aufführung und Aufzeichnung - Kunst der Wissenschaft? «In: Erika Fischer-Lichte/Clemens Risi/Jens Roselt (Hg.): Kunst der Aufführung. Aufführung der Kunst (= Theater der Zeit: Recherchen 18). Berlin: Theater der Zeit, S. 40-50.

Brandstetter, Gabriele (2005): »Figuration der Unschärfe. Der (un)beteiligte Betrachter«. In: Texte zur Kunst 15.58 (Juni). S. 74-79.

Brandstetter, Gabriele (2008): »Rahmen-Verschiebungen zwischen Bild, Tanz und Video. Las Meninas in Übertragung: Evelyn Sussmans >89 Seconds at Alcazar< und Edouard Locks >Velazquez's Little Museum««. In: Joachim Paech (Hg.): Intermedialität - Analog/Digital: Theorien, Methoden, Analysen. München: Fink, S. 481-494.

Campe, Rüdiger (1997): »Vor Augen Stellen: Über den Rahmen rhetorischer Bildgebung«. In: Gerhard Neumann (Hg.): Poststrukturalismus. Herausforderung an die Literaturwissenschaft. Stuttgart, Weimar: Metzler, S. 208-225.

De Man, Paul (1971): Blindness and insight. Essays in the rhetoric of contemporary criticism. New York: Oxford UP.

Derrida, Jacques (1997): Aufzeichnungen eines Blinden. Das Selbstporträt und andere Ruinen [anlässlich der Ausstellung im Louvre-Museum, Hall Napoléon, vom 26. Oktober 1990 bis 21. Januar 1991]. Hg. und mit einem Nachw. vers. von Michael Wetzel. München: Fink.

Eco, Umberto (2006): Quasi dasselbe mit anderen Worten. Über das Übersetzen. München u.a.: Hanser.

Evert, Kerstin (2003): DanceLab. Zeitgenössischer Tanz und neue Technologien. Würzburg: Königshausen und Neumann.

Flusser, Vilém (1993): Lob der Oberflächlichkeit. Für eine Phänomenologie der Medien (Vilém Flusser: Schriften, hg. v. Stefan Bollmann, Bd. 1). Bensheim u.a.: Bollmann.

Forsythe, William (1999): Improvisation Technologies. A Tool for the Analytical Dance Eye. Interactive CD-ROM. Hg. v. ZKM, Karlsruhe. Ostfildern: Hatje Cantz.

Forsythe, William (2005): »Das Publikum muss mitspielen«. In: NZZ, 22.10.2005. http://www.nzz.ch/2005/10/22/ku/articleD8SXF.print.html (26.06.2008).

Gilpin, Heidi (1994): »Aberrations of Gravity«. In: ANY: Architecture New York Nr. 5 (März), S. 50-55. 
Greber, Erika (Hg.) (2002): Materialität und Medialität von Schrift. Bielefeld: Aisthesis.

Kittler, Friedrich (1986): Grammophon, Film, Typewriter. Berlin: Brinkmann \& Bose.

Kotte, Andreas (2005): Theaterwissenschaft. Eine Einführung. Köln u.a..: Böhlau. Luhmann, Niklas (1995): Die Kunst der Gesellschaft. Frankfurt/M.: Suhrkamp. Lyotard, Jean-François (1994): Die Analytik des Erhabenen. München: Fink. Menke, Bettine (2000): Prosopopoiia. Stimme und Text bei Brentano, Hoffmann, Kleist und Kafka. München: Fink.

Mersch, Dieter (Hg.) (2003): Die Medien der Künste. Beiträge zur Theorie des Darstellens. München: Fink.

Pries, Christine (Hg.) (1989): Das Erhabene. Zwischen Grenzerfahrung und Größenwahn. Weinheim: VCH, Acta Humaniora.

Seel, Martin (2000): Ästhetik des Erscheinens. München: Hanser.

Siegmund, Gerald (2006): Abwesenheit. Ein performative Ästhetik des Tanzes. William Forsythe, Jérôme Bel, Xavier Le Roy, Meg Stuart. Bielefeld: transcript.

Sulcas, Roslyn (1999): »Eine neue Welt und in ihr die alte«. In: William Forsythe (1999), S. 29-49.

Stäheli, Alexandra (2004): Materie und Melancholie. Die Postmoderne zwischen Adorno, Lyotard und dem pictorial turn. Wien: Passagen.

Quintilian, Marcus Fabius (1965): Marci Fabii Quintiliani Institutionis oratoriae libri XII. Hg. v. Ludwig Radermacher. Leipzig.

Turrini, Peter (1993): »Alpenglühen«. In: Theater heute 1993 (Nr. 3), S. 42-50.

Virilio, Paul (1993): Krieg und Fernsehen. München: Hanser. 



\title{
TANZ DER FIgUREN - ZUR DARSTELLUNG VON BEWEGUNG IN DEN BILDERN DES HANS VON MARÉES
}

\author{
ISA WORTELKAMP
}

Wie viel Bewegung steckt im Bild? Lässt sich Bewegung im Bild darstellen wenn ja, dann wie? Und: ist über das Bild der Bewegung eine Bewegung des Bildes selbst wahrnehmbar?

Ausgangspunkt der folgenden Überlegungen zum Verhältnis zweier auf den ersten Blick unterschiedlichen und vielleicht voneinander verschiedenen Medien Bewegung und Bild - ist das Mittelbild des HESPERIDENTRIPTYCHONS von Hans von Marées. Es handelt sich dabei um ein mit Öl und Tempera auf Holz gemaltes $175 \times 200 \mathrm{~cm}$ großes Bild, das zwischen einem rechten Flügel und einem linken Flügel von je ca. $170 \times 90 \mathrm{~cm}$ in der Bayrischen Staatsgemäldesammlung in München ausgestellt ist.

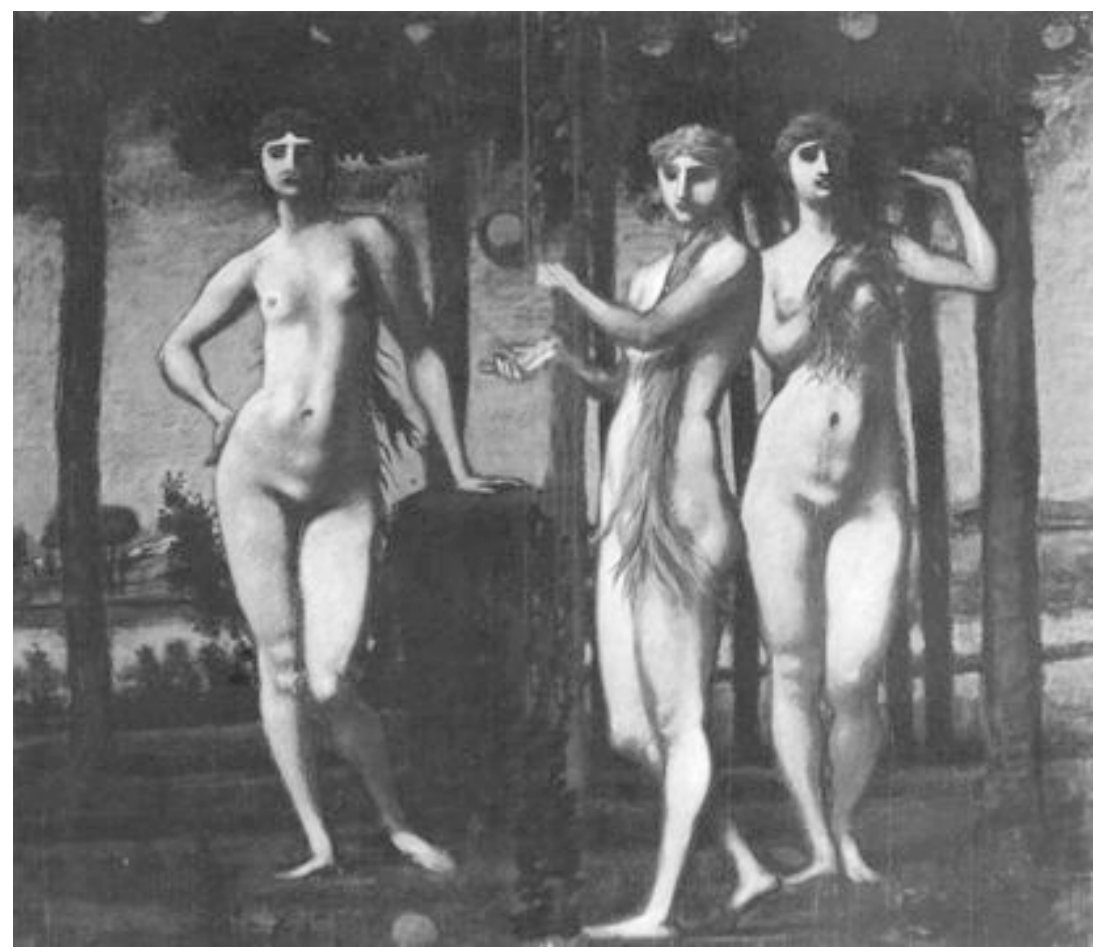

Abbildung 1: Mittelbild des HESPERIDENTRIPTYCHONS von Hans von Marées. 
Die Begegnung mit dem gemeinhin als bedeutendsten deutschen Maler des 19. Jahrhunderts bezeichneten Hans von Marées verdankt sich einem eigenen choreographischen Experiment - und damit einer Auseinandersetzung mit der Darstellung von Bewegung in seinen Bildern. Im Auftrag des Wuppertaler Von der Heydt-Museums ging es darum, anlässlich einer Ausstellung zu Marées eine tänzerische Umsetzung der Figuren seiner so genannten Hesperidenbilder zu entwickeln. ${ }^{1}$ Wir entnahmen den Figuren damals Bewegungen, indem wir ihre Haltungen einnahmen und aus ihnen Schritte und Gänge ableiteten. Es war eine Übertragung eines Bildes in Bewegung - die Übertragung eines Mediums, das in seinem Material statisch und fixiert ist, in das den eigenen Körper transzendierende und transformierende Medium der Bewegung.

Was hier zum choreographischen Material wurde, dient in Bildern der Fotographie oder Malerei vor allem der Tanzforschung als eine wesentliche Quelle der Rekonstruktion: der ikonographisch festgehaltene Bewegungsmoment. Immer wieder werden bei dieser Form der Bewegungsbetrachtung Zweifel laut, ob sich das kinetische und transitorische Ereignis der Bewegung im statisch fixierten Bild beobachten ließe. Bewegung scheint in ihrer flüchtigen und einmaligen Eigenschaft nicht im Bild still zu stellen, nicht in den Rahmen zu passen, der auf den ersten Blick der Bewegungslosigkeit zugeordnet wird. Und doch lassen es Abbildungen von Bewegung $\mathrm{zu}$, diese ab- und herzuleiten, Prinzipien und Strukturen von Bewegung zu beobachten und nachzuverfolgen (vgl. hierzu Jeschke). In jenen Re-Konstruktionen der Bewegungsforschung vollzieht sich eine Über-Setzung und Über-Tragung von Bild in Bewegung, von einer zweidimensionalen ebenen und unbewegten Fläche in den dreidimensionalen bewegten Körperraum.

\section{Zur Bildhaftigkeit der Wahrnehmung von Bewegung}

Bewegung im Bild markiert so gesehen einen Medien-Sprung, einen Sprung, von dem transitorischen Prozess der Bewegung in den statischen Rahmen der fixierten Punkte. Wie aber nehmen wir jenseits des Bildes Bewegung auf und wahr? Der Frage danach, wie viel Bewegung im Bild enthalten sei, schließt sich die Frage nach der Bildhaftigkeit der Wahrnehmung von Bewegung an.

Der Fokus unserer Aufmerksamkeit, die Begrenzung unseres Sichtfeldes, die Unterbrechung des Blicks durch unseren Lidschlag, Schlieren, die über unsere Pupille ziehen, bis hin zur Leerstelle des blinden Flecks - die Wahrnehmung von Bewegung, so viel kann in aller Kürze gesagt sein, ist weder lückenlos noch ungebrochen, ist nicht ohne Ein- und Ausschnitt.

Vielmehr kommt die Wahrnehmung von Bewegung, wie Gabriele Brandstetter (10) zum Verhältnis von Bild und Bewegung und von stasis und kinesis hervorhebt, einem ständigen Sistieren ihrer Bilder gleich, einem Segmentieren einzelner Momente aus dem Kontinuum der Bewegung in Bildsequenzen. »Dazwischen - die Lücken des Entschwundenen, Nicht-Erinnerbaren «.

1 Es handelt sich hier um die Ausstellung »Orangen für Hans von Marées « des zeitgenössischen bildenden Künstlers Erwin Wortelkamp, 05.09.-17.10.1999. Vgl. hierzu Nowald. Die Performance der 1998 in Köln begründeten Formation ArchitekTanz fand zur Vernissage und Finissage statt und wurde 2001 zur Ausstellung in Neapel wiederholt. 
Bewegung in ihrem Entschwinden und Erscheinen, in ihrem steten Vergehen und Vorübergehen wahrzunehmen, heißt auch sie zu erinnern und zu vergessen. Ihre Vergegenwärtigung vollzieht sich in einem unentwegten Aneinanderfügen von Eindrücken: Eindrücke von Standbildern, die im Rückblick erneut laufen lernen.

Die Darstellung von Bewegung im Bild erinnert so an die Bildhaftigkeit unserer eigenen Wahrnehmung von Bewegung, führt diese Wahrnehmung selbst vor Augen. Und: im umgekehrten Prozess können wir uns mittels dieses Bewegungsbildes - im Sinne der im Bild festgehaltenen Bewegung - Bewegung vorstellen, können sie sehen. Bewegung im Bild zu sehen heißt auch, sie in der Erinnerung an unsere Wahrnehmung von Bewegung und im Wissen um unsere eigene Erfahrung von und mit Bewegung, heißt; sie auf gewisse Weise in Bewegung zu sehen. Im Bild dargestellte Bewegung steht nicht still, bewegt sich in den Gedanken unseres Körpers fort. Die Betrachtung von Bewegung im Bild geschieht in der Spannung zur Stillstellung, dort wo die Wahrnehmung zu springen beginnt, zwischen der aufgezogenen Leinwand - still und flach - und der Figur, die bei der geringsten Regung (des Erinnerns oder des Vorgriffs) in Bewegung zu geraten, vor dem Auge zu tanzen vermag. Über die bildnerische Darstellung von Bewegung wird etwas wahrnehmbar, was der Bildbetrachtung per se eigen ist - die Bewegtheit der Wahrnehmung selbst, die in der Konzentration kunsthistorischer Betrachtungen auf den dargestellten Gegenstand und den Inhalt des Bildes lange Zeit verdeckt blieb.

\section{Zur bildnerischen Darstellung von Bewegung im kunsthistorischen Kontext}

Die Frage nach der Beziehung von Bewegung und Bild ist nicht unabhängig von einem kunstwissenschaftlichen Diskurs zu denken, dessen Tradition von einer bis heute anhaltenden Unterscheidung geprägt ist, nach der die bildende Kunst als Raumkunst von den eigentlichen Zeitkünsten der Dichtkunst, Musik und dem Schauspiel abgegrenzt wird. ${ }^{2}$ Die von Lessing im LAOKOON ODER ÜBER DIE GRENZEN DER MALEREI UND POESIE (1766) ${ }^{3}$ ein- bzw. fortgeführte Unterscheidung beruht dabei weniger auf der Wirkung und Wahrnehmung des jeweiligen Mediums als vielmehr auf dessen Materialität. Leinwand, Bronze, Stein, Holz werden als räumlich und unbewegt, der zeitlichen und bewegten Sprache und von Ton entgegensetzt betrachtet. Auch wenn es hier weniger um eine Beschränkung der bildenden Kunst als um eine Befreiung der Poesie ging, verdeckte diese Zuordnung wissenschaftsgeschichtlich das Phänomen der Zeit und damit auch das der Bewegung. So ging die Kunstgeschichte davon aus, dass aufgrund der statischen Be-

2 In der Geschichte der Theaterwissenschaft geht die Besinnung auf die flüchtige und einmalige Aufführung einher mit einer Abgrenzung von der bildenden Kunst, die als im Bild oder in der Skulptur verewigter und greifbarer Gegenstand anders als die Aufführung einer dauerhaften und wiederholbaren Betrachtung zugänglich erscheint. Dabei droht die Kunst angesichts der sicht- und greifbaren Stofflichkeit ihres Gegenstands - wie der Spur eines Pinselstrichs, der Struktur einer plastischen reliefartigen Oberfläche oder der Rahmung und Formung eines Kunstwerks - auf die vordergründige Materialität ihres ästhetischen Gegenstandes reduziert zu werden. Vgl. Lessing 1958: 5.

3 »Die Malerei kann [...] nur einen einzigen Augenblick der Handlung nutzen und muß dabei den prägnantesten wählen, aus welchem das Vorhergehende und Folgende am begreiflichsten wird « (Lessing 1925: 114). 
schaffenheit des Bildes in seiner materiellen Existenz auch seine Gehalte statisch und letzten Endes objektivierbar seien. Der Anschauungsform dafür entspricht der Raum, der im Neben- und Hintereinander der Elemente den Bildaufbau bestimmt. ${ }^{4}$ Die Rede von Zeit im Bild bleibt bis dahin vor allem an die Darstellung von Bewegung und das Studium der menschlichen Figur gebunden. Es geht nicht um die Formulierung von einer Zeitlichkeit des Bildes, sondern um die Zeit, die der abgebildeten Bewegung innewohnt. Sie zeigt sich in einem Moment der motorischen Aktion, den Lessing als fruchtbaren Augenblick beschreibt.

»Kann der Künstler von der immer veränderlichen Natur nie mehr als einen einzigen Augenblick und der Maler insbesondere diesen einzigen Augenblick auch nur aus einem einzigen Gesichtspunkt brauchen; sind aber ihre Werke gemacht, nicht bloß erblickt, sondern betrachtet zu werden, lange und wiederholtermaßen betrachtet zu werden: so ist es gewiß, daß jener einzige Augenblick nicht fruchtbar genug gewählet werden kann« (Lessing 1925: 22f).

Die Dauer und Wiederholbarkeit des Anblicks, bedingt durch den Gegenstand des Kunstwerks, verpflichtet den Künstler zur sorgsamen Auswahl eines fruchtbaren Augenblicks. Fruchtbar ist nach Lessing ein Augenblick dann, wenn er dem Auge nicht das Äußerste zeigt, sondern der Einbildungskraft freies Spiel lässt. So bleibt auch der Schrei in der Plastik des LAOKOON nur in einem Seufzen angedeutet, kann ihn die Einbildungskraft doch nur dann selbst schreien hören, wenn ihr das Abbild diese eigene Einbildung nicht vorwegnimmt: »Je mehr wir sehen, desto mehr müssen wir hinzu denken können. Je mehr wir dazu denken, desto mehr müssen wir zu sehen glauben « (Lessing 1925: 23). Ist der Schrei aber bereits vollendet, kann die Einbildungskraft, so Lessing, von dieser Vorstellung »weder eine Stufe höher, noch eine Stufe tiefer steigen « (ebd.). ${ }^{5}$ Der Bewegung der Einbildungskraft wirkt in der bildenden Kunst jedoch immer wieder der bleibende Anblick und die unveränderliche Dauer des Augenblicks entgegen. Daher müsse der Augenblick »nichts anderes ausdrücken, was sich nicht anders als transitorisch denken läßt« (ebd.).

Lessings Forderung, den Moment transitorisch zu wählen, meint nichts anderes als: durchgängig für den Zeitsinn nach beiden Richtungen der Zeit, dem >Voraus und dem >Gewesen-Sein $<$. Dadurch erst entwickelt sich eine Relation, die zu realisieren eine Aufgabe der Imagination ist, mit der es möglich wird, einer abgebildeten Körperhaltung ihren zeitlichen Ablauf zu entnehmen. Für die Darstellung wie die Wahrnehmung von Bewegung entscheidend ist dabei der Dreh- und Wendepunkt einer Figur, wie sich an zahlreichen Historienbildern aufzeigen lässt. In einer im Schritt befindlichen oder im Stand sich wendenden Figur; im über den Kopf erhobenen Arm, der zum Schlag ausholt, liegt die Zeit der Bewegung im Sinne des fruchtbaren Augenblicks. Der still gestellte Augenblick - die im Moment fixierte Haltung eines Körpers im Bild - zeigt dabei, wie Gottfried Boehm (1987: 18) pointiert, nicht nur, »was er materialiter an sich hat: die Stillstellung, sondern auch das, was er an sich selbst gar nicht besitzt: die Bewegung in der Zeit. «

4 Diese Sicht ist bereits in der Perspektivtheorie der Renaissance angelegt, die von einer vorherrschenden Struktur des konstruierten Bildraumes ausgeht.

5 Hier wendet sich Lessing gegen Winckelmann. Lessing betont den ästhetischen Aspekt in der Gestaltung der Plastik, während Winckelmann den ethischen hervorhebt, der zur Zügelung des Schmerzensschreis geführt haben soll. 


\section{Zeit des Bildes/Zeit der Bewegung}

Die Bindung der Zeit an die Bewegung in der Bildbetrachtung überlagerte in der Kunstgeschichte die Frage nach der Zeitlichkeit des Bildes selbst. Nicht der Zeit der Darstellung, sondern der im Bild dargestellten Zeit galt die Aufmerksamkeit eine Unterscheidung, die Gottfried Boehm in seinen Überlegungen zum Verhältnis von Zeit und Bild hervorhebt. Boehm macht Zeit als eine dem Bild innewohnende Komponente, als eine Grundkategorie der Malerei bewusst. Als solche tritt sie mit der ikonischen Wendung in der Kunst des 19. Jahrhunderts in den Vordergrund der Bildbetrachtung. Jene Wendung beschreibt eine Wendung des Bildes zum Bild selbst, zu den Eigenschaften seines Mediums. Indem Realität nicht mehr nach dem Modell des Abbildes begriffen wird, löst sich auch das Bild von der Funktion als Abbild von Wirklichkeit und wird in seiner eigenen Wirklichkeit bewusst. Während sich das Bild in der Wiedergabe des Abgebildeten selbst aufhebt, im Abbild verschwindet, zeigt sich das Bild nun in seiner eigenen bildlichen Potenz, indem es sich selbst, als Ab-Bild, übersteigt. Das Bild wird bildend. Die poietische Leistung der Bilder beschreibt Boehm als Leitsignal der Kunst des späten 19. Jahrhunderts. Die Leistung dieses historischen Geschehens sei die Entdeckung der genuinen und produktiven Leistung des Bildes selbst. Die Wendung zum Bild impliziert eine Wendung zum Sehen, als deren Begründer Konrad Fiedler, der Vertreter der neueren Bildtheorien im 19. Jahrhundert, gilt. Fiedler befreit das Sehen aus seiner passiven Rolle innerhalb der philosophischen Erkenntnis und rückt das Sehen als »Ursprung der künstlerischen Tätigkeit« in den Mittelpunkt der sinnlichen Wahrnehmung « (149).

Mit der Produktivität des Bildes, die in der Struktur seines Mediums angelegt ist, rückt die damit verbundene Aktivität des Sehens als zeitlicher und bewegter Prozess der Bildbetrachtung in den Vordergrund (vgl. Boehm 1987: 7). Jene Betrachtung vollzieht sich innerhalb des ikonischen Kontrastes, durch den sich ein Bild von seiner Umgebung als Rahmung und Ausschnitt abhebt und durch den das in die Materie ein- oder aufgetragene Bild, so Boehm (1987: 30), »darin einen Sinn aufscheinen lässt, der zugleich alles Faktische überbietet«. Auf ihm gründet sich das Verhältnis zwischen Fläche und Tiefe, innerhalb dessen es zu einem produktiven Oszillieren im Bildsehen kommt. Auf dieser flachen Tiefe des Bildes entspinnt sich eine Beziehungsform der einzelnen Elemente, die sich im Wechsel zwischen simultaner und sukzessiver, zwischen begleitender und fokussierender Wahrnehmung erschließen.

Zeit zeigt sich über das Abbild hinaus, als eine Zeit des Bildes selbst, die sich in der Wahrnehmung ereignet. Indem die Zeit vom Abbild der Bewegung gelöst betrachtet wird, wird auch die Bewegung über ihr Abbild hinaus, als eine Bewegung des Bildes und als eine Bewegung der Wahrnehmung, sichtbar.

\section{Das Mittelbild der Hesperiden - eine bewegte Bildbetrachtung}

Wie bewegt sich mein Blick? Wie wird er bewegt? Inwiefern lässt sich angesichts der Figuren im Mittelbild des HESPERIDENTRIPTYCHONS von Bewegung sprechen?

$\mathrm{Zu}$ sehen sind - vielleicht auf den ersten Blick - drei Frauengestalten, hinter denen durch die Stämme vereinzelter Bäume eine Landschaft sichtbar wird. In den 
Baumkronen über den Köpfen der Frauen, von denen die mittlere eine Frucht in den Händen hält, hängen Orangen. Eine weitere liegt zu Füßen.

Mein Blick findet keine Ruhe in der Liniatur der Gliedmaßen der hell sich abhebenden Figuren. Vielmehr wird er über die Fläche des Bildes gelenkt, entlang der Arme und Beine, im Wechsel der Bewegungsrichtungen der Körperhaltungen selbst bewegt. Die helle Fläche des Standbeines der linken Figur aufnehmend, folgt er den Konturen ihres Körpers, bis ihn das abgewinkelte Bein derselben wieder zum Boden führt. Vom Fuße der nebenstehenden Figur bis zu den Armen aufwärts wandernd, wird der Blick von einer Orange in der linken Hand der Hesperide im oberen Bereich der Bildfläche zentriert. Die von zwei Baumstämmen umrahmte Frucht hält die Bewegung der Betrachtung einen Augenblick an, fixiert ihn innerhalb eines Bildes im Bild. Den Weg des tragenden Armes zurückverfolgend, findet sich dessen abgewinkelte Form im äußeren Arm der dritten Figur in nächster Nähe fortgeführt. Von hier aus springt der Blick zurück zur linken Figur, wo sich der spitze Winkel im weichen Winkel des in der Hüfte aufgestützten Armes gespiegelt findet. Zwei Winkel rahmen die Gruppe und lassen das Auge über die Liniatur der Arme hin und her wandern. Die Formen der Winkel finden sich in den Spielbeinen der Hesperiden wieder, die die Linien der Arme aufgreifen und umlenken, den Blick immer in Bewegung haltend.

Im figuralen Zusammen und Auseinander verhalten sich die Figuren durch eine Anzahl möglicher Verbindungslinien und Richtungsbezüge in bewegter Weise zu einander, die auch das Auge in Bewegung hält. Die Streckung der Figuren und die Ausformung der Gelenke verstärken dien Eindruck von Bewegung. Ihre Formen gestalten in Winkeln, Diagonalen und Parallelen den Bildraum - die Choreographie der Bewegung bestimmt den Aufbau und die Anordnung des Bildes. Dabei wird die Bewegung des Blicks durch die dunklen Stämme der Bäume, die sich hinter den Frauen aufreihen und ihren aufrechten Stand unterstreichen, strukturiert und rhythmisiert. In der Reihung der Vertikalen wird das Sehen veranlasst, sich zwischen Fläche und Tiefe, Figur und Grund zu bewegen, sich zu versenken und wieder schweifen zu lassen. Die Zwischenräume der Körper werden ergänzt um die Zwischenräume der Bäume, deren dichte Anordnung in der rechten Bildhälfte die Bewegtheit der rechten Gestalten unterstreicht; die Ruhe in der linken Hälfte wird durch den weiten Abstand der Stämme ausgedehnt.

Durch die Streckung der Gliedmaßen lässt Marées die Gelenkstellen deutlicher hervortreten und damit, verstärkt durch die Schattengebung, auch die Winkel, die die formale Komposition des Bildes in einem hohen Maße prägen. Die vertraute Anatomie des Körpers wird - wie sich im Unterschenkel des Spielbeines der linken Figur und im Oberschenkel des Spielbeins der mittleren Figur sowie in den im Verhältnis zu den unteren Gliedmaßen sehr kurzen Oberkörpern beobachten lässt verfremdet.

Gerade die Verfremdung der Bewegung - in der Überlängung der Gliedmaßen und Betonung der Gelenke - aber trägt zum Eindruck von Bewegtheit bei. Sie betont das bewegte Verhältnis von Stand- und Spielbein, das dem gestalterischen Prinzip des Gegensatzes folgt - des so genannten Kontrapostes, das in der Malerei zum Ausgleich der menschlichen Gewichtsverhältnisse durch die gegenseitige Abwägung der bewegten Glieder dient. Es bewirkt, wie hier vor allem in der Darstellung der Figuren in der rechten Bildhälfte sichtbar, den Eindruck einer Bewegung zwischen Stehen und Schreiten und damit den Augenblick eines Übergangs. In dem Zwischenstadium von Stand und Gang liegt das Bewegungspotential der Haltung, die aus einer Schrittbewegung hervorgeht und für eine weitere offen ist. 
Es entsteht eine Ambivalenz, die zugleich in der Wahrnehmung von Bewegung im Bild selbst zu liegen scheint. In der Wahrnehmung eines andauernden Stillstandes - eines Stillstandes von der Bewegung im Bild und von etwas, um dessen Bewegung wir wissen, die wir kennen und sehen. Im Wissen um die motorischen Möglichkeiten beginnt der Blick die Figuren zu bewegen, und wird angesichts ihres Stillstandes dieser Bewegung des Blicks gewahr. Es ist Marées selbst, der sagt, eine Figur müsse den Eindruck erwecken, dass sie »jeden Augenblick ihre Stellung ändern « könne und der von der bildlichen Darstellung von Bewegungsabläufen fordert, sie möge, eine »Summe von Momenten« zeigen, die das »Gefühl der Fortsetzung von Bewegung « erwecken (Volkmann: 52). Und tatsächlich scheint der ansetzende Schritt der hinteren Hesperide im rechten Bildfeld in der vorderen Figur fortgesetzt und könnte in der linken mit einer Wendung zu Ende geführt sein, wobei die Arme der Schrittbewegung folgen. - Die Kinesis entspringt der Stasis.

\section{Im Wechselspiel von dargestellter Bewegung und Bewegung der Darstellung}

Weniger die Bewegung der Figuren, vielmehr die durch die Figuren im Bild frei gesetzte Bewegung bestimmt hier das Bildsehen. Mehr noch scheint die im Bild dargestellte Bewegung der Bewegung der Darstellung selbst zu dienen.

Die Frage nach dem Bild der Bewegung und der Bewegung des Bildes sieht sich hier mit einer Überlagerung konfrontiert, die eine Unterscheidung beider Ansichten zu unterlaufen scheint. Die Ansichten der im Bild abgebildeten Bewegung und der Bewegung des Bildes finden sich in einer Unterscheidung zweier Sehweisen wieder, die Max Imdahl in seinem Giotto-Buch von 1980 vornimmt. Es ist die Unterscheidung zwischen einem sehenden und einem wiedererkennenden Sehen - zwischen einem Sehen, das zunächst dem formalen Bildsehen und einem anderen Sehen, das dem inhaltlichen Bildsinn zuzuordnen ist. Imdahl entwickelt die Differenzierung in der Beschäftigung mit modernen Werken, insbesondere Bildern des späten Cézanne und der Kubisten, in denen er eine signifikante Verschiebung innerhalb des Erscheinungsbildes beobachtet (vgl. Boehm 1996b: 29). Sie bestand in einer Verselbständigung einer eigenständigen, »optischen autonomen « Ebene aus den gestalterischen Elementen, die auch in der Darstellung wiedererkennbarer Dinge sichtbar bleibt (Imdahl 1974: 303). Der Nachvollzug jener Ebene erfolgt durch ein Sehen, das sich nicht in der nachträglichen Anschauung eines bereits Gewussten und Be- und Erkannten erschöpft, sondern das Bild in der ihm eigenen optischen Existenz erfasst - ein Sehen, das über das Dargestellte hinaus, das Bild in der Art und Weise der Darstellung sieht. Dabei ist das sehende Sehen, wie Gottfried Boehm (1996b: 30) zur Konzeption Imdahls bemerkt, »kein inhaltsloser, die leere Form realisierender Akt. Es erfasst das Bild vielmehr in der nur ihm eigentümlichen optischen Existenz, die auch jede denkbare Inhaltlichkeit formiert «. Sehendes Sehen und wiedererkennendes Sehen kooperieren auf eine für das einzelne Bild je spezifische Weise miteinander.

In der Malerei des Hans von Marées wechselt die Bildbetrachtung zwischen jenem wiedererkennenden Sehen der dargestellten Bewegung und einem sehenden Sehen, das durch die Bewegung der Darstellung selbst bestimmt ist. Während die Haltungen der Figuren es zulassen, Bewegungen zu erinnern und wiederzuerkennen, wird das Sehen zugleich durch die Strukturierung und Rhythmisierung der formalen Gestaltung auf seine Tätigkeit, die Bewegungen des Blickes verwiesen. 
In diesem Wechsel der Wahrnehmung beginnt der Blick zu springen - kippt zwischen dargestellter Bewegung und der Bewegung der Darstellung selbst.

Es ist jenes »Spiel mit den Referenten«, das Bernhard Waldenfels (120) - die Unterscheidung von sehendem und wiedererkennendem Sehen aufgreifend - in Ordnungen des Sichtbaren beschreibt. Der Referent - hier die wiedererkannte Bewegung - tritt mal in den Vordergrund, mal in den Hintergrund des Bildes, um dem Blick ein »Feld von Möglichkeiten« (120) zu eröffnen. Wird Waldenfels folgend »das >wiedererkennende Sehen $<$, das im >Schon-Gesehenen $<$ seinen Halt findet, durch ein >sehendes Sehen< aus der Bahn geworfen « (124), so findet sich in der Malerei des Hans von Marées das sehende Sehen durch ein wiedererkennendes Sehen eingefangen, auf- und angehalten.

\section{Bewegung der Bildbetrachtung und -beschreibung}

Im Wechselspiel von sehendem und wiedererkennendem Sehen, von dargestellter Bewegung und der Bewegung der Darstellung entwickelt sich das Bild vor dem und im Auge des Betrachters. Die Einzelbilder von Bewegung reihen sich zu einer Abfolge. Die im Bild still gestellte Bewegung setzt sich in Gang, die Figuren beginnen zu schreiten, zu tanzen vielleicht. Die Wahrnehmung von Bewegung im Bild verselbstständigt sich, löst die Figuren aus der Fixierung - verlässt den Rahmen. Die im Bild dargestellte Bewegung ist ebenso wie das Bild selbst nicht an die Leinwand gebunden - sie erschließt sich in und mit der Bewegung des Sehens.

Es ist nicht das Bild, das wir sehen, folgt man Maurice Merleau-Ponty in Das Auge und der Geist (1984 [1960]). - Das Bild als Bild, das in eine Materie gemalt oder gezeichnet ist, in der Begrenzung durch Wand oder Rahmen, in Struktur, Fasern und Farben, in der Komplexität in seiner Gestaltung und Komposition. Wir sehen nicht das Bild, wir sehen mit dem Bild. Wir sehen, was das Bild sichtbar werden lässt (ebd.: 18).

Im steten Verweis auf das Wechselverhältnis von Sehen und Sichtbarem beschreibt Merleau-Ponty die Wahrnehmung des Bildes in der Einbindung des Körpers. Wir sehen nicht nur mit dem Bild, sondern wir sehen auch mit einem Körper. Im Blick auf das Bild erscheint auch immer der Rahmen meiner Augenhöhle, im Blick auf die Bewegung mein eigener Körper. Vielleicht liegt in diesem Körper-Sehen ja auch begründet, dass auch das Bild nicht ohne Bewegungen zu denken ist, denn, so Merleau-Ponty (39), »die Malerei ist niemals ganz und gar außerhalb der Zeit « - und ich erlaube mir zu ergänzen: außerhalb der Bewegung »weil sie immer im Körperlichen ist «.

Welche Auswirkungen hat eine Malerei, die immer im Körperlichen ist, auf die Wahrnehmung des Bildes? Welche Rolle spielt die Wahrnehmung des Körpers und seiner Bewegungen in der Betrachtung des Bildes? Und: wie ließe sich die Bewegung der Wahrnehmung des Bildes beschreiben - wie ließe sich mit der Betrachtung auch die Beschreibung des Bildes als bewegte denken?

Es verwundert nicht, dass die Beschreibung des für seine Bildbetrachtungen bekannten Kunsthistorikers Max Imdahl des Bildes von Marées DIE HESPERIDEN (1884-1887) einer choreographischen Anweisung gleichkommt (1996b: 48). In ihr ist die Rede von »ausponderierten Figuren in erfüllten Bewegungsphasen«, von »Raumschichten« der Figuren, die durch ein Knie, einen vorgehaltenen Arm, oder eine zurückreichende Hand begrenzt sind. Die Bildbeschreibung Imdahls ist durchdrungen von Attributen der Bewegung und von einem beinahe choreographischen 
Blick auf die Komposition von Raum und Bewegung im Bild. Der Tanz der Figuren setzt mit der Wahrnehmung auch die Beschreibung in Bewegung, wird im Lesen sichtbar. Von hier aus ließe sich die Wendung des Bildes zum Bild und damit zur der ihm eigenen Bewegungen weiterdenken. Ekphrasis, die Kunst der Kunstbeschreibung, wäre dann im Hinblick auf die Übertragung der Bewegung des Bildes in das Schreiben zu lesen - im Wechselspiel von beschriebener Bewegung und der Bewegung der Beschreibung selbst.

\section{Literatur}

Boehm, Gottfried (1987): »Bild und Zeit«. In: Hannelore Paflik (Hg.): Das Phänomen Zeit in Kunst und Wissenschaft. Weinheim: Acta Hunmanoria, S. 1-23.

Boehm, Gottfried (Hg.) (1996a): Max Imdahl. Gesammelte Schriften. Reflexion, Theorie, Methode, Bd. 3. Frankfurt/M.: Suhrkamp.

Boehm, Gottfried (1996b): »Die Arbeit des Blickes. Hinweise zu Max Imdahls theoretischen Schriften «. In: Ders. (Hg.): Max Imdahl, S. 7-41.

Brandstetter, Gabriele (2005): Bild-Sprung. TanzTheaterBewegung im Wechsel der Medien. Berlin: Theater der Zeit, Recherchen 26.

Fiedler, Konrad (1991 [1913/14]): »Über den Ursprung der künstlerischen Tätigkeit«. In: Gottfried Boehm (Hg.): Schriften zur Kunst I. München: Fink.

Imdahl, Max (1974): »Cézanne - Braque - Picasso. Zum Verhältnis zwischen Bildautonomie und Gegenstandssehen«. In: Boehm (Hg.): Max Imdahl, S. 283-303.

Imdahl, Max (1996 [1980]): Giotto, Arenafresken. Ikonographie - Ikonologie Ikonik. München: Fink.

Imdahl, Max (1996b): »Marées, Fiedler, Hildebrand, Riegl, Cézanne. Bilder und Zitate«. In: Boehm (Hg.): Max Imdahl, S. 42-93.

Jeschke, Claudia (1999): Tanz als BewegungsText. Analysen zum Verhältnis von Tanztheater und Gesellschaftstanz. Tübingen: Niemeyer.

Lessing, Gotthold Ephraim (1925 [1766]): Laokoon oder die Grenzen der Malerei und Poesie. Stuttgart: Reclam.

Lessing, Gotthold Ephraim (1958 [1767-69]): Hamburgische Dramaturgie. Kritisch durchgesehene Gesamtausgabe mit Einleitung und Kommentar von Otto Mann, Stuttgart: Kröner.

Merleau-Ponty, Maurice (1984, verfasst 1960): »Das Auge und der Geist«. In: Hans Werner Arndt (Hg.): Das Auge und der Geist. Philosophische Essays. Hamburg: Felix Meiner, S. 13-43.

Nowald, Karl Heinz (2000): »Orangen für Hans von Marées. Eine Ausstellung im Von der Heydt Museum Wuppertal, Herbst 1999«. In: Jörg van den Berg/Karen van den Berg/Christoph Brockhaus (Hg.): Erwin Wortelkamp. Papiere...Skulpturen...Räume...Kontexte. Ostfildern-Ruit: Cantz, S. 115-122.

Volkmann, Artur (1912): Vom Sehen und Gestalten. Ein Beitrag zur Geschichte der jüngeren deutschen Kunst. Jena: Diederichs.

Waldenfels, Bernhard (1999): Ordnungen des Sichtbaren. Frankfurt/M.: Suhrkamp. 



\title{
ZeIt des Theaters/Zeit der Fotografie. INTERMEDIALE VERSCHRÄNKUNGEN
}

\author{
JENS RUCHATZ
}

Dem Andenken an Theo Girshausen gewidmet.

Ein Medium gibt es nur dort, wo es auch Medien, andere Medien, gibt. Oder anders gesagt: Etwas verdient den Namen >Medium< nur dann, wenn es - sei es praktisch, sei es diskursiv-beobachtend - zu anderen Phänomenen in Beziehung gesetzt wird, die auch als >Medien< gelten. In seiner Zirkularität mag dieser Definitionsvorschlag fürs Erste wenig hilfreich klingen. Zur Plausibilisierung möchte ich daher zunächst am Verhältnis von Fotografie und Theater - und zugunsten der Prägnanz und Kürze auch nur in Hinsicht auf Zeitlichkeit - exemplarisch darlegen, wie sich solche Medienbeziehungen konkret gestalten, und erst anschließend einige theoretische Erörterungen grundsätzlicherer Art hinterher schicken. Über diesen Umweg wird schließlich die Frage ins Spiel kommen, inwiefern oder - um es angelehnt an Nelson Goodman noch griffiger zu formulieren - wann es sich bei Theater um ein Medium handelt.

Das Erscheinen von Theater in der Fotografie lässt sich nach zwei verschiedenen Strategien und Arbeitsfeldern gliedern, in denen das Verhältnis der Indienstnahme in jeweils verschiedener Richtung orientiert ist. Ich spreche

- von Fotografie im Theater (oder auch von Fotografie im Dienst des Theaters), wenn der Fotograf ins Theater kommt oder zumindest mit der Aufgabe konfrontiert wird, eine gegebene theatrale Gestaltung ins Bild zu setzen;

- $\quad$ von Theater in der Fotografie, wenn der Fotograf auf eigene Initiative theatrale Gestaltungsmittel heranzieht, um als Gegenstand der Aufnahme eine Bildwelt zu gestalten, er also gewissermaßen selbst in seinem Studio zum >Regisseur< wird. ${ }^{1}$

\section{Fotografie im Theater}

Das Problem der Zeit ist, wenn man der einschlägigen Literatur folgt, dem Verhältnis von Theater und Fotografie von Anfang an eingeschrieben. Die im Theaterraum herrschenden Lichtverhältnisse wie auch der technische Stand der Fotografie schlossen Mitte des 19. Jahrhunderts Bühnenfotografien aus. Überhaupt ist die frühe Fotografie geradezu als $>$ zeitfrei< zu bezeichnen, insofern selbst unter freiem Himmel alles, was sich bewegte und so auf das Vergehen der Zeit hätten verweisen können, aufgrund der langen Belichtungszeiten der Abbildung entzogen war. »Angesichts dieser Gegebenheiten«, so Claudia Balk in ihrer nach wie vor singulären Überblicksdarstellung zur Geschichte der Theaterfotografie, »konnten sich Theater-

1 Nicht von ungefähr spricht der amerikanische Kunstkritiker A.D. Coleman in diesem Fall auch von »directorial photography«. 
künstler und Fotografen zu ihren ersten Begegnungen nur im Fotoatelier verabreden « (12f). Im Laufe der Darlegungen klärt sich, dass das kleine Wörtchen >nur wahrhaftiges Bedauern ausdrückt, denn die Atelierfotografie wird - retrospektiv als minderwertiger Ersatz für die Bühnenfotografie aufgefasst, die erst um 1900 unter bestimmten Bedingungen möglich wird, sich um $1930 \mathrm{zu}$ etablieren beginnt und um 1950 zur Regel der Theaterfotografie aufsteigt. Das vom Fotografen - in Kooperation mit dem Schauspieler - inszenierte Bild gilt gegenüber dem Erfassen der vom Bühnenregisseur konzipierten Aufführung als defizitär. ${ }^{2}$ Die den Moment fixierende Bühnenfotografie wird damit schlechterdings zum Telos einer Fortschrittsgeschichte erklärt - und dies nicht nur bei Balk (67). ${ }^{3}$ So erklärt Brechts Mitarbeiterin Ruth Berlau (341):

»Die Theater erlauben einigen Fotografen, in den Pausen der Generalprobe hauptsächlich Standfotos aufzunehmen, die sie zur Reklame brauchen. Die Hauptdarsteller werden dazu in irgendeine effektvolle Stellung zusammengedrängt, die in der Aufführung oft gar nicht vorkommt. Die Darsteller bemühen sich für diese >gestellten< Bilder, mit übertriebener Mimik einen Ersatz für das fehlende lebendige Spiel herzustellen. Standaufnahmen bedeuten, daß der Gegenstand zum Zweck der Aufnahme getötet wurde. Nur während der Aufführung gemachte Aufnahmen vermitteln wahre Eindrücke.«

Der Gedanke, für gestellte Aufnahmen müsse der fotografierte Gegenstand getötet werden, lässt sich mit dem französischen Kunsthistoriker Thierry de Duve (1978; 1987) weiterspinnen, der zwischen Pose und Momentaufnahme als den zwei fundamentalen Modi fotografischer Zeitlichkeit unterscheidet. Partizipiere die Momentaufnahme auf der referentiellen Ebene (verkürzt: im Abgebildeten) am Fließen des Lebens, so herrsche auf der oberflächlichen Ebene (also in der Abbildung) jedoch der Eindruck von Leblosigkeit, einer durch den Apparat eingefrorenen, mitten in vollem Lauf > getöteten< und unwiederbringlich vergangenen Bewegung. Bei der Pose wisse man hingegen sehr wohl um die Bewegungslosigkeit auf der referentiellen Ebene, doch die mit Leben quasi aufgeladene Stillstellung evoziere auf der Oberfläche dafür Lebendigkeit und den Entzug der linearen Zeit. Leben und Tod wären somit in der Differenz von Momentaufnahme und Pose in einem Chiasmus überkreuzt. Die für die Momentaufnahme auf der Bühne reklamierte Lebendigkeit könnte demnach keineswegs verlustfrei verbucht werden.

Der theaterfotografischen Praxis ist es indes gar nicht primär um den aus der einmaligen Aufführung extrahierten Augenblick zu tun, den unwiederholbaren und letztlich nicht vorhersehbaren Augenblick der Momentaufnahme. ${ }^{4}$ Vielmehr werden die Theaterfotografen den halben Weg zur Pose zurück geschickt, denn es ist gerade nicht das Unerwartete, Überraschende, auf das abgezielt wird. »Den Fotografen«, so Berlau, »muß ermöglicht werden, auf Proben anwesend zu sein, um ausfindig zu machen, auf welche Momente es ankommt« (341). Nicht der Augenblick

2 Diese Wertung wird auch damit zu tun haben, dass die Theaterwissenschaft an den fotografischen Aufnahmen primär als Verweis auf und Quelle für die Inszenierungsgeschichte interessiert ist.

3 Als Gegenstimme siehe allerdings Spötter (26), sowie allgemein Sternberger (235): »Aber warum diese Feindschaft gegen die Pose? Ist nicht die Haltung, die das Modell in dem Bewusstsein einnimmt, porträtiert zu werden, ebensosehr ein >Ausdruck der lebendigen Persönlichkeit<, ja vielleicht ein genauerer als diejenige des halb ahnungslosen Gesprächs?«

4 Zur Unterscheidung von fruchtbarem und beliebigem Augenblick vgl. Aumont (180f). 
an sich, in seiner Kontingenz, ist das Ziel; vielmehr wird der Fotografie die Aufgabe zugewiesen, den wesentlichen, den entscheidenden, den, um es mit Lessing (23) zu sagen, »fruchtbaren « Augenblick zu fixieren, der die Essenz des Ganzen, der zeitlich ausgedehnten Aufführung, zu bündeln vermag (vgl. Berlau: 345). Letztlich sollen zwar aus dem Fluss der Handlung Momente herausgegriffen - und eben nicht herausdestilliert - werden, die jedoch posenartig über den singulären Augenblick hinausweisen.

Dieselbe Doppelstrategie empfiehlt Gerhard Starnberger in seinem Handbuch zur Bühnenfotografie. Auch er beschreibt die Geschichte der Bühnenfotografie zentriert auf den epochalen Bruch, mit dem der fotografische Fortschritt das »Mittelalter « der Atelierpose durch die »Neuzeit « des Bühnenschnappschusses ablöste (10). Ebenso sehr, wie es ihm wichtig ist, auf Posieren zu verzichten, steht der Begeisterung für das Momentane das Bestreben entgegen, den Augenblick zu kontrollieren und das Zufällige in Schach zu halten:

»Die geistigen Vorbereitungen des Fotografen zu den Aufnahmen sind ebenso wichtig und ebenso unerlässlich wie der technische Vorgang der Verschlußauslösung. Erst die genaue Kenntnis von Werk und Inszenierung gibt ihm die Möglichkeit das >Wann und Wo zur Aufnahme vorher zu bestimmen, und zwar so, daß es sich für die Bildgestaltung auswirkt. Ich werde also auf der Fotografierprobe [...] nicht vom zufälligen, glücklichen Augenblick überrascht « (Starnberger: 16). ${ }^{5}$

Um seine Erwartungen zu organisieren, greift Starnberger sogar wieder auf ein vorfotografisches Medium zurück und erstellt Vorskizzen (20f). Die Bühnenfotografie konfrontiert damit verschiedene Zeitlogiken: Zum einen geht es ihr darum, Schnitte in den Lauf des Bühnengeschehens einzuziehen, die durch Posieren nicht gegeben, sondern nur per Momentaufnahme aus dem Kontinuum isoliert werden können. Zum anderen ist der Gegenstand der Bühnenfotografie jedoch nicht das Einzigartige einer Aufführung, die in der Pose nicht erfassbare Singularität. Vielmehr ist ihr aufgegeben, gerade das Typische und Reproduzierbare, also das in jeder Vorstellung Erwartbare, herauszuarbeiten. Die einzelne Bühnenfotografie muss beanspruchen, für jede Vorstellung zu dienen, jeden Besucher an sein gehabtes Theatererlebnis zu erinnern oder auf ein künftiges vorauszuweisen, und konstruiert damit so etwas wie einen wiederholbaren Augenblick (26f).

Obwohl die tradierte Definition des Theaters durch die Einmaligkeit und Unwiederholbarkeit des Bühnenerlebnisses das Gegenteil erwarten ließe, kommt die eigentlich komplementäre Potenz der Fotografie, aufgrund ihrer Ko-Präsenz mit dem Fotografierten das absolute Einmalige zu fixieren, nicht zum Zug. Es ließe sich die These formulieren, dass die Bühnenfotografie anstrebt, die Pole von Schnappschuss und Pose, die de Duve selbst als nur konträr, nicht kontradiktorisch auffasst, so auszutarieren, dass ein Maximum des Lebens herausspringt: die Lebendigkeit auf der Ebene des Referenten durch die ungestellte Momentaufnahme zu konservieren, die Lebendigkeit der Oberfläche durch die Konzentration auf posenhafte Zuspitzungen.

5 Vgl. auch Starnberger (30): »Der Bühnenfotograf soll im Prinzip nichts Zufälliges dem Betrachter weitergeben $\ll$. 


\section{Theater in der Fotografie}

Die staged photography greift ihrerseits auf die Pose zurück, um ihre kommunikativen Beschränkungen zu bewältigen: den isolierten Augenblick und die mechanische, zunächst >sinnfreie<, Reproduktion von Wirklichkeit zu überschreiten. Dafür, dass es sich bei fotografischer Inszenierung tatsächlich um ein theatrales Verfahren handelt, lassen sich mindestens drei Argumente anführen:

1. Zunächst ist auf Ebene der Wortsemantik von >Inszenierung<, noch stärker im englischen Ausdruck staged photography, der Bezug zur Bühnenwelt bis heute konserviert.

2. In der Praxis wird in der Tat mit kostümierten und Rollen verkörpernden Akteuren - also in der Logik des Als-Ob - wie auf dem Theater eine Szene erstellt, nur dass diese sich - es sei denn, es handelt sich um eine Serie von Fotos - nicht in der Zeit ausdehnt und vor der Kamera (statt vor einem Publikum aus Fleisch und Blut) stattfindet. Durch das Dazwischentreten der Kamera scheint heutzutage der Film als Bezugsgröße freilich näher.

3. Hier greift schließlich das historische Argument, dass die Fotografie schon Jahrzehnte vor dem Film zum Mittel der Inszenierung griff (vgl. Daniel; Paul: 81-100). Einige Formen der inszenierten Fotografie wie die projizierten life model-Serien können sogar als Vorläufer des narrativen Films gelten (vgl. überblicksweise Ruchatz 2003: 328-333). Wenn die Gestaltung fotografischer Inszenierung sich heute auch an filmischen Vorbildern orientiert, ${ }^{6}$ so bleibt historisch doch stets der Rückbezug auf die theatrale Arbeitsweise maßgeblich, zumal gerade für die zur Pose geronnene, stillgestellte Handlung, wie sie die inszenierte Fotografie voraussetzt, mit den Tableaux vivants ein theatraler Vorläufer vorliegt, der sich bereits im ausgehenden 18. Jahrhundert herausbildet.

Für die so genannten lebenden Bilder ließ man in den bürgerlichen Salons, später auch in Bühnenräumen, von lebenden Darstellern bekannte Gemälde nachstellen, wobei man sich Requisiten, Kostümen und Beleuchtung bediente, um den angestrebten malerischen Eindruck zu komplettieren. Imitiert wurden in aller Regel Historienbilder, die selbst dem Prinzip des fruchtbaren Augenblicks folgten (Folie/Glasmeier: 21-24). Das Tableau vivant zeichnet sich dadurch aus, dass es zwischen Bewegungslosigkeit und Bewegung oszilliert, dass es gewissermaßen >atmet< (9). Es ist diese Ambiguität zwischen Dynamik und Stillstellung, von der die Fotografie profitieren möchte. Ein Tableau präsentiert einen Augenblick, der auf der Kippe zu stehen scheint zwischen dem vorhergehenden und nachfolgenden Geschehen. ${ }^{7}$ Die Fotografie greift diese theatrale Inszenierungsform auf, als diese als Unterhaltungsform eigentlich am Absterben ist (vgl. 30, 37, 40), kehrt jedoch die Relationen um: Das Tableau vivant ist nun nicht mehr Nachbild eines malerischen Vorbilds, sondern selbst Vorbild eines fotografischen Nachbilds, für das es konzipiert und inszeniert wird.

Die Theatralisierung der Fotografie dient offenkundig zuerst dem Ziel, das als mechanisch verrufene Reproduktionsmedium als kunstwürdig zu nobilitieren. Dadurch tritt - im Umkehrschluss - die Eigenschaft umso deutlicher hervor, die das Kunstvermögen der Fotografie in Frage stellt: die Unmöglichkeit, in den chemo-

6 So gibt die neuere staged photography etwa die Kameraposition gegenüber der >Bühne $<$ auf und taucht häufig in den Inszenierungsraum ein.

7 Das Bühnentableau trägt anders als das fotografische außerdem auf der Darstellungsebene seine eigene Vorläufigkeit und Transitorik als Spannungsmoment in sich. 
technischen Prozess der Bildwerdung so einzugreifen, dass das vermeintliche Abziehbild des Gegebenen mit Sinn versehen wird. Roland Barthes (17f) führt in diesem Zusammenhang unter anderem die Pose, die lesbare Geste, als Verfahren an, dem von seiner Denotation her eigentlich sinnfreien fotografischen Bild Bedeutung einzuhauchen. Barthes, dies ist vermutlich der semiologischen Perspektive geschuldet, sieht allerdings nur die Codierung der Gesten selbst. Er vernachlässigt, dass die Bedeutungsstiftung bei der Pose zwar nicht immer, aber doch sehr oft dadurch erfolgt, dass die inszenierte Konstellation zeitlich aufgeladen wird, ihren Sinn also dadurch gewinnt, dass der Bild gewordene Moment das Geschehen erahnen lässt, in das er eingelagert ist. ${ }^{8}$ Als privilegierter Punkt - zuweilen verstärkt durch die Integration in eine Bildserie - gibt die Pose Anlass, das Vorher und Nachher zu erschließen. Das fotografisch aufgezeichnete Tableau ist damit, wie Jeff Wall, einer der prominentesten Vertreter der staged photography, vertritt, kein räumlich und zeitlich dem Lauf der Dinge entrissenes Fragment mehr, sondern eine in sich geschlossene visuelle Aussage (Zit. Paul: 62).

Mit Zeichengebern wie Geste, Kostüm, Requisite und Bühnenbild, nicht zuletzt aber in der narrativen Aufladung stellt die theatrale Inszenierung der Fotografie Möglichkeiten der Sinnproduktion zur Verfügung. Die Fotografie erweist sich umgekehrt als in seiner kommunikativen Potenz beschränktes Medium, das künstlerischen Ausdruck und Bedeutungsstiftung primär durch die Präparierung der zu fotografierenden Wirklichkeit, aber kaum durch den Prozess der Bildwerdung selbst zu leisten vermag. ${ }^{9}$ Um das zeitliche Fragment mit Zeit und Sinn zu versehen, muss die Wirklichkeit selbst in der Pose stillgestellt werden.

\section{Medien durch Vergleich}

Nachdem hier in aller Kürze vorgeführt wurde, wie sich medienspezifische Zeitlichkeiten und Signifikationsstrategien in der Begegnung von Fotografie und Theater konturieren, indem sie komplementär, kompensierend und verstärkend zueinander in Beziehung treten, möchte ich abschließend andeuten, welche theoretischen und methodischen Gewinne eine solche Vorgehensweise verspricht. Auch hier möchte ich zunächst noch beim Problem der Zeitlichkeit verharren.

Theo Girshausen hat argumentiert, dass selbst der vermeintliche Kern der Theatererfahrung, also ihre Ereignishaftigkeit, nicht als überzeitliche Essenz des Theaters bestimmt werden könne. Indem man Lessings berühmte Aussage, die Schauspielkunst sei in ihren Hervorbringungen transitorisch, als Wesensbestimmung nahm, habe man sie - mit gewichtigen Folgen für die Theorie des Theaters in ihrem Aussagewert falsch eingeordnet: »Ich brauche darüber nicht zu reden«, so Girshausen,

»mit welchen Folgen man hier insistiert hat auf der Beobachtung, daß das Theaterkunstwerk transitorisch ist und wie man herumgeritten ist auf dem Argument, demzufolge es das Transitorische sei, das es von anderen Künsten - wie Lessing sagt - >in ihren Werken< unter-

8 Natürlich wird auch in diesem Fall kulturelles Wissen des Betrachters mobilisiert (Méaux: 37-54), nur läuft die Signifikation über Zeit und Narration statt über einen symbolischen Code.

9 Die ausgestellt theatrale Inszenierung, wie sie die künstlerische Praxis der staged photography betreibt, wird aktuell vor allem eingesetzt, um selbstreferentiell die Konstruktivität medialer Bilder zu markieren. 
scheidet. Man hat das, auf diese Formel starrend, wie das Kaninchen auf die Schlange, als Wesensaussage genommen, um die dann in der diesbezüglichen, bekannten Debatte Rekonstruktion hin, Rekonstruktion her - ein langer Grabenkampf über die methodologischen Möglichkeiten oder Unmöglichkeiten der Theaterwissenschaft ausgefochten (Girshausen: 35).

Vielmehr habe Lessing seine Aussage in Hinblick auf eine Orientierung der Praxis getätigt und in dieser Funktion sei sie auch von den modernen Theater-Avantgarden als Richtschnur der eigenen Praxis genommen worden. Es kann freilich als typisch für die Geschichte der Medien gelten, dass diskursive Ist-Bestimmungen in Soll-Bestimmungen, Beschreibungen in Vorschriften transformiert werden, die dann mit der Funktion auftreten, die Ist-Bestimmung zu stützen (Ruchatz 2002: 148).

Girshausen geht es nicht darum, die Transitorik durch andere Bestimmungsstücke zu ersetzen. Vielmehr tritt er für eine radikale Historisierung eines jeden noch so sehr als essentiell gesetzten Kerns ein. Nicht nur in seinen Ästhetiken oder seiner sozialen Funktion, sondern selbst »als Ereignis genommen, bleibt Theater dem geschichtlichen Wandel unterzogen. Geschichtliche Erfahrung bestimmt nämlich die jeweilige Art seiner Ereignishaftigkeit« (Girshausen: 34). Die Hervorhebung des Momentanen und Singulären in der Theaterpraxis - aber auch im theaterwissenschaftlichen Diskurs - kann als Bezugnahme »auf eine sehr beherrschende Zeiterfahrung unserer gegenwärtigen Wahrnehmung « gesehen werden, als Reaktion auf »die Medien-Zeit nämlich, die Wirklichkeit in gewisser Weise fiktionalisiert, indem sie nach Belieben mit Raum und Zeit umspringt « (41). Hier fänden auch die Zeitfragmente der Theaterfotografie ihren Platz. Der >Medienzeit< werde dann im Theater eine gewissermaßen als naturwüchsig verstandene Zeiterfahrung gegenüber gestellt. Als zentrales Bestimmungsstück des Theaters ergibt sich seine charakteristische Zeit demnach nicht aus dem Theater selbst, sondern erst im Kontrast $\mathrm{zu}$ anderen Figurationen und Erfahrungen von Zeit. Und so handelte bereits Lessing nicht vom Theater an und für sich, sondern vom Theater in Differenz zur Literatur - und damit in Abgrenzung zum Speichermedium Schrift. Als Spezifikum des Theaters würde dessen Zeitlichkeit damit erst eigentlich im Medienvergleich entstehen.

Als Ermöglichungsbedingungen für Formen - Texte, Aufführungen, Bilder usw. - können Medien nicht selbst in den Blick geraten, wie der sehr allgemeine, theoretisch jedoch konsequente Medienbegriff von Luhmann (165-173) erinnert. Damit wäre Medienbeobachtung - als Medienbeobachtung - unmöglich, sondern jeweils nur vorauszusetzen, dass es überhaupt so etwas wie ein Medium gibt, das für eine gegebene Formbildung als Voraussetzung angenommen werden muss. Jürgen Fohrmann hat rekonstruiert, wie unter diesen Umständen der Vergleich als Ausweg fungiert: »Alles [...], was sich über ein Medium aussagen lässt, ergibt sich erst aus einem Medienvergleich [...] und nicht aus einer Medienontologie « (7).

Eine solcher Art vergleichende Bezugnahme kann, wie ich meine, nicht nur in Form von Beschreibungen - also im Medium der Sprache - erfolgen, sondern auch in intermedialen Beziehungen der Medienpraxis, wie ich am Fall von Fotografie und Theater zu zeigen versucht habe. In der Verbindung der Medien werden ihre Grenzen und Leistungen überhaupt erst sichtbar gemacht: Das Theater in der Fotografie markiert das Beliebige des fotografischen Augenblicks, indem es die narrative Ladung liefert, die das Fragment zur bedeutsamen Schnittstelle von Vorher und Nachher verwandelt; die Fotografie im Theater formuliert das Paradox von 
Einmaligkeit und Reproduzierbarkeit, Aufführung und Inszenierung, Fragment und Ausdehnung.

Verfolgt man den skizzierten Gedanken weiter, so wird man nicht nur, was das einzelne Medium ausmacht, nicht mehr in ihm selbst, sondern im Vergleich suchen und mediale Identität zu einem an einem >Anderen< gewonnenen Konstrukt reduzieren, sondern im gleichen Zug die Kategorie >die Medien< insgesamt auf solche Vergleichsoperationen zurückführen. Von einem Medium zu sprechen macht nur dann Sinn, wenn man auch andere Medien im Blick hat und damit den Unterschied, den es macht, wenn man - zu welchem Zweck auch immer - nicht dieses, sondern jenes Medium nutzt, oder auch den Gewinn, wenn sich die Vermögen zweier Medien auf die eine oder andere Art verbinden. Die Einheit >die Medien « wird somit aufgrund von Differenz gebildet, nämlich aufgrund von kontrastierenden Bezugnahmen, die jedoch zugleich Vergleichbarkeit - bzw. die Möglichkeit, Beziehungen herzustellen - implizieren. Intermedialität setzt demnach nicht Medien voraus, sondern erzeugt überhaupt erst Medien. Das Feld, auf dem sich die einzelnen Medien anordnen lassen, entsteht durch jeweils konkrete Medienbeziehungen - gewissermaßen als Netz. ${ }^{10}$ Dabei ist zu berücksichtigen, dass die diversen Medienbeziehungen gerade nicht auf dem selben Fundament ruhen müssen, sondern die Hinsicht, die Fotografie und Theater vergleichbar macht, nicht mit der übereinstimmen muss, die Schrift und Theater, Fernsehen und Film usw. verbindet.

Als Medium ließe sich also kurz und knapp definieren, was mit anderen Medien in Beziehung gesetzt wird. Theater, so möchte ich vorschlagen, ist mithin schlicht und einfach dann ein Medium, wenn es als Medium behandelt, also diskursiv-vergleichend oder praktisch-komplementär auf andere Medien bezogen wird. Damit wird auf einen fixen Kriterienkatalog verzichtet, der erlauben würde, simpel und trennscharf zu unterscheiden, was Medium ist und was nicht. Doch wie lässt sich bei solch einem zirkulären Vorgehen Haltlosigkeit vermeiden, damit nicht letztlich alles zu einem Medium erklärt werden kann, weil ja irgendwie alles mit allem verglichen werden kann? Die Antwort kann nur lauten: durch die Beobachtung der tatsächlich aktualisierten praktischen und diskursiv-semantischen Medienkontakte. Und aus dieser Perspektive kann man dann behaupten, dass gerade das andauernde Bestreben, Theater von den Medien - den technischen Medien - abzugrenzen, Theater letztlich in das Feld der Medien eingemeindet.

\section{Literatur}

Aumont, Jacques (1990): L'Image. Paris: Nathan.

Balk, Claudia (1989): Theaterfotografie. Eine Darstellung ihrer Geschichte anhand der Sammlung des deutschen Theatermuseums. München: Hirmer.

Barthes, Roland (1990): »Die Fotografie als Botschaft «. In: Ders.: Der entgegenkommende und der stumpfe Sinn. Frankfurt/M.: Suhrkamp, S. 11-27.

Berlau, Ruth (1952): »Theaterfotografie«. In: Dies. u.a. (Red.): Theaterarbeit. 6 Aufführungen des Berliner Ensembles. Dresden: Dresdner Verlag, S. 341-345.

Coleman, A. D. (1983 [1976]): »Inszenierende Fotografie. Annäherungen an eine Definition«. In: Wolfgang Kemp (Hg.): Theorie der Fotografie. Bd. III. München: Schirmer/Mosel, S. 239-242.

10 Der häufiger gebrauchte Begriff des Systems bezeichnet auch einen Aspekt von interner Organisation, impliziert aber für meinen Geschmack zu viel Kohärenz. 
Daniel, Malcolm (1990): »Darkroom vs. Greenroom. Victorian Art and Popular Theatrical Entertainment «. In: Image, Vol. 33, (no. 1-2), S. 13-20.

Duve, Thierry de (1978): »Time Exposure and Snapshot: The Photograph as Paradox «. In: October, Vol. 5, S. 113-125.

Duve, Thierry de (1987): »Pose et instantané ou le paradoxe photographique«. In: Ders.: Essais datés, I, 1974-1986. Paris: Éditions de la Différence, S. 13-52.

Fohrmann, Jürgen (2004): »Der Unterschied der Medien«. In: Ders./Erhard Schüttpelz (Hg.): Die Kommunikation der Medien. Tübingen: Niemeyer, S. 5-19.

Folie, Sabine/Michael Glasmeier (2002): Tableaux vivants. Lebende Bilder und Attitüden in Fotografie, Film und Video. Wien: Kunsthalle Wien.

Girshausen, Theo (1998): »Ereignis Theater«. In: Theresia Birkenhauer/Annette Storr (Hg.): Zeitlichkeiten - zur Realität der Künste. Theater, Film, Photographie, Malerei, Literatur. Berlin: Vorwerk 8, S. 34-49.

Goodman, Nelson (1990): »Wann ist Kunst?«. In: Ders.: Weisen der Welterzeugung. Frankfurt/M: Suhrkamp, S. 76-91.

Lessing, Gotthold Ephraim (1964): Laokoon oder über die Grenzen der Malerei und Poesie. Stuttgart: Reclam.

Luhmann, Niklas (1995): Die Kunst der Gesellschaft. Frankfurt/M.: Suhrkamp.

Méaux, Danièle (1997): La photographie et le temps. Le déroulement temporel dans l'image photographique. Aix en Provence: Publications de l'Université de Provence.

Paul, Lori (2006) (Hg.): Acting the Part. Photography as Theatre. London/New York: Merrell.

Ruchatz, Jens (2002): »Konkurrenzen - Vergleiche. Die diskursive Etablierung des Felds der Medien«. In: Irmela Schneider/Peter Spangenberg (Hg.): Medienkultur der 50er Jahre. Diskursgeschichte der Medien nach 1945, Bd. 1. Opladen: Westdeutscher Verlag, S. 137-153.

Ruchatz, Jens (2003): Licht und Wahrheit. Eine Mediumgeschichte der fotografischen Projektion. München: Fink.

Spötter, Anke (2003): Theaterfotografie der Zwanziger Jahre an Berliner Bühnen. Gestaltung und Gebrauch eines Mediums. Berlin: Gesellschaft für Theatergeschichte.

Starnberger, Gerhard (1959): Bühnenfotografie. Gestaltung und Technik. Halle a.d. Saale: fotokinoverlag.

Sternberger, Dolf (1979 [1934]): »Über die Kunst der Fotografie«. In: Wolfgang Kemp (Hg.): Theorie der Fotografie II. 1912-1945. München: Schirmer/Mosel, S. 228-240. 


\title{
INTERMEDIALITÄT ALS BEDINGUNG VON THEATER: METHODISCHE ÜBERLEGUNGEN
}

\author{
KATI RÖTTGER
}

Die Anwendung von Intermedialitätskonzepten in der theaterwissenschaftlichen Forschung wird im Allgemeinen mit der zunehmenden Nutzung neuer Technologien bzw. elektronischer Medien auf den zeitgenössischen Bühnen gerechtfertigt (Boenisch: 104). Folgt man diesen Ansätzen, so bedarf das Phänomen des multimedialen Theaters ${ }^{1}$ medientheoretischer Erklärungsmodelle, weil das Wechselspiel zwischen Theater und Technologie mit geläufigen - kulturwissenschaftlichen oder zeichentheoretischen - Methoden der Theaterwissenschaft nicht ausreichend zu erschließen sei. Dabei wird häufig von einer Opposition zwischen >Theater < einerseits und >den Medien< andererseits ausgegangen, sei es in der Gegenüberstellung von »live«-Theater und Medien/Technologie ${ }^{2}$, sei es in der Transzendierung des Theaters zur >Bühne für die Medien< im Sinne einer >Metaphysik< des Hypermediums. ${ }^{3}$

Was diese Ansätze meines Erachtens unberücksichtigt lassen, ist die in den Intermedialitätsbegriff eingeschlossene Dynamik der medialen Transformation oder Transmission, die in und zwischen Medien stattfindet. Schließt man diese Dynamik in die Überlegungen ein, dann lässt sich die Trennung von Theater und Medien/Technologie nicht aufrechterhalten. Im Gegenteil: die Dynamik der (medialen) Transformation ist dem Theater grundsätzlich eigen. Sie zeigt sich bereits in der bekannten Annahme, dass das Theater (genauer: die Theateraufführung) als ein Prozess zu verstehen ist, der sich in einem bestimmten Raum in einer bestimmten Zeit mittels der gleichzeitigen Anwesenheit von (und daher zwischen) Akteuren und Zuschauern konstituiert (Fischer-Lichte 1983: 15). Ausgehend von dieser These möchte ich Theater bzw. die Theateraufführung im Folgenden als ein intermediales Geschehen definieren.

Um diesen Zusammenhang genauer zu erläutern ist es zunächst notwendig, zwei Voraussetzungen zu klären: 1. Ist der Körper ein Medium? 2. Ist das Theater ein Medium? Die Definition des Theaters als intermediales Geschehen erfolgt anschließend mittels des Begriffs der Verkörperung im Zusammenschluss der Konzepte Medialität und Performativität.

1 Multimediales Theater wird häufig nicht trennscharf von intermedialem Theater unterschieden.

2 Vgl. die Beiträge in Leeker.

3 Chapple/Kattenbelt (20): »The first principle [of the conceptional framework that the authors offer] that theatre is a hypermedium that incorporates all arts and media and is the stage of intermediality." 


\section{Ist der Körper ein Medium?}

An der Frage, ob der menschliche Körper im theatralen Kontext als Medium aufzufassen sei, scheiden sich die (theaterwissenschaftlichen) Geister (vgl. dazu ausführlich Röttger: 33-54). Als symptomatisch für die gegenwärtige epistemologische Problemlage innerhalb der Theaterwissenschaft seien hier Erika Fischer-Lichtes (2004: 141-162) schauspieltheoretische Ausführungen zu der Frage »Was verkörpert der Körper des Schauspielers? « dargelegt. Besonders interessant im gegebenen Zusammenhang ist die medientheoretische Implikation, mit der die Titelfrage versehen ist. Sie wird offenbar, indem die angekündigte Reflexion auf die Schauspielkunst als (notwendige) »Reflexion auf die Fähigkeit und Eignung des menschlichen Körpers [...] als Medium zu fungieren« (141) konkretisiert wird. Das Ergebnis, zu dem Fischer-Lichte am Ende ihrer Ausführungen gelangt, könnte eindeutiger nicht sein. Es lautet: »Der Leib [des Schauspielers] ist nicht, er wird: Der Leib ereignet sich. Als ein Medium ist er daher nicht zu begreifen« (161). Gegründet ist diese Aussage auf eine radikale Unterscheidung zwischen den Konzepten der Verkörperung (embodiment) und des Mediums. Während Fischer-Lichte mit dem Konzept der Verkörperung ein unabgeschlossenes Potential im Sinne von aktiver Hervorbringung von Körperlichkeit verbindet, beschränkt sich ihre Verwendung des Medienbegriffs auf eine rein instrumentelle oder semiotische Funktion (des Körpers). Von Medium ist hier nur dann die Rede, wenn der Körper (im Gegensatz zum phänomenalen, werdenden, unabgeschlossenen Leib) als aisthetisch neutraler Träger einer Bedeutung auftritt, als »Material, [...] durch das etwas anderes als es selbst in Erscheinung tritt « (141).

Mit dieser Unterscheidung ${ }^{4}$ wird jedoch eine mittlerweile weit reichende theoretische Fundierung des Medienbegriffs übersehen (und als Chance nicht wahrgenommen), welche auf die heuristische und methodische Produktivität des Konzepts abhebt, die in der Figur der (dem Wort selbst bereits innewohnenden) Vermittlung eingeschlossen ist. Mit dieser Figur wird die statische Trägerfunktion, die FischerLichte dem Begriff zuschreibt, von der (aktiven) Funktion der Übertragung abgelöst. Medien sind dann weder sekundär im Sinne eines Zeichenapriori (als bloße Behälter von Botschaften), noch primär im Sinne eines Technikapriori (als Botschaften schlechthin) zu verstehen. Vielmehr nähert sich auf diese Weise der Medienbegriff dem von Fischer-Lichte vertretenen Verkörperungsbegriff an und muss in einer kulturanthropologischen Perspektive betrachtet werden, die zeigen kann, »wieso Medien im Akt der Übertragung dasjenige, was sie übertragen zugleich mit bedingen und prägen. Es ist die Idee der >Verkörperung < als eine Kultur stiftende Tätigkeit, die es erlaubt, >Übertragung < als >Konstitution< auszuweisen und zu begreifen« (Krämer 2003: 85).

4 Die Opposition zwischen Verkörperung und Medium impliziert hier eine weitere radikale Trennung: die zwischen Performativität und Repräsentation. Während die Repräsentation ebenso wie das Medium dem Zeichenapriori unterstellt wird, steht Performativität hier für Vollzug und Hervorbringung ein. Besonders problematisch hinsichtlich der Übertragung auf Schauspielkunst ist der gegenseitige Ausschluss, durch den notwendigerweise zwei verschiedene Körper des Schauspielers (phänomenaler Leib, semiotischer Körper) eingeführt werden müssen, die in ein und demselben Leib so gesehen keine Vermittlungsinstanz besitzen. Vgl. zu dieser Problematik unter Einführung des Begriffs der Darstellung: Dieter Mersch: http://www.momo-berlin.de/Mersch _Verkoerperung.html (10.10.2006). 
Dass diese Vermittlerfunktion des Mediums oder der Medialität vor allem für den Körper als Medium zutrifft, lässt sich aus phänomenlogischer Perspektive noch etwas präziser mit Bernhard Waldenfels begründen. Auch er hebt den Vermittlungscharakter von Medien ${ }^{5}$ hervor und begründet damit die Funktion des Mediums als Zwischeninstanz. Zwischeninstanzen, so Waldenfels (113), »sind Instanzen, die eingreifen, ohne dass sie das Geschehen, in das sie eingreifen, umgreifen.« Auf diese Weise modalisieren sie die menschliche Erfahrung in Zeichen, Bildern und Klängen mittels geeigneter Werkzeuge und Apparaturen. Damit nehmen sie an der Ermöglichung von Erfahrung teil und dienen nicht lediglich der Wiedergabe bestimmter Inhalte von Erfahrungen. Die erste, zentrale Vermittlungsinstanz medialer Erfahrung ist der menschliche Körper selbst. Das gilt auch dann und zeigt sich besonders, wenn man das Wechselspiel zwischen Erfahrungsweisen und möglichen Darstellungsweisen in Bild- und Klangformen, in Gestik und Mimik, in Worten und Handlungen in Betracht zieht, das dem Schauspielen zueigen ist und die Medialität des Schauspielerkörpers prägt. Diese »durchgehende Medialität unserer Erfahrung « nämlich, und hier folge ich weiter Waldenfels (142), »findet [...] ihren Rückhalt in der Verfassung unseres Leibes, der zugleich sehend und sichtbar, hörend und hörbar, berührend und berührbar ist, aber nie das eine und das andere in nahtloser Einheit«. Damit ist nicht nur die Medialität des Körpers, sondern auch die Verkörperung durch Techniken und Medien angesprochen: So wie der Leib als technischer Apparat (als Registrier-, Bewegungs- und Koordinationsapparat) und als Medium fungiert, verkörpern sich an Sinn und Erfahrung verbundene Phänomene wie Bild, Sprache oder Musik in verschiedenen Medien. Fragen wir vor diesem Hintergrund erneut, ob der Körper ein Medium sei, so erweist sich das Argument der Doppelung von Körper und Leib als ebenso hinfällig wie die Oppositionsbildung zwischen Medium und Verkörperung. Vielmehr müssen wir die doppelte Modalität des >Leibkörpers< (Waldenfels: 138) hervorheben, um festzustellen, dass Körper medialisieren und Medien verkörpern.

Wie ist diese Schlussfolgerung nun auf das Theater zu übertragen?

\section{Ist Theater ein Medium?}

Um diese Übertragung zu leisten, gehe ich von folgender These aus: Theater vollzieht sich mittels einer offenen, dynamischen Konfiguration medialer Transmissionen. Abhängig von dem historischen oder kulturellen Kontext, in dem Theater sich ereignet, ist es dabei jeweils mit denjenigen Medien identisch, in denen seine Struktur bestimmenden Elemente sich verkörpern. Auf seine Minimalbestimmung reduziert, lässt sich sagen, dass Theater sich im Prozess der Übertragung und Konstitution (im Sinne von Eingreifen ohne zu umgreifen) von Erfahrung zwischen agierenden und wahrnehmenden Körpern in einem bestimmten Raum zu einer bestimmten Zeit vollzieht. Damit ist gleichzeitig dessen grundlegende intermediale Qualität benannt.

Um die intermediale Qualität des Theaters genauer zu bestimmen, soll in den folgenden Schritten 1. der Medienbegriff um das Konzept des Performativen erweitert werden, 2. Intermedialität als epistemische Bedingung von Medienerkenntnis (im Theater) beschrieben werden, um 3. schließlich die verschiedenen Modalitäten

5 Waldenfels (113): »Begriffsgeschichtlich verweist [der Begriff des Mediums] auf die Vermittlungsformen des Mittleren, des Zwischen und des Dritten«. 
des Spiels der medialen Erscheinungsweisen, welche im Theater aufgeführt werden können, zu sondieren.

\section{Medialität und Performativität}

Die Prozesse von Verkörperung in und Übertragung durch Medien orientieren sich am Performativen. Ein solches Medien- und Theaterverständnis begreift die mit Erzeugung von Sinn verbundenen Phänomene wie Sprache und Bild als zeitlich situierte Ereignisse, die im medialen Vollzug hervorgebracht werden. Theater ist so gesehen ein Medium, das phänomenalisiert. Es lässt Phänomene erscheinen, macht sie den Sinnen zugänglich und macht damit auch Bezugnahme möglich. Die aktive (sinnliche und kognitive) Teilhabe der Zuschauer am theatralen Ereignis ist dieser Bestimmung implizit. So gesehen erschließt sich die Aufführung nicht als Zeichenoberfläche, die der Analyse nur durch Dechiffrierung zugänglich ist, als sei das Wesentliche des Sinns hinter den Phänomenen verborgen. Ebenso wenig haben wir es mit der Aufführung als partikuläre Form eines vorgegebenen kulturellen Systems zu tun. Wird die Aufführung hingegen in den Modi von Medialität und Performativität als Ereignis verstanden, dann zeigt sich das Wesentliche nicht hinter den Phänomenen, sondern erweist sich im Ereignis des Vollzugs selbst. Die Erfahrung (Teilhabe) ist hier in die Sinngebung eingeschlossen, weil Phänomene stets reicher sind als die Begriffe, die wir uns von ihnen machen (Krämer 2002).

Welchen Anteil hat nun die mediale Übertragung an diesem Vorgang? Wesentliche Bedingung für die Orientierung am Performativen ist die konstitutive Leistung der Medien im Sinne von Verkörperung. Diese setzt voraus, dass Medien nicht als essentialistisch aufgefasst werden können. Gehen wir davon aus, dass das, was uns erscheint, in Medien erscheint und Medien »im Akt der Übertragung dasjenige, was sie übertragen, zugleich mit bedingen und prägen « (Krämer 2003: 85), dann müssen wir das Vermittlungsrepertoire, das Medien bereit stellen, auch in der Potentialität der Unterscheidung mitdenken, welche Medien als Strukturierungsinstanzen (indem sie in Erfahrungen eingreifen) erkennbar machen. Genauer gesagt ist nicht nur die Qualität der Übertragung und Vermittlung, sondern gerade die Potentialität der Unterscheidung und Strukturierung als Medialität zu bezeichnen. Denn Medialität vollzieht sich im Prozess der Übertragung in ein anderes Medium, mit dem die aisthetische Neutraliät (die Transparenz) eines Mediums gebrochen werden kann. Sybille Krämer spricht in Anlehnung an Niklas Luhmann (1995: 165-214) in diesem Zusammenhang von der Übertragung eines Mediums in eine Form. Von besonderem Interesse ist im Kontext der Bestimmung des Theaters als intermediales Geschehen ihre Feststellung, dass es »auf das Erkenntnisinteresse und den Beobachterstandpunkt [ankommt], was bei einer Beschreibung als Medium und was als Form zählt « (Krämer 2003: 82). ${ }^{6}$ Theater nun kann diesen Prozess der Übertragungen direkt vor den Augen und Ohren des Publikums vollziehen und unter Beobachtung stellen, indem es sichtbare und hörbare Phänomene durch

6 Im gegebenen Zusammenhang möchte ich den Begriff der Form im Anschluss an Bernhard Waldenfels und Dieter Mersch um die Dimension der (bildlichen, mimischen, klanglichen, etc.) Darstellungen ergänzen. Das heißt: ein Medium kann im Vollzug der Übertragung in den Modus der Darstellung überführt werden. Von wesentlicher Bedeutung für die folgenden Ausführungen ist hier vor allem der Fokus auf das Erkenntnisinteresse und den Beobachterstandpunkt, der zwischen Medium und Darstellung unterscheidet. 
Übertragungen von einem in das andere Medium als medial vermittelte erkennbar und erfahrbar macht. Mediale Unterscheidungspotentiale (Medialität) und mediale Verkörperungspotentiale (Performativität) sind dabei jeweils an den zeitlichen Vollzug gebunden und nur in Modi der Hervorbringung zu denken. Damit erhält die Aktivität des Blicks im Sinne eines aisthetischen Aktes des Zuschauers (Wagner) einen zentralen Stellenwert im Rahmen des intermedialen Ereignisses >Theateraufführung<. Infolge dessen ist diese nicht im Sinne von Systembildung zu verstehen, sondern als kulturelle Praxis und Kulturtechnik.

\section{Dido \& AEneas von Sasha Waltz}

Zur Veranschaulichung sei an dieser Stelle ein Beispiel angeführt: In der Produktion von DIDO \& AENEAS in der Inszenierung von Sasha $\mathrm{Waltz}^{7}$ werden die $\mathrm{Zu}-$ schauer mit einem antiken Stoff (der Erzählung von Dido und Aeneas in der Textfassung von Nahum Tate) konfrontiert, der sich als sinnliche, synästhetische Erfahrung im Zusammenspiel von Bewegung, Klang, Licht, Rhythmus und Farben vermittelt, das wiederum im Zusammenspiel der Darstellungsmodi von Musik, Tanz, Gesang, Sprache und Bild im Raum der Bühne mediale Unterscheidungspotentiale inszeniert und den Zuschauer somit auf aisthetischer wie noetischer Ebene in das intermediale Geschehen einbezieht. ${ }^{8}$ Gleich zu Beginn stellt Waltz ein >Bild< auf die Bühne, das sich in mehrere mediale Transmissionsschichten auflösen lässt. Anlässlich des Prologs, in dem der Sonnengott Phoebus zusammen mit den Nereiden die Ankunft von Venus besingt, stellt Waltz, unter Begleitung der Orchestermusik Purcells, ein bläulich ausgeleuchtetes, breites, nicht allzu hohes, mit Wasser gefülltes Becken in den leeren Bühnenraum: ein Raum im Raum, der die Medialität der Bühne zugunsten der Fokussierung des Blicks auf die Wasserfläche, in der die Tänzerkörper sich schwerelos bewegen, zunächst ausblendet. Schon jetzt muss sich der Blick des Zuschauers entscheiden zwischen mehreren medialen Strukturierungspotentialen. Denn die (erkennbare) Dreidimensionalität des Wasserbehälters, der die Tänzerkörper wie Fische in einem Aquarium umfängt, ruft gleichermaßen durch seine Breite und mittels der Ausleuchtung den (sinnlichen) Eindruck eines zweidimensionalen bewegten Filmbildes auf, das die Leinwand eines Breitwandkinos füllt. Hier transformiert sich das Wasserspiel im Blick des Zuschauers wortwörtlich zum Lichtspiel, wobei die Medialität des Wassers kurzfristig ebenso ausgeblendet wird wie die Medialität der (Glas)Fläche, hinter/auf der sich die Körper schwerelos bewegen, zugunsten des faszinierenden Gesamteindrucks, den das Bild aufruft. Beides jedoch, Glasfläche wie Wasser, welche das (sinnliche) Phänomen der bewegten Bildkörper hervorbringen oder phänomenalisieren, werden in ihrer konstituierenden Funktion als Medien wahrgenommen, sobald erkennbar wird, dass das Wasser langsam dem Becken entweicht. Die Bewegung des sinkenden Wasser(spiegel)s überführt nicht nur die Schwerelosigkeit der schwimmenden Kör-

7 Eine Ko-Produktion (2005) zwischen der Akademie für Alte Musik Berlin, der Staatsoper unter den Linden, Theatre de la Ville de Luxemburg und der Opera National de Montpellier.

8 Vgl. dazu auch die im Rahmen des Sonderforschungsbereichs »Ästhetische Erfahrung im Zeichen der Entgrenzung der Künste (FU Berlin) im Internet veröffentlichten Texte unter dem Titel »Grenzgänge der Kunst(wissenschaften): Sasha Waltz' Choreographie DIDO \& AENEAS «. Siehe http://www.sfb626.de/veroeffentlichungen/online/grenzgaenge lindex.html (24.02.2008). 
per in die Schlingen der Gravitation, sondern lässt auch die zunächst transparent erscheinende Glasfläche allmählich in ihrer Materialität erscheinen. Durch die Allmählichkeit des Vollzugs dieser Veränderung wird nicht zuletzt auch die Medialität der Zeit, innerhalb derer der Vollzug der Transformation stattfindet, sichtbar und erkennbar. Zu dieser visuellen Dimension fügt sich die akustische, die ebenfalls als Wechselspiel, zwischen (im Becken) schwimmendem und (auf dem Becken) sprechendem Körper, sowie zwischen den Linien der Musik und den Bewegungslinien der Tänzerkörper inszeniert ist. Dabei transformiert sich der Tänzerkörper in der Abfolge der Bewegungsakte (auf das Becken, in das Becken) vom Medium der Stimme zu einem Medium der Musik. Erst in dem Moment, wenn das Bassin langsam von der Bühne gezogen wird, eröffnet sich dem Blick wahrnehmbar die Medialität des leeren Bühnenraumes. ${ }^{9}$ Dieser Moment, der sich in der Stille (ohne Musik) vollzieht, erzeugt einen (durch die spürbare Dauer der Zeit verursachten) Sog, der direkt die sinnliche Erfahrung vermittelt, als Zuschauer unmittelbarer Bestandteil des gemeinschaftlichen theatralen Raumes zu sein.

\section{Intermedialität als epistemische Bedingung von Medienerkenntnis}

Medien eröffnen und inszenieren Perspektiven auf die Welt. Dass dies auch für jene Welt gilt, die das Theater eröffnet, bzw. für die Perspektive des Theaters auf die Welt, ist in einem kurzen Ausschnitt gezeigt worden. Da Medien durch ihre Potentialität der Unterscheidung und Transmission nicht als Einzelmedien zu denken sind, verhalten sie sich grundsätzlich intermedial zueinander. Theater als intermediales Ereignis eröffnet und inszeniert Perspektiven auf die Medien, in denen es wirksam ist. Wenn ein Medium in einem weiteren Medium zur Erscheinung gelangt, dann kann es auch Gegenstand theoretischer Erörterung werden. Mit Sybille Krämer (2003: 82) folgt daraus: »Intermedialität wird somit zu einer epistemischen Bedingung der Medienerkenntnis «. Ausgehend von der Prämisse, dass Perspektivität immer auch im Modus von Theatralität zu denken ist, erweisen sich Theatralität und Medialität wiederum als epistemische Bedingungen für die Erkenntnis von Intermedialität.

Dabei ist es zum einen von der Geschwindigkeit der Transformationen abhängig, inwieweit Medienerkenntnis als solche gewährleistet ist. Je langsamer sich die Medienübertragung vollzieht, umso stabiler erweisen sich die Zeichen-, Sprachoder Bildoberflächen, die sich in Medien verkörpern. ${ }^{10}$ Zum anderen aber spielt auch die Medienkenntnis des einzelnen Zuschauers eine nicht zu unterschätzende Rolle. Denn sobald ein Medium in der Inszenierung als solches unterschieden wird, kommen wir nicht umhin, im Bild des Mediums die Realisierung der medialen Konventionen eines Mediums in einem anderen zu erkennen (vgl. hierzu Balme: 19f). Diese Medienkenntnis, die Bolter und Grusin mit dem Terminus »Remedia-

9 Diese kurze Analyse ließe sich auf die gesamte Inszenierung ausdehnen, soll an dieser Stelle aber nur zur skizzenhaften Veranschaulichung der theoretischen Ausführungen dienen.

10 Dies wäre z.B. bei einer Theatervorstellung der Fall, die strikt der Ästhetik der Vierten Wand gehorcht. 
tion « $(1999)^{11}$ versehen haben, beruht auf den historisch konfigurierten Potentialen, die Medien für kulturelle Praktiken der Verkörperung bereit stellen. In diesem Sinne möchte ich abschließend in kritischer Abwandlung des Konzepts der Remediation mit Sybille Krämer noch einmal auf die besondere Konfiguration verweisen, durch die sich das Theater als intermediales Geschehen und kulturelle Praxis auszeichnet. Diese Konfiguration bewegt sich in einem Spektrum von >Kunst< und $>$ Kulturtechnik<, innerhalb dessen die historisch konfigurierten Potentiale, die Medien für kulturelle Praktiken der Verkörperung bereit stellen, in unterschiedlicher Weise inszeniert werden können. Denn innerhalb dieses Spektrum steht Kunst im besten Sinne für den Bruch mit dem Vertrauten und mit gewohnten Wahrnehmungsweisen, während Kulturtechnik für die »Veralltäglichung, Routinierung, Ritualisierung, Gewohnheitsbildung, Dispensierung der Aufmerksamkeit, kurz: Wiederholung « (Krämer 2003: 85) steht. Jede Kunst zehrt einerseits von übernommenen Kulturtechniken und medialen Konventionen, ist aber gleichzeitig auch in der Lage, diese umzubilden. Das Theater, als intermediales Geschehen verstanden, kann - so habe ich gezeigt - die medialen Modalitäten, in denen Sichtbares und Hörbares, Bild, Sprache und Musik zur Erscheinung gelangen, erkennbar und erfahrbar machen.

\section{Literatur}

Balme, Christopher (2004): »Theater zwischen den Medien. Perspektiven theaterwissenschaftlicher Intermedialitätsforschung «. In: Balme/Moninger (Hg.): Crossing Media, S. 13-32.

Balme, Christopher/Markus Moninger (Hg.) (2004): Crossing Media. Theater Film - Fotografie - Neue Medien. München: epodium.

Boenisch, Peter (2006): »Aesthetic art to aesthetic act: theatre, media, intermedial performance «. In: Chapple/Kattenbelt (Hg.): Intermediality, S. 103-116.

Bolter, Jay David/Richard Grusin (1999): Remediation: Understanding New Media. Cambridge; Massachusetts: MIT Press.

Chapple, Freda/Chiel Kattenbelt (2006): »Key Issues in Intermediality in theatre and performance «. In: Dies. (Hg.): Intermediality, S. 11-26.

Chapple, Freda/Chiel Kattenbelt (Hg.) (2006): Intermediality in Theatre and Performance. Amsterdam/New York: Rodopi.

Fischer-Lichte, Erika (1983): Semiotik des Theaters. Bd.1 Tübingen: Gunther Narr.

Fischer-Lichte, Erika (2004): »Was verkörpert der Körper des Schauspielers? « In: Sybille Krämer (Hg.): Performativität und Medialität. München: Fink, S. 141162.

Krämer, Sybille (2002): »Sprache - Stimme - Schrift: Sieben Gedanken über Performativität und Medialität«. In: Uwe Wirth (Hg.): Performanz: Zwischen Sprachphilosophie und Kulturwissenschaften. Frankfurt/M.: Suhrkamp, S. 323-346.

Krämer, Sybille (2003): »Erfüllen Medien eine Konstitutionsleistung? Thesen über die Rolle medientheoretischer Erwägungen beim Philosophieren«. In: Stefan Münker/Alexander Roesler/Mike Sandbote (Hg.): Medienphilosophie. Beiträge zur Klärung eines Begriffs. Frankfurt/M.: Suhrkamp, S. 78-90.

$11 »$ A medium is that which remediates. It is that which appropriates the techniques, forms, and social significance of other media and attempts to rival or refashion them in the name of the real« (Bolter/Grusin: 65). 
Leeker, Martina (Hg.) (2001): Maschinen, Medien, Performances. Theater an der Schnittstelle zu digitalen Welten. Berlin: Alexander.

Röttger, Kati (2004): »F@ ust vers. 3.0: eine Theater- und Mediengeschichte«. In: Balme/Moninger (Hg.): Crossing Media, S. 33-54.

Waldenfels, Bernhard (2004): Phänomenologie der Aufmerksamkeit. Frankfurt/M.: Suhrkamp.

Wagner, Meike (2003): Nähte am Puppenkörper. Der mediale Blick und die Körperentwürfe des Theaters. Bielefeld: transcript. 


\title{
MULTI-, TRANS- UND INTERMEDIALITÄT: \\ DREI UNTERSCHIEDLICHE PERSPEKTIVEN AUF DIE BEZIEHUNGEN ZWISCHEN DEN MEDIEN
}

\author{
CHIEl KATtEnBELT
}

\section{Einleitung}

Immer mehr wird in heutigen kunst- und medientheoretischen Diskursen darauf hingewiesen, die Künste und Medien nicht nur als einzelne Disziplinen in ihren eigenen historischen Entwicklungen und mit ihren eigenen Gesetzmäßigkeiten zu studieren, sondern gerade auch in dem breiteren Kontext der Medienwechsel und Wechselwirkungen zwischen Medien. Möglicherweise hat dazu auch beigetragen, dass sich unsere Kultur in einem raschen Tempo zu einer Medienkultur oder einer mediatisierten Kultur (vgl. Auslander) - mit allen Inszenierungsmerkmalen, die solch eine Mediatisierung beinhaltet - entwickelt hat. Vielleicht hat auch eine Rolle gespielt, dass die heutige Kunstpraxis sich in steigendem Maße als eine interdisziplinäre Praxis manifestiert. Wie so oft in der Vergangenheit finden Künstler aus verschiedenen Disziplinen einander vor allem im Theater, das nicht nur figürlich, sondern auch buchstäblich einen Raum, eine Bühne bietet, auf der die verschiedenen Künste einander treffen können. Vielleicht könnten wir sogar behaupten: Wo zwei oder mehrere Künste einander begegnen, entsteht wie von selbst ein Prozess der Theatralisierung, nicht nur weil das Theater alle anderen Künste in sich aufnehmen kann, sondern auch weil es als die Kunst des Darstellers die Grundform aller Künste bildet (vgl. Kattenbelt). Letzteres gilt, insofern die Idee der Kunst mit der Selbstdarstellung des Menschen verbunden ist und bleibt, das heißt mit dessen schöpferischem Vermögen, sich mit Wort, Bild (Körper) und Ton für den anderen in Szene zu setzen. Die Selbstinszenierung der Kunst als Mittel der Kommunikation setzt ein ästhetisches Interesse voraus, ein Interesse an »der Vergegenwärtigung von Erfahrungsgehalten, die innerhalb einer gegebenen Lebensform die Aktualität und inwendige Verfasstheit der eigenen Erfahrung zur Wahrnehmung bringen « (Seel: 127).

Um Beziehungen zwischen den Künsten und Medien zu charakterisieren, sind in unterschiedlichen Disziplinen viele Konzepte definiert worden; sei es, um aus einer historischen Perspektive zu skizzieren, wie sich Beziehungen zwischen Künsten und Medien entwickelt haben (mit oder ohne Intention, daraus gewisse Gesetzmäßigkeiten zu destillieren), sei es, um aus einer theoretischen Perspektive Kriterien zu formulieren, durch die Arten von Beziehungen zwischen Künsten und Medien unterschieden werden können. Mein Beitrag ist vor allem ein theoretischer, der jedoch auf historischen Voraussetzungen fußt. Ich bespreche drei Begriffe von Medialität: Multimedialität, Transmedialität und Intermedialität. Kurz gefasst bedeutet >Multimedialität< ein Nebeneinander mehrerer Medien in ein und demselben Objekt, >Transmedialität` den Übergang von einem Medium zu einem anderen 
(Medienwechsel) und >Intermedialität< eine Wechselwirkung zwischen Medien. Für jeden dieser Begriffe gilt, dass sie nicht nur in unterschiedlichen Diskursen verwendet werden, sondern auch oft in ein und demselben Diskurs auf unterschiedlichen Bedeutungsebenen. Diese Ebenen werden oft nicht explizit von einander unterschieden mit der Folge, dass nicht präzise klar wird, was unter den betreffenden Begriffen verstanden wird oder verstanden werden könnte. Meine Absicht ist, darüber einigermaßen Klarheit zu schaffen, indem ich die drei Begriffe in Unterscheidung voneinander $\mathrm{zu}$ definieren versuche. Es ist wichtig im Voraus festzustellen, dass die drei Begriffe einander nicht ausschließen. Es ist eher so, dass die Begriffe für drei unterschiedliche Perspektiven stehen, aus welchen Medienphänomene aufgrund ihrer Medialität analysiert werden können. Da ich die unterschiedlichen Künste auch als Medien betrachte, werde ich nicht länger von Künsten und Medien, sondern nur noch von Medien reden, obwohl ich in diesem Aufsatz vor allem die Künste als Medien denke.

In den vielen Betrachtungen über die Künste unter dem Aspekt ihrer Medialität und über die Beziehungen zwischen den Künsten als Medien, die während der letzten zehn Jahre erschienen sind, finden sich einige immer wiederkehrende Voraussetzungen, die wie folgt zusammengefasst werden können.

Medienwechsel und Wechselwirkungen zwischen Medien bilden seit Anfang des 20. Jahrhunderts wichtige Tendenzen in der Entwicklung der Künste. Sie können mit Erscheinungen wie Grenzverschiebungen und Grenzüberschreitungen zwischen Medien, mit der Hybridisierung medialer Äußerungen, mit intertextuellen Beziehungen zwischen Medien und mit der Reflektion und dem zunehmenden Verweis auf sich selbst als Medien assoziiert werden.

Medienwechsel und Wechselwirkungen zwischen Medien haben zu neuen Formen der Repräsentation, zu neuen dramaturgischen Strategien, zu neuen Strukturierungs- und Inszenierungsprinzipien von Wort, Bild und Ton geführt, wie auch zu neuen Möglichkeiten, Körper in Raum und Zeit zu positionieren, raumzeitliche Beziehungen zu kreieren, Arten der Wahrnehmung zu entwickeln und kulturelle, soziale und psychologische Bedeutungen zu generieren.

Technologische Innovationen haben in der Entwicklung aller modernen und postmodernen Medien und in der Interaktion zwischen diesen eine wichtige Rolle gespielt und spielen diese noch immer.

Die historische Avantgarde hat die notwendigen Bedingungen, unter denen sich Medienwechsel und Medienwechselwirkungen als wichtige Merkmale der (post)modernen Künste entwickelt haben, zustande gebracht, vor allem insoweit es um die Austauschbarkeit der expressiven Mittel und der ästhetischen Konventionen zwischen unterschiedlichen Medien geht. Dies gilt auch für die spielerische Inszenierung der Zeichen, die den (post)modernen Künsten einen ausdrücklich performativen - oder theatralischen -, selbstkritischen und reflexiven Aspekt verschafft.

Diese Überlegungen möchte ich dem Leser als eine historisierende Perspektive mit auf den Weg geben.

\section{Multimedialität}

Der Begriff >Multimedialität< wird in kunst- und medientheoretischen Diskursen gewöhnlich auf zwei unterschiedlichen Ebenen verwendet. Einerseits auf der Ebene der Zeichensysteme (Wort, Bild, Ton, usw.), andererseits auf der Ebene der unterschiedlichen Disziplinen, das heißt wie diese als (institutionalisierte) kulturelle 
Praktiken unterschieden werden können (Literatur, bildende Kunst, Musik, Theater, Film, Fernsehen, Video, Internet, CD-ROMs, Computerspiele, usw.).

Auf der Ebene der Zeichensysteme ist eine Äußerung >multimedial<, wenn sie aus einer Kombination von Wörtern (geschriebenen/gezeigten oder gesprochenen), Bildern (stillstehenden oder bewegten, graphischen oder fotographischen) und/oder Tönen (Umgebungsgeräuschen, >soundscapes<, Musik, Sprache, usw.) besteht. So werden zum Beispiel digitale Objekte wie Websites, die mit Wörtern, Bildern und/oder Tönen ausgestattet sind, oft als >multimedial $<$ betrachtet. Computer, mit denen Wörter, Bilder und Töne generiert, manipuliert und wiedergegeben werden können, werden gewöhnlich >Multimedia Computer $<$ genannt, ursprünglich vor allem von Computerherstellern, die mit diesem Begriff auf die mannigfaltigen Anwendungsmöglichkeiten des Computers für Arbeit und Freizeit (digitale oder digitalisierte Videoaufnahmen montieren, Musik komponieren, Computerspiele spielen, usw.) aufmerksam machen wollten.

Multimedialität wird oft als ein Merkmal der digitalen Medien betrachtet, das in Zusammenspiel mit den Merkmalen Virtualität, Interaktivität und Konnektivität die Spezifität der digitalen Medien konstituiert (Raessens). In Analogie zu digitalen Medien können auf der Ebene der Zeichensysteme Theateraufführungen, Tonfilme, Fernsehsendungen und Videoaufnahmen auch als multimedial betrachtet werden.

Auf der Ebene unterschiedlicher Medien bezieht sich >Multimedialität $<$ auf die Kombination verschiedener Medien. Das bedeutet, dass im strikten Sinne nur das Theater >multimedial< sein kann. Das Theater ist nämlich das einzige Medium, das alle anderen Medien in sich aufnehmen kann, ohne die Spezifität der in sich aufgenommenen Medien durch seine eigene zu beeinträchtigen (vgl. Kandinsky 1973b [1912] und 1973c [1923]), jedenfalls was die Materialität der Medien betrifft. Theater aufgenommen in und mit Film, Fernsehen und Video ist kein Theater mehr, sondern bspw. Film, Fernsehen oder Video. Diese Medien können zwar alles, was sichtbar und hörbar ist - selbstverständlich innerhalb des Bereichs ihrer technisch bedingten Empfindlichkeiten - aufnehmen, aber nichts in sich aufnehmen. Das Theater dagegen kann grundsätzlich alles in die performative Situation der Aufführung einbeziehen und deshalb alles als theatralisches Zeichen verwenden. Als Elemente der Theateraufführung und deshalb als theatralische Zeichen werden die Bilder und Töne des Films, Fernsehens oder Videos nicht nur vorgeführt, sondern auch aufgeführt. Gerade wegen der Möglichkeit des Theaters, alle Medien in sich aufzunehmen, kann das Theater als ein >Hypermedium< betrachtet werden, das heißt als ein Medium, das alle anderen Medien enthalten kann. Vielleicht ist es gerade dieser Besonderheit geschuldet, dass das Theater in dem Austausch zwischen den Künsten eine solch wichtige Rolle gespielt hat und noch immer spielt, wobei im heutigen Theater digitale Technologien oft als Schnittstellen (Interface) funktionieren. Noch einen Schritt weiter gedacht könnte man sagen: Das Theater ist ein Hypermedium im physischen Sinne, so wie das Internet im virtuellen Sinne ein Hypermedium ist. Gerade deshalb bietet das Theater wie keine andere Kunst eine Bühne für Intermedialität. Auf dieser Bühne kann der Darsteller als der >Bespieler der unterschiedlichen Medien in den leeren Räumen zwischen den Medien auftreten. 


\section{Transmedialität}

Der Begriff >Transmedialität< wird sowohl in kunst- als kommunikationstheoretischen Diskursen zur Andeutung einer Übersetzung von einem Medium in das andere verwendet. Die Übersetzung oder der Transfer, von dem hier die Rede ist, kann sich auf den Inhalt (auf das Repräsentierte, auf die Geschichte) und auf die Form (auf die Konstruktionsprinzipien, stilistischen Verfahren und ästhetischen Konventionen) beziehen. Auf der Ebene des Inhalts verweist das Konzept >Transmedialität< vor allem auf die Medienwechsel, für welche gilt, dass im Prozess der Übersetzung die spezifischen Merkmale des Ursprungsmediums völlig verloren gehen. Die meisten Spielfilme, die auf Romanen oder dramatischen Texten basieren (und dies gilt noch immer für mehr als 60 Prozent der internationalen Filmproduktion), sind Übersetzungen der Geschichten, ohne dass Sujet- und Stilkonventionen der ursprünglichen Erzählung in Betracht gezogen werden. Diese Konventionen werden meistens ignoriert: einmal in ein anderes Medium übersetzt oder >konvertiert<, erinnert nichts mehr an die mediale Spezifität des literarischen Originals. Dies hängt auch mit dem Zwang zur Transparenz, der für den Film als Massenmedium gilt, zusammen. Die äußerste Konsequenz eines Films, der sein Publikum als Masse definiert, ist ja, dass der Film seine eigene Medialität durch eine optimale Zugänglichkeit zur möglichen Welt, die der Film darstellt, auswischt.

Diese Transparenz des Mediums ist übrigens wie die Filmkunst selbst eine Erfindung der Romankunst des 19. Jahrhunderts. Im Laufe des 19. Jahrhunderts verbirgt der Erzähler sich mehr und mehr hinter der Erzählung, so als wäre von Vermittlung gar nicht die Rede. Mit seinem Verschwinden hinter der Geschichte verliert der Erzähler die Möglichkeit des Kommentars, womit er in gewissem Sinne auch seine Autorität als Erzähler preisgibt. Dem stehen aber auch zwei neue Möglichkeiten gegenüber: auf der einen Seite die einer genauen und detaillierten Beschreibung der Ereignisse und Handlungen, die in der Geschichte geschehen, auf der anderen Seite die einer ausführlichen Beschreibung der Erfahrungen, die eine oder mehrere Figuren in der Geschichte machen.

Von einer Übersetzung der Konstruktionsprinzipien, stilistischen Verfahren und ästhetischen Konventionen ist die Rede, wenn das eine Medium die Gestaltungs-/Darstellungsprinzipien des anderen Mediums wiederaufnimmt oder imitiert. So ist zum Beispiel ein freier Austausch von Mitteln der Expression zwischen verschiedenen Medien charakteristisch für den deutschen Expressionismus (vor allem hinsichtlich eines Austausches zwischen Theater und Film).

Die Wiederaufnahme oder Imitation der Gestaltungsprinzipien eines anderen Mediums kann auch als eine spezifische, mediumübersteigende Art der Intertextualität funktionieren, dass heißt mit dem einen Medium wird auf ein anderes Medium verwiesen (vgl. Balme: 148-150). In dem Buch Transmedialität (2006) wird der gleichnamige Begriff vor allem verwendet, um auf den Prozess des Übergangs zwischen dem Ursprungsmedium und dem Zielmedium aufmerksam zu machen. So bezeichnet Roberto Simanowski »Transmedialität« als »den Wechsel von einem Medium in ein anderes als konstituierendes und konditionierendes Ereignis eines hybriden ästhetischen Phänomens « (44), wobei Hybridität auf die »Vermischung des Verschiedenartigen « (ebd.) verweist.

Transmedialität aufgefasst als die Repräsentation des einen Mediums in oder durch ein anderes kommt in die Nähe des von Bolter und Grusin (1999) eingeführten und inzwischen sehr bekannten Begriffs »remediation«. Bolter und Grusin verweisen mit diesem Begriff vor allem auf Beziehungen zwischen einem neuen und 
einem alten Medium. Sie fassen Remediation als »a defining characteristic of the new digital media « auf (Bolter/Grusin: 45) und unterscheiden verschiedene Formen oder Grade der Remediation abhängig davon, welches spezifische Ziel verfolgt wird (44-50). Sie erkennen zwei Motive, die bei Remediation wirksam sein können: auf der einen Seite das Motiv der Ehrerbietung des einen Mediums an das andere, wobei das neue Medium sozusagen das alte Medium imitiert und sich selbst mehr oder weniger verleugnet; auf der anderen Seite das Motiv der Rivalität, wobei das neue Medium ältere Medien in eine neuen Kontext setzt oder völlig in sich aufnimmt. Diese beiden Motive korrespondieren mit der >doppelten Logik < der Remediation, nämlich der Logik der »transparent immediacy « und der »hypermediacy«. Die erste Logik zielt darauf, das Medium für den Benutzer unsichtbar zu machen, die zweite Logik dagegen darauf, den Benutzer auf das Medium aufmerksam zu machen. Transparente Unmittelbarkeit und Hypermedialität sind unlöslich miteinander verbunden und stehen beide im Zeichen desselben Bestrebens, nämlich die Beschränkungen der Repräsentation zu übersteigen, um die Erfahrung des $»$ Wirklichen $« \mathrm{zu}$ intensivieren (53).

\section{Intermedialität}

Der Begriff >Intermedialität< ist ebenso wie die Begriffe >Multimedialität $<$ und $>$ Transmedialität< ein Konzept, das in unterschiedlichen Diskursen verwendet wird. Seit einigen Jahren hat das Konzept so viele unterschiedliche Bedeutungen, dass es fast unmöglich geworden ist, die semantische Reichweite des Begriffs systematisch zu kartieren. Mit Recht bemerkt Irina Rajewsky (44), dass jeder, der den Begriff $>$ Intermedialität< anwendet, sich dazu gezwungen sieht, zu definieren was er/sie unter dem Begriff versteht. Insoweit der Begriff vor allem zur Unterscheidung der anderen Medialitätsbegriffe benutzt wird, wird vor allem der Aspekt der wechselseitigen Beeinflussung (Interaktion) betont.

In kunst- und medientheoretischen Diskursen bezieht sich >Intermedialität< denn auch vor allem auf die Wechselwirkungen zwischen unterschiedlichen Medien, aus denen eine Neudefinition und Neusensibilisierung der aufeinander einwirkenden Medien resultiert. Im Gegensatz zu Transmedialität setzt Intermedialität nicht so sehr einen Wechsel vom einen zum anderen Medium als vielmehr eine Wechselwirkung zwischen unterschiedlichen Medien voraus. Die Neudefinition und Neusensibilisierung, von der hier die Rede ist, beinhaltet, dass medienspezifische Wahrnehmungskonventionen durchbrochen werden und neue Dimensionen des Erlebens und Erfahrens exploriert werden können (vgl. Müller: 31-32). Intermedialität hat als Wechselwirkung zwischen unterschiedlichen Medien viel mehr mit Mannigfaltigkeit, Diskrepanz, der relativen Unabhängigkeit der Medien und Hypermedialität im Sinne von Bolter und Grusin zu tun als mit Einheit, Harmonie und Transparenz. Intermedialität setzt einen Zwischenraum - ein Inter - voraus, in welchem Wechselwirkungen stattfinden können.

Bei >Intermedialität< denke ich denn auch viel mehr an die »Bühnenkompositionen« von Wassily Kandinsky (1973a, b und c) als an das »Gesamtkunstwerk « von Richard Wagner (1850). Wagner strebte mit seinen »Musikdramen « eine Wiedervereinigung und Integration der Künste unter dem Primat der Musik an. Was er mit dem »Kunstwerk der Zukunft « beabsichtigte, war, dass der Zuschauer sich völlig in der dargestellte Welt verliert. Kandinsky dagegen strebte mit seinen Bühnenkompositionen nach einem Theater, das als »ein verborgener Magnet « funktionie- 
rend die unterschiedlichen Künste aufeinander einwirken lässt. Das Zusammenspiel der Künste, von Kandinsky als Dynamik musikalischer, malerischer und tanzkünstlerischer Bewegungen vorgestellt (1973a: 125), war seiner Meinung nach nur möglich dank der Tatsache, dass die einzelnen Künste in einer relativen Unabhängigkeit voneinander ein hohes Maße der expressiven Reinheit erreicht haben. Kandinsky beabsichtigte keine Illusion, sondern die Darstellung innerlicher Erfahrungen (»Vibrationen der Seele«). Ich denke auch an das Konzept »Montage der Attraktionen «, das Sergej Eisenstein (16) anfänglich für das Theater entwickelt und später auf den Film angewendet hat: Die unterschiedlichen Elemente >knallen< sozusagen aufeinander mit der Folge, dass neue Energie freigesetzt wird, die direkt, das heißt physisch, als eine Schockerfahrung auf die Zuschauern einwirkt. Auch denke ich an Bertolt Brecht, der in dem Prolog der Oper MAHAGONNY eine »radikale Trennung der Elemente« (zit. in Schwaiger: 102) befürwortete, um gegen eine Verschmelzung der Künste aufzubegehren und damit auch zu verhüten, dass die $\mathrm{Zu}$ schauer »Magie«, »Hypnose« und »unwürdigen Räuschen« (ebd.) unterworfen werden. Die klaren Scheidelinien, die Brecht ziehen will, sollen gerade dafür sorgen, dass leere Zwischenräume entstehen, die von den Zuschauern aktiv ausgefüllt werden müssen. Ich denke auch an die Fragmentierungsstrategien, die Robert Wilson, Alain Platel, Gerardjan Rijnders und Jan Lauwers - um nur einige Theaterregisseure zu nennen - eingesetzt haben, um die traditionellen Unterbrechungstechniken des Theaters aufzulösen. Diese traditionellen Unterbrechungstechniken haben sich im Laufe vieler Jahrhunderte entwickelt, um den Beschränkungen des Hier und Jetzt, worin sich die Theateraufführungen abspielt, zu entrinnen, ohne dass die Geschlossenheit der Geschichte und die Kausalität der Handlung beschädigt werden. Die Fragmentierungsstrategien der genannten Regisseure intensivieren geradezu die Erfahrung der Kontinuität der Aufführung selbst, ohne dass diese einer Illusion der Kontinuität (nämlich der dargestellten Handlung) geopfert wird. Ich denke auch an die Theateraufführungen von Guy Cassiers, der neue Technologien verwendet, um buchstäblich aus unterschiedlichen Perspektiven die Innerlichkeit der Erfahrung und die Äußerlichkeit der Handlung auseinander zu dividieren und sie gerade dadurch wieder auf eine neue Weise aufeinander zu beziehen. So stellt er unterschiedliche Zeiten nebeneinander (eine Verräumlichung der Zeit) und unterschiedliche Welten dar, die jede mit eigenen Formen der Wahrnehmung und Erfahrung verbunden sind (vgl. Merx 2003 u. 2006). Ich denke auch an Peter Greenaway, der wie kein anderer die modularen Strukturierungsmöglichkeiten der digitalen Medien gerade wegen ihrer Anwendung in Theater und Film untersucht hat. Mit den digitalen Medien hat er nicht nur die epischen Darstellungsmethoden des Theaters und Films erweitert, sondern auch die schon vorhandenen Methoden neu hinterfragt.

In kunst- und kulturphilosophischen Diskursen verweist das Konzept >Intermedialität< somit auf die Wechselwirkung zwischen Kunst, Wissenschaft und Ethik (Gesellschaft, Politik) und fungiert als ein bewusstes Bestreben, die Geschlossenheit dieser drei kulturellen Handlungsbereiche zu durchbrechen. Dieses Konzept der >Intermedialität< wird oft direkt auf die historische Avantgarde der Zwanziger Jahre des letzten Jahrhunderts zurückgeführt (vgl. Oosterling). 


\section{Schluss}

In der Einleitung dieses Aufsatzes habe ich einige Voraussetzungen, die sich regelmäßig in Veröffentlichungen über Medienwechsel und Medienwechselwirkungen finden, zusammenfassend formuliert. Aus einer trans- oder intermedialen Perspektive ist es vor allem von Bedeutung, zu untersuchen, welche Medienwechsel und Medienwechselwirkungen für das Entstehen neuer ästhetischer Ausdrucksformen entscheidend gewesen sind. Auch Fragen der ontologischen Bedeutung der Medien sind wichtig, weil die Dynamik trans- und intermedialer Prozesse sich vor allem auf die wechselseitigen Verhältnisse zwischen Materialität, Medialität und ästhetischen Konventionen bezieht. Für Forschungen zur Trans- und Intermedialität ist die heutige interdisziplinäre Kunstpraxis ein wichtiger Referenzpunkt.

\section{Literatur}

Abel, Richard (1988): French Film Theory and Criticism. A History/Anthology, 1907-1939, Vol. 1: 1907-1929. Princeton, NJ: Princeton UP.

Auslander, Philip (1999): Liveness. Performance in a Mediatized Culture. London et al.: Routledge.

Balme, Christopher (2001): Einführung in die Theaterwissenschaft, 2., überarb. Aufl., Berlin: Schmidt.

Bolter, Jay David/Richard Grusin (1999): Remediation. Understanding New Media. Cambridge, Mass. u.a.: MIT Press.

Eisenstein, Sergej (1981 [1923]): »Montage van attrakties«. In: Sergej Eisenstein: Montage. Het konstruktie-principe in de kunst. Nijmegen: SUN, S. 15-21.

Kandinsky, Wassily (1973a [1912]): Über das Geistige in der Kunst. Mit einer Einführung von Max Bill. Bern: Benteli.

Kandinsky, Wassily (1973b [1912]): »Über Bühnenkomposition«. In: Max Bill (Hg.): Kandinsky. Essays über Kunst und Künstler. Bern: Benteli, S. 49-61.

Kandinsky, Wassily (1973c [1923]): »Über die abstrakte Bühnensynthese «. In: Max Bill (Hg.): Kandinsky. Essays über Kunst und Künstler. Bern: Benteli, S. 79-83.

Kattenbelt, Chiel (2006): »Theatre as the art of the performer and the stage of intermediality«. In: Freda Chapple/Chiel Kattenbelt (Hg.): Intermediality in Theatre and Performance. Amsterdam u.a.: Rodopi, S. 31-41.

Merx, Sigrid (2003): »Guy Cassiers, Proust en het gebruik van video«. In: Proust 2: De kant van Albertine, script en werkboek. Amsterdam: Theatre \& Film Books and ro theater, S. 226-233.

Merx, Sigrid (2006): »Swann's way: video and theatre as an intermedial stage for the representation of time«. In: Freda Chapple/Chiel Kattenbelt (Hg.): Intermediality in Theatre and Performance. Amsterdam u.a.: Rodopi, S. 67-80.

Müller, Jürgen (1998): »Intermedialität als poetologisches und medientheoretisches Konzept: Einige Reflexionen zu dessen Geschichte«. In: Jörg Helbig (Hg.): Intermedialität. Theorie und Praxis eines interdisziplinären Forschungsgebiets. Berlin: Schmidt, S. 31-40. Auch online verfügbar unter http://www.unikoeln.de/phil-fak/englisch/helbig/inhalt.htm (18.02.2007).

Oosterling, Henk (2003): »Sens(a)ble Intermediality and Interesse. Towards an Ontology of the In-Between «. In: Intermedialités. Histoire et théorie des arts, des lettres et des techniques, Nr.1 (»Naitre«), S. 29-46. 
Raessens, Joost (2001): »Cinema and Beyond. Film en het proces van digitalisering «. In: E view. Een elektronisch magazine over theater, film, televisie \& digitale media, Nr. 01-1, http://comcom.uvt.nl/e-view/01-1/raes.htm (25.02.2007).

Rajewsky, Irina O. (2005): »Intermediality, Intertextuality, and Remediation: A Literary Perspective on Intermediality«. In: Intermédialités - Histoire et théorie des arts, des lettres et des techniques, Nr. 6 (»Remédier «), S. 43-64.

Schröter, Jens (o.J.): »Intermedialität«. In: Theorie der Medien, http://www.theorieder-medien.de/ (01.03.2007).

Schwaiger, Michael (Hg.) (2004): Bertolt Brecht und Erwin Piscator. Experimentelles Theater im Berlin der Zwanzigerjahre. Wien: Brandstätter.

Seel, Martin (1985): Die Kunst der Entzweiung. Zum Begriff der ästhetischen Rationalität. Frankfurt/M.: Suhrkamp.

Simanowski, Roberto (2006): »Transmedialität als Kennzeichen moderner Kunst«. In: Urs Meyer/Roberto Simnowski/Christoph Zeller (Hg.): Transmedialität. Zur Ästhetik paraliterarischer Verfahren. Göttingen: Wallstein, S. 39-81. 


\title{
The Use of Audio-visual Media IN ITALIAN FUtURIST THEATRE
}

\author{
GÜNTER BERGHAUS
}

The nineteenth century was a period of great changes in the physical and mental landscapes of Europe. A large number of new technologies and inventions, such as electric light, wireless telegraphy, motorcars, cinema, telephones etc., made a profound impact on the everyday life of most citizens in the industrialized world. The revolutionized means of transportation and the new modes of communication shook up people's conception of a linear time-space continuum and altered their cognitive mapping of the world.

By the 1880s, there was agreement amongst intellectuals and the common population that European society had undergone a profound transformation and that a truly modern civilization had come into existence. Artists and writers ushered in an extensive debate, on how this >modern $<$ world could be adequately reflected in their creations. Within a decade, Europe was rife with new schools and movements that rallied behind Rimbaud's call, »Il faut être absolument moderne « (»One has to be absolutely modern «) (Rimbaud: 116).

One of them was Futurism, founded in 1909 by the Italian poet and literary manager Filippo Tommaso Marinetti. It made a major contribution to twentiethcentury avant-garde creativity through the ways in which it applied the most recent technological inventions to the fields of art and literature. Marinetti's articles, interviews and manifestos indicated that he took a great interest in the advances of science and technology, but also the underlying philosophical and aesthetic implications of the changing conceptions of energy, matter, time and space etc.

»Futurism is based on the complete renewal of human sensibility brought about by the great discoveries made by science. Anyone who today uses the telegraph, the telephone, and the gramophone, the train, the bicycle, the motorcycle, the automobile, the ocean liner, the airship, the airplane, the film theatre, the great daily newspaper (which synthesizes the daily events of the whole world), fails to recognize that these different forms of communication, of transport and information, have a far-reaching effect on their psyche (Marinetti 2006: 120).

The whole history of Futurism was predicated on this ideas of employing the most recent discoveries and inventions in order to capture the »frenetic life of our great cities «, the modern »state of mind «, even »dynamic sensation itself « (Apollonio: 25, 27). Marinetti's reflections on the novel experience of the world by means of the telegraph, the telephone and the visual media of photography and cinema resulted in a new type of poetry, communicated in a free graphic style (see illustrations 1 and 2). 


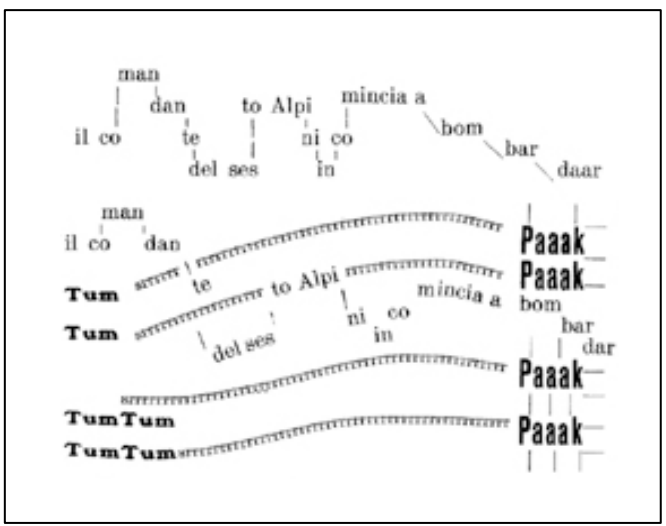

Illustration 1: Danza del Shrapnel; Excerpt from the Dance of the Shrapnel in Marinetti's »Manifesto of Futurist Dance " (L'Italia futurista of 8 July, 1917): »Slow, self-assured, carefree steps of the mountain troops who sing as they march beneath a canopy of continuous, relentless shells. The dancer will light a cigarette, while hidden voices will sing one of many war songs: »the commander of the sixth Alpine regiment is starting his cannonade ...".

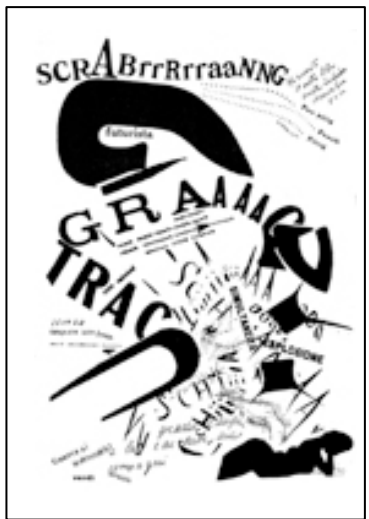

Illustration 2: An example of parole in libertà from Les Mots en liberté futuristes (1919).

In 1914, during one of his many stays in London, Marinetti also began to record his poetry on five $78 \mathrm{rpm}$ discs, ${ }^{1}$ a practice he was going to continue throughout the 1920 s and 30s. In the field of theatre, Marinetti developed several new dramatic genres, designed to capture, »the many-hued, many-voiced tides of revolution in our modern capitals « (Marinetti 2006: 14). But he did not only write plays that $r e$ flected the modern, technologically based forms of communication: he also integrated them in his theatre performances. At the opening of a Futurist exhibition at the Doré Galleries in London, on 28 April 1914, Marinetti recited several passages from his novel ZANG TUMB TUMB. On the table in front of him he had a telephone, which he used to instruct his assistant, the painter Nevinson, in the adjacent room to supplement his recitation with appropriate sound accompaniment. This first recorded use of a telephone in a stage performance was followed a few weeks later, on 17 May 1914, by Marinetti declaiming his latest poetry via telephone from London to a Futurist performance that was taking place at the Sprovieri Gallery in Naples (Berghaus 1998: 172-175, 234-240).

In 1916, he contributed to the first Futurist film, VITA FUTURISTA, which combined elements of painting, sculpture, theatre, music, and poetry (Berghaus 2000: 398-421). As such, it was an expression of the plurisensibilità futurista (Futurist Multisensibility) and produced what in a manifesto was called »a synthesis of life at its most typical and most significant « (Marinetti 2006: 183). When the film was first presented, on 28 January 1917, at the Teatro Niccolini in Florence, it formed part of a programme of Futurist plays performed by the company of Ines Masi and

1 To date, none of the actual disks from the 1910s have been traced, but several of his later recordings have been re-issued on compact disks. 
Giulio Ricci. Such a combination of cinema and theatre was exactly what Marinetti had advocated in the Variety Theatre Manifesto of 1913 (Marinetti 2006: 185-192). It took Marinetti a few years before an integrated use of these media could be considered. The inspiration for this came from Russia and Germany, but also from the development of two other audiovisual media, radio and television.

The invention of wireless telegraphy and radio signalling was of fundamental importance for Marinetti's theory of »wireless imagination « that formed the basis of his literary reform programme of 1912. The Italian government had regulated its radio communication services in a law of 1910 and had placed it under strict State control (Monteleone). In 1924, the first public radio station was installed. Marinetti was amongst the first writers to compose dramas for this new media and became a regular contributor to its programmes. On 18 May 1926, he made his first radio broadcast, delivering a talk on Futurism on Brazilian Rádio Meyrink Veiga. The same year, the Futurists published a radio journal, L'antenna, followed, in 1929, by the first volume in the Edizioni radiofuturiste Electron and the founding of a group called »Radiofuturismo«. On 20 December 1931, the first Futurist radio drama, TUM-TUM by Pino Masnata, was broadcast by the National radio service EIAR, followed, on 19 January 1933, by Marinetti's VIOLETTA AND THE AEROPLANES.

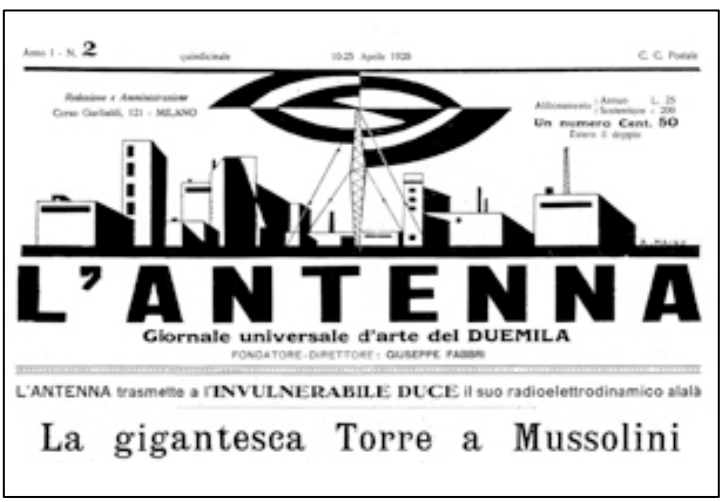

Illustration 3: Titlepage of the radio journal, L'antenna.

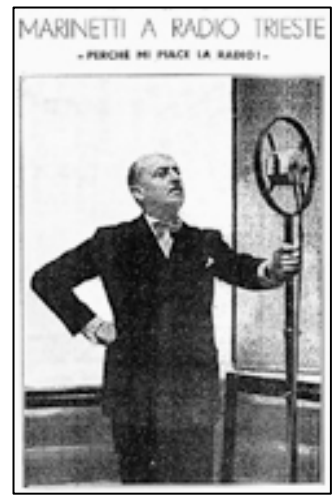

Illustration 4: Marinetti at Radio Trieste, from Radio Corriere, April 1932, p. 9.

As far as the development of an Italian television service was concerned, EIAR was encouraged by the first public demonstrations of a mechanical television apparatus in England (1926) and the USA (1927) to set up their own television laboratory in Milan in 1928. On 9 February 1929, the semi-Futurist newspaper L'impero published an article on »The Progress of Television«, which predicted that within a few years there would be as many television sets in Italy as there were already telephones and radios. In the following months, the Corriere della sera reported on the first televised theatre show by the BBC in London, and on a televised performance of a Montmartre singer in Paris. Marinetti was clearly aware of these events, as in the Manifesto of Futurist Cuisine, published in 1930, he referred to that »immense network of long and short waves that Italian genius [i.e. the radio pioneer Guglielmo Marconi] has flung over the oceans and continents, [and] those land- 
scapes of color, form and sound with which radio-television circumnavigates the Earth « (Marinetti 2006: 396).

Also in Italy, the era of television was now approaching (Grasso). In July 1931, the government gave EIAR the go-ahead to open a service in radiophotography and radiotelevision in Rome, Milan and Turin. A year later, in 1932, Marinetti published his first concrete suggestions for an integrated use of these media in a teatro aero radiotelevisivo. This Theatre of the Skies Enhanced by Radio and Television was going to be performed by specially prepared aeroplanes in the following manner:

1. Huge panels of aeropoetry and screens for television will be hung from special airplanes flying close to the audience and transmit the aerial drama performed high up in the sky by other aeroplanes, which because of their distance would otherwise be difficult to follow.

2. On the ground, special loudspeakers mounted on vehicles camouflaged in a novel way will argue and bicker in their support for one or other of the planes acting up in the sky. When the gambling crowd has placed its bets on the outcome of the aerial drama, the loudspeakers will announce details of the bets to the gamblers in that vast arena.

3. This arrangement will provide a dynamic spectacle of aircraft moving at different speeds and at changing altitudes, and a complementary spectacle in which the machines emit a changing display of coloured smokes (Marinetti 2006: 408-409).

Some of these ideas can already be found, in an embryonic state, in the manifesto, A Theatre of the Skies, by the Futurist aviator Fedele Azari, first launched in a propaganda flight over Milan in April 1919 (Berghaus 1998: 487-490). Here, the aeroplane was treated like a character and was shown to perform dances, dramas, operas and pantomimes high up in the air. Like any good theatrical performer it was costumed, moved in an expressive fashion, and spoke or sung with other characters by means of loudspeakers. Following these "pantomimes of aeroplanes camouflaged as big-bellied bankers, suave Don Juans or as tutu-clad ballerinas [...] performed at the airport of Busto Arsizio « (Marinetti 1969: 177, 247), the first plays for an aerial theatre were written by Marinetti and several of his colleagues.

The Futurist Aviators' Club in Milan carried out a number of experiments, some of which were presented at the Prima Giornata Aerosportiva in Rome in November 1930. By that time, the development of powerful loudspeakers endowed the aeroplanes with a »voice « and enhanced the dramatic complexity of the plot by introducing dialogues and poetic recitations. At the Giornata Aerosportiva of 8 December 1931, Marinetti presented at Taliedo airport an experiment with an aeroplane, »which had on board a loudspeaker, appropriately modified to produce sounds of up to $1,600,000$ volts [...] to emit musical numbers and short propaganda speeches « (Anon). It is likely that these experiments made Marinetti realize that the display in the vast theatre of the skies was not always easy to follow. He therefore seized upon the opportunity to complement and amplify the spectacle by electronic means on huge television screens, just we are still doing nowadays at rock concerts and football matches.

The culmination of all these ideas and experiments was Marinetti's Total Theatre Manifesto of 1933, which foresaw the introduction of cinema, radio and television as complements to the theatrical means of communication in a truly multi-media spectacle. 


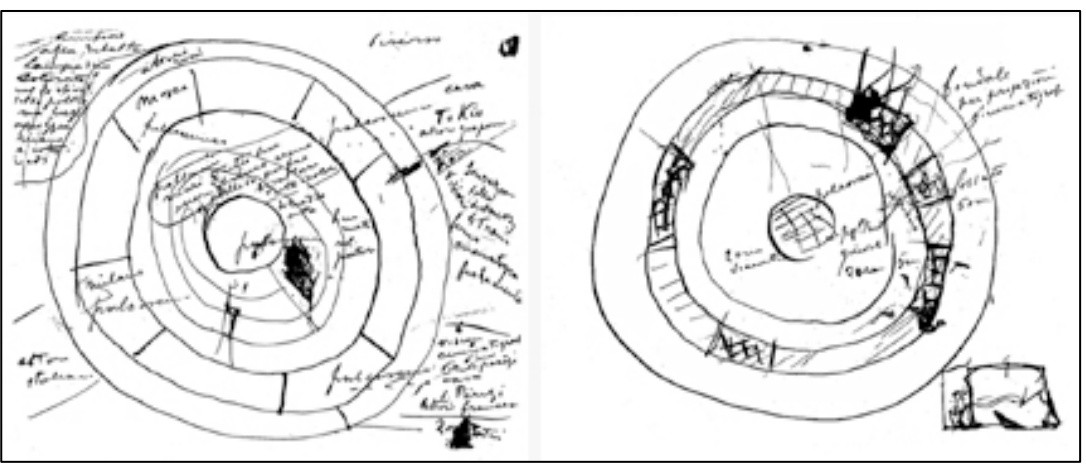

Illustration 5: Two drawings from the manuscript of Marinetti's manifesto, Il teatro totale

The ground plan of this theatre was round and contained several stages: one was like a circular platform surrounding the whole of the stalls area which, in its turn, was surrounded by a trench filled with water deep enough to swim in. A second stage was placed in the middle of the stalls. Around this central stage, every member of the audience had a revolving seat and a little table to eat from. Small groups of spectators were provided with a radio, and a television screen to get close-up views. To give them further possibilities to experience the spectacle, they were encouraged to move about in the theatre:

»The spectators can ... engage in the chance adventures of a journey, participate in the nautical actions unfolding in the trench. Or they can exit, using specially made elevators, into the brightly lit basement for refreshments or a moment of relaxation. Thus, having behaved and performed like actors, and, like dispersed troupes, having speedily communicated with each other with their radio-telephones, they can return to their seats and tables « (Marinetti 2006: 504-505).

These tables were fitted with tactile and odoriferous, moving belts, an idea taken over from the Tactile Theatre, which Marinetti had described in the manifesto of 1921, Tactilism: A Futurist Manifesto:

»We shall have theatres specifically designed for Tactilism. The audience will place their hands on long, tactile conveyor belts which will produce tactile sensations that have different rhythms. One will also be able to mount these panels on turntables and operate them to the accompaniment of music and lights « (Marinetti 2006: 374).

The great circular stage was divided into lots of smaller stages that could be separated one from another by movable perpendicular walls. The different complementary and contradictory actions of a single Futurist drama would take place on these various stages, all at the same time. This drama was conceived as an expression of the simultaneously occurring events in human life or in major historical upheavals. High up in the theatre, an electric sun and moon was moving on metal tracks, as the plays required, through the orbit of the cupola, complemented by a careful simulation of starlight. 
The principle of simultaneity of action was strongly enhanced by the use of cinematic installations. From the trench around the outer circular stage, film projectors would throw a succession of moving images onto a great tilted cyclorama spanning cross the theatre dome. Also animated aeropaintings and aeropoems would be projected onto it. Another array of film projectors, positioned beneath the auditorium, would cast all possible combinations of the fantastic or the realistic onto a large cyclorama surrounding the outer stage. Marinetti writes:

»Presented, in this way, with the illusion of the speed of the great international communication networks, the spectator in this simultaneous, all-embracing theatre will witness not only the dramatic synthesis of a city, but sometimes even a dramatic synthesis of the whole world. [...] In our simultaneous, multi-scenic theatre, the spectator has [...] almost become a collaborator of the actor, and has thus moved to the centre of the dramatic action « (Marinetti 2006: 405).

At the end of the text, Marinetti announced: »A company has already been set up in Milan, for the construction of the great Futurist theatre, with capital amounting to 500.000 lire « (Marinetti 2006: 407). As my research has shown, in 1926, Marinetti did indeed begin to seek public funding for the erection of an ultra-modern and technically advanced, permanent Futurist theatre in Milan. In 1927, he submitted a Memorandum to the Duce, in which he outlined the shortcomings of the existing theatre and acting profession and how these could be overcome in a playhouse, a State acting school, as well as a new type of conservatoire for directors, stage designers and theatre technicians. Mussolini was sympathetically inclined towards the project and had it carefully assessed by the Minister of Education and the Minister of Finances, who eventually turned it down for financial reasons. (Berghaus 1996: 284; Berghaus 1998: 540-541).

\section{Summary}

Marinetti's interest in the advances of science and technology caused him from an early age to recognize the historical significance of the mass media and the new technologies of communication. His writings are not only full of profound reflections on fundamental issues such as time, space, energy, matter and their impact on the human psyche; he also, in a more specific manner, developed a Futurist aesthetic that successively incorporated the new technologies of the telegraph, the cinema, the radio, the television and applied them to different artistic media. The Futurist techniques of fragmentation, simultaneity, collage and polymaterialism allowed the juxtaposition and merging of different media in one work of art.

In the field of theatre, the Futurists reduced the significance of the spoken word and human actor and instead produced purely visual spectacles carried out by robots and machines in a kinetic, luminescent and sound producing architecture. This inspired Marinetti to go a stage further and to incorporate the other senses of smell, taste and tactile sensation. Thus, the idea of a Futurist Total Work of Art was born.

In the 1920s and 30s, Marinetti theorized on and experimented with various types of total theatre. On the one hand there were his explorations of how the different senses could be synaesthetically correlated to arrive at a total experience of theatre - e.g. in his tactile theatre and culinary theatre experiments. On the other hand there were the attempts to integrate new media technologies into the Futurist 
mechanical theatre. For more than ten years Marinetti pursued his concept of a Futurist Theatre of the Skies enhanced by radio and television. But his most complex and Utopian project was that of a Total Theatre formulated in the early 1930s.

\section{Literature}

Anon (1932): »Il primo esperimento del teatro aereo«. In: L’impero. Oggi e domani, 29 January.

Apollonio, Umbro (ed.) (1973): Futurist Manifestos. London: Thames \& Hudson.

Berghaus, Günter (1995): Futurism and Politics: From Anarchist Rebellion to Fascist Reaction, 1909-1944. Oxford: Berghahn Books.

Berghaus, Günter (1998): Italian Futurist Theatre, 1909-1944. Oxford: Clarendon Press.

Berghaus, Günter (ed.) (2000): International Futurism in Arts and Literature. Berlin: De Gruyter.

Grasso, Aldo (1992): Storia della televisione italiana. [2nd. rev. edn, 2000]. Rome: Garzanti.

Marinetti, F. T. (1969): La grande Milano tradizionale e futurista. Milan: Mondadori.

Marinetti, F.T. (2006): Critical Writings. New York: Farrar, Straus \& Giroux.

Monteleone, Franco (1992): Storia della radio e della televisione in Italia, 19221992. Venice: Marsilio.

Rimbaud, Arthur (1972): CEuvres complètes. Paris: Gallimard. 



\title{
DAS INTERMEDIALE JAHRHUNDERT: DIE SAISON 1922/23
}

\author{
KLEMENS GRUBER
}

Mit Intermedialität wurde schon experimentiert, als man vom Medium vor allem in Zusammenhang mit spiritistischen Seancen sprach. Um das Terrain dieser Experimente auszulegen und den Begriff >Intermedialität< analytisch zu öffnen in Hinblick auf dieses Zwischen, >zwischen den Medien<, das er bezeichnet, soll er hier zunächst mit drei anderen Begriffen umstellt werden:

\section{Semiotischer Fundamentalismus}

Die Kunst des frühen 20. Jahrhunderts hatte die naturalistische Landschaft des 19. verlassen und bald auch die herrschaftlich möblierten Interieurs des Fin de siècle. Sie entstand in prinzipieller Auseinandersetzung mit den modernen Massenmedien. Schon die Fotografie hatte die Malerei dazu gebracht, mit allen Formen der Imitation bis hin zur Abstraktion zu brechen. Das Kunstwerk als Abbild - gemalt »nach der Natur « - hatte seinen Sinn verloren, die Künstler waren gezwungen, »nach ihren Ideen « zu arbeiten, wie Marcel Duchamp einmal sagte. Und sie stellten die Welt unter dem Aspekt ihrer Veränderbarkeit dar.

Intermedialität ist heute zur dominierenden kulturellen Realität geworden. Im Jahrhundert der verwischten Genres, der mixed media und der struppigen Codes schuf die Verbindung von Kunst und Technik gänzlich neue Ausdrucksformen, die nicht länger mit den herkömmlichen Begriffen künstlerischer Kreativität beschrieben werden können.

Von Beginn an waren die Elemente der Veränderung vorhanden - in den technischen Erfindungen, die den Transformationen zu Grunde lagen, und in den voluntaristischen Anstrengungen, mit jeder ästhetischen Tradition zu brechen, die den ersten Jahrzehnten des 20. Jahrhunderts ihre bleibende Gestalt verliehen. Was wie ein willkürlicher > großer Bruch< mit allen künstlerischen Konventionen erschien, war eher ein Zusammentreffen mit den neuen Bedingungen der Zeichenproduktion, mit der Industrialisierung der Produktion und Distribution von Zeichen. So sind die analytischen Vorgangsweisen der historischen Avantgarde das Resultat einer Krise der Kunst, ursprünglich hervorgerufen durch die massenhafte Verbreitung von fotografischen Reproduktionen mit ihrer Macht der Ähnlichkeit, die den Status des Kunstwerks, die Rolle des Künstlers und den Standpunkt des Zuschauers nicht unbehelligt ließ. Denn angesichts des SCHWARZEN QUADRATS war der Betrachter gezwungen zu fragen $»$ Wer bin ich, der ich dieses schwarze Quadrat sehe, in welcher Beziehung befinde ich mich zu ihm?«. 


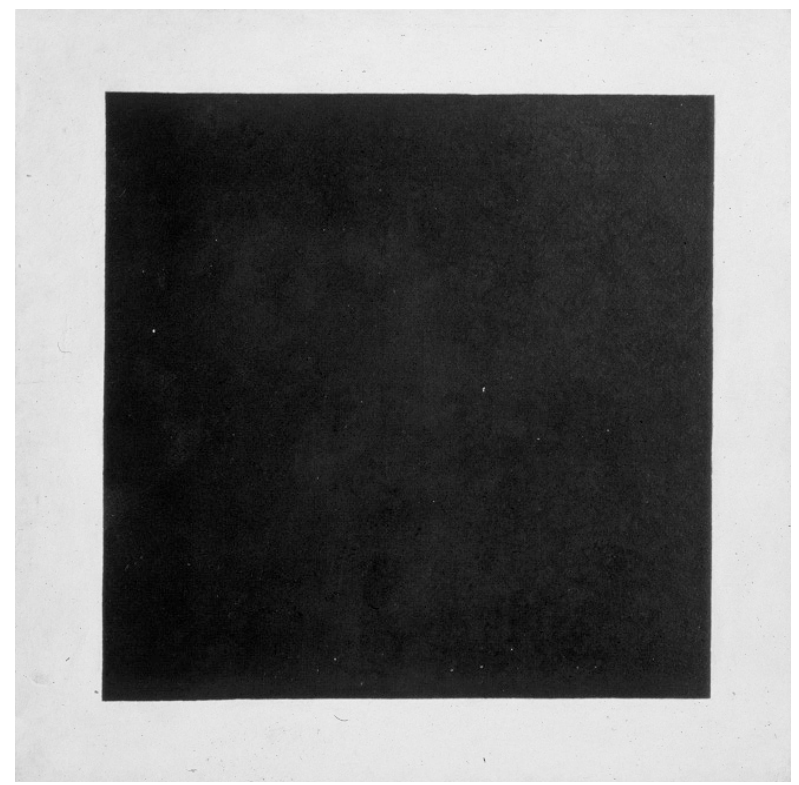

Abbildung 1: Kazimir Malevič: SCHWARZES QUADRAT, 1915/1929.

»Malewitschs Besuche bei mir und unsere Gespräche in den Jahren 1913/1914 galten dem, was wir >die Freisetzung der Energie < in der Malerei und Poesie nannten: nicht-mimetische Malerei und nicht-referentielle Poesie, das waren die Schlagworte, mit denen wir nach Paris aufzubrechen gedachten.«(Jakobson 1976: 293).

Derart bringt Roman Jakobson, der berühmte Sprachwissenschaftler und Weggefährte der russischen Futuristen das ästhetische Programm der frühen Avantgarde auf den Begriff, den Bruch mit Darstellungskonventionen, die im Naturalismus an ihren historischen Endpunkt gelangt waren. Die Verwerfung des Narrativen und Abbildenden »in allen Bereichen der Schönheit « führte tatsächlich zu neuen Aggregatszuständen der Kunst:

- $\quad$ in der Malerei nie gesehene Konstellationen zwischen Fläche, Farbe und Raum;

- in der Literatur eine systematische Exponierung des Sprachmaterials - »Hartnäckig suchte ich sinnvolle Wörter zu vermeiden«, erzählt Jakobson (in Jakobson/Pomorska: 14, hier zitiert in der schönen Übersetzung von Zima: 185);

- $\quad$ in der Musik tritt Ton-, ja Geräuschkunst gegen die Programmmusik an;

- das Theater schließlich sucht die illusionistische Bühne zu verlassen und sich von der Dominanz der Literatur zu befreien: es erforscht den Raum, den Körper in Bewegung, die inszenierte Stimme.

Die Vorherrschaft des Narrativen, Illustrativen und Figurativen wurde ersetzt durch eine Art »semiotischen Fundamentalismus « (Hansen-Löve 1992: 34), jene Strategie, »die jeweilige mediale semiotische Struktur der Kunstformen und Gattungen in ungemischter Form zu präsentieren, um sich auf diese Weise der Regeln einer jeden spezifischen Zeichensprache zu vergewissern« (ebd.: 40). Überall kommt es 
nun zur »Freisetzung der Energie« der jeweiligen Kunstform, zur systematischen Exponierung von ästhetischem Rohmaterial:

»Das Wort als solches « etwa heißt eines der berühmtesten Manifeste der russischen Avantgarde aus dem Jahr 1913 (Chlebnikov: 115), »das selbstgenügsame Wort«, Minimaldefinition der Poesie und ihrer künstlerischen Verfahren (vgl. Jakobson/Pomorska: 185).

Oder das SchWARZE QUADRAT, das Kazimir Malevič erstmals 1915 ausstellte, aber schon zwei Jahre zuvor während der Ausstattung der futuristischen Oper SIEG ÜBER DIE SONNE konzipiert hatte, und das kein Quadrat in der Natur mehr repräsentiert, sondern als Wahrnehmungsereignis, als pure Erregung, »als solches« bestehen soll.

Und wenn Brecht für das epische Theater die »Trennung der Elemente« Wort, Ton und Bild fordert - wie es in den gemeinsam mit Peter Suhrkamp verfassten »Anmerkungen zur Oper AUfSTIEG UND FALL DER STADT MAHAGONY « heißt (Brecht: 79f) -, besteht er ebenfalls auf jener elementaren Energie der jeweiligen Kunstform.

$\mathrm{Zu}$ den Grundlagen der jeweiligen Kunstform zurückzukehren hieß nicht nur Besinnung auf die je spezifischen Mittel, sondern zugleich auch Erforschung ihrer neuen Aufgaben: in der Malerei die Bewegungsdarstellung im unbewegten, statischen Medium Bild, der mobile Blickpunkt und schließlich die Gegenstandslosigkeit; in der Literatur die Arbeit an einer poetischen Sprache, deren Wörter ihre »abgetragenen Bedeutungen « abwarfen - etwa Velemir Chlebnikovs Erfindung der »jenseits des Verstands « liegenden Sprache zaum; und im Theater die Abkehr vom Text/buch, die Inszenierung von Raum, Licht und Konstruktion statt Dekoration und Geschichtenerzählen. Schließlich die Thematik des Zuschauers.

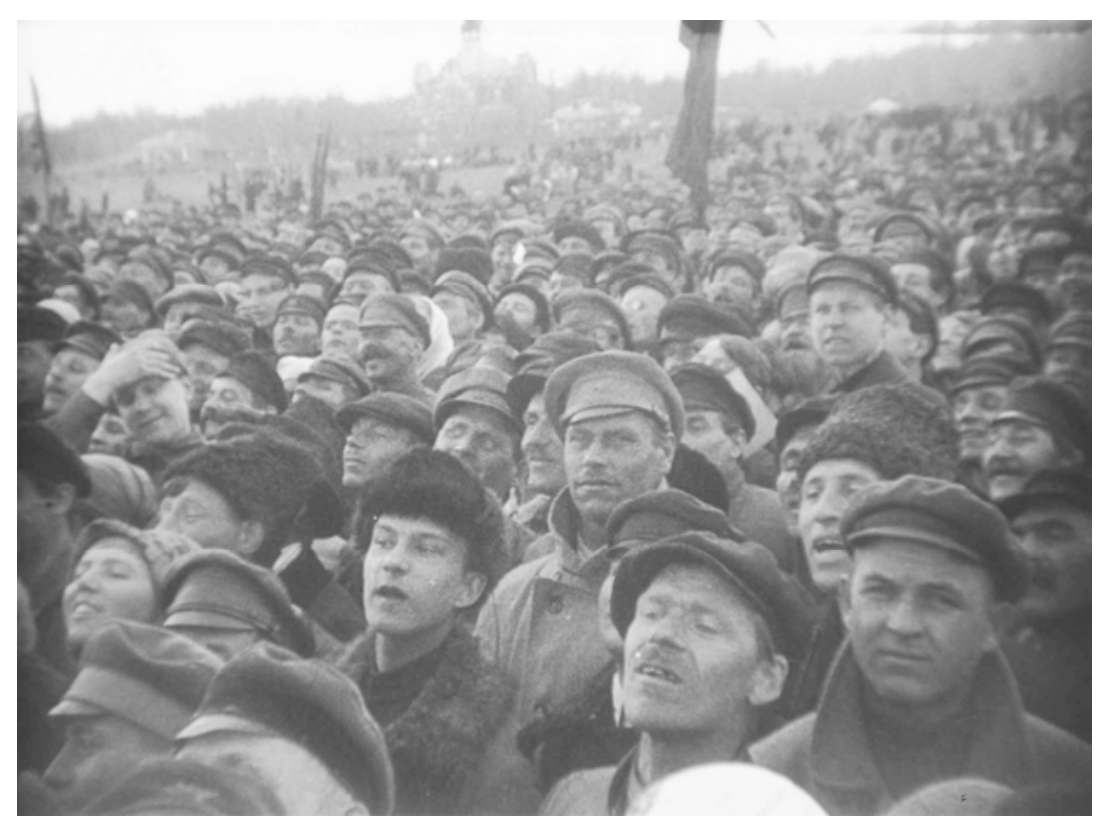

Abbildung 2: Dziga Vertov, KINOPRAVDA Nr. 16, 1923. 
Dies allerdings gilt für alle Künste. In der Neudefinition der Kunst durch die frühe Avantgarde ist schon eine Neubestimmung der Beziehung zwischen Kunstwerk und Betrachter angelegt: Keine Abbilder mehr, sondern Zeichen, Konstruktionen, die dem Betrachter weder Ähnlichkeit noch naturalistische Illusion offerieren und damit seine Position als Zuschauer ins Spiel bringen. Die Malerei hatte mit dem beweglichen Blick und seinen multiplen Perspektiven schon an verschiedenen Formen der Interaktivität zwischen Bild und Betrachter gearbeitet; am Theater wurde die Rampe als unüberbrückbares Hindernis in Frage gestellt. Durch die Konkurrenz mit den Massenmedien aber kam es zu einer ersten allgemeinen Reflexion der kulturellen Bedürfnisse des neuen Publikums, der neuen urbanen Massen. Denn »Für den neuen Zuschauer war die alte Kunst etwas Unbekanntes «, notierte Viktor Šklovskij (1986: 122).
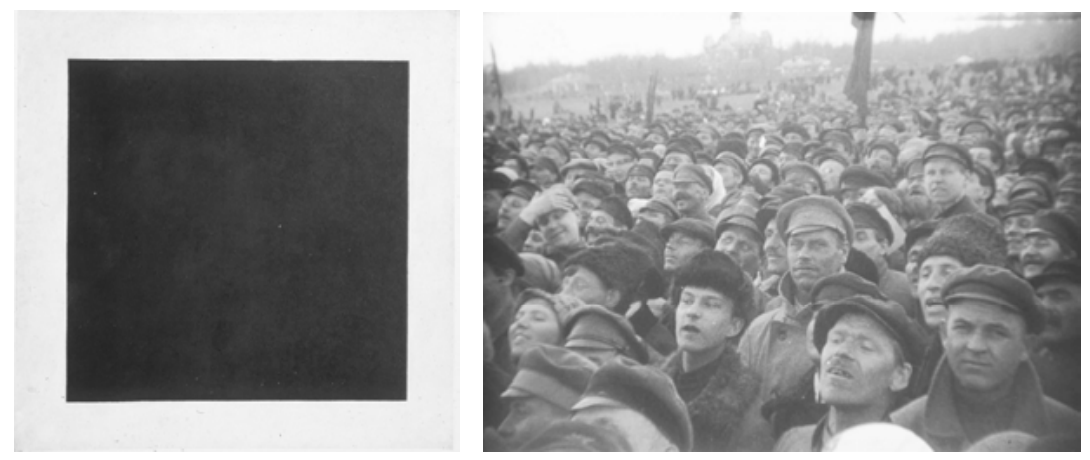

\section{2. Ästhetische Zweckentfremdung}

Verstärkt wurden diese fundamentalistischen Explorationen durch die technische Entwicklung der modernen Medien. Denn die Technologie konnte nun jeweils eine Sinneswahrnehmung in reiner Form isolieren: der Telegraf gab nur die Schrift, das Telefon nur die Stimme, das Grammophon nur die Töne wieder (vgl. Moebius: 151).

Dass es trotz des >semiotischen Fundamentalismus< der einzelnen Künste, auf ihre je spezifische Zeichensprache zu setzen, dennoch zu intensiven Austauschprozessen zwischen ihnen, zu intermedialen Formationen kam - und die Werke wie Biographien der Avantgardekünstler legen davon ein beredtes Zeugnis ab -, ist ein Widerspruch nur auf den ersten Blick. Die Rückbesinnung auf die Grundelemente der einzelnen Künste führte keineswegs zu ihrer Isolation. Im Gegensatz zu ihrer Amalgamierung unterm Opernhimmel als >Gesamtkunstwerk< konnten die Künste jetzt >als solche<, in ihrer Eigenständigkeit und unter Betonung ihrer Grenzen eine selbstbewusste Kombinatorik entfalten.

Dabei entwickelte die internationale Avantgarde ein luzides Bewusstsein von den Grenzen und markierte die Momente des Bruchs, des Übergangs, des Austauschs. »Die Reflexion der medien- und gattungsspezifischen Voraussetzungen « (Hansen-Löve 1992: 35) erlaubte es den avantgardistischen Künstlern, analytische Verfahren zu entwickeln, um jene Grenzüberschreitungen zu organisieren: etwa 
zwischen Schrift und Bild, Bühne und Film, Malerei und Fotografie, aber auch zwischen praktischer und poetischer Sprache, zwischen Kunst und Alltag.

Das generellste dieser Verfahren war die >Vermerkwürdigung < mit dem Ziel einer >Entautomatisierung der Wahrnehmung <, die dann als Verfremdung - jene Haltung erhellender Distanz - weltweit berühmt werden sollte. Und das generöseste Verfahren war das der »Bloßlegung des Verfahrens« (Jakobson 1988: 43) selbst, der »Aufdeckung des Kunstgriffs« - der Öffnung des Laboratoriums.

Die historische Grenze des Modernismus - seines Radikalismus im formalen Bereich - besteht in der Krise der Beziehung zum neuen Massenpublikum (vgl. Buchloh: 86ff). An diesem Punkt wird der Rückzug auf die elementare Energie der jeweiligen Kunst, der Minimalismus der reinen Form, der puren Energie, abgelöst von unterschiedlichen Strategien, denen eine intensive Recherche der Beziehungen zwischen den verschiedenen Medien zugrunde liegt, intermedialen Strategien also und Strategien, die eine Interaktion mit dem Betrachter ins Auge fassen: Die selbstgenügsame Kunst aufzugeben und das ganze Terrain der Massenmedien in die Auseinandersetzung um einen neuen Aggregatszustand der Kunst zu involvieren, der nun auch von den städtischen Massen und ihren kulturellen Forderungen bestimmt ist.

In der KINOPRAVDA NR. 16 von Dziga Vertov sieht man Menschen in Moskau am 1. Mai 1923 fröhlich in die Kamera grüßen und schließlich einen jungen Mann freudig-respektvoll vor ihr den Hut ziehen.

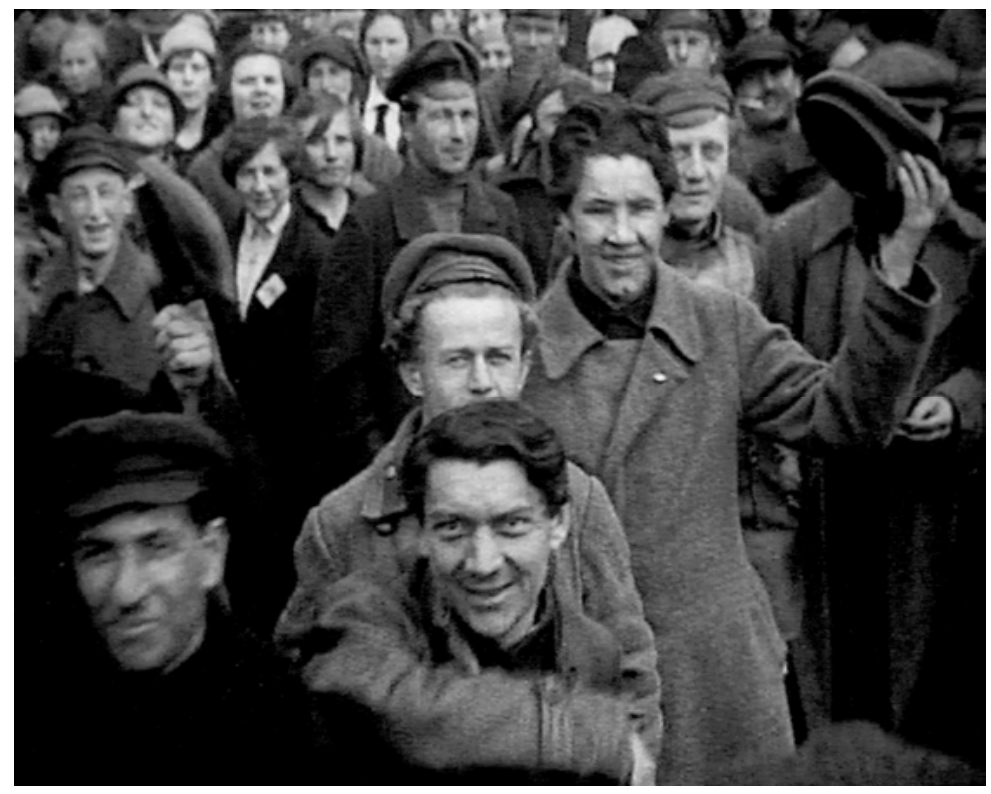

Abbildung 5: Dziga Vertov, KINOPRAVDA Nr. 16, 1923. 
Begünstigt wurden die intermedialen Möglichkeitsformen dadurch, dass die Avantgarde die Herausforderung der modernen Massenmedien annahm, die sie schließlich aus dem Paradies der schönen Künste vertreiben sollten. Die Avantgarde versuchte sich diese Medien anzueignen, sie für ästhetische Zwecke zu entwenden, und natürlich auch politisch nutzbar zu machen.

»Wann erzeugt die Technik ästhetische Werte?« (V. Markov, zit. n. HansenLöve 1989: 213) fragten die Künstler der Avantgarde. Sie erkundeten, wie aus technischen Möglichkeiten - und auch Mängeln oder Zwängen - des Mediums künstlerische Funktionen erwachsen. Das begann mit dem Filmriss und der durch einfaches Zusammenkleben der Filmstreifen entstandenen Möglichkeit, Bilder augenblicklich aufeinandertreffen zu lassen, die in der Realität nicht naheliegen: die Kunst, Bilder und später auch Töne zu einem Zusammenhang zu montieren, der nie zuvor existierte - den kein Mensch je gesehen hat: Sehr früh wurde die Kamera als eine Apparatur begriffen, »die weit mehr vermag, als Illusionswirkungen hervorzurufen (Schulte: 106).

Die Verwendung kunstfernen Materials und der künstlerische Missbrauch der technischen Medien - wobei aus der Möglichkeit des Schnitts die Montage, aus der Finsternis des Kinos »das neue Sehen«, aus der Traumfabrik eine Maschine der Aufklärung entstehen sollte - sind entscheidende Innovationen der historischen Avantgarde. Sie scheinen im übrigen auch heute noch ihr Kennzeichen zu sein.

Vor allem aber - und dies entspricht dem unbekümmerten Grundton der Avantgarde - hat sie nicht gezögert, die neuen Massenmedien ohne Unterschied mit den traditionellen Künsten zu verbinden, zu montieren, aufeinanderprallen zu lassen. Bild und Wort, Theater und Film, Architektur und Rundfunk, Typographie und Ausstellungswesen. Die Kreuzungen, ja Bastardisierungen sind vielfältig.

\section{Epistemologische Euphorie}

Überdies war eine ganze Generation von Künstlern und Intellektuellen erfüllt von dem, was Annette Michelson eine "generalized epistemological euphoria (1990: 21f) genannt hat: Die neuen technischen Instrumente - und allen voran der Film versprachen einen $\gg$ völlig neuen und erfrischenden Zugang zu einem vollständigeren, präziseren und konkreteren Verständnis der Realität, als ihn irgendein Medium bisher ermöglicht hatte«. Die Kamera galt dieser Generation nach dem Ersten Weltkrieg - und Michelson nennt Dziga Vertov, Jean Epstein, Walter Benjamin die Kamera galt ihnen als Wahrheitsmaschine, oder zumindest als ein Apparat zur »Vervollkommnung des Sehens«. Diese Maschine konnte nicht nur Bilder hervorbringen, die dem menschlichen Auge für immer unzugänglich geblieben wären, und somit eine Erweiterung der natürlichen Wahrnehmung erzeugen, sondern vor allem ein umfassendes Verständnis der Realität in Aussicht stellen: »einen Weg, zur Unterseite, zur fernen, dunklen Seite der Realität vorzudringen.« Herbert Molderings nennt diese Entschlossenheit, der Optik eine Erkenntnisleistung beizumessen, die von der neuzeitlichen Philosophie bis dahin nur der Vernunft zugestanden wurde, eine Art »aufgeklärter Optizismus « (Molderings: 8). Wobei das analytische Erfassen der Realität für jene Generation unauflösbar mit dem Projekt einer Veränderung dieser Realität, mehr noch der Welt, der conditio humana insgesamt verbunden war. 


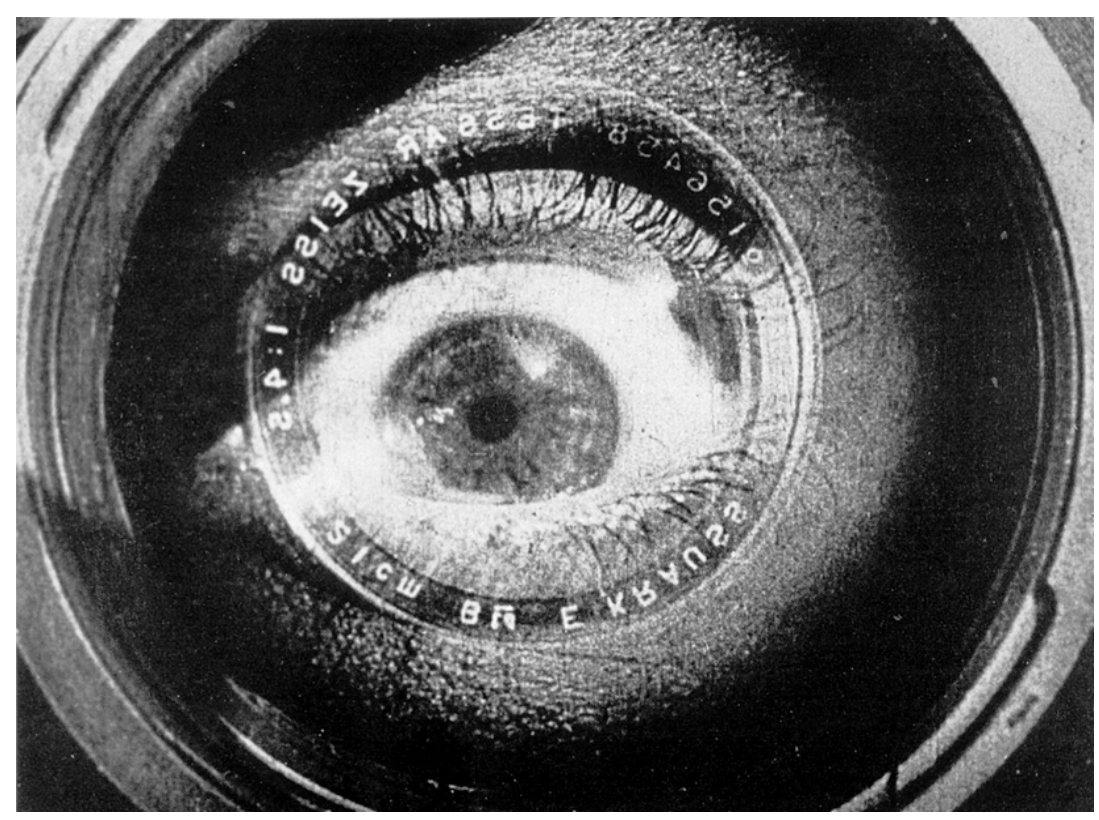

Abbildung 6: Dziga Vertov, Das Kino-Auge, in: DER MANN MIT DER KAMERA, 1929.

So korrespondierten der semiotische Fundamentalismus und die ästhetische Zweckentfremdung der Medien mit einem analytischen Instinkt, einem analytischen Überschwang, den die russischen Formalisten in die einfache Frage fassten: »Wie ist es gemacht? « - wie ist das Kunstwerk konstruiert. Mit derselben Neugier, mit der Kinder ihr Spielzeug, irgendwelche Geräte, ja sogar Bücher in alle Einzelteile zerlegen, mit demselben spielerischen Vergnügen, mit derselben Hartnäckigkeit gingen die Formalisten daran, die Strukturen des Kunstwerks freizulegen: die Regeln ihres Funktionierens - ihre Verfahren.

Mehr noch, das Verfahren selbst wurde zum »einzigen Helden«, wie Roman Jakobson (1972: 33) gesagt hat: nicht länger ein menschliches Subjekt oder ein Fabelwesen, sondern das künstlerische, ästhetische Verfahren selbst ist die Hauptfigur der modernen Kunst.

\section{Nach diesen drei Begriffen}

- semiotischer Fundamentalismus, oder semiotische Radikalität;

- ästhetische Zweckentfremdung, also künstlerischer Missbrauch der Medien;

- epistemologische Euphorie, die mehr ist als Maschinen- oder Medienbegeisterung - dieses >Jubilieren $<$ angesichts der neuen technischen Möglichkeiten sollen drei oder vier mediale Inszenierungen der Saison 1922/23 die entscheidende Rolle vorführen, die die Avantgarde bei der Konstruktion dessen gespielt hat, was man heute Intermedialität nennt: die wechselseitige Erhellung der medialen Verfasstheit. Von einem Medium zu anderen zu wechseln ist gewissermaßen eine Initiation in Intermedialität. Die Konfrontation zweier Darstellungsweisen zerstört die Illusion der Unmittelbarkeit des Angeschauten durch Reflexion auf ihre Gemachtheit: Die Szene wird als mediale Konstruktion kenntlich gemacht. 


\section{GROSSMÜTIGER HAHNREI}

In Meyerholds berühmter Arbeit aus dem Jahr 1922, »die als Inszenierung des GROSSMÜTIGEN HAHNREI ausgegeben wurde«, wie Iwan Axjonow, Popowas Ehemann, sarkastisch anmerkt (Axjonow: 32), der das Stück übersetzt und bearbeitet hat, ersetzt eine Apparatur auf der Bühne die traditionelle Dekoration. Berichte von westlichen Augenzeugen machten den HAHNREI schnell legendär; Bilder des Bühnenmodells und die Szenenfotos haben diesen Ruf bis heute erhalten - sie fehlen in keinem Lehrbuch der Theaterwissenschaft oder Kunstgeschichte.

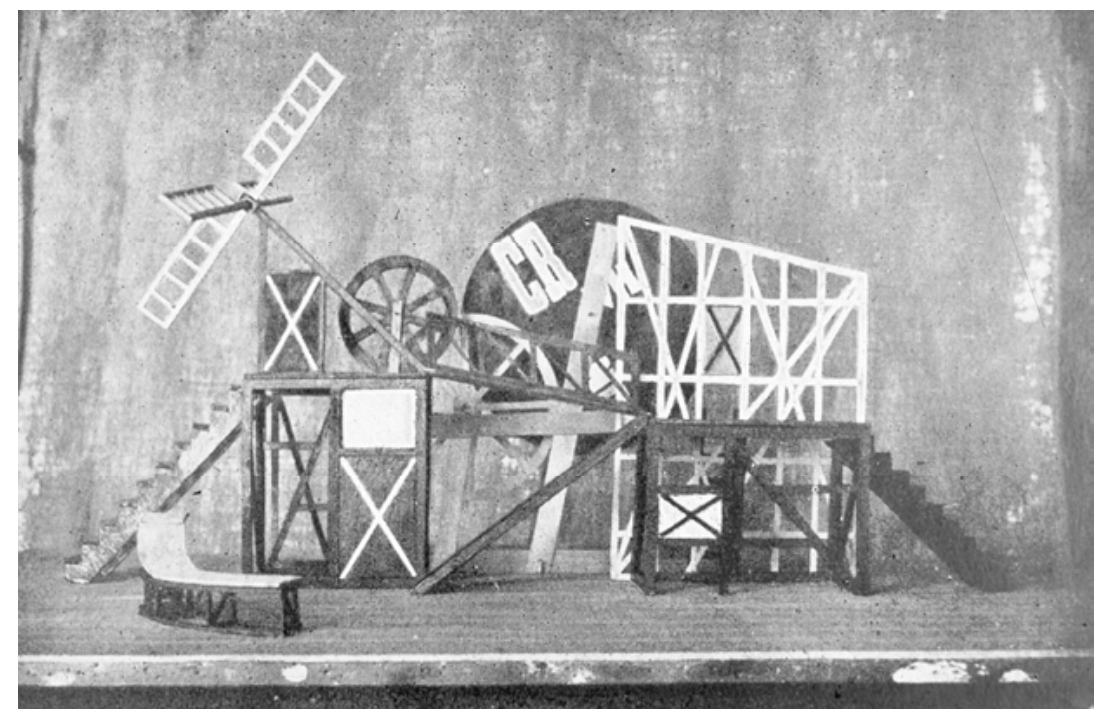

\section{Abbildung 7: Liubov Popova, DER GROSSMÜTIGE HAHNREI, Bühnenmodell.}

Manfredo Tafuri nennt diese Ikone der Theatergeschichte »Modell einer positiven Beziehung zwischen Mensch und Maschine« (Tafuri: 121): nicht mehr Glorifizierung der Maschinerie sondern perfekte Symbiose zwischen Mensch und Maschine.

Anstelle von Dekorationen stellt die Malerin Liubov Popova eine wagemutige Konstruktion auf die leere Bühne. Der Schaupielerkörper ist biomechanisch zugerichtet, um an der Maschine erfolgreich zu spielen; und die von aller darstellenden Funktion befreite Maschine ist einzig konstruiert für die Anforderungen des theatralen Spiels, das »auf der Versöhnung von Arbeit und Spiel« (Tafuri: 121) basiert.

Man kann jedoch diesen szenischen Apparat, jene »Werkbank für das Spiel«, auch lesen als die

»äußerste Unmöglichkeit der verborgenen, internalisierten, diskreten, subtil hervorgerufenen Handlung. Er bietet keinen Raum für beliebige oder ungenau ausgeführte Gesten. Man kann in ihm nicht trödeln, zögern, lümmeln, meditieren oder reflektieren. Was man kann ist schreiten, hochschnellen, rutschen, springen, hervorgerufen von einem Bühnenbild, das eine Maschine für Aktion ist. Nichts, weder die Aktion, die Haltung - noch natürlich die Bühnenmaschinerie selbst - ist verborgen« (Michelson 1973: 33 [Übers. Verf.]). 


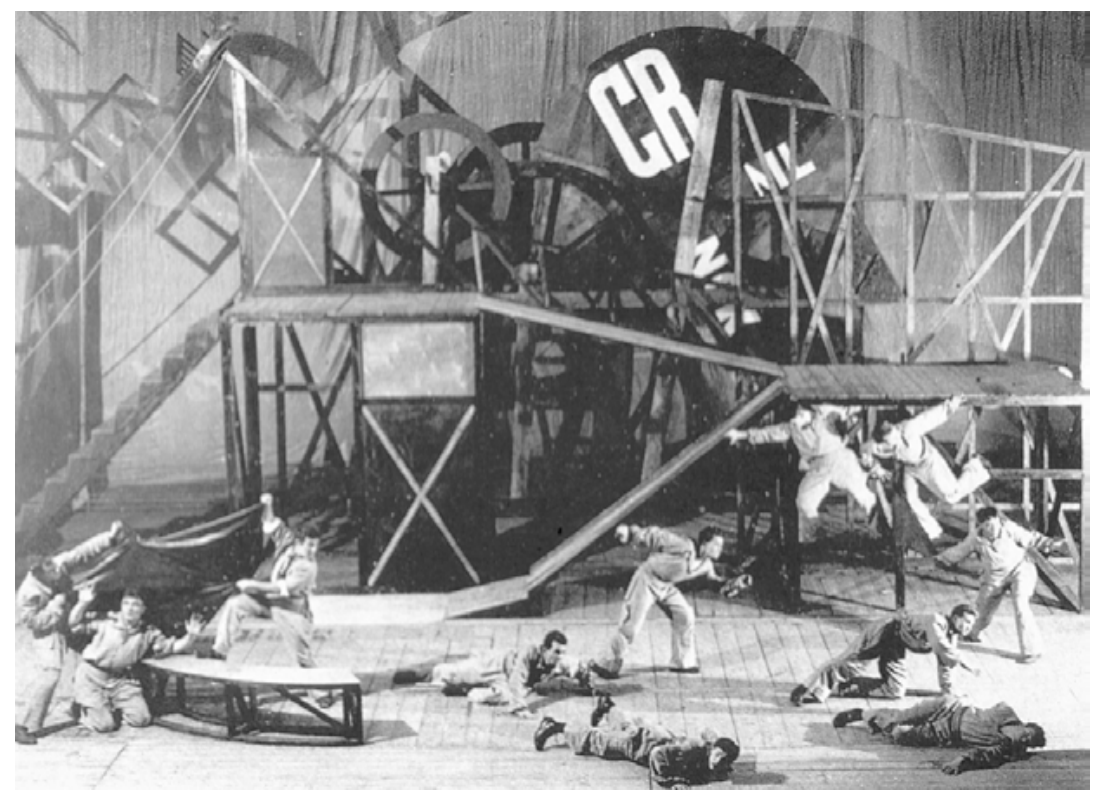

Abbildung 8: Meyerhold, HAHNREI, Moskau 1922, Szenenfoto 3. Akt.

Was aber ist das für eine »lebende Maschine«, die Popova hier gebaut hat, eine Maschine die alles sichtbar macht, alles offenlegt? Zunächst erinnert das Modell wohl an die Geräte eines Kinderspielplatzes oder an das transparente Räderwerk einer Schweizer Uhr denn an die Mühle aus Fernand Crommelyncks Stück.

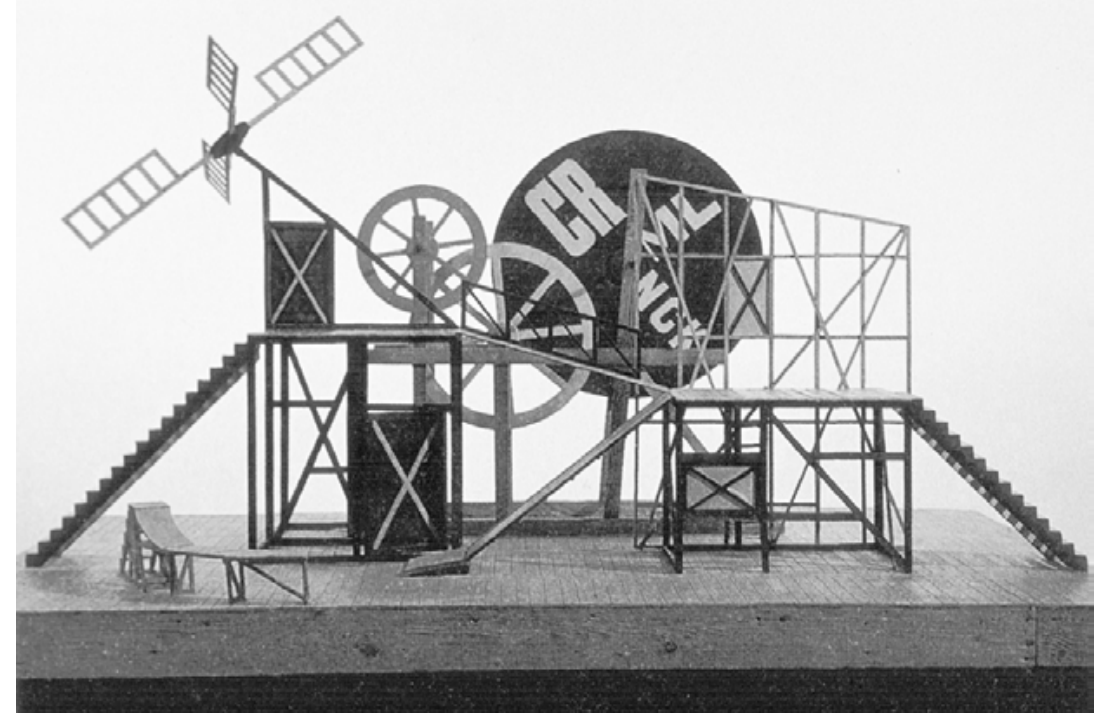

Abbildung 9: Liubov Popova, DER GROSSMÜTIGE HAHNREI, Bühnenmodell. 
Gleichwohl nimmt dieser Apparat jene Jahrhunderte alte Funktion des Theaters in Anspruch, >Schauplatz< zu sein, auf dem Gefühle verhandelt, durchsichtig werden. Und obwohl der Apparat nicht unmittelbar als eine bestimmte Maschine identifiziert werden kann, sondern eher eine »künstlerische Synthese [...] der mechanischen Elemente einer Maschine « (Lodder: 177) darstellt, wodurch sie eine abstrakte Maschinerie wird, könnte man sagen, dass eine derartige Maschine existierte, die imstande war alles zu sehen: der Film, das kinematografische Auge, die Kamera.

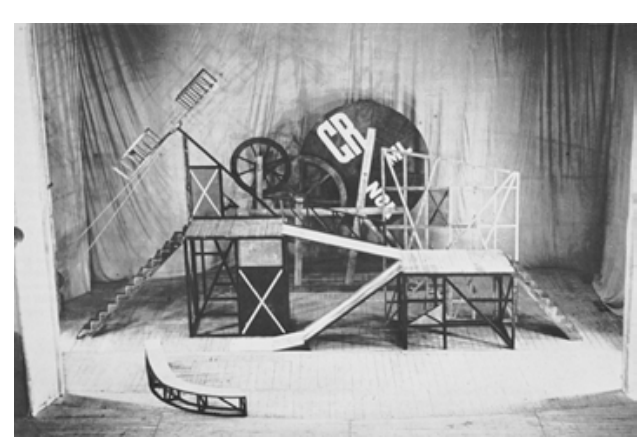

Abbildung 10: Liubov Popova, HAHNREI, Bühnenfoto bei der Wiederaufnahme 1928.

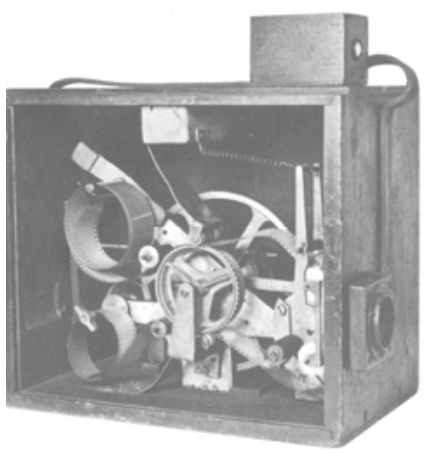

Abbildung 11: 35mm Kamera (1895).

In diesem Sinne, in dieser Hinsicht könnte man weiters sagen, dass Popovas Bühnenkonstruktion zwar eine abstrakte Maschine darstellt, zugleich jedoch einer ganz konkreten ähnelt: einer Filmkamera oder einem Filmprojektor, die damals beide noch in ein und demselben Kasten eingebaut waren; dass sie dem ähnelt, was in diesem Gehäuse, im Inneren der Kiste mit der Kurbel verborgen ist.

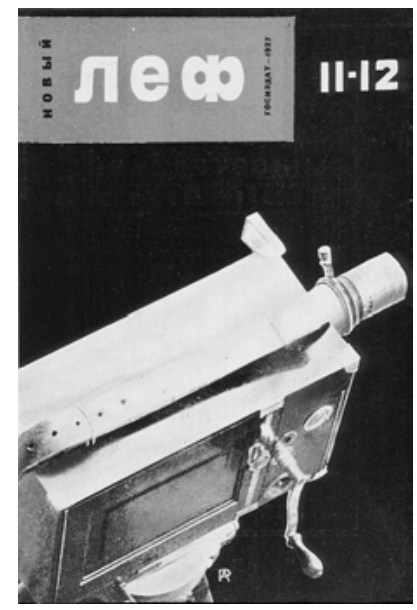

Abbildung 12:

Aleksandr Rodčenko, Umschlag von NOVYJ LEF 12/1927. 


\section{RADIO-ORATOREN}

Die Lautsprechertribünen des lettischen Künstlers Gustav Klucis aus den Jahren 1922/23 sind Resultat einer ähnlichen konstruktivistischen Recherche.

Wie ein utopisches Multimedia-Gestell musste anmuten, was schon durch die Bezeichnung »Lautsprecher-Tribüne « als intermediale Konstruktion vorgestellt wird. Klucis baut dem Medium eine Bühne, stellt den Lautsprecher aus und kombiniert ihn mit einer Projektionsleinwand. Diese Bastardisierung macht die Präsenz des Menschen auf der Bühne hinfällig. Sie führt uns eine bestimmte Haltung im Verhältnis Mensch - Maschine vor: Inszenierung der Apparatur, die an die Stelle des Menschen tritt - während die Technik selbst zu sprechen imstande ist (vgl. Gruber 2005).

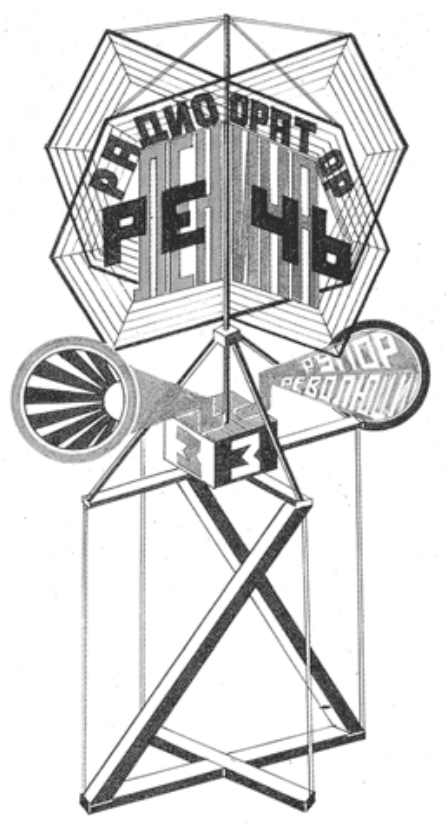

Abbildung 13: Gustav Klucis, Entwurf zur LAUTSPRECHERTRIBÜNE Nr.3, 1922.

Was die immense Schönheit dieser Konstruktionen ausmacht, von denen Klucis nur zwei Exemplare realisieren konnte (vgl. Gaßner/Nachtigäller: 38 u. 113), ist gewiss die Sichtbarmachung ihrer Konstruktion, die Transparenz des Konstruktionsverfahrens, ihr Ausstellungscharakter. Weiters die völlige Abwesenheit des menschlichen Körpers, die Inbesitznahme der Rednertribüne durch die Medien, die das ganze Podium, die ganze Bühne abräumen, alles weg, nur mehr der Lautsprecher ist installiert und die Projektionsleinwand. Reine Apparatur.

Allerdings nennt Klucis die Anordnung RADIO-ORATOR, Radio-Sprecher, Redner also, und vermenschlicht sie damit. Zudem anthropomorphisieren die Lautsprecher, aber auch der Tribünenaufbau in manchen Entwürfen die Konstruktionen 
in extremer Weise und lassen sie wie lebendige Gestelle, vor allem in ihren Umrissen dynamischen menschlichen Gestalten ähnlich erscheinen: Sodass die Verwerfung des Menschen, seine Ersetzung durch die Apparatur an dieser Spuren menschlicher Züge aufblitzen lässt.

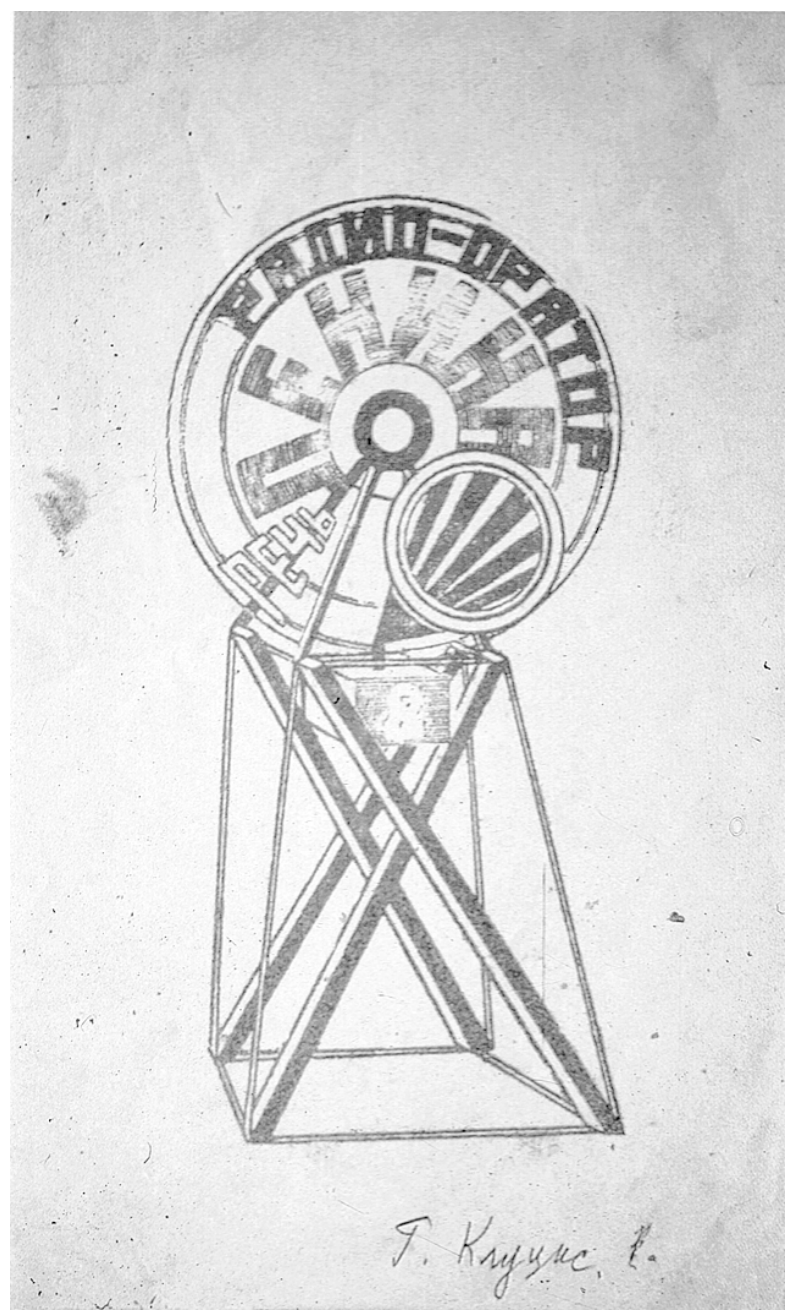

Abbildung 14: Gustav Klucis,

Entwurf zur LAUTSPRECHERTRIBÜNE Nr. 2, 1922.

Schließlich aber rührt die Schönheit der Gestelle vor allem von ihrer Einfachheit, die sich nicht nur einer außergewöhnlichen stilistischen und formalen Intelligenz verdankt, sondern einem sehr alten, elementaren, funktionalen Prinzip folgt, das wir in alten Darstellungen von Jahrmarkttheatern, Commedia dell'arte-Bühnen und dergleichen mehr wiederfinden: 
Die einfachste Form der Bühne besteht aus Brettern, die über zwei Holzböcke gelegt werden. »Scharlatane und Schauspieler in Kostümen und Masken der Commedia dell'arte « erzählt die Bildlegende dieses Aquarells aus dem Stammbuch des Adam von Eck, entstanden zwischen 1592 und 1594. Eine archaische, elegante, mobile Lösung, 400 Jahre alt und gewiss noch viel älter.

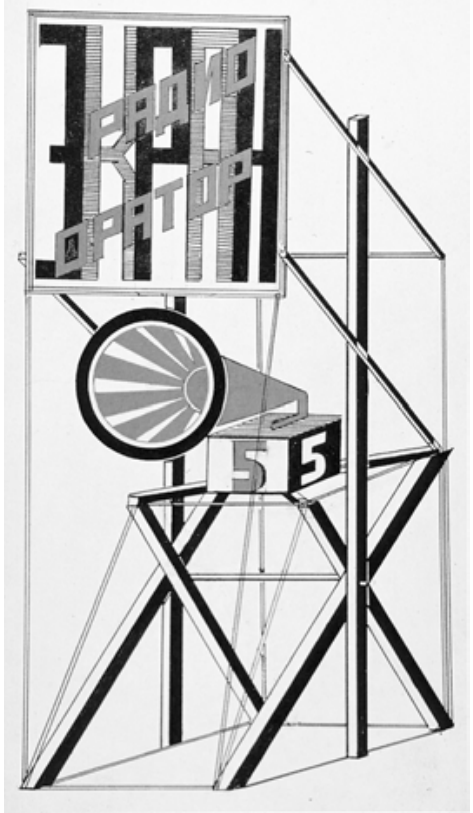

Abb. 15: Gustav Klucis, Entwurf zur LAUTSPRECHERTRIBÜNE Nr. 5, 1922.

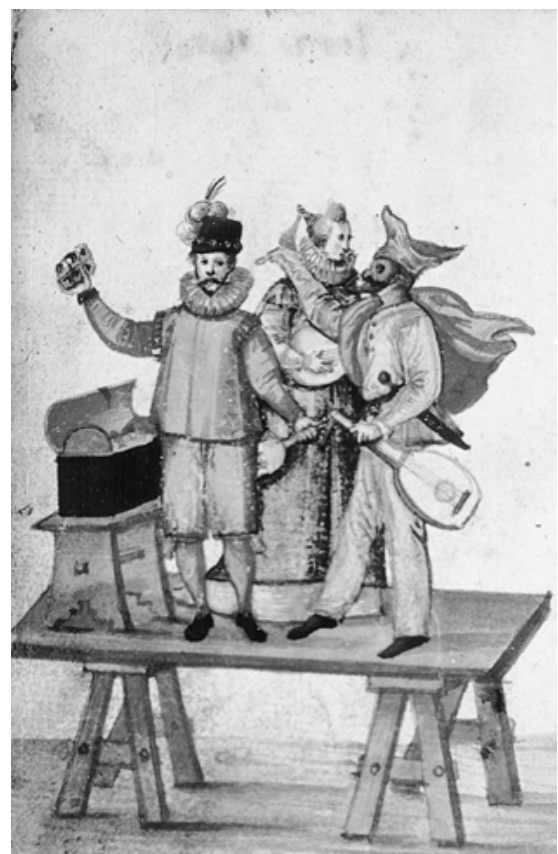

Abbildung 16: Aquarell im Stammbuch des Adam von Eck zwischen 1592 und 1594.

\section{WITHIN THE QUOTA}

Bei dieser Inszenierung der Ballets Suédois 1923 in Paris, einem Stück, das die amerikanische Einwanderungspolitik (dt. etwa: ENTSPRECHEND DER [EINWANDERER-] QUOTE) und den Boulevard-Journalismus aufs Korn nimmt, erklingt Musik von Cole Porter.

Die von Gerald Murphy entworfene Dekoration zeigt ein riesiges ZeitungsTitelblatt voll von überdimensionalen Buchstaben. Vom Dadaismus inspiriert, wendet die visuelle Ironie der Schlagzeilen das Sensationelle ins Satirische und die Seriosität der Fakten ins Lächerliche: die Abbildung links etwa vergleicht den hochgestellten Ozeandampfer »Königin der Meere « mit dem Woolworth-Gebäude in New York, das bei seiner Eröffnung 1913 den Beinamen »Cathedral of Commerce « erhielt und bis 1930 das höchste Gebäude der Welt war. Die zentrale Schlagzeile lautet ganz heutig: »Unknown Banker buys Atlantik«. 


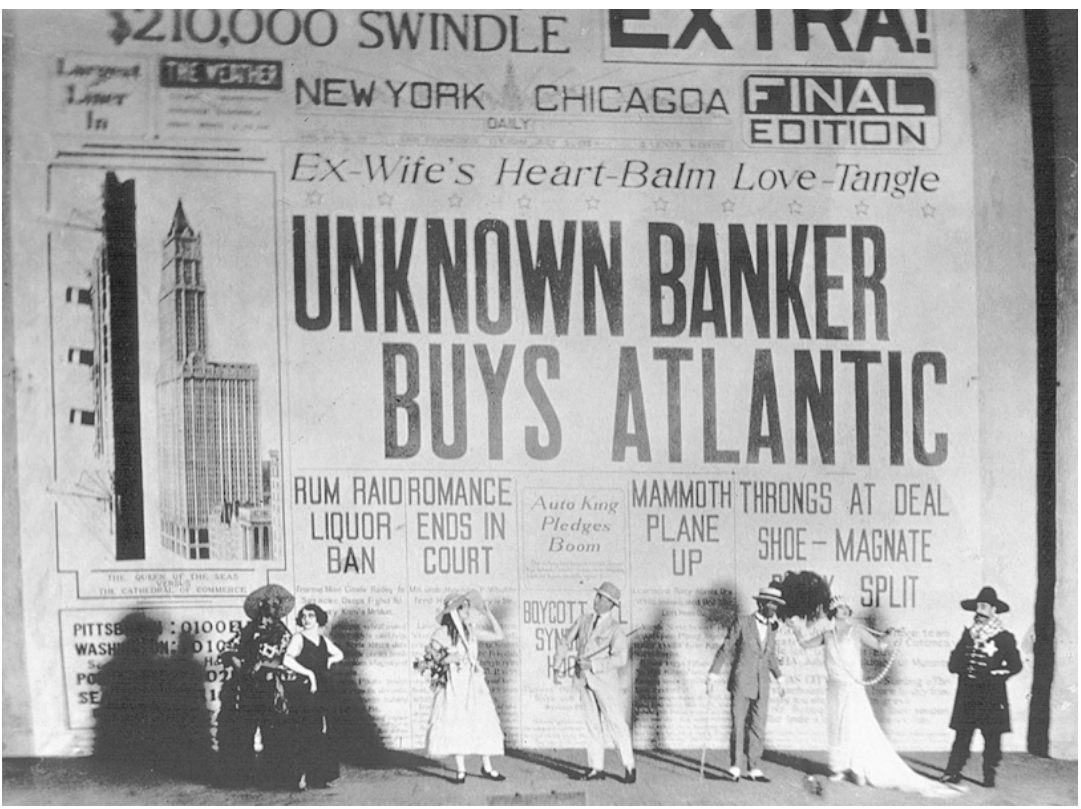

Abbildung 17: Szenenfoto WITHIN THE QUOTA, Paris 1923.

In der Ökonomie der Theater-Wahrnehmung unterbrechen geschriebene Wörter die kontinuierliche Rezeption, Schrift verlangt vom Zuseher erhöhte Aufmerksamkeit, eine besondere Wachheit und Geistesgegenwart - er muss nicht nur lesen. »Das komplexe Sehen muß geübt werden«, schreibt Brecht (1991: 59). Die innere lesende

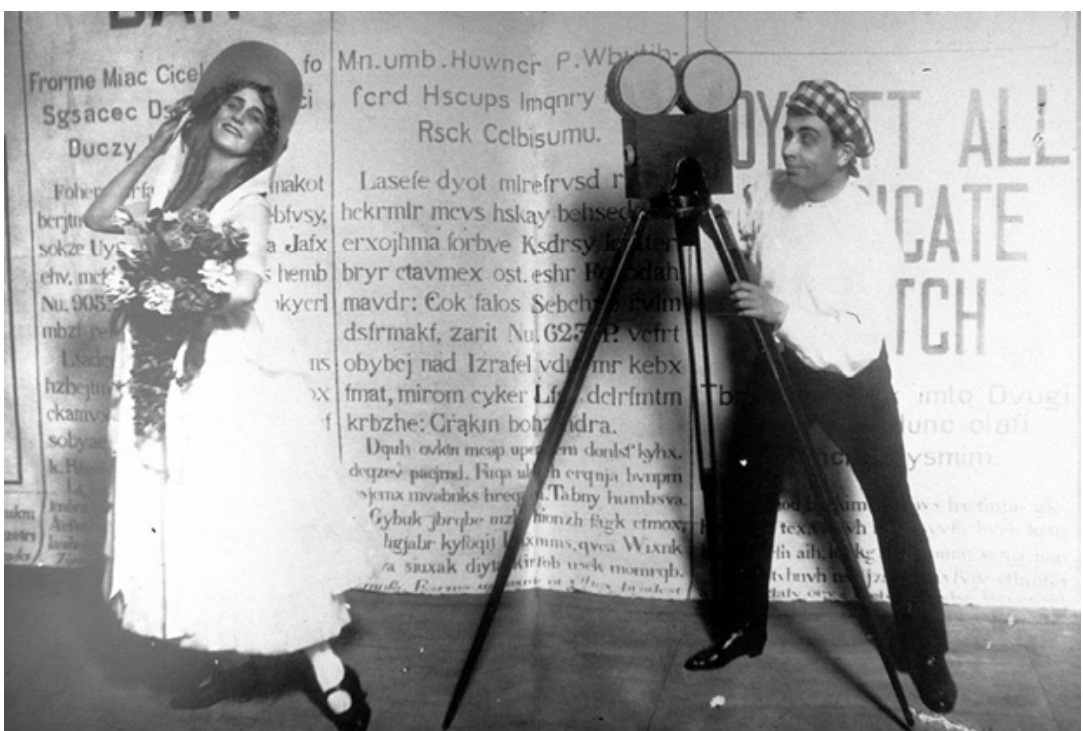

Abbildung 18: Szenenfoto WithIN THE QUOTA, Paris 1923. 
Stimme des Zuschauers überlagert sich dabei mit dem Bühnengeschehen. Es findet eine Aktivierung des Zuschauers statt.

Schon die Schrift auf der Bühne führt zu einer Kollision zweier Darstellungssysteme - obwohl hier die dekorative Präsenz der Lettern bald im Vordergrund steht. Doch wenn in diesem »ballet-ciné-sketch«, wie das Stück bezeichnet wurde, ein Kameramann ständig die Aktion auf der Bühne filmt - oder zu filmen vorgibt -, wird die Illusion des Theaters unterlaufen: es ist deutlich zu sehen, dass es sich um keine funktionstüchtige Kamera handelt, sondern um eine Attrappe, um eine Pappmaché-Kamera, die hier aufgebaut ist als Spielrequisit und als Zeichen, als Modell für Intermedialität. Derart wird der Illusionsraum des Theaters tendenziell in einen kritischen Raum zersetzt (Hansen-Löve 1992: 41), der die mediale Konstruktion selbst ausstellt, auch wenn die Kamera hier eine bloße Attrappe ist.

Der Kameramann ist die charismatische Figur der 1920er Jahre. Vielgestaltig sind die konstruktivistischen Innovationen und Kollisionen. Zuerst erscheint der >kreiselnde Kurbler in Dziga Vertovs KINOPRAVDA NR. 16 aus dem Jahr 1923. Schemenhaft zunächst sich spiegelnd im Glas der Schaufenster eines Modesalons, durch das er die Szene wie die anderen Zuschauer auch betrachtet; dann deutlicher schon im Spiegel hinter den Mannequins die Kurbelbewegung ausführend, im Hintergrund noch, lässt der Kameramann schon Licht darauf fallen, wie die Sache gemacht ist.

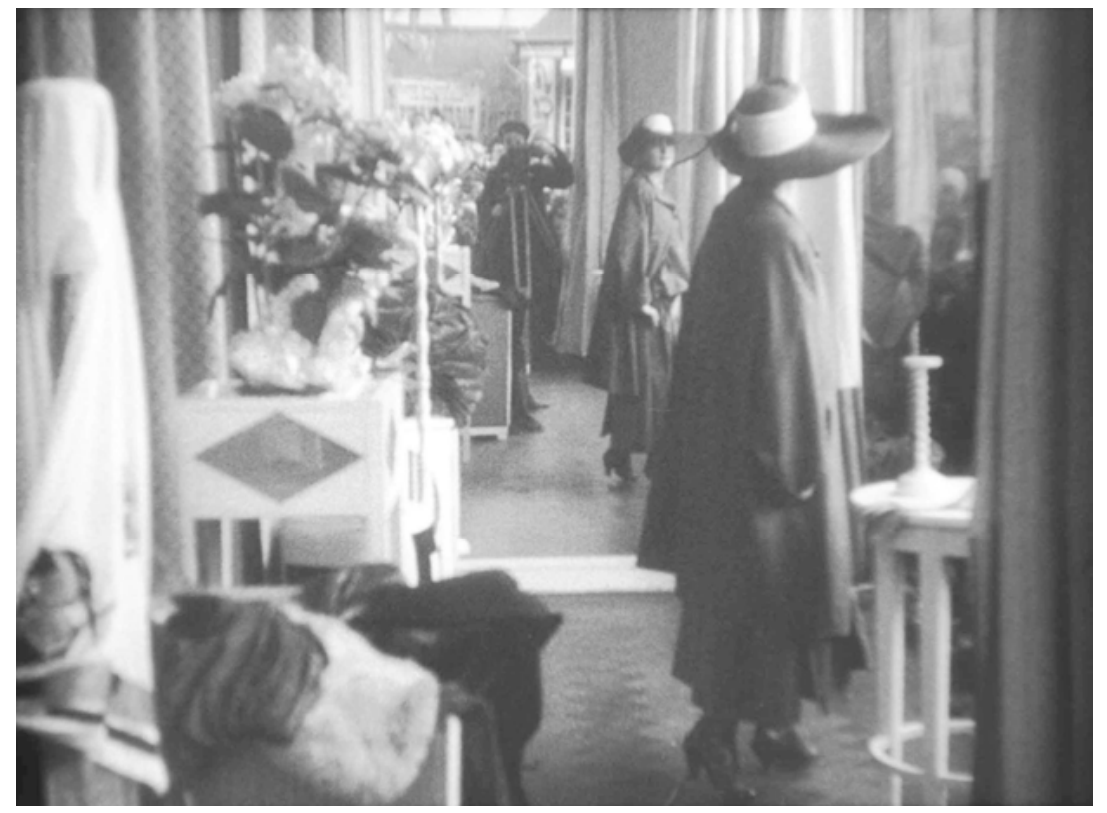

Abbildung 19: Dziga Vertov, KINOPRAVDA NR. 16, 1923.

Eine spielerisch optimierte Synthese von Mensch und Apparatur zeigt uns wenig später das Titelblatt der Wochenzeitschrift Sovietskoe Kino aus dem Jahr 1927. Kombinatorik der Medien, die auch durch ihre Aktualität besticht: heute würde 
man sagen: ein Inline-Skater mit einer Digitalkamera. Der Mann mit der Kamera und den Rollschuhen im Cover von Varvara Stepanova, der Frau von Rodčenko, ist Vertovs Bruder und Kameramann Michail Kaufman.

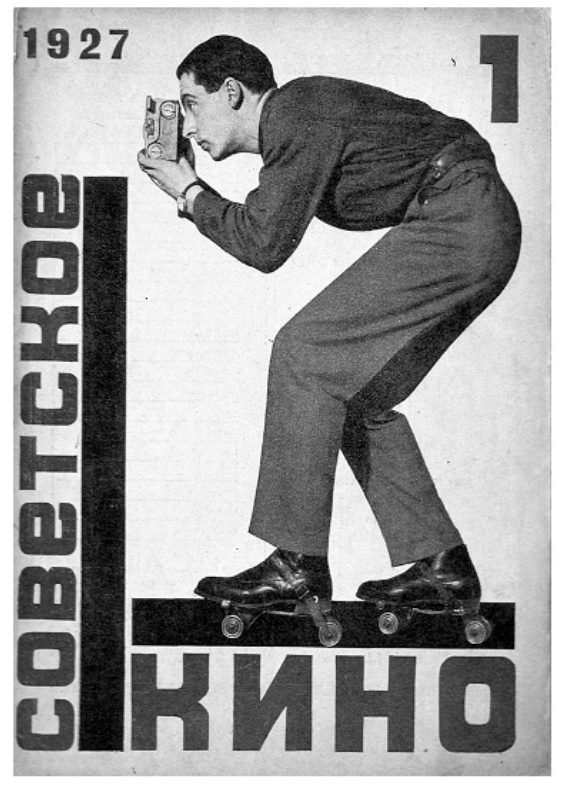

Abbildung 20: Varvara Stepanova,

Umschlag von SOVIETSKOE KINO, 1/1927.

Es ist der Mann mit der Kamera, der sie überallhin mitnimmt, auf alle möglichen Gefährte montiert, auf Motorräder, Züge, Seilbahnen, auf Kräne über reißenden Strömen und natürlich auf Autos. »Ihr habt die Revolution als Schaum in die Stadt ausgegossen, oh ihr Automobile. Die Revolution schaltete den Gang ein und fuhr los« (Schklowskij 1965: 20).
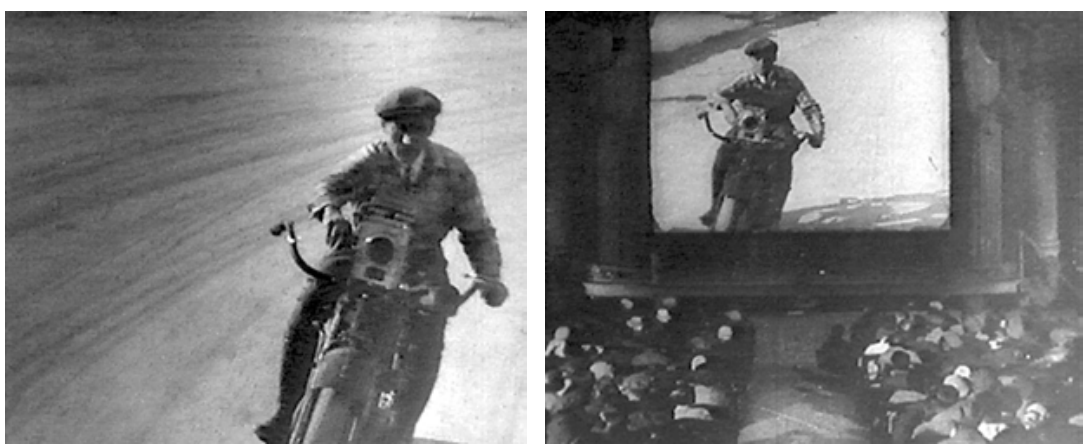

Abbildungen 21 und 22: Dziga Vertov, DER MANN MIT DER KAMERA, 1929. 
Wie sehr die Präsenz der Kamera Medienbewusstsein erzeugen kann, hat uns in jenen Jahren Vertov vor allem in seinem Meisterwerk DER MANN MIT DER KAMERA vorgeführt. Etwa in jener frenetischen Sequenz, in der die Dreharbeiten selbst zu einem Kunststück werden.

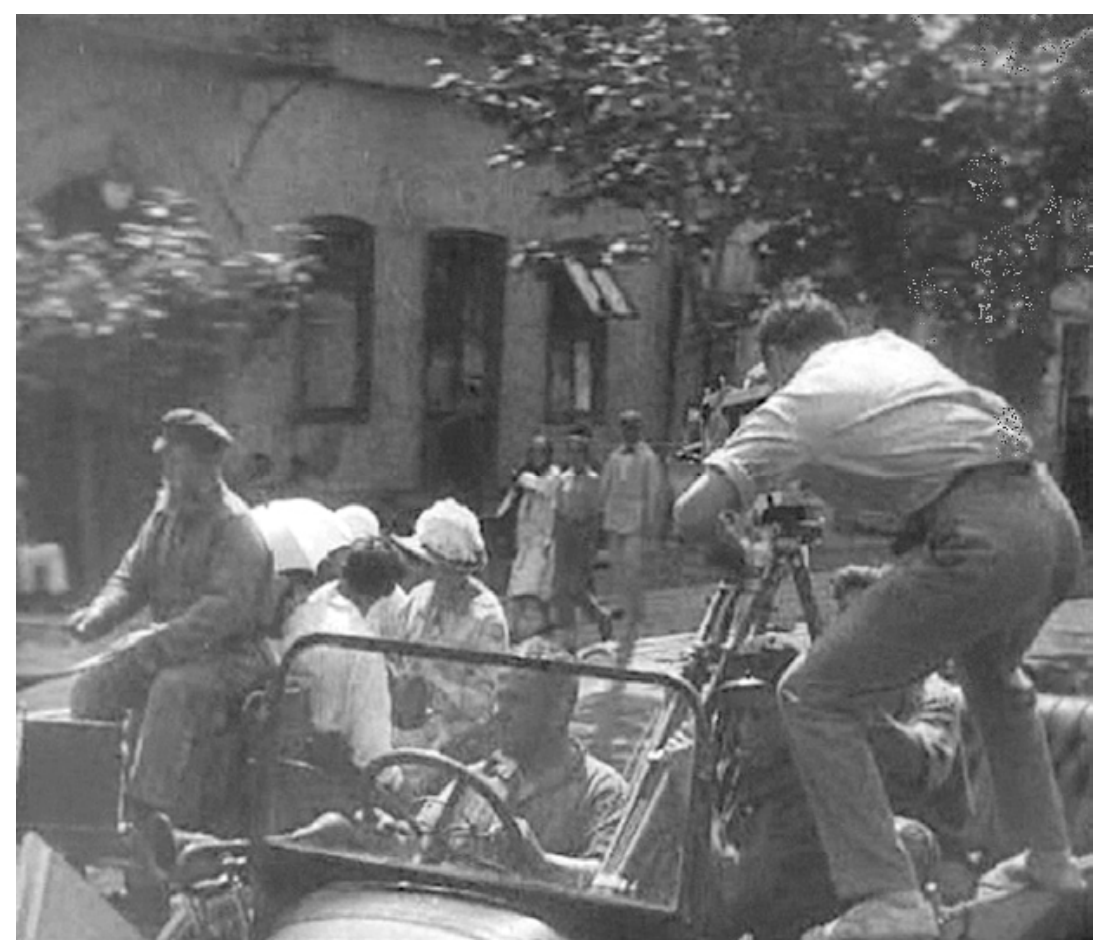

Abbildung 23: Der Kameramann Michail Kaufman

in: Dziga Vertov, DER MANN MIT DER KAMERA, 1929.

Verblüffend ist die Auto- und Kutschenfahrt der Damen des alten und neuen Bürgertums, »nicht so sehr weil sie uns sowohl ihre Fahrt als auch die sie filmende Kamera zeigt, als vielmehr weil sie uns diese aberwitzige Verfolgungsjagd einer zweiten Kamera (die nicht zu sehen ist), die aber die Szene ihrerseits filmt, erahnen lässt « (Comolli: 92). Diese Ahnung erinnert an die Vorstellung, die sich die drei Gefangenen in jenem berühmten Sophisma von Lacan davon machen, was die beiden anderen sich jeweils vorstellen, dass der Dritte zu sehen kriegt - um derart die Freiheit zu erlangen (Lacan: 101-121).

Und selbst im indignierten Nachäffen des Kurbelns, mit dem die beobachtete Bürgersfrau den filmischen Zugriff wenn nicht abwehren, so doch zu bannen versucht, kommt der Herstellungsprozess selbst ins Bild, die Frage: wie ist es gemacht? 


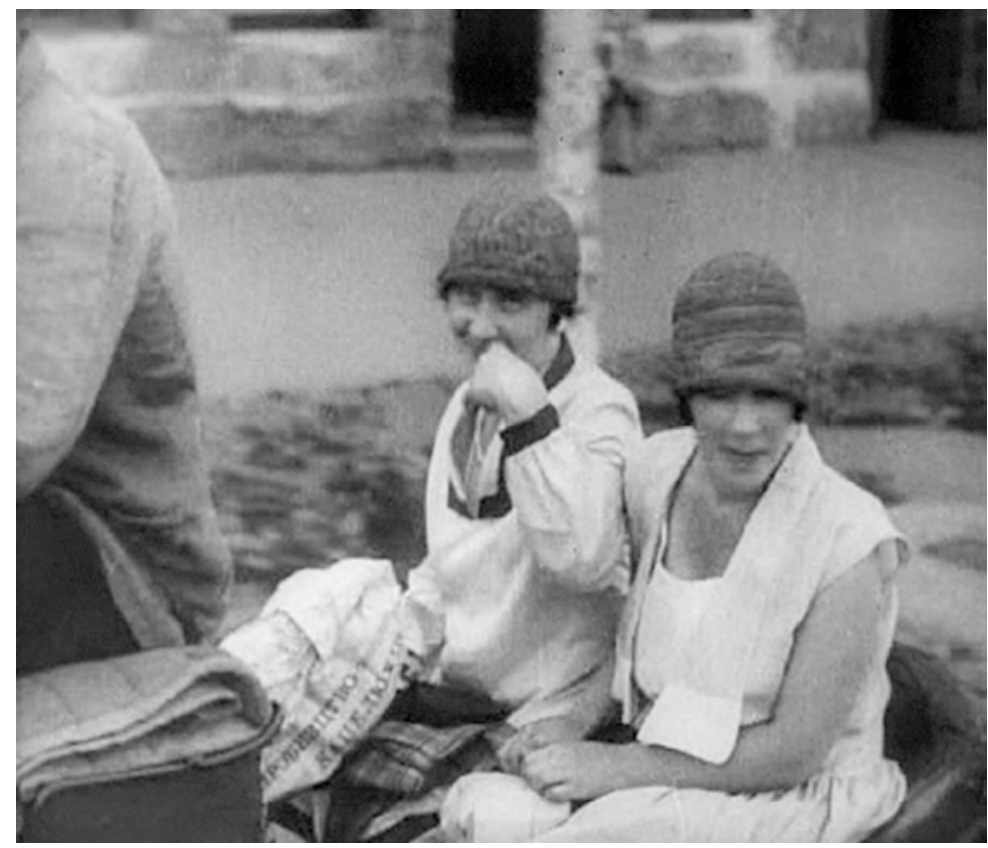

Abbildung 24: Dziga Vertov, DER MANN MIT DER KAMERA, 1929.

Diese Verfahren medialer Reflexion der historischen Avantgarde sind heute gewöhnlich in ihr Gegenteil verkehrt. Mit dem Fernsehen zumal, weit davon entfernt, die Möglichkeiten des Mediums selbst zu erforschen, ist die »epistemologische Euphorie« vom Beginn des 20. Jahrhunderts einer »epistemologische Malaise« an seinem Ende gewichen, wie Annette Michelson sagte. Kein spielerischer Umgang mit dem Medium, keine ästhetische Recherche, keinerlei analytische Schönheit. Erst die heutigen Onliner arbeiten bisweilen an einer semiotischen Kritik, an einer künstlerischen Entwendung der Technik, an einem medialen Halleluja.

\section{Literatur}

Axjonow, Iwan (1997 [1933]): Sergej Eisenstein. Ein Porträt. Berlin: Henschel/arte.

Brecht, Bertolt (1991): Werke. Große kommentierte Berliner und Frankfurter Ausgabe, Bd. 24, Berlin u. Weimar/Frankfurt/M.: Aufbau/Suhrkamp.

Buchloh, Benjamin H. (1984): »From Faktura to Factography«. In: October 30, S. 82-119.

Chlebnikov, Velemir/Aleksej Kručonych (1971): »Das Wort als solches«. In: Velemir Chlebnikov: Werke Bd. 2. Reinbek: Rowohlt.

Comolli, Jean-Louis (2004): »Die Zukunft des Menschen? (Rund um den Mann mit der Kamera)«. In: Der kreiselnde Kurbler. Dziga Vertov zum 100. Geburtstag, Bd. 2, hg. v. Klemens Gruber, mit Aki Beckmann: Maske und Kothurn. Internationale Beiträge zur Theaterwissenschaft, 50. Jg., Heft 1/2004. 
Gaßner, Hubertus/Roland Nachtigäller (Hg.) (1991): Gustav Klucis. Retrospektive, Stuttgart: Hatje.

Gruber, Klemens (2005): »Bastardisierungen und ein >Kollektivbrötler<. Die Lautsprechertribünen von Gustav Klucis und Walter Benjamins Kritik der Apparate durch das epische Theater«. In: Christian Schulte (Hg.): Walter Benjamins Medientheorie. Konstanz: UVK, S. 235-261.

Hansen-Löve, Aage A. (1989): »Faktur, Gemachtheit«. In: Aleksandar Flaker (Hg.): Glossarium der russischen Avantgarde. Graz: Droschl.

Hansen-Löve, Aage A. (1992): »Wörter und/oder Bilder. Probleme der Intermedialität mit Beispielen aus der russischen Avantgarde«. In: Eikon 4.

Jakobson, Roman (1972): »Die neueste russische Poesie. Erster Entwurf. Viktor Chlebnikov« (1919). In: Wolf-Dieter Stempel (Hg.): Texte der russischen Formalisten, Bd. II. München: Fink.

Jakobson, Roman (1976): »Message sur Malévitch « (Aus einem Brief vom 9. Dezember 1975). In: Change, 26/27. Hier in der Übersetzung von Felix Philipp Ingold, in: Individualität, 8. Jg., Nr. 23, Sept. 1989, S. 65.

Jakobson, Roman (1988): »Futurismus« (1919). In: Ders.: Semiotik. Ausgewählte Texte 1919-1982. Frankfurt/M.: Suhrkamp.

Jakobson, Roman/Krysryna Pomorska (1982): Poesie und Grammatik. Dialoge, Frankfurt/M.: Suhrkamp.

Lacan, Jacques (1980): »Die logische Zeit und die Assertion der antizipierten Gewissheit. Ein neues Sphisma«. In: Ders.: Schriften III. Olten und Freiburg: Walter, S. 101-121.

Lodder, Christina (1990): Russian Constructivism. New Haven/London: Yale Univ. Press, 4. Aufl.

Michelson, Annette (1973): »Camera lucida Camera obscura«. In: Artforum, Vol. XI, no. 5, Jan. 1973.

Michelson, Annette (1990): »The Kinetic Icon in the Work of Mourning: Prolegomena to the Analysis of a Textual System «. In: October 52, Spring 1990. Dt. in: Klemens Gruber (Hg.): Verschiedenes über denselben. Dziga Vertov 18961954 (Maske und Kothurn 42). Wien: Böhlau.

Moebius, Hanno (2000): Montage und Collage. München: Fink.

Molderings, Herbert (1996): »Lichtjahre eines Lebens. Das Fotogramm in der Ästhetik Laszlo Moholy-Nagys«. In: Laszlo Moholy-Nagy: Fotogramme 1922-1943. Hg. v. Museum Folkwang Essen, München/Paris/London: Schirmer/Mosel.

Schklowskij, Viktor (1965): Zoo oder Briefe nicht über die Liebe (1922/23). Frankfurt/M.: Suhrkamp.

Schklowski, Viktor (1986): Eisenstein. Romanbiographie. Berlin: Volk und Welt.

Schulte, Christian: »Alles, was Menschen in Bewegung setzt. Dialogische Autorschaft bei Alexander Kluge«. In: Maske und Kothurn 52. Jg. Heft 3, 2006.

Tafuri, Manfredo (1980): La sfera e il labirinto. Avanguardie e architettura da Piranesi agli anni'70. Torino: Einaudi.

Zima, Peter V. (1991): Literarische Ästhetik. Tübingen: Francke. 


\section{Abbildungen/Quellen}

1/3 Kazimir Malevič, SchwarZes QuADRAT 1915/1929.

2/4 Foto: Bernhard Riff.

5 Foto: Bernhard Riff.

6 Aus: Art into Life. Russian Constructivism 1914-1932, Ausst. Kat., Henry Art Gallery, University of Washington, New York: Rizzoli 1990, S. 227.

7 Aus: Denis Bablet (Hg.), Les voies de la création théâtrale. Mises en scène années 20 et 30, Vol. 7, Paris: Centre National de la Recherche Scientifique 1979, S. 18, Abb. 1.

8 Ebda, Abb. 26.

9 Aus: Painters in the Theatre of the European Avant-Garde, Ausst. Kat., Museo National Centro de Arte Reina Sofía, Madrid 2000, S. 279, Abb. 44.

10 Aus: Picon-Vallin, Béatrice, Meyerhold, Coll. Les voies de la création théâtrale no. 17, Paris: Centre National de la Recherche Scientifique 1990, Abb. 41.

11 Aus: C. W. Ceram, Eine Archäologie des Kinos, Reinbek: Rowohlt 1965, S. 170.

12 Aus: Alexandr Rodchenko, Ausst. Kat., hg. v. M. Dabrowski, L. Dickermann, P. Galessi, Museum of Modern Art, New York 1998, Abb. 200.

13 Aus: Gustav Klucis. Retrospektive, hg. v. Hubertus Gaßner/Roland Nachtigäller, Ostfildern: Hatje 1981, Abb. 85.

14 Ebda, Abb. 75.

15 Ebda, Abb. 86.

16 Archiv des Prager Nationalmuseums, Sig. B.c.24.

17 Aus: Nancy Van Norman Baer, Paris Modern. The Swedish Ballet 1920-1925, San Francisco: Fine Arts Museums of San Francisco 1995, S. 121 (Foto: Atelier Sully).

18 Aus: Bengt Häger, Ballets Suedois (The Swedish Ballet), New York: Abrams 1990, S. 216 f.

19 Foto: Bernhard Riff.

20 Aus: Fotografía Pública, Photography in Print 1919-1939, Ausst. Kat., Museo Nacional Centro de Arte Reina Sofía, Madrid 1999, S. 229.

21-24 Dziga Vertov, DER MANN MIT DER KAMERA, 1929. 


\title{
Medium, Theater und Film bei Beckett
}

\author{
FRANZISKA SICK
}

I.

Becketts Umgang mit Theater und Film ist avantgardistische Medienkunst. Unter Medienkunst fasse ich hierbei nicht (oder nicht primär) den Einsatz neuer Medien, sondern Aspekte wie Medienreflexivität und intermediale Strukturanalogien bis hin zur Mediendurchwirktheit von Subjektivität. Es geht deshalb nicht darum, Beckett als Hörspielautor oder Vorläufer der Videokunst vorzustellen, sondern um seine medienreflexiven Theaterstücke aus den frühen 1960er Jahren und um FILM.

Der Avantgardismus Becketts lässt sich mit am genauesten im Kontrast zur Ästhetik des Nouveau Roman bestimmen. Auch die Autoren des Nouveau Roman reflektieren mediale Aspekte von Kunst, doch geht es ihnen dabei primär um die Erneuerung des Romans. Selbst Alain Robbe-Grillet, der sich programmatisch auf den Film bezieht und damit eine vergleichsweise moderne Position vertritt, hebt am Film zuvörderst seine Bildlichkeit hervor und rezipiert ihn damit im Grunde medienkonservativ. Denn einerseits gibt es Bildlichkeit und Beschreibung im Roman bereits vor der Erfindung des Films, und andererseits greift Robbe-Grillet (1963: 19) das eigentliche Novum des Tonfilms, dass bewegte Bilder mit Ton und Sprache unterlegt sind, nicht auf. Nathalie Sarraute weist die Orientierung am Film ganz zurïck. Ihr zufolge ist der Nouveau Roman dialogisch, und sie setzt ihn deshalb in Beziehung zum Theater (1964: 1591). Beide - Robbe-Grillet wie Sarraute - verkürzen in ihrer Apologie des Romans das Referenzmedium, auf das sie sich beziehen: Robbe-Grillet blendet aus dem Film die Bewegung der Bilder und den Dialog aus, Sarraute abstrahiert in ihrer Lesart des Theaters von Gestik und Bühnenbild.

Derlei Abstraktionen finden sich durchaus auch bei Beckett - und dies sogar in größerem Umfang. Sie haben bei ihm eben deshalb jedoch einen anderen Stellenwert. SPIEL OHNE WORTE kommt, wie bereits der Titel annonciert, ohne das aus, was man gängiger Weise von einem Drama erwartet: Worte. Ohne dramatische Wechselrede reduziert sich das Theater auf reine Pantomime. In QUADRAT verzichtet Beckett selbst noch auf den pantomimischen Ausdruck und gestaltet eine Choreographie rein räumlicher Bewegungen. Andererseits schreibt Beckett Stücke, die tendenziell nur aus Sprache bestehen - aus einer rein >dialogischen < Spielsituation wie in SPIEL oder aus einem reinen Monolog wie in NoT I.

Im Grundansatz stellt Beckett damit die frühe technische Medienentwicklung nach. Technikbedingt war diese von Abstraktionen geprägt: Starre Bilder in der Photographie, bewegte, aber stumme Bilder im Film, Sprache ohne Bild im Radio und auf Tonträgern. In unterschiedlicher Weise ist Becketts Theater- und Filmschaffen von diesen Disjunktionen - ohne Worte, ohne Bewegung, mit Bewegung, mit Sprache - durchsetzt, für die er immer neue Spielanordnungen erfindet. Dem technischen Erfindungsreichtum der Medien setzt er einen anderen, primär ästhetisch motivierten entgegen. Im Grundansatz folgt Beckett damit den Surrealisten 
(man denke an Marcel Duchamp, Max Ernst oder Yves Tanguy), die auf den maschinentechnischen Erfindungsreichtum des frühen 20. Jahrhunderts mit der Erfindung abstruser Maschinen antworteten. Beckett überträgt dieses Modell in eine Kommunikations- und Medienästhetik. Seine Modernität besteht mit in diesem Paradigmenwechsel, sein Avantgardismus im Versuch, stets grundlegend neue Spielarten zu erfinden.

Wie sehr Beckett selbst ästhetisch nicht überformte, also bloß technischmediale Beschränkungen als ästhetische Figur wahrnimmt, zeigt seine Vorliebe für den Stumm- gegenüber dem Tonfilm. Technikgeschichtlich läutet der Tonfilm mit der Zusammenführung von Bild- und Tonspur das multimediale Zeitalter ein (Kittler: 254). Beckett verweigert sich dieser Entwicklung. Mit FILM legt er einen Tonfilm vor, der wie ein Stummfilm inszeniert ist. Kein Wort wird in diesem Film gewechselt - mit einer Ausnahme: Als ein Angerempelter aufbrausen will, bringt seine Begleiterin ihn mit einem »Psst « zum Schweigen - den Angerempelten im Film, aber auch den Tonfilm. Trotz dieser Zurückweisung des Tons in FILM hat Beckett sich nicht gescheut, SPIEL, das reiner >Dialog < unter Ausblendung jeglicher Mimik und Gestik ist, zu verfilmen. Beides ist für ihn im Tonfilm erlaubt - der Ton und das bewegte Bild -, nur nicht beides zugleich, zumindest tendenziell.

Medienkunst in Theater und Film ist deshalb bei Beckett nicht primär in einer unmittelbaren Weise zu verstehen, so als würde sie in vollem Umfang die Möglichkeiten eines Mediums ausloten. Vielmehr ist sie als eine Inszenierung unterschiedlicher (quasi) medialer Konstellationen zu bestimmen.

Mediale Basis (in einem engen Sinne des Wortes) solcher Inszenierungen sind Medien, die multimediale Möglichkeiten bieten wie der Film oder das Theater. Dass Beckett sich mit dem Theater eines alten Mediums bedient, tut seinem Avantgardismus keinen Abbruch. Denn entscheidend ist nicht, welches Medium man verwendet, sondern wie medienreflexiv man es einsetzt (Boenisch: 453f). In dem multimedialen Raum, als der sich das Theater zumindest im Rückblick erweist (wie der Tonfilm kann das Theater bewegte, sprechende Körper darstellen), führt Beckett Spielarten medialer Beschränkung vor. Gerade weil das alte Medium vielseitiger ist als die neuen, lässt sich in ihm deren mediale Beschränkung abbilden, aber auch um weitere, erfundene mediale Konstellationen ergänzen.

Nun gehören Beschränkungen wie der Verzicht aufs Wort in Pantomime und Tanztheater zum Grundbestand der Theaterkultur, und es stellt sich deshalb die Frage, ob man die Vielfalt Beckettscher Spielsituationen nicht besser gattungsästhetisch deuten sollte. Um die Frage zu klären, ist wenigstens ansatzweise eine Abgrenzung beider Begriffe (Medium und Gattung) erforderlich: Medien sind Darstellungsräume, die immer auch Darstellungsbeschränkungen beinhalten. So kann ein Radio keine Bilder senden, ein Stummfilm keinen Ton. Gattungen basieren auf Medien und schränken den medialen Darstellungsraum durch Gattungskonventionen zusätzlich ein - in der Pantomime kommt Sprache nicht vor. Unter rein formalen Gesichtspunkten könnte man deshalb die Beckettschen Abstraktionen durchaus auch gattungsästhetisch deuten.

Dennoch besteht ein Unterschied: Man nimmt in einer Ballettaufführung nicht wahr, dass die Tänzer nicht reden, sondern sieht die anderen Ausdrucksformen des Körpers, die durch den Verzicht auf Rede möglich sind. Anders verhält es sich bei Beckett. Die Einschränkung der Spielmöglichkeit erscheint bei ihm wie ein Zwang oder wie eine Grenze, die man nicht überschreiten kann. Das »Psst « in FILM ist auch vor diesem Hintergrund zu deuten. In SPIEL und NOT I sind die Figuren wie zementiert, in QUADRAT umkreisen sie einen Punkt, von dem sie wie von einem 
Magnetfeld angezogen und abgestoßen werden. Becketts Figuren sind wie eingesperrt in eine Spielsituation, der sie nicht entkommen können, und die sie in

ihren Bewegungs- und Äußerungsmöglichkeiten einschränkt. Deshalb erscheinen die Beckettschen Inszenierungen wie Medien.

Ein weiterer Aspekt kommt hinzu. Da bei Beckett die formale Beschränkung der Spielsituation stets reflexiv mit zur Darstellung kommt, können seine Stücke nicht gattungsbildend wirken. Unterlegte man SPIEL einen anderen Text, entstünde kein neues Stück, sondern allenfalls eine Variante des bestehenden.

\section{II.}

In SPIEL stecken drei Figuren in je einer Urne. Ihr Gesicht ist dem Publikum zugewandt. Die Bühne ist dunkel. Die Figuren werden abwechselnd und in schnellem Rhythmus mit einem Spot so angeleuchtet, dass man nur jeweils die angeleuchtete Figur sieht. Wenn eine Figur angeleuchtet wird, fängt sie zu sprechen an, und sie verstummt abrupt, wenn eine andere Figur angeleuchtet wird.

Man hat vielfach darauf hingewiesen, dass der schnelle Lichtwechsel an die Schnitttechnik des Films erinnert. Jedoch lässt sich SPIEL nicht auf solche Oberflächeneffekte und bloße Medienzitate reduzieren. SPIEL definiert einen eigenen intermedialen Raum, in dem Momente der Erzählung, des Films und des Theaters zu einem neuen Darstellungsraum verschmelzen.

Als ein Teil dieser medialen Konfiguration ist die Textform von SPIEL - SPIEL als Lesedrama oder aber auch als Erzählmontage - zu bestimmen. Das Stück besteht aus kurzen Dialogsequenzen. Wenn man diese entgegen der Textanordnung so liest, dass man die Rede einer Figur verfolgt und hierbei jeweils die Reden der beiden anderen überspringt, erhält man drei vergleichsweise kohärente Geschichten. Jede der Figuren stellt ihre Sicht auf das Ehedrama und Dreiecksverhältnis dar, das zwischen den drei Akteuren besteht. Entgegen seinem Titel, der auf das (Schau-)Spiel hindeutet, besteht SPIEL in der textuellen Grundanlage aus drei Erzählungen. Beckett zerschneidet diese Erzählmonologe und überlagert sie zeitlich. Das würde zu einer nicht weiter irritierenden Umsetzung von Erzählperspektiven in das Theatermedium führen, wenn Beckett nicht ein wesentliches Detail äußerst ungewöhnlich gestalten würde: Er verkürzt die einzelnen Erzählausschnitte so stark (sie umfassen zumeist kaum mehr als 1-3 Zeilen), dass sich kein eigenständiger Erzählfokus herausbilden kann. Man kann sich diese mediale Funktionsweise des Stücks in Analogie zum Film vergegenwärtigen. Bekanntlich basiert der Film darauf, dass das menschliche Auge ab etwa 16 Bilder pro Sekunde diese nicht mehr als einzelne Bilder wahrnehmen kann. Da Filme gewöhnlich mit 24/25 Bildern pro Sekunde produziert und abgespielt werden, nehmen wir die Einzelbilder nur als Bewegungsfluss wahr. Würde man einen Film langsamer abspielen, würden die Bilder ruckeln. Beckett überträgt diesen Effekt in eine andere mediale Konstellation: So wie ein Film, der mit der falschen Geschwindigkeit abgespielt wird, ruckelt, so ruckelt in SPIEL die erzählerische Fokalisation (zum Begriff der Fokalisation: Genette: 48-52). Das Stück ist in dieser Hinsicht auch als Travestie des Films anzusehen.

Wie sehr SPIEL an Filmästhetik angelehnt ist, zeigt sich nicht zuletzt an seiner räumlichen Anordnung. So wie im Kino eine Lichtquelle, die sich im Rücken der Zuschauer befindet, ein Geschehen projiziert, so in der Grundkonstellation auch bei Beckett. Als mediale Anordnungen sind auch solche Lichtverteilungen zu verste- 
hen, denn sie erschaffen - unabhängig von den architektonischen Gegebenheiten, die weitgehend stabil bleiben - allererst den (Theater-)Raum und damit das, worin etwas erscheinen kann, also das Medium (vgl. Sick: 47f). Ich kann an dieser Stelle die mediale Relevanz des Lichts im Theaterraum nur stichwortartig skizzieren: Das Sprechtheater im 17. Jahrhundert ist dadurch geprägt, dass die Schauspieler an die mit Kerzen beleuchtete Rampe vortreten müssen, um besser sichtbar zu sein. Das Licht fixiert sie an die Rampe und lässt ein Spiel in der Tiefe des Bühnenraums nicht zu. Noch die so genannte vierte Wand ist entgegen der architektonischen Metapher nichts weiter als ein Beleuchtungseffekt: Man dunkelt den Zuschauerraum ab und markiert damit, dass die Welt auf der Bühne eine eigene ist. Mit dem Kino entsteht eine weitere Beleuchtungsarchitektur und mit ihr ein neuer Fiktionsraum. Ohne dass sich der Aufführungsraum grundlegend verändert, besitzt die »Bühne« im Kino nurmehr den Stellenwert einer Projektionsfläche. Das zeigt sich am genauesten dort, wo sich im Kino atavistischer Weise ein Vorhang öffnet. Denn anders als im Theater gibt der Vorhang im Kino den Blick nicht auf eine andere Welt (den Bühnenraum), sondern nur auf eine weiße Wand frei.

Becketts SPIEL übernimmt vom Kino den Projektor und von der Bühne den Fiktionsraum. In dieser intermedialen Kombination entsteht gegenüber den beiden Ausgangsmedien ein neuer Aufführungsraum, der einigermaßen genau die Schwebe zwischen (Licht-)Projektion und (materieller) Aufführung einhält. Dennoch ist SPIEL immer noch Theater, wenn auch in Schrumpfform. In der intermedialen Konfrontation von Kino und Theater zeigt sich in nachgerade medienanalytischer Weise der irreduzible Rest, der das Theater vom Kino unterscheidet: Theater findet dort statt, wo Menschen sich auf einer Bühne befinden. Der Umstand, dass die Akteure von SPIEL in Urnen stecken, unterstreicht dies. Es geht mehr um die Existenz der Figur als um ihre lebendige Gestik.

So formal diese Spielanordnung ist, so groß ist doch zugleich ihre semantische Wertigkeit. Das lässt sich anhand eines Gedankenexperiments zeigen. Da SPIEL weitgehend auf Lichtprojektionen basiert, könnte man die Schauspieler auf der Bühne durchaus auch durch gefilmte Schauspieler ersetzen. Innerhalb der Aufführung wäre diese Manipulation kaum wahrnehmbar. Dennoch würde eine solche Aufführung das Stück entscheidend verändern: Die filmische Projektion würde das Bild von Figuren zeigen, die sprechen. SPIEL zeigt demgegenüber Figuren, die sprechen, wenn sie angeleuchtet werden. Obwohl das Erscheinungsbild sich für den Zuschauer nicht verändert, nehmen wir beide Situationen unterschiedlich wahr. Entgegen der Fiktion von der vierten Wand verstehen wir, zumindest in einem solchen Grenzfall, das Geschehen auf der Bühne immer auch von seinem Aufführungsrahmen her. Man hat im 20. Jahrhundert die vierte Wand durch vergleichsweise grobschlächtige Aktionen wie die PUBLIKUMSBESCHIMPFUNG einzureißen versucht - Beckett dekonstruiert sie ungleich subtiler: durch intermediale Reflexion.

Wenn eine Figur angeleuchtet wird, spricht sie. Das Licht in Becketts SPIEL ist wie ein Befehl: »Du stehst im (Rampen-)Licht, sprich!« Man kann sich unterschiedliche Szenarien vorstellen, die diese Grundsituation verbildlichen: einen Erzähler, der die Figuren zum Sprechen bringt, oder - an den Befehlscharakter des Lichts anschließend - eine Verhörsituation mit einer Lampe. Indessen sind dies Hilfsvorstellungen, die der Abstraktheit von SPIEL nicht gerecht werden. Der einzige Inhalt, der in diesem Stück gesetzt ist, besagt, dass das Licht befiehlt. Dies allerdings äußerst präzise. Das zeigt kontrastiv die Verfilmung des Stücks, in der, anders als im Bühnenstück, der Sprecherwechsel nicht als harter Schnitt gesetzt ist. 
In der Verfilmung von SPIEL schwankt die Kamera, wenn sie einen neuen Sprecher fokussiert, so als müsste sie ihn erst suchend umkreisen, um erst nach einiger Zeit zu einer ruhigen Bildeinstellung zu gelangen. Während das Licht befiehlt, sucht die Kamera. Man sieht an dieser Stelle, in wie präziser Weise Beckett Medien mit menschlichen Verhaltensweisen in Verbindung bringt.

Dass in SPIEL die Aufführung oder das Medium selbst zur Aufführung kommt, lässt sich theaterästhetisch einigermaßen genau anhand einer weiteren Auffälligkeit von SPIEL belegen. Typischer Weise entspringt die Handlung auf dem Theater der Wechselrede. Ein Wort gibt das andere oder fordert zumindest zur Antwort und Stellungnahme auf. Dem Vorhang kommt dabei lediglich eine rahmende Funktion zu. Er öffnet den Sprechraum und schließt ihn, aber er greift nicht in den Dialograum ein. Becketts SPIEL besitzt eine gänzlich andere Grundgeometrie. In SPIEL entspringt der Wechsel der Rede nicht länger einem dramatisch fundierten Redewechsel, sondern einem Beleuchtungswechsel. Während im Falle des traditionellen dramatischen Redewechsels es dem Gegenspieler zufällt, seinem Kontrahenten das Wort abzuschneiden, verlegt Beckett diese urdramatische Konstellation auf die Ebene der Inszenierung. Obwohl das Licht reines Medium ist, ist es die eigentliche dramatis personae des Stückes. Das Medien-Drama von SPIEL findet, wenn nicht hinter der Bühne, so doch im Rücken der Zuschauer statt.

\section{III.}

Wir haben gesehen, dass bei Beckett Medien wie das Licht oder die Kamera Aktcharakter besitzen. FILM setzt diese mediale Semantik fort - und verschärft sie zugleich. Während in der Verfilmung von SPIEL die Kamera nur beim Schnittwechsel in einer suchenden Bewegung ihren Gegenstand fokussiert, nimmt sie in FILM buchstäblich eine Verfolgungsjagd auf.

FILM setzt ein mit einer Kamera, die eine Mauer abtastet. Bald findet sie ihr gesuchtes Objekt: einen Mann in Rückenansicht. Nach einer Verfolgungsjagd durch die Straßen flüchtet der Mann in ein Zimmer und entfernt in ihm alles, was Augen hat: einen Hund, eine Katze, weitere Okulare verhängt er. Trotzdem ist in dem Zimmer noch eine Sehinstanz verblieben: die der Kamera. Die Schlusseinstellungen machen deutlich, dass dieser verbleibende Rest das Ich selbst ist, nicht als Betrachtetes, sondern als sich Betrachtendes. Das Ich war also in letzter Instanz vor seiner Selbstwahrnehmung auf der Flucht. Eine philosophische Vorbemerkung zu dem Drehbuch, die George Berkeley zitiert und auf René Descartes anspielt, unterstreicht diese Lesart (Beckett 1965: 339): »Die Suche nach dem Nicht-Sein durch Flucht vor der Wahrnehmung anderer scheitert an der Unausbleiblichkeit der Selbstwahrnehmung.«Andererseits entwertet Beckett seine Vorüberlegungen mit dem Hinweis, sie seien bloß als Regieanweisung zu lesen.

Dass FILM trotz dieses philosophischen Gehalts primär medienreflexiv zu verstehen ist, zeigt nachgerade programmatisch der Titel: FILM ist nicht ein Film, sondern der Film, es gibt keinen anderen. Denn FILM zeigt, was Film ist: eine so suchende wie zugleich bewegliche Kamera. Als medienreflexiv ist ferner $\mathrm{zu}$ werten, dass in FILM die Kamera nicht nur etwas zeigt, sondern selbst als Akteur auftritt. Darüber hinaus fällt auf, dass FILM in Anlehnung an den Stummfilm eine Vielzahl clownesker Szenen enthält. Es stellt sich deshalb die Frage, ob FILM philosophisch und ernst (Breuer 1995) oder medienästhetisch und heiter zu interpretieren ist. Gegen eine rein philosophische Ausdeutung von FILM ist einzuwen- 
den, dass die Selbstdeutung des Subjekts immer schon mediengebunden ist. Bereits die Metapher der Reflexion im Begriff der Selbstreflexion deutet darauf hin: Sie ist am Spiegel, also an einem Medium, abgelesen.

Der Glaube an eine adäquate Selbstwahrnehmung löst sich wohl mit am radikalsten mit der Photographie auf. Als die Kamera beweglich wurde, verfielen Photographen auf die Idee, am eigenen Körper herunter zu photographieren. Mit dem dritten, beweglichen Auge der Kamera lässt sich zeigen, was in der alltäglichen Selbstwahrnehmung tatsächlich zu sehen ist: ein fragmentarischer Körper.

Auf den imaginären Charakter der Ich-Bildung hat schon früh Melanie Klein (57-72) hingewiesen - ihre Theorie vom zerstückelten Körper erinnert an die Selbstbilder der frühen Photographen. Später dekonstruiert Jacques Lacan (89-97) mit Verweis auf den imaginären Charakter des Spiegelbildes Kants transzendentale Einheit der Apperzeption. So hat, wenn auch auf Umwegen, die bewegliche Kamera das Vertrauen in die Selbstreflexion erschüttert und abgelöst. Wir können Selbstreflexion nicht länger nach dem Modell des Spiegels, sondern nur noch nach dem Modell der Kamera denken, also als vergebliches Unterfangen.

Genau dieses Modell einer primär technikinduzierten Selbstwahrnehmung und -reflexion führt Beckett in FILM vor. Er greift die Selbstbilder der beweglichen Kamera auf und adaptiert sie an den Film. Und so wird aus den torsohaften Körperbildern, die bewegliche Photoapparate liefern können, das Drama einer Flucht vor sich, das die Filmkamera abbilden kann.

$\mathrm{Zu}$ fragen ist also nicht, ob FILM das Subjekt oder das Medium der beweglichen Kamera darstellt (Schwab 1996), denn beides lässt sich kaum voneinander trennen. Und ebenso wenig ist zu fragen, ob die vorgestellte Auffassung vom Subjekt wahr ist. Sie ist nichts weiter als eine mediale Spielanordnung, vor deren Hintergrund wir uns selbst verstehen. Beckett reflektiert diese Bezüge im Titel FILM, der auf das Medium verweist, und in der Regieanweisung, die die Wahrheit zugunsten der Inszenierung kassiert.

\section{IV.}

So wie FILM ein Selbstverhältnis medial abbildet und zugleich dissoziiert, so auch DAS LETZTE BAND. Das Stück handelt von einem alten Mann, der seine Lebenserinnerungen auf Tonband gesprochen hat. Bevor er weitere Erinnerungen und Selbsteinschätzungen aufnimmt, hört er das Band ab. Er spult dabei das Tonband häufig vor und zurück. Hieraus entsteht folgende verschachtelte Situation: Wir hören vom Tonband den jungen Krapp, wir hören vom Tonband Krapp als Mann mittleren Alters, der über sich als jungen Mann, aber auch über seine gegenwärtige Situation spricht. Und wir hören und sehen auf der Bühne den alten Krapp, der das Band abhört und die Ansichten des jungen und des in die Jahre gekommenen Krapp gestisch, aber auch verbal kommentiert.

In DAS LETZTE BAND zerlegt Beckett das Gedächtnis in nachgerade analytischer Weise in seine Teilfunktionen: Die aktive Funktion der Erinnerung und die passive Funktion der Speicherung treten auseinander und differenzieren sich weiter - in ein System von Registern, Schachteln und Spulen hier und in ein Hervorkramen, Tonband-Einfädeln, Vor- und Zurückspulen dort.

So wie sich in FILM das Subjekt in eine technische Repräsentanz und in einen Subjektrest spaltet, so auch in DAS LETZTE BAND. Obwohl die Aktivitätspotentiale unterschiedlich besetzt sind - in FILM verfolgt die Kamera das leibhaftige Ich, in 
DAS LETZTE BAND kramt das leibhaftige Ich in den medialen Sedimenten des auf Band aufgezeichneten Ich -, ist beiden Konstellationen eine gemeinsame Grundfigur eigen: So sehr Medien den Zugang zu sich allererst eröffnen und objektivieren, so sehr dissoziieren sie das Ich und entfremden es damit von sich. Erst unter dem Auge der Kamera wird deutlich, dass man sich nicht reflexiv selbst wahrnehmen kann, erst unter den Bedingungen des Tonbands zeigt sich in voller, da medialer Schärfe, dass man die eigenen Erinnerungen nicht wahrhaben will. Krapp beschimpft sein eigenes vergangenes Ich und schneidet, das Tonband vor- und zurückspulend, dem jungen Krapp wiederholt das Wort ab.

Indem Beckett einen Aspekt des Subjekts - Selbstwahrnehmung bzw. Erinnerung - analytisch herausgreift und in Medium (Kamera bzw. Tonband) und Subjekt aufspaltet, wird so etwas wie das Drama des Subjekts darstellbar. Ein solches Subjekt-Drama ist erst dort möglich, wo das Subjekt Teilfunktionen von Subjektivität in Medien objektiviert. Nur so kann es auf der Bühne (oder auch im Film) einen geeigneten Widerpart finden und sich in veräußerlichter Weise selbst begegnen. Nur unter dieser Voraussetzung auch kann man auf den Gegenspieler auf der Bühne verzichten und entgegen der Gattungskonvention ein rein monologisches Drama schreiben.

Wie SPIEL lässt sich DAS LETZTE BAND als Inszenierung einer Erzählmontage deuten: So wie in SPIEL die Fokalisation der drei Protagonisten durch das Licht erfolgt, so setzen sich in DAS LETZTE BAND die Erinnerungen des alten Krapp aus Tonbandaufzeichnungen zusammen. Da sich Krapps Erinnerungen vielfältig überlagern, ist ein Vergleich mit Prousts Roman A LA RECHERCHE DU TEMPS PERDU naheliegend (Lommel: 260-264). Was die Aufschreibesituation anbelangt, liegt der Vergleich mit dem Tagebuch jedoch näher. Denn wie ein Tagebuchschreiber zeichnet Krapp zeitnahe Erinnerungen auf. DAS LETZTE BAND ist gleichwohl keinem dieser beiden Bezugsgrößen (Erinnerungsroman und Tagebuch) eindeutig zuzuordnen, da es deren Grunddisjunktion unterläuft. Diese besteht in einer einigermaßen eigenartigen Aufgabenverteilung von deutender Erinnerung und Archivierung der Erinnerung. Während Prousts Ich-Erzähler sein Leben nachträglich zu erinnern und zu deuten versucht, ohne Tagebuch zu führen, hält der Tagebuchschreiber seine Erinnerungen zeitnah fest, ohne sie in einem umfassenden, lebensübergreifenden Sinne zu deuten. DAS LETZTE BAND hebt genau diese Disjunktion auf: Krapp versucht eine Gesamtdeutung seines Lebens auf der Basis aufgezeichneter früherer Erinnerungen. Ironischer Weise misslingt dies, weil frühere Lebensentwürfe mit den aktuellen konfligieren.

Eine vergleichbare Konstellation findet sich in Michel Butors Tagebuchroman L'EMPLOI DU TEMPS, der annähernd zeitgleich mit DAS LETZTE BAND erschienen ist. Butors Tagebuch schreibender Protagonist versucht, mit Hilfe seiner Aufzeichnungen einen Kriminalfall zu lösen. Entgegen der Gattungskonvention des Tagebuchromans und durchaus wie Krapp unterzieht Butors Protagonist seine alten Aufzeichnungen einer wiederholten Relektüre und kommentiert diese. Die Selbstbegegnung mit dem vergangenen Ich ist also nicht primär mediengebunden. Ebenso sehr aber gilt, dass die Möglichkeiten der alten Medien erst nach der Erfindung neuer Medien vollständig ausschöpfbar sind. Erst wenn auf dem Tonband die eigene, vergangene Stimme zu hören ist, verfällt man in der Literatur auf die Idee, einen Tagebuchroman zu schreiben, der von der Vergegenwärtigung des Geschriebenen durch wiederholte Lektüre handelt.

Man kann es auch so ausdrücken: Vor dem Hintergrund neuer medialer Spielmöglichkeiten verlieren die konventionellen Gattungsgrenzen ihre selbstverständ- 
liche Gültigkeit. In SPIEL und DAS LETZTE BAND stellen medieninduzierte Erzählanordnungen die Basis dar (SPIEL beschleunigt den Wechsel der Fokalisation vor dem Hintergrund filmischer Schnitttechnik bereits in der textuellen Anordnung, Krapp kommentiert sein altes Ich). Gleichsam in einem zweiten Schritt überträgt Beckett diese modifizierten Erzählmodelle auf das Theater, um sie dann in einem dritten Schritt mit modernen Medien wie fortgeschrittener Beleuchtungstechnik und Tonband umzusetzen. So verschränkt sind die intermedialen Transformationen zwischen Erzählung und Medium, Erzählung und Theater und dem Einsatz neuer Medien auf dem Theater bei Beckett.

Anders als der große Schweiger Beckett haben die Autoren des Nouveau Roman ihre poetische Praxis vielfach reflektiert. Butors L'EMPLOI DU TEMPS ist strukturgleich mit Becketts DAS LETZTE BAND. Und so stellt sich die Frage, ob man Becketts ästhetisches Verfahren vom Theorieansatz Butors her verstehen kann. Die Antwort auf diese Frage findet sich in einem kleinen Aufsatz, in dem Butor (1964) die alten Medien gegenüber den neuen zu verteidigen sucht, indem er diesen nachrechnet, dass sie so antiquiert sind wie die Buchkultur in ihren Anfängen. Denn so wie Filme und Tonbänder aufgewickelt sind, so waren auch Bücher anfänglich aufgerollt. Über den Fortschritt der Medien mag man sich streiten. Butor stellt meines Erachtens eine grundsätzlichere Frage: Mediale Konstellationen sind zuvörderst von Anordnungsbeziehungen her zu klären, und zu Teilen eröffnen die Anordnungsbeziehungen der technischen neuen Medien allererst den Blick auf die konventionellen und gattungsmäßigen Beschränkungen der alten.

Ich habe Beckett eingangs aufgrund der Analytik seiner Spielsituationen in etwas metaphorischer Weise als Medienkünstler bezeichnet. An dieser Stelle schließt sich die Argumentation: Wenn man bei Beckett >konkrete< Medien zu analysieren versucht, stellt man fest, dass deren Medialität nicht nur in ihrer medialen Dinglichkeit, sondern ebenso sehr in Spielstrukturen und Anordnungsbeziehungen besteht. NOT I gibt zu hören und zeigt eine Stimme: einen sprechenden und beleuchteten Mund und einen Zuhörer. Kein Medium im strengen Sinne des Wortes befindet sich auf der Bühne - und dennoch ist das Stück von derselben Dekomposition des Subjekts geprägt wie DAS LETZTE BAND, an das es in Abwandlungen erinnert, denn auch hier haben wir es mit einem Sprecher und einem Zuhörer zu tun.

\section{Literatur}

Beckett, Samuel (1963): »Spiel«. In: Samuel Beckett (1967): Stücke, S. 311-328.

Beckett, Samuel (1965): »Film«. In: Samuel Beckett (1967): Stücke, S. 337-355.

Beckett, Samuel (1967): Stücke. Kleine Prosa. Auswahl in einem Band. Deutsch von Erika und Elmar Tophoven. Frankfurt/M.: Suhrkamp.

Beckett, Samuel (1973): Not I. London: Faber \& Faber.

Beckett, Samuel (1974): Das letzte Band (1959). Dreisprachig mit Szenenphotos. Frankfurt/M.: Suhrkamp.

Boenisch, Peter M. (2003): »Theater als Medium der Moderne? Zum Verhältnis von Medientechnologie und Bühne im 20. Jahrhundert«. In: Christopher Balme/Erika Fischer-Lichte/Stephan Grätzel (Hg.): Theater als Paradigma der Moderne? Positionen zwischen historischer Avantgarde und Medienzeitalter. Tübingen und Basel: Francke, S. 447-456.

Breuer, Rolf (1995): »Beckett's Film. Philosophical and Poetological Implications«. Germanisch-romanische Monatsschrift, 45, S. 463-467. 
Butor, Michel (1956): L'emploi du temps. Paris: Minuit.

Butor, Michel (1964): »Le livre comme objet«. In: Michel Butor: Essais sur le roman. Paris: Gallimard, S. 130-157.

Genette, Gérard (1983): Nouveau discours du récit. Paris: Seuil.

Kittler, Friedrich (1986): Grammophon Film Typewriter. Berlin: Brinkmann \& Bose.

Klein, Melanie (1930): »Die Bedeutung der Symbolbildung für die Ich-Entwicklung «. In: Internationale Zeitschrift für Psychoanalyse, 16, S. 57-72.

Lacan, Jacques (1949): »Le stade du miroir comme formateur de la fonction du Je«. In: Jacques Lacan (1966): Ecrits I. Paris: Seuil, S. 89-97.

Lommel, Michael (2004): »Synästhesie der Erinnerung: Becketts Krapp's Last Tape«. In: Franziska Sick/Beate Ochsner (Hg.): Medium und Gedächtnis. Von der Überbietung der Grenze(n). Frankfurt/M.: Peter Lang, S. 255-264.

Robbe-Grillet, Alain (1963): Pour un nouveau roman. Paris: Minuit.

Sarraute, Nathalie (1964): »L'Ere du soupçon«. In: Nathalie Sarraute (1996): Euvres complètes. Paris: Gallimard, S. 1551-1620.

Schwab, Martin (1996): Unsichtbares - Sichtbar gemacht. Zu Samuel Becketts $>$ Film<. München: Fink.

Sick, Franziska (2004): »Yvan Golls surreales Filmtheater«. In: Michael Lommel/Isabel Maurer Queipo/Nanette Rißler-Pipka/Volker Roloff (Hg.): Französische Theaterfilme - zwischen Surrealismus und Existentialismus. Bielefeld: transcript, S. 39-64. 



\title{
BILDER, DIE DAS AUGE BERÜHRT - ZUM VERHÄLTNIS VON FILM UND KÖRPERKUNST BEI MATTHEW BARNEY
}

\author{
JÖRG VON BRINCKEN
}

\section{Zur Liaison von Film und Performance}

Der US-amerikanische Künstler Matthew Barney hat in den letzten Jahren mit seinen großangelegten Filmzyklen THE CREMASTER CyCle und DRAWING RESTRAINT für Aufsehen gesorgt. Die Bewertung Barneys als reiner >Filmmaker $<$ ist jedoch problematisch, insofern er als eigentliche Quelle seiner Kunst die körperbasierte Performancekunst angibt, aus der er ursprünglich herkommt. Zwar scheint er damit paradigmatisch für eine aktuelle Tendenz innerhalb der performance art $\mathrm{zu}$ stehen, die, indem sie sich in reproduzierbaren filmischen tentatives ergeht, das ursprüngliche Unmittelbarkeits- und Unwiederholbarkeits-Versprechen der Kunstform geradewegs zu hintergehen scheint (Fischer-Lichte: 116).

Mit ihrer paradoxen Insistenz auf der Physis wirft Barneys Kunst jedoch vielmehr die Frage nach einer keineswegs selbstverständlichen Beziehung von Film, Körper-Performance und damit auch nach einer irreduziblen korporellen Präsenzdimension nicht des Films, sondern des Filmerlebens auf. Film erweist sich damit nicht mehr als bloßes Leinwandgeschehen, sondern als Teil einer distribuierten ästhetischen Erfahrung, die sich prinzipiell über die engeren Grenzen des Mediums und des Artefakts hinaus erhebt.

Für die Diskussion seiner besonderen Perspektive auf Film und Körperlichkeit muss zunächst die intime Liaison der Barneyschen Ästhetik zum Bereich des Sports in Betracht gezogen werden. Im Versuch, den Prozess des Muskelaufbaus nämlich: aus Widerstand Form zu schaffen - auf die Kunst zu übertragen, rückt der ehemalige Profisportler Barney ästhetische Gestaltung in engste Nähe zu physischer Verausgabung (Spector: 4), freilich um den Preis einer Destabilisierung der Grenze nach beiden Seiten hin: Verliert Kunst ihre virtuelle Demarkationslinie, so geriert sich der biologische Körper scheinbar mehr als modellhaft-metaphorische Bezugsgröße denn als sich selbst problemlos (re)präsentierendes Faktum.

Entsprechend wendet sich Barney bereits in den frühen Live-Performances, die über Bildschirme nach außen übertragen wurden, kritisch der Frage zu, inwieweit >live body action< Mediatisierung und Teilhabe überhaupt zulässt. Das eigentliche Modell seiner Kunst ist denn auch weniger der Sport generell als vielmehr der $>$ workout $<$. Jenes, in der Einsamkeit des Bodybuilders zu seinem Extrem kommende Prinzip hypertropher physischer Veränderung, bei dem Verlauf und sichtbares Ergebnis strikt auseinander zu halten sind: Die einwirkenden Kräfte sowie die Prozesse im Inneren des Leibes bleiben - infolge des Fehlens eines Wahrnehmungsorgans für Vorgänge auf zellulärer und molekularer Ebene - nicht nur dem Zuschauer, sondern sogar dem Trainierenden unerschließbar. 
Die radikale Beschränkung von Körper-Wahrnehmung macht es aus Barneys Sicht notwendig, den Körper jenseits seiner organisch-funktionalen Schichtungen und vor aller geschlechtlichen Ausdifferenzierung (Spector: 5f) als hermetisches Kontinuum von formenden Kräften aufzufassen, deren Wirkung sich der unmittelbaren Live-Figuration entziehen und die sich zu einer medialen Auffassung des Körpers diametral verhalten. Damit ist scheinbar eine doppelte Absage formuliert. Zum einen an eine anthropozentrische Auffassung des Films, die sich ohne weitere Problematisierung an dessen Körperaffinität festmacht (Stiglegger: 108ff). Zum anderen aber an die nach wie vor von Klischees der Unmittelbarkeit - sei es affirmativ oder in kritischer Absetzung davon - durchsetzte Körper-Kunst und ihre Theorie.

In der Tat bewegt sich Barneys Ästhetik damit trotz ihrer viel gescholtenen narzisstischen Selbstbezüglichkeit zwischen zwei nach außen gewendeten Gesten: einer der Affirmation an eine Form unentdeckter Körperlichkeit, die sich im Prozess stets aufs Neue ergibt und dem Filmerleben als fluktuierende Affizierungsmacht eingeschrieben ist; und einer der Kritik an den herkömmlichen Vehikeln von Teilhabe: Das betrifft gleichermaßen das >natürliche< Körperempfinden, die Vorstellung mehr oder weniger >authentischer< Kopräsenz innerhalb der Performance, sowie die industrialisierte Vergesellschaftung von Aufmerksamkeit auf den Körper, sprich: diejenigen medialen Formate, die sich anschicken, die Grenzen zwischen Mediatisierung und Liveness in Form sensomotorischer Analogiebildung aufzuheben. Dazu zählen neben den Broadcasts von Sportveranstaltungen, Liveshows und Berichterstattungen auch diejenigen - von Barney als >Wirtskörper $<$ seiner filmischen Narratio verwendeten - Filmgenres, die die zeitlich-räumliche Asymmetrie durch eine besondere Exponierung materiell-leiblicher Elemente wettzumachen versuchen: der Horrorfilm in seiner Splatter- und Gorevariante, die Slapstickcomedy sowie der Pornofilm. Sie alle zielen darauf, direkt den physiologischen Bestand des Menschen zu affizieren. In besonderem Maße scheinen sie damit das Kriterium zu erfüllen, das etwa Alison Landsberg unter den Vorzeichen der Digitalisierung in die Begriffe »filmisches Prothesengedächtnis « und »sinnlichhautnahe Empathie « kleidete (Landsberg: 86; vgl. Shaviro) und das wenig später Laura Marks (138) als filmische Vermittlung von »Kontaktwissen« beschrieb.

Anzumerken wäre jedoch, dass sowohl die entsprechenden Filmexempel als auch die Sport-Schau affektive Arbeit verrichten (Hardt/Negri: 283ff). Sie stiften scheinbar unmittelbare Bezüge zwischen dem Gesehenen und dem Rezipienten, jedoch mittels strategischer Inszenierungsgesten, die schließlich die Ebene der Rohwahrnehmung überspringen, um sich letztlich in identifikationsträchtigen und gemeinschaftsbildenden Imagines zu verfestigen, die freilich ihrerseits von Verausgabungen im Spektakulären nicht zu trennen sind.

Genau dieser double bind macht es nötig, die These von der sinnlichen Anziehungskraft des Films entscheidend zu variieren: Patrick Fuery unterscheidet in seinem Buch New Developments in Film Theory zwischen emotional wirksamen, jedoch botschaftsträchtigen »seductive signs«, deren weltanschauliche Ladung zu verifizieren ist, und den in der Struktur des Films selbst nistenden »signs of seduction«. Für letztere gilt: »Seduction becomes part of the very materiality of film itself « (Fuery: 174; vgl. 160).

Eine solche Auffassung von einer seduktiv-faszinierenden Materialität des Films aber wäre nicht nur als Einspruch gegen die filmische Vermittlung symbolischer Ordnungen, sondern vorrangig auch als Absage an eine sinnliche Dimension des Films im oben anvisierten Sinne von geglückter $>$ Empathie $<$ mit dem vom Film 
präsentierten Sinnlich-Materiellen zu verstehen. Vielmehr wäre sie im Zwischenbereich von reinem Wahrnehmungsvorgang und einem das Klischee-Gedächtnis aktualisierenden Erkennen zu verorten; sprich dort, wo die Distanz schaffende Funktion des Films, die diesem genuin ist, dazu führt, dass sich narrativ-symbolische und sinnlich-emotionale Affizierungsmodi durchdringen, jedoch als Alternativen destruiert werden.

Im Wechselspiel von (Re)Präsentation, Präsenz und virtualisierender Distanzierung ergibt sich in der Tat das, was ich als >körperliches Erleben von Film< bezeichnen möchte, im Unterschied zur Rezeption der Realität des filmisch Gezeigten wie auch zu der Wahrnehmung der bloßen Vorhandenheit des technischen Apparates und der Leinwand. Film in diesem Verständnis ist umfassende, in sich wandelbare präsentisch-performative Realität. Ohne mit dem Screen deckungsgleich zu sein, hat sie doch ihren Ort zunächst auf dessen Oberfläche und ergibt sich aus dem transitorischen Zusammenspiel optischer und akustischer Einwirkungen und deren instantaner Wahrnehmung, die sich nicht in Erkennen verfestigt. Es geht mithin um eine Präsenzdimension, die sich als prozessuale Regulierung von Kräften innerhalb der Kopräsenz von filmischer Bewegung (Zeigen) und körperlicher Rezeption (Sehen) darstellt. In ihrer Fugitivität unterläuft sie sowohl die narrativ-symbolische Hegemonie des klassischen Filmbildes wie die rein sinnlich-taktile und hochemotionale Funktion, die dem Film beispielsweise in aktuellen Theorien zum Kino der Transgression zuerkannt wird.

Barneys Filmkörper-Kunst unterhält zu einer solchen Auffassung intrinsische Beziehungen. Sie zielt darauf, Filmerfahrung gleichsam zu verflüssigen, ihre herkömmlichen Konstituenda von zeitlicher und räumlicher Asymmetrie sowie die körperliche Differenz zwischen Zuschauerkörper und Leinwandgeschehen zu unterminieren.

Beleuchten möchte ich einige seiner Strategien, die in den herkömmlichen Prozess von Filmrezeption eingreifen. Es sind dies: die Veränderung der äußeren Rahmenbedingungen im Umgang mit Film; zweitens die Art und Weise, wie die narrative Geste und das Moment sinnlicher Empathie des Films durch die spezifische Verfassung der abgebildeten Gegenstände und des filmischen Zugriffs auf sie unterlaufen werden; und schließlich die Herstellung einer haptischen Dimension des Filmerlebens.

\section{Entgrenzung des Filmerlebens}

Barney firmiert keineswegs neben, sondern in inniger Verschränkung mit seiner Tätigkeit als Filmemacher zugleich als bildender Künstler. Spezifisch dafür ist der enge Bezug der museal ausgestellten Artefakte zum filmisch Präsentierten. Ausnahmslos handelt es sich um künstlerisch rearrangierte Objekte, Kostümteile und andere Versatzstücke, die in den Filmen gezeigt werden. Hinzukommt die Glaskasten-Präsentation von Materialien, Filmscripts, Prop-Entwürfen, Storyboards und nicht zuletzt der DVD-Versionen der Filme in pretiosenhaft geschmückten Sets. Außerdem zieren die Wände gerahmte Fotos, jedoch nicht etwa in Form von Stills, sondern als eigens inszenierte Aufnahmen. Zeitgleich zur Ausstellung laufen die Filme in einem abgetrennten Saal und auf Fernsehbildschirmen innerhalb der Ausstellungsräume. Dieses Arrangement verweist einmal auf ein im Film selber unsichtbares Außen, ein prozessuales Making-off und nagelt diesen damit an eine ihm vorund nachgängige Realität des Imaginations- und Produktionsprozesses. Jedoch: Die 
vom pragmatischen Standpunkt aus durchweg paradox konstituierten Artefakte gewinnen Sinn und Funktion nur in Bezug auf ihr Wiedererscheinen im irrealen filmischen Kontinuum Barneys. Der unmittelbare Kontakt, in den das zeitlich fugitive Filmgeschehen mit den taktilen, begehbaren Objektlandschaften gerät, führen so zu einer delikaten Irritation, die die reine Film- und die davon abgegrenzte ObjektWahrnehmung gleichermaßen korrigiert. Beide konstituieren sich nur in der gegenseitigen Bezugnahme, eine Referenzbeziehung außerhalb des als solches wahrgenommenen Zusammenspiels von Film und Gegenstand existiert nicht.

Damit verweigert der Film nicht nur die ihm traditionell zugeschriebene Abbildungsfunktion, sondern er verliert seine hegemoniale Stellung innerhalb des Gesamtensembles der Artefakte. Film und Ding befinden sich in einem Verhältnis gegenseitiger metonymischer Verlängerung, die zum einen die festen Gegenstände gleichsam virtuell verflüssigt und zugleich den Film als Objekt, als optisch dynamisierte Version einer Skulptur zu betrachten erlaubt.

In beiden Fällen werden offenbar zwischen den Wahrnehmungsmodi von Berührung und Sehen unmittelbare Beziehungen anvisiert, die sich jedoch in keiner Weise pragmatisch subsumieren lassen, sondern den Generalnenner der concordia facultatem gleichsam zerfasern. Dazu passt, dass Barney seine erste Retrospektive durch einen realen Catwalklauf seiner Filmkreaturen einleitete. Diese offensive modische Ritualisierung, ja Theatralisierung von Filmerfahrung deutet affirmativ auf den weiten aktiv-kreativen Horizont hin, den >Filmrezeption< mittlerweile beansprucht, der jedoch in der gelehrten Diskussion zumeist ausgeblendet bleibt: Starkult, Autogrammjagd, Merchandising, Rollenspiele, Sammelleidenschaft usw., all das nicht mehr als akzidentielle, sondern als intrinsische Elemente einer distributiven Ästhetik des Filmerlebens im postkapitalistischen Zeitalter, das ein transindividuelles Netzwerk von Produzenten-Rezipienten zum aktiven Mitgestalter bestimmt (Munster/Lovink).

Einem ähnlich dezentrierenden Zweck dient die Flexibilisierung des Films durch die DVD-Veröffentlichung: In der Tat trägt Barney auch hier der Tatsache Rechnung, dass sich der Umgang mit Film längst von seiner institutionellen Verankerung im Kino-Dispositiv gelöst hat und in einem gestreuten, intermedialen Milieu verzweigt, das, indem es assoziative, affektive und rein taktile Aspekte subsumiert, nicht auf einen Nenner zu bringen ist.

Die gemeinhin als dem performativen Erlebnis abträglich gescholtene Reproduktion exponiert dabei geradezu den individuellen körperlichen Umgang mit den technisch-materiellen Strukturen des Bildtonträgers als Teil der ästhetischen Erfahrung. Sie exponiert gleichsam deren schlechten Rest, das Hantieren mit dem Medium zwischen Einschalten und Ausschalten als rituelles Ereignis sui generis. Ein Moment körperlicher Affektation, das über den rein visuellen Konsum hinausgeht. Entscheidend auch hier, dass dieser entgrenzende Gestus das Erleben von Film öffnet für eine Vielfalt durchaus divergenter Eindrücke zwischen Erkennen, Sehen, und Hantieren, die unter keinen Umständen auf das funktionalistische Prinzip affektiven Arbeitens reduziert werden können.

\section{Haptisches Sehen}

Das Filmgeschehen, das Barney präsentiert, zeigt typischerweise eine unentwegte Bewegung und Verwandlung von Situationen und Figuren, außerdem werden stets neue seltsame Objekte und installative Topographien in der Kadrierung eingeführt. 
Entscheidend ist einmal, dass solcherlei Verwandlungen und ad hoc-Präsentationen nicht nur, wie etwa im fantastischen Film, vor den Augen der Zuschauer als spektakuläre set-pieces inszeniert werden, dabei die narrative durch eine visuell frappierende consecutio ersetzend. In der Tat lässt Barney diese Transformationen zwar ohne jede Erläuterung, jedoch genuin unaufgeregt, gleichsam dekorativ, sowie, darüber hinaus, immer wieder nur in Form der Schnittmontage oder sogar in der Differenz von einem Film zum anderen stattfinden.

So transformiert sich z.B. die Figur des Mörders Gary Gilmore aus dem zweiten Teil der CREMASTER-Serie im dritten Teil in einen weiblichen Zombie und schließlich in einen Metallblock, und zwar nicht nur ohne dass diese Verwandlung narrativ plausibel gemacht würde, sondern sie passiert nahezu gänzlich außerhalb des visuellen Zusammenhangs. Sie ist ein in die jeweilige Einstellung von außen eingebrachtes Faktum, dessen Zustandekommen der Rezeption mehr oder weniger entschlüpft und nur über Sekundärquellen erschließbar wird. Die vielgescholtene Unauflöslichkeit der Barneyschen Bildwelten hat nicht zuletzt in solchen Techniken des Verschweigens ihren Grund. Stets wird das Filmgeschehen auf das Imaginationssystem des Künstlers bezogen. Dieses aber verschließt sich, wie Körpervorgänge, einer Manifestation in eine nachvollziehbare Abfolge nicht nur des Erzählens, sondern gerade auch des Zeigens. Es fungiert dergestalt viel mehr als Motor, als exzentrischer Impulsgeber, denn als referierbarer Schauplatz. Der wesentliche Gewinn dieser dem filmischen Narrationsprinzip scheinbar zutiefst gegenläufigen Strategie ist es, das einzelne Filmbild oder die Sequenz als sozusagen gerahmtes, abgeschlossenes Wahrnehmungs-Faktum zu konstituieren, das innerhalb der filmischen Zeitspanne mit anderen Sequenzen nicht in einem Verhältnis der inneren Verbindung, sondern, das ist entscheidend, der äußeren Berührung steht. Das Filmbild und die Einstellung werden, ganz entsprechend zur Hängung der Fotos im Museum, zu Teilen eines in die Transitorik des Films eingebundenen Arrangements von Artefakten. So mortifizierend dieser Begriff im Hinblick auf das Filmbild scheinen mag: Gerade die zwischen den Bildern konstituierte Differenz bringt in das Filmerleben Bewegung, indem es innerhalb des Gezeigten offene Fluchtlinien konstituiert, die die homogene Zeit filmischen Erzählens durchbrechen und so eine wiederholende Vergewisserung und Festschreibung selbst beim mehrmaligem Ansehen verunmöglichen (Lehmann: 344).

Es geht Barney also nicht darum, den Screen einfach mit visuell ansprechenden Allegorien zu füllen, sondern die von Bildern bevölkerte Leinwand von jeder klischeehaften und mortifizierenden Wahrnehmung zu befreien. Dem dient auch die Umbesetzung traditioneller filmischer Strategien, vor allem der langsamen Kamerafahrt und der Großaufnahme. Die ihnen gemeinsame Logik verspricht gemeinhin ein Surplus an Erkennbarkeit und - gemäß aktueller Theorien - ein Mehr an sinnlicher Taktilität. In der Tat inszeniert Barney mit Vorliebe allmähliche Kamerafahrten an die jeweiligen Objekte heran, die, indem sie dem nahezu taktilen Modus eines afilmischen »skulpturalen Tempos« folgen, nach und nach den Eindruck einer intensiven Gegenwärtigkeit der gezeigten Dinge und Personen, zumal von deren Körperlichkeit und Materialität, evozieren. Die zunächst zu Buche schlagende Prämisse einer »truth to materials « (1999) aber entpuppt sich als trügerisch, wollte man daraus die Herstellung figurativer Bezüglichkeiten oder einer materiellen Tiefendimension ableiten. Die Annäherung des Kamerablicks sowie die daraus schließlich resultierende Groß- und Detailaufnahme tendieren im Gegenteil dazu, en procès die intelligiblen Umrisse aufzulösen und auf der Oberfläche des Screens ein rein bildlich-ornamentales Arrangement freizulegen. Das jüngste Beispiel für 
diese Technik findet sich in der Eingangszene des Kurzfilms HoIsT, Barneys großartigem Beitrag zu der künstlerischen Pornokompilation DESTRICTED: Ein schlaffes, dunkles männliches Glied, das sich erst ganz allmählich regt und erhebt, bleibt zunächst, da es auf einem mit krautartigem Material dekorierten Torso platziert ist, innerhalb der Kadrierung als solches unerkennbar. Die einsetzende Teilerektion deutet die entsprechenden körperlichen Bezüglichkeiten an, versperrt sich aber als Teil des dekorativen Objektensembles und des Einstellungsgesamts einer geglückten Integration in die Bildform >Organismus $<$. Zweck dieser im Verbund von Make-up, Körpermaterial und Einstellung erreichten Differenzbildung auf der Oberfläche des Gezeigten ist es, die Herstellung sinnlicher Empathie ebenso zu affizieren wie gleichzeitig zu durchbrechen. Die Bilder verführen dazu, sich in der einen oder anderen Weise mit dem Geschehen visuell zu arrangieren, jedoch ist es unmöglich, dies bis zu einem gültigen Ende zu tun. Das qua Einstellung dem eigentlichen Distanzierungsmittel des Films - aus dem menschlichen und gegenständlichen Format befreite Einzelbild wird zu einer verstörenden Größe sui generis: ein flächiges Feld optischer Marken, die intelligible Relationen anreißen, sie aber zugleich ins Diagrammatische auflösen, in ein reines Geflecht von Linien und Verzweigungen, das prinzipiell nach allen Seiten hin offen und verlängerbar scheint, und zwar über die Kadrierung hinaus. Angesichts dieser produktiven Unfertigkeit, die das Auge durch Differenzbildungen und durch den Verweis auf das Unsichtbare geradezu im Stich lässt, terminiert der Akt des Sehens niemals im folgerichtigen Erkennen und auch nicht im Modus sinnlicher Empathie, sondern er gerät zu einer von wechselnden Impulsen regulierten prozessualen Kraftanstrengung: ein jedem Filmerleben unterlegter, jedoch im Filmverstehen ausgeblendeter Aspekt von Körperlichkeit.

Hier nun lässt sich anknüpfen mit einer von Gilles Deleuze theoretisch entworfenen haptischen Dimension des Blicks (62ff). Sie richtet sich gegen das emotional-sinnliche Betroffensein von optischen Fakten wie gegen deren interpretierende Einordnung gleichermaßen.

Haptisch sehen heißt, sich auf jeden Moment des visuellen Vor-Augen-Tretens in einer Weise einzulassen, die die organische Funktion des Auges, sprich: das einordnende, das urteilende und das mit-empfindende Erkennen, zugunsten einer Art von präsentischer livehafter Rohwahrnehmung unterläuft, die freilich - bei Deleuze - eine ahumane Tendenz verzeichnet: Das freigesetzte Auge wird in einen Prozess der reinen Oberflächen-Registration versetzt, es agiert paradoxerweise wie die von tieferer Empfindung zwangsweise emanzipierten Finger eines Blinden, die sich mechanisch von Moment zu Moment tasten, ohne etwas vorstellen oder ein Ende absehen zu können (Deleuze: 33f). Die Filme Barneys verweigern sich ihrerseits dort, wo sie das Sinnliche und Figurative sozusagen in die blinde Markierung hinein auflösen, einem Dahinter, einem vermeintlichen Humanismus der Dreidimensionalität, der auf Verstehen und affektiven Mitvollzug gleichermaßen setzt. Nicht zuletzt kann die motivische Vorliebe Barneys für Hybridbildungen aus menschlichem Leib und Maschine - so jüngst in dem erwähnten HoIST, wo das erigierte Glied schließlich von der Kurbelwelle eines Lastwagens masturbiert wird durchweg als Pendant zur Tendenz seiner Filme gewertet werden, dem Rezipienten seine eigene Körperlichkeit, konzentriert in der Bewegung des Auges, als reines apersonales Spiel von Flüssen und Wechselwirkungen im dünnen Zwischenraum von Retina und Leinwand erlebbar zu machen. Sie schließen sich jenseits der Limits des Subjekts und seines Körpers mit der filmischen Bewegung zu einem fugitiven Geflecht von Kräften und Intensitäten zusammen (Deleuze: 39). 
In dieser ihrer Distribution von Filmästhetik über Mediums- und Subjektgrenzen hinaus assimilieren sich Barneys Filme, trotz oder gerade wegen ihrer überbordenden Fülle bewegter Details, der leeren Oberfläche eines Filmscreens: Sie sind dem Auge nah und dem Erkennen fern.

\section{Filme}

Barney, Matthew (1998): March of the Anal Sadistic Warrior.

Barney, Matthew (1996-2002): The Cremaster Cycle I-V.

Barney, Matthew (2003): The Order (DVD-excerpt from: Cremaster III).

Palm Pictures \& Arthouse Films.

Barney, Matthew (2005): De Lama Lamina, The Gladstone Galery.

Barney, Matthew (2005): Drawing restraint 9.

Barney Matthew (2006): Hoist. In: Marina Abramovic u.a.: Destricted,

Revolver Entertainment/Palomar Pictures/Katapult Film Sales.

\section{Literatur}

Deleuze, Gilles (1995): Logik der Sensation. München: Fink.

Fischer-Lichte, Erika (2004): Ästhetik des Performativen. Frankfurt/M.: Suhrkamp.

Fuery, Patrick (2000): New Developments in Film Theory. New York: Macmillan.

Hardt, Michael/Antonie Negri (2002): Empire. Die neue Weltordnung. Frankfurt/M./ New York: Campus.

Kimmelmann, Michael (1999): »The Importance of Matthew Barney«. In: The New York Times Magazine. http://www.filmforum.org/cremaster/barneynytimesmag. html (Jan. 2007).

Landsberg, Alison (1995): »Prosthetic Memory: Total Recall and Blade Runner In: Mike Featherstone/Roger Burrows (Hg.): Cyberspace/Cyberbodies/Cyberpunk. Cultures of Technological Embodiment. London: Sage, S. 175-189.

Lehmann, Hans Thies (1999): Postdramatisches Theater. Frankfurt/M.: Verlag der Autoren.

Marks, Laura (2000): The Skin of the Film. Intercultural Cinema, Embodiment and the Senses. Durham/London: Duke UP.

Munster, Anna/Geert Lovink (2005): »Theses on Distributed Aesthetics. Or, What a Network is Not«. In: Fibreculture Magazine, No. 7, http://journal.fibrecul ture.org/ issue7/ issue7_munster_lovink.html (Jan. 2007).

Shaviro, Steven (1993): The Cinematic Body. Minneapolis: University of Minnesota Press.

Spector, Nancy (2002): »Nur die perverse Phantasie kann uns noch retten«. In: Matthew Barney: The Cremaster Cycle. Köln: Museum Ludwig, S. 2-91.

Stiglegger, Marcus (2006): Ritual \& Verführung. Schaulust, Spektakel \& und Sinnlichkeit im Film. Berlin: Bertz + Fischer. 



\title{
LARS VON TRIER UND VOLKER LÖSCH ERKUNDEN IHR MEDIUM IN $\gg$ DOGVILLE « 1
}

\author{
ANNETTE BÜHLER-DIETRICH
}

In seiner Trilogie THE U-S-A - LAND OF OPPORTUNITIES stellt Lars von Trier den zum Scheitern verdammten Idealismus seiner Hauptfigur Grace ins Zentrum. Ihr Schicksal in DoGVILLE (2003) knüpft an die märtyrerhaften Frauenfiguren seiner GOLD HEART TRILOGY an (vgl. dazu Bainbridge), während Grace in MANDERLAY (2005) versagt, indem sie sich die Macht über die Plantagenbewohner aneignet. Beide Filme hat Volker Lösch am Staatstheater Stuttgart auf die Bühne gebracht. ${ }^{2}$ Die folgenden Ausführungen beziehen sich vor allem auf DogVILLE. Film und Inszenierung stellen hier ihre Medialität in einer Weise aus, die um die Zeichen und ihre Körper kreist.

Lars von Triers DogVILLE konfrontiert die Medien Schrift, Theater und Film miteinander. Indem der Film eine mit Kreide gezeichnete und beschriftete Stadt zum Ort des Geschehens macht, in der selbst der eponyme Hund nur indexikalisch über Bellen und Zeichnung vertreten ist, thematisiert er auf der visuellen Ebene Zeichenprozesse. Er verweigert damit die Modalitäten des illusionistischen Kinos und Theaters. Stattdessen zitiert er Brechts episches Theater in der Wahl der Bühne und der reduktionistischen Bühnenmittel: wenige Requisiten stehen in den angezeichneten Räumen zur Verfügung. Indem von Trier einen heterodiegetischen Erzähler einsetzt, der im Voice-Over die Handlungen und Dialoge der Figuren auch ironisch kommentiert, Gedankenberichte liefert und über die Dialoge hinwegspricht, distanziert von Trier den Zuschauer von einem Geschehen, dessen Kurzfassung die eingeblendeten Titel liefern (vgl. auch Günther: 1). Trotz dieser Zitation des epischen Theaters aber ist DOGVILLE genuin filmisch. Im häufigen Wechsel der Einstellungen zwischen Weit, Totale, Halbtotale und Großaufnahme, Vogelperspektive, Schwenk und Zoom macht die Kamera auf sich aufmerksam. Sie verbindet sich mit den Kommentaren des Erzählers; Kamera und Erzähler bewahren im Unterschied zu den Figuren den Überblick und die Deutungshoheit.

Auf der Ebene der Figuren aber werden die Lektüre von Zeichen und der Umgang mit Zeichen zum Problem. Insofern ist es stringent, dass von Trier die intermediale Form gerade als Antwort auf diesen Stoff gewählt hat (vgl. Kabel: 8). Denn Grace (Nicole Kidman) darf zu Anfang nicht primär in Dogville bleiben, weil sie in Not ist, sondern weil Tom sie zur Veranschaulichung seiner These verwenden möchte, dass Dogville das Annehmen lernen muss (vgl. Trier: 8-11, 122). Ziel seines Tuns ist die fiktional verwertbare Versuchsanordnung, die ihn zum großen Schriftsteller machen soll. Da Grace aber, derart in die Gemeinschaft eingeführt,

1 Ein hinsichtlich der Inszenierung ausführlicherer Artikel ist erschienen unter Annette Bühler-Dietrich: »Theater im Film - Film als Theater. DoGvILLES Formen der Intermedialität« in: Orth/Staiger/Valentin 2008: 73-86.

2 Ich danke dem Staatstheater Stuttgart für die zur Verfügung gestellten Materialien. 
nur ein Bild ist, ein Mensch und doch ein Zeichen, erlaubt es sich die Gemeinschaft, dieses Zeichen nach Belieben einzusetzen und zu deuten. Als das Experiment versagt, kann Tom Grace ohne Skrupel verraten, weil es ihm um das Experiment, nicht um Grace ging. Doch während Tom der Logik der Illustration folgt und die Versinnlichung einer Idee erstrebt, erfährt Grace diese Reduktion am eigenen Leib. Ihre Auslöschung des Ortes ist dann keine Veranschaulichung, wie Tom meint (vgl. Trier: 124), sondern eine in sich bedeutsame Handlung. Damit vernichtet Grace am Ende des Films die in Dogville institutionalisierte Diskrepanz von Sein und Schein, die alle Lebensbereiche und alle Figuren prägt. Nur indem die gesellschaftliche Verabredung gewahrt bleibt, kann die Diskrepanz aufrecht erhalten werden. Grace als Fremde entlarvt und verändert das Spiel, mit verheerenden Folgen.

Bei dieser Entlarvung übernehmen Schnitt und Kameraführung verschiedene Aufgaben. So kommentiert die Kamera das Geschehen, besonders deutlich in den Fällen, wo sie auf sich weist und z.B. in Zeitraffer und Vogelperspektive Graces grotesk verdoppelten Tagesablauf visualisiert. Wesentlich ist der Wechsel zwischen Groß-, Totale- und Weit-Einstellungen. Isolieren die Großaufnahmen die Figuren, so rücken die Weitaufnahmen aus unterschiedlichen Winkeln die gezeichnete Stadt aufgrund ihrer Transparenz in Ausschnitten oder gesamt in den Blick. Wenn Chuck Grace vergewaltigt, findet dies zwar in Chucks Haus statt, doch zeigt die Weitaufnahme das ganze Dorf so, dass man am hinteren Bildrand Grace am Boden liegen sieht. Die kommunale Zustimmung zu dieser später sanktioniert vollzogenen Vergewaltigung wird so bereits in deren erster filmischer Darstellung sichtbar. Gleichzeitig inszeniert die Kamera die von Grace erfahrene Überwachung. »Auf einmal fühlte sie sich beobachtet. Ja, es stimmte: aus jedem Fenster schaute sie jemand an. Sie taten es zwar heimlich, aber sie passten auf, das stand fest « (Trier: 25). Obwohl Dogville den Schein der Gemeinschaft bietet, treten die Figuren als Einzelne mit eigenen Wohnstätten und Beschäftigungen auf, sie leben nebeneinander, nicht miteinander. In dieser Vereinzelung ist Dialog unmöglich. Konsequenterweise öffnet erst Grace kurzzeitig, von ihrer Ankunft bis zum Fahndungsplakat wegen Bankraubs, den Raum für kurze Dialoge und eine Vertraulichkeit suggerierende Naheinstellung oder Grosseinstellung mit zwei Figuren - wie in der Szene von Toms Liebesgeständnis.

Der Kamera und dem Schnitt ausgesetzt bleibt der leidende Körper. Nähert sich die Kamera bei Chucks erster Vergewaltigung Graces angstverzerrtem Gesicht, so blickt sie nach Chucks Vergewaltigung von oben auf die wie zerbrochen daliegende Grace und distanziert sich dann in einer Spiralbewegung. Der Mahlstrom, in den die Werte der Dogviller Gemeinschaft von nun an geraten, ist darin symbolisiert. In die Unmittelbarkeit des Leidens greifen Kamera und vor allem Schnitt ein. »Ich bitte«, erläutert von Trier (Kabel: 7), »die Schauspieler darum, ein und dieselbe Szene auf fünf verschiedene Weisen zu spielen, immer vor laufender Kamera. Und dann setze ich mich hin und schneide alles zusammen«. Hier verbinden sich brechtsche Schauspieltechnik und Schnitt. Das Resultat dieses Vorgehens ist, besonders bei Kidman, eine Oberfläche, die opak bleibt. So zeigt die immer wieder auf ihrem Gesicht verharrende Kamera eine makellose Fläche mit geringem Mienenspiel und immer korrekt geschnittener Frisur. Die vergehende Zeit äußert sich am Verlauf der Apfelreife und -ernte, sie schreibt sich nicht in Graces Gesicht ein. Über seine Regiearbeit sagt von Trier, »es muss schon ein bisschen weh tun « (Kabel: 8), und Stevenson begründet die Arbeit mit langen Einstellungen in ihrer Wirkung auf den Schauspieler. Ziel sei, »to force genuine reactions and emotions 
out of actors who were trained to give >performances«« (33). Diese Veräußerung im intensiven Schauspiel verbirgt und bricht der Schnitt, der selbst innerhalb einer Replik Großaufnahmen montiert. Daraus aber folgt: »Most of their exchanges had a measured, deliberate, theatrical feel, and were devoid of any spontaneity « (Stevenson: 104). Was als »theatrical « wahrgenommen wird, entsteht gerade durch den Schnitt.

Mit Irina Rajewskys Terminologie lässt sich bei DoGVILLE von einer Systemerwähnung qua Transposition der Art »simulierende Systemerwähnung « (91) sprechen. Dies führt dazu, dass DogVILLE provoziert »by denying us the comforts and familiarity of melodrama. It is not a means of forgetting but a means for realizing becoming more fully aware of - the subterfuges of movies, and of >art < in general « (Horsley: 19). Von Triers intermediales Wechselspiel beleuchtet die Macht der Konvention und die Manipulierbarkeit von Zeichen, im Film, aber auch in der Gesellschaft. Wo Menschen wie Tom für Moral zuständig sind (vgl. Trier: 105), ist es um diese schlecht bestellt. Erst und nur die mehrfache Verstellung: Bühne/Theater, Figur/Schnitt, Dialog/Erzähler erlaubt schließlich die Erkenntnis der notwendigen Einheit von Bezeichnendem und Bezeichnetem, von Handeln und Denken.

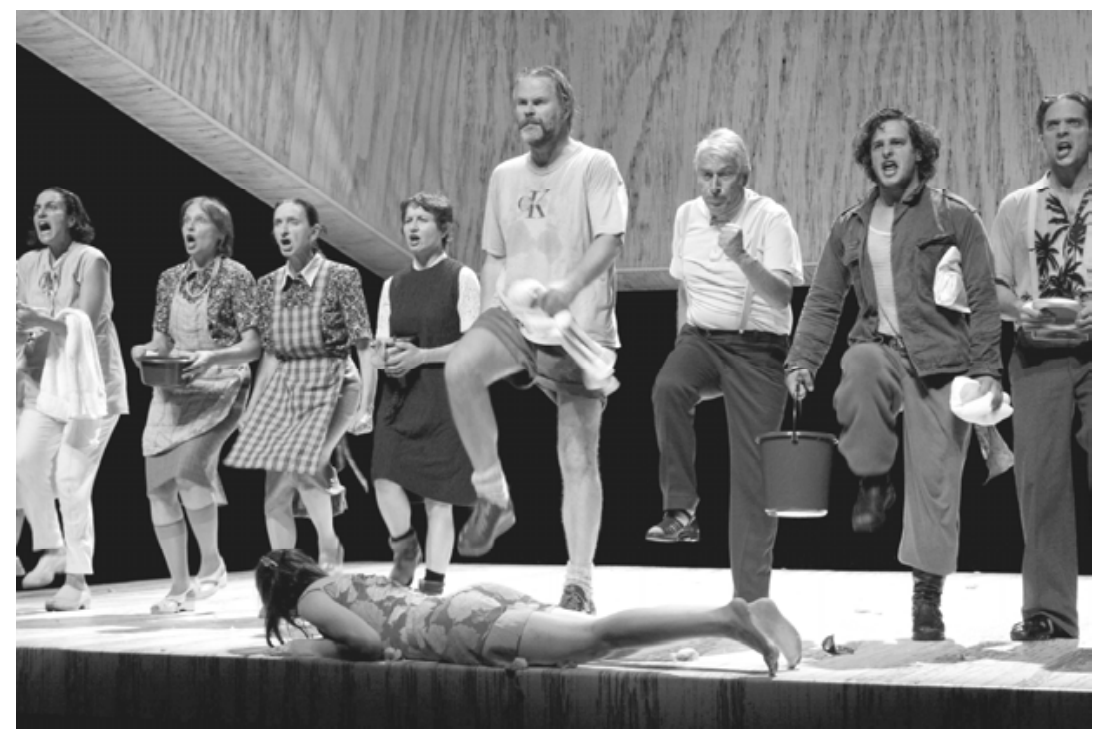

Abbildung 1: Volker Löschs DoGVILLE, Ensemble. Foto: (C) David Graeter.

Obwohl Volker Löschs deutschsprachige Erstaufführung (2005) in Titel und Programmheft auf den Film verweist, nimmt sie weder die filmischen noch die theatralen Elemente des Films auf. Statt die Kreidestriche auf die Bühne zu übertragen, verzichten Lösch und die Bühnenbildnerin Carola Reuther auf eine konkrete Darstellung Dogvilles, das als podestartiger Kubus in grauem Furnier mit schiefer Ebene erscheint. Gespielt wird auch an den Rändern des Kubus, an der und schließlich jenseits der Rampe. Reduziert ist das Personal des Films, das nun einzeln, besonders aber als Sing- und Sprechchor auftritt. Erzähler und Titel fallen weg. Statt der figurenspezifischen Requisiten von Triers - Gläser, Sofa, Sekretär, Schaukelstuhl - und den verschiedenen täglichen Tätigkeiten von Grace setzt Lösch eine 
Tätigkeit ein: Äpfelstampfen. Anfangs zerstampfen die männlichen Dorfbewohner die Äpfel gemeinsam, mit nackten Füßen, dazu singen Männer und Frauen. Dieses Äpfelstampfen wiederholt sich, nachdem Graces Fahndungsplakat angeklebt worden ist. Nun stampft Grace (Dorothea Arnold) alleine, während die Dorfbewohner ihr ihre Tätigkeiten im Film zurufen. Schließlich wird sie von Chuck vergewaltigt. In dieser Transformation bleibt die unermüdliche Bewegung Graces im Film erhalten. Der Wechsel der Stimmen aber ersetzt die Bewegung im Raum. Das Auftreten von Einzelfiguren wie Chuck oder Jason, das kurzzeitig die Bewegung unterbricht, entspricht dem Fokus der Kamera und der Erzählung auf einzelne Häuser und Figuren.

Der zeitliche Verlauf nimmt bei von Trier beinahe ein Jahr ein und reicht von der Apfelblüte zu den gelben Blättern. Bei Lösch bleiben die Äpfel von Anfang bis Ende. Die vergehende Zeit zeigt sich hier allein an der körperlichen Erschöpfung Graces, die schließlich liegend auf der Bühne kauert und sich einzig zu ihrer Anklagerede noch einmal erhebt. Während die Dauer des Filmes eine epische Zeitspanne aufgreift, verbleibt die Inszenierung im Hier und Jetzt der kahlen, selbstreferentiellen Bühne.

Rajewsky (180) betont, dass die Rückübersetzung intermedialer Kunst, bei der das fremdmediale Bezugsmedium ins eigentliche Medium verwandelt wird, zu einem Verlust an Differenz führt. Lösch vermeidet diesen Differenzverlust, indem er gerade die spezifische Intermedialität des Films außer Acht lässt und sie durch eine andere ersetzt: die der Musik. Indem die Figuren selbst singen, und zwar kunstgerecht und nicht mit dem Gestus des Ausstellens, konfrontiert der Gesang eine konnotierte gemeinschaftliche Fröhlichkeit und Innigkeit mit dem militärischen Staccato des Sprechchores. Da Lösch die Repliken der Figuren in freie Verse umwandelt, im Unterschied zur Prosa der Text-Fassung von Triers, bleibt als einzige Form des Redeflusses der Gesang. Der Eindruck seiner Verlogenheit entsteht

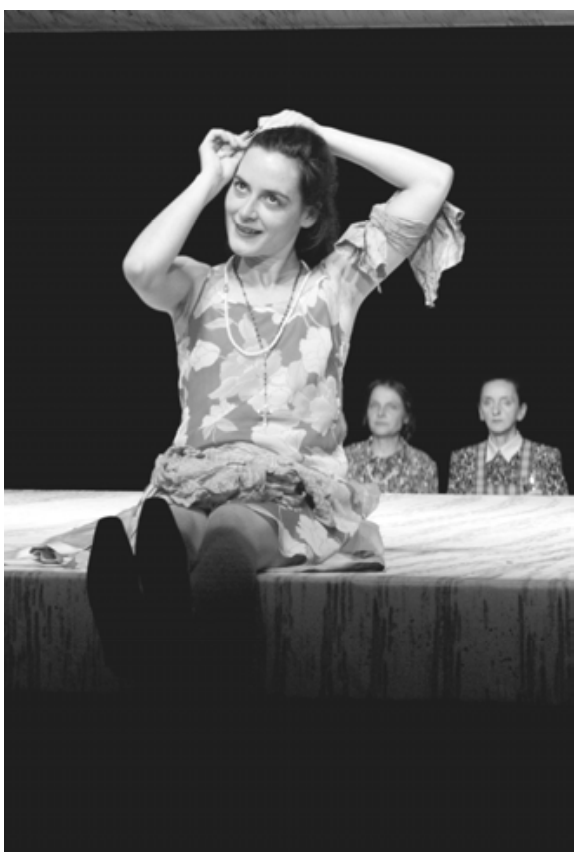
durch die Haltung der Figuren wie durch die Unangemessenheit seines Einsatzes. So singt der Chor das vierstrophige Volkslied »Da unten im Tale«, während alle Männer nacheinander Grace missbrauchen und die Frauen dieser Misshandlung amüsiert zuschauen. Die gemeinsame Misshandlung wird begreifbar als Verdrängtes, das die gemeinschaftliche Einigkeit gründet. In der Wahl lokaler Volkslieder stellt damit die Inszenierung die mit ihnen und ihren Gesangsvereinen einhergehenden Haltungen in Frage - eine Provokation in der Chorstadt Stuttgart, wie Dirk Pilz (2005a: 14) meint.

Abbildung 2: Grace (Dorothea Arnold) schmückt sich für das Fest. Foto: (c) David Graeter. 
Fügt sich der Einzelne im Chorgesang dem Kollektiv, so heben die Szenen des Einzelgesanges die Vereinzelung und den Kontrast hervor. Graces »Tout le jour «, gesungen anlässlich des gemeinsamen Festes, grenzt sie durch die Fremdsprachigkeit wie durch den Inhalt des Liebesliedes von den anderen aus, die ihr zuschauen. Toms (Benjamin Grüter) »Amazing Grace« dagegen zeugt in der Art des Vortrags von einer Selbstgefälligkeit, die die gefährdete Situation Graces verkennt. Im Lied wendet er sich der Idee der Gnade zu: Grace wird als die Personifikation benannt, als die sie Tom von Anfang an einsetzen will.

Nicht das Spiel mit den Zeichen, sondern die Evidenz des Körpers steht im Zentrum von Löschs Inszenierung. Dies gilt für den Einzel- wie für den Gruppenkörper, aber auch für das Bühnenbild. Als Gemeinschaft konstituiert sich Dogville körperlich. Man singt, isst und arbeitet gemeinsam in einer rhythmisch durchformten, verbindlichen Zeit. Schließlich vergewaltigt man gemeinsam, wenn Chuck und Ben gleichzeitig über Grace herfallen. Von dieser Gemeinschaft bleibt Grace ausgeschlossen: alleine wischt sie die Bühne, alleine stampft sie die Äpfel - eine Isolierung, die der Großaufnahme der Figur vor leerem Hintergrund im Film entspricht. Von den männlichen Dorfbewohnern wird sie vergewaltigt und besudelt, die Frauen stoßen und bespucken sie. Die Äpfel, die von der Decke stürzen, erschlagen sie fast. All dies führt zum sichtbar geschändeten Körper der Schauspielerin am Ende des Stückes. Parallel dazu wird der Körper der Bühne selbst glitschig und gärend, von Apfeltrümmern übersät, die sich auf oder um den Kubus herum häufen. Die Wiederholung und die jeweilige Dauer von Vergewaltigung und Anspucken sowie das andauernde Äpfelstampfen führen dabei zur Erschöpfung der Figur, wenn nicht der Schauspielerin, aber auch zur Erschöpfung des Zuschauers. »DOGVILLE is far too long; it is repulsive and eventually becomes boring (once the repulsion becomes too great, and we get bored with being repulsed)«, meint Horsley (16) über den Film. Obwohl die Inszenierung mit zwei Stunden im üblichen Zeitrahmen ist, gilt dieses Zitat auch für die Reaktion mancher Zuschauer auf die Inszenierung. Hier sind es die Ekel und Anstoß erregenden physischen Prozesse, die im Publikum zu hysterischen Reaktionen führen, die vom unpassenden, eruptiven Gelächter bis zum Türen schlagenden Verlassen des Hauses reichen (vgl. Pilz 2005a: 14; Kahle: 23). Körperlich unerträglich wird die Physis des Geschehens im Theater durch die Präsenz des Schauspielerkörpers, im Film durch die Ausdehnung und Wiederholung der Prozesse. Wie im Film ist das abschließende Gespräch zwischen Vater und Tochter in der Inszenierung der herausgehobene dialogische Moment. Hier jedoch entlädt sich die aufgebaute Spannung des Publikums als Unwillen über das Gespräch zwischen der Schauspielerin Dorothea Arnold und dem ehemaligen Leiter der Stuttgarter Mercedes-Niederlassung Thomas C. Zell. Lösch überschreitet die Grenze zwischen Fiktion und Realität, auf der sich bereits die Äpfel, die Körper und die Volkslieder als Metonymien der Lebenswelt situiert haben, und destabilisiert darin die Position des Publikums. Gleichzeitig fordert der komplexe Dialog über heutige Machtverwendung eine andere Aufmerksamkeit als die bisher verlangte, indem er vor allem auf das Ohr wirkt. Inhalt und Form dieses Auftritts kontrastieren mit dem Stück, beanspruchen aber auf gleiche Weise die Geduld des Publikums. Horsley (19) spricht von der reinigenden Wirkung, die Graces Strafgericht im Film einnimmt. Lösch schwächt die reinigende Wirkung durch das lange Gespräch, das von der plötzlichen, kurzen Aktion gefolgt wird, ab. Daraus ergibt sich eine Reaktion des Publikums, die derjenigen der Bevölkerung Dogvilles entspricht: Nur im Ausstoßen des Fremden konstituiert sich die Gemeinschaft erneut. Gerät die Gemeinschaft in die Krise, braucht es ein Opfer, um die 
ausbrechende Gewalt zu steuern. Im Opfer wird die Gewalt der Gemeinschaft kanalisiert, seine Tötung bannt die vorhandene Gewalt (vgl. Girard: Kap. 1). Dies erfährt Grace, und die Nennung von René Girard im Programmheft zeigt, dass sich die Dramaturgin Beate Seidel und der Regisseur dieses Vorgangs bewusst waren. Die Reaktion des Publikums aber erfolgt strukturgleich: Im vorzeitigen Verlassen des Raumes, im Lachen, im Kommentar re-etabliert sich ein Subjekt, das dieser Ausbruch von Gewalt bedroht. In dieser Reaktion macht es die Inszenierung selbst zum Opfer, dessen Ausschluss die Gemeinschaft neu konsolidiert. Dass die Inszenierung eine vergärende, abjekte Bühne bietet, die Ekel erregt, unterstützt diese bedrohliche Destabilisierung des Subjekts (vgl. Kristeva).

In Manderlay, dem zweiten Teil der noch unabgeschlossenen Trilogie, befreit Grace die gleichnamige Plantage, auf der noch in den 1930er Jahren die Sklaverei herrscht. Die Intermedialität von DOGVILLE aufnehmend untersucht von Trier hier die Implikationen eines liberalen Humanismus, der schließlich seine Nachtseite offenbart (vgl. Brown): Am Ende übt Grace peitschenschwingend eben die Gewalt aus, die sie zu Anfang abschaffen will. Bei von Trier flieht Grace im Anschluss an diesen Exzess von der Plantage und irrt unstet über die Landkarte der Vereinigten Staaten. Lösch dagegen lässt Grace die Bewohner des Sweat-Shop/Wohncontainers der Reihe nach durchpeitschen, während Thomas C. Zell über soziale Verantwortung spricht. Bestraft Grace die Hypokrisie Dogvilles, so fügt sie sich in Löschs Manderlay in ein Unterdrückungssystem ein, das sich als Kehrseite liberaler Werte erweist.

Lösch und von Trier nennen »Irritation« (Pilz 2005b: 16) und »Fragen aufwerfen « (Kabel: 9) als Aufgaben ihrer Arbeiten. Im Medienwechsel vom Film zum Theater setzt Lösch in MANDERLAY das Komische ein, wenn Grace demokratische Grundpfeiler tänzelnd lehrt. In Löschs DoGVILLE ist es der Körper von Grace, der wie die Bühne der Verunreinigung ausgesetzt wird und im Mittelpunkt steht. Bleibt Graces erduldete Misshandlung im Film durch die Kamera vermittelt, so erzeugt ihre Unmittelbarkeit auf der Bühne eine Reaktion im Körper des Zuschauers (vgl. Fischer-Lichte: 18-23). Sie stellt sich ein trotz des Wissens um die Differenz zwischen bezeichneten und tatsächlichen Vorgängen, und weil die Inszenierung diese Differenz wiederholt dekonstruiert. Während der Film somit Fragen aufwirft, deren Beantwortung zur diskursiven Herausforderung wird, ist die Irritation von Löschs Inszenierung zuerst im Wortsinn Folge eines physischen Reizes. Er generiert eine Reflexion, die auf diese Art gerade im Theater hergestellt werden kann.

\section{Filme/Inszenierungen}

Dogville (2003). Dir. Lars von Trier. Zentropa Entertainments.

Dogville (2005). Regie Volker Lösch. Schauspiel Stuttgart, Staatstheater Stuttgart. 01.10.2005.

Manderlay (2005). Dir. Lars von Trier. Zentropa Entertainments.

Manderlay (2008). Regie Volker Lösch. Schauspiel Stuttgart, Staatstheater Stuttgart. 21.06.2008. 


\section{Literatur}

Bainbridge, Caroline (2007): The Cinema of Lars von Trier. Authenticity and Artifice. London: Wallflower Press.

Brown, Wendy (1995). States of Injury. Power and Freedom in Late Modernity. Princeton: Princeton University Press.

Fischer-Lichte, Erika (2004): »Einleitung: Theatralität als kulturelles Modell«. In: Dies. u.a. (Hg.): Theatralität als Modell in den Kulturwissenschaften. Tübingen: Francke, S. 7-26.

Girard, René (1999): Das Heilige und die Gewalt. Übers. v. Elisabeth MainbergerRuh, 3. Aufl. Frankfurt/M.: Fischer.

Günther, Matthias (2003): »Echtes Theater? Bigger than Brecht? - Lars von Triers neueste Erfindung Dogville«. In: Theater heute, 11, S. 1-2.

Horsley, Jake (2005): Dogville vs Hollywood. The War Between Independent Film and Mainstream Movies. London: Marion Boyars.

Kabel, Kristine (2004): »Die Kunst, sich ein Bein zu stellen: Kristine Kabel im Gespräch mit Lars von Trier«. Übers. v. Kristine Kabel und Dirk Pilz. In: Theater der Zeit, 12, S. 6-9.

Kahle, Ulrike (2005): »Mit geballter Faust «. In: Theater heute, 11, S. 20-23.

Kristeva, Julia (1980): Pouvoirs de l'horreur. Essai sur l'abjection. Paris: Seuil.

Orth, Stefan/Michael Staiger/Joachim Valentin (Hg.) (2008): Dogville-Godville. Methodische Zugänge zu einem Film Lars von Triers. Marburg: Schüren.

Pilz, Dirk (2005a): »Diesseits des Klassenkampfes. Ein Versuch, das politische Theater zu finden «. In: Theater der Zeit, 11, S. 12-15.

Pilz, Dirk (2005b): »Den Bogen spannen, bis die Sehne reißt. Ein Gespräch mit Volker Lösch über Wut und politisches Theater von Nikolaus Merck und Dirk Pilz«. In: Theater der Zeit, 11, S. 16-19

Rajewsky, Irina O. (2002): Intermedialität. Tübingen: Francke.

Stevenson, Jack (2003): Dogme Uncut. Lars von Trier, Thomas Vinterberg, and the Gang That Took on Hollywood. Santa Monica, CA: Santa Monica Press.

Trier, Lars von [o.D.]: Dogville. Dram. v. Christian Lollike. Übers. v. Maja Zade. Reinbek b. Hamburg: Rowohlt Theater. 



\title{
Seriendramaturgien als Performance? KONVERGENTE ENTWICKLUNGEN IM THEATER UND IN DER POPULÄREN FERNSEHSERIE SEIT DEN 1960ER JAHREN
}

\author{
ANDREAS ENGLHART
}

Ein abwehrender Reflex gegen die amerikanischen Fernsehserien ist einer kulturwissenschaftlichen Tradition geschuldet, die, Pierre Bourdieu (23) zufolge, dem Fernsehen »eine Art faktisches Monopol bei der Bildung der Hirne eines Großteils der Menschen « zuschreibt. Das gesellschaftliche >Leitmedium< Fernsehen ist, wie Marshall McLuhan früh erkannt hat (1962), ein Medium der in Deutschland keineswegs überall als Chance begriffenen Globalisierung, da es alle Ereignisse im globalen Dorf simultan erscheinen lässt. Und es steht generell unter dem Verdacht, wie es Theodor W. Adorno (200f) formuliert, als »Medium selbst [...] ins umfassende Schema der Kulturindustrie zu fallen«. Damit wiederhole das Fernsehen die "prekären Leistungen der Anpassungen, die [die Konsumenten] einmal [in der Kultur] vollbracht haben, immer aufs neue « und verberge im Akt des Zuschauens hinter der Fernsehwelt als Erscheinung die Ideologie, die der Erscheinung inhärent ist. Das Verbergen gelinge dem Fernsehen insbesondere aufgrund seines medialen Vermögens, die »gesamte sinnliche Welt in einem alle Organe erreichenden Abbild noch einmal zu haben«, kurz: ein »Duplikat der Welt« herzustellen. Dieses ist, wenn man die Welt auf das räumlich und sozial engere persönliche Umfeld eines westlichen Mittelstandsbürgers begrenzt, die $>$ Welt $<$ der Fernsehserie. Ihr eignet aufgrund der Gattungsmerkmale des >Seriellen< und >Natürlichen< ein hohes Maß an Anpassungsfähigkeit an die Vorstellungswelt der Zuschauer, die sich mit den handelnden Figuren weitgehend identifizieren. Der daraus resultierende Vorwurf des Trivialen trifft keine in sich homogene Gattung, der Begriff der Serie umfasst den weiten Bereich zwischen billig produzierter »Day Time Soap Opera « über die »Telenovela « zur »Primetimeserie « und zum »Serial« und eine Vielfalt an Genres wie Familien-, Kriminal-, Sciencefictionserien etc. (Boll 1994). An dieser Stelle soll es weniger um die billig gemachte Soap, die ihre eigenen Regeln hat, sondern um die Primetimeserie amerikanischer Provenienz gehen.

Ein genauerer Blick in die momentane Serien-Landschaft lohnt sich, denn das Stereotyp des Trivialen trifft nicht mehr zu (wenn es denn je wirklich in vollem Maße zugetroffen hat). 24, CSI, DESPERATE Housewives, LOST, CRIMINAL MINDS, SOPRANOS oder etwa SIX FEET UNDER orientieren sich als Angebote eines Popularmediums keineswegs an den Merkmalen, die als kennzeichnend für sogenanntes »Unterschichtenfernsehen « betrachtet werden, hierzu weisen sie zu komplexe Strukturen auf und vermeiden durchaus nicht eine potentielle Überforderung der Zuschauer. Sowohl auf dramaturgischer als auch auf bildästhetischer Ebene bedienen sie sich wie selbstverständlich aller nur möglichen Elemente aus dem Archiv der Mediengeschichte. Selbstverständlich konnte man schon vor Jahren 
anspruchsvolle Serien, wie etwa David Lynchs TwIN PEAKS sehen, dennoch fällt auf, dass diese tendenziell von der Ausnahme zur Regel geworden sind.

Was ist nun das >Innovative< und >Avancierte< an der heutigen Fernsehserie? Drei Veränderungen im Vergleich zu den 1960er Jahren fallen auf, sie lassen sich mit einem gewissen $\mathrm{Maß}$ an Vereinfachung um die folgenden Punkte gruppieren:

- die Elemente einstmals >avantgardistischer< Dramaturgie und Bildästhetik,

- die formale und inhaltliche Intertextualität, und

- diskussionsanregende inhaltliche Grenzüberschreitungen und Tabubrüche.

Zu Punkt 1: Die Serien integrieren ästhetische Elemente der Avantgarde und Neoavantgarde in einem solchen Maße, dass die traditionelle Grenze zwischen >Mainstream < und >Arthouse < obsolet geworden ist. Die Integration ist das Resultat eines sukzessiven Einwanderns der filmischen Avantgarde in den >Mainstream<, und zwar nicht direkt, sondern über den >Umweg< der Videoclipästhetik. Mit Filmavantgarde ist insbesondere der in den 1920er Jahren entstandene abstrakte oder absolute Film gemeint, der auf narrative Strukturen und zum Teil auch auf figurative Elemente verzichtete und sich an der abstrakten Malerei Wassily Kandinskys, den Kubisten und den Futuristen orientierte. Diese filmischen Experimente eines Hans Richter mit seinem >optischen Rhythmus<, eines Walther Ruttmann mit seiner $>$ Malerei mit Zeit<, die Abstrahierung realer Objekte durch Man Ray, Fernand Léger oder Marcel Duchamp und das >Cinéma purく eines Lászlo Moholy-Nagy waren die Vorläufer der heutigen Videoclips. Dies vor allem in Hinsicht auf die Ästhetik der Bewegung an sich und die visuelle Musik, wobei in den Avantgardefilmen im Gegensatz zum Musikvideo nicht die vorhandene Musik bebildert, sondern die Musik den vorgegebenen Bildern angepasst wurde (Bühler: 165). In den Musikvideos finden wir auch die assoziative Montage, die wir aus den surrealistischen Filmen René Clairs und Luis Buñuels kennen. Und natürlich auch die sentfesselte Kamera<, deren vielfältige Möglichkeiten u.a. Abel Gance in seinem NAPOLEON von 1926 so umfassend erprobte, dass heutige Regisseure vor Neid erblassen würden. Man sieht in NAPOLEON Split Screens, Reißschwenks, Überblendungen, eine wacklige, subjektive Handkamera, rasante Fahrten, teilweise hat Gance die Kamera sogar geworfen. Abstrakte Ästhetiken, eine entfesselte Kamera und dramaturgische Experimente sind gegenwärtig - das bestätigt jeder Blick in Serien wie CSI, CRIMINAL MINDS UND 24 - Standard. So drängt sich neben der Narration vermehrt die Attraktion in den Vordergrund. Es kann fast von einer Eisensteinschen Attraktionsmontage gesprochen werden, die Einstellungen nicht flüssig verbindet, sondern durch schockartige Bildassoziationen die filmische Erzählung dialektisch vorantreibt. Regelverstöße gegen die etablierten Konventionen sind derzeit selbst bereits Konvention, der >klassische < >Jump-Cut<, von JeanLuc Godard noch als Mittel der Verfremdung durchaus im Brechtschen Sinne verstanden, ist ein gängiges ästhetisches Mittel. Man orientiert sich daher keineswegs am Ideal des klassischen Hollywoodfilms, dem >unsichtbaren Schnitt<, macht vielmehr den filmischen Gestus überdeutlich.

Zu Punkt 2: Obwohl sich der Anspielungsreichtum der Serie oft erst im wiederholten Sehen erschließt, was von den Produzenten durchaus gewollt ist, um den DVD-Absatz anzukurbeln, soll hier Intertextualität mit Manfred Pfister (1985) nicht allein als »globales Modell des Poststrukturalismus «, sondern im hermeneutischen Sinne als »bewußter, intendierter und markierter Bezug « verstanden werden. Die Serien vertrauen augenscheinlich auf das immense Medienwissen der jungen medienerfahrenen Generation. Die betonte Künstlichkeit des Sets der DESPERATE 
HousEwiVES, das nicht nur einem David-Lynch-Film entnommen zu sein scheint, sondern in dem wirklich $1 \mathrm{zu} 1$ Häuser aus berühmten Filmen der Filmgeschichte wie PSYCHO nachgebaut sind, oder die ständigen Bezüge der SOPRANOS auf bekannte Mafiafilme, die soweit gehen, dass Protagonisten zum Vergnügen ihrer Kollegen ganze Filmpassagen aus dem PATEN zum Besten geben, machen auch dem uninformierten Zuschauer klar, dass die Serien-Welt als Intertext eine Konstruktion ist.

Zu Punkt 3: Noch in den 1960er Jahren wurden in den Serien wie WaLtons oder BONANZA traditionelle Werte unreflektiert vermittelt: Ethnische Minderheiten waren meist Dienstboten, sexuelle Minderheiten waren grundsätzlich unsichtbar. Frauen spielten in der Serien-Welt, die meist strikt zwischen privater und öffentlicher bzw. beruflicher Sphäre trennte, oft nur im Haushalt eine Rolle. Diese scheinbar $>$ harmlose $<$, politisch aber problematische Serien-Welt gibt es nicht mehr. So sind in DESPERATE HOUSEWIVES die Männer das durchweg dümmere und ständig unterlegene Geschlecht. SEX AND THE CITY kann bei bestem Willen keine konservative Sexualmoral unterstellt werden, die Staatsanwältin in CLOSE TO HoME arbeitet weit professioneller als ihre männlichen Kollegen, und die härteste fiktionale Dokumentation über den Politikbetrieb seit Machiavelli sehen wir momentan in Welcome, Mrs. President. Homosexuelle Lebenswelten, in den 1960er Jahren noch so tabuisiert, dass Werke von Kenneth Anger nur als Undergroundfilme möglich gewesen sind, werden in QUEER AS FOLK oder THE L-WORD zu einem populären Seriengenre. In der Kultserie SIX FEET UNDER ist die homosexuelle Partnerschaft gar die einzig >beständige< Verbindung zwischen den neurotischen heterosexuellen Verhältnissen, wobei diese Serie zudem das Tabuthema Nummer 1 im westlichen Kulturkreis, die Kontingenz des Lebens sowie den Tod, zum Genremerkmal macht. Natürlich kann von einer totalen Gleichberechtigung von Frau und Mann noch nicht gesprochen werden, weiterhin definiert sich eine Frau in der Serie mehr über ihr Aussehen, der Mann mehr durch Wissen, Entscheiden und Handeln, aber der Fortschritt ist unverkennbar. Auffallend ist, dass die Serien, wenn auch oft überspitzt, gerne Tabugrenzen überschreiten. Damit versuchen sie natürlich, die Quote zu erhöhen, irritieren damit aber unzweifelhaft traditionelle Werthaltungen und regen zur Diskussion an.

Wenn man die drei Entwicklungen auf einen vorläufigen Nenner bringt, dann kann man sagen, dass im Vergleich zu den 1960er Jahren eine Tendenz zur EntEssentialisierung der einstmals von der >normalen $<>$ Natur $<>$ vorgegebenen $<$ sozialen Serien-Welt beobachtbar ist. Die Verhältnisse, seien es die zwischen >oben $<$ und >unten<, privat und öffentlich, weiblich und männlich, homo- und heterosexuell, etc., werden verstärkt als relationale ausgewiesen. Die Serien-Welt verbirgt ihren Konstruktcharakter immer weniger, der >seriale< Gestus zeitigt vermehrt ein gewisses $\mathrm{Maß}$ an Verfremdung oder gar an Selbstreferentialität. Somit wäre es erlaubt, die heutigen Serien-Welten tendenziell und in gewichtigen Teilen als Performance im Sinne einer weitgehenden Absenz von wahrnehmungsleitendem kausalen und temporalen Handlungsverlauf, der Abkehr von Re-Präsentation, der Abschwächung der Bedeutung des Gezeigten und der Betonung der augenblicklichen Attraktion des Wahrzunehmenden zu bezeichnen (wiewohl der Höhepunkt dieser Entwicklung, wie wir weiter unten sehen werden, bereits überschritten wurde). Genau das hat in der Serienforschung Irmela Schneider bereits 1995 getan, als sie gravierende Veränderungen von Erzählformen in US-amerikanischen Serien des Fernsehprogramms seit den 1960er Jahren feststellte. 
Im Folgenden werden zum leichteren Verständnis drei den komplexen Sachverhalt vereinfachende Schemata vorgestellt, die sich an Schneiders These, dass Serienereignisse zunehmend als Performance zu begreifen sind, und darüber hinaus an den bekannten normativen Strukturen Syd Fields, Christopher Voglers und der momentan ausgereiftesten Filmdramaturgie von Michaela Krützen orientieren.

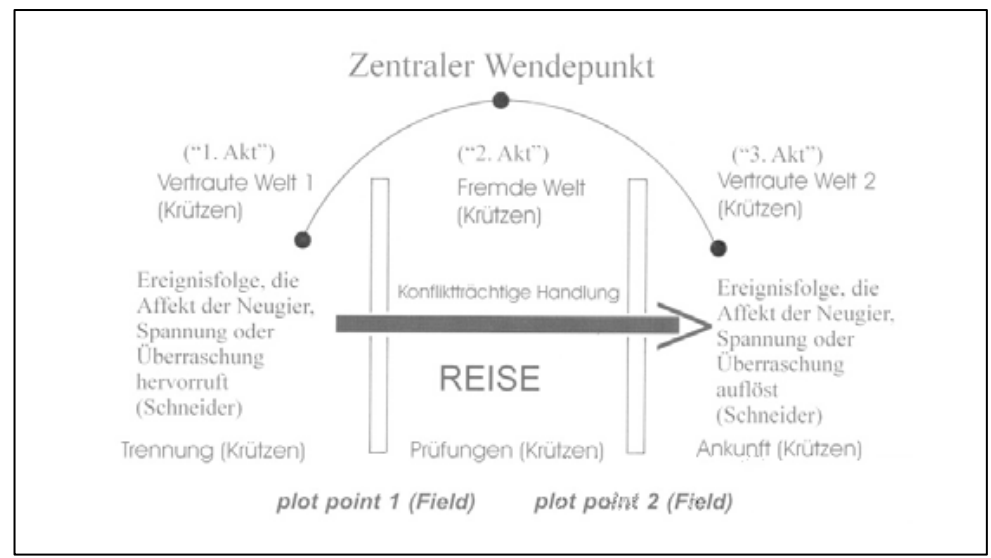

Abbildung 1: Traditionelle Erzählstruktur der Fernsehserie der 1960er Jahre.

Im ersten Schema ist die traditionelle Erzählstruktur der Fernsehserie der 1960er Jahre zu sehen. Erkannt werden kann am Anfang eine »Ereignisfolge, die einen der drei Affekte [Neugier, Spannung oder Überraschung] hervorruft. Am Ende steht dann eine Ereignisfolge, die diesen Affekt auflöst « (Schneider: 43f). Dazwischen findet nach der Theorie Voglers eine Reise des Helden in eine ungewohnte, andere, letztlich fremde Welt als konfliktträchtige Handlung statt. Die dreiteilige Struktur erinnert an Victor Turners Übergangsritus. Dieses kanonische Schema verändert sich in den 1970er Jahren dahin gehend, dass »neben den kanonischen linearen Erzählformen « Serien zu sehen sind, in denen verschiedene »Diskurs-Strukturen addiert werden «, indem zwei bis drei eigene Handlungen mit ihren Wendepunkten in einer Serienfolge hintereinander gesetzt werden.

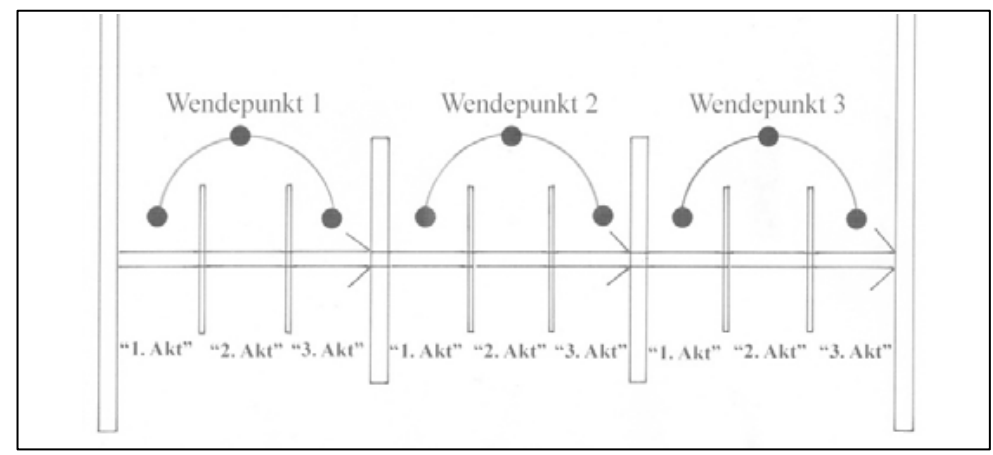

Abbildung 2: Zwei bis drei eigene Handlungen in einer Serienfolge hintereinander gesetzt. 
Dabei bleibt es jedoch nicht, denn in den 1980er und 1990er Jahren fügt die »nächste Entwicklungsstufe « nicht mehr »additiv die unterschiedlichen Diskursstrukturen aneinander, sondern verschachtelt sie « (Schneider: 44). Die Handlung kommt nie zu einem definitiven Ende, es folgt nicht einen Handlung auf die nächste, sondern geboten wird eine aufmerksamkeitserregende Aneinanderreihung der Wendepunkte.

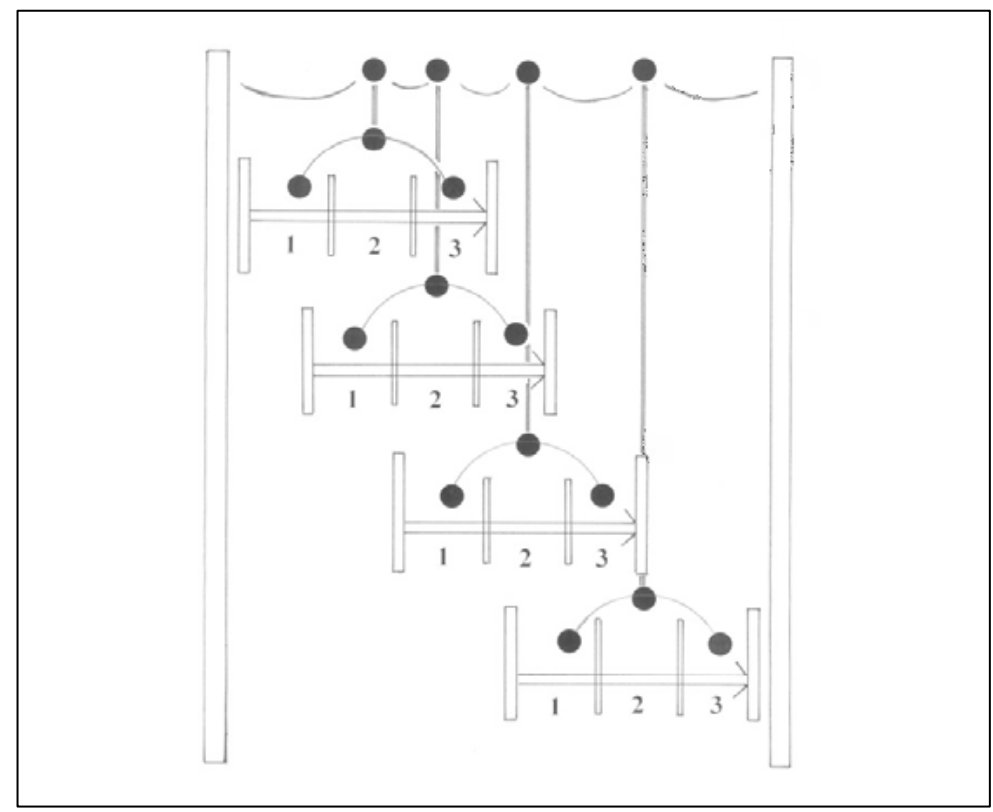

Abbildung 3: Aufmerksamkeitserregende Reihung der Wendepunkte durch Verschachtelung der Mikrohandlungen.

Während daher eine Ereignisfolge »Spannung ausgelöst hat, findet - bevor diese Spannung aufgelöst ist -, ein Ereignis statt, das Neugier auslöst. Bevor die Neugier aufgelöst ist, findet wiederum ein Ereignis statt, das Überraschung auslöst«, usw. Das Resultat ist, dass zwar die »Affekte « noch »evoziert [werden], aber ihre Auflösung [...] nicht mehr so wichtig [ist.] Die [Serien-]Welt besteht gewissermaßen nur noch aus der aufsteigenden Linie von Sensationen, deren Ende wenig interessiert «. Die Rezeption der Serie, so Schneider (45), »wird zur Stimulation, zum Reizmittel «. Parallel werden die Einstellungszeiten immer kürzer. Ort und Zeit des Geschehens werden nicht nur unwichtiger, sondern sind zunehmend unbestimmter, wenn man die Funktion des Ortes als Ambiente außen vor lässt. Wichtiger ist daher nicht so sehr die Handlung bzw. »was dargestellt wird«, es interessiert vielmehr die Ästhetik, »das Design einer Serie, ihre Ausstattung, ihr Erscheinungsbild «. Ein sehr gutes Beispiel hierfür wäre Michael Manns MiAMI VICE aus den 1980er Jahren. Diese Serie ist exemplarisch für die von Andrzej Wirth eigentlich für das avancierte Theater festgestellte »Ästhetik der Präsentation« im Sinne eines »Überwiegen des Performativen« (Wirth: 233). Traditionelle Fragen nach dem Sinnverstehen verlieren vermehrt an Bedeutung, Serienfolgen lösen sich als Werkeinheit eher auf und kanonische dramaturgische Schemata mit Konflikten, Normverletzungen und Lösungen treten gerne zugunsten der Bilderreize, des Arrangements und einer ver- 
schachtelten, alinearen Affektdramaturgie in den Hintergrund. In diesem Kontext ist die These des Medientheoretikers Vilém Flusser (9) aus den 1980er Jahren bemerkenswert, dass die neuen Medien den Menschen »nicht mehr dramatisch, sondern in Beziehungsfelder « einbetten. Somit wäre eine Tendenz zum nicht mehr Dramatischen sowohl im Theater als auch in der Serien-Welt zu beobachten.

Damit sollen die medienspezifischen Unterschiede zwischen Theater und Fernsehen nicht wegdiskutiert werden, die »Erotik der Signifikanten« (Roland Barthes) eines Körpers als Signifikant des Begehrens in einem theatralen Ereignis zeitigt andere mediale Spezifizitäten als der Reiz der elektronischen Bilder. Dennoch ist auffällig, dass in beiden Medien seit den 1960er Jahren das Sinnverstehen partiell zugunsten der ästhetischen Wirkung in den Hintergrund tritt und der ereignishafte, oft visuelle Reiz auf Kosten narrativer und mimetischer Elemente deutlicher wird.

Woran könnte das liegen? Der Beginn dieser Entwicklung für beide Medien liegt in der Zeit der Neoavantgarde. John Cages UnTITLED EvENT von 1952 hat ein Pendant in Nam June Paiks Fluxusfilm ZEN FÜR FILM von 1964, in dem über 8 Minuten eine weiße Leinwand zu sehen ist. Beide Medienereignisse forcieren das Energetische auf Kosten des Figuralen, was auf die Legitimationsschwierigkeiten jeder Gestalt in einer allumfassenden Medienwelt vorausweist. Diese konstituiert sich mit dem Fernsehen und der Videotechnik parallel zur Entwicklung von einer Kultur des »Spektakels « (Guy Debord), die noch eine Position der Kritik und Subversion >außerhalb< des Systems zuließ, zu der jede Gegenposition integrierenden »Simulation « (Jean Baudrillard). Spätestens seit den 80er Jahren scheint in der visuellen Medienwelt jede Referenz in den unendlichen Regress der anhaltenden Verweise der Bilder auf andere Bilder usf. zu führen. Diese Entwicklung wäre im Theater von Peter Handkes PublikumsBeschimPFung, in welcher der theatrale Gestus die Mittel der Sprache sichtbar zu machen hat, so dass die politisch-gesellschaftlichen Strukturen als veränderbare begriffen werden, bis zu Rainald Goetz' FESTUNG nachzuzeichnen. In diesem Theatertext verschwindet jeder legitime Ort der Kritik außerhalb des medialen Gesamtsystems - unlängst wieder ein Thema von Falk Richters SYSTEM I-IV. Letztlich wird jede Befragung der Welt zu einem kybernetischen Closed-Circuit der Medien-Bilder, allgemeine Aussagen müssen daher in Anführungsstriche gesetzt werden. In der medialen Immanenz stellt sich dann die Frage, ob es dem Theater gelingen kann, den elektronischen Medien etwas >Substantielles< entgegenzusetzen. Denn Zuschauer im Theater sind auch Rezipienten der populären anderen Medien, so dass sich im wahrnehmungsprägenden Gedächtnis mentale Stereotypen verfestigen, die nicht so medienspezifisch sind, wie es die Apologeten eines Theaters der reinen Präsenz vielleicht gerne hätten. Es geht deshalb nicht so sehr um das individuelle Medienereignis, sondern um die Wahrnehmungsschemata im Kopf. Diese haben bereits massive Auswirkungen auf das Theater. Auffallend ist, dass immer mehr Theateraufführungen wie etwa die Michael Thalheimers nicht länger dauern als ein Kinofilm. Beobachtbar ist eine durchaus medienaffine Ästhetik der jüngeren Regiegeneration, etwa die eines Roger Vontobel, der Figurationen der Videoclipästhetik integriert, oder eines David Bösch, bei dem ein populäres Filmzitat das nächste ablöst.

Der Höhepunkt der »Ästhetik der Präsentation« (Wirth: 233) scheint in den 1980er und 1990er Jahren erreicht worden zu sein, so dass heute sowohl für das Theater als auch für die Primetime-Serie eine weitere Trendwende im Sinne einer partiellen ästhetischen und politischen Re-Aktion konstatiert werden kann. Nicht nur gesellschaftlich, sondern auch kulturell wird die Hinwendung zu neuen Werten, zum Glauben, zum >Helden $<$ und zu einer $>$ Geschichte $<$, insgesamt die Suche nach 
Stabilität, Vertrauen und nach einer $>$ Realität $<$ jenseits des Spiels der Signifikanten durchaus wieder ein Thema. Die Revolution richtet sich diesmal eher gegen die allgegenwärtige Ironie und den Radikalskeptizismus der Postmoderne. Spätestens mit dem 11. September 2001, der als Medienereignis in den Kommentaren eines Karlheinz Stockhausen, Jean Baudrillard oder Carl Hegemann allerhand Unsicherheiten über die Referenz einer >inszenierten< menschlichen Katastrophe sichtbar machte, ist wohl der Höhe- und Endpunkt einer Entwicklung der Entsubstantialisierung seit den 1960er Jahren erreicht. Momentan ist daher die Situation auf formaler und inhaltlicher Ebene höchst ambivalent: In der Serie CSI sieht man etwa lange Einstellungen und lineare Handlungsstränge neben einer gewagten Videoclipästhetik. Konservative Werthaltungen gehen mit liberalen Verhältnissen einher: In der machtkritischen Serie 24 werden >Entscheidungsnotstände< oft mit Folter gelöst und die DESPERATE HousEwIVES werden für ihre Intrigen am Ende immer durch eine dramaturgische >invisible Hand < für ihre >Sünden< bestraft. Liberale Mütter würden in den GILMORE GIRLS und den DESPERATE HOUSEWIVES in ihrem Lebenschaos untergehen, wenn ihnen ihre konservativen Töchter nicht stets aus der Patsche helfen würden. Diese Ambivalenz scheint nicht nur den Serien, sondern auch der zeitgenössischen Dramatik eigen, die sich vielfach wieder der >harten < sozialen Realität zuwendet und mehr abzubilden als zu dekonstruieren scheint. Man denke nur an die Texte eines Marius von Mayenburg, Oliver Bukowski, Händl Klaus, Moritz Rinke, Igor Bauersima oder Jon Fosse. Ökonomische Realitäten werden trotz oder gerade wegen der umfassenden Medialisierung der Lebenswelt zum Thema, wie wir bei Falk Richter, Roland Schimmelpfennig, Fritz Kater, Gesine Dankwart, Andres Veiel und Kathrin Röggla bemerken. Dea Loher und Lukas Bärfuß wagen es gar, wie einstmals Friedrich Schiller, das Theater wieder als moralische Anstalt zu verstehen, für Bärfuß (39) soll die ZuschauerIn »den Appell spüren: Ändere dein Leben! Ich will, daß das Theater wieder Fragen stellt. Wozu dient Freiheit? Wie gehen wir miteinander um?«. Es scheint, als würde gegenwärtig sowohl im Theater als auch in der Fernsehserie als »Duplikat der Welt« der ästhetische Raum neu erkundet.

\section{Literatur}

Adorno, Theodor W. (2004 [1953]): »Prolog zum Fernsehen«. In: Günter Helmes/ Werner Köster (Hg.): Texte zur Medientheorie. Stuttgart: Reclam, S. 199-203.

Bärfuß, Lukas (2005): Interview. Chrismon 10/05, S. 39.

Böhme, Gernot (1995): Atmosphäre. Frankfurt/M.: Suhrkamp.

Boll, Uwe (1994): Die Gattung Serie und ihre Genres. Aachen: Alano.

Bourdieu, Pierre (1998): Über das Fernsehen. Frankfurt/M.: Suhrkamp.

Bühler, Gerhard (2001): Postmoderne auf dem Bildschirm, auf der Leinwand. St. Augustin: Gardez!

Field, Syd (2003): Drehbuchschreiben für Fernsehen und Film. München: Ullstein Flusser, Vilém (1985): Ins Universum der technischen Bilder. Göttingen: Vice Versa.

Creeber, Glen (2004): Serial Television. Big Drama on the Small Screen. London: British Film Institute Publishing.

Hickethier, Knut (1994): »Die Fernsehserie und das Serielle des Programms«. In: Günter Giesenfeld (Hg.): Endlose Geschichten. Serialität in den Medien. Hildesheim: Olms, S. 55-71. 
Jurga, Martin (1999): Fernsehtextualität und Rezeption. Wiesbaden: Westdeutscher Verlag.

Keppler, Angela (1994): Wirklicher als die Wirklichkeit? Das neue Realitätsprinzip der Fernsehunterhaltung. Frankfurt/M.: Fischer.

Krützen, Michaela (2004): Dramaturgie des Films. Frankfurt/M.: Fischer.

McLuhan, Marshall (1962): The Gutenberg Galaxy. Toronto: University of Toronto Press.

Pfister, Manfred (1985): »Konzepte der Intertextualität «. In: Ulrich Broich/Ders. (Hg.): Intertextualität. Tübingen: Niemeyer, S. 1-30.

Schneider, Irmela (1995): Vom Ereignis zur Performance. Zur Erzählstruktur und Erlebnisfunktion von Serien. In: Dies. (Hg.): Serien-Welten. Opladen: Westdeutscher Verlag, S. 42-51.

Vogler, Christopher (1997): Die Odyssee des Drehbuchschreibers. Frankfurt/M.: Zweitausendeins.

Wirth, Andrzej (1992): »Interkulturalität und Ikonophilia im neuen Theater«. In: Sigrid Bauschinger/Susan L. Cocalis (Hg.): Vom Wort zum Bild. Das neue Theater in Deutschland und den USA. Bern: Francke, S. 233-243. 


\title{
THEATERSOAP UND TALKSHOW-OPER: ÜBER THEATER IM FERNSEHFORMAT UND FERNSEHEN ALS THEATRALES EREIGNIS
}

\author{
BIANCA MiCHAELS
}

Fernsehen fungiert heute als bedeutender kultureller Kontext und Bezugspunkt unserer Weltwahrnehmung. An neueren Entwicklungstendenzen im Theater zeigt sich, inwiefern das Fernsehen nicht nur in unserer Wahrnehmung ganz allgemein, sondern gerade auch im Theater deutliche Spuren hinterlässt. Phänomene wie die Talkshow-Oper oder die so genannten Theatersoaps, die Fernsehformate explizit auf die Theaterbühne übertragen, können als Beispiele für die Hybridisierungstendenzen der Produktions- wie auch Rezeptionskonventionen von Theater und Fernsehen betrachtet werden. Während sie die Ubiquität audiovisueller Medien als Referenzrahmen verdeutlichen, erneuern sie zugleich auch dramaturgische und mediale Konventionen des Theaters. Anhand von ausgewählten Beispielen wie der Theatersoap FRIEDRICHSTRASSE von Katrin Spira und Catja Baumann sowie Mikel Rouse's Talkshow-Oper DENNIS CLEVELAND wird im Folgenden untersucht, wie diese Produktionen die an den medialen Rahmen des (Musik-)Theaters geknüpften Erwartungshaltungen mit Wahrnehmungskonventionen des Fernsehens in Beziehung setzen.

Im Mittelpunkt steht hierbei weniger die Frage, wie technische Mittel auf der Bühne eingesetzt werden, als vielmehr die, wie in den genannten Produktionen das Verhältnis zwischen Theater und audiovisuellen Medien sowie zwischen deren jeweiligen medialen Bedingungen und Rezeptionsgewohnheiten verhandelt wird. Eine zentrale Rolle spielen dabei intermediale Bezüge zwischen Fernsehen und Theater: im intermedialen Zusammenspiel von Fernsehformat und theatralem Aufführungsrahmen werden Wahrnehmungsgewohnheiten des Mediums Fernsehen im Theaterrahmen realisiert und gleichzeitig die jeweils zugrunde liegenden Wahrnehmungs- und Produktionsbedingungen offengelegt. Dieses akzentuierte Ausstellen der unterschiedlichen medialen Bedingungen hebt hervor, wie stark heutige Rezeptionsgewohnheiten von audiovisuellen Medien geprägt sind. FRIEDRICHSTRASSE und DenNis Cleveland nutzen dies zum produktiven Spiel mit den Differenzen zwischen (Fernseh-)Muster und Variantenbildung.

\section{Formatprogrammierung und Serialität}

Fernsehen ist immer auch Formatfernsehen, wobei sich Format als ein in Inhalt, Binnenstruktur und Präsentation auf ein klar abgegrenztes Zuschauersegment und einen bestimmten Programmplatz abgestimmtes mehrteiliges Sendekonzept beschreiben lässt. Nach Peter Hoff hat die Serie als traditionelle Form der Populärkunst auf ihrem Weg durch die Institutionen zur Produktion und Distribution dar- 
stellender Kunst heute ihre Heimat im Fernsehen gefunden, so dass Serie und Fernsehen eine untrennbare Symbiose eingegangen zu sein scheinen (vgl. Hoff: 33). Da die wesentliche Zielsetzung von Formatprogrammierung in der Zuschauerbindung besteht, ist ihr Erscheinungsbild primär nach Aspekten der Wiedererkennbarkeit und Wiederholbarkeit konzipiert. Eine wesentliche Rolle spielt hierbei die Serie unter institutionellem Aspekt als besondere Programmform des Fernsehens. Mit Knut Hickethier (12) lässt sich dies anhand der Einrichtung wiederkehrender Programmplätze beschreiben, welche »zur seriellen Produktion von Programm und damit auch zur Serienproduktion [führt], bei der dieses Strukturprinzip des Programms zum Strukturprinzip des Produkts wird«. Metonymische Bezugnahmen von der Serie innerhalb des Fernsehprogramms auf >das< Fernsehen im Allgemeinen liegen somit nicht nur darin begründet, dass das Fernsehen heute stark von Serien geprägt ist, sondern auch darin, dass die Serialität des Programms zur Struktur des Fernsehens selbst gehört. Die Serie kann demzufolge als »Prototyp für die gesamte Programmpräsentation im Fernsehen « (Giesenfeld: 2) oder auch als »mediencharakterisierende Form « (Faulstich: 47) betrachtet werden.

FRIEDRICHSTRASSE und DENNIS CLEVELAND spielen auf solche Fernsehformate an, die in Reihe produziert und (regelmäßig) rezipiert werden. Obgleich eine Fernsehtalkshow nicht als Serie im engen Sinn bezeichnet werden kann, weist sie doch aufgrund ihres festgelegten Rahmens und ihrer Integration in das Fernsehprogramm ebenfalls seriellen Charakter auf. Dieser serielle Charakter entsteht jedoch nicht durch narrative Fortsetzungszusammenhänge, sondern betrifft die Merkmale Periodizität, konstanter Publikationsort (d.h. Sendeplatz) und Wiedererkennbarkeit im Programmfluss durch gleiche Aufmachung und gleichen Umfang und somit vor allem institutionelle Aspekte.

\section{FRIEDRICHSTRASSE}

Die Theatersoap FRIEDRICHSTRASSE steht als Beispiel für eine Entwicklung, die bereits seit einigen Jahren in Deutschland zu beobachten ist, denn Theatersoaps haben Konjunktur. Beispiele von Theaterserien und Theaternovelas im deutschsprachigen Raum sind u.a.: PENSION SCHMIDT (Thomas Matschoß), WORLD WIDE WEB-SLUMS (René Pollesch), Gutes WedDing - Schlechtes Wedding (Constanze Behrens, Oliver Tautorat) sowie Scharfe SCHNITTE - DiE KLINIK-SoAP (Felix Benesch, Lukas Langhoff). Der Begriff der Theatersoap bezieht sich auf das Fernsehformat der Soap Opera als einer Serie, deren Folgen im Fall der >Daily Soap < täglich (zumeist im Vorabendprogramm) ausgestrahlt werden, während die Folgen von >Prime Time Soaps< abends zur Hauptsendezeit gezeigt werden:

»Die Bezeichnung >Soap Opera< oder kurz >Soap< für >Familienserie< geht zurück auf die bereits seit den 1930er Jahren im kommerziellen Rundfunksystem übliche Praxis, die Finanzierung der Serien von Firmen übernehmen zu lassen, die sie dann als Werbevehikel für ihre Produkte, eben zumeist Waschmittel, einsetzen konnten« (Krah: 434).

Die Heidelberger Theatersoap FRIEDRICHSTRASSE wurde 2005 von Katrin Spira und Catja Baumann, Dramaturgin und Regieassistentin am Theater und Philharmonischen Orchester der Stadt Heidelberg, initiiert. Schauplatz der Handlung ist der Theaterbetrieb Heidelberg. Die Folgen werden in etwa vierwöchigem Abstand jeweils ein Mal von einem Ensemble aus Laienschauspielern, welches von Schau- 
spielern aus dem Ensemble des Theaters unterstützt wird, aufgeführt. In klaren Anspielungen auf aktuelle Ereignisse der Stadt und des lokalen Kulturgeschehens entfaltet sich die Handlung im Theaterbetrieb. Die Welt der Figuren in der FRIEDRICHSTRASSE ist entsprechend der Formatvorlage von Fernsehserien nicht eine Schöpfung oder Funktion der Charaktere. Vielmehr stellen diese umgekehrte Metaphern für den dargestellten Erfahrungsraum dar (vgl. Giesenfeld: 4).

Die Parallelen zum Genre der Fernsehsoap sind vielgestaltig und reichen von der narrativen Serienstruktur mit fest gefügtem Rahmen, Cliffhangern etc., über explizite intermediale Anspielungen ${ }^{1}$ auf das Medium Fernsehen und seine Produktionsbedingungen. Hier sind insbesondere die in jeder Folge von FRIEDRICHSTRASSE wiederkehrenden Werbeunterbrechungen zu nennen, die sich mitten in einer Szene als deutlicher Cut ereignen: Discokugel-Beleuchtung erscheint, Fahrstuhlmusik erklingt im Hintergrund und einer der Schauspieler löst sich aus dem Szenenzusammenhang, wendet sich direkt an das Theaterpublikum, um den $\mathrm{Zu}$ schauern im Supermarktwerbetonfall neue Stücke des Theaters Heidelberg anzukündigen, während das übrige Geschehen im Hintergrund eingefroren bleibt. Nach rund 20 Sekunden Unterbrechung nimmt der Werbesprecher wieder seinen Platz in der Szene ein, Discokugel und Hintergrundmusik werden ausgeblendet und die Szene nimmt ihren weiteren Verlauf. In ähnlicher Weise werden auch Rückblenden und Traumszenen inszeniert.

FRIEDRICHSTRASSE ist jedoch nicht nur durch zahlreiche intermediale Bezüge zum Fernsehen im Allgemeinen gekennzeichnet, sondern weist auch in seinen Produktionsbedingungen Parallelen zur Fernsehserie auf: Ähnlich wie die Seifenopern ist auch die Heidelberger Produktion sehr kostengünstig produziert. Spielstätte ist die ehemalige Probebühne des Stadttheaters, die Bühne ist mit einfachsten Mitteln ausgestattet, die Darsteller spielen ohne Honorar und der Eintritt ist kostenlos.

Insgesamt dominiert in der Produktion der Live-Charakter des Geschehens, der ironische Umgang mit Formatkonventionen gerade durch das weitgehende Fehlen audiovisueller Medien in der Aufführung und eine Verstärkung der Ironie aufgrund des improvisiert wirkenden Spielorts und des Einsatzes von Laienschauspielern. Der Erfolg der Produktion ist somit nicht in erster Linie auf ihre Ästhetik oder die Qualität der schauspielerischen Leistung zurückzuführen, sondern beruht vermutlich in erster Linie auf der produktiven Spannung zwischen Erfüllung und Enttäuschung der massenmedial geprägten Erwartungshaltungen in der performativen Aktualisierung innerhalb des Rahmenmediums Theater.

\section{DenNis Cleveland}

In seiner Talkshow-Oper DENNIS Cleveland, die 1996 in >The Kitchen< in New York uraufgeführt wurde, zeigt sich das Fernsehstudio als Ort, an dem sich Oper entfaltet. Der 1957 geborene amerikanische Komponist Mikel Rouse betrachtet den Akt des Fernsehproduzierens selbst als theatral und opernhaft, wobei die Konzep-

1 Intermedialität im engeren Sinne ist hier definiert als »Versuch, in einem Medium die ästhetischen Konventionen und/oder Seh- und Hörgewohnheiten eines anderen Mediums zu realisieren « (Balme: 19). Diese sowohl die Produktionsseite wie die Wahrnehmungsseite, die technologische wie auch ästhetische Dimensionen von Intermedialität einbeziehende Konzeption bietet die Möglichkeit, sowohl den Medien auf der Produktionsseite wie auch den Rezeptionsgewohnheiten und der Medienkompetenz der Rezipienten Rechnung zu tragen. 
tion von DENNIS ClEVELAND deutlich macht, dass es ihm nicht darum geht, Fernsehen in einer Oper zu thematisieren, sondern - indem sich Oper live im Fernsehstudio abspielt - Fernsehen als Oper und damit als theatrales Ereignis zu inszenieren.

Die Formatvorlage, auf der DENNIS Cleveland beruht, ist die so genannte $>$ Daytime Talkshow<. Ebenso wie die Soap Opera ist auch die >Daytime Talkshow< ein Fernsehformat, das reichlich Möglichkeit zur Werbung bietet und gleichzeitig kostengünstig zu produzieren ist, da sie hoch standardisiert und repetitiv strukturiert ist. Unter den Oberbegriff der Talkshow lassen sich zahlreiche unterschiedliche Ausprägungen subsumieren, wie beispielsweise >Morning Talkshows $<$, >Celebrity Talkshows $<$, >Daytime Talkshows $<$ und $>$ Late Night Talkshows $<$ sowie zahlreiche Kombinationen aus diesen Varianten. Die für DENNIS CLEVELAND als formales Vorbild herangezogene $>$ Daytime Talkshow $\iota^{2}$ stellt die entwicklungsgeschichtlich jüngste Form dar und ist seit Anfang der 1990er Jahre insbesondere im amerikanischen Fernsehen allgegenwärtig:

»Die täglichen Talkshows sind mediale Inszenierungen für ein Studiopublikum und für das Publikum vor den Bildschirmen. Sie folgen einer bestimmten Dramaturgie und die Moderatoren und Moderatorinnen fungieren als eine Art Zeremonienmeister. Die Sitzordnung der Gäste ist so, dass sie nebeneinander dem Publikum frontal gegenübersitzen, aber nicht einander zugewandt sind. Zudem sitzen sie meist auf einer Art Bühne, die gegenüber dem Zuschauerraum leicht erhöht ist. Die Studiodekoration, die Anwesenheit der Kameras und der Moderatoren sowie des Studiopublikums, alles deutet darauf hin, dass hier eine Show für das Fernsehen inszeniert wird « (Mikos 1998: 446).

Das Theaterpublikum von DenNIS Cleveland ist wie das Studiopublikum von Daytime Talkshows in aufsteigenden Reihen vor der Bühne angeordnet, zwei überdimensionale Videoleinwände geben Nahaufnahmen und Publikumsreaktionen wieder. Wie im Fernsehvorbild steht der Moderator im Zentrum des Geschehens, welches umrahmt wird von Platzanweisern und >Warmuppern $<$, die das Publikum zu Beginn der Aufführung anheizen und darüber informieren, dass die Show gleichzeitig aufgezeichnet wird. Auf der Bühne befinden sich acht Sänger als Gäste, die teilweise als eine Art Chor fungieren, und im Publikum sind Solisten zwischen den Zuschauern verteilt. Die Solisten und der Chor sind verbunden über Interaktionen mit dem Moderator Dennis.

Die Idee, eine Oper im Talkshowformat zu konzipieren, beruht auf der Feststellung des Komponisten, dass das Procedere einer Talkshowproduktion im Fernsehstudio auf einer theatralen Grundsituation basiert und eine Reihe von Merkmalen aufweist, die sich gerade auch in der Bühnenoper wieder finden. Obgleich auf den ersten Blick die sozialen Systeme Kunst und Massenmedien ebenso wenig zueinander zu passen scheinen wie die unterschiedlichen Assoziationen mit den beiden kulturellen Praktiken der Oper und des Fernsehens, zeigen sich bei genauerer Betrachtung unübersehbare Parallelen zwischen dem Fernsehformat Talkshow und der Bühnenoper. Zu nennen ist hier beispielsweise die Kommunikation der Gäste auf der Bühne, welche vergleichbar der Tradition des Rampensingens nur auf das Publikum (und im Fall von DeNNIS Cleveland auf die Kameras) ausgerichtet sind,

2 Da sich der Ausdruck >Daytime Talkshow< inzwischen vor allem in den USA durchgesetzt hat und sich eine angemessene deutsche Übersetzung bislang nicht etabliert hat, wird der Ausdruck im weiteren Verlauf beibehalten. Zur Vereinfachung wird der Begriff der Talkshow folgend synonym mit dem der Daytime Talkshow verwendet. 
jedoch nicht in erster Linie mit ihren Nachbarn auf der Bühne interagieren. Als weitere Parallele ist die Differenzierung von introspektiven Arien (häufig mit bekenntnishaftem Charakter) und Ensembleszenen zu nennen. Ebenso wie die Arien nehmen auch die v.a. zu Beginn einer Talkshow geäußerten Ansichten der einzelnen Gäste häufig den Charakter eines Bekenntnisses an. Auch das in Daytime Talkshows häufig zu beobachtende Phänomen, dass mehrere Personen über längere Zeit gleichzeitig sprechen, so dass sich eine Überlagerung von Gesprächen und Zwischenrufen ergibt, findet sich in DENNIS CleVELAND und weckt deutliche Assoziationen an die Simultanszene in der Oper. Rouse betont die gleichzeitig ablaufenden unterschiedlichen Vorgänge zusätzlich, indem er ihnen unterschiedliche Rhythmen zuweist und Sprech- und Singstimmen einander gegenüberstellt.

Neben den Parallelen lassen sich auch zahlreiche Unterschiede zur traditionellen Bühnenoper beobachten, die vor allem in ihrer Medialität begründet sind. So erfordert und ermöglicht es das Konzept, eine Oper als Fernsehereignis zu rahmen, im Fall der Talkshow-Oper DenNIS Cleveland, die Proszeniumsstruktur zu verlassen und über weite Teile der Aufführung ohne vierte Wand zu spielen. Insgesamt vereinigt der äußere Rahmen von DENNIS CLEVELAND durch die Anordnung des Publikums und der Proszeniumsbühne Elemente sowohl des Theaters als auch des Fernsehens, wobei dies unter Rekurs auf ästhetische Konventionen der Oper geschieht, die sich in der Rolle der Musik und vor allem des Gesangs manifestieren. ${ }^{3}$ Denn der wesentliche (und offensichtliche) Unterschied zur Fernsehtalkshow besteht - neben der Tatsache, dass die Show nicht für das Fernsehen produziert wird - in der Musikalisierung des Geschehens.

\section{Vertrautheit und Distanz durch Wiederholung}

DenNis Cleveland und FriedrichSTRASSE kombinieren in einem Neben- (und Mit-)einander verschiedene Elemente aus unterschiedlichen kulturellen Bereichen. Wenn Fernsehen als Oper stattfindet, indem eine Oper als Fernsehereignis konzipiert und inszeniert wird, wie dies bei der Talkshow-Oper der Fall ist, so ist von einem intermedialen Transformationsprozess zu sprechen. Da sich jedoch die Bezüge bei den zwei hier untersuchten Produktionen nicht nur auf das Medium Fernsehen allgemein beschränken, sondern darüber hinaus jeweils ganz konkrete Formen dieses Mediums zitiert werden, ist an dieser Stelle vom ästhetischen Mittel des Formzitats zu sprechen. Darunter ist der reflektierte Rückgriff auf Formen zu verstehen, »die wegen der kulturellen Distanz ihres üblichen, erwartbaren Kontextes zu dem, in dem sie als Zitate auftreten, im letzteren fremd erscheinen « (Böhn: 18). Im Formzitat zeigt sich der reflektierende Verweischarakter intermedialer Elemente, während im Unterschied dazu bei hybriden Phänomenen die unterschiedlichen Elemente nicht mehr zu unterscheiden sind. Die intermedialen Formzitate dienen

3 Die Musik von Mikel Rouse verbindet klassische Techniken und Formen mit Elementen populärer Musik (Rock, Serielle Musik und außereuropäische Einflüsse) und wird elektronisch eingespielt mit einer Instrumentation, welche von Schlagwerken, elektrischer Gitarre, E-Bass, Streicher und Synthesizer dominiert wird. Die Komposition vereinigt Elemente u.a. von HipHop, Rhythm and Blues, Romantik und gregorianischem Choral, wobei der Rhythmus der Komposition gegenüber Melodie und Harmonik eine bestimmende Rolle einnimmt. So singen auch die Sänger in einer dem Sprechgesang ähnlichen Weise, die an Rapmusik erinnert und von Rouse als >Counterpoetry< bezeichnet wird. 
so der markierten Reflexion des Verhältnisses der Live-Performance zum Medium Fernsehen.

DenNis Cleveland als Talkshowoper zeigt in mehrfacher Hinsicht eine Veränderung zur Form der (konventionellen) Bühnenoper. Zum einen betrifft dies die oben bereits erwähnten medialen Verschiebungen wie beispielsweise die Auflösung der Proszeniumsstruktur. Zum anderen verändert DENNIS CLEVELAND wenn nicht die Form des Fernsehens selbst, so aber die Beobachtungsperspektive auf das Fernsehen, genauer gesagt auf das Fernsehformat der Daytime Talkshow. Ähnliches lässt sich auch für die Theatersoap FRIEDRICHSTRASSE festhalten: auch hier begünstigen die formzitierenden Bezüge eine distanzierende Beobachtungsperspektive auf das Fernsehen und seine Konventionen. Hierbei wird deutlich, dass der Einsatz audiovisueller Medien auf der Bühne gerade nicht notwendig ist, um den intermedialen Bezug zum Fernsehen herzustellen, da die mediale Grundsituation des Serienformats beim Publikum so verinnerlicht ist, dass diese als Referenz auf das Medium genügt und auf diesem aufbauen kann, ohne dass das Medium technisch oder narrativ explizit thematisiert werden muss.

Bei Betrachtung der beiden Produktionen fällt auf, dass sowohl Theatersoap als auch Talkshow-Oper ihre Produktionsbedingungen offen legen. Mit der sichtbaren Video- und Fernsehtechnik wird beispielsweise in DENNIS CLEVELAND einerseits das thematische Medium Fernsehen eingeführt, andererseits wird die theatrale Situation einer Fernsehtalkshow während der Aufnahme im Studio thematisiert. Die szenographische Einrichtung mit der starken Betonung des Studiocharakters und der dazugehörenden Elemente wie Fernsehkameras, Kameraleute etc. legt die Bedingungen der Produktion offen und ermöglicht den Blick des Zuschauers auf den Herstellungsprozess der Aufführung. DenNIS Cleveland betont den Produktionsprozess der Talkshow, indem dieser ins Spiel integriert wird und in der gesamten Konzeption sowohl die technische Welt der Medien als auch deren Inszenierungsund Manipulationstechniken ausgestellt und explizit thematisiert werden.

Während jedoch DENNIS CLEVELAND in erster Linie die Produktionsbedingungen des Referenzmediums Fernsehen in Szene setzt, sind es bei FRIEDRICHSTRASSE insbesondere die Produktionsbedingungen des Theaters, welche ausgestellt werden. Indem auf der Ebene der Repräsentation wie auf der Ebene der Realisierung, d.h. nicht nur innerhalb des Rahmenmediums Theater, sondern ebenso mit den Bedingungen und Möglichkeiten des auch als Binnenmedium fungierenden Theaters, die Kommunikationsbedingungen des Mediums Fernsehen nachgespielt werden, erscheint die Theatersoap in ihrer Wiederholung des Fernsehformats gerade nicht als Kopie, sondern vielmehr als Wiederholung des Musters mit einer klaren Betonung der Differenz zu diesem Muster. Diese Betonung der Differenz innerhalb der intermedialen Bezugnahme erreicht Rouse mit einer ganz anderen Strategie: hier fungiert die $\mathrm{Mu}-$ sik als distanzstiftendes Element, welches die Unterschiede zwischen den Wahrnehmungsgewohnheiten der Oper und des Fernsehens deutlich hervortreten lässt.

Trotz dieser Distanz stiftenden Elemente bewirkt die Übertragung von Formaten aus dem Fernsehen auf die Live-Performance jedoch auch eine große Vertrautheit, die durch den hohen Wiedererkennungseffekt hervorgerufen wird. Diese Vertrautheit lässt sich mit den Worten Søren Kierkegaards folgendermaßen beschreiben:

»Die Liebe der Wiederholung ist in Wahrheit die einzig glückliche. Sie hat nicht wie die der Erinnerung die Unruhe der Hoffnung, nicht die beängstigende Abenteuerlichkeit der Entdeckung, aber auch nicht die Wehmut der Erinnerung, sie hat die Gewissheit des Augenblicks« (Kierkegaard: 4). 
Kierkegaard betont insbesondere den existentiellen Charakter der Wiederholung, indem er diese als spezifische Form der Strukturierung von Lebenszeit betrachtet. Wie zentral der Aspekt der Wiederholung für das Fernsehen insgesamt ist und welche Funktion ihm für die Rezipienten zuzuschreiben ist, betont der kanadische Historiker und Kulturkritiker John Ralston Saul. Seiner Ansicht nach geht es im Fernsehen grundsätzlich nicht um Inhalt, weshalb jegliche Kritik an der Programmgestaltung und den Inhalten am eigentlichen Kern vorbeilaufe. Ihm zufolge ist Fernsehen vor allem deshalb so erfolgreich, weil es den Zuschauern Sicherheit und Verlässlichkeit durch das Ritual der Wiederholung bietet:

»The most accurate context in which to place television programming is that of general religious ritual. Unlike court etiquette or specific types of drama, religious ritual is designed to satisfy everyone [...]. People are drawn to television as they are to religions by the knowledge that they will find there what they already know. Reassurance is consistency and consistency is repetition « (Saul: 454).

Die von Kierkegaard beschriebene >Gewissheit des Augenblicks < wird in den LivePerformances von FRIEDRICHSTRASSE und DENNIS CLEVELAND hergestellt, indem jeweils im Laufe der Theater- bzw. Opernaufführung durch unterschiedliche Mittel Wahrnehmungskonventionen des Fernsehens realisiert werden.

Die starke Gewöhnung an das Medium Fernsehen als selbstverständlichen kulturellen Kontext verdeutlicht die von Monika Elsner und Thomas Müller geprägte Metapher des »angewachsenen Fernsehers« (392). Während Elsner/Müller die scheinbar unproblematische Verfügbarkeit des Mediums Fernsehen als Indiz dafür betrachten, dass dieses gerade deshalb, weil es nicht auffällt, Wirkung entfalten kann, erhält die Metapher im vorliegenden Zusammenhang eine weitere Bedeutung: Der angewachsene Fernseher kann hier als Markierung für das Verschwinden der Differenz zwischen >natülicher $<$ Wahrnehmung und technisierter Fernsehwahrnehmung, zwischen Alltagswirklichkeit und Fernsehwirklichkeit betrachtet werden. Theatersoap und Talkshowoper verweisen gleichzeitig auf das eigene Rahmenmedium (Theater bzw. Oper) und das thematische Medium Fernsehen. Hierbei werden die Zuschauer durch die Ubiquität der Sendeformen nahezu gezwungen, das Fernsehen und mit ihm auch seine Inhalte immer mitzudenken.

Fernsehsoap und Talkshowoper stellen also distanzgewährende Modelle dar, indem sie den angewachsenen Fernseher und seine daraus resultierenden Wahrnehmungsgewohnheiten bewusst werden lassen. Die beschriebenen Produktionen schaffen somit Beobachter zweiter Ordnung, die nicht nur das Geschehen auf und neben der Bühne beobachten, sondern vor allem auch beobachten, wie Theater Fernsehen beobachtet. So entsteht automatisch das, was Umberto Eco den kritischen Zuschauer im Unterschied zum naiven Zuschauer nennt: den Rezipienten, der nicht nur die Geschichte sieht, sondern zugleich sieht, wie sie gemacht ist und dabei auch immer die Differenz zum >Heimatmedium < des Formats mitsieht.

Wenn, wie von Vertretern der Postmoderne hervorgehoben, die Wiederholung die Differenz zu dem, was wiederholt wird, deutlich macht (vgl. u.a. Eco), ist im vorliegenden Zusammenhang das Verhältnis von Theatersoap und Talkshow-Oper zu Serie und Talkshow folgendermaßen zu beschreiben: Die Wiederholung der Fernsehformate in der Live-Performance thematisiert gleichzeitig die Differenz zu diesen Formaten - ebenso wird in der Differenz zu den Fernsehformaten die Wiederholung ihrer >Muster< sichtbar. Die hier betrachteten Produktionen betonen einerseits das Muster, indem sie die mediale Differenz hervorheben, heben aber ge- 
rade dadurch - nämlich durch die >differenzierte< Wiederholung der Wiederholung - andererseits auch die Differenz ihrer jeweiligen medialen Wahrnehmungsbedingungen hervor.

\section{Literatur}

Balme, Christopher (2004): »Theater zwischen den Medien: Perspektiven theaterwissenschaftlicher Intermedialitätsforschung «. In: Christopher Balme/Markus Moninger (Hg.): Crossing Media. Theater - Film - Fotografie - Neue Medien. München: epodium, S. 13-31.

Böhn, Andreas (2001): Das Formzitat. Bestimmung einer Textstrategie im Spannungsfeld zwischen Intertextualitätsforschung und Gattungstheorie. Berlin: Erich Schmidt.

Bolter, Jay D./Richard Grusin (1999): Remediation: Understanding New Media. Cambridge/MA: MIT Press.

Eco, Umberto (1987): Streit der Interpretationen. Konstanz: Universitätsverlag Konstanz (= Konstanzer Bibliothek 8).

Elsner, Monika/Thomas Müller (1988): »Der angewachsene Fernseher«. In: Hans U. Gumbrecht/K. Ludwig Pfeiffer (Hg.): Materialität der Kommunikation. Frankfurt/M.: Suhrkamp, S. 392-415.

Faulstich, Werner (1994): »Serialität aus kulturwissenschaftlicher Sicht«. In: Günter Giesenfeld (Hg.): Endlose Geschichten. Serialität in den Medien. Hildesheim, Zürich, New York: Olms-Weidmann, S. 46-71.

Giesenfeld, Günter (1994): »Serialität als Erzählstrategie in der Literatur«. In: Ders. (Hg.): Endlose Geschichten. Serialität in den Medien. Hildesheim, Zürich, New York: Olms-Weidmann, S. 1-11.

Hickethier, Knut (1992): »Die Fernsehserie - eine Kette von Verhaltenseinheiten. Problemstellungen für die Seriendiskussion«. In: Hoff/Wiedemann (Hg.): Serie, S. 11-18.

Hoff, Peter (1992): »Fernsehserien. Kunst im Alltag oder Wendung der Kunst ins Alltägliche? «In: Hoff/Wiedemann (Hg.): Serie, S. 28-40.

Hoff, Peter/Dieter Wiedemann (Hg.) (1992): Serie - Kunst im Alltag (= Beiträge zur Film- und Fernsehwissenschaft; Jg. 33, Bd. 43). Berlin: Vistas.

Kierkegaard, Søren (1980) [1843]: Die Wiederholung. Gesammelte Werke Abt. 5/6. Gütersloh: Gütersloher Verlagshaus Mohn.

Krah, Hans (2003): »Serie«. In: Jan-Dirk Müller (Hg.): Reallexikon der deutschen Literaturwissenschaft, Bd. 3. Berlin u.a.: de Gruyter, S. 433-435.

Mikos, Lothar (1992): »Serien als Fernsehgenre. Zusammenhänge zwischen Dramaturgie und Aneignungsweisen des Publikums«. In: Hoff/Wiedemann (Hg.): Serie, S. 19-27.

Mikos, Lothar (1998): »Die Inszenierung von Privatheit: Selbstdarstellung und Diskurspraxis in Daily Talks «. In: Herbert Willems/Martin Jurga (Hg.): Inszenierungsgesellschaft: ein einführendes Handbuch. Opladen: Westdeutscher Verlag, S. 435-451.

Saul, John Ralston (1993): Voltaire's Bastards: The Dictatorship of Reason in the West. New York: Vintage Books. 


\section{TEIL 2}

\section{Theater in (ANDEREN) Medien}





\title{
AN EARLY FILM ADAPTATION OF SOPHOCLES' 》OEDIPUS THE KING«: Cinema, Theatre, Photography
}

\author{
PANTELIS MICHELAKIS
}

It is common for accounts of the reception of Greek tragedy in cinema to begin with a silent film of Aeschylus' PrOMETHEus which was produced in Greece in 1927. ${ }^{1}$ As the record of a theatre production, the film falls neatly into an evolutionary narrative which wants early film adaptations of Greek tragedy (i) to be tools at the service of contemporary theatre productions rather than serious contenders and, perhaps, (ii) to originate from the same geographical region where Greek tragedy was born. However, even a quick look at film archives and collections in Europe and America suggests that between 1908 and 1934 more than twenty-five films of Greek tragedy were adapted for the screen, of which the Delphi PrOMETHEus is one of the last. These included adaptations of Aeschylus' ORESTEIA, Sophocles' Antigone, Ajax and Electra, Euripides' Hippolytus and MedeA, and Aristophanes' LYSISTRATA. The two plays which have been most popular with silent cinema are OEDIPUS TYRANNUS, of which we now know of four adaptations, and PROMETHEUS of which we know of five.

Many of these films are now lost but those that have survived, together with production stills, posters and other ephemera, testify to a fascinating but hitherto neglected chapter in the history of early cinema. For someone working at the intersection between classics, theatre studies and film studies, the significance of this body of films is difficult to overestimate. On the one hand its challenges evolutionary and teleological narratives which privilege later paradigms of cinema and which recycle stereotypical views of the silent era as primitive and naive. Ranging from documentaries of stage performances to ambitious reworkings of the original plays for the new medium, the films in question shed light on a diversity of traditions, methods, technologies, and spectatorial practices available to early cinema. On the other hand, this body of films challenges the foundations of the neo-Aristotelian, logocentric tradition that celebrates the originality of the dramatic text and condemns the derivative and ministerial role of its modern enactments. Silent cinema does not dispense with the dramatic text altogether but it recasts it into images, intertitles, and often pre-performance lectures and music, in ways which have profound implications for the tragic narratives concerned. What I want to do in this paper is to substantiate some of these claims while also exploring some of the methodological issues raised by research into lost films with the help of examples drawn from one case study.

1 See, for instance, Mackinnon. The film was the recording of a stage production of Aeschylus' (?) Prometheus produced in Delphi during the first theatre festival to take place in modern Greece. 
The best-documented, and arguably most important, among the now lost films on Oedipus is the one in which the French stage actor Jean Mounet-Sully starred towards the end of his long career, in $1912 .{ }^{2}$ Entitled THE LEGEND OF OEDIPUS (LA LÉGENDE D'OEDIPE), the film was directed by Gaston Roudès and consisted of four acts, each corresponding to one film reel or fifteen to seventeen minutes of screening time. ${ }^{3}$ The film must have been just over an hour long, that is, longer than any other film of Greek tragedy that I am aware of from this period. The extant stills from this film with which I am familiar are scattered in collections in Paris (Bibliothèque du Film and Bibliothèque-Musée de la Comédie Française) and Vienna (Österreichische Nationalbibliothek). One of them illustrates the scene of Oedipus' encounter with the Sphinx. The composition engages with a pictorial tradition that includes well-known nineteenth-century paintings of Oedipus and the Sphinx such as those by Gustave Moreau and Dominique Ingres and which goes all the way back to Attic red-figure vase paintings of the fifth century BC (see, for instance, the red-figure kylix from the so-called Oedipus Painter, ca. 470 BC, Museo Gregoriano Etrusco, Inv. no. 16541). Other stills illustrate the arrival at Thebes of a young Oedipus played by Jean Hervé, the supplication by the citizens of Thebes of a more mature Oedipus, played by Mounet-Sully, in a composition reminiscent of the opening scene of Sophocles' OEDIPUS THE KING, the encounter between Oedipus and the prophet Tiresius, and Jocasta, surrounded by priests and citizens of Thebes, appealing to Apollo to purify the city in a scene also familiar from Sophocles' play. Two stills depict Oedipus' discovery of Jocasta's body after the revelation of his true identity. Another still shows the blind Oedipus and his two daughters shortly before he goes into exile. If the first of the stills mentioned above invites comparison with the pictorial tradition of the encounter between Oedipus and the Sphinx, this last one has a different intertext, a photograph of the stage production of Mounet-Sully as Oedipus predating the film by some ten years, which travelled around the world on the front cover of the French theatre magazine Le Théâtre. ${ }^{4}$

THE LEGEND OF OEDIPUS was released in France in December 1912, in the USA in January 1913, and in Austria in March of the same year. It was an ambitious film not only in terms of its huge and expensive décors, glamorous costumes, technically demanding outdoor scenes, and its neo-classical atmosphere and meticulous attention to historical accuracy, but also in terms of narrative composition. The film is not the recording of a stage production but, as its title suggests, an attempt to tell the whole story of Oedipus, to retell Sophocles' play in a manner appropriate to the generic parameters of the new art form. Breaking away from the narrative of the theatrical original and challenging the neo-Aristotelian unity of time and space of contemporary theatre, the film included episodes such as Oedipus' killing of Laius, his encounter with the Sphinx and his confrontation with the body of the dead Jocasta (Birett: 209, 341).

Only the last two of the four acts of the film were devoted to the events dramatised in Sophocles' play. But even these displayed a preoccupation with action and

2 On Mounet-Sully's life and career see Mounet-Sully and recently Penesco 2000 and 2005.

3 See Chirat/Le Roy, no 03830; Bush; The Catalog of Copyright Entries: 601. MounetSully was the protagonist of a much more theatrical version of the same subject, entitled OEDIPE-ROI, which was directed by André Calmettes in 1908. On this film, see Chirat/Le Roy; Bardèche/Brasillach: 44-5.

4 This photograph is reproduced in Armstrong. Production stills and posters of the film are reproduced in Bush, Tarbox: 147; Werner. 
with showing rather than telling which is alien to Sophocles' original. Some thirty years after Mounet-Sully's first triumph at the Comédie Française in the role of Oedipus, the star now provided a new and ambitious version of the myth and the character of Oedipus for a different medium. In this, Mounet-Sully anticipated Pier Paolo Pasolini's EDIPO RE (1967), with its bold condensation of the narrative of Sophocles' play and its reordering of the sequence of events in line with their chronological occurrence, by more than fifty years.

Although little is known about the reception of LA LÉGENDE D'OEDIPE in the various countries in which it was released, the censorship records of Germany and Austria enable us to catch a glimpse of the sensitivities of the time. Mounet-Sully's Oedipus was deemed unsuitable for children in both Austria and Germany. In Germany, no less than six scenes were cut in addition: Oedipus' killing of his father, his killing of the Sphinx, his cutting off of her head, his display of the head in Thebes, the display of Jocasta's hanging body, and Oedipus' blinding of himself (Birett: 209 and 341; Werner: 125).

Greek drama may be obsessed with social taboos such as patricide, incest and self-mutilation, but it rarely visualises the often vivid narratives of violence and horror which are usually reported by eye-witnesses. The film on the other hand did not only gesture towards - but in fact centred its attention on episodes which were only verbal in the original. The still of Oedipus' confrontation of the hanging corpse and blank gaze of dead Jocasta illustrates how early cinema could operate both as an apparatus of horror and as a vehicle for the melodramatic exhibition of bodily suffering and pain. Similarly, Oedipus' decapitation of the Sphinx, and the display of her severed head as trophy in Thebes mark the film's departure from both Sophocles and classical mythology, and align Oedipus with the action heroes of silent cinema. By focusing on taboo issues under the veil of serious drama and art, the film shows how early film adaptations of Greek drama blurred the distinction between high art and popular entertainment, cultural conventions and their transgression. Early cinema could challenge bourgeois morality and aesthetics while also seeking to reaffirm them.

What I have tried to show so far is how an early film adaptation of a Greek play, for all its institutional and aesthetic affiliations with Greek tragedy as a dramatic text and as a living theatrical tradition, maintains its artistic autonomy from theatre. What I would like to do next is to show that the relation between cinema and photography raises similar methodological challenges to the film historian. Moving away from the rhetoric of authenticity and objectivity conjured up by terms such as >evidence< and >data<, I will try to challenge the idea that the cinematic performance can be recovered in a more or less pristine state if the salterations and distortions < of photographs, posters and other types of >sources< are ironed out. The appeal to film reception of the empirical methodology of sources and of the simpartiality< of the research practices of historiography may be strong, not least because of the sometimes large amount of new knowledge and information into which it taps. However, the most interesting work in film reception, as, I would add, in performance reception, takes place not at the level of accumulation and sequential listing of empirically accurate knowledge, a necessary but not sufficient condition for analysis best left to theatrical annals or cinema databases, but at the level of identification, evaluation, and analysis of this knowledge.

Like the stills of theatre productions, the stills of lost films have a double history, serving different functions before and during the release of a film and when the 
film is no longer screened and fades from personal and collective memories. ${ }^{5}$ As instruments of the publicity mechanisms of film promotion and distribution, production stills stand for a spectacle yet to be seen. As objects at the hands of film or theatre historians, they become traces of a text which can no longer be read. In the former case they perform the function of teasing and provoking. In the latter case they appear as incomplete, impoverished fragments. In both cases the production still plays with the notion of death and discloses competing and conflicting takes on it. Like photography in general, stills thematize death both as absence, as ghostly and shadowy presence, and as permanence and fixity. A good example for thinking about the playful attitude of photography with death as both permanence and absence is the still which displays with shocking realism the hanging body of Jocasta. Showing what should not be seen, what prompts Oedipus to blind himself and what is never enacted on stage in Sophocles' tragedy, the still had an important role to play in the publicity campaign of the film. However the scene to which the still refers was censored and could not be shown. If the still promised a complete and literal objectification of the female body, a moment of masculine, voyeuristic pleasure, the censor forbade the screening of the relevant scene as one in which social norms break down, where voyeuristic pleasure threatens to destroy, rather than sustain, reality. Photography, then, illustrates not what the original spectators of THE LEGEND OF OEDIPUS saw, but what they were first promised, and what they were then forbidden to see. In doing so, it provides an alternative way of seeing, providing insights not only into the assumptions about the supposed pleasure of viewing but also into the regulatory mechanisms of early cinema. The still may shed light on a censored scene but at the same time severs the composition from its original narrative context, stealing something from cinema and reducing it to a frozen frame. The filmic narrative is not the only context from which the picture severs its subject. A different version of the same photograph, held in the BibliothèqueMusée de la Comédie Française, includes the beams which support the roof of the studio above the sets of the film, breaking the illusion of realism and exposing the $>$ constructedness $<$ of spectacle the picture seeks to communicate. If the production still reveals what one must not see (whether one identifies with Oedipus gazing at Jocasta or with the spectator watching the censored version of the film), at the same time it also hides the larger picture of the realities of its own production, circulation and preservation. In its turn, the picture which discloses the workings of the production still has its own larger context which, however hard one looks at the picture itself, will not be revealed. Like the theatrical conventions of fifth-century Athens and the regulatory mechanisms of early cinema censorship, the politics of acquisition and public display of pictures in the context of contemporary research in the humanities provides a context in which the desire to know and the pleasure of seeing can be mutually exclusive.

In Sophocles' OEDIPUS THE KING, the issues of knowledge and vision are juxtaposed in unexpected and challenging ways. These same issues intersect in the methodologies involved in the reception of lost films. To reconstruct the LEGEND OF OEDIPUS one needs to draw not only on Sophocles' dramatic text but also on early twentieth-century theatre, ancient and modern iconography, censorship records, posters, and photography. The film has been transmitted to us neither as a material object nor as a self-contained narrative but through its visual and textual traces. None of these traces is filmic. They are scattered in a variety of media with their own preoccupations, possibilities and limitations. What is more, some of these

5 On the relation between photography and theatre, see Hodgdon. 
traces relate to segments of the filmic narrative which were not screened. Far from unproblematic, then, filmic traces hide things they should show and show things they should hide, always concealing at least as much as they reveal. Filmic traces are not so much pieces of a jigsaw waiting to be reconstructed for the larger image of the film to come forth in all its glory. On the one hand they are like the negatives of a photograph, or backstage glimpses of a theatre performance. On the other hand they act as nested Chinese boxes or Russian dolls that never end. Unlike the deathlike certainties of the fictions projected onto the cinematic screen, the realities behind the screen defy closure. Neither irretrievably lost nor fully present, early films of Greek tragedy emerge through an uneasy and complex relation between knowledge and vision, past and present, between cinema, theatre and photography.

\section{Literature}

Armstrong, R. H. (1999): »Oedipus as Evidence: the Theatrical Background to Freud's Oedipus Complex«. In: PsyArt 3. www.clas.ufl.edu/ipsa/journal/1999/ armstr01.htm (10.10.2006).

Bardèche M. \& R. Brasillach (1938): The History of Motion Pictures. New York: W.W. Norton \& Company/The Museum of Modern Art.

Birett, H. (ed.) (1980): Verzeichnis in Deutschland gelaufener Filme: Entscheidungen der Filmzensur 1911-1920 Berlin, Hamburg, München, Stuttgart. Munich: Saur.

Bush, W. S. (1913): »Oedipus Rex«. In: The Moving Picture World 15 (January $25), 346$.

Chirat, R. \& E. Le Roy (eds.) (1995): Catalogue des Films Français de Fiction 1908-1918. Paris: Cinémathèque française.

Hodgdon, B. (2003): »Photography, Theater, Mnemonics; or, Thirteen Ways of Looking at a Still«. In W. B. Worthen/P. Holland (eds.): Theorizing Practice: Redefining Theatre History. London: Palgrave Macmillan, 88-119.

Mackinnon, K. (1985): Greek Tragedy into Cinema. London: Croom Helm.

Mounet-Sully, J. (1917): Souvenirs d'un tragédien. Paris: P. Lafitte.

Penesco, A. (2000): Mounet-Sully et la partition intérieure. Lyon: Presses Universitaires.

Penesco, A. (2005): Mounet-Sully: >L'homme aux cents cours d'hommer. Paris: Les Éditions du Cerf.

Tarbox, C. H. (1983): Lost Films (1895-1917). Los Angeles, CA: Film Classic Exchange

The Catalog of Copyright Entries, Motion Pictures 1912-1939 (February 3, 1913) (1951) Washington, D.C.: The Library of Congress,

Werner, G. (1987): »König Ödipus als Film? Reinhardt, Hofmannstahl und der frühe deutsche Stummfilm«. In: Hofmannsthalblätter 35/36, 121-28. 



\section{Reading Classical Drama on Film}

\section{EDWIN HEES}

My starting point is that filming ancient Greek tragedy is simply a continuation of a process that has been occurring over centuries, even millennia (cf. Allen: 101-108), and as such represents the phenomenon of cultural transmission. In this article my focus will be on perceptions of the meanings of these ancient texts, and - like any other texts - these texts may be thought of as sign systems that move through history, acquiring and shedding meanings as they go along. So it's clear that I do not subscribe to any idea of the autonomy of texts, universality of meaning or authenticity of representation, but I am interested rather in the processes of signification - the social and cultural factors that engender the meanings of texts in their contexts - recalling the Derridean notion that texts are context bound, but contexts are boundless. In this highly unstable sphere I take some small comfort from TS Eliot's famous dictum on Shakespearean scholarship: »About anyone so great as Shakespeare, it is probable that we can never be right; and if we can never be right, it is better that we should from time to time change our way of being wrong « (Eliot: 126).

The four films I want to comment on as representative examples to conclude this paper are: MEdEA (Pier Paolo Pasolini, 1970), MEDEA (Lars von Trier, 1988), EleCtRA (Michael Cacoyannis, 1961) and ElECTREIA (also known as ElECTRA, My LOVE) (Miklós Jancsó, 1975). Before considering the four films themselves within this semiotic framework, I want first to describe very briefly two instances of this process of cultural transmission that will (I hope) crystallise a number of points I want to raise about appropriation, authenticity and cultural memory. The one takes us back to the 1590s and the other to the 1780s. And the key issue here one might sum up as being that of >authenticity of representation $<$, often a sticking point for sceptical commentators for whom the very medium of film has a relatively low cultural status - perhaps because the commercial imperatives driving it are so strong. Let me present a short quotation on this woolly-sounding notion of >cultural memory<, and then I want to glance at Monteverdi and Mozart before moving on to the movies.

»The term cultural memory signifies that memory can be understood as a cultural phenomenon as well as an individual or social one ... [in cultural studies] it has displaced and subsumed the discourses of individual (psychological) memory and of social memory ... The interaction between present and past that is the stuff of cultural memory is, however, the product of collective agency rather than the result of psychic or historical accident « (Bal et al.: vii).

In this understanding, adaptations and appropriations are not wilful substitutions for, or even worse, violations of, the classical texts, but more a matter of constant and unavoidable assimilation and regeneration within given cultural contexts (and 
all the complexity that that implies). In the field of literary studies, even the most cursory glance at the stage histories of Shakespeare's plays, for example, make it abundantly evident how aspects of their meanings have changed over the past 400 years - a post-Freudian kind of reading of HAMLET would probably have seemed wilfully obtuse and eccentrically reductive in the $18^{\text {th }}$-century, which had a very different conception of personal identity. This phenomenon of multiple meanings manifesting themselves over the course of time is not simply a question of »multiplicity of meaning « (Roman Jakobson in Lloyd-Jones: 45) which may be inferred from a text (e.g. one's understanding of Hamlet in his pursuit of revenge could simultaneously encompass a range of quite contradictory responses - so could one's responses to Medea murdering her children be profoundly ambivalent). These multiple meanings generated over the course of time are more a matter of constantly changing representation - or more precisely resignification - of these figures in a way that engages a contemporary audience. Example would include Hamlet as disaffected punk teenager in New York in 2000, as played by Ethan Hawke in Michael Almereyda's 2000 film; Electra as a revolutionary Hungarian heroine in Jancsó's film; Medea as a feminist victim in Lars von Trier's film. The chance invention of opera provides a familiar but instructive example of just how unpredictable the process of cultural reconstruction can be. So, a bit of a detour into the world of opera - which is widely acknowledged as a performance mode that has been highly creative in keeping Greek tragedy >alive< in Western civilisation.

I like David Wiles' very direct approach to the idea of cultural memory in his Greek Theatre Performance (179):

»We can only understand what Greek theatre was like in the past by looking through the eyes of the present [...]. An objective view of the ancient world is impossible. However, by seeing how different generations have reinterpreted Greek tragedy, we can gain some sort of perspective on the complex relationship of past and present [...]. What seems authentic to one generation seems stilted and irrelevant to the next $[\ldots]$ the past is constantly being rediscovered.«

He points out that the first Greek tragedy to be performed in modern translation (Sophocles' OEDIPUS, Aristotle's »ideal « tragedy) was presented in northern Italy in 1585 - the aim of those involved was fidelity to the original, but their endeavours had entirely unexpected and unintended consequences. Two aspects of the production deserve special notice in terms of this discussion. The first was an issue raised immediately by a contemporary critique - the nature of the translation, which was regarded as most unsatisfactory. The second issue was the decision not to use masks - and the reason is interesting: because masks were widely worn in Italy at this time by the gentry seeking anonymity at carnival time, and by mountebanks and comic actors, they could not be reconciled with the spirit of tragedy. So the whole notion of an >authentic $<$ performance of a Greek tragedy is undermined the very first time it was tried in Western Europe.

But this production was only part of wider attempts to revive >authentic $<$ Greek tragedy that were underway in Italy at about this time (1590s). These efforts arose out of the very detailed debates on the nature of the declamatory style of Greek drama, contemporary understanding of vocal harmony, and the conflicting claims of counterpoint and monody - often with detailed reference to Plato and Aristotle (see Donington: 22 passim). The whole enterprise was driven by an attempt to 
ascertain the relative status of music and words as they were used in classical Greek choruses.

The first such >Greek tragedy< of which we have the music complete is Peri's EURIDICE (Florence 1600) and within only half a dozen years of that appeared the first indisputable masterpiece of what we now call »opera « - Monteverdi's ORFEO (Mantua, 1607). But it would be quite wrong to think of Monteverdi as a selfconscious revolutionary innovator (Dent: 32 ) - he was simply developing wellestablished attempts to appropriate the >authentic < principles of classical drama into modern performance modes - specifically, the idea was to revive the musical declamation of ancient Greek tragedy (as they understood it) and almost inadvertently Monteverdi and his fellow dramatists/composers created an extremely powerful new musical form of expression, namely opera, which we would distinguish quite clearly from Greek drama. The issue here is not one of categorisation, but very specifically one that revolves around the inescapable processes of appropriation and signification.

To remain with opera for a moment, Mozart's first mature opera IDOMENEO (1781) offers a particularly interesting instance of culture-specific appropriation that quite cavalierly (and brilliantly) disregards any preoccupation with >authenticity<. In the first part of the $18^{\text {th }}$ century German writers were (also) advocating a revival of Greek drama through opera as part of a wider reform of German culture, encouraging German composers in the task of creating a modern Euripidian drama (cf. Till: 62-63).

The plot briefly is this: Idomeneo is on his way home from the Trojan war - to secure safe passage he makes a vow that he will sacrifice the first person he meets to Neptune (an almost archetypal recipe for tragedy). This person (surprise!) turns out to be his son, Idamante. But what is interesting in our context is that there are two women who love Idamante, namely Ilia (a captured Trojan princess) and most strangely - Electra. Her presence in the IDOMENEO story has no legendary precedent and the character of Electra first appears in an opera libretto on IDOMENEO just a few years before Mozart embarked on his own opera. But why Electra specifically? She has no driving function in the plot - everybody ignores her and anybody could have served as a deranged foil to Ilia as Idamante's lover.

Her significance is that her very presence in the story is a strong signifier that functions in a specific way in the Enlightenment context of the opera. Primarily she exists to bring with her into the story all the associations of sacrifice and retribution which haunt the family of Agamemnon - the alternation between reason (Ilia) and unreason (Electra). Electra is unable to overcome her passions and so is destroyed by them (Till: 73). Nicholas Till points out in his wonderful study Mozart and the Enlightenment that sacrifice is such a dominant theme in $18^{\text {th }}$-century opera and literature - think of Gluck's and Goethe's preoccupation with story of Iphigenia precisely because it enables artists to contrast in a very dramatic way the outmoded pieties about submission to the gods and the new emphasis on natural law. Perhaps, then, Electra's dramatic function in IDOMENEO is to go mad precisely because she can neither submit gracefully to the process whereby Neptune ultimately endorses natural law (by saving Idamante from being sacrificed by his father Idomeneo and granting him Ilia, the Trojan princess, as his queen), nor can she ultimately escape the furies that have been pursuing her and her brother Orestes since their murder of Clytemnestra. She is the archetypal doomed antagonist. Till's explanation of her insanity is convincing in the Enlightenment context - the values of reunion, regeneration, fusion and harmony had to be >officially< endorsed in the opera. She 
has therefore been appropriated from another, loosely related story (Agamemnon and the Trojan Wars - see Mann: 253-288, for a full account) in order to give what she represents dramatic weight as a kind of counter in the cultural negotiations of the Enlightenment.

Now may be a good time to fix the focus more specifically on the concept of >appropriation< - by means of a rather long quotation from a detailed study on appropriations of Shakespeare's play into, among other things, the medium of film:

»To appropriate: to take possession of for one's own; to take to one's self. Associated with abduction, adoption and theft, appropriation's central tenet is the desire for possession. It comprehends both the commandeering of the desired object and the process of making this object one's own, controlling it by possessing it. Appropriation is neither dispassionate not disinterested; it has connotations of usurpation, of seizure for one's own uses. In the world of literary studies, the process is both necessary and unavoidable. As Hans Robert Jauss writes: >A literary event can continue to have an effect only if those who come after it still or once again respond to it - if there are readers who again appropriate the past or authors who want imitate, outdo, or refute it $<. .$. Scrutinised dispassionately, every act of interpretation can be seen as an act of appropriation - making sense of a literary artefact by fitting it within our own parameters« (Marsden: 1).

So: every act of interpretation is an act of appropriation; the process of appropriation is both necessary and inevitable. In other words, this process is not an alternative to some other process which guarantees greater authenticity or the truth. Greek tragedy was appropriated into the medium of film because the vast social, cultural and technological networks of twentieth-century communication (each one with its own specific history) made possible a specific way of engaging with past experience that was considered viable and valuable - but it was an inevitably mediated process. In the few sketchy comments that follow I just want to hint at the way that the medium of film mediates meaning.

\section{ELECTRA}

Cacoyannis's ELECTRA (1961) is the one of these four films that was probably intended as the most direct >translation< of Euripides' tragedy. But it's inevitable implication in the signifying systems of the film medium - to say nothing of Cacoyannis's understanding of Euripides and his assessment of what would work as tragedy on the screen - means that it generates meanings that could not even have been conceived by Euripides. Like the other three films, this one makes striking use of the enormously expressive capacity of the medium to use landscape as a powerful metaphor to communicate (among many other things) Electra's sense of isolation, while camera angles and editing can suggest relative power relationships and degrees of distance and intimacy that are not possible on the stage.

But it is Cacoyannis's decision to shoot the film in black and white that has particularly interesting consequences (i.e. regardless of what was or was not possible with his budget). It places the film within a very specific and highly influential tradition of post-war filmmaking, namely that of Italian Neorealism, which was counter-hegemonic in relation to commercial cinema in at least one crucial way: it conveys a sense of harsh realism that at least one commentator feels has the effect 
of making the film more tragic than Euripides' play (MacKinnon: 77) by eliminating some of the more deliberately mundane qualities, and the ambiguities and alienating effects in Euripides' depiction of the action. Also, the removal of the play's dei ex machina at the end of the film (another consequence of the Neorealist mode) means that Electra and Orestes simply drift off into a guilt-ridden exile by wandering into an utterly barren and dark landscape - they quite literally become diminished figures in this landscape. This works >against< contemporary readings of Euripides as a much more sardonic, even anti-tragic, dramatist.

In contrast, Miklós Jancsó's ELECTRA, MY LOVE (1975) (based on a popular Hungarian play which was in turn based on Euripides) is far more explicitly and self-consciously a politicised >rewriting < of the Electra story both advocating and celebrating the need for another Hungarian >revolution< (the play apparently makes the allusion to the 1956 uprising more explicit - the playwright also wrote the screenplay). Much of the visual imagery - including a recurring image of the herd of horses circling the protagonists on the open plains, where the story is worked out in terms of oblique references to the overthrow of dictators, and the >death $<$ and revival of Electra and Orestes - draws attention to this circular pattern. The film's mise en scene sometimes suggests a medieval or seventeenth-century setting in places, but at the end Elektra and Orestes are whirled off victorious in a bright red helicopter, while we hear the story of the phoenix in voice-over as a parable about social justice. As is fitting in a film about a successful revolution (even as a kind of fantasy), there is something upbeat and uplifting about the ending.

\section{MEDEA}

What is of particular significance about the two MEDEA films is their highly distinctive visual styles - >cinematically< distinctive, that is (even though Von Trier's film was made for television). Although they may depart more radically than Cacoyannis's version of Electra from the source text, they have (I think) more successfully preserved the tensions, ambiguities and even contradictions which Euripides has built into his narrative - even though Pasolini interrogates what are quite contemporary cultural conflicts (he was making his NOTES FOR AN AFRICAN ORESTEIA at the same time), while feminist discourses inform Von Trier's film.

Pasolini opens the film with a lengthy sequence of highly evocative images; for example, at the beginning of the film we see a number of shots of Medea as high priestess or sorceress in Colchis. And as someone with an appreciation of the principles of semiotics, Pasolini constructs these scenes visually so that two sets of signified are possible for each signifier. The sacrifice of the young man and subsequent distribution of his blood is both an >othered < barbaric ceremony (in which blood and holy water are conflated) and also a fertility ritual accorded great and detailed respect by Pasolini. Medea throws herself on the flames outside of the temple housing the golden fleece and is simultaneously hurt and purified. The dismemberment of her brother is filmed with an unsensationalised objectivity which bears testimony to Medea's ruthlessness and her intense love for Jason. And, of course, Maria Callas brings to the film her strong associations with Cherubini's opera and yet she remains a virtually silent and often rather wooden presence on the screen. In two perceptive readings of this film Ian Christie (2000) and Kenneth McKinnon (1986) offer interpretations with slightly different emphases, but they concur that visually the film strikingly evokes two contrasting worlds held in an 
ambivalent and ambiguous tension - precisely what Euripides does at the end of his play. Ian Christie places Von Trier's MEDEA quite explicitly (and quite correctly, in my view) within the context of late-twentieth-century filmic conventions when he notes that Von Trier's style »points to the possibility of a form of visual drama which is less dependent on >linear narration than on the accumulation of meaning within and between images, in a developed form of Eisensteinian >montage « (Christie: 159). Dialogue is minimal - an austerity that may derive from the script originally written by Carl Theodore Dreyer - but the highly expressionistic use of colour, focus and lighting convey an oppressive sense of doom in what is a very quiet and dramatically understated film. »Von Trier has responded to the challenge of classical tragedy by forging a novel visual language to accommodate the essential absence of narrative causality in MEDEA « (Christie: 159). For example, at the end of the film he breaks all the rules of classic frame composition to indicate Jason's total, paralysing disorientation after he discovers his sons' bodies - Jason drifts randomly in and out of the frame, which is sometimes just left >empty<; for long moments (cinematically speaking) we see - in an extremely high-angle shot only the empty field of wild grass and hear only the wind. Parallel editing shows us Medea sitting absolutely still and apparently disconsolate on Aegeus' boat, waiting to be transported away, but because the focus is so intensely on the visual, when she suddenly undoes her hair and lets it falls to her shoulders, we cannot help but read that as a kind of release, if not vindication. Von Trier has used a technology and a medium that Euripides could not even have dreamt of in order to capture a very Euripidean moment - summed up recently as one in which »heroism is dead « (McDonald/Walton: xvi).

\section{Literature}

Allen, William (2002): Euripides: Medea. London: Duckworth.

Bal, Mieke/Jonathan Crewe/Leo Spitzer (1999): Acts of Memory: Cultural Recall in the Present. Hanover, London: Dartmouth College.

Christie, Ian (2000): »Between Magic and Realism: Medea on Film«. In: Edith Hall/Fiona Macintosh/Oliver Taplin: Medea in Performance 1500-2000. Oxford: Legenda, 144-165.

Dent, Edward (1965): Opera. Harmondsworth: Penguin.

Donington, Robert (1981): The Rise of Opera. London: Faber and Faber.

Easterling, Pat E. (ed.) (1997): The Cambridge Companion to Greek Tragedy. Cambridge: Cambridge UP.

Eliot, Thomas S. (1976): Selected Essays. London: Faber and Faber Ltd.

Hall, Edith/Fiona Macintosh/Oliver Taplin (2000): Medea in Performance 15002000. Oxford: Legenda.

Lloyd-Jones, Hugh (1982): Classical Survivals: The Classics in the Modern World. London: Duckworth.

Mann, William (1977): The Operas of Mozart. London: Cassel.

Marsden, Jean I. (ed.) (1991): The Appropriation of Shakespeare: Post-Renaissance Reconstructions of the Works and the Myth. New York: Harvester/Wheatsheaf. MacKinnon, Kenneth (1986): Greek Tragedy into Film. London: Croom Helm.

McDonald, Marianne/J. Michael Walton (2004): »Introduction«. In: Marianne McDonald/J. Michael Walton (eds): Euripides: Electra. London: Nick Hern Books, v-xxii. 
Rosenstone, Robert A. (1995): Visions of the Past: The Challenge of Film to Our Idea of History. Cambridge, Mass.: Harvard UP.

Snyder, Stephen (1980): Pier Paolo Pasolini. Boston: Twayne Publishers.

Till, Nicholas (1992): Mozart and the Enlightenment: Truth Virtue and Beauty in Mozart's Operas. London: Faber and Faber.

Wiles, David (2000): Greek Theatre Performance: An Introduction. Cambridge: Cambridge UP. 



\title{
StAGE DOOR - ÜBER DEN KINEMATOGRAPHISCHEN BLICK AUF DEN BÜHNENEINGANG
}

\author{
STEFANIE DIEKMANN
}

\section{Vom Theater handeln}

Was zeigt ein Spielfilm, der das Theater als Setting und Sujet behandelt? In jedem Fall (und auf den ersten Blick): eine je spezifische Darstellung des Theaters, die mit den Realitäten der Theaterarbeit mehr oder weniger viel zu tun hat. Dann: Bilder zu einer Diskursgeschichte des Theaters, da die filmische Darstellung von Theaterproben und -produktionen, Theaterkünstlern, -publikum, -vorstellungen etc. keineswegs unschuldig ist, sondern gesättigt mit Vorstellungen davon, >was das Theater ausmacht $<$. Schließlich auch: Bilder zu einer Diskursgeschichte des Kinos, denn wo das Kino vom Theater handelt, handelt es immer auch von sich selbst.

Das Kino als das Andere des Theaters, das Theater als das Andere des Kinos sind zentrale Motive der Debatten, die in den 1910er und 1920er Jahren über das Verhältnis der beiden Künste geführt werden (vgl. Albersmeier; Schweinitz). Für die spätere Filmtheorie verlieren diese Debatten an Bedeutung, aber das heißt nicht, dass das Theater für das Kino erledigt wäre, oder dass es für dessen Selbstverständigung keine Rolle mehr spielte. Auf dem Schauplatz der Leinwand dauert die Auseinandersetzung an. Sie beginnt ebenfalls um 1910, 1920 und setzt sich bis heute fort, denn nach wie vor werden Filme über das Theater gemacht und nach wie vor ist in jedem dieser Filme etwas zu finden: ein Motiv, eine Szene, von denen eine Erzählung über die Geschichte von Theater und Kino ihren Ausgang nehmen könnte.

Die Bühnentür gehört zu diesen Motiven. Als Koordinate der theatralen Topographie ist sie in einer ganzen Reihe von Filmen zu finden und spielt in einigen eine etwas größere Rolle, unter anderem in drei Hollywood-Filmen aus den Jahren um 1940, 1950, die (nicht ganz zufällig) mit dem Thema des Theaterdebüts befasst sind.

\section{Literalität der Topologie}

STAGE DoOR (USA 1937) - »Bühneneingang « - ist der Titel eines Films von Gregory La Cava, in dem allerdings nicht eine einzige Szene vor einem Bühneneingang spielt. Tatsächlich erscheint der Bühneneingang nur für eine Minute oder zwei als Hintergrundbild des Filmvorspanns und danach kein weiteres Mal, da die folgenden Szenen entweder in der Theatergarderobe, auf der Theaterbühne oder im Zuschauerraum des Theaters angesiedelt sind, vor allem aber in einer kleinen Pension, in der die Schauspielerinnen auf einen Termin zum Vorsprechen und auf ihre große Chance warten. Der Salon der Pension ist der Hauptschauplatz des Films, für 


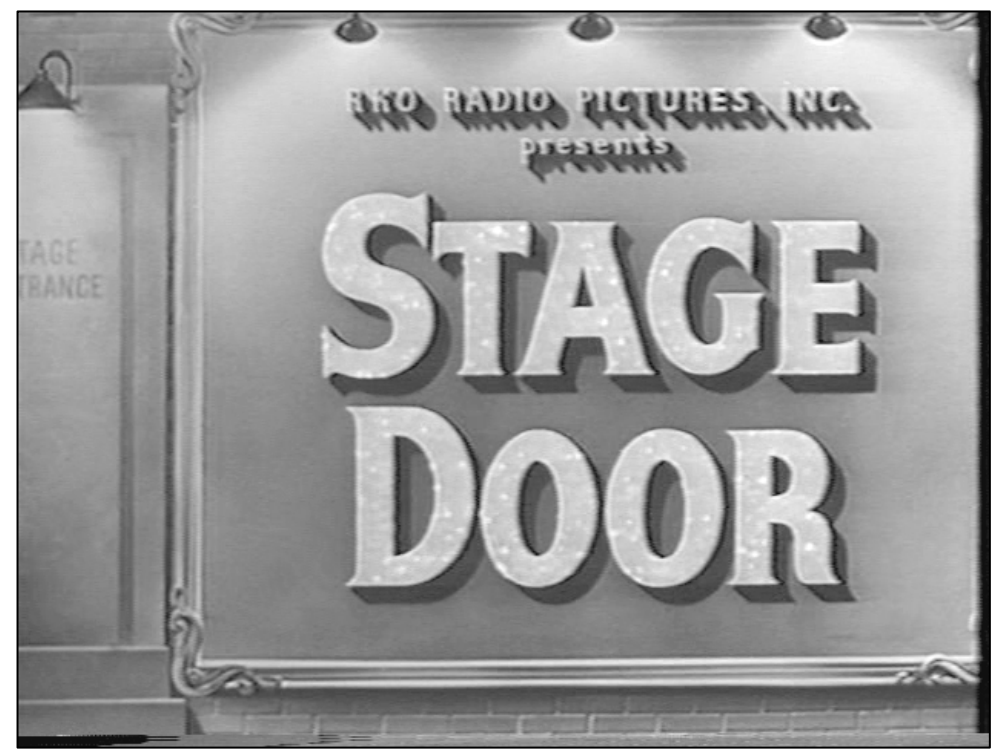

Abbildung 1: Der Bühneneingang als Binnenmotiv, aus: Gregory La Cava, STAGE DOOR (1937).

die meisten Figuren des Films die einzige Bühne, die sie je betreten werden; zugleich aber auch etwas wie ein Antichambre, i.e. jener Raum, in dem man sich auf den Eintritt in die Welt des Theaters vorbereitet.

Die Theatergängerin aus J. L. Mankiewiczs Film All About Eve (USA 1950) wird sich für eine andere Taktik entscheiden: nicht für die langwierige Prozedur des Wartens - Bangens - Vorsprechens - Wieder Wartens, sondern für eine individuelle und, wenn man so will, direktere Annäherung, auch wenn das Warten dabei ebenfalls eine gewisse Rolle spielt. Wochenlang steht Eve Herrington (Anne Baxter) in der Passage, die von der belebten Straße zum Bühneneingang des Broadway-Theaters führt. Sie steht dort, wenn der Theaterstar Margo Channing (Bette Davis) ein paar Stunden vor der Vorstellung das Theater betritt; sie steht wieder dort, wenn Margo nach der Vorstellung das Theater verlässt, Abend für Abend, bei Wind und Wetter, und es ist nur eine Frage der Zeit, bis man sie einlädt, ebenfalls durch den Bühneneingang zu treten und der Garderobe des Theaterstars einen Besuch abzustatten. Enter Eve: Mankiewicz hat seinen Film so angelegt, dass Eves erster Eintritt in das Theater und ihr Eintritt in die Diegese ziemlich genau koinzidieren, und wie sich bald zeigen wird, ist sie von da an nicht so leicht wieder loszuwerden.

Die junge Heldin in George Cukors THE ACTRESS (USA 1953) ist nicht so erfolgreich, wenngleich es auch ihr gelingt, den Bühneneingang zu passieren. Diese Figur (Jean Simmons) ist >drin<, fast ehe sie es sich versieht, aber fast noch schneller ist sie wieder draußen, aus dem Theater gewiesen und somit erneut in die Position der Außenstehenden (dem Theater nicht Zugehörigen) gebracht. Ihr zweiter Versuch, im Theater Aufnahme zu finden, wird dann eher nach dem Muster von STAGE Door gestaltet sein, doch ist er, in einem nicht uninteressanten Komplementärverhältnis zu All ABOUT EvE, ebenfalls an den Grenzen der Diegese situiert: 


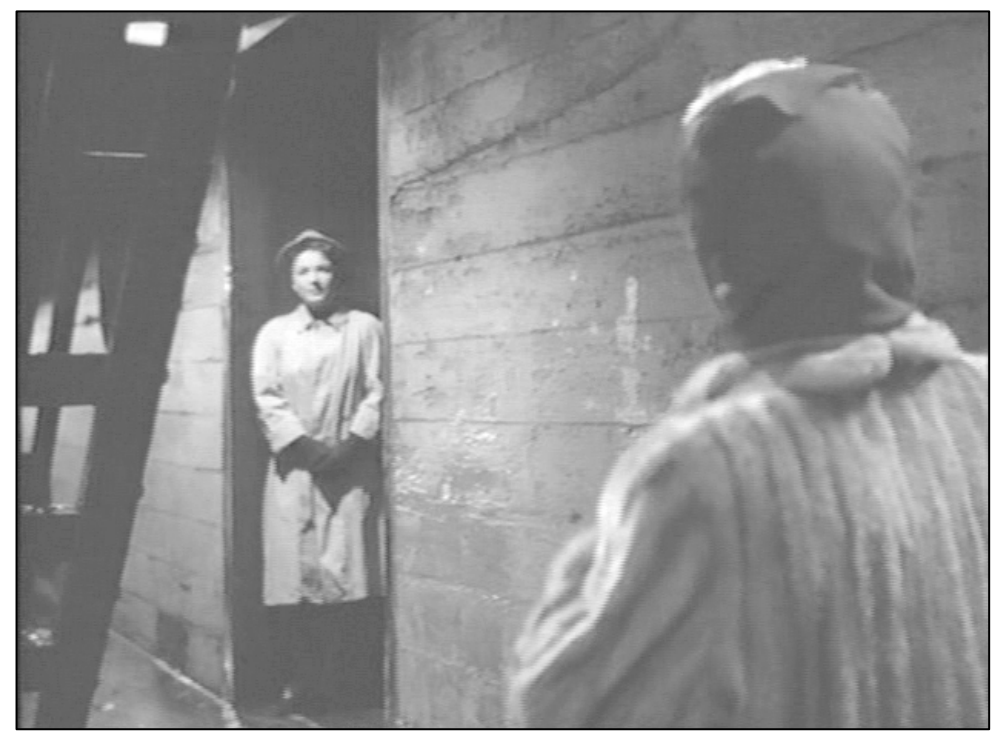

Abbildung 2: Warten vor dem Bühneneingang, aus: Joseph L. Mankiewicz, ALL ABOUT EVE (1950).

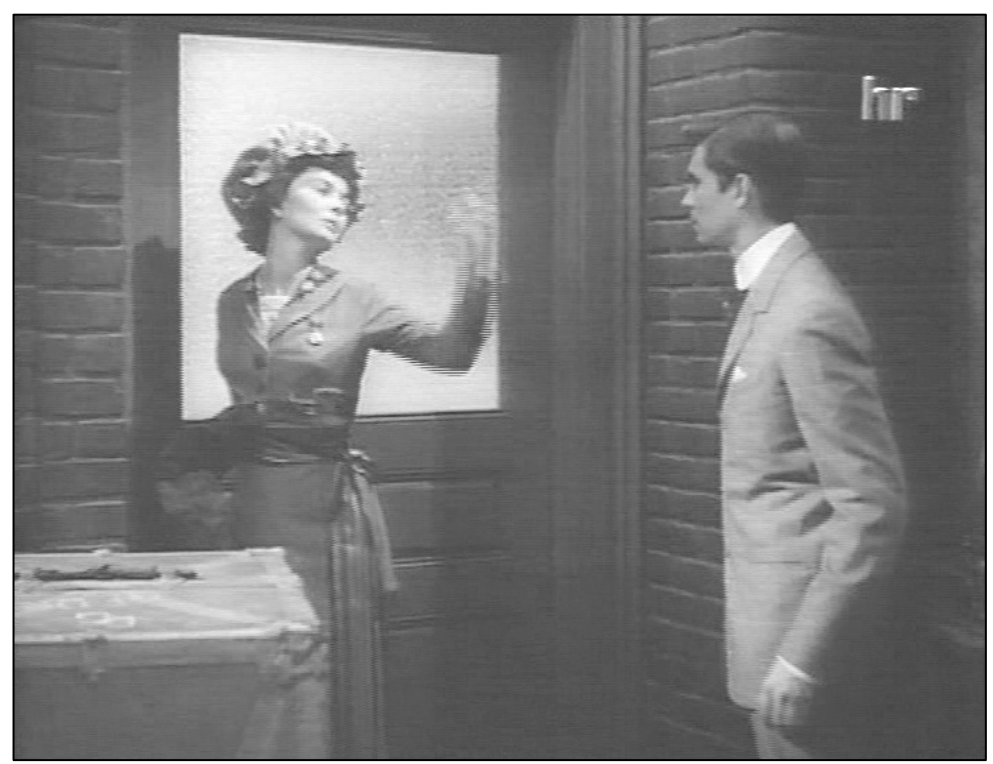

Abbildung 3: Übertritt als Große Szene, aus: George Cukor, THE ACTRESS (1953).

eine andere Geschichte, von der Cukors Film bereits nicht mehr erzählt. (Stattdessen verortet er sie >am Horizont<, in der Ferne einer noch unbestimmten Zukunft, auf die sich die Heldin in der letzten Einstellung zubewegt.) 
Drinnen, draußen. Im Theater angekommen, aus dem Theater verabschiedet; im Zentrum der Aufmerksamkeit; an der Grenze (zur Aufnahme, zur Zurückweisung); auf der Schwelle, im Übergang, in Wartestellung; im Begriff, Zutritt zu erhalten, oder auf eine marginale Rolle reduziert. Auffällig an Filmen wie STAGE Door, All About Eve, The ACTREss ist die Interferenz zwischen dem Figurativen und dem Literalen, den räumlichen Metaphern der Rede und der mise-en-scène von Räumen und räumlichen Anordnungen. Was in diesem Ensemble der figurativen und der manifesten, der inszenierten und doch oft wie beiläufig behandelten Topologien sichtbar wird, ist nicht allein eine Idee vom Theater (seinem Aufbau, seinen Funktionsweisen), sondern auch davon, wie man sich am besten zum Theater positioniert.

\section{Übertritt/Große Szene}

Kaum war sie drin, hat man sie schon wieder vor die Tür gesetzt. Sie hatte sich das anders vorgestellt und ihren ersten Schritt durch den Bühneneingang als eine große Szene imaginiert. Ruth, die Actrice, die noch keine ist, wird in THE ACTRESS vor der Tür an der Rückseite des Theaters auf ihren Verehrer treffen; sie wird ihn auf die Beschriftung der Tür aufmerksam machen (»Stage Door «), auf den Ereignischarakter des Übertritts (»ich werde jetzt durch diese Tür gehen «), dann auf dessen zäsurale Qualität (»dahinter liegt mein ganzes Leben«), um ihm am Ende einen Abschiedskuss zu geben und zu erklären: »Fast schon - von einer Schauspielerin«. Fast schon. Noch nicht ganz. Aber doch so gut wie. Cukor platziert sie in diesem lang gezogenen Moment buchstäblich auf der Schwelle, und wenngleich er die Stilisierung des Übertritts ganz an seine Figur zu delegieren scheint, hat es zugleich den Anschein, dass der Film an dieser Stilisierung partizipiert - sie sogar affirmiert und fortführt, wenn Ruth im nächsten Augenblick die Tür zum Bühneneingang öffnet und hinter sich schließt und die Kamera auf der anderen Seite, im Außenraum, zurückbleibt.

Die Markierung des Eingangs als Grenze und der Hinterbühne als exklusive Sphäre erfolgt in THE ACTRESS oder in ALL ABOUT EvE nach einem vergleichsweise komplexen, chiastisch strukturierten Muster: eine Markierung im Modus der Überschreitung, da die Grenze zwar überquert, ihre Bedeutung jedoch im selben Zug unterstrichen wird. Einen vergleichbaren Effekt hat Bazin mit Blick auf eine andere Demarkationslinie des Theaters vermerkt, als er einige Transgressionsbewegungen über die Bühnenrampe beschrieb: »Daß im 17. Jahrhundert junge Adlige Zugang zur Bühne hatten, leugnete die Rampe nicht; im Gegenteil, sie wurde dadurch bestätigt, daß es ein Privileg war, sie als Grenze zu überschreiten; auch wenn heute Orson Welles am Broadway Schauspieler unter die Zuschauer mischt und mit Revolvern auf sie schießen läßt, schafft er die Rampe nicht ab, er begibt sich nur auf die andere Seite« (Bazin: 188).

Nicht viele Filme über das Theater gestalten die Passage durch den Bühneneingang so umfassend aus wie THE ACTRESS, aber man kann sagen, dass sie fast immer daran arbeiten, in den Geschichten des Eintritts, Übertritts die Demarkationen des theatralen Raumes hervorzuheben. Sie tun dies auf vielfältige Weise: zum Beispiel indem davon erzählt wird, wie sich eine Figur die Erlaubnis zum Übertritt erarbeitet, im Fall von ALL ABOUT EvE etwa durch die Demonstration einer gewissen Leidensbereitschaft; im Fall des Leutnants Sobinski in Lubitschs To BE OR Not To BE (USA 1942) durch den stetigen Besuch von Theatervorstellungen (»er 
sitzt Abend für Abend in der dritten Reihe«) und durch ebenso stetige Gesten der Huldigung gegenüber der von ihm verehrten Schauspielerin. In anderen Filmen, zum Beispiel Pedro Almodóvars Todo Sobre Mi MAdRE (S 1999) oder Yolande Moreaus/Gilles Portes QUAND LA MER MONTE (F 2004) dringen einzelne Theatergänger in die Räumlichkeiten hinter der Bühne vor, um dann umgehend daran erinnert zu werden, dass sie kein Recht haben, sich dort aufzuhalten. Wieder andere, zum Beispiel OPENING Night (USA 1977) von John Cassavetes, kontrastieren die Bilder der Passage mit den Bildern der Außenstehenden vor dem Bühneneingang; oder sie gewähren, wie in THE ACTRESS, das Recht auf Teilnahme am Innenleben des Theaters nur, um es einen Moment später schon wieder zu entziehen.

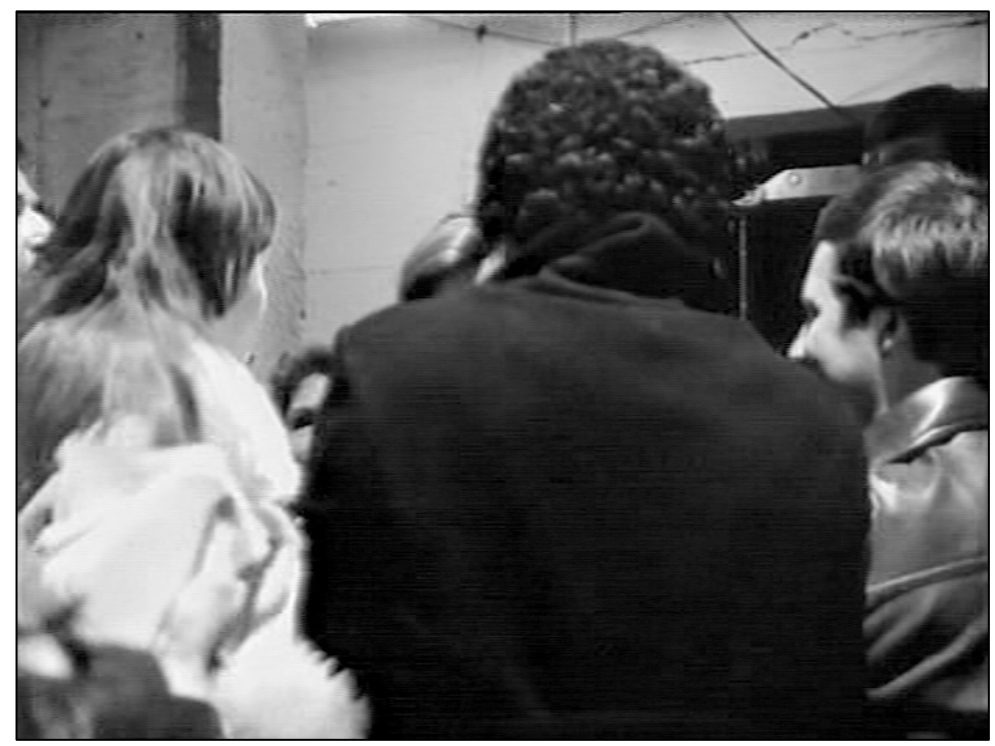

Abbildung 4: Die Wartenden, aus: John Cassavetes, OPENING NIGHT (1977).

Mit der Politik der Demarkation, dem Wechsel von Einlass und Ausschluss, verbinden sich eigene Formen des Begehrens, auch: des Versprechens, durch das etwas wie Begehren erst produziert wird, und das sich hier als Versprechen auf eine Enthüllung beschreiben ließe. »Das Verborgene«, schreibt Roland Barthes (110), »ist für das westliche Denken wahrer als das Sichtbare«, die als unzugänglich/abgeschirmt markierte Sphäre der Hinterbühne mithin wahrheitsverheißend: designierter Schauplatz von >Wahrheiten über das Theater<, die sich denjenigen eröffnen, die als Filmzuschauer an der Erkundung des theatralen Terrains partizipieren.

\section{Ortswechsel}

Wenn man sie partizipieren lässt. Tatsächlich ist dies der Normalfall, von STAGE DOOR bis EsTHER KAHN etwas wie der Status quo der kinematographischen Annäherung, doch kann es von Fall zu Fall auch anders aussehen, zum Beispiel so wie in der Übertrittsszene aus THE ACTRESS. Die Kamera fokussiert die Bühnentür, die 
Figur passiert den Eingang, unbegleitet, während nicht nur der verlassene Verehrer, sondern auch die Kamera auf der anderen Seite verharrt. Es ist dieser Moment des Verharrens, der THE ACTRESS zu einem bemerkenswerten Film macht. Im Allgemeinen nämlich bewegt sich die Kamera in den Räumlichkeiten hinter dem Bühneneingang ungehindert und zwischen den verschiedenen Sphären des Theaters ( $\mathrm{Zu}$ schauerraum, Bühne, Hinterbühne) vollkommen beiläufig, als sei solche Mobilität nicht anders denn als selbstverständlich zu betrachten. Ein auffallender Gegensatz besteht zwischen den Geschichten des aufwändigen Übertritts, wie sie von La Cava, Mankiewicz, Lubitsch erzählt werden (bei Cassavetes wird der Einlass grundsätzlich verweigert, bei Almodóvar oder Porte/Moreau wird er sanktioniert), und den Ortsund Positionswechseln, die die Kamera im Verlauf der Filmerzählung vornimmt.

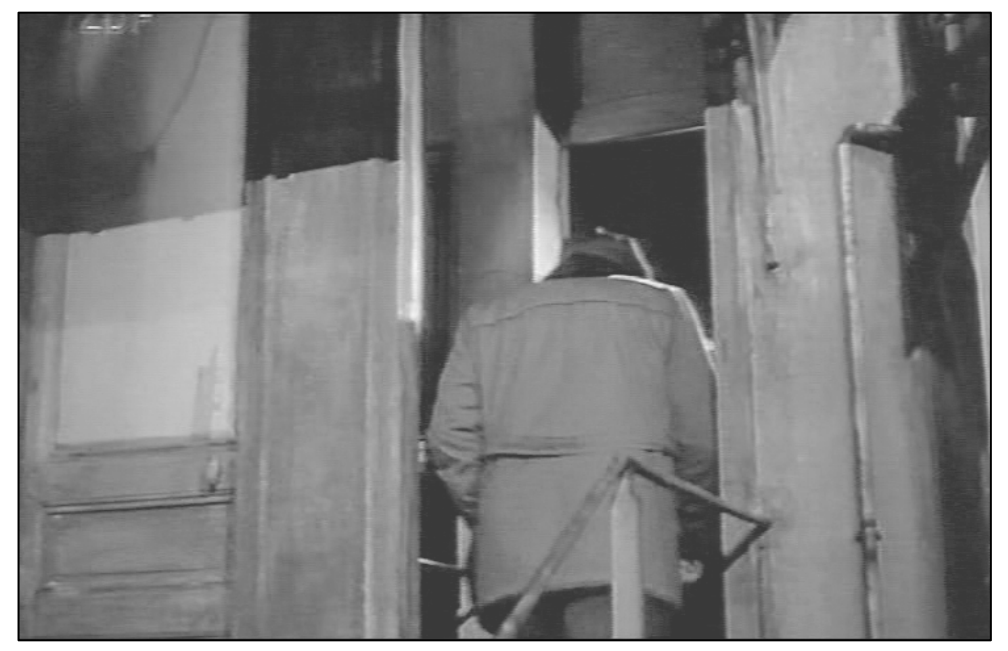

Abbildung 5: Die beiläufige Passage, aus: François Truffaut, LE DERNIER MÉTRO (1980).

Die Einstellungswechsel in All About Eve oder in To BE OR Not To BE sind für diesen Gegensatz ein gutes Beispiel. Wenn Eve im Gefolge einer anderen Figur durch den Bühneneingang nach langem Warten zum ersten Mal das Reich der Hinterbühne betritt, wird sie dort von der Kamera in Empfang genommen, die, in einer Ecke des Raumes postiert, den Schritt durch die Tür in einer Halbtotalen aufzeichnet. Und wenn Eve kurz darauf angehalten wird, noch einmal einige Minuten vor der Garderobentür zu warten, unterliegt die Kamera keineswegs derselben Beschränkung, sondern befindet sich, kaum ist die Tür für einen Moment geöffnet, bereits im Inneren der Garderobe, wo sie sich dann über vier oder fünf Minuten einrichtet, bevor die Tür ein weiteres Mal geöffnet und Eve (»ich dachte, Sie hätten mich vergessen «) von den anderen Figuren hineingebeten wird. In TO BE OR NOT TO BE und in OPENING NigHT, aber auch in so ungleichen Filmen wie EsTHER Kahn (F 2000), Being Julia (USA 2004) und Stage BEaUty (USA 2004), finden sich korrespondierende Szenen, die dahingehend vergleichbar sind, dass einer Filmfigur der Eintritt in die Garderobe erschwert oder verwehrt wird, während die Kamera längst dort Aufstellung genommen hat, so wie sie auch sonst ohne viele Umstände von Außen nach Innen, von der Bühne hinter die Kulissen oder von einer Ecke des Auditoriums in eine andere wechselt. 
Noch wo sie sich als Erfolgsgeschichten präsentieren, erinnern die Übertrittsversuche der Filmfiguren mithin daran, dass es sich hier um unselbstverständliche Bewegungen handelt: um Ausnahmefälle, die mit der allgemeinen Realität der Theatergänger nicht viel zu tun haben. Folgt man den Darstellungen der Theaterhistoriker, so besteht diese Realität seit den Theaterreformen der Aufklärung zu einem guten Teil in der Immobilisierung des Publikums, einem Prozess der Selbstbeobachtung und Disziplinierung, zu dessen Höhepunkten die Abschaffung des Stehparketts (Matthes), die sukzessive Ausrichtung der Blicke auf die Bühne (Lehmann) und die strikte Aufteilung des theatralen Raumes gehören. Auf der einen Seite die Bühne, auf der anderen das Auditorium; auf der Szene die Darsteller, ihnen gegenüber das »im Sitzparkett befriedete Publikum « (Matthes: 197); zwischen ihnen das Proszenium und über alldem ein Regime, das wesentlich darauf abzielt, alle Akteure der Veranstaltung an ihrem Platz zu halten.

Dies also die imaginäre Folie, auf der sich die Übertritte zwischen den verschiedenen Sphären des Theaters abspielen: Der Zuschauer, der auf seinem Theatersitz im Auditorium verbleiben muss, ist hier eine implizite Vergleichsgröße und muss dazu nicht einmal ins Bild gesetzt werden. (Dass er in der Geschichte des Kinos dennoch eine gewisse Präsenz behauptet, dokumentiert der Film PLAY (D 2003) von Matthias Müller und Christoph Girardet. In einem Querschnitt durch etwa 50 Filme aus sechs Jahrzehnten der Kinogeschichte finden sich dort die erstaunlich ähnlichen Haltungen und Gesten kompiliert, aus denen die Darstellung von Theaterzuschauern auf der Leinwand zusammengesetzt ist. In Analogie zum Warburgschen Konzept der Pathosformel könnte man von Theater- oder von $\mathrm{Zu}$ schauerformeln des Films sprechen.)

\section{Dichotomie der Blicke: statisch/mobil}

Das disziplinierte Publikum: nicht durchweg im Bild, aber in den Szenen des Übertritts immer irgendwie präsent, der Regelfall zur Ausnahme und den begünstigten Figuren, die die Grenze zur Hinterbühne überqueren, viel näher, als es zunächst den Anschein hat. Denn sicher handeln die beschriebenen Filmen von einer konstitutiven Differenz der Blickerfahrung, nur ist diese nicht zwischen den privilegierten Theatergängern und denjenigen zu suchen, denen nur die Sicht auf die Bühne bleibt, sondern zwischen dem beweglichen Blick der Kamera und einem stillgestellten, nur in Ausnahmefällen mobilisierbaren Blick, der der Figur des Theaterzuschauers zugeordnet wird.

Dieser Blick: Auf der Leinwand sieht man ihn seit 1910, 1915 immer wieder, doch könnte es sein, dass er seinen nachhaltigsten Auftritt auf dem Schauplatz der Schrift hat. Genauer gesagt handelt es sich um viele Auftritte, eine ganze Serie, zu deren frühesten die Texte von Dziga Vertov gehören, der die Theateraufführung als Anachronismus beschrieb (1990a: 31) und den Theaterzuschauer als die Inkarnation eines vom Prinzip der Trägheit bestimmten Sehens, dem die Mobilität des Kino-Auges in jeder Hinsicht überlegen sei (1972; 1990b). Andere Darstellungen gestalten sich weniger polemisch, aber das ändert nichts an der Beobachtung, dass sich die frühe Filmtheorie wesentlich in einer Reihe von Abgrenzungsbewegungen gegenüber dem Theater entwickelt, dass dabei die Konzeptionalisierung des Blicks entlang der Dichotomie träge/mobil (auch: statisch/dynamisch) eine zentrale Rolle spielt, und dass sie in den Schriften von Vertov, Eisenstein, Pudovkin, aber auch 
denen von Rudolf Arnheim oder Erwin Panofsky einem durchaus ähnlichen Schema folgt. »Die Geschichte des Films «, ist rückblickend konstatiert worden,

»wird häufig als eine Geschichte seiner Emanzipation vom Vorbild des Theaters verstanden: Zunächst als Befreiung von der >Frontalität< des Theaters: die unbewegliche Kamera, die die Situation des Theaterbesuchers reproduziert, der von seinem Sitz aus ein Schauspiel verfolgt« (Sontag: 213).

Der Kinobesucher verfolgt das seine ebenfalls von einem Sitz aus, doch stellt sich die Sache in seinem Fall anders dar: nicht als Festlegung auf eine Blickachse, sondern als virtuelle Mobilität, eine stetige Variation der Blickpunkte und -distanzen (Koch: 11). Kinematographische Ortswechsel zu phantasieren, ist in den Schriften der Filmtheorie von Vertov bis Panofsky ebenso ein wiederkehrendes Motiv wie der Verweis auf die Umständlichkeit des Szenenwechsels auf der Bühne, überhaupt auf die Immobilität der theatralen Blicke und Räume, die man nunmehr abgelöst, verabschiedet sieht (Vertov 1990a; Arnheim; Panofsky).

Den Kinogänger beschrieb Walter Benjamin als einen Zuschauer, der aus der Tiefe seines gepolsterten Sitzes »gelassen abenteuerliche Reise unternimmt (36). Die kinematographischen Ortswechsel zwischen den Sphären des Theaters gehören zu diesen Reisen, und auch wenn sie sich lange nicht so abenteuerlich gestalten wie manche andere, sind sie doch gut geeignet, die alte Leitdifferenz in Erinnerung zu bringen, einfach weil es sich beim Blick auf die andere Seite des Theaters eigentlich um jenen handelt, der den Theaterzuschauern mehr als jeder andere versagt ist. Es ist also ein privilegierter Blick, der in Filmen wie TO BE OR NOT TO BE und All About Eve, in Todo Sobre Mi Madre, in Quand La Mer Monte und in vielen anderen eingeübt wird. Ein überlegener Blick, das auch, Blick des Kinos an jene Orte, die für den Blick der Theaterzuschauer verschlossen bleiben; Einblick, exklusiver Zugang; sie sehen hier, so könnte es im Vorspann all dieser Filme stehen, was Ihnen das Theater niemals zu sehen gibt, und was Ihnen erst durch das Kino zugänglich wird.

\section{Filme}

Almodóvar, Pedro (1999): Todo Sobre Mi MAdre, S.

Cassavetes, John (1977): OPENING NIGHT, USA.

Cukor, George (1953): THE ACTRESS, USA.

Desplechin, Arnaud (2000): ESTER KAHN, F/UK.

Eyre, Richard (2004): STAGE BEAUTY, UK/D/USA.

La Cava, Gregory (1937): STAGE DooR, USA.

Lubitsch, Ernst (1942): TO BE OR NOT TO BE, USA.

Mankiewicz, Joseph L. (1950): All ABOUT Eve, USA.

Moreau, Yolande/Porte, Gilles (2003): QuAND LA MER MonTe, F.

Müller, Matthias/Girardet, Christoph (2003): PlAY, D.

Szábo, István (2004): BEING JULIA, USA.

Truffaut, François (1980): LE DERNIER METRO, F. 


\section{Literatur}

Arnheim, Rudolf (2002): Film als Kunst. Frankfurt/M.: Suhrkamp.

Barthes Roland (1989): Die helle Kammer. Bemerkung zur Fotografie. Frankfurt/M.: Suhrkamp.

Bazin, André (2004): »Theater und Film«. In: Ders.: Was ist Film?, hg. von Robert Fischer, mit einem Vorwort von Tom Tykwer und einer Einleitung von Hartmut Bitomsky. Berlin: Alexander, S. 162-216.

Benjamin, Walter (1977): »Das Kunstwerk im Zeitalter seiner technischen Reproduzierbarkeit«. In: Ders.: Das Kunstwerk im Zeitalter seiner technischen Reproduzierbarkeit. Drei Studien zur Kunstsoziologie, Frankfurt/M.: Suhrkamp, S. 7-44.

Eisenstein, Sergej M./Vsevolod I. Pudovkin/W. Alexandrov (1990): »Manifest zum Tonfilm«. In: Franz-Josef Albersmeier (Hg.): Texte zur Theorie des Films. Stuttgart: Reclam, S. 42-45.

Koch, Gertrud (2005): »Einleitung«. In: Dies. (Hg.): Umwidmungen. Architektonische und kinematographische Räume. Berlin: Vorwerk 8, S. 8-20.

Lehmann, Johannes Friedrich (2000): Der Blick durch die Wand. Zur Geschichte des Theaterzuschauers und des Visuellen bei Diderot und Lessing. Freiburg: Rombach.

Matthes, Isabel (1995): >Der allgemeinen Vereinigung gewidmet . Öffentlicher Theaterbau in Deutschland zwischen Aufklärung und Vormärz. Tübingen: Niedermeyer.

Panofsky, Erwin (1991): »Stil und Medium im Film«. In: Ders.: Stil und Medium im Film \& Die ideologischen Vorläufer des Rolls-Royce-Kühlers. Frankfurt/M.: Fischer, S. 21-57.

Pudovkin, Vsevolod I. (1990): »Über die Montage«. In: Franz-Josef Albersmeier (Hg.): Texte zur Theorie des Films. Stuttgart: Reclam, S. 77-99.

Schweinitz, Jörg (Hg.) (1992): Prolog vor dem Film. Nachdenken über ein neues Medium 1909-1914. Leipzig: Reclam.

Sontag, Susan (1982): »Theater und Film«. In: Dies.: Kunst und Antikunst. 24 literarische Analysen. Frankfurt/M.: Fischer, S. 213-235.

Vertov, Dziga [als Dsiga Wertow] (1972): »Vom >Kino-Auge< zum >RadioAuge «. In: Karsten Witte (Hg.): Theorie des Kinos. Ideologiekritik der Traumfabrik. Frankfurt/M.: Suhrkamp. S. 88-92.

Vertov, Dziga (1990a): »Kinoki-Umsturz«. In: Franz-Josef Albersmeier (Hg.): Texte zur Theorie des Films. Stuttgart: Reclam. S. 24-37.

Vertov, Dziga (1990b): »Kinoglaz«. In: Franz-Josef Albersmeier (Hg.): Texte zur Theorie des Films. Stuttgart: Reclam, S. 39-41. 



\title{
DER BÜHNENTOD IM FILM
}

\author{
THOMAS KLEIN
}

I.

Mit dem Bühnentod ist einerseits der im 20. Jahrhundert immer wieder postulierte Tod des Theaters gemeint, gleichsam der Abgesang auf eine darstellende Kunst, die in Konkurrenz zu den technischen Medien den Kürzeren ziehe. Überdies ist vom Bühnentod dann die Rede, wenn eine Dramenfigur, meist als Höhepunkt eines tragischen Konflikts, stirbt. Für den Schauspieler bedeutet dies eine außergewöhnliche Herausforderung. Ob theatralisch oder mit der Reduktion des Alltäglichen: Das Sterben auf der Bühne ist dazu geeignet, die schauspielerische Könnerschaft in herausragender Weise zum Ausdruck zu bringen. Den Tod auf der Bühne zu spielen ist für den Schauspieler ein Höhepunkt seines Schauspieler-Lebens. Der Bühnentod, von dem im Folgenden die Rede sein soll, ist noch existentieller. Er überschreitet die Fiktion. Nicht nur die Figur, sondern auch der Schauspieler stirbt auf der Bühne. Sich auf den Brettern, die für ihn die Welt bedeuten, aus dem Leben zu verabschieden, das ist, wie wir wissen, für den Komödianten, den Vollblutschauspieler, eine ideale Vorstellung. Im Folgenden geht es aber letztendlich doch wieder um eine Fiktion: die Inszenierung des Bühnentodes im Theaterfilm.

Ausgehend von meiner Studie »Ernst und Spiel: Grenzgänge zwischen Bühne und Leben im Film«, in der ich das Sujet >Theater im Film « anhand paradigmatischer Filme unter Verwendung der »Rahmen-Analyse « von Erving Goffman untersucht habe, ließe sich der Bühnentod als eine spezifische Situation in den »filmästhetischen Rahmungen der Dialektik von Bühne und Leben« (Klein: 41) interpretieren, in der das Wechsel- und Verwirrspiel zwischen Ernst und Spiel auf die Spitze getrieben wird. Modulation und Täuschung, die beiden zentralen Paradigmen des Theatersujets im Film, verdichten sich beim Bühnentod zu dem Grenzgang zwischen Bühne und Leben schlechthin.

Für die Analyse der filmischen Inszenierung des Bühnentodes spielt erstens das Verhältnis von Bühne und Zuschauerraum, von Darstellern und Publikum eine wichtige Rolle. Wenn für den sterbenden oder die anderen Akteure auf der Bühne ein Bruch des Theater-Rahmens stattfindet, muss dies nicht in gleicher Weise für die Zuschauer im Film gelten. Vor allem dann nicht, wenn der wirkliche Tod im Rahmen der fiktiven Bühnenereignisse nachvollziehbar ist bzw. wenn der Handlungsverlauf den Tod einer Figur notwendig oder zumindest möglich macht. Dann könnten die Zuschauer immer noch davon ausgehen, der so echt wirkende Tod sei Teil der Theateraufführung. Eine weitere Bedingung dafür, dass der wirkliche Tod auf der Bühne nicht zu einer Modulation des Theater-Rahmens (durch die Zuschauer) führt, besteht darin, dass dieser auf der Bühne vom betroffenen und von den anderen Darstellern, sofern auf der Bühne anwesend, nicht als solcher transparent gemacht wird. Dass jemand tatsächlich stirbt, würde dergestalt in das Spiel integriert. Was wiederum bedeutet, dass die Zuschauer getäuscht werden, indem die 
Akteure so tun, als sei das Geschehen auf der Bühne noch im Rahmen des >als ob< $\mathrm{zu}$ verorten. Der wirkliche Tod wiederum kann auch derart kongruent mit der Handlung auf der Bühne sein, dass selbst das Ausbrechen der Darsteller aus ihrer Rolle von den Zuschauern nicht als Rahmenbruch wahrgenommen wird.

Die Inszenierung des Bühnentodes geht zweitens einher mit der dargestellten Theaterform, damit, ob es sich z.B. um eine Guckkastenbühne oder eine den Zuschauer stärker einbeziehende Bühnenform handelt. Meine These lautet, dass der Bühnentod von den Zuschauern im Film vor allem dann nicht als solcher wahrgenommen wird, wenn die Theaterform die Improvisation und die Interaktion mit den Zuschauern impliziert. Der Theaterraum kann ferner sogar filmisch entgrenzt werden oder ausgehend vom filmischen Diskurs können Mischformen auftreten, die zwischen Theater, Performance und Ritual oszillieren, wodurch der Bühnentod weitere Konnotationen erhält.

\section{II.}

Ein frühes und originelles Beispiel für einen Bühnentod im Film findet sich in Ernst Lubitschs To BE OR Not To Be (SEIN ODER NichtSEIN, 1942), wenn der Spion Professor Siletsky von dem Theaterensemble durch eine konzertierte Täuschung entlarvt wird, worauf es zu einer Verfolgungsjagd im Theatersaal kommt, die mit Schüssen und dem betont theatralisch gespielten Tod von Siletsky auf der Bühne schließt. Den bislang intensivsten Versuch die Grenzen zwischen Sein und Schein, zwischen Theater und Leben als höchst durchlässig zu gestalten, hat Peter Greenaway ein halbes Jahrhundert später mit THE BABY OF MÂCON (DAS WUNDER VON MACON, 1993) unternommen. Im Zeitalter des Barock angesiedelt, hat THE BABY OF MÂCON viele Berührungspunkte zum Topos des Theatrum Mundi. Was auf der Bühne geschieht, hebt die Grenze zwischen Schein und Sein auf. Tiere und auch Darsteller kommen zu Tode. Die grausame Massenvergewaltigung einer Frau zum Tode vergegenwärtigt die Strategie des Films in besonderer Weise: »Sukzessive lässt Greenaway das Spiel in den existentiellen Ernst übergehen «(Klein: 221). Das Vergehen der vorsätzlichen Täuschung einer jungfräulichen Geburt wird im Rahmen der Theateraufführung im Film bestraft, indem es aus dem Rahmen des $>$ als ob< herausgerissen wird und zu einem Tötungsritual avanciert, das sowohl die Bestrafung der im Rahmen des Theaters dargestellten Figur als auch die Bestrafung der Darstellerin selbst vorsieht. »What a fine actress «, ist der zynische Kommentar eines der Vergewaltiger, als die Frau blutüberströmt und leblos aus dem Bett zu Boden sinkt und es stellt sich durchaus die Frage, ob nicht auch die Filmschauspielerin Julia Ormond damit gemeint ist.

In Baz Luhrmanns Moulin Rouge (2001) stellt der Bühnentod der von Nicole Kidman gespielten Kurtisane Satine den tragischen Höhepunkt einer Geschichte dar, die zahlreiche Wechselprozesse zwischen Bühne und Leben aufweist. Motiviert sind diese durch die Situierung der Handlung Ende des 19. Jahrhunderts im Milieu der Vergnügungsstätten und Cabarets in Paris, Theaterformen, die sich durch partielle Öffnungen des klassischen Theater-Rahmens auszeichnen. Der Grenzgang zwischen Bühne und Leben, um den es in MouLIN RougE zum einen geht, besteht darin, dass die Kurtisane ein Leben zwischen Theater und Prostitution führt, auf der Bühne ihre Erotik schillern lassen und für den Mäzen des Theaters ihren Körper verkaufen muss. Der junge Schriftsteller Christian scheint sie hingegen wahrhaftig zu lieben, wobei auch seine Rolle ambivalent ist, stammt die Ge- 
schichte, die wir sehen, doch aus seiner Feder, wie es die Rahmenhandlung und gelegentliche Zwischenbilder zeigen. Das entbehrungsreiche Leben führt dazu, dass Satine an Schwindsucht erkrankt. Der andere Grenzgang des Films besteht in seiner Ästhetik. Er schafft ein derart künstliches, selbstreferentielles, aus allen Bereichen der populären Kultur sich speisendes, alle nur denkbaren filmischen Mittel einsetzendes Spektakel, dass der Filmzuschauer herausgefordert wird, überhaupt noch etwas Wahrhaftiges wahrnehmen zu können. Dazu gehört auch, den wirklichen Tod Satines überhaupt noch als etwas Tragisches wahrzunehmen. Hierzu werden die filmischen Mittel reduziert, auch hier wird die Bühne in einen intimen Raum transformiert. Der Vorhang ist gefallen, die Zuschauer sehen nicht mehr, was sich wirklich abspielt. Sie applaudieren einem furiosen Finale, das durch die persönliche Tragödie von Satine und Christian bereits mehrfach codiert wurde. Doch die Zuschauer haben die Rahmenbrüche nicht als solche wahrgenommen. Nach dem Fall des Vorhangs ist das Geschehen auf der Bühne ohne ihr Wissen endgültig in eine individuelle Leidensgeschichte übergegangen. Zuschauer sind nun die Mitglieder des Ensembles, die die beiden Liebenden Satine und Christian beobachten - und wir. Es ist ein Moment der intimen Tragik, der vor allem für den Kinozuschauer inszeniert ist.

\section{III.}

Ich will nun auf zwei Filme genauer eingehen, die in meinen bisherigen Überlegungen zum Theatersujet noch keine Berücksichtigung gefunden haben, um einen weiteren theoretischen Ansatz vorzustellen: MARQUISE (1997) von Véra Belmont und M. BUTTERFLY (1993) von David Cronenberg. Auf wahren Begebenheiten beruhend erzählt MARQUISE die Geschichte der Marquise Duparc (Sophie Marceau), die als Tänzerin Therese von Molière und seinem Weggefährten Gros-René Duparc in Paris entdeckt, in ihre Truppe aufgenommen und alsbald von ihrem Förderer René geheiratet wird. Leider stellt sich heraus, dass sie zwar eine großartige Tänzerin, ihr Talent zum komödiantischen Schauspielen aber begrenzt ist. Insbesondere die für die Auftritte der Truppe essentiellen Improvisationen bereiten ihr Probleme. Als sie Racine kennen lernt, wendet sich das Blatt. Er erkennt, dass die Marquise durchaus schauspielerisches Talent besitzt, indes weniger für das komische als für das tragische Fach. Racines Avancen kommt sie zunächst nur bedingt entgegen, sie bleibt bei René, bis dieser krank wird und stirbt. Dies ist die erste Szene, auf die ich mich beziehen will, denn René stirbt während einer Aufführung auf der Bühne. Die zweite Szene ist der Schluss des Films. Wegen einer Erkrankung und einer Schwangerschaft (von der außer ihr niemand weiß) nicht dazu in der Lage aufzutreten, erlaubt die Marquise ihrer Garderobiere für sie einzuspringen. Unmittelbar nach einer Vorstellung von Racines »Andromaque « kommt es zum letzten großen Auftritt der Marquise.

$\mathrm{Zu}$ Beginn der ersten Szene, die Aufführung nimmt noch ihren geplanten Verlauf, wird das Bühnengeschehen aus der Perspektive des Theaterpublikums gezeigt. Als René spürt, dass sein Ende naht, rückt die Kamera näher an das Geschehen heran. Die Perspektive entspricht nun den Mitspielern und Freunden auf der Bühne, denen René seinen unmittelbar bevorstehenden Tod ankündigt. Überwiegend Close Shots kommen zum Einsatz und die Lautstärke des Gesprächs wird derart stark reduziert, dass sich unter den Theaterzuschauern jemand beschwert, er verstehe nichts mehr. Dem Kinozuschauer wird eine Nähe zum Geschehen gewährt, die dem 
intradiegetischen Theaterpublikum nicht möglich ist. Das Publikum wird nur noch als Störung inszeniert (Hüsteln), als ein Publikum, das nicht erkennt und nicht verstehen kann, dass jemand wirklich stirbt.

Eine andere Qualität hat der Bühnentod der Marquise am Ende des Films. Wenn sie nach dem Schlussapplaus einer Aufführung von »Andromaque « auf die Bühne kommt, gehört dies nicht mehr zur Inszenierung des Stückes von Racine, sondern zur Inszenierung des Lebens der Marquise. »Sie spielt nur eine Rolle, ich spiele mein Leben«, kommentiert sie den Unterschied zwischen ihr und ihrer Garderobiere, die an der Bühnenrampe steht, wo sie kurz zuvor noch den Schlussapplaus entgegengenommen hat. Reaktionen der Zuschauer sind kaum hörbar. Selbst als die Marquise geschwächt zu Boden sinkt, ist kein Aufschrei, nicht einmal ein Raunen im Publikum zu hören. Ein Zeichen des Respekts vor der umjubelten Schauspielerin? Dafür spricht der Applaus des Publikums, als Racine sie aus dem Saal trägt. Es ist der Schlussapplaus für ihr Leben, von dem sie sich so meisterlich verabschiedet hat. Auch hier finden sich zwei Variationen der Mise-en-scène. Einerseits wird der Auftritt der Marquise zunächst annähernd als Bühnenauftritt gezeigt, mit Einstellungsgrößen und Perspektiven, die der Entfernung und der Blickrichtung anwesender Zuschauer zur Bühne vergleichbar sind. Als sie vor Schwäche zu Boden sinkt, Racine sie in seinen Armen hält und erfährt, dass sie schwanger ist, wird dem Filmzuschauer - wie beim Tod Renés - eine intime Nähe gewährt, die dem Theaterpublikum verwehrt bleibt: Wir sind so nahe am Geschehen dran, wie es die Theaterzuschauer nie sein können. Das Sterben und der Tod selbst sind zwar weiterhin öffentlich, wenn man den Raum Off-Screen mitdenkt. Doch die cadrage schließt diesen Raum aus, um ihn erst, wenn alles Leben aus dem Körper der Marquise gewichen ist, wieder zu integrieren. Oder besser: Der Körper wird filmisch in diesen Raum zurück getragen, als Racine den Leichnam tragend die Bühne verlässt und durch die Reihen der Zuschauer zum erleuchteten Ausgang schreitet.

\section{IV.}

David Cronenbergs M. BUTTERFLY nach einem Bühnenstück von David Henry Hwang handelt von dem für den französischen diplomatischen Dienst arbeitenden Buchhalter René Gallimard (Jeremy Irons), der sich im Peking des Jahres 1964 in die Pekingoper-Schauspielerin Song Liling verliebt. Die Romanze wird jäh unterbrochen, als sich herausstellt, dass Gallimard von Liling für den chinesischen Geheimdienst ausspioniert wurde und Liling zudem das biologische Geschlecht eines Mannes besitzt. Viele Jahre später treffen sich Gallimard und Liling wieder, als er wegen Spionage vor Gericht steht und sie zu den Zeugen zählt. Gallimard kommt ins Gefängnis, wo er sich das Leben nimmt.

Offensichtlich spielen hier zwei Rahmen eine wesentliche Rolle: der des Theaters und der der Spionage. Beide Rahmen kollidieren miteinander. Die Täuschung im Rahmen der Spionage realisiert sich als Vortäuschung eines anderen Geschlechts. Gender könnte demzufolge als der Diskurs bezeichnet werden, der die Kollision der beiden Rahmen dramaturgisch lenkt. Geht man davon aus, dass Gallimard diese Täuschung eigentlich erkennt, sie aber systematisch verkennt, ließe sich sagen, dass der Theater-Rahmen den Rahmen der Täuschung sozusagen aussticht. Die Täuschung als Strategie unterliegt der Dominanz einer psychischen Internalisierung und Transformation von Elementen des Theater-Rahmens. 
Dieser im Verlauf des Films geschaffene Kontext dient auch als Interpretationsfolie für den Schluss des Films, wenn Gallimard im Gefängnis Selbstmord begeht. Der Suizid ist eingebettet in eine paratheatrale Inszenierung, die Züge von Performance und Ritual trägt. Sie besteht darin, dass Gallimard seinen Körper mit Schminke, Kostüm und Perücke in den von Madame Butterfly transformiert, währenddessen er seine Handlungen sprachlich kommentiert. Dabei lässt er vom Band die Arie »Un bel di vedremo« aus Puccinis Oper laufen. Die restlose Verwandlung sieht vor, sich, wie Madame Butterfly, das Leben zu nehmen. Ein Handeln aus dem Theater-Rahmen ist dergestalt Vorbild für die Selbstinszenierung in dem von ihm geschaffenen Performance-Rahmen. Wie er selbst während der Performance sagt, ist sein Selbstmord motiviert dadurch, dass er einen ehrenhaften Tod einem Leben in Schande vorziehe. Dadurch, dass er eine Frau liebte, deren Entgegnung seiner Gefühle aber nur eine Maske war, hinter der sich ein chinesischer Agent verbarg, der ihn ausspionierte, habe er sich in der französischen Öffentlichkeit lächerlich gemacht.

Die Gefängnisinsassen als Zuschauer stehen offenbar in Bezug zur Öffentlichkeit, in der sein Handeln als Diplomat wahrgenommen und verspottet wurde. Dieses Performance-Publikum befindet sich ebenerdig in einem Halbkreis zur kleinen, von Gallimard hergerichteten Bühne und erhöht auf kreisförmigen Umgängen, wo sich auch die Gefängniszellen befinden. Dieses räumliche Arrangement erinnert an Jeremy Benthams Konzept des Panoptikums, wonach die Architektur eines Gefängnisbaues dann eine optimale Kontrolle der Gefangenen ermögliche, wenn die mit zwei Fenstern versehenen Zellen für die Gefangenen ringförmig um einen Turm angeordnet sind, in dem selbst wiederum Fenster angebracht sind, durch die alles, was sich in den Zellen abspielt, einsehbar ist. Michel Foucault sah mit dem Panoptikum eine neue Dimension im Diskurs von >Überwachen und Strafen< eingeleitet, weil es ein Wahrnehmungsdispositiv konstituiere, in dem die Macht »automatisiert und entindividualisiert « (Foucault: 259) werde. Ein ähnlicher Raum der Macht wird in M. BUTTERFLY in einen performativen Raum umcodiert. Wenn der »performative Raum«, wie Erika Fischer-Lichte (189) schreibt, »sich gerade dadurch aus[zeichnet], dass er auch eine andere als die vorgesehene Verwendung ermöglicht «, dann trifft dies auf den Gefängnisraum in M. BUTTERFLY in besonderer Weise zu. In einem Raum, der die visuelle Kontrolle über die Gefangenen ermöglichen soll, wird etwas Anderes sichtbar gemacht: die Transformation des Körpers von Gallimard über eine fiktive Figur hin zum Tode. Neben seiner Absicht eines ehrenhaften Todes, vollzieht er eine symbolische Inszenierung, die jeglichen Machteinfluss zu unterlaufen sucht, indem der Suizid als ultimativer freiheitlicher Akt vollzogen wird.

Bezug genommen wird auf ein weiteres Wahrnehmungsdispositiv. Dabei kommt dem Motiv des Spiegels eine zentrale Bedeutung zu. Mit Hilfe eines kleinen Taschenspiegels schminkt sich Gallimard. Als die Maske fertig gestellt ist, sehen wir sein Spiegelbild, während er davon spricht, was er im Spiegel sehe (»I see nothing but ...«). Daraufhin verkündet er, dass René Gallimard und Madame Butterfly ein Amalgam gebildet hätten und schneidet sich abschließend mit der Kante des Spiegels die Halsschlagader auf. Zum Motiv des Spiegels schreibt Michael Grant (142):

»Narcissus-like, he is drawn to his own image, but it is an image of himself as made up. Having put on face-paint and lipstick, and having inscribed parodic cupid's bows on his lips that make of his face a grotesque mask, and wearing a wig, he looks at himself. The image he sees is a reflection of all that remains to him of himself: an image anticipating 
death. As he sees the reflection, he utters almost inaudibly the word >nothing $<$, and his voice trails away, the utterance seemingly unfinished. In creating himself as art, as the diva of the opera into which he has transformed his being, he has transformed creation also into an act endowing nothingness with presence. Gallimard has become at last neither himself nor someone else. He is no one.«

Grants schlüssige und originelle Interpretation impliziert eine Trennung zwischen der Performance Gallimards und der Art und Weise, wie der Film diese Performance filmt. Wenn Gallimard kaum hörbar »I see nothing but ...« sagt und währenddessen sein Spiegelbild zu sehen ist, wird der Theater-Rahmen filmästhetisch gesprengt. Das Spiegelbild als »image anticipating death « sieht nur der Rezipient des Films. Das Publikum der Gefängnisinsassen kann das Spiegelbild nicht sehen, die sprachliche Äußerung dazu akustisch nicht verstehen. Diejenigen, die unten sitzen (im Parkett gewissermaßen), sehen noch die Lichtreflexion des Spiegels auf Gallimards Gesicht, diejenigen oben auf den >Rängen< sehen vielleicht nicht einmal, dass Gallimard einen Spiegel in der Hand hat. Die Performance und das filmische Bild davon sind auf der Ebene der Narration natürlich nicht zu trennen. Es handelt sich nicht um eine Performance, die unabhängig vom Film stattgefunden hätte. Alles, was wir sehen und wie wir es sehen, ist Inszenierungsstrategie des Films. Dennoch impliziert die Sequenz einen Kommentar zum Verhältnis zwischen Theater und Film.

\section{V.}

In beiden Filmen markiert das Wechselspiel von Nähe und Distanz zum Bühnentod eine Differenz zwischen der Form des Films und der Form des Theaters. So lassen sich theoretisch jeweils zwei Inszenierungen des Todes unterscheiden: eine intradiegetische, die eine theatrale Situation repräsentiert, und eine für den Filmzuschauer präsentierte, die der spezifischen Ästhetik des Mediums Film entspricht. Die Inszenierung der Theaterzuschauer im Film macht dies bereits deutlich. Sie rücken für die Zeitspanne, die dem Bühnentod unmittelbar vorausgeht, vorübergehend ins Off, um einen spezifisch filmischen Raum zu öffnen, der dem Kinozuschauer größtmögliche Nähe zu einer existentiellen Grenzsituation bietet. Beschränkt sich MARQUISE vor allem auf diese Strategie, um eine Differenz zwischen Theater und Film zu inszenieren, so geht M. BUTTERFLY insofern raffinierter vor, als mit dem Spiegel ein für den Film essentielles Formelement und eine von Filmtheoretikern immer wieder herangezogene Kinometapher Anwendung findet. Mit Joachim Paech ließe sich sagen, dass der Blick in den Spiegel und die filmische Nahaufnahme des Spiegelbildes als Qualität der Differenz zwischen den Medien Film und Theater figurieren. 


\section{Literatur}

Fischer-Lichte, Erika (2004): Ästhetik des Performativen. Frankfurt/M.: Suhrkamp. Foucault, Michel (1977): Überwachen und Strafen. Die Geburt des Gefängnisses. Frankfurt/M.: Suhrkamp.

Grant, Michael (2000): Cronenberg and the poetics of time. In: Ders. (Hg.): The Modern Fantastic. The Films of David Cronenberg. Westport: Praeger, S. 123147.

Klein, Thomas (2004): Ernst und Spiel. Grenzgänge zwischen Bühne und Leben im Film. Mainz: Bender.

Paech, Joachim (1998): »Intermedialität«. In: Franz-Josef Albersmeier (Hg.): Texte zur Theorie des Films. 3. Aufl., Stuttgart: Reclam, S. 447-475.

Riepe, Manfred (2004): Bildgeschwüre. Körper und Fremdkörper im Kino David Cronenbergs. Bielefeld: transcript. 



\title{
Geschlossene Anstalt: SCHAUSPIELSCHÜLER IM DEUTSCHEN FILM
}

\author{
HANS-FRIEDRICH BORMANN
}

»Wir erinnern uns doch eher an die Filme, die wir gesehen haben, als an die Dinge, die wir mit unseren Eltern gemacht haben.« Diese Äußerung des Regisseurs Stefan Pucher (zitiert nach Dietz: 14) bringt zum Ausdruck, dass technische Medien (hier: Kino und Fernsehen) nicht nur ein Moment des Zugangs zur Welt sind, sondern unser Selbst von Beginn an prägen. Es sei dahingestellt, ob es sich dabei um eine generationsspezifische Einsicht handelt und inwieweit sie verallgemeinerbar ist (zumal auch der Literatur oder dem mündlichen Erzählen eine vergleichbare Bedeutung zuzurechnen wäre). Gleichwohl ist Puchers Äußerung im Kontext des Theaters von Bedeutung, denn der hier angedeutete Einfluss der Medien betrifft nicht nur die individuelle Biographie, sondern auch das Verhältnis von Selbst und Rolle, das zum Grundbestand der theatralen Darstellung gehört. Zudem vollzieht sich im Theater der Gegenwart (und in den jüngeren Publikationen zur Theorie des Schauspiels, vgl. exemplarisch Lehmann und Matzke) ein doppelter Abschied: von der an der dramatischen Figur orientierten Darstellung und vom Selbst als deren weltanschaulicher Voraussetzung. Allerdings bleibt die Institution des Theaters davon weitgehend unangetastet, sie gewinnt sogar - in einer Umkehrung des Topos vom theatrum mundi - an Bedeutung: als Labor für die Reflexion eben dieser Veränderungen. Andererseits verbleibt das Theater selbst dann und gerade dort, wo es >Subjekt als Projekt< (vgl. Flusser) vorführt und zum Gegenstand eines Spiels erklärt, diesseits der Darstellung. Das passive Moment, die skandalöse Dimension dieses Abschieds bleibt dabei zumeist ausgeklammert - wie übrigens auch in Puchers Äußerung, in der von den Dingen, die unsere Eltern oder die Filme mit uns gemacht haben, keine Rede ist. Dabei handelt es sich um kein inhaltliches Problem, das sich durch eine entsprechende Themenwahl bearbeiten ließe: Es ist die Verpflichtung auf Darstellbarkeit selbst, die eine Einsicht in ihre eigenen Voraussetzungen versperrt. Ein Indiz dafür ist die anhaltende Konjunktur des Kriteriums der >Authentizität<, die sich nun nicht mehr auf die Illusion einer vierten Wand, sondern auf die theatralen Bedingungen selbst bezieht. Der Abgrund jedoch, der die Möglichkeit eines Gelingens allererst stiftet, bleibt hier wie dort unsichtbar; der oder das Andere, von dem sich das Selbst/Selbe abhebt, artikuliert sich allein in der und als Negation (vgl. Bormann u.a.).

Diese Paradoxie ist der Anlass, das Verhältnis von Selbst und Darstellung in einer weiteren Verschiebung, auf einem zugleich nahen und entgegengesetzten Schauplatz zu betrachten, nämlich dem Genre des >Theaterfilms< (vgl. dazu Klein 2004 sowie die Beiträge von Diekmann und Klein im vorliegenden Band): Filme, deren Protagonisten und Schauplätze auf die Institution des Theaters bezogen sind. Von besonderem Interesse ist dabei, welche Vorstellungen von den Möglichkeiten der theatralen Darstellung des Selbst sich dort artikulieren und welche spezifischen Möglichkeiten der Film bereitstellt, deren Paradoxien zur Erscheinung zu bringen. 
Ausgewählt wurden zwei deutschsprachige Filme der Gegenwart, in denen das Theater als Institution zwar nur am Rand vorkommt, genau deswegen aber zum Fluchtpunkt der Handlung zu werden vermag, die sich dem Prozess der Selbstfindung ihrer Protagonisten widmet. Sowohl KLEINE HAIE von Sönke Wortmann von 1992 als auch DIE SPIELwÜTIGEN von Andres Veiel von 2004 erzählen von einer kleinen Gruppe von (angehenden) Schauspielschülern, die sich durch das Interesse am Theater oder durch Zufall zusammenfinden. Die Handlung führt von ihrem Entschluss, Schauspieler zu werden, über die Aufnahmeprüfung an der Schauspielschule bis zu dem Moment, in dem sie die Möglichkeit haben, ihr Interesse zum Beruf zu machen. Insofern handelt es sich um Filme, die eine Art Vorgeschichte des Schauspiels zeigen - eine Vorgeschichte, für die auf der Bühne des Theaters selbst kein Platz (mehr) ist. Zugleich, und dies ist ebenso wichtig, gehen beide Filme von einer fraglosen Ineinssetzung von Schauspiel und Leben aus, was sich sowohl in der manifesten Handlung und den Kommentaren der Protagonisten niederschlägt, als auch in der Inszenierung, die in beiden Fällen auf das (hier: auf spezifisch filmische Weise artikulierte) Problem der Authentizität verweist. Demgegenüber rückt die Unterscheidung zwischen dem Dokumentarfilm (dem Veiels Film zuzurechnen wäre) und dem Spielfilm (Wortmann) in den Hintergrund. Es könnte sich sogar zeigen, dass diese Unterscheidung gerade für die Frage nach der Selbstdarstellung irrelevant ist: weil der Film bereits als Medium eine genuine Beziehung zum Imaginären unterhält.

Die inhaltliche Ausgangskonstellation der beiden Filme ist durchaus vergleichbar: Die Protagonisten werden als junge Erwachsene vorgestellt, die ihre Elternhäuser verlassen haben, jedoch noch keine (oder keine befriedigende) Beschäftigung gefunden haben; sie sind auf der Suche nach einer eigenen, eigenständigen Rolle in der Gesellschaft. Die Schauspielschule erscheint dabei als ein möglicher Bezugspunkt, und zwar auf doppelte (und deswegen, wie sich sehr bald zeigt, spannungsgeladene) Weise: Einerseits erscheint sie als Möglichkeit, den in der Kindheit verwurzelten, spielerischen Umgang mit möglichen Selbstentwürfen zu verlängern, andererseits erweist sie sich als Organ der sozialen Disziplinierung, in dem die Lehrer an die Stelle der Eltern treten. Das Theater selbst ist in dieser Konstellation ein ferner, zunächst unerreichbarer Ort, an dem das ausgebildete, und das heißt auch: festgestellte Selbst tätig werden kann. >Schauspieler-Werden< bedeutet in diesen Filmen, eine gesellschaftliche Rolle zu erlernen. Dabei lenken die Filme den Blick auch immer wieder in den Abgrund, der die Sehnsucht nach einem >authentischen< Selbst allererst stiftet. Neben der Handlung und dem Kommentar betrifft dies vor allem die filmische Inszenierung, die diese Einheit des Selbst zugleich behauptet und zerstört, indem sie ihre eigenen Mittel ausstellt und - für den Kinozuschauer - lesbar macht.

\section{Die Spielwuitigen}

Was dies bedeutet, zeigt sich bereits in den ersten Bildern des Vorspanns von DIE SPIELWÜTIGEN. Dieser ist deswegen von besonderem Interesse, weil er nicht nur eine konventionelle formale Rahmung darstellt und Informationen zum Titel und zu den am Film Beteiligten liefert, sondern zusätzlich, in einer Art Exposition, eine kurze Charakteristik der vier Protagonisten - Prodromos Antoniadis, Constanze Becker, Karina Plachetka, Stephanie Stremler - bietet. Mit Hilfe von Spiel-Szenen, in denen (wie der Zuschauer später erfährt) auf Texte zurückgegriffen wird, die für 
das Vorsprechen an der Schauspielschule vorbereitet wurden (z.T. versehen mit einem kurzen Selbst-Kommentar) findet hier eine Verschaltung von Rollen- und Selbstdarstellung statt. Insbesondere die Titelsequenz kann - über die Vorstellung der Protagonistin Stremler hinaus - als programmatisch für das gesamte Projekt angesehen werden. Vier Einstellungen seien hier exemplarisch durch Videostills und eine Beschreibung wiedergegeben:
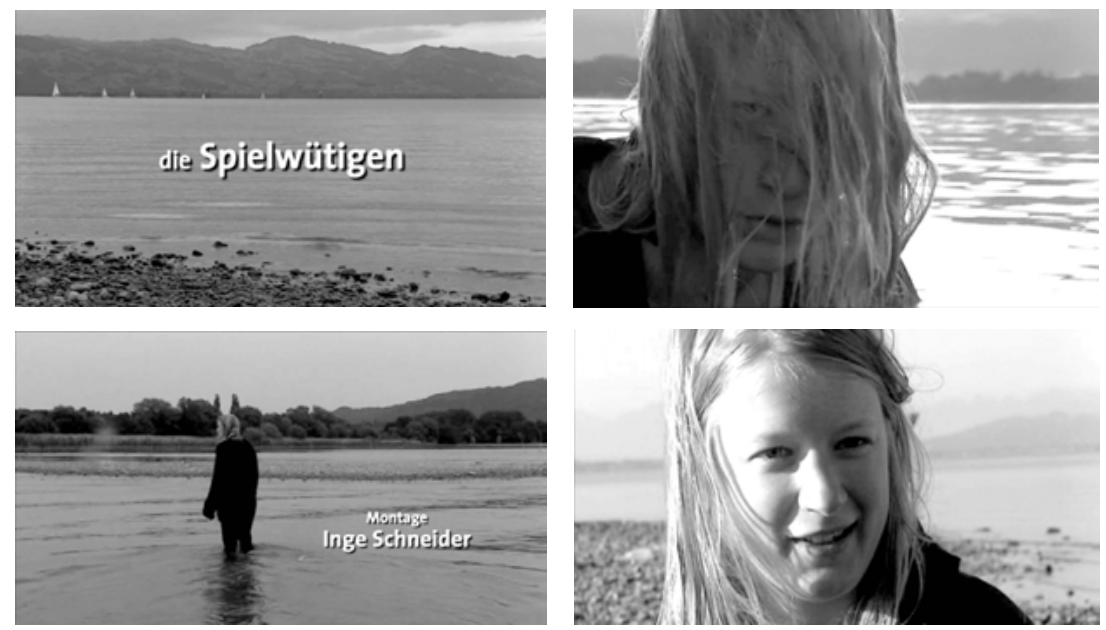

Abbildungen 1 bis 4: Videostills aus DIE SPIELWÜTIGEN (D 2004).

Ein Seepanorama in morgendlich-kühlem Licht. Zu hören ist eine Klaviermusik mit wenigen Akkorden und einer Melodielinie. Während die Schrifttafeln laufen, sehen wir eine einzelne Figur, die im Wasser auf- und abtaucht, dann eine Nahaufnahme, die uns zeigt, dass es sich um eine junge Frau handelt, die bekleidet und frierend im (offenbar kalten) Wasser steht. In diesem Moment wird sie als die Sprecherin erkennbar, die bereits aus dem Off einen Satz des Gretchens aus der Kerker-Szene von Goethes FAUST gesprochen hat: »Stumm liegt die Welt wie das Grab.« In der dritten Einstellung sehen wir, wie sie ans Ufer geht, wo sie dann in gelöster Haltung von und für sich selbst spricht: »Für mich gibt es erst einmal keine Grenze. Also keine ... Warum sollte ich auch für >Schauspiel< eine tiefere Grenze setzen als fürs Leben? « ${ }^{1}$ Der programmatische Anspruch auf eine Auflösung der Differenz zwischen dem >Schauspiel< auf der einen und dem >Leben< auf der anderen Seite ist hier auch ein Moment der filmischen Inszenierung: So wie Gretchens Rede von der Welt als Grab mit der Kälte des Wassers korrespondiert, so wird Stremlers Rede von der Entgrenzung in der Weite des Bodensees reflektiert.

Der klassische Text, der die Enge der Welt behauptet und eine aussichts- und trostlose Haltung beschwört, wird hier mit Bildern konfrontiert, die auf eine Dimension verweisen, die den filmischen Rahmen ebenso zu sprengen scheint wie jede denkbare Umsetzung auf einer Bühne. Auch die Konfrontation der unsicheren, kältegeschüttelten Stimme mit dem selbstbewussten, gelösten Ton des Kommentars verweist auf jene Spannung, die alle vier Protagonisten gleichermaßen und ihre filmische Selbstdarstellung insgesamt betrifft: Die Hoffnung auf einen Zuwachs an

1 Transkription nach der Tonspur der DVD-Veröffentlichung: Bormann. 
Freiheit, der sich an das Erwachsenwerden knüpft, bricht sich immer wieder an jenen Ein- und Abgrenzungen, an der Anerkennung von Grenzen, Regeln und Konventionen, die das Subjekt überhaupt erst konstituieren. Dies ist die Lektion, die die vier Schauspielschüler lernen müssen, und die Ausbildung zum Schauspieler scheint es ihnen zu erlauben, diesen Prozess bewusst (nach-) zu vollziehen.

So kommt es auch in der folgenden Handlung immer wieder zu Konflikten zwischen Schülern und Lehrern, die teilweise offen und krisenhaft ausgetragen, teilweise im Gespräch mit den Protagonisten beschrieben werden. Beispielsweise muss sich Plachetka während ihrer Ausbildung von ihrer Lehrerin anhören: »Das Problem scheint mir doch zu sein wieder das alte: Du entscheidest dich nicht«, und als sie daraufhin zu weinen scheint: »Nun sei nicht traurig. Das ist das Leben, jaja. $\aleph^{2}$ Dennoch greift es zu kurz, DIE SPIELWÜTIGEN allein als inhaltliche Kritik autoritärer Praktiken an einer bestimmten Ausbildungsstätte zu verstehen. Vielmehr besteht sein skandalöses Moment darin, dass er die Selbstverwirklichung als widersprüchlichen und schmerzvollen Prozess schildert, der im Zeichen des Abschieds und der Trauer stattfindet.

Entscheidend ist dabei, dass der Regisseur diesen Prozess nicht nur abbildet, sondern bewusst und aktiv mitgestaltet. So erfahren wir beispielsweise aus Interviews mit Veiel und den Protagonisten, die z.T. bereits dem Pressematerial beilagen und auch in das Begleitheft der DVD-Veröffentlichung aufgenommen wurden, dass Veiel allen Schauspielschülern, die an der Mitwirkung interessiert waren, zur Bedingung gemacht hat, ihren Eltern in ihrem jeweiligen Heimatort eine Szene vorzuspielen. Dies war nicht nur, wie Veiel erzählt, »eine große Hemmschwelle«, sondern auch ein »Belastungstest « für die künftige Zusammenarbeit. ${ }^{3}$ Und tatsächlich sind auch im Vorspann in ihrer Intimität peinigende Szenen zu sehen, in denen die Eltern, so scheint es jedenfalls, erstmals mit dem ihnen noch unbekannten Selbst ihrer Kinder konfrontiert werden.

Dessen Hervorbringung aber ist eben nicht nur auf die Entscheidung zurückzuführen, Schauspieler zu werden - sie steht in direktem Zusammenhang mit der Person des Regisseurs und der Produktion des Films. Denn Veiel nimmt - ohne jemals in Erscheinung zu treten - die Rolle eines persönlichen Mentors, zuweilen die eines Therapeuten ein, wovon alle vier Protagonisten übereinstimmend, wenn auch mit unterschiedlicher Akzentsetzung berichten. »Andres [Veiel]«, sagt etwa Stremler über eine zwei Jahre dauernde Krisenphase während der immer wieder unterbrochenen Dreharbeiten, »war der einzige Halt für mich«. Antoniadis:

»So waren Folgen des Sieben-Jahre-Drehs, dass man präziser über sich reflektieren und sich selber und seine Situation besser akzeptieren lernte. Das Gespür, was ein Schauspieler braucht, um zu wissen, wann bin ich wahrhaftig, wann nicht, konnte ich durch das entstandene Bildmaterial überprüfen.«

Plachetka adressiert ihren Kommentar persönlich an Veiel: »du kamst nicht, um etwas besonderes zu filmen, sondern du machtest es dazu. [...] alles wandte sich einem ziel zu und wurde zur eindeutigkeit gezwungen«. Und Becker erzählt:

2 Transkription nach der Tonspur der DVD-Veröffentlichung: Bormann.

3 Vgl. Andres Veiel im Interview mit Jörg Taszman, veröffentlicht unter dem Titel »Ich wollte einen Film über das Erwachsenwerden machen« im Beiheft der DVD-Veröffentlichung von DIE SPIELWÜTIGEN, o.J., o.P. Auch alle folgenden Zitate entstammen, soweit nicht anders gekennzeichnet, diesem Beiheft. 
»Ich habe Andres viel erzählt, auch ohne Kamera. Von der Schule, von meinem Leben, von besonderen Momenten. Die wollte er natürlich dann auch im Film haben. Dann saß ich wieder da und alle warteten. Auf Tränen, die ich gestern geweint hatte - oder morgen weinen würde. [...] Als er einmal vorschlug, dann >ist heute eigentlich gestern, beziehungsweise heute ist morgen $<$ da habe ich die ganze Idee verflucht. Alles Lüge, ich mag nicht mehr für die Kamera mein Leben nachspielen.«

Offenbar fallen für die Protagonisten die Produktion des Films, die Ausbildung zum Schauspieler und die Verwirklichung eines, ihres Selbst zusammen: Biographien werden hier nicht allein erzählt, sondern gestiftet. Dabei wird auch der Blick auf die Brüche und Widersprüche dieses Prozesses gelenkt. Allerdings, und dies macht der Blick auf den Vorspann deutlich, vermag die Verstrickung des Films nur an wenigen Stellen sichtbar zu werden - explizit wird sie sogar erst in den nachgetragenen Erzählungen der Protagonisten. Insofern könnte man kritisch argumentieren, dass jene Disziplinierungen, die der Film selbst seinen Protagonisten unter dem Siegel des Genres Dokumentarfilm zufügt (genauer: die sie sich selbst zufügen, indem sie sich an dieser Form der Inszenierung ihres Selbst beteiligen, sich auf sie einlassen), zumeist so unsichtbar bleiben wie die Figur des Regisseurs.

\section{Kleine Haie}

Dies gilt auch für den Spielfilm KLEINE HAIE, in dem wir allerdings von vornherein mit einem anderen Genre konfrontiert sind. Dennoch lassen sich nicht nur inhaltliche, sondern auch inszenatorische Parallelen aufzeigen. Auch Wortmanns Film geht von einer Ineinssetzung von Schauspiel und Leben aus und stellt die Frage nach der Selbstverwirklichung ins Zentrum. Der entscheidende Unterschied zu DIE SPIELWÜTIGEN liegt jedoch in der Umkehrung des Verhältnisses von Schauspiel und Leben. Denn in diesem Fall werden die Konflikte der Selbstfindung nicht von der Unbedingtheit einer existentiellen Entscheidung, sondern vom Spiel her bestimmt. KLEINE HAIE ist ein Schauplatz kontinuierlicher (kalkulierter, beabsichtigter, aber auch unfreiwilliger, untergründiger) Verstellungen. Deswegen kann er sich auch auf ein selbstreflexives Spiel mit den filmischen Konventionen einlassen und darin sogar die Strategien des Dokumentarfilms integrieren.

KLEINE HAIE erzählt von drei Protagonisten, die sich zufällig kennenlernen und einige turbulente Tage während der Aufnahmeprüfung bei der Otto-FalckenbergSchule in München verbringen, bevor sich ihre Wege wieder trennen. Der von Kai Wiesinger verkörperte Johannes ist der einzige der drei, für den die Entscheidung, Schauspieler zu werden, eine existentielle Dimension besitzt, doch selbst ihm fehlt jene $>$ Wut $<$, die Veiels Protagonisten auszeichnet. Zudem bleibt ausgerechnet ihm der Zugang zur Ausbildung zunächst verwehrt, da er in allen Aufnahmeprüfungen (auch der in München) scheitert. Der anfangs etwas antriebslose Gelegenheitsschriftsteller Ingo (Jürgen Vogel) dagegen kommt nur aufgrund eines Missverständnisses zum Schauspiel: Zu Beginn des Films wird erzählt, wie er erfolglos einen von der Schauspielschule ausgeliehenen Stuhl zurückgeben will und dabei zufällig vor die Prüfungskommission gerät, die seinen (eben echten und nicht gespielten) Ärger als gelungene Schauspielimprovisation sieht. Entsprechendes gilt für Ali (Gedeon Burkhard), der selbsternannte Anführer der Gruppe, der zwar als äußerst begabt vorgestellt wird, aber - wie sich erst kurz vor Schluss herausstellt - 
die gesamte Unternehmung nur als unterhaltsame Alternative zu seinem lukrativen Beruf versteht.

In der Szene, die im Folgenden exemplarisch vorgestellt werden soll, kommen nicht nur die unterschiedlichen Positionen klar zum Ausdruck, sondern auch eine subtile Selbstreflexion des Mediums Film.

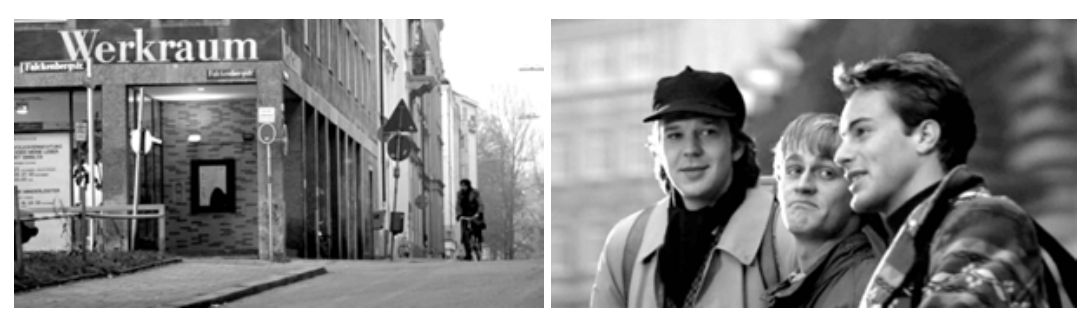

Abbildungen 5 und 6: Videostills aus KLEINE HAIE (D 1992).

Nach ihrer ersten Nacht in München stehen die drei vor dem Gebäude der Schauspielschule. Dort findet folgender Dialog statt:

Ingo: Hier isses. Sieht doch ganz normal aus von außen. Johannes: Cornelius hat auch hier studiert. Ali: Wer? Johannes: Cornelius! Kennste den nicht? Ali: Sollte ich? Johannes: Cornelius! Kammerspiele, Thalia, Schaubühne ... der Schauspieler überhaupt! Ali: In welchen Filmen hatt'n der mitgespielt? Johannes: Der macht keine Filme. Der spielt nur Theater. Theater ist viel ... wahrhaftiger, weißte? Ali: Ah ja. Ingo: Is' echt wahrhaftig. Ali: Theater is' dermaßen wahrhaftig. Johannes: Banausen. ${ }^{4}$

Das Argument der Wahrhaftigkeit gehört sicherlich zu den am häufigsten bemühten rhetorischen Figuren des zeitgenössischen Theaterdiskurses, und auch die proklamierte Verweigerungshaltung dem Film gegenüber taucht darin immer wieder auf. In dieser Szene jedoch ist das Argument teils offenkundigen, teils subtilen Um-Wendungen ausgesetzt. Auffallend ist etwa, dass »der Schauspieler überhaupt « als eine fiktive Figur, als eine Figur der Fiktion eingeführt wird, die zudem - wie die Institution des Theaters - außerhalb der filmischen Handlung angesiedelt ist. Mit anderen Worten: Die Wahrhaftigkeit, die Johannes im Namen des Theaters einklagt, hat unter den (zugleich: inhaltlichen und technisch-medialen) Bedingungen des Films keinen Ort. Dem entspricht der ironische Tonfall, mit dem Ingo und Ali das Argument aufnehmen, was in der Transkription nicht präzise wiedergegeben werden kann. Denn tatsächlich wird in dieser Szene gar kein Konflikt zwischen den Protagonisten etabliert, sondern im Gegenteil: eine neue Form der Solidarität. Die Kommentare von Ingo und Ali sind ein rhetorisches Spiel, das nicht in einen Disput, sondern in ein gemeinsames Lachen mündet. Johannes wendet sich zwar verärgert von den »Banausen« $a b$, doch geschieht dies mit einem Lächeln. Diese über das Lachen hergestellte Solidarität weist über die dargestellten Charaktere hinaus: Nicht nur wird der Zuschauer im Kino bzw. vor dem Fernseher - der eben diesen Film sieht und Cornelius ebenfalls nicht kennen kann - in

4 Transkription nach der Tonspur der DVD-Veröffentlichung von KLEINE HAIE, 2003. Das unter www.filmevona-z.de/filedb/D_Haie.pdf (28.02.2007) veröffentlichte Drehbuch von Jürgen Egger und Sönke Wortmann weicht davon in einigen Details ab. 
die Position von Ingo und Ali versetzt. Letztlich gibt sich, wenn auch fast unmerklich, der Film hier selbst als inszeniertes Spiel zu erkennen. Wer mitlacht (und die Wirkung dieser Szene hat durchaus etwas Bezwingendes), solidarisiert sich mit den dargestellten Figuren ebenso wie mit den Schauspielern, die sie (nicht mehr) verkörpern.

Am Schluss des Films wird dieses Moment der Selbstreflexion, das hier nur angedeutet und unbestimmt bleibt, in radikalisierter Weise wieder aufgenommen, und es ist sicher nicht zufällig, dass sich dies abermals an der Grenze des Films selbst vollzieht: im Abspann.
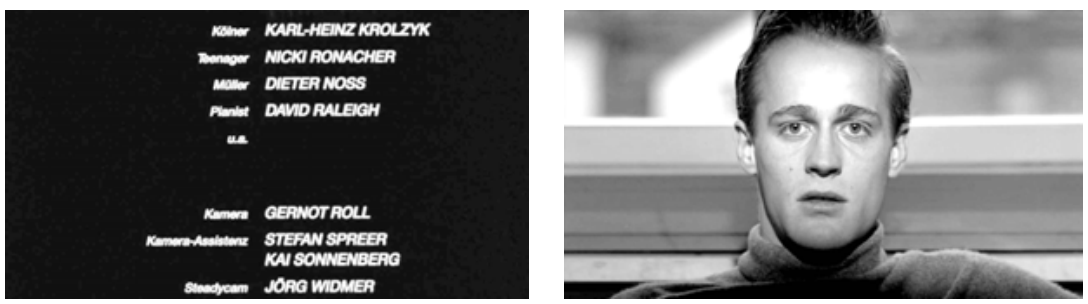

Abbildungen 7 und 8: Videostills aus KLEINE HAIE (D 1992).

Nachdem die Handlung schon zu einem Ende gefunden hat und die Rolltitel fast eine Minute gelaufen sind, folgt ein Epilog: Wir sehen Ingo auf einem Sofa sitzen, der seinen Blick zunächst nach unten richtet und von rechts nach links wandern lässt, um sich dann direkt an die Kamera zu wenden - so, als ob er sich auf das Aufstehen des Kinopublikums beziehen würde. ${ }^{5}$ Er sagt: »Hey! Was issn hier los? Es gibt doch noch'n paar offengebliebene Fragen zu klären! « ${ }^{6}$. Diese nicht allein inhaltliche, sondern auch strukturelle Intervention bricht mit den Konventionen des Spielfilms und verändert auch die Rolle selbst: Ingo erscheint unvermittelt als allwissender Erzähler, der zudem noch um die medialen Bedingungen seines Erzählens weiß - und dies auch zeigt. Auf der anderen Seite gehört auch diese Szene noch ganz der Handlung des Films an, denn die »offengebliebenen Fragen « betreffen auch ihn selbst: Ingo hat die Möglichkeit eines Schauspielstudiums ausgeschlagen, ist nach Hause zurückgekehrt und hat eine Familie gegründet, die später auch die Szene betritt. Seine Erzählungen über seine Freunde werfen jedoch neue Fragen auf. Ingo erzählt, dass Johannes in Berlin zur Schauspielschule zugelassen worden sei und seine Ausbildung inzwischen beendet habe (demnach sind zwischen dem Ende der Handlung und dem Epilog einige Jahre vergangen), während Ali das Studium in München zwar angetreten, aber wieder abgebrochen habe. Bebildert werden diese Erzählungen mit stummen Einstellungen, die aus der zurückliegenden Handlung zu stammen scheinen und deswegen keine visuellen >Belege < für das Gesagte sein können. Letztlich bleibt unklar, welcher Kontakt zwischen den Protagonisten zu diesem Zeitpunkt noch besteht und woher Ingos Informationen stammen.

5 Man könnte diese Einstellung nicht nur als mediale Selbstreflexion, sondern auch als Hommage an das Kino ansehen, die im Kontext des Fernsehens (mit dem vereinzelten Zuschauer vor den Bildschirmen) sinnlos, wenn nicht gänzlich unverständlich ist, da der Blick und die imaginäre Interaktion mit dem aufbrechenden Publikum buchstäblich ins Leere gehen.

6 Transkription nach der Tonspur der DVD-Veröffentlichung von KLEINE HAIE, 2003. 
Für Ingo selbst jedenfalls ist die Selbstfindung an den Verzicht geknüpft, jemand (anderes) werden zu wollen: Die Reise nach München erscheint als vorübergehende Krisenphase und als Katalysator für die Entscheidung, das vorhandene durch Konventionen und Klischees (des Ruhrpotts, der bürgerlichen Familie) bestimmte - Selbst anzuerkennen. Die bewusste Negation der emphatischen Form der Freiheit, wie sie das Theater darstellt, ist dann eine ebenso notwendige wie lustvoll vollzogene Konsequenz.

Man kann in der letzten Szene aus KLEINE HaIE, die auf paradoxe Weise (nicht) zur Handlung des Films gehört und gerade deswegen die filmische Verfassung der gesamten Unternehmung zur Erscheinung zu bringen vermag, einen doppelten Gegenentwurf zur Selbstfindung der SPIELWÜTIGEN sehen - zum einen auf inhaltlicher Ebene, aber auch auf der Ebene der filmischen Mittel. Wichtig ist dabei, dass die Fiktionalität bis zum Äußersten belastet, aber nicht gesprengt wird, dass die Konventionen des Genres aufs Spiel gesetzt, aber nicht vollständig aufgekündigt werden. Deswegen ist es letztlich auch möglich, in Ingos Fortschreibung der Handlung das Werk (s)einer (schriftstellerischen?) Phantasie zu sehen, und letztlich könnte man - seinen erweiterten Status als Erzähler berücksichtigend nun sogar die gesamte Handlung, den Film als solchen als Fiktion einer Fiktion ansehen, als Ausdruck einer Trauerarbeit, die den Verlust anerkennt, den die Genese des Selbst bedeutet. Die explizite Adressierung des (Kino-)Publikums wäre dann zugleich der Versuch, eine Haltung zu etablieren, in der die Aufgabe des Anspruchs auf >Wahrhaftigkeit< zum Ausdruck einer (wieder-)gewonnenen Freiheit wird.

Diese letzten Einstellungen machen auch deutlich, inwiefern die medialen Bedingungen des Theaterfilms das Problem der theatralen (Selbst-)Darstellung verschieben: Nicht nur erscheint das Selbst als Rolle - dies wäre noch das theatrale Dispositiv von Darstellung, wenn auch zweiter Ordnung. Ihm wäre auch der dokumentarische Film weitgehend zuzurechnen. Der Spiel-Film aber kündigt die Opposition zwischen Selbst und Rolle vollständig auf; unter seinen Bedingungen macht bereits die Frage nach dem Selbst keinen Sinn mehr. Zur Erscheinung kommt eine Darstellung der Darstellung der Darstellung ..., die auf keinen Ausgangspunkt und keinen Träger verweist (auch nicht auf die Körperlichkeit des Schauspielers), weil ihr Schauplatz weder die Bühne noch das Filmset, sondern die Imagination des Zuschauers ist. So verweist der Film auch auf die imaginäre Verfassung unseres eigenen Selbst - und stellt zugleich die Möglichkeit bereit, die damit verbundenen Brüche und Widersprüche, Spannungen und Aporien nicht nur wahrzunehmen, sondern auch zu genießen. 


\section{Literatur}

Bormann, Hans-Friedrich/Gabriele Brandstetter/Michael Malkiewicz/Nicolai Reher (2000): »Freeing the Voice. Performance und Theatralisation«. In: Erika Fischer-Lichte u.a.: Inszenierung von Authentizität (Theatralität, Band 1). Tübingen/Basel: Francke, S. 47-57.

Dietz, Georg (1997): »DJ und Dieb«. In: Spiegel Kultur extra, Heft 9/1997, S. 14. Flusser, Vilém (1998): Vom Subjekt zum Projekt. Menschwerdung. Frankfurt/M.: Fischer.

Klein, Thomas (2004): Ernst und Spiel. Grenzgänge zwischen Bühne und Leben im Film. Mainz: Bender.

Lehmann, Hans-Thies (1999): Postdramatisches Theater. Frankfurt/M.: Verlag der Autoren.

Matzke, Annemarie M. (2005): Testen, Spielen, Tricksen, Scheitern. Formen szenischer Selbstinszenierung im zeitgenössischen Theater. Hildesheim: Olms. 



\title{
Die Öffentlichkeit der Oper - Alexander Kluges THEMATISIERUNG DER OPER IN SEINEM FILM 》DIE MACHT DER GEFÜHLE«(1983)
}

\author{
CHRISTOPH ERNST
}

Wenn ein deutscher Intellektueller die Oper zum Gegenstand seiner ästhetischen Praxis gemacht hat, dann Alexander Kluge (vgl. Koch). Betrachtet man das filmische Gesamtwerk Kluges, gehört die Oper zu den Grundmotiven. Das Hauptstück von Kluges Auseinandersetzung mit der Oper fällt in die Zeit der späten 1970er und frühen 1980er Jahre. Ursprünglich als einer der Wortführer des »Neuen Deutschen Films « (vgl. Elsaesser) angetreten, blickt Kluge bis dahin auf eine rund 20jährige Filmpraxis zurück. Besonders in seinen späten Werken versucht Kluge, eine reflexive Haltung zu den Möglichkeiten des Mediums Film einzunehmen. Begleitet von einer komplexen theoretischen Reflexion lassen sich die Filme dem Genre des >Filmessays< zuordnen. ${ }^{1}$ Die medien- und kulturtheoretischen Implikationen dieser essayistischen Auseinandersetzung mit dem Medium >Oper $<$ sollen im Folgenden erörtert werden.

\section{Theoretische Aspekte der Reflexion auf die Oper bei Kluge}

In seinem Imaginären Opernführer schreibt Kluge: »Wir machen also nicht das synthetische Produkt, das im 19. Jahrhundert Oper heißt, zum Mittelpunkt. Auch nicht die Wendung von Wagner, der diese Oper erneuert. Weder geht es um die Grand Opéra noch um die Operette« (2001: 18). Vielmehr interessiert Kluge ein »extremes Gefühl«, das die Oper in einen »exklamativen Ausdruck « transformiert:

»Wenn einer [...] in höchster Not um Hilfe schreit, dann ist das davon der eine Pol, und der andere Pol ist der schöne Gesang, der liegt ganz im anderen Extrem. Dabei kann man nicht sagen, dass der Hilfeschrei grammatisch wäre, dass er eine Sprache wäre« (Kluge 2001: 18, vgl. 36).

Hinter diesem »Hilfeschrei «, der nicht »grammatisch« bzw. keine »Sprache« ist, verbirgt sich eine Anspielung auf Kluges Erfahrungstheorie. Das Motiv des »Hilfeschreis « deutet an, dass es Kluge in dieser Theorie um Erfahrungen geht, die sich nicht in die gewohnten Erfahrungsraster einpassen lassen. Stattdessen bezieht sich

1 Zu Kluges späten Filmen zähle ich alle Filme nach dem Kollektivprojekt DEUTSCHLAND IM HERBST (1978), also die zweite Fassung von DiE PATRIOTIN (1979), DER KANDidAT (1980), Die MACHT DER GEFÜHLE (1983), DER ANGRIFF DER GEGENWART AUF DIE ÜBRIGE ZEIT (1985) und VERMISCHTE NACHRICHTEN (1986). 
das »extreme Gefühl « auf Selbstentzüge der Erfahrung, also Erfahrungen, in denen die Erfahrung außer sich ist und sich selbst überschreitet. ${ }^{2}$

Niedergelegt ist Kluges Erfahrungstheorie in dem (mit Oskar Negt verfassten) Werk Öffentlichkeit und Erfahrung (1978) ${ }^{3}$. Dort heißt es, »Erfahrung « sei ein $»$ Rohstoff «, dem man nur in einer durch Massenmedien (»Bewusstseinsindustrie«) bearbeiteten Form begegnet (246). Was übrig bleibt, sind »andere« Erfahrungen, die in der bürgerlichen Öffentlichkeit nicht repräsentiert werden (69). Hiergegen stellen Negt und Kluge die Forderung nach einer »Gegenöffentlichkeit«. Sie soll jene Erfahrungsdimensionen repräsentieren, die in den Produkten der »Bewusstseinsindustrie « keine Berücksichtigung finden (7). Die Entstehung dieser »Gegenöffentlichkeit « soll u.a. durch den >Neuen deutschen Film < befördert werden. Das Ziel seiner ästhetischen Strategien ist es, die Verkürzungen der Erfahrungsrepräsentation zu kompensieren.

\section{Kluges Ästhetik des »dritten Bildes«}

Kluge entwickelt dafür die Idee der Filmästhetik eines »dritten Bildes«. Darunter versteht er ein durch kontrastierende Montage von zwei Filmbildern, welche verschiedenen Darstellungsmodi (z.B. Dokumentation und Spielfilm) angehören, erzeugtes »drittes Bild «. Bei der Hervorbringung des »dritten Bildes« greift die Einbildungskraft des Rezipienten auf jene Erfahrungen zurück, die sich den Imperativen der Bewusstseinsindustrie (etwa dem Postulat der Homogenität der repräsentierten Erfahrung) entziehen. Die Einbildungskraft des Zuschauers aktiviert im Prozess derjenigen Schlussfolgerungen, die das »dritte Bild « hervorbringen, Erfahrungspotenziale, die in der bürgerlichen Öffentlichkeit unterdrückt bleiben (vgl. Kluge 1999: 59, 120ff, 131f; Kluge/Koch: 115).

Rein formal ist diese Idee plausibel, wenn man das »dritte Bild « in Anlehnung an den dreistelligen Zeichenbegriffs von Charles S. Peirce als Interpretanten auffasst. Der Interpretant ist Peirce zufolge die Dimension der Semiose, in der die Relation von einem Objekt (die Referenz des Zeichens) zu einem Repräsentamen (das Zeichen für das Objekt) etabliert wird (sich also ein Repräsentationsverhältnis allererst konstituiert). Vereinfacht gesagt, ist Kluges »drittes Bild« dann die »bedeutungstragende Wirkung « (Peirce 1991: 510ff) der Relationierung zweier Bilder, sprich: das Produkt der Leistung der Einbildungskraft eines Zuschauers in Reaktion auf die Bildkonfiguration des Films. Allerdings müssen hierbei zwei Interpretanten, der »unmittelbare« und der »dynamische « Interpretant, unterschieden werden. ${ }^{4}$

2 In den Worten der Phänomenologie kann man dies als »Diastase « innnerhalb eines notwendig »pathischen« Erfahrungsgeschehens bezeichnen. Vgl. Waldenfels: »Die Phänomenologie einer gebrochenen Erfahrung gruppiert sich um zwei Leitmotive, die sich als Pathos und Diastase bezeichnen lassen. Das alte Wort Pathos verweist auf Widerfahrnisse, die uns zustoßen, uns zuvorkommen, uns anrühren und verletzen, keine Grundschicht also, sondern ein Geschehen, in das wir wohl oder übel und auf immer verwickelt sind. Das seltenere Wort Diastase bezeichnet die Gestaltungskraft der Erfahrung, die etwas oder jemanden entstehen lässt, indem sie auseinandertritt, sich zerteilt, zerspringt« (2002: 9f).

3 Weiter ausgearbeitet wird sie in Geschichte und Eigensinn (Negt und Kluge 1982) sowie Kluges medientheoretischen Essays der 1980er Jahre (vgl. Kluge 1999: 165ff).

4 Die Diskussion des dritten Interpretanten, des »finalen« Interpretanten, lasse ich hier beiseite. 
Streng genommen enthält der Film kein »drittes Bild «. Erst der Kontrast zweier Bilder im Film erzeugt eine Leerstelle, einen »unmittelbaren Interpretanten«. Dieser ist die »unmittelbar relevante, mögliche Wirkung [des Zeichens, C.E.] in ihrer unanalysierten, elementaren Ganzheit« (Peirce 2000: 224f, Hervorh. C.E.). Als mögliche Wirkung definiert der »unmittelbare Interpretant « einen Spielraum, an den die Einbildungskraft des Zuschauers anschließen kann. Der Anschluss selbst ist dann der »dynamische « Interpretant: die »Wirkung, die in einem gegebenen Interpreten bei einem gegebenem Anlass bei einer gegebenen Phase seiner Erwägung des Zeichens erzeugt wird « (225, vgl. 216). Als »emotionale«, »energetische« und »logische« Zeichen sind der »unmittelbare« Interpretant (die mögliche Wirkung des Bildkontrastes) und der »dynamische « Interpretant (dessen tatsächliche Wirkung) auf die Erfahrungsdimensionen von »Gefühl«, »Handlung« und »Gewohnheit « bezogen (225). Das sind die Dimensionen, auf deren Repräsentationsbedingungen es Kluges Erfahrungs- und Öffentlichkeitstheorie ankommt.

Zusammenfassend gesagt, konzentriert sich Kluges Ästhetik eines »dritten Bildes « somit auf die semiotische Übersetzung, die zwischen »unmittelbaren « und »dynamischen « Interpretanten stattfindet und dadurch Repräsentation ermöglicht. Kluge begründet diese Ästhetik sowohl (a) erfahrungstheoretisch, weil er die semiotische Übersetzung als kreative Leistung der Einbildungskraft konzipiert, welche auf Grenzzustände der Erfahrung verweist, als auch (b) gesellschaftskritisch, indem das »dritte Bild « die Aufgabe übernimmt, im Zuschauer eine Erfahrung zu erzeugen, welche die durch die Produkte der Bewusstseinsindustrie induzierten Erfahrungsverkürzungen in der bürgerlichen Öffentlichkeit auszugleichen in der Lage ist.

Wenn Kluge in Bezug auf die Oper nun davon spricht, die Oper sei auf die Aktivierung der diastatischen Momente der Erfahrung abgestellt - und infolgedessen das Problem der öffentlichen Repräsentation von Gefühlen - mithin: die Spannung zwischen »extremem Gefühl « und »exklamativem Ausdruck « als zentrales Problem für die Bewertung der Oper anzusehen ist - dann stellt sich die Frage, wie Kluge die Spezifik dieser Relation im Rahmen seiner Filmästhetik des »dritten Bildes« ausarbeitet. Verfolgen kann man dies anhand des Filmessays DIE MACHT DER GEFÜHLE. ${ }^{5}$

\section{Die Thematisierung der Oper in DiE MACHT DER GEFÜHLE}

Wie kaum ein zweiter Film Kluges wird DIE MACHT DER GEFÜHLE von dem Motiv der Oper zusammengehalten. Das Verhältnis von Oper und Gefühl ist die zentrale »Isotopieebene« (vgl. Rastier) des Films. Definiert wird die Oper in DIE MACHT DER GEFÜHLE als »Kraftwerk der Gefühle «. ${ }^{6}$ In der typischen Manier seiner späten

5 Vgl. für eine Analyse der Oper unter spezieller Berücksichtigung von Die MACHT DER GEFÜHLE: Kluge und Koch 1989. Koch sucht den Zugang über Aspekte wie Kluges Weiterdenken bestimmter szenisch-theatralischer Potenziale der Oper in der Filmhandlung. Mir geht es in Ergänzung dazu vor allem um die intermediale Dimension der Fragestellung, also um die Frage, inwieweit die >Medien< Oper und Film nicht inhaltlich, sondern formal in ihren wechselseitigen Repräsentationsmöglichkeiten aufeinander bezogen werden.

6 Eine Aussage, die Kluge später wieder zurückgenommen hat, weil sie impliziert, die Oper »produziere« Gefühle. Tatsächlich stelle die Oper, so Kluge, nur Möglichkeiten zur Verfügung, die dann mit Gefühlen besetzt werden (vgl. 2001: 37). 
Filmästhetik >analysiert< Kluge die Beziehung zwischen Oper und Gefühl durch Parallelisierung von dokumentarischen Szenen, fiktionalen Passagen und montierten Filmzitaten. Auffällig ist an dieser Praxis, dass Kluges Konzept zwei Strategien bei der Thematisierung der Oper einsetzt.

In der ersten Strategie geht es darum, die Kunstform der Oper nicht in ihrer regulären Rezeptionssituation zu zeigen. Die Kamera verbleibt hinter oder oberhalb der Bühne, bietet also einen regulär verborgenen Blick auf das Bühnengeschehen. Offensichtlich versucht Kluge auf diese Weise, die Oper von den Produktionsverhältnissen ihrer Aufführungspraxis (ihren >Inszenierungsbedingungen $<$ ) her ins Visier zu nehmen (Bühne, Kostüme, Opernhaus etc.). Dazu nutzt Kluge die dokumentarische Qualität des Filmbildes, dessen vermeintliche Authentizität in seiner Ikonizität und seiner Indexikalität (vgl. Peirce 2005: 65) begründet ist - also in Ähnlichkeits- und Kausalverhältnissen, die einen ungebrochenen Bezug zur vorfilmischen Realität evozieren.

Just diese >Authentizität< des Filmbildes wird durch die zweite Strategie in Frage gestellt, wenn Kluge die dokumentarische Ebene mit Filmzitaten aus Stummfilm-Verfilmungen von Opern (hier v.a. AIDA) parallelisiert und reflexiv markiert. ${ }^{7}$ Jetzt wird der Film zum Gegenstand der Untersuchung. Diese Parallelaktion erfüllt die Funktion, die Medialität des Films zu thematisieren. Die ikonisch-indexikalische Abbildungsleistung des Films (und daraus folgende Implikationen wie z.B. Authentizität) wird durch die dokumentarisch aufgewiesene Symbolizität der Oper konterkariert - wobei unter >Symbolizität< der Oper die Gesamtheit der diesem Medium zugesprochenen konventionalisierten Repräsentationsmodi (Kostüme, Bezug zwischen Gesang und Libretto etc.) zu verstehen ist (vgl. Peirce 2005: 65f).

Einerseits rückt Kluge der Oper mit Hilfe der dokumentarischen Abbildungsleistung des Films zu Leibe, setzt also auf Ikonizität und Indexikalität des Filmbildes, um zu »zeigen« wie die Oper »Gefühle« inszeniert. Andererseits bricht er mit Verweisverhältnissen (und macht sie einer Reflexion zugänglich), wenn er die symbolischen Qualitäten der Oper in die Stummfilmzitate (im Sinne eines systemtheoretischen $>$ re-entrys $<$ ) wieder in den Film einschreibt. ${ }^{8}$

Die Oper ist folglich der Bezugspunkt der reflexiven Problematisierung der durch die ikonischen und indexikalischen Referenzverhältnisse nahe gelegten Authentizität des Filmbildes. Dazu vermerkt Kluge in seinen filmtheoretischen Überlegungen: »Endlich zu begreifen wäre: des Kinematografen oft zitierte >dokumentarische Authentizität< ist nichts anderes als die hohe Stilisierung der Oper « (Kluge 1999: 116), und: »Das so genannte Filmische, gleich ob im Dokumentarfilm oder im Spielfilm, beginnt >mit dem Realen und Konkreten, der wirklichen Voraussetzung « (120).

Von einer >Wiedereinschreibung $<$ ist hierbei zu sprechen, weil die Perspektive der AIDA-Sequenz aus einer reflexiven Selbstbefragung des Films heraus die Unfähigkeit des Stummfilms vor Augen führt, die symbolische Qualität der Oper einzu-

7 Bei Kluge ist der Stummfilm immer eine Chiffre für die eigene Filmpraxis. Die »reflexive Markierung « kommt durch Kluges, in seinen Filmen öfter eingesetzte, »Fernglas«-Perspektive zustande. Das ist eine Einstellung, in der der abgebildete Stummfilm nur durch zwei, wie bei einem Fernglas nebeneinander liegende, Kreise beobachtet werden kann.

8 Solche >Wiedereinschreibungen< bzw. >re-entrys< sind für gängige Intermedialitätskonzepte konstitutiv. Joachim Paech fasst Intermedialität zum Beispiel »als eine spezifische Form medialer Selbstreferenz, als Wiedereinführung desselben oder eines anderen Mediums als Form auf der Formseite des Mediums« (1997: 337). 
holen. Konzipiert ist diese Wiedereinschreibung als Mediendifferenz zum Film: »der Alltag des Zuschauers und das besondere Erlebnis [...] [in] der Oper [sind,] strikt getrennt. [...] Im Kino ist diese Distanz zunächst aufgehoben. Das Kino suggeriert unmittelbare Präsenz « (87). ${ }^{9}$

Die Wiedereinschreibung der symbolischen Dimension der Oper in das Medium Film stellt somit eine Affirmation der >Distanz< der Oper dar, also die Affirmation einer originären Repräsentationsleistung des Mediums Oper. Für Kluge besteht diese Eigenleistung in der epistemologischen Durchsichtigkeit ihrer ostentativen Inszenierung von »extremen Gefühlen« im Rahmen einer Kombination von »Sinn « und »Spektakel« (bzw. im Offenlegen der Konventionalität der Symbolizität). Das Filmbild negiert diese Eigenleistung, indem es die eigene Medialität hinter eine quasi-authentische Abbildungsleistung zurücktreten lässt. Im Unterschied dazu kommuniziert die Oper die Spannung zwischen »Sinn« und »Spektakel«. Das audiovisuelle Filmbild hebt diese Differenz auf. Darin unterscheiden sich das $>$ theatralische< Medium Oper und das >bildliche< Medium Film. Es ergibt sich eine $M e-$ diendifferenz zwischen Oper und Film

\section{Medien- und kulturtheoretische Konsequenzen}

Unschwer zu erkennen ist, dass Kluge mit dieser Thematisierung der Oper Bezüge zu Theodor W. Adornos Musiksoziologie herstellt. Gemäß seines kunstsoziologischen Ansatzes ist für Adorno im Fall der Oper die Frage, wie sich das Verhältnis von ästhetischer Form und gesellschaftlicher Funktion gestaltet (vgl. 1968: 234ff; 1978: 10). Ähnlich wie Kluge sieht Adorno als das Entscheidende hier »die Identifikation des Hörers mit gesungenen Emotionen« (vgl. 1968: 83f) an. Diese Identifikation kann die Oper laut Adorno ab ca. 1910 nicht mehr leisten (87ff). Das Medium Film ist der Erbe des Spektakelcharakters der Oper (vgl. 90f). Das Problem am Film, oder besser: am Filmbild, ist allerdings, dass es Adorno zufolge nicht in der Lage ist, das ästhetische Potenzial, das der Oper als Kunstform zu eigen war, einzuholen. Das Filmbild negiert, was in der Oper an ästhetischem Fundament noch enthalten war: dass die Differenz zwischen Sinn und Spektakel explizit ist (vgl. Pfeiffer).

Das deckt sich auf den ersten Blick mit Kluges Ideen. Auch für Kluge ist die Oper im Gegensatz zum Filmbild in der Lage, die Differenz zwischen Sinn und Spektakel mitzukommunizieren. Wie das Beispiel aus DIE MACHT DER GEFÜHLE verdeutlicht, ist es aus Kluges Sicht allerdings grundfalsch, dem Film dieses Defizit kulturkritisch vorzuhalten. Das hat etwas damit zu tun, dass Kluge die Oper als Medium problematisiert: Zwar behält Kluge die bei Adorno exponierte Grundspannung zwischen Form und Funktion der Oper als analytische Perspektive bei. Im Gegensatz zu Adorno verhandelt Kluge die Spannung zwischen Form und Funktion

9 Weil die Mediendifferenz zwischen Oper und Film expliziert wird, kann man behaupten, dass es um einen intermedialen Bezug geht: Nach der Klassifikation von Rajewsky handelt es sich bei dieser Thematisierung der Oper mit den Mitteln des dokumentarischen Bildes um eine »explizite Systemerwähnung « (d.h. ein Medium reflektiert das andere; Mediendifferenzen sind explizit); bei den mit Opernmusik unterlegten Filmzitaten, also der Selbstreflexion des Films, die sich an der Referenz zum Medium Oper entzündet, dagegen um eine »Systemerwähnung qua Transposition « (d.h. die Elemente der Oper werden mit den Mitteln des Films (teil-)reproduziert, evoziert oder simuliert). 
aber nicht als ästhetisches, sondern als ein mediales Problem. ${ }^{10}$ Für Kluge ist nicht der Bezug der Oper zur Gesellschaft das Wesentliche. Ihn interessiert der Bezug der Oper zur Öffentlichkeit ${ }^{11}$, also zu einer medial konstruierten Umwelt der Gesellschaft. ${ }^{12}$ Es kommt ihm darauf an, die Medialität der Oper zu beobachten, ohne zu leugnen, dass diese Beobachtungsleistung selbst wieder auf ein Medium angewiesen wäre.

Um diese Prämisse einzuholen, erzeugt Kluges Konfrontation zweier medialer Perspektiven (als Auftauchen eines Mediums im anderen) eine Distanz, die einen Übersetzungsprozess im Sinne des »dritten Bildes « initiieren soll. ${ }^{13}$ Weil Kluge die Oper damit primär als Medium und bloß sekundär als Kunstform thematisiert, wird in die Oper keine ästhetische Substanz hineinprojiziert, die, wie noch bei Adorno, vermeintlich verloren geht (vgl. Adorno 1968: 87). Vielmehr ist innerhalb der Oper eine Spannung anzuzeigen, die für dieses Medium kennzeichnend ist: dass die Differenz von >Sinn< und >Spektakel< in der Oper seit jeher eine prekäre war.

Unterschwellig verlegt Kluges Thematisierung der Oper damit das Problem der »Entfremdung «, das Adorno in der Rezeption der Oper Mitte des 20. Jahrhunderts als Ausdruck für die »Inadäquanz des ästhetischen Gegenstands und seiner Rezeption« (Adorno 1968: 95) ausmacht, in die Oper selbst. Die Oper ist für Kluge nie die einheitliche ästhetische Form gewesen, von der Adorno ausgeht. Sondern die Spannung zwischen »extremem Gefühl « und »exklamativem Ausdruck « ist immer schon die einer Entfremdung. Die Entfremdung ist der Oper konstitutiv eingeschrieben. Wo Adorno das Aushandeln dieses Verhältnisses noch als Prozess der Gewinnung der ästhetischen Substanz der Oper anspricht (vgl. 1978: 31, 37), sieht Kluge in Spannungen wie dieser eine Entfremdung am Werk, die es geboten erscheinen lässt, die Oper von ihrer Mediendifferenz zu anderen Medien her zu problematisieren.

\section{Ergebnisse: Das Verhältnis von Oper und Film}

Das Medium Film ist bei Kluge also nicht einfach das Nachfolgemedium, das die Oper, wie Adorno in seiner Einführung in die Musiksoziologie behauptet, »um das pompöse Dekor, das imposante Spektakel, berauschende Buntheit und sinnliche

10 Adorno weist zwar auf die »öffentliche Dimension« der Oper hin (vgl. 1968: 91, Anm. 3), zieht aber nicht die Konsequenz, die Oper selbst als >Medium < zu betrachten. Wenn Adorno auf intermediale Fragen zu sprechen kommt, dann einzig, wenn es um die »Spannung zwischen dem musikalischen Medium und dem szenischen « (Adorno 1978: 39) geht, also z.B. um das Verhältnis von Sprechtheater und Musiktheater.

11 Damit soll keineswegs gesagt werden, dass das Problem der Öffentlichkeit bei Adorno keine Rolle spielt. Im Gegensatz zu Kluges Ansatz ist es bei Adorno bei der Betrachtung der Oper jedoch von untergeordneter Bedeutung. Ausgehend von seinen Überlegungen zur Kulturindustrie erörtert Adorno zwar Medien wie Film und Fernsehen als Konstituenten der Öffentlichkeit, nicht aber die Kunstform der Oper. Das ist die Prämisse, die Kluge unterläuft: Oper und Film bewegen sich strukturell gesehen als Medien für die und in der Öffentlichkeit auf einer Ebene.

12 Die Forschung hat des Öfteren bemerkt, dass der Öffentlichkeitsbegriff von Negt und Kluge Parallelen zum systemtheoretischen Öffentlichkeitsbegriff von Niklas Luhmann aufweist (vgl. Hohendahl 2000: 99ff, insb. 105ff; Luhmann 1970 sowie 2004: 184ff).

13 Versteht man das »dritte Bild « als einen Interpretanten im Peirceschen Sinne (vgl. Peirce 2005: 67ff), nähert man sich dem, was in der Übersetzungstheorie als >tertium comparationis< gefasst wird: Ein »drittes Konstrukt« der Einbildungskraft, das einen Vergleich ermöglicht (vgl. im Kontext Schönrich 1999: 65ff). 
Lockung « (1968: 90f) erleichtert, also aus der Oper die »Aura« abzieht und nur die Oberfläche zur Schau stellt (vgl. 1978: 29f). Kluge macht aus Adornos kulturkritischem Argument ein medienästhetisches: In der inszenatorischen Brüchigkeit der Beziehung zwischen Sinn und Spektakel behält die Oper in genau dem Moment ihren Eigenwert (ihre $>$ Valenz $<$ ), in dem man sie - in scharfem Gegensatz zu ihrer tradierten Funktion als Stütze der bürgerlichen Öffentlichkeit - als ein Medium zur Repräsentation von in der bürgerlichen Öffentlichkeit nicht-repräsentierten Erfahrungen begreift. Darauf deutet Kluges intermediale Konfiguration der wechselseitigen Übersetzung von Medienbeobachtungen in dem Filmessay DIE MACHT DER GEFÜHLE hin.

Die >Unentscheidbarkeitsästhetik < von Kluges Filmen ist im vorliegenden Fall eine >Übersetzungsästhetik $<$, die auf die Fähigkeit des Zuschauers abgestellt ist, beide Medien in Verbindung zu setzen. Das Ziel von Kluges Praxis aber ist nicht auf die Integration der Medien Film und Oper abgestellt. Kluge sieht den Sinn dieser Übersetzung vielmehr in der Mitrepräsentation der Mediendifferenz zwischen Oper und Film. Mediendifferenzen werden in einem tertium comparationis explizit, dadurch aber für eine Reflexion auf die Repräsentationsmöglichkeiten des jeweiligen Mediums transparent. ${ }^{14}$ Die Thematisierung der Oper als Medium führt von daher zu dem, was Kluges essayistische Filmpraxis zur Etablierung einer »Gegenöffentlichkeit « beitragen möchte: die Inszenierung als konstitutives Merkmal der Authentizität des Films zu verstehen.

Oder, nochmals mit Kluge gesprochen: »Die authentische Distanz des Kinoprodukts drückt sich darin aus, dass treffende Filme zu keinem Zeitpunkt darüber täuschen, dass sie etwas Dargestelltes sind « (1999: 146). ${ }^{15}$

\section{Literatur}

Adorno, Theodor W. (1968): Einführung in die Musiksoziologie. Frankfurt/M.: Suhrkamp.

Adorno, Theodor W. (1978): »Bürgerliche Oper«. In: Ders.: Musikalische Schriften I-III. Frankfurt/M.: Suhrkamp, S. 24-39.

Hohendahl, Peter Uwe (Hg.) (2000): Öffentlichkeit. Geschichte eines kritischen Begriffs. Unter Mitarbeit von Russel A. Berman, Karen Kenkel und Arthur Strum. Stuttgart: Metzler.

14 Deshalb spricht Kluge auch von »Leerstellen« bzw. »Zwischenvalenzen« der Medien (vgl. Sombroek 2005: 105). Jedes Medium besitzt seine je eigene »Repräsentationsvalenz«, die mit Interpretanten besetzt wird. Medien, und ebensolche sind in ihrer Minimaldefinition Zeichen im Peirceschen Sinne, eröffnen Spielräume für die Interpretanten, ihre Inhalte (bzw. Objekte) in bestimmter Weise zu repräsentieren (zu der hier anschließenden Theorie der »Diagrammatik« bei Peirce vgl. Hoffmann 2005).

15 Aus dieser >Übersetzungsästhetik< entwickelt sich Kluges Authentizitätsbegriff. »Authentizität heißt: dass eine Situation stimmig ist, nicht bloß, dass ein Sachverhalt oder die Formen stimmen. Authentisch ist auch die direkte Konfrontation von kollektivem Umfeld und Individualität, die nicht gegeneinander verwischt werden, sondern auch einen Moment der Produktion von Individualität beinhalten. [...] Dies ist genau das, was wir mit entspannter Distanz zulassender Kommunikation für den Film meinen. Man kann sie nicht steigern wollen, die Situation verstärkt sich oder sie verstärkt sich nicht, das geschieht selbstreguliert. Verborgen ist darin eine Art Gastrecht, den Standpunkt eines Fremden zunächst einmal anzunehmen, bis er sich prüfen lässt« (1999: 147f). 
Hoffmann, Michael H.G. (2005): Erkenntnisentwicklung. Ein semiotisch-pragmatischer Ansatz. Frankfurt/M.: Klostermann.

Elsaesser, Thomas (1994): Der neue deutsche Film. Von den Anfängen bis zu den neunziger Jahren. München: Heyne.

Kluge, Alexander (1999): In Gefahr und größter Not bringt der Mittelweg den Tod. Texte zu Kino, Film, Politik. Berlin: Vorwerk 8.

Kluge, Alexander (2001): Herzblut trifft Kunstblut. Erster imaginärer Opernführer. Berlin: Vorwerk 8.

Kluge, Alexander/Gertrud Koch (1989): »Die Funktion des Zerrwinkels in zertrümmernder Absicht. Ein Gespräch zwischen Alexander Kluge und Gertrud Koch«. In: Rainer Erd u.a. (Hg.): Kritische Theorie und Kultur. Frankfurt/M.: Suhrkamp, S. 106-124.

Koch, Gertrud (1989): »Alexander Kluges Phantom der Oper«. In: Rainer Erd u.a. (Hg.): Kritische Theorie und Kultur. Frankfurt/M.: Suhrkamp, S. 95-105.

Luhmann, Niklas (1970): »Öffentliche Meinung«. In: Politische Vierteljahresschrift, Nr. 11, S. 2-28.

Luhmann, Niklas (2004): Die Realität der Massenmedien. Wiesbaden: VS Verlag für Sozialwissenschaften.

Negt, Oskar/Alexander Kluge (1978): Öffentlichkeit und Erfahrung. Zur Organisationsanalyse von bürgerlicher und proletarischer Öffentlichkeit. Frankfurt/M.: Suhrkamp.

Negt, Oskar/Alexander Kluge (1982): Geschichte und Eigensinn. Geschichtliche Organisation des Arbeitsvermögens. Deutschland als Produktionsöffentlichkeit. Gewalt des Zusammenhangs. Frankfurt/M.: Suhrkamp.

Paech, Joachim (1997): »Paradoxien der Auflösung und Intermedialität«. In: Martin Warnke/Wolfgang Coy/Georg Christoph Tholen (Hg.): HyperKult. Geschichte, Theorie und Kontext digitaler Medien. Basel: Stroemfeld, S. 331-367.

Peirce, Charles S. (1991): Schriften zum Pragmatismus und Pragmatizismus. Frankfurt/M.: Suhrkamp.

Peirce, Charles S. (2000): Semiotische Schriften, Bd. 3: 1906-1913. Frankfurt/M.: Suhrkamp.

Peirce, Charles S. (2005): Phänomen und Logik der Zeichen. Frankfurt/M.: Suhrkamp.

Pfeiffer, Karl-Ludwig (1999): Das Mediale und das Imaginäre. Dimensionen kulturanthropologischer Medientheorie. Frankfurt/M.: Suhrkamp.

Rajewsky, Irina O. (2002): Intermedialität. Tübingen: Francke.

Rastier, Francois (1974): »Systematik der Isotopien«. In: Werner Kallmeyer u.a. (Hg): Lektürekolleg zur Textlinguistik, Bd. 2. Frankfurt/M.: Athenäum Fischer, S. 150-190.

Schönrich, Gerhard (1999): Semiotik zur Einführung. Hamburg: Junius.

Sombroek, Andreas (2005): Eine Poetik des Dazwischen. Zur Intermedialität und Intertextualität bei Alexander Kluge. Bielefeld: transcript.

Waldenfels, Bernhard (2002): Bruchlinien der Erfahrung. Phänomenologie, Psychoanalyse, Phänomenotechnik, Frankfurt/M.: Suhrkamp. 


\title{
Die Theatralität der GeSElLSChAFt geSPIEgELT IN DER THEATRALITÄT DES FILMISCHEN. > UMBRÜCHE < IM RUMÄNISCHEN ZEITGENÖSSISCHEN KURZFILM ${ }^{1}$
}

\author{
AlEXANDRA VLAD
}

Die Umbrüche der Transformationszeit, die mit der politischen Wende im Jahre 1989 in Rumänien angefangen hat, werden vorwiegend im Hinblick auf die politische Geschichte und die diskursive Herstellung von Identität im öffentlichen Raum untersucht. Im Gegensatz dazu stellt dieser Aufsatz Filmgeschichte in den Vordergrund. Insbesondere soll analysiert werden, ob und wie sich ein ästhetischer Wandel im rumänischen Filmwesen durch die Einwirkung des Theaters niedergeschlagen hat.

Somit werde ich den rumänischen Film vor dem Hintergrund einer Kultur, deren Aufmerksamkeit mehr und mehr auf Formen inszenierten Handelns gerichtet ist, unter dem Aspekt des theoretischen Modells der Theatralität betrachten. Im Anschluss an Theorieansätze, welche das Konzept von einem erweiterten Theaterbegriff ableiten (Fiebach sowie Fischer-Lichte 2000), betrachte ich Theatralität im weiteren Sinne (innerhalb und außerhalb des Theaters) als dynamischen und prozessualen Vollzug der Interaktion zwischen Darstellenden und Zuschauern, wobei ein Zusammenwirken von Korporalität, Performance, Inszenierung und Wahrnehmung festzustellen ist. ${ }^{2}$

Dadurch, dass ich Theater in einer intermedialen Reflexion einschließe, die »die Prozesse der Medialisierung der Öffentlichkeit, der Inszenierbarkeit privater und öffentlicher Schauspiele zugleich darzustellen und zu analysieren « versucht (Lommel/Queipo/Rißler-Pipka: 9), umfasst die Theatralität in meiner Konzeption mehr als die traditionelle Verwendung von Theaterelementen im Film und perspektiviert Schauspiel, Schaulust, Inszenierung und Simulation als Elemente einer »société du spectacle« (Debord).

Meine Überlegungen richten sich auf eine exemplarische Auswahl zeitgenössischer rumänischer Kurzfilme, in denen sich Theatralität als wesentliches Element der >Darstellung < und >Inszenierung < von Welt (Fischer-Lichte 2000) artikuliert.

Ziel meines Beitrages ist, bezogen auf Theatralität, zweierlei: Zum einen möchte ich ausgehend von einer »kinematographischen Theatralität« (Deleuze: 251) an den exemplarischen Kurzfilmen untersuchen, wie diese mit theatralen Mitteln die »Welt zur Schau geben«, indem sie Film- und Theatertraditionen kombinieren,

1 Eine leicht geänderte Fassung dieses Aufsatzes wurde unter dem Titel »Zur Theatralität des Filmischen« veröffentlicht, Vlad 2007.

2 Die Theatralität wird in einer semiotischen Auffassung von Erika Fischer-Lichte (Fischer-Lichte 1998: 11-30) als ein Zusammenspiel der vier Aspekte Korporalität, Performance, Inszenierung und Wahrnehmung beschrieben. 
um dadurch die Theatralisierung der Gesellschaft darzustellen. ${ }^{3}$ Zum zweiten soll gezeigt werden, wie der Einsatz von Theatralität im Film - in bestimmten Kontexten (als Bruch mit der Tradition) - durchaus ästhetische Verschiebungen bewirkt hat, welche einen qualitativen Umbruch und die Entwicklung des zeitgenössischen rumänischen Filmwesens ermöglicht hat.

\section{Theatralität im neuen rumänischen Filmwesen}

Die seit einigen Jahren äußerst lebendige und produktive rumänische Filmszene wird in letzter Zeit öfters als eine »Neue rumänische Welle« (Brătan) bezeichnet. Diese Etikettierung wird aber von den Repräsentanten der »neuen Generation ${ }^{4}$ von Filmemachern abgelehnt, indem nicht auf eine gemeinsame konstante Bewegung, sondern auf einzelne Anstrengungen oder Experimente hingewiesen wird. So Cristi Puiu: »There is no Nouvelle Vague; there are just a few desperate film directors $\aleph^{5}$.

Auch wenn das facettenreiche rumänische Filmschaffen von diesen z.T. sehr jungen rumänischen Regisseuren wie Cristian Mungiu, Cătălin Mitulescu, Corneliu Porumboiu und Cristi Puiu nicht unter einer einzigen Stilrichtung zusammen gebracht werden kann, stehen sie doch alle im Gegensatz zu den traditionellen Filmen der >alten Garde<, der Regisseure der kommunistischen Zeit (Bauer). Außerdem können auch gemeinsame Merkmale betont werden: der scharfe, sehr oft schonungslose, aber immer wieder ironische Blick auf die Zustände in der rumänischen Gesellschaft (Brătan).

\section{Theatralität des SCHAU-Spiels}

Vor der Wende folgte der Darstellungsstil der Filmschauspieler noch dem Modell der Theatertradition, so dass er übertrieben, unangemessen und lächerlich erschien. Der Filmkritiker Laurențiu Brătan (2006) stellt fest, dass die Sprache in den meisten rumänischen Filmen forciert, ja artifiziell war. Die Sprache der Filmdarsteller (hauptsächlich Bühnenschauspieler) hörte sich wie eine hohle Deklamation an.

Zusätzlich von theatralen Gesten begleitet, wirkte dieser Stil bombastisch und übertrieben, wie eine Burleske. Die Schauspieler verzerrten ihre Gesichter und brüllten ihre Dialoge über das Natürliche hinaus. Der Filmkritiker Florian Dumitrescu wirft der Schauspielkunst vor, sie leide unter der »fatalen Maladie des rumänischen Filmes - dem Theatralischen ${ }^{6}$.

3 Die »kinematographische Theatralität« ist, in einem erweiterten Sinne, außerhalb der Kunstform und der Institutionsform des Theaters zu verorten und kennzeichnet die inhaltlichen und formellen Bezüge zum Theater: die Art und Weise des Inszenierungsprozesses, den eine Gesellschaft bzw. eine Kultur durch die Kombination von Theaterund Filmkonventionen darstellt, sowie den Wahrnehmungsmodus des Zuschauers, das Beobachtete als Inszenierung wahrzunehmen.

4 Brătan spricht von einer »neuen Welle« und setzt die zeitgenössischen Filme den Filmen der alten Diktatur, der »glorreichen Epoche« entgegen. Dumitrescu bezeichnet die aktuellen Filmemacher als eine »neue Generation«.

5 Zitiert nach dem Programmtext »Zeitgenössisches Kino aus Rumänien«.

6 Im Original: »[...] jocul actorilor suferă de maladia fatală a filmului românesc, teatralitatea 
Der rumänische Film, der wegen dieser theatralisch überspitzten Darstellung sehr oft als ein anachronistisches und lächerliches Melodram angesehen wurde, löst sich gegenwärtig von diesem schrillen Bild (Gorzo: 15). Die Gegenposition des zeitgenössischen Kurzfilmes thematisiert die Künstlichkeit der Personen bzw. des Schauspiels. Im Gegensatz zu dem vergangenen artifiziellen, laut-deklamierenden Typus werden äußerst stille Personen und Situationen dargestellt. Exemplarisch dafür betrachte ich die >minimalistische ${ }^{7}$ Gegenposition in dem Kurzfilm UN CARTUŞ DE KENT ŞI UN PACHET DE CAFEA ${ }^{8}$ von Cristi Puiu.

Durch eine radikal reduzierte Bildkomposition und mit wenigen Kameraeinstellungen wird ein Gespräch zwischen Vater und Sohn über verschiedene Bestechungsmöglichkeiten und -verfahren inszeniert. Die Begegnung findet in einem öffentlichen Lokal statt, wo ein minimalistisches Theaterdekor und eine ausgestellte Künstlichkeit der Kommunikation die Distanz zwischen beiden unterstreichen und eine Interpretation fördern, nach der die beiden als Repräsentanten von zwei Generationen gesehen werden müssen. Sie haben sich nur getroffen, damit der alte, arbeitslos gewordene Vater seinem Sohn, einem eigentlich erfolgreichen Geschäftsmann, die Bestechungsobjekte zur Beschaffung einer neuen Arbeitsstelle geben kann. Dadurch, dass die Kommunikation zwischen ihnen bis hin zur >Objektebene< entleert wird - es geht auch nach der Wende nur um eine Stange Kent und eine Packung Kaffee - wird eine gesteigerte Dramatisierung der Vater-Sohn-Beziehung erzeugt. Die inszenierten Familienverhältnisse stellen die rumänische Gesellschaft vor und nach der Wende unter demselben Symbol der Kent-Stange und des Kaffeepäckchens dar: im ersten Falle vom Vater und im zweiten vom Sohn verkörpert.

\section{Theatralität der Inszenierung}

\section{II.1. Technisch-theatrale Inszenierung des Raumes bzw. des Dekors}

Insgesamt lässt sich feststellen, dass die rumänischen Autoren auf exzessive filmische Darstellungsmittel verzichten. Sie erzählen ihre Geschichten linear, ruhig und ohne Spezialeffekte oder besonders originelle Kameraeinstellungen. In dem Kurzfilm UN CARTUŞ DE KENT ŞI UN PACHET DE CAFEA ähnelt der filmische Raum einer Theaterbühne, welche die Personen jederzeit betreten und auch verlassen können. Die Kamera zeigt in einer starren Einstellung eine durchsichtige Glasfassade. Vor ihr, scheinbar in unserer unmittelbaren Nähe, sitzen zwei Gestalten an einem Tisch in einem Lokal. Auf der anderen Seite, im Hintergrund, ein >Zuschauender $<$, der ins Café blickt. Dieser alte Mann betritt kurz darauf das Café (immer noch dasselbe statische Bild), was stark an den Auftritt eines Theaterakteurs erinnert, und nimmt selbst Platz an einem anderen Tisch. Dadurch entsteht eine Handlungssituation: die Begegnung des Vaters und des Sohnes in einer theatralen Anordnung. Die weiterhin starre Kameraperspektive, die auf ein einziges Dekor (mit dunklen Vorhängen)

7 Die Faszination einer minimalistischen Position lässt sich in folgender Aussage des Regisseurs Cristi Puiu erkennen: »Ich war Maler, als ich das Kino mit Jim Jarmuschs STRANGER THAN PARADISE entdeckte. Sein von der amerikanischen Unterhaltungsindustrie meilenweit entfernter trockener Humor und Minimalismus begeisterten mich. [...] Ich liebe Rohmers sparsame Mittel, seine Moral«.

8 Cristi Puiu (Regie) (2004): Un CARTUS DE KENT SI Un PACHET DE CAFEA. România: Temple Film. Deutsche Übersetzung des Filmtitels: EINE STANGE KENT Und EIN PÄCKCHEN KAFFEE. 
ausgerichtet ist, erzeugt den Eindruck einer Theaterszene, was wiederum auf die dramatisierten Familienverhältnisse aufmerksam macht: es sind keine >authentischen $<$ Verhältnisse, sondern nur > gespielte<.

Dominierend ist die Totale, die der Perspektive eines Theaterzuschauers entspricht, und die mit seltenen Nahaufnahmen verknüpft wird. Somit wird die Betrachtungsweise eines Theaterbesuchers, die im Allgemeinen für die optische Distanz steht, nicht zerstört, sondern mit filmischen Mitteln kombiniert, um den Raum, die Handlung und damit auch den Film an der Schwelle zwischen Nähe und Distanz, Alltagswelt und >Bühne des Lebens`, sowie zwischen der Authentizität und Inszenierung zu situieren.

\section{II.2. Meta-Diskurs. META-TECHNISCHE Verfahren der Theatralität}

Zeitgenössische filmische Kunstwerke beziehen sich mit dem, was ich als neues Paradigma des intermedial Brüchigen auffasse, auf ihre eigene Substanz - >Film zu sein $<$. Innerhalb einer > Welt der Simulakren $<$ wird >meta-technisch $<$ verfahren. Die Filme sind anti-mimetisch, selbstreferentiell; sie stellen die >Gemachtheit $<$, deren Artifizialität zur Schau, indem sie ein artifizielles Bild der rumänischen Gesellschaft, die sich immer noch in einer Mischung von Alt und Neu verfängt, darstellen.

Innerhalb des Filmes UN CARTUŞ DE KENT ŞI UN PACHET DE CAFEA wird eine solche Zur-Schau-Stellung thematisiert. Das filmische Geschehen wird einerseits in der Wirklichkeit und, andererseits, auf der Bühne des öffentlichen Lokals, in einem intendiert bühnenähnlichem Dekor situiert. Dadurch wird für den Filmzuschauer der konstruierte Charakter des Gesehenen betont.

Die Illusion von Wirklichkeit und Künstlichkeit entsteht durch die Glasfassade. Sie unterstreicht, dass man sich auf dem ambivalenten Terrain des Gesehenen und des Gesehen-Werdens, sowie der Absenz/Präsenz befindet: die Anwesenheit der Cafészene verweist auf die Abwesenheit (in der Welt des Films) des Zuschauers, der aber zu jeder Zeit selbst präsent sein kann. Das ist am Anfang des Filmes in der Einstellung deutlich, wo der spätere Akteur des Cafégesprächs selbst vor der Glasfassade einem anderen Gesprächspaar so lange zusieht (>Theater im Schaufenster<), bis er selbst in die Szene eintreten kann.

Denn die Glasfassade entspricht im Film einer Schnittstelle zwischen der wirklichen und der künstlichen Welt; sie betont die Differenz. Aber dadurch, dass sie transparent ist, ermöglicht sie auch die Überschreitung der Grenze zwischen den zwei Welten. Somit wird dem Artefakt-Objekt mit den beiden dargestellten Welten die doppelte Funktion gewährt: den Bruch zwischen Realität und Fiktion zu veranlassen, aber auch deren Interaktion. Die Fiktion ist in der Wirklichkeit (des Filmes) sowohl an- als auch abwesend, und genauso umgekehrt. Dadurch wird das Spiel zwischen Wirklichkeit und Fiktion am Ende des Filmes erneut unterstrichen. Die letzte Szene wird wie ein Verlassen der Theaterszene dargestellt: die Gestalten stehen auf, verlassen das Café, indem sie wieder die >Straßenszene< betreten. Die Glasfassade ist noch einige Sekunden zu sehen, bis sie durch eine Abblende, die dem Vorhang im Theater entspricht, verschwindet und nur noch das klirrende Geräusch der Tassen und Gläser zu hören ist; ganz zum Schluss noch der schwarze Bildschirm. 


\section{II.3. Inszenierung der Gesellschaft}

Dieses Spiel zwischen >wirklichem< und >inszeniertem< Sein deutet auf die Möglichkeit, >alles< in Szene zu setzen - nicht nur das Alltagsleben (hier die VaterSohn-Konstellation), sondern auch die Gesellschaft. Eine Inszenierung in der Darstellung der Gesellschaft, die sich auf einen theatralischen Schaueffekt stützt, kann als >Theatralisierung des Lebens ${ }^{9}$ betrachtet werden. Beispielhaft ist die Inszenierung des privaten kommunikativen Ereignisses in Raum und Zeit, so dass die Diskrepanz zwischen Sein und Schein auch zu öffentlichen Gegebenheiten in Beziehung gesetzt werden kann. Das Gespräch ist vor/hinter der Glasfassade des Cafés (als Bühne der Gesellschaft) platziert, es findet nach der Wende statt und es unterstreicht den Unterschied zwischen der Art, in der sich die »neue« Generation mittels neuer, aber vorgetäuschter Werte darstellt, und der Tatsache, dass sie dieselben alten korrupten Verfahren einsetzt. In der Szene, in der der Vater seinem Sohn die Bestechungsobjekte überreicht, wird die ernsthafte Lage mit Komik dargestellt: der Vater vergisst in der Tasche mit den Bestechungsobjekten ein billiges Massiergerät, welches er auf der Hand des Sohnes ausprobiert, worauf dieser - sonst eher ernst gezeichnete - lachen muss. Somit wird der Gesellschaftskritik eine zusätzliche satirische Note verliehen.

Was in den Filmen der >alten Garde $<$ zu sehen war - misslungen gefilmte, exzentrische, hysterische Situationen - wird jetzt reflexiv herangezogen, um es aus einer ironischen und satirischen Perspektive darzustellen. In dem Film CĂLĂTORIE LA ORAŞ ${ }^{10}$ wird eine burleske, komische Gesellschaft inszeniert. Der Film enthält eine parodistische Anspielung auf die historischen Filme der >goldenen Epoche<. Es ist in Sprache und Handlung eine Maskerade, die im Hintergrund der Tagung »854 Jahre Geschichte und Zivilisation« stattfindet. Die Veranstaltung, die scheinbar von historischer Größe und Bedeutsamkeit ist, bietet aber nur Gelegenheit für eine übertriebene Show. Eine Band und Luftballons sorgen für die feierliche Stimmung, dann ein letzter, betrunkener Musikant unter vielen ausgetrunkenen Flaschen. Schief klingende Trompetentöne tragen dazu bei, ein Ambiente von Spott und Clownerie zu schaffen. Die Bilder der historischen Leiter des römischen und dakischen Zeitalters im Hintergrund werden dadurch ins Lächerliche gezogen, und die »854 Jahre Geschichte und Zivilisation« wird als eine Geschichte des Spektakulären inszeniert.

\section{Die Wahrnehmung der Inszenierung und Konstruktion der Gesellschaft bzw. der Kultur des Spektakels}

Die Kurzfilme schaffen, indem sie die gegenwärtige Gesellschaft und Kultur weitgehend als Spielformen der Inszenierung darstellen - sei es in komischer oder tragikomischer Weise - jeweils Grenzsituationen, die auf der Wahrnehmungsebene

9 Die >Theatralität< erhielt in letzter Zeit eine Rolle als Modell der Beschreibung von Politik und gesellschaftlicher Konstruktion von Wirklichkeit. Da sich die Realität des Einzelnen und der gesellschaftlichen Gruppen >inszenieren< lässt, wird von einer >Ereignis- und Spektakelkultur< (Fischer-Lichte 2000) gesprochen.

10 Corneliu Porumboiu (Regie) (2003): CĂLĂTORIE LA ORAȘ. Rumänien: UNATC. Deutsche Übersetzung des Filmtitels: DIE REISE IN DIE STADT. 
die gewohnten klaren Oppositionen von Sein und Schein in Frage stellen und auflösen. Durch die »Einwanderung ${ }^{11}{ }^{11}$ des Spektakulären werden die Schnitt- und Trennflächen zwischen Fiktion und Realität und dadurch auch zwischen Theater und Film transzendiert.

Die reflektierte Problematik des Unterschiedes zwischen Wirklichkeit und Fiktion lässt sich abschließend als Zusammenspiel von Trennung und Überbrückung als wahrnehmende bzw. semiotische Überschreitung - in Bezug auf Theatralität exemplarisch an der Endszene des Filmes TURKEY GIRL ${ }^{12}$ von Cristian Mungiu zeigen. Er verwendet das stilistische Mittel des an die Zuschauer gerichteten à-partSprechens: der Soldat (in Nahaufnahme) schaut zusammen mit dem Mädchen in die Kamera, d.h. er blickt den Kinozuschauern in die Augen und fragt: »Was sieht er denn an?«. Es ist als würde er das Zusehen des Zuschauers in Frage stellen. Durch dieses Stilmittel wird die filmische Distanz aufgelöst und in den Zuschauerraum >eingegriffen $<$. Wenige Augenblicke später wird diese Konstruktion zerstört: ein Truthahn entpuppt sich als derjenige, der etwas ansieht. Mittels einer rasanten Montage mit einem abrupten Kameraschwenk wird gezeigt, was das Tier anschaut: zwei riesengroße Straßenlöcher, welche von ihm aufgrund der ihm beigebrachten Unterscheidung Kreis-Quadrat wahrgenommen und erkannt werden. In dieser Schlussszene erscheint wieder eine Umrahmung des Bildes ähnlich wie von einem Vorhang. So werden die Straßenlöcher zu Zeichen: Der Filmzuschauer erkennt, dass er als Beobachter an einer Inszenierung der rumänischen Gesellschaft teilhat, deren gegenwärtiges Bild eigentlich von Straßenlöchern geprägt ist. Somit wird der Wahrnehmungsaspekt der Inszenierung aufgezeigt: Differenzen können erlernt, beobachtet und (wieder-)erkannt werden, jedoch hängt das von der Perspektive, von dem Wahrnehmungsmodus ab. ${ }^{13}$

Resümierend möchte ich unterstreichen, dass der theatrale Um-Bruch im zeitgenössischen rumänischen Kurzfilm, in der rumänischen Kultur, nicht nur das Verhältnis von Theater und Film neu bestimmt, sondern auch eine qualitative Filmentwicklung ermöglicht hat. ${ }^{14}$

Indem er interagierende und intermediale Spielräume und Kombinationsmöglichkeiten zwischen Theater und Film entdeckt und diese für die Inszenierung einer postkommunistischen, sich stark wandelnden Gesellschaft eingesetzt hat, bricht der rumänische Kurzfilm mit der Ästhetik der > glorreichen Epoche< und setzt eine neue Darstellungsweise der Gesellschaft durch. Ohne zu verschönern, sondern indem er aktuelle, private wie öffentliche $>$ Schauspiele $<$ inszeniert und analysiert.

Mittels Theatralisierungsstrategien wie etwa der Inszenierung der Dialoge in einem Theaterdekor (als Reflexion über die Künstlichkeit der Personen und ihres Schauspiels), der übertriebenen Präsentation von Handlungen und Ereignissen (als

11 Der Eingriff des Theatralischen ins Leben wird von Erika Fischer-Lichte (1998: 14) mit dem Begriff »Einwanderung « bezeichnet.

12 Mungiu, Cristian (Regie) (2005): TURKEY GIRL. Kurzfilm. In: Stefan Arsenijevic u.a. (Regie). LOST AND FOUND. 6 Glances AT a GENERATION. Deutschland u.a: Icon Film. Deutsche Übersetzung des Filmtitels: DAS MÄDCHEN UND DER TRUTHAHN.

13 In der rezeptionsästhetischen Perspektive von Elizabeth Burns wird die Theatralität als »determined by a particular viewpoint, by a mode of perception« (Burns: 12) aufgefasst.

14 Roloffs (2000) Betrachtungen über die Bedeutung der Filme der Nouvelle Vague für eine neue Beziehung zwischen Film und Theater können auch auf die rumänischen Filme, die mit der Nouvelle Vague verglichen wurden, bezogen werden. 
Inszenierung einer Gesellschaft des Spektakels), der Metastrategien der Betonung von Gemachtheit und Artifizialität der Filme selbst und der Konfrontation des $\mathrm{Zu}$ schauers mit seiner Beobachterrolle und -funktion, schafft der zeitgenössische rumänische Kurzfilm eine Differenz zu der >Unnatürlichkeit< und dem artifiziellen Charakter sowohl der rumänischen Gesellschaft als auch des filmischen Schaffens der kommunistischen Zeit.

\section{Literatur}

Bauer, Markus (2004): »Ursprüngliche Landschaften und technisches Know-how. Rumäniens Kinowirtschaft entwickelt ihre künstlerischen und ökonomischen Potenziale«. In: Neue Züricher Zeitung vom 24.03.2004. http://www.nzz.ch/ 2006/03/24/fi/articleDOMZC.html (23.01.2007).

Brătan, Laurențiu (2006): »Legături către un nou val? « (Beziehungen zu einer Neuen Welle? - Übers. d.V.). In: Revista 22, XV (841). [Elektronische Version]. http://www.revista22.ro/ (23.01.2007).

Burns, Elizabeth (1972): Theatricality. A Study of Convention in the Theatre and Social Life. London: Longman.

Debord, Guy (1967): La société du spectacle, Paris: Editions Buchet-Chastel.

Deleuze, Gilles (1991): Das Zeit-Bild. Kino 2 (1. Aufl.). Frankfurt/M.: Suhrkamp.

Dumitrescu, Mircea (2004): »Dinu Tănase - Damen Tango«. In: respiro. http://www.respiro.org/Issue15/TF/theatre_dumitrescu2.htm, 23.10.2006.

Fiebach, Joachim (1998): Keine Hoffnung, keine Verzweiflung. Versuche um Theaterkunst und Theatralität (Berliner Theaterwissenschaft, Bd. 4). Berlin: Vistas.

Fischer-Lichte, Erika (1998): »>Ah, die alten Fragen...< und wie Theatertheorie heute mit ihnen umgeht«. In: Hans-Wolfgang Nickel (Hg.): Symposion Theatertheorie. Berlin: Institut für Spiel- und Theaterpädagogik, S. 11-30.

Fischer-Lichte, Erika (2000): »Theatralität und Inszenierung«. In: Dies./Isabel Pflug (Hg.): Inszenierung von Authentizität. Tübingen/Basel: A. Francke, S. 11-27.

Gorzo, Andrei (2002): »Cum se prezintă filmul românesc? « (Wie stellt sich der rumänische Film dar?). In: Dilema. 507, S. 15.

Lommel, Michael/Isabel M. Queipo/Nanette Rißler-Pipka (Hg.) (2004): Theater und Schaulust im aktuellen Film. Bielefeld: transcript.

Nickel, Hans-Wolfgang (Hg.) (1998): Symposion Theatertheorie. Berlin: Institut für Spiel- und Theaterpädagogik.

Puiu, Cristi (2005): »Der Tod des Herrn Lazarescu«. In: StadtkinoZeitung vom 13.12.2005, 423, S. 3. http://www.stadtkinowien.at/imgs/filme/158/stadtkino_ 423.pdf (23.01.2007).

Roloff, Volker (2000): »Theater und Theatralität im Film«, in: Ders./Scarlett Winter $(\mathrm{Hg})$ : Theater und Kino in der Zeit der Nouvelle Vague. (Siegener Forschungen zur romanischen Literatur- und Medienwissenschaft, 8). Tübingen: Stauffenburg, S. 5-9.

Roloff, Volker (2001): »Spielformen der Intermedialität am Beispiel französischer Theater/Filme (Carné - Renoir - Ophüls)«. In: Beate Ochsner/Charles Grivel (Hg.): Intermediale. Kommunikative Konstellationen zwischen Medien (Siegener Forschungen zur romanischen Literatur- und Medienwissenschaft, 10). Tübingen: Stauffenburg, S. 199-217. 
Vlad, Alexandra: »Zur Theatralität des Filmischen. Intermediale Brüche und Veränderungen des rumänischen gegenwärtigen Kurzfilmes«. In: Studia Universitatis Babeş-Bolyai. Philologia. LII. 1/2007, S. 107-118.

»Zeitgenössisches Kino aus Rumänien« In: Arsenal. Dez. 2005. http://www.fdkberlin.de/de/arsenal/programmtext-anzeige.html?tx_ttnews $\% 5 B$ year\%5D=2005 \&tx_ttnews \%5Bmonth\%5D=12\&tx_ttnews\%5Btt_news\%5D=424\&tx_ttnews $\% 5$ BbackPid $\% 5 \mathrm{D}=212 \& \mathrm{cHash}=2 \mathrm{~b} 4464 \mathrm{f} 2 \mathrm{~d} 3$ (23.01.2007). 


\title{
VON DER > HÖRBÜHNE< ZUM HYBRIDMEDIUM. THEATER UND HÖRFUNK
}

\author{
PETER SEIBERT
}

\section{I.}

»Es darf nicht geduldet werden, dass es sich die Bühnenwerke in den Polstern des Rundfunks bequem machen, wogegen das Hörspiel als das legitime Kind vor der Tür warten muss, bis es dann und wann vorgelassen wird « (Prager: 33).

Wenn eine solch vehemente Polemik gegen eine Verbindung von »Bühnenwerken« und Radio wiederholt auftritt, ist es nicht mehr verwunderlich, dass eine systematische oder historisch angelegte Untersuchung jener Hörfunkformate, bei denen Theater als Referenzmedium konstitutiv ist, weitgehend ein Forschungsdesiderat geblieben ist. Wie sehr man auf Seiten der Forschung eher auf Abwehr bedacht war als auf Thematisierung des breiten Spektrums medialer Interferenzen, die über eine Adaption von Bühnentexten weit hinausgehen, verdeutlicht auch die Position des Medienwissenschaftlers Friedrich Knilli, der selbst im »literarischen Hörspiel« noch Elemente des bühnentheatralen Codes ausmacht, aber nicht, um diese als Forschungsgegenstand zu begreifen, sondern sie zu verwerfen: »Das literarische Hörspiel ist heute«, so Knilli 1970,

»als Modell erschöpft. Doch die Theaterhasen bauen wie anno 1924 ihre naturalistischen Hör- und Radiobühnen mit akustischen Kulissen, Hintergrundgeräuschen, Keysound und hetzen ihre Hörspieler oder deren Ton-Double über kostspielige Steinpflaster, Holzplanken, Sand- und Kieswege, teure Geräuschstiegen oder lassen sie recht oft groteske Quietschtüren öffnen und schließen« (44).

Sicherlich waren, als Knilli sein Plädoyer für eine von theatralen Spuren »gereinigte« Radiokunst vortrug, jene Forschungsparadigmen noch nicht ausformuliert, die Medien nicht mehr als Monomedien entwarfen, sondern Medienwechsel, Medientransformationen, Intermedialität, Multimedialität und mediale Hybridisierungen fokussierten. Aber auch die Karriere dieser Paradigmen in den achtziger und neunziger Jahren änderte wenig daran, dass die Beziehungen von Hörfunk und Theater, verglichen beispielsweise mit dem Komplex des Theaterfilms oder der fernsehmedialen Theateradaptionen, in der Forschung eher randständig blieben.

Umso nennenswerter sind die vereinzelten Arbeiten, in denen - auch wenn sie weder theaterwissenschaftlich zentriert, noch in einer Forschungskontinuität zu verorten sind - beide Medien in einer Weise in Beziehung gesetzt werden, dass die qualitative und quantitative Bedeutung beider Medien für einander wenigstens punktuell aufscheinen konnte. Diese Bedeutung wurde für die Weimarer Republik aus programmgeschichtlicher Perspektive von Susanne Großmann-Vendrey in 
ihrem Beitrag zum radiogeschichtlichen Standardwerk Programmgeschichte des Hörfunks in der Weimarer Republik wenigstens markiert, in dem Aufsatz von Theresia Wittenbrink »Rundfunk und literarische Tradition« in derselben von JoachimFelix Leonhard 1997 herausgegebenen Publikation schon deutlicher konturiert.

Eine zweite Arbeit, eine aufschlussreiche Fallstudie, ist in diesem Zusammenhang zu erwähnen, die, wenn sie sich auch nicht auf das Verhältnis von Theater und Rundfunk konzentriert, sondern das eines Autors zum Radio insgesamt diskutiert, dabei aber wesentliche intermediale Aspekte erfasst und vor allem Ansätze zu deren Systematisierung bietet: Michael Schaudigs medienhistorische Untersuchung »Des Meisters Werk und Stimme: Gerhart Hauptmann im zeitgenössischen Radio. Ein Beitrag zur Frühgeschichte des deutschen Hörfunks «. ${ }^{1}$

\section{II.}

Radiosendungen, die sich auf das Theater (einschließlich seiner Texte) als Referenzmedium beziehen, wurden prima vista nicht nur von der Forschung wenig Kredit eingeräumt. In den Medien selbst sah man diese Referenz von Anfang an kritisch kritisch auf Seiten des Hörfunks, kritisch auf Seiten des Theaters. Das Theater fürchtete im ersten Rundfunkjahrzehnt wie schon beim Film und wie später noch einmal beim Fernsehen die Konkurrenz; die Vertreter des Hörfunks werteten die »Theatersendung « - ob funkeigene Adaption oder Übertragung - ebenfalls nicht als den Königsweg zu einer genuinen radiophonen Kunst und damit zu der angestrebten kulturellen Nobilitierung des jungen Massenmediums. Bekannt sind auch die Äußerungen Bertolt Brechts (128), dass der Hörfunk in seiner ersten Phase nur als »Stellvertreter « fungiert habe, als »Stellvertreter der Oper, des Konzerts, der Vorträge « - als Stellvertreter eben auch des Theaters. Nicht nur für Brecht, auf dessen Position noch einmal differenzierter einzugehen sein wird und dem selbst an einer Veröffentlichung und/oder Bearbeitung seiner Stücke durch den Funk sehr gelegen war, standen Theatersendungen im Rundfunk gegen die Entfaltung des Hörspiels als Inbegriff einer >arteigenen< (!) oder >originären< Hörfunkkunst. Am Ende der 1920er Jahre warnte z.B. der frühe Hörspieltheoretiker M. Felix Mendelsohn vor einem Verdrängungswettbewerb der jungen Hörspielkunst durch die »funkischen « Theateradaptionen: »Es ist in der letzten Zeit an allen deutschen Sendern sehr still um das Hörspiel geworden, das in Gefahr ist, von den Bühnenstücken völlig verdrängt zu werden, die ursprünglich neben arteigenen Hörspielen ihren Platz haben sollten « (zit. nach Krug: 36). Von Alfred Döblin, um auf der Seite jener Autoren zu bleiben, die sich auf den Hörfunk als wichtiges literarisches Medium einließen, war 1929 auf der Kasseler Arbeitstagung »Dichtung und Rundfunk « das apodiktische Urteil zu hören:

»Man kann keine [...] Dramen im Rundfunk aufführen. Ich halte alle Behauptungen, die etwas anderes besagen, für irrig, und ich habe mich durch viele Rundfunkaufführungen von dieser Tatsache überzeugt. [...] Was der Rundfunk an Theaterspielen sendet, sind Reproduktionen von der Art des Schwarzweißdrucks, der von einem farbigen Bild genommen ist (Döblin: 235).

1 Vgl. auch Schaudig 1992. Kleinere Arbeiten finden sich auch zu dramatischen Texten anderer Autoren, z.B. Helmensdörfer. 
Der Intendant der Berliner Funk-Stunde, Hans Flesch, von dem das erste gesendete deutsche Hörspiel, ZAUBEREI AUF DEM SENDER, stammte, bemühte 1931 ein ähnliches Bild, um die theoretische und praktische Unvereinbarkeit von Hörspiel und Theaterstück zu postulieren, als er davon sprach, dass ein »gefunktes Theaterstück « nur ein »Torso « (74) sei. An Positionen der Kasseler Tagung erinnernd wiederholte in den dreißiger Jahren Rudolf Arnheim unter dem Titel »Lob der Blindheit: Befreiung vom Körper« die These vom ästhetisch Defizitären solcher Sendungen, defizitär gegenüber Theater und Rundfunk gleichermaßen:

»Verdammenswert und des Rundfunks unwürdig [...] sind Übertragungen aus Opern, Theatern [...]. Jedem Kunstwerk, auch dem bescheidensten noch, tut man bitter Unrecht, wenn man aus dem optisch-akustischen Ganzen das Hörbare roh herausreißt und allein präsentiert« (Arnheim: 90).

Dass die wertende Unterscheidung zwischen Hörspiel und medialer Theatertransformation lange nachwirkte, demonstriert noch die erste Geschichte des deutschen Hörspiels (1963) von dem in praktischer Hörspielarbeit erfahrenen Ernst Schwitzke, der einen Zusammenhang zwischen »Funkbearbeitungen klassischer und moderner Dramen« und den »Anfängen des Hörspiels« (56, Anm. 15) nicht erkennen wollte.

\section{III.}

Diese Abwertung der funkmedialen Umsetzung von Theater zugunsten des Hörspiels geschah von Positionen aus, die wenig später bei den Debatten um Theateradaptionen im Fernsehen noch einmal virulent werden sollten. ${ }^{2}$ In beiden Medien entwickelte sich aber, unbeeindruckt von diesen Debatten, zumindest auf der quantitativen Ebene eine intensive intermediale Beziehung, zehrte das stoffhungrige Radio (ebenso wie später das Fernsehen) vom Theater und von Stücken, die nicht für das Radio, sondern primär für die Bühne geschrieben waren. Dazu nur ein paar Beispiele: Nach Kurt Pinthus (53-65) wurde im Berliner Rundfunk schon im Monat nach Aufnahme des Sendebetriebs mit der regelmäßigen Ausstrahlung von - zunächst - Dramenfragmenten begonnen. 1926/27 brachte dieselbe Anstalt bereits einen Zyklus Das deutsche Drama aus zwei Jahrhunderten (Pinthus: 58). In einer der jüngsten Hörspielgeschichten spricht Hans-Jürgen Krug davon, dass die Adaptionen schon früh einen festen »und manchmal sogar zwei- bis dreistündige[n] Programmanteil« ausmachten: »Bereits 1926 wurden rund 600 Werke von 280 Dramatikern « (Kurg: 16f) gesendet. Von den 1932 ausgestrahlten 854 »dramatischen Sendespielen« - so Hans Flesch (72) - waren 321 adaptierte Theaterstücke. »Die meisten Sender boten schon wenige Wochen oder Monate nach ihrer Eröffnung die vollständige oder auf die Länge einer Stunde gekürzte Wiedergabe eines Theaterstücks«, resümiert Theresia Wittenbrink (1040) die Rundfunk-Präsenz von Theaterstücken in den ersten Radiojahren. Rainer Strzolkas Chronologie einer Hörspielgeschichte der Weimarer Republik unterstützt nicht nur diese Aussage, was die Häufigkeit der audiophonen Inszenierungen von Theaterstücken anbelangt (Strzolka: 20-38), sie weitet sie auch aus auf die gesamte Weimarer Zeit. Der Programm-

2 Nur dass in diesen Debatten die >Bekunstungsstrategien< des jüngeren TV-Mediums über die Definition des Fernsehspiels als der medienspezifischen Kunstgattung laufen sollten. 
anteil solcher Sendungen hatte Mitte der zwanziger Jahre dazu geführt, dass die Zeitschrift »Der deutsche Rundfunk « die Rubrik »Schauspiel und Oper im Berliner Sender « einrichtete. Lapidar konnte Leopold Jessner (165) schließlich feststellen: »man braucht nicht mehr ins Theater zu gehen, um heute >Egmont<, >Don Carlos und die zeitgenössische Literatur zu hören«, da »der Funk sich des Theaterstücks bemächtigt hat . $^{3}$

\section{IV.}

Von Beginn an griff der Rundfunk, indem er sich der Theatertradition und des Bühnenrepertoires bediente, notwendigerweise auch in eben dieses Repertoire und diese Tradition ein. Die implizite Auswahl und implizite Wertung, die er durch seine Adaptionspraxis vornahm, bezog sich zunächst auf die Dramatik. Damit fungierte er als wichtige Dramenagentur. Von Forschungsinteresse müsste sein, ob und wann das Radio eine Selektion bis hin zur Kanonisierung von dramatischer Literatur und theatraler Repertoirebildung primär nachvollzog, d.h. eine als Bildungsgut anerkannte Dramatik bloß affirmierte und an ein sozial heterogeneres und diversifiziertes (Hörfunk) Publikum vermittelte. Dass mit der Übernahme einer FAUST-Inszenierung aus dem Hamburger Schauspielhaus (November 1924) die radiophonen Theaterübertragungen begannen (der Sendebetrieb beim ARD-Fernsehen und dem ZDF wurde bekanntlich ebenfalls mit FAUST I bzw. dem »Vorspiel auf dem Theater « aufgenommen), ist sicherlich ebenso aufschlussreich für die Ausrichtung des Mediums auf das klassische Theaterrepertoire wie die Tatsache, dass mit einer FAUST-Adaption die Hörspiel-Geschichte des NS-Rundfunks endete. Als weitere »Theaterklassiker« wurden allein 1924 u.a. gesendet: Goethes LAUNE DES VERLIEBTEN (Hamburg); Hofmannsthals DER TOD DES TIZIAN (Hamburg); Goethes EGMONT (Frankfurt); Kleists DER ZERBROCHENE KRUG (München); Ibsens PEER GYNT (Leipzig); Shakespeares EIn SOMMERNACHTSTRAum (Leipzig); Hebbels DiE NIBELUNGEN; Hauptmanns HANNELES HIMMELFAHRT. Auf FAUST I/II folgte 1925 als weiteres klassisches Stück WALLENSTEINS LAGER in der Bearbeitung von Alfred Braun, auf eine Theaterübertragung eines Klassikers also eine Klassiker-Bearbeitung für das Radio. Keineswegs aber trat der Rundfunk mit seinen Theatersendungen nur als »bildungsbürgerliche« Vermittlungsinstanz auf. Was die zeitgenössische Dramenliteratur und ihre Inszenierungen betrifft, so bescheinigt Wittenbrink dem Radio auch eine starke Orientierung gerade an den aktuellen »große(n) Theatererfolge(n) der Weimarer Zeit, die von mehreren Sendegesellschaften ins Programm übernommen wurden« (1062), darunter Inszenierungen von Dramen Georg Kaisers, Carl Zuckmayers, Paul Raynals, Bertolt Brechts, Arnolt Bronnens, Ernst Tollers u.a..

3 Stichproben bestätigen, dass der Hörfunk der Weimarer Republik - ungeachtet der Kritik an dieser Tendenz - sich am Ende dieser Phase als zweite Bühne für die Inszenierung von dramatischen Texten etabliert hatte. In der Ausgabe vom 27. März 1931 von Funk. Der Wochenzeitschrift des Funkwesens finden sich z.B. in der Sparte »Übersicht der Abendveranstaltungen« für den 3. April (Karfreitag) folgende »Hörund Sendespiele« aufgeführt: Leipzig: Torquato TASso, Berlin: JEDERManN, Mühlacker/Frankfurt: PASSION CHRISTI, Hamburg: CAIN (Byron), Königsberg: TROERINNEN (Euripides/Werfel). Die Bedeutung solcher Adaptionen für den frühen Rundfunk wird evident, wenn 1928 eine der ersten funkrechtlichen Dissertationen überhaupt sich mit dem juristischen Problem der Wiedergabe von Bühnenwerken im Rundfunk in ihrer urheberrechtlichen Bedeutung (Knöpfke 1928) auseinandersetzte. 


\section{V.}

Wenn neben dem traditionellen Theaterrepertoire Stücke vom Hörfunk adaptiert wurden, die (noch) nicht den Weg auf die deutschen Theaterbühnen gefunden hatten, machte sich darin aber bereits früh eine bemerkenswerte Rollenverschiebung im Verhältnis der beiden Medien in Bezug auf Selektion und Wertung geltend: Das Medium Radio blieb, und dies im Prinzip auch schon für das erste Rundfunkjahrzehnt, nicht darauf fixiert, lediglich nachzuvollziehen, was das Theater vorgab. Schon 1928 hatte Kurt Pinthus postuliert, »dass man sich nicht mit ausprobierten Bühnenstücken [...] begnügen « möge, »sondern gerade unter den weniger aufgeführten Dramen Werke finden solle, die für den Rundfunk besonders geeignet sind « (51). Dementsprechend richtete die Münchener Sendegesellschaft im Winter 1931/32 eine Reihe mit dem Titel Das unbekannte Drama ein (Wittenbrink: 1066). Brechts DIE HEILIGE JOHANNA DER SCHLACHTHÖFE konnte, um ein bekanntes Beispiel zu nennen, 1932 nur mehr im Rundfunk aufgeführt werden. Stücke u.a. von Carl Hauptmann und Alfred Döblin erlebten ihre Uraufführung gleichfalls im Rundfunk, bisweilen blieb ihnen eine Bühnengeschichte ganz versagt.

Dass es folglich bisweilen schwierig ist, Primär- und Sekundärmedium in diesen Transformationsprozessen zu bestimmen, gilt ebenso und vielleicht in erstaunlicher Breite auch für die weiteren intermedialen Entwicklungen nach 1945. Neben jenen Stücken aus dem Theaterrepertoire waren es beim Wiederaufbau des Rundfunks Dramen, die ebenfalls noch nicht auf deutschen Bühnen aufgeführt worden waren, jetzt aber im Radio produziert wurden: Stücke der jungen Generation, des Exils, des Auslands. Dieser »Rollentausch« der Medien hielt an: Auch hierfür einige eher willkürlich herausgegriffene Beispiele. Leopold Ahlsens PHILEMON UND BAUCIS wurde zunächst vom Bairischen Rundfunk produziert (1955), dann von den Münchener Kammerspielen übernommen (und schließlich wieder für das Fernsehen inszeniert). George Tabori wurde als Stückeschreiber nicht von der Bühne, sondern vom RIAS Berlin entdeckt und durchgesetzt, wobei Jörg Jannings als Hörspielregisseur beim RIAS auch späterhin dafür sorgte, dass Tabori-Stücke ihre Erstinszenierung im Rundfunk hatten. Als eine besondere Beziehungsgeschichte, in der der Hörfunk alles andere als die Position eines Sekundärmediums einnahm, ist der Inszenierungsverlauf von Heiner Müller-Stücken in den achtziger und neunziger Jahren zu beschreiben. Die radiophonen Heiner-Goebbels-Produktionen mit den Einstürzenden Neubauten haben nicht nur Radio-, sondern auch Theatergeschichte geschrieben. Dies gilt ebenso für die Inszenierungsgeschichte des letzten Müller-Stücks GERMANIA 3, das vor allen Bühnenuraufführungen vom Deutschlandfunk produziert und gesendet worden war. (Wobei sich diese Produktion gleichzeitig absetzte von der radiophonen Inszenierungstradition Müllers, wie sie Heiner Goebbels begründet hatte.)

\section{VI.}

Damit rückt eine zweite Selektionsarbeit des Radios ins Blickfeld, die auf das Theater selbst, auf Inszenierungen, Bühnen, Regisseure, Schauspieler zielen musste. Sie begann bereits mit der Diskussion der zwanziger Jahre, welche Bühnen mit einer Übertragungstechnik an die Rundfunkanstalten angeschlossen werden 
sollten. ${ }^{4}$ Eine dominante Präsenz jener Bühnen (vor allem der Berliner), deren Inszenierungen über den Hörfunk distribuiert wurden, bedeutete notwendigerweise immer auch eine Anerkennung und ein Durchsetzen von Regie- und Schauspielstilen. Heinrich George war in den zwanziger Jahren nicht nur ein Theaterstar, er war gleichzeitig in Radiotheatersendungen präsent, sowie Gustaf Gründgens in den fünfziger Jahren nicht nur Regie im Theater führte, sondern auch bei der Radioproduktion des FAUST I im Radio. Theaterhistorisch bemerkenswerte Aufführungen der Weimarer Republik wie z.B. die des LINDBERGH-FLUGS von Bertolt Brecht im Rahmen der »Baden-Badener Musiktage« 1929 wurden vor allem durch das Radio zum kulturellen Ereignis: von der Schlesischen Funkstunde wurde die öffentliche Generalprobe des LINDBERGH-FLUGS live übertragen, von fast allen deutschen Sendern zwei Tage später die Uraufführung. In welchem Maße der Rundfunk in den späten zwanziger Jahren eine aktive Rolle gegenüber dem Theater eingenommen hatte, dieser sich geradezu als Retter in der damaligen Theaterkrise verstand, wurde spätestens evident, als 1930 eine »Theaterwoche der deutschen Sender « veranstaltet wurde, die z.B. auf Seiten des Theaters von Fritz Engel als »Akt der Großmut « der Sender begrüßt wurde: »Denn der Rundfunk ist Herr der Lage, und das Theater, für das er eintritt, ist der geschlagene oder doch der zurückgedrängte Nebenbuhler« (666).

Dass das Auftreten des Rundfunks das Theater selbst, über die impliziten und expliziten Wertungs- und Selektionsverfahren hinaus, nicht unbeeinflusst lassen konnte, Medientransformationen sich eben nicht einfach auf das StellvertreterSchema reduzieren lassen, hat Brecht selbst erkannt und formuliert. Die Entstehung seines epischen Theaters leitet er nicht zuletzt aus radiophonen Produktionszusammenhängen ab: »Auch das alte Drama der shakespearischen Dramaturgie ist nahezu unbrauchbar für den Rundfunk «. So drängt Brecht mit dem Ziel einer Förderung seines Theaterprojekts auf die Intensivierung der Kooperation zwischen Rundfunk und Bühne, einer Kooperation, die bereits als Voraussetzung die Entwicklung einer »pädagogisch-dokumentarischen Darstellung « (132) haben müsste.

\section{VII.}

Für das Verhältnis von Radio und Theater ist es mehr als anekdotisch, wenn Arnolt Bronnen von seiner Hörfunkbearbeitung von Schillers WALLENSTEINS LAGER (3. Januar 1925) berichtet, die Schauspieler hätten die Sendung in »Kostümen und

4 Die systematische Erschließung »vor allem der repräsentativen Häuser bei vielen Sendern (setzte) ziemlich rasch ein «, schreibt Ludwig Stoffels in seinem Beitrag »Kunst und Technik« (692). »So hatte die Berliner-Funkstunde spätestens Mitte 1924 Übertragungsleitungen u.a. zur Staatsoper Unter den Linden, zum Thalia-Theater [...] verlegt« (ebd.). In München wurden drei Spielstätten, National-, Residenz- und Prinzregententheater mit festen Mikrophonen ausgestattet, in Berlin wurde in der Wintersaison 1925/26 aus der Staatsoper und dem Großen Schauspielhaus übertragen; im Winter 1931/32 kamen dazu: Kroll-Oper, Städt. Oper Charlottenburg, Theater des Westens, Volksbühne am Bülowplatz, Theater im Admiralspalast, Piscator-Bühne am Nollendorfplatz. Großmann-Vendrey betont, dass auch in der Frage der Übertragung die Diskussion um »Theater und Rundfunk« weiterging: »Ein einheitlich positiver Standpunkt [zur Übertragungsfrage; PS] ließ sich jedoch [...] nicht erreichen: Ästhetische Bedenken gegen die akustische Vermittlung genuiner Bühnenkunst ließen sich nicht ohne weiteres entkräften und spielten in der Diskussion >Übertragung: Ja oder Nein $<$ weiterhin eine Rolle« (Großmann-Vendrey: 793). 
Mantel, in Wehr und Waffen « (162f) aufgenommen. Im Film dieser Zeit als dem zweiten epochensignifikanten Medium waren die Schauspieler ihrer Stimme beraubt gewesen, was zu einer Veränderung der theatralen Zeichen bei der medialen Transformation geführt hatte, zu einer semiotischen Überdeteminierung bzw. Überbelastung z.B. von Mimik und Gestik, zu einem neuen Austarieren des Verhältnisses von Sprache, Text und Körper. Bei den radiophonen Transformationen nun der umgekehrte Prozess: die Stimmen werden körperlos, der Schauspielerkörper verschwindet und muss - wie Kulissen, Requisiten u.a. - durch neue, akustische Zeichen kompensiert werden: »Lob der Blindheit: Befreiung vom Körper « - um eine Quintessenz aus Arnheims »Rundfunk als Hörkunst« noch einmal zu zitieren. Dass WALLENSTEINS LAGER noch in »Wehr und Waffen « für den Rundfunk inszeniert wurde, demonstriert die anfänglichen (und auch fortdauernden) Schwierigkeiten der Kompensation dieses Zeichenverlustes und der Generierung neuer akustischer Zeichen. Welche Neuansätze der Interpretation klassischer Theaterstücke die Generierung radiophoner akustischer Möglichkeiten implizieren konnte, wurde in der frühen Rundfunkzeit z.B. bei einer radiophonen Bearbeitung von Gorkis NACHTASYL evident: Man »sprengte«, so Pinthus 1928, hier

»die Technik des Dichters, indem man den Einheitsraum des Stückes sprengte: der enge proletarische Raum erweiterte sich ins Unendliche, so dass die Zuhörer durch Straßen, Maschinensäle, Armeleutewohnungen schweiften; und aus dieser Welt der Elenden und Erniedrigten erhoben sich dann proletarische Stimmen, um ein gesprochenes Lied des Leids ertönen zu lassen $\ll(63) .^{5}$

\section{VIII.}

Wenn seit den neunziger Jahren die radiophone dramatische Kunst die unterschiedlichen aisthetischen Medienerfahrungen selbst reflektiert und dabei intendiert, Bühne und damit Visualität und Körperlichkeit zurück zu gewinnen, geschieht dies nicht mehr im Sinne einer Pluri- oder Multimedialität, wie man sie in Ansätzen schon im ersten Rundfunkjahrzehnt ausprobierte, ${ }^{6}$ sondern als Hybridsierungsexperiment, das die theatralen Zeichen in neuen medialen Konfigurationen und ästhetischen Verfahrensweisen durchspielt. »So, wie früher einmal Theaterstücke

5 Die Rehabilitierung vor allem der Stimme als Zeichenträger (und die Ausdifferenzierung und Präzisierung der übrigen akustischen Zeichen) wirkte sich in der Folge auch auf das Bühnentheater aus, am fassbarsten dort, wo auf der Bühne selbst die Trennung von Körper und Stimme re-inszeniert wird. Evident wird dies z.B., wenn akustische Medien eine dramaturgische Funktion erhalten: In Brechts DIE GEWEHRE DER FRAU CARRAR wie in Werfels JAKOBOWSKY UND DER OBERST sind dies die Radioansprachen, in Becketts KRAPP'S LAST TAPE übernimmt das Tonband diese Funktion und trennt nicht nur Schauspielerkörper und Stimme, sondern legt zusätzlich eine historische Distanz in diese Trennung.

6 Als ein Beispiel für Multimedialität der Weimarer Zeit sei die mediale Adaption Erich Kästners LEBEN IN DIESER ZEIT erwähnt: »Einen kleinen multimedialen Erfolg [...] erreichte die Schlesische Funkstunde mit Erich Kästners >Leben in dieser Zeit< (1929). Während der Rundfunk sonst an den Kassenschlagern der Theater teilzunehmen versuchte, fand hier einmal der umgekehrte Prozess statt. 1931 wurde $>$ Leben in dieser Zeit< vom Alten Theater in Leipzig inszeniert, anschließend von vielen weiteren Bühnen übernommen, so dass am 17. April 1932 die Schlesische Funkstunde ihr eigenes Auftragswerk aus dem Breslauer Stadttheater übertragen konnte« (Krug: 33). 
für das Hörspiel adaptiert wurden«, sagte Andreas Ammer in seiner Dankrede bei der Entgegennahme des Hörspielpreises für die Produktion von APOCALYPSE LIVE des Bayerischen Rundfunks und des Bayerischen Staatsschauspiels, »gilt es heute, Hörspiele zu schreiben, die aus dem Medium heraus in der Welt ihren Platz finden, vielleicht auch auf Bühnen funktionieren können« (zit. nach Krug: 112). In Beispielen wie Hartmut Geerkes NO POINT scheint dieses Postulat eines neuen hybriden Verhältnisses von Theater und Hörfunk, unter Einschluss des World Wide Webs, eingelöst worden zu sein: diese Produktion wurde live im Münchener Marstall-Theater aufgeführt, in Bayern Radio 2 zeitgleich gesendet und zudem im Internet verbreitet, wobei in einem Chat Zuschauer unmittelbar reagieren und eingreifen konnten. »Kommunikationsereignis« (zit. nach Krug: 134) nannte der BR diese Produktion, bei der ein weltweit interaktiver Kreislauf zwischen Bühne, Radio und Internet hergestellt worden sei.

\section{IX.}

Noch immer findet sich auch das »alte« Format »Theater im Rundfunk « im Programm, bisweilen selbst an privilegierten Sendeplätzen. So richtete 2001 der WDR an den Samstagabenden eine »WDR 3 Bühne: Radio« ein, auf der abendfüllende Stücke des »traditionellen« Sprechtheaters ausgestrahlt wurden. Zugleich haben die skizzierten Entwicklungen in der Audiokunst eine hohe, stets Theater einbindende intermediale Komplexität erreicht: Beides sollte bereits genügen, um wenn über »Theater und Medien « gehandelt wird - einen Blick auch auf die Transformationen der beiden hier verhandelten Medien zu legitimieren.

\section{Literatur}

Arnheim, Rudolf (2001): »Rundfunk als Hörkunst«. In: Ders.: Rundfunk als Hörkunst und weitere Aufsätze zum Hörfunk. Frankfurt/M.: Suhrkamp, S. 7-178.

Brecht, Bertolt (1976): »Der Rundfunk als Kommunikationsapparat«. In: Ders.: Gesammelte Werke, Bd. 18. Frankfurt/M.: Suhrkamp, S. 127-134.

Bronnen, Arnolt (1954): Arnolt Bronnen gibt zu Protokoll. Hamburg: Rowohlt.

Döblin, Alfred (1975): »Literatur und Rundfunk «. In: Gerhard Hay (Hg.): Literatur und Rundfunk 1923-1933. Hildesheim: Gerstenberg, S. 230-236.

Engel, Fritz (1930): »Rundfunk und Theater. Zur Theaterwoche der deutschen Sender«. In: Die Sendung, H. 4, S. 664-667.

Flesch, Hans (1931): »Bemerkungen zum Hörspiel«. In: Funk, Nr. 3, S. 73-74.

Flesch, Hans (1931): »Bemerkungen zum Hörspiel«. In: Funk, Nr. 10, S. 72-73.

Funk. Die Wochenzeitschrift des Funkwesens, 27.03.1931.

Großmann-Vendrey, Susanne (1997): »Rundfunk und etabliertes Musikleben«. In: Joachim-Felix Leonhard (Hg.): Programmgeschichte des Hörfunks in der Weimarer Republik, Bd. 2. München: dtv, S. 752-846.

Helmensdörfer, Urs (2005): »Nestroy am Radio - ein Unding? Zur Hörspielproduktion von >Der alte Mann mit der jungen Frau««. In: Nestroyana. Blätter der internationalen Nestroy-Gesellschaft, Nr. 25, H. 1 u. 2, S. 31-36.

Jessner, Leopold (1984): »Rundfunk und Theater«. In: Irmela Schneider (Hg.): Radio-Kultur in der Weimarer Republik. Eine Dokumentation. Tübingen: Gunter Narr, S.163-170. 
Knilli, Friedrich (1970): Deutsche Lautsprecher. Versuche zu einer Semiotik des Radios. Stuttgart: Metzler.

Knöpfke, Friedrich (1928): Wiedergabe von Bühnenwerken im Rundfunk in ihrer urheberrechtlichen Bedeutung (Diss. jur., o.O.).

Krug, Hans-Jürgen (2003): Kleine Geschichte des Hörspiels. Konstanz: UVK.

Pinthus, Kurt (1975): »Die literarischen Darbietungen der ersten fünf Jahre des Berliner Rundfunks.«In: Gerhard Hay (Hg.): Literatur und Rundfunk 19231933. Hildesheim: Gerstenberg, S.41-68.

Prager, Gerhard (1951): »Mörderische Angelegenheit«. In: Der Spiegel, Nr. 16, S. 33.

Schaudig, Michael (1992): Literatur im Medienwechsel. Gerhart Hauptmanns Tragikomödie >Die Ratten< und ihre Adaptionen für Kino, Hörfunk, Fernsehen. Prolegomena zu einer Medienkomparatistik. München: Verlag für Filmschriften (Diskurs Film: Bibliothek 4).

Schaudig, Michael (2002): »Des Meisters Werk und Stimme: Gerhardt Hauptmann im zeitgenössischen Radio. Ein Beitrag zur Frühgeschichte des deutschen Hörfunks «. In: Jörg Hucklenbroich/Reinhold Viehoff (Hg.): Schriftsteller und Rundfunk. Konstanz: UVK (Jahrbuch Medien und Geschichte), S. 13-76.

Schwitzke, Heinz (1963): Das Hörspiel. Dramaturgie und Geschichte. Köln/Berlin: Kiepenheuer \& Witsch,

Stoffels, Ludwig: »Kunst und Technik«. In: Joachim-Felix Leonhard (Hg.): Programmgeschichte des Hörfunks in der Weimarer Republik, Bd. 2. München: dtv, S. 682-724.

Strozlka, Rainer (2004): Abriss zur Geschichte des Hörspiels in der Weimarer Republik. Hannover: Verlag für Ethnologie.

Wittenbrink, Theresia (1997): »Rundfunk und literarische Tradition«. In: JoachimFelix Leonhard (Hg.): Programmgeschichte des Hörfunks in der Weimarer Republik, Bd. 2. München: dtv, S. 996-1195. 



\title{
Poetische Sichtbarmachung: \\ BE- UND ER-SCHREIBUNGEN IN TANZKRITIKEN DES 19. JAHRHUNDERTS
}

\author{
CHRISTINA THURNER
}

Leidenschaftlich verehrten sie ihre Stars, die sie selbst zu solchen gemacht hätten, schreibt der Tanzkritiker Jules Janin in einer Rezension zu GISELLE, OU LES WILIS im Journal des Débats (Janin 1841: 1). Die Zeit, in denen Ballerinen in Massenmedien wie Tageszeitungen zu Göttinnen hochgeschrieben wurden, ist zwar heute (fast) vorbei; der aktuelle Tanz auf den Bühnen hat sich vom romantischen Handlungsballett mehrheitlich weit entfernt, und doch ist der Gestus der Mythisierung auch im 21. Jahrhundert noch nicht ganz aus dem Genre der Tanzkritik verschwunden. Wir lesen - und schreiben - von unmittelbar Bewegendem und von bewegten Wirkungen ohne Worte, die uns im Innersten treffen usw. Dieser Diskurs ist u.a. ein Relikt aus dem Feuilleton des 19. Jahrhunderts, das nicht nur das Bild der entsprechenden historischen Tanzform bis heute nachhaltig prägt, sondern auch die Auffassung von der Wirkung von Tanz generell. In welchem Kontext die feuilletonistische Tanzkritik entstanden ist, wie sich die Kritiker gegenüber >ihrer Kunst verhielten beziehungsweise positionierten und welche textlichen Verfahren sie etablierten, darum soll es im Folgenden gehen. Dabei wird einerseits untersucht, wie der Tanz in dem Massenmedium jener Zeit, der Zeitung, vorkommt. Es wird also ein klassischer Medienbegriff verwendet, der zunächst Mittel, Mittler und Verfahren bezeichnet, die der Verbreitung von Information dienen. Andererseits und vor allem aber soll gezeigt werden, wie der Feuilletonist als >Instrument< des Kommunikationsmittels Zeitung nicht einfach Informationen vermittelt, sondern Bilder entwirft, die sich als Vorstellungen von dem, was Tanz ist und sein soll, in das kulturelle Gedächtnis eingravieren.

Die Tanzkunst sei unter ihren Schwestern die subjektivste, und sie nehme »mehr als Poesie, Musik und Plastik die Mitthätigkeit in Anspruch «, meint Albert Czerwinski (5) in seiner Geschichte der Tanzkunst. Damit schreibt sich der Danziger Tanzlehrer in den Diskurs seiner Zeit ein, der die Wechselwirkung zwischen Tanz Ausübenden und Rezipierenden als ein dynamisches Verhältnis begriff und im Gegenzug zur immer stärkeren Reglementierung der Ballettcodes eine betont subjektive Wirkungsweise der Tanzkunst installierte. »Kann ich dir in irdische Worte bannen das himmlische Aethergebild? «, heißt es in einem Konversationslexikon (Herloßsohn: 19) im Eintrag Tanz, und weiter: »Frage dein eigenes Herz hierüber, dein eigen Gefühl«. Diese subjektive Wirkungsweise der Tanzkunst galt deren Verfechtern als umso bewegender, anregender und insbesondere lebendiger.

Die Suche nach neuen Möglichkeiten einer sprachlichen Erfassung des sogenannten Unsagbaren war die logische Konsequenz. Das geeignete Genre dafür bot das zu Beginn des 19. Jahrhunderts sich etablierende Feuilleton. Sprache, Selbstverständnis und Anspruch der Kritiker wandelten sich in den ersten Jahrzehnten 
nach 1800 insbesondere in Frankreich, wo sich das Feuilleton an ein kulturinteressiertes, kultiviertes Publikum richtete und eine Mischung aus dokumentarischer und literarischer Vermittlung pflegte. Während die frühen Ballettbesprechungen etwa von Castil-Blaze und Hector Berlioz noch eher einem klassizistischen Kunstverständnis verpflichtet waren und meist im größeren Zusammenhang der Rezeption musikalisch-dramatischer Gattungen wie der Oper standen, entwickelte sich in Paris ab den 1830er Jahren, nach einem journalistischen Generationswechsel, ein romantischer Feuilleton-Stil. Vor allem zwei Kritiker haben den feuilletonistischen Diskurs im Hinblick auf den künstlerischen Tanz entscheidend geprägt: Jules Janin und Théophile Gautier. Beide Kritiker waren von der einzigartigen Wirkung der romantischen Tanzkunst überzeugt und entwickelten eine spezifische Art der Vermittlung.

Janin (1858: 278) beispielsweise stellt eine enge Korrelation zwischen dem Ballett seiner Zeit und seinem Schreiben her, indem er die ersten glorreichen Auftritte der Ballerina Marie Taglioni mit den Anfängen seiner feuilletonistischen Tätigkeit in Verbindung bringt. ${ }^{1}$ Die Aussage Janins ist in mehrfacher Hinsicht signifikant für das Selbstverständnis und die Intention des Kritikers. Dieser bindet sich, sein Sehen und Schreiben eng an die Kunst der Tänzerin an (»je m'attachai à cette gloire «), in deren Glanz und Ruhm er seinen Diskurs stellt. Demgegenüber überträgt er diesen Glanz aber auch auf sein eigenes Tun, indem er ihn als ihr Rezensent metonymisch in das Bild eines leuchtenden Edelsteins fasst, den er sich anstecken und am eigenen Leib tragen kann (»je l'ai portée à mon épingle, en guise d'améthiste et de rubis«). Interessant ist auch, dass er scheinbar ohne Grund und Motiv schreiben will (»j'écrivais avec rien, sans motif et sans cause «), was die Notwendigkeit einer Legitimation des Schreibens dezidiert von der Hand weist. Dieses geschehe vielmehr aus purer Freude (»uniquement pour le bonheur d'écrire «), erklärt der Kritiker seinen Impuls. Obwohl er seine Rede an den gesehenen Tanz anlehnt, bezeichnet er diese als frei (»libre«), also als subjektiv, und den Gegenstand als einen, der der ewigen Erzählung lohnt (»raconter l'histoire éternelle«) und Bände füllt (»on ferait un beau tome«).

Bereits die Frühromantiker haben ein produktives rezeptives Verhältnis des Kritikers zur Kunst stark gemacht und diese Haltung "poetisches Gefühl « genannt, das einen subjektiven kreativen Akt auslöse. Friedrich Schlegel formuliert dies folgendermaßen: »Das Wesen des poetischen Gefühls liegt vielleicht darin, dass man sich ganz aus sich selbst afficieren [...] kann« (285). Walter Benjamin nennt dieses »poetische Gefühl« in seiner Dissertation zur Kunstkritik der deutschen Frühromantik auch den »Indifferenzpunkt der Reflexion« (58). Als Ausgangspunkt der Reflexion des Kritikers wird nicht die Kunst selbst betrachtet, sondern das Gefühl, das diese bei ihm auslöst.

Auch wenn Benjamin sich nicht auf die französischen Romantiker und schon gar nicht auf die Feuilletonisten im Bereich Ballett bezogen hat, so trifft seine

1 Die Stelle lautet: »Je commençais alors à écrire, lorsqu'elle [d.i. Taglioni, C.T.] commençait à danser; j'écrivais avec rien, sans motif et sans cause, uniquement pour le bonheur d'écrire et de parler, librement, à quiconque veut entendre incessamment raconter l'histoire éternelle du rein du tout! Alors, et naturellement, la voyant reluire, à la façon du ver luisant, dans les gazons de l'été, je m'attachai à cette gloire volage et volante; pendant dix ans, je l'ai portée à mon épingle, en guise d'améthiste et de rubis, ce papillon volage. Il a été, dix ans durant, le thème enchanté de mes frêles discours. Elle dansait, et j'écrivais, et rien qu'avec mes louanges à sa jeunesse inspirée, on ferait un beau tome! «. 
Folgerung in Bezug auf >den Kritiker< doch auch insbesondere auf Janin und Gautier zu: »Es ist klar: für den Romantiker ist Kritik viel weniger die Beurteilung eines Werkes als die Methode seiner Vollendung. In diesem Sinne haben sie poetische Kritik gefordert, den Unterschied zwischen Kritik und Poesie aufgehoben « (Benjamin: 63f). Théophile Gautier (1856: 4) betont entsprechend, er sei in der Funktion des Kritikers ein Poet und kein Magister. Seine Ballettrezensionen zeugen von einer Praktik der Poetisierung. Eine Manifestation derselben lässt sich insofern charakterisieren, als sie das Wahrgenommene mit Imaginiertem verbindet und mit dichterischen Mitteln zu einem poetischen Ausdruck bringt. Ein solches Verfahren lässt sich an zahlreichen Passagen in den romantischen Rezensionen darlegen. Die Tänzerin auf der Bühne in der romantischen Kulisse ist dem Kritiker Inspiration für seine poetische Schrift. Er beschreibt nicht nur, was zu sehen ist, er sieht und schildert vielmehr auch, was über den beschränkten Theatersaal hinausweist; er malt also den Bühnenraum mit Attributen aus und erweitert ihn um poetisch gezeichnete Landschaften, die er zudem in sein eigenes Licht rückt. So erscheinen etwa die schattig kühlen Täler, von denen Gautier (1995: 78) und Janin (1858: 276) erzählen, dem rezensierenden Betrachter und damit auch dem Leser, der Leserin nicht als konkretes Bühnenbild, sondern als Bild gewordene Atmosphäre, die von der Tänzerin aus- und über ihren individuellen Körperausdruck hinausgeht.

Diese bunten, detailreich geschilderten Bilder entwickelt der Kritiker nicht allein aus der Anschauung. Ein besonders kreatives Beispiel für die imaginär sich verselbständigenden Reflexionen und sprachlich eingefangenen Bilder findet sich in einer Besprechung Gautiers (1995: 78) anlässlich der Wiederaufnahme der SYLPHIDE an der Pariser Oper:

»Quand Fanny [Elßler, C.T.] danse, on pense à mille choses joyeuses, l'imagination erre dans des palais de marbre blanc inondés de soleil et se détachant sur un ciel bleu foncé, comme les frises du Parthénon; ils vous semble être accoudé sur la rampe d'une terrasse, des roses autour de la tête, une coupe pleine de vin de Syracuse à la main, une levrette blanche à vos pieds et près de vous une belle femme coiffée de plumes et en jupe de velours incarnadin; on entend bourdonner les tambours de basque et tinter les grelots au caquet argentin.«

Der Bewegung der Tänzerin auf der Bühne folgt die bewegte Fantasie des Kritikers; in Gedanken geht ihm dabei eine Welt auf, die Elemente des Gesehenen aufnimmt und mit dazu Imaginiertem vermischt. In dieser Beschreibung ist so nicht mehr erkennbar, was sich auf der Bühne und was sich in der Imagination des Rezensenten abgespielt hat. Die Beschreibung lässt keine eindeutigen Rückschlüsse über das tatsächliche Bühnengeschehen zu, entfernt sich aber in der Bildwahl auch nicht so weit, dass mit dem Text eine ganz neue, unabhängige Kreation vorläge. In Anlehnung an Walter Benjamin könnte man ein solches Verfahren als immanente Reflexion bezeichnen:

»[D]as Experiment besteht nicht in der Reflexion über ein Gebilde, welche dieses nicht, wie es im Sinn der romantischen Kunstkritik liegt, wesentlich alterieren könnte, sondern in der Entfaltung der Reflexion, d. h. für den Romantiker: des Geistes, in einem Gebilde« (Benjamin: 60).

Die poetische Kritik wird offenbar als ein ästhetisches Experiment verstanden. Gautier (zit. in Guest: 25) etwa sagt über das Experimentelle an seinem Schreiben, 
er werfe seine Sätze in die Luft und er wisse, dass sie, wie Katzen, auf ihren Füssen landeten. Auf diese Weise beansprucht er für seine eigene Sprache metaphorisch dieselbe Leichtigkeit, die er auf der Bühne an den Tänzerinnen bewundert. Die Sätze entspringen nämlich dem romantischen Kritiker zwar buchstäblich, sie sind dann aber - so kann die Stelle gelesen werden - selber wiederum eigene Subjekte innerhalb eines ästhetischen Feldes. Der Schreibende bleibt also sogar in der Metareflexion, die von der Reflexion über den Tanz hier nicht mehr zu trennen ist, im »Kunstgebild «, obwohl sein Gegenstand kein verbaler - wie vorwiegend bei den von Benjamin behandelten Frühromantikern -, sondern eben ein nonverbal bewegter ist.

Diesem Gegenstand werden jedoch von den romantischen Tanzkritikern nicht nur poetische Qualitäten zugeschrieben, er wird vielmehr von ihnen nachdrücklich als poetisch charakterisiert. So beschreibt etwa Gautier (1845: 23) den Pas de deux von Carlotta Grisi und Marius Petipa in GISELLE mit poetologischen Begriffen: »[Ils] ont fait de ce dernier acte un véritable poëme, une élégie chorégraphique«. Der Kritiker belegt die Erscheinung der Tänzerin mit Ausdrücken wie »poésie vivante « (Gautier 1995: 161), als »madrigal dans un mot « (153), oder erklärt, dass ihre »ronds de jambes « und ihre Ondulationen der Arme langen Gedichten gleichkämen (28).

In solchen Äußerungen überträgt der Rezensent die Qualitäten der Poesie auf die Tanzkunst, er setzt beide Genres in eins und versteht gar letztere als die Verkörperung der ersten. Mit diesen Zuschreibungen suggeriert der Rezensent, dass seine Reflexion sich durchaus in ein und demselben Kunstgebilde bewegt: der Poesie. Gautier wehrt sich denn auch gegen jeglichen objektiven Anspruch, dem seine Kritiker-Vorgänger sich noch verpflichtet fühlten, und macht dagegen die individuelle Vorstellungskraft stark. In einer Rezension über das Ballett LA FILLE DE MARBRE reflektiert er das Verhältnis zwischen Gesehenem und sprachlich Wiedergegebenem. Er verweist dabei ganz auf die Imagination des Kritikers, indem er verbal ein - zunächst überraschendes - Bild kreiert:

"Dans ce fourmillement de kaléidoscope, chacun voit ce qu'il veut; c'est comme une espèce de symphonie de formes, de couleurs et de mouvement dont le sens général est indiqué, mais dont on peut interprêter les détails à sa guise, suivant sa pensée, son amour ou son caprice« (Gautier 1995: 223).

Das Kaleidoskop ist ein optisches Spielzeug, das durch mehrfache Spiegelung Gegenstände bei Bewegung in wechselnden Figuren zeigt. In dieser Stelle dient es als Bild für das Gesehene und verweist so bereits auf eine erste reflexive Dynamisierung durch den Rezipienten. Die Wahrnehmung eines Gewimmels, einer Symphonie von Formen und Farben verstärkt den Eindruck der sensuellen Bewegtheit. In diesem dynamischen Feld nimmt sich der Autor als subjektiver Betrachter wahr. Interessant ist, wie er dabei wiederum die Metapher des Kaleidoskops weiterspielt, indem er die Bewegung sogar noch genauer beschreibt als eine Drehung, deren generelle Richtung (»sens général «) vorgegeben ist, aber im Detail nach eigenem Belieben interpretiert werden könne. Zudem heißt »sens « ja nicht nur Richtung, sondern auch Bedeutung, Sinn und Empfinden. Mit dieser Wortspielerei baut Gautier somit sein eigenes verbales Kaleidoskop, an dem man drehen kann und das, je nach Position und Wendung, auch etwas darüber aussagt, wie die Interpretation der Interpretation zu fassen sei: eine allgemeine Bedeutung, ein generelles Empfinden weist die Bewegung zwar aus, aber die Auslegung beziehungsweise Sinngebung 
erfolgt dann gemäß den individuellen Vorlieben und Gedanken. Der Kritiker dreht und schüttelt sich also seine eigenen Bilder und die Interpretationen gleich dazu.

Die Beschreibung wird in dieser Konstellation nicht als eine nachträgliche Vermittlung begriffen und dargestellt, sondern als ein Bestandteil des dynamischen ästhetischen Ganzen. Diese Auffassung erklärt denn auch den Gestus, der die Verfahren der Poetisierung bedingt, und der folgerichtig von einer starken Affizierung geprägt ist. Der Kritiker versteht sich dabei als ein buchstäblich Involvierter, der selber in die dynamischen Prozesse mit eingebunden und der affiziert ist - vom Geschehen auf der Bühne, von seiner Anschauung, Reflexion und schließlich von den Worten, die ihm zufallen. Das Resultat dieser Haltung ist ein enthusiastischer Diskurs, der einstimmt in die feierliche Atmosphäre. Denn begeistern lassen wollte sich nicht nur das Publikum, sondern - als Teil davon - auch der Kritiker.

Diese Haltung ist in der Forschung etwas unspezifisch als Mode in den Feuilletons sowie als Konsequenz der großen Sympathie der - v. a. männlichen - Zuschauer für die Tänzerinnen gesehen worden (vgl. u. a. Guest: 49). Bisher zu wenig berücksichtigt wurde m. E., dass allerdings gerade der Tanzdiskurs von einem neuen Selbstverständnis des Kritikers zeugt, weil sich dieser innerhalb des Kunstgebildes wahrnahm und zu positionieren strebte. Damit einher geht nicht nur eine glorifizierende Verklärung der ihrerseits auf Verklärung bedachten Tanzkunst, sondern schließlich auch eine Selbst(v)erklärung des Kritikers. Die Bewunderung wird als bevorzugter Habitus des Zuschauers und damit auch des Rezensenten stark gemacht. Mit weniger will sich der Kritiker nicht zufrieden geben. Die als >süß< bezeichnete Admiration versteht er dabei nicht etwa als passive Haltung, sondern als einen dynamischen, kreativen Prozess: »Admirer un grand artiste, c'est s'incarner avec lui, entrer dans le secret de son âme; c'est le comprendre, et comprendre c'est presque créer « (Gautier 1995: 161). Indem der Kritiker sich also auf den bewunderten Künstler einlässt, begreift er das Bewunderte und kreiert um die Künstlerfigur eine Innen- und Außenwelt, die er gleichzeitig in einen von ihm erzeugten, für ein (Lese-)Publikum (neu) erfahrbaren Zusammenhang transponiert.

Diese Transposition des Gesehenen in die wörtliche Sprache beschreibt Gautier (1856: 4) zunächst durchaus analytisch als Übersetzung von einer Kunst in die andere; dabei ist er sich der Schwierigkeiten einer solchen Übertragung offenbar bewusst, wenn er einräumt, dass zuweilen die verfügbaren Mittel ausgereizt würden beziehungsweise man auf nicht exakt Entsprechendes ausweichen müsse. Damit macht der Feuilletonist jedoch keineswegs ein Zugeständnis irgendeines Unvermögens seines Tuns, vielmehr macht er auf die Freiheiten aufmerksam, die er sich als schreibender Betrachter nimmt. Der Augenzeuge wird so gewissermaßen zum »erweiterte[n] Autor «, wie es Novalis (470) - in Bezug auf den lesenden Rezipienten - formuliert hat. Seinem >Gegenstand < begegnet der Ballettrezensent vorsätzlich mit Begeisterung und Begierde, die sich wiederum - wie Gautier (1856: 4) nicht ohne Selbstironie festhält - im Text niederschlagen soll: »L'Écriture parle quelque part de la concupiscence des yeux, concupiscentia oculorum; - ce péché est notre péché, et nous espérons que Dieu nous le pardonnera.« Indem er den >auctor auctorialis schlechthin, Gott, nennt, kokettiert Gautier in dieser Stelle damit, dass er als Autor seiner Texte über das Ballett den (Über-)Blick von außen gar nicht etwa für sich in Anspruch nimmt, sondern sich seiner subjektiven Wahrnehmung lieber sinnlich teilhabend als objektivierend hingibt - auf die (durchaus in Kauf genommene) Gefahr hin freilich, sich zu >versündigen $<$, d.h. dem >Gegenstand < im Gestus der Begierde einerseits zu nahe zu treten, ihn zu vereinnahmen, und sich andererseits aber auch in der eigenen Anschauung und Übertragung von 
ihm zu entfernen. Der Kritiker kreiert schreibend seine Sichtweise, die wiederum für die Lesenden als Sichtbarmachung im Medium der Schrift rezipiert werden soll.

Um diesen Vorgang zu bestimmen, scheint mir der Begriff der >Emphase $<$ hilfreich. Emphase, von griechisch émphasis, meint übersetzt »Nachdruck «, aber auch »Darstellung, Bezeichnung einer Sache, Kraft des Ausdrucks, der mehr andeutet und ahnen lässt, als er ausspricht « und beinhaltet etymologisch als Ableitung von emphaínein einen performativen Akt des Sichtbarmachens, des zur Anschauungbringens (vgl. Pfeifer: 281). Dieses Sichtbarmachen in emphatischen sprachlichen Bildern und Metaphern charakterisiert die romantischen Ballettkritiken. Die Rezensenten gehen in ihren feuilletonistischen Texten demnach von etwas aus, das für sie im Moment der Aufführung sichtbar war; in deren mimetischer Beschreibung erschöpfen sich die Texte jedoch keineswegs. Vielmehr kommt bildhaft zum Ausdruck, was über das konkrete Geschehen auf der Bühne hinausweist. Der Kritiker selbst wird dabei zum Schöpfer, indem er insbesondere Bewegung übernimmt, vermittelt und überträgt.

Seit dem 19. Jahrhundert haben sich die Kunstform Tanz, das Selbstverständnis des Kritikers, der Kritikerin und auch die Ansprüche der Feuilletons freilich verändert. Dennoch würde ich behaupten, dass der Tanzkritik noch heute etwas von diesem emphatischen Diskurs anhaftet, gerade weil die Tanzrezension - mehr als die klassische Schauspiel- und Musiktheaterkritik - auf der Imagination des Betrachters fußt. »Frage dein eigenes Herz [...], dein eigen Gefühl«, bevor du das Gesehene in Worte fasst, scheint sich auch heute noch mancher Rezensent mit dem anfangs zitierten Lexikoneintrag jeweils zu sagen - nur dass Herz und Gefühl halt nie außerhalb von Kontexten frei umherschwirren, sondern in kulturellen Körpern stecken.

\section{Literatur}

Benjamin, Walter (1973): Der Begriff der Kunstkritik in der deutschen Romantik. Frankfurt/M.: Suhrkamp.

Czerwinski, Albert (1862): Geschichte der Tanzkunst bei den cultivirten Völkern von den ersten Anfängen bis auf die gegenwärtige Zeit. Leipzig: Weber. Faks. Hg. v. Kurt Petermann Leipzig 1975.

Gautier, Théophile (1845): »Notice sur Giselle«. In: Théophile Gautier/Jules Janin/Philarète Chasles (Hg.): Les Beautés de l'Opéra ou Chefs-D'Oeuvre Lyriques illustrés par les premiers artistes de Paris et Londres sous la Direction de Giraldon. Avec un texte explicatif rédigé par Théophile Gautier, Jules Janin et Philarète Chasles. Paris: Soulie, S. 1-24.

Gautier, Théophile (1856): »Introduction«. In: L’Artiste: revue de Paris. 14.12., S. 3-5.

Gautier, Théophile (1995): Écrits sur la Danse. Arles: Actes Sud.

Guest, Ivor (1974): The Ballet of the Second Empire. London: Pitman.

Herloßsohn, C. (1838): Damen Conversations Lexikon. Ed. im Verein mit Gelehrten und Schriftstellerinnen. Bd. 10. Leipzig: Adorf.

Janin, Jules (1841): »Feuilleton«. In: Journal des Débats politiques et litteraires, 30.6., S. 1-2.

Janin, Jules (1858): Les Symphonies de l'Hiver. Paris: Morizot. 
Novalis (1981): »Vermischte Bemerkungen und Blüthenstaub«. In: Richard Samuel u.a (Hg.): Novalis. Schriften. Bd. 2: Das philosophische Werk. Stuttgart: Kohlhammer, S. 439-470.

Pfeifer, Wolfgang (1993): Etymologisches Wörterbuch des Deutschen (2. Aufl.). Berlin: Akademie.

Schlegel, Friedrich (1906): »Fragmente«. In: J. Minor (Hg.): Friedrich Schlegel. 1794-1802. Seine prosaischen Jugendschriften. Bd. 2: Zur deutschen Literatur und Philosophie. Wien: Konegen, S. 203-307. 



\section{TEIL 3}

Medialität \& Medien IM Theater 



\title{
Schau-Spiel-Technik Und Medien ALS REPRÄSENTATIONSTECHNOLOGIEN
}

\author{
ANJA KLÖCK
}

Die Darstellungen von Körperwissen in schauspieltheoretischen Schriften und schauspielmethodischen Programmen sind sowohl historisch kontingent als auch eingebunden in historische Langzeitprozesse, welche seit der frühen Neuzeit eine Verwebung von kulturellen Praktiken, ästhetischen Formen, technischen Neuerungen und Strategien der Wissensproduktion und -transmission bedingen. Die Leitbegriffe der Schau, des Spiels und der Technik, die der Titel des Beitrags ausstellt, eignen sich zur Konturierung dieses historischen Langzeitprozesses. Sie markieren die jeweils spezifische Schnittzone aus Strategien der Wissensproduktion und -transmission zum menschlichen Körper und jeweils anders definierten und praktizierten spielerischen Handlungen, der spezifisch verorteten Schau und einer jeweils anders organisierten und materialisierten Auffassung von Technik. Sie bieten die Möglichkeit, anstatt einer vorschnellen Grenzziehung zwischen >technischen< und >sinnhaften< Prozessen den spielerischen Umgang mit Techniken im Sinne von Artefakten, Apparaten wie auch Repräsentationsstrategien »als einen konstitutiven, aber regelhaften und den Intentionen von Akteuren unverfügbaren Bestandteil kulturtechnologischer Konstellationen « (Lösch u.a.: 12) zu verstehen. Damit unterscheidet sich der hier vorgestellte Ansatz von der handlungstheoretischen Techniksoziologie bzw. Technikforschung einerseits wie auch andererseits von einer in der kulturwissenschaftlichen Medientheorie kristallisierten Tendenz zur Determinierung des Sozialen oder Kulturellen durch »eine technische Materialität der medialen Informationssysteme« (ebd.). Der Leitbegriff der Technik soll in diesem Beitrag den Blick schärfen für den jeweiligen historisch situierten Technikbegriff, der in jenen diskursiven Konstruktionen des idealen Schauspielers kristallisiert die Schauspielen für erlernund regelbar halten. Der Begriff der Schau verweist auf eine historisch bedingte Koppelung von Wissen an sinnliche Wahrnehmung in öffentlichen Räumen (ähnlich wie in Schau-Platz, SchauSteller, Schau-Bühne), an eine Art der

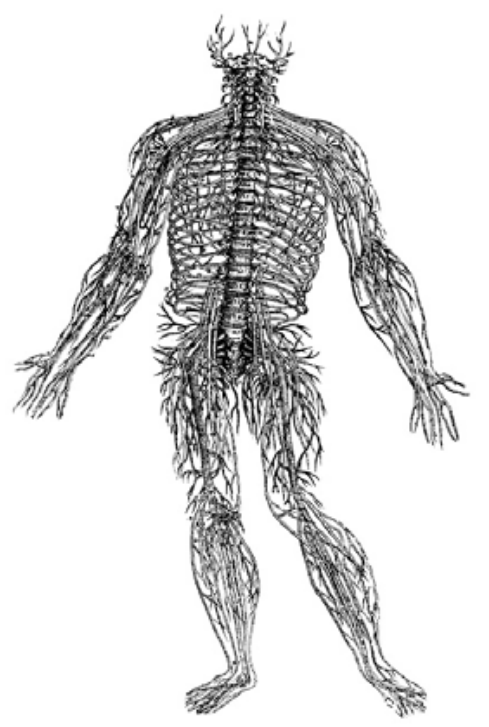

Abbildung 1: Visualisierung des Nervensystems. Quelle: Vesalius 1543. 
Wahrnehmung also, die immer schon an eine Erfahrung öffentlicher Räume gebunden bzw. durch diese bedingt ist. Der Begriff des Spiels meint den körperlich-spielerischen Umgang mit organisiertem Material und materialisierten Organisationen, der Spuren hinterlässt ohne dabei kausal-deterministischen oder linearen Logiken unterworfen sein zu müssen.

In den anatomischen Theatern und Diskursen verbindet sich in Europa im 16. und 17. Jahrhundert ein nicht theologisches Interesse am toten Leib mit Formen zur Darstellung der Grenzen zwischen Innen und Außen eines menschlichen Körpers (vgl. Sawday; Schramm/Schwarte/Lazardzig; Calbi). In der Schnittzone von medizinischen Diskursen, wissenschaftlichen Methoden, kulturellen Konventionen, ästhetischen Formen und einer zunehmenden Betonung des Sehens als einem Modus der Wissensproduktion lassen sich Praktiken des Sezierens von Körpern und des Repräsentierens ihrer Körperlichkeit in das Zentrum einer aktuellen kulturwissenschaftlichen Arbeit rücken.

Die Darstellungen der verschiedenen Teile und Schichten eines organisch definierten Körpers in den anatomischen Büchern und Tafeln des 16. und 17. Jahrhunderts erinnern nämlich nicht nur an die Unmöglichkeit, in unbetäubtem Zustand das Inwendige des eigenen Körpers zu erblicken ohne auch heute auf Repräsentations-

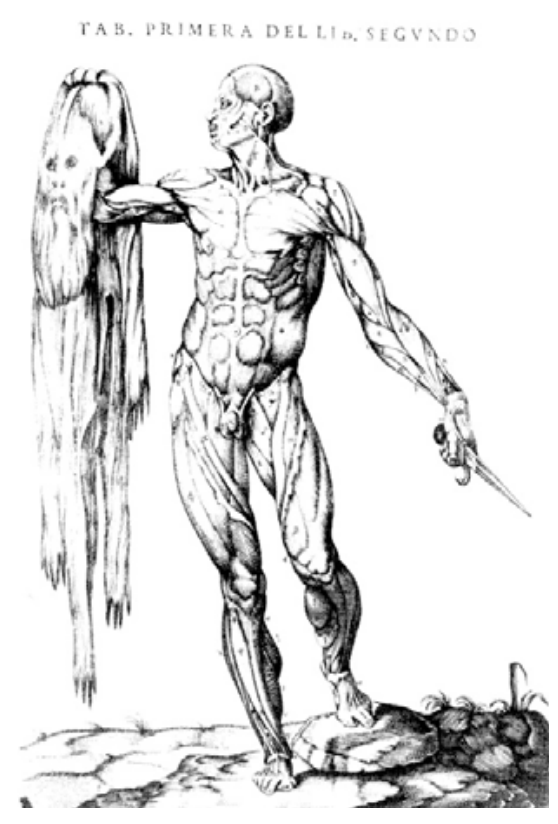
technologien wie Röntgenbilder oder Visualisierungen von Ultraschallwellen zurückzugreifen. Sie erinnern nicht nur daran, dass, in einem optischen Raum, Wissen über die innere Beschaffenheit und äußere Erscheinung unseres eigenen Körpers immer schon von Repräsentationspraktiken und -medien abhängig ist. Sie markieren auch das Verlangen, das Körperwissen, welches vermittelt oder erinnert werden soll, mit Hilfe von medialen Repräsentationsstrategien zu stabilisieren, zu konservieren, zu transformieren und $\mathrm{zu}$ verbreiten. Erst durch diese wird das Körperinnere sichtbar für den $\mathrm{Zu}$-Schauer: Was gesehen werden kann und wie es sichtbar wird ist abhängig von einem Zusammenspiel aus anatomischen Diskursen und Praktiken, Instrumenten, kulturellen Konventionen, Medien im engeren Sinn (wie Zeichnungen, Stiche, Radierungen), ästhetischen Formen und historischen Vorgängen.

Abbildung 2: Darstellung von Muskeln und Sehnen.

Quelle: Valverde de Amusco 1556.

So wird das Innere in einer Darstellung von Andreas Vesalius (1543) beispielsweise durch eine transparent gewordene Haut visualisiert, um physiologische Systeme wie das Nervensystem sichtbar zu machen; so ist bei Juan Valverde de Hamusco (1556) ein Mann dargestellt, der seine eigene Haut mit einem Messer von seinem Körper abgetrennt hat und, diese wie eine geisterhafte Erscheinung vor sich 
haltend, somit den Anblick seiner Muskeln und Sehnen für den Betrachter preisgibt; so präsentieren Abbildungen bei Pietro Berretini da Cortona (entstanden 1618-1620) anderweitig unversehrte weibliche Figuren in architektonisch strukturierten Räumen, die ihr Inneres selbst enthüllen, indem sie Teile der eigenen Haut für den Betrachter auffalten wie ein Tuch oder Vorhänge, die einen barocken Präsentationsrahmen bilden; oder, wie bei Adriaan van de Spiegel (1627), entblättern sich Gebärmutter und Fötus aus einem Frauenkörper in einer Landschaft als Teil einer idealisierten und als vergänglich inszenierten Natur. ${ }^{1}$ Jede dieser Abbildungen macht andere Strategien in der Darstellung von Sezierung sichtbar. Jede dieser Abbildungen konstruiert die Grenze zwischen Innen und Außen anders und markiert somit eine jeweils andere Schnittzone von anatomischen und ästhetischen Diskursen und Techniken mit Strategien der Produktion und Transmission von Wissen über den menschlichen Körper.

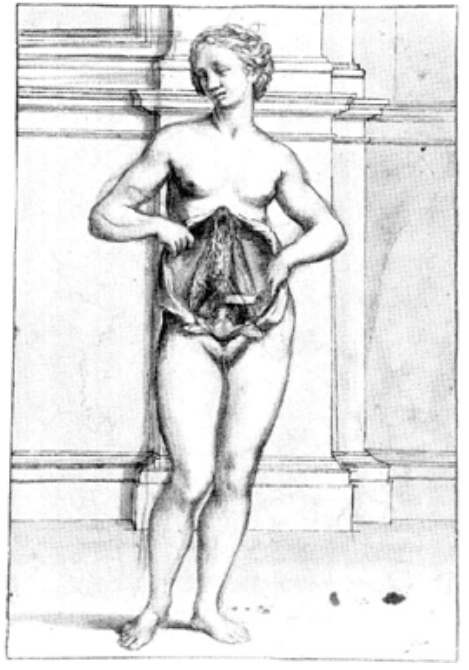

Abbildung 3: Sich selbst entfaltende Frau. Quelle: Cortona 1741.

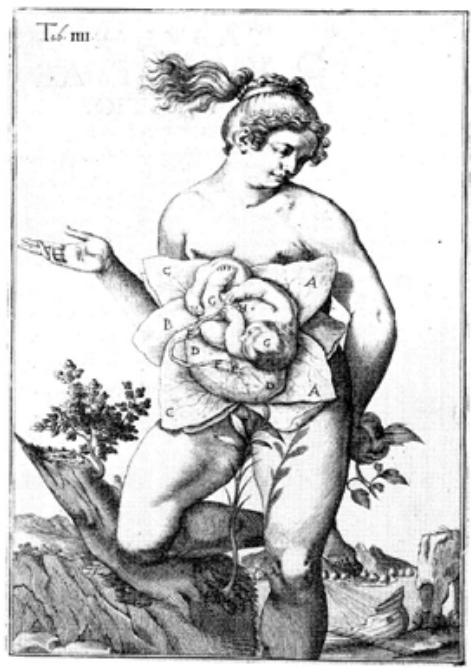

Abbildung 4: Entblätterter Fötus. Quelle: Spiegel 1926.

Der spezifisch anatomische Technikbegriff kann sich dabei sowohl aus den Instrumenten für die Sezierung herleiten, als auch aus dem Können des Anatom, aus der »Schnitttechnik «, die den gewünschten Einblick in den Körper gewährt und durch deren Beherrschung er als Spezialist wahrgenommen wird, sowie auch aus den medialen und kulturellen Repräsentationstechnologien, die das Denkbare und Darstellbare mit bedingen und Sezierung bzw. die Grenze zwischen Innen und Außen nach gewissen Regeln durchspielen und in Erscheinung treten lassen. So ist die anatomische Schau in den anatomischen Theatern eine statisch-geometrische, die sich auf die voluminöse Ausdehnung des toten Körpers im Raum hin zentriert. Um die

1 Nerven- und Venensystem in Andreas Vesalius De Humani Corporis Fabrica (1543); gehäutete Figur in Juan Valverde de Hamusco. Historia de la composicion del cuerpo humano (1556); sezierte Frauenfigur aus den Tabulae anatomicae des Pietro Berrettini da Cortona (1618-1620); sich selbst zeigende Figur von Adriaan van de Spiegel und Giulio Casseri. De formato foetu (1626). 
innere und äußere Ausdehnung des Körpers im Raum durch Wahrnehmung ermessen zu können, um die inneren Organe und äußeren Glieder im Rahmen der anatomischen Klassifikation lokalisieren und benennen zu können, wird der Körper skulptural durch den anatomischen Blick fixiert, was heißen soll still gelegt. In den Worten Anke Haarmanns impliziert die Erkenntnis des anatomischen Körpers demnach »seine Petrifizierung zur statischen Gestalt, nicht weil der Anatom traditionell die bewegungslosen Körper der Toten öffnet, sondern weil die anatomische Wahrnehmungsart eine statisch-geometrische ist « (140).

Die anatomische Schau trug sich jedoch nicht nur auf toten Körpern aus und bezog sich nicht nur auf das organisch definierte Material unter der Haut. Auch an lebendigen Menschenkörpern bzw. an unterschiedlichen Begriffen von Lebendigkeit kristallisierte sich seit dem 16. Jahrhundert zunehmend die Frage, wie Innen und Außen korrespondieren und wie der menschliche Körper in einem nicht theologischen Sinn spielerisch-technisch neu definiert und kontrolliert werden könnte.

In der Dissertatio de Actione Scenica von Franciscus Lang, die postum 1727 veröffentlicht wurde, tritt beispielsweise eine Topologie der Körperteile des Schauspielers in Erscheinung, die von eben dieser statuenhaften Wahrnehmung und Darstellung des Körpers als voluminösen Körper der Anatomie zeugt. In dieser Abhand-

\section{Figura 1,}

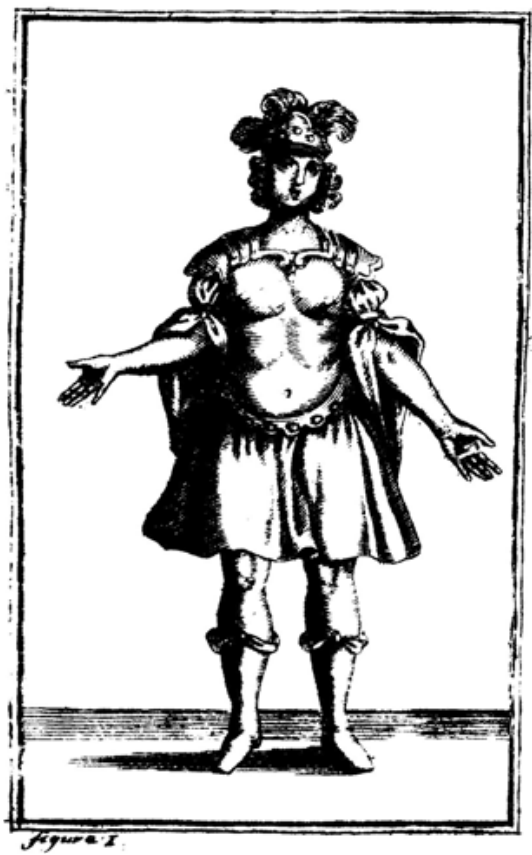
lung wird der Körper des Schauspielers im Sinne idealisierter Stellungen und Bewegungen von den Fußsohlen her aufgebaut. Sich an den Grundsätzen zur kunstvollen Darstellung >geschmackvoller Körperbewegungen und ausgesuchter Anordnungen der Glieder aus der Bildhauer- und Malkunst orientierend, mahnt Franciscus Lang zu Beginn seiner Dissertatio, ${ }^{2}$

»hauptsächlich auf diejenigen Körperteile $\mathrm{zu}$ achten, mit welchen sämtliche richtigen und natürlichen Bewegungen ausgeführt werden: zuerst auf die Fußsohlen und die Füße selbst; ferner auf die Knie, auf Stand, Schritt und Bewegung der Füße; dann auf die Hüften, Schultern und den eigentlichen Rumpf des Körpers; außerdem auf die Arme, Ellenbogen und Hände; ja sogar auf Hals, Kopf, Gesicht und Augen. Das allein ist schon über die Lage und Bewegung der Glieder zu lernen, ohne die Aussprache der Worte, worüber später zu sprechen sein wird« (1975: 169).

Abbildung 5: Figura I. Quelle: Lang 1975.

2 Die folgenden Zitate entstammen dem Neudruck von 1975. 
Die Abhandlung ist in 16 chronologisch nummerierten Paragraphen verfasst, wobei die Paragraphen 11 bis 15 vornehmlich dramentheoretische und dramaturgische Ausführungen beinhalten. In der ersten Hälfte der Abhandlung, in den Paragraphen vier bis sieben, wird der Körper »über die Fußsohlen und Füße«bis hin zum Haupt, dem >vornehmsten Teil des Menschen<, in Einzelteile zerschnitten und von unten her wieder aufgebaut. Die hier konstruierte und vermittelte Technik der Zerlegung des Körpers in einzelne Teile ist geprägt von einer statisch-geometrischen Schau, die besonders durch Langs Konzept des Bühnenkreuzes deutlich wird:

»Beim Niedersetzen der Fußsohlen also, was das erste ist, muß darauf geachtet werden, daß sie niemals in gleicher Richtung, sondern immer um ein beträchtliches von einander abgekehrt auf die Bretter gestellt werden, und zwar so, daß, während die Zehen des einen Fußes auf die eine Seite weisen, der zweite sich zur anderen wendet. Es sei erlaubt, diese Art des Stehens und Gehens künftig Bühnenkreuz zu nennen, damit wir einen Ausdruck haben, mit dem wir das Gemeinte anschaulich bezeichnen« (1975: 172).

Lang veranschaulicht das Konzept des Bühnenkreuzes mit der Darstellung einer falschen Stellung des Schauspielers (Abb. 5) und mit einer richtigen (Abb. 6). In ihnen kristallisiert das Verlangen, in der Flächigkeit des gewählten Repräsentationssystems, den Körper des Schauspielers nicht als frontale zweidimensionale Erscheinung, sondern in seiner Ausdehnung im Raum gemäß der Regeln der Perspektive aufzubauen. So fordert Lang anhand letzterer Figur, dass beide Arme sich nicht in gleicher Ausdehnung und in gleicher Weise bewegen sollen, sondern der eine sei höher, der andere gesenkter, der eine mehr gestreckt und gerade, der andere gebeugter, auch wenn er erhoben ist, während die Ellenbogen immer vom Körper entfernt gehalten werden. Das muss durchaus geschehen, und das beachten erfahrene Maler und Bildhauer in ihren Werken wohl (1975: 179).

Die Vorstellung von höfischem Spiel, also der Regeln höfischer Repräsentation und körperlichen Ausdrucks (vgl. Roselt), und der Anspruch an die körperliche Beredsamkeit aus der rhetorischen Tradition verbinden sich in Langs Schrift mit ästhetischen und anatomischen Techniken des Sezierens des menschlichen Körpers zur Bestimmung und Kontrolle der Anordnung seiner Glieder und Organe im Raum.

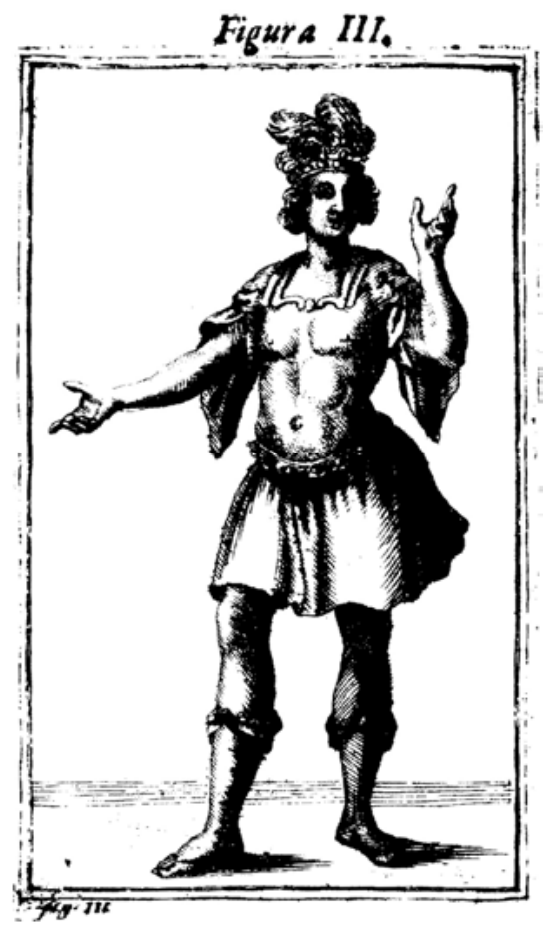

Abbildung 6: Figura III. Quelle: Lang 1975. 
Im Rahmen einer statisch-anatomischen Schau folgt die Schnitt- und Bautechnik bei Lang daher architektonischen Grundsätzen, die den Aufbau des idealen Schauspielers vom Fundament bis zum Dach, also von der Sohle bis zum Scheitel, bedingt. In den Ausführungen des Jesuitenpaters und Pädagogen verbindet sich ein explizit didaktisches Interesse an der Vermittlung von Körperwissen aus der Arbeit mit seinen Zöglingen im Schultheater mit einem instrumentellen Technikbegriff im anatomischen Sinne: Die Regeln und Instrumente der Sezierung dienen der Durchdringung, spielerischen Perfektionierung (im Sinne der Aristotelischen mimesis) und geometrisch-statischen Schau des im Raum ausgedehnten und sich im Raum bewegenden Körpers. ${ }^{3}$ Dabei bebildert das Körperäußere des Schauspielers idealiter die innere Bewegtheit seiner selbst und, durch die Gliederung der Bewegungen des äußerlich wahrnehmbaren Körpers, auch die innere Bewegtheit seiner Zuschauer. Augen und Gesicht des Schauspielers werden von Lang zum Spiegel par excellence der Affekte stilisiert:

»Hinsichtlich des Gesichts und der Augen aber, gleichsam dem wichtigsten Sitz der Affekte, [...] ist ganz allgemein festzuhalten, daß in ihnen die Gemütsverfassung des Schauspielers wahrgenommen und das Gefühl offenbar wird, das ihn innerlich bewegt oder das durch den Inhalt des Bühnenstückes hervorgerufen werden soll, so daß demgemäß auch die Zuschauer von ihm ergriffen werden« (Lang 1975: 190).

Der Körper des Schauspielers wird also, wie der Körper der sezierten menschlichen Figuren in den Abbildungen von anatomischen Büchern, ein Ort, an dem die Grenze zwischen äußerlich wahrnehmbaren und innerlich verborgenen Aspekten des Seins in representationem spielerisch-technisch verhandelt wird. ${ }^{4}$ Gleichzeitig schreibt sich in die entwickelte Technik die Konstruktion der Grenze ein, an der sie zu vermitteln vorgibt, sowie auch die Imagination eines abgeschlossenen Innenraums, einer Innerlichkeit.

Mit der Grenze und Korrespondenz zwischen sowie der Ausdehnung von Innen und Außen des menschlichen Körpers und anderer Materie hatte sich bereits René Descartes gut ein Jahrhundert vor der Veröffentlichung von Franciscus Langs Abhandlung beschäftigt. Während bei Franciscus Lang der anatomische Blick von außen den Körper petrifizierenden ästhetischen Spielregeln unterwirft, verhandelt Descartes das Konzept der Ausdehnung der Körper im Raum nicht nur statischgeometrisch von einem unangezweifelten Blick her, sondern auch physikalischabstrakt vom Inneren des Körpers her. Die Klärung der Korrespondenz zwischen Innen und Außen verlegt Descartes beim Menschen, bei dem für ihn Körper und Geist trotz substanzieller Trennung untrennbar vereint sind, in das Konzept von innerer Bewegung mit Hilfe von spiritus animales. Nach Descartes setzt der Geist die spiritus animales in Bewegung. Diese können wiederum

3 Mit ausführlichen Anweisungen und Übungsvorschlägen bringt Lang den zunächst statisch aufgebauten Körper insbesondere auch durch seine Ausdehnung und Stellung im Raum, in Bewegung. So entsprechen beispielsweise in der Grundposition die das Bühnenkreuz beachtet Fußstellung und Position der Arme der vierten Position im Tanz. Sie wird entsprechend auch als Ausgangspunkt für das Schreiten durch den Bühnenraum beschrieben.

4 Vgl. Schwarte: 77, »Zu den experimentellen architektonischen Operationen zählt natürlich auch die Reduktion des theatralen Raumes auf die Dimension der Zeichnung, des Stichs, der Abbildung «. 
»auch die Glieder zu Bewegungen veranlassen [...], die ebenso verschiedenartig sind und auf äußere Eindrücke und innere Erregungen ebenso treffend antworten wie die unwillkürlichen Bewegungen unserer Glieder. Dies wird dem keineswegs sonderbar vorkommen, der weiß, wie viele verschiedene Automaten oder bewegungsfähige Maschinen menschliche Geschicklichkeit zustandebringen können, und dies unter Verwendung nur sehr weniger Einzelteile verglichen mit der großen Anzahl von Knochen, Muskeln, Nerven, Arterien, Venen und all den anderen Bestandteilen, die sich im Leib jedes Tieres finden. Er wird diesen Leib als eine Maschine ansehen, die aus den Händen Gottes kommt und daher unvergleichlich besser konstruiert ist und weit wunderbarere Getriebe in sich birgt als jede Maschine, die der Mensch erfinden kann« (Descartes: 91).

Das Konzept innerer Bewegtheit, der Affekte (passions) - hier mit Erregungen übersetzt - wird bei Descartes auf eine physikalische Grundlage im Sinne einer Körpermechanik gestellt. In seinem Gedankenexperiment spielt er die Möglichkeit durch, dass Gott den Menschen wie eine Maschine geschaffen haben könnte, die er in Bewegung setzte. Der Geist, substanziell von dieser Maschine getrennt und Unterscheidungsmerkmal für den Mensch von Tieren oder Automaten, bedarf der ihr immanenten Körpermechanik. Ihr liegt das Automatenkonzept der Räderuhr zugrunde, die sich, einmal aufgezogen, von selbst bewegt. Sie bildet in Descartes' Schriften einen Begriffskomplex, der nicht nur metaphorisch zu deuten ist, sondern in Wechselwirkung steht mit der Automatenbaukunst seiner Zeit und Einfluss nimmt auf den sich entwickelnden Technikbegriff und die Popularität menschenähnlicher Automaten, oder Androiden, in der höfischen Spielkultur und auf den merkantilen Messen des 18. Jahrhunderts (vgl. Fleig: 117-130). Geht bei Lang der anatomisch-architektonische Technikbegriff einher mit der Vorstellung einer idealisierten und perfektionierten Spiegelung innerer Affekte im äußeren Ausdruck und in dessen Schau, ist im Gedankenexperiment Descartes der anatomisch-architektonische Technikbegriff gekoppelt an eine mechanistische Definition von Körperlichkeit und an einen »Innenraum des imaginären Kontrastes zum Körperlichen « (Schwarte 2003: 89).

In seinem »Essay on the Art of Acting «, der 1753 drei Jahre nach seinem Tod und eine Generation nach Langs Text in London erschien, konstruiert Aaron Hill (1685-1750) den mechanisch definierten Körper, der bei Descartes im Gedankenexperiment noch als von Gott in Kopie des natürlichen Menschen geschaffen erscheint, als Ideal, das vom Schauspieler zu bedienen und zu perfektionieren ist: ${ }^{5}$

»1st, The imagination must conceive a strong idea of the passion.

2ndly, But that idea cannot strongly be conceived, without impressing its own form upon the muscles of the face.

3dly, Nor can the look be muscularly stamp'd, without communicating, instantly, the same impression, to the muscles of the body.

4thly, The muscles of the body ... must, in their natural, and not to be avoided conse-

5 Aaron Hill, Lyriker und Autor von insgesamt 17 Dramen, wurde im Alter von 24 Jahren Leiter des Theatre Royal, Drury Lane, in London und produzierte dort die Premiere der Händel-Oper RINALDO. Seine Aufsätze, Briefe und Gedichte wurden 1753 posthum veröffentlicht, darunter auch das hier zitierte »An Essay on the Art of Acting $\ll$. 
quence, by impelling or retarding the flow of the animal spirits, transmit their own conceiv'd sensation, to the sound of the voice, and to the disposition of the gesture.

And this is a short abstract of the Art, in its most comprehensive and reduced idea « (356).

Diesem »abstract « folgen zehn »applications«, Anwendungen, der hier beschriebenen Körpermechanik für jene zehn Arten von innerer Bewegtheit, welche Hill als »Dramatic Passions « bezeichnet: »Joy, Grief, Fear, Anger, Pity, Scorn, Hatred, Jealousy, Wonder, and Love« (357).

Damit setzt Aaron Hill für seine Abhandlung über Schauspielkunst Descartes Erklärung der inneren Körpermechanik durch spiritus animales als Körperwissen voraus. Der Technikbegriff ist hier nicht mehr angelehnt an das anatomische Instrument, das den Körper durchdringt, sondern der Körper selbst hat a priori eine Technizität, die wissbar, erfahrbar und perfektionierbar ist. Geht es bei Lang noch um die Perfektionierung der Natur des anatomischen Blicks im architektonischen Raum mit höfischen Spielregeln, so lässt Aaron Hill die mechanische Kopie des Menschen aus Descartes Gedankenexperiment als das Vorbild für das Original erscheinen. Der Körper wird zum Instrument, das der Schauspieler bedienen, spielen und perfektionieren lernen muss.

Mit der Gründung von Schauspielakademien in Europa, wie beispielsweise Konrad Ekhofs Schweriner Akademie (1753), wird dieses Verständnis des Schauspielerkörpers als ein nach »natürlichen « Regeln funktionierendes Instrument, wird die Epistemologisierung der Expressivität des Schauspielers im Verhältnis zu seinen nicht einsehbaren innerkörperlichen Vorgängen rationalisiert und institutionalisiert (vgl. Roselt). Ein Residuum der kulturellen Praktiken, die um die Grenze zwischen Innen und Außen des menschlichen Körpers in den anatomischen Theatern des 16. und 17. Jahrhunderts kristallisierten spielen sich seither auf den Körpern der sogenannten professionellen Schauspieler in der europäischen Tradition aus. Der »Wahrheitskörper« des Schauspielers wird auf der historisch immer wieder neu definierten Grenze zwischen Innen und Außen imaginiert, die ein Faszinosum in der Auseinandersetzung mit dem materialen Körper darstellt und wechselweise mit dem Tod, sozialen und religiösen Tabus oder einem außergewöhnlichen Status innerhalb der gesellschaftlichen Ordnung assoziiert wird.

Beansprucht Sawday diese Sonderstellung für den Anatom, »a rare cultural status as mediator between the exterior and the interior worlds « (12), so nimmt der Schauspieler diese Sonderstellung gleich in doppeltem Sinne ein: Einerseits ist er der Leib, das Material das sich in representationem dem Blick des Zuschauers zur Verfügung stellt, andererseits ist er auch der Anatom, der chirurgische Spezialist, der über eine Technik und über Körperwissen verfügt, mit welchen er seinen eigenen Körper sozusagen bei lebendigem Leibe durchdringt; nicht um Wissen für die medizinische Behandlung und Heilung anderer $\mathrm{zu}$ ermöglichen, sondern um Wissen über die physische Kontrolle von Affekten in öffentlichen Darstellungen zu vermitteln. Das Ziel der Technik, nämlich die Deckung von Affekt und körperlichem Ausdruck, das bereits bei Franciscus Lang in der Spiegelfunktion von Augen und Gesicht in Erscheinung tritt, wird aber in der spielerischen Praxis nicht immer nur einfach angestrebt oder gar erreicht. Gerade in der spielerischen Überschreitung oder Subversion des jeweiligen Technikbegriffs werden Schauspieler wie auch Betrachter auf das Imaginierte zurückgeworfen. Der sich fortschreibende Mythos der Innerlichkeit und das dem Regelwerk entgleitende oder dieses überschreitende Spiel führen immer wieder zu einer Suche nach einem künstlerischen Mehr, das der technischen Beschreibung entgeht. Der Schauspieler kann seine Haut nicht 
vor den Zuschauern sezieren oder abziehen, um einen tieferen Einblick in die innere Beschaffenheit des menschlichen Körpers spielerisch-technisch zur Schau zu stellen. Wohl aber kann man anhand historischer Langzeitprozesse nachvollziehen, wie der Schauspieler in den Schauspielpoetiken zum Instrument und Spezialisten zugleich avanciert und Schauspielkunst als erlernbar institutionalisiert wird. Die Leitbegriffe der Schau, des Spiels und der Technik könnten sich in einer weiteren Konturierung dieses Langzeitprozesses als dienstbar erweisen.

\section{Literatur}

Calbi, Maurizio (2005): Approximate Bodies. Gender and Power in Early Modern Drama and Anatomy. London: Routledge.

Cortona, Pietro da (1741): Tabulae anatomicae a Pietro Berrettini Cortonensi et a Cajetano Pietrioli Roman, Romae: Impensis Fausti Amidei, Ex typographia Antonii de Rubeis.

Descartes, René (1990): Von der Methode des richtigen Vernunftgebrauchs und der wissenschaftlichen Forschung. Franz.-dt., übers. u. hg. v. Lüder Gaebe, Hamburg: Meiner.

Fleig, Anne (2002): »Automaten mit Köpfchen. Lebendige Maschinen und künstliche Menschen im 18. Jahrhundert«. In: Annette Barkhaus/Anne Fleig (Hg.): Grenzverläufe. Der Körper als Schnitt-Stelle. München: Fink, S. 117-130.

Haarmann, Anke (2001): »Der Körper des Menschen als Vorstellung und Simulationsmodell. Das > Visible Human Project««. In: Andreas Lösch u.a. (Hg.): Konstruktionen von Wissen, Medien und Körpern. Heidelberg: Synchron, S. 7-20.

Hill, Aaron (1753): »Essay on the Art of Acting«. In: Ders.: The works of the late Aaron Hill. Vol IV, London: Printed for the benefit of the family.

Lang, Franciscus (1727): Dissertatio de actione scenica, cum figuris eandem explicantibus, et observationibus quibusdam de arte comica. München: Riedlin.

Lang, Franz (1975): Abhandlung über Schauspielkunst, übers. und hg. von Alexander Rudin. München: Francke.

Lösch, Andreas u.a. (2001): »Technologien als Diskurse - Einleitung «. In: Dies.: Konstruktionen von Wissen, Medien und Körpern. Heidelberg: Synchron, S. 7-20.

Roselt, Jens (2005): Seelen mit Methode. Schauspieltheorien vom Barock- bis zum postdramatischen Theater. Berlin: Alexander.

Schramm, Helmar/Ludger Schwarte/Jan Lazardzig (Hg.) (2003): Kunstkammer, Laboratorium, Bühne. Schauplätze des Wissens im 17. Jahrhundert. Berlin: de Gruyter.

Sawday, Jonathan (1996): The Body Emblazoned. Dissection and the Human Body in Renaissance Culture. London: Routledge.

Schwarte, Ludger (2003): »Anatomische Theater als experimentelle Räume«. In: Helmar Schramm/Ludger Schwarte/Jan Lazardzig (Hg.): Kunstkammer, Laboratorium, Bühne. Schauplätze des Wissens im 17. Jahrhundert. Berlin: de Gruyter, S. 75-102.

Spiegel, Adriaan van de/Casseri, Giulio (1626): De formato foetu liber singularis. Padua: Io. Bap. de Martinis \& Livius Pasquatus.

Valverde de Amusco, Juan (1556): Historia de la composicion del cuerpo humano. Roma: Impressa por A. Salamanca, y A Lafrerij.

Vesalius, Andreas (1543): De humani corporis fabrica libri septem. Basileae: Ex officina Ioannis Oporini. 



\title{
SCHAUSPIEL DURCH MEDIEN. DiE VERDECKTE FUNKTION DER TECHNE BEI Konstantin Stanislawski Und Alexander MoIssi ${ }^{1}$
}

\author{
WOLF-DIETER ERNST
}

Schauspiel durch Medien: Ein Plädoyer, die theatrale Repräsentation als rhetorische Techne zu begreifen

In aktuellen Inszenierungen der etablierten Theater wird der Schauspieler mehr denn je von Medienapparaten begleitet. Dabei scheinen sich zwei Verfahren des Medieneinsatzes herauszubilden. Zum einen der Einsatz als dramaturgisches Mittel, zum anderen der Einsatz als rhetorische Technik. Als dramaturgisches Mittel dienen mediale Effekte der Darstellung, helfen den Spannungsbogen zu etablieren. Als rhetorische Technik sind Medien selbst der Raum der schauspielerischen Darstellung. Sie sprengen die geschlossene Form auf und spielen sich selbst als QuasiAkteur in den Vordergrund.

Im Folgenden geht es nun nicht um die Wiederaufnahme möglicher normativer Bestimmungen oder gar um eine Wertung dieser Verfahren, sondern um Medientechnik als eine darstellungstheoretische Größe. Jede Darstellung erfordert und aktualisiert immer bereits technisches Denken und Entwerfen. Die jeweiligen apparativen Konfigurationen, die Leinwände, Bildschirme und Lautsprecher auf der Bühne sind dann lediglich als spezifische Ausformulierungen dieses Denkens anzusehen. Rhetorische Technik unterscheidet sich also von technischen Mitteln, indem sie sich keinem Zweck fügt, sondern selbst >mit spricht<, selbst beredt ist. Dies hat freilich Folgen für die Darstellung und das Dargestellte: Als Technik mit Mitspracherecht ist sie nicht ersetzbar durch ein anderes Bühnenmittel, ohne die Darstellung grundlegend zu ändern. Um diesen zwingenden Zugriff auf Technik soll es in der folgenden Betrachtung zur Schauspieltechnik gehen. Man könnte die Rhetorizität der Technik - die von den alten rhetorischen Körpertechniken bis zu neusten Medientechniken reichte - als Schauspiel durch Medien bezeichnen, um klar zum Ausdruck zu bringen, dass die Technisierung und Medialisierung notwendige Bedingungen der Darstellung und des Nachdenkens über die Darstellung waren und sind. Von Schauspiel durch Medien wäre die begriffliche Addition Schauspiel und Medien zu unterscheiden, in welcher Medien als optionale Mittel eines an sich unveränderlichen Darstellungsmodells genutzt werden.

Die rhetorischen Mittel ließen sich niemals auf technische Effekte im Sinne der Industrie reduzieren, sondern waren immer auch Techne, d.h. Wissen, Listen und Verfahren im Sinne der Künste. ${ }^{2}$ Wie Anselm Haverkamp erläutert, ist

1 Dies ist eine gekürzte Fassung eines Textes, der im Forum Modernes Theater. 1/2007, S. 33-46 erschienen ist. Ich danke an dieser Stelle Christopher Balme, Gabriele Brandstetter, Günter Heeg und Petra Maria Meyer für wichtige Anregungen, Jens Malte Fischer für seine Hilfe bei der Materialbeschaffung im Terrain historischer Aufnahmen. 
»Technik keine Entwicklung des offenkundigen Funktionierens oder Nichtfunktionierens [...], sondern - rhetorisch, wie sie ist - die Geschichte eines weitgehend verdeckten Funktionierens. [...] Das rhetorische Axiom, das in der technischen Halbierung der Rhetorik [auf >persuasive Kommunikation $<$ und >Anwendung<, W.D.E.] verdeckt liegt, besteht in nichts anderem - nicht mehr und nicht weniger - denn der prinzipiellen Verdecktheit der Mittel aller Rhetorik oder, genauer, dem dialektischen Wechselspiel von Verdeckung und Aufdeckung in der Mittelbarkeit rhetorischer [...] Mittel« (Haverkamp: 77).

Haverkamp verdeutlicht diesen Befund am Beispiel der Pygmalion-Geschichte, deren Pointe darin bestünde, den Effekt der Verlebendigung des Marmors in Form der Statue nicht nur vorzuführen, sondern ihn als Verfahren zu beschreiben, in Szene zu setzen. Dieser Prozess der In-Szene-Setzung kann jedoch nur als Latenz von Sein und Schein gelingen, in der »ästhetisch perfekten, untergründig unheimlichen Belebung der Phantasmen« (ebenda).

Die Kunst bestehe also darin, ihre eigene Technik in die Latenz von Zeigen und Verbergen zu bringen, was so ziemlich das Gegenteil der aktuellen Debatte um >die Medien< und deren Präsentationsleistung darstellt. Die Frage wäre daher, ob in aktuellen Inszenierungen tatsächlich Experimente gewagt werden, die sich diesem verdeckten Funktionieren der Technik widmen, die Latenz erzeugen, oder ob lediglich der mediale Effekt vom Schauspieler verstärkt wird. Werden die Mittel ausgereizt, gar erweitert, oder helfen mediale Apparaturen dort aus, wo der dramaturgische Bogen des Literaturtheaters nach einer affektiven Intensität ruft, die sich mit der Deklamation der Verse nicht mehr einstellen will?

Eine grundlegendere Problematisierung der Technik müsste also den Aspekt der Nicht-Verfügbarkeit von Technik als einem wesentlichen Charakteristikum künstlerischer Experimente stark machen. Im Moment der Nicht-Verfügbarkeit, dem verdeckten Funktionieren der Technik, sehe ich daher auch die Parallele von >neuerer $<$ Szenografie mit audiovisuellen Medien und >älterem $<$ Schauspieler-Theater, die im Folgenden mein Thema sein werden: Beide Darstellungsweisen können als rhetorische Technik auf die Momente ihrer verdeckten Funktion hin betrachtet werden.

Wie aber sieht diese verdeckte Funktion der Körpertechnik des Schauspielers aus? Diese Frage soll hier auf die visuelle Rhetorik des Schauspiels, die Arbeit mit den so genannten »Vorstellungsbildern ${ }^{3}$, bzw. den Bildkonzepten der antiken Mnemotechnik eingegrenzt werden. Was wird im Akt der Rollenverkörperung übertragen? Die Norm des Literaturtheaters würde dies etwa wie folgt festschreiben: »Der Sprechende lässt die befreiende und formende Kraft des dichterischen Werkes auf sich einwirken und umgekehrt das Kunstwerk durch seine Persönlichkeit Gestalt werden« (Aderhold: 22, Kapitel »Atmung und Dichtung «).

2 Techne bezeichnet »jede Art von Können, Geschicklichkeit, Kunst(fertigkeit) und [...] Wissen « (Der kleine Pauly: 552); Technitai wurden im frühen Hellenismus die so genannten »Festkünstler « genannt, zu denen »Schauspieler von Tragödien, Komödien, Satyrspiel, Choreuten, Chorlehrer, Tänzer, Sänger und Instrumentalmusiker aller Art, Herolde, Dichter Kostümverleiher und Bühnenrequisiteure« gehörten (ebenda). Vgl. auch zum Verhältnis von Technik und Künsten: Börringer: 10.

3 Konkret zu finden bei Stanislawski (1981a: 85, auch Anm. 20), worin der Begriff der >inneren Vorstellungsbilder auch auf akustische Eindrücke ausgedehnt wird und mit dem Konzept des emotionalen Gedächtnisses in Beziehung gebracht wird. Stanislawskis Rekurs auf Bilder ist zudem durch die Medientechnik seiner Zeit beeinflusst, etwa wenn er die Reihe von Vorstellungsbildern als »Film« umschreibt. 
Aber dieser Mechanismus zwischen Dichterwerk und Bühnengestalt funktioniert so nicht. Was jede Praxis anschaulich macht und jede Dialektik von Innen und Außen in der Schauspieltheorie schon formulierte, ist doch dies, dass es in der Arbeit an der Rolle immer um spezifische Über- und Unterbietungen eines idealen Modells gehen muss, mithin also um Experimente mit per se offenem Ausgang. Man schaut sich die x-te Wiedergabe einer bekannten Rollenfigur ja nur deshalb an, weil es immer auch um die spezifische Übertragung selbst geht. Man muss also im Sinne der rhetorischen Technik die Latenz der Übertragung selbst als eine Darstellung der Darstellung bedenken.

Diese Latenz der Übertragung kann auf die Körpertechnik des Schauspielers bezogen unter dem bildrhetorischen Begriff der visuellen Energie diskutiert werden. Das mediale Szenario und die mediale Problematik bestehen dann genauer gesagt in dem Vorhaben, die visuelle Energie des Vorstellungsbildes als ein Mittel der Übertragung nutzen zu wollen und - so die Eigenlogik der Medien - nicht auf einen Nutzen reduzieren zu können.

Wie Schauspiel als Arbeit mit visueller Energie funktioniert, werde ich in drei Schritten entwickeln:

- Erläuterung zur visuellen Energie als einer rhetorischen Technik;

- Funktion dieser Technik in der Darstellungstheorie am Beispiel Stanislawski;

- Wirkung dieser Technik in Franz Kafkas Beschreibung eines Auftritts von Alexander Moissi (1912).

\section{Visuelle Energie als rhetorische Technik}

Energie ist eine Relation. Dies zeigt die vielschichtige Entstehungsgeschichte der Mnemotechnik ebenso wie die semantische Überkreuzung von energeia und enargeia, bzw. deren durch Cicero erfolgten lateinischer Übersetzung als evidentia. ${ }^{4}$ Immer geht es dabei um ein Wechselspiel an sichtbarer Form, bzw. sichtbarem Eindruck, und basaler Kraft oder Grundlage der Sichtbarkeit.

In der AUSBILDUNG DES REDNERS beschreibt Quintilian die Arbeit mit visueller Energie am Beispiel einer Rede vor Gericht in einem Bild:

»Ich habe Klage zu führen, ein Mann sei erschlagen. Kann ich da nicht all das, was dabei, als es wirklich geschah, vermutlich vorgefallen ist, vor Augen haben? Wird nicht plötzlich der Mörder hervorbrechen? Nicht das Opfer voll Angst aufschrecken? Wird es schreien, bitten oder fliehen? Werde ich nicht den Schlag fallen, das Opfer zusammenbrechen sehen? Wird sich nicht sein Blut, seine Blässe, sein Stöhnen und schließlich sein letzter Todesseufzer meinem Herzen tief einprägen?« (Quintilian: 711)

Quintilian malt ein Schreckensbild aus, dramatisiert den Fall vor Gericht über tatsächliche oder eben vorgestellte visuelle Details. Angesprochen ist hier die Kraft

4 Rüdiger Campe (230) weist darauf hin, dass die Aristotelische energeia einem ontologisch-dynamischen Sprachkonzept entstamme und zunächst einmal eine Bewegung meine. Die enargeia hingegen sei immer schon visuell gedacht. Das Konzept gehe auf die Stoiker zurück und beschreibe im Sinne eines repräsentationslogisch-statischen Sprachkonzepts die Deutlichkeit, Klarheit einer Sache: Eine Sache, die deutlich und klar ist, habe einen bleibenden, materiellen Abdruck auf die Seele, gleich einem Siegelstempel. 
der Vorstellungsbilder, eine eigene Realität zu suggerieren, einen anderen Aufmerksamkeitszustand zu generieren, den $>$ Fall zu gebieten $<$, wie es im lateinischen Lehrsatz fortis imaginato generat causum heißt. ${ }^{5}$ Diese Kraft der meist gewaltsame Szenen beinhaltenden Vorstellungsbilder macht man sich in der Schauspielausbildung zu nutze. Dabei geht es überhaupt noch nicht um Überredung oder Manipulation des Zuschauers, wie ein häufig geäußerter Verdacht der Rhetorik gegenüber lautet. Die Kraft, den Fall zu gebieten, wird tatsächlich als Prinzip der Aufladung gedacht, ist der Beginn eines Darstellungsprozesses, nicht die Darstellung selbst. Die bedarf, um zu gelingen, immer eines Maßes, einer Hemmung sowie des Abgleichs der Wirkung an den Reaktionen jener, die über den Fall zu Gericht sitzen.

Das Verfahren Quintilians wird von Konstantin Stanislawski aufgenommen. In DIE ARBEIT DES SCHAUSPIELERS AN SICH SELBST lässt er einen fiktiven Schauspielschüler zum Zeugen eines Verkehrsunfalls werden, um zu zeigen, wie dieser schreckliche Anblick zur überzeugenden Darstellung einer pathetischen Szene zu nutzen wäre. So berichtet der Schüler:

»Vor mir lag in einer großen Blutlache ein alter Bettler mit zermalmtem Unterkiefer. Die Hände und ein halber Fuß waren abgetrennt worden. Das Gesicht des Toten sah furchtbar aus, der gebrochene Unterkiefer mit den alten, faulen Zähnen war ausgerenkt und hing vor dem blutigen Schnurrbart. Die Hände lagen getrennt vom Körper, und es sah aus, als hätten sich die Arme in die Länge gezogen und vorgestreckt, um Gnade zu erflehen. Der eine Finger stand empor, als drohe er irgendwem. Die Schuhspitze mit Knochen und Fleisch lag auch für sich. Der Straßenbahnwagen stand neben seinem Opfer und wirkte riesig und furchtbar. Wie ein Tier schien er die Zähne zu fletschen und den Toten anzufauchen« (Stanislawski 1981a: 196).

Die Parallelen zur visuellen Detailtreue des von Quintilian beschriebenen Totschlags sind auffallend. Die Zergliederung des ganzen Körpers, die Farbsymbolik, die hier bemüht wird, ebenso wie die Geste der flehenden Hände wirkt geradezu malerisch komponiert und zielt auf maximale Schock-Wirkung. Das Auge soll überquellen wie eine Schale.

Mit dem Perspektivenschwenk auf die Straßenbahn finden wir auch das Mittel der Verlebendigung. Die Maschine wird zum Raubtier, das nach erfolgreicher Hatz, bereits eingeleitet durch die doppelte Verlebendigung der Leichenteile (die flehenden Hände, der drohende Finger), sein Mahl einnimmt. Der Aufbau dieses Bildes folgt der Sinnfigur der Augenscheinlichkeit, der energeia: Eine Darstellungsweise, der es gelingt, das Dargestellte detailliert und energetisch, d.h. in Wirksamkeit begriffen, vorzuführen. ${ }^{6}$

5 Sie geht zurück auf die von Aristoteles in DE ANIMA entwickelte Idee der Vorstellungsbilder, die das Denken notwendig begleiten und es vermögen, die Seele in der gleichen Weise zu bewegen, als stünden die wirklichen Dinge vor Augen. »Der denkenden Seele sind die Vorstellungsbilder wie Wahrnehmungseindrücke gegeben. Wenn sie sie als gut oder schlecht bejaht oder verneint, so flieht oder erstrebt sie sie. Darum denkt die Seele niemals ohne ein Vorstellungsbild « (Aristoteles 1950: 336).

6 Aristoteles zeigt dies bei Homer auf, wenn jener Unbeseeltes als Beseeltes darstellt, etwa vom »stürmenden Erz« spricht, der »die Brust durchbohr« (Aristoteles 1980: $1411 \mathrm{~b}, 24 \mathrm{ff})$. 


\section{Arbeit mit visueller Energie im System der Verkörperung nach Stanislawski}

Die Arbeit mit Vorstellungsbildern wird von Stanislawski unter dem Begriff des affektiven Gedächtnisses entwickelt. Es macht jedoch wenig Sinn, die visuelle Energie bei Stanislawski allein an diesem Element aufzeigen zu wollen. Denn diese Form des Gedächtnisses, welches in speziellen Erinnerungsaufgaben zu trainieren sei, kann leicht als Motivationsinstrument des Schauspielers missverstanden werden - und wurde in seiner Rezeption durch Lee Strasberg auch als emotionales Gedächtnis verkürzt. Die visuelle Energie jedoch durchzieht alle Stufen des Systems und dies deshalb, weil sie sich jeweils an szenischen Details heraus kristallisiert. Zwei konkreten Darstellungsaufgaben können diese Schauspieltechnik verdeutlichen: die Entwicklung szenischer Spielideen und die Gestaltung einer lebendigen Sprache auf der Bühne. Dabei beziehe ich mich auf Stanislawskis Lehr-Inszenierung von Molières TARTUFFE, an der der Theaterpädagoge bis zu seinem Tode 1938 arbeitete und von denen wir umfangreiche Probenskizzen haben, die sein Lieblings-Schauspieler Wassili Ossipowitsch Toporkow verfasste.

Die Entwicklung szenischer Spielideen muss man sich ganz konkret vorstellen. Im TARTUFFE etwa wollen die Verwandten den verblendeten Orgon daran hindern, seine Tochter Marianne unglücklich zu verheiraten. Die Ereignisse überstürzen sich, als Orgon bereits mit dem fertigen Kontrakt durchs Haus eilt und jeden Moment auf der Szene erscheinen wird. Wie aber stellt man Erregung, stürmische Beratung und Handlungsdruck einer Menschenmenge dar, ohne Chaos zu verursachen? Stanislawski wählt dafür das Bild des »Verrückten mit einem Messer«. »Er sucht seine Tochter, um sie zu erstechen.« Er dramatisiert also den Fall, um ihn sogleich an konkreten Details plastisch zu machen.

»Durch welche Tür kann der Verrückte eindringen? Auf diese Tür konzentrieren Sie Ihre ganze Aufmerksamkeit oder, noch besser, nicht auf die Tür, sondern auf ihre Messingklinke« (Toporkow: 480).

Als diese Anweisung noch nicht die gewünschte szenische Dynamik zeitigt, löst sich Stanislawski von der Textvorlage und erfindet ein Spiel:

»Niemand der im Zimmer Anwesenden hat das Recht, sich von der Stelle zu rühren, bevor sich die Türklinke bewegt. Verstecken Sie [das Mädchen], wohin sie wollen, aber machen Sie es so, daß sie verschwunden ist, wenn die Tür aufgeht« (ebenda).

Das Schreckensbild der Verrückten mit dem Messer ist also in zwei Schritten in eine szenische Aktion übersetzt worden. Zunächst wird ein visuelles Detail (die Klinke) zum Träger des Affekts, sodann wird dieses Detail zum Auslöser und ZeitRahmen eines Spiels (Verstecken der Marianne).

Die Pointe ist natürlich, dass das Spiel nicht gewonnen werden kann, dass wir es also mit einem Affekt und einer Aufladung der Bewegung zu tun haben, die sich gerade aus dem Nicht-Gelingen speist. Das steht im Widerspruch zu allen Überlegungen von der Maßhaltigkeit und der harmonischen Form, die Stanislawski an anderen Stellen propagiert und als »Überaufgabe « aus der literarischen Vorlage heraus präparierte. Wie das Beispiel zeigt, gibt es nur die Alternative zwischen affektiver Entladung im Spiel und der Deklamation des Textes. 
Die experimentelle Offenheit zeigt sich jedoch auch in der Arbeit am Vers selbst, also an jener Vorschrift, die eigentlich die Systematik und Hierarchie der Theatermittel garantieren soll. Auch für das Sprechen empfiehlt Stanislawski den Einsatz der dramatisierenden Vorstellungsbilder als Subtext der gesprochenen Verse. Die Kontrahenten Cleant und Orgon mögen sich so verhalten, als säßen sie »auf der heißen Herdplatte« (Toporkow: 503). In der daraus resultierenden Hitze sollen auch die Verse vorgebracht werden, und wieder geht es bis ins Detail einzelner Kommata.

»Sie machen in dem Satz $>\mathrm{Ja}$, würden Sie den Mann nicht lieben, Schwager $<$ hinter $>\mathrm{Ja}<$ eine Pause. [...] Welchen Gedanken will Orgon denn hier ausdrücken? $>$ Ja, würden Sie den Mann nicht lieben, Schwager, den Sie getroffen hätten wie ich ihn?< Sie liebten ihn, statt ihn zu hassen, das will Orgon hier sagen. Warum sollte er also eine sinnlose Pause hinter $>\mathbf{J a}<$ machen? Das haben Sie sich zur Ausschmückung der Phrase ausgedacht« (Toporkow: 500).

So Stanislawski kolportiert durch Toporkow. Die Situation auf der Herdplatte verträgt sich nicht mit der Ausschmückung, welche Stanislawski an anderer Stelle auch als die »rhetorischen Ergüsse Cleants« erkennt und welche überwunden werden müssten. Die Ironie des Systems freilich liegt nun darin begründet, dass Stanislawskis Idee einer lebendigen Sprache wiederum der antiken rhetorischen Konzeption der energeia entspricht, also der Rede, die die Dinge scheinbar vor Augen stellt.

In eben jener Weise der Quasi-Übertragung der Dinge im Bild gestaltet Stanislawski das Deklamieren der Repliken, wenn er den Schauspielern rät, »sich gegenseitig mit Vorstellungsbildern« (Toporkow: 506) zu überschütten.

»Sehen Sie den Augenausdruck mit denen [ihr Partner] sie anschaut. Sie müssen erreichen, daß dieser Ausdruck anders wird, daß sein Blick sich aufhellt. Sie müssen ihm Ihre Vorstellungen vermitteln. Er muß alles mit Ihren Augen sehen« (Toporkow: 502).

Stanislawski denkt die Repliken tatsächlich als eine Art Containerverkehr, mit dem sich visuelle Energie übertragen lässt und die das »lebendige Wort « entstehen lässt. Aber wiederum geht seine Beschreibung des Darstellungsvorgangs über das intendierte Ziel hinaus. In metaphorischer Beschreibung sagt er an anderer Stelle: »Das lebendige Wort besitzt einen inneren Gehalt, es hat ein bestimmtes Gesicht « (Stanislawski 1981b: 49). Was Stanislawski hier als Gesicht bezeichnet, ist freilich nichts anderes als die Medialität des gesprochenen Wortes selbst, wie sie nach der sprechtechnischen Analyse erscheint. Vergessen wir nicht, dass Stanislawski auch Gesangsunterricht nahm, sich in Operettenrollen versuchte und entsprechend einen musikalisch-analytischen Zugriff auf Lautbildung und Stimmsitz kannte. ${ }^{7}$ In den entsprechenden Passagen zur Artikulation spricht er auch davon, »den Ton so weit wie möglich in die Maske zu verlegen « (Stanislawski 1981b: 39-107), also in die Resonanzräume des Kopfes zu verlegen, damit der Ton verstärkt hervor tritt. Aber das Wort selbst wird nicht nur im Gesicht geformt und vom Dialogpartner aufgenommen, es tritt - und darauf kommt es an - gleichsam als ein Drittes zwischen die Dialogpartner. Um dieses Dritte, dieses Dazwischen zu beschreiben, braucht man Medientheorie. Denn es geht um eine Übertragung, die es schafft, als Übertragung

7 Vgl. Stanislawski 1981b, Abschnitt Stimme und Sprechen, S. 39-107, und Anm. 5; ferner S. 281ff. (= Über die Musikalität des Sprechens). 
selbst sinnstiftend zu sein, eigene >Gesichter-Worte $<$ zu kreieren. Diese Worte, die uns mit einem »bestimmten Gesicht « anblicken, sind jedoch nichts anderes als Sprach-Bilder, also wiederum energetische Überschüsse einer rhetorischen Technik, die den literalen Wortgehalt überborden.

\section{Moissi rezitiert: Ein Szenario der Übertragung}

Eben diesem energetischen Überschuss der Übertragung sieht sich am 28. Februar 1912 Franz Kafka ausgesetzt, als er einen Vortragsabend des Reinhardt-Schauspielers Alexander Moissi besucht. Drei Tage später notiert er in seinem Tagebuch

»Er [Moissi] sitzt scheinbar ruhig, hat womöglich die gefalteten Hände zwischen den Knien, die Augen in dem frei vor ihm liegenden Buch und lässt seine Stimme über uns kommen mit dem Athem eines Laufenden $\ll\left(\right.$ Kafka: 48). ${ }^{8}$

Dem Eindruck folgt eine Gedankenstrich und sodann eine nüchterne Analyse des Stimmeffekts.

»Gute Akustik des Saales. Kein Wort verliert sich oder kommt auch nur im Hauch zurück, sondern alles vergrößert sich allmählich als wirke unmittelbar die längst anders beschäftigte Stimme noch nach, es verstärkt sich nach der ihm mitgegebenen Anlage und schließt uns ein $\ll$ (ebenda). ${ }^{9}$

Was Kafka im zweiten Teil beschreibt, ist der Saal als eine Verstärkeranlage der menschlichen Stimme des Schauspielers. Kafka denkt also die energetische Übertragung relational und man kann seine Beschreibung durchaus als Einspruch gegen die uni-direktionale Gerichtetheit der Ansprache Moissis lesen, wenn er ihn als »[w]idernatürliche[n] Anblick « beschreibt, den er hin und her gerissen verfolgt.

»Unverschämte Kunstgriffe und Überraschungen, bei denen man auf den Boden schauen muss und die man selbst niemals machen würde: Singen einzelner Verse gleich im Beginn z.B. Schlaf Mirjam mein Kind, ein Herumirren der Stimme in der Melodie; rasches Ausstoßen des Mailiedes, scheinbar wird nur die Zungenspitze zwischen die Worte gesteckt; Teilung des Wortes November-Wind, um den >Wind < hinunter stoßen und aufwärts pfeifen lassen zu können. Schaut man zur Saaldecke, wird man von den Versen hochgezogen« (Kafka: 48$){ }^{10}$

Kafka beschreibt rückblickend das, was man medientheoretisch als Immersion bezeichnet, Eintritt in den Datenraum, und zum Teil eines medialen Dispositivs wer-

8 Vgl. zu diesem Auftritt Moissis Schaper: 91ff.

9 Die angegebenen Stücke, soweit überliefert, sind: SCHLAFLIED FÜR MIRJAM von Richard Beer-Hofmann, NoveMBERWIND von Emile Verhaerens, vgl. Schaper: 94.

10 Über Kafkas Suche nach der »litterarischen Bestimmung « (Kafka: 47) als sein Thema in dieser Zeit ist viel geschrieben worden, ebenso wie auch bekannt ist, dass Kafka sich selbst mit dem Rezitieren und dessen Scheitern befasste. Vgl. Tagebucheintrag vom 04.01.1912 über das Vorlesen vor seinen Schwestern (Kafka: 11) und Eintrag vom 25.02.1912 zu Kafkas Vortrag über jüdischen Jargon am 18.02.1912 (Kafka: 35). 
den. Die Klangbilder, die Moissi produziert, gebieten den Fall und Kafka windet sich aus dem »uns « des Publikums, dessen Teil er doch ist.

Zugleich sind seine Beobachtungen der Machart dieser Darstellung bereits distanziert und analytisch, zuweilen auch ironisch. Wenn er etwa von der Zungenspitze spricht, die zwischen die Worte gesteckt wird, so hat das Ähnlichkeit mit jener analytischen Sprachbehandlung, wie man sie in sprecherzieherischen Übungsbüchern für Schauspieler findet. »W Stimmhafter Engellaut. Unterlippe gegen Oberzahnreihe [...]; geringe Kieferöffnung; Zunge liegt flach, Zungenspitzenkontakt mit den unteren Schneidezähnen «(Aderhold: 36). ${ }^{11}$

Das ist natürlich eine unerhörte Reduktion der Sprachmusik. Moissi arbeitet nach allen Regeln der Kunst, und Kafka, der werdende Künstler der Moderne, schaut bereits von einer Meta-Ebene auf diese Regeln der Darbietung Moissis, gleichsam noch berührt, jedoch bereits medial aufgeklärt, anti-illusionär.

Der entscheidende Punkt jedoch ist, dass Kafka in der nach geordneten Reflexion des Vortrags auf jenes mediale Szenario des vor Augen-Führens einer Dritten Gestalt stößt. Er schreibt:

»Der Künstler, scheinbar unbeteiligt, sitzt so wie wir, kaum dass wir in seinem gesenkten Gesicht die Mundbewegung hie und da sehn und lässt statt seiner über seinem Kopf die Verse reden. - Trotzdem so viele Melodien zu hören waren, die Stimme gelenkt schien wie ein leichtes Boot im Wasser, war die Melodie der Verse eigentlich nicht zu hören« (Kafka: 49). ${ }^{12}$

Damit ist der qualitative Umschwung des Verses bezeichnet, der uns hier in Gestalt eines »leichten Bootes im Wasser « erscheint, und dies ist nichts anderes als ein energetischer Überschuss, der durch die Unverfügbarkeit der Technik evoziert wird. Kafka lässt - freilich mit unüberhörbarer Skepsis - die Entstehung eines neuen Bildes, einer eigenen Vision $\mathrm{zu}$, welche dem nicht mehr glaubhaften Bild des rezitierenden Moissis an die Seite gestellt wird: Die Stimme schien gelenkt »wie ein leichtes Boot im Wasser«. Ich möchte rhetorisch (an)schließen: Gibt es ein schöneres Bild für visuelle Energie als das einer Stimme über dem orakelnden Körper, die leicht gelenkt wie ein Boot den Raum erfüllt?

11 Die Beschreibung der Konsonantenbildung erfolgt nach der »physiologischen Bildungsnorm« (Aderhold: 10), welche auf dem Atlas deutscher Sprachlaute von HansHeinrich Wängler aus dem Jahre 1958 basiert.

12 Was Kafka hier beschreibt, ist die rhetorische Figur der Prosopopoiia, d.h. einen Text als Stimme und Person lesen, die von einem Abwesenden, Toten herrührt. Und das ist das Gegenteil zur alten Vorstellung von der Verwandlung, bei der der Schauspieler als >Gestalt der Dichtung spricht. Persona ist hier nicht die Maske »wohindurch es hallt« (Benjamin: 347), sondern eine rhetorische Figur, die etwas bewirkt, die also vor dem Ertönen angeordnet ist. Vgl. hierzu Menke: 140. Die Differenz von Textstimme und Theatermaske wird von Menke richtig gesehen, lässt sich aber auch vom Theater des Lesens auf das Schauspiel ausweiten. Allerdings bezöge sich die Exegese dann nicht auf den dramatischen Text allein, sondern immer auch auf die gültigen Regel- und Methodentexte des Schauspiels, die ebenfalls eine Stimme und Person bewirken. In diesem Sinne wäre die Theatermaske nicht akustisch, sondern rhetorisch zu verstehen. 


\section{Fazit}

Verlassen wir Kafka und Stanislawski für einen Moment und besinnen uns auf einige grundsätzliche Bemerkungen zur Arbeit mit visueller Energie im Schauspiel. Wie gezeigt wurde, lassen sich die Spuren dieser Arbeit sowohl in der Produktion des Schauspielers - aufgezeigt an der wohl umfänglichsten und einflussreichsten methodischen Schrift der Jahrhundertwende - als auch in der Rezeption zumindest eines Moissi durch Franz Kafka nachweisen. Mit der visuellen Energie wurde hier eine Suchformel vorgestellt, die die Debatten um die Erweckung und Kontrolle von Affekten durch den Schauspieler neu positioniert. Diese kreisten seit je um eine Verortung des Affekts, wahlweise in der Physis oder der Psyche des Schauspielers, ohne freilich den energetischen Aspekt derart erklären zu können - geschweige denn ihn methodisch zu erfassen. Die Re-Lektüre von Stanislawski und durch sie der antiken Rhetorik nimmt gerade diesen Aspekt von Unverfügbarkeit als Indiz für die Sache selbst. Es bietet sich folglich an, visuelle Energie als negative Bestimmung, als Überschreitung und zugleich Unterbietung von Begrifflichkeit und Regelhaftigkeit im Schauspiel zu lesen, um das Phänomen Schauspiel neu zu beleuchten. Anders gesagt: Die historischen Debatten, Paradoxien und Widersprüche sind selbst bereits von der Rhetorik - und damit von einer Bildlichkeit - gekennzeichnet, die sie zu erklären vorgeben.

In Hinblick auf aktuelle Tendenzen eines Theaters durch neuere Medientechnik - und hier schließt sich der Bogen - lassen sich hoffentlich Konstanten erkennen. Wer sich heute aufmacht, um mit Handkamera und Videoschirm eine Inszenierung zu gestalten, wird das Wechselspiel von versprochener Verfügbarkeit und erfahrener Un-Verfügbarkeit, ja Unkontrollierbarkeit technischer Mittel kennen, wenn nicht gar sich darin verlieren. Nichts anderes finden wir in Stanislawskis Suche nach dem System des Schauspiels, wenn er sich bei Kommata und Tonhöhe der Deklamation aufhält.

Hier ist die rhetorische Technik am Werk, die gleichsam parasitär an jeweils spezifischem Erfahrungswissen und dem allgemeinen (theoretischen) Wissen partizipiert, selbst aber nicht eigentlich zu bestimmen ist. Technik, das meint eben immer künstlerische, technologische und listige Handgriffe, eine Praxis des Werdens $^{13}$, die sich gerade nicht in der Anwendung und Reproduktion vorhandener Mittel erschöpfen darf. Im Sinne der Technik als einer Latenz und Unverfügbarkeit des Technischen und >der Medien ‘ ginge es darum, theatrale Repräsentation - und das meint auch das hier verhandelte Schauspiel durch Medien - als immer schon medialisiert und technisiert, als Theater durch Medien zu begreifen.

13 So unterscheidet Klaus Bartels einen statischen und dynamischen Begriff der antiken Techne bei Aristoteles. »Die Bewegung der Werkzeuge enthält den Begriff der Techne und in ihm den der Form des Hergestellten, [...] Die Bewegung der Werkzeuge ist die Tätigkeit (Energeia: das >Am-Werk-Sein $<$ ) der Techne, die Techne die Form des Herstellens« (Bartels: 282). 


\section{Literatur}

Aderhold, Wolf (1989): Sprecherzieherisches Übungsbuch. Berlin: Henschel.

Aristoteles (1950): Von der Seele (= De Anima). Zürich: Artemis.

Aristoteles (1980): Rhetorik. III Buch. München: Fink.

Bartels, Klaus (1965): »Der Begriff der Techne bei Aristoteles«. In: Hellmut Flashar/Konrad Gaiser (Hg.): Synusia. Festgabe für Wolfgang Schadewaldt zum 15. März 1965. Pfullingen: Neske, S. 275-287.

Benjamin, Walter (1991): Gesammelte Schriften. Bd. II.1. Frankfurt/M.: Suhrkamp.

Börringer, Hannes (1989): Das hölzerne Pferd. In: Ars Electronica (Hg.), Philosophien der neuen Technologie. Berlin: Merve, S. 7-26.

Campe, Rüdiger (1990): Affekt und Ausdruck. Zur Umwandlung der Literarischen Rede im 17. und 18. Jahrhundert. Tübingen: Niemeyer.

Haverkamp, Anselm (2001): »Repräsentation und Rhetorik. Wider das Apriori der neuen Medialität«. In: Georg Stanitzek/Wilhelm Vosskamp (Hg.): Schnittstelle. Medien und kulturelle Kommunikation. Köln: DuMont, S. 77-84.

Kafka, Franz (1994): Tagebücher 1912-1914. Frankfurt/M.: Fischer.

Kleine Pauly, der. Lexikon der Antike (1975). München: Druckenmüller.

Menke, Bettine (2000): Prosopopoiia. München: Fink.

Quintilian, Marcus Fabius (1971): Ausbildung des Redners. Darmstadt: Wissenschaftliche Buchgesellschaft.

Schaper, Rüdiger (2000): Moissi. Triest, Berlin. New York. Berlin: Argon.

Stanislawski, Konstantin (1981a): Die Arbeit des Schauspielers an sich selbst. $B d$. 1. Berlin: Das Europäische Buch.

Stanislawski, Konstantin (1981b): Die Arbeit des Schauspielers an sich selbst. $B d$. 2. Berlin: Das Europäische Buch.

Toporkow, Wassili (1981): »K.S. Stanislawski bei der Probe. Erinnerungen«. In: Konstantin Stanislawski: Die Arbeit des Schauspielers an der Rolle. Berlin: Das Europäische Buch, S. 279-541.

Wängler, Hans-Heinrich (1958): Atlas deutscher Sprachlaute. Berlin: Akademie. 


\title{
KALEIDOSCOPIC ENCOUNTERS. THE ACTOR, ChARACTER AND SPECTATOR IN INTERMEDIAL PERFORMANCES
}

\author{
LIESBETH GROOT NIBBELINK
}

$\gg$ I can take any empty space and call it a bare stage. A man walks across this empty space whilst someone else is watching him, and this is all that is needed for an act of theatre to be engaged. « Let us take a brief look at these famous opening lines of Peter Brook's The empty space (1968). The implicit image evoked here is that of someone looking at another presented as the distinctive feature of theatre. Looking at the actor is the way one usually >enters< a performance. However, when the actor on stage is filmed by a video camera and this video image is at the same moment projected on a screen, the actor is no longer the only focal point. Live video interferes with the live presence of the actor on stage. The spectator is offered a multi-perspective view. This article explores the intermedial relationship between an actor, live video and the spectator, and will address the question of whether a $>$ character $<$ is still an adequate concept when analysing these relationships.

\section{Actor in manifold}

A fine example of the use of live video in theatre is seen in the performance STUKGOED - A BEAU MENTIR QUI VIENT DE LOIN (1996), presented by the Flemish theatre company TgSTAN. In this performance a girl is in search of her identity, which translates as a longing to travel. She is reluctant to leave her home however, which is reflected in the way the actress presents herself in front of three different video cameras surrounding the scene. She carefully moves in and out of the >gaze< of the cameras. On screen alternate views of her face are seen, including a partial profile, her back, a close or a distant view. The way the actress approaches the cameras serves as a metaphor for the question if the girl wants to travel, but is scared to do so. It also reflects the way the story is told, through subjective and objective perspectives. As a spectator, all of these different images must be combined to produce meaning.

In performances like this, the physical presence of the actor is confronted by his or her >absent double $<$. His or her presence is no longer taken for granted, but is questioned. Because the actor is no longer the only one responsible for his or her presentation, it could now be argued that his or her authority is questioned as well. This authority is partly replaced by technology and the spectator. It is the spectator who is invited to combine the different, and often contradicting, images and qualities of the actor and his or her double (or triple, etc.) and to compare them in order to produce meaning. The combination of the terms »presence « and »authority « has been used by Philip Auslander, to substantiate that American postmodern perfor- 
mance is much more political than many theoreticians thought (Auslander 1992). Stripped of the political aspect, these concepts are very useful tools in analysing the changed position of the actor in a >mediatised < performance. Moreover, they draw attention to the role of the spectator, in particular to his or her awareness of perceiving and constructing meaning (see also Groot Nibbelink). The absence of a clear authority reveals various and unexpected ways of >entering < a performance. Therefore Auslander, quoting Josette Féral, speaks of »an authorless, actorless, directorless infratheatricality« (Auslander 1992: 45). Nowadays this »infratheatricality « would be replaced by »intermediality « but this word should be retained, as it is associated with notions of infrastructure, the penetrating infrared light and the fusion of formerly separated domains. I understand >intermediality< similarly: one medium interferes with or penetrates into other media. It is this interference that evokes meaning or experience.

\section{In search of characters}

An interesting dramaturgical issue is the concept of character in this type of intermedial performance. For traditional representation, an actor plays a role: thus, he creates a character, either disappearing behind that character or not. However, what happens with the concept of character when the actor is no longer the only party responsible for creating a character, for example when part of this presence and authority is replaced by or at least confronted with, technology? In Guy Cassiers' opera THE WOMAN WHO WALKED INTO DOORS (2001) the main >character< is represented by an actress, video projections of this actress, and an opera singer. During this intermingling of sights and sounds a hint of a character emerges. But more important, this opera is not necessarily aiming at creating an sentire < character. The autonomous images, texts, sounds and music reveal a story about a woman who is struggling with a husband who beats her, but does so by showing a landscape where all these autonomous parts interfere with each other and not by presenting a linear dramatic world evoked by characters. In short, it is problematic to speak of a character here.

The 20th century has given many examples in which the relationship between actor and character has been discussed, including the observation of film theorist André Bazin, who believed that in theatre, the actor, because of his physical presence, never totally disappears behind a character, Gordon Craig's vision of the actor as »Übermarionette«, and the acting style of Brecht, which lives on in the $>$ transparent acting < of several contemporary Dutch and Flemish theatre companies. Elinor Fuchs, in The death of character, argues that in the early $20^{\text {th }}$ century, a character was already replaced by a more dominant dramaturgical pattern (47). A pattern that naturally changed again and again throughout that century: »Each epoch of character representation [...] constitutes at the same time the manifestation of a change in the larger culture concerning the perception of self and the relations of self and world « (8). Today's concept of self or the construction of subjectivity has been fundamentally changed by the way individuals move through and live in a mediatised culture.

Which concepts should be used then, after >the death of a character $<$ ? One possible answer is given by the Flemish dramaturg Erwin Jans, who for many years cooperated with Guy Cassiers. In his writings about new ways of acting in intermedial performances, Jans states that $>$ character $<$ is a notion belonging to the dramatic 
theatre, whereas in postdramatic theatre the actor (re-)appears as both a performer and body (20). In this case the actor as a performer should not be interpreted in the traditional sense of acting, but as an actor who is not pretending to be someone else and whose primary concern is being >himself< on stage. Jans' approach could be further extended. It could be proposed that in intermedial performances the concept of character is substituted by the actor as a performer, by the actor as a body, by technology and by >the performativity< of the spectator (i.e. his physical and/or perceptual activity). This article is restricted to two arguments: the substitution of the concept of character by >the actor as a performer < and by >the performativity of the spectator<. In order to do so a performance by the Dutch theatre company Space will be described. In this performance the use of technology and aspects of presence and authority are realised rather differently than in the aforementioned example of TgSTAN. However it sheds an interesting light on aspects of performativity.

\section{$A(n)$ (anti-)televisual performance}

In 2005 Space presented a performance called THE PLACE WHERE WE BELONG. The audience was situated in a room on the fourth floor of a former office building behind a glass window, overlooking the streets below. One of the two members of Space, Petra Ardaí, was positioned down on the street. Petra Ardaí is a Hungarian artist who has been living in the Netherlands for the past 17 years. Because of growing animosities against foreigners - reflected in stringent immigration policies and a fierce debate about Dutch identity in which radical statements were magnified by the media -, she has begun to feel more and more a foreigner herself, although she has a Dutch passport and is married to a Dutchman (who is in fact the other member of Space). During the performance she walked around the streets below, equipped with a video camera and a microphone, asking people whether she should go back to Hungary or resist this dominant political attitude. From behind the window, the audience followed her quest and observed these interviews via small video screens positioned in front of them. Interviews were heard through headphones alternating with fragments from her diary and instructions from her husband, a white, Dutch male, who was with the audience in the room. He was instructing Petra to behave »more Dutch « and to act casual when approaching passers-by. The people interviewed were unaware of the observing audience. (In the performance attended by the author, there was not a single person who advised Petra to go back to Hungary.)

This performance reflects upon a mediatised society and public opinions that are strongly influenced by media, but the means to do so also strongly depend on the use of these media forms. The interaction between the live and on-screen images is explored using an intriguing method. On the small screen the audience sees >the common man in the street< recognized from television. However this time the $>$ common man< is personally approached and gives a less narrow-minded reaction than is expected. The audience looking through and at the window is a metaphor for watching television. Because they can see from where the screened image originates, the usual distance between source and screened image disappears. The screen doesn't guide the audience's attention >elsewhere $<$, but stresses the $>$ here and now $<$. The screen can be compared with the source. The >screened live $<$ and the >physical live< are both similar and full of contrasts. The distance between the audience and the performer outside induces reflection, while the close-up images on the 
small screen and the pre-recorded diary fragments on the headphones bring about an experience of intimacy. Another contrast is the safe position of being inside versus the rather vulnerable position of the performer outside. This physical opposition corresponds with other contrasts, such as the cultural insider/outsider, Dutch/ non-Dutch and observing/acting. Altogether, these different sensations strongly address the spectator on a personal level. This address is intensified by the use of headphones, which emphasizes the impression that the story is told to each spectator personally.

Although portrayed somewhat differently, once again we see a deconstruction of presence and authority. Petra Ardaí is in fact absent; she is not with the audience in the same room, but is present by means of camera and screen, microphone and headset. The authority of the actor is questioned because she takes up herself different roles, as will be shown in the following.

\section{Persona}

The actress in this performance is a very clear example of the actor as a performer. Actress Petra Ardaí presents herself using her own name. Her personal questions are the main input for the performance and the interviews. Of course, she transforms herself into something resembling a character; she is becoming >Petra Ardaí, the foreigner - as she is perceived by the Dutch people<. But in this instance, it seems problematic to speak of >character $<$. She is merely adopting a certain role. Ironically, on the level of the dramatic narrative, this is the role she doesn't want to play. This process of taking over a certain role could be described as the adoption of a role strongly embedded in the personal biography of the performer or "persona «. This is again a concept taken from Philip Auslander, who introduced the concept of »performance persona« (1997: 39). He particularly refers to Willem Dafoe, who has become a well known film actor. The perception of his appearance on stage is influenced by the audience's knowledge of Dafoe as a performer. Their awareness of the act of performing is further emphasized by Dafoe's self-referential style of >acting <. He does not disappear behind a character, even if he wants to (which he doesn't). A similar situation exists in Dutch theatre as a lot of theatre actors are primarily known by the larger public through appearances in commercials, soaps operas, television plays and films. However, Petra Ardaí is not famous. »Performance persona « is not an adequate term for this situation, but >persona $<$ may be. The word >persona $<$ is etymologically connected with a $>$ mask $<$ and $>$ giving voice to<. >Persona< is thus firmly rooted in the theatre. Auslander's »performance persona « also reveals its close connection with the personal or social life of the performer, in this case, Dafoe's profession as a film actor (which intensifies the blending of the personal and the performative). »Persona « thus refers to the way individuals present themselves in daily life, including the different masks used, in order to > give voice < to the way they like to perceive themselves and be perceived by others. In THE PLACE WHERE WE BELONG, Petra Ardaí blurs the boundaries between private and performative personae and thus displays and deconstructs the performative self. For interviews on the street, she presents herself as a foreigner; in the prerecorded diary fragments, she appears as an ordinary human being and a mother; in the live dialogue with her husband, she is a quarrelling partner and, at the same time, the co-creator of the theatrical event. These different personae, together with the interference of different media, question the authority of the actor/performer. 


\section{The performativity of the spectator}

Dutch theatre and film theorist Chiel Kattenbelt distinguishes two ways of the performativity of the spectator. In some cases the spectator enters the theatrical or performance space. The physical barrier between the performer and spectator disappears, as the spectator becomes a participant. The second way of performativity occurs when during a performance the role and activity of the spectator becomes the central theme. The act of perceiving, experiencing, and creating meaning then becomes the performance's main content. These performances try to induce »the audience to watch themselves as subjects which perceive, acquire knowledge and partly create the objects of their recognition « (Malgorzata Sugiera, quoted in Lehmann: 6). In the performance by Space both ways are recognized, where the second is the most important. The first is present because the performance and audience space are mixed. The second category is present because of the firm responsibility of the spectator to compare the on-screen images with the live performance, to (dis)assemble different personae, to personally connect with questions asked and to become aware of his position behind the window. The spectator is not sitting in the dark, but is being exposed. Through all those different aspects the spectator becomes very much aware of himself as a subject who perceives. On a personal note, this awareness was accompanied by an almost physical experience of shock when I realised I often take my own nationality for granted. By inviting the spectator to experience and reflect upon his own perception, Space moves the theatrical communication into the realm of reality. Instead of relating to a fictional character, the spectator is confronted with himself as a perceptive subject.

The Flemish dramaturg Marianne van Kerkhoven once raised the question of how contemporary performance artists relate to the expansion of performativity in modern society (19). THE PLACE WHERE WE BELONG presents a possible answer to that question. By presenting different personae, the performance invites the spectator to become aware of oneself as a subject who perceives; it opens up modes of perception and actually discloses different personae within the spectator as well. Surprisingly, while society is taking its performative turn, this everyday performativity is brought back to and explored on the stage. Beginning with a more theoretical point-of-view, Kattenbelt arrives at a similar observation: in a culture where signs are more real than the objects to which they refer, society becomes a hyper reality, in which theatre is one of the few places where the staging of reality is being exposed and deconstructed. One method would be to present the actor as performer and tap into the performativity of the spectator. Through the absence of characters, theatre becomes, as Umberto Eco once stated, an act of showing (Eco, quoted in Chapple/Kattenbelt: 22) and - my addition - a place of sensory perception, reflection and experience. 


\section{Literature}

Auslander, Philip (1992): Presence and Resistance. Postmodernism and Cultural Politics in Contemporary American Performance. Ann Arbor: The University of Michigan Press.

Auslander, Philip (1997): From Acting to Performance. Essays in Modernism and Postmodernism. London/New York: Routledge.

Brook, Peter (1968): The empty space. London: MacGibbon \& Kee.

Chapple, Freda/Chiel Kattenbelt (2006): »Key Issues in Intermediality in theatre and performance «. In: Freda Chapple/Chiel Kattenbelt (eds.): Intermediality in Theatre and Performance. Amsterdam/New York: Rodopi, 11-25.

Fuchs, Elinor (1996): The Death of Character. Perspectives on Theatre after Modernism. Bloomington etc.: Indiana UP.

Groot Nibbelink, Liesbeth (1999): »Verhevigde werkelijkheid«In: E-view 99 (1). http://comcom.uvt.nl/e-view/99-1/groot.htm (01.03.2007).

Jans, Erwin (2005): »De speler weggecijferd. Acteren in een tijdperk van technische reproduceerbaarheid «. In: Etcetera, 96, 17-21.

Kattenbelt, Chiel (2006): »Theater en de ontmaskering van de werkelijkheid als enscenering «, In: Chiel Kattenbelt et al. (eds.): Theater en openbaarheid. Maastricht/Amsterdam: Toneelacademie Maastricht/Theater Instituut Nederland, 26-48.

Kerkhoven, Marianne van (2006): »Statements«, In: Maaike Bleeker et al (eds.): Theatre Topics 2. De maker als onderzoeker. Amsterdam: Amsterdam UP, 18-19.

Lehmann, Hans-Thies (2006): Postdramatic theatre. Transl. Karen Jürs-Munby. London/New York: Routledge. 


\title{
Media-bodies. ChOREOgRaPhIERTE KörPer ALS WISSENSMEDIUM BEI WILLIAM FORSYTHE
}

\author{
SABINE HUSCHKA
}

Mit der Neukonstitution der Forsythe Company im Jahr 2004 sucht William Forsythe verstärkt Formate einer installativen ästhetischen Praxis auf. Arbeiten wie YOU MADE ME A MONSTER (2005) oder HUMAN WRITES (2005) entfalten sich in einem intermedialen ${ }^{1}$ und interaktiven Raum. Gegenüber früheren Installationen wie White Bouncy CASTLE $(1997)^{2}$, City of ABstracts $(2000)^{3}$ oder SCATTERED CROWD (2002) ${ }^{4}$, die begehbare Ereignisräume von Bewegung oder medial vermittelte Perspektiven auf choreographische Ordnungen im öffentlichen Raum schufen, positioniert Forsythe seine neuen Produktionen bewusst im theatralen Kontext und bringt sie in Theater-Foyers oder freigeräumten und begehbaren Aufführungsflächen zur Aufführung. Unter dem frischen Label der Installations-Performance führen sie Besucher und Performer interaktiv zueinander und verschränken Bewegungs- und Wahrnehmungsformen, die auf den Körper als Terrain und Agens aufgezeichneter Bewegung verweisen. In ihrer Intermedialität legen sie Erfahrungen und Strukturen körperlicher Bewegung frei, die mit Fragen nach dem Status physisch-mentaler Modalitäten umgehen, um in Zuständen choreographischer Un/Ordnung Bewegung zum Medium produzierter Bezüge zu machen. Hierbei folgen sie der Frage, wie die Kunst des Choreographierens - respektive die Kunst körperlicher Bewegung - zu Formen, Verbindungen und Dynamiken finden kann, die wahrnehmbare Bezüge ihrer Performativität offen legen.

\section{Ästhetische Modi der Bewegungsaufzeichnung}

Ungeachtet ihrer ästhetischen Tragweite verweist jene Frage auf den Status des Körpers als generierendes, erinnerndes und nachvollziehendes Organ von Bewegung, die, gleichwohl ihre Vollzüge wahrnehmbare Spuren zeigen, auf das Körperliche zurückweist. Mit dem Begriff der Bewegungsaufzeichnung suche ich im Folgenden die ungreifbare Beziehungen zwischen Bewegung und Wahrnehmung zu

1 Intermedialität ist hier streng von einer Multimedialität zu unterscheiden, da letztere das theatrale Setting von Tanz ohnehin bestimmt, ohne dass die beteiligten Künste konzeptionell ineinander ragen müssen, wie es für ihre intermediale Konzeption charakteristisch ist.

2 White Bouncy CASTLE. Installation von Dana Caspersen, William Forsythe und Joel Ryan. Beauftragt von ARTANGEL, London. Premiere: 26.03.1997, The Roundhouse, Chalk Farm, London.

3 CiTY OF ABSTRACTS. Installation von William Forsythe. Video software: Philip Bußmann Premiere: 24.11.2000, Opernplatz/Hauptwache, Frankfurt/M.

4 SCATtered CrowD. Installation von William Forsythe. Premiere: 15.03.2002, Halle 7, Messe Frankfurt, Frankfurt/M. 
beschreiben, die einer solchen Kunst des Choreographischen in besonderer Weise eignet. Denn beachtet man neben den Installations-Performances YOU MADE ME A MONSTER und HUMAN WRITES die Installationen des bildenden Künstlers Peter Welz, die aus der Zusammenarbeit mit Forsythe hervorgegangen sind, so wird die Frage nach der medialen Kompetenz eines Körpers-in-Bewegung, der hier als sichtbare Spur konkreter Wahrnehmungsvollzüge auftritt, in anderer, vielleicht sogar weitaus prekärerer Weise aktuell. Die beiden bislang entstandenen Arbeiten WHENEVER ON ON ON NOHOW ON / AIRDRAWING (2004) und die unlängst im Pariser Louvre aufgebaute Installation RETRANSLATION / FINAL UNFINISHED PORTRAIT (FRANCIS BACON) I FIGURE INSCRIBING FIGURE I [TAKE 02] (2006) ${ }^{5}$ des als Bildhauer ausgebildeten Peter Welz loten ein gefilmtes Bewegungsmaterial in ihren gestalterischen Aspekten des Figürlichen und Skulpturalen aus. ${ }^{6}$ Hierzu überstellen sie die aufgezeichneten und z.T. nachgezeichneten Bewegungen einem intermedialen Arrangement, das mit dem Körper als performatives Wissensmedium umgeht. Die von Forsythe getanzten Improvisationssequenzen werden auf mehrere große Leinwände projiziert, die jeweils in Körpergröße den gesamten Ausstellungsbereich säumen.

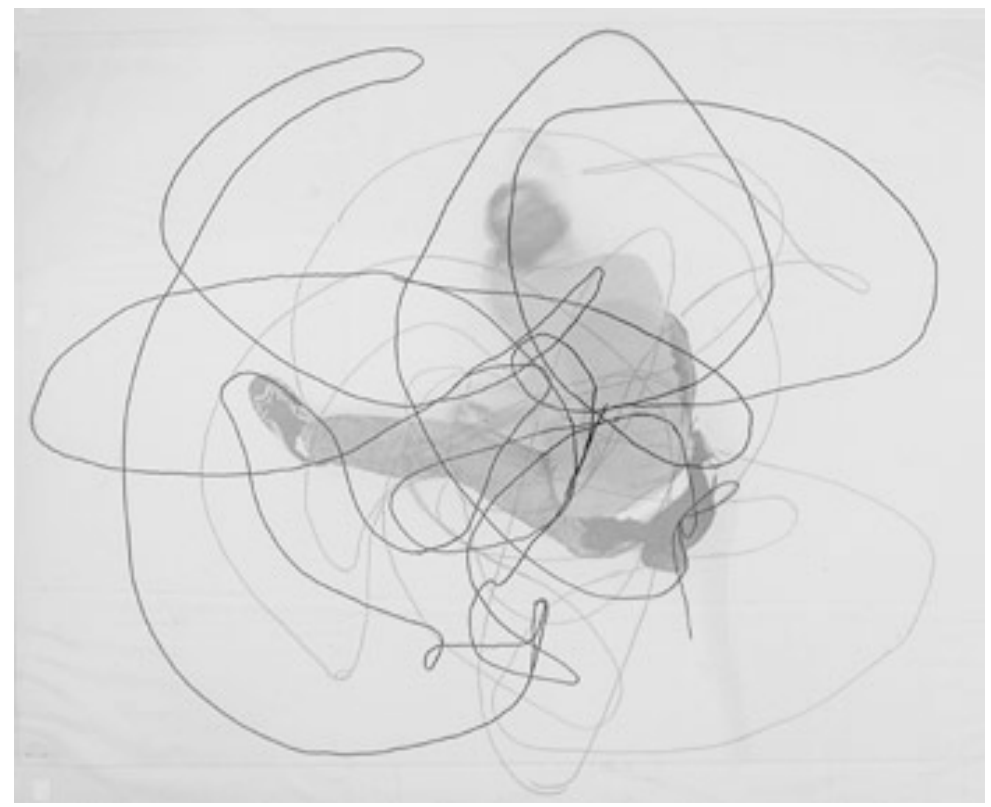

Abbildung 1: airdrawing / study movement of the right hand (black) left hand (red) / above computer print onto photo paper, permanent marker, gaffa tape, PVC foil - $61 \mathrm{~cm} \times 86 \mathrm{~cm}$, 2000. (www.peterwelz.com).

5 RETRANSLATION I FINAL UNFINISHED PORTRAIT (FRANCIS BACON) I FIGURE INSCRIBING FIGURE I [TAKE 02] three channel video installation, drawing $3,60 \mathrm{~m} \times 5,50 \mathrm{~m}$, 2005.

6 Beide Installationen ebenso wie die neueste Arbeit ARCHITECTURAL DEVICE FOR FORSYTHE MOVEMENT (2006) sind reine Installationen, in denen nicht performt wird (www.peterwelz.com). 
Gleichwohl methodisch different - arbeiten die Installations-Performances mit Körpern, die live das installative Setting erschließen, die Kunst-Installationen von Welz indessen mit gefilmten Bewegungsgestalten - operieren beide InstallationsTypen mit Modi körperlicher Bewegungsaufzeichnung, die über die Möglichkeiten der Neuen Medien (Video und Computer-Sofware) informiert sind. Das Verhältnis der Bewegung zu ihrer Aufzeichnung, wie es der Begriff der Bewegungsaufzeichnung klassischerweise anzeigt, hat sich unterdessen verkompliziert, da deren traditionelle Funktion des Sichtbarmachens und Reproduzierens unterlaufen wird. Die eingesetzten Medien der Bewegungsaufzeichnungen, sei es das technisch oder künstlerisch bearbeitete Videobild oder das nachvollziehende Memorieren der Körperbewegung selbst, legen im Gegensatz zu schlichten Videoaufzeichnungen und Notationsverfahren die Differenz zwischen der körperlichen Bewegung und ihrer Aufzeichnung in Schrift/Bildern offen und verweisen auf den beidseitig gegebenen Prozess ihrer generierenden Performativität.

Der Begriff der Bewegungsaufzeichnung wird im Folgenden daher metaphorisch verwandt und bezeichnet all jene Modulationen des Körperwissens von Bewegung, das in verschiedenen (Auf)-Zeichnungsmodi operiert, um wahrnehmbar zu werden. Dem Begriff liegt somit eine doppelte Struktur inne. Die Zeichnungsmodi manifestieren und generieren Wahrnehmungsvollzüge von Bewegung, die vom Körper in Bewegung geschrieben werden und eine choreographische Organisation hervorbringen. In diesem Sinne führen sowohl die Installationen von Welz, als auch die Performance-Interaktionen in HUMAN WRITES, wie auch die improvisatorischen Bewegungssequenzen der Tänzer in YOU MADE ME A MONSTER Auseinandersetzungen mit Modi der Bewegungsaufzeichnung vor Augen.

\section{Wahrnehmungsgrade körperlicher Bewegung}

Generell bleibt zu bedenken, dass sich der Einsatz Neuer Medien in der Arbeit von William Forsythe ebenso wie die Schaffung medialer Installationen nur unzureichend als ein Prozess ästhetischer Selbstreflexion beschreiben lässt, mittels derer die Grenzen und Optionen körperlich ästhetisierter Bewegung choreographisch ausgelotet würden. Im Gegensatz zu intermedialer Arbeit wie etwa jener von Nick Haffner und Thomas McManus - beide ehemalige Tänzer des Ballett Frankfurt die mit Bernd Lintermann am ZKM in Karlsruhe das Motion Capture Projekt TIMELAPSES realisiert haben, ${ }^{7}$ operiert Forsythes choreographische Arbeit nicht mit der sinnlichen und aisthetischen Differenz von physischem Körper und virtuellem Bewegungsbild. Forsythes Interesse an Neuen Medien und Technologien richtet sich nur z.T. auf deren Einsatz als inszenatorisches Verfahren, um Videobilder mit lebenden Körper(bilder)n in Kontrast zu setzen. Primär interessieren ihn indessen die technologisch durch die Medien eröffneten Modulationsformen körperlicher Bewegung, die Sichtbarkeiten und aufmerkende Wahrnehmungen des Körpers-inBewegung erzeugen. Es geht Forsythe um eine Art der Bewegungszeichnung, über die sich verschiedene Körper in Beziehung setzen.

Im Vordergrund stehen performative Wahrnehmungsformen körperlicher Bewegung, die Choreographie im Sinne eines durch und im Körper (fort)geschriebenen Wissens behandeln. Hierfür greift Forsythe auf computergenerierte Aufzeichnungsmodi zurück, denn sie erlauben analytische und visuelle Zugriffe, die einen

7 http://www.timelapses.de. 
Pool an Informationen in den Prozess improvisatorischer und choreographischer Bewegungsgenerierung zurückspielen. Mithin als lerntechnische Apparatur verwandt, fungieren die in den Improvisation Technologies aufgezeichneten Bewegungsbeispiele als choreographisches Material, das sichtbare Organisationshilfen vermittelt und ein Bewegungswissen an die Tänzer zurückspielt. Jene Formen und Artikulationsweisen einer medialisierten Wahrnehmung des bewegten/sich-bewegenden Körpers erzeugen eine ästhetische Wahrnehmungstechnologie. ${ }^{8}$

Während Computerspezialisten wie Paul Kaiser, der maßgeblich an der Erarbeitung der Improvisation Technologies beteiligt war, vor allem das verkörperte Bewegungswissen von Forsythe verstehen wollten, ${ }^{9}$ sucht Forsythe mittels der Neuen Medien den Wahrnehmungsgraden des Empfindens auf die Spur zu kommen. ${ }^{10}$

»I'm certainly not concerned with form from an objective point of view, but rather what is the sensation of formation as the body continuously moves from one state to another. The body is interesting as a perceiving mechanism « (Lista: 35$)$.

Aus computertechnologischer wie auch theatraler Perspektive bleibt die Frage nach der Sichtbarmachung der durchlaufenen Wahrnehmungsgrade offen und ungelöst. In den Improvisation Technologies mit ihren ins Videobild eingetragenen graphischen Spuren geht es mithin um eine solche Sichtbarmachung, die geradewegs als Sichtbarmachung mentaler Vorstellungen und physischer Organisation im Bewegungsvollzug auftreten und darin die Vergegenwärtigung der Wahrnehmungsoptionen nicht nur bewirken, sondern sie geradewegs erzeugen. Vergleichbar zu den fotographischen Verfahren der Bewegungsaufzeichnung von Etienne-Jules Marey am Ende des 19. Jahrhunderts erfährt hier ein Bewegungsvollzug computertechnologisch, also allein durch die auf Sichtbarkeit drängende Apparatur seine Realisierung (vgl. Snyder: 148). Denn weder die Grundfigur der Improvisation Technologie »point-point-line « ${ }^{11}$ noch irgendeine andere graphische Figur weisen jenseits des Videobildes eine Sichtbarkeit auf, sondern bezeichnen einen imaginären Prozess.

Aber Forsythe ist nicht Marey. Sein choreographisches Interesse liegt nicht darin, Wahrnehmungsgrade der Empfindung in und von der Bewegung Sichtbarkeit zu geben. Hierdurch würden allenfalls Re-präsentationen geschaffen, der performative Charakter der choreographischen Arbeit aber käme zum Erliegen.

8 Gegenüber dem Begriff der Wahrnehmungs- oder Bewegungstechnik setzt sich der Begriff der Technologie von einem zweckorientierten Gebrauch des Körpers ab und bringt eine >quasi übergeordnete Perspektive< ins Spiel, die die >Lehre von dieser Technik anzeigt. Eine Bewegungstechnologie gibt danach Kunde von der Verarbeitung der Bewegung und lehrt Kenntnisse über dessen Handwerk. (Vgl. Hüser/Grauer: 194). Vgl. zur Wahrnehmungstechnologie bei Forsythe: Huschka 2005.

9 Vgl. Paul Kaiser, zitiert in: deLaHunte: 182.

10 Er spricht von »degress of awareness of sensation«. Forsythe im Gespräch mit Welz und der Kuratorin Marcella Lista am 17.08.2006 in Frankfurt anlässlich der Pariser Ausstellung (Lista: 35).

11 Das Kapitel findet sich als imagine lines auf der CD-Rom Improvisation Technologies im Kapitel Lines unter point-point-line. Vgl. ZKM Karlsruhe (1999). 


\section{HumAN Writes (2005) ${ }^{12}$ - Ein Aktionsraum der Bemühung}

Tatsächlich ist Forsythe mit seinen neuen installativen Arbeiten an einer Entgrenzung der Gattung Tanz, respektive Ballett, gelegen, um - im Kontext seiner früheren Choreographien gelesen - eine Aktualisierung vorzunehmen. Ohnehin bezeichnet Tanzkunst für Forsythe, wie Gerald Siegmund (264) treffend charakterisiert, einen »performativen Akt «, dessen ästhetisches Konzept sich nunmehr im Übertritt in den Kunstkontext radikalisiert. Forsythe verschiebt die perspektivischen Setzungen des Theatralen, um sich in einem neuen Genre wiederzufinden, das ebenso entgrenzend arbeitet wie Forsythes bewegungstechnischer Umgang mit dem klassischen Tanz. Gerade die »Ästhetik der Installation« streicht, wie Juliane Rebentisch (81f) betont, »theoretische Fragen nach den Merkmalen einer möglichen neuen Gattung « aus. Hybride im Charakter, finden sich Dinge, Materialien, Projektionen, Medien und Körper in Bewegung in einem Raum von ungewöhnlicher zeitlicher Länge ein, die - akustisch zu einem cluster verwoben - eine Sphäre des Intermedialen bilden.

Sinnfällig und erfahrbar wird eine andere als für das Ballett prägende perzeptive und rezeptive Positionierung der Besucher, die sie in eine wahrnehmungsästhetisch ungesicherte Beziehung innerhalb der performativen Anordnung führt.

Ein Raum mit hohen Wänden, gesäumt von Bannern übereinander gehängter Zeichnungen. Bemalt mit schwarzer Kreide - verwischt, verschmiert zeigen sie Bilder eines Irgendwie. Sie zeigen irgendwas. Spuren, Zeichen, Spuren von Zeichen. Dass sie ein Gedächtnis tragen, nämlich dessen, was augenblicklich im Raum geschieht, verdeutlicht sich später. Die Zeichnungen sind Residuen der Performance-Installation, die über 30 Tänzer und bis an die 150 Besucher in einen Raum einer unmerklich anwachsenden Anstrengung zusammenführt, um die 49 Artikel der Menschenrechte nachzuschreiben, wie sie 1948 von der Generalversammlung der UNO verfasst wurden.

Was mit ENDLESS House (1999) in dessen 2. Teil im Bockenheimer Depot begann, das die Zuschauer einlud in den Performance-Raum einzutreten, zeigt sich in HUMAN WRITES (2005) als eine interaktive Performance, in der Besucher mitarbeiten - in der vermeintlichen Absicht, zu helfen.

»Unwissend, wozu meine Hilfe dienen soll, hat die Kreide, die ich angestrengt in einer Position in der Luft hielt, so dass über sie der Tisch hinweggleiten konnte, der von einem Performer, der unter dem umgedrehten Tisch lag, hin und her bewegt wurde, Spuren hinterlassen. Zu meiner Überraschung haben wir zusammen ein $>A<$ gemalt, das schön in seinen Konturen später auf dem wieder umgedrehten Tisch zu sehen war. Der Performer tauchte von unten auf. Ein A aus Artikel 7 der Menschenrechte > Alle sind vor dem Gesetz gleich Als ich später wieder vorbeikam, war aus dem A ein M geworden« (Eigener Erfahrungsbericht).

HUMAN WRITES stellt keine körperlich virtuose Bewegungskunst aus, sondern fordert Kontakt ein: »Würden Sie bitte das Bein an der Schnur halten und führen? « So findet man sich selber in der Performance eingebunden wieder. Die Handlungs-

12 Human Writes. Performance-Installation von William Forsythe und Kendall Thomas. Premiere: 08.09.2006. Festspielhaus Hellerau, Dresden. 3 Std., zur Eröffnung der neuen Spielstätte der Forsythe-Company. 
optionen sind eng. Bemüht, es irgendwie richtig zu machen, am Ende der Kommentar einer Tänzerin: »Das war zu einfach - es müsste ein bisschen mehr kompliziert sein.«

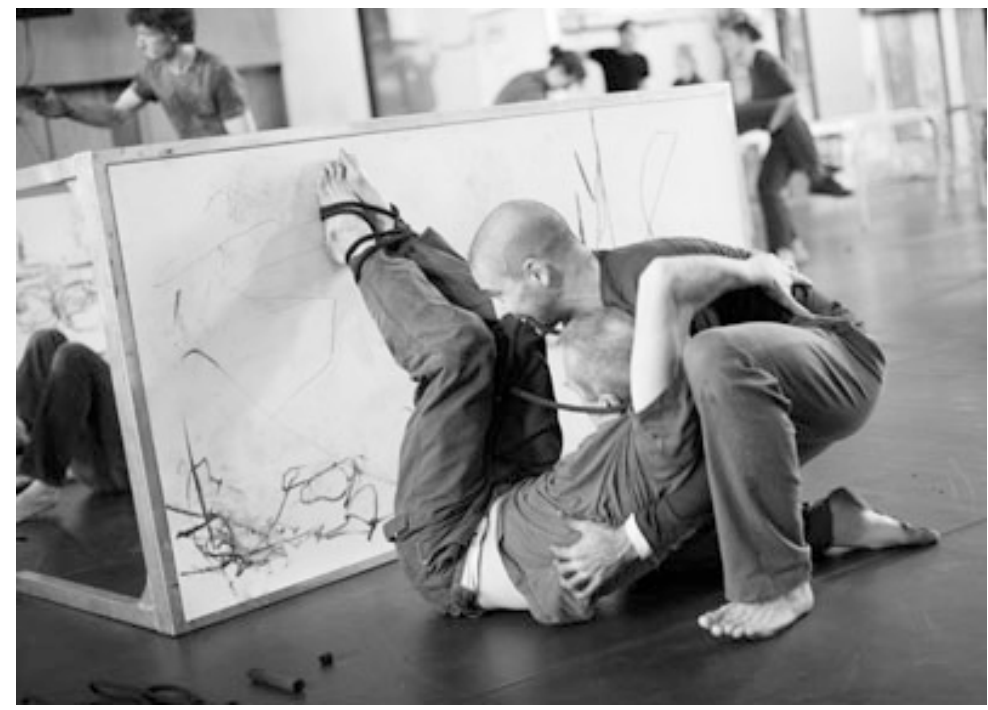

Abbildung 2: William Forsythe und Ander Zabala in HUMAN WRITES (2006). Foto: () Dominik Mentzos.

Tatsächlich finden sich die Besucher in einem Saal vollgestellt mit reihig angeordneten großen Aluminiumtischen wieder, an oder auf denen meist ein Performer steht, liegt, lehnt, hängt, kniet oder in anderer Lage die vorgeschriebenen Lettern nachzuzeichnen sucht. ${ }^{13}$ Als Graphein dienen Bleistifte oder schwarze Kreide, die ihre Spuren nach und nach überall hinterlassen, werden sie doch in der Armbeuge oder im Mund festgehalten, an den Hinterkopf gebunden, zwischen die Zehen geklemmt o.ä.. Der auferlegte Handlungsrahmen verhindert das Schreiben. Stattdessen wird Kreide manisch abgerieben, Graphitstaub gepustet, mit geschlossenen Augen oder koordinativ völlig überfrachtet mit allen Gliedern gleichzeitig geschrieben. Die vorgezeichneten Buchstaben werden gekritzelt, gehauen, schraffiert, gestreift und immer wieder überzeichnet. Eine Performance am Grad exaltierter Anstrengung. ${ }^{14}$

Das Medium der Schrift verwischt zu performativen Spuren, die ihre kulturstiftende Funktion eingebüßt hat, als primäre Kulturtechnik soziale Übereinkünfte zu tradieren. Hierdurch treten jene performativen Akte hervor, in denen Körper situativ operieren und zu Schreib-Akteuren werden. Ihre allesamt konzeptionell eingebundenen Bewegungsabläufe verlaufen inmitten einer Intermedialität, in der die symbolische Ordnung von Körper und Schrift, Handlung und Gesetz geblockt ist. Die Körper dynamisieren vielmehr ihre Beziehung, ja die Performance-Körper medialisieren selbst zu einem Terrain der Beziehung, das auf die eigenen Schranken

13 Vgl. Videoausschnitt unter http://www.art-tv.ch/human_writes.html.

14 Patrick Primavesi spricht zu Recht von einer zurückbleibenden »Enttäuschung im besten Sinn, [einem] Schrecken über die Folterähnlichkeit dieser Schreibarbeit« (57). 


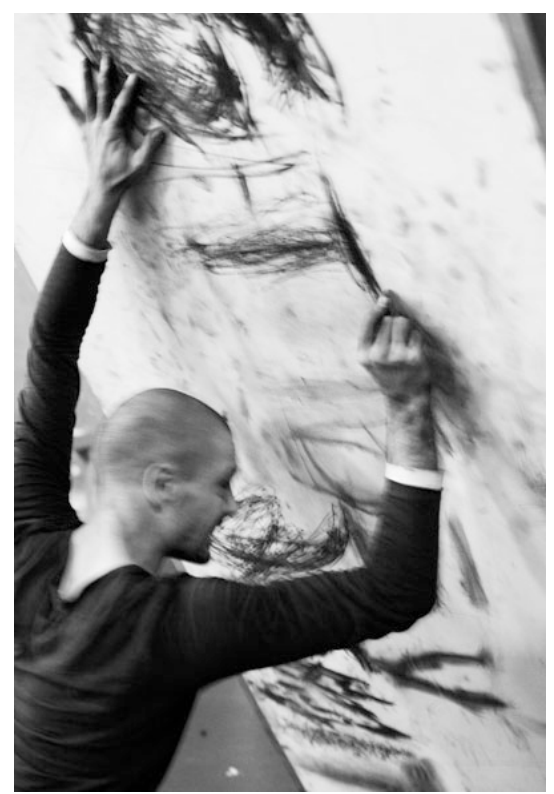

verweist. Zurück bleiben Bewegungszeichnungen, die Spuren jener Körperbewegungen tragen, über die sich verschiedene Körper in Beziehung gesetzt haben. Mit jener performativen Kunst der Installation, die sich »gegen einen objektivistischen Begriff von Kunst und ihrer Erfahrung richtet « (Rebentisch: 81), eröffnet Forsythe ein Arrangement, in dem Körper, Bewegung, Schrift, Töne, Bilder (Neue Medien), Dinge und Materialien in eine Beziehung des ReAgierens inmitten von Vermögen und Unvermögen treten.

\section{Abbildung 3: Ander Zabala in HUMAN WRITES (2006). Foto: (C) Dominik Mentzos.}

\section{YOU MADE ME A MONSTER (2005)}

Auch in YOU MADE ME A MONSTER ${ }^{15}$ ist eine Intermedialität am Werk, die sich als choreographische Kunst des In-Beziehung-Setzens entfaltet und die ästhetische Praxis des Betrachtens reflektiert. Gegenüber HUMAN WRITES agieren die Tänzer hier inmitten einer performativen Bewegungsführung, die die Zerstörung ihrer geordneten Erscheinung medialisiert.

YOU MADE ME A MONSTER bringt in persona von »my wife« die am 13. Februar 1994 verstorbene Tänzerin Tracy Kai Maier des Ballett Frankfurt (1989-1994) und Lebenspartnerin von Forsythe in Erinnerung, die - wie alle Besucher aus einem ausliegenden Text erfahren - einem Krebsleiden erlag. ${ }^{16}$ Der Text erscheint als Laufspur auf einer groß aufgespannten Videoleinwand, die eine Seite der offen begehbaren Aufführungsfläche säumt. Bei Eintritt in den Performanceraum fallen zunächst jene auf großen Tischen ausgelegten Bastelbögen aus beige-farbiger Pappe auf, in die Schablonen der menschlichen Anatomie gestanzt sind. Mit Hilfe von Klammern und Gestellen können die Besucher ihre Segmente zusammenbauen, umgeben von einem wummernden, schrill-surrenden und hämmernden Klangvolumen. Mehrere Performer bewegen sich improvisatorisch durch sie hindurch und

15 You MADE ME A MONSTER. Performance Installation von William Forsythe. Premiere: 28.05.2005, Teatro Piccolo Arsenale, Venedig. $50 \mathrm{~min}$.

16 Die Unfassbarkeit jenes Krankheitsverlaufes schildert der Ich-Erzähler in knappen Sätzen. Berichtet wird von falschen und voreingenommenen Diagnosen seitens der Ärzte, einem nicht enden wollenden Blutfluss während der Probenarbeit zu ALIE/NA(C)TION (1992), einer als gelungen eingestuften Operation und jenem unmerklichen Beugen des Körpers, das schließlich zum Tode führte. Erzählt wird auch von Ridley Scotts Science Fiction-Film ALIEN, in dem ein fremder Körper territorial in einen anderen eindringt und ihn besetzt. 
stoßen im dramatischen Crescendo spitze erbärmliche Schreie ins Mikrofon, keuchen und röcheln. Inmitten inwendiger Bewegungsekstasen veräußern sie jenes erbärmliche Leiden eines kranken Körpers, das ihn von Innen her auswuchert und des eigenen Gefühls beraubt, ihn aushöhlt, beugt und umstülpt, bis er monströs entstellt ist: YOU MADE ME A MONSTER.

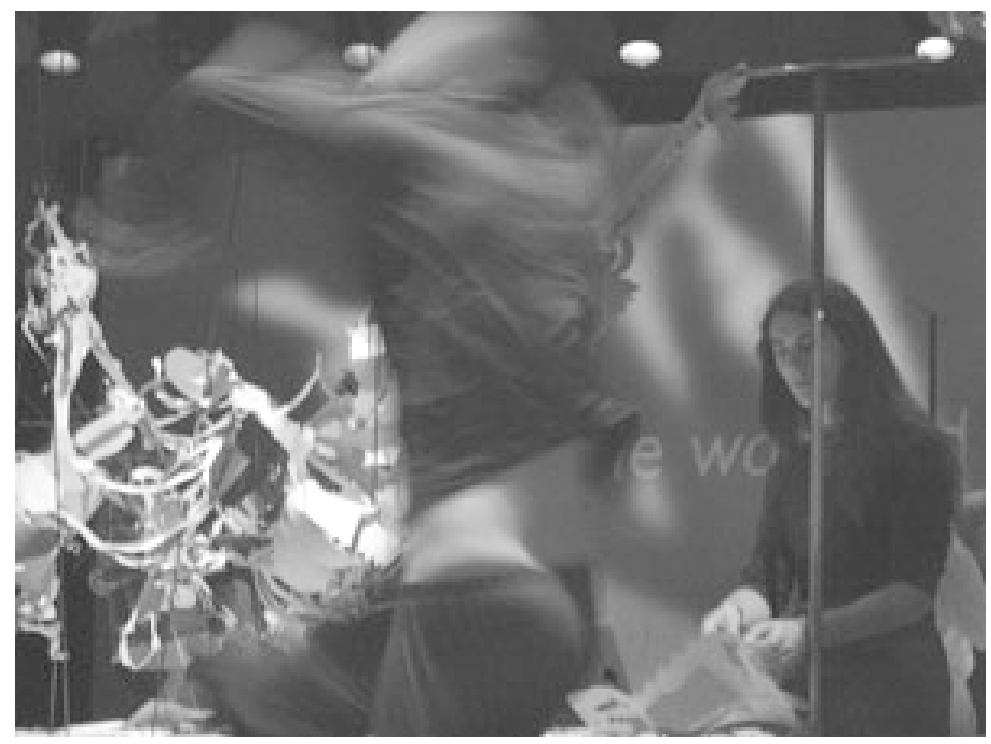

Abbildung 4: Besucherin und Christopher Roman in YOU MADE ME A MONSTER. Foto: Marion Rossi. (C) The Forsythe Company.

Der Abend entfaltet den Krankheitsverlauf intermedial. Materialien, Formgebilde, Videobilder, Klänge, Stimmen und Geräusche treffen inmitten sich-bewegender Körper und Blicke aufeinander, ohne sich pathetisch in einem Satz oder klaren Bildern festzuschreiben. Stattdessen liegt ein atmosphärisches Grauen über der Szenerie, eingesunken in die Handlungen der Besucher und Bewegungen der Performer. Ein performatives Geflecht des Gefühligen breitet sich in dem abgedunkelten Raum aus, der den Besuchern stets die Wahl lässt, die Tänzer zu beobachten, dem Erzählgang auf dem Videoschirm zu folgen oder Bastelbögen zu anatomischen Gebilden zusammenzusetzen. Inmitten des Geflechts aus Blicken und Aktionen nehmen die Performer, anders als in HUMAN WRITES, keinerlei Kontakt mit den Besuchern auf.

Der physische Verfall selbst wird zum choreographischen Fixpunkt, den die Performer improvisatorisch anspielen. Ihre Bewegungen medialisieren das Leiden, zeichnen es metaphorisch auf: Tanzen im Sinne einer körperlich-energetischen Bewegungsleidenschaft findet nicht statt. Stattdessen operieren die Tänzer innerhalb strenger thematischer Bezüge, die ihre Bewegungen kontradiktorisch organisieren. Ihre Wahrnehmung ist auf all jene Momente gerichtet, die sich dem eigenen Körper in den Weg setzen, sich entgegenschrauben, unwillkürlich entstehen, um woanders zu landen, in anderen Zeiten und Rhythmen. Die Körper greifen unter steten Wahrnehmungsshifts in ein Anderes, rücken in fremde Terrains vor und gebären Fremdartiges. 


\section{Der choreographierte Körper als Medium der Wahrnehmung}

YOU MADE ME A MONSTER und HUMAN WRITES reihen sich bruchlos in den choreographischen Grundgedanken von Forsythe ein, Denken in Bewegung als einen intermedialen Prozess des Körperlichen zu zeigen. Die Abläufe verschränken projizierte, imaginierte, physisch-reale und organische Körper, die längst zu einer eigenen improvisatorischen Technik der Company geworden ist (vgl. Siegmund; Huschka 2004). Dabei greifen die Tänzer auf Techniken ihres angeeigneten Körperwissens zurück, um sich durch dessen Strukturen und Operationen hindurch neu zu organisieren. Ihr Fokus richtet sich nicht auf ein virtuoses oder fluidal schönes Antlitz ihrer Bewegungskörper, sondern darauf, der Bewegung auf der Spur zu bleiben, um »residuals «, wie es Nicole Peisl und David Kern in einem persönlichen Interview beschrieben haben, ${ }^{17} \mathrm{zu}$ finden: Löcher im eigenen Bewegungswissen. Die Kunst des Nicht-intentionalen, eines nachhörenden Achtgebens auf den Körper, basiert auf performativen Wahrnehmungsvollzügen. Der Körper wird zum Medium einer Wahrnehmungsarbeit, in der verschiedene mentale und physische $\mathrm{Zu}$ stände zusammentreten, um einen Performance-Körper zu bilden, der, wie auch Dana Caspersen reflektiert, in Kommunikation mit erinnerten, gefilmten, projizierten oder imaginierten Körpern steht.

Wie wenig diese Wahrnehmungsvollzüge nachzuzeichnen sind, sondern allein medialisiert durch Bewegung auftreten, zeigen die improvisatorischen Sequenzen von Forsythe in den Installationen von Peter Welz. Als Materialgrundlage verwandt, tritt Forsythe in einen intermedialen Prozess, der sein Körperwissen in Korrespondenz zu einem Satz (whenever on on on nohow on / airdrawing) und einem Bild bringt. In RETRANSLATION / FINAL UNFINISHED PORTRAIT (FRANCIS BACON) trifft Forsythe auf ein unvollendetes Portrait von Francis Bacon und improvisiert. Die Bewegungen zeichnen die Zeichnung von Bacon voluminös nach, indem Forsythe seinen Körper auf die Spur jener aufscheinenden Figürlichkeit in der Zeichnung setzt. Eine intermediale Beziehung von Bild, Körper und Bewegung, die Welz in seine Videoarbeit überträgt und installativ ausstellt. Es dominiert eine performative Beziehung von Sichtbarem und Unsichtbarem, Wissen und Nicht-Wissen, die verschiedene Körper als Bewegungszeichnung in Kontakt führt.

»Yes, in fact, when I draw I think sculpture: I am trying to use my body as an invisible sculpture template, and the drawing is in the end just what >got in the way« (Lista: 31). Die Zeichnung setzt sich dem Körper in den Weg. Den Körper als Schablone zu benutzen, ihn zu entleeren, ohne ihn zu entmaterialisieren markiert jenen Ort, an dem Choreographie beginnt und endet. Dieser choreographische Ort ist für Forsythe wie Michel Foucault (25f) jene »gnadenlose Topie, [...] von dem es kein Entrinnen gibt, an den ich verdammt bin«.

17 Nicole Peisl und David Kern im Gespräch mit Sabine Huschka anlässlich einer Aufführung von HUMAN WRITES in Dresden, Festspielhaus Hellerau im September 2006. Unveröffentlicht. 


\section{Literatur}

Caspersen, Dana (2004): »Der Körper denkt: Form, Sehen, Disziplin und Tanzen«. In: Siegmund (Hg.): Denken in Bewegung, S. 107-116.

deLaHunte, Scott (2006): »Sharing Questions of Movement«. In: Maaike Bleeker/Lucia van Heeteren/Chiel Kattenbelt/Kees Vuyk (Hg): De theatermaker als onderzoeker: Theater Topics II. Amsterdam: University Press, S. 182-186.

Foucault, Michel (2005): Die Heterotopien. Der utopische Körper. Zwei Radiovorträge. Frankfurt/M.: Suhrkamp.

Haffner, Nick (2001): »Multimediale Partnerschaften. Perspektiven von Tanz und Technologie«. In: Martina Leeker (Hg.): Maschinen, Medien, Performances. Theater an der Schnittstelle zu digitalen Welten. Berlin (Europäische Werkstatt für Kunst und Kultur Hellerau e.V.), S. 295-305.

Hüser, Gisela/Manfred Grauer (2005): »Technologischer Wandel und Medienumbrüche «. In: Ralf Schnell/Georg Stanitzek (Hg.): Ephemeres. Mediale Innovationen 1900/2000. Bielefeld: transcript, S. 193-216.

Huschka, Sabine (2004): »Verlöschen als ästhetischer Fluchtpunkt«. In: Siegmund (Hg): Denken in Bewegung, S. 95-106.

Huschka, Sabine (2005): »Hinter den Spiegel sich wendend. Die vergängliche Ballettkunst von William Forsythe«. In: Erika Fischer-Lichte/Matthias Warstat/Christian Horn (Hg.): Diskurse des Theatralen. Basel: Francke, S. 65-88.

Lista, Marcella (2006): »A figure in space, Interview with William Forsythe and Peter Welz by Marcella Lista«. In: Corps étrangers. Ausstellungskatalog. Musée du Louvre. Lyon: Fage éditions, S. 18-37.

Primavesi, Patrick (2007): »Was schreibt die Geste«. In: ballettanz. 13. (no 1), S. 54-57.

Rebentisch, Juliane (2003): Ästhetik der Installation. Frankfurt/M.: Suhrkamp.

Siegmund, Gerald (Hg.) (2004): Denken in Bewegung. Der Choreograf William Forsythe. Berlin: Henschel.

Siegmund, Gerald (2006): Abwesenheit. Eine performative Ästhetik des Tanzes. William Forsythe, Jerome Bel, Xavier Le Roy, Meg Stuart. Bielefeld: transcript.

Snyder, Joel (2002): »Sichtbarmachung und Sichtbarkeit«. In: Peter Geimer (Hg): Ordnungen der Sichtbarkeit. Fotografie in Wissenschaft, Kunst und Technologie. Frankfurt/M.: Suhrkamp, S. 142-167.

ZKM Karlsruhe/Deutsches Tanzarchiv Köln/SK Stiftung Kultur (Hg.): William Forsythe: Improvisation Technologies. Karlsruhe: ZKM digital arts edition. 


\title{
Zur Medialität des Performativen \\ IM ZEITGENÖSSISCHEN TANZ/THEATER
}

\author{
SABINE SÖRGEL
}

\section{Theoretische Vorüberlegungen}

»Das Theater - als System - ist heute ein konservatives, statisches Medium für Randgruppen« (Faulstich: 41).

Betrachtet man das Theater aus der medienwissenschaftlichen Perspektive als System, so bezieht man sich dabei oft - wie hier exemplarisch Werner Faulstich ausschließlich auf die sich gesellschaftlich wandelnde Institution und weniger die ontologische Bestimmung des Theaters in seiner medienspezifischen Differenz. Hingegen widerlegt gerade die letztere Perspektive im Vergleich zu entwicklungsgeschichtlich späteren Medien Faulstichs These der Statik des Systems, ist doch mithin gerade das Wesen des Theaters als ältestes Medium der Menschheit, dass es 1.) prozessual in Erscheinung tritt und 2.) den vergänglichen Menschen selbst in den Mittelpunkt der medialen Verhandlung stellt. Als Ort ist das Theater damit zwar anthropozentrisch orientiert, aber keinesfalls »Menschmedium « per se, wie das Werner Faulstich in erwähnter Studie weiter zu fassen sucht (2004). Das physische Vis-à-vis zwischen Darstellern und Rezipienten im Theater kreiert somit die ontologische Grundvoraussetzung von Theater - die medial vermittelte Wahrnehmung des Selbst im Anderen - und damit einhergehend jenen komplexen Grad kritischer (Selbst)Reflexion über mediale Wahrnehmungs- und Vermittlungsstrategien, den man in neueren Medien nicht selten vermisst. Vielmehr ist Theater also im Sinne Peter Brooks zu verstehen als jener oft zitierte »leere Raum« (1969) performativer Identitätsbestimmung von Kultur und Gesellschaft schlechthin, der fast immer und überall gegenwärtig werden kann und dazu nicht notwendig der Institution als solcher bedarf. Aufgrund seiner ontologischen Phänomenalität ist das Theater somit eben nicht nur semiotischer, sondern auch kinästhetischer Raum, was mitunter das medienspezifische Differenzkriterium des Theaters zu anderen Medien auszumachen scheint.

So sind Schauspieler und Tänzer auf der Bühne interessanterweise nie >Mensch allein, sondern eben die >Figur $<$ - jenes sonderbare Zwitterwesen zwischen Anrufung und Inbesitznahme vormals göttlicher, heute zumeist nur mehr egozentrischer, bestenfalls diffizil körpertechnischer Inspiration. Die Figur ereignet sich demzufolge im Zwischenraum der Darstellung und Rezeption. Als simultan individuell und/oder kollektiv wahrgenommene Sinngebung, tritt die Figur also im Sinne körperlicher Aneignung einer wie auch immer aufzufassenden Rolle, Tanztechnik oder metaphysischen Inspiration als deren Präsenz oder Anwesenheit vor Ort, wenngleich sie selbst paradoxerweise als solche abwesend bleibt. Die Figur ist auf dem Theater als solche also weniger intellektuell zu fassen als viel mehr kinästhetisch 
spürbar, verbleibt sie doch am Nicht-Ort der Imagination. Wie Einar Schleef, der Doyen körperlicher Chorexerzitien, diesen Zusammenhang zwischen Anrufung, Theater und Tod im Interview mit Helmut Schödel so treffend erklärt:

»Das ist Erinnerung. Das ist Anwesenheit. Die Toten sind anwesend. Und die sprechen? Logo. Das kann man doch keinem aufgeklärten Menschen erzählen. Sagen Sie, die antworten auch? Klar. Aber logo. Das sind Mitteilungen an die Seele. Das sind Obsessionen. Ich habe diese Obsessionen nie vermieden. Vielleicht ruft man die Toten auch an, daß sie über einen kommen. Wie im Theater. Im Theater ist das doch auch ganz klar. Der Schauspieler wird von seiner Figur eingenommen. Er ruft sie an. Das Kostüm ist nur ein Hilfsmittel. In anderen Kulturen weiß man das« (Schleef: 42).

Entgegen einer solchen Ontologie des Körpertheaters verkünden Thesen wie die Paul Virilios (vgl. 1996) jedoch zeitgleich die Endzeit des handelnden Körpers im digitalen Zeitalter. Angesichts der vermeintlichen Übermacht der schnellen Medien wie Fernsehen, Film, Tagespresse und Internet, prophezeit die Medientheorie nunmehr den Untergang des »klapprigen Vehikels« Theater, das sich in Anbetracht der Allgegenwart medialer Bildtransformation nahezu vom Verschwinden bedroht sehe. ${ }^{1}$ Ob der Körper aber - insbesondere im Theater und Tanz der Gegenwart tatsächlich so unwiederbringlich entrückt erscheint, wie Virilio das unter dem Stichwort der »Eroberung des Körpers « durch die neuen Medien suggeriert, wirkt fraglich, wenn man neben den bereits erwähnten noch weitere ästhetische Positionen zeitgenössischer Regisseure und Choreographen näher in den Blick nimmt.

\section{Medialität und Körpergedächtnis: Der Tanzkörper zwischen Präsenz und Abwesenheit}

Während die postmoderne Kritik in den letzten Jahrzehnten des vergangen Jahrhunderts mehr oder minder erfolgreich versucht hat, alle Essentialismen aus den Diskursen zu vertreiben, hält sich - wie bereits gezeigt - ein Essentialismus doch recht hartnäckig: der des Körpers. Nur wer oder was dieser Körper uns heute noch sein soll, wird zunehmend kritisch in Zweifel gezogen. Im Zuge zeitgenössischer Theoriebildung zu Performanz und Performativität erscheint es daher sinnvoller, heute von Formen der Verkörperung denn von dem Körper per se zu sprechen, insofern der Körper in seiner Prozessualität nicht länger als fixes Objekt oder Subjekt der Analyse gedacht werden kann (vgl. Fischer-Lichte/Horn/Warstat; Fraser/Greco; Siegmund). Interessanterweise jedoch spielt das zeitgenössische Tanztheater genau auf den leisen Zwischentönen dieses Akkords zeitgenössischer Dekonstruktion, insofern die Phänomenalität des Tanz-Körpers sich beständig zwischen Präsenz und Auflösung temporärer Identitätsentwürfe und individueller Biografie-Analyse bewegt (vgl. Sörgel 2006).

Sarah Kanes dramatisches Werk - insbesondere die beiden letzten Stücke GIER und 4.48 PSYCHOSIS, die vielfältig autobiographisch gelesen wurden - findet in diesem Zusammenhang mit Wanda Golonkas Regiearbeiten am Schauspiel Frankfurt eine nahezu kongeniale tänzerische Umsetzung solch postdramatisch-performativer

1 Die Metapher des »klapprigen Vehikels « für die Rolle des Theaters im digitalen Zeitalter entlehnt sich einem Zitat der Gießener Performance-Gruppe Showcase Beat Le Mot. 
Subjektkonstitution (vgl. Lehmann 1999). Während sich das Publikum in Golonkas A VERY LONG SILENCE. 4.48 PSYCHOSIS, auf frei hängenden Schaukeln über die Probebühne des Frankfurter Schauspiels im Raum verteilt - wortwörtlich in schwebender Bewegung - fand, bildet die Dynamik des Arena-Arrangements für GIER einen gruppendynamischen Kreiseffekt durch zwei eng hintereinander liegende Publikumsreihen in eben jenem Raum. Durch die Wahl der intimen Atmosphäre der Probebühne kreiert die Regisseurin so einen Ort der verhältnismäßig unmittelbaren Übertragung kinästhetischer Energien zwischen Zuschauern und Performer/n. Sowohl in 4.48 PSYCHOSIS als auch in GIER wird das Publikum körperlich von der Energie der Performer affiziert, die oftmals auf Augenhöhe im Umkreis sich nahezu überlappender Kinesphären zwischen Zuschauern und Performern agieren. Phänomenalität und Zeichenhaftigkeit der Textinterpretation treten damit reziprok in Erscheinung, insofern die selbstbezügliche Materialität des Schauspielerkörpers und seine Aussage als theatrale Konfiguration ein dichtes Spannungsgefüge etablieren. Als besonders interessanter Aspekt solch theatral überformter Ritualität in Golonkas GIER erscheint im Zusammenhang dieser Analyse neben dem von mir bereits besprochenen Rückbezug auf die Tanzmoderne (vgl. Sörgel 2006) vor allem der darin implizite empathische Gestus in der vertanzten Auseinandersetzung mit der Autorenfigur Sarah Kane, die als Abwesende - gerade in der autobiographischen Lesart der beiden letzten Stücke - hier nun in unsere Mitte zwischen Performern und Zuschauern als abwesend-präsente Figur imaginiert wird.

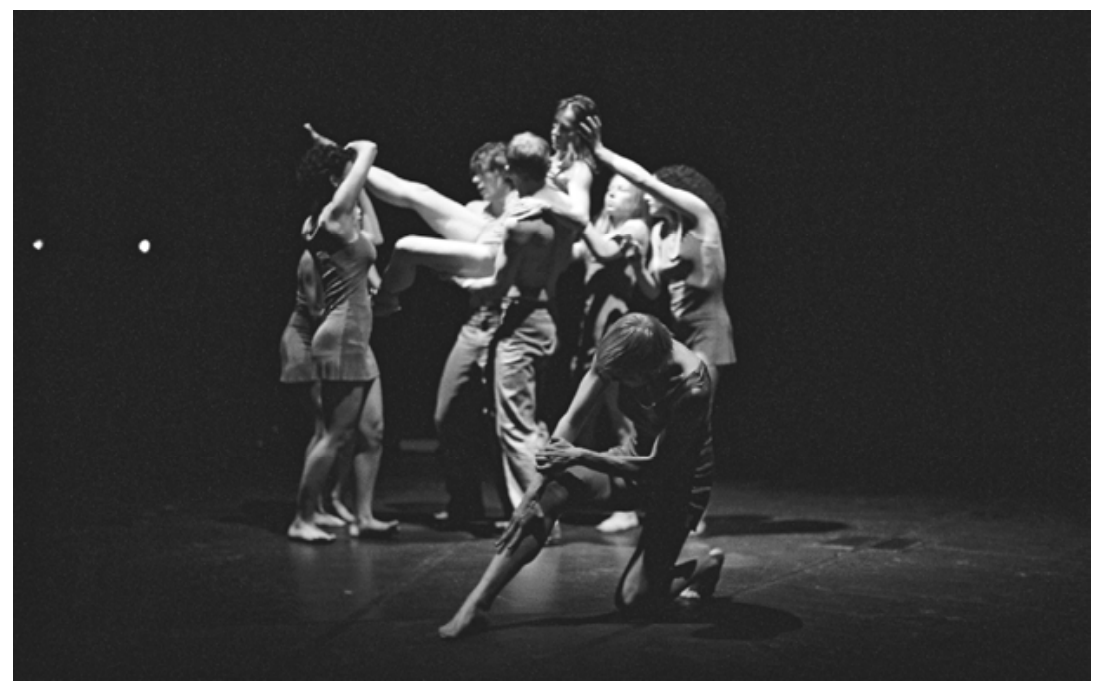

Abbildung 1: Ensemble in Wanda Golonka: GIER. Foto: (C) Yvonne Kranz.

In der direkten Gegenüberstellung von sowohl chorischen wie monadischen Figurationssequenzen der Tanzchoreographie vollführen die Tänzer wechselweise Solopartien in zeitgenössischem Vokabular sowie Chorsequenzen des neo-expressionistisch/modernen Repertoires, was in der Opposition den Chor gegen das Individuum auszuspielen scheint. Entgegen den fließend-tragenden Bewegungen der Gruppe agiert der Einzelne kontrastiv in gebrochen-kontraktiven Bewegungsmustern des zeitgenössischen Tanzrepertoires, welche die autobiographische Lesart der Inszenierung als innere Vielstimmigkeit der Autorenfigur sowie die damit einhergehende 
Möglichkeit zur psychologischen Teilidentifikation auf Seiten der Rezeption zwar nicht erzwingen, aber durchaus im Sinne der Schleefschen Beschwörung der Autorin als abwesend/präsente Figur zulassen. ${ }^{2}$ Wie David Greig festgestellt hat, besteht die Stärke der elliptischen Schreibweise Kanes dabei gerade darin, das Persönliche allgemeingültig werden zu lassen, indem sie den Raum für die Imagination des $\mathrm{Zu}$ schauers öffnet:

»It is as though by excavating herself rather than attempting to capture an invented character's consciousness, Kane has opened her writing out to the audience, leaving a space in which they can place themselves and their own experience« (Greig: xiv).

Diese poetische Offenheit der Sehnsuchtsmotivik des Stücks zieht sich in der körperlichen Übertragung als Bewegungsmotor durch die Choreographie und bietet dem Zuschauer sowohl imaginative als auch körperliche Assoziationspunkte. Als erweiterte Variation eines solchen Assoziationsraums der Rezeption wiederholt Golonkas Inszenierung nahezu motivisch den Monolog des A, dessen monotone Musikalität in der französischen Übersetzung als monologisch-wiederkehrendes InSich-Selbst-Kreisen bis zur transzendierenden Identitätsauflösung bzw. des kreisenden Verschmelzens der Figuren/Zuschaueridentität zusätzlich betont wird:

$»[\ldots]$ und in der Stadt herumirren und denken sie ist leer ohne dich und wollen was du willst und denken ich verliere mich selbst aber wissen dass ich in Sicherheit bin bei dir und dir das Schlimmste von mir erzählen und versuchen dir mein Bestes zu geben weil du kein bisschen weniger verdienst und deine Fragen beantworten wenn ich es lieber nicht täte und

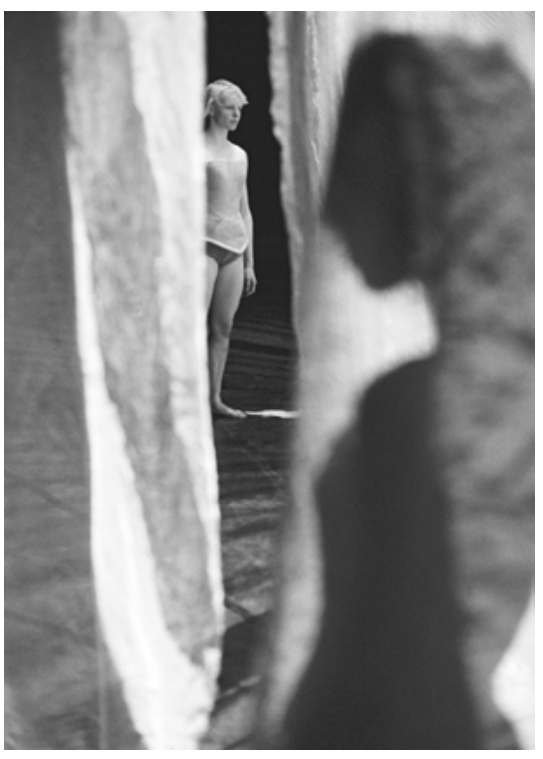
dir die Wahrheit sagen wenn ich es wirklich nicht will und versuchen ehrlich $\mathrm{zu}$ sein weil ich weiß das ist dir lieber und denken es ist alles vorbei aber noch wenigstens zehn Minuten ausharren bevor du mich rausschmeißen wirst aus deinem Leben und vergessen wer ich bin und versuchen dir näher zu kommen weil es schön ist dich kennen zu lernen und die Mühe sehr wert und in schlechtem Deutsch auf dich einreden und hebräisch noch schlechter und mit dir schlafen um drei Uhr morgens und irgendwie irgendwie irgendwie etwas mitteilen von der überwältigenden unsterblichen übermächtigen bedingungslosen allesumfassenden herzbereichernden verstanderweiternden anhaltenden niemalsendenden Liebe die ich für dich empfinde« (Kane 1999: 63). ${ }^{3}$

Abbildung 2: Anne Mueller in Wanda Golonka: GIER. Foto: (C) Yvonne Kranz.

2 David Greig hat in diesem Zusammenhang auf die Musikalität des dramatischen Texts als Vielstimmigkeit des fragmentierten Selbst verwiesen (ix-xviii).

3 Vgl. hierzu auch Programmheft zu GIER, Schauspiel Frankfurt 2006. 


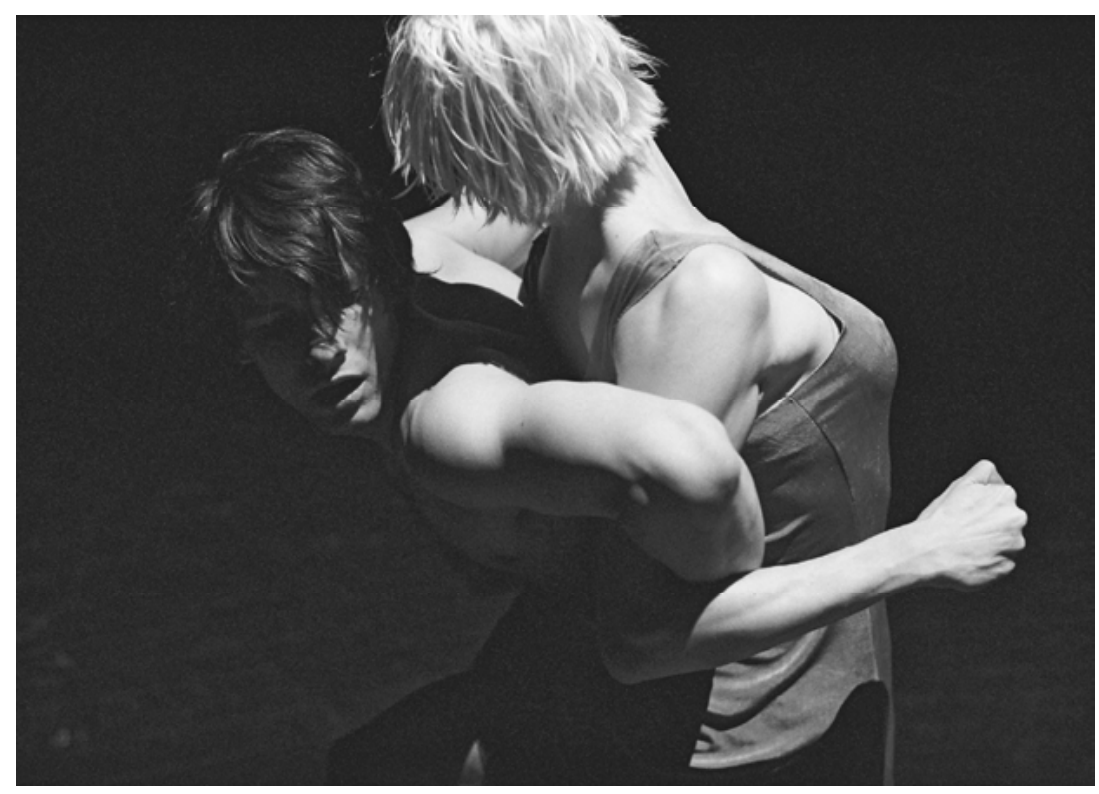

Abbildung 3: Bert Tischendorf und Anne Mueller in Wanda Golonka: GIER. Foto: (C) Yvonne Kranz.

Wanda Golonkas Inszenierung greift diese metaphorisch-kreisende Textschleife somit nicht nur für die choreographisch-akustische Gestaltung des Raums auf - der den rituellen Kreis über die Arenabühne zusätzlich als knarrende Holzdielenkonstruktion performativ gleich einer langsam mahlenden Drehmühlenrotation als Soundscape in Erscheinung treten lässt -, sondern erweitert diesen in Hinblick auf die Funktion des Zuschauers, der gleichsam zum Mit-Tänzer wird, eingenommen von der Figur der Autorin, die vermittels der TanzKörperBilder in ihm oder ihr selbst entsteht. Während die Performer also im Kreis direkt an den Zuschauern vorbei laufen, nimmt der Zuschauer sich selbst als ohrenbetäubend monoton Gedrehter war, ganz so als säße man auf einer sich langsam fortbewegenden Karussellmaschinerie.

Wenngleich dieser Effekt einer optischen Täuschung geschuldet ist, dient er doch der Verunsicherung und gleichsam wirkenden Entrückung des Zuschauers, dessen derart in Bewegung gesetzte Körperlichkeit für die Einnahme der Figur geöffnet wird, wie dies im Übrigen ganz ähnlich mit den Schaukeln für 4.48 PsYCHOSIS funktioniert. Indem wir uns als Zuschauer selbst im Kreis drehen, den Monolog wieder und wieder hören, den Bewegungen der Tänzer in der Intimität der Atmosphäre direkt folgen, wird körperliche Nähe beinahe unmittelbar auf der eigenen Haut spürbar, schreiben sich Wärme und Atem der Performer bis in die zweite Reihe ins Gesicht der Zuschauer und rufen so eine Vielzahl körperlicher Reize und deren ureigene Körpererinnerungen im jeweiligen Gedächtnis wach. Es ist diese Art der körperlichen Erinnerung kinästhetischer Verletzlichkeit, vermittels derer wir als Zuschauer schließlich selbst in den Kreis vorrücken, ja die Gemeinschaft im Sinne des geteilten Körpergedächtnisses wahrnehmen können. Als gemeinsam erspürtes Gedenken tritt so zum einen die Figur Sarah Kanes, zum anderen das uns allen gegenwärtige Trauma der Individuation und ihrer uneingelösten 
Sehnsucht nach Berührung und Geborgenheit vor Augen. Der rituelle Kreis wird damit zum bestimmenden Vektor der Inszenierung, die im Stück selbst wie folgt thematisch wird:

»Ein Kreis ist die einzige geometrische Form, die von ihrem Zentrum definiert wird. Keine Frage nach Huhn oder Ei, erst kam das Zentrum, der Umfang folgt. Die Erde hat, per Definition, ein Zentrum. Und nur der Depp, der das weiß, kann hingehn, wo es ihm gefällt, weil er weiß, das Zentrum wird ihn unten halten, verhindern, dass er aus der Umlaufbahn fliegt. Aber wenn sich dein Sinn fürs Zentrum verschiebt und schwirrend an die Oberfläche kommt, dann ist das Gleichgewicht weg. Das Gleichgewicht ist weg. Das Gleichgewicht, mein Kleines, ist weg« (Kane 1999: 66).

Selbstredend ist der Kreis als Zentrum der Inszenierung nicht nur eine intertextuelle Referenz auf den Modernismus von W. B. Yeats, dessen Gedicht THE SECOND COMING (1919) Kane hier zu paraphrasieren scheint (»Turning and turning in the widening gyre/ The falcon cannot hear the falconer;/ Things fall apart; the centre cannot hold «), sondern gleichzeitig auch eine theaterspezifische Referenz auf die Medialität des Tanzes und mithin auch des Theaters in seinem chorischen Ursprung, dessen elementarste Form der rituellen Gemeinschaft eben auch der archaische Kreis ist.

Tatsächlich transformiert die kinästhetische Intensität der körperlichen Darstellung den Betrachter dahingehend, dass er der modernen Vereinzelung des Individuums im Theater auf merkwürdige Weise zugleich nahe und entrückt gegenübersteht. Körperlich eingenommen von der Kinästhesie der Performer, dem dadurch lebendig werdenden eigenen Körpergedächtnis sowie der gemeinsamen Beschwörung der Autorenfigur über den Text, oszilliert somit eine Vielzahl subjektiver Körpereinschreibungen im theatralen Raum, der das individuelle Erinnern zur gemeinschaftlichen Empathie gerinnen lässt. Zwar ist die jung verstorbene Autorin selbst abwesend, sie wird dennoch in einem jeden Zuschauer individuell präsent als verklärter Mythos einer allgemein menschlichen Verletzlichkeit des eigenen Körperbilds als Subjekt in der Bewegung. Wie Gerald Siegmund (44f) beschreibt:

»Handelt es sich im Tanz doch stets um Subjekte in Bewegung, um Subjekte, die sich durch Bewegung konstituieren, indem sie sich mit jeder neu anhebenden Bewegung wieder verlieren. Der Raum des Subjekts wird gleichsam mit jeder Bewegung erneut ausgehoben als dynamischer Raum, der dem Subjekt erst einen Ort gibt, von dem aus es sprechen können wird. Die Bewegung ist, diesseits ihrer spezifischen Codifizierungen in Tanztechniken, keine Sprache. Sie ist, obwohl sie sich immer in ihr befindet, Geste auf diese hin. Der Weg, den das Subjekt zu diesem Ort zurücklegen wird, ist sein Tanz. Tanz ist Abwesenheit, die mit jeder Bewegung wiederholt und wiedergeholt wird «.

Wenngleich also die Bewegung keine im Sinne der Sprache kodifizierte ist, trägt doch jeder Zuschauer seinen individuellen Code körperlicher Erinnerung, der sich hier kommuniziert. Und vielleicht wäre gerade dieser Akt des Wiederholens solcher Erinnerung aus den psychologischen Untiefen des Körpergedächtnisses, jener U-Topos menschlichen Begehrens nach Co-Präsenz. Denn wenngleich der Andere uns uneinholbar entrückt, ermöglicht gerade die theatrale Aneignung der Figur die vielleicht weitestgehende Identifikation. Wie Siegmund für den Begriff der Abwesenheit - der ja keine »Leere« manifestiert - beschreibt: 
»In der Erfahrung des Tanzes geht es um mehr als um den intentionalen und intersubjektiv abgesicherten Austausch von Zeichen. Vielmehr impliziert sie das Subjekt in seinem Sein, dessen Grenzen im liminalen Raum der Bühne neu gezogen werden können. Die Abwesenheit als Motor eines Subjektentwurfs bezeichnet jedoch keine Leere. Durch das Vergehen der Bewegung, die sich in ihrer Flüchtigkeit ständig neu hervorbringt, schreibt sich die Abwesenheit in die Bewegung selbst ein. Damit höhlt sie einen Zwischenraum aus, der das, was ansonsten unerfahrbar bliebe, aufscheinen lässt« (Siegmund: 104f).

So erwiese sich letztlich das Theater als Ort des kollektiven Gedächtnisses, d.h. der Anwesenheit des Abwesenden in der Anrufung der Figur. Die mediale Ontologie des Theaters beruht demnach bei aller Abwesenheit dennoch auf der menschlichen Co-Präsenz als Konfrontation des Selbst mit dem Anderen. Dies allerdings ist keinesfalls neu und auch nicht überholt: Tanz und Theater als älteste Menschmedien der Kommunikation wissen seit jeher um die menschliche Misere, die Uneinholbarkeit des Subjekts in freiem Fall, wenngleich sie darum nicht müde werden, den Menschen in seinen vielfältigen Figurationen beständig neu gegen die Grausamkeit der Götter und weltlichen Götzen zu behaupten.

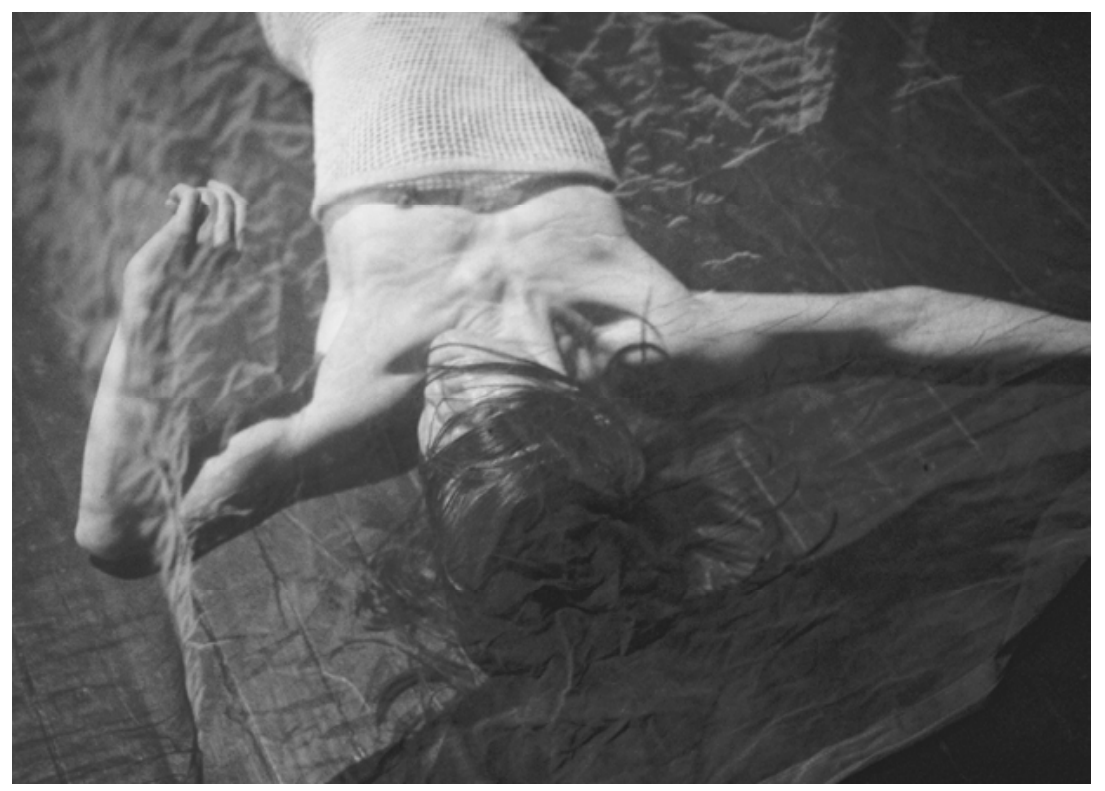

Abbildung 5: Véronique Dubin in Wanda Golonka: GIER. Foto: (C) Yvonne Kranz.

\section{Abschließende Bemerkung}

»Im traditionellen Sprechtheater hat der Schauspieler den Traum vom Individuum zu erfüllen - aber wo gibt's denn heute ein Individuum? >Bei mir zu Hause ist kein Individuum da bin ich, und da ist der Fernseher« (Einar Schleef in: Kümmel: 33). 
Wenn das traditionelle Sprechtheater dergestalt dem ontologischen Bedürfnis nicht länger Rechnung trägt und auch der Fernseher der Individuation entsagt, so ist vielleicht eine der letzten möglichen Freiheiten, die des tanzenden Körpers und seiner kinästhetischen Grenzüberschreitungen des individualisierten Subjekts. Zwar hat Günther Heeg (19f) in diesem Zusammenhang eher kritisch auf den Chor als »Wiedergänger « und »Gespenst « der postmodernen Gesellschaft verwiesen, dessen Wiederauftauchen im Theater der Gegenwart er als »ästhetisches Surrogat « der utopiefernen Sinnleere zeitgenössischer Regiearbeiten zu deuten versucht. Und doch: wäre nicht gerade der Kern dieses Surrogats darin begründet, den Körper, sein Gedächtnis und die damit einhergehenden Genealogien erneut bedeutsam werden zu lassen, d.h. insofern er in seiner Phänomenalität den symbolischen Widerpart zur visuell-logozentrischen Diskursivität als verkörperten Habitus unserer normierten Gesellschaft gebiert? Ganz so wie in GIER der Chor das Gedächtnis Sarah Kanes beschwört und damit unsere innere Vielstimmigkeit zum Klingen bringt, so coagiert auch der Zuschauerkörper, wenn das Theater seine anrufende Macht wirksam werden lässt. Mag das Theater der Medienwissenschaft also durchaus als »ein konservatives Medium für Randgruppen « gelten, so kann hier abschließend nur darauf verwiesen werden, dass ja gerade für den interkulturellen Zusammenhang es häufig »Randgruppen « und prophetische Stotterer gewesen sind, von deren theatraler Imagination ausgehend der gesellschaftliche Widerstand nicht selten revolutionär wirksam wurde (vgl. Sörgel 2007). Wie ein sehr weises jamaikanisches Sprichwort unserer westlichen Trauer um Vergänglichkeit verheißt:

»We call the dead, they answer,

We call the living, they do not answer.

The dry leaves on the earth are dead,

crackle when trodden on

whereas green leaves, the living,

make no sound when we step

on them.«

\section{Literatur}

Brook, Peter (1969): Der leere Raum. Hamburg: Hoffman und Campe.

Faulstich, Werner (2004): Medienwissenschaft. München: Fink.

Fischer-Lichte, Erika/Christian Horn/Matthias Warstat (Hg.) (2001): Verkörperung. Tübingen und Basel: Francke.

Fraser, Mariam/Monica Greco (Hg.) (2005): The Body. A Reader. London und New York: Routledge.

Greig, David (2001): »Introduction«. In: Sarah Kane: Complete Plays. London: Methuen Drama.

Heeg, Günther (2006): »Chorzeit. Sechs Miniaturen zur Wiederkehr des Chors in der Gegenwart «. In: Theater der Zeit, (4), S. 19-23.

Kane, Sarah (1999): Gier. Dt. Marius von Mayenburg. In: Theater Heute (12), S. 60-67.

Kane, Sarah (2001): Complete Plays. London: Methuen Drama.

Kümmel, Peter (2001): »Der Chor ist wahr, das Individuum lügt«. In: Die Zeit, 09.08.2001, S. 33. 
Lehmann, Hans-Thies (1999): Postdramatisches Theater. Frankfurt/M.: Verlag der Autoren.

Schleef, Einar (1997): »Beim Tanzen ist man dem Tod am nächsten«. In: Die Zeit, 04.07.1997, S. 41-42.

Siegmund, Gerald (2006): Abwesenheit. Eine performative Ästhetik des Tanzes. Bielefeld: transcript.

Sörgel, Sabine (2006): »Tanz(Ge)schichte(n) der Moderne im Tanztheater der Gegenwart am Beispiel von Kurt Jooss, Pina Bausch, Sasha Waltz und Wanda Golonka«. In: Forum Modernes Theater (21/1), S. 61-78.

Sörgel, Sabine (2007): Dancing Postcolonialism. The National Dance Theatre Company of Jamaica. Bielefeld: transcript.

Virilio, Paul (1996): Die Eroberung des Körpers. Vom Übermenschen zum Überreizten Menschen. Frankfurt/M.: Fischer Taschenbuch. 



\title{
Die PROMISKUITÄT DER MUSIK - ÜBER INTERMEDIALE VERFREMDUNGSSTRATEGIEN IN DER ZEITGENÖSSISCHEN INSZENIERUNG VON OPER
}

\author{
ROBERT SOLLICH
}

Die Affinität zwischen medienwissenschaftlichen Forschungsperspektiven und dem Phänomen »Theater« ist in den letzten Jahren vielfältig beschrieben und dabei gerne auf die grundlegende Hybridität von Theater abgehoben worden. Im Gegensatz zu anderen Künsten integriert Theater bekanntlich notwendig Elemente ganz unterschiedlicher materieller Provenienz wie Raum, Körper, Objekte und Licht und setzt sie zueinander in Beziehung. Aufgrund eben dieses permanenten »synchronen und diachronen Einsatz(es) verschiedener Zeichensysteme, Medien und Materialien«, formuliert in diesem Sinne exemplarisch Doris Kolesch (238), eigne dem Theater eine konstitutive Multimedialität, die es wiederum zu einem privilegierten Feld für intermediale Operationen mache.

Geht man von einer solchen Veranlagung des Theaters im Allgemeinen aus, dann spricht einiges dafür, diese im Musiktheater im Besonderen als noch einmal gesteigert anzunehmen. Ist die beschworene Hybridität, die sich aus der Konfrontation der beteiligten medialen Faktoren ergibt, hier doch grundsätzlich noch einmal dadurch verschärft, dass mit der Musik eine weitere hochkomplexe, in anderen Theaterformen eher randständige Komponente hinzutritt, die auf der Ebene des Klanges das übrige theatrale Geschehen gleichsam kommentiert und dabei - wie gezeigt werden soll - auf dessen Wahrnehmung notwendig einwirkt. Die Hypothese, dass visuelle und auditive Wahrnehmung schwerlich voneinander abzukoppeln, sondern immer aufeinander bezogen sind und sich Musiktheater insofern kaum je im bloßen multimedialen »Nebeneinander medialer Zitate und Elemente « erschöpft, sondern konsequent auf das »konzeptionelle [eben inter-mediale] Miteinander « (so ein Differenzierungsvorschlag von Jürgen E. Müller: 31) zielt, möchte ich im Folgenden exemplarisch aufführungsanalytisch zu untermauern versuchen. Dabei wird mein Augenmerk nicht auf Beispiele aus dem Bereich des sogenannten »neuen«, häufig mit technischen Medien experimentierenden Musiktheaters gerichtet sein, wo dieser Zusammenhang womöglich von spontan größerer Evidenz ist. Vielmehr will ich mich hier der zeitgenössischen Inszenierung von Oper widmen, für die der intermediale Charakter meines Erachtens jedoch mindestens ebenso einschlägig ist. Das, was wir uns angewöhnt haben, denkbar unscharf, mit dem Begriff »Regietheater « zu bezeichnen, hat, so meine These, ganz maßgeblich mit wechselseitigen Austauschprozessen zwischen traditionell in der Kunstbetrachtung als distinkt angesehenen Erscheinungen zu tun.

Das Zusammenspiel verschiedener Medien in einem künstlerischen Zusammenhang ist als ästhetische Realität selbstredend sehr viel älter als der Begriff der Intermedialität. Die Tatsache, dass diese ästhetische Realität über lange Zeit so wenig Beachtung fand und der Begriff eben erst in jüngerer Zeit theoretisch 
ausgearbeitet wurde, hängt mutmaßlich mit seinem Störpotential gegenüber einer traditionell auf »Arbeitsteiligkeiten und Spezialisierungen« (Müller: 32) aufbauenden kunstwissenschaftlichen Praxis zusammen. Dort wo die Idee »isolierter Medien-Monaden«, wie Müller (31) es nennt, auch vormals nie wirklich glaubhaft behauptet werden konnte, also etwa beim Theater, bestand die Strategie dann zumeist in einer strengen Hierarchisierung der verschiedenen medialen Bestandteile. Das legitimierte es vermeintlich, sie wiederum separat zu betrachten, und lief im Falle der Oper meistens auf eine Nachordnung der Szene hinter bzw. unter die Musik hinaus. Warum derlei Rangordnungen - wie sie vom Prima la musica-Streit des 18. Jahrhunderts bis zur »Werktreue«-Debatte unserer Tage gepflegt worden sind den heterogenen Gegenstand »Musiktheater« notwendig verfehlen und dass sie zumal dort in die Irre gehen, wo mit der Theatralisierung der Oper in den letzten Jahrzehnten eine Emanzipation der Szene vom Primat der Musik programmatisch geworden ist, möchte ich hier in einer Einzelfallstudie zu skizzieren versuchen.

Ein Wort der Klärung noch vorab: Intermedialität im Theater wird gerne mit der Verwendung technischer Medien assoziiert, wie sie in der jüngeren Vergangenheit auf dem Theater selbstverständlich geworden ist. Mein Medienbegriff ist demgegenüber im Anschluss an Koleschs und Müllers Ausführungen dezidiert weiter gefasst, weshalb hier eine Inszenierung exemplarisch betrachtet werden kann, die sich auf die Benutzung »klassischer « Medien des Theaters beschränkt, also den sich im Raum bewegenden Körper und den sich gleichfalls im Raum entfaltenden Klang des Orchesters und der menschlichen (Sing-)Stimme: Peter Konwitschnys 1995 in Leipzig entstandene Interpretation von Peter Tschaikowskis EUGEN ONEGIN. Die Konzentration soll dabei einer einzigen Sequenz der Inszenierung gelten, die man allerdings mit einigem Recht als deren Schlüsselszene begreifen kann. Es handelt sich um den Moment des Übergangs vom II. auf den III. Akt, wo das Publikum in den meisten Inszenierungen - durchaus mit gutem Grund - in die Pause geschickt wird. Markiert die Aktpause doch einen Zeitsprung von etlichen Jahren. Der Titelheld Eugen Onegin hat die stürmischen Liebesbekenntnisse der jungen Landadligen Tatjana in den ersten Akten zurückgewiesen, woraufhin sich beide aus den Augen verloren. Zufällig begegnen sie sich Jahre später wieder auf einem Fest im Hause des Fürsten Gremin, dessen Frau Tatjana mittlerweile geworden ist. Noch bevor es zum unverhofften Wiedersehen kommt, erklingt zum Auftakt des Balles eine Polonaise, die mit ihrem eingängigen, auftrumpfenden G-DurThema zur mutmaßlich bekanntesten Nummer der Oper avancierte und deren Bekanntheit jene der übrigen Oper bei weitem übersteigt.

So populär Tschaikowskis Polonaise beim Publikum geworden ist, so unspektakulär nimmt sich gleichzeitig ihre akademische Rezeption aus. Viele Stückanalysen befassen sich mit ihr gar nicht erst, offenbar weil ihnen die Machart uninteressant simpel, die musikalisch-dramaturgische Funktion allzu evident erscheint. Wo sie doch Forschungsgegenstand ist, wird sie fast durchgängig als Stück Lokal- bzw. Sozialkolorit begriffen, in dem, wie stellvertretend der sowjetische Musikwissenschaftler Boris Assafjew-Glebow (105) formuliert, »der Prunk und die eitle Geschäftigkeit der großen Welt « paradierend vorbeiziehe und das Motiv der »von Onegin gesuchten Zerstreuung « zum Ausdruck komme. Auch Ulrich Schreiber (756) unterstreicht die atmosphärische Funktion der Nummer und beschreibt sie als Kontrastmittel, als »Totale gegenüber der jeweiligen Großaufnahme, die jede Hauptfigur der drei Akte in Monologen zeigt«.

Von Prunk oder von Zerstreuung hat die Polonaise bei Konwitschny indes herzlich wenig, auch einen Perspektivwechsel realisiert sie nicht. Sie ist nicht ein- 
mal Bestandteil eines Balles, sondern an die vorangegangene Szene herangerückt und damit in einen völlig neuen Kontext gestellt. Anders als in vielen »herkömmlichen « Inszenierungen bildet sie hier nicht den Auftakt zum zweiten Teil des Abends, vielmehr hat die Pause schon zwischen den beiden Szenen des zweiten Aktes stattgefunden. Danach ist es zum fatalen Duell gekommen, in dem Onegin seinen Freund Lenskij aus einem nichtigen Grund erschießt, und an das der Beginn des III. Aktes unmittelbar anschließt. Der Schuss und die letzten Takte des zweiten Aktes sind kaum verklungen, der Halbkreis der sich um die Leiche Lenskijs gebildet hat, löst sich gerade erst auf, da platzen die den Tanz eröffnenden Fanfaren der Blechbläser in die Stille hinein, zu deren Klängen Onegin den leblosen Freund heftig schüttelt, an sich drückt und ihn in dieser Pose mit sich über das Parkett zu schleifen beginnt. Der große aristokratische Reigen, der sonst an dieser Stelle zumeist in Szene gesetzt ist, wird mithin ersetzt durch einen makaberen Pas de deux auf kahler Bühne.

$\mathrm{Zu}$ analysieren, was im beschriebenen Ausschnitt der Aufführung geschieht, namentlich das Verhältnis zwischen Szene und Musik zu bestimmen, tut sich die Opernforschung methodisch nach wie vor sehr schwer. Noch immer großer Beliebtheit erfreuen sich dort orthodoxe hermeneutische Positionen, die von einem unhintergehbaren, aufzuschließenden Stückkern ausgehen und Inszenierungen normativ auf die Übersetzung dessen verpflichten. Folgte man dieser Prämisse, dann ließe die offenkundige Diskrepanz zwischen den von mir herbeizitierten philologischen Exegesen und der betrachteten szenischen Interpretation nur zwei Schlussfolgerungen zu: Entweder läge die Regie falsch oder die wissenschaftliche Deutung irrte. Beides geht hier jedenfalls offenkundig nicht in eins. Was Assafjew konstatiert hat, wird bei Konwitschny konsequent dementiert, ja nachgerade in sein Gegenteil verkehrt. Das prunkvolle Defilée bleibt aus. Die Fanfaren spielen nicht auf zum fröhlichen Tanz, sondern begleiten einen weinenden Onegin beim verzweifelten Totentanz mit der Leiche des Freundes.

Damit verwandelt sich auch die emotionale Wirkung der vorgeblich so heiteren Musik. Was gewöhnlich die Atmosphäre pulsierenden gesellschaftlichen Trubels heraufbeschwört, ruft in der Leipziger Inszenierung geradezu konträre Empfindungen hervor. Statt den Raum zu weiten, erfüllt mich als Rezipient dieselbe blechlastige Musik mit eisiger Beklemmung. Was ist passiert, dass uns eine bekannte Musik auf einmal so anders in den Ohren klingt? Kaum zusammenhängen kann die differente Wahrnehmung damit, dass das Leipziger Gewandhausorchester das bekannte Stück hier fundamental anders interpretiert hätte. Es ist rein musikalisch durchaus als solches wiedererkennbar und überrascht weder hinsichtlich der Instrumentation, noch der Tempi oder sonstiger musikalischer Parameter. Wenn wir es dennoch ganz anders hören, so muss dies als Indiz dafür gelten, dass bestimmte Erkenntnisse aus der Synästhesieforschung auch vor ästhetischen Erfahrungen im Musiktheater nicht haltmachen: Unsere Sinne funktionieren keineswegs autonom, sondern vermögen einander heftig zu durchkreuzen. Im schlechtesten Fall mag das dazu führen, dass sich Ton- und Bildspur gänzlich voneinander abkoppeln und man die verschiedenen wahrgenommenen Daten als völlig zusammenhanglos empfindet. In der beschriebenen Szene jedoch erwächst aus der Spannung zwischen den vermeintlich konkurrierenden Eindrücken, jedenfalls in meiner Wahrnehmung, keine Abstoßungsreaktion. Vielmehr lassen sich die zunächst widersprüchlichen Informationen, die wir auf den unterschiedlichen Kanälen der Wahrnehmung erhalten, umgehend äußerst produktiv aufeinander beziehen. Das von den gravitätischen Trompetenklängen normalerweise provozierte Gefühl der Weite eines repräsentati- 
ven Gesellschaftsraums verkehrt sich unter dem Eindruck des großen, kargen Bühnenraumes so einerseits zu einem Gefühl der Leere, im Angesicht der an Onegin klebenden Leiche andererseits zu einem Gefühl der Beklemmung.

Das Verblüffende an der geschilderten Sequenz bestand dabei für mich in der Selbstverständlichkeit, mit der hier Szene und Musik miteinander »reagierten « und die mitgebrachten Vorerwartungen an die Wirkung der Musik abgeschüttelt waren. Obgleich der orchestral angeschlagene Tanzrhythmus nicht wirklich von den Darstellern aufgenommen und in elegante Schrittfolgen übersetzt, sondern durch die eckigen, schwerfälligen Bewegungen eigentlich konterkariert wurde, wirkte die audiovisuelle Liaison so zwingend, als hätte man die Musik nie anders gehört und als könnte man sich als Rezipient gegen den behaupteten Zusammenhang gar nicht verwehren. Und doch liegt genau dort, in der Rezeption, natürlich der Schlüssel zum »intermedialen Miteinander «. Nur wenn wir unterschiedliche mediale, gleichzeitig stattfindende Ereignisse aufeinander beziehen können, vermögen die unterschiedlichen Medien Körper, Raum und Klang miteinander zu interagieren, kann die Musik, deren herkömmliche Wirkung von Assafjew und Schreiber ja durchaus treffend beschrieben ist, von der Szene gleichsam adaptiert werden. Inwieweit dies ge- oder misslingt, ist, wie die zahlreichen Publikumskonflikte gerade in der Oper belegen, ganz vom individuellen Rezipienten abhängig.

Bei Prozessen der audiovisuellen Anverwandlung, wie hier beschrieben, handelt es sich natürlich nicht um eine Einbahnstraße. Vielmehr hat man es dabei mit Wechselwirkungen zu tun, bei denen sich visuelle und auditive Wahrnehmung reziprok zu destabilisieren und mit neuen Attributen semantisch und emotional aufzuladen vermögen. Inwieweit diese Operation genauso auch in die umgekehrte als die von mir beschriebene Richtung funktioniert, sich also eine visuelle Erscheinung von akustischen Ereignissen beeindrucken lässt, ist trefflich an Phänomenen wie der Filmmusik oder der Verwendung von Musik etwa in der Werbung zu studieren. Im zeitgenössischen Operntheater mit seinem Repertoirebetrieb hingegen scheint mir die Veränderung der Musik durch die Szene zu dominieren. Schließlich ist die Musik hier die Konstante, ihre Wiederholung Programm. Die Ausprägung eines überschaubaren und nunmehr seit Jahrzehnten relativ stabilen Stückekanons ist als Zug der Musealisierung der Gattung Oper immer wieder heftig beklagt worden. Paradoxerweise birgt derlei gleichzeitig, wie hier zu sehen, jedoch auch ein Potential der Innovation. Ist doch die Verengung des Repertoires auf wenige bekannte und immer wieder neu interpretierte Stücke die Voraussetzung für die beschriebenen audiovisuellen Durchkreuzungen, insofern sie eine Popularität einzelner musikalischer Einheiten mit sich brachte, die wiederum äußerst konkrete Erwartungen an deren »Bebilderung « zu provozieren neigt. Verlässt eine Inszenierung dann den Pfad der Konvention und begibt sich optisch in Differenz zu den semantischen und emotionalen Aufladungen der Musik, so vermag diese sich darüber selbst zu verändern. Nur weil etwas bekannt ist, so die dialektische Logik, kann es verfremdet werden und dann neue Bedeutungen annehmen ${ }^{1}$.

Wiederholung und Differenz sind mithin (nicht nur) in dieser Inszenierung eines Repertoire-Klassikers so fundamental wie dialektisch aufeinander bezogen. Innovativ ist die Wiederholung natürlich nur deshalb, weil sie nur scheinbar eine Wieder-Holung ist. Tatsächlich wird nie einfach etwas Vorgängiges bloß aktuali-

1 Die Hypothese, im Falle Konwitschnys mit dem Begriff der Verfremdung durchaus in seiner berühmtesten, nämlich der brecht'schen Ausprägung operieren zu können, vermag im Rahmen dieses Textes nur geäußert, nicht erörtert werden. 
siert, sondern in dieser Aktualisierung unweigerlich »ent-stellt« (Frank: 207). Dabei ist die Abweichung freilich nicht ohne die Konvention, von der sie abweicht, zu denken. Die Wirkung der Szene speist sich nicht nur aus dem, was gemacht wird, sondern auch aus dem, was nicht gemacht wird, aus der Reibung an der Erwartungshaltung des Rezipienten. Unverkennbar schwingt in Konwitschnys Inszenierung von Tschaikowskis Polonaise die alte Hörgewohnheit mit ihren Bedeutungen noch im Dementi nach. In seiner Traurigkeit zu ergreifen vermag der Moment gerade in der Erinnerung an die hier ins Gegenteil verkehrte Heiterkeit.

Auch diese nachklingenden, >herkömmlichen< Bedeutungen von Tschaikowskis Polonaise stellen freilich keine überzeitliche hermeneutische Wahrheit, kein »transzendentales Signifikat « (Derrida: 85) dar, sondern sind in jeder Hinsicht historisch kontingent. Zum einen, weil die Komposition auf Hörkonventionen rekurriert und bewusst an Gestaltungsprinzipien der Instrumentation, Ton- oder Taktart anknüpft, die in der Tradition der westlichen Musik mit bestimmten Zuschreibungen konnotiert sind - und dabei natürlich einem ständigen historischen Wandel unterliegen. Es wird doch niemand ernsthaft behaupten, dass wir einen Zugang zur Gefühlswelt beispielsweise von Tschaikowskis Zeitgenossen hätten. Zum anderen sind die Bedeutungen, die ein Assafjew oder ein Ulrich Schreiber der Musik zuschreiben, aber auch das Ergebnis der Rezeptionsgeschichte des konkreten Stückes. Wir assoziieren mit den Klängen der Polonaise die Atmosphäre einer mondänen Petersburger Adelsgesellschaft, weil die Inszenierungsgeschichte des Stückes es so »bebildert « und sich damit in die Musik eingebrannt hat. Dass insofern auch die kanonischen Lesarten von Stücken als bereits intermediale Konstruktionen zu begreifen, weil in ein permanentes performatives Spiel mit Bedeutungen eingebunden sind, musste die Werkästhetik nachgerade programmatisch ausblenden.

Einem performativen Spiel mit Bedeutungen unterworfen zu sein, würde Musik, wie sie in ihrer Theoriegeschichte so gerne als zumindest sprachähnlich charakterisiert worden ist, durchaus mit anderen Sprachen verbinden. Bereits Walter Benjamin hat bekanntlich, lange bevor der Begriff der Dekonstruktion etabliert war, mit der Vorstellung aufgeräumt, dass Sprache ein »verabredetes System von Zeichen ist « (1977: 212), und aus seinem dynamischen Verständnis von Sprache eine »Nachreife« auch von Texten abgeleitet. Selbst wenn ein Text äußerlich unberührt erhalten bleibt, so Benjamin, ist er doch aufgrund einer sich ändernden Umwelt einem ständigen Wandel unterworfen. Allein der Umstand, dass sich die Sprache, in der er gehalten ist, in der ständigen »Benutzung « permanent weiterentwickelt und dabei immerfort neue Bedeutungen ausprägt und alte Konnotationen in Vergessenheit geraten lässt, macht auch ihn zu einer höchst instabilen Erscheinung. »In seinem Fortleben «, heißt es dazu pointiert bei Benjamin (1991: 12), »ändert sich das Original. Es gibt eine Nachreife auch der festgelegten Worte «.

Es spricht einiges dafür, dass ein solches Prinzip der Nachreife im Falle der Musik, ganz grundsätzlich, besonders ausgeprägt ist. Auf die lange, in diesen $\mathrm{Zu}$ sammenhang zielende Diskussion über eine spezifische, anderen Zeichensystemen gegenüber möglicherweise unverbindlichere Semiotizität der Musik kann hier nur stichwortartig verwiesen werden (genannt seien stellvertretend Langer und Monelle). Festgehalten indes sei, dass die semantische Offenheit von Musik sich mutmaßlich dort nochmals potenziert, wo sie regelmäßig dem Theatergebrauch ausgesetzt ist. Indem sie sich an wechselnden Inszenierungen reibt, riskiert sie verschiedenste, sich immer wieder überschreibende Einschreibungen, was ich im Titel meines Beitrags etwas reißerisch als »Promiskuität« annonciert habe. 
Die fortwährende Ent-stellung von Bedeutungen durch audiovisuelle Dekonstruktionsprozesse wäre demnach als ein grundlegendes und unhintergehbares Prinzip in einem intermedialen Terrain wie dem des Musiktheaters zu begreifen. Einiges spricht gleichwohl dafür, dass dieses Prinzip mit dem sogenannten »Regietheater « in der Oper, der Verlagerung des »schöpferischen Ehrgeiz von der Produktion auf die Reproduktion«, wie es Leo Karl Gerhartz (538) bestimmt, eine besondere Dynamik bekommen hat und explizit geworden ist. Erstaunlicherweise schlagen derart dekonstruktivistische Figuren im Operndiskurs bislang kaum durch. Noch immer firmiert dort die vermeintliche Wahrheit der Werke als eine weithin verehrte heilige Kuh, nicht zuletzt interessanterweise unter den Regisseuren selbst. So kühn auch immer der inszenatorische Zugriff - fast immer wird er treu-hermeneutisch mit der »besseren Lektüre « gerechtfertigt, mit dem Argument, doch nur dem Werk zu seinem Recht verhelfen und es unter den falschen Konventionen der Aufführungstradition wieder zum Vorschein bringen zu wollen. Bei aller Attraktivität weist dieses Archäologie-Modell, das hier nach wie vor so gerne bemüht wird (vgl. etwa Zehelein), meines Erachtens aber mindestens insofern einen gravierenden Fehler auf, als es den Medienwechsel vom Werk in die Aufführung als unidirektionale Bewegung denkt. Tatsächlich vollzieht eine Inszenierung, zumal eine überzeugende, aber nicht nur eine Bewegung aus der Partitur heraus, sondern, wie ich zu zeigen versucht habe, auch eine Bewegung in die Partitur wieder hinein, insofern sie unser Verständnis eines Stückes wandeln kann und sich so in es einträgt. Sie wirkt auf das Stück, dem sie sich widmet, zurück, und dergestalt, mit Benjamin, auf dessen Nachreifeprozess ein. Ich jedenfalls höre die Polonaise seit Konwitschny anders.

\section{Literatur}

Assafjew-Glebow, Boris (1949): Tschaikowskys >Eugen Onegin<. Versuch einer Analyse des Stils und der musikalischen Dramaturgie. Potsdam: Potsdamer Verlagsgesellschaft.

Benjamin, Walter (1977): »Über das mimetische Vermögen«. In: Ders.: Gesammelte Schriften. Band II.1. Frankfurt/M.: Suhrkamp, S. 210-213.

Benjamin, Walter (1991): »Die Aufgabe des Übersetzers«. In: Ders.: Gesammelte Schriften, Band IV.1. Frankfurt/M.: Suhrkamp, S. 9-21.

Derrida, Jacques (1983): Grammatologie. Frankfurt/M.: Suhrkamp.

Frank, Manfred (1984): »Die Grenzen der Beherrschbarkeit der Sprache«. In: Philippe Forget (Hg.): Text und Interpretation. München: Fink, S. 181-213.

Gerhartz, Leo Karl (1981): »Regietheater im Opernhaus - Sakrileg oder Auftrag?« In: Österreichische Musikzeitschrift 36, 10-11, S. 530-538.

Kolesch, Doris (2002): »Robert Wilsons >Dantons Tod $<$ Das nomadische Auge und das Archiv der Geschichte«. In: Jutta Eming/Annette Jael Lehmann/Irmgard Maassen (Hg.): Mediale Performanzen. Historische Konzepte und Perspektiven. Freiburg/Br.: Rombach, S. 237-250.

Langer, Susanne K. (1979): Philosophie auf neuem Wege. Das Symbol im Denken, im Ritus und in der Kunst. Mittenwald: Mäander.

Monelle, Raymond (1992): Linguistics and semiotics in music. Philadelphia: Harwood Academic.

Müller, Jürgen E. (1998): »Intermedialität als poetologisches und medientheoretisches Konzept. Einige Reflexionen zu dessen Geschichte«. In: Jörg Helbig 
(Hg.): Intermedialität. Theorie und Praxis eines interdisziplinären Forschungsgebiets. Berlin: Erich Schmidt, S. 31-40.

Schreiber, Ulrich (2001): Opernführer für Fortgeschrittene. Die Geschichte des Musiktheaters. Das 19. Jahrhundert. Kassel: Bärenreiter.

Zehelein, Klaus (2002): »Archäologie als Metapher«. In: Juliane Votteler (Hg.): Musiktheater heute. Klaus Zehelein. Dramaturg und Intendant. Hamburg: Europäische Verlagsanstalt, S. 68-75. 



\title{
SIMULTANEITÄT - IMMATERIALITÄT - \\ PERFORMATIVITÄT. ASPEKTE DER INTEGRATION \\ ELEKTRONISCHER UND LIVE-ELEKTRONISCHER MEDIEN \\ IM ZEITGENÖSSISCHEN MUSIK-THEATER
}

\author{
REGINE ELZENHEIMER
}

\section{Bernd Alois Zimmermann: DIE SOLdATEN}

Reflektiert man den Medieneinsatz und den Aspekt des Multimedialen in der Geschichte des neueren Musiktheaters, so markiert Bernd Alois Zimmermanns Oper DiE SOLDATEN (1965) nach dem zweiten Weltkrieg eine initiale Position. Diese Oper hat nicht nur die Tabuisierung des diskreditierten Genres durch die Nachkriegsavantgarde und deren material- und fortschrittsorientierte, a-historische Ästhetik durchbrochen. Sie ist auch die musiktheatralische Ausformung einer von Zimmermann selbst »pluralistisch « genannten Kompositions-Ästhetik, die Ausdruck eines an Husserl und Bergson anschließenden komplexen Bewusstseinsmodells der Gleichzeitigkeit des Ungleichzeitigen ist. Zimmermanns Modell einer »Kugelgestalt der Zeit« (1974a: 35) als Verräumlichung zeitlichen Bewusstseins, als ZeitRaum, der den transitorischen Charakter von Musik aufhebt, liegt seiner Technik integralen Komponierens zugrunde: Er nutzte die einheitsstiftende Funktion der Reihe bei einer gleichzeitigen Pluralisierung der musikalischen Zeitschichten und des klanglichen Materials, unter anderem in der Verwendung musikalischer Zitate, Collagen und Allusionen. Dieses Prinzip der Gleichzeitigkeit verschiedener historischer und kultureller Schichten in einer pluralistischen Gegenwart hat Zimmermann in seiner zunächst als >unaufführbar geltenden Oper auf die theatralen und medialen Mittel im Sinne eines stotalen Theaters< ausgedehnt. Aus der Idee im Raum koexistierender Zeitschichten resultiert sein Entwurf einer »Zukunft der Oper« (so der gleichlautende Aufsatz), der sowohl architektonisch als auch in Bezug auf die intendierte Multimedialität an die Ideen des > Totaltheaters < anschließt, allerdings ohne dessen massenkulturellen politischen Impetus:

»Das neue Theater muß ein Großraumgefüge, vielfältig moduliert, sein; [...] mit Film-, Fernseh- und elektronischen Studios - das neue Theater wird notwendigerweise vor allem ein technisches Theater sein: ein Theater, welches nicht schlechter ausgerüstet sein sollte als ein Weltraumschiff, Weltraumschiff des Geistes; insgesamt eine Großformation, die einer ganzen Stadtlandschaft ihr Gepräge zu verleihen vermag: als Dokumentation einer geistigen, kulturellen Freiheit, die Theater als elementarsten Ort der Begegnung im weitesten Umfang begreift« (Zimmermann 1974b: 44f, Hervorh. i.O.).

Mit den SoldATEN evozierte Zimmermann Mitte der 60er Jahre völlig konträr zur >Nullpunkt<-Ästhetik von Karlheinz Stockhausen und Pierre Boulez sein Credo 
einer ästhetischen und geschichtlichen Simultanerfahrung, die sich musiktheatralisch auch durch den Einsatz verschiedener audiovisueller elektronischer Medien aktualisiert. Den im gleichnamigen Drama von Jakob Michael Reinhold Lenz sich immer mehr verdichtenden atemlosen Szenenwechsel zwischen über zehn verschiedenen Orten hat Zimmermann an zwei Stellen zu Simultanszenen zusammengedrängt und im vierten Akt die Heterogenität des aktuellen Bühnengeschehens durch die in der Partitur vorgeschriebene und zeitlich festgelegte Einspielung von vorproduziertem Bild- und Klang-Material auch medial in andere Zeit- und Bewusstseinsräume hinein erweitert. Die Möglichkeit einer szenischen Historisierung des Stückes wird durch eine multimediale kompositorische Verschränkung mit der jüngsten Vergangenheit des Zweiten Weltkriegs durchkreuzt. Sie ist jedoch so angelegt, dass auch eine historisierende Festlegung auf diesen Krieg nicht intendiert ist, vielmehr ist das Material der medialen Zuspiele so bestimmt, dass man hinter diesen nicht zurück kann. Gleichzeitig wird ein instabiles Verhältnis von Bühnen- und medialer Ebene angestrebt, wenn Zimmermann schreibt, dass die Filmleinwände »die Illusion nähren [sollen], daß das Filmgeschehen sich in die Szene hinein fortsetzt, resp. aus ihr hervorwächst« (o.J.: 427).

In der Vergewaltigungsszene - der zweiten großen Simultanszene - zu Beginn des vierten Aktes werden die Medien zum ersten Mal kumuliert. In der Partitur heißt es:

»Diese Szene hat den Charakter eines Traumes: das Geschehen mehrerer Szenen spielt sich, losgelöst von deren Raum und Zeit, der Handlung vorgreifend, auf sie zurückgreifend, gleichzeitig auf der Bühne, in drei Filmen, und in den Lautsprechern ab. [...] Diese Szene spielt - wie die gesamte Oper: heute, ebenso wie gestern und morgen « (Zimmermann o.J.: 427).

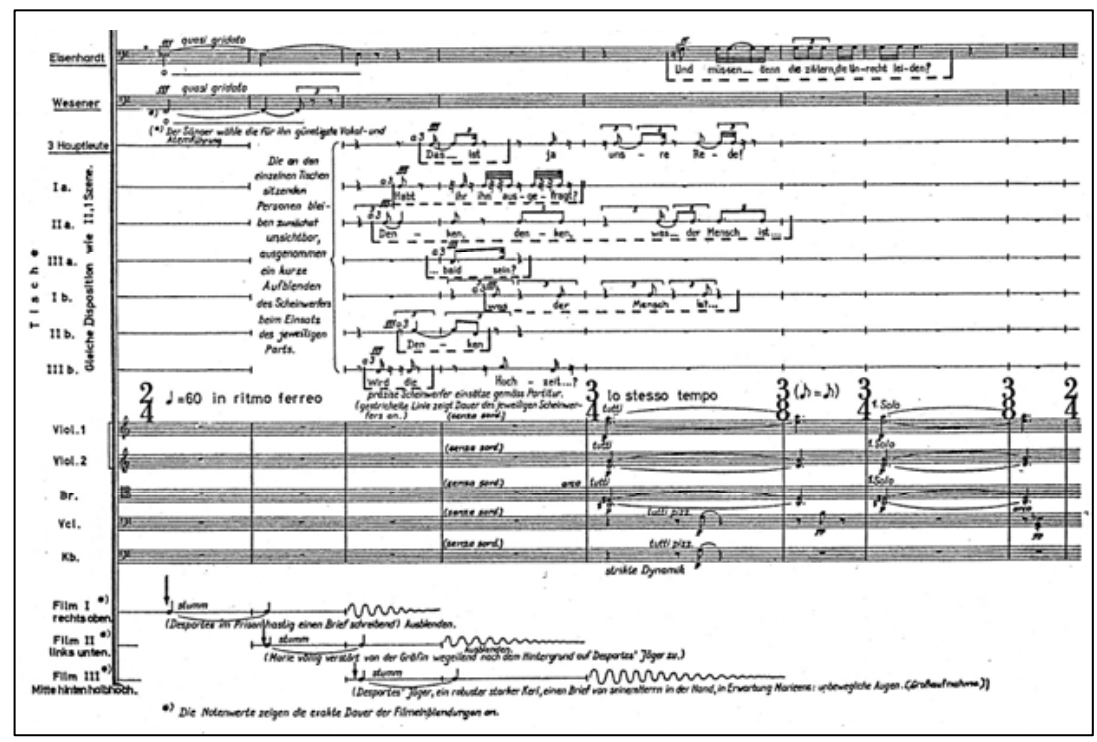

Abbildung 1: Bernd Alois Zimmermann, DIE SolDATEN, Partitur, S. 428. (C) Mit Genehmigung der Schott Music GmbH \& Co. KG, Mainz. 


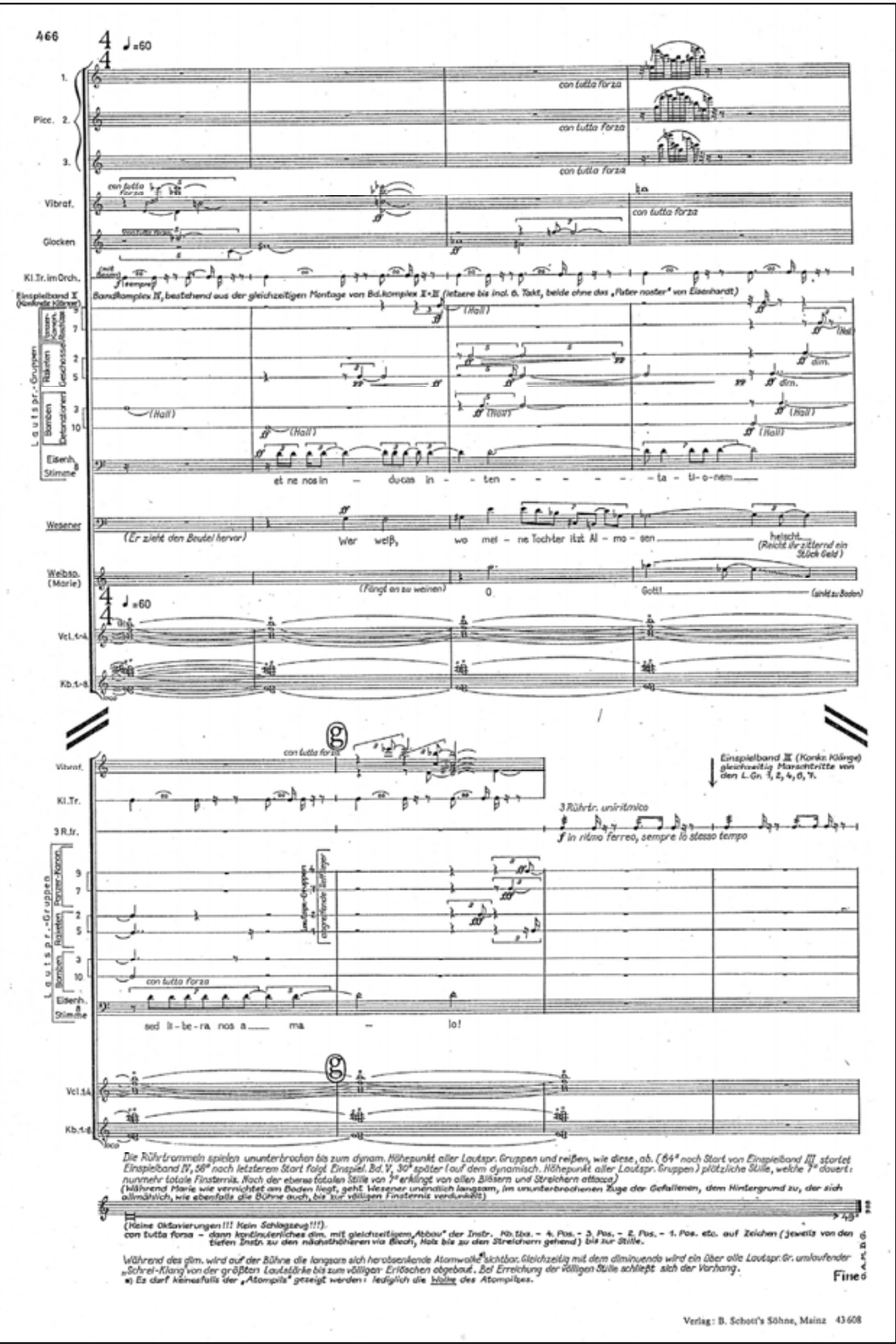

Abbildung 2: Bernd Alois Zimmermann, DIE SOLDATEN, Partitur, S.466. (C) Mit Genehmigung der Schott Music GmbH \& Co. KG, Mainz.

Die Szene, die auch eine Szene klanglicher und medialer Überwältigung ist, forciert die selektive Wahrnehmung und weist die medialen Mittel gleichzeitig als intermediales kompositorisches Element aus, das die Grenze von Stück und Insze- 
nierung instabil werden lässt. Ein verzichtender Eingriff wäre nicht nur eine Inszenierungsfrage, sondern zugleich ein Eingriff in den musikalischen Text. Das gleiche gilt für die Schlussszene, in der diese Simultaneität im Bild einer geschichtlichen Apokalypse kulminiert, in der musique concrète und Filme in Form von Militärgeräuschen und Kriegsszenen sich mit elementaren Lebensäußerungen von Liebe, Geburt, Tod und Glauben überlagern, bis die individuelle Katastrophe Maries mit der möglichen universalen Katastrophe atomarer Vernichtung zusammenfällt. ${ }^{1}$

Der Einsatz audiovisueller Medien ist hier integraler kompositorischer und nicht nur inszenatorischer Bestandteil, der die Trennung zwischen Text, Inszenierung und Aufführung destabilisiert. Während die Komposition über die visuellen Medien in die Inszenierung hineinreicht, ragen die Einspielbänder als quasi >gefrorene< Zeit auch in die aktuelle Aufführungszeit hinein. Somit wird Simultaneität nicht nur auf der inhaltlichen Ebene als ästhetische Erfahrung pluralistischer Wirklichkeit inszeniert, sondern sie bedeutet auch produktionsästhetisch einen Vorgang des Ineinanderschiebens von kompositorischer, inszenatorischer und AufführungsEbene.

\section{Luigi Nono: Prometeo}

Mit der Entwicklung der Live-Elektronik, die auf das kompositorische Interesse zurückzuführen ist, eine Verbindung zwischen den Errungenschaften der elektronischen Musik und den performativen Qualitäten der Live-Aufführung herzustellen, bekommt der Aspekt der Simultaneität eine weitere Dimension als Gleichzeitigkeit von Live-Klang und seiner elektronischen Transformation. In Luigi Nonos PROMETEO von 1984/85 wird hierdurch ein Moment von Performativität freigesetzt, das bereits bei der Entwicklung des Klang-Materials eine große Rolle spielt. Darüber hinaus war die Schaffung eines immateriellen elektronischen Klang-Raums ein wesentliches Interesse Nonos bei der Arbeit an seiner >Tragödie des Hörens<, die so nachhaltig wie vielleicht kein anderes Werk des Musik-Theaters die Frage nach den Grenzen des Genres und seinem traditionellen Gattungsmerkmal - der Darstellung - aufgeworfen hat. Eine kritische Reflexion der Repräsentation fand bei Nono vor allem über die Frage des Raumes statt. Zunächst ist das Stück eine inselhafte Anordnung von Klang-Gruppen und Zuschauern, die allein vom architektonischen Raum eine Alternative zur Monoperspektivität und Zweiteilung herkömmlicher Theaterräume erfordert. Für die Ur- und die Folgeaufführung des Stückes in San Lorenzo in Venedig und im Mailänder Stabilimento Ansaldo hatte der Architekt Renzo Piano in den Aufführungsraum seine berühmt gewordene $>$ Arche < hineingebaut: einen materialen Resonanzraum, eine großdimensionierte Holzkonstruktion, die Nono »[I]nstrument, und nicht: Bühnenbild « (47) nannte. Zusätzlich zu diesen beiden Räumen - dem geschichtlich-architektonischen und dem konstruierten ästhetischen Raum - kam ein durch die Live-Elektronik konsti-

1 Zimmermann hat mit Nachdruck notiert, dass am Schluss die Wolke des Atompilzes, nicht aber dieser selbst sichtbar werden soll, was ich als Indiz dafür ansehe, dass es nicht allein um die mit diesen Bildern verbundenen konkreten historischen Atombombenabwürfe im Zweiten Weltkrieg geht, sondern um das unkontrollierbar in die Zukunft reichende atomare Vernichtungspotential allgemein. Die Entstehung der Wolke markiert zudem bei der Atomexplosion den Moment der unkontrollierten Ausbreitung nach der Konzentration der Energie im sogenannten >Pilz<. 
tuierter immaterieller Klangraum. Das Hauptanliegen Nonos bestand darin, der Statik materialer Räume einen durch die Beweglichkeit des Klangs - den >suono mobile< - erzeugten nicht-statischen und nicht-bildlichen Raum entgegenzusetzen, was dazu führte, dass er nach der zweiten Aufführung auch auf die >Arche< verzichtete. Die Nutzung der Live-Elektronik im PrOMETEO und in Nonos Spätwerk überhaupt hatte eine doppelte Funktion: zum einen die der Analyse des klanglichen Materials im Hinblick auf seine akustisch nicht wahrnehmbaren, vor allem mikrotonalen Qualitäten. Zum anderen die aus dieser Analyse abgeleitete Erzeugung synthetischer Klänge durch elektronische Transformation der Live-Klänge in Echt-Zeit sowie die computerbasierte Steuerung von Synchronisations- und Raumverteilungsprozessen. Nonos Anspruch an die Live-Elektronik ist Benjamins Utopiebildung einer »gegenseitigen Durchdringung von Kunst und Wissenschaft « in seinem Kunstwerk-Aufsatz vergleichbar, wenn dieser dort die Möglichkeiten des Films darin beschreibt, das »Optisch-Unbewußte « wahrnehmbar $\mathrm{zu}$ machen und uns »eines ungeheuren und ungeahnten Spielraums [...] zu versichern«.

»Unter der Großaufnahme dehnt sich der Raum, unter der Zeitlupe die Bewegung. Und so wenig es bei der Vergrößerung sich um eine bloße Verdeutlichung dessen handelt, was man >ohnehin< undeutlich sieht, sondern vielmehr völlig neue Strukturbildungen der Materie zum Vorschein kommen, so wenig bringt die Zeitlupe nur bekannte Bewegungsmotive zum Vorschein, sondern sie entdeckt in diesen bekannten ganz unbekannte (Benjamin: 499f).

Nono überträgt diesen technisch vermittelten Möglichkeitssinn auf die immateriellen Strukturbildungen des Klangs als

»zu hörende Räume für neue Gedächtnisse, für unerhörte Augenblicke, für mehrdimensionale und unzeitliche Zeiten. [...] Und andere Gedanken werden auch in der technologischen Sprache entstehen, mit anderen Wahrnehmungsweisen und unerwarteten Hörweisen: das ist die Unruhe und die Angst vor dem Unbekannten« (Nono: 41, Hervorh. i.O.). ${ }^{2}$

Für Nono war der Einsatz und die Erforschung neuester technischer Medien im Sinne Wittgensteins auch eine Methode, durch das Wissen und das Wissbare hindurch (nicht an ihm vorbei und nicht in Opposition dazu) die Grenzen des Wissens zu zeigen. Man könnte mit Erika Fischer-Lichte auch von seiner »Unverfügbarkeit« (37) sprechen. Über diese Grenzen des Wissens ereignet sich bei Nono eine performative Erweiterung des Notentextes durch die Live-Elektronik. Zum einen generiert er sein kompositorisches Material in enger Zusammenarbeit mit den Interpreten im Studio und im Probenprozess. Zum anderen hat die gleichzeitige Anwesenheit des Klangs und seiner elektronischen Transformation in Jetzt-Zeit den Spielraum der Ausführenden insofern modifiziert und erweitert, als sie zwar nicht die programmierten Prozesse der Transformation, wohl aber die Nuancen der eingehenden Signale und damit die entstehenden Klänge beeinflussen und in einem ständigen dynamischen Prozess auf sich selbst und andere reagieren. Nono schreibt: »Der Spieler hört sich selbst, ein verwandeltes, im Raum irrendes Selbst, und greift immer wieder in sich selbst ein, in Realzeit (wie auch bei den anderen Spielern), interpretiert, dem Raum nachfolgend, dessen Artikulation« (47). Die elek-

2 Benjamin hatte die technischen Möglichkeiten des Films mit denen der Psychoanalyse verglichen, mit dem Wahrnehmbarwerden des »Triebhaft-Unbewußten« (500). 
tronische Transformation des Klangs durch Filter, seine dynamische Steuerung durch Gates, aber auch die raumzeitliche Manipulation durch Verzögerer oder die Bewegung des Klangs im Raum durch das Halaphon, also die räumliche und zeitliche Entfernung eines Klangs vom Ort seines individuell-körperlichen Impulses bis hin zur $>$ Unortbarkeit<, haben eine bewusst gesetzte destabilisierende Funktion bei der Ausführung, durch die der Interpret im Zugriff auf seine instrumental- und vokaltechnischen Gewissheiten irritiert und in seiner aktiven Gestaltung des fragilen Hier und Jetzt herausgefordert wird. Dieser Real-time-Prozess wird maßgeblich vom Klangregisseur mitgestaltet, der Spieler, Regisseur und Co-Komponist zugleich ist.
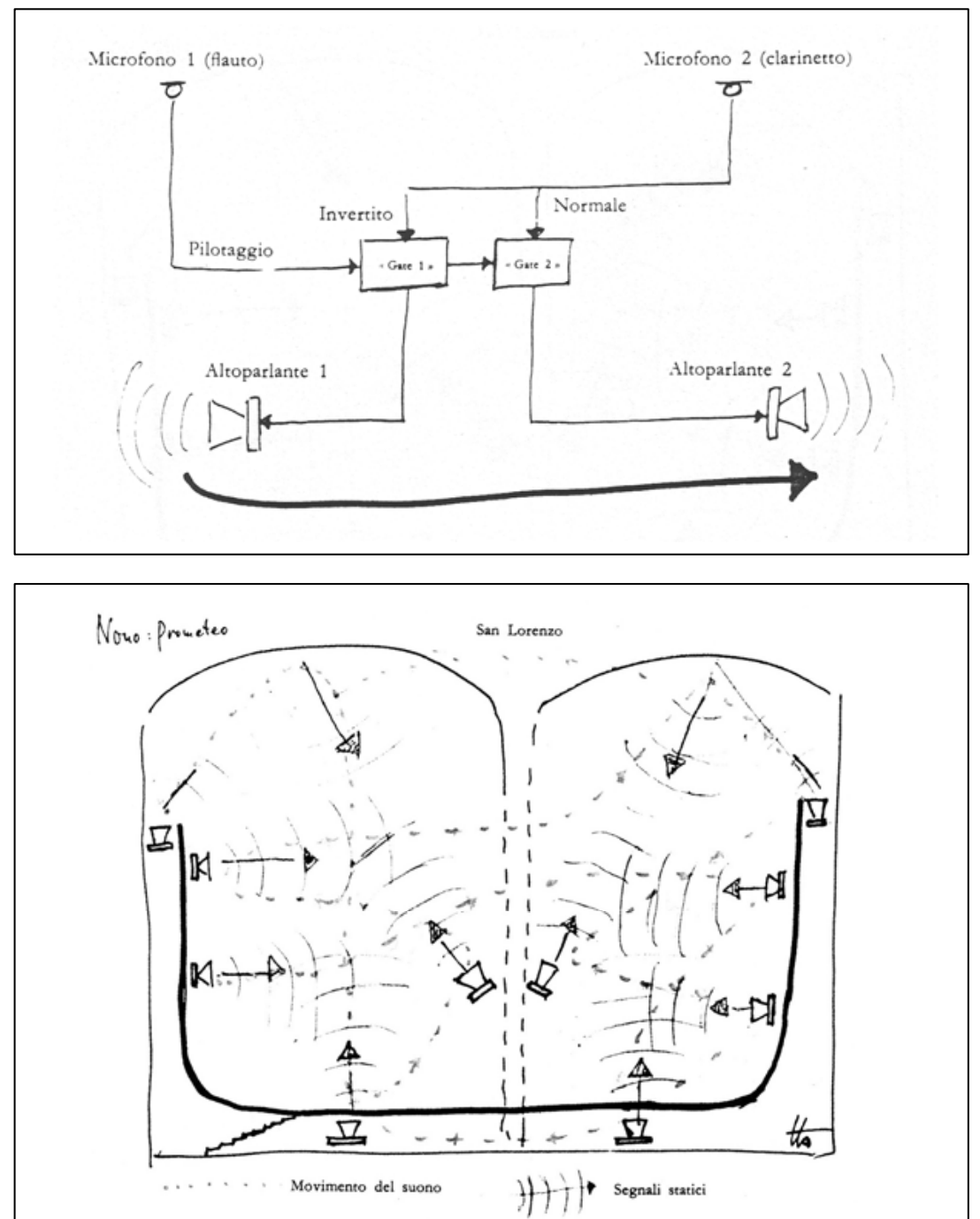

Abbildungen 3 und 4: Skizzen des Klang-Regisseurs Hans-Peter Haller zur Klangsteuerung im PROMETEO. Quelle: Nono 1987: $79 f$. 
In diesem gestaltenden Hören, in der Interaktion mit dem immateriellen elektronischen Raum bei einem gleichzeitigen völligen Verzicht auf visuelle Narration und Darstellung, in der Substitution eines sprachlich oder visuell vermittelten tragischen Konflikts durch dieses konflikthafte und aktive Hören, das im übrigen Ausführende und Rezipienten gleichermaßen betrifft, liegt bis heute die größte theatrale Provokation des PROMETEO. Der durch den kompositorischen Rahmen begrenzte Aspekt des Improvisatorischen beim späten Nono ist durch Jürg Stenzl auch mit Hinweis auf die Notwendigkeit einer »oral history « (39) für die Aufführungspraxis beleuchtet worden. Nonos Partituren geben meist ein unvollständiges Bild des Stücks und markieren durch die Notation von Interpreten-Namen ihren performativen Anteil. Martin Zenck hat diesen Aspekt einer performativen Partitur jüngst fokussiert: Ihr sei zum einen ein »corporale[r] Subtext« (120) eingeschrieben (neben dem Körper des Komponisten auch die Körper der Musiker, mit denen die Klänge entwickelt wurden), und zum anderen bringe sie durch ihre Fragmentarizität in der schriftlichen Notation und die live-elektronischen Prozesse auch in der jeweiligen Anpassung an den Aufführungsraum als Aufführung ein Ereignis hervor, das »etwas von der angedeuteten Intention zwar Ausgehendes, aber in seinem Klangresultat und Klangereignis vollkommen Unabsehbares oder besser Unabhörbares ist « (130). ${ }^{3}$

\section{Jörg Mainka: VOYEUR}

Die Live-Elektronik ist zusammen mit einem intermedial angelegten Kompositionsbegriff auch bei jüngeren Komponisten besonders in ihrer Auseinandersetzung mit dem Musiktheater von entscheidender Bedeutung, handelt es sich doch um zwei Möglichkeiten, sowohl die Geschlossenheit des musikalischen Textes im Sinne einer performativen Verräumlichung, als auch die sequentielle Abfolge von Komposition und Inszenierung aufzubrechen und stattdessen Text, Inszenierung und Aufführung ineinander zu schreiben.

Am Forum Neues Musiktheater der Staatsoper Stuttgart, das unter Klaus Zehelein der Erforschung neuer Produktionsstrategien von Musiktheater unter besonderer Berücksichtigung des Einsatzes neuer Medien verpflichtet war, hat der Komponist Jörg Mainka 2004 seine erste Musiktheater-Arbeit realisiert. Ausgangspunkt und Material waren Alain Robbe-Grillets Roman LE VOYEUR, der als eines der Hauptwerke des >nouveau roman< gilt, und Ludwig Wittgensteins Tractatus logicophilosophicus. Zusammen mit einem Theaterteam (Regie: Hans-Werner Kroesinger, Video und Raum: Philip Bußmann, Dramaturgie und Textfassung: Regine Elzenheimer) entstand das Projekt VOYEUR, dessen Erzählstrategie die mediale Selbstreflexivität beider Texte aufgriff und von Anfang an intermedial angelegt war. Es existierte keine durchgehende Partitur, vielmehr bestand der Arbeitsprozess darin, auskomponierte und live-elektronisch generierte Teile mit Sprachteilen, Video-Projektionen, live-elektronischer Transformation und körperlich-szenischem Geschehen zu verzahnen, wobei der größte Teil des Materials erst im Verlauf der

3 Hierzu ist allerdings anzumerken, dass der Ricordi-Verlag in Kooperation mit einem herausgeberischen Komitee und mit den Interpreten, die persönlich mit Nono gearbeitet haben, an einer >Stabilisierung < des fragmentarischen Notenmaterials in Form von kommentierten >kritischen< Partituren arbeitet, um auch die künftige Aufführbarkeit der Kompositionen zu gewährleisten. 
Auseinandersetzung entstand. ${ }^{4}$ Jeder Teil war nicht in einer konkreten Referenz auf andere Teile - also beispielsweise die Inszenierung auf die Musik oder das Video auf die Inszenierung - bezogen, sondern jede Ebene bildete eine eigene - auch personal eigene - Lektüre des Ausgangsmaterials: Wittgensteins Erkundungen des Verhältnisses von Sprache, Denken und Welt, die mit den Mitteln der formalen Logik die Grenzen der Sprache und ihrer Repräsentationsfähigkeit abschreiten, und Robbe-Grillets Kriminalroman um die Reise eines pathologisch gezeichneten Uhrenverkäufers auf eine Insel und dessen mutmaßlichen Mord an einem jungen Mädchen dort, der in der Sprache eine verschachtelte Montage verschiedener Wirklichkeits- und Wahrnehmungsebenen mit filmischen Mitteln betreibt. In der Frage nach der medialen Spezifik der verschiedenen »Annäherungsweisen an die Welt « (Hans-Werner Kroesinger in: Mainka: 14), die auch eine Frage danach ist, inwieweit Wirklichkeit durch die verschiedenen Medien überhaupt erst konstituiert wird, wurde die technisch-mediale Ebene visuell und akustisch gerade im Kontrast mit körperlich-szenischer Präsenz und Live-Klang und an deren Übergängen konstitutiv. Als stets medial vermittelte erzeugten sich klangliche, bildliche und sprachliche Wirklichkeiten, die stellenweise auch dem Zugriff des Komponisten, des Regisseurs und der Ausführenden entzogen waren: als live-elektronische Transformation der gesprochenen Sprache, die durch bestimmte Konsonantenfilterung eine zweite Geräuschebene erzeugt, die die Schauspieler - ähnlich wie die Musiker bei Nono - in ihrem Sprechen verunsichert; als Computergeneration eines musikalischen Teils, indem das Programm in unvorhersehbarer Folge auf gesampeltes Material aus der vorigen Komposition zugriff und diese willkürlich fortzeugte; oder als Solo eines Midi-Klaviers, in dem sich in einer Szene das zuvor gespielte musikalische Material über eine irrsinnige Temposteigerung verselbständigt. Der Raum war als immaterieller Projektionsraum gestaltet, in dem sich die verschiedenen visuellen Darstellungs-Ebenen überlagerten. Das Publikum saß an den Längsseiten des Raums auf zwei gegenüberliegenden Tribünen, in der Mitte eine schmale, lange Spielfläche mit einem Tisch und zwei Stühlen, die auf allen Seiten durch eine semipermeable Gaze begrenzt war, die als Projektionsfläche diente und je nach Beleuchtung transparent oder blickdicht werden konnte. Man hatte also nirgends einen direkten Blick auf die Szene, vielmehr sah man die Darsteller immer durch die Gaze, manchmal durch die darauf projizierten Bilder und manchmal auch in Überlagerung mit den auf der anderen Seite projizierten Bildern und dem dahinter sitzenden Publikum. Das Video vermittelte verschiedene Ebenen der Überblendung von Projektion und körperlicher Bühnenwirklichkeit. Auf der Bühne gab es eine für den Zuschauer zunächst nicht erkennbare winzige Live-Kamera, die in Form einer Bürolampe auf einem Tisch installiert war und das Gesicht der dort sitzenden Darstellerin überlebensgroß auf die seitliche Gaze projizierte, hinter der das Orchester saß. In einem separaten, nicht einsehbaren Raum auf der gegenüberliegenden Seite der Bühne produzierte eine große, programmierbare Live-Kamera während der Aufführung Bilder einer dort aufgebauten Miniaturszenerie (räumliche Innenansichten der realen und imaginierten Schauplätze des Romans). Die maschinellen Bewegungen dieser Kamera-Apparatur wurden an zwei Stellen des Stücks als Rückprojektion ihres Schattens auf der den Raum abtrennenden Projektionsfläche sichtbar. Die in diesem Raum produzierten Bilder wurden dann in einem Live-Schnitt zusammen mit vorproduziertem Videomaterial (unruhige und unscharfe Außenaufnahmen der bretonischen Ile d'Ouessant, deren Topographie

4 Hierbei ist allerdings zu bemerken, dass der musikalisch-kompositorische Anteil im Verhältnis einen langwierigeren Entstehungsprozess hat als die anderen Teile. 
den vermeintlich authentischen Ort des Geschehens abzubilden scheint), auf die längsseitigen Gazen vor dem Publikum projiziert. Für das Publikum waren die vorproduzierten und die aktuell entstehenden Bilder eigentlich nur in Bezug auf die simultane körperliche Präsenz der projizierten Darstellerin zu unterscheiden.

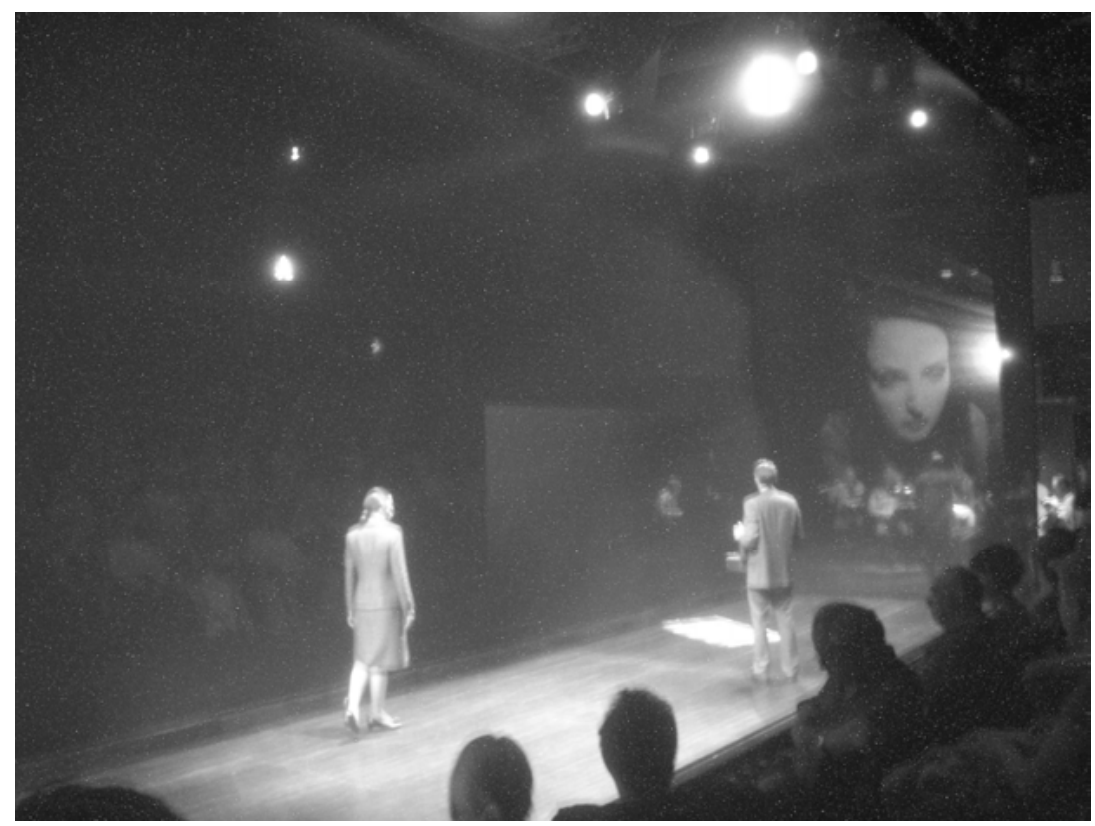

Abbildung 5: Jörg Mainka, VOYEUR, UA, Forum Neues Musiktheater der Staatsoper Stuttgart 2004. Foto: (C) Vettka Kirillova.

Die in beiden Texten exponierte Frage nach der medial prädisponierten Konstitution von Wirklichkeit prägte schließlich eine durch die verschiedenen Medien fragmentierte Aufführung, deren Thema die fragile Grenze von Vorstellung, Wahrnehmung und Darstellung war. Die mediale Disposition ästhetischer Wirklichkeit wurde in der Arbeitsform zugleich zurückprojiziert auf die Frage nach der (Un)Möglichkeit einer kohärenten Perspektive im Rahmen eines immer schon intermedialen musiktheatralen Werks.

\section{Realtime-Scores}

Zuletzt soll hier noch ein kurzer Ausblick auf einen Extrempunkt der medialen und intermedialen Hinterfragung der kompositorischen $>$ Werk $<-$ Gestalt (und im übrigen auch der Inszenierungspraxis) gegeben werden, den der Komponist Gerhard Winkler mit seiner Konzeption der »Realtime-Scores « markiert hat, auf der basierend auch sein 2002 im Rahmen der Münchener Biennale uraufgeführtes Musiktheater HePtAMERON entstanden ist. Hier wird die Partitur unter Einbeziehung der LiveElektronik über mediale Interaktion der Musiker, aber auch über Bewegungssensoren, die kinetische in akustische Signale transformieren, während der Aufführung direkt auf einem Computerbildschirm erzeugt. Winkler suchte mit diesem Ver- 
fahren einen dritten Weg zwischen schriftlich fixierter Partitur (dem Werk) und der Indeterminiertheit der Improvisation (dem Performativen) als Möglichkeit einer nicht-linearen Kommunikation zwischen Mensch und Maschine. Die veränderte Rolle des Komponisten sieht er hier als »creator of a set of >potentialities « (Winkler: 5).

In dieser durch die elektronischen Medien eröffneten Dimension des >Möglichen< schießen die ästhetischen Kategorien der Simultaneität, der Immaterialität und des Performativen zusammen. Insbesondere die Dynamisierung des kompositorischen Textes durch live-elektronische und intermediale Verfahren bildet einen Ansatzpunkt, die theatertheoretische Dichotomie von autonomem $>$ Werk $<$ und performativem Präsens in Bezug auf das Musiktheater zu relativieren. Darüber hinaus erfährt das Leibliche durch die Simultaneität von leiblichem und medial vermitteltem Körper und Klang eine Markierung, die es vor falsch verstandener >Authentizität< bewahrt.

\section{Literatur}

Benjamin, Walter (1991): »Das Kunstwerk im Zeitalter seiner technischen Reproduzierbarkeit « (Dritte Fassung). In: Ders.: Gesammelte Schriften I/2, hg. v. Rolf Tiedemann/Hermann Schweppenhäuser. Frankfurt/M.: Suhrkamp, S. 471-508.

Fischer-Lichte, Erika (2004): »Die Wiederverzauberung der Welt. Eine Nachbemerkung zum Begriff des postdramatischen Theaters«. In: Patrick Primavesi/Olaf A. Schmitt (Hg.): AufBrüche. Theaterarbeit zwischen Text und Situation. Berlin: Theater der Zeit, S. 36-43.

Mainka, Jörg (2004): Voyeur. Programmheft Forum Neues Musiktheater der Staatsoper Stuttgart.

Nono, Luigi (1987): Prometeo. Programmheft Alte Oper Frankfurt/Frankfurt Feste.

Stenzl, Jürg (1999): »Improvisation im Schaffen Luigi Nonos«. In: Thomas Schäfer (Hg.): Luigi Nono. Aufbruch in Grenzbereiche. Saarbrücken: Pfau, S. 36-43.

Winkler, Gerhard E. (2004): »The Realtime-Score. A missing-link in computermusic performance «. http://recherche.ircam.fr/equipes/repmus/SMC04/scm04 actes/P3.pdf (12.10.2007).

Wittgenstein, Ludwig (2003 [1921]): Tractatus logico-philosophicus, Logischphilosophische Abhandlung. Frankfurt/M.: Suhrkamp.

Zenck, Martin (2006): »Luigi Nono - Marina Abramovic. Eingeschriebene, bewegte und befreite Körper zwischen Aufführungspartitur, Live-Elektronik und freier Improvisation/Performance «. In: Petra Maria Meyer (Hg.): Performance im medialen Wandel. München: Fink, S. 119-145.

Zimmermann, Bernd Alois (1974a): »Vom Handwerk des Komponisten«. In: Ders.: Intervall und Zeit. Aufsätze und Schriften zum Werk, hg. v. Christof Bitter. Mainz: Schott, S. 31-37.

Zimmermann, Bernd Alois (1974b): »Zukunft der Oper«. In: Ders.: Intervall und Zeit. Aufsätze und Schriften zum Werk, hg. v. Christof Bitter. Mainz: Schott, S. 38-46.

Zimmermann, Bernd Alois (o.J.): Die Soldaten. Oper in vier Akten nach dem gleichnamigen Schauspiel von Jakob Reinhold Michael Lenz. Studien-Partitur. Mainz: Schott. 


\title{
DiE UNRUHE HINTER DER UHR ZU LESEN SUCHEN. VoM UMgang MIT den NeUen Medien IN DER OPERNARBEIT
}

\author{
JOHANNA DOMBOIS
}

»... für eine Theorie on stage«. (Jörg Huber)

I.

Das grundstürzend Neue an den neuen, digitalen Medien ist wohl primär das Technische. Man könnte sagen, erst aus dem Technischen entsteht eine neue Medialität - ersteres zieht letztere nach sich wie der Funken das Feuer, nicht umgekehrt. Allein, schaut man genauer hin, so hat sich ausgerechnet dieser eine, neuralgische Punkt halb ungehindert, halb unbeachtet zu einer Sollbruchstelle entwickelt. Statt wechselseitiger Durchdringung von Medium und Message kommt es in der Bühnenarbeit allzu oft nur zu Projektionen, deren technische Simulationen oberflächlich bleiben. Bevor sie erreicht ist, geht ein Riss durch die Einheit von Kunst und Technik, die in einem erweiterten Sinn auch eine Einheit von Theorie und Praxis sein sollte.

Vor einiger Zeit gab die Trisha Brown Compagnie in der Zeche Zollverein in Essen ein Gastspiel. Notabene: In der Zeche Zollverein, einem Raum, der per se technisch ist und als solcher nicht trotz, sondern wegen seiner Brekzien vom Theater erobert wurde. Wie in allen Industriedenkmälern ist man auch hier stolz auf die Fusion von Kohlenschacht und Kulisse, Lastenfahrstuhl und Leseprobe, Impetanz und Intendanz, und dies vollkommen zu Recht. De facto jedoch sah die Sache anders aus. Unmittelbar vor der Vorstellung kam folgende Abkündigung:

»Liebe Zuschauer, wegen aufwendiger technischer Umbauten müssen wir Sie heute leider bitten, den Saal gleich nach dem ersten Stück wieder zu verlassen. Die Verwandlungen auf offener Szene scheinen uns weder für Sie noch unsere Bühnentechniker angenehm zu sein.«

Ich übersetze die Aussage des Essener Dramaturgen in den Kontext des TheaterMedien-Bezuges: Die technische Machbarkeit erzeugt auch in den Bühnenkünsten eine akzelerierende Nachfrage nach neuen Ausdrucksmöglichkeiten. Formale und ästhetische Diskrepanzen jedoch herrschen nach wie vor zwischen der Darstellung und der Herstellung von Theater. Vor allem im Musiktheater, und damit möchte ich die Oper und das traditionelle Repertoire miterfassen, erzeugen die Produktionsbedingungen, allzumal sie sich auf die Neuen Technologien kaprizieren, eine Distanz zum Zuschauer, was wundersam zu nennen ist. Denn genau diese Distanz soll ja durch den Einsatz interaktiver Medien etwa verringert werden. Dass aber eine theatrale Mitteilung ab ovo immersiv gedacht werden kann, ist gewiss etwas 
kategorial anderes, als einen Zuschauer davon zu überzeugen, Teil einer Handlung zu werden, die er zunächst nur zu schauen, nicht zu schaffen kam.

Woran liegt es also, dass das Nahe fern wirkt? Zum einen an der eingeschnurten Resistenz des Opernbetriebs, die ungleichen Schwestern >Theater $<$ und $>$ Technik< gemeinsam auf das Familienbild vorrücken zu lassen. Bei immer größerer technologischer Unrast scheint sich das Pflichtgebot nach dem Motto >Vorwärts in die Vergangenheit< zu organisieren. Die Ritualisierung von Goldtresse und Samtvorhang (in Essen übrigens ein nachtblaues Exemplar) feiert fröhliche Urständ. Und obschon jedermann, der, sagen wir: einer Tasse Kaffee nicht gerade lebensphilosophisch abgeneigt ist, einräumen würde, dass die Sprinklerdüse einer Espressomaschine von deren Kulinarästhetik nicht zu trennen ist, macht sich im Theater Befremden breit, sobald dessen technischer Background als Teil eines künstlerischen Foregrounds ausinszeniert wird, der noch nie insular funktioniert hat.

Ein anderer Grund für die Schieflage ist in den strukturellen Bedingungen der Opernproduktion selbst zu suchen. Fast alle konkreten Regieaufgaben im Musiktheater sind je schwieriger $\mathrm{zu}$ lösen, desto offensichtlicher die ästhetischen und sozialen Hierarchien des Betriebs quer zu den Erfordernissen des Codes und der Schaltkreise stehen. Hier: Aufhebung von Schwellen, sphärisches Grundrauschen der Informationen, Darstellung von Prozessualität. Dort: kategoriales Grenzbewusstsein und Formalisierung eines in harten Etappen gestaffelten Güterausstoßes. Es gibt keinen Zweifel daran, dass die Neuen Medien die Medienfrage neu stellen und uns insofern dazu herausfordern, die Grundlagen dessen zu überdenken, was wir mit ihnen über die Rampe bringen wollen. Nimmt man das aber auch für die Oper ernst, wird man deren geheime Akteure, all die Maschinen, Techniken, Vokabularien und Theorien, kurz, den Hintergrund des Vordergrundes ans Licht holen und zu Sinnbildern verdichten müssen. Und mögen die Neuen Medien auch einem Hype dienen, ohne sie droht uns Musealisierung, und zwar - da wir uns im Theater befinden - bei lebendigem Leibe. Kein sehr würdiges Finale. ${ }^{1}$

Gegenentwurf: Wie sieht es aus, wenn man in der Opernarbeit trotz der neuen Medienvielfalt, trotz interaktiver und multilinearer Dramaturgiemuster weder auf die Auseinandersetzung mit dem traditionellen Repertoire noch auf zeitlich determinierte Partituren verzichten will? Wie lässt sich historisch-theatrale Musik ohne Verlust ihrer Gestalt und Struktur erhalten, wenn sie erst durch ein Nadelöhr technischer Systeme hindurch muss, um ausinszeniert werden zu können? Wie etwa sind musikalische Bilder zu erzeugen, die inszenatorisch über das Analogverfahren hinaus analytisch sein wollen? Noch konkreter: Hat man digitale Werkzeuge auf der einen, einen Orchestersatz des 18. Jahrhunderts auf der anderen Seite und übergeordnet die Aufgabe, das eine durch das andere zur Darstellung zu bringen, wie lassen sich inkompatible Systeme vernetzen? Und: Ist Oper noch das, was sie sich nennt, wenn ihr musikalisches Strömen dem Datenfluss notwendig bei-, um nicht zu sagen untergeordnet werden muss? Ich greife rhetorisch kurz voraus: Die Fragen lassen sich beantworten, sobald man Musikvisualisierung mit Hilfe von Musiktheorie betreibt, und zwar mit der diesem Fach üblichen Akribie. Gewiss darf das kein Gang zu den Müttern werden. Das Neue lässt sich aus dem Bestehenden nicht vollständig entwickeln. Aber gegenseitige Inanspruchnahme hilft. Sprung zurück. Um das Cluster der Problemstellungen weiter zu entzerren, möchte ich im Folgenden von einer meiner Inszenierungen berichten.

1 Die Diskrepanz zwischen Produktions- und Präsentationsbedingungen im Musiktheater habe ich detailliert beschrieben in Dombois 2006. 


\section{II.}

Es geht um FIDELIO, 21. JAHRHUNDERT, eine Produktion, die 2001-04 auf der Grundlage einer Zusammenarbeit zwischen dem Beethoven-Haus Bonn und dem Fraunhofer Institut für Medienkommunikation entstanden ist und kraft derer ein Standardwerk der Opernliteratur ausschließlich mittels Neuer Medien interpretiert wurde (Abbildungen 1-3). Dieser FIDELIO ist eine > virtuelle Oper<, in anderen Worten, wir wollten das technische Maximum, und wir bekamen das technische Maximum, eine Situation, in der man sich beiweilen gleichzeitig wie im Schlaraffenland und auf einer Großbaustelle vorkommt: Echtzeit-Computer-Graphik, $>$ Immersive Virtual Reality Technology<, Passiv-Stereoprojektion und dreidimensionale Bildquellen, Verzicht auf leibhaftiges Sängerpersonal und statt dessen - als Umdeutung des lebendigen Prinzips - Einsatz von kooperativer Zuschauerinteraktion, daneben Wiederbelebung der gegebenen Klangkonserve ${ }^{2}$ durch EchtzeitTonmischung und $>3 \mathrm{D}$ Interactive Soundscape $<.^{3}$

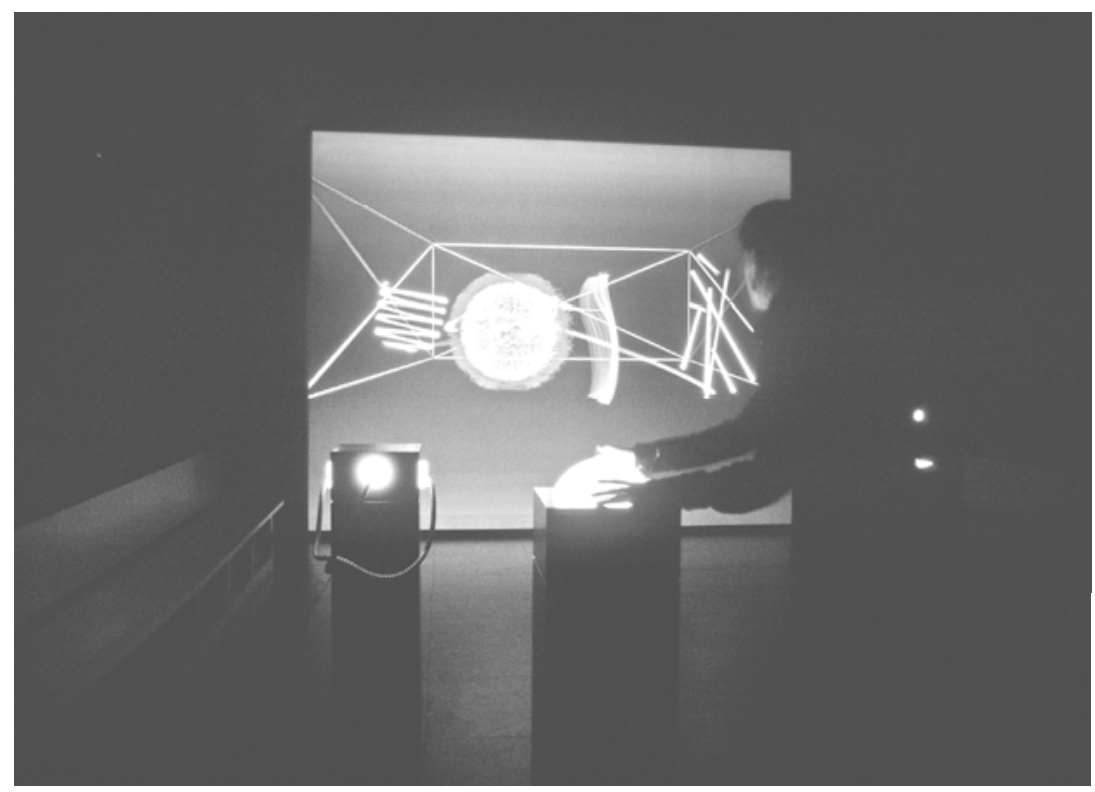

Abbildung 1: Die virtuelle Inszenierung FIDELIO, 21. JAHRHUNDERT, Bühne für Musikvisualisierung/Beethoven-Haus Bonn. Foto: (C) Dombois.

2 ...ohne die Musik im virtuellen Raum bislang nicht inszeniert werden kann. >Liveness< entsteht hier nicht durch psychologische oder physiologische, sondern durch technische Parameter und den sog. >Echtzeit<-Anspruch. Vgl. Dombois 2008.

3 Ein Video-Ausschnitt der Inszenierung war in der Ausstellung art_clips .ch .at .de im Medienmuseum des ZKM Karlsruhe zu sehen (14.01.-25.03.2007) und ist es noch in der dazugehörigen DVD-Publikation (Lischka 2006). Im April 2008 wurde die Produktion im Theatermuseum Köln archiviert und mit einer Ausstellung dokumentiert; im Ausstellungskatalog findet sich weiteres Bild- und Textmaterial, vgl. Theaterwissenschaftliche Sammlung Schloss Wahn 2008. 


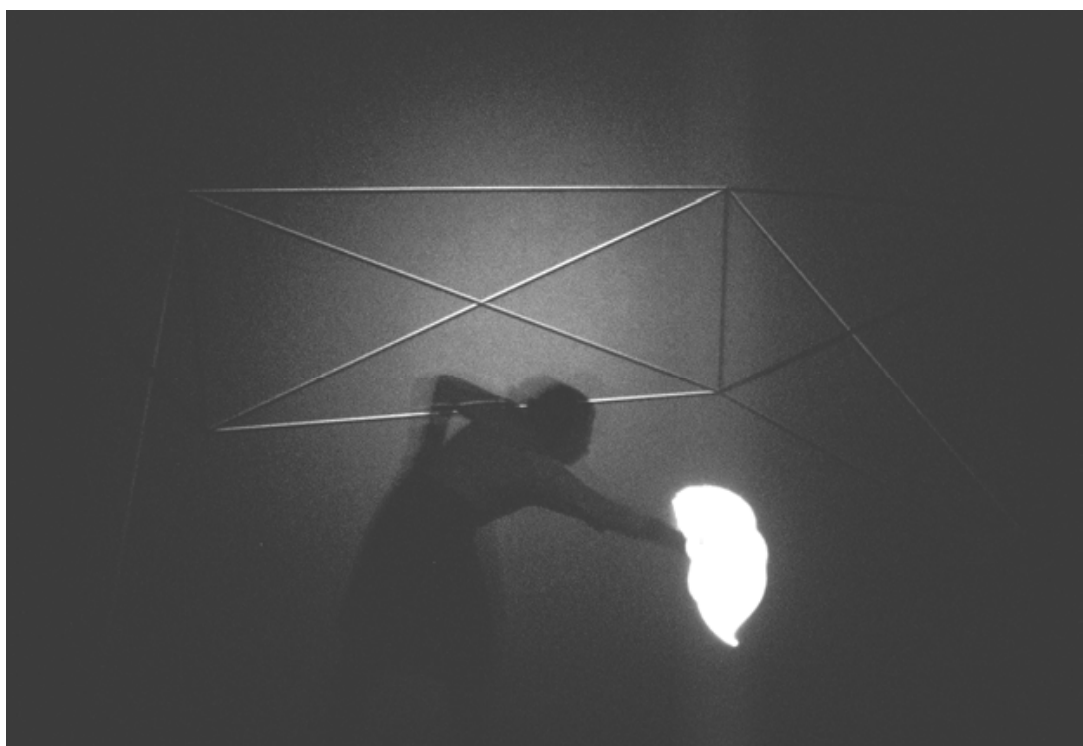

Abbildung 2: FIDELIO, 21. JAHRHUNDERT, »Gott, welch Dunkel hier! «, Rezitativ Florestan, 2. Akt. Foto: (C) Dombois.

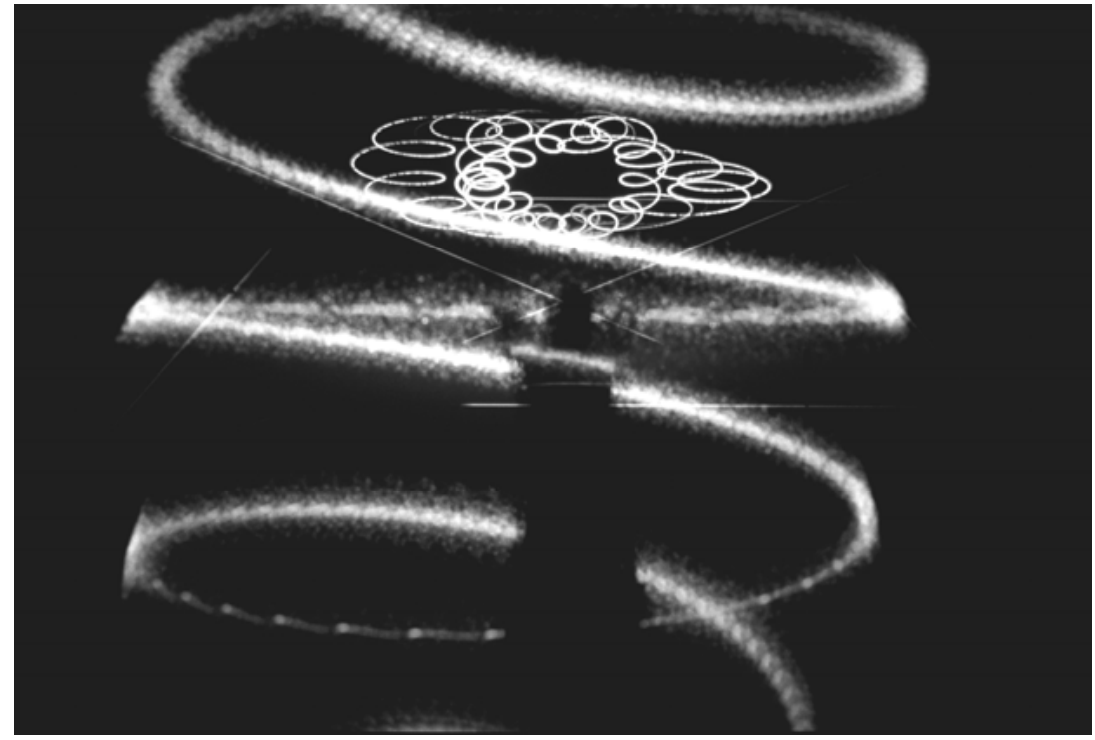

Abbildung 3: FIDELIO, 21. JAHRHUNDERT, »Und spür ich nicht linde, sanft säuselnde Luft«, Arie Florestan, 2. Akt. Foto: (C) Dombois. 
Auf alle Aspekte dieser Inszenierung einzugehen, ist hier nicht der Ort. Ich will mich auf das konzentrieren, was sich unter dem Terminus >Musikalische Parametrisierung< subsumieren lässt. Bereiche wie Einspielung, Schnittfassung, Figurenentwicklung, Interaktionskonzept, Zuschauer- und Klangdramaturgie, Visuelle Effekte, Programmierung und Installation, die ebenso zentral sind, allzumal für den virtuellen Raum nichts nach-, sondern alles nebeneinander erarbeitet werden muss, lasse ich außen vor. Nur dies vielleicht für das basale Verständnis: Was unsere Charaktere betrifft, die ausschließlich durch Daten generiert wurden, so sind wir nicht von Avataren, sondern abstrakt-geometrischen Trägerfiguren ausgegangen, einem anti-realistischen Personal also, das als Repräsentant sinnlicher Wahrnehmungen einsetzbar ist. Gemäß den Prinzipien einer Musikvisualisierung sollten unsere vier Figuren (Florestan, Leonore, Pizarro, Rocco) weniger durch szenische Mitteilungen als durch die Musik selbst erregt und in Bewegung gesetzt werden. Das heißt, es ging vorderhand nicht um Interpretation, welche immer nur je einzelne Momente aus dem Musikfluss herausheben kann. Es ging um ein visuelles Porträt der Musik und damit um deren prozedurale Strukturen.

Für das Vorhaben mussten wir freilich analytisch vor- und deshalb zum Quellenmaterial zurückgehen. Sowohl die Partitur (1814) als auch die Einspielung (Bernstein, 1978) musste mit Blick auf unser Zielmedium (2004) befragt werden. Aufgabe war es, eine möglichst große Reihe sinnvoller Informationen so aus den historischen Quellen herauszufiltern, dass diese vom Rechner verstanden und von dort an das rezipiente Bildmaterial weitergeleitet werden konnten. Die Kardinalfrage war: Wie gelangt die Musik Beethovens überhaupt in die virtuellen Trägerfiguren hinein? Welche Vorkehrungen sind dafür nötig? Mit Cut und Paste ist es nicht getan, da es sich generell um einen Wechsel des Ausgabemediums handelt. Eine akustisch-musikalische Bewegung ist auch digital nicht leichterdings in eine visuelle umzuwandeln, vorausgesetzt man gibt sich nicht mit einem Verschnitt zufrieden. Wir hatten es demnach mit einem Transsubstantiationsvorgang zu tun. Der Klang sollte zum Bild, die Ton- zur Datenreihe und die Wiener Klassik zum Code werden.

Die Lösung lag in einem Verfahren, das ich oben als »Musikalische Parametrisierung « bezeichnet habe und dessen Procedere sich grosso modo wie folgt darstellt: a) Durchkämmen der FIDELIO-Partitur und -Einspielung nach Aussagen, die konstant, dicht und aussagekräftig genug sind, um flüssige Bilder hervorzutreiben, b) Fokussierung auf eine Auswahl, in unserem Fall auf vier Parameter (»Energie-, Harmonie-, Atem- und Adrenalinparameter «) sowie erste Hör- und Notierungsproben, die ausloten, auf welche Weise sich die musikalischen Informationen auf einer Zeitachse eintragen lassen würden (Abbildung 4), c) Entwurf diverser Umrechungsformeln, mit deren Hilfe sich die musikalischen Mitteilungen als Parameterwerte für das Binärsystem des Rechners schematisieren ließen, d) Transponieren der Parameter in Datenwerte, e) Einspeisen der Datenmasse in einen Editor, zunächst in formatierte Tabellen (Abbildung 5), die dann auf diese Art vom Prozessor erkannt werden können, f) Zusammenziehen der edierten Daten zu kontinuierlichen Kurven und last but not least g) Eingabe aller vier Parameterkurven in die vier Figuren, so dass sich deren Modelle zeitgleich mit dem Abspielen der Klangkonserve und gemäß vorab bestimmter visueller Effekte in Bewegung setzen konnten. Die Musik zeigt sich am Ende Bild; vermittelt wurde das eine dem anderen mit Hilfe von musikwissenschaftlichem Handwerkszeug. Will sagen: Ohne theoretische Winkelzüge, ohne den Umweg über die vermeintlich kalte Realität der 
Zahlen und ohne den Forschungsanspruch, der sich hinter all dem verbirgt, hätte der geschilderte Prozess gar nicht vollzogen werden können. ${ }^{4}$

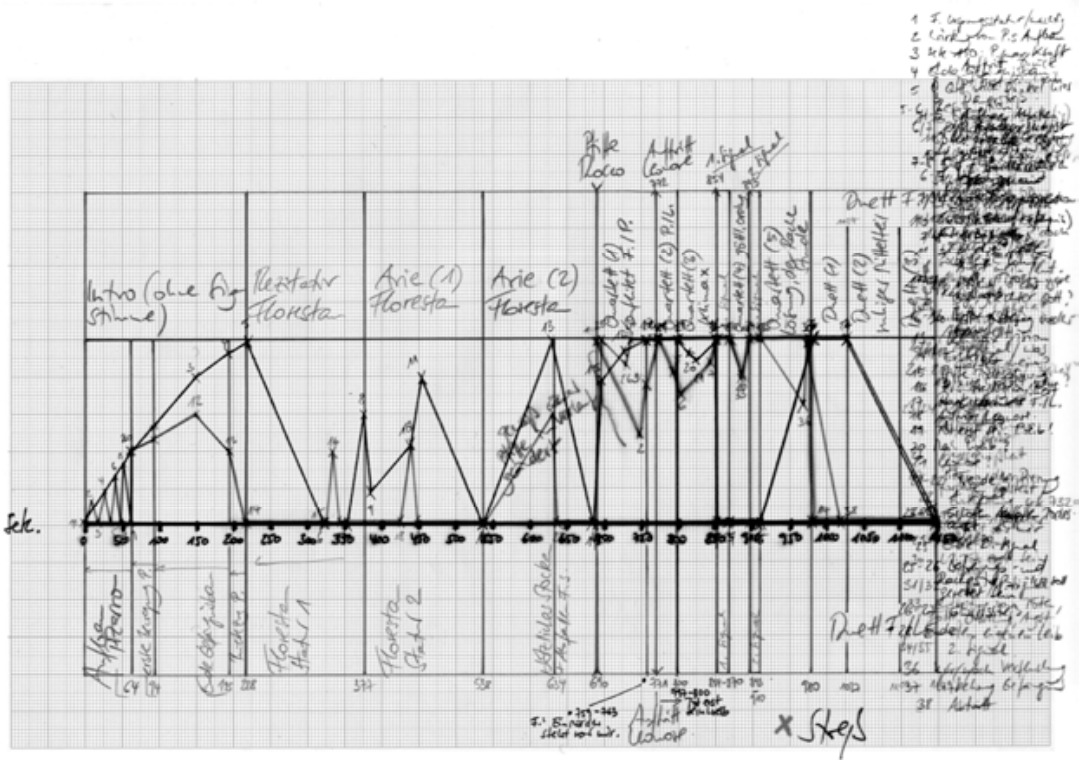

Abbildung 4: FIDELIO, 21. JAHRHUNDERT. Vorstudien zu einem der vier musikanalytischen Parameter (»Adrenalin-Parameter«); Introduktion bis 1. Finale, 2. Akt; handschriftlicher Auszug aus dem Regiebuch.

Skizze/Foto: () Dombois.

Nun könnte man fragen: Aber auch für eine herkömmliche Opernproduktion werden doch Partituren und Einspielungen konsultiert? Ist Regieführung nicht etwa eine Übersetzungsleistung, deren Sinn darin liegt, ein Werk aus seinen jeweiligen Quellen zu erschließen? Gewiss, nur geschieht dies für gewöhnlich nicht mit zehntelsekundengenauem Detaillierungsgrad. Im konventionellen Opernbetrieb wird nichts mikroperforiert. Genau das aber war gefragt in einem Medium, das neu und datenhungrig ist. Denn im Virtual Environment wird jede Informationslücke auf musikalisch-parametischer Ebene zu einem Störfaktor auf visueller Ebene. Ein digitaler Charakter, dem keine Daten zugeführt werden, härtet augenblicklich aus und wird je unmusikalischer, je grobmaschiger sein Datengerüst ist. Das meint, dass ausgerechnet jener Hang zur Theorie, der dem herkömmlichen Betrieb subversiv vorkommt, konstitutiv ist, sobald man sich in der Opernarbeit entschieden mit einem Neuen Medium auseinandersetzt. Zumindest für FIDELIO, 21. JAHRHUNDERT war die musikwissenschaftliche Arbeit keine Beratung von der Seite, sondern integraler Bestandteil der Inszenierung. Theorie war für uns eine in Bewegung geratene Praxis.

4 In extenso ist das musikanalytische Verfahren nachzulesen in Dombois 2007. Aus demselben Artikel sind auch für Abschnitt III einige Formulierungen übernommen. 


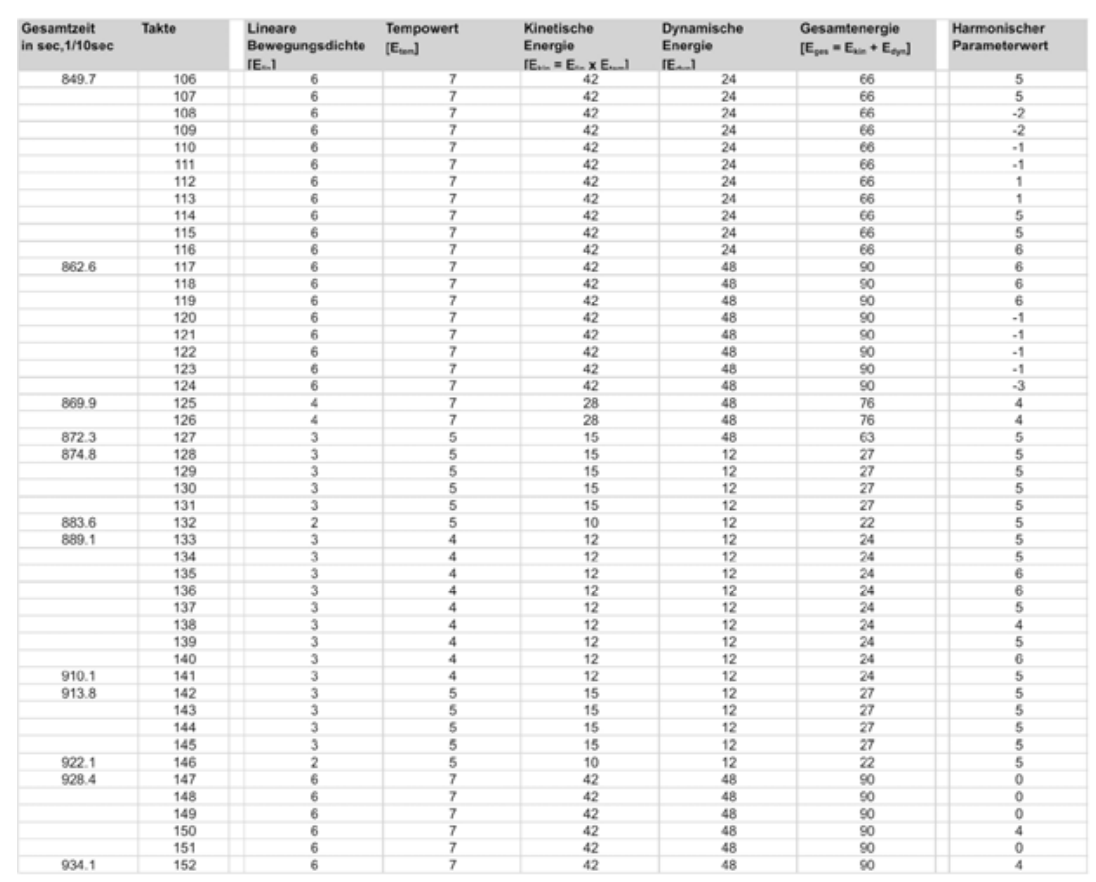

Abbildung 5: FIDELIO, 21. JAHRHUNDERT. Musikanalytische Vorlage für die Digitalisierung des »Energie-« und »Harmonie-Parameters «; »Töt erst sein Weib! «, Quartett-Klimax, 2. Akt. Tabelle: S. Klemm.

\section{III.}

Mögen Zahlen, Millimeterpapier, Kurven, Tabellen, Diagramme und Editoren in der Oper nun auch partout als sektiererisch gelten, so können solche Umwege sehr wohl zu Hauptstraßen werden, wenn die Hauptstraßen unter dem Druck technischer Neuerungen plötzlich in Sackgassen münden. »Angesichts der schwierigen Weltlage hilft nur eines, den Schwierigkeitsgrad der Kunst zu erhöhen«, sagte einmal Alexander Kluge im Kontext seines Films DIE ARTISTEN IN DER ZIRKUSKUPPEL. Bezogen auf die Oper heißt das, dass eine theoretische Retardation auch zugunsten einer Verdichtung geschehen kann. Jede Theorie fordert dazu heraus, immer wieder geprüft zu werden; Theorien neigen zu Abweichungen, je länger ihnen der Beweis durch die Praxis vorenthalten wird, und das ist für die Bühnenarbeit nicht nur irritant, sondern auch äußerst produktiv, insofern nicht nur ein Code erst durch Fehlermeldungen gescheit wird. Bei der Arbeit mit den Neuen Medien scheint es fast, als gelange man erst durch die Lust zum theoretischen Überschuss zu szenischen Lösungen, die notwendig so neu sein müssen wie die Medien, durch sie aufgerufen werden.

Welche Konsequenzen solch ein Bekenntnis zur Hypertrophie hat, sollte man allerdings auch nicht verhehlen. In einem Wort: Detailexplosion. In mehreren: Es geht hier um einen Mehraufwand, der organisatorisch wie künstlerisch einem Glücksschock gleicht, insofern allein die szenische Arbeit am Code mehr Zeit in 
Anspruch nimmt, als einer landläufigen Opernproduktion für alle Proben zugestanden wird. Kaum war unsere in Datenwerte zergliederte Beethoven-Partitur in den Rechner eingespeist, musste dort jede punktuelle Information in Bezug auf das visuelle Gesamtergebnis kontrolliert werden. Es stellte sich heraus, dass nicht jeder Wert, der rechnerisch präzise schien, dies auch szenisch war - auch digital geht fast nichts automatisch - die Steuerung von Bewegungen ist keinesfalls dasselbe wie der Eindruck, den diese Bewegungen hinterlassen. Jedes Bild besitzt eine natürliche Trägheit gegenüber seiner Datengrundlage, und jede Übersetzungsfunktion ruft Verschleifungen hervor. Jedes unserer Bilder musste im Verhältnis zum Code also auf seine Passgenauigkeit hin überprüft werden. Ausschlaggebend war demnach nicht, ob das Regieteam für Sek. 1154 in der 3. Szene des 2. Akts den Wert 3,86 für Florestans Energieparameter analysiert hatte, ausschlaggebend war, ob man in der Aufführung den Wert 3,86 szenisch wiedererkennen konnte in Proportion zu seinen Nachbarwerten. Das bedeutet, und es ist dies der überwältigende Eindruck der Handarbeit, der sich diesem FIDELIO eingeprägt hat: Kein einziger Datenwert war per se verbindlich. Verbindlich wurde er erst, sobald er mit anderen Werten innerhalb eines dynamischen Gleichgewichts Sinn erzeugte. Der Code mag von vornherein ein Korsett sein, technisch, »nackt « und »unzweideutig« (Bentley: 37). Aber auch er kann zu einem Gewebe werden, das durch eine gewisse Handwärme schmiegsam wird.

Ein Widersinn war es deshalb nur dem Anschein nach, aber je kleinteiliger wir das Datenmaterial behandelten, je eher man bereit war, es vom Sekunden - in den Zehntelsekundenbereich herabzustufen, um es dort dramaturgisch nachzujustieren, je stärker wir die musikalische Grundlage fragmentierten, desto dichter kamen wir heran an die Fragen der Interpretation, desto flüssiger wurden die visuellen Symbole, desto eher konnte sich das Werk als Einheit präsentieren. Dank der Zahlendichte, die unser theoretisches Bezugssystem einforderte, konnte die Codierung der FIDELIO-Partitur immer nur in einem Bereich ungenau werden, den man anderswo als übergenau bezeichnen würde. Das aber meint, dass die Praxis überall dort in die Theorie zurückschwingt, wo sie sich jenen disziplinären Selbstbefragungen aussetzt, die einem vermeintlich die meiste Zeit stehlen. Je detaillierter das Handwerk, desto größer der Fragendruck. Florian Waldvogel sagte einmal ganz richtig: »Kunst und Theorie sind meinem Verständnis nach beides Praxisformen « (24). Albrecht Puhlmann hat dies auf die Zielgerade gebracht: »Oper [ist] selber theoriefähig « (»Dialog: Musiktheater«: 129). Ich würde das Rezept um einen einzigen Nebensatz ergänzen wollen: Ja, theoriefähig - weil sie uns zur Praxis verführt.

\section{Literatur}

Bentley, Peter J. (2003): »Der Sinn des Code«. In: Gerfried Stocker/Christine Schöpf (Hg.): Code - The Language Of Our Time. Code = Law Code = Art Code = Life. Ars Electronica 2003. Ostfildern-Ruit: Hatje Cantz, S. 33-39.

»Dialog: Musiktheater « (O.J. [2004]): »Gespräch zwischen Sieghart Döhring, Albrecht Puhlmann und Clemens Risi«. In: Hajo Kurzenberger/Annemarie Matzke (Hg.): TheorieTheaterPraxis. O.O. [Berlin]: Theater der Zeit, S. 128-134.

Dombois, Johanna (2006): »Scheinschwangerschaften. Neue Technologien im klassischen Musiktheater - Nahaufnahmen «. In: Lettre International, Frühjahr 2006, (no 72), S. 86-91. Wiederabdruck in: Deutsche Oper am Rhein (Hg.): 50 Jahre 
Musik-Theater. DOR - Deutsche Oper am Rhein 1956-2006. O.O. [Köln]: DuMont, S. 184-195.

Dombois, Johanna (2007): »Musikstrom. Inszenieren mit Neuen Medien am Beispiel >Fidelio««. In: Musik \& Ästhetik, 11, (no 41), S. 91-107.

Dombois, Johanna (2008): »Master Voices: Opernstimmen im Virtuellen Raum. $>$ Fidelio, 21. Jahrhundert««. In: Doris Kolesch/Vito Pinto/Jenny Schrödl (Hg.): Stimm-Welten. Philosophische, medientheoretische und ästhetische Perspektiven. Bielefeld: transcript 2008 [im Druck].

Lischka, Gerhard Johann/ZKM $\mid$ Zentrum für Kunst und Medientechnologie Karlsruhe (Hg.) (2006): art_clips .ch .at .de - 90 Kurzvideos aus der Schweiz, Österreich, Deutschland. O.O. [Karlsruhe und Ostfildern-Ruit]: ZKM digital arts edition, Hatje Cantz.

Theaterwissenschaftliche Sammlung Schloss Wahn (Hg.) (2008): cOmPutER. >Wo mein Fidelio Frieden fand $<$. Fotografien, Skizzen und Modelle in Wahn von Johanna Dombois ->Fidelio, 21. Jahrhundert< in der Theaterwissenschaftlichen Sammlung Schloss Wahn. [Ausstellung zum Anlass der Archivierung vom 18.02.-24.04.2008]. Köln.

Waldvogel, Florian (2006): »Who Needs Words When You got Arts. $31 \ll$. In: Das Magazin des Instituts für Theorie der Gestaltung und Kunst, Dezember 2006, (no 08/09), S. 23-30. 



\title{
DURCHQUERUNGEN. BRECHTS LEHRSTÜCK als Medien- und Theaterexperiment
}

\author{
PATRICK PRIMAVESI
}

Bertolt Brechts Radiolehrstück DeR OzEANFlug und das BADENER LEHRSTÜCK VOM EINVERSTÄNDNIS werden zumeist getrennt voneinander interpretiert und inszeniert, sofern sie überhaupt noch von Theatermachern bearbeitet werden. Der inhaltliche und entstehungsgeschichtliche Zusammenhang der beiden Stücke ist aber grundlegend für die Wahrnehmung des Lehrstücks als eines Theater- und Medienexperiments. Die von Brecht Ende der 1920er Jahre eröffnete Versuchsreihe miteinander eng verknüpfter Texte bietet auch für die aktuell zu beobachtenden Umbrüche der Theaterpraxis und für ihre Beziehung zu technischen Medien einige Aufschlüsse. Liegt dem Lehrstück doch eine Auffassung von Medium und Apparat zugrunde, die weit über die Funktionen von Übermittlung, Reproduktion und Speicherung hinaus das Dazwischen der Medien reflektiert: ein der theatralen Darstellung auch früherer Epochen immanentes Spiel mit der Schwelle zwischen Präsenz und Abwesenheit, ein phantasmatisches, gespenstisches Moment in aller Vergegenwärtigung und Darstellung. Dazu kommen bei Brecht das Motiv der Durchquerung, eines raumzeitlichen Prozesses, der Momente von Reise und Transport ebenso wie eine Erfahrung der Veränderung und Auflösung individueller Persönlichkeit umfasst, und schließlich ein Denken des Theaters weniger als Aufführung von Werken denn als Übung, die das Zuschauen als solches thematisiert. Mit Blick auf diese verschiedenen Aspekte wird im Folgenden skizziert, inwieweit die Lehrstückpraxis für postdramatische Theaterformen produktiv kann. Dabei soll es auch um neuere Inszenierungen gehen, besonders Chris Kondeks Produktion HIER IST DER APPARAT und seine Arbeit an einem Projekt zum BADENER LEHRSTÜCK.

Eine elementare Bedingung von Theater, die Kopräsenz von Akteuren und Zuschauern, kann durch die Arbeit mit technischen Medien auf neue Weise bewusst gemacht werden, durch ein immer weiter gehendes Spiel mit der Spannung zwischen Distanz und Nähe, Entzug und Kontakt, Reproduktion und liveness. Dem entsprechen vielfältige Strategien der Verunsicherung von Wahrnehmungsweisen, die ein heutiges Publikum im alltäglichen Gebrauch der Kommunikations- und Unterhaltungstechnologie angenommen hat. Deren umfassende Kommerzialisierung hat sich aber auch in der Theaterpraxis auf affirmative Weise niedergeschlagen. So ist die Verwendung von Medien im gegenwärtigen Theater (wie schon in den 1970er und 80er Jahren) kein per se schon innovativer Faktor. Umgekehrt wäre es genauso abwegig, den - seit Beginn des 20. Jahrhunderts immer wieder neu beschworenen - Niedergang des Theaters bloß den technischen Medien anzulasten, sei es einer Rivalität auf dem Unterhaltungsmarkt oder dem Eindringen von Film-, Video- und Reproduktionstechnologie ins Theater. Das Vorhandensein von Monitor oder Kamera auf der Bühne sagt über eine Theaterarbeit noch wenig aus, kann ebenso dekorative wie konzeptionell begründete Funktionen haben. Für die historischen Avantgarden ist aber davon auszugehen, dass ihre Auseinandersetzung mit 
den damals neuen Medien Film und Rundfunk ein verändertes Denken des Theaters befördert hat. Dieses Potential der Arbeit des Theaters mit technischen Medien ebenso wie der Reflexion seiner eigenen (Inter)Medialität wird zumal durch Brechts Lehrstücke LINDBERGHFLUG/OZEANFLUG und das anschließende BADENER LEHRSTÜCK vom Umgang mit den gestürzten Fliegern erhellt. Um zu begreifen, worin bis heute die Herausforderung des Theaters durch diese frühen Medienexperimente liegt, bleiben die Texte aber - gegen ihre immer noch vorherrschende Reduktion auf eine autoritäre Belehrungsdramatik oder auch auf musikpädagogisch motivierte Gesangskonzerte - neu zu befragen.

\section{Vom LINDBERGHFLUG zUm BADENER LEHRSTÜCK}

Brechts erstes Lehrstück hieß anfangs DER LindBERGHFLUG, dann DER FLug DER LINDBERGHS, seit 1950 aber, aufgrund von Charles Lindberghs Kollaboration mit den Nazis, Der OzEANFlug. Dieser Versuch sollte die damalige Begeisterung für technische Pionierleistungen vorführen und zugleich für eine radikale Veränderung von Theater und Rundfunk nutzen. So ging es von Anfang an um das Wechselverhältnis von drei Apparaten bzw. >Medien<: die Flugmaschine, in den 1920er Jahren noch kein alltäglicher Gebrauchsgegenstand, sondern utopischer Schauplatz von Heldentaten für die ganze Menschheit; das Rundfunkgerät, kurz Radio, dessen Verbreitung ebenfalls von einer Aura des Ätherischen und Metaphysischen begleitet war; und schließlich das Theater, das auf eine jahrtausendelange Geschichte zurücksah, in der modernen Massengesellschaft aber so unzweckmäßig erschien, dass allenthalben seine Erneuerung versucht wurde. Brecht wollte in einer gemeinsamen Versuchsanordnung die Funktionsmöglichkeiten der drei unterschiedlichen Apparate ausprobieren, und für das Theater wie auch für den Umgang mit technischen Medien ist der OzEANFLUG eine bis heute uneingelöste Herausforderung: 1.) Schon im Stücktext deutet sich an, dass der physische Transport ersetzt werden kann durch einen medialen, eine Durchquerung von Kanälen oder Funkwellen, die Zeit und Raum auf ein Minimum schrumpfen lässt. Dazu kommt 2.) Brechts Idee, den Rundfunk aus einem Distributionsapparat in einen Apparat der Kommunikation zu verwandeln. Angesichts immer größerer Perfektibilität der Medien ist umso bemerkenswerter, dass 3.) der Erfolg von Brechts Experiment für das Theater darin lag, sein eigenes Scheitern integrieren zu können. Gerade aus dem Misserfolg der ersten Aufführung sollte etwas gelernt werden. Wichtig ist, dass die Vorführung selbst das Experiment war, dass sich auch das Publikum als Teil der Versuchsanordnung begreifen sollte. Dem entsprach 4.) die Orientierung der Lehrstückpraxis nicht an den Zielen der Werkaufführung, sondern am Prinzip einer bewussten $\ddot{U}$ bung, durch die Einbindung von Selbstreflexion und Theorie ins Spiel. Dabei wurde aber 5.) auch die Theorie aufs Spiel gesetzt und die Frage aufgeworfen, was eigentlich das szenische Potential der neuen technischen Medien sein könnte.

»Hier ist der Apparat, steig ein.« So beginnt der OzEANFLug, mit der Aufforderung eines Gemeinwesens an jedermann, den Flug des Fliegers zu wiederholen: »Durch das gemeinsame / Absingen der Noten / Und das Ablesen des Textes« (Brecht BFA 3: 9). Der Apparat wird ausgerichtet auf den Prozess einer Wiederholung und er bezeichnet bereits die Schwelle des Mediums, das eine virtuelle Teilnahme ermöglichen soll. Die gegenüber der ersten Version erweiterte Fassung des Stückes von 1930 enthält 17 kurze Szenen: die Vorstellung des Fliegers, seine Begegnungen mit den Elementen Nebel, Schneesturm und Wasser sowie 
Dialoge mit dem personifizierten Schlaf und dem Flugzeugmotor. Dazwischen Kommentare zu diesem Flug durch Radio und Zeitungen bis hin zum Bericht über das Unerreichbare bzw. »Noch nicht Erreichte«. Als Dokument einer medialen Versuchsanordnung erweist sich der Lehrstücktext schon mit Blick auf die Umstände der Uraufführung bei den Baden-Badener Kammermusiktagen, die das Thema »Radiokunst für die Massen im technischen Zeitalter« zum Motto hatten. Mit Musik von Kurt Weill und Paul Hindemith fand die erste Aufführung am 27. Juli 1929 im Aufnahmestudio des Kurhauses statt, wurde dort mit Lautsprechern in andere Säle übertragen, um wie bei den übrigen Konzerten auch eine Radioübertragung zu simulieren (gesendet wurde das Stück mit gleicher Besetzung erst bei einer erneuten Aufführung im Frankfurter Funkhaus am 29. Juli).

Bei einer für den Vormittag des 27. Juli geplanten Generalprobe wollte Brecht die neue Verwendung des Rundfunks auch szenisch vor anwesendem Publikum demonstrieren. Diese Generalprobe musste aber ausfallen, da der Vortrag von Karl Willy Wagner über elektro-akustische Probleme der Klangwiedergabe im Rundfunk zu lange gedauert hatte. So konnte Brecht erst am 28. Juli, am Tag nach der radiophonen Uraufführung, auch die szenische Demonstration veranstalten, die durchaus als ein »theatralisches Experiment « gelten kann. (Klaus-Dieter Krabiels Einwände hiergegen können nicht überzeugen, da er die Lehrstücke nur als musikpädagogische Praxis deutet und dabei einen viel zu engen Theaterbegriff voraussetzt, den Brecht aber offenkundig überwinden wollte (vgl. Krabiel 1993: 225 u. 2001: 221). Brechts Versuchsanordnung diente dazu, mit der Aufführung des LiNDBERGHFLUGS zugleich die medialen Bedingungen des Rundfunkempfangs szenisch sichtbar zu machen und in eine neue Form von Praxis zu überführen.

Auf eine Leinwand projiziert wurden Brechts »Radiotheorie« überschriebene Ideen zur Funktion von Rundfunk und Musik als Übung:

»um [...] ablenkungen zu vermeiden, beteiligt sich der denkende an der musik, hierin auch dem grundsatz folgend: tun ist besser als fühlen, indem er die musik mitliest und in ihr fehlende stimmen mitsummt oder im buch mit den augen verfolgt oder im verein mit anderen laut singt« (Steinweg 1976: 38).

In dem umfangreicheren Text, den Brecht zunächst für die Projektion vorgesehen hatte, folgte noch der abschließende, das Ziel dieser Musikpraxis zusammenfassende Satz: »so gibt der staat eine unvollkommene musik aber der einzelne macht sie vollkommen« (vgl. Steinweg 1976: 38). Vor dieser Leinwand war auf dem Podium ein Zimmer angedeutet, worin ein Mann mit der Partitur am Tisch saß und den Part des Fliegers bzw. des Hörers übernahm (Schild: Der Hörer). Daneben ein kleines Orchester und in der Mitte ein Lautsprecher für die von Schallplatten abgespielten Geräusche, also alle im Stücktext mit »Radio« bezeichneten Stimmen, die Kontinente, Naturgewalten und die Masse der wartenden Zuschauer. Das Radio sollte dem Hörer nach Hause liefern, was er selbst nicht produzieren konnte. So sollten die Lehrstücke schließlich auch den Theaterzuschauer zum aktiven Teilnehmer an einer Übung machen. Der Hörer und Zuschauer wurde zugleich ausgestellt und virtuell in Bewegung versetzt. Schon das »Einsteigen in den Apparat « versprach einen Prozess der Durchquerung eines veränderten Erfahrungsraumes. In seinen späteren Erläuterungen beschreibt Brecht diesen Vorgang dann bereits im Sinne (medien)politischer Strategie als »eine Art Aufstand des Hörers, seine Aktivisierung und seine Wiedereinsetzung als Produzent « (Steinweg 1976: 67f). 


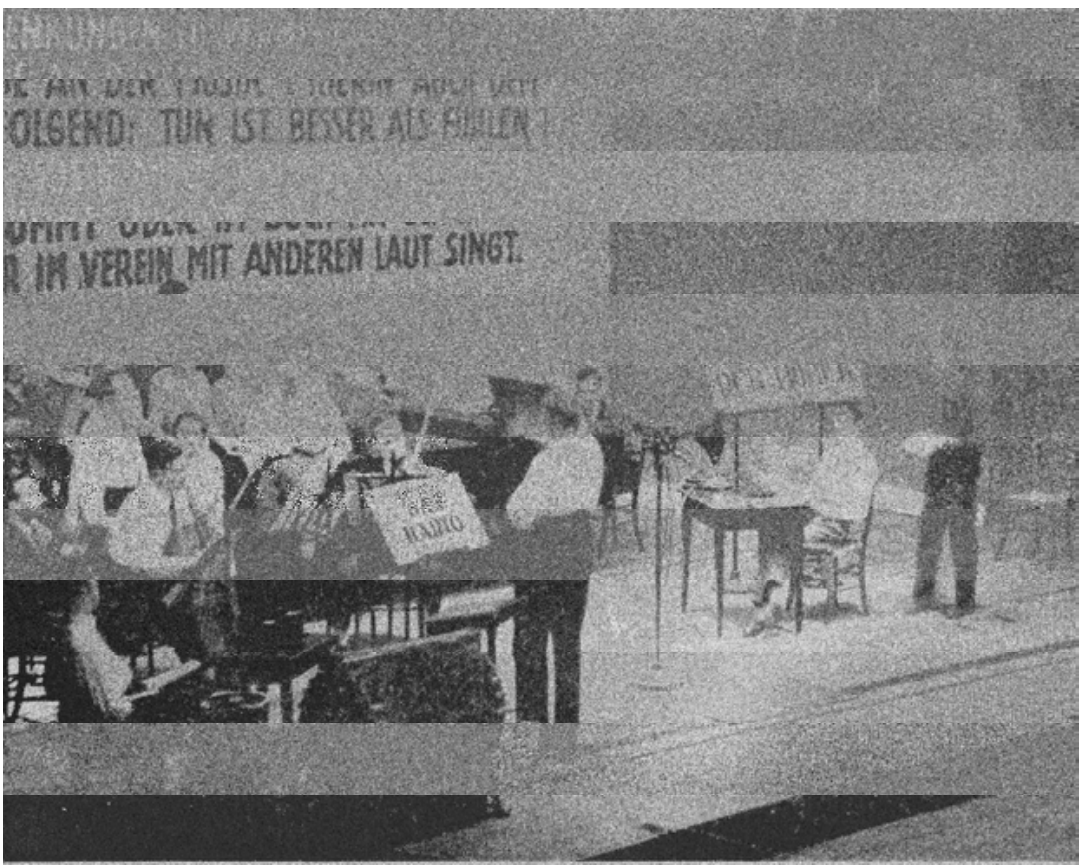

Abbildung 1: Szenische Demonstration des LINDBERGHFLUGS von Brecht, Baden-Baden 1929.

Festzuhalten bleibt, dass das Lehrstück als Theaterentwurf wesentlich geprägt wurde von der Reflexion einer bei der Uraufführung noch unbefriedigenden Praxis. Bei der nachträglichen szenischen Demonstration experimentierte Brecht nicht zuletzt mit der Möglichkeit einer chorischen Wiedergabe des Fliegerparts: »Nur durch das gemeinsame Ich-Singen kann ein Weniges von der pädagogischen Wirkung gerettet werden « (Brecht, Erläuterungen zum FLUG DER LINDBERGHS im Versuche-Heft 1930, vgl. Steinweg 1976: 69). Dieser Korrektur entsprachen Veränderungen des Textes: Gegenüber der ersten Veröffentlichung 1929 in der Rundfunkzeitschrift $U h u$ wurde im Text der Versuche das »Ich« des Fliegers zum »Wir«. Die Problematik der Einfühlung ist ausgestellt, indem der Part des Fliegers als Plural, die Flieger, bezeichnet wird. Und auch die Ideologie des Fortschritts wird dekonstruiert. So wendet sich der Kampf gegen die primitivere Technik gegen das heroisch verklärte Ich und seine Identifikation mit der Maschine. Der im Abschnitt »Ideologie« als Chiffre von Unwissenheit verworfene Gott kehrt später aber als Nothelfer wieder, den der Flieger bei einer drohenden Bruchlandung anruft. Und während des gesamten Fluges sprechen die Zeitungen und die Stimme Amerikas im Radio von dem Glück, das der Flieger haben muss, um anzukommen.

Die Medien stehen damit zum einen für eine rückständige, von überkommener Ideologie geprägte Technik. Andererseits scheint mit der Möglichkeit der Bildtelegraphie (»Wir werden ihn erkennen / Nach dem Bild in der Zeitung, das / Vor ihm herüberkam «) eine Dimension von Medientechnik auf, deren Konsequenzen für die Wahrnehmungsverhältnisse der modernen Zivilisation bereits absehbar waren: die Übertragung von Bild und Stimme des Menschen mit einer das Flugzeug noch übertreffenden, geographische Räume überwindenden Geschwindigkeit. Auch un- 
ter diesem Aspekt erscheint der Flug als Scheitern, durchgeführt von einem naiven Flieger im Dienste der falschen Ideologie, mit einer Technik, die bereits überholt ist durch den virtuellen Transport der Medientechnik. Das Stuick stellte aber auch den Apparat des traditionellen Theaters in Frage, die Funktion der Ausführenden ebenso wie des Publikums. So lässt sich der Text nicht nur als Heldenlied, sondern vielmehr als profanes szenisches Ritual lesen, mit dem das Theater auf dem Podium, im Zeitalter von Wissenschaft und Technik, als ein zeremonieller Prozess vorgeführt wird, der das Verhalten der Zuschauer mit reflektiert. Wie schon Walter Benjamin zum LINDBERGHFLUG anmerkte, kommt es nach Brechts Selbstkorrektur bei der Uraufführung darauf an, nicht etwa die Erregung des Publikums über die Heldentat, sondern eine Erfahrung von Arbeit für das Theater zu nutzen, die Erschöpfung und Scheitern einschließt (Benjamin: 537).

Mit der Masse, aus der sich der Flieger erhebt und in die er zurückkehrt, geht es auch um den Tod, den der Flug als rite de passage symbolisch durchquert. Was Brecht schon im OzEANFLUG anklingen lässt, ist das symbolische Opfer des Einzelnen. Wichtig ist dafür eine Stelle, deren Bedeutung als unaufgelöster »Rest « der dialektischen Ökonomie Rainer Nägele hervorgehoben hat (Nägele: 309), die Ankunft, Szene 16, wo die Flieger rufen: »Ich bin Lindbergh. Bitte tragt mich / In einen dunklen Schuppen, daß / Keiner sehe meine / Natürliche Schwäche. (Brecht BFA 3: 23) In dem Moment, da der Flug geglückt ist, will bzw. soll der Flieger verschwinden. Die >Natürliche Schwäche< könnte für Erschöpfung stehen und für den An-flug einer Scham, die das medial vorausgeeilte Bild des Helden nicht mit dem realen Körper des Fliegers beschädigen möchte. Oder das Individuum erträgt die Feier des erfolgreichen Fluges nicht, solange nicht auch die anderen an der Leistung Beteiligten gerühmt werden. Oder es ist »der Schatten Nungessers «, des noch kurz zuvor auf dieser Strecke abgestürzten Fliegers, der ihn eingeholt hat, seinen Anteil am Ruhm verlangt. Schließlich eine Art Bestrafungsphantasie, da der Flieger auch für den Tod Gottes verantwortlich gemacht wird.

Offenkundig steht diese 1930 nachgetragene Szene in Zusammenhang mit dem Sturz der Flieger im BADENER LEHRSTÜCK, das einen Prozess gegen die Gestürzten führt, bis hin zu der Szene >Die Austreibung<, wo der Flieger die Bühne verlassen muss (Brecht BFA 3: 44f). Sein Urteil ist, dass er durch sein Beharren auf individuellem Ruhm sein Amt und seine (vom Kollektiv her verstandene) Menschlichkeit eingebüßt hat und daher sterben soll. Dieser Vorgang betrifft aber zugleich die Funktion der Zuschauer, in deren Namen der Flug wie auch die Austreibung vollzogen wird. So führt der Begriff der Durchquerung im Kontext der Lehrstücke vom OZEANFLUG, als einem symbolischen Akt, der die Elemente durchquert, die Kontinente Amerika und Europa verknüpft und in das symbolische Raumgefüge von Erde, Meer und Himmel eingreift, bis hin zur symbolischen Durchquerung des Todes im Akt des Sterbens, der im BADENER LEHRSTÜCK erlernt werden soll.

Die erste, bloß LEHRSTÜCK genannte Fassung umfasste sieben Nummern: den allgemeinen Bericht vom Fliegen als dem Inbegriff technischen Fortschritts und ein Gespräch des Chors mit dem Gestürzten, der auf seinem Ruhm besteht und den Chor bzw. die Menge um Wasser bittet; die Untersuchung, »ob der Mensch dem Menschen hilft«; die Verweigerung der Hilfe durch den Chor; die Betrachtung von Bildern des Todes; eine Belehrung über die Notwendigkeit, mit dem Tod einverstanden zu sein; eine Szene mit zwei Clowns, die einen dritten (Herrn Schmitt) auf dessen eigenen Wunsch hin demontieren; das abschließende Examen, bei dem der Gestürzte zeigt, dass er gelernt hat, seine Identität preiszugeben. Diese Fassung, die mit Musik von Hindemith am Abend des 28.07.1929, nur wenige Stunden nach der 
szenischen Demonstration des LINDBERGHFLUGS aufgeführt wurde, hat Brecht dann 1930 noch um mehrere Szenen erweitert und inhaltlich zugespitzt: Den gestürzten Flieger begleiten im BADENER LEHRSTÜCK die drei Monteure, die das Sterben als Aufgehen im Kollektiv lernen, während allein der Flieger nun bis zuletzt auf seiner Individualität beharrt und dafür bestraft wird mit der Austreibung, als einer symbolischen Verstoßung aus der Gemeinschaft.

Die Parallelen zum LiNDBERGHFLUG sind offenkundig: das LEHRSTÜCK entstand gleichzeitig, wurde am selben Tag szenisch uraufgeführt und im gleichen Zeitraum überarbeitet; dabei hat Brecht das Thema des individuellen Ozeanflugs und seiner Bewertung durch Menge und Chor jeweils auf eine kollektive Leistung hin neu gefasst. Die beiden in den Versuche-Heften vorliegenden Stücktexte von 1930 machen Leistung und Status des Individuums im Verhältnis zur Gemeinschaft zum Problem: Im FLUG DER LINDBERGHS deutet die Szene 16 bereits an, was im BADENER LEHRSTÜCK zum Hauptthema geworden ist. Insofern ist der Zusammenhang der beiden Texte nicht bloß »antithetisch«, wie Krabiel annimmt (Krabiel 2001: 217). Dass das LEHRSTÜCK als Fortsetzung und Variation konzipiert war, zeigt sich schon an der ersten Fassung dadurch, dass es mit dem Schlussbericht des LINDBERGHFLUGS beginnt. Die Überarbeitung verdeutlicht, dass Brecht dazu tendierte, Flug und Sturz zu verbinden als Aspekte eines symbolischen Prozesses der Durchquerung, die den Raum des Kollektivs ebenso betrifft wie die Stellung des Individuums zur Gemeinschaft. Wenn diese auch erst im LEHRSTÜCK adäquat dargestellt ist, nämlich in der Spaltung zwischen Chor und Menge als den Instanzen eines Untersuchungsprozesses, so ist doch schon im LiNDBERGHFLUG von Anfang an das »Gemeinwesen« präsent, das den Flieger/Hörer beauftragt, in den Apparat einzusteigen.

Wie die vergleichende Betrachtung der Texte zeigt, ist es gerade die Position von Chor und Menge, die im LINDBERGHFLUG durch Instanzen und Apparate der medialen Übertragung eingenommen wird: Amerikanische und Französische Zeitungen sowie - als Stimmen oder Geräusche im Radio - die Stadt New York, ein Schiff, Europa und eine Riesenmenge/große Masse am Flugplatz bei Paris. Die besondere, von Brecht demonstrierte Qualität des Ozeanflugs war ja der Umstand, dass dieses Ereignis von Anfang an ein Medienereignis war, seine Bedeutung vor allem durch die begleitende Berichterstattung und die zumindest bei Start und Landung mögliche Bild- und Tonübertragung erhielt. Der LiNDBERGHFLUG füllte die gegenüber einer Live-Kamera noch bestehende - Lücke der Übertragung des Fluges selbst aus, indem der Hörer/Zuschauer an die Stelle des Fliegers treten und dessen Part mitsingen sollte. Beim LeHrstüCK dagegen hatte das Publikum den Part der Menge, die in die Untersuchung über Hilfe und Hilfeverweigerung einbezogen wird. Ansonsten war der Versuchsaufbau, das Podium mit Tisch, Orchester und Leinwand im Hintergrund fast identisch mit dem des LINDBERGHFLUGS, und auch die mitwirkenden Solisten und Chormitglieder waren zum großen Teil dieselben. Wie in logischer Fortsetzung des ersten Experiments wurde beim LEHRSTÜCK der von der Menge (unterstützt von einigen im Saal verteilten Laiensängern) zu singende Text auf die Leinwand projiziert, um das anwesende Publikum zu aktivieren.

Die Aufführung des LEHRSTÜCKS wurde zwar in Baden-Baden weder aufgezeichnet noch gesendet, hatte aber eine intermediale Struktur, die extreme Reaktionen auslöste. Bei der Szene Nr. 4 »Betrachtet den Tod« wurde dem Publikum der Film Totentanz mit Valeska Gert vorgeführt, und im Anschluss an die Clownsszene war ein weiterer Film mit Toten zu sehen, den Brecht wiederholen ließ, als das Publikum revoltierte: 
»der stückschreiber wies den clowns öffentlich den platz für ihre darbietung an und als die menge den film der tote menschen zeigte mit großer unruhe und unlust ansah, gab der stückschreiber dem sprecher den auftrag, am schluß auszurufen: >nochmalige betrachtung der mit unlust aufgenommenen darstellung des todes «, und der film wurde wiederholt « (Steinweg 1976: 165).

Indem Brecht die erneute Filmvorführung explizit ankündigen ließ, machte er mit der »Unlust « das Zuschauen selbst zum Thema. Dabei war es wohl auch der Kontrast zwischen den Filmbildern und der komischen Grausamkeit der Clownsszene, was das Konzertpublikum provozierte. Als den bis dahin noch mitsingenden $\mathrm{Zu}$ schauern eine für damalige Verhältnisse extreme Medien-Performance über Gewalt zugemutet wurde, waren sie plötzlich mit der Verantwortung für die eigene Teilnahme an diesem Prozess konfrontiert. So wird die Funktion der Medien im Theatervorgang als Störung, als Dazwischenkunft im Moment der Darstellung deutlicher noch als im LINDBERGHFLUG. Der Zusammenhang beider Stücke zeigt aber, dass das Projekt der Lehrstücke von Anfang an mit der Erfahrung einer wechselseitigen Intensivierung von Live-Performance und Reproduktionstechnik spielte und dass es dabei auch um ein verändertes Verhältnis zum Publikum ging.

\section{Lehrstückarbeit zwischen Aufführung und Übung}

Angesichts gegenwärtiger Versuche zur erneuten Einbeziehung von Zuschauern in theatrale und intermediale Prozesse, stellt sich die Frage nach dem Projekt der Lehrstiucke auf neue Weise. Angesichts immer noch bestehender organisatorischer, rechtlicher und künstlerischer Probleme auch mit der Aufführung der zu den Lehrstücken komponierten Musik ist die Radikalisierung von Brechts Position um 1930 wichtig. Damals wurde absehbar, dass die Lehrstücke mit der Ästhetik des traditionellen Theaters auch dessen Instanzen in Frage stellten: Autor, Werk, Schauspieler und Zuschauer. Die davon aufgeworfenen Konflikte haben dazu beigetragen, dass die Sprengkraft der Lehrstücke für neuere Theaterformen weniger in Aufführungen der Lehrstücktexte zur Geltung kam als in einer eher indirekten Auseinandersetzung mit ihnen. Dafür war der Aspekt eines sozial- oder auch musikpädagogisch motivierten Mitmachens aber keineswegs entscheidend. Schon Brecht hat in Abgrenzung von Hindemith und der Idee der Gebrauchsmusik nachträglich betont, dass er nicht etwa ein Mitsing- oder Mitspieltheater wollte, das in der künstlichen Herstellung einer harmonischen Gemeinschaft von Akteuren die Probleme der Zeit verharmlost hätte: »wäre eine solche künstliche und seichte Harmonie doch niemals imstande, den die Menschen unserer Zeit mit ganz anderer Gewalt auseinander zerrenden Kollektivbildungen auf breitester und vitalster Basis auch nur für Minuten ein Gegengewicht zu schaffen « (Steinweg 1976: 59f). Ähnlich sah Brecht den Wert des Stückes DER FLug DER LINDBERGHS weniger im künstlerischen Werk als im Moment einer Schulung und Übung, die die Ausführenden gerade die Spannung zwischen Individuum und Kollektiv erfahren lassen sollte.

Zu der von den Lehrstücken ermöglichten Übung zählt auch ihre Unterbrechung, die Brecht zufolge »am besten durch einen Apparat geschieht « (Steinweg 1976: 66). Erst durch die Integration ihrer eigenen Störung kann die Übung eine Veränderung des Wahrnehmungsapparates bewirken, in der Auseinandersetzung mit der Unzulänglichkeit der technischen und institutionellen Apparate - durch deren Selbstreflexion. Diese auch als Medienkritik intendierte Kehrseite des »Radiolehr- 
stücks « ist aber noch kaum auf der Bühne oder in technischen Medien angekommen. Im Gegenteil haben die wenigen Produktionen eher das Medium verklärt, wie der Film LindBerghFlug/OzEANFLug von Jean-François Jung (1992), wo das Lehrstück didaktisch bebildert ist, abgerundet mit Photos von den amerikanischen Lindbergh-Feiern. Um das pädagogische Potential dieses Radiolehrstückes »für Knaben und Mädchen « zu realisieren, müssten diese selbst zu Ausführenden werden, wie in einer Hörspielproduktion von Kurt Veth und Tilo Medek (1969). Unter Verzicht auf die Originalmusik wurde da mit einfachen Geräuscheffekten gearbeitet und die Stimmen der Kinder chorisch inszeniert, was aber nicht nur die Lehre des Fortschritts beglaubigt, sondern auch die rhythmische und semiotische Qualität des Textes hörbar gemacht hat. Im Theater gab es in den letzten Jahren vor allem den OzEANFLUG von Robert Wilson am Berliner Ensemble, in einer Montage mit Texten von Heiner Müller und Dostojewski (1998). Die glatte Oberfläche der zum Perfektionismus neigenden Ästhetik des späten Wilson wurde dabei nur selten durchbrochen, etwa durch die Stimme von Bernard Minetti als >Nebel< oder durch einige Szenen zu Müllers LANDSCHAFT MIT ARGONAUTEN. Insgesamt kamen zwar die gespenstischen und komischen Elemente des OzEANFLUGS zum Vorschein, kaum aber das Potential des Medienexperiments, das Zuschauen in Frage zu stellen.

Im Unterschied dazu führt die Produktion HIER IST DER APPARAT von Chris Kondek (Brüssel/Berlin 2006) am OZEANFLUG besonders den experimentellen Umgang mit Medien vor, ausgehend von Marshall McLuhans grundlegender These, dass ein Medium erst durch seine Vorführung in einem anderen Medium kenntlich wird (re-mediation). Zuvor hat Kondek das erfolgreiche DEAD CAT BounCE gezeigt, eine szenische Einführung in die Börsenwelt, bei der über Internet live am New Yorker Stock Exchange mit dem Eintrittsgeld der Zuschauer spekuliert wird. Ansonsten ist er als Videokünstler bekannt, der lange mit der Wooster Group gearbeitet und auch viele neuere Produktionen im deutschen Theater geprägt hat, u.a. von Wanda Golonka, Jossi Wieler, Stefan Pucher und Meg Stuart. Sein Umgang mit Brechts OzEANFLUG reflektiert parallel zum Stücktext bereits dessen Aufführungsgeschichte und die Mediengeschichte des 20. Jahrhunderts, im Format einer Talkshow in drei Teilen: Radio, Television, Cyberspace.

Noch bei Arbeitslicht kommt zuerst Kondek selbst als Moderator »Gary« auf die Bühne, erzählt beiläufig von Brechts OzEANFLUG und der Begeisterung für das neue Medium Rundfunk als gemeinschaftsstiftenden Apparat, außerdem von der Entstehung seines eigenen Projekts. Weitere Akteure treten auf und gehen an ihre Tische: Christiane Kühl als Produzentin »Jane Seymour« und Victor Morales als »Side Kick«. Während Dias von der Uraufführung gezeigt werden, taucht Julie Bougard als Talkshowgast »Veronica del Fuego« auf (beim Kunstenfestival in Brüssel 2006 wurde der Part noch von Astrid Endruweit gespielt). Sie stellt sich gemäß Brechts späterer Textfassung als »der Flieger Derundder« vor und spricht die »Aufforderung des Apparats an jedermann«, während sie mit dem Mikrophon an einem alten Tonbandgerät ein lautes Propellergeräusch hervorbringt. Im Dialog mit den anderen entfaltet sie die in den 1920er Jahren verbreitete, auch von Thomas A. Edison geäußerte Idee, dass durch Rundfunkgeräte die Stimmen der Toten aus dem Jenseits zu empfangen seien. Als eine Art magischer Seance spielt sich der Radio-Teil weitgehend im Dunkeln ab, begleitet von extremen Geräuscheffekten. 


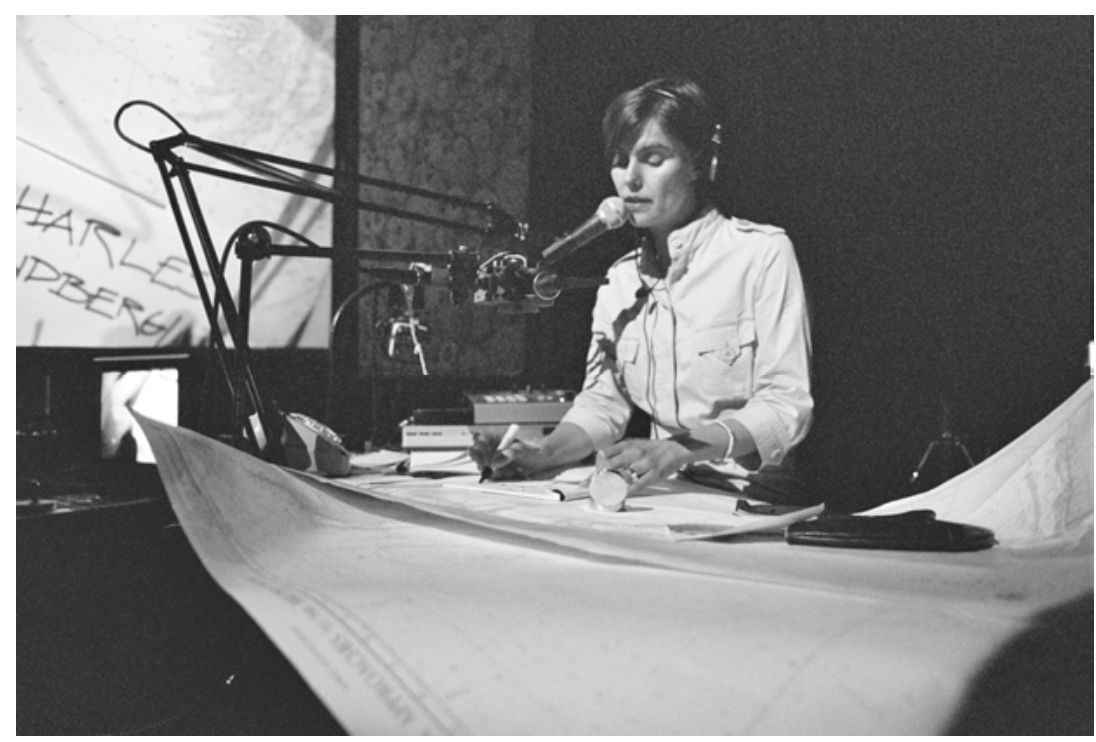

Abbildung 2: Christiane Kühl verfolgt den Kurs von Charles Lindbergh in HIER IST DER APPARAT von Chris Kondek (2006). Foto: (C) Giannina Urmeneta Ottiker.

Aus dem Jenseits empfangen wird dabei u.a. die Stimme Brechts beim Verhör vor dem Ausschuss für unamerikanische Tätigkeiten: »My name ist Bertolt Brecht, I'm living in 34 West 73rd Street New York ...«. Dazwischen kommen einige Szenen des OzEANFLugs, öfters auch in Englisch, bis zum Übergang in den zweiten Teil des Abends, einen Schnelldurchlauf durch die Geschichte des Fernsehens (TV).

Wieder gibt Kondek eine Einführung, in der er die Ideologie des Fernsehens als Weg zu einer Gemeinschaft der Massen erörtert. Umgeben von Kameras beginnt die Late Night-Show »Hier ist der Apparat!«, als deren erster Gast Marshall McLuhan zu Wort kommt: »It's impossible to have a point of view in the electric age. And (to) have any meaning at all. [...] you have to be participating in everything going on at the same time, and that is not a point of view. «Diese Einsichten korrespondieren auf vielfältige Weise mit Brechts Lehrstück. Momente der Aufführung, in denen man auf einer projizierten Seekarte den Flug durch den Schneesturm verfolgen kann, wechseln mit Filmmaterial aus den 1960er und 70er Jahren, Bilder von Panzern, Demonstrationen, Polizei, während im Vordergrund die Talkshow weiterläuft. Durch die im Fernsehen übliche Einblendung von Gelächter und Beifall erlebt das Theaterpublikum, dass >seine< Reaktionen jederzeit verfügbar sind. Dazu wird der Abschnitt »Ideologie« aus Brechts Text konfrontiert mit einem Zitat von McLuhan zur Idee des Fernsehens: »TV turns us all into a big tribe, we read a book alone, but watch TV together.« Das Gegenteil sagt Talkshowgast Veronica: Fernsehen sei in ihrer Kindheit der einzige Weg gewesen, aus dem täglichen Familienkrieg im Wohnzimmer zu entfliehen. Diese private Geschichte vom Ende des Privaten umkreist die paradoxe Relation von Stillstand und totaler Mobilisierung, die das Zuschauen im Medienzeitalter prägt. Wie Emil Hrvatin den »terminal spectactor « beschreibt, werden soziale Verhaltensweisen zu telematischen, über Bildschirme und Schnittstellen bestimmt durch die Fiktion einer panoptischen Allgegenwart sowie durch eine verantwortungslose Teilnahme an Spektakeln aller 
Art. Daher richten sich Strategien der Beteiligung in gegenwärtigen Theaterformen oft gerade auf den Entzug des Spektakels: "participation is only possible when there is nothing to participate in, when the public becomes a theatre event and perceives itself as such « (Hrvatin: 25). Kondek weist mit seiner Lehrstück-Deutung in die gleiche Richtung, auch wenn sich das Spiel mit medialen Wahrnehmungsbedingungen bei ihm mitunter verselbständigt.

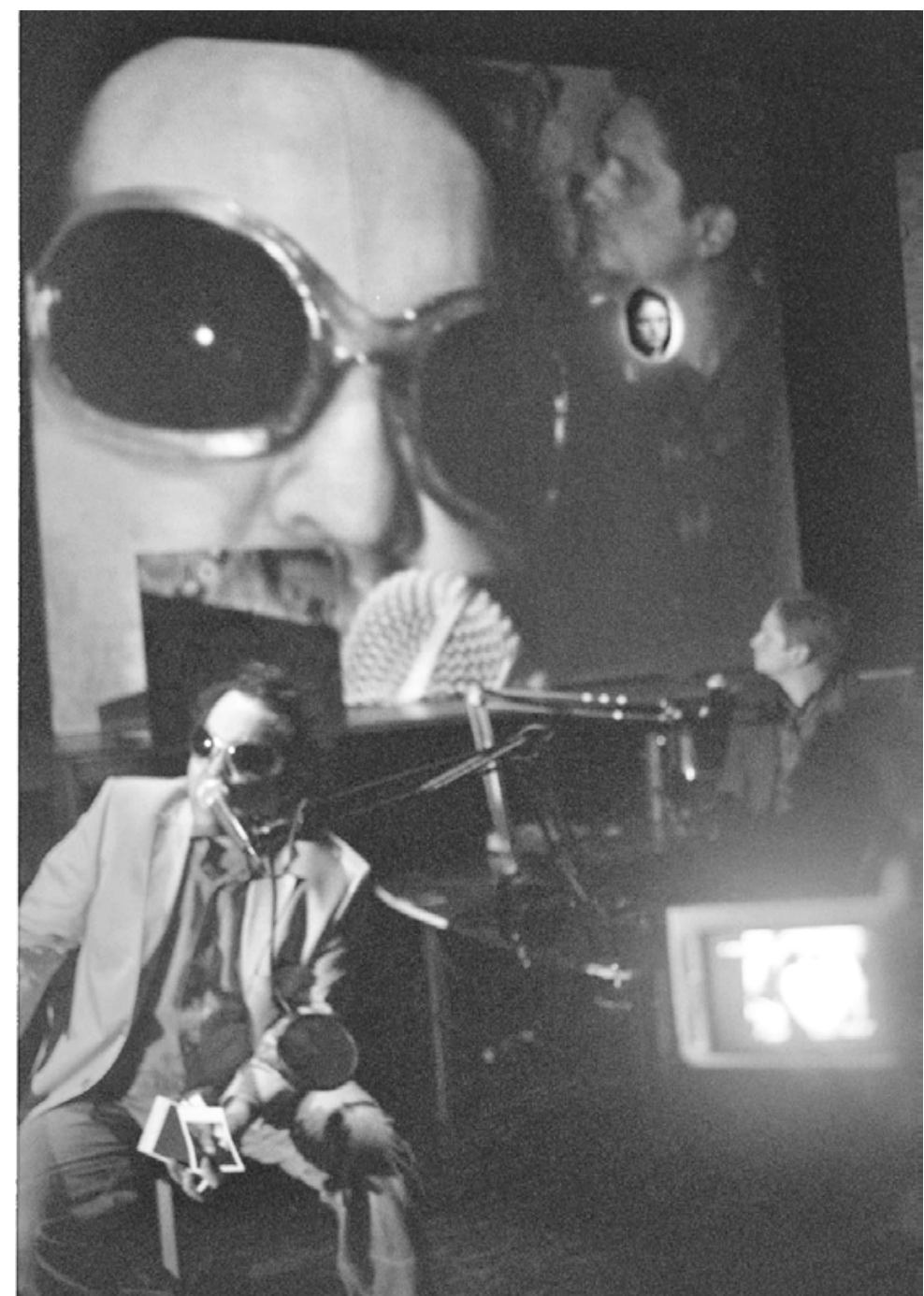

Abbildung 3: Victor Morales und Chris Kondek in HIER IST DER APPARAT von Chris Kondek (2006). Foto: (C) Giannina Urmeneta Ottiker.

Der dritte Teil des Abends führt in den Cyberspace, in dem die Akteure als Avatare auftauchen und immer wieder durch das Zielfernrohr eines Ego-Shooters erledigt werden. Diese in Computerspielen gängige Technik wird aber auch dazu einge- 
setzt, ein rotes Sofa mit Rädern und Flügeln zu versehen. Ein wunderbares Bild, das erinnern könnte an Walter Benjamins Kommentar zum epischen Theater, das (in diesem Punkt orientiert an der Erfahrung des Romanlesens auf dem Sofa) ein »entspanntes, der Handlung gelockert folgendes Publikum« verlangt (Benjamin: 532). Oder an Paul Virilios Hinweis, dass ein am Straßenrand geparktes Fahrzeug »nichts als ein Sofa mit vier oder fünf Plätzen« ist und seine besondere Bedeutung erst im unsichtbaren »Hier und Jetzt der Geschwindigkeit und der Beschleunigung « erhält (Virilio: 19).

Die Vision der Ideologie-Szene, dass durch die Beherrschung der Technik eine neue Form von Natur zu erfinden sei, wird hier verkörpert durch Kunstfiguren, die fliegen und schwebend tanzen können, beim Einsatz des Ego-Shooters aber Ziele für ein großes Massaker abgeben. So erhellt Kondeks APPARAT nicht zuletzt die oft übersehene Bedeutung des Asozialen und Destruktiven für die Lehrstücke. Brecht hat in dieser Versuchsreihe, zumal im BADENER LEHRSTÜCK und im FATZER-Fragment, stets die Auseinandersetzung mit dem Asozialen gefordert: »gerade die darstellung des asozialen durch den werdenden bürger des staates ist dem staate sehr nützlich « (Steinweg 1976: 70f). Das Durchspielen und Ausagieren der asozialen Triebe wird dabei sogar als Grundlage für die Verknüpfung von Theater und Pädagogik verstanden. An diesem Punkt hat auch die Analyse der gegenwärtig wieder produktiven Impulse von Brechts Lehrstücken für postdramatische Theaterformen anzusetzen (vgl. Vaßen und Lehmann: 44ff, 239f, 396). Am Schluss von Kondeks Inszenierung steht aber die schon erwähnte Szene 16, mit den Worten des gelandeten Fliegers: »My name is So and So. Carry me to the dark shed so no one could see my natural weekness. « Der Moderator fährt fort: »But tell the boys in San Diego their work was good. The machine was without any faults. « Gerade im Verweis auf die Arbeit des Kollektivs erscheint die Leistung des Individuums immer noch unzulänglich. Im Umgang mit der Produktivität der eigenen Fehler versteht sich auch Kondeks APPARAT weniger als eine Aufführung des Lehrstücktextes, vielmehr als Übung, als Auseinandersetzung mit neuen Kontexten.

Im Sommer 2007 hat Kondek mit Studenten am Frankfurter Mousonturm auch eine Produktion des BADENER LEHRSTÜCKS erarbeitet. Im Bühnenaufbau der (vorher nochmals gezeigten APPARAT-Produktion) wurde die zentrale Frage nach dem Verhältnis von Gewalt und Einverständnis verknüpft mit dem Phänomen der SnuffFilme und der von Medien gesteigerten Faszination an >live< dokumentierter Gewaltausübung. Die Zuschauer wurden dabei nicht mehr nur als Voyeure oder Teilnehmer angesprochen, sondern auch als Zeugen, die sich ihrer eigenen Verantwortung für das Geschehen bewusst wurden - in einem Experiment mit offenem Ausgang. Mit der Bearbeitung von Szenen des BADENER LEHRSTÜCKS verband sich die Produktion eines Snuff-Films, wobei die dem Genre entsprechende Mischung aus fake und Dokument, Professionalität und Unbeholfenheit vorgeführt wurde. Das Bühnengeschehen teilte sich in einige zumeist hinter der Leinwand angedeutete und als Film darauf projizierte Gewaltszenen und eine davor stattfindende Situation zwischen Talkshow und (TV-)Gerichtsprozess. Dazu kamen vorproduzierte $>\mathrm{Ge}-$ waltfilme<, mit Photoshop bearbeitete (entstellte) Gesichter und Montagen, wie etwa bei der Clownsszene, die als Massaker an Gemüsefiguren auf einige durch die Leinwand gesteckte Köpfe von Darstellern projiziert wurde. Der Impuls zu helfen, den einzelne Zuschauer schließlich demonstrierten, indem sie den Gestürzten ein Glas Wasser reichen wollten, wurde mit der Komik der dadurch entstehenden Bühnensituation (»das ist aber mein Wasser! «) wie auch mit Brechts Text über die Einheit von Hilfe und Gewalt konfrontiert. 


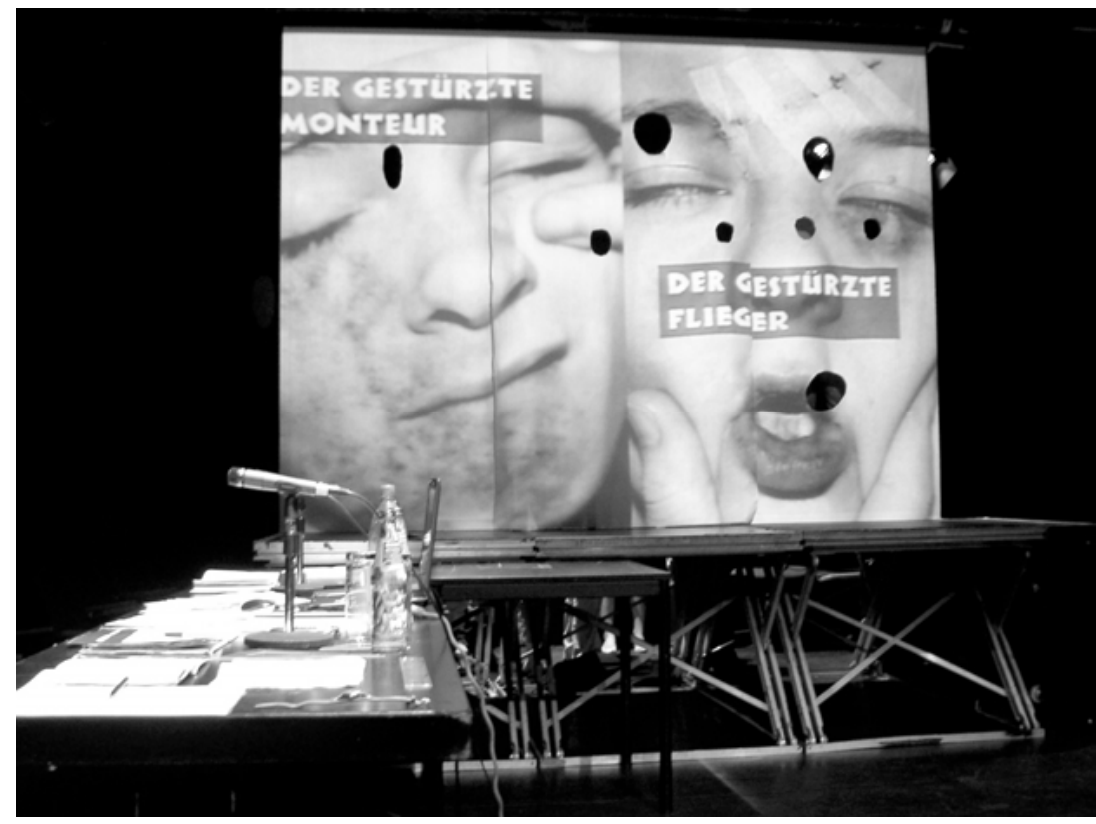

Abbildung 4: Photoshop-Gesichter beim LEHRSTÜCK-Projekt von Chris Kondek mit Studierenden in Frankfurt/M. (2007). Foto: (C) Jan-Peter Schmidt.

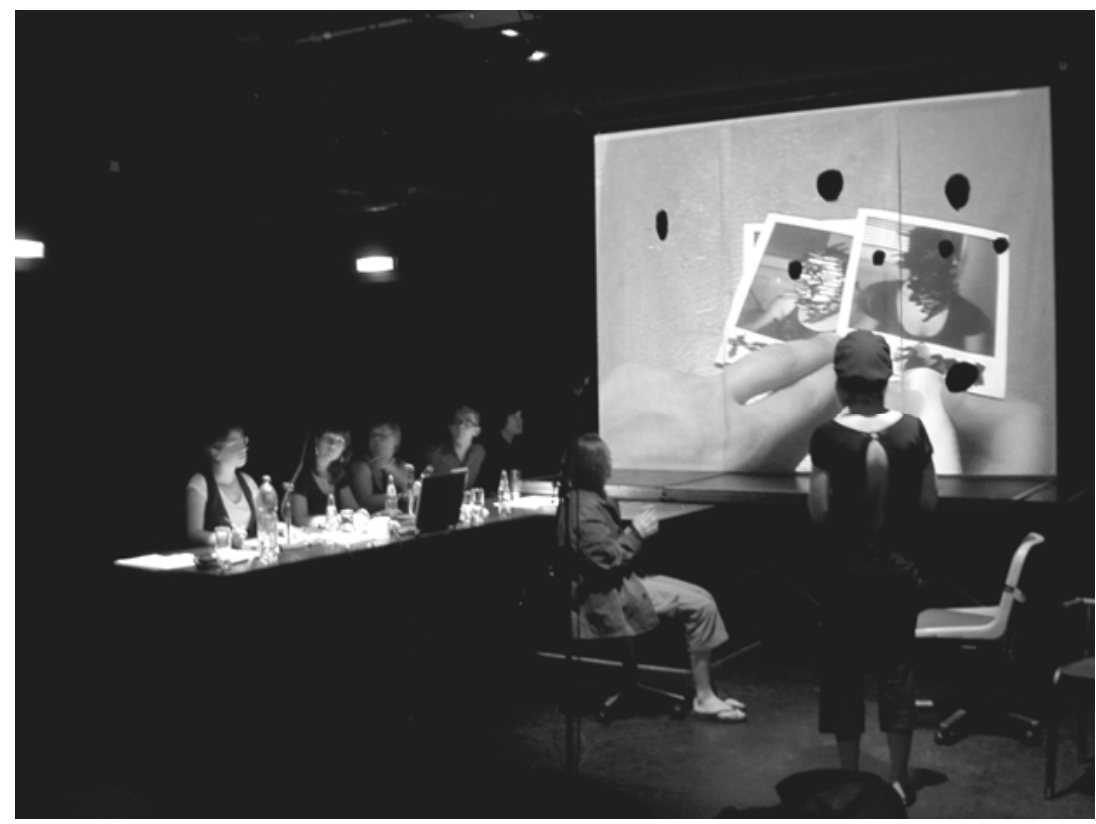

Abbildung 5: Polaroids von Zuschauern beim LEHRSTÜCK-Projekt von Chris Kondek mit Studierenden in Frankfurt/M. (2007). Foto: (C) Jan-Peter Schmidt. 
Die zu Beginn des Abends angefertigten Polaroids von Zuschauern wurden später auf die Leinwand projiziert und dabei mit willkürlich gewählten Todesdaten versehen, worauf die Zuschauer betroffen, die Akteure mit einem offenkundig gespielten, in Gelächter umschlagenden Mitleidsausbruch reagierten. So wurde aber gerade im Durchspielen der Lehrstückszenen zum Einverständnis mit dem Sterben das prinzipielle Einverständnis des Zuschauers mit der Theatersituation in Frage gestellt. Dem entsprach die Arbeit an verschiedenen Spielweisen: Der Part des gestürzten, auf seiner individuellen Leistung bestehenden Fliegers wurde von einer Schauspielstudentin übernommen, während die übrigen, > ungelernten< Projektteilnehmer mit der Spannung zwischen den (ohnehin zirkulierenden) Rollen des Lehrstücks und ihrer alltäglichen Person spielten. Wie zuvor schon Kondeks HIER IST DER APPARAT zeigte auch dieses Lehrstückprojekt, dass eine Chance von Theater bei der Auseinandersetzung mit technischen Medien gerade im Nicht-Perfekten liegt, in einer Störung und Unterbrechung der Kanäle und der Wahrnehmungsgewohnheiten. Gegenwärtige Theaterarbeit, die Brechts Lehrstückentwürfe ernst nehmen will, hat jedenfalls von der Infragestellung auch des eigenen Apparats auszugehen Theater im Stadium seiner produktiven Selbstentfremdung. Wenn es nicht mehr nur um die Vermittlung von Informationen und Botschaften gehen kann, und auch nicht um eine autoritäre Vorgabe von Haltungen, dann bleibt gleichwohl der Grundimpuls der Lehrstücke für neuere Theaterformen wichtig: die Durchquerung medialer Räume und das Durchspielen existentieller Zustände und Erfahrungen im szenischen und symbolischen Raum eines Publikums, das mit sich selbst konfrontiert ist.

\section{Literatur}

Benjamin, Walter (1939/1980): »Was ist das epische Theater?« (Zweite Fassung). In: Gesammelte Schriften, hg. von Rolf Tiedemann und Hermann Schweppenhäuser. Frankfurt/M., Bd. 2, S. 532-539.

Brecht, Bertolt (1986ff): Werke. Große kommentierte Berliner und Frankfurter Ausgabe (BFA), hg. von Werner Hecht u. a. Frankfurt/M., Berlin und Weimar: Suhrkamp/Aufbau.

Hrvatin, Emil (2006): »The terminal spectactor«. In: Martina Hochmuth u.a. (Hg.): It takes place when it doesn't. On dance and performance since 1989. Frankfurt/M: Revolver Books, S. 17-26.

Krabiel, Klaus-Dieter (1993): Brechts Lehrstücke. Entstehung und Entwicklung eines Spieltyps. Stuttgart: J. Metzler.

Krabiel, Klaus-Dieter (2001): »Lindberghflug/Lehrstück«. In: Brecht-Handbuch, hg. v. Jan Knopf. Stuttgart: J. Metzler, Bd. 1, S. 216-237.

Lehmann, Hans-Thies/Lethen, Helmut (1978): »Ein Vorschlag zur Güte. Zur doppelten Polarität des Lehrstücks«. In: Reiner Steinweg (Hg.), Auf Anregung Bertolt Brechts .... Frankfurt/M.: Suhrkamp, S. 302-318.

Lehmann, Hans-Thies (1999): Postdramatisches Theater. Frankfurt/M.: Verlag der Autoren.

Nägele, Rainer (1984): »Brechts Theater der Grausamkeit: Lehrstücke und Stückwerke«. In: Walter Hinderer (Hg.): Brechts Dramen. Neue Interpretationen. Stuttgart: Reclam, S. 300-320.

Schachtsieck-Freitag, Norbert (1973): »Der Ozeanflug«. In: Text+Kritik, Sonderband Bertolt Brecht (II), S. 131-137. 
Steinweg, Reiner (1973): »Das Badener Lehrstück vom Einverständnis - Mystik, Religionsersatz oder Parodie«. In: Text + Kritik, Sonderband Bertolt Brecht (II), S. 109-130.

Steinweg, Reiner (1976) (Hg.): Brechts Modell der Lehrstücke, Frankfurt/M.: Suhrkamp.

Vaßen, Florian (1995): »Bertolt Brechts >learning play<: Genesis und Geltung des Lehrstuicks«. In: Brecht then and now/damals und heute. (The brecht yearbook/Brecht-Jahrbuch 20), S. 201-215.

Virilio, Paul (1978): Fahren, Fahren, Fahren, übers. von Ulrich Raulf. Berlin: Merve.

Wöhrle, Dieter (1988): Brechts medienästhetische Versuche. Köln: Böhlau. 


\title{
Armes Theater oder Medienspektakel?
}

\author{
LUTZ ELLRICH
}

\section{Die Abstraktheit der Welt und die Krise der Repräsentation}

Goethe war zutiefst davon überzeugt, dass sich die Natur in die Sichtbarkeit hinein entfalte und folglich »hinter den Phänomenen nichts zu suchen sei«. Solcher Glaube an die Sichtbarkeit und an die Erkenntnispotentiale der Sprachbilder bzw. der theatralischen Darstellungsmittel schwindet in der Moderne. Man begreift jetzt, dass »die Letztelemente « von Natur und Gesellschaft »sich der anschaulichen Vorstellbarkeit oder Abbildbarkeit überhaupt entziehen «. Mit diesen Worten beschreibt Arnold Gehlen 1960 (42) die Differenz zwischen der Position, die der Autor des FAUST und der FARBENLEHRE noch vertreten konnte, und dem aktuell gültigen Standpunkt. »Die Kunst der Gegenwart ist unabwendbar Reflexionskunst « (136) geworden. Alles was sie zeigt, sinnlich präsentiert, wird nun so dargeboten, dass es den begrifflichen Kommentar als notwendige Ergänzung einschließt. Auch im Bereich der Theaterpraxis und -theorie ist die Darstellungskrise der Moderne zum Thema geworden. Die bekannten Arbeiten von Appia und Craig, Stanislawski und Meyerhold, Schlemmer und Artaud vermitteln einen hinreichenden Eindruck von den konzeptionellen Bemühungen, auf das Repräsentationsproblem angemessen zu reagieren. Brechts These, »die eigentliche Realität [sei] in die Funktionale gerutscht « (161), liefert wohl die knappste und pointierteste Diagnose. Seine Stücke und Inszenierungen sollen Modelle liefern, die die Welt so darstellen, dass ihre nicht mehr wahrnehmbaren Strukturen auf ästhetischen Umwegen in den Blick kommen und zugleich als Konstruktionen erkennbar werden, die durch gezielte menschliche Eingriffe zu verändern sind.

Man wird mit der Einschätzung nicht fehl gehen, dass sich die Lage inzwischen eher verschärft als entspannt hat. Die gravierenden Erkenntnis- und Darstellungsprobleme der Kunst (insbesondere der Theaterkunst) stehen immer noch auf der Agenda. Es ist daher kein Zufall, dass Patrice Pavis (243) konstatiert: »Der Einzug der Medien in die Theateraufführung [...] bestätigt und vertieft die Krise der Repräsentation «.

In dieser Diagnose erscheinen die audiovisuellen Medien teils als Phänomene, die die Krise widerspiegeln, teils als Agenten, die für einen weiteren ProblemSchub verantwortlich sind. Etwas mehr Klarheit über die Verstrickung der Medien in die aktuellen Repräsentationsprobleme, die immer auch politisch relevante Handlungsprobleme sind, lässt sich vielleicht gewinnen, wenn man zwei extreme Reaktionen auf die genannte Krise etwas näher betrachtet. Ich meine erstens ein Theater, das sich durch eine ästhetische Radikalkur von medialen Beimengungen reinigt, und zweitens ein Theater, das die Medien, die aus dem Alltag der spätmodernen Subjekte gar nicht wegzudenken sind, exzessiv integriert und als Medien 
ostentativ ausstellt. (Damit leugne ich keineswegs die Ergiebigkeit anderer, heuristisch ebenso tauglicher Verfahren.)

\section{Der Reichtum des >Armen Theaters}

Als Beispiel für die reduktionistische Methode greife ich auf die Theaterpraxis und -theorie von Jerzy Grotowski zurück. Dabei kommt es mir natürlich sehr gelegen, dass Grotowskis Bemühungen mit Gedanken zur Medienkonkurrenz einsetzen. So heißt es in einem Text von 1964:

»In unserem Zeitalter, wo eine Sprachverwirrung herrscht wie im Turm von Babel, wo sich alle ästhetischen Gattungen vermischen, ist das Theater vom Tode bedroht, da Film und Fernsehen seine Grenzen verletzen. Das bringt uns dazu, das Wesen des Theaters zu untersuchen, worin es sich von den anderen Kunstformen unterscheidet und was es unersetzbar macht $«($ Grotowski: 21).

Zunächst setzt uns bei der Lektüre dieser Passage die These von der Vermischung der Gattungen in Erstaunen. Man weiß nicht genau, ob Grotowski auf die damals äußerst beliebte Kreuzung von Tragödie und Komödie anspielt oder ob ihm schon jener erstaunliche, Genres und Formate verwischende »Flow « vor Augen steht, auf den Raymond Williams einige Jahre später aufmerksam gemacht hat.

Trotz dieser Unklarheit wird die Kernidee von Grotowskis Überlegungen deutlich: Die audiovisuellen Medien - so lautet der entscheidende Vorwurf - kolonisieren das Theater. Sie rauben es aus, indem sie bewährte Darstellungs-, Ausdrucksund Repräsentationsmittel übernehmen. Das ist jedoch kein Grund zur Resignation. Denn »es gibt [...] ein Element, das Film und Fernsehen dem Theater nicht rauben können: die Nähe des lebenden Organismus« (Grotowski: 32). Daher empfiehlt Grotowski folgendes Vorgehen: Das Theater verteidigt nichts von dem, was ihm genommen werden kann. Es stützt sich allein auf das Material, welches ihm verbleibt; ja es begreift das an ihm begangene Verbrechen der Ausplünderung als eine unumgängliche Entschlackungskur. Es begrüßt geradezu die Reduktion, um auf ihrer Basis »Eigenkomplexität« aufzubauen, wie man mit Niklas Luhmann formulieren könnte. Die entstandene »Armut«, die Grotowskis Theaterkonzept seinen Namen gibt, lässt sich auf diese Weise als eine bislang unentdeckte Quelle des Reichtums verstehen. Der als Theater-Material übrig gebliebene Körper wird mithin einer Selbststeigerungsprozedur unterworfen und entwickelt sich schließlich zu einem genuinen Wert, zu einer eigenen ästhetischen Totalität.

Die Arbeit mit dem Körper ist jedoch einer ganzen Reihe von Gefahren ausgesetzt, die es zu meistern gilt. Grotowski zeigt, dass die neuen Medien das Theater nur deshalb ausrauben, weil sie eine spezifische Funktion innerhalb der Gesellschaft aktiv übernehmen. Erst die Kritik an der Rolle der Massenmedien macht deutlich, warum es überhaupt sinnvoll ist, sich weiterhin der Theaterpraxis zu widmen. Das Theater erhält jetzt eine Aufgabe, die keine andere soziale Institution auf derart hohem Niveau erfüllen kann: Es geht um die Abwehr der negativen Effekte von massenmedialer Unterhaltung, Zerstreuung und ideologischer Indoktrination, letztlich um den Widerstand gegen die Erzeugung habitualisierter, in den Körper regelrecht eingeschriebener Formen des inauthentischen Daseins.

Der Körper als Basismaterial ist aber nur eine Komponente des »Armen Theaters «. Er besetzt gleichsam die Stelle der >Armut als Charakteristikum für Art und 
Umfang des medialen Einsatzes. Was meint Grotowski mit dem Ausdruck »Theater «? Inwiefern handelt es sich bei dem, was er praktiziert, noch um Vorführungen oder Aufführungen? ${ }^{1}$

Als das > Wesen $<$ des Theaters bestimmt Grotowski die Begegnung von Schauspieler und Zuschauer. Diese Bestimmung klingt zunächst reichlich trivial. Denn einsame Körper- und Stimmübungen vor dem Spiegel, Aktivitäten ohne einen Anderen, der angesprochen oder >adressiert< wird, wie es neumodisch heißt, würden nicht unter die Kategorie >Theater < fallen. Grotowski verknüpft die Urszene der Begegnung von Spieler und Zuschauer mit dem Konzept eines kunstvoll und gezielt durch Verarmung ${ }^{2}$ angereicherten Körpers. Damit die Begegnung von Spieler und Zuschauer im strengen Sinne >körperhaft $<$ ist, muss sie durch »Nähe « charakterisiert sein. Dieser physische Direktkontakt sorgt nämlich - wie Grotowski hervorhebt - dafür, dass »jede Herausforderung durch den Schauspieler [...] zu etwas Großem, Außergewöhnlichen [wird], zu etwas, das sich der Ekstase annähert«. Im Detail bedeutet das:

»Die Distanz zwischen dem Schauspieler und dem Publikum [muss] abgeschafft werden, indem die Bühne eliminiert wird, alle Grenzschranken abgebaut werden. Die drastischen Szenen sollen Auge in Auge mit dem Zuschauer stattfinden, so dass er auf Armeslänge vom Schauspieler entfernt ist, seinen Atem spüren kann, seinen Schweiß riecht. Dies macht ein Theater von der Größe eines Kammerspiels notwendig« (Grotowksi: 32).

Welches konkrete Ziel verfolgt aber die Produktion von Nähe und in welchem Verhältnis steht das Ziel, das die Schauspieler erreichen sollen, zu der angestrebten Wirkung auf die Zuschauer?

Bei der Suche nach einer Antwort auf diese Frage stößt man auf eine merkwürdige Konstellation. Grotowski gibt dem Problem des Mimetischen, an dem sich das traditionelle Theater jahrhundertelang abgearbeitet hat, eine ebenso simple wie aufschlussreiche Wendung: Der Schauspieler soll sich auf der Bühne authentisch verhalten, er soll keine Gefühle, charakteristischen Gesten etc. imitieren, sondern den Zuschauer dazu anleiten, die Schauspieler als Avantgarde der Echtheit und Unverstelltheit zu betrachten und ihrem Vorbild nachzueifern. Ort und Funktion des mimetischen Vollzugs werden also markant verschoben: An die Stelle der Schauspielkunst als Wiedergabe von Realität durch mimetische Praxis tritt das >Modell-Lernen< des Zuschauers, das mit Akten der Nachahmung einsetzt. Während die Schauspieler, vorbereitet durch lange intensive Übungen und Meditationen, sich vor den Augen des Publikums die Alltagsmaske herunterreißen, sind die Zuschauer gehalten, diese Leistung als Anstoß und Leitlinie für eigene Anstrengungen zu nehmen. Und wenn den hingebungsvollen Schauspielern eine glaubhafte Präsentation gelingt, geben sie den Zuschauern »die Möglichkeit, einen ähnlichen Prozess der Selbstdurchdringung zu beginnen« (Grotowksi: 205). Heilsame Funktionen besitzt eine solche mimetische Annäherung des Zuschauers an die Theater-

1 In den 1960er Jahren stand die Differenz von Aufführung qua Performance einerseits und Darstellung im Sinne einer symbolischen Repräsentation realer Dinge und Ereignisse andererseits noch nicht im Zentrum der Diskussion. Sie gehörte aber bereits wie sich an der breiten Artaud-Rezeption und Derridas dekonstruktivistischer ArtaudKritik (1967/1972) ablesen lässt - zu den wichtigen Themen der Zeit.

2 Um möglichen Missverständnissen vorzubeugen: Dies hat nichts mit den Verfahren der >Art of Impoverishment $<$ zu tun, die das Bedeutungslose und Banale ins Zentrum der Betrachtung zu stellen sucht. 
Akteure, weil sie den ureigensten, unter den gegenwärtigen Bedingungen aber systematisch verstellten Intentionen der Zuschauer entspricht. Grotowski begründet diesen quasi-therapeutischen Anspruch seines Theaters mit einer sozialpsychologischen Diagnose, die nicht nur für die kommunistischen Verhältnisse, sondern auch für die westlichen Industriegesellschaften zutreffend sein soll: Der medial geprägte

»Lebensrhythmus in der modernen Zivilisation ist charakterisiert durch Tempo, Spannung, ein Gefühl des Unheils, durch den Wunsch, unsere persönlichen Motive zu verbergen, durch das Annehmen einer Reihe von Rollen und Masken im Leben (unterschiedliche in unserer Familie, bei der Arbeit, unter Freunden oder im geselligen Leben usw.)« (Grotowski: 26).

Zahlreiche Menschen sehnen sich zwar nach einem anderen Zustand, aber es gelingt ihnen nicht, den fatalen Lebensrhythmus, den die Moderne ihnen aufnötigt, zu durchbrechen. Die notorischen Ausbruchsversuche scheitern oder führen auf Abwege. »In unserer Suche nach Befreiung geraten wir ins biologische Chaos. Am meisten leiden wir unter einem Mangel an Totalität, während wir uns wegwerfen und vergeuden« (Grotowski: 205).

Das »Arme Theater« versteht Grotowski als Anleitung zu einer bewussten und kontrollierten Form der Befreiung, deren Pointe darin liegt, jedem, der sich dieser Prozedur zu unterziehen bereit ist, genau das zu nehmen,

»woran er für gewöhnlich sehr hängt: seine Widerstände, Beschränkungen, seine Neigung, sich hinter Masken zu verbergen, seine Halbherzigkeit, die Hindernisse, die sein Körper dem kreativen Akt in den Weg stellt, seine Gewohnheiten und sogar seine normalen >guten Manieren« (Grotowski: 211).

Die praktische Umsetzung des ambitionierten Projekts ist nun allerdings mit mancherlei Schwierigkeiten behaftet. Die Darsteller sind zweifach gefährdet: Wenn sie für das Publikum spielen, so erliegen sie allzu leicht ihren narzisstischen Neigungen; spielen sie aber für sich selbst, so mündet das oft in Heuchelei oder Hysterie. Grotowski ersinnt daher ein aufwendiges Regelwerk, das nicht allein das Verhältnis des Schauspielers zum Publikum betrifft, sondern auch die Beziehungen des Spielers zu den anderen Mitgliedern der Truppe. So werden etwa die gängigen Klatschgeschichten unter Schauspielern und die nicht minder üblichen Liebesaffären mit einem Tabu belegt.

Aber auch das Publikum ist ein riskanter Faktor; denn es kann sich von Fall zu Fall durch Ignoranz, Borniertheit, oberflächliche Neugier, Sensationslust etc. auszeichnen.

Angesichts dieser Probleme nimmt es nicht wunder, dass Grotowski auf dem Höhepunkt seines Erfolges eine radikale Wende vollzog und sich auf die Durchführung so genannter >para-theatralischer $<$ Experimente konzentrierte. Die Differenz von Schauspieler und Zuschauer wurde nun völlig aufgehoben. ${ }^{3}$ An die Stelle von

3 Dieses Programm ist vergleichbar mit Bertolt Brechts Konzept eines politisch-pädagogischen Theaters. Die sogenannten Lehrstiucke sollen (zumindest im Prinzip) nicht vor einem Publikum gespielt, sondern als Textvorlagen für szenische Übungen genutzt werden, die Akteure, in jeweils wechselnden Rollen, sich selbst die unterschiedlichen Aspekte eines sozialen Konflikts vor Augen führen und schließlich zu einem begründeten Urteil gelangen, das die politische Praxis anzuleiten vermag. 
Aufführungen traten Gruppenprozesse. Das Leben selbst wurde zum Drama gemacht. Praktisch lief dies darauf hinaus, dass man gemeinsam eine Scheune baute oder nachts durch unwegsames Gelände streifte und versuchte, ein bestimmtes Ziel (z.B. eine alte Burg) zu erreichen.

\section{Medienspiel ohne Grenzen}

Bevor ich versuche, den aktuellen Wert von Grotowskis reduktionistischem Programm zu bestimmen, möchte mich einer anderen, ähnlich radikalen Antwort auf die Krise der Repräsentation, nämlich dem exzessiven Medieneinsatz, zuwenden. Als Beispiel wähle ich Frank Castorfs Inszenierungen. ${ }^{4}$ Sie bieten sich insbesondere deshalb an, weil sie Medien nicht bloß »als Fremdkörper « (Pavis: 243) zur Schau stellen, die alles vereinnahmen, sondern als vielschichtige kulturelle Errungenschaften, die Erfahrungswelten ebenso eröffnen wie verschließen. ${ }^{5}$ Zunächst einmal nutzt Castorf neue mediale Techniken, um eine den heutigen gesellschaftlichen Verhältnissen angemessene Darstellungsform zu erreichen. Sodann bilden Medien ein konstitutives Element in Aufführungen, die den Zusammenhang von »Kapitalismus und Depression « (Hegemann) einsichtig machen sollen. ${ }^{6}$ Und schließlich fungieren Medien als Katalysatoren in einem Prozess, der das prekäre Dasein des Schauspielers in neuer Manier offenlegt.

Mit dem ersten Punkt sind Fragen der Wahrnehmung, der Erkenntnis, der Rezeption angesprochen. Hier illustriert der Medieneinsatz auf der Bühne die Vermutung, dass wir die Welt kaum noch unmittelbar wahrnehmen können. »Was wir über unsere Gesellschaft, ja über die Welt, in der wir leben, wissen «, so heißt es bei Niklas Luhmann (9), »wissen wir durch die Massenmedien «. Herrscht dieser Eindruck vor, so lässt sich von jeder medialen Darbietung auf mögliche Manipulationen schließen. Baudrillard spricht in diesem Zusammenhang vom »perfekten Verbrechen «, das die Medien begehen, um alle Zuschauer in die paradoxe Lage von passiv Beteiligten versetzen, die zwischen Täter und Opfer nicht mehr sinnvoll unterscheiden können. Das Theater des exzessiven Medieneinsatzes setzt aber auch noch einen weiteren wichtigen Aspekt des aktuellen Diskurses in Szene: Denn neben diesem Manipulationsverdacht, der unweigerlich aufkommt und doch keinen Halt mehr finden kann, bieten die elektrischen und elektronischen Medien auch Anlass für die Vorstellung, dass nur sie und keine anderen Erkenntnismittel tiefe Einblicke in jene Räume der Macht gewähren, die vorher verborgen waren. So gelten bekanntlich das Fernsehen und das Internet als Informationstechniken, die nicht nur Oberflächenreize (vgl. Reckwitz) bieten und auf den >Vorderbühnen< der Ereignisse verweilen, sondern >Hinterbühnen< öffnen und damit Demokratisie-

4 Ein aufschlussreiches Beispiel liefert auch die Arbeit von Erwin Piscator aus den 1920er und 30er Jahren. Als Theaterregisseur setzt Piscator das gesamte Arsenal vorhandener Medien ein, um die totalisierende Struktur des kapitalistischen Systems und die komplexe Situation des Klassenkampfes aufzuzeigen.

5 Als weitere mögliche Beispiele hätte man auch die Zusammenarbeit von Heyme und Vostell, die Produktionen der Wooster Group oder die Inszenierungen von Robert Lepage heranziehen können.

6 Mit dieser morbiden Zusammenstellung, die Alain Ehrenbergs Theorie aufgreift, wird die bekannte, weit optimistischere Kombination von Kapitalismus und Schizophrenie (vgl. Deleuze/Guattari) verabschiedet. Zur Kritik der Depressionsthese aus normalistischer Warte vgl. Ellrich 2007. 
rungsprozesse initiieren oder unterstützen (vgl. Meyrowitz). Allem Anschein nach verringert sich der Abstand zwischen Männern und Frauen, zwischen Regierenden und Bevölkerung, zwischen Eltern und Kindern. Man erfährt sehr viel mehr als früher voneinander. Diskretion und Intimität sind Phänomene, die im gleißenden Licht der medial generierten Öffentlichkeit entschwinden. Zugleich wird deutlich, dass diese Art des Wissens, das alle ehemaligen Arkanzonen erhellt, die Probleme nicht verringert.

Und genau an diesem Punkt im Veranschaulichungs- und Erkenntnisprozess verändern die von Castorf eingesetzten Medien ihre Rolle. Sie fungieren nicht mehr nur als Darstellungsmittel, die ostentativ vorgezeigt werden, sondern verwandeln sich selbst in Elemente der Darstellung. Sie sind nun Teil der Handlung. Die Darstellung wird nicht mehr reflexiv gebrochen, sondern erhält einen quasirealistischen Charakter.

Dieser Umschwung markiert auch die Wende von der Komödie zur Tragödie. Bei der Inszenierung einer Komödie verlässt man sich darauf, dass die reflexive Brechung der Handlung durch das Mit-Darstellen der Darstellungsmittel komische Effekte erzeugt. Die Erkenntnis, dass die Welt nicht so erscheint wie sie ist, sondern durch Medien konstruiert wird, gepaart mit der Einsicht, dass dennoch alles so bleibt, wie es ist, löst jenes Gelächter aus, das sich nach einer überstandenen Gefahr einstellt.

Aber diese Erheiterung schlägt in Erschrecken um, wenn die Medien als reale Mitspieler im sozialen Leben identifiziert werden. Dann geht die Komödie in die Tragödie über. Die Medien treten nicht länger als Agenturen der Weltkonstruktion in Erscheinung, sie sind jetzt vielmehr Instanzen des Sollens. Ihnen obliegt es, die neuen Werte und Normen zu verkünden. Sie flüstern uns diese Richtlinien und Forderungen förmlich ein. Und sie tun dies weit weniger offensichtlich und direkt als die einstigen Sozialisations- und Disziplinierungsinstanzen (Familien, Schulen, Kirchen, militärische Einrichtungen, Behörden, Firmen, Fabriken etc.). Wir aber so zeigen es Castorfs und Hegemanns Arbeiten mit pathetischer Inbrunst - sind diesen Forderungen kaum gewachsen. Denn die neuen, medial präsentierten Ansprüche sind weit schwieriger zu erfüllen als die früheren Befehle. Statt Folgsamkeit und Gehorsam verlangen sie in erster Linie Eigeninitiative, Genussbereitschaft, Verantwortung etc. Aber die neuen Ich-Leistungen können von den vorhandenen Subjekten nicht oder noch nicht in vollem Umfang erbracht werden. Depressionen stellen sich ein und das Leben wird als verfehltes Leben sichtbar.

Castorfs Medienspektakel erweisen sich folglich als Tragödien. Es sind jedoch Tragödien, die durch den spezifischen Einsatz der Medien zugleich auch immer die Tragödienform in Frage stellen. Denn mit den Medien wird in den Inszenierungen beständig gespielt. Im Rahmen des theatralischen Arrangements sind sie nicht nur Quellen sozialer Pathologien, sondern auch stets Objekte eines distanziert ironischen, mitunter gar albernen Umgangs mit den Basiselementen unserer Weltkonstruktion und unserer Neigung, den Verlockungen des Sollens nachzugeben.

Mithin kehrt die Komödie von Szene zu Szene als medien-verspielte MetaTragödie $^{7}$ zurück. Diese doppelbödige Art der Komödie spielt sich aber nie als Pädagogik der emanzipatorischen Medienverwendung auf. Die mögliche Alternative ist nicht Gegenstand des Spiels, sie scheint nur auf. Sie wird nicht etwa durchgespielt, sondern nur angespielt.

Die totale, geradezu totalitäre Präsenz der Medien auf und hinter der Bühne scheint folgende Diagnose zu veranschaulichen: Wir leben heute zwar nicht mehr

7 Zum Begriff der Meta-Tragödie vgl. Abel sowie Menke (152ff). 
in einer Disziplinargesellschaft voller repressiver, geschlossener Institutionen, aber in einer pseudo-liberalen Kontrollgesellschaft, in der die mediale Überwachung eine zentrale Rolle spielt (vgl. Ellrich 2006).

Freilich lässt sich das politische Klima, welches in Kontrollgesellschaften herrscht, auch mit herkömmlichen Theatermitteln ausgezeichnet darstellen. Wenn man Jan Kotts Beschreibung jener berühmten Krakauer Hamlet-Inszenierung vom 30. September 1956 (Regie: Roman Zawistowski, Bühnenbild: Tadeusz Kantor) liest, kann man durchaus den Eindruck gewinnen, dass die buchstäbliche BühnenDemonstration der neuesten Video-Überwachungstechnik das Phänomen eher banalisiert als nachhaltig ins Bewusstsein hebt (vgl. Kott: 72ff).

Castorfs forcierte Mediennutzung in seinen Inszenierungen ermöglicht den Aufbau eines komplexen Spannungsfeldes zwischen zwei Polen: Auf der einen Seite die Tragik post-fordistischer Arbeits- und Lebensverhältnisse, die zwangsläufig jene subjektiven Defizienzgefühle erzeugen, denen die Schauspieler durch ihre Bereitschaft zur Selbstentblößung das Bühnen-Siegel der Echtheit aufdrücken. Auf der anderen Seite die komische Verwandlung der neuesten Kollektivmentalität >Depression< in das kulturelle Kapital einer pubertären Verspieltheit, die im Notwendigen den Zufall und in allen Konsumgütern den Abfall entdeckt.

Es handelt sich um ein Programm, das - trotz mancher Vorbehalte, die es im Detail erwecken mag - sowohl in gesellschaftstheoretischer als auch ästhetischer Hinsicht auf hohem Niveau angesiedelt ist. Wir haben es hier mit raffinierter Reflexionskunst zu tun, die mit legeren Improvisationen aufwartet, naive Unmittelbarkeit und fröhlichen Dilettantismus pflegt und sich zuweilen als psychodramatische Kur hochneurotischer Darsteller geriert, die unbedingt Einblicke in die Abgründe ihres Seelenlebens gewähren wollen.

\section{Engführung und Ausblick}

Konzeptionell lässt sich diese Art des Theaters, das perfekt auf die »neue Unübersichtlichkeit « (Habermas) der Gesellschaft zugeschnitten ist, schwerlich überbieten; dennoch wirken die Ergebnisse auf der Bühne oft blass, zerfahren und flau. Vergleicht man Castorfs Arbeiten mit den verfügbaren Dokumenten und Aufnahmen von Grotowskis Projekten, so gewinnt man leicht den Eindruck, dass sich Grotowskis Inszenierungen - trotz des veränderten historischen Kontextes - eine Intensität des Ausdrucks bewahrt haben, die man in der Berliner Volksbühne vergeblich sucht.

Um Klarheit über diesen bemerkenswerten Effekt zu erhalten, möchte ich den Blick noch einmal zurück auf Grotowski wenden. Denn bei ihm lässt sich eine antimediale Stoßrichtung erkennen, die tiefer zielt als der bloße Versuch, den Übergriffen von Film und Fernsehen angemessen zu begegnen. Es geht buchstäblich um die Vermeidung von Medialität im Sinne von Vermittlung. Ziel des »Armen Theaters « ist Unmittelbarkeit, Echtheit, Authentizität, Präsenz. Ein ähnliches Anliegen hatte schon Antonin Artaud in seinen Schriften aus den dreißiger Jahren vorgebracht. Grotowski sieht sich deshalb gezwungen, die Differenz zwischen seinen und Artauds Ideen deutlich zu markieren. Vorbereitet durch die eher beiläufige Kritik an Artauds Atmungstheorie (Grotowski: 98) entfaltet er sein zentrales Argument: Im >Armen Theater ist das verwendete Zeichen »artikuliert«, kein Schrei, kein Delirium des in Szene gesetzten Körpers (101). Die angestrebte »Trance « (29) entbehrt der fatalen Nähe zur Hysterie, die für Artaud so charakteristisch ist, sie 
besitzt eher den Charakter jenes nüchternen Rausches, den Walter Benjamin beschrieben hat.

Es geht Grotowski folglich um das Herstellen, nicht um das Ausstellen von Authentizität. Als völlig verfehlt würde ihm daher die heute grassierende Praxis erscheinen, echte Arbeitslose, Ausländer, Krüppel, geistig Behinderte und sonstige stigmatisierte Personen auf die Bühne zu stellen, um den theatralischen Mehrwert des Authentischen zu erwirtschaften.

In diesem Punkt stimmen Grotowski und Castorf trotz aller Unterschiede bzw. Gegensätze überein. Beide versuchen von vorn herein, eine Gefahr zu meiden, auf die seit 1924 mit besonderer Eindringlichkeit Helmuth Plessner hingewiesen hat: Gemeint ist »die bekannte Erfahrung, daß der Schauspieler, welcher sich seinem echten Gefühl überläßt, um eine Rolle überzeugend zu machen, an Evidenz verliert« (Plessner: 311). Grotowskis und Castorfs Regiearbeiten setzen sich - anders als etwa Stanislawski - nicht primär zum Ziel, durch bestimmte Techniken eine Bühnenrolle überzeugend zu machen. Vielmehr wird das Rollenspiel als Medium genutzt, um zum Kern des Individuums vorzustoßen. Allerdings verbinden beide ganz unterschiedliche Erwartungen mit ihrem Vorgehen. Während Grotowski einen verschütteten Ursprung freilegen möchte und sich heilsame Wirkungen erhofft, hat es Castorf eher auf die Entdeckung des traumatischen Kerns im Subjekt abgesehen, dessen Offenbarung bei Akteuren wie Betrachtern ein mitunter recht schmutziges Genießen - eben jene durch Lacan (1975) und Žižek (1999) berühmt gewordene >jouissance< - auslöst.

Grotowskis praktizierte Reduktion des Theaters auf das >Wesentliche< lässt sich in zwei Aspekte zerlegen: Einerseits löst die radikale Fixierung auf den menschlichen Körper und die Essenz der Schauspieler-Zuschauer-Beziehung letztendlich das Theater in Gruppenexperimente und Workshops auf. Im günstigsten Falle führt dies zu einer Verbesserung der Lebenskunst. Andererseits erzeugt die formalistische Komponente des theatralischen Reduktionsverfahrens eine Leere, die extrem anfällig für semantische Aufladungen ist. Und nichts eignet sich für derartige Sinn-Aufladungen besser als eine strenge Moral. Daher ist Vorsicht geboten: Jeder radikale - ästhetische ebenso wie politische - Reduktionismus produziert das Verlangen nach Fülle. Dann paaren sich der Wille zur Askese mir der Inbrunst des Glaubens an uralte Ideen oder brandneue Werte.

Wir können daher »nicht einfach zu Grotowski zurückkehren« (Pavis: 243). Wenn aber ein umstandsloses Revival unmöglich geworden ist, dann drängt sich die Frage auf, ob sich vielleicht ein komplizierter und raffinierter Weg finden lässt, auf dem man die Intensität des >Armen Theaters< retten und bewahren könnte. Besteht überhaupt noch die Möglichkeit, puristische Theaterarbeit so zu betreiben, dass ihre Radikalität nicht zu unbedarften und obsoleten Positionen führt? Lässt sich (mit anderen Worten) mediale Armut und szenische Intensität zu Formen der Theaterkunst verbinden, die eine ästhetisch stimulierbare Ethik der Reflexion attraktiv machen und nicht mit naiven moralischen Appellen oder Provokationen Eindruck zu schinden suchen?

Als Studienobjekt könnte man die aktuelle Performance-Kunst in Betracht ziehen. Ein schon legendäres Beispiel - nämlich Marina Abramovićs Performance LIPS OF THOMAS - liefert wertvolles Anschauungsmaterial. Mit der ausführlichen Analyse dieses Ereignisses startet Erika Fischer-Lichte ihr Buch zur > Ästhetik des Performativen $<$. Bemerkenswert an Abramovićs Vorführung ist der Versuch, die Zuschauer in eine Krise zu stürzen: Sollen die Betrachter sich schlicht und einfach moralisch ansprechen lassen, Fürsorge und Anteilnahme zeigen und eine exzentrische Künstlerin vor Akten der Selbstschädigung bewahren? Oder sollen sie - 
ganz im Gegenteil - die Warte ästhetischer Distanzierung und Reflexion einnehmen, die Freiheit des Subjekts respektieren und die Trennung von Kunst und Moral genießen, welche sich zu Beginn des 19. Jahrhundert durchzusetzen begann und in Thomas de Quinceys Lippenbekenntnis ON MURDER CONSIDERED AS ONE OF THE FINE ARTS von 1827 eine Art Programmschrift besitzt? ${ }^{8}$

Ist aber nicht allein schon der intentional hochambitionierte Versuch, die Betrachter mit derartigen Entscheidungsproblemen zu konfrontieren, erstaunlich mühsam und überdreht? Abramović predigt keine Moral mehr, lässt auch das Authentische in der Schwebe, sondern unterzieht das Verhältnis von ästhetischer Coolness und moralischer Betroffenheit einem Test. Doch dieser Test, wie auch immer er jeweils ausfällt, ist ohne jede praktische Bedeutung. Er sagt nichts über tatsächliche moralische Gesichtspunkte, Affekte und Begründungsformen aus. Die Betroffenheit aller Beteiligten speist aus dem mehr oder minder deutlichen Wissen um die historisch generierte Differenz des ästhetischen und moralisch-praktischen Diskurses. Und diese Diskursgeschichte hat den Status eines Rahmens, der auch von der radikalsten Performance nicht aufzusprengen ist. Keine noch so angestrengte Produktion theatralischer Intensität kann dahinter zurückführen.

Wer unter diesen Bedingungen eine »Ästhetik der Präsenz« beschwört, die »mit existentiellem Einsatz spielt« und davon ausgeht, dass »der Moment intensiver Präsenz [...] eine intrikate Verbindung zum Tod und zur Sterblichkeit « (Kolesch: 67) unterhält, wiederholt nicht allein Michel Leiris' überspanntes Programm von 1939, »Literatur als Stierkampf « in Szene zu setzen, sondern nährt auch Illusionen, gegen die die forcierte ästhetische Reflexion gerade immun macht.

Wahrscheinlich - so möchte man beim gegenwärtigen Stand der Dinge räsonieren - kann man einstweilen nur Meta-Betrachtungen anstellen (wie FischerLichte sie am Beispiel der Abramović-Darbietung vorexerziert hat) oder statistische Erhebungen über die Zuschauerreaktionen bei reduktionistisch angelegten Performances durchführen und diese dann in geeigneten Publikationsorganen veröffentlichen, um die Rückkopplungseffekte zu studieren. Offensichtlich ist jedenfalls, dass die performative Entfernung aller anrüchigen medialen Repräsentationstechniken den gleichen Effekt erzeugt wie eine medial hochgerüstete Fernsehshow, die die Zuschauer mit dem Versprechen anlockt, echte Prominente im echten Urwald in echten Stresssituationen auf dem Bildschirm zu präsentieren. Das ist nicht intensiv, sondern echt fade. - Die Recherche nach dem Theater der Zeit geht also weiter.

8 Dass Abramović mit ihrer Performance auf den wahrhaft ungläubigen Thomas de Quincey anspielt, liegt auf der Hand, steht aber selbstverständlich nicht außer Frage. 


\section{Literatur}

Abel, Lionel (1963): Metatheatre. A New View of Dramatic Form. New York: Hill and Wang.

Artaud, Antonin (1964 [1938]): Le théâtre et son double. Paris: Gallimard.

Baudrillard, Jean (1996 [1995]): Das perfekte Verbrechen. München: Hanser.

Brecht, Bertolt (1967): Gesammelte Werke 18. Frankfurt/M.: Suhrkamp.

Deleuze, Gilles/Felix Guattari (1974 [1972]): Anti-Ödipus. Frankfurt/M.: Suhrkamp.

Ehrenberg, Alain (2004 [1998]): Das erschöpfte Selbst. Depression und Gesellschaft in der Gegenwart. Frankfurt/New York: Campus.

De Quincey, Thomas (1977 [1827]): Der Mord als schöne Kunst betrachtet. Frankfurt/M.: Insel.

Derrida, Jacques (1972): »Das Theater der Grausamkeit«. In: Ders.: Die Schrift und die Differenz. Frankfurt/M.: Suhrkamp, S. 351-379.

Ellrich, Lutz (2006): »Die Überwachungstechnik als Herausforderung der Kritischen Theorie und Praxis«. In: Barbara Becker/Josef Wehner (Hg.): Kulturindustrie reviewed. Bielefeld: transcript, S. 127-142.

Ellrich, Lutz (2007): »Normativität und Normalität«. In: Christina Bartz (Hg.). Spektakel des Normalismus. München: Fink, S. 25-51.

Gehlen, Arnold (1986 [1960]): Zeitbilder. Zur Soziologie und Ästhetik der modernen Malerei, 3. erw. Aufl. Frankfurt/M.: Klostermann.

Fischer-Lichte (2004): Ästhetik des Performativen. Frankfurt/M.: Suhrkamp.

Grotowski, Jerzy (1969 [1968]): Für ein Armes Theater. Velber: Friedrich.

Hegemann, Carl (Hg.) (2000/2001): Kapitalismus und Depression, Bde. I-III. Berlin: Alexander.

Kolesch, Doris (1999): »Ästhetik der Präsenz«. In: Erika Fischer-Lichte u.a. (Hg.): Transformationen. Theater der neunziger Jahre. Berlin: Theater der Zeit, S. 57-69.

Kott, Jan (1970 [1965]): Shakespeare heute. München: Pieper.

Lacan, Jacques (1975): Encore. Paris: Editions du Seuil.

Luhmann, Niklas (1996): Die Realität der Massenmedien. Opladen: Westdeutscher Verlag.

Menke, Christoph (2005): Die Gegenwart der Tragödie. Frankfurt/M.: Suhrkamp.

Meyrowitz, Joshua (1985): No Sense of Place (2. Aufl.). New York: Oxford University Press.

Pavis, Patrice (2001): »Die zeitgenössische Dramatik und die Medien«. In: Josef Früchtle/Jörg Zimmermann (Hg.): Ästhetik der Inszenierung. Frankfurt/M.: Suhrkamp, S. 240-259.

Plessner, Helmuth (1983 [1967]): »Der Mensch im Spiel«. In: Ders.: Gesammelte Schriften VIII. Frankfurt/M.: Suhrkamp, S. 307-313.

Reckwitz, Andreas (2006): Das hybride Subjekt. Weilerswist: Velbrück.

Williams, Raymond (1975): Television: Technology and Cultural Form. New York: Schocken Books.

Žižek, Slavoj (1999): Liebe Deinen Nächsten? Nein, Danke! Die Sackgasse des Sozialen in der Postmoderne. Berlin: Volk \& Welt. 


\title{
LIVING IN A BOX - ZUR MEDIALITÄT RÄUMLICHER ANORDNUNGEN
}

\author{
ANNEMARIE MATZKE
}

Ich sitze in einem Zimmer und um mich herum spukt es. Am Fenster sind Schatten zu erkennen, eine Jalousie bewegt sich - scheinbar von selbst. Hinter mir höre ich Stimmen, neben mir Schritte. Doch niemand ist zu sehen. Vor mir, im verrauschten Videobild, taucht ein Geist auf und spricht zu mir.

In den Bühnenraum des Praters der Volksbühne am Rosa-Luxemburg-Platz ist ein großes Zimmer gebaut, in dessen Mitte die Sitzplätze der Zuschauer angeordnet sind. Die Wände sind aus Versatzstücken zusammengewürfelt: Sperrholzwände, beklebt mit Fototapeten, einige mit Türen, andere mit Fenstern, manche mit Jalousien versehen. An der Stirnseite des Raumes gibt es eine große Leinwand. Die Zuschauer sind in das Zimmer eingeschlossen und gleichzeitig vom szenischen Geschehen ausgeschlossen. Kein Darsteller betritt während der Aufführung den Raum. Ihre Aktionen finden nur hinter den Wänden statt, teils durch die Fenster sichtbar, teils nur über Videoübertragung zu sehen. Sie bewegen sich um die Zuschauer herum. Man hört Schritte, Stimmen durch die Wände, ohne ihnen eine konkrete Person zuordnen zu können. Wie Geister tauchen die Darsteller immer dort wieder auf, wo man sie nicht vermutet, ohne sich allerdings je völlig zu zeigen.

Die Inszenierung ME, THE MONSTER des deutsch-englischen Performance-Kollektivs Gob Squad hatte im Juni 2006 Premiere und stellt die Frage nach dem Monster in uns allen. Gespielt wird mit Momenten des Verdachts, der Unsicherheit, des Unheimlichen. Und diese Thematiken nimmt die Rauminstallation der Inszenierung auf. Als Zuschauerin bin ich permanent damit beschäftigt, die verschiedenen räumlichen und medialen Darstellungsebenen zu differenzieren und zu verorten, wo sich die Darsteller gerade befinden, dem Gesehenen einen Raum zuzuordnen, mich innerhalb des räumlichen Aufbaus zu orientieren. Anders als im traditionellen Theaterraum, der durch die frontale Anordnung des Zuschauers gegenüber der Bühne die Blickrichtung vorgibt, wird hier die Orientierung im Raum zur Zuschaueraufgabe und zur permanenten Überforderung.

Es stellt sich die Frage, wie sich die Wahrnehmung des Raums ändert, wenn in den Theaterraum Film- oder Videoprojektionen integriert werden? Im Mittelpunkt steht dabei weniger die Frage nach dem performativen Raum des Theaters, der in der Aufführung konstituiert wird ${ }^{1}$ als vielmehr nach der Medialität der räumlichen Anordnung selbst.

1 Bereits Max Herrmann unterscheidet zwischen dem architektonischen Raum des Theaters und dem »theatralischen Raum«, der in der Aufführung entsteht (Herrmann: 502). Vgl. dazu auch Roselt. 


\section{Theatraler Raum - Filmischer Raum}

Das Kino hat vom traditionellen Theaterbau die frontale Ausrichtung des Zuschauers vor der Leinwand übernommen. ${ }^{2}$ Zugleich sieht die frühe Filmtheorie in einer veränderten Raumwahrnehmung ein Kriterium zur Unterscheidung von Theater und Film:

»Im Kino [...] hat der Zuschauer einen festen Sitzplatz inne, aber nur äußerlich, nicht als Subjekt ästhetischer Erfahrung. Ästhetisch ist er in permanenter Bewegung, in dem sein Auge sich mit der Linse der Kamera identifiziert, die ihre Blickweite und -Richtung ständig ändert. Und ebenso beweglich wie der Zuschauer ist aus demselben Grund, der vor ihm erscheinende Raum. Es bewegen sich nicht nur die Körper, der Raum selbst bewegt sich, nähert sich, weicht zurück, dreht sich, zerfliest und nimmt wieder Gestalt an [...]. Eine Welt von Möglichkeiten eröffnet sich, von denen das Theater niemals träumen kann« (Panofsky: 22).

Der Kunsthistoriker Erwin Panofsky trennt zwischen dem physisch anwesenden Zuschauer, der statisch vor der Leinwand festgesetzt ist, und dem Zuschauer als Subjekt ästhetischer Erfahrung. Das Verhältnis des wahrnehmenden Subjekts zum Raum ist flexibel, instabil, ständig in Veränderung. Dabei offenbart sich ein ganz eigenes Paradox des Filmzuschauers: zwischen der Stasis des auf die Leinwand ausgerichteten Betrachters und der Mobilität der bewegten Bilder, zwischen der Materialität des Zuschauerraums und der Immaterialität der Bilder.

In der von Panofsky beschriebenen Überlegenheit des Films gegenüber dem Theater sehen Theatertheoretiker des frühen 20. Jahrhunderts allerdings keinen Nachteil, sondern eine Möglichkeit zur Erweiterung theatraler Raumerlebnisse. In der Verbindung von theatralem Raum und filmischem Raum soll eine physische Mobilisierung der Zuschauer erreicht werden. Beispielsweise der Entwurf des »Totaltheaters « von Walter Gropius und Erwin Piscator durch eine neuartige Bühnenarchitektur, den Einsatz von Licht- und Filmprojektionen, bewegliche Bühnenund Zuschauerpodeste auf eine Überwältigung der Zuschauer. Dabei grenzt Gropius in seinem Programm den Entwurf von traditionellen Bühnen als »gerahmten Fenstern« wie auch von der »Mattscheibe eines fotographischen Apparates«ab. Anders als der Filmzuschauer soll der Zuschauer im Theater selbst physisch in Bewegung gesetzt werden. Ziel ist dabei, durch eine »Verlebendigung des ganzen Schauhauses « die Zuschauer aus ihrer »intellektbetonten Apathie aufzurütteln« (Gropius: 166). Piscator spricht in diesem Zusammenhang von der Idee, »die Bühne $\mathrm{zu}$ entmaterialisieren « und von einer »raumlosen« Bühne (Piscator: 440). Auffällig ist, dass sowohl Filmtheorie wie auch Theaterentwürfe durch den Einsatz von Filmprojektionen nach einer »Auflösung « des materiellen Raums streben mit dem Ziel einer Dynamisierung der Zuschauerposition.

\section{Das Haus auf der Bühne}

Im zeitgenössischen Theater hat der Einsatz von Film- und Videoprojektionen eine ganz andere Funktion. In dem Mittelpunkt rückt dabei das Verhältnis von Bühnenbild bzw. Bühnenarchitektur und filmischer Projektion. In vielen Bühnenentwürfen

2 Zur historischen Entwicklung des Kino-Dispositivs vgl. Brauns. 
finden sich Häuser auf der Bühne, die in ihrer Materialität ausgestellt werden. Auffällig oft werden Bungalows, Boxen oder Container auf die Bühne gestellt, die für den Zuschauer nicht einsichtig sind, in denen aber dennoch ein Großteil des szenischen Geschehens stattfindet. Beispiele lassen sich zahlreiche finden: die Inszenierungen HAMLET von Peter Zadek, Close ENOUGH TO KISS der Gruppe Gob Squad oder CAVEMAN des amerikanischen Regisseurs Richard Maxwell. Vor allem aber die Bühnenräume des Bühnenbildners Bert Neumann für die Inszenierungen von Frank Castorf oder René Pollesch bestehen aus Häusern oder Wohnungen, die mit der medialen Übertragung aus dem nicht einsehbaren Innenraum spielen. Entwirft er für DÄMONEN (1999) einen Bungalow, der durch seine Glaswände den Blick auf das Innere freigibt, beginnt Neumann ab der Inszenierung ENDSTATION AMERIKA (2000) mit Räumen auf der Bühne zu arbeiten, die den Zuschauern die Einsicht verwehren. Die Probleme, die sich daraus ergeben, beschreibt der Dramaturg der Inszenierung, Carl Hegemann:

»Die Aufgabe des Regisseurs besteht im Grunde genommen in nichts anderem als dafür zu sorgen, daß die Schauspieler sich nicht gegenseitig die Sicht nehmen. Und jetzt kommt Bühnenbildner Neumann - das fing an mit >Endstation Sehnsucht $<-$ und baut ein vollkommen geschlossenes Badezimmer und sagt, dann hört man die Schauspieler eben nur, die drin sind. Dazu sagt Castorf, daß er das nicht machen kann. Neumann meint, die Tür ist auf, man kann doch durch die Tür gucken. Castorf sagt, nein, das widerspricht allen Grundverabredungen des Theaters. Bert Neumann wollte als Experiment mal probieren, die vierte Wand nicht zu beseitigen, sondern sie komplett zu schließen und zu gucken, was passiert. Er hat immerhin noch extrem große Fenster eingebaut und dann auch Mikrophone. Castorf wollte fast alles im Badezimmer spielen lassen und dann kam der geniale Gedanke - vor Big Brother - wir stellen die Kamera da rein« (Hegemann: 9).

Die Bühnenarchitektur macht die Videoübertragung des Nicht-Sichtbaren notwendig. Aus der Verweigerung gegenüber dem theatralen Pakt von Zeigen und Schauen resultiert der für die jüngeren Castorf-Inszenierungen charakteristische Videoeinsatz.

Auffallend ist, dass Neumann und Castorf keine Videoleinwand nutzen, sondern mit einem Fernsehmonitor arbeiten, dessen Bild für die Zuschauer aus den hinteren Reihen kaum zu erkennen ist. Die Entscheidung für den Fernseher ist direkt mit dem Raumkonzept der Wohnung verbunden. Als Bestandteil nahezu jeder Wohnungseinrichtung steht der Fernseher für die Herausforderung des Wohnraums durch die Integration von Medien: als Einbruch des Öffentlichen in die Privatheit des Wohnraums. Der Fernseher thematisiert damit das Verhältnis von Innen und Außen, das jedem Haus innewohnt. Gemeinhin ist das Wohnhaus nach Innen privat und nach außen geöffnet. Der Fernseher verwischt diese Grenze, bringt die Öffentlichkeit in den Wohnraum. Bert Neumann thematisiert dieses Verhältnis von Wohn-Architektur und Medien in seinen Entwürfen. Die Grenze zwischen Innen und Außen wird auf der Bühne durch die ausgestellten Häuser sichtbar und durch medialen Übertragungen zugleich wieder unterlaufen. Architektur und Medieneinsatz bedingen sich gegenseitig. Seine theatralen Rauminstallationen sind in diesem Sinne selbst als mediale Dispositive zu untersuchen. 


\section{Zwischen Panoptikum und Peepshow: DER IDIOT}

Eine der jüngeren Inszenierungen von Frank Castorf, DER IDIOT (2003), eine Adaption von Dostojewskis Roman, spielt in der so genannten »Ersatzstadt«. Neumann stellt in den Theaterraum der Volksbühne eine eigene Stadt, mit Stehbierhalle, Friseursalon, Plattenbau, Puff und russischer Datscha, gebaut aus Holzplatten, Metallgerüsten und Bau-Containern. Geschäfte, Bars, ein Casino sind um eine große Treppe herum arrangiert. Das Publikum sitzt in verschiedenen Kammern auf einem großen Stahlgerüst, das beweglich ist und sich jeweils zum szenischen Geschehen hin ausrichtet.

Dass die Inszenierung in der Kritik oft mit dem Begriff des Totaltheaters beschrieben wird, ${ }^{3}$ scheint vor dem Hintergrund des Gropius'schen Entwurfs auf den ersten Blick einleuchtend. Neumann bebaut den gesamten Theaterraum. Die traditionelle, frontale Position des Zuschauers ist aufgehoben. Die Zuschauer werden selbst in Bewegung gesetzt. In den Bühnenraum sind verschiedene Projektionsflächen integriert. Allerdings zeichnet sich der Raumentwurf wiederum durch Häuser aus, deren Materialität ausgestellt wird. Statt an der Auflösung des Theaterraums zu arbeiten, wird ein zweiter Raum hineingebaut, der in sich geschlossen ist. Der Einsatz von Videoprojektionen hat eine andere Funktion als die »Aufhebung der Distanz zwischen Bühne und Zuschauerraum« (Piscator: 439).

Gespielt wird meist hinter den Häuserfassaden, so dass für das Publikum immer nur ein Teil des Geschehens sichtbar ist. Ein Kamerateam zieht mit den Schauspielern durch den Raum und überträgt das Geschehen auf eine große Leinwand sowie diverse Monitore. Die Zuschauer haben je nachdem, wo sie auf dem Gerüst sitzen, andere Einsichten in das szenische Geschehen. Sitzen sie oben, schauen sie auf das Geschehen herab, oder direkt in ein gegenüberliegendes Fenster hinein, sitzen sie unten können sie oft nur Schemen hinter den Fenstern oben entdecken. Permanent wechselt der Blick zwischen dem realen Geschehen, der Leinwand und den Fernsehmonitoren. Das Publikum erfährt die Aufführung wie das Making-Of eines Films. Die Zuschauer sehen die Kameramänner und die Tonleute bei der Aufnahme ihrer Bilder. Oft verdecken ihnen diese sogar die Sicht auf die Schauspieler. Ausgestellt wird die Herstellung der Videobilder.

In diesem Aufbau überlagern sich zwei verschiedene mediale Dispositive. Die Zuschauertribüne in der Mitte, die sich immer wieder neu gegenüber dem szenischen Geschehen ausrichtet, die unzähligen Videokameras, die verschiedenen Boxen und Fenster mit ihren Jalousien erinnern an einen panoptischen $\mathrm{Raum}^{4}$ : die $\mathrm{Zu}$ schauer werden zu Überwachern, ohne für die Akteure sichtbar zu sein. Der Zuschauerturm, die Kameras und Mikrophone verweisen auf ein System der Überwachung, das an keinen konkreten Blick gebunden werden kann. Die Schauspieler können sich nie sicher sein, von wo aus und von wem sie beobachtet werden. Der Aufbau hat damit nichts mit dem in der Theatertheorie verhandelten Konzept der >vierten Wand zu tun. Wenn nach Denis Diderot die Schauspieler spielen sollen, als gäbe es eine Wand zum Zuschauerraum, dann sind die Schauspieler in der Castorf-Inszenierung in einer ganz anderen Situation. Auch wenn sich die Schau-

3 Vgl. beispielsweise Briegleb.

4 Der Aufbau erinnert an die panoptische »Sehmaschine «, die von Jeremy Bentham im 18. Jahrhundert entworfen wurde: »Vor dem Gegenlicht lassen sich vom Turm aus die kleinen Gefangenensilhouetten in den Ringen des Ringes genau ausnehmen. Jeder Käfig ist ein kleines Theater, in dem jeder Akteur allein ist, vollkommen individualisiert und ständig sichtbar. [...] Er wird gesehen, ohne selber zu sehen« (Foucault: 256). 
spieler in einem von den Zuschauern abgetrennten Raum befinden, ist ihrem Spiel der Blick von Außen eingeschrieben. Der Blick der Kamera ist allgegenwärtig, gerade weil die Schauspieler nicht wissen, welche Bilder von ihnen übertragen werden. Ihnen ist die Kontrolle über das Gezeigte entzogen.

Das andere Dispositiv ist das der Peep-Show. Der Zuschauer wird in die Rolle des Voyeurs gebracht, der wie durch das Guckloch einer Peepshow späht. Immer wieder eröffnen sich ihm Einblicke, werden Gardinen geöffnet, Rollos hochgerollt. Sie weisen auf den Übergang zwischen Innen und Außen. Besonders augenfällig sind die Jalousien, die nur einen partiellen Blick in die Zimmer ermöglichen, ohne dass der Betrachter selbst gesehen werden kann. Das von der Jalousie verschlossene Fenster gibt das Versprechen, Einblick in den Back-Stage-Bereich zu gewähren, auf das was nicht gezeigt werden soll oder darf. Inszeniert wird ein Moment des Intimen.

Ob Überwacher oder Voyeur, die Position des Zuschauers ist keine machtvolle. Der Sichtbereich wird immer wieder eingeschränkt, durch Wände, Rollos, verschlossene Fenster. Der Zuschauer ist dem Raumaufbau und seinen Implikationen genauso ausgeliefert wie dem Blick der Kamera. Die übertragenen Videobilder zeigen zwar Einsichten in die Räume, jedoch versuchen sie nicht, einen Eindruck des Raums über konventionelle filmische Techniken zu vermitteln. Es gibt keine Totalaufnahmen der Innenräume. Gezeigt werden meist Nahaufnahmen. Zudem ist der Zuschauer permanent gezwungen, sich zu entscheiden: zwischen der szenischen Aktion und dem Videobild, zwischen verschiedenen Monitoren. Der Raumeindruck bleibt somit immer fragmentarisch, zusammengesetzt aus den wenigen direkten Einblicken in die Räume und dem übertragenen Videobild.

Der Aufbau stellt den Zuschauer vor eine besondere Orientierungsleistung. Die Position des Publikums, eingeschlossen auf dem Drehgerüst, die Häuser und Fassaden, mit den verstellten Einsichten und vereinzelten Durchblicken und die übertragenen Videobilder fordern permanent die Verortung des Gesehenen im Tatsächlichen und unterlaufen diese. Die Einsicht in ein Fenster widerspricht beispielsweise dem übertragenen Blick der Kamera. Von der Szene, die im entfernten Glascontainer spielt, zeigt das Videobild nur Großaufnahmen. Die unvermittelt beobachteten szenischen Aktionen decken sich nicht mit dem Videobild. Abgebildeter Raum und tatsächlicher Raum lassen sich nicht zu einem einheitlichen integralen Raumerlebnis verarbeiten. Es ist eine Strategie der Überforderung. Insofern kann der Bühnenentwurf der Inszenierung als >raumlose< Bühne bezeichnet werden, nicht im Sinne von Piscator und Gropius, sondern seiner Auflösung des Bühnenraums in unzählige Räume, einer eindeutigen Perspektive, in der widersprüchlichen Überlagerung und Verschachtelung von Räumen.

\section{Der Container als Theater}

Diese Überlagerung zeigt sich auch an den von Neumann für die Bühne entworfenen Häusern. Neumann arbeitet mit Versatzstücken, Sperrholzwänden, Containern, die ihre Konstruiertheit und Unfertigkeit nicht verbergen. Es sind »Realitätsfragmente«, die benutzbar und begehbar sind. Die Häuser sollen »autonom funktionier[en] « auch jenseits der Bühne. Sie haben weder auf der Bühne noch außerhalb einen bestimmten Ort, sie können »überall hingesetzt« werden (Neumann: 35).

Die Häuser werden zur Kulisse für die Filmaufnahmen. Was sich auf der Bühne als konstruiert und unfertig zeigt, wirkt im Filmbild wie ein vollständiger 
Raum. Neumann spielt mit dem Wirklichkeitseindruck des filmischen Raums auf der Theaterbühne. Zugleich ist die Architektur des Film-Sets selbst durch Vorläufigkeit geprägt. Nach dem Dreh wird die Kulisse für einen anderen Film verwendet. Nur was nötig ist, um den Eindruck eines vollständigen Raumes herzustellen, wird gebaut. Die Kulisse verweist auch immer auch ihre ungestaltete Rückseite. Die Rückseite wird in den Entwürfen von Neumann nicht versteckt, sondern neben den Illusionseindruck des Videobilds gestellt.

Den Aspekt der Vorläufigkeit thematisieren auch die Container, die Neumann auf die Bühne stellt. Der Container ist ein Behälter für alles Mögliche. Standort wie Inhalt sind beliebig, begrenzt nur durch Standardmaße. Flexibilität und Mobilität in räumlicher wie funktionaler Hinsicht zeichnen ihn aus. In der städtischen Architektur steht er für eine temporäre, vorläufige Nutzung. Jederzeit kann er wieder abtransportiert werden. Der Container verweist damit auf die Idee der Bühne als Black Box, die jeden beliebigen Ort hervorbringen kann. Neumann setzt die Box selbst auf die Bühne und schließt den Zuschauer dabei aus. Zugleich stellt er mit dem Haus als Container dessen provisorischen Charakter aus. Nicht Verwandlung oder Transformation als eine Möglichkeit der traditionellen Theaterbühne sind seine Themen, sondern Austauschbarkeit, Überlagerung und Bewegung von Räumen.

Dieses Moment der Bewegung greift ein anderes Theaterprojekt auf, das den Container auf ganz andere Weise benutzt: die Inszenierung CARGO SOFIA BERLIN ${ }^{5}$ von Stefan Kaegi, Mitglied des Regie-Trios Rimini Protokoll. Hier sitzen die Zuschauer selbst im Container. In einen LKW sind Sitzplätze für 47 Menschen eingebaut. An der Stelle der Seitenplane gibt es ein Panoramafenster, das auch zur Leinwand werden kann. Die Zuschauer werden mit dem Lastwagen an verschiedene Orte gefahren. Dabei spielt die Inszenierung mit der Überlagerung von zwei Fahrten: der realen Fahrt durch die Stadt der jeweiligen Aufführung, sichtbar durch das Panoramafenster, und einer fiktiven Fahrt von Sophia nach Deutschland, übertragen auf die Projektionsleinwand. Beide Fahrten verschmelzen miteinander. Der virtuelle und der tatsächlich zurückgelegte Raum überlagern sich. Hält beispielsweise der Laster an einer Ampel, so stoppt auch die Projektion, fährt er weiter, läuft auch der Film weiter. Die Zuschauer werden in Bewegung gesetzt. Der Theaterraum ist selbst mobil. Im fahrenden Container wird die Auflösung des Raumes in der globalisierten Welt augenfällig. Der transportierbare Container selbst ist immer in Bewegung, an keinen Ort gebunden, ein Provisorium, das immer neu beladen und definiert wird.

5 Die Inszenierung wird nach dem jeweiligen Aufführungsort benannt. Ich beziehe mich auf die Inszenierung CARGO SOFIA BERLIN im Juni 2006. 


\section{Literatur}

Böhringer, Hannes (1993): »Container«. In: Ders.: Container und Orgel. Berlin: Merve, S. 7-34.

Brauns, Jörg (2007): Schauplätze. Berlin: Kadmos.

Briegleb, Till (2004): »Ironische Trostlosigkeit. Der Bühnenbildner Bert Neumann«. In: www.goethe.de/kue/dos/de134107.htm (12.06.2006).

Diderot, Denis (1968): »Von der dramatischen Dichtkunst«. In: Ders.: Ästhetische Schriften, Bd. 1. Berlin: Europäische Verlagsanstalt, S. 239-347.

Foucault, Michel (1989): Überwachen und Strafen. Frankfurt/M.: Suhrkamp.

Gropius, Walter (1982): »Der Theaterbau«. In: Manfred Brauneck (Hg.): Theater im 20. Jahrhundert. Reinbek bei Hamburg: Rowohlt, S.161-169.

Hegemann, Carl (2004): »Was bewirkt die Kamera auf der Bühne bei den Schauspielern?«. In: Dramaturgie 2004/1, S. 8-9.

Herrmann, Max (2006): »Das theatralische Raumerlebnis«. In: Jörg Dünne/Stephan Günzel (Hg.): Raumtheorie. Grundlagentexte aus Philosophie und Kulturwissenschaften. Frankfurt/M.: Suhrkamp, S. 501-513.

Hurtzig, Hannah (2001): Imitation of Life. Bert Neumann, Bühnenbilder. Berlin: Theater der Zeit.

Neumann, Bert (2001): »Imitation of Life. Der Kostüm- und Bühnenbilder Bert Neumann im Gespräch mit Anja Nioduschewski«. In: Theater der Zeit. 10/2001, S. 31-35.

Panofsky, Erwin (1993): Die ideologischen Vorläufer des Rolls-Royce-Kühlers \& Stil und Medium im Film. Frankfurt/M.: Suhrkamp.

Piscator, Erwin (1980): »Totaltheater und totales Theater«. In: Ders.: Theater Film Politik. Berlin: Henschel, S. 439-441.

Roselt, Jens (2004): »Wo die Gefühle wohnen«. In: Hajo Kurzenberger/Annemarie Matzke (Hg.): TheorieTheaterPraxis. Berlin: Theater der Zeit, S. 66-76. 



\title{
MONTAGe der kULturellen Attraktionen. FRANK CASTORFS MEDIENÄSTHETISCHE THEATERPRAXIS DER 80ER JAHRE
}

\author{
ERHARD ERTEL
}

1.

In Abwandlung eines legendären Frank Zappa Zitats, dass die Anzahl der verkauften Platten nichts über die Qualität der Musik sage, kann man konstatieren, dass die Anzahl der Kameras, Monitore und Projektionswände (noch) nichts über die (medial) spezifische Theaterästhetik sagt. Vergleicht man aus dieser oberflächlichen Perspektive zwei der extremsten Theaterproduktionen Castorfs der letzten Jahre, MEINE SCHNEEKÖNIGIN ${ }^{1}$ (Null Medientechnik) und DER IDIOT ${ }^{2}$ (eine Orgie von Mikrophonen, Lautsprechern, Kameras, Monitoren, Leinwänden und Kabelkilometern), bleibt nur die sachliche Feststellung, dass sie sich kaum voneinander unterscheiden, funktionieren sie doch letztendlich beide über dasselbe Medium: über herausragende darstellerische Leistungen. Aus einer anderen Perspektive jedoch erweisen sich beide in einem jeweils anderen Sinn als sehr medial, benutzen sie doch extrem unterschiedliche Erzählweisen, Gesten des Erzählens, in Abhängigkeit des je benutzten Mediums - des Märchens als Erzählform einerseits, der ausufernden, vernetzt wuchernden epischen Erzählung andererseits.

Der Medienbegriff wird heute sehr heterogen gehandhabt, sein analytischer Gebrauch erübrigt sich schnell in abstrakten akademischen Konstruktionen. Möglicherweise wird er auch deshalb so häufig bemüht, weil uns selbstverständliche $\mathrm{Zu}$ griffe auf theaterspezifische Arbeitsweisen verloren gegangen sind. Hier soll deshalb nicht mehr als ein Blick auf Castorfs Theaterarbeit der 1980er Jahre geworfen werden, auf die Besonderheiten konkreter Inszenierungen, auf denkbare theoretische und lebenspraktische Kontexte sowie sich herausbildende Konturen spezifischer Methoden der Inszenierungsarbeit.

\section{2.}

Frank Castorf kam aus der Tiefe des Raumes - der Provinz, Anklam. Hier im kulturfernen norddeutschen Tiefland beginnt seine spiralförmige Odyssee, auf der er sich in den achtziger Jahren auf Berlin zu bewegen wird, um dort durch die Hinter-

1 MeINE SCHNEEKÖNIGIN, Ein Märchen nach Hans Christian Andersen, Regie und Bearbeitung: Frank Castorf, Volksbühne am Rosa-Luxemburg-Platz Berlin, Premiere am 16. Dezember 2004.

2 DER IDIOT nach Fjodor Dostojewski, Regie und Bearbeitung: Frank Castorf, Volksbühne am Rosa-Luxemburg-Platz Berlin, Premiere am 15. Oktober 2002. 
tür $^{3}$ in jenes Haus einzutreten, in dem er in den neunziger Jahren Theatergeschichte schreiben wird.

Auf dieser Odyssee entwickelt er in teilweise legendären Inszenierungen seine Theaterästhetik, deren Strukturen in Anklam ${ }^{4}$ entfaltet, dann on the road ${ }^{5}$ erprobt und weitergetragen werden.

Der archaische Ausbruch dieser damals ungewöhnlichen Art, Theater zu spielen, geschieht mit Shakespeares OTHELLO (1982). Frühzeitig folgt möglicherweise der spielerische Höhepunkt mit Ibsens NORA (1985). Über Müllers BAU (1986) und Lorcas BERNARDA AlBAS HAUs (1986) kommt er mit Zechs TRUNKENEM SCHIFF ${ }^{6}$ (1988) in Berlin an. Mit Schillers RÄUBER ${ }^{7}$ als Epilog (1990) wird diese Epoche ein Ende finden, vor allem auch deshalb, weil sich mit dem Umbruch nach 1989 entscheidende politische und ästhetische Koordinaten für Castorfs Theater verändern. Als Konstante bleiben seine Unbeirrbarkeit und die Absicht, Störfaktor zu sein. In beiden Phasen seiner Theaterarbeit aber entbehrt diese Haltung nicht einer gewissen Tragik. War es vor 1989 das Risiko, dass die Störung in sich barg, so ist es heute die Risikolosigkeit, mit der jede Störung entmachtet wird.

\section{3.}

Frank Castorf kam nicht aus dem Nichts. Auch nicht aus dem Nichts-Tun. In Shakespeares KÖNIG LEAR ${ }^{8}$, Castorfs erster Inszenierung als Intendant der Volksbühne, wird Joachim Tomaschewsky als Graf von Gloster aus dem Untergrund heraus rufen: »Aus nichts wird nichts!« Die intellektuelle, politische und kulturelle Prägung Castorfs hatte im Zentrum begonnen, in Berlin. Aus dem Dunkel des ersten Scheiterns und subkultureller Verkanntheit herausgeschleudert, gewährleistete das Anklamer Exil, dass aus dem Auf-sich-selbst-zurückgeworfen-sein ein radikales Sich-selbst-finden wurde. Der Witz, mit dem diese Situation später betrachtet wurde, bestätigt umso mehr ihre fundamentale Bedeutung. In seiner Laudatio auf den Schauspieler des Jahres 1994, Henry Hübchen, wird Frank Castorf nicht dessen Leistung, sondern seiner eigenen Vorleistung gedenken.

»Also ich saß vor einer Gasheizung, schaute in Pankow aus einer Wohnung, wo mir Kost und Herberge und Liebe geboten wurden, auf [...] eine Kastanie, und es ist Mittag, und ich frühstücke im Morgenmantel und lamentiere über meine nun schon jahrelang anhaltende

3 Nicht auf der großen Bühne der Volksbühne, sondern im 3. Stock inszenierte Frank Castorf 1988 DAS TRUNKENE SCHIFF nach Motiven des Stücks von Paul Zech, Premiere 9. September 1988.

4 Frank Castorf inszeniert im Theater Anklam: DIE NACHT NACH DER ABSCHLUSSFEIER (1981), Die SCHLACHT (1982), OTHELLO (1982), DER AUfTRAG (1983), TROMMELN IN DER NACHT (1984), NORA (1985).

5 Clavigo, Theater Gera 1986; DeR BaU, Städtische Theater Karl-Marx-Stadt 1986; BERNARDA AlBas Haus, neues theater halle 1986; EIN VolKSFEIND, Städtische Theater Karl-Marx-Stadt 1988; WOLOKOLAMSKER ChAuSSEE, Kleist-Theater Frankfurt/O. 1988.

6 Siehe Anmerkung 3.

7 Siegfried Wilzopolski (16) spricht in seiner Dokumentation zur Theaterarbeit von Frank Castorf von der »letzte(n) DDR-Inszenierung überhaupt«.

8 KÖNIG LEAR von William Shakespeare, Regie: Frank Castorf, Volksbühne am RosaLuxemburg-Platz Berlin, Premiere am 8. Oktober 1992. 
Erfolglosigkeit. Da klingelt es, Frau G.G. erhält Besuch vom ebenfalls arbeitsscheuen Fernsehschauspieler Hübchen, als etwas anderes hatte ich ihn nicht kennen gelernt, [...] also da kam noch so ein arbeitsscheues Subjekt und soff mir den Kaffee weg, [...] immerhin konnten wir dabei ganz angenehm über die Zone meckern und über die Bonzen, die unserem Talent bösartig im Wege standen« (Castorf: 37).

Die Beschreibung ist unvollständig. Sie verschweigt den kleinen Bücherstapel, der immer am linken Tischrand, auf der Gasheizungsseite lag. Und den Bücherschrank gegenüber, der zum Plattenschrank mutiert war, obenauf der Granat-Plattenspieler ständig im Einsatz, ebenso wie das Tesla-Tonbandgerät auf dem Hocker rechts daneben, gefolgt von einem Sessel, in dem der Bruder von G. über die kommunistischen Schauprozesse monologisierte und dem Fernseher, der ständig lief. Ganz zu schweigen von den nachmittäglichen Ausflügen in die Stadtbibliothek und etwas später ins Kino. Was sich hier wirklich abspielte, war ein uneingeschränkter Prozess der ursprünglichen kulturellen Akkumulation. Dieser hatte lange davor in einem intensiven Studium an der Universität ${ }^{9}$ begonnen, und noch länger davor in der Universität des Alltags, wie die von Jürgen Balitzki erfragten Erinnerungsreihen (11 u. 19) belegen. Der Prozess des Akkumulierens ist unverkennbar und ebenso der enorme Anteil an medialer (oder medial vermittelter) Kultur. Hier werden nicht nur Erfahrungswelten aufgehäuft, Weltsichten ausgeformt, sondern wird auch ein Materialdepot angelegt, das als Ausdrucksrepertoire für eine lange Inszenierungskarriere reicht.

\section{4.}

Versteht man Kulturen als geformte und verdichtete Alltagserfahrungen, kann man sie gleichzeitig als Medien sozialen Agierens und als abrufbares Wahrnehmungsreservoire verstehen. Die technisch-medialen Bedingungen der zweiten Hälfte des 20. Jahrhunderts machten dieses Reservoire allgegenwärtig und permanent verfügbar. Und je mehr davon durch Individuen wie soziale Gruppen akkumuliert wurde, umso mehr sinnliches Material konnte in die ästhetische Kommunikation eingebracht werden. Castorfs Theater der 1980er Jahre lebte in starkem Maße vom Abrufen und Montieren dieser medial präsenten kulturellen Erfahrungen. So stehen in seinen Inszenierungen Märchen und philosophisches Traktat ebenso dicht nebeneinander wie Opernarie und Schlager, Dramentext und Witz, Kinderlied und Rockmusik, historische Ton- und Bilddokumente und Versatzstücke der Alltagskultur.

Als kulturelle Medien in die Inszenierungen integriert, sind es aber nicht nur verschiedenartige Wahrnehmungs- und Erlebnisangebote, sondern vor allem auch verschiedenartige Perspektiven auf ein und dieselbe Sache. Das Bruchstückhafte, Sprunghafte, Montierte schafft eine neue Kontinuität des Perspektivwechsels. Die Montage kultureller Attraktionen genügt dabei auf einer komplexeren Ebene dem Brechtschen Fabelbegriff, als Gesamtkomposition aller gestischen Vorgänge.

Wesentlicher noch als bei Brecht knüpfte Frank Castorf in den 1980er Jahren instinktiv (im Sinne des Abrufens akkumulierter wissenschaftlicher Auseinandersetzungen während des Studiums) an Eisenstein und dessen Montage der Attrak-

9 Frank Castorf studierte von 1972 bis 1976 Theaterwissenschaft am gleichnamigen Bereich der Humboldt-Universität zu Berlin, einem für DDR-Verhältnisse weltoffenen, denkfreudigen, liberalen Institut. 
tionen an. Castorf hatte sich bereits vor seiner ersten Inszenierung von einem »abbildend-illusionistischen Erzähltheater « verabschiedet und produzierte seine Entwürfe eher im Sinne eines »Schaulaboratoriums«. Jenseits der Eisensteinschen Euphorie geht es aber auch bei Castorf um ein radikal montiertes Wahrnehmungsangebot (bis zur Wahrnehmungsattacke) für (auf) den Zuschauer. Alle akkumulierten Erfahrungen in ihrer jeweiligen medialen Ausprägung kommen hier, »als selbständiges und primäres Konstruktionselement einer Aufführung - als molekulare Einheit (das heißt Bestandteil) der Wirksamkeit eines Theaters und der Bühnenkunst überhaupt « (Eisenstein: 12) zum Einsatz. Vernachlässigt man die illusorische wissenschaftliche, ja mathematisch-exakte Kontrollierbarkeit dieser Wirkungsmechanismen, so gilt auch für Frank Castorfs Inszenierungen der 80er Jahre: »Eine Attraktion (bezogen auf das Theater) ist jedes aggressive Moment des Theaters, das heißt jedwedes seiner Elemente, das den Zuschauer einer sinnlichen oder psychologischen Einwirkung aussetzt « (ebd.). Interessant und entscheidend ist, dass Castorf wie Eisenstein diesen Prozess als Produktion begreift, diese als solche auch ausstellt, und diese Montagephilosophie keineswegs als bloß formal, als Methode, sondern als Geschäft des Theaters begreift und praktiziert. Die Eisensteinsche Idee der Attraktionsmontage beschreibt ziemlich genau Castorfs damaliges Theaterverständnis:

»anstelle der statischen >Widerspiegelung nisses und der Möglichkeit, es ausschließlich mit Hilfe von Wirkungen zu gestalten, die logisch mit der Handlung verknüpft sind, wird eine neue Methode vorgeschlagen - die freie Montage von willkürlich ausgewählten, selbständigen (auch außerhalb dieser vorgegebenen Komposition und Handlungslinie funktionierenden) Einwirkungen (Attraktionen), allerdings mit einer genauen Orientierung auf einen bestimmten thematischen Endeffekt die Montage der Attraktionen. [...] Gleichzeitig wird das Einflechten ganzer >abbildender Passagen < in die Montage ebenso zulässig wie das Einarbeiten eines logisch durchgestalteten, zusammenhängenden Handlungsknotens, jedoch nicht mehr als Selbstzweck und alles entscheidendes Element, eher als eine bewusst für die gegebene Intention ausgewählte und stark einwirkende Attraktion, weil nicht das >Aufschließen der Autorenkonzeption<, nicht die >richtige Interpretation des Verfassers< und ebenso wenig eine > getreue Abbildung der Epoche und dergleichen - sondern Attraktionen und ihr System einzige Grundlage für die Wirksamkeit einer Aufführung sind «(Eisenstein: 13f).

In diesem Sinne Eisensteins versteht Frank Castorf in den 1980er Jahren Theater als Organisation/Komposition/Montage von Wirklichkeits- und Wirkungssegmenten mit den entsprechenden Attraktions- und Assoziationspotentialen. Diverse Textsorten aber auch kulturelle Erzählformen, Musik- und Musizierformen, kulturelle Praktiken und diverse vor allem alltägliche Verhaltensweisen, darstellerische Techniken und gestische Ausdrucksformen des Körpers und natürlich Versatzstücke der technischen Medien werden in die brüchigen Montagen seiner Inszenierungen integriert. Im weitesten Sinne sind sie alle als Medien der Wahrnehmung und als Medien der Darstellung zu verstehen. Dass das problemlos funktioniert, liegt nicht zuletzt daran, dass Frank Castorf diese Montagen niemals als strukturierende und strukturierte Welterklärungsmodelle verstand, sonder eher als sinnlich wie intellektuell beschleunigtes Wahrnehmungs- und Erfahrungskarussell. Mitte der 1990er Jahre wird sich diese Einsicht auch in entsprechenden Auskünften verdichten: 
»Zu vieles in der Literatur gaukelt ein Modell der Erkennbarkeit und der Beherrschbarkeit von Welt vor. Es liegt für mich inzwischen etwas Lächerliches im Erklären der Dinge. Übersichtlichkeit ist niederschmetternd. Weil es Lüge ist. Deshalb bin ich misstrauisch gegenüber tradierten narrativen Strukturen, gegenüber den Klarheiten in einer Geschichte. Deshalb nehme ich sehr rasch Schraubenzieher und Trennsäge. Aber wir bleiben ja beim Zertrümmern nicht stehen. Da wird auch wieder etwas zusammengesetzt, etwas aufgebaut, in Beziehung und in neue Konstruktion gebracht. Es entsteht plötzlich ein völlig anderer, negierender, irritierender Zustand. Und die Leute fragen sich vielleicht: Warum machen die denn das jetzt? Man ist erschrocken, will so was nicht sehen. Einige sagen sogar: Die dürfen das nicht! Also: Mich interessieren die überraschenden Richtungen, die eine Sache einschlagen kann, ich bewege mich gern von Erwartungen weg« (Schütt: 14f).

\section{5.}

1982 überlebt Castorfs OTHELLO ${ }^{10}$ die Premiere nicht. Tradierte kleinstädtische Erwartung ist von der Inszenierung verstört, die angereisten subkulturellen Sympathisanten aus Berlin sind begeistert. OTHELLO ist die Inszenierung, in der das Konzept der Montage der kulturellen Attraktionen konsequent den theatralen Diskurs strukturiert, die akkumulierten kulturellen und gedanklichen Wirklichkeits- und Wirkungssegmente zur spielerischen Verwertung freigibt. Die rasant aufeinander folgenden Bruchstücke sind in einer selbstverständlichen Alogik montiert, die Brüche hart und der Eigenwert der Nummern in ihrer kulturellen Substanz ideales Material, mit dem Shakespearschen Stoff theatralisch und gedanklich zu spielen. In Anlehnung an Eisensteins Beispiele kann die dramaturgische Konstruktion der OTHELLO-Inszenierung so beschrieben werden: 1. ein Gespräch zweier alter Damen in Pelzmänteln über die politische Lage, »Was soll man glauben? « (Fragwürdigkeit medialer Informationspolitik); 2. Cassio füllt einen Kühlschrank mit Bier für die neue Macht (»Bier für den Neger«); 3. ein Musiker tritt auf und singt die Schnulze »Ganz in weiß«, zu der Cassio und die Damen tanzen; 4. die beiden Damen thematisieren in ihrem Gespräch Theatererfahrungen, eine Methode, mit der Castorf auch später immer wieder in der Aufführung das Medium selbst thematisiert. »Ich bin gern ins Theater gegangen «, »Ich auch, aber lieber noch in den Zirkus oder zu irgendwelchen Sportveranstaltungen. $\ll{ }^{11} 6$. Emilia und Bianca treten auf und beenden ein scheinbar langes Gespräch »Lass doch den Neger, nimm doch mich«; 7. der Rockklassiker »House of the rising sun « wird intoniert; 8. Montano, ein Clown und Gratiano treten auf, versichern sich mit dem Satz »es gibt einen der zu dir hält « aus dem Tophit »Marmor, Stein und Eisen bricht« ihrer Solidarität; 9. Jago und Rodrigo betreten, angelehnt an eine Mischung aus Italowestern und den Politthrillern Damiano Damianis die Szene; 10. Jago, enttäuscht, dass Othello Cassio bevorzugt hat, fragt sich »Warum soll ich dem Neger dienen?« Von Rodrigo angestachelt

10 OTHELlo von William Shakespeare (Fassung des Theaters Anklam), Regie: Frank Castorf, Theater Anklam, Premiere: 6. November 1982.

11 Castorfs interessiertes Desinteresse am traditionellen Theater wird hier schon konfrontiert mit der eigenen theaterästhetischen Präferenz - es gibt da spektakuläre, performative Veranstaltungen, denen eine andere Kraft innewohnt, die energetischer sind und eine andere Art von Realität behaupten, mit einer anderen Authentizität und Wahrhaftigkeit, mit einer anderen sinnlichen Wucht. Die Verweise auf die Kraft von Sport und Rockmusik werden sich durch seine gesamte weitere Theaterarbeit ziehen. 
»dann dien' ihm doch auch nicht « lehnen sie sich in den Kinoklappsitzen auf der Bühne leger zurück und ergehen sich in einer Aufzählungsarie von Quälversionen.

In diesem Sinne folgen etwa zwanzig weitere Attraktionen, die sich ausnahmslos um Fragen der Macht (wer mit wem in einem komplexen, kaum zu durchschauenden Machtspiel) und der Liebe (alle lieben Desdemona) bewegen und aussichtslos immer neue Wendungen nehmen.

Besonders brüchig bietet sich derartige Dramaturgie in der Inszenierung von Heiner Müllers BAU ${ }^{12}$ in Karl-Marx-Stadt 1986 dar. Die Inszenierung beginnt mit einer leeren Bühne, auf der aus einem scheppernden Lautsprecher die Nachricht von Radio Moskau vom ersten Kosmosflug eines Menschen (Juri Gagarin, 1961) tönt. Die Szene ist symptomatisch - Senden und Empfangen, diese einfachste, fast mechanische, technisch fundierte Medienauffassung spielt in der Inszenierung eine zentrale Rolle, ist das Modell der meisten szenischen Konstruktionen. So ist die Inszenierung auch als kulturelle Montage von Sende- und Empfangssituationen zu lesen. Arbeiter Dreier kommt auf die Bühne, angezogen von der Lautsprecherübertragung, die ihm faszinierend und zugleich rätselhaft erscheint. Über die Schulter trägt er sein Akkordeon - Zeichen seines eigenen Sendepotentials. Auf die Differenz von Plan (Illusion) und Produktion (Realität) verweisend, spielt Arbeiter Dreier auf seinem Akkordeon »Kauf dir einen bunten Luftballon«, gesungen vom Oberbauleiter (Sender), der damit den neuen Parteisekretär, der als Empfänger im Hintergrund auf seinem Koffer sitzt, begrüßt. Das sich versammelnde Empfangskommitee konstruiert mit der Attraktionsnummer »Wann wir schreiten Seit an Seit«, eine absurde politisch-formale Grundkonstellation, die mit der nächsten Attraktion sofort gebrochen wird, indem der Oberbauleiter die Missstände auf dem Bau als Opernarie, gemäß der Redewendung >sing hier keine Opern<, vorträgt. Später wird Ingenieur Hasselbein der Ingenieurin Schleef eine Liebeserklärung im Stile eines Fluxus-Konzertes machen, indem er mit einem Schrubberbesen auf dem Plastikboden rhythmisch zu scharren beginnt und sich in ein regelrechtes Geräusch-Erregungs-Konzert hineinsteigert. Die Montage und wechselseitige Kommentierung der (Medien)Attraktionen wird deutlich, wenn Brigadier Barka den neuen Parteisekretär Donath im Zimmermanns-Tanz/Kampf besiegt und erklärt »Keine Politik auf der Baustelle. Ich kenne alle Märchen«, worauf vom Band O-Ton Walter Ulbricht zum Mauerbau eingespielt wird und alle wie gebannt auf das Medium, den Lautsprecherkasten in der linken Bühnenecke starren. Immer wieder zeigt sich, dass das Pendel, das zwischen Senden und Empfangen hin und her schwingt, ein Pendel ist, das zwischen Macht und Ohnmacht schwingt.

\section{6.}

Eine andere wesentliche Seite der Theaterarbeit Frank Castorfs ist die konsequente Einbindung von Medien und Medienerfahrungen in die szenischen Aktionen auf der Bühne selbst. Sie sind Teil des Spiels, Teil der Vorgänge, die auf der Bühne gezeigt werden, sowohl hinsichtlich ihrer je eigenen Materialität, ihrer sinnlichen Qualitäten als auch ihrer kulturellen Aufladungen. Die oben beschriebe Szenenmontage des OTHELLO von 1982 lässt das mehr als ahnen. Eine Schlüsselszene ist der Auftritt von Jago und Rodrigo. Nachdem zuvor Cassio schon die Etablierung

12 DeR BAU von Heiner Müller, Regie: Frank Castorf, Städtische Theater Karl-MarxStadt Schauspielhaus, Premiere: 27. Juni 1986. 
der neuen Macht (Othello) als kulturelle Verschiebung vorgeführt hat, indem eine neue Getränkekultur (»Bier für den Neger«) eingeführt wurde, wird mit dem Auftritt von Jago und Rodrigo klar, dass die neue Macht eine neue Kultur bedeutet und damit natürlich auch eine neue Medienkultur. Den Revolver in der einen Hand führt Jago in der anderen eine kulturelle Waffe mit sich - ein Tonbandgerät. Demonstrativ stellt er dieses auf dem Klavier ab. Deutlicher kann der kulturelle Umschwung, der ein radikaler Medienumbruch ist, nicht ausgespielt werden. Und während das alte Medium schweigt, wird das Bandgerät sofort in Betrieb genommen - der Raum wird erobert von einem Medium, das weniger schwerfällig als das Klavier operativ mitgeführt und installiert werden kann, das einen ganz eigenen Sound produziert, eine neue Musikkultur verbreitet. Bezeichnenderweise wird die neue Musik nicht für die anderen gespielt, man spielt sie für sich selbst, sie ist Teil eines eigenen Lebensstils, eines eigenen Lebensraums - Ausdruck einer Macht, die ihre Herrschaftsräume medial-kulturell definiert. Geradezu programmatisch hören Jago und Rodrigo einen Song der Rolling Stones von einem Album mit dem offenbarenden Titel LET IT BLEED ${ }^{13}$, eine programmatische Anspielung auf die Gefährdungen eines undurchschaubaren Machtgefüges ebenso wie auf das Herzblut, das Desdemona bei allen Männern in Bewegung gebracht hat. Zweifellos bei den meisten platonisch, geben sie sich doch alle dieser Liebe hin, verwickelt in Rivalitäten und Eifersuchtsvorstellungen, die denen der Macht gleichgestellt sind. Das Tonbandgerät, der laufende Song ist dabei zunächst die unmittelbare Projektionsfläche der Liebe zu Desdemona. Während Jago sich mit geschlossenen Augen ans Klavier gelehnt diesen Klängen ergibt, treibt es Rodrigo in die Verzweiflung. Die auf konträre Art entfachte Leidenschaft, die sich darin zeigende Rivalität wird dann auch in einem kinotauglichen Duell ausgetragen. Rodrigo geht langsamen, aber entschlossenen Schritts wie im Western auf Jago zu und schaltet das Tonbandgerät ab. Dieser fixiert seinen Gegner mit tötenden Blicken und dreht sich zeitlupenartig um, die Musik wieder anschaltend. Dies wiederholt sich mehrere Male, bis Jago in unmissverständlicher Geste den Rivalen endgültig zum Aufgeben zwingt. Dass es nicht nur um hoffnungslose Liebesmüh geht, sondern um ein komplexeres Machtgefüge, wird abrupt deutlich, wenn Cassio auftritt und den Machtkampf hinter dem Rücken Othellos als Kulturkampf weiterführt, indem er fordert »Machen sie das Gedudel aus und stimmen sie das Klavier«. Die neue Kultur wird sich im Laufe der Inszenierung behaupten und in ihrer medialen Präsenz die szenischen Vorgänge strukturieren.

Das Tonbandgerät und der Rolling Stones Song spielen auch für das Schicksal Desdemonas die entscheidende szenische Rolle. Das wird offenbar, wenn sich nach der dramaturgisch ans Ende gesetzten Pause nur noch der Mord an ihr ereignet: Der Vorhang öffnet sich, die Szene wird beherrscht von einem nervenden, wahnsinnig provokanten Geräusch, das ins Gehör schneidet - der Song ist abgelaufen, die Musik ist aus, aber das Tonband selbst dreht sich noch, und in einem unglaublich brutalen Rhythmus schlägt das Bandende peitschenartig gegen die Teile des Gerätes. Das Geräusch ist von unglaublicher Eindringlichkeit und wird die Szene als Soundtrack begleiten. Sowohl der sachliche Zustand des abgelaufenen Bandes als auch das nervende Geräusch zeigen unmissverständlich an, dass das Spiel aus ist. Das unumkehrbare Ende, die unausweichliche Bedrohung wird noch gesteigert, wenn ein dröhnender Wasserstrahl den Zinkeimer füllt, in dem Desdemona wie eine Katze ersäuft wird. Nach geschehener Tat setzt sich Othello ans Klavier und

13 The Rolling Stones, LET IT BLEED, 1969. Der in der OTHELLO-Inszenierung gespielte Titel war You Got THE SILVER. 
schaltet das sinnlos drehende Tonbandgerät ab. Absolute Stille. Jago geht mitleidig zum Kühlschrank (zu Othello »Ich hol dir'n Bier, ja?!«), öffnet diesen, ein Knall, mit blutüberströmten Gesicht setzt sich Jago in die Kinoklappsitze, zu hören ist allein Othellos Lachen. Und wenn der Vorhang zugeht, ertönt wie aus einer anderen Welt über die Lautsprecher des Theaters noch einmal der Rolling Stones Song.

Diese Art des szenischen Gebrauchs von Medien und Medienkultur wird sich differenziert in den folgenden Inszenierungen wiederholen. Ibsens NoRA beginnt im Nichts, in völliger Dunkelheit und Stille, aus der sich traumhaft langsam eine Welt abzuzeichnen beginnt, wie im Entwicklerbad eines Fotolabors. Allmählich entstehen erkennbare Umrisse, ein Mann der in einem sonderbaren Raum verharrt, begleitet von schwebenden Klängen, die sich in einem langsamen Rhythmus in Gang setzen. ${ }^{14}$ Es ist wie ein medial stimulierter Transformationsprozess, ein Diffundieren in eine andere Welt, in ein ästhetisches Sein mit eigenen Zeit- und Raumkoordinaten, auf das sich Darsteller wie Zuschauer gleichermaßen einlassen. Theater als eine Art Wachtraum, als medialer Zustand des Andersseins und damit der anderen Wahrnehmung.

Vor allem aber soziale Grundsituationen, Figurenbeziehungen können durch den Gebrauch kultureller Medien scheinbar überzeugend beherrscht werden. Die Scheinbarkeit, die Illusion offenbart sich für den Zuschauer in der grotesken und selbstgefälligen Form, in der Torwald Helmer sich dieser Medien bedient. So arrangiert er als Hausherr einen Weihnachtsabend, der ihn als einen Mann auf der Höhe der Zeit zeigt, indem er seine Familie mit einem Text zur Evolutionstheorie zu beglücken glaubt, anschließend den Abend mit einem Schuss Unterhaltung ausklingen lassen möchte, wozu er einen Schmalfilmprojektor herbeischleppt und an die Zuschauerrückwand des Theaters Micky Maus Filme projiziert. Einen Höhepunkt im szenischen Umgang mit kulturellen Erfahrungen erreicht die Inszenierung, wenn Nora sich auf ihren Auftritt auf dem Maskenball vorbereitet. Die im Stück angelegte Provokation, die bürgerliche Gesellschaft durch ein Versatzstück fremder plebejischer Kultur zu überraschen, einer von der Italienreise mitgebrachten Tarantella, wird von Castorf in die Rock-Ära übersetzt. Nora studiert HONKY TONK WOMAN der Rolling Stones ein. Zunächst noch mit zaghaften Versuchen, sich selbst am Klavier begleitend. Torwald steht entsetzt auf, um seine Gitarre zu holen. Die Dissonanz, in der sein Gitarrenspiel und Noras unangemessener Arienstil scheitern, kommentiert Nora nur noch verzweifelt mit der kapitulierenden Feststellung »Das ist nicht meine Kultur.«Die Medienkette wird dann perfektioniert, wenn nach Klavier und Gitarre Torwald nach nebenan geht, dort die Bandmaschine in Gang setzt und durch die offene Tür die Originalversion der Rolling Stones dröhnt. Torwald lehnt mit einer Haltung der Überlegenheit am Türpfosten. Immer wieder entsteht ein Gesamtgestus durch die Montage von eigener darstellerischer Haltung mit dem Gestus der stellvertretend für den Akteur sprechenden Musik, entscheidend geprägt weniger durch die Erkennbarkeit der zitierten Titel als vielmehr durch ihre konkrete sinnliche Kraft. Das die neue Kultur, die die Figuren benutzen, um szenische Vorgänge zu etablieren, vor allem eine Medienkultur ist, wird permanent daran erkennbar, dass die Apparate ihrer Produktion (eigentlich eher ihrer Reproduktion) auffällig benutzt werden. Im Karl-Marx-Städter BAU (1986) ist Arbeiter Dreier Stones-Fan und im Besitz des notwendigen Apparates, eines Minitonbandgerätes, damit Herrscher über die neue Kultur. Die Aneignung derselben, sprich die Umfunktionierung zum eigen Ausdrucksmedium, erfolgt in doppelter Hinsicht: als hörender Konsument und als Produzent, indem Dreier versucht, auf

14 Van Morrison, BeAutiful Vision, 1982. Gespielt wurde der Titel SCANDinAVIA. 
seinem Akkordeon den Titel ${ }^{15}$ nachzuspielen. Dabei bedarf er der Hilfe des Intellektuellen (Ingenieur Hasselbeins), der englisch spricht und damit den Text im doppelten Sinne versteht.

In Castorfs Inszenierung von Ibsens VOLKSFEIND ${ }^{16}$ taucht auf der Bühne der erste Monitor auf und dies in einer radikal szenischen Funktionalität. Nicht ein mögliches Programm, das er verbreitet, macht dramaturgisch Sinn, sondern seine Nutzung als Apparat, als Medium an sich, als szenisches Spielobjekt. Verbunden mit einer Videokamera zeigt der Monitor einen nicht einsehbaren Spielvorgang hinter der Bühne. Badearzt Thomas Stockmann droht mit einer ungeheuerlichen Wahrheit an die Öffentlichkeit zu gehen - mit der Erkenntnis, dass das Wasser des Badeortes durch die Hemmungslosigkeit der einheimischen Wirtschaft total verseucht sei. Sein Bruder Peter Stockmann, Stadthauptmann und Vorsitzender der Kurverwaltung, weiß dies im Interesse der Badeindustrie und der daran hängenden Existenz der Stadt, also gestützt von der »kompakten Majorität«, rigoros zu verhindern. Nämlich indem er seinen Bruder mit seinen Enthüllungen einfach einsperrt, allerdings nicht ins Gefängnis, sondern ins Medium Fernsehen. Hier mag der Badearzt wettern so viel er will, sein Wirken bleibt wirkungslos bis zur nicht verhinderbaren Abschaltung. Sinnlich erlebbar als Eingesperrtsein in einen Kasten, dessen Enge Stockmann mit seinen Händen zu weiten versucht, bleibt auch die Wahrheit in diesen Raum wirkungslos verbannt. Das Medium Fernsehen als verbreitetstes Medium der Kommunikation, als scheinbar grenzenlose Öffentlichkeit, erweist sich schnell als Medium der größten möglichen Kontrolle und damit Wirkungslosigkeit.

\section{Exkurs: Medium Rockmusik ${ }^{17}$}

Frank Castorf gehört zu einer Generation, die weltweit durch das kulturelle Phänomen der Rockmusik geprägt wurde. So verwundert es kaum, dass er in einem Interview gefragt wird: »Ihr Theater ist wie Ihre DDR-Existenz undenkbar ohne Konditionierung durch Musik. [...] Musik gleichsam als Verdichtung dessen, was man selber fühlte. Musik als Vitalitätsspritze« (Schütt: 120). Bestätigend und konkretisierend antwortet Castorf:

»Ich mochte The Who und bestimmte US-Gruppen, wie Doors, Jim Morrison, Leute aus dem Jimi-Hendrix-Umfeld. Eine Mischung von Avantgarde, Film und Musik förderte das Untergrundbewußtsein in dieser klanglosen DDR. [...] Ich mochte das Wuchtige, Drän-

15 Die Rolling Stones Version des Blues-Klassikers LitTLE Red RoOsteR.

16 EIN VolKSFEIND von Henrik Ibsen (Fassung für die Städtischen Theater Karl-MarxStadt), Regie: Frank Castorf, Städtische Theater Karl-Marx-Stadt Schauspielhaus, Premiere: 12. Februar 1988.

17 Es ist interessant, dass auch Siegfried Wilzopolski in der ersten umfangreicheren Publikation zu Frank Castorf (Wilzopolski 1992) dessen Theaterarbeit in Kapitel gliedert, die programmatisch mit Titelnamen von Rolling Stones Songs und einem Canned Heat Song überschrieben sind. So wird der kompromisslose Start in Anklam übertitelt mit YOU CAN'T ALWAYS GET WHAT YOU WANT, seine Odyssee durch die Theater der DDR mit ON THE ROAD AGAIN, der provozierte Freiraum zwischen Köln und Berlin mit BETWEEN THE BUTTONS und schließlich der Beginn der Nachwendeära prophetisch mit EXILE ON MAIN STREET. 
gende, Harte, alles, was nach Pflasterstein roch - Troggs, Kinks, Animals, Yardbirds « (Schütt: 121).

Zweifellos war neben der Philosophie die Rockmusik ein kulturell verbreitetes Ausdrucksmedium, um Inszenierungen durch eigene Erfahrungen, durch Assoziationsmöglichkeiten, durch verfremdende Perspektiven zu brechen. »Diese Brüche und das Hineinholen von Welterfahrung über bestimmte Medien waren sehr spannend. Rockmusik war immer so ein Punkt «, resümiert auch Theaterkritiker Martin Linzer später (Balitzi: 43f). Rockmusik als kulturelles Medium im Allgemeinen und die konkreten Songs als ihre Produkte im Besonderen fungieren hier als Konzentrat, als Verdichtung historisch konkreter Wahrnehmung und Erfahrung. Sie entfalten eine eigendynamische Sprache, die generationsspezifische Blicke auf die Welt ermöglicht. Diese Eigenart hat auch Peter Wicke im Blick, wenn er in einem nicht zufällig »My Generation« betitelten Buchkapitel schreibt:

»Rockmusik hat sich als Bestandteil komplexer kultureller Zusammenhänge entwickelt, in denen ihre Spielweisen und Stilformen einen jeweils spezifischen Sinn erhalten, Bedeutungen und Werte tragen, die sie zum Medium gelebter Alltagserfahrungen werden lassen. Sie ist weder ein in Klang gefasster Spiegel der Realität noch bloßes Mittel zur Unterhaltung. [...] Es sind ihre jeweiligen Fans, die ihr darin genau definierte Bedeutungen zuweisen, eine dialektische Beziehung von musikalischer Form und kulturellem Gebrauch in Gang setzen, aus der immer wieder neue Spielweisen hervorgegangen sind«(Wicke: 107).

Dies ist der zentrale Nerv in Castorfs Theaterästhetik der 1980er Jahre, wenn es um den Gebrauch von Musik auf der Bühne geht - ihr Potential als Medium gelebter Alltagserfahrung, als Medium der Lebenswahrheiten, der Lebensgestaltung und der Weltbetrachtung. Die einmontierten Songs sind keine Zitate, keine eigenständig dramaturgisch gesetzten Bedeutungsebenen, sie sind komplexe kulturelle Gesten, mit denen szenisch agiert wird.

\section{7.}

Die hier beschriebene medienästhetische Dimension der Theaterarbeit Frank Castorfs, die unter dem Stichwort der Attraktionsmontage gefasst wurde, basiert vor allem auf kulturellen Veränderungen der zweiten Hälfte des 20. Jahrhunderts, die sich in einem neuartigen Alltagsverhalten, einem neuen Verhältnis zu Realität äußerte - in dem gewaltigen Einbruch von Medienerfahrungen und den damit einhergehenden Formen des Mediengebrauchs. Diese entscheidende Koppelung von Medienbegriff und Realitätsbegriff aber verweist auf weitere Felder medienästhetischen Denkens bei Castorf, von denen eines abschließend wenigstens benannt sein sollte. Es geht dabei um zwei sonderbare und merkwürdige Formen von Realität und Realitätswahrnehmung - die Erinnerung und den Traum. Als Existenzformen von Realität und ihrer Wahrnehmung sind sie zweifellos auch Medien ästhetischer Präsenz, Medien der Lebensgestaltung, des Daseins, der Wahrnehmung. Gerade der Bezug auf andere Welten, auf andere reale wie irreale Daseinsformen, produzierte in Castorfs Inszenierungen in starkem Maße immer wieder jene Irritationen, die seine Theaterästhetik auszeichneten und die Inszenierungen so faszinierend und verstörend zugleich machten. Castorfs Theaterarbeit dieser Zeit kann in diesem Sinne auch als Erinnerungs- und Traumarbeit verstanden werden. In der 
NORA spielen diese Bezüge auf den Traum in Anlehnung an die Psychoanalyse eine geradezu verhaltenskonstituierende Rolle, im BAU oder auch im VOLKSFEIND als utopischer, visionärer, aber gleichzeitig illusionärer Blick in die Zukunft eine politisch desillusionierende. Inszenierungspraktisch gelingt Castorf in dieser Zeit eine ästhetische Konstruktion, die die Bühne mit darstellerischen Vorgängen, materialintensiven Bühnenwelten etc. anfüllt, die so gut organisiert sind, dass sie am Ende der Aufführung alle wieder von der Bühne verschwunden sind und man sich fragt, ob das, was man gerade über mehrere Stunden in so sinnlicher Eindringlichkeit erlebt hat, wirklich wahr ist, wahr im Sinne von wirklich stattgefunden, oder ob es nicht gar nur ein Traum war.

Das Abrufen von Erinnerungen und ihre aktuelle Versinnlichung zeigten sich als eine zentrale schauspielerische Technik, vor allem im Sine einer vehementen Mobilisierung der eigenen Biographie. Frank Castorfs Inszenierungsarbeit ist bis heute eine erinnerungstechnische Reaktivierung oder Revitalisierung jenes Prozesses ursprünglicher Akkumulation, der am Anfang beschrieben wurde. Theaterarbeit ist dabei das geistesgegenwärtige Jetzt, das sich als ein Dazwischen definiert, gekennzeichnet durch das Ab- und Anrufen der Vergangenheit (Erinnerung) und durch die Projektion von Zukunft (Traum). In der in den 1990er Jahren beginnenden Inszenierungsphase verschieben sich diese Koordinaten, in Koexistenz zu neuen Inszenierungsinteressen. Die Erinnerung findet Asyl im Erinnerungshotel, der Traum verkommt zum Albtraum oder weicht der Ernüchterung. Einer der großen Verlierer heißt Poesie.

\section{Literatur}

Balitzki, Jürgen (1995): Castorf der Eisenhändler. Theater zwischen Kartoffelsalat und Stahlgewitter. Berlin: Christoph Links.

Castorf, Frank: »Held Hübchen!«. In: Theater heute. Jahrbuch 1994. Sondernummer 1994, hg. v. d. Redaktion der Zeitschrift »Theater heute«, Erhard Friedrich Verlag in Zusammenarbeit mit Klett-Cotta, S. 37-39.

Eisenstein, Sergej (1988 [1923]): »Montage der Attraktionen«. In: Ders.: Das dynamische Quadrat. Schriften zum Film. Hg. von Oksana Bulgakova und Dietmar Hochmuth. Leipzig: Philipp Reclam jun., S. 10-16.

Schütt, Hans-Dieter (1996): Die Erotik des Verrats. Gespräche mit Frank Castorf. Berlin: Dietz.

Wicke, Peter (1987): ROCKMUSIK. Leipzig: Philipp Reclam jun.

Wilzopolski, Siegfried (1992): Theater des Augenblicks. Berlin: Zentrum für Theaterdokumentation und -information. 



\title{
ZUR INTERMEDIALITÄT DES TIERES. THE BAA-LAMB'S HOLIDAY
}

\author{
JÖRG WIESEL
}

Eine Musik geht nicht mehr aus dem Kopf, die die Inszenierung, die hier analysiert werden soll, rhythmisiert und begleitet, ja, unterbrochen hat. Es handelt sich um George Delerues Musik zu Jean-Luc Godards Film LE MÉPRIS (DIE VERACHTUNG) aus dem Jahr 1963. Und bei der Inszenierung handelt es sich um DAS FEST DES LAMMS $^{1}$, das 1940 entstandene Drama (THE BAA-LAMB's HolidAY) der 1917 in Lancashire, England, geborenen Leonora Carrington. Frank Baumbauer, der Intendant der Münchner Kammerspiele, trug dieses Stück seit Jahren mit sich herum. Erst in München, zu Beginn von Baumbauers Kammerspiel-Intendanz (in der zweiten Spielzeit), bot sich eine konkrete Inszenierung an. Premiere war am 30. April 2003: mit dem Regisseur Jossi Wieler und dem Dramaturgen Tilman Raabke, dessen Münchner Textfassung jetzt vorliegt. Das Stück ist spätestens in seiner französischen Übersetzung als LA FÊTE DE L'AGNEAU und seit seiner Uraufführung als Musiktheater unter dem Titel BÄHLAMMS FEST nicht mehr unbekannt. Der österreichischen Komponistin Olga Neuwirth gelang 1999 der Durchbruch mit der Textvorlage Carringtons, das Libretto stammte von Elfriede Jelinek. Und ohne diese musiktheatrale Umsetzung als BÄHLAMMS FEST sind Inszenierung und Dramaturgie der Münchner Kammerspiele - so meine These - nicht zu denken.

Die Geschichte, die das Drama, die Oper und die Inszenierung erzählen, ist so kompliziert wie einfach: Während des Weihnachtsfestes, dem Fest des Lamms, tragen sich im Haus der matriarchal dominanten Mrs Margret Carnis merkwürdige Dinge zu. Das Haus, dessen Beschreibung in der Münchner Inszenierung dem Diener Robert (gespielt von Matthias Bundschuh) in den Mund gelegt wird, ist eine gespenstische Herberge, ein unheimliches Heim lebender Toter, ein Hotel für sexuell unruhige Figuren, deren familiärer Zusammenhalt einzig durch die Autorität der Mutter (Hildegard Schmahl) beglaubigt wird, deren Name programmatisch die Fleischlichkeit ihres Körpers und die Lust zur Überschreitung desselben markiert. Die zweite Ehe ihres alkoholkranken ältesten Sohnes Philip mit Theodora kriselt seit langem und droht am Ekel und der sich zunehmend entwickelnden Verachtung der jungen Frau zu zerbrechen:

»Dieses ganze Haus stinkt nach Alter. Nach Alter und Tod. Laß mich in Frieden. Ich krieche dir nicht nach. Warum kannst du mich nicht einen Augenblick in Ruhe lassen? Ich tue niemandem etwas Böses, nicht einmal deiner ekelhaften, verfressenen Mutter « (Münchner Kammerspiele 2002/03a: 6).

Theodoras Wunsch nach einem emphatisch besetzten anderen Leben, das nicht nur sexuell intensiver als das Leben in ihrer Ehe sein soll, findet sie in der Begegnung

1 Regie: Jossi Wieler, Bühne: Jens Kilian, Kostüme: Gesine Völlm. 
mit Jeremy, dem jüngeren Bruder Philips und - der Text legt diese Spur auf jeden Fall aus - Sohn einer Beziehung zwischen Mrs Carnis und ihrem Lieblingshund Henry (Walter Hess).

Jelineks Libretto szenographiert Henry in einem Setting, das die Reflexion von (Musik-)Theater und Film und Morphing ausbuchstabiert: Jeremys (gespielt in München von Hannes Hellmann) diabolischer Auftritt im zweiten Akt ist der eines wilden Tieres, einer Figur zwischen Mensch und Tier, eines Werwolfs, dem die Spaltung in Mensch und Tier als Zeichen seiner ungeheuerlichen Zeugung immer schon eingezeichnet ist. In dieser surrealen »zoo-politischen Metamorphose « hat Jeremy als Sohn eines Hundes und einer Frau das

»Wölfische am Wolf, das undankbare oder diskriminierende Schicksal übernommen, jene Grenze zu ziehen, die nicht das Tier vom Menschen, sondern eben das menschliche Leben vom menschlichen Leben, den Bürger vom Bürger trennt« (Matala de Mazza/Vogl: 285).

Neben der deutlichen Rezeption surrealistischer Paradigmen wie Salvador Dalís/ Luis Buñuels UN CHIEN ANDALU (1928), der bereits mit Schnitten zwischen Mensch und Tier, Mädchen und Werwolf arbeitete ${ }^{2}$, bewegen sich Carringtons Text und Neuwirths/Jelineks Musiktheater in einer Geschichte von »Verwandlungen, von Metamorphosen, [...] mit denen sich die Politik die Grenze des Politischen und die Menschen-Gesellschaft die Grenze des Geselligen erzählt.« (Matala de Mazza/ Vogl: 286). Jeremy ist als hybrides Geschöpf »an den Rändern des homogenen Kollektivkörpers « (ebd.: 292) situiert; auf ihn fällt am Weihnachtsabend der Verdacht, wenn der Schafhirte Joe Green zuerst ein getötetes, gerissenes Lamm hereinbringt, dann selbst in Gegenwart der Familie tot umfällt.

Jeremy ist bei Carrington die zwitterhafte Bestie mit enorm erotischer Ausstrahlung, seine Animalität ist das Abjekte einer bürgerlichen Genealogie und Gemeinschaft:

»Das Ungeheuerliche der Mischwesen lässt sich darum nicht auf eine Akkumulation verschiedenartiger Bestimmungen zurückführen, auf eine Monstrosität, die aus der Überdeterminierung des Tierhaften am Tier erwächst. Das Unheimliche, Ungeheuerliche der Menschenwölfe geht vielmehr aus dem Verlust symbolischer Markierungen hervor, von Markierungen, die zugleich die Grenze aller Demarkierungen setzen. Es ist die Defiguration in der Figur, es ist der Grund oder Abgrund, vor dem sich die Menschen-Form selbst abzeichnet - ein aufsteigendes Tier, eine aufsteigende Tierheit oder Bestialität« (Matala de Mazza/Vogl: 292f).

So ist die Geschichte des Textes und seiner Inszenierung scheinbar leicht erzählt; sie lässt aber eine ganz zentrale Ebene des Dramentextes unerwähnt: die bei Leonora Carrington surrealistisch in die 1. Szene des dritten Aktes montierte Weihnachtssequenz eines erotisch aufgeladenen Tanzes der Schafe. Während dieses Tanzes erscheint Jeremy mit Theodora. Jeremy ist als Erzengel Gabriel, Theodora als eine »mindere Heilige« (Münchner Kammerspiele 2002/03b: 16) kostümiert. Im Dramentext tötet Jeremy das Schaf Mary, aus dem Tilman Raabke in seiner Münchner Fassung die Figur des Dienstmädchens Violet gemacht hat. Der surreal anmutende Einbau sprechender Tiere in der rhetorischen Figur der Prosopopoiia ist eine Sequenz, die das klassische Theater sprengt, es an seine Grenzen der Reprä-

2 Dazu ausführlich Reck (1994: 261-270). 
sentation treibt, es anhält, stillstellt und unterbricht. Jeremy, der Mörder, wird in der letzten Szene der Münchner Inszenierung von Elizabeth, Philips erster Frau, erschossen und erscheint Theodora als Gespenst.

In der Oper bedient sich Neuwirth für die Darstellung von Jeremy, der hier immer in der Meute, im Rudel von Wölfen auftritt (vgl. Deleuze/Guattari: 326ff), eines Verfahrens von Klangmorphing, es war ihr Wunsch, das klangliche Verschneiden von Mensch und Wolf live zu generieren. Am Grazer Institut für Elektronische Musik hat sie das Timbre kanadischer Wölfe analysiert und herausgefunden, dass sie der Stimmlage eines Countertenors entsprechen. »Dazu musste die Klanganalyse des Countertenors [Jeremy: Andrew Watts, J.W.] im Moment des Singens stattfinden und gleichzeitig der interpolierte Klang resynthetisiert werden « (Höldrich: 42). ${ }^{3}$

Es ist jetzt wichtig für meine Argumentation, dass der im Drama Carringtons angelegte Prozess des Tier-Werdens im intermedialen Einsatz eines anderen Mediums - des Films - in der Münchner Inszenierung aufgefangen, wiederholt und gedoppelt wird. Genauer: Der anfangs erwähnte Film Jean-Luc Godards, LE MÉPRIS, der auf dem Roman IL DISPREZZO (1954) von Alberto Moravia basiert, wird allein über seine Tonspur in die Inszenierung von Jossi Wieler integriert. Jeremys erster Auftritt im zweiten Akt der Münchner Inszenierung artikuliert sich in der Textfassung wie folgt:

»DIE STIMMEN (Jeremy spricht synchron.) I reread the Odyssee last night ... I finally found something that I've been looking for for a long, long time. Something that is just as indispensible for the movies as in real life: poetry « (Münchner Kammerspiele 2002/03a: 21).

Die Untermalung der Szene mit Musik von Georges Delerue, das blaue Licht im Hintergrund und der gelbe Bademantel Theodoras referieren ganz klar auf Godards Film. Der ein zweites Mal in der Textfassung zitierte, in der Inszenierung wieder gestrichene Satz ist einer zentralen Sequenz aus Godards LE MÉPRIS entnommen. Dieser Film erzählt vom Plan eines Filmteams, das in Cinecittà und auf Capri Homers ODYSSEE (ver-)filmen möchte, Regisseur ist Fritz Lang. Paul Naval (Michel Piccoli), ein junger Theaterautor, arbeitet an einem Drehbuch, mit dem der amerikanische Produzent Jeremy Prokosch (Jack Palance) in zentralen Punkten nicht einverstanden ist; es ist ihm zum Teil zu intellektuell. Paul versucht unauffällig, Jeremy seine Frau Camille (Brigitte Bardot) anzubieten; er lässt sie in dessen Auto fahren, drängt sie ihm geradezu auf. Camille reagiert auf diesen Plan irritiert,

3 »Für BÄHLAMMS FEST wurde als solche Klangrepräsentation die sogenannte >Additive Resynthese< gewählt. Dabei versucht man, einen Klang als Überlagerung von Teiltönen [...] mit zeitlich veränderlicher Tonhöhe und Lautstärke zu erzeugen. In einer ersten Analysestufe werden die zeitlichen Verläufe dieser Teiltöne so bestimmt, wie sie den Klang am besten beschreiben. Mit den gefundenen Tonhöhen- und Lautstärkenparametern wird eine Gruppe von Sinusgeneratoren gesteuert, deren Ausgangssignale für jeden Zeitpunkt addiert werden und so einen vom analysierten Original ununterscheidbaren Resyntheseklang ergeben. Sind solche Parameter für Ausgangs- und Zielklang bestimmt, lässt sich Morphing dadurch bewerkstelligen, dass bei der Resynthese zwischen den Teiltonparametern der beiden Klänge interpoliert wird. Beim Morphing von Countertenor zu Wolf würden zum Beispiel die Sinusgeneratoren am Beginn durch die Gesangsparameter gesteuert werden und im Verlauf immer stärker die Tonhöhen- und Lautstärkeverläufe des Wolfsheulen wiedergeben.« (Höldrich: 41). 
verwirrt und zunehmend mit Verachtung. In dieser Sequenz begeben sich die vier Hauptfiguren des Films in ein römisches Filmtheater, in dem Prokosch das Casting für die Rolle der Nausikaa in der zu filmenden ODYSSEE organisiert hat. Godard unterbricht diesen Blick der vier Protagonisten (eine frontale Kameraeinstellung) auf die Leinwand ein erstes Mal durch den Kameraschuss eines Photographen sowohl auf die Kamera Godards im off, wie auch den Blick auf uns als Zuschauer auf der metadiegetischen Ebene. Die Position der Kamera wechselt um $180^{\circ}$, begleitet vom Blitzlicht der Photokamera und der Unterbrechung/Stillstellung der Casting-Musik. Camille und Paul nehmen Platz zwischen Fritz Lang und Jack Palance (Jeremy), aber getrennt durch den Gang. Das mehrsprachig geführte Gespräch unterbricht Godard permanent durch die Arbeit der Übersetzerin (Georgia Moll). In diesem Kontext fällt der Satz Jeremys, den die Münchner Fassung integriert: Das Zwischen-Wesen bei Carrington und Wieler zitiert das Interdiktum des Produzenten aus Godards Film. Dessen Vorstellung von poetry ist während des Gesprächs der vier Akteure - gefilmt als Parallelfahrt - zu sehen und zu hören. Die dramaturgische Konzeption der Inszenierung bezieht sich an dieser zentralen Stelle auf eine Sequenz, die bereits in sich mehrfach gespalten ist und Intermedialität in höchstem Maße reflektiert.

$»$ Vor diesem Hintergrund stellt sich für jeden Film Godards die Frage, welche Funktionen darin als Kategorien und reflexive Genres fungieren. Im einfachsten Fall sind es die ästhetischen Genres: Epos, Theater, Roman, Tanz und das Kino selbst. Zum Kino gehört ebenso eine Reflexion über sich selbst wie über die anderen Gattungen, insofern die visuellen Bilder nicht bloß auf unabhängig von ihnen bestehende Tänze, Romane, Theaterstücke oder Filme verweisen, sondern sich selbst anschicken, für die Dauer einer Serie oder einer Episode Kino, Tanz, Roman, Theater zu >machen« (Deleuze: 241).

Im Film Godards zitiert Fritz Lang in seinem Gespräch mit Paul (Piccoli) über die Realität der Welt der ODYSSEE eine Strophe der 1942 entstandenen HollywOODELEGIEN Bertolt Brechts und intendiert mit Horkheimer und Adorno eine Verfilmung der ODYSSEE, wo der Mythos bereits Aufklärung ist und die Aufklärung in Mythologie zurückschlägt.

\section{»JEDEN MORGEN, MEIN BROT ZU VEDIENEN}

Fahre ich zum Markt, wo Lügen gekauft werden.

Hoffnungsvoll

Reihe ich mich ein unter die Verkäufer.«(Brecht: 115)

Der Film stellt Lang aus, der Brecht in der Zusammenarbeit zu HANGMEN ALSO DIE (1942) mehrfach desavouiert hatte, indem er bestimmte, ihn nicht allein für das Drehbuch verantwortlich zeichnen zu lassen. Godard aber, und mit ihm die Nouvelle Vague, reflektieren die filmkritische Position der Dialektik der Aufklärung (1947): Die Faszination für das Hollywoodkino der fünfziger und frühen sechziger Jahre (John Ford, Howard Hawks, Alfred Hitchcock) wird in diesen Reflexionen einer kinematographischen Autorschaft übernommen und im intermedialen Vergleich deutlich akzentuiert.

Zurück zu Jeremy: Die Münchner Inszenierung, die den Soundtrack des Films als rhythmisierendes Intermedium integriert, dabei aber die Bildspur Godards nur auf der imaginären Ebene mitlaufen lässt, sucht ihre Theaterbilder mit der Endlosschleife Delerues zu amalgamieren. Ton und Bild verschmelzen im Affekt des Be- 
trachters. In dieser intermedialen Dramaturgie liegt aber das Potential einer Reflexion über Intermedialität, wie auch die Möglichkeit, das Theater mit sich selbst zu unterbrechen. Im Konzept der Münchner Dramaturgie liegt der Ansatz, dem sperrigen, surrealen Text Leonora Carringtons mit intermedialen Einsätzen zu begegnen.

Die Interrogation des je einen Mediums mit den Mitteln des jeweils anderen bleibt aber auf halber Strecke stehen, was zum einen dem immensen Erwartungsdruck auf die zweite Spielzeit Frank Baumbauers an den Münchner Kammerspielen und zum anderen der Schönheit des Films Godards geschuldet ist, der die Inszenierung erliegt. Auf dem Spiel aber steht eine medientheoretische Position, die Intermedialität als - politische - Chance der Unterbrechung, der Stillstellung, des Aussetzens von Entscheidung versteht:

»Medien übertragen Botschaften, Sichtweisen, Ästhetiken, sind aber definitionsgemäß als Bote und Bedeutungsträger - nicht die Botschaft selbst. Diese Eigenschaft der Medien, nämlich nur Botschaften, Informationen und Daten zu übertragen, ohne ihren Sinn zu beeinflussen, markiert den Ansatzpunkt einer Metaphorologie der Medien, die in diesem Sinnvorbehalt und Sinnaufschub der Medien eine grundlegende Bestimmung von Medialität als Mit-Teilbarkeit zu begründen versucht. Die permissive Durchlässigkeit oder Disponibilität der Medien, mit der wir im Zeitalter der digitalen Simulation konfrontiert sind, ist jenes seltsame Vermögen, vorgegebene Bedeutungshorizonte zu eröffnen, zu verschieben und zu unterbrechen. Die Medialität der Medien konturiert den Horizont, in dem sie selbst nicht >aufgehen< kann: Medien sind indifferent gegenüber dem, was sie speichern, übertragen und verarbeiten. Eben diese Gleichgültigkeit oder Indifferenz gegenüber dem Sinn der Botschaft ist vielleicht auch als In-Differenz lesbar, d. h. als Dazwischenkunft der uns teilenden und dadurch verbindenden Medien, mithin als das, was uns vorausgeht bzw. den anthropologischen Fixpunkt dieses >Uns< oder >Wir< dezentriert« (Tholen: 8f).

Dass Raabkes und Wielers Konzept so prägnant ist, dann aber nicht klar weitergeführt wurde, zeigt die Figur Jeremy in der Münchner Inszenierung exemplarisch an: seine Interposition als die zwischen Mensch und Tier wird im intermedialen Einsatz gedoppelt und unterbrochen. Die bei Carrington angelegte surreale Intermedialität des Menschen selbst, als Spaltung in Mensch und Tier (als Figur einer begehrenden Bestie), ihre - mit Tholen als »anthropologischer Fixpunkt« eingeschriebene intrahumane Trennung, zeigt auf Giorgio Agambens Überlegungen zu Mensch und Tier. Der intermediale Einsatz der Tonspur des Films von Jean-Luc Godard in der Münchner Inszenierung genau an der Stelle, wo der Mensch Tier und das Tier Mensch ist, überzieht die politische Brisanz des Dramas von Carrington mit der Tonspur von beider Verschmelzung. Die Radikalität aber, die sowohl der Text wie auch Godards Film besitzen, öffnet uns für die Überlegungen Agambens in ganz besonderer Weise:

»Aber wenn das zutrifft, wenn die Zäsur zwischen Mensch und Tier in erster Linie das Innere des Menschen durchzieht, dann muss die Frage nach dem Menschen - und dem »Humanismus « - als solche neu gestellt werden. In unserer Kultur ist der Mensch immer als Trennung und Vereinigung eines Körpers und einer Seele gedacht worden, eines Lebewesens und eines lógos, eines natürlichen (oder tierischen) und eines übernatürlichen, sozialen oder göttlichen Elements. Wir müssen hingegen lernen, den Menschen als Er- 
gebnis der Entkoppelung dieser zwei Elemente zu denken und nicht das metaphysische Geheimnis der Vereinigung, sondern das praktische und politische der Trennung zu erforschen. Was ist der Mensch, wenn er stets der Ort - und zugleich das Ergebnis - von unablässigen Teilungen und Zäsuren ist? Diese Teilungen zu untersuchen, sich zu fragen, auf welche Weise der Mensch - im Menschen - vom Nichtmenschen und das Animalische vom Humanen abgetrennt worden ist, drängt mehr, als zu den großen Fragen, den sogenannten menschlichen Werten und Menschenrechten, Stellung zu beziehen« (Agamben: 26).

Jeremys Hybridität ist in der Inszenierung eine doppelte:

»Hybride oder intermediale Zwischenräume sind also mehr und anderes als die unbezweifelbar zunehmende Konvergenz der Medien, welche sich der digitalen Integration vormals getrennter Medien in einem Medienverbund verdankt « (Tholen: 197f).

Mit Georg Christoph Tholen nehme ich »beide Bedeutungen des Hybriden beim Wort, nämlich Mischung und Maßlosigkeit « (Tholen: 198) und begreife die Intermedialität des Tieres als einen Punkt der theatralen und theoretischen Untersuchung von Animalität jenseits einer »Humanität, die das Mandat der integralen Verwaltung der eigenen Animalität übernommen hat« (Agamben: 86), indem sie über das Menschsein im Ausschluss des Tierseins entschied und entscheidet. Und es wären diese politischen und ästhetischen (theatralen) Grenzziehungen zu erforschen und zu diskutieren - nicht nur im Fest des Lamms -, weil es eben keine »unteilbare Grenze zwischen dem MENSCHEN und dem TIER « (Derrida/Roudinesco: 115) geben kann.

\section{Literatur}

Agamben, Giorgio (2003): Das Offene. Der Mensch und das Tier. Aus dem Italienischen von Davide Giuriato. Frankfurt/M.: Suhrkamp.

Brecht, Bertolt (1988): Gedichte 2. Sammlungen 1938-1956 (= Bertolt Brecht. Werke. Große kommentierte Berliner und Frankfurter Ausgabe. Hg. v. Werner Hecht, Jan Knopf, Werner Mittenzwei, Klaus-Detlef Müller, Bd. 12). Berlin/ Weimar: Aufbau; Frankfurt/M.: Suhrkamp.

Chion, Michel (1990): L'Audio-vision. Son et image au cinéma. Paris: Éditions Nathan.

Deleuze, Gilles (1997): Das Zeit-Bild. Kino 2. Übersetzt von Klaus Englert. Frankfurt/M.: Suhrkamp.

Deleuze, Gilles/Félix Guattari (1992): Tausend Plateaus. Kapitalismus und Schizophrenie. Aus dem Französischen übersetzt von Gabriele Ricke und Ronald Voullié. Berlin: Merve Verlag.

Derrida, Jacques/Elisabeth Roudinesco (2006): Woraus wird Morgen gemacht sein? Ein Dialog (2. Aufl.). Aus dem Französischen von H.D. Gondek. Stuttgart: Klett-Cotta.

Höldrich, Robert (2003): »Klangmorphing«. In: Olga Neuwirth: Bählamms Fest. CD, Klangforum Wien, Johannes Kalitzke. Wien: Kairos, S. 40-42.

Matala de Mazza, Ethel/Joseph Vogl (2002): »Bürger und Wölfe. Versuch über politische Zoologie«. In: Sylvia Sasse/Stefanie Wenner (Hg.): Kollektivkörper. 
Kunst und Politik von Verbindung. Bielefeld: transcript (= Masse und Medium, 2), S. 285-298.

Münchner Kammerspiele (2002/03a): Leonora Carrington. Das Fest des Lamms. Fassung von Tilman Raabke. München.

Münchner Kammerspiele (2002/03b): Leonora Carrington - >Das Fest des Lamms . Programmheft. München.

Neuwirth, Olga (2003): Bählamms Fest. CD, Klangforum Wien, Johannes Kalitzke. Wien: Kairos.

Reck, Hans Ulrich (1994): »Dunkle Erkundungen eines verstummenden Echos. Natur im surrealistischen Film, Natur des surrealistischen Films: Zu einer beispielhaften Poetik des Sequentiellen«. In: Karin Orchard/Jörg Zimmermann (Hg.): Die Erfindung der Natur: Max Ernst, Paul Klee, Wols und das surreale Universum. Freiburg im Breisgau: Rombach, S. 261-270.

Tholen, Georg Christoph (2002): Die Zäsur der Medien. Kulturphilosophische Kulturen. Frankfurt/M.: Suhrkamp. 



\title{
Mediating PhèdRe
}

\author{
JOHAN CALLENS ${ }^{1}$
}

The Wooster Group, the New York based performance company led by director Elizabeth LeCompte, is well-known for their iconoclastic productions of canonical texts. These productions mediate between different texts, languages, disciplines, genres, and cultures, the live arts and mechanically as well as digitally reproduced arts, now marking, now confounding the specificity of each and all. TO YOU, THE BIRDIE! (PHÈDRE) (2001) is an exemplary case in that it starts from Paul Schmidt's translation into American English of Racine's 1677 neo-classical play, reframes it by fragments from Euripides' HIPPOLYTUS, and expands it with choreographical and visual intertexts pertaining to the mythical material in which Phèdre's story is embedded. After briefly sketching this story's pre-text for comprehension's sake and summarizing Schmidt's performative view of translation, this article will discuss some of the production's technological interventions and gender implications, before ending with a consideration of Luis Buñuel's BELLE DE JOUR (1967), fragments of which were viewed on stage. These provide not only a gestural vocabulary and extend the intermedial web with occasional painterly and iconographic references, but also open up for debate women's ways of coping with patriarchal power structures.

Racine's play, as is well known, draws on Greek myth. Less familiar, and worth recapitulating, are the unsettling details of the story which provide a foil to Phèdre's illicit love for her stepson, Hippolytus, in the reckless adventures of her philandering and negligent husband. Phaedra and her sister Ariadne were the daughters of King Minos and Pasiphae, whose passion for a bull spawned the Minotaur, later kept hidden in the mythical labyrinth at Knossos. For three years Minos exacted from the city of Athens a human tribute, which he fed to the monster. To put an end to these sacrifices Theseus, the son of the Athenian ruler, Aegeus, sailed to Crete. After slaying the beast and finding his way back, thanks to the ball of string provided by an enamoured Ariadne, he took her and her sister with him when sailing home, but abandoned Ariadne on Naxos. In addition, Theseus forgot to change the ship's black sail into a white one to announce his victory to the watchmen, thus causing his father to drown himself before the arrival of his son's fleet. Theseus succeeded Aegeus, but instead of simply assuming his responsibilities as King of Attica, he again embarked on a series of expeditions. From that against the Amazons, he returned with Antiope, who bore him a son, Hippolytus, although Theseus repudiated her to marry Phaedra. On a subsequent foray into Sparta, he and his friend Peirithous carried off Helen, who fell to Theseus when the men drew lots. In compensation, he joined his friend into the Underworld to abduct

1 A complementary article, focussing on the choreographic intertexts, is forthcoming under the title »Reconfiguring the Text and the Self: The Wooster Group's To You, The Birdie! (Phèdre) « in: Feminist Theatrical Revisions of Classic Works: Critical Essays, edited by Sharon Friedman and published by McFarland (Jefferson, NC). 
Persephone, a hazardous journey from which Hercules had to rescue him. It was during this exploit that Phaedra's incestuous longing for her stepson took a turn for the worst, the disastrous consequences of which Racine, and prior to him Euripides, so poignantly dramatized (Larousse: 176-9).

Schmidt's first draft of Racine's play, dating from 1993 and commissioned by LeCompte, was a radically condensed version. The second one, made for Liz Diamond's 1998 premiere at the American Repertory Theatre (Cambridge, MA), was more faithful, though still written in the translator's rather typical colloquial idiom (Diamond: 94). In general, Schmidt (1934-1999) believed »translating is performing and performing is translating. You have to be able to let someone else's words come through you, and not impose your voice«, listen for the playwright's individual »voiceprint « and »recreate in American English a voice which echoes [...] the same way « in the target as in the source language (qtd in Langworthy: 167). Schmidt here compares translation to an act of ventriloquism that sets up an echo chamber, which becomes emblematic for the mediations involved in staging a pre-existing text.

When LeCompte finally tackled Racine, she used Schmidt's longer translation, yet adhered to the Wooster Group practice by, on the one hand, again cutting scenes and characters, and on the other hand, adding material. The story's Greek roots were visually referenced by two truncated pillars and the male performers' parodies of athletes' and classical sculptures' semi-nude poses. In Jim Findlay's set, sliding plexi-panels made for a baroque confusion since these could be made to look transparent or throw off reflections, so that echoes of the Minotaur's mythical labyrinth fused with the Sun King's spectacular court, full of intrigues. For the rest LeCompte's pseudo-classical palace complex seemed to include a gymnasium with pool, locker rooms, sauna, ànd badminton court, which explains some of the more arcane text additions. Venus, the goddess slighted by Hippolytus' vow of chastity, had been hoisted high on a video monitor, whereas the badminton referee and her two line-markers formed a depleted choir, delivering »love songs «, all but one built around phrases from the play and compiled on a CD marketed via the Wooster Group's website. Clearly, the performance company's reconfiguration of Phèdre spanned 2500 years, from ancient Greece to the postmodern culture industry. It never did so gratuitously, but with the effect of exposing the reigning power discourses, whether those put into place by Greek patriarchy, Louis XIVth's absolutist reign, houses of care, or theatre and film's technologies of perception and identityconstruction. The power structures of the contemporary culture industry were involved, too, as the Wooster Group's independently produced and distributed audio CD represents a gesture of defiance to the official marketing circuit.

Different temporalities and geographies therefore intersected and overlapped in To You, THE BIRDIE!, playing fast and loose with the neoclassical unities. The Wooster Group's reliance on badminton, for instance, invoked the converted courts for ball games or jeux de paume, where seventeenth century plays were performed before buildings specifically conceived for theatre were erected (Lawrenson: 164). In turn, these improvised spaces conjure the Wooster Group's own Performing Garage, the product of the search for alternative venues by the experimental theatres of the nineteen-sixties, notably Richard Schechner's Performance Group under whose name LeCompte's earliest shows came into being (1975-1980). Badminton or tennis rackets were already featured in MisS UNIVERSAL HAPPINESS, a show from 1985 in which Richard Foreman directed LeCompte and other Wooster Group members. Despite eventual misgivings about reducing tragedies like PHÈDRE to 
camp (Diamond in Kiger: 249), Foreman's Ontological-Hysteric Theatre would seem particularly apt to the protagonist's condition as portrayed by the Wooster Group, even if Foreman's interest in classical psychiatry's hysterical syndrome primarily pertains to nineteenth century naturalist drama and its basic psychological triangles, which his work tries to open up (Foreman in Aronson: 135).

In LeCompte's version, Racine's neoclassical protagonist suffered from bourgeois neuroses. After all, Foucault has identified the bourgeoisie as a privileged locus of sexual repression (1998: 1-13, 120-127). As played by Kate Valk, Phèdre displayed an obsession with interior decorating, shoes, and clothes, all failing fetishistically to substitute for a deeper satisfaction. Some of the video footage on the house monitors guiding the performers' movement patterns (including the cropped images of Valk's feet) were derived from Buñuel's BELLE DE JOUR (1967), a movie set in the nineteen-sixties and revolving around the secret activities (dreamt and real) of a bourgeois woman in a maison close or brothel, disguised as a fashion house. Setting, costumes, and props of To You, THE BIRDIE! also possess overtones of a psychiatric ward. Phèdre appeared cooped up and under constant surveillance by the goddess Venus, her line markers were acting like wardens equipped with straightjackets, the spying and eavesdropping Enone (Sheena See) was wearing handcuffs, and a Talker (Scott Shepherd) expropriated and echoed Phèdre's voice from a control booth reminiscent of the Wooster Group's RUMSTICK ROAD (1977), not to mention the wire mesh covering the smaller upstage monitor like the bars of a prison window. Once again, it is Foucault who chronicled the historical development of hospitals into houses of care reserved for criminals and the insane, with the Great Confinement of the poor and mad in seventeenth century France marking a particularly important phase of this process (1988: 38-64; 1994; 1995). Granted, the cartoon-like effects in To YOU, THE BIRDIE!, of slamming doors reverberating on the speakers and an ear magically expanding onto the large, downstage monitor, at times turned the intrigues into those of French boulevard theatre, that bourgeois genre par excellence. One critic, however, judged the hunting chorus opening Euripides' HIPPOLYTUS »more at home in the world of Viennese operetta than Greek tragedy « (Walton: 133-134) - so there are precedents for the Wooster Group's clashes of style and genre in their treatment of this neoclassical material.

Still, no matter how risible the Queen's hysterics in To YOU, THE BIRDIE! occasionally became, her symptoms (varying from faintness, lack of appetite, shortness of breath, and neurasthenic irritability to sexual fantasies) also formed the disturbing effect of patriarchal medical diagnoses and therapies. An important case in point are the repeated purgings and douchings to which Phèdre was subject, related as they are to the alleged congestion of blood in the sexual organ, retention of uterine »humours «, and constipation, thought to result from stimulated yet ungratified sexual desire (Maines: 22-33, 52-53, 60). In the nineteenth century developed techniques of vulvar and colonic irrigation, even flogging with wet towels, complemented the manual massage and baths honoured since antiquity, as means of restoring circulation and evacuating excessive fluids. If these treatments, popular from Bath to Saratoga Springs, offered so-called hysterical and frigid women vicarious satisfaction through the orgiastic »hysterical paroxysm«, they simultaneously pathologized their sexuality and exonerated their male partners from any responsibility (Maines: 5, 8, 36-7, 72-81).

Apart from being amply documented in the medical literature since Hippocrates, such androcentric hysterisation is also manifest in Euripides' PHAEDRA. Unlike 
Racine's heroine, who poisons herself, Phaedra, in the absence of her husband, first starves, and then hangs herself in punishment for her unreturned love. She thereby confirms Plato's belief that the uterus of the hysteric (named after the Greek word for womb), whether crawling up into the chest and windpipe or full of unexpended $»$ seed «, suffocated the patient. Nineteenth century physiccians also subsumed anorexia under the hysterical syndrome (Maines: $8,24,130 \mathrm{n} 31$ ), and in one critic's interpretation of TO YOU, THE BIRDIE!, the scatological allusions (Phèdre's onstage peeing and defecation) suggested that repressing her devouring passion had led to an eating disorder, causing intestinal problems and physical weakening (Maurin: 210). During her confession to Enone, Valk's Phèdre almost choked on Hippolytus' name, as if it were a piece of food. By the same token, the Wooster Group could have invoked particularly feminine eating disorders like bulemia after the abundant meals served to the aristocrats at Louis XIV's court to symbolize his wealth. In an equally perverse manner, the hydrotherapy in To YOU, THE BIRDIE! personalizes and mirrors Versailles's spectacular fountains (Apostolidès: 101-104). After all, the expensive water works and banquets were complementary means of disciplining the aristocracy and »impressing « it into the Sun King's service.

Phèdre's regimentation in To YOU, THE BIRDIE! was compounded by the Talker, who spoke most of her lines from what looked like a movie studio's sound booth. This filmic impression was enhanced by the theatre production's occasional appropriation of camera viewpoints. When during Theseus' massage the blurred image of Willem Dafoe's face on the central flat-screen monitor suddenly went into focus, it was as if the camera, and with it the spectators, had been allowed into the glass-panelled room, whether sauna or Turkish bath. Bathing's traditional association with licit and illicit sexuality was further underscored by Theseus' fondling of a line referee's breast. LeCompte also had Phèdre confess her love for Hippolytus next to the pool.

The dramatic implications of the secret's paroxysmal spilling were enhanced by showing Séverine's fantasized flogging and gang rape by two coachmen in the Bois de Boulogne, the opening scene from Buñuel's BELLE DE JOUR, on the stage monitors. In this crucial intertext, the icy Séverine (Catherine Deneuve) becomes involved with Marcel (Pierre Clémenti), the younger charge of a Murcian gangster, Hippolyte (Francisco Rabal), who adds the kicks of a breached decorum, social disgrace, and vicarious criminality to her enforced sensual pleasure (Wood: 29-30, 32, 42). Hippolyte's Spanish provenance and the country's tauromachia ostensibly explain the setting for another fantasized scene of defilement, this time in a pasture full of bulls, introduced by a tableau parodying Jean-François Millet's painting, ThE ANGelus (1857-59) (Wood: 35, 49-50). With equal irreverence, Theseus' martyr-like poses in To You, THE BIRDIE! play off Martin Scorsese's THE LAST TEMPTATION OF CHRIST (1988), in which Jesus (Willem Dafoe), while suffering on the cross, imagines having sex with Mary Magdalene (Barbara Hershey). Just so, Séverine's defilement while she is tied to a pole calls forth Pasiphaë's coupling with the Minotaur. The incest at the heart of the mythical story is implied during the gangsters' first visit to the brothel. Since Marcel immediately claims Séverine, Hippolyte, out of generosity, makes do with the other two prostitutes, but not without taking a premature interest in Mme Anais's underage niece, who, as the daughter of Pallas, the brothel's maid, cannot avoid being confronted with the clients. Conversely, Marcel's eagerness to make love to Séverine is somewhat cooled by her tâche de naissance or birthmark, which in Dutch is also called a moedervlek or »mother's mark «. By the end of the movie, Marcel's obsession for Séverine (fed by 
her repeated inaccessibility and cool behaviour) has taken such proportions that it causes a falling out with Hippolyte, which indirectly leads to his death. No longer restrained by the father figure, Marcel shoots Séverine's husband Pierre (Jean Sorel) upon his arrival home and is shot in turn after a chase by the police. Or so it seems, since Séverine may have imagined this finale; whose chase conspicuously resembles that ending Jean-Luc Godard's A BOUT DE SOUFFLE (1960). And when Pierre gets up from the wheelchair to which the shooting seems to have confined him, the viewer cannot tell whether he is cured of his paralysis or was never paralyzed to begin with.

The neo-classical pretext does not allow for such eventual undoing of events or for an open ending. Upon learning of Phèdre's (fantasized) rape, Theseus rashly curses his son by asking Neptune to raise a sea monster, which causes Hippolytus' death by frightening his horses. The sea god obliges because of an earlier promise, and the power which this outstanding debt grants Theseus over his son is still mirrored in the control Marcel acquired over his surrogate father by once saving his life. In Euripides, however, Neptune's act confirms the god's mythical paternity of Theseus and thereby explicitly reasserts patriarchal rights in the face of Phaedra's and Hippolytus' infringement upon them, as does the father's absolution by the boy and Artemis. Racine's dying Phèdre still exonerates Theseus, who wishes the memory of her misdeed would die with her. But the dramatic emphasis shifts from the intimate parting of father and son to that of wife and husband. The latter's mourning for Hippolytus is even cut short with a rehabilitation of his beloved, Aricia, which LeCompte (after Schmidt) omitted, presumably because Theseus' recognition of her as his »daughter « all too obviously reduces the woman to an object of exchange, just as Helen had been a currency between Theseus and Peirithous.

The Wooster Group prolongs Racine's tentative shift of emphasis to Phèdre, also evident in his new title, by further problematizing her victimization, albeit in ambiguous and unprescriptive ways that provide no closure to the production. One preferred masculine strategy is to reclaim for women a Freudian Oedipal agency, in actuality or fantasy, personally or vicariously, by identifying with the male victimizer within the hierarchic patriarchal social intercourse. Venus' muscle-flexing from the recovered exposition of Euripides' HIPPOLYTUS, in this respect, hardly differs from that of Dafoe's Theseus when he is trying to discipline his apparently rebellious son. Equally befitting the strategy of inverting the patriarchal hierarchy is Phèdre's face to face confrontation with Hippolytus and her seizing his phallic sword upon which to immolate herself, whereas in the Greek play it is Enone who betrays her mistress's secret offstage. Both plays, however, as a corollary to the women's assumption of male prerogatives, feminize Hippolytus, who from the start is described and treated like a virgin waiting to be deflowered and silenced. In To You, THE BIRDIE! Ari Fliakos's skirt, which exposes his genitals during the opening scene with Theramenes (Scott Shepherd), is more than a historical touch, then. Like his nakedness during the confession scene, his exposure here turns a man rather than a woman into the object of the male and female spectators' voyeuristic gaze. LeCompte makes them conscious of this gaze by framing and mediating the men's genitals on the downstage flat screen monitor.

To all appearances, Buñuel's movie merely mirrors the stage situation. In the brothel Séverine is first made to look, and subsequently cannot prevent herself from looking, through a peep-hole in the wall at a male client's dealings with Charlotte. That this client is a gynaecologist (played by François Maistre) who is chastised by a female dominatrix doubles the gender inversion of the speculari- 
zation, and the latter's compulsiveness, as in the case of To YOU, THE BIRDIE!'s opening scene, makes the viewers aware of the movie theatre's nature as disciplinary viewing machine: a setup that forces people to look. True, when Séverine and Charlotte later bungle their role in the doctor's sexual charade, he disrupts the illusion and chides them. This proves that like a theatre director he still controls the theatrical situation and the women performing in it, much as in the external world male doctors control and objectify women's bodies (Evans 160-161). This is a point LeCompte, the ultimate director figure framing all others, already made in RUMSTICK ROAD, when she and Spalding Gray questioned the psychiatric treatment of his mother. By the same token Séverine willingly returns to her bourgeois prison after being forced by Mme Anais to enjoy the liberating heterosexual contacts missing from her wedded life with Pierre, another doctor.

Buñuel, however, complicates the picture with additional reactions to patriarchal victimization, like the more egalitarian relationships and possibly lesbian pleasures among the women in the brothel, pleasures intimated when Mme Anais kisses Séverine, or Valk, Sheena See to seal Phèdre and Enone's pact against Hippolytus. From the feminine perspective, the satisfaction which Séverine, and the viewers identifying with her, derives from heterosexual contacts may also involve a pre-Oedipal and pre-Symbolic Deleuzian masochism, relinquishing agency and control. This much is argued by Gaylyn Studlar with regard to the movies of Joseph von Sternberg, whose THE DEVIL IS A WOMAN (1935) is based on the same book by Pierre Louys as Buñuel's CET OBSCUR OBJET DU DÉSIR (1977) (Evans: 117$118,153)$. Several of Séverine's fantasies indeed attest to a masochistic submissiveness that need not be castigated in the Freudian sense of a pathological perversion or sadism introjected (Freud 1984: 415; Evans: 131). In the case of Phèdre, such perverted enjoyment would only collapse discipline's dynamic of punishment and gratification into one (Foucault 1995: 180).

Séverine's masochistic fantasies may or may not include her childhood molestation in a bathroom, the traumatic cause for her self-prostitution in Buñuel's source, Joseph Kessel's 1928 novel, which lacks any daydreams altogether. The bathroom setting certainly helps to account for the hydrotherapeutic treatment of Phèdre's hysterics in To YoU, THE BIRDIE!. The postulated trauma, however, marks the revolution Freud caused in the two thousand five hundred year old history of hysteria, even if during his career he, too, prevaricated with regard to the actual or fantasized nature of this trauma (Maines: 44-45). So does Buñuel, now making Séverine's fantasies look real, now giving away the game (Wood: 45-47). LeCompte, too, plays tricks on her audience, when leaving open whether Valk relieves herself on stage or pretends to. If the director is here playing on the illusionism of traditional narrative film and the popular trompe l'oeil of Racine's baroque era, she is also aided by the transgressiveness of late twentieth century performances and art in which the body and its excretions have been used as legitimate material. And ever since the surrealists and Freud, fantasies should be included as another, less material product of lived experience, granted that Buñuel balked at the manner in which Freud's socially repressive psychology and psychotherapy tried to resolve the complexities and irrationalities of the human psyche (Wood: 57-58), and that LeCompte presumably recoils from the androcentric bias of Freud and some surrealists alike (Suleiman: 15-16, 124).

In the last resort, the filmic and theatrical levelling of fantasy and reality in Belle De Jour and To You, THE BIRDIE!, like that of art and life, undermines the absoluteness of fictional events and their constitutive role with regard to the gen- 
dered identity of the characters submitted to these events, just as Racine's text is opened up again by Schmidt's performative view of translation and LeCompte's framing of it with Euripides. To the extent that Séverine's and Phèdre's identities are shown to be permeable, conditioned by unpredictable fantasies like any other reality, the notion of a coherent individual psychology is exposed as a repressive social construct similar to the age-old clinical typology of hysteria. Like the brothel Séverine attends from two to five in the afternoon, her mind proves a performative space where fragments of different selves interact. It is an open house rather than a psychiatric ward, prison, or maison close. So, too, with the Wooster Group's intermedial and intertextual To YOU, THE BIRDIE!, which dissolves the integrity of Racine's PHÈDRE to demonstrate its social and historical construction and to expose the patriarchal forces at work in it.

\section{Literature}

Apostolidès, Jean-Marie (1981): Spectacle et politique au temps de Louis XIV. Paris: Editions de Minuit.

Aronson, Arnold (2000): American Avant-Garde Theatre: A History. London: Routledge.

Deleuze, Gilles (1991 [1967]): »Coldness and Cruelty«, Trans. Jean McNeil, In: Masochism. New York: Zone Books.

Euripides (1996): Hippolytus. In: Alcestis and Other Plays. Trans. John Davie, Introd. and Annot. Richard Rutherford. Harmondsworth: Penguin.

Evans, Peter William (1995): The Films of Luis Buñuel: Subjectivity and Desire. Oxford: Oxford UP.

Foucault, Michel (1988): Madness and Civilization. Trans. Richard Howard. New York: Random House.

Foucault, Michel (1994): The Birth of the Clinic: An Archeology of Medical Perception. Trans. A.M. Sheridan Smith. New York: Random House.

Foucault, Michel (1995): Discipline and Punish: The Birth of the Prison. Trans. A.M. Sheridan. New York: Random House.

Foucault, Michel (1998): The Will to Knowledge. The History of Sexuality, vol.1. Trans. Robert Hurley. Harmondsworth: Penguin.

Freud, Siegmund (1962 [1896]): »The Aetiology of Hysteria«. In: James Strachey/ Anna Freud (eds.): Complete Psychological Works, vol. 3. London: Hogarth Press, 189-208.

Freud, Siegmund (1984 [1924]): »The Economic Problem of Masochism«, In: James Strachey and Albert Dickson (eds.): On Metapsychology, The Pelican Freud Library, vol. 11. Harmondsworth: Penguin Books, 409-426.

Kiger, Jennifer (1999): »Liz Diamond: Facing the Monster«. In: Arthur Holmberg (ed.): The Lively ART. Chicago: Ivan Dee, 246-249.

Langworthy, Douglas (1993): »Wordschmidt«. In: American Theatre, Sept., 16-20.

Lawrenson, T.E. (1957): The French Stage in the XVIIth Century. Manchester: Manchester UP.

New Larousse Encyclopedia of Mythology (1968) Introd. Robert Graves. London: Hamlyn.

Maines, Rachel P. (1999): The Technology of Orgasm: Hysteria, the Vibrator and Women's Sexual Satisfaction. Baltimore: Johns Hopkins UP. 
Maurin, Frédéric (2004): »A Case of Belated Recognition: The Wooster Group in France«. In: Johan Callens (ed.): The Wooster Group and Its Traditions. Brussels \& Bern: P.I.E.-Peter Lang, 203-216.

Suleiman, Susan Rubin (1990): Subversive Intent: Gender Politics and the AvantGarde. Cambridge: Harvard UP.

Studlar, Gaylyn (1988): In the Realm of Pleasure: Von Sternberg, Dietrich, and the Masochistic Aesthetic. Urbana: Illinois UP.

Walton, Michael J. (1984): The Greek Sense of Theatre: Tragedy Reviewed. London: Methuen.

Wood, Michael (2000): Belle de Jour. London: British Film Institute. 


\title{
Towards a Rich Theatre: Where Does the Wooster Group Take Technology? Where Does Technology Take Theatre Performance?
}

\author{
SERAP ERINCIN
}

- »What keeps us watching this one man twenty-four hours a day - eating, sleeping, working, sitting for hours in contemplation?«

- »It has to be the reality. We've become tired of watching actors give us phony emotions, bored with pyrotechnics and special effects. [...] there's nothing fake about Truman himself. No scripts, no cue cards. It's not always Shakespeare but it's genuine. That's how he can support an entire channel« (TRUMAN SHOW - Niccol: 85-86).

Two decades ago, in his preface to BREAKING THE RULES, Peter Sellars said that Wooster Group is »inventing theatrical vocabulary that ten and twenty years from now will become the lingua franca of a revivified American Theatre (Savran 1986: xvi). In his recent essay entitled ThE DEATH OF THE AvantGarde, David Savran states that the last wave of the avant-garde is epitomized by the Wooster Group. Company director Elizabeth LeCompte's treatment of technology as an inseparable element of the production process has resulted in new approaches to staging, performing/acting, directing, and building the relationship between the spectators and the performers. The Wooster Group utilizes technology in building techniques to create a task based performance.

Wooster Group's main objective on stage is to do nothing that is not real. The performers are aided by high-tech devices the whole time both during the rehearsals and performances. People do not live with these high-tech devices the whole time in »real life «. It may seem contradictory, but it is partially their use that allows the Wooster Group performers »to do nothing that is not real«. However, the use of these high-tech devices such as the wireless in-ears, microphones, plasma sets and TV monitors enables the performers to be »real in the moment «, and to really grasp the essence of a theatrical event, in that it is a live event. The more the performers depart from performance techniques that aim for a >realistic $<$ performance, the closer they are to being >real< during their interaction with the spectators in the performance space. Though a considerable part of the American avant-garde uses technology in their productions to enhance the spectacle or contribute to the plot. In the examples discussed here, on the other hand, the Wooster Group uses technology not to impress the spectators with visual or audio effects, or to add to the plot, but as an aid to fostering spontaneity. Before their European tour with POOR THEATRE, in June $2005^{1}$, the ensemble was working on a new scene. Its primary material was a tape of one of the earliest rehearsals of POOR THEATRE, made when they were working with a trainer on Grotowski's techniques called the plastiques. In

1 By this time, POOR THEATRE had already been performed over two different seasons. 
June 2005 the group were rehearsing a new piece based on HAMLET. Many of the rehearsals at this time involved the performers working on scenes from a taped production of HAMLET starring the British actor Richard Burton. ${ }^{2}$ The performers tried to recreate the scenes in the performance space through the use of in-ear devices and monitors. In traditional Western rehearsal methods, a company usually starts by reading the play text, which continues until the text is memorized. One can say that the Wooster Group's first steps with a new play are quite similar to this; the company very often uses classic texts, but their interaction with these texts is not always in the form of reading from paper - there is often much film. Instead of only reading the words off a page and interpreting them in an »actorly « way, the Wooster Group members read the bodies of the performers in the footage and try to recreate them in their actual timing in the performance space. They do not look for new forms. LeCompte stated several times that she is not at all interested in creating new form (personal communication, May 9, 2005). Instead the company puts together the different texts which almost always results in the creation of a new text since they never merely imitate a single text. Often the result is an intercultural performance practice where different texts and forms from a variety of disciplines, cultures, geographies, time periods and traditions are juxtaposed and are »read « by the spectators by means of the bodies of the performers. Thus the final image that reaches the spectators is actually a reflection of the Wooster Group performers who have themselves looked at the reflection of different materials.

Throughout the rehearsal process when the performers are »imitating « a certain scene, they are in fact trying to get to the heart of the dominant perspective in the source work. In other words, capturing the soul of the »imitated scene « is far more important then presenting a replica. While they were rehearsing scenes from HAMLET, the performers had screens around them, situated so that wherever they turned they would easily see a screen. Depending on their positioning the technicians flip the image on the screen so that the performers do not get disoriented between their left and their right as they move. They also have in-ear devices, through which they hear the soundtrack of the footage. During the rehearsals the performers are not expected to learn their lines perfectly. For LeCompte, this is not important. She wants the performers to grasp the spirit of the source performers, and let their own sounds out even if they are becoming completely incomprehensible. Kate Valk, one of Wooster Group's performers, says that they are trying to copy the source performers in the way someone goes to the museum and copies a master piece in order to have an idea what this master piece is about.

$\mathrm{K} . \mathrm{V} \gg$ The person I am copying in Acropolis, Rena, she is very different than me, [...] I am mushy, she is like a rod, she is like a lightning bulb, I am like a flower, so it is very very different, I resonate from here (she hits her chest), she resonates here (shows her head), she is very different and I had a very hard time, $[\ldots]$ it is not about us being as good as them, it is about a third thing, you have the thing and then you have us attempting to get in that somehow, which is the third thing, which is the performance to watch, so there is so much room in this piece for me.«

2 In 1964 Richard Burton starred in a very successful Broadway production of HAMLET at the Lunt-Fontanne theatre. For the film production of this performance, the crew deliberately performed in the style of a dress rehearsal, but performed in front of a live audience. The production was directed by Sir John Gielgud. The actors are in street clothes instead of period costumes, and the sets are minimal. 
S.E. »Why is it interesting to you? Why do you enjoy performing that? «

K.V. »Because at this point we're very facile with it, it's just what we do, we like all this stuff, it's fun« (Kate Valk, personal communication, May 2005).

The Wooster Group's rehearsal process is very dynamic. Every rehearsal is recorded and can become source material for later rehearsals and performances. In one POOR THEATRE rehearsal, before a new European tour, the company watched a video of one of their own rehearsals from the research period for the production. LeCompte deliberately went back to that time and wanted the company to look at themselves being introduced to the work of Grotowski. Looking at this video the performers found a lot of elements were hilarious to them. However, they also found an element of the company's experience that they wanted to incorporate in the production two seasons later. The trainer of the plastiques - the physical exercises Grotowski designed for training performers - used a red suitcase in his work with the company in order to resonate their own experience at that stage. LeCompte brought the red suitcase back to the rehearsal/performing space. At that point she had a very precise idea of what she wanted the scene to look like. She explained to them »we are trying to imitate what really was the awkwardness of it «.

There is a section in POOR THEATRE when the performers improvise westerns and dances. The material for the section was first created by Johan Collins and it is all live. Collins has a collection of sounds on a sampler that he has generated over the course of the rehearsal process from To You THE BIRDIE. He uses these sounds as a kind of vocabulary. So during the show, the performers are making movements and sound based on what they see on these monitors and what they hear. What they do is totally improvised because the technicians Geoff Abbas and Iver Findlay are >feeding < material to them. This creates different dynamics of interaction with each other and with the performers. The choices of the material they decide to use are affected by the performers and by the material each technician uses. Geoff, for instance, can see one of the performers Ari Fliakos fall on to the floor as he is copying a video that Iver »fed « in one of the screens. Seeing this happen, Geoff may decide to make the sound of someone falling or a glass breaking. Or he may see a performer doing something with his hands and he may >feed in< a gunshot sound into the performance space. The spectators never directly see most of the visual material. They may hear some, but not all of it. The performers on the other hand are interacting with the technology they are surrounded by. LeCompte expects them to respond immediately so that the gap between thought and event is avoided. In traditional acting, the actor's body moves according to the choices they make cognitively. It is as much an intellectual process as an intuitive one. Since the brain is engaged also on an intellectual level, and commands the body what it is supposed to do, there is a lag time between the thought and the actual action taking place. In LeCompte's technique the lag time between the perception of the audio and video is much more minimal, much more like an involuntary or reflex reaction. In POOR THEATRE, the performers are like instruments that technology uses in order to channel AKROPOLIS through them. The performers of course think that they copy the material, but it is a physical thinking process rather than an intellectual process. In this type of interaction the Wooster Group performers are much more similar to a dancer than to a traditionally trained actor. The performers think through their bodies.

According to Sam Louise Gold, the Wooster Group performers use technology as a kind of substitute for the inner spiritual life that Grotowski's performers 
attempt to reach. Gold says »with the exception of ten words over the course of the whole evening, everything that was said by a performer in POOR THEATRE was in their ear while they said it, and they are not in control of what is in their ear«.

K.V.: »... so I can be something else, I am not very good at being myself.«

S.E.: »Interesting, Liz says that the screens will make you do everything for the first time. Right? Then, $[\ldots]$ you have done Poor Theatre so many times $[\ldots]$ so is it still immediate response?«

K.V.: » ...we can do it without the screens but our consciousness would be different, we'd be in control of it «.

S.E.: »So you are not in control of it when there are the videos? «

K.V.: »Yeah, because you can't go before or after, you have to try and get it.«

S.E.: »But still you know it so well, that your body knows it, right?«

K.V.: »It is different; it is just different that's all I can tell you.«

In the second part of POOR THEATRE, LeCompte wished to incorporate a text by Max Ernst however she wanted a more abstract interpretation rather than a direct reference of the Ernst text. This was achieved with the use of technological devices. During rehearsals, Sheena See, the performer, narrated Ernst's words on a microphone. The other performers meanwhile were »fed « with See's narration of the Ernst text through their in-ears and recited what they heard into their microphones which »fed « Sheena's in-ear. The feed into Sheena's in-ear alternated consecutively between different recitals from the performers. The group repeated this about a hundred times and then chose one version to be the material played into Sheena's ear during the performance. So, during the performance, See/Sheena would hear Fliakos, Shepherd, Valk or other performers reciting the Ernst material from her own recital. Thus the awkwardness on the stage was achieved. During the performances See/Sheena also views films made by the group on different monitors. These films feature the group recreating an Ernst film/piece, in which See/Sheena is playing Ernst. So, during the performances, See/Sheena sees herself playing; Ernst as well as a video of Liz on another monitor. Through technological devices, she changes the words eventually so that they are taken away from Ernst and they become about LeCompte.

S.E.: »Sheena was sort of like Liz in that scene [...]. It was so clear to me that I thought maybe she had a tape of Liz in the ear ...«

S.L.G: »That is another fun little technical element. There is a very small LCD monitor that was pointed at Sheena during the show and it was playing a loop of hours of Liz directing. ... over the course of a few weeks and she would get up and talk to everybody and she was being filmed, I don't think even she knew it, and then that footage was played so that Sheena could every once in a while do something that Liz could do.... Sheena got a lot of pleasure in imitating Liz, so she was encouraged ... one day in rehearsal Liz said >you gotta be more like me<, and Sheena said >I can't make it up, we don't make things up, play something for me< and Liz said >do we have any footage of me? « (Sam Louise Gold, personal communication, May 20, 2005).

During the epilogue of POOR THEATRE, the performers once more recreate a scene from Grotowski's production of AKROPOLIS. They are surrounded by monitors where the last scene of the AKROPOLIS is shown while they hear a sound score of 
the tape through their in-ears. However, the physical score of the actors in this scene is not an exact imitation of the physical score of the actors in AKROPOLIS. There were two other sources for the physical score of the performers. The first one was the material from the earlier parts of the performance, from both the westerns and the Forsythe dances, that the video and the sound technicians would mix in to the footage from AKROPOLIS. In that way AKROPOLIS was »infected « by the dance improvisations from Act 2 of POOR THEATRE and the western improvisations from the second half of the show. The second source was a video of the Wooster Group performers re-creating the last section of AKROPOLIS. At the end of AKROPOLIS the performers enter the crematorium. The Wooster Group re-creates this scene by using a trap door in the aisle within the audience. They wound up going into the hole in the floor. The performers were recorded during a rehearsal. This recording was flipped in reverse and played on the flat panel screen in the performance space, so it seemed as if the flat panel was only a piece of glass that reflected what the performers were doing as they were going into the hole.

After the performers go into the hole the flat panel screen, that is now facing the spectators, shows again the video of AKROPOLIS featuring the spectators getting up and leaving. All that is heard is the spectators leaving. Unintentionally, the spectators standing up and leaving the Wooster Group performance are copying the spectators in the tape of AKROPOLIS. These spectators have now become performers in the AKROPOLIS footage, or the flat panel screen is simulating the spectators in the Performing Garage. LeCompte is now in fact directing the spectators in the Performing Garage. The spirit of the AKROPOLIS video is captured. The performers have disappeared from the performance space. The spectators, feeling a little awkward, start moving. That is all that is left happening both in the video and in the Performing Garage. The relationship between the big flat panel monitor and the spectators is similar to that between the performers and the monitors surrounding the performance space. In certain moments of the performances, it is unclear whether the Wooster Group performers copy the mediatized performers, or the media is reflecting the live performers' action. LeCompte creates a similar ambivalence for the spectators exiting the garage as they look at the bare stage with the video of spectators exiting the Polish Laboratory Theatre.

LeCompte occasionally brings in images from the company's collective past. The peak of her heartfelt desire is evident throughout POOR THEATRE, which is a performance that has been built on the loss of many things. It is a piece about the feeling of loss. It is also a piece about the Wooster Group, a reflection of LeCompte's journey, survival and feeling of loss within the group. What makes Wooster Group the Wooster Group is its director Elizabeth LeCompte. She herself also acknowledges the fact that, if she left, the company would end. POOR THEATRE was made at a time when LeCompte was experiencing many losses of lifetime relationships. A picture can easily be drawn just by looking at a production from Three Places IN Rhode Island. The members of the Wooster Group in that picture were very close to LeCompte not only professionally but also on a personal level. Of those Ron Vawter and Spalding Gray have both died at a relatively young age, one died from an incurable illness, the other committed suicide. Libby Howes is away after being institutionalized, LeCompte's relationship with Willem Dafoe, another founding member of the company, has ended. Of the earlier members Paul Schmidt and Michael Kirby are also dead and Peyton Smith is far from New York. The ghosts in the garage are not only those of Jerzy Grotowski, Billy Forsythe's company and Max Ernst. They are also the ghosts of the founding members of the 
Wooster Group who are present in LeCompte's consciousness when she is creating new work with mostly a new generation of performers from different backgrounds devoted not only to the Wooster Group.

Just as the moon reflects the light from the sun, in POOR THEATRE, performers reflect the light of the performers of Grotowski. When we look at Wooster Group performers we see the reflections of Grotowski's performers. But just as how the moon merely reflects the light of the sun and does not give us neither warmth nor energy, the work of Wooster Group and the work of Grotowski - or other source texts used - are as different from one another as day and night. The images we see, the simulacra, change form depending on how much the performers are looking at and how much they reflect. In many moments of the copying, The Wooster Group performers may be reflecting exactly the same light. The effect of this light on the performance and spectators is very different, though. The spectators build a different connection to the members of the Wooster Group copying, than the relationship between the spectators and performers of AKROPOLIS. The substantial material and the distance are very different.

Before the company started using copying so much in creating their scores, LeCompte was still looking for ways to stop performers from trying to be natural in the performance space. Most of the time she came up with task oriented commands. She did not want to invent situations for each performer. The use of the technological devices discussed here let her reach the pinnacle of her active experimentation on task-based performance.

\section{Interviews of author with:}

Fliakos, Ari, May 2005, Soho, New York.

Gold, Sam Louise, 20 May 2005, Performing Garage, New York.

LeCompte, Elizabeth, May and June 2005, Soho, New York.

Valk, Kate. May 2005, Soho, New York.

\section{Literature}

Aronson, Arnold (2000): American Avant-Garde Theatre: A History. New York: Routledge.

Bottoms, Stephen J. (2004): »Poor Theater: A Series of Simulacra«, Theatre Journal - Volume 56, Number 4, December, 693-695.

Brantley, Ben (2005): »Critic's Notebook: A Troupe Tailor-Made for an Age of Anxiety«, New York Times, 28 February 2005.

Callens, Johan. Ed. (2005): The Wooster Group and Its Traditions. Brussels: Peter Lang Publishing.

Dunkelberg, Kermit (2005): »Confrontation, Simulation, Admiration: The Wooster Group's Poor Theatre«, The Drama Review 49:3 (2005) 43-57.

Gray, Spalding (1978): »Playwright's Notes (Rumstick Road)«, PAJ, 3, 2, 87-91. Gray, Spalding/Elizabeth LeCompte (1978): »Rumstick Road «, PAJ, 3, 2, 92-115.

Grotowski, Jerzy (1968): Towards a Poor Theatre. New York: Routledge.

LeCompte, Elizabeth (1978): »An Introduction (Rumstick Road)«, PAJ, 3, 2, 81-86.

Marranca, Bonnie (2003): »The Wooster Group: A Dictionary of Ideas «, PAJ, 25, $2,1-18$. 
Niccol, Andrew (1998): Truman Show. Newmarket Press: New York.

Savran, David (1986): Breaking The Rules The Wooster Group. Ann Arbor, Michigan: UMI Research Press.

Savran, David (2005): »The Death of the Avantgarde«, The Drama Review 49.3, $10-42$.

Shank, Theodore (2002): Beyond the Boundaries: American Alternative Theatre. University of Michigan Press. 



\title{
Filmic Photogénie in the Theatre
}

\author{
SIGRID MERX
}

Between 2003 and 2005, the Flemish theatre director Guy Cassiers produced four performances based on Marcel Proust's novel A LA RECHERCHE DU TEMPS PERDU. Since my research focuses on the influences of (live) video technology on the representation of time in theatre, the work of Cassiers, characterized by a sophisticated use of video technology, may provide interesting insights in the role technology plays in staging Proust's novel, which touches upon temporal experiences and ideas, in particular, the process of remembering.

Cassiers shares with Proust an interest in representing the subjective world. They both experiment with creating a perceivable inner world of thoughts, dreams and sensory experiences. They also use cinematographic techniques, such as zooming in and out and close-ups, to represent and express this inner world. This paper will introduce the filmic concept of photogénie as a useful analytical tool, which sheds light on how and why Cassiers uses these techniques in his Proust performances to represent the subjective world of the main character, Marcel.

During early French film debates, photogénie was one of the most widely circulated concepts. Filmmaker Louis Delluc first introduced the concept, which had origins in the field of photography, and used it to describe how the film camera showed reality in a new way. Delluc believed that >the real< (or what he also termed »the factual « and »the natural «) was the material of film, but that it was transformed by the camera and the projection screen into something new, without becoming any less real (Abel: 110). The camera de-familiarized the familiar and presented the spectator with a new perspective on reality. It is important to realize that photogénie, as understood by Delluc and many other participants in the film debate, assigns the aesthetic and transformational power >of looking at things in a new way< not to the artist, but to the technological device. Photogénie has to do with the possibility of the camera creating and installing a perspective, even before cinematographic techniques are implemented, such as editing, framing and camera positioning, to create perspectives for a possible narrative.

The French film debate originated in early $20^{\text {th }}$ century Paris and was centred around questions regarding the specificity, function and effects of film and the aesthetic possibilities of film as art. Filmmakers and critics participated in this debate, primarily conducted in newspapers and magazines. The question of how to represent modern temporality - particularly aspects including velocity, memory and simultaneity - with cinematographic means was one of the recurring topics in the debate. A group of French impressionists, including important advocates such as Riciotto Canudo, Emile Vuillermoz and Germaine Dulac, dominated the debate. The French impressionists, also referred to as »The First Avant-Garde« or »Narrative Avant-Garde «, felt that film should become a site for experimenting with and sharpening the expression of modern experiences, specifically, the subjective experience. In particular, the photogenic powers of film would instil a new mode of 
observation. These French impressionists were seeking for >a subjective cinema $<$ as an alternative to classical narrative cinema. They considered film the ultimate medium for expressing the subjective, which, in their opinion, was on the brink of elimination due to such modernization processes as industrialization and urbanization.

Almost a century later, Cassiers has made similar remarks regarding theatre. He feels that in this mediatised world, the subjective perception should be safeguarded. He views theatre as the threshold of the sensory experience, an intermedial stage where various media can come together, each in a different way, to address and titillate the senses. The aesthetics of both the French impressionists and Guy Cassiers, although occurring during different time periods, can be characterized as predominantly lyrical, focusing on the representation of an inner, subjective world full of memories, desires, needs, anxieties, thoughts and sensory experiences. They are less interested in the representation of an outer world, characterized by unfolding coherent actions based on the principles of causality, continuity and linearity. These latter principles, according to the French impressionists and Cassiers, do little justice to the dynamics of the subjective world. They both assign a special power to the technology of the camera in creating this subjective perspective in art. As Germaine Dulac stated in 1924 during one of her film lectures,

»What is more mobile than our psychological life with its reactions, its manifold impressions, its sudden movements, its dreams, its memories? [...] The cinema is marvellously equipped to express these manifestations of our thinking, our emotions, our memories « (Abel: 310).

For the motto of one of his performances, Cassiers borrows a quote from Lewis Caroll: »Learn to look at everything as if you are mentally cross-eyed.« During interviews and lectures, he never stops emphasizing his purpose of looking for a point of view, or language, which puts the individual memories of the spectator into another perspective, searching for that special moment in which their perception of reality shifts. In the case of Cassiers, the photogenic powers of the camera and film projection are explicitly employed to implement this shift and activate the audience's senses.

The French impressionist Louis Aragon closely ties the concept of photogénie and the idea of creating a new mode of observation to the use of the close-up. By zooming in on objects, the photogenic qualities of the camera isolate, enlarge and re-contextualize these objects, freeing them from their function within the narrative and exposing them as independent poetic objects, or bearers of modern beauty (Abel: 111). As such, these objects stimulate the senses of the spectator.

The extremely large close-up is one of the most powerful elements of Cassiers' artistic language. In one of his Proust performances, the camera zooms in on the face of the actress who is playing the role of the mother of Marcel. The zoom stops when the whole frame is filled with the sight of her cheek. Showing an image in extreme close-up disconnects the object from what is outside the frame. A head from which one can only see a cheek loses its meaning as a head, as well as its meaning as a cheek. Instead, it is viewed as a mere landscape of skin. The image becomes texture, material, and independent. It transforms into a new sensory image. In the case of real-time video, this creates an exciting tension between the live - the physically present actor - and the mediatised - the extreme close-up. 
The relationship between the projection and the physical object of projection is always very meaningful in Cassiers' performances. Their simultaneous presence on stage shifts the audience's focus to the differences between them. As Delluc states, the film image as a photogenic image forms a new reality. In Cassiers' Proust performances, the fact that the projection is different from what is shown on stage transforms what is on the stage, offering different perspectives. In so doing, it addresses the larger Proustian theme. In the case of the extreme close-up of Marcel's mother, Cassiers uses the zoom-technique to literally reduce the role of the mother to that of her cheek.

In his novel, Proust describes how every night, the young Marcel would wait for his mother to come upstairs to give him the opportunity to kiss her goodnight. $\mathrm{He}$ is eager for her to come to his room, but at the same time, fears the moment that he may kiss her because it means that she will soon leave him alone again. For the young Marcel, his mother is primarily the cheek to be kissed. The image of the cheek, together with the physical presence of the performer, expresses how Marcel experiences his mother. Together, with their intermedial interaction, they create an internal, highly subjective perspective.

Regarding the novel of Proust, Gilles Deleuze distinguishes between three different worlds, each of them having its own principles of representation. The World of Love contains characters who tend to love the image that they have formed of their loved ones. These images are coloured by subjective wishes, fantasies and anxieties, and have become disconnected from reality. The World of the Salon is all about showing off - showing imaginations, pretensions, and the outer image of one's self to the world. Proust characterizes the salon as an exchange of images without any content; it is inhabited by, as he says, »the dead«. Finally, The World of Art transforms reality, not into a fixed image, but into vivid, lively images which stimulate the senses and enable the audience to regain lost time.

These three worlds and their modes for creating images and transforming reality are all represented in the Proust performances of Cassiers with the use of video. By showing video images of the women Marcel loves, while the same women are on stage, for example, in PROUST 1: THE SIDE OF SwANN, the audience is forced to see that these video images do not represent the physically present women. Instead, these images, such as the case of the close-up of the cheek, are highly subjective images of Marcel's longing. By playing a pre-recorded movie without sound and letting the physical actors dub the movie on the spot, PROUST 3: THE SIDE OF CHARLUS allows the audience to view how the salon is a world full of imitation and make-believe. The actors mimic their virtual doubles in almost every detail. They do not create an original image of themselves. Instead, they take upon themselves a role already filled for them. In doing this, they demonstrate how presenting one's self in the bourgeois world means nothing more than any acting, according to fixed conventions.

Finally, Proust 4: THE SIDE OF MARCEL demonstrates how a projection of Vermeer's painting VIEW AT DELFT, referred to in PROUST 1, 2 AND 3, is digitally manipulated. In a series of deconstructive movements, the realist image of the city is transformed into one big yellow screen. Earlier in the performance, Marcel Proust sees this painting at an exhibition and is so stunned and touched by this beautifully painted piece of yellow brick wall that he would have traded his life for it. Here, art is presented as a pure sensory experience that stimulates the senses and imagination and does not offer fixed images. 
Cassiers not only uses video projections and cameras to create a subjective perspective, he also simultaneously stages technology within the live performance, visible to the audience. Not only does the camera possess transformational (photogenic) powers, but the live performance does as well, making the technological process of transforming reality and different ways in which this process can manifest itself visible on the stage.

In the work of Cassiers, the photogénie of the video projection is not only active as a process, but staged within a theatrical context. It therefore demonstrates a process for producing meaning. The theatre spectator is forced to reflect on these characteristics that induce meaning, whereas in most films, the spectator is immersed in the illusion of the diegetic world. The film spectator is not aware of the photogenic potential of the camera to create a new perspective and a new way of observation, but is aware of the live performance, with its capacity to stage other media and develop such levels of awareness among the theatre audience.

The call for reflection in the Proust performances is strongest with the simultaneous presence of the physical subject and its projection. The spectator is challenged to compare the two and constantly shift between perspectives. During this act of comparison, differences come into focus and call for a more reflexive attitude on the part of the spectator, who is put in a position where he or she must actively assign meaning to these differences, thus taking up an active, creative role in which he or she fills gaps between live and mediatised performances, using his or her own imagination. The imagination of the spectator in this sense is endowed with the same transformational power as the camera; it is able to create a new, subjective perspective on reality.

One thing observed at the very onset is that photogénie assigns aesthetic and transformational power to look at things in a new way in relation to camera and projection screen technology. How can this concept help an audience understand why and how Cassiers employs video in his performances? It can be concluded that Cassiers uses the possibilities offered by video to visually create a dynamic inner world of subjective experiences on the theatrical stage. At the same time, Cassiers assigns the exact same transformational power of film to a live performance. Although he uses the photogenic qualities of the camera to create images that, when interacting with the physically present performers, demonstrate how people always construct subjective images of the world around them, thereby transforming it, he does not limit this transformational power to the technology of the camera. The technological potential of the camera to create a subjective perspective functions primarily as a tool and points to one of the dominant themes of the Proust performances: how individuals deal with life by constructing their own version of reality.

Sometimes, as in the case of the guests of the salon, this construction is meant to keep up appearances. At times, as in the case with Marcel's impressions of the important women in his life, this construction is not realistic, but is instead based on desire and longing. Finally, as is the case with art, sometimes the artist's construction of reality invites the spectator to take a new, fresh look at his or her own version of reality. In the work of Cassiers, technology plays a crucial role in this invitation. Cassiers employs video and video projections to titillate the senses and stimulate his audience, allowing them to become more aware of not only how a camera transforms reality and produces meaning, but also how their own inner experiences affect their subjective construction of reality. 


\section{Literature}

Abel, Richard (1993): French Film Theory and Criticism: Volume I 1907-1929. Princeton: Princeton UP.

Deleuze, Gilles (1964): Proust et les signes (3d ed.). Paris: Presses Universitaires de France. [English Translation: Proust and Signs. Trans. Richard Howard. New York: George Braziller, 1972]. 



\title{
> LITERATURTHEATER < MIT DER VIDEOKAMERA? Zu STEFAN PUCHERS INSZENIERUNG VON SHAKESPEARES $\gg$ OTHELLO $\ll$ AM HAMBURGER SCHAUSPIELHAUS
}

\author{
HAJO KURZENBERGER
}

Kaum eine Aufführung auf deutschen Bühnen verzichtet derzeit auf Videokamera und Videoscreen, kaum eine Klassikerinszenierung kommt ohne Bildschirm und Filmeinspielung aus. Mit Vehemenz setzen die Regisseure den vielbeschworenen Iconic turn auf dem Theater um bzw. in Szene. »Kaum fällt auf, dass der Abend am Ende zu möglicherweise 80 Prozent auf dem zentral gehängten Videoscreen stattgefunden haben wird «, schreibt die taz über Castorfs szenische Romanversion von GIER NACH GOLD (Haas 2004), für die er zwei Kameramänner mitten im Bühnengeschehen platziert hat, die dessen Live-Aufnahmen liefern. Ist die alte Schaubühne »ein Paradies für Voyeure « geworden, wie Franz Wille (2000) über Castorfs ENDSTATION AMERIKA schreibt, wo dem Zuschauer dank Videokamera auch nicht die Intimitäten des Badezimmers verborgen bleiben. »Ein Paradies für Voyeure «diese Formulierung ist mehr als eine schnelle Pointe. Sie verweist auf die Verführung und die Macht der Bilder, wie sie unsere medialisierte gesellschaftliche Kommunikation zunehmend umfassender bestimmen. Es gibt also hinreichend Material und gute Gründe, mit der Kamera auf der Bühne variantenreich und medienreflexiv umzugehen, auch medienkritisch in dem Sinne, mediale Normierung und ästhetische Konvention zu durchbrechen und damit bewusst zu machen.

Wechselt man vom gesellschaftlichen in den theatergeschichtlichen Kontext, wird der Paradigmenwechsel anders beschreib- und sichtbar. Dem Literaturtheater folgt im Medienzeitalter ein Theater der Bilder. Eine logozentrische Dramaturgie, die seit der Aufklärung und dem 18. Jahrhundert Wort und Sprache auch auf der Bühne favorisiert, ja absolutiert hat, wird gleichsam mundtot gemacht. An deren Stelle agieren nicht nur im sogenannten postdramatischen Theater Körper und Kamera. So lautet in gebotener Kürze und Verkürzung der erste Befund. Er ist deshalb von Interesse und weiter zu denken, weil er eine mediengeschichtliche Grenze markiert. Wo das Literaturtheater vom Bildertheater unterwandert oder erweitert, verdrängt oder bereichert wird, sehen und erleben wir mediale Differenzen, entwickelt sich ein besonderer und genauerer Blick auf die Tradition und das Neue, auf die ästhetischen Konventionen und Innovationen der beteiligten Medien. Das vorgegebene Thema ist also am Beispiel des Theaters vor allem intermedial zu begreifen und zu erörtern.

Ich möchte dies konkret am Beispiel einer Aufführung tun, die nicht nur beim Berliner Theatertreffen 2005, der Leistungsschau des deutschsprachigen Theaters, Furore gemacht hat: Stefan Puchers Inszenierung von Shakespeares OTHELLO am Hamburger Schauspielhaus. »Sex und Videos: >Othello< eröffnet Berliner Theater- 
treffen« titelt die Kritikerin Corina Kolbe (2005) und gibt mit der folgenden Unterzeile eine Kurzcharakteristik der Veranstaltung: »Othello als glitzernder Entertainer: Stefan Pucher versetzt in Berlin Shakespeares Drama um Eifersucht, Wahnsinn und Mord ins Medienzeitalter «. In der Süddeutschen Zeitung ist aus gleichem Anlass zu lesen, dass fün nach Berlin eingeladene britische Jungregisseure »ausnahmslos begeistert « von dieser Shakespeare-Inszenierung gewesen seien. Sie vergleichen Puchers Medienästhetik mit dem heimischen Zugriff auf Shakespeare:

»Bei uns gehen die meisten Regisseure weniger intellektuell an die Texte heran; sie nehmen sie wörtlich und fühlen sich dem social realism verpflichtet. Das deutsche Theater dagegen versucht, Dramentexte zu verdichten und die Essenz in Bilder zu übersetzen« (Menden).

Gehen wir dieser Behauptung nach. Ist die von Pucher freigesetzte Bilderflut, sind die »bühnenfüllende[n] Projektionen«, die das Geschehen angeblich bildlich verdoppeln und verdreifachen, eine »Verdichtung « des Shakespeare-Textes (Burkhardt)? Oder geht es in dieser Bilderfülle, die ein anderer Kritiker als »Divertimento « (Henrichs) beschreibt, gar nicht um die sogenannte Essenz des Textes? Meint >Verdichtung < hier vielleicht eher seine multimediale Weiter- oder Neuformulierung, vor allem eine Shakespeare-Transformation ins Visuelle? Um diese Fragen diskutieren zu können, wäre erst zu klären, welche Funktion die Film- und Videobilder in der Aufführung übernehmen. Vorweg schon ist zu konstatieren, dass es sich bei den Ein- und Überblendungen um bewegte Bilder handelt, die in und neben den szenischen Bühnenvorgängen platziert sind. Hinzu kommt: Puchers Shakespeare-Bebilderung ist vielfältig. Zwar gibt es Bildwiederholungen, aber nur innerhalb jeweils neuer Bildsequenzen. Und kaum eine der Video- und Filmeinblendungen hat dieselbe Funktion und Wirkung. D.h., sie stehen immer in einem eigenen, besonderen Zusammenhang, im spezifischen Kontrast oder in spezifischer Analogie zu den von Shakespeare entworfenen Handlungs- und Figurenkonstellation, nicht zuletzt zum Sprechen der Bühnenfiguren.

Ich beschreibe hier die ersten sechs Bildeinblendungen und mit ihnen sechs verschiedene Bildfunktionen und Bildwirkungen der Inszenierung.

Wenn Jago im Zuschauerraum das Spiel eröffnet und sich dem Publikum erklärt, er diesem seine Rivalität zu Cassio offenbart und seinem »Hass auf den Schwarzen«, der den Rivalen bei der Beförderung vorgezogen hat, erscheint Othellos Bild überlebensgroß über Jago und der gesamten Bühne: Othello ein junger Militär im Kampfanzug mit Ami-Käppchen. Sein Blick verheißt wenig Gutes, macht deutlich, wer hier beansprucht der Chef zu sein. Am Ende von Jagos Rede löst sich Othellos Standbild auf, gleitet der schwarze General weg in einen Vorhangschlitz, der auch ein Militärzelt sein könnte. Mit der Wiederkehr des Motivs und der Formulierung »Ich hass den Schwarzen« in Jagos Schlussmonolog am Ende des ersten Aktes taucht Othellos Bild erneut auf. Es monumentalisiert Othello jetzt in noch unheimlicherer Bildvariante: das Gesicht erscheint nun in schwarzweiß, mit wechselndem expressiven Ausdruck, entsetzt aufgerissenen Augen, die dem eines Tieres zwischen Angst und Aggression gleichen. Sieht der Zuschauer hier das von Jago zum Phantom verzerrte Bild Othellos? Ganz offenkundig: Othellos Bild sitzt Jago im Nacken. Der Regisseur hat, diese Metapher wörtlich nehmend, Othellos Bedrohung zur Bildtotalen gemacht. >Essenz $<$ heißt hier also die optische Vergrößerung und visuelle Dynamisierung eines Seelenzustandes, der die Ambiguität des Bildes zu einer Frage an den Zuschauer nutzt: handelt es sich um 
ein Abbild Othellos und seiner Emotion oder kommen hier diejenigen seines Widersachers Jago zum Ausdruck und zur Erscheinung?

Die zweite Bühneneinblendung dient weniger einer visualisierten Psyche, der Jagos oder der Othellos, als vielmehr einer visuell beschleunigten Dramaturgie. Desdemonas Vater hat Othello beim Dogen verklagt, ihm seine Tochter verhext und geraubt zu haben. Wo bei Shakespeare nach des Dogen Befehl »Holt Desdemona her!« Othello weitschweifig die Geschichte seiner jungen Liebe erzählen darf und muss, bis die Geliebte herbei geschafft ist, wird das optische Herbeizitieren im Computerzeitalter durch Maus-Klick in Sekundenschnelle vollzogen. Die junge Dame erscheint per Video vielgesichtig, farbig und schwarz-weiß, den Kopf um $180 \mathrm{Grad}$ verdreht oder mit blonder Sexy-Perücke versehen. Diese Desdemona ist zugleich multilokal, d.h. an vielen Orten abgelichtet, seltsamerweise auch auf einer Probebühne und in einer Bildfolge, die erst viel später im Verlauf der Aufführung sich als halb private Eifersuchtsszene zwischen ihr und Othello, der Schaupielerin und dem Schauspieler entpuppt und wichtig wird. Eine rasche Bild- und Ortsfolge also, die die Verschiedenheit eines Gesichts zeigt: ein visuelles Angebot an den $\mathrm{Zu}-$ schauer, das ihn in seiner Deutung zwischen Bewerbungsvideo der Darstellerin oder Figur und den vielen Bildvarianten schwanken lässt, die dem verliebten Othello von ihr im Kopfe spuken mögen. Die beschleunigte und beschleunigende Bildfolge mündet in >richtiges< Theater, erzeugt eine Bild- und Realitätsverschiebung, wenn Desdemona leibhaftig und in Normalzeit als Bühnenfigur auftritt, in braver Schuluniform eindeutig Kontur zeigt und bühnenreal ihre Liebe und Hochzeit öffentlich bekennt, um sich schließlich mit ihrem Ehegemahl in einem Love-Song $\mathrm{zu}$ vereinigen: »Its all because of you «. >Verdichtung < heißt hier: rasante Bildvarianz, dann der zweimalige Wechsel der Realitätsebenen und der Darstellungsstile: vom Video ins Theater, vom Theater in den Pop-Song.

Die Filmeinblendung Nummer drei bedient klassische Dramaturgie: Sie ist Mauerschau und Vorausschau in einem. Freilich formuliert sie sich nicht in der linearen Abfolge und Klarheit eines verbalen Boten- oder Seherberichts. Im Gegenteil: Othellos Aufbruch nach Zypern, den bevorstehenden Krieg gegen die Türken, den Untergang ihrer Flotte, das bevorstehende Militär- und Besatzerleben auf der Insel formulieren Bilder und Textschnipsel in der Manier eines Video-Clips. Er ist gleichsam die visuelle Version des hörbaren Rufs »Attacke! «: Kriegsbilder wie von CNN mischen sich mit solchen aus Piraten- und Seefahrerfilmen. Der visualisierte Kriegstaumel wird durch Schrifteinblendungen wie Zypern, Cypros etc. scheinbar verortet und geordnet. Dazwischen geschnitten sind die erotischen Verheißungen des Soldatenlebens auf der Insel: bäuchlings räkelt sich eine nackte Frau (Desdemona?), tanzt ein nackter Cassio, dazwischen die neuen Herren Zyperns in Siegesposen oder die gehauchten guten Wünsche Desdemonas »Beschütz Othello! «. Diesmal zeigt der Übergang des Videos in die Bühnenrealität nicht mediale Differenz, sondern spielt mit der medialen Angleichung von Video und Theater. Die Filmposen der Männer werden von den bühnenrealen der Theaterfiguren gedoppelt, beide Medien verschwimmen ineinander, was wiederum fließend übergeht in den Pop-Song von James Brown »Hey hey hey. I feel all right «. Der Feldherr des Zypern-Unternehmens rockt als Vor- und Eintänzer der Meute zur Siegeshymne. >Essenz< heißt bei diesem Beispiel: bewegte Bildcollage, die Schrift, Ton und Bild übereinander schichtet, die Heterogenes verschränkt, die einen Bilder- und Textstrudel erzeugt, der in die bühnenreale Irrealität einer Überblendung mündet. Diese Siegesfeier ist ein Schatten- und Gespenstertanz in einem medialen Zwischenreich. 
Die vierte Videoeinblendung und Bildfunktion ist im Gegensatz dazu zunächst einmal keine der Kunst. Sie basiert auf dem gesellschaftlichen Realgebrauch von Videokameras. Othello mischt sich überlebensgroß bedrohlich als Videoüberwacher in den Streit, zu dem Cassio provoziert und verführt wird und schickt seinen Leutnant per Life-Einschaltung in die Wüste. Der riesige ins Insel-Bühnenbild gesetzte Videoschirm fungiert als »Intercom, als visuelle Gegensprechanlage aus Othellos Schlafzimmer« (Müller 2004). Privates und Öffentliches wird so provokant gemischt. Während die Soldateska lärmt und prügelt, vergnügt sich Othello mit Desdemona. Aber auch der Privatraum ist ein öffentlicher, der schwarze General so demonstriert die Überwachungseinblendung - ist omnipräsent, die gelangweilt vernachlässigte, halbnackte Desdemona im Bildhintergrund wird zum Accessoire und Statussymbol dessen, der überall seine Gewalt ausüben kann. Nicht nur für Othello gilt: Wer die Bildmedien besitzt und zu handhaben weiß, hat die Macht. $>$ Verdichtung< heißt hier aktuelle Neukontextualisierung von Shakespeares Drama. Gesellschaftliche, militärische Macht wird im Zeitalter multimedialer Telekommunikation zum Bedrohungspotenzial unkontrollierter, willkürlicher Entscheidungen.

Auch dort, wo die Bilder im ästhetischen Kontext entgleisen, ist in Puchers Inszenierung Gefahr im Verzug. Der fünfte hier zu beschreibende und zu unterscheidende Bildgebrauch ist ein sich zunehmend steigerndes Bilder-Chaos, in das der Regisseur sein Insel-Zypern und die dieses repräsentierende Drehbühne versetzt. Eine zunehmend visuelle Verunklarung zeigt, dass Jagos Intrige sichtbare Früchte trägt (»Irgendwas bewirkt das schon«). Die Figuren werden jetzt zu Überblendungsmustern, zu Ornamenten in einem (scheinbar) selbsttätigen Videomechanismus und einem Theaterspiel, das jetzt vor allem durch die Drehbühne in Gang gehalten wird. >Verdichtung < heißt hier visuelle Undeutlichkeit, die der Undurchschaubarkeit des Handlungsverlaufs und des Intrigengeschehens entspricht.

Die sechste und vorerst letzte Bildfunktion und Bildwirkung spielt mit der scheinbaren Intimität des Privaten und Darstellungskonventionen heutiger Videoästhetik. Das erste >Privat-Video< folgt auf jene Szene, in der Jago Othellos Verdacht und Eifersucht kräftig angeheizt hat (III,3). Es ist schwarz-weiß und zeigt die abgeschminkten Schauspieler quasi als Privatpersonen, seltsamer Weise aber im Handlungszusammenhang des Stücks: eine besorgte Nicht-Desdemona (»Ist dir nicht gut? «) verbindet einen schmerzgebeutelten Nicht-Othello mit dem ominösen Taschentuch die Stirn. Wenig später eine zweite halbprivate Einblendung, die die Theater-heute-Kritikerin Barbara Burckhardt wie folgt beschreibt und auswertet:

»Und alles dreht sich, dreht sich im Kreise zu Popmusik und Videos, die auch einmal einen noch ungeschwärzten Othello auf der Probe am Tisch mit einer ungestylten Desdemona zeigen, Momente von Authentizität und Verletzlichkeit, die nur noch mit der Handkamera zu haben sind. Denn im wirklichen (Bühnen-)Leben ist alles Show « (Burckhardt 2004).

Ob die medialen Unterschiede der Videodarstellung, die Pucher kennt und nutzt, den Gegensatz von authentisch und Show behaupten wollen, scheint mir eher fraglich. Zu sehr sind die Privat-Videos einer BIG-BROTHER-Ästhetik nahe, wird der Text gerade im Eifersuchtsprobenvideo häufig banalisiert (»Geh weg, geh weg, weg!«). Was den Regisseur offenbar reizt, ist feste Zuordnungen der Darstellung aufzulösen. Die Figur wird im Video privat, wird zur Person des Schauspielers und spielt doch das Theater Shakespeares weiter, wenn auch mit heutigen AlltagsSprechkürzeln. Statt dem szenischen oder gefilmten Ergebnis dargestellter Eifersucht also ein Probenvideo über Eifersucht mit Beobachtern im Hintergrund und 
einer Bierflasche auf dem Tisch. Intimität wird hier eher behauptet, Authentizität ist dank wackelnder Handkamera ein Darstellungstrick. Die Show, ob privat oder öffentlich, ist überall, echte Gefühle sind eine Schimäre, die auch das privateste Video nicht einfangen oder herstellen kann.

Hier sind wir im Zentrum nicht nur des Pucherschen Bildkonzepts, sondern auch seiner OTHELLO-Interpretation. Sie gipfelt in einer spektakulären Shownummer des Titelhelden, der mit höchstem Körpereinsatz und Körperrisiko eben dies erzählt: Gefühl ist Pose. Bis zur völligen körperlichen Verausgabung rappt und stürzt der Othello Alexander Scheers die Bühnenklippen Zyperns hinunter, die von den eigenen weit aufgerissenen Augenpaaren videoüberblendet sind. Angetrieben wird er von einem Eminem-Song. Das ergibt ein völlig neues Eifersuchtsdrama. Der Pop-Song dient dem Showstar Othello zur Vergrößerung seines Seelenzustandes, der Pop-Song entzieht ihm aber auch das Dramatische, gibt der rasenden Emotion Form und Konvention. »Othellos Eifersucht bleibt Pose « schreibt Peter Michalzik. In der Tat, hier regiert der Narzissmus des Schmerzes. Als Publikumsbeifall die Show-Nummer unterbricht, brüllt der Schauspieler »Nein - ich bin ja noch nicht fertig! « und fällt lustvoll erneut über die Klippen und in seine eigenen Abgründe. Puchers Othello stürzt hier im wörtlichen und übertragenen Sinne ab in die »Leere am Grund der Liebe« (Michalzik 2004). Das ist so heutig wie die ganze Realitätskonstitution dieser Video-Theater-Bühne.

Sie mag uns zum Schluss zu einigen grundsätzlicheren Feststellungen und Überlegungen führen. Bilder sind in Puchers Inszenierung vor allem Menschenund Körperbilder, die durch genau kalkulierten Wechsel des Bildmediums Video/Film und dem herkömmlichen Theater nicht nur mehrfach codiert und damit zu Fragen an den Zuschauer werden, sonder auch immer in Bewegung bleiben. Bild heißt hier nie »reiner Ausschnitt mit sauberen Rändern«(Barthes: 95). Auch »erlischt« im Bild nicht der »szenische Vorgang«, wie Kotte dies generalisierend behauptet. Im Gegenteil: der szenische Vorgang wird in der Interaktion zwischen lebendigem Theater und reproduzierendem Bildmedium zusätzlich dynamisiert und intensiviert. Auch wenn grundsätzlich gelten mag, dass in der (medialen) »Bildwerdung « »die Leibhaftigkeit« verschwindet und mit dem Bild etwas hergestellt wird, was grenzenlos speicherbar ist (Kotte: 256), zeigt die von Pucher genutzte intermediale Konstellation von Theater und Video, wie stark gerade dadurch Körperlichkeit und Präsenz des Darstellers hervortreten, d.h. wahrnehmbar und bewusst werden. Und dies geschieht keineswegs einseitig zugunsten einer absoluten Echtheit und Wahrheit des Körpers und seiner Liveness, die von essentialistischen Theaterverteidigern gern zum Garanten der Wirklichkeit und der Besonderheit von Theater erklärt werden. Erst im medialen Wechselverhältnis, in der, wie wir gesehen haben, klaren und unscharfen Trennung des traditionellen und des bildelektronischen Mediums, werden Mensch, Figur und Körper einander ähnlich und einander unähnlich-fremd, werden sie vielgestaltig und unüberschaubar. In Puchers Video-Theater wird jene Spanne vermessen, die sich auftut, wo Mimesis und Darstellung im Zeichen der Tradition und moderner Technologie zugleich stehen (vgl. Leeker: 292). Thematisiert werden mediale Differenzen und mit ihnen grundlegende Fragen des Wahrnehmens und Sehens. Das verbindet sich in Shakespeares OTHELLO mit dem Grundproblem der Titelfigur, der Sein und Schein, Wahrheit und Lüge nicht unterscheiden kann, der sich im Wahn verliert und erst mit der Ermordung Desdemonas eine unwiderrufliche Realität schafft. Zentral gesetzt ist in dieser OTHELLO-Inszenierung nicht nur der venezianische Mohr als heutiger schwarzer Show-Star. Im Zentrum steht hier auch die Gegenwartserfahrung des heutigen 
medialisierten Zuschauers. Denn das Bedrohende und Unkontrollierbare, also Aggression, Sexualität, Tod, werden mit Hilfe Shakespeares und der elektronischen Bildlichkeit einem unabschließbaren Fixierungsversuch und misslingenden Kontrollprozess unterzogen. Bei Puchers zentraler Vergegenständlichung und medialer Verbildlichung des Bedrohlichen gibt es keinen Stillstand. So wie sich die Körper der Darsteller nicht in feste Bilder fügen oder in ihnen aufgehen, ist es mit der Erfahrung der Bildproduzenten und jener der Zuschauer. Sie transferieren die von Shakespeare angestoßene Erfahrung in heutige elektronische Bilder und Zeichen. Diese Bilder und Zeichen produzieren eine Erfahrung, die die gegenwärtige mediale anthropologische Verfasstheit mit einem alten Dramentext aus dem 16. Jahrhundert in Beziehung setzt und abgleicht, aber nicht zur Deckung bringen will oder kann. So ist auch zu erklären, dass sich der scheinbare Primat des Visuellen dieser Inszenierung oft wieder verflüchtigt in Stimmungen und Dynamiken, die spürbar sind und wirksam werden, die in ihrer Intensität und Energie dabei aber Anleihen machen (müssen) bei einer Popkultur, die die großen Menschheitsfragen, Liebe, Eifersucht, Wahnsinn und Mord, noch auf dem Programm und im Sound haben.

Wo aber bleibt das Wort? Es ist, wie gezeigt, in dieser Inszenierung keineswegs verloren, wenn damit der Geist Shakespeares gemeint ist. Sucht man es als wörtliches, werkgetreues Zitat, trägt es - reduziert zwar, aber nicht sinnentstellt die szenisch-mediale Handlung. Die Inszenierung behandelt Sprechen und Dialog nicht nebenbei, stellt sie allerdings auch nicht in den Vordergrund. Mit einer Ausnahme: Jago ist in Puchers Inszenierung auch medial Othellos Antagonist. Ist dieser vor allem Bild-Körper-Medium, nicht nur in seinen hervorgehobenen ShowEinlagen, bleibt Jago immer der Mann der kalkulierten Sätze. Er beherrscht den von Shakespeare vorgegebenen Text und die in ihm eingesponnene Intrige mit dem sanften Lächeln des modernen Zynikers. Zwar sucht auch er, wie alle anderen Figuren, mit seinen Worten beständig den direkten Kontakt zum Publikum, ist telling hier auch immer showing, im Sinne des zitierenden Zeigens eines Sprachgestus oder einer gesellschaftlich geformten Sprechhaltung. Dass Jago während der ganzen Aufführung nie bildfähig wird, medial also der Schrift zugeordnet und verhaftet bleibt, fällt auf. Dass sein ungutes verbales Tun im Stück- und Aufführungsverlauf mörderischen Erfolg hat, müssen wir aber wohl kaum als medienkritischen Kommentar zur Inszenierung lesen. 


\section{Literatur}

Barthes, Roland (1990): Der entgegenkommende und der stumpfe Sinn. Frankfurt/M.: Suhrkamp

Burckhardt, Barbara (2004): »Aus weiter Ferne, ganz nah«. In: Theater heute 11/2004, S. 7.

Burkhardt, Werner (2004): »Vertrautes Chaos«. In: Süddeutsche Zeitung, 18.09.2004.

Haas, Alexander (2004): »Wir sitzen alle in der Plusfiliale«. In: taz, 07.05.2004.

Henrichs, Benjamin (2005): »Theater? Theater! Shakespeare gegen Westerwelle«. In: Süddeutsche Zeitung, 14.05.2005.

Kolbe, Corina »Sex und Videos: >Othello< eröffnet Berliner Theatertreffen «. In: netzeitung.de, http://www.netzeitung.de/kultur/337455.html (07.05.2005).

Kotte, Andreas (2005): Theaterwissenschaft. Eine Einführung. Köln: Böhlau.

Leeker, Martina (1995): Mime, Mimesis und Technologie. München: Fink.

Menden, Alexander (2005): »Das ist die Berliner Kluft«. In: Süddeutsche Zeitung, 20.05.2005.

Michalzik, Peter (2004): »Bruder Othello«. In: Frankfurter Rundschau, 15.09.2004.

Müller, Tobi (2004): »Schuhwichse als cooles Kriegswerkzeug«. In: Tagesanzeiger, 23.09.2004.

Wille, Franz (2000): »Am Kapitalismus leiden heißt lustiges Leiden«. In: Theater heute 10/2000, S. 12. 



\title{
Medial ReAl oder: Die ÖKonomie der Präsenz ALS PRÄSENZ DER ÖKONOMIE
}

\author{
KATHARINA PEWNY
}

Medien gelten den Kulturwissenschaften als »Beglaubigungssiegel« für Realität: Realität wird als real wahrgenommen, sobald sie medial vermittelt ist (Welsch: 238). Gilt dies auch für Aufführungen der Performing Arts (Theater, Tanz und Performancekunst), die - um mit Philip Auslander zu sprechen - ihrerseits medialisiert sind? Auszugehen ist von einem komplexen Verhältnis von medialisierter Realität und Medialität des Theaters. Dieses zu besprechen, unternimmt der vorliegende Beitrag anhand von Rimini Protokolls SABENATION und von Jochen Rollers PERFORM PERFORMING. Zuvor aber sei der diskursive Kontext der Frage nach dem Erscheinen von (medialisierter) Realität im Theater hergestellt.

An deutschen Theatern finden Debatten wie etwa eine Podiumsdiskussion, die »Radikal sozial. Wie kommt das Soziale auf die Bühne? « titelt, statt. ${ }^{1}$ Veranstaltungen wie die genannte reagieren auf die deutliche Anhäufung von Inszenierungen in deutschen Theatern, die sich mit sozialer Hoffnungslosigkeit und Armut auseinandersetzen. Beispielhaft aus dem Hamburger Umfeld wären zu nennen: Thomas Manns Roman BudDENBROOKS, von John van Düffel in eine Bühnenfassung gegossen und von Stephan Kimmig mit Schwerpunkt auf den »sozialen Abstieg « der reichen Kaufmannsfamilie inszeniert (Gutjahr 2006). Die preisgekrönte Dramatikerin Anja Hilling stellt in PROTECTION (Thalia Theater 2005) zwei Obdachlose (sie erfriert, er überlebt), behinderte Schwule und eine traumatisierte türkische Frau auf die Bühne. Andreas Kriegenburg inszeniert erfolgreich WHITE TRASH, ebenfalls am Hamburger Thalia Theater (2004/2005). WHITE TRASH basiert auf Interviews mit Jugendlichen, die in »gesellschaftlichen Randgebieten « leben: »Wir waren schon als Kinder Scheiße« ist ihr Slogan (siehe Programmheft).

Welches Verhältnis von Realität und Theater aber wird in den diesbezüglichen Diskursen hergestellt? Während die Fragestellung der Podiumsdiskussion »Wie kommt das Soziale auf die Bühne?« ein lineares Verhältnis von vorangehender $>$ Realität< (des Sozialen) und nachfolgender Abbildung, oder nachfolgendem Erscheinen auf Theaterbühnen suggeriert, führen rezente theaterwissenschaftliche Theoreme und Entwürfe weg vom >Theater der Repräsentation< hin zu der >Ereignishaftigkeit $<$, >Präsenz $<$ und dem >Präsens $<$ des so genannten $\gg$ postdramatischen $«$ Theaters (Lehmann). Vorauszusetzen ist daher kein unproblematisches Verhältnis von $>$ Realität $<$ und $>$ Abbildung $<$ oder medialer $>$ Beglaubigung $<$. Auszugehen ist vielmehr von einer Präsenz anderer Realitäten ${ }^{2}$ auf der Ebene theatraler Verfahrensweisen: Der Einsatz von >Authentizität $<$ und $>$ Selbstinszenierung $<$ (Matzke) und die

1 So der Titel einer Podiumsdiskussion in den Berliner Sophiensälen im November 2006. Zu nennen ist weiters die Tagung der Dramaturgischen Gesellschaft »Wie bringt man die Realität ins Theater?« in Basel 1998.

2 Ich setze den Terminus »andere Realität« in Differenz zu der Realität des Theaters ein. 
Reflexion des Verhältnisses von Alltag und Theater (Hentschel: 145) in den Performing Arts sind beispielsweise auf der Ebene der Verfahrensweisen anzusiedeln. Die letztgenannten Phänomene verdichten die Dynamik des infinite loop zwischen den Performing Arts und anderen Realitäten, von dem ich mit Richard Schechner ausgehe. Das Bild des infinite loop erlaubt erstens das Bedenken von Medialisierung und Medieneinsatz als Phänomene, die in der >unendlichen Schleife< zwischen Theater und anderen Realitäten zirkulieren, ohne die Medialität des Theaters mit der Medialität anderer Realitäten gleichzusetzen. Zweitens setzt es Gleichzeitigkeit des Zirkulierens in beide Richtungen (von Theater zu den anderen Realitäten, und vice versa) voraus, ohne von Linearität (der Abbildbarkeit, die einem >Original< folgt) auszugehen.

\section{Rimini Protokolls SABEnAtION}

SABENATION wurde 2004 auf dem Brüsseler Kunsten Festival des Arts und in Folge auch in Braunschweig, Rotterdam, Berlin, Essen und Hamburg gezeigt. Hier - ebenso wie in KREUZWORTRÄTSEl BoXENSTOPP, DEUTSCHLAND 2 und DEAD LINE - arbeitet das Regie-Kollektiv Rimini Protokoll mit dem Einsatz von >Authentizität< oder, wie Miriam Dreysse titelt, mit dem Auftreten von »Spezialisten in eigener Sache «. Auf der Bühne sind sechs Performer/-innen, die als ehemalige Angestellte der belgischen Sabena Airlines präsentiert werden und ein Mädchen, die als Adoptivtochter der Performerin auftritt. Je mehr SABENATION fortschreitet, desto mehr Platz erhalten >Zeitungsausschnitte < und >Fernsehinterviews $<$, die auf eine Leinwand projiziert werden und die Kündigungen der Sabena-Angestellten zu dokumentieren scheinen. Scheinbar individuelle Biografien, Karriereverläufe und Zukunftsängste werden medial in Erscheinung gebracht. Einem dieser anscheinend $>$ dokumentarischen< Teile - über ihre Entlassung, die die 12.000 Sabena-Angestellten durch das Fernsehen erfahren - entstammt auch der Untertitel der Performance: »Go home and follow the news «. ${ }^{3}$

\section{I.1. Moderne Identitäten als medial vermittelte Nachträglichkeit}

Der Einsatz von Medien in SABENATION startet nicht mit den genannten fernsehähnlichen Projektionen, sondern mit einem Medium älterer Natur: Auf einer Textrolle auf der Bühne sind zu Beginn von SABENATION die Identitäten der Performer zu lesen: Ihre Namen, Geburtsdaten und Geburtsorte, ihre Sabena Roll Numbers, ihre Berufe und die Eckdaten ihrer Beschäftigungsverhältnisse sind dort notiert. In einem zweiten Schritt werden ihre Passfotos (vier identische Fotos, die wie Passfotos angeordnet sind) auf die Leinwand im Bühnenhintergrund projiziert. Die genannten Insignien der symbolischen Ordnung der europäischen Nationalstaaten und moderner Arbeitswelten (Name, Passfoto, Geburtsort, berufliche Eckdaten) sind Ausgangs- und Fluchtpunkte einer Historie, die auf den Niedergang der kolonialen, nationalstaatlichen Ökonomie verweist. ${ }^{4}$ Sie sind ausschließlich medial vermittelt und stellen daher auf der Bühne das her, was durch die Präsentation als vorausgesetzt erscheinen wird: Die Eckdaten europäischer Identitäten. Medien

3 Den Sabena-Mitarbeiter/-innen wurde ihre Entlassung von der Firmenleitung wie folgt begründet: »Just go home and follow the news «.

4 Sabena Airlines wurden in den 1920er Jahren für Flüge in den Kongo, der damals belgische Kolonie war, gegründet. 
leisten zu Beginn von SABENATION demnach den >performativen Akt< der Instituierung eines staatlich getragenen Rechtssystems, das sich in der Analyse als solcher (als performativer Akt) erweist: Die vorgeführten Identitäten sind weder vorauszusetzen noch werden sie ausschließlich durch die Authentizität des Auftretens der Performer/-innen hervorgebracht, sondern durch die Performanz rechtsstaatlicher Institutionen erst aufgerufen (Butler: 175).

Nach der Identitätssetzung zu Beginn werden die Berufskarrieren der Performer/-innen inszeniert. Kris Depoorters anfängliche Setzung als Sabena-Angestellter (in der Textrolle) wird gleich darauf gebrochen, denn ebenfalls in der ersten Szene markiert er seine täglichen Wege als Arbeitsloser im Haus auf dem Bühnenboden. In der zweiten Szene wird ein Satz im Format einer printmedialen Kurzmeldung auf den Screen projiziert: Kris' Frau fordert ihn auf, das Haus mehr zu verlassen: »Seitdem ist er mehr mit den Hunden unterwegs. «In demselben Format findet eine Rückblende in Kris' Vergangenheit als Skilehrer statt. Später beginnt seine jüngste Vergangenheit als Arbeitsloser, der sich Krawatte um Krawatte umbindet, wobei jede Krawatte für ein erfolgloses Vorstellungsgespräch steht. Mittels dieser »kleinen Geschichten oder Snapshots « (Brandstetter: 116-135) werden insgesamt fünf Mal während der Performance die Arbeit bei Sabena Airlines und ihr Verlust inszeniert. Diese lose Anordnung der medialen >Snapshots<springt zwischen Vergangenheit und Gegenwart und wirkt damit jeglicher Linearität der Erzählung entgegen: Ihre spezifische Historizität stellt sich über das Verfahren der Fragmentierung und des Durchrüttelns biografischer Linearität, die sich in einer ebensolchen (linearen) Berufskarriere abbilden könnte, her. ${ }^{5}$ Die Reihenfolge der eingesetzten Medien hingegen wiederholt die historische Abfolge ihrer Entstehung von der Textrolle über das Printmedium bis hin zum Fernsehformat. Die als individuell erscheinenden, national gerahmten Momentaufnahmen des Scheiterns linearer Berufskarrieren werden durch die Mimesis der Mediengeschichte linear geordnet. Die theatrale Doppeltheit von Durchkreuzung und (medialer) Instituierung von Linearität ist jedoch nicht die einzige Auseinandersetzung mit dem Prinzip der (linearen) Abfolge, die in SABENATION geführt wird. Sehr offensichtlich ist diese Auseinandersetzung in der Präsentation des Bankrotts von Sabena Airlines.

\section{I.2. Die Einwanderung der Leere in den Screen oder Sabenas finale Bruchlandung}

Sabena Airlines sterben mehrfache Tode und erstehen insgesamt fünf Mal im Laufe der Aufführung wieder auf, bevor sie am Ende eine finale Bruchlandung in Gestalt eines kleinen transparenten Flugzeugs vollführen werden. Auf dieser Ebene ist ein Kreislauf von Vernichtung und Wiederkehr inszeniert, der Slavoj Žižeks Theorie der Inszenierung von zwei- oder »mehrfachen « Toden in kulturellen Artefakten von Shakespeare bis Hitchcock (Žižek: 70) aufruft. Innerhalb dieses Zyklus findet eine markante Veränderung statt: Je öfter er durchlaufen wird, desto mehr wandern Sabena Airlines in den Bildschirm ein und desto entfernter erscheinen sie von den Körpern der Performer/-innen, an denen sie zu Beginn noch haften.

In der fünften Szene berühren und beschnuppern die Performer Sabena-Handtücher, T-Shirts und Jacken. Sie reichen die Kleidungsstücke weiter und betonen deren sinnliche Qualität. Gleich darauf fliegt erstmals ein Flugzeug über die Bühne in Richtung des Bildschirms. Das Fluggeräusch und die Armbewegung eines Per-

5 »Spezifische Historizität« meint die gegenwärtig auch im europäischen Raum diagnostizierte »Zerstörung der Mittelschichten« (Bologna). 
formers zeigen die Flugbahn an. ${ }^{6}$ Kurz danach sind wiederholt Flugzeuge auf dem Bildschirm zu sehen und nicht mehr mit den Körpern und Körperbewegungen der Performer/-innen verbunden.

Zum letzten Mal wird die Projektion der Flugzeuge auf den Screen eingesetzt, um einen (>echt< wirkenden) Motivationsfilm für Sabena Mitarbeiter abzuspielen. Der Titelsong des Films ist: »Welcome now «. Damit wird eine Gegenwart gesetzt, die die Abbildungen von Sabena Airlines in die Vergangenheit verweist: Von nun und für die verbleibende Zeit der Aufführung wird der Bildschirm leer bleiben. Sabena Airlines erscheinen nur noch ein Mal, als transparentes Spielzeug-Flugzeug verdinglicht, auf der Bühne, um eine kleine Runde zu fliegen und schlussendlich eine finale Bruchlandung zu vollführen. Das »signifikante Netz«, laut Žižek (75f) notwendig für die symbolische Tötung eines »verlorenen Objektes«, spannt sich zwischen dem leeren Bildschirm und dem transparenten Flugzeug auf. Dieses »signifikante Netz« entsteht demnach nicht ausschließlich oder primär über erzählte Inhalte (von der Kündigung, etc.), sondern wie besprochen durch den Einsatz der Projektionsleinwand, des Werbefilmes - kurz, von Medien. Die Leere der Leinwand am Ende von SABENATION spricht weniger für das Einmünden in unvermittelte Bühnenpräsenz, sondern für eine Gegenwart (»Welcome now«), die so medialisiert ist, dass sich der sichtbare Einsatz von Medien erübrigt hat. Die - mit Guy Debord gesprochen - »pseudozyklische Zeit« der gelungenen Verkörperung und Entkörperung, der mehrfachen Wiederauferstehung und des finalen Absturzes von Sabena Airlines ist durchbrochen, der Bildschirm leer, die Performance kann enden. Am Ende von SABENATION - dem Ende moderner Erwerbsarbeitsverhältnisse - setzt PERFORM PERFORMING mit einem aktuellen Konzept an: mit dem Konzept der prekären Kunst- und Kulturarbeit.

\section{Jochen Rollers Perform Performing - die mediale Erzeugung von Tanzen als Arbeiten}

PERFORM PERFORMING ist eine dreiteilige Soloarbeit Jochen Rollers, die u.a. 2005 im Berliner HAU gezeigt wurde. ${ }^{7}$ Der Begriff des >Performens < erscheint hier in seiner Mehrfachbedeutung des Aufführens, des Handelns und des Erbringens von Leistung. PERFORM PERFORMING steht in dem Kontext der Auseinandersetzungen um prekäre (ungesicherte) Arbeitsverhältnisse, die in den vergangenen Jahren in vielen europäischen Ländern stattfanden, und hat Roller zahlreiche Einladungen verschafft: PERFORM PERFORMING ist eine gelungene Performance, denn sie macht, was sie sagt - sie verbessert den ökonomischen Status des Performers. Auf dieser Ebene sind Theater und andere Realitäten unauflöslich verschränkt, sie treffen sich, metaphorisch gesprochen, in dem Kreuzungspunkt des infinite loop (siehe oben).

Der prekäre Status von Tanz(kunst) als Arbeit wird in den ersten beiden Teilen »No money, no love « und »Art Gigolo« der Trilogie im Wechsel von Erzähl- und Bewegungsszenen aufbereitet. Unterfinanzierung der Tanzkunst und Arbeit bei

6 Das >Flugzeug< fliegt im Laufe der Aufführung zwei Mal quer >über< die Bühne und in den Screen. Diese Flüge verleihen der Leinwand eine spezifische Räumlichkeit, deren Penetration durch die >Flugzeuge $<$ als Mimesis des 11.09.2001 gelesen werden kann.

7 Die folgende Analyse basiert auf der Videodokumentation vom 23.01.2005 im HAU (Berlin), des Mime Centrums Berlin und auf der Aufführung auf Kampnagel (Hamburg). PERFORM PERFORMING ist eine Koproduktion Jochen Rollers mit Kampnagel Hamburg, Podewil Berlin, Industriekultur Saar und dem FFT Düsseldorf. 
H\&M, im Call Center, und ironisch als »Art Gigolo« zeichnen den ökonomischen Status des Performers aus. Im dritten Teil stellt der Einsatz von Video, Telefon und Mikrofon das Performen - im Vergleich mit und in Differenz zu anderen traditionellen - Berufen als Arbeit her. Die Vervielfältigung des Performers wird im dritten Teil mit dem Titel »That's the way I like it « fortgesetzt: Roller spielt auf der Bühne Mitschnitte von Telefonaten ab, die er mit andern Männern, die den gleichen Namen (Jochen Roller) tragen, führt. Er fragt sie nach ihren Berufen und nach Terminen für Interviews. Der Performer spricht seinen Part live ins Mikrofon, die Antworten der angerufenen (Namensgleichen) werden vom Band abgespielt (kommen also aus der Vergangenheit), die Dialoge sind verstärkt durch das Mikrofon zu hören. Unklar ist, ob sie >echt< oder >inszeniert< sind, denn alle Stimmen ähneln in Modulation und Tonfall der des Performers. Die Melange von Identität und Differenz (der Jochen Rollers) erscheint als Melange von live- und aufgezeichnetem Sprechen der Stimme(n). Die Faltungen von Stimmen, Realitätsgraden, Medien und Zeiten bilden den liminalen Raum eines Wechselverhältnisses von Identität und Differenz zwischen den diversen Jochen Rollers. In diesem liminalen Raum wird die Bedeutung von Arbeit (des Weinbauern, des Lokomotivschlossers, des Ökonomen und des Performers) verhandelt. Was mit dem Telefon beginnt, wird mit Videoausschnitten fortgesetzt. Medien werden als Scharniere zwischen dem Performer und den anderen Männern, zwischen dem Beruf >Tänzer/Performer < und anderen Arbeitspraktiken eingesetzt. Sie sind Schaltstellen unterschiedlicher Berufe und Identitäten. In einer zentralen Videosequenz sind die Gesichter der insgesamt vier Jochen Rollers in immer kürzer werdenden Sequenzen hintereinander geschnitten. Der unterbrochene Satzfluss wird abwechselnd weiter gesprochen, sodass ein Polylog entsteht. Der Satz »Mein Name ist ... ich bin in .... geboren, mein Beruf ist ... « stellt hier (ähnlich wie in SABENATION) via Medium die Eckdaten von Identitäten als berufliche Identitäten her. Bild und Text münden in die Gestalt des Performers, der sich zum Ende hin >vollständig< präsentiert: Nicht mehr als »Art Gigolo « (wie im zweiten Teil), nicht mehr als arbeitsloser Künstler (wie im ersten Teil), sondern als ausgebildeter Tänzer und Performer. Medien erweisen sich auch hier als produktiv in der Erzeugung von Realität (Krämer). Sobald diese Realität erzeugt ist, müssen sie nicht mehr offensichtlich zum Einsatz kommen: Auch Rollers Performance endet mit einem leeren Bildschirm.

\section{Willkommen in der Ökonomie der Präsenz als Präsenz der Ökonomie}

Ich fasse im Folgenden zusammen, was bezüglich des Einsatzes von Medien in den besprochenen Aufführungen evident wurde:

Erstens: >Medienpräsentationen< fungieren weniger als >Beglaubigungssiegel< für Realitäten, sondern sie »erzeugen Welt« (Krämer): Sie erzeugen in SABENATION den Verlust von Arbeit bei Sabena Airlines als Einverleibung und Verdinglichung des Sabena-Flugzeugs, und sie erzeugen in PERFORM PERFORMING die Anerkennung einer prekären Tätigkeit - des Performens - als Arbeit. In beiden Aufführungen kommen die modernen Medien (Film, Fernsehen, Telefon und Printmedien) da zum Einsatz, wo ein modernes Berufsverständnis zu Ende geht.

Zweitens: In beiden Performances werden Screens erst als Projektionsflächen eingesetzt und gegen Ende wieder entleert. Dies ist jedoch nicht als Rückkehr zu einer wie auch immer gearteten »Liveness« (Auslander) zu verstehen, sondern als 
geglückte Medialisierung und als Erzeugung von Präsenz aufzufassen: Die »Ökonomie der Präsenz«, die William Mitchell dem »Mythos Internet « zuschreibt, ist ihrerseits medialisiert und bedarf daher keines expliziten Medieneinsatzes mehr. Daher mündet SABENATION mit dem bezeichnenden Song »Welcome now « in Gegenwart der Präsenz der Ökonomie.

\section{Literatur}

Auslander, Philip (1999): Liveness. Performance in a mediatized culture. London u.a.: Routledge.

Bologna, Sergio (2006): Die Zerstörung der Mittelschichten. Thesen zur neuen Selbständigkeit. Graz: Nausner \& Nausner.

Brandstetter, Gabriele (2005): Bild-Sprung. TanzTheaterBewegung im Wechsel der Medien. Berlin: Theater der Zeit.

Butler, Judith (1997): Haß spricht. Zur Politik des Performativen. Berlin: Berlin Verlag.

Debord, Guy (1996): Die Gesellschaft des Spektakels. Berlin: Bittermann; Edition Tiamat.

Dreysse, Miriam (2004): »Spezialisten in eigener Sache«. In: Forum modernes Theater 1/2004, S. 27-42.

Gutjahr, Ortrud (2006): Buddenbrooks von und nach Thomas Mann. Würzburg: Verlag Königshausen \& Neumann.

Hentschel, Ulrike (2005): »Das so genannte Reale. Realitätsspiele im Theater und in der Theaterpädagogik«. In: Gabriele Gabriele Klein/Wolfgang Sting (Hg.): Performance. Positionen zur zeitgenössischen Kunst. Bielefeld: transcript, S. 131-147.

Krämer, Sybille (2004): Medialität und Performativität. Frankfurt/M.: Suhrkamp.

Laplanche, J./J.-B. Pontalis (1992): Das Vokabular der Psychoanalyse. Frankfurt/M: Suhrkamp.

Lehmann, Hans-Thies (1999): Postdramatisches Theater. Frankfurt/M.: Verlag der Autoren.

Matzke, Annemarie M. (2005): Testen, Spielen, Tricksen, Scheitern. Formen szenischer Selbstinszenierung im zeitgenössischen Theater. Hildesheim u.a.: Georg Olms.

Schechner, Richard (2002): Performance Studies. An introduction. London u.a.: Routledge.

Welsch, Wolfgang (1998): »Eine Doppelfigur der Gegenwart: Virtualisierung und Revalisierung«. In: Gianni Vattimo/Wolfgang Welsch (Hg.): Medien-Welten Wirklichkeiten. München: Fink, S. 229-249.

Žižek, Slavoj (1991): Liebe Dein Symptom wie Dich selbst! Jacques Lacans Psychoanalyse und die Medien. Berlin: Merve. 


\title{
(Un-) Glauben. Das Spiel mit der Illusion ${ }^{1}$
}

\author{
NIKOLAUS MÜLLER-SCHÖLL
}

\section{(1) These}

Glaubt man den Trendforschern der Theaterkritik und des Betriebs, so ist das Gegenwartstheater seit der Jahrtausendwende geprägt von der »Rückeroberung der Wirklichkeit auf der Bühne« (Theaterkanal/Theatertreffen) ${ }^{2}$, der »Rückkehr des Dokumentarstücks « (Laudenbach: 11), ja von einem »Théâtre sans illusion « (Biet/ Frantz: 565). Meine Hypothese lautet dagegen, dass dieses angebliche »Wirklichkeitstheater « Columbus gleichend, der Indien suchte und Amerika fand, tatsächlich nolens volens auf dem Wege seiner Suche nach dem Realen die unauflösbare Ambivalenz des Glaubens an die Illusion wiederentdeckt hat. Nicht »reality strikes back«, wie eine Konferenz des Düsseldorfer FFT im September 2006 mit Blick aufs Theater der Gegenwart behauptete ${ }^{3}$, sondern »illusion «. Mit ihr, einem angezählten »Motiv « im »postdramatischen Theater des Realen « (Lehmann 1999a: 67, vgl. 1999b: 185-193), wird hier gespielt. Kalkuliert oder im eigenen Kalkül gestört, enthüllen gerade die besonders an der Realität oder am Realen interessierten Theatermacher, was es heißt, im Medium von Theater und Sprache gleichsam verstrickt zu sein (vgl. Chartin/Lacoue-Labarthe/Nancy/Weber: 234). Nach einem kurzen problemgeschichtlichen Abriss möchte ich dies an zwei besonders exponierten Beispielen des sogenannten »Wirklichkeitstheaters « etwas ausführlicher erläutern, an Stefan Kaegis »bulgarische(r) LKW-Fahrt durchs Ruhrgebiet [...] CARGO SofIA ZOLLVEREIN ${ }^{4}$ sowie Walid Raads Arbeiten MY NECK IS THINNER THAN A HAIR: ENGINES (vgl. Nakas/Schmitz: 96-103) und I FEEL A GREAT DESIRE TO MEET THE MASSES ONCE AGAIN ${ }^{5}$. Abschließend werde ich dann einige Vorschläge zu einem heutigen Verständnis der Illusion unterbreiten.

\section{(2) Problemgeschichtliche Rekapitulation}

Ein gerader Strohhalm, den wir, weil in Wasser getaucht, als geknickten sehen - an diesem vielzitierten Beispiel lässt sich schnell erläutern, was unter einer Illusion zu verstehen sei: Etwas, woran geglaubt wird, obwohl man weiß oder zu wissen

1 Erstmals erschienen in: Forum Modernes Theater, Bd. 22/2 (2007), S. 141-151.

2 Vgl. den Mitschnitt einer Diskussion dieses Titels im Rahmen des Berliner Theatertreffens 2006, die als Download zur Verfügung steht unter

http://www.theaterkanal.de/fernsehen/monat/05/204323382 (25.03.2007).

3 Vgl. http://www.forum-freies-theater.de/archiv/09sept/symposium.html (25.03.2007).

4 CARgo Sofia-Zollverein, R: Stefan Kaegi, Rimini Protokoll. Premiere: 07.07.2006 im Choreographischen Zentrum PACT Zollverein, Essen.

5 Lecture Performance. Premiere am 23.06.2005 im Rahmen des Festivals »Theater der Welt « im Stuttgarter Kunstmuseum. 
glaubt, dass es der Wirklichkeit nicht entspricht, ein spontaner Glaube an Unglaubliches, oder, wie jüngst ein Philosoph schrieb, »wissensresistentes Wirklichkeitsbewusstsein von etwas, was nicht wirklich existiert« (Wiesing: 89).

Die lückenlose Illusion herstellen, so lässt sich das Projekt und vielleicht zugleich Phantasma der Theatertheoretiker des 17. und 18. Jahrhunderts auf den Punkt bringen (vgl. Strube 1976: 204-215; Pavis: 167-169; Frantz: 30-32; Ladzarzig: 140-142). Dieses Projekt entspringt in den Theorien des späten 17. und frühen 18. Jahrhunderts den Forderungen der Wahrscheinlichkeit, der Natürlichkeit, der Wahrheit und der Kausalnotwendigkeit der Handlung und dabei mal einer von Aristoteles abgeleiteten angeblich ewigen Regel, mal der Doktrin der Vraisemblance, mal dem auf die Wirkung des Mitleids oder der moralischen Belehrung ausgerichteten Zweck und ist in jedem Fall auf Totalität aus: Im Kunstwerk soll eine Welt angeschaut werden (vgl. Kern: 172), und der Betrachter soll dabei mehr oder (im Falle Mendelssohns, Schillers und Goethe ${ }^{6}$ ) weniger - vollkommen den Rahmen vergessen, der ihm diese Welt anschaubar werden ließ. Aus einem Blickwinkel des 20. Jahrhunderts lässt sich das Projekt der Doktrinäre der französischen Klassik und der Ästhetiker des 18. Jahrhunderts als Teil eines teleologischen Prozesses beschreiben, der mit den Bühnenformen der Neuzeit seinen Anfang nahm und dessen Teloi die Guckkastenbühne des 19. Jahrhunderts und ihre Pendants der Kinoleinwand und des Fernsehbildschirms sind (vgl. Haß 2005; Heeg). Pointiert: Theater und Bild-Medien arbeiten vom 18. bis 20. Jahrhundert daran, die Utopie des 17. Jahrhunderts, das von der ungestörten Illusion nur träumen kann, zu verwirklichen: Technische Veränderungen wie die Abschaffung der illusionshemmenden Bühnenbänke, Gas- und später elektrische Beleuchtung der Bühne bei gleichzeitiger Verdunkelung des Saales und darüber hinaus die Gestaltung des Bühnenbildes als Illustration im Dienst der Fiktion tragen dazu bei, dass sich das Theater aus dem diskursiven Versammlungsraum der gekreuzten Blicke des 17. Jahrhunderts (vgl. Biet 2002 u. 2005) zu jenem illusionsstiftenden Bildraum entwickelt, dem dann die theaterpraktischen Rebellionen der Avantgarden des frühen 20. Jahrhunderts gelten werden.

Den Wendepunkt in der Geschichte der theatralen Illusion wie ihrer Störung stellen Brechts praktische Übungen wie theoretische Überlegungen zum Umgang mit ihr dar. Seine Wendung gegen die Illusion ist bekannt: Das Theater stellt die Distanz zur illusionierten Sache dar, indem es bei ihrer Vorstellung die eigene Realität seiner Mittel - den Körper des Schauspielers, die Scheinwerfer, etc. - nicht in Vergessenheit geraten lässt. Doch bereits die im bruchstückhaft übermittelten Lehrdia-, bzw. -polylog des MESSINGKAUFS (Brecht 1993: 695-869, vgl. Brecht 1967: 500657) ${ }^{7}$ überlieferte Position ist komplexer als dieser im Brechtismus zur Doktrin

6 Vgl. dazu Strube 1971: 85ff u. 181ff; Koch/Voss: 7.

7 Der MESSINGKAUF stellt ein besonders anschauliches Stück Brechtscher Theoriearbeit dar: Brecht arbeitete daran von 1937-1955 und hinterließ schließlich eine nicht synthetisierbare Masse von Bruchstücken in Typoskriptform mit handschriftlichen Anmerkungen. Die Herausgeber der Ausgabe von 1967 versuchten, auf der Grundlage der nachgelassenen Schriften eine »editorische Rekonstruktion« (Brecht 1967: Anm. 3), eine »Lesefassung «, die »lesbare[...] Anordnung « sein sollte, gleichwohl die »Nahtstellen« sichtbar bleiben lassen wollte. Das Resultat ist heute nur noch als Dokument des Brecht-Bildes der 1960er-Jahre von Interesse. Die neue Brecht-Ausgabe gibt durch ihre Anordnung der Fragmente nach dem Prinzip der Chronologie einen genaueren Eindruck vom fragmentarischen Charakter und dabei speziell auch von den unterschiedlichen Tendenzen Brechts: Zur Ordnung einerseits, zur Auflösung von Ordnung 
erhobene Anti-Illusionismus. Die womöglich als Kapiteltitel vorgesehene Formulierung »abbau der illusion und der einfühlung « (BBA 124/88, vgl. Brecht 1993: 719), die nicht zuletzt auf den Ort des Gesprächs anspielen dürfte, eine Bühne, »deren dekoration von einem bühnenarbeiter langsam abgebaut wird « (BBA 126/13, Brecht 1993: 773), beschreibt zugleich treffend, dass hier eine in 200 Jahren aufgebaute Ideologie wieder abgebaut, der »Vormarsch [...] zurück zur Vernunft « (BBA 127/48, Brecht 1993: 803) angetreten werden soll. Doch nur, wo etwas aufgebaut worden ist, kann abgebaut werden, und so geht auch Brechts forsches Nein zu Illusion und Einfühlung mit einem verhaltenen Ja einher, hier wie an anderen Orten: »es kann nicht schlechtweg behauptet werden, dass diese Dramatik oder irgendeine Dramatik ganz und gar auf alle illusionären Elemente verzichten kann « (Brecht 1993: 612f), schreibt er einmal, und der Philosoph, sein alter ego im Messingkauf, gesteht eine schwache Einfühlung zu, obwohl er damit doch riskiere, dass »dem ganzen alten unfug wieder ein türlein« (BBA 127/55, Brecht 1993: 823) geöffnet wird.

In ihrer Distanz zur propädeuticums-notorischen Brechtschen Distanz eröffnet die in Brechts Schriften zu findende Position des Abbaus der Illusion einen Spielraum, den die am Realen interessierte Theaterpraxis der vergangenen Jahre auslotete. ${ }^{8}$ In ihr dient der Einsatz von neueren Medien nicht mehr der weiteren Optimierung der Illusion, sondern vielmehr ihrer Unterbrechung oder aber dem Spiel mit ihr. Wir entdecken den Rahmen, den wir vergessen müssten, sollte die Illusion perfekt sein, und dies vermittelt

über die nicht enthüllende, sondern nur anders verhüllende Video-Aufnahme im Theater bei Castorf, ${ }^{9}$

- über die Nachahmung nicht-illustrativer Filmhandlungen oder Choreographien auf der Bühne, die ein unvermitteltes Gebahren der gelernten Illusionsschauspieler verhindert, bei der Wooster Group, ${ }^{10}$

- $\quad$ über den kalkulierten Konflikt zwischen dem Timing der Musik und dem des Tanzes bei Grace Ellen Barkey, etwa in ihrer Produktion CHUNKING (2005),

- oder über den unklärbaren Status des Filmes, der - vielleicht live - das verdeckte Geschehen des Abends in den Theatersaal übermittelt, etwa bei Heiner Goebbels. ${ }^{11}$

Ich könnte die Reihe noch fortsetzen, doch reichen die Beispiele vermutlich aus, um daraus abzuleiten, dass es eines neuen Begriffs bedarf, um diese gegenwärtige

entsprechend der auftauchenden Fragen und Probleme andererseits. Gleichwohl lässt auch sie den Leser leicht verkennen, dass die Wiederholungen, Korrekturen, Widersprüche, Revisionen und letztlich das Scheitern Brechts am zu Beginn avisierten und konzipierten Lehrbuch mindestens ebenso große Aufmerksamkeit verdient wie die in den Texten niedergelegten Inhalte. Darüber hinaus greift sie durch die Auflösung der fast durchgängigen Kleinschreibung massiv in Brechts Text ein, der deshalb, wo möglich, im Folgenden nach den im Brecht-Archiv liegenden Typoskripten zitiert wird.

8 Vgl. zur Formulierung der »Distanz zur Distanz« Lehmann 2005: 40, wobei ich mit Blick auf die hier untersuchte Textpassage allerdings hinzufügen möchte, dass diese Haltung nicht erst in Absetzung von Brecht, etwa bei Heiner Müller, sondern bereits bei Brecht selbst zu finden ist.

9 Vgl. etwa Castorfs Produktionen ENDSTATION AMERIKA und FOREVER Young. Für ENDSTATION AMERIKA hat dies beispielhaft Ulrike Haß (2004) herausgearbeitet.

10 Ausführlich habe ich dies am Beispiel der Wooster Group-Produktion To YoU, THE BIRDIE! zu zeigen versucht (vgl. Müller-Schöll 2007).

11 Heiner Goebbels: »Eraritjaritjaka. Das Museum der Sätze« (2004, vgl. Koch 2006: 62f). 
Tendenz des fortwährenden Entzugs der einen Illusion und des gleichzeitigen beständigen Spiels mit den Möglichkeiten von Illusion überhaupt pointiert auf den Punkt zu bringen. In Anlehnung an Jacques Derridas Formulierung, wonach es in der Dekonstruktion darum gehe, zu begreifen, dass wir in »plus d'une langue « verstrickt sind - in mehr als eine und zugleich überhaupt keine mehr (vgl. Derrida 1988: 31) - könnte man davon sprechen, dass es im Theater des Abbaus der Illusion immer um »plus d'une illusion« geht: Mehr als eine, gar keine mehr. Dafür möchte ich nun zwei besonders eindrückliche Beispiele etwas ausführlicher betrachten.

\section{(3) Cargo Sofia Zollverein (Rimini Protokoll, Stefan Kaegi)}

Ihrem Anspruch nach entfalten die Arbeiten von Rimini-Protokoll, dem, so Theater der Zeit, »Begründer eines neuen Reality Trends auf den Bühnen ${ }^{12}{ }^{2}$, das theatrale Potential der heutigen Wirklichkeit, und dies, indem entweder Experten aus den unterschiedlichsten Bereichen auf die Bühne geholt oder aber Orte zum Spielplatz einer Erkundung mit Mitteln des Theaters werden, an denen eine auch theatral verfasste Wirklichkeit zu betrachten ist. Produktionen wie ZEUGEN! EIN STRAFKAMMERSPIEL, SABENATION. Go HOME \& FOLLOW THE NEWS oder DEUTSCHLAND 2 sind so umfangreich durch Artikel und Aufsätze dokumentiert und analysiert, dass ich mir hier die weitere Vorstellung der Gruppe spare, nicht ohne auf ihre eindrucksvolle Homepage zu verweisen. ${ }^{13}$

Was den Reiz von Stefan Kaegis Produktion CARgo SofIA ZoLlverEIN ausmacht, die ich hier diskutieren möchte, ist zunächst, dass sie eine der überzeugendsten Antworten auf die Frage gibt, wie man etwas über die heutigen ökonomischen Vorgänge erzählen, wie man deren namenlose Akteure in Szene setzen, wie ihre letztlich nicht ganz erschließbaren Gesetze beleuchten kann, ohne deren Komplexität zu reduzieren, aber auch ohne sie als gänzlich unbekannte zu dämonisieren und in untätige Kontemplation zu verfallen. Die Arbeit ging nach der Premiere im Mai 2006 auf Tour durch ganz Europa. Eine der Stationen war das Essener choreographische Zentrum PACT Zollverein. ${ }^{14}$

47 Zuschauer werden einen Abend lang auf die zur Tribüne umgebaute Ladefläche eines LKWs geladen, um von dort aus, gleichsam als Ware, chauffiert von zwei bulgarischen Truckern, die Umgebung zu erkunden und dabei mit der Welt jener Lohnsklaven in Berührung zu kommen, die im Auftrag deutscher Unternehmer zu bulgarischen Löhnen Fracht aus den Billiglohnländern des europäischen Ostens in die Metropolen des Westens fahren. Eine Seite des Lastwagens ist verglast und so zur buchstäblichen vierten Wand mutiert, hinter der sich abspielt, was die Zuschauer aus ihrem Guckkasten heraus dann betrachten können: Der Parcours führt an Nicht-Orten ${ }^{15}$ wie einem Container-Hafen oder einem von LKW-Fahrern bevorzugten Parkplatz am Stadtrand vorbei, macht die banale Autobahn zum alltäglichen Theater und das Theater zum vergnüglichen Unterricht in Sachen Globa-

12 Zit. nach http://www.dramaturgische-gesellschaft.de/dramaturg/2005_02/24.pdf.

13 Vgl. http://www.rimini-protokoll.de/project_frontend_index.php.

14 Die folgende Beschreibung bezieht sich auf die Vorstellung in Essen am 10.07.2006.

15 Vgl. zum Begriff des Nicht-Orts Augé (97-144), der ihn zu einer zeitspezifischen Erscheinung dessen erhebt, was er mit Blick auf die heutige Gegenwart als »Surmodernité « beschreibt. 
lisierung. Auf einer Leinwand, die herunterfährt, wenn es draußen gerade nichts zu sehen gibt, wird die Geschichte des schwäbischen Unternehmers Willi Betz erzählt, der nach dem Umbruch im Osten das einstige staatliche bulgarische Transportunternehmen SOMAT kaufte und mit erlaubten und unerlaubten Mitteln (Lohndumping, Bestechung, illegale Zulassungen) das LKW-Geschäft billig und für alle Beteiligten gefährlich machte. Ein Autobahnpolizist erzählt von seinem Alltag bei der Kontrolle übermüdeter Lastwagenfahrer und gefährlich aussehender Frachten. In einer Spedition wird den Zuschauern von einem Mann in Anzug auf der Laderampe die komplexe Logistik der Transporteure vermittelt, in vom Band eingespielten Statements erfahren sie en passant, was wäre, wenn man die LKW-Fahrer wieder anständig honorieren würde: Die Transportkosten würden steigen, die Auslagerung großer Teile der Produktion sich nicht mehr lohnen, der Abbau von Arbeitsplätzen hierzulande gestoppt.

Man kann CARGo SOFIA ZOLLVEREIN als eine Art >Sightseeing< wahrnehmen und sich wundern, wie viel Fremdes in unmittelbarer Nähe des Vertrauten in den Gebieten einer Stadtlandschaft wartet, die man sonst allenfalls im Vorbeifahren wahrnimmt. Man kann darin auch einen ssinnlich gestalteten, unakademischen Seminarabend s sehen, in dessen Verlauf man erfährt, dass in einem Container 10.000 Anzüge transportiert oder zwei Gastarbeiter untergebracht werden können, dass die Kohle auf den Gleisen des Güterbahnhofs mitten im einstigen »Kohlenpott « Ruhrgebiet aus China kommt und 7.000 Sattelzüge in Westeuropa mit osteuropäischen Fahrern zu osteuropäischen Löhnen unterwegs sind. Man kann sich anhand der Geschichten der zwei Fahrer ein Bild von den kleinen Vergnügungen und der großen Einsamkeit des Lastwagenfahrerdaseins machen, sieht die Prostituierten am Straßenstrich, den Kollegen, der alte Autos nach Georgien transportiert und sich den freien Abend mit einer Flasche Schnaps vertreibt und hört von den erlaubten und unerlaubten Mitteln, mit denen sich die Fahrer wach halten. Das ist die eine Seite.

Doch die interessante Begegnung mit einer fremd gewordenen Nachbarschaft bliebe Volkshochschul-kompatible Heimatkunde, wäre sie nicht Teil eines klugen Samplings von insgesamt fünf Geschichten, die auf kunstvolle Weise synchron erzählt werden und einander beständig wechselseitig unterbrechen: Da ist zum ersten die Geschichte einer fiktiven LKW-Fahrt von Sofia nach Essen, die von Bulgarien über Serbien, Italien und die Schweiz führt. Sie setzt sich aus Anekdoten und »Originalgeräuschen « zusammen, die durch Filmausschnitte illustriert werden und zusammen ein dichtes Bild der fiktiven Reise mit ihren Wartezeiten auf Autobahnen und ihren kleinen Abenteuern mit korrupten Zöllnern an blockierten Grenzübergängen ergeben. Zum zweiten wird die Kriminalgeschichte des expandierenden schwäbischen Unternehmens erzählt, in kleinen Happen, die von der Firmengründung in den 1950er-Jahren bis zum kuriosen Bau der Privatvilla des Unternehmers inmitten des Firmengeländes und zu einer schon legendären Großrazzia im Jahr 2003 reicht. Zum dritten zeigen die zwei Fahrer Familienbilder und erzählen Anekdoten aus ihrem Leben, was via Headphone und qua Kamera direkt aus dem Führerhaus in den Laderaum übertragen wird. Eine vierte Geschichte ist diejenige der Fahrt, an der die Zuschauer gerade teilnehmen. Die fünfte Geschichte aber ist jene, die alle anderen Geschichten ins Zwielicht rückt, die der Inszenierung. Während man bei den meisten früheren Arbeiten der Gruppe in theatralischer Hinsicht schlichtes Einfühlungstheater mit Laien geboten bekam, wird hier beständig mit Beginn und Enden der Illusion gespielt: Immer wieder begegnet der LKW mit den Zuschauern einer jungen Frau, die mal live in einem Park singt, mal einige 
Pakete auf dem Trottoir neben der Straße mit dem Fahrrad transportiert. Nachdem man vom Autobahnpolizisten verabschiedet worden ist und die Spedition verlassen hat, begegnen der Polizeiwagen und ein Laster der Spedition dem Publikum noch einmal auf der Autobahn, lassen die Grenze zwischen dem, was echt ist und dem, was den Eindruck der Echtheit produziert, fließend werden und nähren so den Zweifel am Dokumentarischen dieses »Dokumentartheaters«. Es wird deutlich, dass das Anliegen ein grundlegend anderes ist als etwa in den Stücken von Peter Weiss, Heinar Kipphardt oder Rolf Hochhuth: Es geht hier nicht nur darum, Wirklichkeit abzubilden, sondern zugleich und im Verlauf des Abends zunehmend auch darum, über die Bilder der Wirklichkeit nachzudenken. Hatten frühere Arbeiten von Rimini Protokoll im Einklang mit der akademischen Theatralitätsforschung das alte Vorurteil bestätigt, die ganze Welt sei irgendwie auch eine Bühne, so lässt diese ahnen, dass das Theatrale der Wirklichkeit, nimmt man es ernst, dazu führt, dass es keine Aussage über die Wirklichkeit gibt, die nicht schon kontaminiert wäre von deren Inszenierung. ${ }^{16}$ Am Ende wird so beides fragwürdig: Das Theater wie die Welt - weder nämlich ist es sicher, dass man Vorstellungen wie CARGO SOFIA ZOLLVEREIN zurecht noch als »Theater « bezeichnen kann, noch andererseits, dass man, was sie vorführen, noch als »Wirklichkeit« betrachten sollte. Mit dem Zwielicht aber, in das Rimini Protokoll dergestalt taucht, was es vermeintlich doch bloß vorstellt, greift die Gruppe jenen epistemologischen Zweifel auf, den einst Brecht formulierte, als er davon sprach, dass eine $»$ einfache $>$ Wiedergabe der Realität«« weniger denn je »etwas über die Realität aussagt. Eine Photographie der Kruppwerke oder der AEG ergibt beinahe nichts über diese Institute «. Woraufhin er, der oben angedeuteten Logik folgend, festhält: »Es ist also tatsächlich >etwas aufzubauen $<$, etwas >Künstliches $<$, >Gestelltes $<\ll .{ }^{17}$ Mit der Entdeckung, dass die Annäherung an die Wirklichkeit über die bloße Abbildung hinaus auch das Abbilden selbst zum Thema erheben muss, die Illusion nicht nur billigend in Kauf zu nehmen hat, sondern mit ihr kalkulieren muss, nähert sich Kaegis Arbeit einer konzeptionellen Arbeit an, deren beinahe einziges Thema zunächst das Abbilden, doch darüber vermittelt dann das Unabbildbare ist, den Photographien, Video-Arbeiten und Lecture-Performances des in New York und Beirut lebenden Libanesen Walid Raad.

\section{(4) Walid Raad - Erinnerung im Medium}

Walid Raads Thema ist der Krieg - der im Libanon zwischen 1975 und 1991, mit dem er aufwuchs, wie auch der aktuelle gegen den Terror, daneben die mit dem Krieg verbundenen traumatischen Ereignisse, soweit sie eine kollektive historische Dimension haben, und bei alledem und vor allem die Art, wie Film, Video, Photographie und Theater diese Ereignisse, überhaupt die psychologische und physische Gewalt zu repräsentieren beanspruchen. Die Repräsentation des Krieges unternimmt und untersucht er auf dem Weg eines beständigen Aufbaus der Illusion, Geschichte $\mathrm{zu}$ schreiben, Spuren $\mathrm{zu}$ sichern, Opfer $\mathrm{zu}$ identifizieren und kleine Geschichten am Rande der großen Geschichte zu archivieren. Alle seine Arbeiten

16 Vgl. zum hier nur angedeuteten, sehr spezifischen Begriff von Theatralität MüllerSchöll 2002: insb. 45-71 u. 183f sowie Weber 2004.

17 Vgl. Brecht 1992: 469; vgl. dazu auch, darauf aufbauend Kluge: 203. Die Affinität der Arbeiten von Rimini Protokoll und Walid Raad mit Alexander Kluges Arbeiten, speziell für das Fernsehen, wäre an anderer Stelle ausführlicher zu beleuchten. 
könnten als historische Dokumente eines imaginären Archivs bezeichnet werden, das von einer ebenfalls imaginären Stiftung, der »Atlas group «, unterhalten wird, als deren Gründungsmitglied Raad sich bezeichnet - weitere Mitglieder sind allerdings nicht bekannt. Raad macht meines Wissens nirgendwo explizit, was im Lauf der Betrachtung seiner vor allem in Kunsträumen ausgestellten »historischen Dokumente « allmählich und in seinen Lecture-Performances irgendwann schlagartig deutlich wird, dass es sich durchweg um fiktives, manipuliertes oder >gefälschtes $<$ Material handelt. ${ }^{18}$

Ein nur schlaglichtartig vorgestelltes Beispiel: In der Serie MY NECK IS THINNER THAN A HAIR: ENGINES sind auf Tafeln an der Wand Fotografien von Motoren zu sehen, die inmitten mehr oder weniger zerbombter Stadtlandschaften liegen und von mal kleineren, mal größeren Gruppen von Leuten umringt werden. Neben den Fotografien ist deren Rückseite zu sehen, auf der amtlich aussehende Stempel, Notizen und Signaturen die Authentizität der Aufnahme zu bestätigen scheinen. Raad ergänzt die Serie, die er auch in einer Lecture-Performance vorführt, im $\mathrm{Mu}$ seum durch den Hinweis:

»Der einzige Teil, der nach der Detonation eines Autos übrig bleibt, ist der Motor. Er wird mehrere zehn, manchmal sogar Hunderte Meter weit geschleudert und landet auf Balkonen, Dächern oder in Nebenstraßen. Während der Kriege veranstalteten die Fotojournalisten einen Wettlauf, wer die Motoren zuerst finden und fotografieren würde« (Zit. nach Nakas/Schmitz: 96).

Motoren, Reste, die von den, wie man auch liest, 3.641 Autobomben der Kriege übrigbleiben (ebd.), werden hier gleichsam zu Allegorien des nicht dargestellten und in jeder Darstellung tendenziell verratenen, verfälschten, verkitschten und mit wohlfeiler Emotionalität aufgeladenen Leids und Schreckens der Detonationen, zu einer Wiederholung ohne Urbild, einer Repräsentation ohne Abbildcharakter, einer Schrift oder Spur, die, Ruinen gleichend, von der Gewalt hinterlassen wurde, als ein das Bildverbot wahrendes Mal der Zerstörung. Was wir über die Wirklichkeit erfahren, ist nicht auf den Bildern repräsentiert und nicht Gegenstand von Raads das Bildmaterial präsentierender Installation.

In seiner Lecture-Performance I FEEL A GREAT DESIRE TO MEET THE MASSES ONCE AGAIN, deren Premiere 2005 im Rahmen des Theater der Welt-Festivals in Stuttgart stattfand ${ }^{19}$, erzählt Raad von einem längeren Verhör durch Polizei und FBI nach einer kurzen Flugreise in den USA bei der Rückkehr am Rochester International Airport. Schnell gerät der Immigrant arabischer Herkunft unter Verdacht und - wie ihm retrospektiv klar wird - in Gefahr, wie viele andere gebürtige Araber - etwa der mittlerweile bekannt gewordene deutsche Staatsbürger Khaled elMasri aus Neu-Ulm - verschleppt, verhört und gefoltert zu werden - und die weitere Performance trägt die nur notdürftig verschleierte Spur des 2005 noch weitgehend unbekannten Wirkens der amerikanischen Geheimdienste im Umgang mit vorwiegend arabischen Terrorverdächtigen zusammen. Was Raad verdächtig wer-

18 Eine Auswahlbibliographie zu Veröffentlichungen von und über Walid Raad findet sich bei Nakas/Schmitz: 133. Die folgende Darstellung stützt sich daneben auf eine persönliche Begegnung mit Raad im Rahmen des von Christine Peters kuratierten »Performer's Guesthouse«, Theater der Welt/Akademie Schloss Solitude, Stuttgart, 23./24.06.2005. Siehe auch die Homepage Raads: www.theatlasgroup.org.

19 Meine Darstellung bezieht sich auf die Performance vom 23.06.2005 im Kunstmuseum Stuttgart. 
den lässt, ist nichts anderes als seine in den Augen der Verhörenden wertlose Kunst, die nutzlosen Bilder: Von sich, nackt vor Wolkenkratzern in New York, von toten Tieren, von Sicherheitshinweisen verschiedener Flugzeuge und eben von Autobomben-Explosionen im Libanon, die durch arabische Inschriften bezeichnet sind. Erst als der Verhörer erkennt, dass er es mit einem Künstler zu tun hat kommt Raad frei. Was ihn, wie er sagt, gerettet hat, war die Tatsache, dass der Polizist in seiner Freizeit Hobby-Maler war.

Raad sitzt bei dieser Lecture-Performance mit Laptop vor einer Leinwand und wenig unterscheidet ihn dort zunächst von den Handelsvertretern, Managern und Dozenten, die sich heute in ihren Vorträgen der einfach zu bedienenden Powerpoint-Präsentationsform bedienen. Und doch wird schnell deutlich, dass diese Form hier entgegen dem ersten Anschein Teil des Konzepts ist. Ihr Minimalismus lässt Raad so flexibel und autonom bleiben wie nur irgend möglich ${ }^{20}$ und vermindert zugleich jenen »Himmelsrest des Scheins zu tragen peinlich «, der, um es mit Adornos Verdikt über den Dadaismus zu formulieren, künstlerischen Versuchen anhaftet, die dem Schein absagen wollen und doch von der »realen politischen Wirkung abgeschnitten « bleiben, die sie ursprünglich inspirierte (vgl. Adorno: 159). Dass Raad seine Erzählung im Stuttgarter Kunstmuseum präsentiert, und nicht zum Beispiel vor dem Hauptquartier der amerikanischen Streitkräfte in Stuttgart-Vaihingen, also als öffentliche Demonstration, wird vielleicht vor allem dadurch gerechtfertigt, dass er in diesem der Kunst gewidmeten Raum mit Vorsatz die Kunst verlässt, um die Möglichkeit von Kunst zu behaupten, sein in anderen Arbeiten verfolgtes Spiel mit der Illusion zu verteidigen. Ausgehend von einer Vorstellung der eigenen spielerischen Anfänge - des Jungen, der zum Vergnügen photographierte und ohne Nutzen sammelte, was er in seiner vom Krieg gezeichneten Heimatstadt Beirut vorfand, des jungen Mannes, der Kunst studierte, später in die USA zog und dort die amerikanische Staatsbürgerschaft annahm - nähert er sich zügig dem Ereignis im Herbst 2004, das im Zentrum seiner Powerpoint-Performance steht, dem Verhör und der Praxis der amerikanischen Sicherheitsbehörden. Der merkwürdige, in der Performance unerklärte Titel - »Ich verspüre eine große Begierde, den Massen wieder einmal zu begegnen « - kann dabei nicht zuletzt als ironischer Kommentar einer Aktion begriffen werden, deren politische Intention ins Leere läuft, solange das Unrecht, von dem sie Zeugnis ablegt, Massen betrifft, die nicht als Massen in Erscheinung zu treten vermögen, weil sie sich aus unzähligen, global zerstreuten marginalisierten Einzelfällen zusammensetzen. Das aufgekratzte, wohlsituierte Premierenpublikum, welches statt den begehrten »Massen « seinen Bericht entgegennimmt, wird nolens volens zur lebendigen Skulptur in dieser Performance, zeugt modo negativo vom illusionären Charakter des im Performance-Titel ausgedrückten Begehrens. ${ }^{21}$

20 Raads Minimalismus verbindet ihn mit einer ganzen Reihe von libanesischen Künstlern, die am Politischen interessiert sind, etwa mit Rabih Mroué oder Ali Cherri. Inwiefern das Fehlen von Mitteln für aufwendigeres politisches Theater dabei den Ausschlag für die Wahl dieser Form gab, muss dahingestellt bleiben. Bei Raads Arbeiten handelt es sich erkennbar um künstlerische Setzungen, die nicht zuletzt im Kontext zeitgenössischer Konzeptkunst und Konzepttheaters weiter zu betrachten wären.

21 Vgl. zur Definition der Illusion im Ausgang von der Motivierung eines Glaubens durch die Wunscherfüllung Freud: 165. Freuds Definition der >Illusion< und des Glaubens an sie kann derjenigen am ehesten verglichen werden, die wir hier nachfolgend ausgehend von Kant und in Affinität zum Ideologiebegriff bei Marx vorschlagen, insofern sie einerseits absieht vom Verhältnis der Illusion zur Wirklichkeit, andererseits ihrer Tendenz nach erneut eine unvermeidliche, ja notwendige Täuschung bezeichnet. 
Was die konzeptuelle Lecture-Performance darüber hinaus deutlich werden lässt, ist die politische Dimension von Raads Spiel mit der Illusion: Das Reale kommt in diesem Spiel vor als Leerstelle zwischen der bekannten, mit tagesjournalistischen Bildern erzählten Geschichte und Raads mit diesen Bildern erzählten anderen, kunstvoll erfundenen Geschichten. Das Spiel des Kindes und später des Künstlers mit den nutzlosen Resten unbekannter Geschichten ist der Anfang einer Aufkündigung jener »transzendentalen Illusion« (Derrida 2001a: 86), die in allen medialen Formen »realistischer Darstellung « unerkannt am Werk ist - in Dokumentationen, journalistischen Berichten und Polizeiprotokollen. Aufgekündigt wird die Verwechslung gewisser Vorurteile über die Welt - etwa eines narrativen Prinzips: des durch Kausalität verknüpften linearen Handlungsverlaufs - mit der Wirklichkeit und dies durch nichts anderes als das Insistieren auf dem, was dem ungebrochen an die Illusion der »Realität « gläubigen als bizarr, absurd, verquer, kurz: als sinnlos erscheinen muss und unter Umständen wie den in der Lecture-Performance vorgestellten als verdächtig. Raad betreibt, anders gesagt, den Abbau des Glaubens an die eine, mit ökonomischer, politischer und - wie der Abend über das Verhör zeigt - auch polizeilicher Macht autorisierte und verbreitete Geschichte, lässt sie auf dem Weg des Aufbaus einer anderen, gleichsam homöopathisch wirkenden Illusion als selbst illusionär erscheinen und befördert dergestalt das Nachdenken über die Macht der Bilder und den Glauben an die Illusion. »Die Geschichte, die man sich erzählt und der Aufmerksamkeit und Glauben geschenkt wird «, so schreibt er, »mag nichts mit dem zu tun zu haben, was in der Vergangenheit geschehen ist, aber es ist jene Geschichte, die in der Gegenwart und für die Zukunft von Bedeutung sein mag« (zit. nach Nakas/Schmitz: 24).

\section{(5) (Un-)Glauben}

Galt es im Falle Kaegis darüber nachzudenken, ob Theater mit Wirklichkeitsmaterial nicht lediglich einen illusionären Schein der Wirklichkeit erzeugt, so in Raads Fall, ob Theater auf dem Weg der Erzeugung einer Illusion nicht gleichwohl etwas über die Wirklichkeit verrät. Wird im ersten Fall der Glauben an die $1 \mathrm{zu} 1$ abgebildete Realität des Vorgestellten im Lauf der Vorstellung sukzessive erschüttert, so stellt sich im zweiten allmählich ein Glauben an den Realitätsgehalt noch des bloß Imaginären, Fiktiven, noch der durchschauten Illusion ein. Nebeneinander montiert verraten beide Fälle etwas über das Verhältnis von Illusion und Realität, was man vielleicht als kantische Einsicht bezeichnen könnte: Illusion kann paradox als »notwendiger« oder »objektiver Schein« begriffen werden, als Verkennung der Wirklichkeit, die zugleich den einzig möglichen Zugang $\mathrm{zu}$ ihr darstellt. ${ }^{22} \mathrm{Sie}$ gleicht dem, was der junge Marx unter dem Begriff der Ideologie (vgl. Marx/Engels; de Man), die Psychoanalyse unter dem des Phantasmas beschrieb. Als notwendige Täuschung behält die Illusion insofern ein Recht, als sie selbst eine Realität ist, auch wenn das Illudierte keiner Realität entspricht, ja qua Definition das Reale verfehlt. Was das Spiel mit der Illusion in theatralen Formen der Gegenwart nahelegt, ist ein anderer Wahrheits- und ein anderer Realitätsbegriff, ein Begriff, der diese nicht länger nach dem Modell der adequatio intellectu et rei zu fassen versucht, sondern vielmehr als niemals restlos bestimmbare, gleichwohl auch nicht inexistente Größen. Obwohl oder eben weil sie sich uns immer entziehen,

22 Vgl. dazu die Kant-Deutungen von Deuber-Mankowsky 2006 und 2007. 
müssen wir an ihnen festhalten, wenngleich nicht länger im Modus des Habens, als vielmehr in dem des Glaubens an eine immer schon im Abbau befindliche Illusion.

Der französische Schauspieler und Essayist Daniel Mesguich illustriert die Paradoxie des Glaubens an die Illusion, der immer auch ein Un-Glauben ist, mit der folgenden These der Psychoanalytikerin Maud Mannoni: »Eine Wolfsmaske ängstigt uns nicht nach Art eines Wolfs, sondern nach Art des Wolfsbildes, das wir in uns tragen. ${ }^{23}$ Mesguich bemerkt dazu, dass man im Theater weder glaube, noch nicht glaube, weder je direkt schaue, noch direkt höre. Man sehe und höre vielmehr das Kind oder den Idioten in uns, der glaubt. Jacques Derrida analysiert diese Bemerkung mit dem Kommentar, dass man im Moment der Beobachtung des glaubenden Kindes oder Idioten in uns zugleich das identifikatorische Gedächtnis wie auch die absolute Trennung betrachte. Man erfahre die Teilung im Theater das Teilen im Sinne der Teilnahme wie im Sinne einer Spaltung. Der Übergang vom teilnehmenden Kind zum die Teilung vollziehenden Erwachsenen scheint ihm dabei undefinierbar und unreduzierbar zu bleiben. Weshalb er seinen Kommentar zu Mesguichs Bemerkung mit einer unbeantworteten Frage schließt: »Was ist ein Akt des Glaubens im Theater? Warum muss man ans Theater glauben? Man muss. Aber warum muss man?« (Derrida 1993: 6).

Worauf der Philosoph der »Dekonstruktion«, eines anderen Ab-baus, dabei hinzuweisen scheint, ist zweierlei: Zum einen dürfte sein wiederholter Hinweis darauf, dass ihn das Phänomen des »Glaubens « ans Theater - aber auch an den Film, wie er an anderer Stelle bemerkt (Derrida 2001b: 78) - interessiere, darauf hindeuten, dass für Derrida die Spaltung des illudierten Betrachters in das glaubende Kind und eine um dessen Illusion wissende Instanz der Vernunft ein Sonderfall in der Geschichte des dezentrierten neuzeitlichen Subjekts darstellt. Diese Einschätzung wäre in theaterwissenschaftlichen Untersuchungen in Beziehung zu setzen zur bemerkenswerten Tatsache, dass es eine Illusionsbühne erst im neuzeitlichen Theater gibt, wie es sich, beginnend mit der Renaissance, herausbildet. Die theatrale Illusion, so könnte man als heuristische Hypothese im Anschluss an Derridas Bemerkung formulieren, ist co-originär mit der Geschichte des Subjekts der Neuzeit und von dessen Herausbildung nicht ablösbar. (Am Rande sei erwähnt, dass in diesem Zusammenhang auch das Verhältnis des die Illusion quasi-transzendental begründenden Glaubens zur Bildung von Gemeinschaft(en) zu bedenken wäre.)

Mit Blick auf das Verhältnis von Theater und Medien wäre schließlich anknüpfend an Derridas Bemerkung festzuhalten, dass die Auseinandersetzung mit der Illusion eine Auseinandersetzung mit dem In-der-Welt-sein ist, insofern aber auch mit dessen medialer Verfasstheit: Eben weil wir (und genauer: jede(r) einzelne und jede(r) anders) immer schon in Illusionen verfangen sind, vermögen wir sie niemals restlos zu beseitigen. Es erhält sich ein Rest von Glauben. Eben deshalb, weil wir andererseits redlicher Weise niemals nur in einer Illusion zu verharren vermögen, gehen wir nie restlos in ihnen auf, verkehrt sich der Glaube im Angesicht anderen Glaubens in (Un-)Glauben. Was bleibt, ist ein Wissen um die gleichzeitige Unumgänglichkeit wie Unendlichkeit des Abbaus der Illusion im (un-)gläubigen Spiel mit ihr. 


\section{Literatur}

Adorno, Theodor W. (1989): Ästhetische Theorie. 9. Aufl., Frankfurt/M.: Suhrkamp.

Augé, Marc (1991): »Des lieux au non-lieux «. In: Ders.: Non-Lieux. Introduction à une anthropologie de la surmodernité. Paris: Seuil, S. 97-144.

Biet, Christian (2002): »L'avenir des illusions ou Le théâtre et l'illusion perdue «. In: Litteratures classiques, No 44, S. 175-214.

Biet, Christian (2005): »Rechteck, Punkt, Linie, Kreis und Unendliches. Der Raum des Theaters in der Frühen Neuzeit«. Aus dem Franz. von Nikolaus MüllerSchöll. In: Nikolaus Müller-Schöll/Saskia Reither (Hg.): Aisthesis. Zur Erfahrung von Zeit, Raum, Text und Kunst. Schliengen: Edition Argus, S. 52-72.

Biet, Christian/Pierre Frantz (Hg.) (2005): Le théâtre sans l'illusion. Critique, Nr. 699-700.

Brecht, Bertolt (1967): »Der Messingkauf«. In: Ders.: Gesammelte Werke 16. Schriften zum Theater 2. Frankfurt/M.: Suhrkamp, S. 497-657, hier S. 578-585.

Brecht, Bertolt (1992): Werke. Bd. 21, Schriften 1. Berlin und Weimar, Frankfurt/M: Aufbau, Suhrkamp.

Brecht, Bertolt (1993): Werke. Bd. 22, Schriften 2. Berlin und Weimar, Frankfurt/M: Aufbau, Suhrkamp.

Chartin, Jean-Jacques/Philippe Lacoue-Labarthe/Jean-Luc Nancy/Samuel Weber (1980): »Zum Kolloquium: >Die Gattung«. In: Glyph, 7, Baltimore und London: The Johns Hopkins Press, S. 233-237.

de Man, Paul (1989): »The resistance to theory«. In: Ders.: The Resistance to Theory. Minneapolis: University of Minnesota Press, S. 3-20.

Derrida, Jacques (1988): Memoires für Paul de Man. Aus dem Franz. v. Hans-Dieter Gondek. Wien: Passagen.

Derrida, Jacques (1993): »Le Sacrifice. La Métaphore«, No 1. http://www.hydra. umn.edu/Derrida/sac.html (10.05.2006).

Derrida, Jacques (2001a): »Above All, No Journalists!« In: Hent de Vries/Samuel Weber (Hg.): Religion and Media. Stanford: Stanford U.P., S. 56-93.

Derrida, Jacques (2001b): »Le cinéma et ses fantômes«. In: Cahiers du Cinéma, No. 556, S. 74-85.

Deuber-Mankowsky, Astrid (2006): »)Eine Aussicht auf die Zukunft, so wie in einem optischen Kasten $<$. Transzendente Perspektive, optische Illusion und beständiger Schein bei Immanuel Kant und Johann Heinrich Lambert«. In: Gertrud Koch/Christiane Voss (Hg.): ... kraft der Illusion, S. 103-120.

Deuber-Mankowsky, Astrid (2007): Praktiken der Illusion. Kant, Nietzsche, Cohen, Benjamin bis Donna J. Haraway. Berlin: Verlag Vorwerk 8.

Diderot, Denis (1968): »Von der dramatischen Dichtkunst «. In: Friedrich Bassenge (Hg.): Denis Diderot. Ästhetische Schriften. Aus dem Frz. v. F. Bassenge u. T. Lücke. Frankfurt/M.: Europäische Verlagsanstalt, S. 239-347.

Frantz, Pierre (1998): L'esthétique du tableau dans le théâtre du XVIIIe siècle. Paris: Presses Universitaires de France.

Freud, Sigmund (1982): »Die Zukunft einer Illusion«. In: Ders.: Studienausgabe Band IX. Fragen der Gesellschaft. Ursprünge der Religion. Frankfurt/M.: Fischer, S. 135-190.

Haß, Ulrike (2004): »Wo glaubten die Szenographen, daß sich ihr Publikum befände. Eine genauso alte wie neue Frage« [Vortrag im Rahmen der Tagung »Theater sucht Publikum«. Evangelische Akademie Tutzing, 05.-07.03.2004]. 
Haß, Ulrike (2005): Das Drama des Sehens. Auge, Blick und Bühnenform. München: Fink.

Heeg, Günther (2000): Das Phantasma der natürlichen Gestalt. Frankfurt/M. und Basel: Stroemfeld.

Kern, Andrea (2006): »Illusion als Ideal der Kunst«. In: Gertrud Koch/Christiane Voss (Hg.): ...kraft der Illusion, S. 159-174.

Kluge, Alexander (1975): Gelegenheitsarbeit einer Sklavin. Zur realistischen Methode. Frankfurt/M.: Suhrkamp.

Koch, Gertrud/Christiane Voss (2006): ...kraft der Illusion. München: Fink.

Koch, Gertrud (2006): »Müssen wir glauben, was wir sehen? Zur filmischen Illusionsästhetik «. In: Dies./Christiane Voss (Hg.): ...kraft der Illusion, S. 53-70.

Ladzarzig, Jan (2005): »Illusion«. In: Erika Fischer-Lichte/Doris Kolesch/Matthias Warstat (Hg.): Metzler Lexikon Theaterheorie. Stuttgart und Weimar: Metzler, S. 140-142.

Laudenbach, Peter: »Hexenküche Wirklichkeit. Theatertreffen 2006: Das Dokumentarstück ist wieder da«. In: Süddeutsche Zeitung, 22.5.2006, S. 11.

Lehmann, Hans-Thies (1999a): »TheatReales«. In: Theater der Welt 1999 in Berlin. Arbeitsbuch. Berlin: Theater der Zeit, S. 65-59.

Lehmann, Hans-Thies (1999b): Postdramatisches Theater. Frankfurt/M: Verlag der Autoren.

Lehmann, Hans-Thies (2006): »(Sich) Darstellen. Sechs Hinweise auf das Obszöne«. In: Krassimira Kruschkova (Hg.): Ob?Scene. Zur Präsenz der Absenz im zeitgenössischen Tanz, Theater und Film. Wien u.a.: Böhlau, S. 33-48.

Lessing, Gotthold Ephraim (1981): Hamburgische Dramaturgie. Stuttgart: Reclam.

Marx, Karl/Friedrich Engels (1978): »Die deutsche Ideologie «. In: Dies.: Werke. Band 3, Berlin: Dietz, S. 9-580.

Müller-Schöll, Nikolaus (2002): Das Theater des »konstruktiven Defaitismus«. Lektüren zur Theorie eines Theaters der A-Identität bei Walter Benjamin, Bertolt Brecht und Heiner Müller. Frankfurt und Basel: Stroemfeld.

Müller-Schöll, Nikolaus (2007): »Lügen Tränen nicht? Ausdruck, Konvention und Körper in der Wooster Group-Produktion >To you the birdie (Phèdre) « «. Noch unveröffentlichtes Manuskript.

Nakas, Kassandra/Britta Schmitz (2006): The Atlas Group (1989-2004) A Project by Walid Raad. Köln: Verlag der Buchhandlung Walther König.

Nakas, Kassandra (2006): »Bilder der Verfehlung, fehlende Bilder«. In: Kassandra Nakas/Britta Schmitz (2006): The Atlas Group (1989-2004) A Project by Walid Raad. Köln: Verlag der Buchhandlung Walther König, S. 21-24.

Pavis, Patrice (1996): »Illusion«. In: Ders.: Dictionnaire du Théâtre. Paris: Dunod, S. 167-169.

Strube, W. (1976): »Illusion«. In: Joachim Ritter (Hg.): Historisches Wörterbuch der Philosophie. Darmstadt: Wissenschaftliche Buchgesellschaft, S. 204-215.

Strube, Werner (1971): Ästhetische Illusion. Bochum: Inaugural-Dissertation.

Weber, Samuel (2004): Theatricality as Medium. New York: Fordham U.P.

Wiesing, Lambert (2006): »Von der defekten Illusion zum perfekten Phantom. Über phänomenologische Bildtheorien«. In: Gertrud Koch/Christiane Voss (Hg.): ...kraft der Illusion, S. 89-102. 


\title{
SPIELRÄUME ZWISCHEN MEDIENKUNST UND VIRTUELLER REALITÄT
}

\author{
SUSANNE VILL
}

Die Technologieentwicklung der neuen Medien hat die virtuelle Bühnenraumgestaltung um eine Fülle von Möglichkeiten bereichert, die dem Zuschauer vielfältige Interaktionen in multimedialen Installationen, Environments oder im Internet anbieten.

In präsentativen Formen von Theaterdarbietungen sind die Zuschauer meist physisch passiv. Das Interaktionsangebot von Medienkunstwerken hingegen bietet mehr persönliche Verbindlichkeit oder gar Berührung in der Auseinandersetzung des Rezipienten mit dem Werk, work in progress oder als Mitautor in public domains (vgl. Dietz). ${ }^{1}$ Die aktive Beteiligung des Zuschauers als Mitakteur intensiviert das Erlebnis und die Reflexion über Sinn und Bedeutung des Kunstwerks. In der erweiterten Realität prozessualer Kunst mit und in den Medien, in den hybriden Prozessen, in denen die performative Medienkunst zwischen Kunst und Leben, real und medial operiert (vgl. Frieling), verändert sich nicht nur die Wahrnehmung des Zuschauers. Auch die Themen weichen ab von traditionellen Dramaturgiemustern, deren Schemata wie etwa: A liebt B und C ärgert sich darüber, fast keine Rolle mehr spielen. Häufig werden soziale und politische Themen sowie Wahrnehmungs- und Kommunikationsformen bearbeitet, die zwischen Wissenschaft, Kunst und Spiritualität angesiedelt sind.

Unsichtbares sichtbar zu machen, ist eine alte Zielsetzung des Theaters, der mit den neuen Medien neue visuelle Dimensionen zuwachsen. Die Großaufnahme erschließt der Bühne filmische Intimität, Videos und VR expandieren Raum, Zeit und die Erlebnisqualität, mit globalen Bilddatenbanken werden dokumentarische und künstlerische virtuelle Bildräume erschaffen, mittels eye-tracking wird Kommunikation auch mit ALS-Kranken möglich ${ }^{2}$, Kameras auf der Bühne bringen visuelle Reflexionsebenen ein, Tricktechnik und digitale Bildbearbeitung in Echtzeit schaffen Irritationen über die Realität und formen Erlebnisräume von live-Transformationen und spirituellen Themen, der Körper des Akteurs wird transparent und von Fremden steuerbar, biologische Prozesse, Gefühle und Gedankenformen werden visualisiert, künstliches Leben wird geschaffen, Zeitreisen in simulierte historische Räume werden möglich, nie erbaute Architektur, Denkräume wissenschaftlicher Dokumente oder Phantasieräume werden begehbar, und in Public Domains ist die Kooperationen und Mitautorschaft bei der Komposition visueller und akustischer Ereignisse möglich.

1 Erläuterungen zu den Begriffen Public Domain, Digital Commons, Creative Commons, freie Software, Open Source, Copyleft, Netzwerk-Gesellschaft, Informationsökonomie in: Kluitenberg; sowie Steve Dietz: Public Sphere_s.

2 Christoph Schlingensief: KUNST UND GEMÜSE, Performance, Volksbühne Berlin 2005. 
Das Theater sucht sich mit Großprojektionen die Sogwirkung der Immersion zu erschließen, die von audiovisuellen Großbildräumen ausgeht. Das Eintauchen in Großbild-Immersionsräume, die den Körper des Zuschauers oder Mitakteurs vollständig integrieren, entwickelte sich vom Rundfresko, Panorama, Stereopticon, Cinéorama und IMAX-Kino (mit Kuppel) bis zu den Immersionsverfahren digitaler Gegenwartskunst, wie sie etwa der CAVE erzeugt. Andere Möglichkeiten bieten direkt vor den Augen getragene Apparaturen, wie Perspektivkästen, Stereoskope, Stereoscopic Television, Sensorama und nun das Head-mounted Display, das ein visuelles Eintauchen in ein simuliertes 3D-Environment ermöglicht. ${ }^{3}$ HMD und CAVE suggerieren ein völliges Eintauchen in den Bildraum und Bewegungen in Echtzeit, wobei der umgebende Raum auch umgestaltet werden kann.

Spätestens seit Richard Wagner suchte das Theater sich Wirkungen der Immersion zu erschließen. Die von Klängen wesentlich unterstützte immersive Kraft der Visionen wurde seitdem aber auch kritisiert als Vereinnahmung und Betäubung des Zuschauers, die im Gegensatz steht zur kritischen und Aufklärungsfunktion des Theaters, welche von Metaphorik, Verfremdung und Dekonstruktion geprägt ist. Eine möglicherweise entmündigende Wirkung der digitalen Bild- und Medienwelten wird thematisiert in den Diskussionen um den iconic turn. ${ }^{4}$ Die Interfacegestaltung wird daraufhin befragt, ob sie den Nutzern die medialen und ikonischen Grundlagen bewusst macht oder verschleiert (vgl. Grau). Als Kunstwerke, die Elemente der Wissenschaft verwenden können, aber nicht ihrer Aufklärungsfunktion verpflichtet sind, sondern ihre stärksten Wirkungsmöglichkeiten in den magischmythischen Bereichen des Faszinosums haben, bewegen sich die meisten Medienkunstwerke aber zwischen Aufmerksamkeit und Immersion. ${ }^{5}$ Mittels einer Visualisierungstechnologie, die dem Stand der Kunstentwicklung entspricht, wird das Konzept der Immersion weiter entwickelt.

»Mit den Parametern Raumorganisation, Arrangement der Freiheitsgrade, Avatargestalt, Narrationsstrategie und - im Falle evolutionärer Bildprozesse - der Bestimmung eines Selektionsrahmens gelangen bild-, kunst- und medientheoretisch noch kaum absehbare Gestaltungsmittel in Künstlerhände. In welcher Weise, so soll nun gefragt werden, versuchen Künstler heute, immersive Strategien im Digitalen zu entwickeln, Strategien, die sich etwa auf jene permanent wandelnde Schnittstelle zur Maschine, das Interface, beziehen, die Technik der Telepräsenz einschließen oder Softwaregestaltung für Interaktion und Evolution durch genetische Algorithmen? Diese Elemente zeigen - so die These - in ihrer Kombination auch die Weiterentwicklung des Konzepts der Immersion mittels einer dem State of the Art entsprechenden Visualisierungstechnologie« (Grau).

Die in den letzten Jahren realisierten Konzepte von Medienkunst ${ }^{6}$ und Theater mit Medien überraschen mit immer neuen Innovationen, doch können von den zahlreichen Beispielen hier nur wenige erwähnt werden.

3 Das Head-mounted Display erfand Ivan Sutherland.

4 Als »Iconic Turn« bezeichnete William J. Mitchell den aktuellen kulturellen Wandlungsprozess, den Vilém Flusser, Jonathan Crary, Hans Belting, Horst Bredekamp, Martin Jay, Lev Manovich, Oliver Grau u.a. diskutieren.

5 »between attention and immersion« ist der Untertitel der Interconnect@-Ausstellung am ZKM mit Medienkunst aus Brasilien 02.09.-15.10.2006.

6 Medienkünstler formen heute so unterschiedliche Bereiche wie Telepresence Art, Biokybernetische Kunst, Robotik, Netzkunst, Space Art, Experimente im Nanobereich, Artificial Life Art [z.B. von Karl Sims oder Tomas Ray], Kreation von virtuellen 
Die japanische Multimediakünstlergruppe Dumb type unter Teiji Furuhashi gehörte schon in den 1990er Jahren zu den prominenteren Vertretern. In ihrer Medienperformance $\mathrm{S} / \mathrm{N}^{7}$ (1995) kombinierte sie Live-Aktionen auf der Bühne mit Videoprojektion, computerbasierter Text- und Bildbearbeitung und akustischen Effekten.

Die katalanische Gruppe La Fura dels baus hat 1999 mit F@UST.VERSION 3.0 eine dekonstruktionistische Multimedia-Version des Faust-Stoffes geschaffen, in der computergenerierte Bilder - auch ein Computer-Rollenspiel - als Videos projiziert werden.

\section{Interaktive Installation}

Interaktiv-prozessuale Bildwelten bergen ein großes ästhetisches Potenzial, das genutzt wird zur Gestaltung von Medienkunstwerken, die zwischen Wissenschaft und Kunst angesiedelt sind.

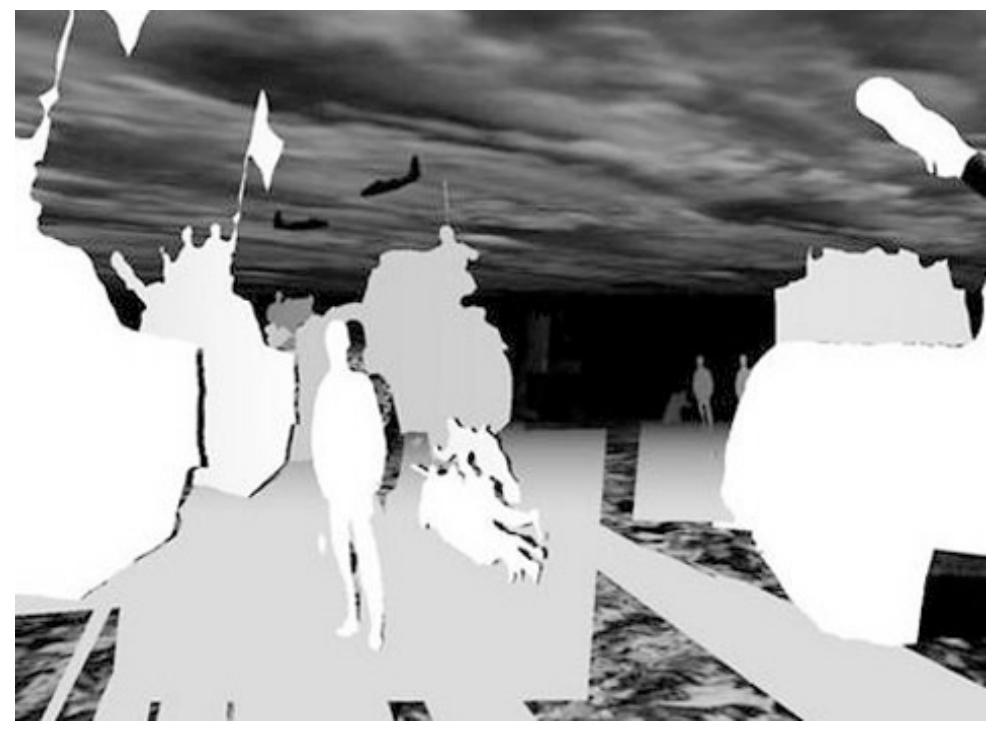

Abbildung 1: Maurice Benayoun: WORLD SKIN (1997). Screenshot.

Für Christa Sommerer und Laurent Mignonneau war es seit ihren ersten interaktiven Installationen ein besonderes Anliegen, Erlebnisräume zu schaffen, in denen der Besucher seine Verantwortlichkeit für die Impulse, die er aussendet, erfahren kann. In der Installation The InTERACTIVE Plant Growing (1993) ${ }^{8}$ sind vier le-

Agenten und Avataren, Datamining, Mixed Realities, datenbankgestützte Kunst und so weiter. Diese Spezialdisziplinen lassen sich wiederum, grob skizziert, in die Gebiete Telematische, Genetische und Immersiv-Interaktive Kunst ordnen und unter dem Oberbegriff $>$ Virtuelle Kunst $<$ fassen.

7 Ausschnitt in »Spiel.ARTen mit Input«. Bericht von Susanne Vill über das Spiel.ArtFestival 1995, Bayerisches Fernsehen 13.11.1995.

8 http://www.medienkunstnetz.de/werke/the-interactive-plant-growing/video/1/ (01.10.2006). 
bende Pflanzen aufgestellt, an deren Wurzeln Sensoren angebracht sind. Der Besucher wird aufgefordert, die Pflanzen zu berühren, wodurch ein bildgebender Impuls ausgelöst wird, der auf den frontalen Screens virtuelle Pflanzen wachsen lässt. Wird der Kaktus berührt, so werden die virtuellen Pflanzen gelöscht. Die Installation will die Erfahrung vermitteln, dass selbst eine nur leichte Berührung eines Blattes die Pflanze bis in die Wurzeln »erschüttert«. Die Sensoren visualisieren diese Bewegung als Schnittstelle zwischen vegetativem und apparativem System, Mensch und Maschine.

SONOMORPHIS (1997 und 1998) ${ }^{9}$ von Bernd Lintermann und Torsten Belschner, ist ein organisches Objekt, das aus einzelnen Formen wie Kugeln, Blättern und Armen besteht, die ständig in Bewegung sind. Erzeugt wird es in einer interaktiven stereoskopischen Installation mit genetischen Grafiken und Klängen, die direkt vor Ort und/oder über das Internet gesteuert werden kann. Das System generiert sechs automatische Variationen der projizierten Struktur, aus denen der Besucher mittels einer Interface-Box mit drei Knöpfen die Mutationen des Objekts wählen und mit acht Reglern dynamische Parameter des Objekts und Kamera-Position verändern kann. Zwei Beamer projizieren die vom SGI Computer als Echtzeit-Animation generierten Bilder auf eine Leinwand. Der Zuschauer nimmt mit Stereobrille die Bilder als 3D-Objekt im Raum wahr. Die visuelle Form des Objekts ist gekoppelt an zwei Macintoshs, die die Klänge generieren und über sechs Lautsprecher übertragen. Die zusätzlichen Elemente der vom Spieler gewählten Veränderungen wachsen aus der projizierten Form heraus, fehlende verschwinden. Aus der letzten angewählten Form entwickeln sich weitere Mutationen. Das Spiel mit den Reglern und dem Tempo gleicht dem auf einem Musikinstrument, wobei das Temperament des Spielers umgesetzt wird. Er wählt einen Pfad durch $10^{80}$ mögliche Formen, und mit dieser Zahl stellt Lintermann eine Analogie her zur Anzahl aller Atome des Weltalls.

Wie Sommerer/Mignonneau fordert auch Maurice Benayoun von den Besuchern seiner interaktiven Installation WORLD SKIN (1997) Verantwortung zu übernehmen für die Konsequenzen der eigenen Neugier und mithin auch für die Tatsache, dass Kriege heute z.T. um der Medienereignisse willen geführt werden.

Mit Fotoapparaten bewaffnet bewegen sich die Besucher quasi auf einer >Fotosafari< in einem Land, in dem Krieg herrscht. In einem CAVE werden Fotos und Nachrichtenbilder verschiedener Kriegsschauplätze projiziert, die durch Stereobrillen als rundum laufende, virtuelle Objekte plastisch wirken. Die Besucher sollen nun ihre Erinnerungsfotos $>$ schießen $<$, doch mit jedem Foto verschwindet der foto-

9 ZKM Sammlung; vgl. Information bei der Ausstellung DAS DIGITALE BAUHAUS, Kunstfest »pèlerinages« Weimar 2006; vgl. Grau: »Varianz und Erweiterung erfuhr das Konzept spielerischer Kombinatorik durch die fast zeitgleich am ZKM entstandene Installation SONOMORPHIS (1998) von Bernd Lintermann und Torsten Belschner. Auch im Bildraum von SONOMORPHIS lassen sich immer neue, auf genetischen Algorithmen basierende biomorphe Körper >schöpfen<. Lintermann versetzt die artifiziellen Wesen in permanente Rotation und unterstützt die räumliche Wirkung durch Stereosound, der gleichfalls auf Zufallsprozessen beruht und beabsichtigt die interaktive Struktur der Installation flexibel, wie ein Instrument, zu begreifen, ein Instrument, das sich in diesem Fall aus visuellen und akustischen Komponenten zusammenfügt. 10 hoch 80 verschiedene Formen sind möglich, womit er eine Analogie zur Anzahl aller Atome des Weltalls zieht. Wie dem auch sei, die Anzahl der möglichen Varianten ist in SONOMORPHIS unvorstellbar komplex und nicht im Ansatz erfahrbar«. Vgl. http://www.medienkunstnetz.de/werke/sonomorphis/ (01.10.2006). 
grafierte Gegenstand aus der Installation und hinterlässt eine weiße Fläche - die zweite, die visuelle >Haut< der Welt, die im Bewusstsein der Medienkonsumenten die Wirklichkeit überlagert, bekommt Löcher. Der Bildraum von WORLD SKIN reagiert wie beim 1991 von ART+COM entwickelten >Zerseher<, wo sich das Bild unter den Blicken des Betrachters zersetzt: die fotografierten Kriegsschauplätze werden zum >Eigentum< des Besuchers, der die Ausdrucke seiner Fotos mitnehmen kann. Auf der Website von WORLD SKIN werden die fotografierten Bilder abrufbar. $^{10}$

\section{Interaktives Environment}

MEMORY THEATER VR (mit Vorführung einer VR) $(1997)^{11}$ von Agnes Hegedüs ist ein interaktives Environment, das, an die Tradition der italienischen Humanisten anknüpfend, einen Tempel der Erinnerung schafft als Speicher für das Wissen der Welt, Gedächtnistheater als virtuelle Denkräume. Der Besucher betritt einen zylindrischen Raum mit Videokamera und großer Leinwand, in dessen Mitte ein Miniaturmodell des »Memory Theater « steht. Wird die Kamera in diesem Modell bewegt, so erscheinen auf der Leinwand Bilder über Täuschung im Raum und manieristische, futuristische oder dekonstruktivistische Konzepte der virtuellen Realität (vgl. Schwarz: 121; ZKM: 33). Den vier Richtungen sind Themenkreise zugeordnet sowie Bilder phantastischer Räume, Namen berühmter Wissenschaftler, Philosophen und Künstler, Visionen von Futuristen, Surrealisten, »Alice im Wunderland « und - wie im folgenden Video - ein Ausschnitt aus Cocteaus Film ORPHÉE mit dem Eintauchen des Dichters ins Totenreich durch den Spiegel seines Schlafzimmers.

Lenkung des Blicks und Entscheidung in realen wie theatralen Konfliktsituationen thematisiert Daniela Alina Plewe in Ultima Ratio (1999) mit VR-Environment. Plewe sucht nach einer dem Theatergeschehen entsprechenden visuellen Sprache, welche die logische, innere, der Handlung vorausgehende Argumentation der Protagonisten widerspiegelt.

»In diesem VR-Environment werden menschliche Paradoxa und Dilemmata als logische Strukturen dargestellt. Ein System zur Entscheidungshilfe aus der Forschung zur Künstlichen Intelligenz beurteilt daraufhin Fragestellungen wie: Soll Hamlet Claudius töten ..., soll jeder nach seinen Idealen streben, auch wenn man den eigenen Tod riskiert ... usw.? [...] Das System generiert innere Monologe der Personen und visualisiert diese in 3D-Diagrammen. Die Ambivalenz der Fragen werden als Bilder mentaler Räume erfaßt« (Plewe).

Obwohl die Argumente hier nur als fragile, abstrakte Repräsentanten der Bedingungen, Denkprozesse und Dynamik der Situationen erscheinen, wird doch die Vision eines offenen Theatersystems erkennbar, in dem das Publikum spielerisch an komplexen Entscheidungsmodellen beteiligt wird. Oliver Grau erkennt in dem »immersiven Narrationspfad - eine Symbiose virtueller Kunst mit dem Theater«.

10 http://www.art-of-immersion.com/projects_g.html\#2 (01.10.2006); vgl. Grau.

11 http://www.medienkunstnetz.de/werke/memory-theater-vr/video/1/. 


\section{Interaktives Environment/Performance}

DESERT RAIN ${ }^{12}$, eine Kombination aus virtueller Realität, Installation und Performance, entwickelte die Gruppe Blast Theory in Zusammenarbeit mit dem Mixed Reality Lab (der University of Nottingham). Sechs Teilnehmer werden in einem interaktiven virtuellen Environment auf eine Mission in eine virtuelle Welt des Krieges, hier: des Golf-Kriegs, geschickt. Jeder bekommt eine Magnetkarte einer Person, die er finden soll. In separaten Zellen können sie auf ihrer 30-MinutenReise in die virtuelle Welt die Navigation durch die VR-Environments mittels Fußplatten steuern. Die VR wird auf einen Waterscreen von 4 Meter Durchmesser projiziert. Die Spieler erkunden auf ihrer Suche nach den Menschen Motels, Wüsten, Tunnels, Bunker. Über Kopfhörer können sie sich verständigen und ihre Suche beenden. Wenn sie ihr Ziel erreicht haben, tritt ein Performer durch den Waterscreen und gibt ihnen eine Magnetkarte. Durch einen Untergrund-Hangar nach irakischem Vorbild muss der Ausgang gefunden werden. Die Spieler verlassen die virtuelle Welt durch den Waterscreen, steigen über einen Sandhügel und gelangen in den letzten Raum - ein Hotelzimmer.

Die Performance problematisiert die Grenze zwischen real und virtuell, die durch die Medien-Events systematisch durchbrochen wird. Jean Baudrillards These, der Golfkrieg sei ein virtueller Krieg gewesen, zielt ab auf die generelle Ungewissheit, ob die Events, über die die Medien berichten, auch tatsächlich stattgefunden haben (vgl. auch die Mondlandung). Reale Ereignisse verlieren ihre Identität, wenn sie in den raschen Informationsfluss geraten.

Die Verschmelzung der Gattungen und auch der Medien gilt seit den 1990er Jahren als ein Signum der virtuellen Kunst und der sie tragenden Technik. Jeffrey Shaw entwickelte mit Michael Gleich, Lawrence Wallen, Bernd Lintermann und Torsten Belschner im Jahre 2000 das interdisziplinäre Projekt zwischen Kunst und Wissenschaft WEB OF LIFE. ${ }^{13}$ Diese Installation, für die ein besonderer, quasi theatraler Umraum gestaltet wurde, ermöglicht dem Besucher die Beeinflussung einer aus dreidimensionalen Computergrafiken, projizierten Videobildern und akustischen Ereignissen bestehenden Umgebung. Ein Interface scannt die Haupthandlinien des Besuchers und fügt sie ein in das Netz der Handlinien vorheriger Besucher. Auf der großen Projektionsfläche erscheint das wandelbare algorithmische Muster miteinander verknüpfter Bild- und Klangwelten, die durch das Netz der Handlinien ständig neu aktiviert und verändert werden, ${ }^{14}$ denn sobald die neuen Handlinien andere berühren, lösen sie eine Veränderung aus. Mit Stereobrillen wird das Bild als 3D gesehen. Hinter dem Liniennetz laufen aus einem Gesamtrepertoire von 64 vorgefertigten Videos ausgewählte Videos. ${ }^{15}$ Die Einspielung und Koordination mehrerer Videos in ineinander fließende, bewegte Teilscreens wird von der Software gesteuert. Das Projekt, zu dem auch ein Buch und eine Website gehören, ist mit vier weiteren mobilen Stationen weltweit vernetzt.

12 www.blasttheory.co.uk/bt/work_desertrain.html (01.10.2006). vgl. hierzu: Dixon 616ff.

13 General concept: Jeffrey Shaw, Michael Gleich - Projected imagery concept: Bernd Lintermann - Projected video concept: Lawrence Wallen - Audio concept and sound design: Thorsten Belschner. ZKM installation architecture concept and design: Manfred Wolff-Plottegg and Arne Böhm - User interface concept and design: Michael Gleich, Jeffrey Shaw, Bernd Lintermann - Produced at the ZKM Institute for Visual Media. Homepage: www.web-of-life.de/index.html.

14 Irina Koutoudis, Informationstext im ZKM.

15 Diese Videos sind auf einem Touchscreen vor der Installation separat abrufbar. 


\section{Theater in einem interaktiven Environment}

Auf der Suche nach Erweiterungen der traditionellen Darstellungsmöglichkeiten im Theater durch Computer- und Videotechnologie hat Bruno Cohen ein interaktives Environment kreiert: CAMERA VIRTUOSA (1996) spielt mit Wahrnehmung und Selbstwahrnehmung in einer quasi theatralen Situation.

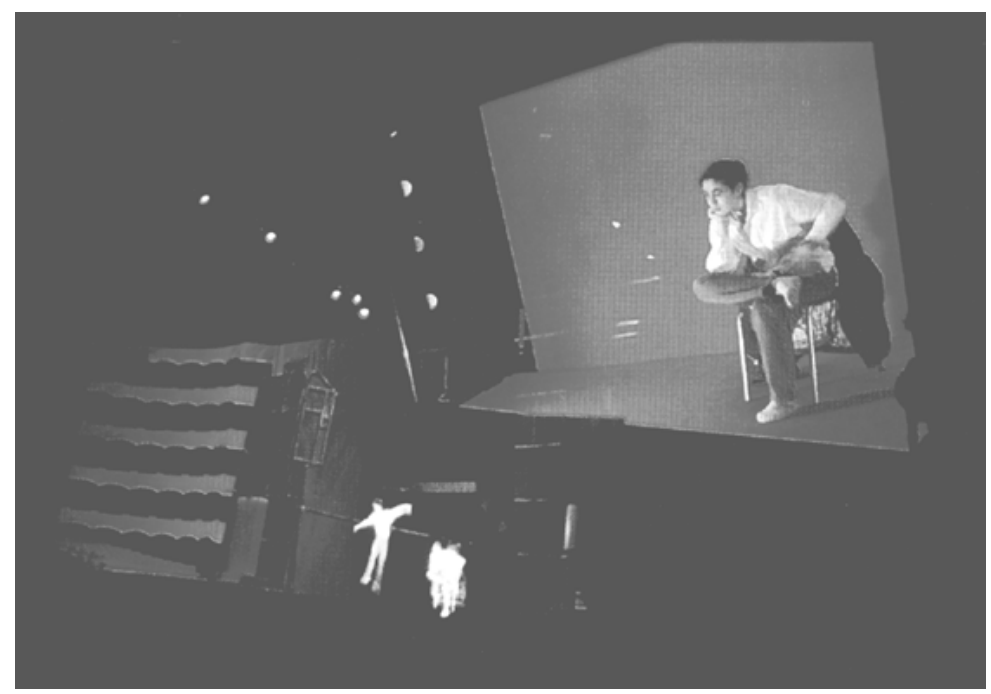

Abbildung 2: Bruno Cohen: CAMERA VIRTUOSA (1996).

Der Besucher betritt eine Künstlergarderobe. Stellt er sich vor den halbtransparenten Spiegel an der Wand, so verschwindet die eigene Reflektion und er sieht dahinter eine Miniaturbühne. Per Videoaufnahme wird nun der Teilnehmer selbst auf dieser Bühne eingeblendet, wo er sich als virtuelles Abbild unter anderen Schauspielern sieht, die ihn zu Aktionen auffordern und auf seine Bewegungen reagieren. Je nach Aktion des Besuchers erscheinen unterschiedliche Darsteller: bei Inaktivität ein gelangweilter Schauspieler, bei künstlerischer Bewegung ein Tänzer etc. Der Besucher kann virtuelle Handlungen vorantreiben, Schauspieler auf- und abtreten lassen, Dekor, Geräusche und Beleuchtung verändern, und dabei sein virtuelles Selbst beobachten.

Während der Aktion vor und auf der Miniaturbühne können andere Besucher das Geschehen in der Garderobe und auf der Bühne auf zwei außen angebrachten Monitoren beobachten. Die CAMERA VIRTUOSA verschiebt die Grenzen zwischen Schauspieler, Mitakteur, Zuschauer und Regisseur, die sich an verschiedenen Orten aufhalten, oder als verkleinertes Spiegelbild auf einer virtuellen Bühne agieren können. ${ }^{16}$

Zentrales ästhetisches Reizmoment der interaktiven Installation wie auch des Theaters im VR-Raum ist der Live-Charakter der intermedialen Interaktion, die dem Zuschauer erlaubt, Komposition zu erleben als performativen Akt spontaner

16 Vgl. Evelyn Edtmaier (1996) Bruno Cohen/Camera Virtuosa. Informationstext. ZKM Karlsruhe. 
Umsetzung von multiplen Impulsen. Als Studie der Interaktion zwischen Text, Musik, Bewegung und Bild entstand TRANS in der Theaterwerkstatt der Universität Bayreuth 2005. ${ }^{17}$ Einen eigenen Text, collagiert mit Fragmenten aus Gedichten in fünf Sprachen über die Transformationen, die Menschen im Verlauf ihres Lebens in der Natur, in der Liebe, in Tod und Reinkarnation erleben, habe ich als Vokalimprovisation mit Live-Elektronik realisiert, wobei der Stimmklang mittels Vocoder verfünffacht und ausharmonisiert sowie mit bis zu 16 Delays eines Echos aufgesplittet und seine Raumwirkung durch verschiedene Hallformen gestaltet wurde. Zwei Tänzer setzen die Impulse von Text und Musik um in Bewegungen und Kontaktformen, die von den im Raum verteilten Sensoren und Kameras aufgenommen wurden. Die Programmierung der visuellen Umsetzung der Impulse von Sensoren und Kameras mit Max/MSP/Jitter nahmen Melchior Hoffmann und Domingo Stephan vor. Die Bildbearbeitung des Inputs von Sensoren und Kameras wurde live gesteuert und erzeugte variable Formen, Kontrastwirkungen und Effekte wie Farbänderungen, Fragmentierung, Invertierung etc., die auf eine Leinwand projiziert wurden. Die so entstandenen Bilder, Formen, Farben, ihre Dichte und ihr Rhythmus beeinflussten wiederum die Erfindung der Musik und die Bewegung der Tänzer.

\section{Virtuelle Realität/Theater}

1996 kreierten Jeffrey Shaw, Agnes Hegedüs und Bernd Lintermann ein interaktives Environment, dessen Bildraum sich mit den vom Besucher an einer Gliederpuppe ausgeführten Bewegungen verändert: CONFIGURING THE CAVE. Die Installation, so erklärt Jeffrey Shaw,

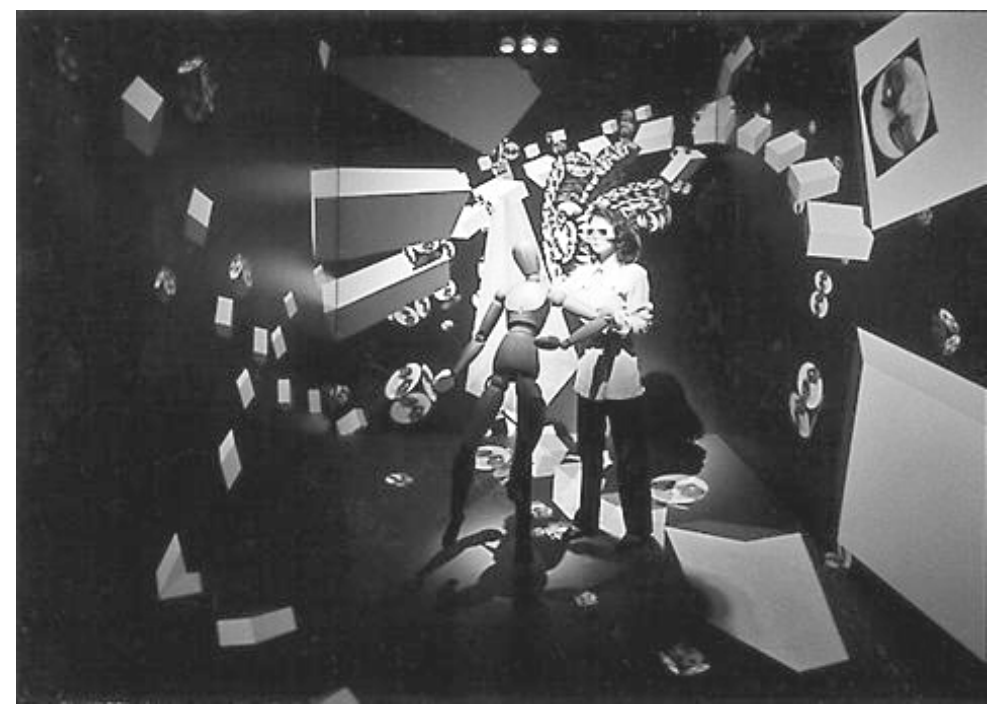

Abbildung 3: Shaw/Hegedüs/Lintermann: CONFIGURING THE CAVE (1996).

17 Susanne Vill (Konzept, Text, Musik), Melchior Hoffmann, Domingo Stephan (Max/ MSP/Jitter Programmierung), Melchior Hoffmann, Julia Blankenburg (Tanz). 
»konfrontiert den Besucher mit sieben einander folgenden audio-visuellen, virtuellen Welten. Die Besucher werden mit einer 3D-Brille ausgestattet und betreten das Medientheater. In der Mitte des Raumes steht ein Computermonitor vor einer riesigen Projektionsfläche. Auf dem Monitor ist eine virtuelle Modellierpuppe zu sehen. Die Besucher sind eingeladen, die Puppe zu manipulieren: ihren Kopf zu neigen, ihre Gliedmaßen zu bewegen, sie horizontal oder vertikal zu drehen. Auf diese Weise können sieben unterschiedliche computergenerierte Welten erkundet und kontrolliert werden. Indem der Besucher mit den Händen der Puppe ihre Augen verschließt und wieder öffnet, kann er sich in die nächste dreidimensionale Welt begeben. In jeder der projizierten Umgebungen variiert die interaktive Funktion der Puppe, und so ist es die Aufgabe des Besuchers, die unterschiedlichen Parameter der Bilderwelten herauszufinden. ${ }^{18}$

Für die Produktion A Midsummer Night's DreAM, ${ }^{19}$ die Mark Raeney vom Institute for the Exploration of Virtual Realities, University of Kansas, ${ }^{20}$ gemeinsam mit Kent Interactive Digital Design Studio for KIDDS im Jahr 2000 kreierte, wurden drei Leinwände mit VR- und live-Kamera-Bildern bespielt.

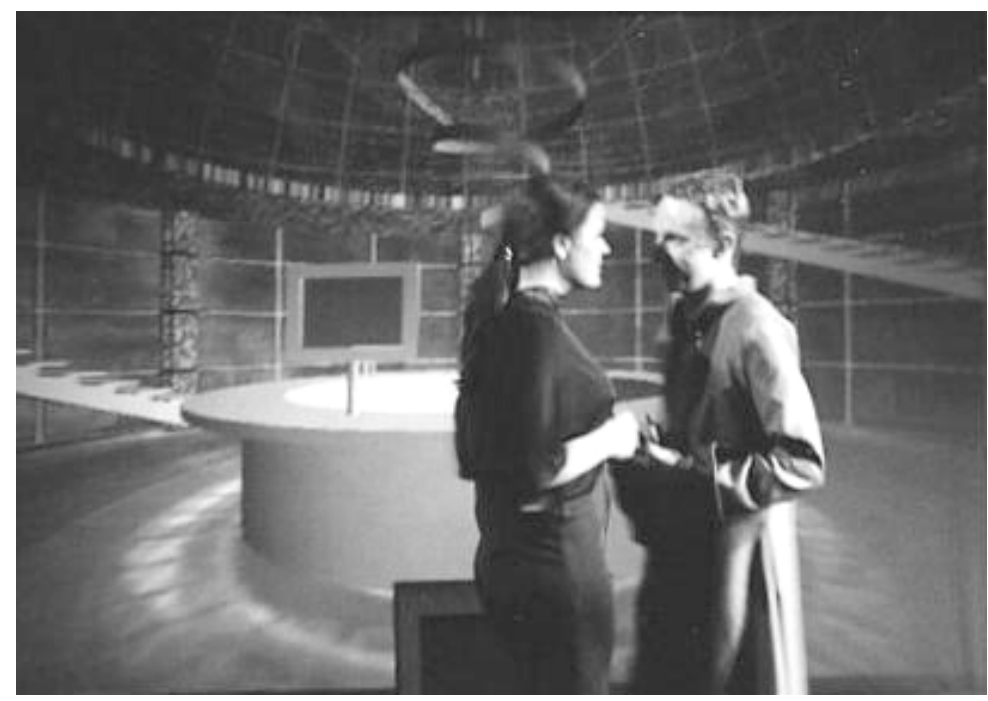

Abbildung 4: Mark Reaney, i.e.VR / Kent Interactive Digital Design Studio for KIDDS: A MIDSUMMER NIGHT'S DREAM.

18 http://www.medienkunstnetz.de/werke/configuring-the-cave/ (01.10. 2006).

19 UA am Lumley Studio Theatre, University of Kent, Canterbury 2000.

20 Mark Reaney (Production Designer) Josephine Le Grice (Director), Michael Gold (Scenic Designer); Die Produktion entstand unter der Leitung von i.e.VR Direktor Mark Reaney in Zusammenarbeit mit dem i.e.VR und den Kent Interactive Digital Design Studio for KIDDS, einer Gruppe, die Computeranwendungen entwickelt für theatrale Visualisierungen zu historischen und praktischen Zwecken. Homepage: http://www2.ku.edu/ ievr/midsummer/ (01.10.2006). Vgl. Reaney. 
Die Szenerie wurde hinter der Bühne auf Computern als 3D VR-Bilder kreiert und auf durchsichtige Leinwände projiziert, vor denen die Akteure agierten. Die Navigation durch die VR-Hintergründe steuerte ein Techniker live, um flüssig durch die simulierten Räume zu gelangen oder die Bewegung der Hintergründe den Bewegungen der Darsteller anzupassen. Die virtuelle Szenerie gibt manchmal die konkrete Location der Handlung wieder, manchmal zeigt sie auch Gedanken, Phantasien, Ängste u.a. psychologische Details der Charaktere. Das Publikum trägt 3DBrillen, wodurch die Illusion entsteht, dass das virtuelle Set der Bühne mit der Handlung der Akteure verbunden ist.

Für Shakespeares Stück wurde mit Computerspielen, Cyberspace und Science fiction-Elementen eine Zauberwelt kreiert, die von Feen und Elfen bewohnt und kontrolliert wurde.

Diese Synthese aus live gespieltem Theater und Computertechnologie ist visuell sehr reich und als theatrale Spielform neu. Sie eignet sich gut für dekonstruktionistische Inszenierungen, die trotz des hohen Reflexionsgehaltes aufgrund der Immersion der Bilder eine starke Suggestionskraft haben, wobei die Wirkung der Immersion weitgehend von der Größe der Leinwände abhängt.

\section{Immersionsräume}

Raquel Kogan, Architektin und Künstlerin aus São Paulo, befasst sich vor allem mit der Entstehung von Räumen in digitalen Medien. REFLEX̃̃O \#2 (2005) ${ }^{21}$ ist eine interaktive Multimedia-Installation, die mit einem dunklen Raum arbeitet, in dem an zwei gegenüberliegenden Wänden Spiegel angebracht sind. Betritt ein Besucher den Raum, so aktiviert er mittels Sensoren die Installation, und eine Projektion von Zahlenreihen, die auf dem Boden von der Mitte des Raums auf die Spiegelwände zulaufen, schaffen durch die Spiegelungen einen den Körper des Besuchers einschließenden Raum. Die interaktive Installation will die Selbst-, Fremd-, Raum- und Körperwahrnehmung thematisieren.

Kurt Hentschläger und Ulf Langheinrich haben mit GRANULAR $\approx$ SYNTHESIS $^{22}$ eine Reihe von Raum-Klang-Installationen geschaffen, in denen das Publikum audio-visuelle Grenzerfahrungen erleben kann. RESET $(2001)^{23}$ ist das minimalistischste Werk der Gruppe und arbeitet mit psychedelischen Effekten. Die Installation läuft in einer Schleife von zwei synchronisierten DVD-Playern, die auf zwei Screens an gegenüberliegenden Wänden projizieren. Die Beschallung läuft über multikanal audio und sub-audio.

21 »Interconnect@ between attention and immersion. Medienkunst aus Brasilien« Ausstellung im ZKM Karlsruhe 02.09.-15.10.2006, Katalog.

22 Bei der Installation $<360>$ GRANULAR $\approx$ SYNTHESIS sind 16 Leinwände und 16 Lautsprecher im Kreis aufgestellt. Auf die Leinwände werden Videos mit unterschiedlicher Farb- und Formgestaltung projiziert. Das Publikum sitzt im inneren Kreis. Von Innen ist es ein Horizont aus Licht und Klängen; von außen eine kinetische Skulptur.

23 IMMERSIVE WORKS, GRANULAR $\approx$ SYNTHESIS, Kurt Hentschläger/Ulf Langheinrich, DVD 2004 by ZKM Karlsruhe, S. 37; www.granularsynthesis.info. 


\section{Mediatisierung des Körpers}

Die Exploration des Körpers geschieht nicht nur als Darstellerkörper, sondern auch als Bühne: Stelarcs Projekte und Performances suchen nach Erweiterungen körperlicher Funktionen durch zusätzliche Interfaces und Apparaturen. Seine THIRD HAND ist eine angefügte Technologie, STOMACH SCULPTURE nutzte medizinische Diagnosemethoden als bildgebende Quelle, in EXOSKELETON kreierte er eine sensorkontrollierte Roboterextension seines Körpers, in PING BODY (1996) erlaubte er Zuschauern über Internet einen Zugriff auf seinen Körper.

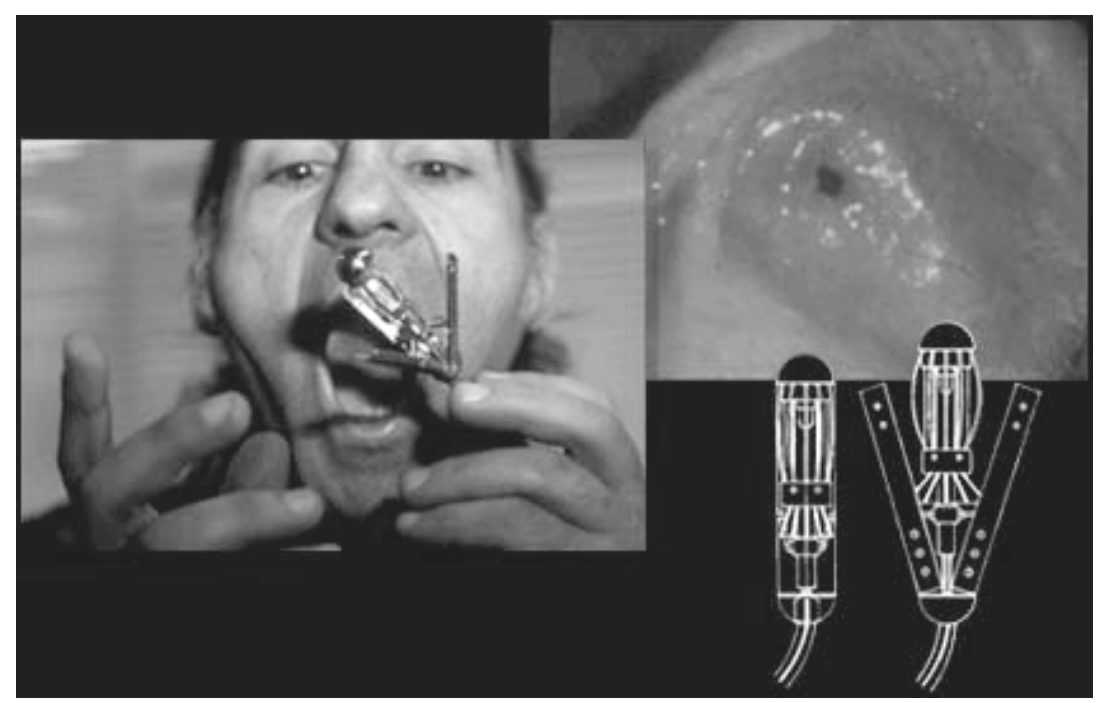

Abbildung 5: Stelarc: STOMACH SCULPTURE.

Stelarc erklärte, es gehe ihm um eine Verlagerung von Bewegung von einem am Netz angeschlossenen Körper zu einem anderen. ${ }^{24}$ Für die webbasierte Performance PING BODY ${ }^{25}$ wurden beim Telepolis »Fractal Flesh «-Event (1995) drei Städte $^{26}$ elektronisch verbunden und Netzbesucher konnten Stelarcs Körper mittels

24 »Agency could be shared in the one body or in a multiplicity of bodies in an ELECTRONIC SPACE OF DISTRIBUTED INTELLIGENCE, a body with TELEMATIC SCALING OF THE SENSES, perceiving and operating beyond its biology and the local space and human scale it now occupies, a body remapped and reconfigured, a body directly wired into the Net, a body that manifests the statistical and collective data flow, as a socio-neural compression algorithm. A body whose proprioception responds $[\ldots]$ to the external stimulation of globally connected computer networks.«In: www.stelarc.va.com.au/fractal/index.html.

25 Performance-Assistenz: Gary Zebington (programming and graphics), Rainer Linz (sound design), Dmitri Aronov (Unix ping software), Mic Gruchy (video) und die Merlin Crew. Berater waren Adam Burns (Pegasus), Andrew Garton (Toy Satellite) und Andrew Pam (State Film Centre).

Quelle: http://www.stelarc.va.com.au/pingbody/index.html.

26 Paris (Centre Pompidou), Helsinki (The Media Lab) und Amsterdam (Doors of Perception Conference). 
eines »computer-interfaced muscle-stimulation system « manipulieren. Die Körperbewegungen waren dann zwar unwillkürlich, doch konnte Stelarc seine »Dritte Hand « aktivieren und eine Reihe von Bildern auf die Website hochladen. Die Performance konnte live im Internet verfolgt werden.

Virtualisierungen des Körpers, die seine reale Präsenz an einem bestimmten Ort mit Strategien der Dislozierung und Mediatisierung verbinden und experimentieren mit Telematik und Internetanbindung in Echtzeit sind zum Beispiel in Christian Zieglers SCANNED V (2001) erkennbar. ${ }^{27}$ Der Medienkünstler dazu:

»In der Performance SCANNED V ist die Choreografie Material eines bildnerischen Prozesses. Bewegung wird digitalisiert und gescannt. Es entwickelt sich ein visueller und akustischer Dialog zwischen Performance und Live-Sampling. Auf der Bühne entsteht ein verdichtetes zeitliches und räumliches Abbild der Choreografie einer Aufführung. SCANNED V verbindet in ,gemalter' Bewegung Tanz und Malerei, darstellender mit visueller Kunst. $\ll^{28}$

Mit Videoprojektionen auf als Bluebox blau bemalte Körperteile experimentierte schon 1982 Bernd Kracke in MEdia GAMES. ${ }^{29}$ Nach dem Prinzip der Projektion auf bewegte Körper gestaltete der Medienkünstler und Komponist Klaus Obermaier in Zusammenarbeit mit dem Choreographen und Tänzer Chris Haring die »digital amplified video engine « D.A.V.E. (1998-2000) als eine innovative Synthese von Video-Art, Tanz und Musik. Am Körper des Performers auf der Bühne werden Neugestaltungsmöglichkeiten des menschlichen Körpers mittels Gen-, Bio- und Computertechnologie visuell vorgeführt. D.A.V.E. dekonstruiert den Körper im Zeitalter der biotechnologischen Reproduzierbarkeit und macht eine Utopie der Entgrenzung des natürlichen Körpers sichtbar, die Erlebnisse von Alterität ermöglicht. Der Tänzerkörper und sein virtuelles Double durchlaufen Gestalt- und GeschlechtsWandel, Mutationen und Metamorphosen, bis sie sich auflösen in strömende digitale Bildwelten.

Als »eine Untersuchung der unterschiedlichen Geschwindigkeiten von Mensch/ Natur und Technologie/Informationsgesellschaft bzw. deren Beschleunigung, ein Experiment zur Aufhebung des Raum-Zeitkontinuums « ${ }^{30}$ bezeichnet Obermaier VIVISECTOR (2001/02). Einzelne Körperteile werden durch die Beleuchtung akzentuiert, andere ausgeblendet, Bewegungsabläufe werden granuliert, zeitlich neu geordnet und »videotechnische Eingriffe in organische Strukturen ${ }^{31}$ vorgenommen. Die Konzentration auf Videolicht und -projektion erzeugt eine suggestiv koordinierte Wirkung von Licht, Körper, Video und Klangraum.

27 http://www.medienkunstnetz.de/werke/scanned5/video/1/ (01.10.2006). Vgl. Frieling.

28 Teil 1 (Installation): SCANNED V verarbeitet die Bewegung der Zuschauer beim Einlass in den Theaterraum; Teil 2 (Tanz - gescannt): Das Computersystem scannt die Bewegung des Tänzers, verarbeitet die Informationen in Echtzeit und projiziert den fortlaufenden Prozess. Kurze Bewegungsabschnitte werden für Teil 3 digitalisiert; Teil 3 (re - scan): Ein Operator (VJ) reorganisiert diese Bewegungen und fügt die Einzelteile zu einem neuen Bild der Choreografie zusammen. Die Choreografie entsteht im Kopf des Betrachters. (Christian Ziegler in: www.medienkunstnetz.de/werke/scan ned5/).

29 http://www.aec.at/de/archiv_files/19821/1982_045.pdf (03.07.2008).

$30 \mathrm{http} / / / \mathrm{www}$. exile.at/vivisector/ (03.07.2008).

31 Ebd. 
In APPARITION (2004) wird das interaktive System zum Partner des Darstellers während der Performance:

»Das für APPARITION entwickelte kameragestützte Motion-Tracking-System setzt komplexe Bilderkennungsalgorithmen ein, um die Konturen des sich bewegenden Tänzers vom Hintergrund - sowohl für die ständig aktualisierte Körperprojektion als auch die qualitative Berechnung bestimmter dynamischer Größen wie Geschwindigkeit, Richtung, Intensität und Lautstärke - zu isolieren. Die auf diesen Berechnungen basierenden Informationen bestimmen dynamisch die Echtzeitgenerierung der Visuals, die entweder direkt zurück auf den Körper und/oder großformatig als Hintergrund projiziert werden. Die präzise Synchronisierung der Projektionen auf den Hintergrund und die Körper ergeben eine Materialisierung eines ganzheitlichen immersiven kinetischen Raums/einer virtuellen Architektur, die zugleich fließend und starr sein kann, sich ausweiten und kontrahieren, sich wellen, krümmen und verzerren kann, um auf die Bewegungen des Darstellers zu reagieren oder sie zu beeinflussen. $\ll^{32}$

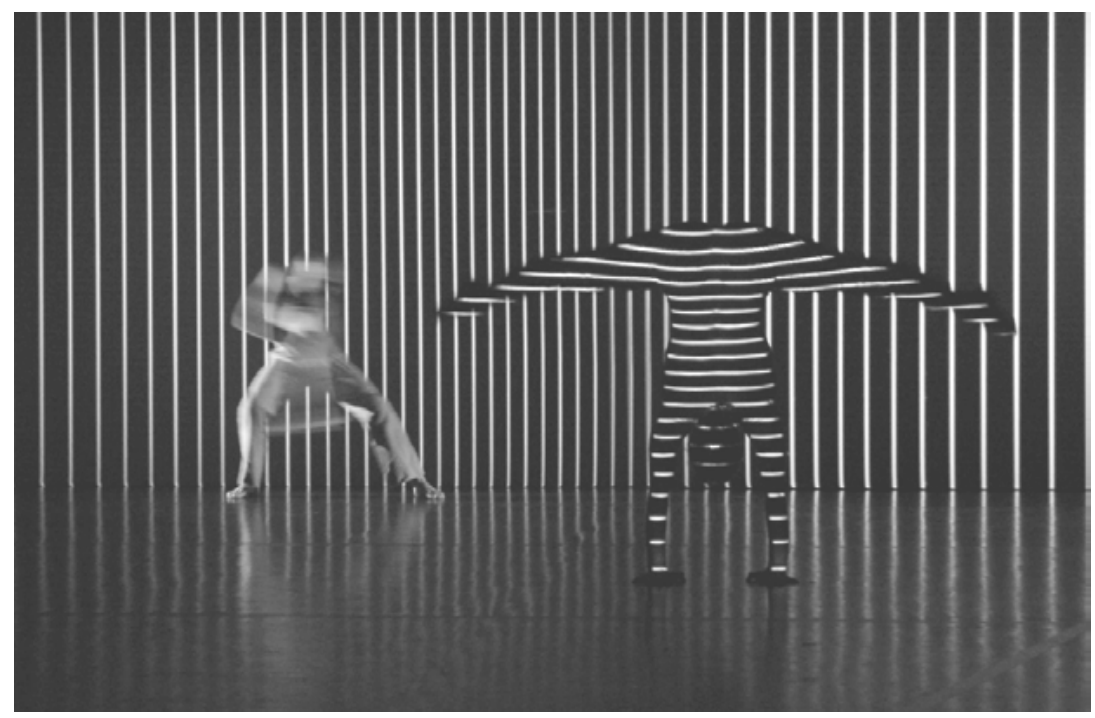

Abbildung 6: Klaus Obermaier mit dem Ars Electronica Futurelab: APPARITION, feat. Desireé Kongerød und Robert Tannion.

Die Immersion des Zuschauers wird noch wesentlich verstärkt durch die von Obermaier mit dem Ars Electronica Futurelab für seine Inszenierung von Strawinskys LE SACRE DU PRINTEMPS, AN INTERACTIVE STEREOSCOPIC DANCE AND MUSIC PERFORMANCE $(2006)^{33}$ entwickelten stereoskopischen Kamerasysteme, deren Bilder

32 http://www.exile.at/apparition/ (03.07.2008) Klaus Obermaier in Zusammenarbeit mit dem Ars Electronica Futurelab, Robert Tannion und Desireé Kongerød (Tanz), Christopher Lindinger, Robert Praxmarer und Peter Brandl (Interaction-Designer und Programmierer), Hirokazu Kato (Analyse- und Motion-Tracking-System). Text: Scott deLahunta (Übers. Michaela Meth).

33 http://www.exile.at/sacre/ Projekt (03.07.2008). 
durch Computer gefiltert, bearbeitet und projiziert werden. Die Musik selbst transformiert mit ihren Motiven, Stimmen, Instrumenten, ihrer Dynamik und Struktur interaktiv die Avatare der Tänzerin Julia Mach wie auch die 3D-Projektionen der Echtzeit-generierten virtuellen Räume, die wiederum mit der Tänzerin interagieren. ${ }^{34}$

Schon 1966 wollte Alex Hay »die leisesten Körpergeräuschen aufzeichnen, Gehirnströme, Herztöne, Muskeltöne, und diese Aktivitäten, ihre unterschiedlichen Tempi und Wertigkeiten, verstärken « (Whitman). 15 Jahre später schloss Mark Boyle seine Akteure an EKG und EEG an, um deren Herzfrequenzen und Gehirnströme in Echtzeit vorführen zu können (die Oszilloskope der beiden Apparate wurden als Closed-circuit-Video mit Hilfe eines »Eidofor«-Videoprojektors auf einen großen Bildschirm projiziert). Seitdem wurde die »Instrumentalisierung « und Verbildlichung des Körpers weiter entwickelt. Körperprozesse als bildgebende Verfahren in Echtzeit einzusetzen wird in performativen und partizipatorischen Closedcircuit-Installationen mit Sensoren, Interfaces oder mit Implantaten durchgeführt.

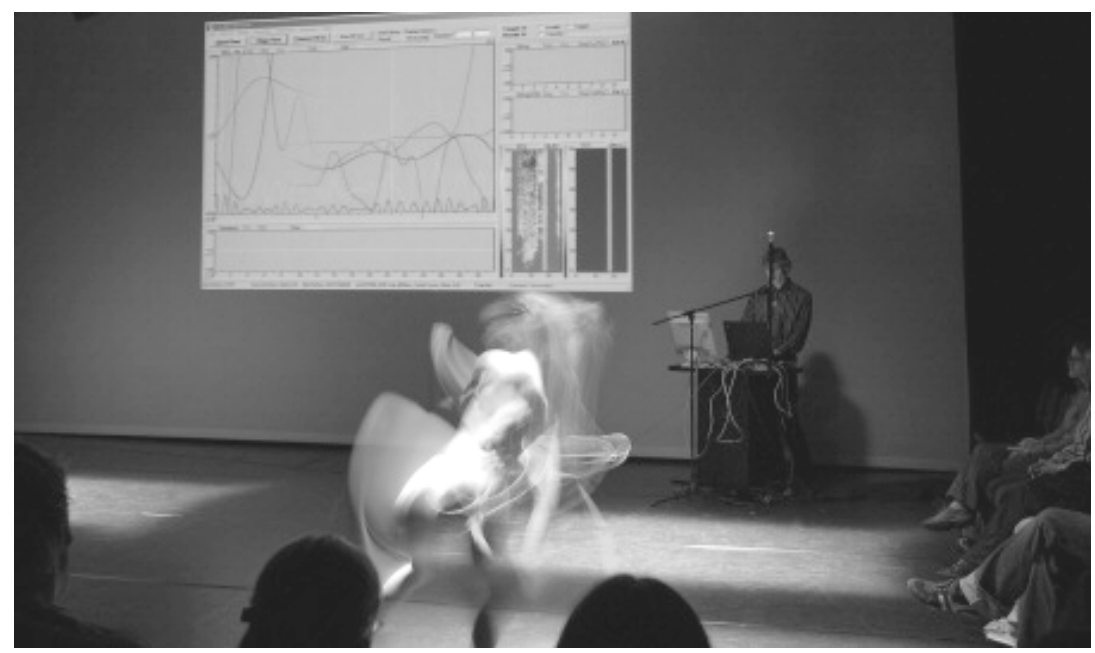

Abbildung 7: Carla Pulvermacher in Thilo Hinterberger, Ottmar Gendera: BRAINDANCE / BRAINMUSIC.

Thilo Hinterberger hat unter dem Label »POSER « eine Software entwickelt, mit der es technisch möglich ist, in Realzeit Gehirnsignale in Töne zu transformieren. ${ }^{35}$ Daraus kreierte er gemeinsam mit Ottmar Gendera BRAINMUSIC / BRAINDANCE (2004) ${ }^{36}$ in dem die Tänzerin Carla Pulvermacher in ihrer Aktion die Klänge mittels Sensoren steuert, die mit einer Computersoftware aus einem gesampelten Klangvorrat abgerufen und komponiert werden.

34 Vgl. ibd. In dieser computergesteuerten Transformation der Musik in Choreographie findet George Balanchines Konzept des Symphonischen Balletts eine neue, technologische Ausprägung.

35 http://www.retrogradist.de/v2/index.php?page=brainmusic (03.07.2008).

36 Das Konzept von BRAINMUSIC / BRAINDANCE kreierten Ottmar Gendera (freier Journalist) und Thilo Hinterberger (Physiker, spezialisiert auf medizinische Psychologie und Verhaltensneurobiologie). Dieter Heitkamp choreographierte die Bewegungen der Tänzerin Carla Pulvermacher. Zu diesem Projekt vgl. auch: Birringer/Fenger. 
Die Arbeit an biogenetischen Konzepten hat auch in der Medienkunst seit den 1990er Jahren die Verknüpfung von Mensch und Computer in hybride Wesen thematisiert. Thilo Hinterberger hat ein Verfahren zur Sonifizierung von Gehirnrhythmen entwickelt, das Hirnsignale mittels Elektroden am Schädel abnimmt, misst und akustisch umsetzt. Unsichtbare Aktionen im Kopf des Tänzers werden sichtbar und hörbar. Die Impulse werden mit einem bildgebenden Verfahren auf der Leinwand für die Tänzerin und die Zuschauer sichtbar und überdies hörbar gemacht durch einen Computer, der verschiedene Klänge den Impulsen zuordnet. Die Tänzerin komponiert während des Tanzens die Impulsdichte und Intensität, der Bediener des Computers ruft die Klangfarben ab. Indem die Tänzerin im weiteren Verlauf auf die visuellen und akustischen Ereignisse reagiert, die sie hervorgebracht hat, entsteht eine Feedbackschleife, die das gesamte Geschehen umfasst. Die Performance ist auch mit zwei interagierenden Tänzern realisierbar.

\section{Telematisches Theater}

In Telematic Dreaming ${ }^{37}$ kreiert Paul Sermon die Illusion, auf einem Bett hoch aufgelöste Bilder eines weit entfernten Partners in lebendiger, intimer Nähe erleben zu können. Der Partner wird lichtstark projiziert, und seine Bewegungen reagieren nahezu in Echtzeit auf die eigenen Bewegungen im Bett. Sermons Ziel ist es, dass die reale Person durch die Bewegungen des Partners die Suggestion einer Berührung erlebt. Hand und Auge verschmelzen gewissermaßen in einem synästhetisch gewonnenen sinnlichen Eindruck, der diese Arbeit auszeichnet. ${ }^{38}$

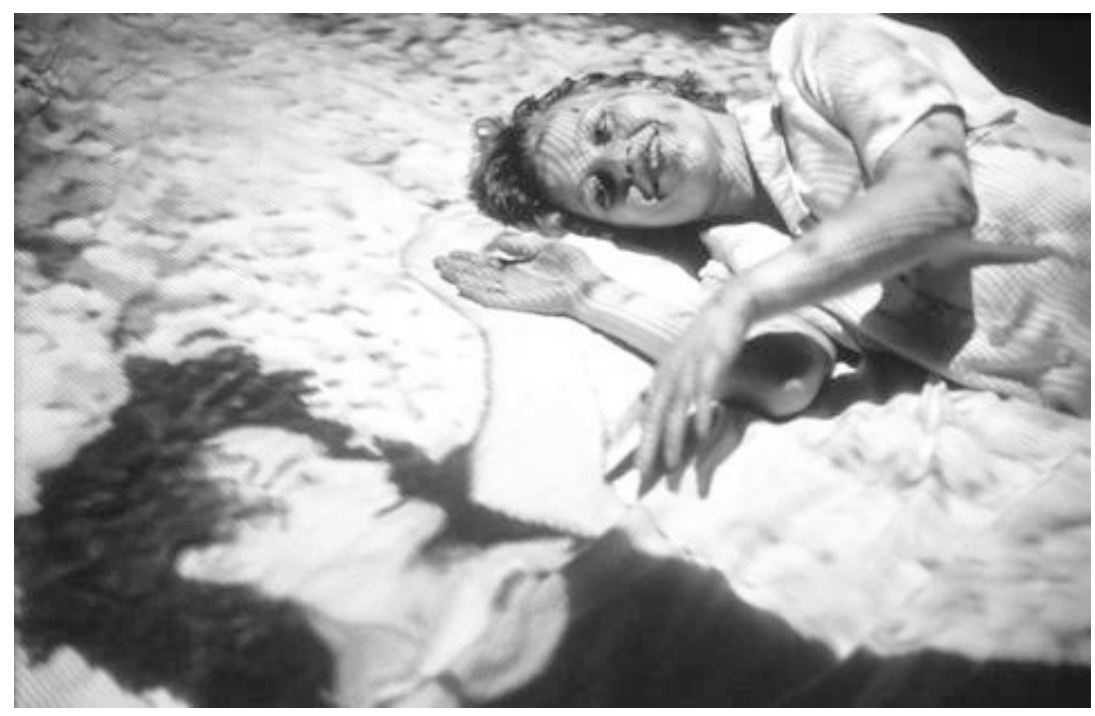

Abbildung 8: Paul Sermon: TELEMATIC DREAMING.

37 www.medienkunstnetz.de/werke/telematic-dreaming/video/1/ (03.07.2008).

38 Vgl. Oliver Grau a.a.O. 
A Body Of WATER (1999) von Andrea Zapp und Paul Sermon ist eine Videokonferenz-Installation zur Verbindung von Museumsraum und historischen Orten, eine interaktive ISDN-Video-Installation mit einem wasserbasierten Interface, einem Water-screen. Die Bilder der Besucher eines alten Duschraums der Ewald/ Schlaegel Eisenmine in Herten werden mit denen der Besucher des Wilhelm Lehmbruck Museums in Duisburg vermischt und auf den Water-screen projiziert. ${ }^{39}$

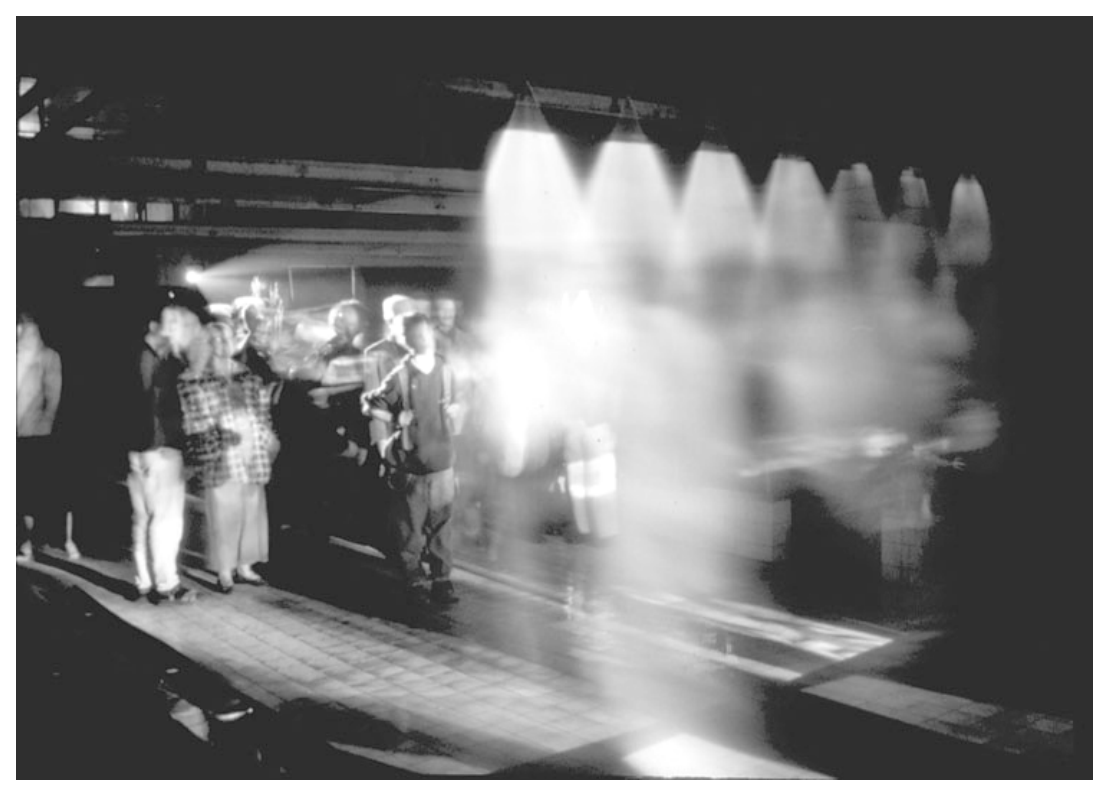

Abbildung 9: Paul Sermon, Andrea Zapp: A BODY OF WATER.

39 »A BODY OF WATER war eine mehrteilige Videoinstallation, die für das Ruhrgebiet konzipiert wurde. Sozio-kulturell disparate Orte und getrennte Handlungsräume wurden über Live-Videoschaltung visuell miteinander in Beziehung gebracht. Von zwei Installationsräumen in der Waschhalle-Herten (Duisburg) aus konnte man die Besucher im Duisburger Wilhelm-Lehmbruck-Museum sehen: Die Personen in den einzelnen Installationsmodulen wurden mittels Chroma-Key-Verfahren separiert und beispielsweise im Duschraum der Waschkaue auf einen Wasservorhang projiziert. Auf der Rückseite dieser fließenden Projektionsfläche wurden Filmsequenzen mit duschenden Bergarbeitern gezeigt. Auch die Museumsbesucher befanden sich in einem heterogenen Environment, in dem historische Accessoires - Gebrauchsgegenstände zum Themenkomplex des Waschens - die Gegenwart gleichsam überlagerten. Fernsehmonitore ermöglichten den Zuschauern im Museum eine Einsicht in die Geschehnisse der Waschhalle. Da die Videobilder von allen Orten jeweils zu einem Bild montiert wurden, kam es zu nonverbaler, gestischer Kommunikationen zwischen den Besuchern der räumlich getrennten Situationen.« In: http://netzspannung.org/cat/servlet/ CatServlet?cmd=netzkollektor\&subCommand=showEntry\&entryId=148393\&lang=de. 


\section{Interaktives Theater im Cyberspace}

Steve Dixon hat mit der Gruppe Chameleons die interaktive Cybertheater Performance CHAMELEONS 3: NET CONGESTION ${ }^{40}$ kreiert. In einem Theaterstudio agierten die Darsteller live vor drei Projektionswänden, auf die vorgefertigte digitale Videos projiziert wurden. Im Theater war kein Publikum, aber über drei Kameras wurde die Performance ins Internet eingegeben. Wer sich bei dem live-Event einloggte, konnte den angeschlossenen Chatroom nutzen, um Bilder, Charaktere und Dialogpassagen einzugeben, mit denen die Darsteller dann improvisierten. Teile der Show waren vorprobiert, andere wurden ganz improvisiert nach den Vorschlägen der Zuschauer.

Theater im Internet wirft die Frage auf, ob Theater und Performance, die sich im Cyberspace der Mitwirkung von vielen unkoordinierten Mitspielern öffnen, damit zu künstlerisch befriedigenden Ergebnissen kommen können.

\section{Abbildung 10: Steve Dixon: CHAMELEONS 3: NET CONGESTION.}

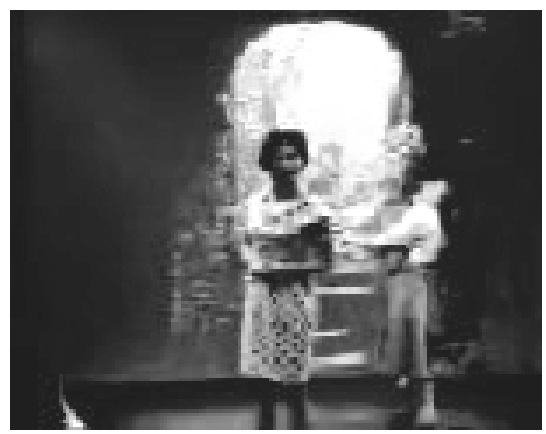

Eine gleichzeitige musikalische Interaktion von online-Teilnehmern und live agierendem Publikum kreierten Tod Machover und sein Team von über 50 Künstlern und Wissenschaftlern am M.I.T. Media Labatory 1996 mit BRAIN OPERA. ${ }^{41}$ Diese interaktive, musikalische Reise ins Gehirn, die simultan im physischen Raum und im Cyberspace präsentiert wurde, war die erste derartige Musikaktion. Teilnehmer verschiedenster musikalischer Herkunft - Fans von Mozart, John Cage, Grunge Rock, Verdi, Rapper etc. - waren aufgefordert, sich an der Gemeinschaftsimprovisation/-komposition zu beteiligen. Demonstriert wurden dabei die wechselseitigen Einflüsse von Sinneswahrnehmung, musikalischen Strukturen, Sprache und Emotionen. Die Brain Opera gliedert sich in die Teile Mind Forest, Brain OpERA Performance und Net Music. Höhepunkt ist eine 45 Minuten Performance, in der drei Performer vorkomponierte und vom Publikum kreierte Elemente formen, wählen und interpretieren. Speziell konstruierte Hyperinstrumente kamen zum Einsatz wie der Sensor Chair und die Gesture Wall, die Körperbewegungen in Klang transformieren, und der Digital Baton, der Sensoren für Richtungsangaben, Druck und Bewegung kombiniert. Auf einer großen runden Leinwand wurde von mehreren Projektoren ein permanenter Bilderfluss erzeugt, koordiniert mit der Musik, die er illustriert, kontrapunktiert oder die Aktionen der Performer beleuchtet. Im Finale

40 Chameleons 3: Net Congestion - Devised and Performed by: Steve Dixon, Joanne Harding, Joanne Hartley, Paul Murphy, Joe O'Byrne, Anita Ponton, Wendy Reed, Charlotte Whitehouse. Vgl. http://dpa.ntu.ac.uk/dpa_search/result.php3?Project=360. Videos auf:www.mdx.ac.uk/www/epai/presencesite/html/dixvid.html; Dixon: 503-509

41 http://brainop.media.mit.edu/indexold.html; Das Debut von BRAIN OPERA war vom 23.07.-03.08.1996 beim ersten Lincoln Center Festival in New York City. Danach ging sie bis 1998 auf Welttournee mit Stationen u.a. bei der Ars Electronica in Linz, dem NexOpera Festival in Tokio, Singapore, und dem Electronic Cafe International in Copenhagen. Als endgültige Version der BRAIN OPERA wurde Future Music BlENDER 2000 in Wien installiert. 
kamen weitere Klänge hinzu, erzeugt vom Tanz des Publikums auf einem mit Sensoren ausgestatteten Teppich.

Auch in Manfred Stahnkes OrPHEUs Kristall - OPER IN ZWEI MEDIEN: THEATER UND INTERNET - $(2002)^{42}$ gab es zusätzlich zum Bühnenensemble noch >Internetmusiker $<$, die an verschiedenen Orten real spielten. Im Mythos ist Orpheus eins mit der Natur, der Welt, und kann mit ihr spielen. Dafür wurde gleichnishaft das Internet eingesetzt: Orpheus spielt mit externen Musikern, er improvisiert, sie hören ihn, spielen mit ihm, antworten, und ihre Musik strömt über Lautsprecher in den Saal.

Für die Interaktion von Bühnenkünstlern und Musikern andernorts setzte Georg Hajdu die Software »Quintet.net « ein, die Orpheus' Gesang und den Schlagzeugpart codierte und im Netz übertrug an Musiker in Amsterdam, New York und San Francisco. Diese hörten und sahen die Musik in Notenschrift in Echtzeit auf ihren Bildschirmen, reagieren mit ihren Instrumenten darauf, und ihre Improvisationen wurden, im Netz übertragen, zu visuellen und akustischen Bestandteilen der Aufführung. Weltweit vernetzte Computer und der daraus resultierende zeitgleiche Austausch musikalischer Daten zeugen von einer neuen Idee von Oper.

$\mathrm{Zu}$ den Opern, die zum Thema »Oper als virtuelle Realität« (vgl. auch Vill 2004; Vill 2006: 117-126) im Auftrag der Münchener Biennale 2002 komponiert und inszeniert wurden, gehört neben ORPHEUS KRISTALL auch Gerhard Winklers HEPTAMERON (2002). ${ }^{43}$ Das interaktive Musiktheater arbeitet mit sog. »Relationskernen«, aus denen die Musik, die szenische Aktion und das Bühnenbild sich konkretisieren. Winklers Absicht war, »Beziehungssysteme als interaktive Modelle zu gestalten « (34). ${ }^{44}$ Darum wurde die Enge der Beziehungsverflechtungen in den sieben Erzählungen aus Margarete von Navarras HEPTAMERON ${ }^{45}$ musikalisch-szenisch umgesetzt als Bezüge in einem interaktiven Environment von Musik, Bühnenbild, szenischer Aktion und Licht.

In der Aufführung wurden von den Akteuren die vorgegebenen Materialien verarbeitet und situative Einflüsse von den auf die Monitore übertragenen musikalisch-szenischen Anweisungen und Materialsequenzen realisiert. An der Technologie hat Gerhard Winkler mit zehn Technikern des ZKM jahrelang gearbeitet.

Die Schauspieler, Tänzer und Sänger tragen an ihrem Körper Sensoren, die auf Bewegung, Richtung, Geschwindigkeit und Neigungswinkel der Gliedmaßen reagieren. Das Computerprogramm setzt diese Informationen um in Befehle an die Lichtund Partitursteuerung. Auch am Stehpult und einem Computer-Tablett, auf dem $>$ Kratzgeräusche< freigesetzt werden können, sind Sensoren angebracht. Ein tragbarer >Ultrasonic $<$ spricht auf großräumige Bewegungen und Entfernung an, und

42 Die zweiteilige Arbeit, bestehend aus einer Bühnen- und einer Internetversion, thematisiert den antiken Orpheusstoff aus einem auf die Gegenwart bezogenen Blickwinkel. Das Projekt wurde im Künstlerteam Georg Hajdu, Simone de Mello, Peter Staatsmann, Manfred Stahnke, Bettina Wackernagel und Bettina Westerheide entwickelt. www.orpheuskristall.com/.

$43 \mathrm{http} / / / \mathrm{on} 1 . z \mathrm{~km} . \mathrm{de} / \mathrm{zkm} / \mathrm{stories} /$ storyReader\$2667 (01.10.2006).

44 Zehn Szenenfotos unter: Humatic ${ }^{\circledR}$ Hypermedia*Interactive Screens - Heptameron, Opera by Gerhard Winkler, Stage: L. P. Wallen, Flash-Artist: S. Gandl, Dynamic Media-Control System: Humatic ${ }^{\circledR}$ - www.humatic.de/partner/02heptapic/index.htm (01.10.2006).

45 Sammlung von 72 Erzählungen. 
ein >Radio-Baton< (Sensor) reagiert auf Entfernungen, Bewegungsrichtungen und -geschwindigkeit.

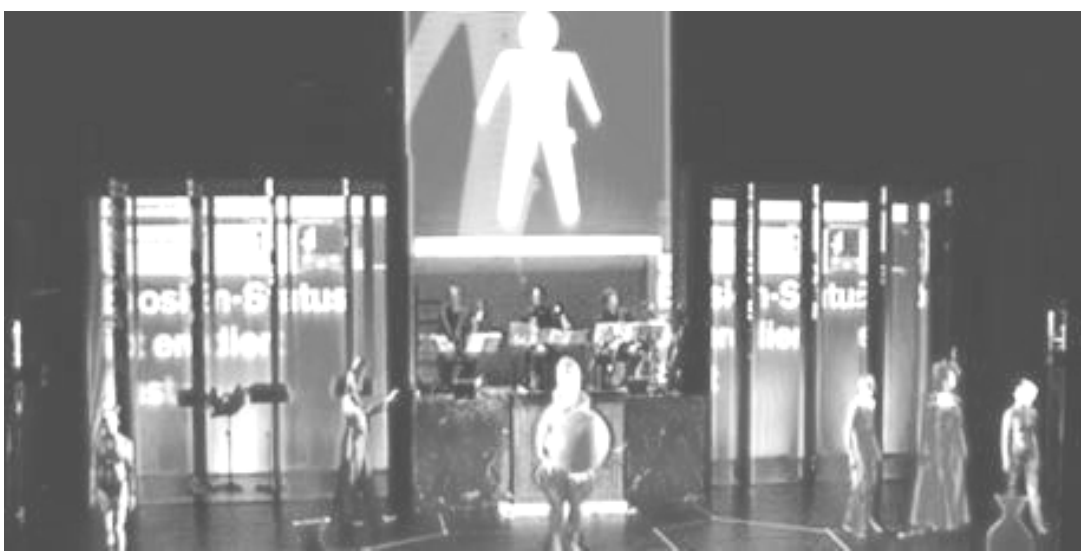

Abbildung 11: Gerhard Winkler: HEPTAMERON (2002).

Großräumige Bewegungen samt Richtung und Geschwindigkeit nimmt ein >Big Eye< auf, das Video-Ausschnitte von einer Kamera steuert. Mikrofone reagieren auf die Stimmen. Computerprogramme setzen die Informationen um in Anweisungen an die Musiker und an die Bühnenbildprojektoren. ${ }^{46}$

Die Musik mischt sich aus Computerklängen, Gesang und dem, was die Musiker aus Partituren oder Stimmen spielen, die sie auf einen Bildschirm sehen. Die Signale von den Sensoren der Akteure werden im Computer verarbeitet: aus den >score-files< wird etwas kombiniert, angeordnet und an die Laptops der Musiker gesendet. Anweisungen zu Lautstärke, Klangfarbe, Artikulation, Verknüpfung der Töne, Geschwindigkeit von Tongruppen etc. sind festgelegt. Aus den Klangdatenbanken der Computer wird Musik eingespielt, auch gut 300 Samples von Körperklängen, die Winkler mit Spezialmikrofonen aufgenommen und verarbeitet hat. Diese Körperlaute, die das Repertoire körperlicher Klangerzeugung erweitert, wovon die traditionelle Oper nur das Singen nutzt, fügt Winkler den Klängen hinzu, die die Sänger live produzieren. ${ }^{47}$

Die digitale Performance hat Spielräume für theatrale Aktionen geschaffen, die die Funktionen des traditionellen Theaterraums erweitern um konkrete, metaphorische, abstrakte, phantastische und visionäre Gestaltungen von Locations und psychischen Innenräumen, in denen andere Themen und neue Erlebnisformen Ereignis werden können.

46 Vgl. »Heptameron« Technik (Presseinformationen der Münchener Biennale 2002).

47 Ebd.: 35. 


\section{Literatur}

Birringer, Johannes/Josephine Fenger (Hg.) (2005): Tanz im Kopf. Dance and Cognition. (Jahrbuch Tanzforschung Bd. 15). Münster: Lit.

Dietz, Steve: »Public Sphere_s.«In: http://www.Medienkunstnetz.de/themen/ (28.06.2008).

Dixon, Steve (2007): Digital Performance. A History of New Media in Theater, Dance, Performing Art, and Installation. Cambridge, Mass., London, Engl.: The MIT Press.

Frieling, Rudolf: »Real/Medial - Hybride Prozesse zwischen Kunst und Leben.« In: http://www.medienkunstnetz.de/themen/medienkunst_im_ueberblick/ Performance/ (01.10.2006).

Grau, Oliver: »Medienkunst im Überblick. Vom Rundfresko zum interaktiven Bildraum «. In: http://www.medienkunstnetz.de/themen/medienkunst_im_Ueber blick/ immersion (01.10.2006).

Kluitenberg, Erik: $(\mathrm{Hg}) »$ Frequently Asked Questions about the Public Domain« Debates \& Credits. Amsterdam: De Balie (Version 6.0 Februar 2004).

Peine, Sibylle (Red.) (1997) ZKM, Zentrum für Kunst und Medientechnologie Karlsruhe, Red.: Sibylle Peine, München, New York: Prestel.

Plewe, Daniela Alina: http://www.medienkunstnetz.de/werke/ultima-ratio/bilder/5/ (01.10.2006).

Reaney, Mark (2001): »A Midcyber Night's Dream. Digital Performance«. Vol. n. 2 Anomalie Digital arts. Paris.

Schwarz, Hans-Peter (Hg.) (1997): Medien Kunst Geschichte, ZKM Medienmuseum. München: Prestel.

Vill, Susanne (2004): »Virtuelle Oper mit Kammerensemble?« Vortrag bei der Tagung der Europäischen Musiktheater-Akademie Kammeroper: Von der Kunst der kleinen Form. Wien, 21./22.02.2004 [im Druck].

Vill, Susanne (2006): »Virtuelle Oper und Medienperformance - eine zukünftige Alternative?«. In: Manfred Jochum/Isolde Schmid-Reiter (Hg.): Teure Kunstform Oper. Musiktheater im neuen Jahrtausend (Europäisches Forum Alpbach/ Europäische Musiktheater-Akademie). Innsbruck: Studien-Verlag, S. 117-126.

Whitman, Simone (1966): »Theater and Engineering. An Experiment. Notes by an Observer«. In: Art Forum Vol. 5, no 6, (February 1967), S. 26-30.

Winkler, Gerhard E.: »Heptameron als interaktive Oper. Das Werk im Gespräch«. In: 8. Münchener Biennale 2002 Internationales Festival für neues Musiktheater. Das Programm. 


\section{Abbildungen/Quellen}

1 (C) Maurice Benayoun In: www.medienkunstnetz.de/werke/world-skin/ (01.10.2006).

2 Foto: (C) Christian Legay, in: ZKM Zentrum für Kunst und Medientechnologie Karlsruhe. Museumsführer, München, New York: 1997, S. 34.

3 Installationsansicht, 1997 | Courtesy: NTT InterCommunication Center (ICC), Tokio I @ Shaw/Hegedüs/Lintermann. In: http://www.medienkunstnetz.de/ werke/configuring-the-cave/ (01.10.2006).

4 In: www2.ku.edu/ ievr/midsummer/ (01.10.2006).

5 In: www.stelarc.va.com.au/stomach/stomach.html (01.10.2006).

6 (C) Klaus Obermaier. In: http://www.exile.at/apparition/ (29.6.2008).

7 In: www.interactivebrain.de/horkunstfestival.html (01.10.2006).

8 In: http://creativetechnology.salford.ac.uk/paulsermon/dream/ (26.6.2008).

9 In: http://netzspannung.org/cat/servlet/CatServlet?cmd=netzkollektor\&sub Command=showEntry\&entryId=148393\&lang=de (29.6.2008).

10 In: www.mdx.ac.uk/www/epai/presencesite/html/dixvid.html (01.10.2006)

11 In: www.humatic.de/partner/02heptapic/index.htm (01.10.2006). 



\title{
Theater in DeR Ambivalenz ZUM TeChNISCHEN - ANTHROPOLOGISCHE DIMENSIONEN VON INTERNET PERFORMANCES ${ }^{1}$
}

\author{
JULIA GLESNER
}

\section{Systematik der Produktionen}

Bereits seit Dezember 1993 finden theatrale Aufführungen im Internet statt. Diese Internet Performances, wie sie im Folgenden genannt werden sollen, lösen bei simultaner Produktion und Rezeption die uns von anderen Theaterformen vertraute physische Kopräsenz von Darstellern und Zuschauern auf. Sie stellen eine Unterform der Distributed Performances dar (siehe Abbildung 1). Als solche werden Aufführungen bezeichnet, die bei definiertem Beginn und Ende der Aufführungen die physische Kopräsenz von Darstellern und Zuschauern durch den Einsatz von Telekommunikationstechnologien auflösen.

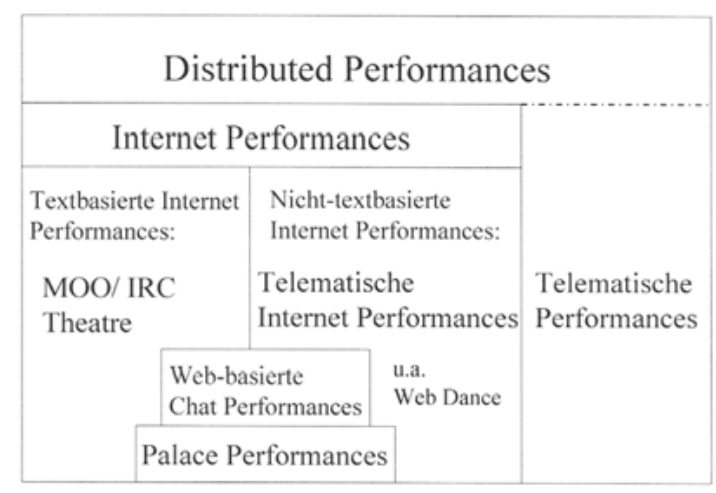

Abbildung 1: Das System der Distributed Performances

Internet Performances setzen das Internet und seine Dienste auf höchst unterschiedliche Art und Weise ein. ${ }^{2}$ Auf einer ersten Ebene können textbasierte von so genannten telematischen Internet Performances unterschieden werden. In textbasierten Internet Performances wird die theatrale Aktion - also Körper, Raum und

1 Für eine erweiterte Fassung dieses Textes siehe Glesner 2005.

2 Als Dienst bezeichnet man in der Telekommunikation eine standardisierte Form der Übermittlung mit definierten technischen Eigenschaften und Schnittstellen für Endgeräte. Für Internet Performances ist vor allem die Unterscheidung des Internets von seinem bekanntesten Dienst, dem WWW, von Bedeutung. Vgl. Langenscheidt-Redaktion/Süddeutsche Zeitung: 97. 
Handlung - in Diensten des Internets repräsentiert, die ausschließlich über Text funktionieren. Dies betrifft den Internet Relay Chat (IRC), der nicht in das WWW integriert ist, die Multi User Dungeons (MOOs), die früher nur über Telnet, heute jedoch auch über das WWW erreicht werden können, oder andere, web-basierte Chat-Räume. ${ }^{3}$ Telematische Internet Performances arbeiten mit Technologien, die audiovisuellen Zeichen übertragen (bspw. webcams) und erlauben unterschiedliche Formen der Interaktion zwischen topographisch verteilten Teilnehmer- und $\mathrm{Zu}$ schauergruppen. Innerhalb der telematischen Internet Performances können noch Tanzproduktionen unterschieden werden.

Im Folgenden werden eine textbasierte und eine telematische Internet Performance vorgestellt und methodisch-theoretische Grundlagen und die anthropologischen Dimensionen von Internet Performances diskutiert. Hierbei soll ihre Position in der Ambivalenz zum Technischen im Vordergrund stehen.

\section{Beispiel 1: Der IRC und die Hamnet Players}

Unter einem IRC versteht man heute ein nicht web-basiertes Programm, das mittels des Internets eine zeitgleiche Kommunikation zwischen einer unbegrenzten Anzahl an Teilnehmern ermöglicht. Diese Teilnehmer sind untereinander über ihre Spitznamen (nick names) bekannt. Alle Nachrichten, die ein Teilnehmer während der Kommunikation eingibt, erscheinen für alle anderen Teilnehmer sichtbar unter diesem Spitznamen. Die Teilnehmer kommunizieren über die Kanäle (channels), die den IRC strukturieren.

Die Hamnet Players wurden von Stuart Harris gegründet, einem in Großbritannien geborenen Schauspieler, der jetzt in den USA lebt. Harris begeisterte sich für die Kommunikationskultur im IRC, bemängelte jedoch das inhaltliche Niveau. Er entwickelte die Idee, den IRC für die Aufführung von Dramen im Internet zu nutzen. Mit der Welt-Uraufführung ihrer ersten Produktion HAMNET, einer Adaption von Shakespeares HAMLET, am 12. Dezember 1993, begann die Geschichte der Internet Performances. Berücksichtigt man die frühe Entwicklungsphase des Internets und das Stadium seiner Verbreitung im Jahre 1993, wird die Pionierleistung der Hamnet Players in den Jahren 1993 bis 1995 erkennbar.

Für die Produktion HaMnet, die am 12. Dezember 1993 und am 6. Februar 1994 aufgeführt wurde, erstellte Stuart Harris aus Shakespeares HAMLET eine 80zeilige Adaption, in die Harris mit Rollen wie >PROLOGUE<, >SCENE<, >Audience $<$, >Enter $<$, >Exit< $<$, Prompter $<,>$ Drum $<$ und $>$ Colours $<$ weitere Handlungsträger einbaute. Strukturelle Analogien zum Ablauf einer Theater- beziehungsweise Filmvorführung bleiben erkennbar: Das Skript beginnt mit Informationen zu Auf-

3 Im Übergang zwischen den textbasierten und den telematischen Internet Performances können die Palace Performances positioniert werden, die mittels des Chat-Systems Palace, bei dem die Teilnehmer über zweidimensionale graphischen Vorstellungen repräsentiert werden, Aspekte der theatralen Aktion, beispielsweise die Szenerie und Figuren, visualisieren. Telematische Internet Performances wiederum unterscheiden sich von Distributed Performances darin, dass sie Telekommunikationstechnologien die Videodateien übertragen (beispielsweise die Media Player), Videokonferenztechnologien oder webcameras - in das Internet bzw. das WWW integrieren. Im Bereich der telematischen Internet Performances kann noch die Subkategorie des Web Dance unterschieden werden. 
führungszeit sowie -ort, zu den Rechten am Text sowie die Handlungsangabe, dass sich nun der Vorhang öffne. Auf diese Angabe folgt eine ASCII-Graphik, die das Schloss Elsinore darstellt. ${ }^{4}$ Die Darstellung des Schlosses verdeutlicht Harris' Absicht, internetspezifische Äquivalente für die herkömmliche Produktionsform von Theater zu finden (siehe Abbildung 2). ${ }^{5}$

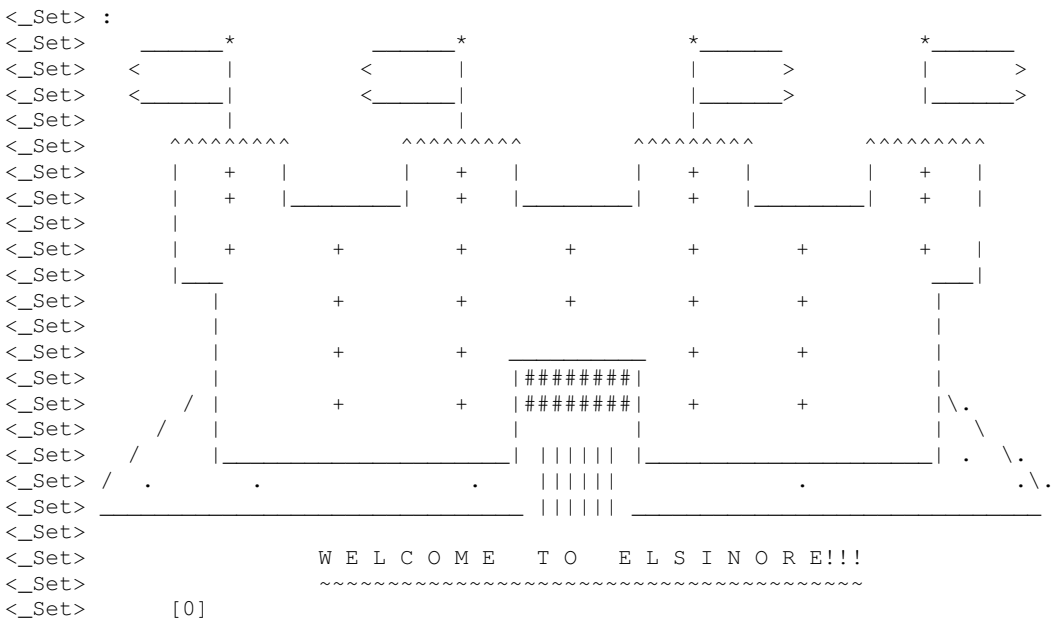

Abbildung 2: Schloss Elsinore.

\section{Methodisch-theoretische Parameter: Drama und Internet}

\section{Das Internet als Produktions- und Rezeptionsort}

Die verschiedenen Dienste des Internets werden in textbasierten Internet Performances als Produktions- und Rezeptionsort gleichermaßen eingesetzt. Das Potential der Dienste, topographisch verteilte Teilnehmer über eine schriftliche Form der Kommunikation miteinander zu verbinden, stellt die Ausgangsbedingung der Produktionen dar. Kein anderes Medium könnte die für textbasierte Internet Performances kennzeichnende Form der Medialität - insbesondere in der Kombination von verteiltem Schreiben und Lesen mit visuellen Elementen wie den Szenenbildern beim IRC - ermöglichen. Das Internet wird hier in seiner site-specificity eingesetzt, da die technischen Möglichkeiten des IRC die Kommunikationsmöglichkeiten dieser Produktionen maßgeblich bestimmen. Site-specific art soll hier verstanden werden als für eine spezifisch räumliche Umgebung konzipiert, von der sie nicht getrennt werden kann, ohne dass sich ihre Wahrnehmung und Bedeutung veränderte (vgl. Kaye: 2).

4 ASCII steht für American Standard Code for Information Interchange und bezeichnet den Code, den fast alle Computerhersteller unterstützen können, um Buchstaben, Zahlen und Sonderzeichen darzustellen.

5 Vgl. http://www.marmot.org.uk/hamnet/hscript.htm (18.07.2008). 


\section{"Verschriftlichung der Sprache»}

Der Gebrauch von geschriebenen Zeichen im Internet führt nach Mike Sandbothe zu einer Veränderung im System der Zeichen insgesamt, die er in drei Transformationstendenzen beschrieben hat. Die erste dieser Tendenzen bezeichnet er als »Verschriftlichung der Sprache«. In synchroner, computergestützer Kommunikation verflechten sich Merkmale, die bisher als Differenzkriterien zur Unterscheidung von Sprache und Schrift dienten. Schrift übernimmt im vernetzten Mediensystem des Internets zentrale Funktionen der Sprache. Die traditionelle Auszeichnung der gesprochenen Sprache als »Medium der Präsenz« wird »durch die >appräsente Präsenz< der Teilnehmer im geschriebenen Gespräch in Frage gestellt « (Sandbothe 1998: 219).

»Im Online-Chat fungiert Sprache als Schrift, d.h. das gesprochene bzw. zu sprechende Wort realisiert sich im Schreiben als Zeichen von Zeichen. Dieses performative Schreiben eines Gesprächs, in dem Sprache interaktiv geschrieben statt gesprochen wird, läßt sich als $>$ Verschriftlichung der Sprache< beschreiben« (Sandbothe 2001: 196).

Als ein solches performatives Schreiben eines dramatischen Dialogs, in dem Sprache interaktiv geschrieben wird, ist der Aufführungsmodus textbasierter Internet Performances zu charakterisieren.

\section{Semiotisierung des Körperlichen}

Konnte Theater unter den Bedingungen physischer Kopräsenz als Medium bestimmt werden, »das Zeichen nicht von der Materialität und Medialität der Zeichenmittel ablöst und durch eine spezifische >Mobilität der Zeichen< zwischen verschiedenen Zeichensystemen und Medien gekennzeichnet ist « (Meyer: 77), so tritt in textbasierten Internet Performances ein neuer Modus des theatralen Zeichengebrauchs auf: Schrift übernimmt die Funktionen anderer Zeichensysteme. Leiblich-visuelle und auditive Signifikanten werden durch schriftlich-textuelle Signifikanten ersetzt.

\section{>Präsenz des Vorgestellten<}

Indem textbasierte Internet Performances die theatrale Aktion mit all ihren Komponenten verschriftlichen und die Wahrnehmung der Aufführung einem Vorgang des Lesens entspricht, ist das Gelingen solcher Aufführungen auf die Imagination der dramatischen Handlung durch die Teilnehmer, mithin auf die Produktion innerer Bilder angewiesen. Ebenso wie die Verbindung der Teilnehmer über das Internet als technische Komponente unabdingbar für das Gelingen der Aufführung ist, so ist es auch die Imagination der dramatischen Handlung als wirkungsästhetische Komponente. Charakteristisch für die mentale Kooperation textbasierter Internet Performances ist eine Form von Präsenz, die mit einer Formulierung Isers als »Präsenz des Vorgestellten « (Iser 1994: 225) charakterisiert werden kann. In ihrer Ima-gination produzieren die Teilnehmer von textbasierten Internet Performances innere Bilder der theatralen Handlung. Sie sind gleichzeitig »in der Präsenz des Vorgestellten« (ebd.). ${ }^{6}$ Textbasierte Internet Performances treten vom Selbstverständnis

6 Iser spricht auch vom »Text als Prozeß« (vgl. Iser 1994: VII). 
her im Bezugsrahmen des Performativen und des Theaters auf, vom Wahrnehmungsmodus jedoch im Bezugsrahmen der Literatur und des Lesens. Dieses Changieren zwischen Theater und Literatur kennzeichnet nicht nur ihren intermedialen Status, sondern kann auch innerhalb der Tradition der Lesedramen gesehen werden.

\section{Beispiel 2: Das Cassandra Project der NYU}

Innerhalb der telematischen Internet Performances nimmt das CASSANDRA PROJECT eine besondere Position ein. Viele der Produzenten von Internet Performances arbeiten im universitären Bereich, doch in nur wenigen Produktionen arbeiteten künstlerische Praxis und Forschung so eng zusammen und in keinem anderen Projekt standen über Jahre hinweg ausreichend personelle und finanzielle Mittel zur Verfügung, um die neu entstandenen Technologien direkt anzuwenden. Das CASSANDRA PROJECT ist eine Vielzahl von einzelnen Aufführungen seit 1996, in der meist verschiedene technologische Konzeptionen zum Einsatz kamen.

Das CASSANDRA PROJECT wurde von John Gilbert und Dinu Ghezzo von der New York University (NYU) 1996 initiiert. Ursprünglich verband das CASSANDRA PROJECT simultan Musik und Dichtung zuerst über ISDN-Leitungen, dann auch über das Internet. Lisa Naugle, zu diesem Zeitpunkt Tänzerin und Choreographin an der Simon Fraser University, British Columbia, und ständiger Kooperationspartner der NYU, führte Tanz in das Projekt ein. Seit 1996 produziert das Team jährlich mehrere Performances, zum Teil auch mit anderen Partnern und erprobt dabei unterschiedliche Telekommunikationstechnologien. 1996 basierte das CASSANDRA PROJECT auf der Videokonferenztechnologie CUSeeMe, mit der im internationalen Gebrauch häufig Kompatibilitätsprobleme auftraten.

Die Aufführung vom 29. November 2001 fand als Zusammenarbeit zwischen dem Dance Studio der UCI und dem Loewe Theatre der NYU statt. Beide Bühnen waren über Internet 2 miteinander verbunden. Als Internet 2 wird ein gemeinsames Forschungsprojekt von rund 120 US-amerikanischen Universitäten bezeichnet, dessen Ziel es ist, ausgewählte Universitäten mit dem state-of-the-art der Netzwerktechnologien $\mathrm{zu}$ versorgen und ihre Forschungen in diesem Bereich zu unterstützen.

Das Konzept teilte die Aufführung in eine einleitende Sequenz, die Einspielung des Titels und vierzehn Szenen unter genauen Zeitangaben für insgesamt 60:45 min ein. Die Einteilung sah Szenen vor, in denen die Darsteller Improvisationen gestalteten, die durch die Vorgaben der anderen Bühne bedingt waren. So improvisierten die Tänzer in Irvine zu improvisierter Musik aus New York. Die Zuschauer in Irvine sahen den Tanz im selben Raum und hörten die übertragene Musik aus Lautsprechern; die Zuschauer in New York hörten die Musik und sahen die übertragenen Bilder der Tänzer aus Irvine, und die online-Zuschauer nahmen beide Elemente elektronisch übertragen wahr. Die Auswahl der Bilder unterlag der Entscheidung des Bildmischers. Vereinbarte Handlungen signalisierten Übergänge zwischen den Szenen (z.B. das Ende einer Flötenmusik; ein Darsteller verlässt die Bühne etc.). 


\section{Methodisch-theoretische Parameter}

\section{Digitalisierbarkeit als mediale Bedingung}

Die Medialität telematischer Internet Performances ist durch ein spezifisches Verhältnis analoger, digitalisierter und digitaler Materialien gekennzeichnet, die über Interface-Konstruktionen die geographisch verteilten Teilnehmer miteinander verbinden. Dominierender Rahmen ist das WWW, das die verschiedenen Materialien und Technologien integriert. Die Digitalisierbarkeit der Materialien stellt die mediale Bedingung telematischer Internet Performances dar.

\section{Das Internet zwischen Datenübertragung und Handlungsraum}

Der Hauptunterschied zwischen telematischen Performances und telematischen Internet Performances liegt vor allem in der Möglichkeit, über das Internet vorher nicht notwendigerweise definierte Zuschauer topographisch distribuiert an einer Aufführung teilnehmen lassen zu können. Auch für das CASSANDRA PROJECT muss die Wahrnehmungssituation der verschiedenen Teilnehmergruppen differenziert werden. Die online-Zuschauer hatten hier keine Option auf Interaktion, da die Bildmischung bereits vor der Übertragung vorgegeben war. Für die Zuschauer in New York und Irvine war die Internet 2-Übertragung die technologische Bedingung, um zwei Bühnenräume miteinander zu kombinieren und in einen neuen Bild- als Aufführungsraum zu transformieren.

So kann beim CASSANDRA PROJECT auch von drei verschiedenen Teil-Aufführungen gesprochen werden. Für die Zuschauergruppen in New York und Irvine war die Übertragung ins WWW nicht notwendig. Mit dem Einsatz von ISDN-Leitungen wären die gleichen Effekte auf die Zuschauer möglich gewesen. Für die onlineZuschauer hingegen war die Internetverbindung die Voraussetzung die Aufführung zeitgleich verfolgen zu können.

\section{Inszenierung der »Exzentrizität des Menschen« unter der net_condition}

Alle Theaterformen besitzen das Potential, existentielle menschliche Fragen zu behandeln. Sie setzen es ein, indem sie die >Exzentrizität des Menschen $<$, verstanden als seinen reflexiven Abstand zu sich selbst, inszenieren. Der Begriff der »Exzentrizität des Menschen « stammt aus der philosophischen Anthropologie Helmuth Plessners, der anhand der Differenz zwischen Mensch und Tier versucht, die Identität des Menschen zu bestimmen. Der Mensch im Unterschied zum Tier steht laut Plessner zu sich selbst in einem dialogischen, einem exzentrischen Verhältnis: Er kann über Fragen der eigenen Person reflektieren (vgl. Plessner: 290-308). Die Exzentrizität des Menschen, versteht Plessner als seine >ex-zentrische Positionalität<: Nur weil der Mensch zu sich selbst in eine exzentrische Position treten kann, ist er auch in der Lage, Rollen zu verkörpern, sowohl im Theater als auch im Spiel. Damit bildet die Exzentrizität des Menschen nicht nur die anthropologische Basis jeder Theaterform, sondern auch des Spiels.

Auch Internet Performances als Theaterform der Netzwerkgesellschaft im beginnenden 21. Jahrhundert übernehmen diese anthropologische Funktion, die »Exzentrizität des Menschen« in einer durch die verteilende Infrastruktur des Inter- 
nets bestimmten Gesellschaft, unter den Bedingungen der net_condition, zu inszenieren. Dabei setzen textbasierte und telematische Internet Performances jeweils andere Schwerpunkte.

Textbasierte Internet Performances stellen Imagination als wahrnehmende Tätigkeit des Lesens in den Vordergrund. Im Prozess des Lesens ist Imagination die Grundlage literarischen Fingierens. Um etwas fingieren zu können, muss nach Iser ein gewisser Grad an »Ekstase« erreicht sein, ein Zustand, der die Außenperspektive auf sich selbst erlaubt, mithin die Positionalität der Exzentrizität (vgl. Iser 1990: 7f, 23).

In telematischen Internet Performances hingegen steht aus anthropologischer Perspektive die Transformation dreidimensionaler Körperlichkeit in zweidimensionale Bildlichkeit im Vordergrund. Diese Transformation wird oftmals als »Bedrohung des anthropologischen Selbst« (Leeker 1996b: 268, vgl. 269) durch die Neuen Medien gedeutet, obwohl nur eine bestimmte Vorstellung vom Körper abgelöst wird. Gemeinsam ist textbasierten und telematischen Internet Performances jedoch das Interesse an einer weiteren anthropologischen Dimension der Netzwerkgesellschaft, nämlich der Tendenz, Zugang als neue Form der conditio humana zu setzen.

\section{Generation@: Zugang als neue Form der conditio humana}

Einer der machtvollsten Mechanismen, um Menschen von Netzwerken auszuschließen, ist es, den Knotenpunkt zu kontrollieren, von dem aus sie Zugang zum Netzwerk bekommen könnten. So bezeichnet Jeremy Rifkin Zugang als das »Zauberwort des Jahrhunderts« (Rifkin 2000b: I) ${ }^{7}$; der neue Dualismus von Vernetzten versus Unvernetzten bringt die politische Bedeutung des Begriffs zum Ausdruck. Rifkin wertet Zugang als »Metapher des kommenden Zeitalters «, über die wir die Transformationen in unserer »Wahrnehmung von Welt und Wirtschaftsgeschehen « nachvollziehen können. Das 21. Jahrhundert sieht Rifkin von ökonomischen Grundlagen bestimmt, die im Gegensatz zur klassischen Marktwirtschaft stehen. Zitat Rifkin:

»Netzwerke treten an die Stelle der Märkte, Verkäufer und Käufer werden zu Anbietern und Nutzern, und was bislang käuflich war, wird >zugänglich $<$. Zugang, Zugriff, >Accessく sind die Schlüsselbegriffe des anbrechenden Zeitalters. Der Wandel von einem Regime des Besitzens, das auf der Vorstellung von weit gestreutem Eigentum basiert, zu einem des Zugangs, das die kurzfristige und begrenzte Nutzung von Vermögenswerten sichert, die von Anbieternetzwerken zur Verfügung gestellt werden - dieser Wandel wird das Wesen ökonomischer Macht in den kommenden Jahren radikal verändern ... Nicht vernetzt zu sein, bedeutet das Ende der sozialen Existenz« (Rifkin 2000a: 251f).

Eine Zugangsberechtigung zu den Kommunikations- und ökonomischen Gemeinschaften der Netzwerkgesellschaft zu besitzen, prägt auch Internet Performances. Um an Internet Performances teilnehmen zu können, muss man vernetzt sein und

7 Die Formulierung einer »Politics of Access« war von Landow bereits 1992 benutzt worden. Vgl. Landow: 185. 
die entsprechende Medienkompetenz besitzen. ${ }^{8}$ Zwar forderten auch andere historische Theaterformen von ihren Zuschauern spezifische Kompetenzen, diese betrafen jedoch fast immer Wahrnehmungsmodi oder die Bereitschaft, neue Wahrnehmungsmodi einzuüben, jedoch nicht die Bedienung einer technisch derart anspruchsvollen Infrastruktur.

Während in der vernetzten Wirtschaft immer mehr Erfahrungen und Erlebnisse des Menschen zur Ware werden und der Zugang zur Kultur von globalen Konzernen vermarktet wird, stehen Internet Performances in einem widersprüchlichen Verhältnis zwischen Ware und Ereignis. Einerseits müssen Teilnehmer zumindest eine Zugangsmöglichkeit zur technischen Infrastruktur besitzen. Andererseits ist die Aufführung selbst kostenlos; sie ist ein potentiell nur schwer vermarktbares, ephemeres Kulturerlebnis. Die Art des Zugangs bestimmt dabei auch die Form von theatraler Öffentlichkeit.

\section{Theatrale Öffentlichkeit in Internet Performances}

Begreift man den sozialen Raum als gleichermaßen performativ wie diskursiv erzeugten, kann man das Theater als eine spezielle Form des sozialen Raumes verstehen, die sich in zahlreichen historischen Theaterformen auch in einer spezifischen Architektur manifestiert hat. In Internet Performances verliert das Theatergebäude als eines der historisch konstantesten architektonischen Objekte in der westlichen Kulturgeschichte seine Bedeutung. Doch obwohl Internet Performances nicht mehr auf dieser Architektur beruhen, entstehen gleichermaßen auf Macht beruhende Strukturen. Historisch und kulturell kontingente Konzeptionen des Raumes etablieren immer auch Macht- und Kontrollmechanismen, die sich direkt auf die Konstruktion und Wahrnehmung kultureller Repräsentationen auswirken. Auch die Vorstellung des telematischen Raumes als eines nicht-physischen, metaphorisch verstandenen Raumes wird mit Utopien und ideologischen Vorstellungen aufgeladen. Die durch das telematische Verbunden-Sein in Internet Performances entstehende Form theatraler Öffentlichkeit lässt sich nicht mit der üblichen Dichotomie von Privatem und Öffentlichem beschreiben. Internet Performances individualisieren und verteilen die vom Theater unter den Bedingungen physischer Kopräsenz bekannte Form von Öffentlichkeit. Die szenographischen Strukturen von Internet Performances stehen für eine »modellhafte Neubestimmung eines gewandelten gesellschaftlichen Raumes« (Dinkla: 73), für die weiterhin das Primat des Sozialen (»primacy of the social« - McAuley: 248) gilt. Die Erfahrung des Sozialen in Internet Performances wird dabei maßgeblich von den Erfahrungen des Körperlichen bestimmt.

8 Nur wenige Produktionen bilden hier eine Ausnahme. Dazu gehörten die Plaintext Players, die den dramatischen Dialog zusätzlich zur Kommunikation im MOO auf eine Leinwand projizierten, und The Finalists, deren Videoübertragung im Rahmen des Festivals SPIEL.ART ebenfalls auf Fernsehbildschirmen vergrößert übertragen wurden. 


\section{Erfahrungen des Körperlichen im Angesicht der Technologie}

»Die Rhetorik einer Verabschiedung des Körperlichen oder seiner technischen Exteriorisierung «, so Sybille Krämer (471), sei in digitalen Welten »nahezu allgegenwärtig «. ${ }^{9}$ Sie wird durch die Trennung von physischer und bildlicher Gegenwart im telematischen Körper provoziert, die auch für Internet Performances kennzeichnend ist. Von einer solchen Position, die von einer >Verabschiedung des Körperlichen< ausgeht, gilt Theater im Zeitalter der Technologie als »Reservat authentischer Kunst und höherer Kultur« (Heinze: 127). Zusammenfassend können hierbei zwei Argumentationsstränge unterschieden werden. Der eine geht von der Dominanz des Technologischen aus, die den Körper zur Anpassung an die Technologie zwingt ${ }^{10}$ und steht in der Tradition der Kritischen Theorie, die von einem grundsätzlichen Erfahrungsverlust und dem herrschaftsstabilisierenden Potential von Medien ausgeht. Der andere Argumentationsstrang schreibt Aufführungen unter den Bedingungen physischer Kopräsenz einen höheren kulturellen Wert zu. ${ }^{11}$ Begründet wird diese letzte These mit dem >magischen Potential<, das >Live Performances< zugeordnet wird. ${ }^{12}$ Diese Argumentation steht mediengeschichtlich in der Tradition, den Wert älterer Medien »als Träger authentischer Wahrnehmung und Erfahrung« (Schanze: 217) gegenüber neu entstandenen Medien höher anzusetzen. Zwischen diesen Positionen lässt sich vermittelnd formulieren, dass mit Gernot Böhme in der Tat eine »Tendenz zur Leibfreiheit unserer Zivilisation« (126) zu beobachten ist. Andererseits funktioniert theatrale Kommunikation immer über spezifische Mediationsprozesse, wie Martina Leeker betont: »Theater ist ein Medium. Es gibt nicht das Authentische, Unmittelbare auf der Bühne« (1996a: 99). Indem Internet Performances das »Abstandsphänomen Körper« (Faßler: 222) als »Instanz kontinuierlicher Grenzverschiebungen « (Becker: 98) inszenieren, kann potentiell auch eine Sensibilisierung körperlichen Erlebens erreicht werden. Hierin liegen die »Chancen für eine Wiederentdeckung und eine Neubestimmung des Anthropologischen « (Leeker 1996b: 270).

These soll im Folgenden sein, dass eine solche Neubestimmung des Anthropologischen erfolgen kann, wenn eine Produktion die eigene Medialität ins Zentrum der Reflexion stellt. In dieser Strategie liegt die Möglichkeit, den Einfluss von Technologien in medialen Konstellationen auf die Erfahrung des Körperlichen nachzuvollziehen. Mehr noch: Wie Böhme betont, können leibliche Möglichkeiten nur im Vollzug wirklich verstanden werden (vgl. Böhme: 128, Anm. 23). Demnach ist der Vollzug des telematischen Körpers eine der Möglichkeiten, die Auswirkungen von Telekommunikationstechnologien auf unsere Kultur nachvollziehen und Weisen des Umgangs mit diesen Auswirkungen erproben zu können. Internet

9 So spricht beispielsweise auch Fischer-Lichte vom »Verschwinden des Körpers«. Vgl. Fischer-Lichte 1997a: 205.

10 So formulierte beispielsweise Leeker in ihrer Dissertation von 1995 noch folgende These: »Der Körper ist gezwungen, sich die neuen Formen medialer Kommunikation und Wahrnehmung anzueignen. Der Mensch beginnt im Umgang mit Medien seine eigene Physis unter der Vorgabe des Fremden zu simulieren.« Leeker 1995: 296.

11 Beispielsweise bei Phelan, die folgende These aufstellt: »Performance's independence from mass production, technologically, economically, and linguistically, is its greatest strength.«Phelan: 149. - Vgl. ebenfalls Fischer-Lichte 1997c: 34.

12 So ist das Theater für Fischer-Lichte einer der »very rare places where bodies can unfold their aura or even magic potential« (Fischer-Lichte 1997b: 22). 
Performances als Theaterform der Netzwerkgesellschaft stehen mit diesem Ansatz in der Tradition des Theaters, gesellschaftliche Vorstellungen vom Körper zu artikulieren. Theaterformen, die auf der leiblichen Kopräsenz aller Teilnehmer basieren, stellen nur eine der möglichen Antworten des Theaters auf die Telematisierung unserer Kultur dar; Internet Performances hingegen gehen vom Telematischen als einer bestimmenden kulturellen Größe aus. Je nach Konzeption positionieren sich die Arbeiten mehr oder weniger kritisch gegenüber den Auswirkungen der Telematik auf unsere Kultur sowie den damit verbundenen gesellschaftlichen und ideologischen Implikationen. Obwohl auch textbasierte Internet Performances den Fokus auf die kommunikative Bedeutung an den Körper gebundener Zeichen lenken, betrifft die polarisierende Diskussion um die Erfahrungen des Körperlichen vor allem die telematischen Internet Performances. Abhängig von der Art und Weise, wie diese Körperlichkeit vermitteln und körperliche Erfahrungen für die Teilnehmer möglich werden lassen, positionieren sie sich gegenüber dem Telematischen entweder affirmativ oder kritisch.

\section{Conclusio: Internet Performances als distanzgewährendes Modell}

Aus anthropologischer Perspektive realisiert sich Theater »stets als modellhafte Gestaltung spezifischer Wahrnehmungsbedingungen«, die für die jeweilige Kultur von Bedeutung sind. Über die Ebenen der Inszenierung, Wahrnehmung und Aufführung bzw. Performanz zeigt sich die jeweilige Theaterform als kulturelles Modell, das die Bedeutung dieser Faktoren und ihr Verhältnis untereinander auf ihre kulturtheoretische Relevanz hin befragt (vgl. Fischer-Lichte 2001: 23). Internet Performances zeigen sich hier primär als distanzgewährendes Modell, über das zentrale Aspekte der Netzwerkgesellschaft hinterfragt und Antworten darauf entwickelt werden können. Indem Theaterformen einen Diskurs über aktuelle kulturell-gesellschaftliche Transformationsprozesse erzeugen, übernehmen sie die Funktion, diesen kulturellen Wandel modellhaft nachzuvollziehen. Bereits die alsStruktur in der Aussage, Internet Performances als Reflexion, als Befragung und als Experiment gleichermaßen bezeichnen zu können, deutet auf deren Potential hin, Distanz zu aktuellem Geschehen gewähren zu können. Aus einer Meta-Perspektive thematisieren Internet Performances zentrale Aspekte westlicher Gesellschaften im Übergang zum 21. Jahrhundert, so zum Beispiel:

- Netzwerke als gesellschaftliche Organisationsformen,

- Formen der Subjektkonstruktion im Internet,

- das Internet als gesellschaftlichen Raum,

- Entwürfe für ein Menschenbild der telematischen Gesellschaft,

- den Einfluss des Technischen auf menschliche Erfahrung und Wahrnehmung

- und weitere Transformationen durch die und innerhalb der Netzwerkgesellschaft.

Internet Performances begegnen dabei der Herausforderung, Orientierung in einer abstrakter werdenden Wirklichkeit zu ermöglichen. In ihrer modellhaften Neubestimmung eines gewandelten gesellschaftlichen Raumes greifen Internet Performances auf Verfahren und Mittel des Theaters als Formen der Repräsentation zurück. Internet Performances sind so Spiegel der Gesellschaft, zeigen gleichzeitig jedoch auch humane Bedürfnisse angesichts der zunehmenden Informatisierung der Kultur auf. So wie sich das heutige Verständnis des Begriffs >live< erst durch das 
Aufkommen televisueller Medien herausbildete, steht auch die kulturelle Bedeutung des Leiblichen und leiblicher Erfahrung erst seit dem Aufkommen televisueller und telematischer Medien im Zentrum der Aufmerksamkeit.

Indem sich Internet Performances mit der Ambivalenz des Technischen, also den positiven wie negativen Auswirkungen von technischen Innovationen, auseinandersetzen, besitzen sie trotz ihres geringen Bekanntheitsgrads soziale Relevanz. Mit Internet Performances als Theaterform der Netzwerkgesellschaft im Übergang zum 21. Jahrhundert, die die Ambivalenz des Technischen reflektiert, so ist zu hoffen, bleibt das Theater auch weiterhin der bevorzugte Ort des Anthropologischen.

\section{Literatur}

Becker, Barbara (2003): »Philosophie und Medienwissenschaft im Dialog «. In: Stefan Münker/Alexander Roesler/Mike Sandbothe (Hg.): Medienphilosophie. Beiträge zur Klärung eines Begriffs. Frankfurt/M.: Fischer, S. 91-106.

Böhme, Gernot (1985): Anthropologie in pragmatischer Hinsicht. Darmstädter Vorlesungen. Frankfurt/M.: Suhrkamp.

Dinkla, Söke (2001): »Das flottierende Werk. Zum Entstehen einer neuen künstlerischen Organisationsform«. In: Peter Gendolla/Norbert Schmitz/Irmela Schneider/Peter Spangenberg (Hg.): Formen interaktiver Medienkunst. Frankfurt/M.: Suhrkamp, S. 64-91.

Faßler, Manfred (1996): »Umgebungen postheroischer Körper«. In: Frithjof Hager (Hg.): KörperDenken. Aufgaben der Historischen Anthropologie. Berlin: Reimer, S. 222-231.

Fischer-Lichte, Erika (1997a): »Die Verklärung des Körpers. Theater im Medienzeitalter«. In: Dies.: Die Entdeckung des Zuschauers. Paradigmenwechsel auf dem Theater des 20. Jahrhunderts. Tübingen: Francke, S. 205-220.

Fischer-Lichte, Erika (1997b): »Introduction. Theatre Studies from a European Perspective«. In: Dies.: The Show and the Gaze of the Theatre. A European Perspective. Iowa: University of Iowa Press.

Fischer-Lichte, Erika (1997c): »Performance Art and Ritual: Bodies in Performance «. In: Theatre Research International 22/1, S. 22-37.

Fischer-Lichte, Erika (2001): »Zwischen >Text $<$ und >Performance $<$. Von der semiotischen zur performativen Welt«. In: Dies.: Ästhetische Erfahrung. Das Semiotische und das Performative. Tübingen: Francke, S. 9-23.

Glesner, Julia (2005): Theater und Internet. Zum Verhältnis von Kultur und Technologie im Übergang zum 21. Jahrhundert. Bielefeld: transcript.

Heinze, Thomas (1990): Medienanalyse. Ansätze zur Kultur- und Gesellschaftskritik. Opladen: Westdeutscher Verlag.

Iser, Wolfgang (1990): Fingieren als anthropologische Dimension der Literatur. Konstanzer Universitätsreden. Konstanz: Universitätsverlag.

Iser, Wolfgang (1994): Der Akt des Lesens. Theorie ästhetischer Wirkung. München: Fink.

Kaye, Nick (2000): Site-specific art. Performance, place and documentation. London: Routledge.

Krämer, Sybille (2001): »Medien - Körper - Performance«. In: Martina Leeker (Hg.): Maschinen, Medien, Performances. Theater an der Schnittstelle zu digitalen Welten. Berlin: Alexander, S. 471-479. 
Landow, George (1992): Hypertext. The Convergence of Contemporary Critical Theory and Technology. Baltimore: The Johns Hopkins University Press.

Langenscheidt-Redaktion/Süddeutsche Zeitung (2000): Langenscheidts Internet Wörterbuch Englisch-Deutsch. Berlin: Langenscheidt.

Leeker, Martina (1995): Mime, Mimesis und Technologie. München: Fink.

Leeker, Martina (1996a): »Die Zukunft des Theaters im Zeitalter technologisch implementierter Interaktivität«. In: Johannes Werner Erdmann (Hg.): Kunst, Kultur und Bildung im Computerzeitalter. Berlin: Hochschule der Künste, S. 85-103.

Leeker, Martina (1996b): »Like Angels. Wohl bekomm's dem Körper in den S(t)imulatoren vom Flug bis zum Sex «. In: Johannes Werner Erdmann (Hg.): Kunst, Kultur und Bildung im Computerzeitalter. Berlin: Hochschule der Künste, S. 267-282.

McAuley, Gay (1999): Space in Performance: Making Meaning in the Theatre. Michigan: University of Michigan Press.

Meyer, Petra Maria (2001): Intermedialität des Theaters. Entwurf einer Semiotik der Überraschung. Düsseldorf: Parerga.

Phelan, Peggy (1993): Unmarked. The Politics of Performance. London: Routledge.

Plessner, Helmuth (1975 [1928]): Die Stufen des Organischen und der Mensch. Einleitung in die philosophische Anthropologie. Berlin: de Gruyter.

Rifkin, Jeremy (2000a): Access. Das Verschwinden des Eigentums. Warum wir weniger besitzen und mehr ausgeben werden. Frankfurt: Campus.

Rifkin, Jeremy (2000b): »Die Teilung der Menschheit«. In: FAZ vom 12. August 2000, Tiefdruckbeilage S. I f.

Sandbothe, Mike (1998): »Theatrale Aspekte des Internets. Prolegomena zu einer zeichentheoretischen Analyse theatraler Textualität«. In: Udo Göttlich/JörgUwe Nieland/Heribert Schatz (Hg.): Kommunikation im Wandel. Zur Theatralisierung der Medien. Köln: Halem, S. 209-226.

Sandbothe, Mike (2001): »Pragmatische Medientheorie des Internets. Überlegungen zu einer integralen Konzeption zeitgenössischer Medienwissenschaft «. In: Peter Gendolla/Norbert Schmitz/Irmela Schneider/Peter Spangenberg (Hg.): Formen interaktiver Medienkunst. Frankfurt/M.: Suhrkamp, S. 183-201.

Schanze, Helmut: »Integrale Mediengeschichte«. In: Ders. (Hg.): Handbuch der Mediengeschichte. Stuttgart: Kröner, S. 207-248. 


\title{
TEIL 4
}

\author{
Theatrale Praktiken \\ IN DER MEDIENGESELLSCHAFT
}





\title{
KRIEGSPROPAGANDA MULTIMEDIAL. SPEKTAKEL, VARIÉTÉ UND KINO IM ERSTEN WELTKRIEG
}

\author{
EVA KRIVANEC
}

Der erste Weltkrieg kann als erster großer medienvermittelter und -gestützter Krieg gelten - von den beliebten Kriegsbildern im Kino über die auflagenstarke illustrierte Presse bis hin zur Nutzung von Grammophonen und Telefonen in den Schützengräben reichen die damals noch durchweg neuen Mediennutzungen zur Verbreitung von Informationen und Unterhaltung im Krieg (vgl. Baumeister: 136-140). ${ }^{1}$ Zugleich gehörte, gerade in den europäischen Großstädten, der Theaterbesuch nach wie vor zum festen Bestandteil der Freizeitgestaltung großer Teile der städtischen Bevölkerung. In dem Jahrzehnt vor dem ersten Weltkrieg etablierte sich strukturell jene moderne Massenkultur, deren Grundprinzipien bis heute gelten.

»Im Mittelpunkt standen ein neues Publikum mit Freizeiterwartungen, die von städtischem Leben und moderner Lohnarbeit geprägt wurden, sowie ein neues System kommerzieller Populärkünste. [...] Die Anbieter schöpften aus einem internationalen Fundus an Erfolgsrezepten, und ihre Produkte wurden über moderne Medien und Transportmittel weltweit verbreitet « (Maase: 20).

In allen größeren Städten fanden sich neben staatlichen Bühnen und kommerziellen Unterhaltungstheatern viele kleinere und größere Vergnügungsetablissements, die sich mit Variétés, Cabaret, Revuen, Zirkuspantomimen oder technisch aufwändigen »Sensationsstücken« im intermedialen Feld zwischen Theater, Tanz, Musik, Artistik und Film etabliert hatten.

Sämtliche Bereiche dieser städtischen Unterhaltungskultur wurden im August 1914 in den Krieg führenden Ländern auf der einen wie auf der anderen Seite der Front von einer großteils spontanen »kulturellen Mobilmachung « für den Krieg und die nationale Sache erfasst. Bereits im Sommer 1914, während Theater und Filmpaläste noch geschlossen hatten, gaben arbeitslose SchauspielerInnen und $\mathrm{Mu}$ sikerInnen spontan zusammengestellte patriotische Programme in Gaststätten, Cafés und auf der Straße zum Besten und suchten die Aufmerksamkeit der versammelten Bevölkerung zu gewinnen, vielfach auch mit dem Hinweis auf einen wohltätigen Zweck (vgl. Baumeister: 33-42). Der öffentliche Raum der Straße oder der Cafés und Restaurants wurde in den ersten Kriegswochen zur Bühne, zum Repräsentationsraum für die kriegerisch-patriotische Zurschaustellung nationaler Einheit. Aber schon im September 1914 »erfolgte der Schritt von spontanen Siegesfeiern zu organisierten, theatralisch inszenierten Großkundgebungen« (39), wie etwa

1 Zum historischen und theoretischen Verhältnis von Krieg und Informationstechnik vgl. etwa: Kittler; Virilio. 
eine »große evangelisch-patriotische Kundgebung « im Zirkus Schumann in Berlin, am 6. September 1914 (vgl. 39, Fußnote 60).

In diesem Beitrag möchte ich einigen Beispielen populärer multimedialer Bühnenkunst nachgehen, die im Ersten Weltkrieg entstanden und die - mit oder ohne staatlicher Intervention oder Unterstützung - der Kriegspropaganda dienten. Die dahinterliegende Frage könnte, sehr allgemein formuliert, so lauten: Griffen die Theateravantgarden der 1920er Jahre in ihren Bühnen- und Medienexperimenten ${ }^{2}$ nicht implizit auf die - zum Teil recht innovative - Ästhetik dieser Kriegs-Unterhaltungskunst zurück, die mit der Verbindung von Schauspiel, Film und Bühnentechnik experimentierte?

Der Eintritt in den Krieg brachte in allen kriegführenden Staaten eine Reihe von Maßnahmen und Beschlüssen zum Boykott von Theaterstücken und Filmen aus dem feindlichen Ausland hervor. Dies brachte die Planungen der Theater- und Kinobetreiber für die Herbstsaison deutlich durcheinander. Internationale Bühnenerfolge wurden zunächst vor allem durch schnell verfertigte Kriegsstücke in den beliebten Unterhaltungsgenres - Operette, Volksstück, Posse, Revue - ersetzt. Für die noch relativ junge, aufstrebende Filmbranche, die von Beginn an international ausgerichtet war (vgl. etwa Kessler/Lenk: 17-32), bedeutete der - selbst auferlegte - Abbruch der Austauschbeziehungen zwischen verfeindeten Ländern einen radikalen (und folgenreichen) Bruch. Wolfgang Mühl-Benninghaus spricht in seiner Studie zum deutschen Film im Ersten Weltkrieg vom »Ende der Internationalität des Mediums « (20). ${ }^{3}$ Gerade in Deutschland und Österreich führte der Boykott von Filmen aus dem »feindlichen Ausland « vor allem auch zu einen akuten Filmmangel (29f). ${ }^{4}$ In dieser Situation griffen viele Kinobetreiber auf das Modell des »Kinovariétés « zurück, von dem sich der Film gerade erst in den Jahren unmittelbar vor dem Ersten Weltkrieg emanzipiert hatte (vgl. Müller 1998: 55-60), diesmal allerdings kamen Künstler und Artisten in die Lichtspielhäuser und gestalteten - in Kombination mit den ersten kriegsbezogenen Filmen - »bunte Abende « mit patriotischem Charakter (vgl. etwa Mühl-Benninghaus: 30-32; »Patriotische Films «: 24). Das Wiener Kosmos-Kino kündigte zwischen »chronologisch kinematographischer Kriegsberichterstattung (vom deutsch-russischen Kriegsschauplatz)« und dem »Sensationsprogramm der Kunst-Lichtspiele« den Schauspieler und Regisseur des Theaters in der Josefstadt Egon Brecher am Lesepult an, der unter anderem ein Kriegsgebet von Anton Wildgans vortragen sollte (vgl. Theater und Vergnügungen: Wiener Kosmos [Ankündigungen] 1914: 14). Ähnlich gemischt war auch das

2 Als zentrale bewegungsübergreifende Charakteristika dieser europäischen Avantgarden (Futurismus, Expressionismus, Agitprop (Piscator u.a.), Dada, Surrealismus, etc.) sehe ich etwa die Synthese bzw. Konfrontation mehrerer Medien und Künste, das Spiel mit intermedialen Verschränkungen, das Interesse an der Technik und am Spektakulären, sowie den Zusammenbruch traditioneller narrativer Strukturen, die Hervorhebung des Fragmentarischen, Zerrissenen, sowohl in den Inhalten und Figurenkonzeptionen als auch in der dramaturgischen Form. Die narrative Einheit und Entwicklungslogik wird nicht mehr hergestellt, sie wird ersetzt durch >Nummern $<$ oder $>$ Bilder $<$ wie im Zirkus, im Variéte oder im Kino.

3 Vgl. auch Mühl-Benninghaus: »Mit der Abschottung aller Grenzen gegenüber den Kriegsgegnern und den Einschränkungen im internationalen Verkehr brach der internationale Filmaustausch für die Dauer von etwa 10 Jahren völlig zusammen« (25).

4 Vgl. auch: »Die deutsche Filmproduktion«, 1914: »In der gegenwärtigen Kriegszeit wendet sich unser Interesse naturgemäß hauptsächlich der deutschen Filmproduktion $\mathrm{zu}$, die neben der italienischen und dänischen und den wenigen Films österreichischer und amerikanischer Herkunft ausschließlich den Markt beherrschen« (1). 
Programm von LIEB' VATERLAND am 10. Oktober 1914 im großen Musikvereinssaal in Wien: Lichtbilder-Vortrag, neueste Kriegskinematogramme, musikalische und humoristische Einlagen wechseln einander ab (vgl. »Lieb' Vaterland «: 3). Das Beispiel dieser beiden genannten Orte in Wien (das Kosmos-Kino in Wien-Neubau, der Musikvereinssaal als traditionsreicher Konzertsaal) zeigt auch, dass die Grenzen zwischen Hochkultur einerseits und Unterhaltungskultur andererseits deutlich flexibler und durchlässiger waren, als man meinen könnte.

Unabhängig davon, von welcher Seite man sich der Interaktion von Kino und Theater in dieser Zeit nähert, die Verbindungen sind deutlich enger und vielfältiger als es aus heutiger Perspektive oder auch aus der Perspektive des noch in großem Maße kinofeindlichen Feuilletons der 1910er Jahre aussieht. Um einmal auf die andere Seite der verfeindeten Kriegslager zu schauen, hier ein Beispiel aus Frankreich. Der junge aufstrebende Theaterautor und Schauspieler Sacha Guitry, Sohn des berühmten Schauspielers Lucien Guitry, beschloss noch im Herbst 1914 - auch in Reaktion auf das »Manifest der deutschen Intellektuellen«, in dem diese stramm die Haltung von Wilhelm II. und der deutschen Heeresleitung sowie den Einmarsch in Belgien verteidigten - einen Film zu drehen, in dem jene berühmten Künstler bei der Arbeit zu sehen sein sollten, die für ihn die Höhepunkte »französischer Kunst und Denkweise« repräsentierten (vgl. Guitry 1939; Gidel: 243f). Dieser Film mit dem Titel CEUX DE CHEZ NOUS ${ }^{5}$ - der chauvinistische Anklang war wohl durchaus beabsichtigt - zeigt Auguste Rodin beim Bildhauern, Edmond Rostand beim Schreiben, André Antoine bei einer Molière-Inszenierung, Claude Monet, wie er seine Leinwand vorbereitet, Anatole France, der seine Bibliothek ordnet, Camille Saint-Saens am Klavier, Auguste Renoir, schon alt und krank, doch unermüdlich beim Malen mit der Hilfe seines Sohns Jean, Sarah Bernhardt beim Rezitieren und schließlich Edgar Degas, der sich eigentlich geweigert hatte, gefilmt zu werden, den Guitry aber dann zufällig mit Kamera auf der Straße traf. Gezeigt wurde dieser Film erstmals zur (Wieder-)Eröffnungsvorstellung im Théâtre des Variétés am 23. November 1915, anstatt der üblicherweise in diesem Theater gespielten Komödien und Operetten, begleitet von direkt auf der Bühne gesprochenen Kommentaren von Sacha Guitry und seiner Partnerin Charlotte Lysès; zum Theaterabend gehörten noch Chansons, Monologe und ein Einakter von Sacha Guitry (UnE VILAINE FEMME BRUNE) (vgl. Guitry 2005: 147-162). In diesem historisch bedeutenden Moment war offenbar der Wunsch, bleibende Bilder zu schaffen, die auch künftigen Generationen einen lebendigen Eindruck dieser KünstlerInnen vermitteln sollten, sehr groß - und auch in der Kritik wurde dies als herausragender Verdienst Guitrys hervorgehoben (vgl. Gignoux 1915b).

In der Revue - als nicht-lineares, aus der Montage einzelner Nummern bestehendes Genre wohnt ihr grundsätzlich eine Tendenz zur Intermedialität und darüber hinaus zur Selbstreflexion bzw. zur Persiflage der eigenen szenischen Strategien inne - wird das Spiel mit dem Medium Film bald aufgenommen und zum Teil in virtuoser Weise umgesetzt. Ein besonders ausgeklügeltes Beispiel findet sich in der Pariser Kriegsrevue Nouvelle REVuE 1915, die am 6. Oktober 1915 im Théâtre Antoine, das vor dem Krieg eher für die Inszenierung zeitgenössischer Dramen als für Revuen bekannt war, erstmals gespielt wurde (vgl. Gignoux 1915a; Brisson). Charles Prince, Schauspieler in dieser Revue, war dem Publikum gut bekannt als Darsteller von Rigadin, einer der beliebtesten komischen Figuren im fran-

5 Der Film CeuX DE CHEZ NOUS befindet sich in der Fassung von 1915, sowie in einer Bearbeitung für das Fernsehen von 1952 (44 min.) in den Archives Françaises du Film (Bois d'Arcy) des $\mathrm{CNC}$ - Centre National de la Cinématographie. 
zösischen Film zu dieser Zeit. ${ }^{6}$ In der Revue spielt er nun einen Notar aus der Normandie namens Maître Rigadin, der empört ist über den Missbrauch seines Namens auf Filmplakaten. Auf diesen Plakaten könne man etwa lesen, dass Rigadin in sein Stubenmädchen verliebt sei - was für ein Aufruhr in der kleinen Stadt, in der Maître Rigadin lebt und arbeitet (vgl. Bidou). Der aufgebrachte Notar fährt also nach Paris, um gegen diese Kampagne zu protestieren. Er geht dort ins Kino und sieht sich selbst auf der Leinwand. Rigadin, der Notar, beginnt mit Rigadin, dem Filmhelden, zu sprechen, als sich letzterer plötzlich auf der Leinwand zu ihm umdreht und ihm antwortet. Kaum versucht der Notar Rigadin sein alter ego zu verfolgen, wird er plötzlich selbst Teil des Films. Der Theaterkritiker Henry Bidou schrieb dazu: »Die Figuren treten in die Leinwand ein und aus ihr heraus, als wäre sie ein Zimmer« (Übersetzung: E.K.).

Mit multimedialen Schau-Stücken verschiedenster Art versuchten auch die als propagandistische Großprojekte konzipierten sogenannten »Kriegsausstellungen « ein breites Publikum anzulocken, $\mathrm{zu} »$ belehren« und $\mathrm{zu} »$ überzeugen « (vgl. ArbeitsAusschuss: 3-5). Im Wiener Prater, dem Ort des Vergnügens und der Freizeitgestaltung der Wiener und Wienerinnen schlechthin, fand die erste »Kriegsausstellung « unter zentraler Koordination der Heeresverwaltung von Juli bis Oktober 1916 statt. Der Publikumsandrang scheint groß gewesen zu sein, die Wiener Zeitung berichtete schon am 4. Juli 1916 von 61.000 Besuchern am ersten geöffneten Sonntag der Kriegsausstellung in Wien (vgl. »Kriegsausstellung Wien 1916«: 8). Im Vorwort zum Ausstellungskatalog hieß es:

»Inmitten des tobenden Krieges, da die Welt in Waffen starrt und die Zentralmächte gegen eine Übermacht von Feinden mit Löwenmut kämpfen und den Gegnern ihre wuchtige Pranke fühlen lassen, erhebt sich auf den Gründen des Kaisergartens und der angrenzenden Galizinwiese als ein leuchtendes Wahrzeichen friedlicher Tätigkeit im Kriege die Kriegsausstellung, weithin verkündend, dass die Kultur in der Reichshauptstadt ihre Bedeutung gewahrt und eine mächtige Förderung gefunden hat« (Arbeits-Ausschuss: 3).

Der Anspruch der Ausstellung war umfassend: Sie sollte von den militärischen, politischen und sozialen »Errungenschaften « berichten, technische Innovationen preisen, eine Plattform für die österreichische Wirtschaft und Industrie darstellen, vor allem aber sollte sie die Kultur im Krieg hochhalten. Auf dem Gelände der Kriegsausstellung befanden sich ein Theater, ein Kino, mehrere Ausstellungssäle für Kunst, Literatur und Photographie (vgl. »Lageplan der Kriegsausstellung Wien 1916«: XCVI) und, in der Abteilung »Im Felde«, der Nachstellung von Schützengräben, Befestigungen und Fronteinrichtungen, gab es als besondere Attraktion das MARINESCHAUSPIEL IM SCHÜTZENGRABEN (vgl. »Schützengraben im k.k. Prater« [Plakat]), mit den vier Akten »Kriegserklärung im Heimathafen«, »Ein Unterseebootangriff «, »Der Angriff der Flotte auf den feindlichen Kriegshafen « und »Nach dem Kampfe« zu bewundern. Im Programmheft wurde die erste Szene so beschrieben:

6 Die Serie der RigadiN-Filme unter der Regie von Georges Monca besteht insgesamt aus über 500 Filmen, die zwischen 1908 und 1920 ungeheuren Erfolg hatten, sowohl in Frankreich als auch weit darüber hinaus. Anders als Max Linder, der in den letzten Jahren als Komiker des frühen Kinos wiederentdeckt wurde, ist Charles Prince alias Rigadin bislang kaum entsprechend gewürdigt worden (vgl. Richard). 
»Es ist gegen fünf Uhr nachmittags. Heller Sonnenschein breitet sich über Meer und Hafen aus. Die Kunde von der erfolgten Kriegserklärung ist bereits in der Hafenstadt bekannt. Abfahrbereit liegt die Kriegsflotte. Auf einmal erscheint ein Torpedoboot und meldet jedem Kriegsschiffe die erfolgte Kriegserklärung, welche jedes Mal mit einem donnernden $>$ Hurra< aufgenommen wird « (»Programm des Marine-Schauspiels« [Faltblatt]).

Als Akteure und Sprecher wurden hier das Torpedoboot und die Kriegsschiffe genannt, Menschen kamen offensichtlich gar nicht vor.

Das Kino der Kriegsausstellung eröffnete am 4. Juli 1916 mit dem speziell für die Ausstellung gedrehten Propagandaspielfilm WIEN IM KRIEG (vgl. Büttner/Dewald: 35$){ }^{7}$ Im Programmheft zum Film hieß es: »Das ganze Bild atmet Wiener Humor und wirft Streiflichter auf alle durch den Krieg gezeitigten außerordentlichen Verhältnisse« (»Programm >Wien im Krieg«« [Faltblatt], 1916). Neben dieser Kriegsromanze im Wienerischen Milieu konnte man im »Kriegskino«, schon wenige Tage nach der Ausstellungseröffnung, den Film DIE ERÖFFNUNGSFEIERLICHKEITEN DER KRIEGSAUSSTELLUNG sehen.

Nach der 200. Aufführung von WIEN IM KRIEG, am 11. August 1916, wurde erstmals die Verfilmung von Nestroys Lustspiel EINEN JUX WILL ER SICH MACHEN unter der Regie von Emil Leyde gezeigt (vgl. Büttner/Dewald: 35). Mehrere der im Film auftretenden SchauspielerInnen (z.B. Ida Rußka, Viktoria Pohl-Meiser) standen zugleich, schräg gegenüber, im neu eröffneten Bundestheater in der Kriegsausstellung unter der Direktion von Oscar Fronz, dem Gründer und Direktor des Wiener Bürgertheaters, in Edmund Eyslers Operette WARUM GEHT'S DENN JETZT? auf der Bühne (UA: 5. Juli 1916) (vgl. Eysler).

Diese Operette stand in bewusstem Kontrast zur ernsten und bombastischen Tendenz der Kriegsausstellung. Die Kritik der Eröffnungsvorstellung in der Österreichischen Volkszeitung beginnt auch mit der Feststellung, dass die Operette großen und gerechtfertigten Erfolg haben wird, wenn sich »die Besucher der Ausstellung von dem ernsten Gesicht, das diese zur Schau trägt, oder von dem noch ernsteren, das das Leben unserer Tage zeigt, dem heiterlächelnden der burlesken Kunst zuwenden« (»Warum geht's denn jetzt?«: 8). Und tatsächlich weist nichts in dem Stück auf den Krieg hin, außer vielleicht, zwischen den Zeilen, ein Seitenhieb auf die Modetänze (Tango, Ausdruckstanz), die alle nicht so viel Freude bereiteten wie ein guter alter Wiener Walzer (vgl. Eysler: 22). So baute Eysler auch vollständig auf eingängige Walzermelodien und eine mit ein paar unbedenklichen Pikanterien gespickte Handlung rund um zwei in Konkurrenz stehende Kaufleute einer Kleinstadt in der Nähe von Wien (vgl. b.: 4f).

Gerade der Zirkus, in dessen Geschichte »die Nähe zum Kriegerischen und Militärischen « (Peter: 29) eine wichtige Rolle spielte, darf bei der Untersuchung von propagandistischer Unterhaltungskunst im ersten Weltkrieg nicht fehlen. Exemplarisch stelle ich die Aktivitäten des in Dresden ansässigen Zirkusdirektors Hans Stosch-Sarrasani dar, der bis 1914 ein Zirkusunternehmen mit mehr als 500 MitarbeiterInnen geschaffen hatte (vgl. Günther/Winkler: 121). Sarrasanis Erfolgsrezept war die Integration traditioneller Zirkuselemente (Pferde-, Tierdressur, Zauberer, Clowns, Jongleure, Akrobaten, etc.) mit dem spektakulären Einsatz neuer Technologien - Autos, Flugzeuge und Filmprojektionen waren integraler Bestandteil seiner Shows. Diese lebten auch stark von der Faszination des (imaginierten)

7 Das Filmarchiv Austria hat diesen Film von einer fragmentarischen Fassung rekonstruiert und restauriert. 
Exotischen, das er häufig in märchenhaften Orientalismen oder amerikanischen Wild-West-Shows, bediente (vgl. Otte). Sarrasani selbst stellte seinen Anspruch an die Seite von dem Richard Wagners - er strebe nach einem Universalkunstwerk, im doppelten Sinn von weltumspannend und alle Sinne und Kunstformen vereinigend (vgl. 535). Auch Sarrasani war zu Kriegsbeginn vom Zusammenbruch der internationalen Unterhaltungsbranche betroffen, viele seiner >exotischen< Akteure und Artisten mussten fluchtartig Deutschland verlassen (vgl. 538). Und auch er stellte sein Programm ganz auf den Krieg ein. In Berlin allerdings hatte Sarrasani sowohl vor als auch während des Kriegs Schwierigkeiten, Fuß zu fassen (vgl. Baumeister: 183-186). Zum einen wehrten sich die großen ansässigen Zirkusunternehmer Schumann und Busch gegen die Konkurrenz von außen und zum anderen redete die Berliner Zensurbehörde ein deutliches Wörtchen mit. Die Zensoren verboten im September 1916 das seit Dezember 1914 immer wieder eingereichte >Manegenschaustück< EUROPA IN FLAMMEN endgültig (vgl.: 186). Dieses in Dresden sehr erfolgreiche Stück stellte mit enormem bühnentechnischem Aufwand eine Reihe politischer oder militärischer Kriegsschauplätze nach, darunter den Zarenhof, den Überfall auf Belgien, den U-Bootkrieg oder die masurischen Seen, für die die Manege unter Wasser gesetzt wurde. Die Berliner Zensurbehörde vermerkte allerdings, dass dieses Schaustück »Vorgänge aus der Zeit vor dem Kriegsausbruch und während des Krieges in einer sensationellen, zur Aufregung und Beunruhigung der Zuschauer geeigneten Weise « darstelle und erteilte keine Genehmigung (vgl.: 185). Erst im Sommer 1917, mit zunehmender Unzufriedenheit sowie punktuellem Widerstand in der Bevölkerung und der Reaktion der deutschen Militär- und Polizeibehörden im Sinne einer Verstärkung der direkten, staatlich gelenkten »Inlandspropaganda « auch mit den Mitteln der Unterhaltungskultur, besonders des Kinos, aber auch der großen Schauspektakel wie etwa Zirkus und Revue, änderte sich die Situation für Sarrasani. Und während sowohl Front als auch Heimatfront von Hunger und Erschöpfung gebeutelt waren und in einzelnen Meutereien und Streiks sich auflehnten, ließ Hans Stosch-Sarrasani im Berliner Zirkus Busch von Ende Juni bis Anfang September 1918 sein Militär-Schaustück TORPEDO - LOS! spielen. Martin Baumeister schreibt dazu: »Mehr als alle bisherigen Schaustücke Stoschs setzte es auf die >Überwältigung < der Zuschauer durch einen geballten Einsatz von Menschen, Tieren und Technik, die in eine reißerische, von spektakulären Effekten getragene Handlung eingebunden waren « (188). Von der Explosion einer Werft zur Versenkung eines feindlichen durch ein deutsches U-Boot, vom »Flottenballett « zur Bombardierung Londons, das alles war hautnah mitzuerleben. Es wurde, im Wortsinn, sämtliches noch vorhandene Pulver verschossen.

Zeigen möchte ich mit diesen - unter vielen anderen möglichen gewählten - Beispielen medienübergreifender Unterhaltungskunst im Ersten Weltkrieg vor allem drei Dinge: Nämlich erstens, dass intermediale Verschränkungen und das Spiel mit den Medien in der Unterhaltungskunst der 1910er Jahre sowohl möglich waren als auch mit Experimentierfreude ausgelotet und umgesetzt wurden; zweitens, dass der gesamte Komplex von ideologischer Aufrüstung, der Beschleunigung des Fortschritts von Technik und Medientechnik, sowie Brüchen der Wahrnehmung im ersten Weltkrieg eine enorme Zusammenballung erfahren hat; und drittens, wie eingangs gesagt, dass die Theater-Avantgarden der 1920er Jahre und deren medienästhetische Experimente nicht nur fundamental geprägt waren von den Erfahrungen des Weltkriegs, sondern auch von den sie umgebenden ästhetischen Strategien der Unterhaltungskunst, die ihrerseits lernen musste, mit dem Krieg umzugehen. Oder, 
noch einmal konkret gewendet: Verdanken die Dada-Abende und -Matineen in Zürich, Berlin oder Paris ihre Struktur nicht auch dem Variété? Brauchen die Tanzpantomimen von Valeska Gert nicht auch die Komik von Stummfilm und Revue mit ihren Typisierungen, ihrer Körperlichkeit? Finden wir nicht in Erwin Piscators Revuen Roter RuMmel und TROTZ AlLEDEM! Elemente von StoschSarrasanis Kriegsspektakel wieder?

\section{Filme}

Guitry, Sacha (1915): CEUX DE CHEZ NOUS, Frankreich.

Freisler, Fritz (1916): WIEN IM KRIEG, Österreich (Sascha-Meßter-Filmfabrik).

Leyde, Emil (1916): EINEN JUX WILL ER SICH MACHEN, Österreich (Robert MüllerFilm).

\section{Literatur}

Arbeits-Ausschuss [Präsident: Anton Ritter von Vukovic] (1916): »Vorwort«. In: Arbeits-Ausschuss (Hg.): Offizieller Katalog der Kriegsausstellung Wien 1916. Wien: Buchdruckerei »Industrie«, S. 3-5.

b. (1916): »Eröffnung des Bundestheaters in der Kriegsausstellung«. In: Wiener Abendpost, 06.07.1916, S. 4f.

Baumeister, Martin (2005): Kriegstheater. Großstadt, Front und Massenkultur 1914-1918. Essen: Klartext.

Bidou, Henry (1915): »Théâtre Antoine: LA NOUVELLE REVUE, par Rip«. In: Le Journal des Débats, Nr. 283, 11.10.1915.

Brisson, Ad[olphe] (1915): »Théâtre Antoine«. In: Le Temps, 18.10.1915.

Büttner, Elisabeth/Christian Dewald (2002): Das tägliche Brennen. Eine Geschichte des österreichischen Films von den Anfängen bis 1945. Salzburg/Wien: Residenz.

Denscher, Bernhard/Franz Patzer (Hg.) (1988): Das schwarz-gelbe Kreuz. Wiener Alltagsleben im Ersten Weltkrieg. Wien: Stadt Wien.

»Die deutsche Filmproduktion« (1914). In: Die Film-Woche (Wien), Jg. II, Nr. 74, 27.09.1914, S. 1-6.

Eysler, Edmund (1916): Warum geht's denn jetzt? Burleske Operette in 3 Akten, Wien: Doblinger.

Gidel, Henry (1995): Les deux Guitry, Paris: Flammarion.

G[ignoux], R[égis] (1915a): »Au Théâtre Antoine: LA Nouvelle Revue, de Rip (suite à 1915)«. In: Le Figaro, 09.10.1915.

Gignoux, Régis (1915b): »Courrier des Théâtres. Théâtre des Variétés: CEUX DE CHEZ NOUS, causerie par M. Sacha Guitry et Mme Charlotte Lysès «. In: Le Figaro, 24.11.1915.

Günther, Ernst/Dietmar Winkler (1986): Zirkusgeschichte. Ein Abriß der Geschichte des Deutschen Zirkus, Berlin: Henschel.

Guitry, Sacha (1939): »Extrait du prologue au commentaire du film«. In: http://www.geocities.com/Hollywood/Set/8100/frceux.html (06.02.2007).

Guitry, Sacha (2005): »Une vilaine femme brune«. In: Ders: Pièces en un acte, Paris: Omnibus, S. 147-162. 
Kessler, Frank/Sabine Lenk (1996): »Gallischer Hahn und Deutscher Adler. Filmkontakte vor dem Ersten Weltkrieg. «In: Sibylle M. Sturm/Arthur Wohlgemuth (Hg.): Hallo? Berlin? Ici Paris! Deutsch-französische Filmbeziehungen 19181939, München: Ed. text + kritik, S. 17-32.

Kittler, Friedrich A. (1986): Grammophon, Film, Typewriter. Berlin: Brinkmann \& Bose.

»Kriegsausstellung Wien 1916«(1916). In: Wiener Zeitung, 04.07.1916, S. 8.

»Lageplan der Kriegsausstellung Wien 1916 (1916). In: Arbeits-Ausschuss (Hg.): Offizieller Katalog der Kriegsausstellung Wien 1916 (XCVI). Wien: Buchdruckerei »Industrie«.

»Lieb' Vaterland« (1914). In: Ilustrirtes Wiener Extrablatt, 10.10.1914, S. 3.

Maase, Kaspar (2001): Grenzenloses Vergnügen. Der Aufstieg der Massenkultur 1850-1970, 3. Aufl., Frankfurt/M.: Fischer (=Europäische Geschichte).

Mühl-Benninghaus, Wolfgang (2004): Vom Augusterlebnis zur UFA-Gründung. Der deutsche Film im 1. Weltkrieg, Berlin: Avinus.

Müller, Corinna (1998): »Variationen des Kinoprogramms. Filmform und Filmgeschichte«. In: Corinna Müller/Harro Segeberg (Hg.): Die Modellierung des Kinofilms. Zur Geschichte des Kinoprogramms zwischen Kurzfilm und Langfilm 1905/06 bis 1918. München: Fink. (=Mediengeschichte des Films 2), S. 43-75.

Otte, Marline (1999): »Sarrasani's Theatre of the World: Monumental Circus Entertainment in Dresden, from Kaiserreich to Third Reich«. In: German History, Vol. 17, No. 4, S. 527-542.

»Patriotische Films« (1914). In: Die Film-Woche (Wien), Jg. II, Nr. 75, 04.10.1914, S. 2-4.

Peter, Birgit (2001): Schaulust und Vergnügen. Zirkus, Variété und Revue im Wien der Ersten Republik (Diss.). Wien: Univ. Wien.

»Programm des Marine-Schauspiels« [Faltblatt] (1916). In: Druckschriftensammlung der Wienbibliothek, C 67.052 (= Kriegssammlung aus den Jahren 19141919; 7.1., [Konvolut]).

»Programm Wien im Krieg« (Rochus-Kino, Wien III.) [Faltblatt]. In: Druckschriftensammlung der Wienbibliothek, C 67.052 (= Kriegssammlung aus den Jahren 1914-1919; 7.1. [Konvolut]).

Richard, Jacques (2002): »Prince Rigadin et son monde«. In: Archives (Perpignan), Jg. 17, Nr. 92.

»Schützengraben im k. k. Prater« [Plakat] (1916). In: Plakatsammlung der WienBibliothek, P 35.355.

»Theater und Vergnügungen: Wiener Kosmos« [Ankündigungen] (1914). In: Ilustrirtes Wiener Extrablatt, 01.10.1914, S.14.

Virilio, Paul (1989): Krieg und Kino. Logistik der Wahrnehmung. Frankfurt/M.: Fischer.

»Warum geht's denn jetzt? Uraufführung im neueröffneten Bundestheater« (1916). In: Österreichische Volkszeitung, 06.07.1916, S. 8.

Weiss, Jeffrey S. (1994): The Popular Culture of Modern Art. Picasso, Duchamp and Avant-Gardism. New Haven: Yale UP. 


\title{
Medialität des Terrors. Theater und Fernsehen IM UMGANG MIT DEM 11. SEPTEMBER 2001
}

\author{
MATTHIAS WARSTAT
}

Historisierende Perspektiven auf die Anschläge von New York und Washington und deren kulturelle Folgen erscheinen heute, ein halbes Jahrzehnt nach dem 11. September 2001, möglich und nötig - auch im Hinblick auf das Verhältnis von Terrorismus und den Künsten. Während bislang meist prospektiv gefragt wurde, wie sich die Künste angesichts der terroristischen Herausforderung verändern müssten, kann man allmählich, aus einem gewissen zeitlichen Abstand, die Perspektive umkehren und fragen, wie sich die Künste seit 2001 tatsächlich verändert haben. Dabei erscheint ein Medienvergleich als Ausgangspunkt sinnvoll, denn die weltweite Wahrnehmung von Terroranschlägen ist so untrennbar mit dem Medium Fernsehen verbunden, dass letztlich die Reaktionen aller Künste - auch des Theaters, das primär auf andere Medien wie Raum, Körper und Stimme zurückgreift in der einen oder anderen Weise auf das Fernsehen bezogen blieben. Bis heute kann keine Kunst auf den neuen Terrorismus anspielen, ohne beim Publikum Bilder zu evozieren, die zuvor vom Fernsehen konstruiert wurden. Aber trotz dieser unumgänglichen intermedialen Referenz hat Theater auf den 11. September erkennbar anders reagiert als das Fernsehen. Erst im Vergleich zum Fernsehen treten die Eigenheiten der Reaktion von Kunsttheater und Performancekunst deutlich hervor.

Schon die Frage nach solchen generellen Tendenzen und erst recht die damit verbundene verallgemeinernde Vergleichsperspektive sind methodologisch mit großen Problemen behaftet: Kann man Reaktionen des Theaters seriös mit Reaktionen des Fernsehens vergleichen? Dies scheint nur dann vertretbar, wenn die Diskurse, auf die man den Vergleich bezieht und von deren spezifischem Theaterbegriff man ausgeht, in ihrer Begrenztheit von Anfang an explizit markiert werden. Was die Theaterseite anbelangt, beziehen sich die folgenden vergleichenden Ausführungen (nur) auf Diskurse, die an die kommerziellen Theater und an die etablierte Performancekunst-Szene in den USA gebunden sind.

Nach einem Modell des Hamburger Medienwissenschaftlers Stephan Alexander Weichert (90-97) lässt sich der Umgang der großen Fernsehanbieter mit dem 11. September in fünf Phasen untergliedern. Die erste Phase nennt er Liveness: Gemeint sind die Minuten und Stunden unmittelbar nach dem Anschlag, als auf allen Kanälen Live-Bilder vom Ort der Zerstörung zu sehen waren. In Paul Greengrass' Film UNITED 93 (USA 2006) wird eindrucksvoll gezeigt, wie in dieser Phase auch die Entscheidungsträger in den Flugsicherungszentren und Aufsichtsbehörden zentrale Akteure des Ereignisses - immer wieder gebannt auf die Fernsehbilder aus Manhattan starrten. Diese Rückkopplung ist für die erste Phase charakteristisch. Alle anderen Tagesereignisse sind marginalisiert, und das Fernsehen schließt die Akteure in Echtzeit mit ihrem eigenen Ereignis kurz, dessen Abbild in eine weltweit versendete Wiederholungsschleife eintritt. Die zweite Phase, von Weichert 
eher unpassend als » ̈̈sthetisierung « bezeichnet, sorgt für Interpretation und Aufbereitung des Ereignisses. Mit Trailern, Montagen, Split-Screen-Verfahren und anderen ihm eigenen Gestaltungsmitteln bemächtigt sich das Fernsehen des Ereignisses und formt dessen verschiedene Aspekte zu einer höchst selektiven Einheit, die fortan für die Zuschauer das Geschehen repräsentiert. Im Falle des 11. Septembers folgte diese Phase, in die ein hohes Maß an Inszenierungsanstrengungen eingeht, schon wenige Stunden nach dem Anschlag. Sie ging nahtlos in die dritte Phase, in eine Zeit der Dramatisierung über: Sobald die Bilder vom Einsturz der Türme für sich alleine die Aufmerksamkeit nicht mehr ausreichend fesselten, erging sich das Fernsehen in jenen schicksalhaften Geschichten von Tätern, Rettern und Opfern, die die Programme über Wochen hinweg bestimmen sollten. Aus krassen Entgegensetzungen von gut und böse, Freund und Feind wurden einfache Spannungsbögen generiert, die in ihrem Wiederholungscharakter schon auf die vierte Phase, die Periode der Codierung vorauswiesen. Ein flexibel adaptierbarer Code entsteht, indem das komplexe Geschehen auf ein Minimum an Schlüsselbegriffen und -bildern reduziert wird: das Konterfei Osama Bin Ladens, die Videos mit den Todespiloten beim Einchecken und natürlich die Bilder der einstürzenden Twin Towers selbst konnten fortan als pars pro toto für die terroristische Bedrohung einstehen. Solche Etiketten waren es auch, auf die das Fernsehen in der letzten Phase wieder und wieder zurückgriff - eine Phase, die bis heute andauert und in der eine Historisierung des Geschehens beginnen kann.

Man kann darüber streiten, ob Weicherts Modell die medialen Verläufe präzise genug beschreibt oder ob nicht gerade die zeitlichen Rhythmen und Überlagerungen zwischen den Phasen differenzierter bestimmt werden müssten. Mir kommt es hier aber auf eine andere Frage an: Was für Beobachtungen ergeben sich, wenn man versucht, Weicherts Idee eines Verlaufsmodells - und die zentralen Begriffe seines Modells - auf den Umgang von Theater und Performancekunst mit dem 11. September zu übertragen? Sind die fünf Schritte von Liveness, Interpretation, Dramatisierung, Codierung und Historisierung womöglich von einer so intermedialen Gültigkeit, dass sie, mit geringen Modifikationen, auch auf die theatralen Künste angewendet werden können?

Die Antwort ist ein klares Nein, und es ist vielleicht kein Zufall, dass die Differenz des Theaters gleich zu Beginn eines Vergleichs der Phasenverläufe an dem vieldeutigen Begriff der Liveness hervortritt. $\mathrm{Zu}$ konstatieren ist, dass Theater und Performancekunst als die gleichsam klassischen Ausprägungen von Live-Art überraschenderweise keine Live-Beziehung (im Sinne von Weichert) zu den Ereignissen des 11. Septembers entwickelt haben. Während das Fernsehen gerade in den ersten Minuten und Stunden nach den Anschlägen fieberhafte Aktivität entfaltete, reagierten die theatralen Künste in bemerkenswert verhaltener Weise. Es gab in den ersten Tagen zwei Reaktionsmuster von Seiten des US-amerikanischen Theaterbetriebs: Theater in größerer Entfernung zum Tatort, d.h. in anderen amerikanischen Bundesstaaten, etwa in den Metropolen der Westküste, setzten ihr reguläres Programm ungebrochen fort. Bei den Theatern in unmittelbarer Nähe zum Tatort, insbesondere in Manhattan und anderen Stadtteilen von New York, kam es dagegen nicht nur zu einer Unterbrechung des regulären Programms, sondern zu einer Unterbrechung jeglichen Programms. Für vier bis fünf Tage fand schlicht kein Theater mehr statt. In dieser Entscheidung für ein Moratorium (vgl. Blau: 305) unterschieden sich die Theater diametral vom Fernsehen und verhielten sich dagegen völlig parallel zu anderen konkreten Orten des öffentlichen Lebens wie etwa Restaurants, Sportstadien, Flughäfen oder der Börse. Man sieht an dieser speziellen kulturellen 
Konstellation in Zeiten der Krise gut, dass die Liveness des Fernsehens mit der Liveness des Theaters im Grunde wenig gemein hat. Während der Begriff in Bezug auf das Fernsehen primär ein zeitliches Verhältnis meint, nämlich die Übertragung eines Ereignisses in Echtzeit, bezeichnet die Liveness des Theaters eine vorrangig räumliche Relation: die gemeinsame Anwesenheit von Akteuren und Zuschauern an einem konkret zu situierenden Ort.

Theater ist als Kunstform Teil eines konkreten öffentlichen Raums, der infolge der Anschläge des neuen Terrorismus dramatisch einschrumpft. Die Schrumpfung des öffentlichen Raums erscheint als eine Konsequenz der wachsenden terroristischen Bedrohung, vor allem allerdings einer verhängnisvollen Politik der westlichen Regierungen, die sich mit repressiven Antiterrorgesetzen gewollt oder ungewollt an dieser Schrumpfung beteiligen. Viele Menschen in der näheren Umgebung der Katastrophe hatten nach dem 11. September ganz einfach Angst, sich an öffentliche Orte zu begeben, die sie von einem Tag auf den anderen plötzlich als bedroht, instabil und gefährlich wahrnahmen. Wie an der weitgehend gegenstandslosen Anthrax-Panik gezeigt worden ist, grassierten noch Monate nach den Anschlägen in den USA irrationale Ängste vor einem diffusen, todbringenden Bösen, das den öffentlichen Raum unbemerkt infiltrieren und in einem unerwarteten Moment hinterhältig zuschlagen könnte (vgl. Sarasin). Da die spezifische Liveness der Aufführung aber - im Gegensatz zu der des Fernsehens - unweigerlich ein Sich-Einlassen auf öffentliche Orte verlangt, fanden viele Theater, besonders diejenigen in größerer örtlicher Nähe zu Ground Zero, tagelang kein Publikum.

Das Moratorium des Theaters dauerte nicht ewig, und dennoch markiert im Falle eines Anschlags, d.h. eines schlagartig verdichteten Ereignisses, eine solche Lücke von wenigen Tagen bereits die entscheidende Differenz zwischen denen, die das Ereignis machen und denen, die auf das Ereignis zu reagieren haben. Das Fernsehen war als Medium strukturell Teil des Ereignisses selbst, denn seine Bilder schufen die weltweite Wirkung, die sich die Terroristen erhofften. Jegliches Theater war dagegen erst Teil der Reaktion auf das Ereignis. Interpretationen und Analysen, wie sie das Fernsehen im Stundentakt lieferte, standen dabei nicht im Vordergrund. Dagegen muss man feststellen, dass ein Großteil der Reaktionen des Theaters explizit oder implizit um das Motiv der Heilung kreiste. Wer spät reagierte, wurde offenbar automatisch in die Rolle desjenigen gedrängt, der die geschlagenen Wunden zu verarzten hat. Auch der Diskurs der Feuilletons und der amerikanischen Theaterzeitschriften gruppierte sich ganz um die Dichotomie von Krise und Heilung und konfrontierte das Theater mit der Erwartung, in der einen oder anderen Weise therapeutisch auf das Trauma des 11. Septembers einzugehen. Was auch immer die verschiedenen Theater in den Folgewochen unternahmen - es konnte als therapeutischer Versuch deklariert werden. Drei Reaktionsmuster waren vorherrschend:

Erstens: Viele Theater nahmen etwa eine Woche nach den Anschlägen schlicht ihr normales Programm wieder auf. Beobachter glaubten dennoch, eine Veränderung in der Haltung von Zuschauern und Akteuren zu bemerken. Die Rückkehr zur Normalität hat nach einem erlittenen Trauma zweifellos eine wichtige und auch heilsame Wirkung. Handlungen, die in normalen Zeiten routiniert, beiläufig oder gar unbewusst ablaufen, werden nun mit Nachdruck und innerer Überwindung ausgeführt und erhalten dadurch besondere, fast rituelle Bedeutung. In einer von der Zeitschrift Theater in den ersten Wochen nach 9/11 durchgeführten Umfrage unter Theaterdirektoren zeigten sich viele überzeugt, mit ihrem unveränderten Programm heilsame Wirkungen erzielen zu können. Charakteristisch für diese Haltung ist ein 
Statement von Rob Orchard vom American Repertory Theatre in Cambridge, Massachusetts: »We feel comfortable doing what we're doing, because we're contributing to an environment that's helping people cope. [...] We feel that people having an artistic experience in our theatre are going to be better " (Grinwis u.a.: 8). Von der Kunstform Theater per se - ganz gleich, was man mit ihr anstellte - schien bereits eine heilsame Menschlichkeit auszugehen: »What happened to the World Trade Center was big«, erklärte zum Beispiel Anna Deavere Smith vom New Yorker Institute on the Arts and Civic Dialogue,

»The Trade Center was big and its collapse was big. The bombs that we are using are big. And we are already seeing an incredible rise of interest in poetry because people are desperate to find something that is at human scale. Live theater is at that scale« (Grinwis u.a.: 5).

Auf der Grundlage eines solch idyllischen Theatermodells konnte jede Wiederaufnahme des Alltagsbetriebs mit therapeutischen Vorzeichen versehen werden. Wenn das Geschehen des 11. Septembers zum Beispiel recht schnell zum Stoff für konventionelle Theaterstuicke wurde, die - wie etwa Anne Nelsons THE GuYs (2001) oder Neil LaButes THE MERCY SEAT (2002) - allen Anforderungen des well-made plays genügten, so ließ sich das als Integration des Traumas in ein bestehendes Wertesystem interpretieren und mithin als therapeutischen Erfolg verbuchen.

Zweitens: Die therapeutische Ausrichtung galt aber noch mehr für die zahlreichen Versuche, Theateraufführungen tatsächlich in Trauer-, Erinnerungs- und Heilungsrituale zu transformieren. Vielerorts wurden Benefiz-Galas, Zeremonien und Versammlungen ins Programm genommen, auf denen man der Opfer gedachte, patriotische Gedichte rezitierte und sich an gemeinsamen Liedern erbaute. Viele Theaterleute berichten rückblickend von gelungenen Versuchen, ihre Theater in öffentliche Erinnerungsorte oder gar Kirchen zu verwandeln. Susan Booth von der Alliance Theatre Company in Atlanta konzipierte

»an event that would be something like a townhall meeting, something like a church service, but in theatrical terms. [...] The evening would include many short readings, some from dramatic sources and others from the great documents of American identity and of peace $\ll$ (Grinwis u.a.: 5).

Abseits solcher zeremonieller Produktionen von Mainstream-Theatern versuchten auch anerkannte Stars der Performanceszene - mit im Grunde sehr ähnlichen Konzepten - bei der Erinnerungs- und Trauerarbeit mitzuwirken. Karen Finley produzierte noch ganz unter dem Eindruck der Anschläge die Performance THE DISTRIBUTION OF EMPATHY (2001), die sie zunächst in New York, später auch in anderen US-amerikanischen Städten sowie in Kanada und Norwegen vorstellte. Es war ein Abend für kleine Theater- oder Ausstellungsräume mit intimer Atmosphäre. Dem meist überschaubaren Publikum wurden Getränke und ein kleiner Imbiss gereicht, darunter der so genannte »Ground Zero Hero sandwich«. Finley beschreibt den Ablauf wie folgt:

»I would start the performance by walking through the audience and they would give their firsthand accounts of witnessing $9 / 11$. I only performed the piece on Tuesdays. Tuesday was still sacred, for 9/11 was on a Tuesday. Gary Indiana, the writer, told us the story of how his brother was supposed to have been the pilot on the plane that went into the Pentagon. But his brother changed his flight schedule because he had to move that day. For 
a day, Gary thought his brother was dead. Hearing stories like that, in this small room, was very intimate and close, profound and cathartic. Usually at the end of my performance the audience would be in tears« (Finley: 52).

Zum festen Zeremoniell des Abends gehörte es, dass die Performerin mit ihrem Publikum stehend die Nationalhymne intonierte. Zwar habe sie, so Finley, bei allen Beteiligten Widerstand gegen diese Geste gespürt, aber die ordnende, heilsame Wirkung von Musik und gemeinsamem Singen habe überwogen (ebd.).

Drittens: Ein drittes Reaktionsmuster arbeitete direkt gegen die Schrumpfung des öffentlichen Raums. Auch mit diesem Muster geriet das Theater in eine heilende, therapeutische Relation $\mathrm{zu}$ den Traumatisierungen des 11. Septembers. Und auch hier reichte die Bandbreite einschlägiger Projekte vom kommerziellen Mainstream-Theater bis zur politischen Performancekunst. Der Performer Guillermo Gómez-Peňa und die Gruppe La Pocha Nostra starteten Ende September 2001 in San Francisco eine Veranstaltungsreihe mit dem Titel EL LAB, die bald in die Gründung des Netzwerks Re:Group mündete. Mit den regelmäßigen Sessions von Re:Group etablierte sich ein theatraler Raum, in dem gegen das repressive Gebaren der Bush-Administration Prinzipien der sexuellen Diversität, Multiethnizität und radikalen politischen Devianz hochgehalten wurden. Die Akteure trafen sich abends zunächst zu Kontaktimprovisationen und einem gemeinsamen warm up, wählten dann aus einem Fundus zusammengetragener Requisiten und Kostüme und schminkten und dekorierten sich gegenseitig. Auf diese Weise entstanden hybride, spontan konstruierte Verkörperungen, die zu Lebenden Bildern und Szenen zusammengefügt und mit ad hoc produzierter elektronischer Musik unterlegt wurden:

»We then begin to embody >hybrid personas<, which are not specific impersonations of easily identifiable characters but rather an infusion and composite collage of the political, religious, social, and sexual concerns we consciously or inconsciously wish (or need) to address. [...] Most tableaux begin still and then slowly acquire movement and sound throughout the evening. At times, when a single image is too good, just one or two performers are left alone to create the whole composition; the rest of us merely witness until the image loses its power and it's time for a third performer to intervene (Gómez-Peňa/emael/McKee: 72).

Ziel scheint es zu sein, genau die Möglichkeiten auffallender und abweichender Selbstdarstellung zurückzuerobern, die mit den Angriffen des »USA PATRIOT Act « auf die Freiheit der Kunst eingeschränkt worden waren. Mit ähnlicher Stoßrichtung, allerdings viel milder und unverbindlicher in der Form, bekannten sich nach dem 11. September auch viele Direktoren kommerzieller und unterhaltungsorientierter Häuser zum Theater als öffentlichem Forum und als Ort des Austauschs differierender Identitäten, Ansichten und Interessen - »a safe place where different kinds of people can come together around something thought-provoking and eyeopening and possibly provocative«, wie Carey Perloff vom American Conservatory Theater in San Francisco es formulierte (Grinwis u.a.: 10).

Es waren letztlich sehr traditionelle Attribute von Theater, die angesichts der Krise exponiert wurden: seine relative Kleinheit, seine lokale Bezogenheit, seine Reziprozität. Man erkannte die Heilsamkeit des Theaters in der gegebenen Krisensituation darin, dass es direkte Begegnungen an öffentlichen Orten ermöglichen, Menschen in überschaubaren Räumen zusammenführen und ihnen dort einen intimen Rahmen für wechselseitige Anteilnahme und für eine Beschäftigung mit dem 
gemeinsamen Schicksal bereitstellen kann. Mit Kleinheit, Lokalität und Reziprozität wurden aber auch Zuschreibungen betont, die das Theater in einen Gegensatz zum Fernsehen und die die Aufführung in einen Gegensatz zum terroristischen Anschlag bringen.

Kleinheit, Lokalität und Reziprozität sind Qualitäten, durch die sich das Theater vom Fernsehen markant unterscheiden kann. Fernsehen erweitert das heimatliche Wohnzimmer ins Globale, es sorgt für Anschluss an große Netze, weite Distanzen und entlegene Räume. Die mit dem Fernsehen verbundene Nivellierung raumzeitlicher Differenzen negiert tendenziell die Relevanz von Lokalitäten. Das CNNStudio in Atlanta sieht wenig anders aus als das CNN-Studio in London oder Delhi. Fernsehen kann man überall, und durch weltweite Fernsehanbieter wie CNN kann man überall auch ziemlich genau dasselbe sehen. Zugleich hat das Fernsehen trotz aller Bemühungen um interaktive Beteiligung der Zuschauer bei weitem nicht das $\mathrm{Ma}$ an Reziprozität erreicht, das etwa im Theater oder im Internet möglich ist.

Kleinheit, Lokalität und Reziprozität sind zugleich Qualitäten, durch die sich die Aufführung als mediales Dispositiv vom terroristischen Anschlag unterscheidet. Aufführung und Anschlag teilen zwar die Zuspitzung auf das Punktuelle, die zeiträumliche Verdichtung und das Ideal größtmöglicher Wirksamkeit, aber sie weisen auch deutliche Unterschiede auf, und die liegen - unter anderem - in den Gegensätzen von Kleinheit und Größe, Lokalität und Entortung, Reziprozität und Unilinearität. Eine Aufführung ist ein begrenztes, lokales, wechselseitiges Geschehen. Der Anschlag dagegen verbindet einen kleinen Raum, ein Flugzeug, ein einzelnes Gebäude, ein Getreidefeld mit großen Bedrohungen und globalen Netzwerken. Diese Konfrontation geht zu Lasten der kleinen Einheit, deren Lokalität ausgelöscht wird. Der größte Unterschied zwischen Anschlag und Aufführung besteht darin, dass der Anschlag keine wechselseitige Kommunikation herstellt. Der Anschlag ist ein klassischer Fall von Unilinearität: Hat der Empfänger das Signal empfangen, dann wird er vom Signal zerstört und ist zu keiner Antwort mehr fähig.

Diese möglichen, wenn auch klischeehaften Gegenüberstellungen - die von der Theaterpraxis zweifellos unterlaufen werden können - fügen sich passgenau in einen Diskurs, der das Theater nach dem 11. September auf therapeutische Ziele verpflichten wollte. Im Rückblick ergeben sich allerdings gravierende Zweifel an dieser Art der Einpassung des Theaters in die Dichotomie von Trauma und Therapie.

Fraglich ist zum einen, inwieweit und in Bezug auf welche Abstufungen von Betroffenheit und Zeugenschaft man die psychischen Auswirkungen des 11. Septembers überhaupt in traumatologischen Kategorien beschreiben darf. Wenn nicht von den Opfern, ihren Angehörigen und den Augenzeugen vor Ort die Rede ist, sollte mit dem Traumabegriff vorsichtiger umgegangen werden. Wie empirische psychologische Untersuchungen (z.B. Schechter/Coates/First: 274) ergeben haben, differierten die Reaktionen auf die WTC-Anschläge schon innerhalb der Einwohnerschaft New Yorks stark. Vor dem Hintergrund solcher Differenzen erscheint es problematisch, wie selbstverständlich sich Theaterprojekte in allen Teilen der Vereinigten Staaten an ein >traumatisiertes< Publikum richteten und dabei von einer gesicherten Diagnose ausgehen zu können glaubten. Vom Erinnerungsabend für die verstorbenen Helden der New Yorker Feuerwehr bis zu Karen Finleys Trauerperformance - alle Projekte richteten sich an traumatisierte >ZuschauerPatienten $<$, ohne genauer zu definieren oder erkennen zu lassen, worin das zu behandelnde Trauma eigentlich bestehen sollte. Dabei darf nicht einmal der Zwang, die Bilder vom Einsturz der Twin Towers immer wieder anschauen zu müssen - an 
sich symptomatisch für die posttraumatische >Intrusion< (vgl. Herman: 58-65) - als sicheres Indiz für eine Traumatisierung gewertet werden, denn diese vom Fernsehen ermöglichten Wiederholungsschleifen könnten auch, wie Žižek (bes. 15-39) und Baudrillard (bes. 11-35) argumentiert haben, auf eine geheime Lust an der Zerstörung hinweisen.

Zum anderen stellt sich die grundsätzlichere Frage, ob Theater überhaupt das richtige Forum ist, um auf akute Traumatisierungen therapeutisch $\mathrm{zu}$ reagieren. Schon die elementaren Arbeitsprinzipien der psychotherapeutischen Traumatologie legen eine skeptische Antwort nahe. In der ersten Phase der Genesung von einem Trauma kommt es allein darauf an, für den Betroffenen eine sichere Umgebung zu schaffen, um ihm ein elementares Gefühl der Beständigkeit und des Vertrauens zurückzuerstatten (vgl. Herman: 215-245). Als safe space, als die sichere Umgebung, die der Traumapatient in der Frühphase seiner Therapie am dringendsten benötigt, kommt eine Theateraufführung aber kaum in Frage. Aufführungen verlangen von ihren Teilnehmern den Kontakt zu einer Menge unvertrauter Menschen, deren Solidarität und Wohlwollen man sich nicht sicher sein kann. Forschungen der letzten Jahre haben darüber hinaus eine gesteigerte Unberechenbarkeit, Liminalität und Kontingenz als Kennzeichen der Medialität von Aufführungen betont. Die den alltäglichen Routinen enthobene Beziehung von Akteuren und Zuschauern im Theater ist prinzipiell nicht sicher, weil beide Gruppen in einem solchen Rahmen füreinander schwer berechenbar sind. $\mathrm{Zu}$ überprüfen wäre deshalb, ob nicht viele therapeutisch gemeinte Theaterprojekte nach dem 11. September ihre Rechnung in Wahrheit ohne den Wirt gemacht haben.

\section{Literatur}

Baudrillard, Jean (2003): Der Geist des Terrorismus, 2. Aufl.. Wien: Passagen.

Blau, Herbert (2003): »Kunst und Krise. >Homeland security< und der noble Wilde«. In: Christel Weiler/Hans-Thies Lehmann (Hg.): Szenarien von Theater (und) Wissenschaft. Berlin: Theater der Zeit, S. 295-313.

Finley, Karen (2003): »Make Love«. In: The Drama Review, Vol. 47, No. 4, S. 51-69.

Gómez-Peňa, Guillermo/e-mael/Alexis McKee (2003): »Re:Group/No homeland. A Post-9/11 Intercultural Poltergeist«. In: The Drama Review, Vol. 47, No. 4, S. $70-75$.

Grinwis, Emmy et al. (2002): »Up Front. American Theaters Reflect on the Events of September $11 \ll$. In: Theater, Vol. 32, No. 1, S. 1-21.

Herman, Judith (2006): Die Narben der Gewalt. Traumatische Erfahrungen verstehen und überwinden, 2. Aufl., Paderborn: Junfermann [USA 1992].

Sarasin, Philipp (2004): `Anthrax . Bioterror als Phantasma. Frankfurt/M.: Suhrkamp.

Schechter, Daniel S./Susan W. Coates/Elsa First (2003): »Beobachtungen von akuten Reaktionen kleiner Kinder und ihrer Familien auf die Anschläge auf das World Trade Center«. In: Thomas Auchter/Christian Büttner/Ulrich SchultzVenrath/Hans-Jürgen Wirth (Hg.): Der 11. September. Psychoanalytische, psychosoziale und psychohistorische Analysen von Terror und Trauma. Gießen: Psychosozial Verlag, S. 268-279. 
Weichert, Stephan Alexander (2003): »Von der Live-Katastrophe zum MedienDenkmal. Das mediatisierte Krisenereignis >11. September«. In: Michael Beuthner/Joachim Butler/Sandra Fröhlich/Irene Neverla/Stephen A. Weichert (Hg.): Bilder des Terrors - Terror der Bilder? Köln: Herbert von Halem, S. 74-102.

Žižek, Slavoj (2004): Willkommen in der Wüste des Realen. Wien: Passagen [USA 2002]. 


\title{
MEDIENPÄDAGOGIK UND THEATERPÄDAGOGIK AN DER SCHULE. ÜBER DAS (NICHT-)VERHÄLTNIS ZWEIER FREMDER SCHWESTERN
}

\author{
LEOPOLD KLEPACKI
}

Medien spielen in der Schule eine nicht zu übersehende Rolle. Insbesondere in didaktischen bzw. methodischen Konzeptionen wird die Bedeutung des Medieneinsatzes im Unterricht hervorgehoben. Der Begriff Medium ist dabei ziemlich weit gefasst: Arbeitsblätter, die Tafel, der Overhead-Projektor, der Fernseher, Laptop und Beamer, Flip-Chart usw. werden unter dem großen Begriff der Unterrichtsmedien geführt, wobei es unter didaktischen Gesichtspunkten vornehmlich darum geht, herauszustellen, welche Potentiale bzw. welche >blinden Flecken< ein bestimmtes Medium im Hinblick auf Aspekte des individuellen Lernens, des Vermittelns von Inhalten, der Motivation und Aufmerksamkeitslenkung oder der Wahrnehmungsschulung besitzt (vgl. von Martial/Ladenthin). Aber auch der medialisierte Alltag der Schülerinnen und Schüler soll auf pädagogischer Ebene in der Institution Schule aufgegriffen und damit die spezifischen lebensweltlichen medialen Erfahrungsmodi und Medienpraxen der Kinder und Jugendlichen thematisiert und reflektiert werden.

Im Gegensatz zu dem doch eher neuen schulischen Bereich der Medienpädagogik ist das Theater, historisch betrachtet, ein traditioneller Bestandteil der Schule, insbesondere der Schulkultur (vgl. Klepacki 2005). Aus einem pädagogischen Blickwinkel sind hierbei die theatrale Praxis und die damit verbundenen Gesichtspunkte des Lernens, der ästhetischen Bildung und der kreativen Entfaltung von besonderem Interesse. Ausgehend von seinem Selbstverständnis, bewegt sich das Theater in der Schule zwischen den drei Polen Kunstform, Sozialform und Unterrichtsform (vgl. Klepacki 2004: 15-40).

Sowohl dem medienpädagogischen als auch dem theaterpädagogischen Bereich werden unter heutigen An- und Herausforderungen des Lebens und vor dem Hintergrund der viel thematisierten gesellschaftlichen Transformationsprozesse zentrale sozialisatorische und bildungs- bzw. qualifikationstheoretische Potentiale zugeschrieben. Gleichzeitig hat man es hier jedoch mit zwei schulischen Feldern zu tun, die institutionell eher eine randförmige Position im Schulalltag einnehmen. Darüber hinaus sind die Ansätze, Praxen und Ziele in den beiden Bereichen höchst unterschiedlich und von deutlich differierenden Traditionen geprägt. Beiden gemeinsam ist jedoch die Tatsache, dass sie innerhalb des Schulbetriebs Aufgaben übernehmen sollen, die von anderen Fächern bzw. die im regulären Klassenunterricht nicht oder nur unzureichend bewältigt werden können. Beide haben somit, mehr oder weniger offiziell, eine Kompensationsfunktion.

An der Schule gibt es aber weder Medienpädagogik noch Theaterpädagogik als solches. Medienpädagogik ist kein schulisches Fach. Es ist ein diffuses Themenund Handlungsfeld, das in der Regel im Rahmen des Deutschunterrichts seinen 
Platz findet und bei dem es zumeist um Aspekte der Medienerziehung geht. Ein zweiter medienpädagogischer Bereich ist die Vermittlung von technologischem Wissen und Können im Hinblick auf Medien, also die Frage nach der Notwendigkeit der Beherrschung medialer Hard- und Software.

Wenn es innerhalb des schulischen Rahmens um Theater geht, dann spricht man normalerweise von >Darstellendem Spiel<, >Dramatischem Gestalten $<$ oder auch immer noch von >Schulspiel<. Das Darstellende Spiel kann sogar die Position eines Faches einnehmen, je nachdem, wie hoch in einem deutschen Bundesland der Stellenwert von schulischem Theaterspiel eingestuft wird. Natürlich finden sich im Darstellenden Spiel theaterpädagogische Methoden, trotzdem ist Darstellendes Spiel als ein eigenständiges methodisch-schulisches theatrales Konzept und Schultheater als eine strukturell eigenständige Kunstform anzusehen.

Im Folgenden soll nun erstens die Bedeutung medien- und theaterpädagogischer Dimensionen für die Institution Schule dargelegt werden, zweitens das jeweilige Selbstverständnis der beiden Disziplinen im schulischen Rahmen vor dem Hintergrund einschlägiger fachtheoretischer Hintergründe erörtert und letztlich die Frage nach dem strukturellen, methodischen und inhaltlichen Verhältnis von Medienpädagogik und Darstellendem Spiel im Praxisfeld Schule aufgeworfen werden.

\section{Darstellendes Spiel in der Schule}

Neben Kunst und Musik ist das Darstellende Spiel der dritte künstlerische Bereich der Schule (vgl. Linck). Im Gegensatz zu Kunst und Musik nimmt es eigentümlicherweise zugleich eine prominentere und eine nischenförmigere Position ein. Obwohl das Darstellende Spiel an keiner Schulart ähnlich fest institutionalisiert ist wie Kunst und Musik, nimmt es trotzdem oftmals eine zentrale Stellung innerhalb schulischer Reform- und Innovationsansätze ein. Ästhetische Bildung, soziales und praktisches Lernen sowie der Aspekt der Ganzheitlichkeit sind dabei die prominenten Schlagworte von sowohl pädagogischen als auch politischen Reformentwürfen. Die umfassende Bedeutung des Theaterspiels für das spielende Subjekt steht dabei im Zentrum. Auf institutioneller Ebene kommen noch die Dimensionen der Kultivierung des Schulalltags und die Möglichkeit der Öffnung der Schule hinzu. Darstellendes Spiel ist sozusagen ein zumindest potentiell öffentliches Fach (vgl. Liebau 2003).

Darstellendes Spiel will dezidiert weder als Mittel der Erziehung durch oder zum Theater, noch als Schule des Theaters im Sinne einer pädagogisch-moralischen Lehranstalt verstanden werden. Ebenso wenig verfolgt Darstellendes Spiel einen sozialpädagogischen Hilfeanspruch zur Lebensbewältigung oder gar ein therapeutisches Ziel. Vielmehr resultieren die dem Darstellenden Spiel zugesprochenen pädagogischen und schulischen Wirkungspotentiale aus den Grundlagen der Ästhetik des Theaterspiels: also aus der strukturellen Verbindung von Subjektivität und Objektivität, von Prozessualität und Produkthaftigkeit, sowie von Rezeptivität und Produktivität im künstlerischen Tun, d.h. in semiotisch-performativen Handlungskontexten.

Im Kern ist das Theaterspiel also auf diejenigen ausgerichtet, die es produzieren und nicht auf die Zuschauer. Dies gilt auch dann, wenn es um die Präsentation eines Stückes vor einem Publikum geht. Die Aufführung wird als Teil des Bildungsprozesses der Schülerinnen und Schüler verstanden. Spielprozess und theatrales Produkt sind daher als zwei sich gegenseitig ergänzende Teile mit je spezi- 
fischen Bildungspotentialen innerhalb eines umfassenden theatralen Bildungsprozesses zu erachten (vgl. Sting).

Vorausgesetzt wird dabei in der Regel bei allen Argumentationen, dass das Darstellende Spiel in der Schule Freiräume für besondere Entfaltungs-, Bildungs-, Erfahrungs- und Qualifikationsprozesse jenseits des Klassenunterrichts schaffen kann. Wie weitreichend oder wie intensiv derartige Prozesse letztendlich sein können, hängt immer auch vom Grad der Reglementierung ab. Permanent befindet sich das Theater in der Schule im Spannungsfeld von institutionellen Handlungsspielräumen und deren organisatorischen Grenzen. Das Darstellende Spiel ist schließlich auch ein ganz normaler Bestandteil von Schule: organisatorisch, rechtlich, zeitlich, räumlich, personell und moralisch.

\section{Medienpädagogik in der Schule}

Den zentralen Bezugspunkt für Medienpädagogik in der Schule stellt die Frage nach der Medienkompetenz der Schülerinnen und Schüler dar. Ein schwieriger Begriff, der vielfältige Implikationen besitzt und der vielfältige Interpretationen zulässt.

Ralf Vollbrecht (53ff) stellt in seiner Einführung in die Medienpädagogik Medienkompetenz in pädagogischen Zusammenhängen als ein bildungstheoretisches Konzept dar, das vom Prinzip der kommunikativen Kompetenz ausgeht. Das Konzept versucht dabei, die inflationäre und dadurch verwaschene Verwendung des Begriffes Medienkompetenz »als irgendetwas, das man benötigt, um mit Medien >vernünftig « umgehen zu können« (53), zu überwinden.

Kinder und Jugendliche sollten sich nicht ausschließlich ein Bündel von Wissen, Fertigkeiten und Technologien aneignen, vielmehr sollte es um die Ausbildung spezifischer kognitiver Strukturen gehen. Medienkompetenz als »Fähigkeit im Umgang mit Wissen über mediale Kommunikation« (Vollbrecht: 59) meint also das Schaffen von medienbezogenen Handlungsspielräumen, die mündiges, selbstbestimmtes Handeln zulassen. Diese strukturale Konzeption von Medienkompetenz wird nach Ansicht Vollbrechts in der Praxis häufig ausgeblendet bzw. stark simplifiziert.

Wenn nun aber unter Medienkompetenz eine subjektive Wahrnehmungs-, Wissens- und Handlungsstruktur auf Basis des von Dieter Baacke so genannten »Diskurs[es] der Informationsgesellschaft « (20) verstanden wird, dann handelt es sich um ein komplexes Geflecht aus Medienkunde, Mediennutzung, Mediengestaltung und Medienkritik.

In der Schule jedoch wird Medienkompetenz oftmals zu stark technologisch bzw. zu strikt moralisch-inhaltlich ausgelegt. Informationstechnologische Grundbildung und Medienerziehung in einem engen Sinn sind dabei die Kernpunkte.

Neben dieser Verkürzung liegt ein weiteres Kernproblem schulischer Medienpädagogik in der Person des Lehrers. Die Schülerinnen und Schüler, die aus ihrem Alltag eine enorme Fülle an unsystematisierten, aber auch reflektierten Medienerfahrungen mitbringen, sehen im Lehrpersonal, also in den Alten, oftmals keine mediale Kompetenz. Internet, Handy, Bluetooth, W-Lan, SMS und MMS, MP3, voice-over-IP, ICQ, der iPod usw., all das ist Bestandteil jugendlichen Alltags. Fernsehen, Kino, Radio oder gar die steinzeitlichen Printmedien erscheinen in diesem Umfeld aus Sicht der Jugendlichen als nicht mehr thematisierungswert. Die Institution Schule und die Lehrer sehen das anders: Vor allem die Beschäftigung mit spezifischen Inhalten, wie Werbung, Gewalt, Berichterstattung oder die Frage 
nach medialer Informationsgewinnung, sollen in einer deutlichen Aufklärungstradition zu medialer Mündigkeit führen.

Nicht nur, dass die Lehrer an diesem Punkt oftmals auf einer technologischen Ebene das Nachsehen haben, z.B. im Hinblick auf den Umgang mit ComputerHard- und Software, wo sich zu weiten Teilen das klassische pädagogische Verhältnis umgedreht hat und die Jungen den Alten etwas beibringen, nein, es ist insbesondere die Art und Weise des Umgangs mit Medien und der subjektive Bezug dazu, der eine große Lücke zwischen den Alten und den Jungen entstehen lässt. Die größte Schwierigkeit findet sich hierbei im Medium der Sprache. Ein einfaches Beispiel hierfür wären Semantik, Grammatik und Pragmatik der SMS-Kommunikation. Die Kommunikation der Kinder und Jugendlichen in und über Medien verläuft auf einer Ebene, die im Unterricht nur schlecht aufgenommen werden kann. Über den jugendlichen Bezug zu Medien, über das Verhältnis der Jugendlichen zu medial vermittelten Inhalten und Welten, lässt sich oftmals nur in der Sprache der Jugend reden. Für die Lehrer ist das dann schwierig. Die zweckrationale, distanzierte und didaktisierte Kommunikation über Medien lässt das affektive und emotionale Element weitgehend außen vor. Kinder und Jugendliche reagieren genau aus diesem Grund letztlich nicht selten skeptisch auf die schulisch-unterrichtliche Aufarbeitung von Medien, Medienumgang und Medienerfahrung.

\section{Theatrale und mediale Bildung in der Schule}

Natürlich, wir leben in einer Medienwelt. Das ist unübersehbar und unüberhörbar. Insbesondere die so genannten Massenmedien stellen dem einzelnen Individuum eine enorme Vielzahl von Inhalten zur Verfügung, mit denen man sich in Bezug auf seinen Körper, sein Aussehen, seine Kleidung, seine Kommunikationsfähigkeit, seine Gegenwart, seine Zukunft und seine Vergangenheit, ja in Bezug auf die Gesamtheit seines Habitus, in einer unendlichen Reihe sowohl selbst bespiegeln als auch zu generalisierten Formen und Inhalten in Bezug setzen kann. Medienkompetenz in der eingangs aufgezeigten Form eines umfassenden bildungstheoretischen Konzepts muss deshalb ein zentrales pädagogisches Anliegen sein, um dem Subjekt einerseits eine angemessene, umfassende Teilhabe an der Gesellschaft zu ermöglichen und ihm andererseits auch Umgangsmöglichkeiten mit den medial bedingten Zwängen der Selbstreflexion zu eröffnen. Eine Medienpädagogik im Sinne einer Bewahrpädagogik wäre hier offensichtlich völlig fehl am Platz.

Die vielzitierte, vielbeschworene und vieldiskutierte postmoderne Gesellschaft steht unter dem Vorzeichen »radikaler Pluralität«, wie Wolfgang Welsch (4) es beschreibt. Die Pluralität von Sinn-, Wahrnehmungs- und Handlungsmustern ist im Alltag präsent, ja, sie ist sozusagen allgemeinverbindlich geworden. In ihrer von Welsch (6) so genannten Anti-Totalität führt die Postmoderne dem Menschen vor Augen, dass alles auch immer anders sein könnte. Die sich dabei eröffnenden Möglichkeitshorizonte führen gerade bei Jugendlichen nicht nur zu individuellen Freiheiten, sondern zu komplexen Entscheidungszwängen.

Der Hintergrund dieser Zwänge ist zum Großteil medial mitkonstituiert. Er lässt einerseits immer weitere Lebensbereiche und Lebensformen als individuell realisierbar erscheinen, hat andererseits jedoch zur Folge, dass all diese Bereiche, Formen und Kulturalitäten innerhalb der Pluralität von Lebensstil-Angeboten auch problematisierbar und v.a. austauschbar werden. Somit eröffnet dieses Wissen dem einzelnen nicht nur kulturelle Spielräume, sondern begründet auch ein umfassendes 
Kontingenzbewusstsein, so dass »aus den in der Moderne eröffneten Denkmöglichkeiten [nun] Verunsicherungsnötigungen werden « (Ziehe: 123). Im Zuge dieser Entwicklung verschärfen sich folglich die lebensweltlichen individuellen Sinnproblematiken, die nun nach Thomas Ziehe (126ff) ihrerseits zu verstärkten kulturellen Suchbewegungen in drei Richtungen führen.

Die erste Suchbewegung kann als Subjektivierung bzw. als »Sehnsucht nach Expressivität « (127) charakterisiert werden. Hierbei handelt es sich vornehmlich um den Wunsch, sich in seiner gewählten Lebensform authentisch ausdrücken zu können. Aufbauend auf dieser Suche geht es darum, ein Korrektiv zur im Alltag erfahrenen Kontingenz aufzufinden. Es ist dies die Suche nach Gewissheit, nach Ganzheitlichkeit und Echtheit in einer für das Individuum unübersichtlich gewordenen Gesellschaft. Im Gegensatz dazu zielt die dritte Suchbewegung auf eine kunstförmige Aufladung der Welt mit Bedeutung, auf eine Verkünstlichung des Alltags ab. Das Ziel ist hier folglich nicht Authentizität oder Gewissheit, sondern Intensität und Ästhetizität.

Sowohl das Mediale als Prinzip dispositiver Vermittlung von Wirklichkeit als auch das Theatrale als Ort authentischer Nicht-Authentizität sind tief in diesen Suchbewegungen verwurzelt: Zeichenhaftigkeit, Bildlichkeit, Textualität, Inszenierung, artifizielle Wirklichkeit, Produktion und Rezeption, Rollenhaftigkeit und Performativität sind dabei die Kernbegriffe, die nicht nur für eine Kommunikation über Medien oder über die Kunst des Theaters eingesetzt werden, sondern mit denen lebensweltliche Zusammenhänge charakterisiert werden. Die oft gestellte Frage nach der Notwendigkeit einer Vermittlung von Schlüsselqualifikationen in schulischen Kontexten kann an diesem Punkt angesetzt und gleichzeitig auf eine qualitativ andersartige Ebene gebracht werden. Mündigkeit und Selbständigkeit als aufklärerische Ziele der Erziehung sind von unbestreitbarer elementarer Bedeutung. Jedoch ist es notwendig, vor dem Hintergrund der oben aufgezeigten Entwicklungen einen Schritt weiter zu gehen und das Prinzip der Bildung als ein tief im Ästhetischen verwurzeltes Prinzip der lebenslangen Selbstbildung stärker in den Blick zu rücken, um dem heranwachsenden Subjekt auf Dauer gesellschaftliche Teilhabemöglichkeiten zu eröffnen.

Eine Pädagogik der Teilhabe, wie sie Eckart Liebau (1999) ausformuliert hat, muss es sich deshalb zur Aufgabe machen, im Rahmen eines kultivierten Schulalltags den Schülerinnen und Schülern Räume zu eröffnen, in denen der Umgang mit kulturellen Zeichen und Bedeutungen, mit ästhetischen Handlungs- und Wahrnehmungsmustern, mit Künstlichkeit und Lebenswelt sowohl in rezeptiver als auch in produktiver Hinsicht geübt werden kann. Mediale und theatrale ästhetische Bildung muss deshalb zu einem grundlegenden Element schulischer Arbeit aufgewertet werden.

Die Begriffe der Praxis, der Subjektivität, der Erfahrung und der Alphabetisierung könnten hierfür einen systematischen Ausgangspunkt bilden. Beide, Medienpädagogik und Darstellendes Spiel, zielen, zumindest konzeptionell, auf den Aspekt reflektierten Handelns, auf Praxis, ab. Sowohl die theatrale als auch die mediale Praxis sind unhintergehbar an das tätige Subjekt gebunden. Im einen Fall, weil die theatralen, performativ-zeichenhaften Handlungen nicht vom produzierenden Subjekt zu trennen sind, im anderen Fall, weil der Umgang mit Medien eine elementare Entgrenzung subjektiver Existenz darstellt. Die Erfahrung eigener LeibPräsenz ist die Folge. Der praktische Umgang mit Medien bzw. mit der Kunst des Theaters ist immer ein formal-inhaltlicher, d.h. Formen und Inhalte stehen in je gegenseitigen, spezifisch gerahmten Verweisungszusammenhängen, die Wirklich- 
keiten jenseits der Lebensrealität konstituieren, was wiederum zu spezifischen Regelhaftigkeiten in Produktion und Rezeption führt. Für den Mediennutzer bzw. für den Theaterspieler heißt das letzten Endes, dass er Alphabetisierungsprozesse durchlaufen muss, die es ihm ermöglichen, innerhalb medialer bzw. theatraler Frames kommunizieren zu können. Regeln, technische Aspekte, Erscheinungsformen, Verhaltensweisen usw., also die Fragen nach dem $>$ Wie $<$, müssen dabei den Fragen nach dem $>$ Was $<$, also den Inhalten, vorausgehen. Da jedoch Formen ohne Inhalte leer sind, sind sowohl Medien als auch das Theater ohne konkrete Inhalte nicht denkbar und v.a. nicht behandelbar. Sowohl in medialen als auch in theatralen ästhetischen Bildungsprozessen müssen formale und inhaltliche Aspekte schließlich konstitutiv zusammenfallen. In ein sinnvolles methodisch-inhaltliches Verhältnis können Medienpädagogik und Darstellendes Spiel jedoch nur treten, wenn die Medienpädagogik das ästhetische Element von Medien zum zentralen Ausgangspunkt macht und das Darstellende Spiel anerkennt, dass mediale Erfahrungen ebenfalls sinnlich-leibliche Primärerfahrungen darstellen.

\section{Literatur}

Baacke, Dieter (1996): »Medienkompetenz - Begrifflichkeit und sozialer Wandel «. In: Antje von Rein (Hg.): Medienkompetenz als Schlüsselbegriff. Bad Heilbrunn: Klinkhardt, S. 112-124.

Klepacki, Leopold (2004): Schultheater. Theorie und Praxis. Münster: Waxmann.

Klepacki, Leopold (2005): »Die Geschichte des Schultheaters in Deutschland «. In: Eckart Liebau u.a. (Hg.): Grundrisse des Schultheaters. Weinheim/München: Juventa, S. 9-30.

Liebau, Eckart (1999): Erfahrung und Verantwortung. Werteerziehung als Pädagogik der Teilhabe. Weinheim/München: Juventa.

Liebau, Eckart (2003): »Schul-Theater«. In: Kunibert Bering u.a. (Hg.): KulturKompetenz. Oberhausen: Athena, S. 420-436.

Linck, Dieter (2005): »Organisation des Schultheaters am Beispiel Bayerns «. In: Eckart Liebau u.a. (Hg.): Grundrisse des Schultheaters. Weinheim/München: Juventa, S. 152-167.

Martial, Ingbert von/Volker Ladenthin (2002): Medien im Unterricht. Grundlagen und Praxis der Mediendidaktik. Hohengehren: Schneider.

Sting, Wolfgang (2000): »Theaterlernen ist Theaterproduzieren«. In: Ernst Cloer u.a. (Hg.): Welche Lehrer braucht das Land? Notwendige und mögliche Reformen der Lehrerbildung. Weinheim/München: Juventa, S. 190-201.

Vollbrecht, Ralf (2001): Einführung in die Medienpädagogik. Weinheim/Basel: Beltz.

Welsch, Wolfgang (2002): Unsere postmoderne Moderne. Berlin: Akademie Verlag. Ziehe, Thomas (1991): Zeitvergleiche. Jugend in kulturellen Modernisierungen. Weinheim/München: Juventa. 


\title{
IN ECHT ODER GETRICKST? \\ DRITTKLÄSSLER ÜBER DIE UNTERSCHIEDE ZWISCHEN THEATER, FILM UND FERNSEHEN
}

\author{
INA GOMBERT
}

Welche Funktionen erfüllen theatrale Künste in einer Medienwelt? Welche Funktion hat Theater? Was unterscheidet theatrale von medialen Events? Worin bestehen für den Zuschauer die wesentlichen Unterschiede zwischen Theater, Film und Fernsehen? Was gilt wem als attraktiv - und warum?

Für viele Erwachsene ist Theater untrennbar verbunden mit einer Vorstellung von »hoher Kunst«, wohingegen sie Film und Fernsehen der Populär- oder Unterhaltungskultur zuordnen. Dies hat zur Folge, dass mit einem Theaterbesuch tendenziell Anstrengung, mit einem Kinobesuch oder Fernsehabend eher Entspannung assoziiert wird. Mit Theater verbinden viele etwas Gehaltvolles, Schweres. Das Fernsehen stellt den Gegenpol dar: es wird häufig als eher flach, seicht, leicht wahrgenommen. Das Kino steht irgendwo dazwischen: hier ist beides möglich. Je nach Film kann man dort anspruchsvolle Kunst erleben oder seichte Unterhaltung genießen. - Soweit die üblichen Wahrnehmungsschemata, die gängigen Images.

Lassen sich die Unterschiede zwischen Theater, Film und Fernsehen darauf reduzieren? Die genannten Wahrnehmungsschemata implizieren normative Kategorien und Erwartungen, die beim Durchlaufen von Sozialisationsprozessen erworben werden. Inwieweit sind Kinder bereits ebenfalls in dieser Hinsicht vorgeprägt? Gelangen sie möglicherweise zu anderen Beschreibungen?

Im Rahmen meiner Dissertation über das Bild von Kindertheater in der Öffentlichkeit sprach ich mit Drittklässlern auch über Kunst, Theater, Film und Fernsehen. ${ }^{1}$ Sie beschrieben die in ihren Augen zentralen Merkmale und zeichnen so ein Bild von Theater, Film und Fernsehen, das die Unterschiede zwischen diesen Disziplinen deutlich hervortreten lässt.

\section{Kunst oder nicht Kunst?}

Die Forschungsergebnisse zeigen, dass die Etikettierung eines kulturellen Angebots, die Einordnung eines Mediums als Kunst oder nicht Kunst, als geistige Anregung oder entspannende Unterhaltung, wie dies durch Erwachsene häufig geschieht,

1 Die Gespräche fanden am 13.02.2006 mit allen 19 Schülern und Schülerinnen der Klasse 3a der Nürnberger Uhlandschule statt. Jeweils 20 bis 30 Minuten befragte ich im Raum der Mittagsbetreuung (also nicht in einer unterrichtsähnlichen Situation im Klassenzimmer) eine Kleingruppe von durchschnittlich drei Kindern. Zu methodischen und methodologischen Grundlagen und Prämissen bei Befragungen von bzw. Rezeptionsforschung mit Kindern vgl. Gombert (2007: 186-212), Wardetzky (1993: 182-290 und 2004: 33-48), Wartemann (2004: 91-97). 
für Kinder absolut irrelevant ist. In den Gesprächen wurde deutlich, dass Kinder mit dem Wort »Kunst « beinahe ausschließlich das Schulfach Kunsterziehung und damit verbunden »Alles, was mit Malen und Bildern zu tun hat« assoziieren. Auf Theater, Kino und Fernsehen wird der Kunstbegriff von ihnen nicht angewendet.

\section{Erwartungshaltungen}

Für Kinder sind Theater, Kino und Fernsehen drei zunächst gleichwertige Möglichkeiten der Freizeitgestaltung, von denen keine per se besser oder schlechter als die jeweils anderen ist. Die grundsätzlichen Anforderungen, die Kinder an eines dieser Medien stellen, sind immer dieselben: vorausgesetzt wird eine hohe handwerkliche Qualität und ein im weitesten Sinne unterhaltender Charakter der Darbietung.

Ein Beispiel: Ich fragte die Kinder, wie es im Theater sein müsse, damit es ihnen dort gefällt. »Spannend « wurde da häufig spontan genannt, »lustig « oder für manche auch »gruselig«. Hinzu kamen vergleichende Beschreibungen: »so wie im Kino « (Marius), »so wie Unendliche Geschichte « (Florian). Umfassend formulierte Melissa ihre Anforderungen an gutes Theater: »Manchmal muss es lustig für mich sein, manchmal spannend und manchmal auch traurig «.

Deutlich wird: Sie wollen vor allem emotional angesprochen werden, wollen etwas erleben. Die dargestellte Geschichte, der Inhalt des Stücks spielt dabei für die befragten Kinder eine wichtige Rolle. Dass jedoch auch die handwerkliche Qualität der Aufführung nicht zu kurz kommen darf, verdeutlicht folgende gemeinschaftliche Definition von »gutem Theater«:

Cindy: »Die müssen gut sprechen, denke ich.«

Lea: »Laut und deutlich.«

Cindy: »Ja genau, und auch laut, dass ich's höre oder auch die andern.«

Lea: »Ja, und auch, es muss auch so, wie soll man's sagen, so, nicht so, dass die so reden: >jaaa, uuund dann kooommt dann der Peeter und der maaacht daaann die Gaaartentür auf $\prec$ - so, sondern so'n bisschen spannender.«

Melissa: »Ja genau, weil wenn die das so ganz normal reden, das wär’ ja ganz langweilig.«

Diesen einführenden Sätzen folgten diverse Beispiele guten und schlechten Sprechens, die sich hier nur schwerlich wiedergeben lassen. Wichtig erscheint mir festzuhalten, dass die Kinder eine überzeugende Darbietung wünschen. Ihnen geht es dabei sowohl um Verständlichkeit als auch um Ausdruck. Das Sprechen der SchauspielerInnen fungiert dabei nur als Beispiel. Die Ansprüche lassen sich ebenso auf den Schauspielstil, die Inszenierung, die Dramaturgie, die Kostüme, das Bühnenbild usw. übertragen.

Theater muss »gut « sein. Für Kinder ist das unabdingbar. Ob das, was auf der Bühne geschieht, sich nun Kunst nennt oder irgendwie anders, ist völlig unwichtig. Es muss überzeugend sein, es muss sie ansprechen, vor allem emotional. Es muss »gut« sein. Das ist es, was zählt.

Dies bedeutet: die befragten Kinder formulieren deutlich einen Professionalitäts- und einen Unterhaltungsanspruch (auch wenn beides nicht so genannt wird). Professionalität und Unterhaltung sind dabei für sie kein Gegensatz, sondern eine Einheit - beides ist unabdingbar, um Gefallen zu erzeugen. 
Für unsere Fragestellung entscheidend ist dabei: für das Kino gelten dieselben Anforderungen. Gutes Theater ist »wie im Kino«, sagte Marius. Und von einer Kinovorstellung wird dasselbe erwartet wie von einer Theateraufführung: Professionalität, Unterhaltung, Emotionen.

\section{Präferenzen}

Kinder stellen also grundsätzlich an jedes Medium dieselben Anforderungen. Dennoch erfüllen alle drei genannten Medien unterschiedliche Funktionen. Wenn man spezifischer fragt, dann geben detaillierter formulierte Erwartungshaltungen auch Aufschluss über Funktionszuschreibungen. Wo liegen die Präferenzen? Was sind die Unterschiede zwischen Theater, Kino und Fernsehen?

Ich stellte den Kindern die Frage: »Wo möchtest du am liebsten einen freien Nachmittag verbringen: im Kino, zu Hause vor dem Fernseher oder im Theater? « Hier drei exemplarische Antworten:

Cindy: »Wenn's für mich spannend klingt, würd' ich ins Theater. Wenn der Kinofilm spannend ist, dann würd' ich ins Kino gehen.«

Yvonne: »Ich würd' eigentlich, kommt drauf an, was im Fernsehen läuft, wenn was ganz Doofes kommt, dann würd' ich nicht schauen [...]. Ich würde einfach, hmmm, ins Theater, glaub' ich, weil da läuft schon meistens was Gutes.«

Doro: »Erst würd' ich gern ins Theater gehen, dann würd' ich halt Kino und dann würd' ich erst fernsehen oder Computer spielen oder so was.«

Die Antworten illustrieren zum einen, dass es den Kindern deutlich nicht nur um ein bestimmtes Medium geht, sondern ihre Entscheidung auch davon beeinflusst wird, was es dort jeweils zu sehen gibt. Zum zweiten deuten die Antworten bereits an, dass dem Fernsehen offensichtlich andere Funktionen zugeschrieben werden als Kino und Theater. Fernsehen und Computerspielen wiederum scheinen ähnliche Funktionen zugeordnet zu werden. Und beide stehen sie am Schluss der Präferenzen: Es handelt sich um Beschäftigungen, die man tut, wenn man nichts Besseres vor hat.

Insgesamt entschieden sich knapp die Hälfte der befragten Kinder (9 von 19) auf die Frage hin für den Kinobesuch, etwa ein Drittel für den Theaterbesuch. Zwei Schülerinnen wollten je nach Programmangebot zwischen Kino und Theater entscheiden, und ein Mädchen rechnete sich aus, dass sie ja an einem Nachmittag auch ins Kino und ins Theater gehen könne, wenn nur der Zeitplan stimme. Für das Fernsehen entschied sich niemand, denn »Fernseh gucken kann man ja die ganze Zeit« (Lea).

Hier findet sich also eine Differenzierung in Bezug auf die Funktionszuschreibungen: Fernsehen ist Teil des Alltags und als solches nichts Besonderes. Kino und Theater hingegen werden als Event wahrgenommen, ihr Besuch ist ein Gesamtereignis. Dies hängt sicher auch mit dem für einen Kino- oder Theaterbesuch notwendigen Ortswechsel zusammen und damit, dass für beide Veranstaltungsarten ein Eintrittsgeld erhoben wird. 


\section{Unterschiede}

Auf die Frage »Was ist denn im Theater anders als im Kino oder beim Fernsehen? « benannten die Kinder verschiedene Punkte. Die Rezeptionsumgebung wurde erwähnt: im Kino ist es »so schön dunkel « (Cindy) und es gibt dort »schönere Sitze« (Melissa) als im Theater, die sich dadurch auszeichnen, »dass man da sein Trinken reinstellen kann « (Melissa). Positiv bewerten die Kinder am Kino außerdem, »dass man da auch Popcorn kaufen kann« (Melissa).

Wesentlich wichtiger ist den Kindern aber die Präsentationsfläche. Fast alle Kinder formulierten diesbezüglich Unterschiede. Ein Beispiel:

»Beim Fernsehen ist der Bildschirm ein bissle kleiner als im Kino und beim Kino ist der Bildschirm größer als beim Fernseher. [...] Und beim Theater haben die Leute keinen Bildschirm wie beim Kino und beim Fernsehen, beim Theater, da spielen die Leute immer so auf einer Bühne«(Vanessa).

Im Zitat von Vanessa klingt bereits ein weiteres oft genanntes Merkmal an: im Theater »spielen die Leute« in dem Moment, wo man ihnen zusieht, während im Kino und im Fernsehen vorproduzierte Filme gezeigt werden.

»Im Kino kommen halt so neue Filme raus, die kann man anschauen im Kino, aber beim Theater spielt man das ja vor.« (David)

»Im Kino, da spielen die ja eigentlich nichts vor, das wird alles mit 'ner Kamera so gefilmt, und beim Theater wird das dann gleich richtig gespielt und geübt.«(Yvonne)

»Beim Theater kommen halt nicht so Filme, meistens spielen die Leute mit so Puppen oder mit so, ähmm, also mit sich selber halt, Menschen«(Lea).

Thematisiert wird also der Live-Charakter des Theaters: »Im Theater ist es halt so, da spielen's die Leute selbst, dann spielen die's gleich, nicht erst nachspielen überall.« (Cindy) - Wie wird dieser Live-Charakter einer Theateraufführung nun gewertet? Zunächst einmal: »Im Theater ist es echt « (Mert) bzw. »echter « (Johannes). »Echte « Menschen stellen eine Geschichte dar. Das was sie tun, tun sie »in echt $\ll$.

»Beim Theater find ich's gut, dass man sieht, wie viel Mühe sie sich auch geben, dass sie uns das vorspielen können, dass sie so viel lernen, um's uns vorzuspielen, das find ich auch schön« (Cindy).

Wenn hier von der Mühe die Rede ist, die sich die Schauspieler und Schauspielerinnen geben müssen, so deutet dies schon an, dass den Kindern die Gemachtheit einer Theateraufführung deutlich bewusster ist als der Artefakt-Charakter eines Films. Zum Theaterbild der befragten Kinder gehört die Erwartung eines Unterschieds zwischen dargestellter Figur und darstellender Person. Selbstverständlich: Auch ein Filmschauspieler muss sich »Mühe geben « - nur sehen Kinder dies während der Rezeption des fertigen Films nicht, dementsprechend wird das Agieren der SchauspielerInnen hier auch nicht als ein mit »Mühe« verbundener Vorgang wahrgenommen.

Als besondere Elemente des Theaters erwähnten die Kinder auch, »dass da die Schauspieler sich verkleiden« (Doro), dass es Kulissen gibt (»Leinwände oder so«, 
Doro), Requisiten (»die machen ja kein echtes Feuer, sondern die malen das «, Cindy), Lichteffekte und Theatertricks. Natürlich ist dies alles auch Teil der meisten Film- und Fernsehproduktionen. Doch der entscheidende Punkt ist wiederum: dort nehmen die Kinder es nicht wahr. - Zwei Theaterbeobachtungen von Marius:

»Im Theater, wenn ein Flugzeug fliegen will, wird's von so Schnüren gezogen. [...] Ich hab' mal im Theater gesehen, wie einer mit einem Schlitten beim Weihnachtsmann so geflogen ist, und dann haben die so mit Scheinwerfern gemacht, so dass man das sieht, aber der ist da nur von oben von der Decke gesprungen.«

Marius sagte das leicht verächtlich, abgebrüht. Diese Tricks hat er durchschaut. Keiner kann ihm hier etwas vormachen. - Darin offenbart sich für Kinder das Hauptmerkmal des Theaters: die Tricks sind durchschaubar, der Zuschauer kann nachvollziehen, was auf der Bühne geschieht und wie es geschieht. Denn was da passiert, passiert »in echt « - selbst wenn alles nur »getrickst « ist.

Im Theater gibt es nichts, was sich nicht erklären ließe, während man im Kino »ja Sachen machen kann, die's gar nicht gibt « (Cindy). Die Theatertricks sind durchschaubar und betonen deshalb den Als-ob-Charakter des Theaters - es ist zugleich echt und nicht echt. Diese Gleichzeitigkeit empfinden Kinder als das Faszinosum des Theaters. Auffallend häufig legen sie im Theater großes Interesse für den technischen Apparat an den Tag, während Kino und Fernsehen als Illusionsmedien selten hinterfragt werden.

Das Bewusstsein für die Gemachtheit des Gezeigten innerhalb eines Mediums beinhaltet zugleich die Möglichkeit einer Bewertung der Darbietung in diesem Sinn: etwas kann gut gemacht sein oder schlecht. »Ist doch nur ein Trick«, urteilte Marius über den von ihm beschriebenen fliegenden Weihnachtsmann. Und Florian fügte hinzu: »Das kann ich auch!«.

Bei Film und Fernsehen fehlt die Möglichkeit, einen klärenden Blick hinter die Kulissen zu werfen. Die gezeigte fiktionale Welt präsentiert sich als undurchschaubare Einheit, die Tricks werden nicht aufgelöst. Die reale Welt verschwindet aus dem Bewusstsein, der Zuschauer taucht ein in die Illusion. Deshalb fühlen sich Kinder im Kino häufig emotional umfassender angesprochen als im Theater. Eingedenk der oben dargelegten Beobachtung, dass das emotionale Erlebnis eine wichtige, wenn nicht sogar die zentrale Erwartungshaltung (neben Unterhaltung und Professionalität) darstellt, scheint es mir nur logisch, dass für das Gros der befragten Kinder das Kino an erster Stelle auf der Beliebtheitsskala steht. Voraussetzung dafür ist und bleibt jedoch die Wahrnehmung eines Medienerlebnisses als etwas Besonderes. Deshalb bleibt das Fernsehen weitestgehend außen vor: Es hat diesen Status hat nicht - Fernsehen gehört für die Mehrheit der Kinder zum Alltag.

\section{Zusammenfassung}

Versucht man die Unterschiede zwischen Theater, Film und Fernsehen zu beschreiben und dabei der Sichtweise von Kindern zu folgen, muss zunächst die Dichotomie zwischen Kunst und Unterhaltung aufgehoben werden: Ob Theater Kunst ist oder nicht, spielt keine Rolle. Stattdessen sind Theater, Kino und Fernsehen zunächst schlicht als unterschiedliche Möglichkeiten der Freizeitgestaltung anzusehen. 
An alle drei Medien werden von den potenziellen Rezipienten grundsätzlich dieselben Anforderungen gestellt. Erwartet werden in jedem Fall eine hohe handwerkliche Qualität und ein im weitesten Sinne unterhaltender Charakter. Die zentrale Funktion medialer wie auch theatraler Events ist das emotionale Erlebnis. Dafür sind sowohl der Inhalt des Gezeigten als auch die Form der Präsentation, also das Was und das Wie eines Mediums, gleichermaßen wichtig.

Während das Fernsehen Teil des Alltags ist, werden Kino und Theater als Gesamtereignis, ihr Besuch als Event wahrgenommen. Damit unterscheidet sich die Fernsehrezeption grundlegend von der Film- und Theaterrezeption.

Film und Fernsehen funktionieren für die Kinder als Illusionsmedien, der Prozess der Entstehung der gezeigten Inhalte ist nicht Teil ihres Bildes dieser Medien. Die Gemachtheit von Theater hingegen kann als das zentrale Merkmal des Theaterbildes der befragten Kinder bezeichnet werden: Theater erscheint zugleich als »echt « und »getrickst«. Das Durchschauen der Illusion, das möglich wird durch die Gleichzeitigkeit von »echt « und »nicht echt«, stellt das Faszinierende am Theater dar, während der Reiz des (Kino-)Films gerade im völligen Eintauchen in diese Illusion liegt.

\section{Literatur}

Gombert, Ina (2007): Kindertheater - Kinderkram. Das Bild von Kindertheater in der Öffentlichkeit. Aachen: Shaker.

Wardetzky, Kristin (1993): »Der andere Blick. Reaktionen von Kindern auf Theater«. In: Jürgen Kirschner/Kristin Wardetzky (Hg.): Kinder im Theater. Dokumentation und Rezeption von Heleen Verburgs »Winterschlaf « in zwei Inszenierungen. Frankfurt/M.: Kinder- und Jugendtheaterzentrum in der Bundesrepublik Deutschland, S. 182-270.

Wardetzky, Kristin (2004): »Nie sollst du mich befragen ... Methodologische Probleme der Rezeptionsforschung «. In: Jürgen Kirschner (Hg.): Kinder und Jugendliche als Theaterpublikum. Startinformationen zwischen Bühne und $\mathrm{Zu}$ schauerraum. Frankfurt/M.: Kinder- und Jugendtheaterzentrum in der Bundesrepublik Deutschland, S.33-48.

Wartemann, Geesche (2004): »Theater als Wechselspiel. Ein Seminar zur Rezeptionsforschung im Kinder- und Jugendtheater an der Universität Hildesheim in Kooperation mit dem >theaterspielplatz<, Staatstheater Braunschweig, 2001/ 2002 «. In: Jürgen Kirschner (Hg.): Kinder und Jugendliche als Theaterpublikum. Startinformationen zwischen Bühne und Zuschauerraum. Frankfurt/M.: Kinder- und Jugendtheaterzentrum in der Bundesrepublik Deutschland, S. 91-97. 


\section{THE INTERMEDIAL THEATRON:}

\section{A Paradigm Shift in Education and Performance IN THE PUblic SPHERE?}

FREDA CHAPPLE

This paper assesses a pilot research project into the impact of digital technology on British theatre practice and learning set in the context of government education and skills policies in the UK, and as a result of the findings poses the wider question of whether the intermedial theatron is a paradigm shift in education and performance in the public sphere with the potential to impact the curriculum and pedagogy of British Higher Education in Theatre and Performance studies.

\section{The Research Framework: Intermedial relationships between education, media and theatre}

»Education, education, education« was a ringing phrase in the 1997 election manifesto of the English Labour Party, which helped sweep >new< Labour, under $\mathrm{Mr}$ Tony Blair, to a landslide election victory and into the Government. In June 2007, at the time of writing this paper, Mr Gordon Brown, the Chancellor of the Exchequer since 1997, was set to become the next UK Prime Minister. During the decade 1997-2007, Higher Education Institutions have been funded by the Government Department for Education and Skills, and British theatre has been funded largely by Arts Council England via the Government Department for Culture, Media and Sport. In 1997, the Report of the National Committee of Inquiry into Higher Education, chaired by Sir Ron Dearing set the agenda in which higher education, theatre, and new media were to play their part; the Dearing (1997) Report not only defined problems within higher education, but also contained a vision.

»The vision that emerged is not just about higher education, but about the role of a total national education system in supporting and enriching a society and an economy. The role of universities and colleges is seen embedded in a world of compulsory education, of professional and vocational learning throughout life, and the use of educational resources for personal development; in other words of a learning society« (Watson/Taylor: xiii).

This vision of a learning society forms the backdrop of this paper. In 1997 the British theatron (derived from the Greek word for >a viewing place $<$ ) was well placed to present a Labour vision of an inclusive learning society, for it has strong roots in British Socialism. It is epitomised in the work of Joan Littlewood's plans 
to create a >playground of learning < in the deprived East End of London (Nicholson: 1) and is enshrined in the growth of the regional repertory theatre companies during the Labour government under Harold Wilson (1964-70 and 1974-76), three of which form the focus of this paper: Nottingham, Sheffield, and Leeds. The Wilson government used the analogue television medium of the British Broadcasting Corporation $(\mathrm{BBC})$ to deliver mass higher education via a blend of live and mediatized learning by creating the Open University in 1969.

Today, >new labour < has built a new digital >open university< through Learning online initiatives broadcast via the BBC (www.bbc.co.uk), which acts as a national learning hub with connections to local courses, partner centres, and learning zones. Here we find networked links to the performing arts, where theatre is located as one of the >Creative Industries < and part of the Culture online web-learning opportunities. This has led me to coin the phrase >the intermedial theatron<, for on the World Wide Web digital representations of theatre online become a very visible $>$ viewing place $<$. Inter-acting with theatre online places our bodies in an intermedial position where we are located in-between the live theatre performance and its representation in digital coding within a network of Government led skills-based learning initiatives. There are many pathways in, out, and around the intermedial theatron, but all connect to the hub at www.culture.gov.uk, which is accessed via the >human-computer interface< (Manovich).

A notable theatron web-presence within Culture online is www.stagework.org, which is endorsed by the Department for Culture, Media and Sport, located on the web page of the British National Theatre and produced by the aptly named Illuma Digital Ltd and Simulacra companies. The site provides information about the back-stage working of theatre productions and provides on-line education packs regarding dramatic texts and their cultural context; these are linked directly to key stages of the national education curriculum for schools and for the general public who wish to learn about theatre, via recorded interviews with stage directors, actor diaries, and weblogs from the community of stage and lighting directors who have created the concept of each production. Furthermore, www.stagework.org is a government sponsored web site that links what the government considers to be flagship theatre companies, including the National Theatre and the Royal Shakespeare Company, and provides a web-based networked display of key British National Theatre. In turn, Culture on-line resonates with Europe-online and European initiatives to deliver theatre performances via new media, for example, Theatron.

What we can see emerging is a pattern of change driven by digital media. There is the potential to move the experience of live theatre performance from one where the individual citizen attended the local theatron to view and participate in a live representation of their community, to a mediatized simulacrum of theatrical representation accessed via digital technology, which is linked directly to the education and skills agenda of the Labour government, thus widening participation and direct links between professional theatre and education. 


\section{The research project - The impact of digital technology on British Theatre practice and learning}

Working as a solo researcher with a grant from British Society for Theatre Research, the pilot project was a speculative investigation undertaken with the intention that if the findings proved fruitful an application would be made for larger funding to enable a national project. Given my location at the University of Sheffield, I limited the pilot to a reasonable travelling distance from Sheffield, which gave me access to a triangle of northern cities and an interesting mix of building-based theatre companies:

- The Crucible Theatre at Sheffield, the Nottingham Playhouse, and the West Yorkshire Playhouse at Leeds are repertory producing houses.

- The Lyceum Theatre at Sheffield and the Royal Centre in Nottingham (a combination of the Theatre Royal and the Concert Hall) are receiving houses for touring productions in theatre, dance, classical, and popular music.

- The Grand Theatre at Leeds is both a receiving house and the home base of Opera North - a major opera company in the UK, with a remit to tour nationally.

\section{Research questions}

I sub-divided the central research question of »What is the impact of digital technology on British theatre practice and learning? « into the following specific questions:

1. What impact, if any, does digital technology have on programming?

2. What impact, if any, does digital technology have on performance practice?

3. Is the presence of the digital within the theatre complex changing the way the buildings are being used?

4. Is the inter-active nature of digital technology changing the nature and location of theatre education?

5. Could the inter-active nature of digital technology change the relationship between the community it serves and the theatre as provider of artistic performance? Should it?

6. Theatre and Citizen - Has digital technology changed the balance between citizen and artist?

7. In what areas would the theatres like to increase their use of digital technology? What might inhibit an increase?

One reason for these sub-sections is to offer a contextual framework for discussions I hoped to have with people working with digital media as part of their daily practice. Another was because this enquiry grew out of the work of the I.F.T.R. research group into Intermediality in theatre and performance (Chapple/Kattenbelt), which had completed a mapping process of intermediality in theatre and performance. Conscious that the perspective we had used then was essentially from the audience, I recognised that our assumptions and research results into the concept of intermediality needed further testing, and from the perspective of back stage. Essentially, I was acting on a speculative hunch that digital media was more firmly 
embedded in daily theatre practice than is generally visible and that change would be happening and therefore formal and informal learning processes might be taking place.

\section{Methodology}

Data was collected via semi-structured interviews between January 2005 and January 2006. Initial contact with the theatres was by post, enclosing an outline of the proposed research. The theatres selected who was available for interview and interested in participating. Table 1 gives an overview of the participating theatres and specialists who have been willing to participate in the research. They represent the areas: (a) Marketing and Development, (b) Production Management, and (c) Education.

\begin{tabular}{|c|c|c|c|c|}
\hline $\begin{array}{l}\text { City and Category } \\
\text { of Theatre } \\
\text { Buildings }\end{array}$ & $\begin{array}{l}\text { AREA: A } \\
\text { Marketing and } \\
\text { Development. }\end{array}$ & $\begin{array}{l}\text { AREA: B } \\
\text { Production } \\
\text { Management. }\end{array}$ & $\begin{array}{l}\text { AREA: C } \\
\text { Education (schools, } \\
\text { lifelong learning) }\end{array}$ & $\begin{array}{l}\text { Number } \\
\text { of } \\
\text { interviews }\end{array}$ \\
\hline $\begin{array}{l}\text { NOTTINGHAM } \\
\text { Nottingham } \\
\text { Playhouse } \\
\text { (Repertory) }\end{array}$ & $\begin{array}{l}\text { Head of Marketing } \\
\text { Box Office / } \\
\text { Customer Services } \\
\text { Manager }\end{array}$ & $\begin{array}{l}\text { Head of Lighting } \\
\text { Production } \\
\text { Manager }\end{array}$ & $\begin{array}{l}\text { Head of Education } \\
\text { programme }\end{array}$ & 5 \\
\hline $\begin{array}{l}\text { NOTTINGHAM } \\
\text { The Royal Centre } \\
\text { (Receiving House) }\end{array}$ & General manager & N/A & Education Officer & 2 \\
\hline $\begin{array}{l}\text { SHEFFIELD } \\
\text { The Crucible Theatre } \\
\text { (Repertory) and } \\
\text { Lyceum Theatre } \\
\text { (Receiving House) }\end{array}$ & $\begin{array}{l}\text { Box Officer / } \\
\text { Marketing Manager }\end{array}$ & $\begin{array}{l}\text { Production } \\
\text { Manager }\end{array}$ & $\begin{array}{l}\text { Director of Creative } \\
\text { Development } \\
\text { programme } \\
\text { Adult Learning Co- } \\
\text { ordinator }\end{array}$ & 4 \\
\hline $\begin{array}{l}\text { LEEDS } \\
\text { West Yorkshire } \\
\text { Playhouse } \\
\text { (Repertory) }\end{array}$ & $\begin{array}{l}\text { Box Office Manager } \\
\text { Website Manager } \\
\text { Press Officer }\end{array}$ & $\begin{array}{l}\text { Director of digital } \\
\text { technology }\end{array}$ & $\begin{array}{l}\text { Director of Education } \\
\text { Cyber café manager }\end{array}$ & 6 \\
\hline $\begin{array}{l}\text { LEEDS } \\
\text { Grand Theatre, } \\
\text { (Receiving House } \\
\text { and Home base of } \\
\text { Opera North }\end{array}$ & $\begin{array}{l}\text { Marketing Manager } \\
\text { Development } \\
\text { manager }\end{array}$ & $\begin{array}{l}\text { Production } \\
\text { Manager }\end{array}$ & $\begin{array}{l}\text { Education } \\
\text { Special projects }\end{array}$ & 5 \\
\hline
\end{tabular}

Table 1: The theatres and areas within performance practice represented in the research. 


\section{Results}

Not all specific questions could be answered. Access to the senior management, for instance, was not available so it is not possible to comment on the area of programming (research question 1), but interviews with the production staff (Area B) revealed that all of the theatres use digital technology for stage design and lighting and sound operation, with associated patterns of change in their working practice and learning. In addition, in marketing and development (Area A) and Education (Area C) digital technology became a structural element of the theatre production process. In the discussion of the results, I restrict myself to the research questions $2,4,5,6$, and 7 .

To make the voices of the experts I interviewed clearly heard, I have chosen to present parts of the interviews as illustrations for selected results. Although the citations are extracted from longer interviews, they can stand for the whole, as each theatre identified similar patters of change.

\section{1. (Research Question 2) Impact of digital technology on performance practice}

The general feeling regarding the introduction of digital technology within the performance practice is well characterised by means of the following citation:

»I think initially, as the new technology came in generally, it became used in theatre productions because theatre people had an interest in it, and this is the essence of theatre a lot of theatre is packed with people who self-learn out of a passion, out of a desire to see what they can do with new things, out of an interest and then they apply that process to theatre. But, obviously, once it's become an accepted fact, then you've got to do something about formal training because there are people who haven't done things and therefore need to learn« (Production Director, Opera North).

In addition, within the production area clear tendencies could be deduced from the interviews for the following specific functions:

\section{- Set Design - change due to the influence of computer programmes}

»If one looks at it industry-wide in Europe and the UK in terms of set design, automated CAD packages have been in use to a greater or lesser extent for the last 10 or 12 years, primarily on the scenic producing side. Not a lot of designers design with them, they don't use them as a design tool. [...] So what we do is translate their drawings onto AutoCAD and it works very well. [...] We just didn't have the time to employ banks of draughtsmen to continually update changes for each venue, whereas now one person very quickly can make the alterations and do the printouts, so in scenery terms that's a big plus « (Technical Director, Opera North).

\section{- Lighting - changes to boards and lanterns requires more stage time}

»We have a computerized lighting desk that drives the whole thing, but instead of a lantern having just one function, we've now got digital multi-functional moving lanterns, so we need to plot their position, colour, gobo and whether they are moving, so although we may 
have fewer lanterns in the rig they do more jobs. There's a lighting session that didn't really used to have to happen before, but if that session does go in with the lights, it saves an enormous amount of time later on« (Head of Lighting, Nottingham Playhouse).

\section{- Digital video projection - the arrival of a new discipline in theatre practice}

»My department used to be a department of two disciplines, with lighting and sound, but now there's this third discipline because it's a creature all on its own « (Head of Lighting, Nottingham Playhouse).

\section{- Sound - Informal learning happens as a result of medial advances}

»Sound is the area that has changed the most whilst I've been in the industry by going digital - I trained on real tape, and by the time I finished my training the tape had been turned into minidisks, so I just picked it up as I was working, and then digital sound desks started to come in. With digital sound desks you don't have to go away and re-record anything; it's all just there and you just build it in chunks - cut and paste « (Head of Lighting, Nottingham Play-house).

\section{- Operational redundancies and job description changes}

»There are certainly fewer people needed. I've done very complex sound and video designs that have been operated by the stage manager from the corner. It's pretty much parcel of the West End. Unless it's absolutely necessary they will not pay for sound operators and they will not pay for video operators. It used to be just on straight plays with few cues that this was the case, but last year Brand, which had probably 120 sound cues was operated by the DSM, and this year I have had DSM's operating both the sound and the video and calling the show as well« (Director of Digital technology, West Yorkshire Playhouse).

\section{- Stage management, props, and the Internet}

»Stage management prop from E-bay because they can buy period items there. It has completely revolutionised how we prop because you can say »is that the sort of thing you mean« to a designer. We had to get the kind of sword that Byron was given when he fought an Albanian, and we found one on E-bay. Where would we find one otherwise? « (Production Manager, Nottingham Playhouse)

So far the research reveals a clear need for training in the computer programmes that now underpin contemporary theatre practice. This result is confirmed also by the answers to the general research 7:

\section{2. (Research question 7) What more would they want to do with digital media?}

»I want the CAD packages and training, because none of them are useful without training. Training would be absolute priority. If we had absolutely no limit on the money I'd want to have a stage in the Crucible with hydraulic computerised lifting sections in it because at the moment all our work on stage is manual. So every time we build any levels or reduce 
the height of the stage at all, it's all done manually and it's a bit >cave man« (Production Manager, Crucible Theatre).

With respect to the need for training in digital technology in theatre practice the government stands ready to fill the skills gap ${ }^{1}$ and thence a link to Learn Direct, which is part of the government-sponsored University for Industry, with a remit to provide high quality post-16 training. We need to notice this transfer in learning from the higher education sector to industry as it may be significant.

The research has revealed informal learning taking place as theatre staff adjusts to new ways of working, and we can see knowledge transfer between the different theatre departments.

The research brings the unseen elements of the intermedial theatron to the surface, for driving the audience and the actors' experience of the performance is the digital media of the lighting desk, the sound desk, and parts of the scenery on the stage and in the fly floor. Whether or not projectors are visible, digital media is running underneath the performance, which raises ontological issues for the >live< theatre performance. All performances are remediated to become an intermedial mix of live and mediatized performance.

The research raises the question of the ontology of digital media itself, as theatre has borrowed and adapted digital media designed for other areas, such as architecture (AutoCAD), popular culture (digital multi-functional lanterns), and music (sequencing and sampling software). With the transfer of media across disciplines, people, and spaces comes knowledge transfer.

The research questions 5 and 6 relate mainly to the box office, publicity, marketing and development section of the project.

\section{3. (Research questions 5 and 6) The relationship between theatre (or artist) and community (or citizen)}

The research questions 5 and 6 mainly relate to the Box Office, Publicity, Marketing, and Development sections of the project. The Box Office, one of the interfaces between theatre and citizens, uses digital programmes to sell tickets. This technology remains more or less invisible for the community. The lack of visibility on the part of the box office represents a striking contrast with the area of Publicity, Marketing, and Development where the marketing officers actively use the theatre web sites to promote productions. ${ }^{2}$ Since the pilot finished it is notable that the web sites continue to change and become artistic performances in their own right. Opera North, with its musical sound and image bites, is evidence of a particularly good practice.

The inter-active nature of the web sites is taken up by the community, contributing to the on-line comment list about the productions, as in Back-chat on the Sheffield site, which links directly to the national newspapers' critical reviews of Sheffield productions; this feature is repeated on the other sights. There is also a section where members of the public can comment on the facilities that the theatre has to offer.

1 via www.bbc.co.uk/learning/subjects/performing-arts.shtml.

2 www.nottinghamplayhouse.co.uk, www.operanorth.co.uk, www.royalcentre-nottingham.co.uk, www.sheffieldtheatres.co.uk, www.wyplayhouse.co.uk. 


\section{4. (Research Question 4) Inter-activity and the changes to theatre education}

This has been referred to earlier in the discussion of www.stageworks.org, which took as its model the work done on the Sheffield Creative Development Programme web site. The Crucible education site is a separate website accessed by a link to the Crucible web page, and so positions the education programme as connected to the centre of the theatre and looking out to the community. Their creative development programme encourages the community to come into the theatre for learning about stagecraft, acting, and playwriting through contact with the professional actors and directors associated with the Crucible Theatre, thus connecting with the national trend.

At West Yorkshire Playhouse, a cyber café is located in the large open theatre foyer, which is open all day to the community. Here there are free skills courses offered to the general public that are operated by Learn-Direct, and so again we see the national picture of the government skills agenda emerging. In this project, a large increase in community drama for all ages is a common feature in regional theatres, and links into the government widening the participation and social inclusion agenda, which continues to gain national momentum.

\section{Conclusion}

Analysis of the research project reveals that the impact of digital technology on British Theatre practice is considerable, and that if this pilot project were repeated at a national level there is a weight of evidence to suggest that formal and informal learning is taking place in the theatre nationally. What is required now is to consider whether we can now say that the intermedial theatron is a paradigm shift in education and performance in the public sphere. It is clear that the repertory companies have grouped around the funding opportunities offered by the government policies in widening participation and lifelong learning. We have seen a vision of a learning society that is enhanced by the communication offered via digital web sites, and where the community can experience an intermedial theatron - as far as the programme will let them enter; however, ultimately, the computer programme only offers a simulacrum of the live theatre experience.

Although the evidence of the interviews does indicate a paradigm shift in British theatre performance practice, there is limited evidence to support a paradigm shift in education. However, there is a new initiative from Arts Council England Arts, enterprise and excellence: strategy for higher education (November, 2006), which promotes a closer involvement of professional theatre to Higher Education, and I am persuaded that this might be the beginning of a paradigm shift. If the policy becomes fully implemented, then Theatre Departments in Higher Education Institutes in Britain will need to consider the potential impact on HE Theatre curriculum, pedagogy, and practice, as this will bring the UK closer to both European and global movements in educational policy and social inclusion debates worldwide (Kenway). 


\section{Literature}

Arts Council England (2000): The Arts Council of England's National Policy for Theatre in England. London: ACE.

Arts Council England (2006): Arts, enterprise and excellence: strategy for higher education. London: ACE.

Arts Council England (2006): Creative Industries: Performing Arts. London: ACE.

Arts Council England (2006): Theatre policy. London: ACE.

Arts Council England (2006): Public Investment in the Arts: a decade of change. London: ACE.

Chapple; Freda/Chiel Kattenbelt (Eds.) (2006): Intermediality in Theatre and Performance. Amsterdam/New York: Rodopi.

Dearing, R (Chair) (1997): Higher Education in the learning Society: Report of the National Committee of Inquiry into Higher Education. London: HMSO \& NICHE Publications.

Department for Culture, Media and Sport (2000): Creative Industries Mapping Document.

HMSO (2003): The Future for Higher Education. London: HMSO

Kenway, J (2001): »The Information Superhighway and Postmodernity: the socialpromise and the social price«. In: Carrie Paechter/Margaret Preedy/David Scott/Jasnet Soler (Eds): Knowledge, Power and Learning. London: Paul Chapman \& Open University Press.

Manovich, Lev (2001): The Language of New Media. Cambridge Mass: MIT press.

McDonnell, Bill and Shellard, Dominic (2006) Social impact study of UK theatre. London: Arts Council England.

Nicholson, Helen (2005): Applied Drama. London: Palgrave Macmillan.

Shellard, Dominic (2004): Economic Impact Study of UK Theatre. London: ACE.

Watson, David/Richard Taylor (1998): Lifelong Learning and the University. London: Falmer Press. 



\title{
WWW.THEATERTHEORIE.NET
}

\author{
ANTON REY/THOMAS GRÜEBLER
}

Im letzten Jahrzehnt sind in der Theaterwissenschaft richtungweisende Werke publiziert worden wie, um nur drei der bekanntesten zu nennen, Erika Fischer-Lichtes Ästhetik des Performativen, Frankfurt/M. 2004, Hans-Thies Lehmanns Postdramatisches Theater, Frankfurt/M. 1999, Stefan Hulfelds Theatergeschichtsschreibung als kulturelle Praxis, Zürich 2007. Insbesondere auch für Studierende, die für die Theaterpraxis ausgebildet werden, sind Werke wie die drei erwähnten von großer Bedeutung.

Oder vielmehr, sie wären von großer Bedeutung, würden sie gelesen. Leider ist der Sachverhalt nicht zu leugnen: Die künftigen Theaterpraktiker und -praktikerinnen (im Folgenden wird zur Vereinfachung die männliche Form gewählt) und angehenden Performer scheuen den Umgang mit wissenschaftlichen Theorien und Publikationen, wollen lieber ungeduldig Körper und Stimme auf Bühnen erproben als epistemische Erkenntnisse in dicken Büchern studieren. Aristoteles, Riccoboni, Lessing, Craig und weitere, es gibt sie in kondensierter Form und beispielsweise ein Schauspielstudent kann sie spielend erproben, aber wozu Theorien wie die Ästhetik des Performativen, Postdramatisches Theater oder die Theatergeschichtsschreibung, und sei es als kulturelle Praxis? »Wozu soll das auf der Bühne helfen?«, »Sind theoretische Kenntnisse für einen Tänzer, Spieler oder Akteur nicht eher hinderlich?«, fragen sich diese Studierenden.

Am Zürcher Institute for the Performing Arts and Film (ipf) wurde daher vor fast drei Jahren der Versuch unternommen, den Studierenden der Zürcher Hochschule der Künste (ZHdK) einige dieser Theorien auf eine andere Art nahe zu bringen. Weder in Buchform noch als Rezension, nicht in Seminaren oder Vorlesungen, sondern in Form eines interaktiven, jederzeit zugänglichen Web-Tools, welches ein Videoclip-basiertes, komplex gegliedertes Wissensnetz beinhaltet und sich durch eine innovative Navigation auszeichnet. ${ }^{1}$

1 An dieser Stelle seien jene Stationen aufgezählt, deren es bedurfte, um das Werkzeug transdisziplinär zu realisieren: Ausgegangen wurde von einer Idee im Forschungsausschuss der damaligen Hochschule Musik und Theater Zürich (HMT, jetzt ZHdK), die Projektverantwortlichen wurden unterstützt und herausgefordert durch einen Assistenten im Rahmen eines Studierendenprojekts des Institut HyperWerk der Hochschule für Gestaltung und Kunst Basel (HGKB), durch den e-learning Beauftragten der HMT und durch didaktische Beratung aus der Pädagogischen Hochschule Zürich (PHZH), durch einen großzügigen finanziellen Beitrag des Competence, Service, Production Center der Zürcher Fachhochschule (CSPC), durch ein Videoteam für die Aufnahmen (Kameraleute, Cutter, Nachbearbeiter) zusammengestellt aus einem Studierendenprojekt Abteilung Bildende Kunst - Medienkunst (wiederum HGKB), durch Studierende und Dozierende aus der Studienvertiefung Interaction Design/Game Design (IAD) sowie der Studienvertiefung Visuelle Kommunikation (SVK) der vormaligen HGKZ (heute ebenfalls ZHdK) in der Entwicklung eines innovativen Navigationsdesigns und in der anspruchsvollen Programmierung eines Backend, durch Spezialisten bei der 
Auf der inzwischen fertig gestellten Plattform www.theatertheorie.net werden nun theater-, respektive kunsttheoretische Konzepte und Begriffe kritisch und interaktiv auf ihre Praxisrelevanz hin befragt und fruchtbar gemacht. Die (bisher) drei Theaterwissenschaftler stellen ihre Positionen vor und treten in Dialog mit bekannten Theaterschaffenden anhand von Beispielen aus deren ästhetischer Praxis.

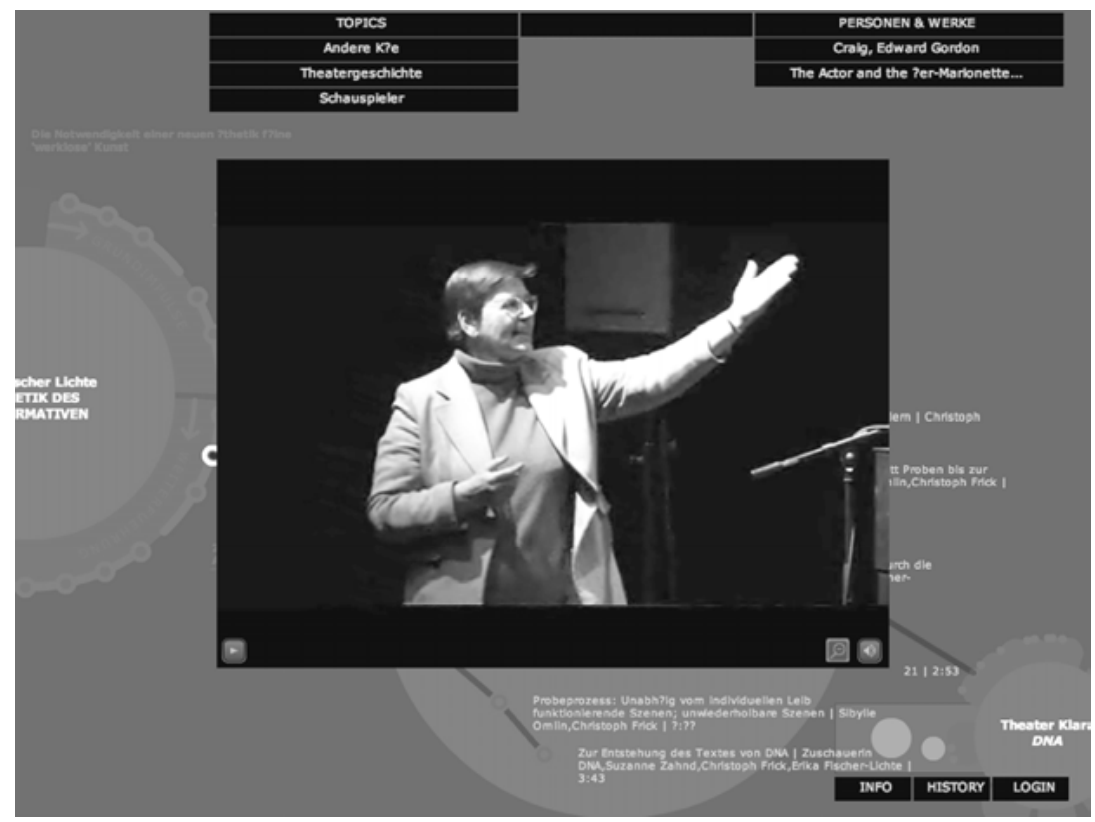

Abbildung 1: Erika Fischer-Lichte auf www.theatertheorie.net.

Der Mehrwert von www.theatertheorie.net gegenüber konventionellen Mitteln zur Wissensspeicherung und -vermittlung ergibt sich durch die spezifische Verbindung von Inhalt (kunsttheoretische Positionen, Beispiele ästhetischer Praxis, ihr Bezug zueinander) und Form (das Web mit seinen Strukturierungs-, Verknüpfungs- und Visualisierungsmöglichkeiten). Kurze Video-Sequenzen von Vortragsabschnitten, in denen die Referenten Teilaspekte ihrer Ansätze vorstellen und Begriffe klären, sind unmittelbar neben Diskussions- und Aufführungs-Sequenzen gestellt, in denen die Praxisrelevanz der theoretischen Ideen verhandelt und exemplifiziert wird. In diesem hypermedialen Zusammenhang mit seinen Argumentationspfaden von der Theorie zur Praxis und umgekehrt sind die einzelnen Beiträge zusätzlich mit indexikalischen Informationen versehen. Dies ermöglicht zum einen den Zugriff zu

Geduld fordernden Programmierung des Frontends, durch das InformationstechnologieZentrum (itz) der ZHdK, das ein ununterbrochen zuverlässiges Hosting sowie Beratung und Serverleistung zur Verfügung stellte, und durch folgende Partner für die Realisierung und gegen mögliche Verhinderungen: die Sektion Zürich der Vereinigten Theaterschaffenden Schweiz (VTS Zürich), das Theaterhaus Gessnerallee Zürich, und nicht zuletzt Lukas Bangerter, Erika Fischer-Lichte, Christoph Frick, Wowo Habdank, Stefan Hulfeld, Hans-Thies Lehmann, Mike Müller, Sybille Omlin, Heiko Pfost, Barbara Weber und Suzanne Zahnd. 


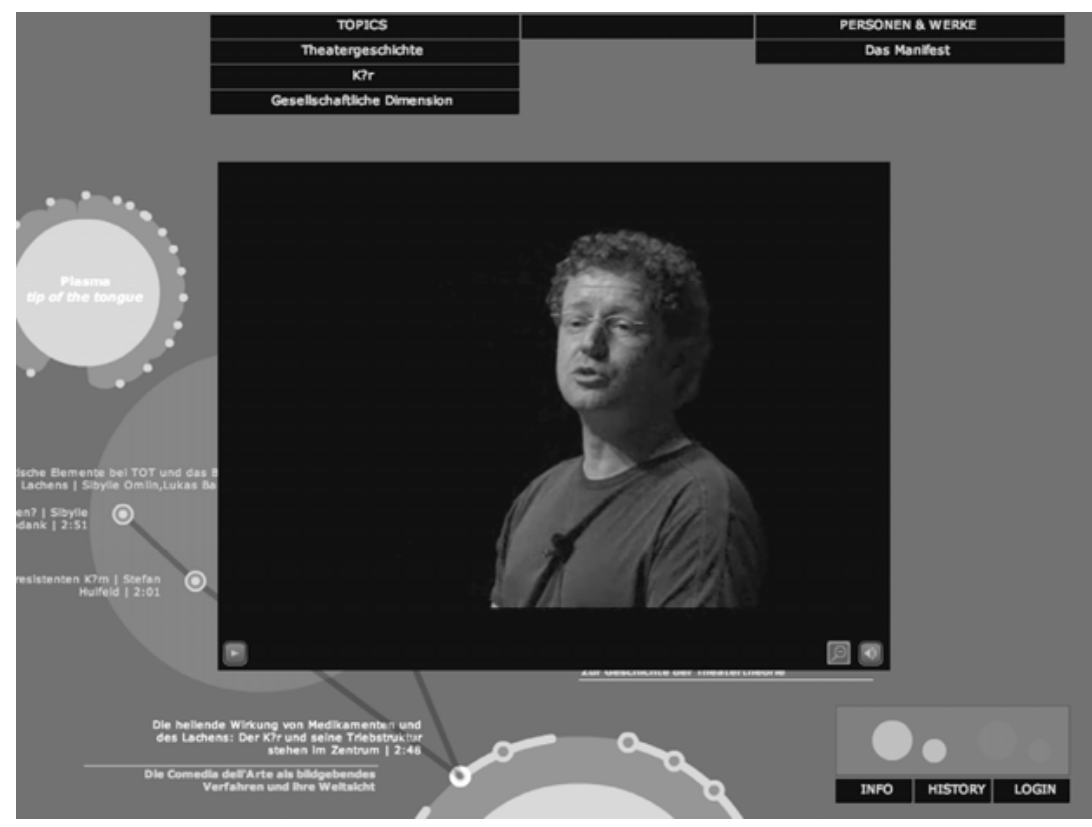

Abbildung 2: Stefan Hulfeld auf www.theatertheorie.net.

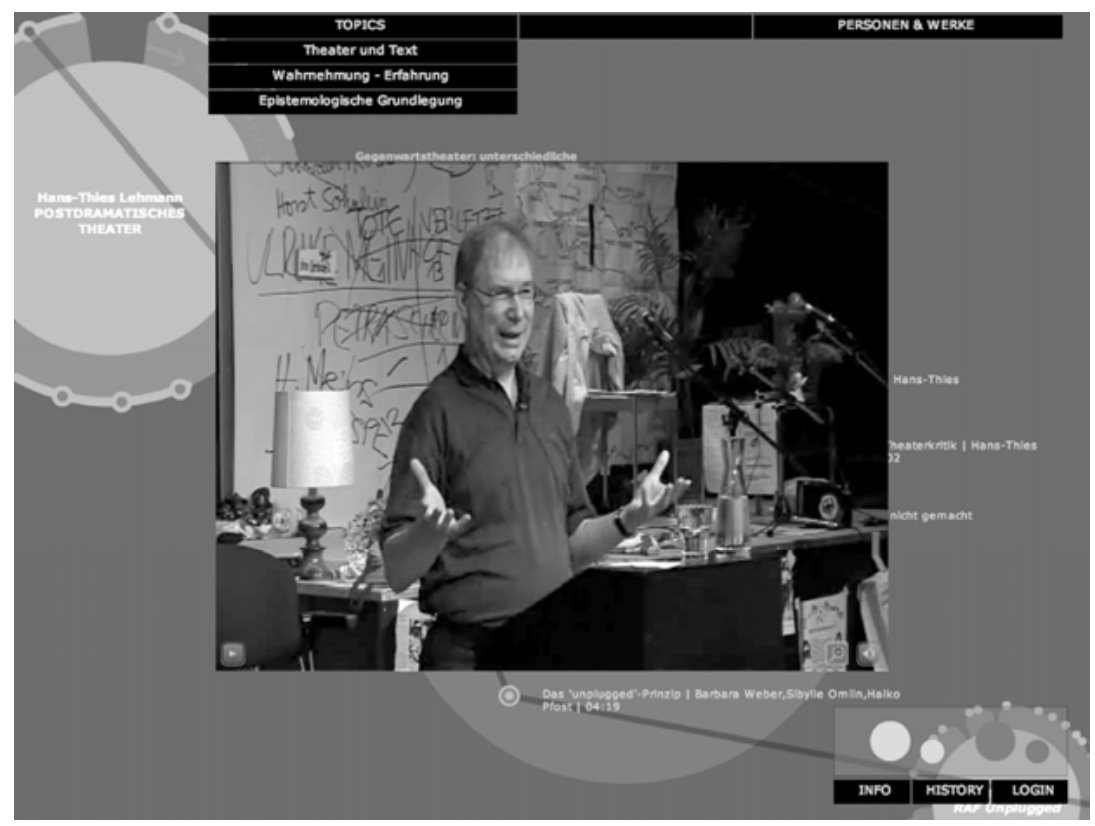

Abbildung 3: Hans-Thies Lehmann auf www.theatertheorie.net. 
den Beiträgen über ein ansatzübergreifendes Schlagwortverzeichnis, zum anderen finden sich Informationen und Referenzen zu allen in den Beiträgen erwähnten Personen und Werken.

Das Tool www.theatertheorie.net stellt damit ein komplexes Wissensnetz dar, das vielfältige Querverbindungen schafft und gleichzeitig einfach zu navigieren ist. Dem Benutzer wird die Wahl gelassen, auf welche Art er sich Zugang zu den theoretischen Konzepten und Begriffen verschafft - in welchem Moment er sie von ihrem Autor theoretisch verhandelt sehen will, wann er ihrem Praxisbezug nachgehen, wieweit er vergleichend recherchieren oder in welchem Argumentationszusammenhang er sich ausführlicher auf dokumentierte Ausschnitte künstlerischer Praxis einlassen will.

Damit sind bislang drei Theatertheorien über ästhetische, dramatische, historiographische Fragen von drei Professoren mit unterschiedlichen performativen Qualitäten in einem virtuellen Auditorium Maximum publiziert. Sie können von angehenden Performern oder theatertheoretisch interessierten Rezipienten frei durchgewählt, »durchgeblättert « oder vielmehr »durchgezappt « werden, mit der dazu gehörenden Beispielen von Theateraufführungen und Podiums- respektive Zuschauerdiskussionen. Aus der Koexistenz divergierender Theaterkonzepte ist ein interaktives Werkzeug entstanden. Das scheint für viele Theaterpraktiker einladender zu sein als die Lektüre der Bücher. Diese, bislang »viel zu dick, zu theoretisch und so untheatralisch «, sind als interaktive Homepage, als Web-Plattform für begleitetes Lernen, so genanntes Blended Learning, nicht nur gewissermaßen handlicher, sondern verleiten tatsächlich zahlreiche Studierende, auch von Theaterhochschulen, sich am Ende doch das dicke, handfeste, blätter- und hineinschreibbare Buchexemplar zu besorgen.

Eine Evaluation des Tools aus theaterwissenschaftlicher Perspektive steht noch aus und kann an dieser Stelle nicht erfolgen.

\section{Literatur}

Fischer-Lichte, Erika (2004): Ästhetik des Performativen. Frankfurt/M.: Suhrkamp. Hulfeld, Stefan (2000): Zähmung der Masken, Wahrung der Gesichter. Theater und Theatralität in Solothurn 1700-1798. [Theatrum Helveticum 7, hg. v. ITW Bern] Zürich: Chronos.

Hulfeld, Stefan (2007): Theatergeschichtsschreibung als kulturelle Praxis. Wie Wissen über Theater entsteht. [Materialien des ITW Bern 8, Hg. v. ITW Bern] Zürich: Chronos.

Lehmann, Hans-Thies (1999): Postdramatisches Theater. Frankfurt/M.: Verlag der Autoren. 


\title{
Coming Soon to a Cinema/Television/ Website/Video Game/Theatre Near You...: Theatre, Intellectual Property Rights, ANd the CONTROL OF AMERICAN CULTURE
}

\author{
KIMON KERAMIDAS
}

Intellectual property rights have quickly become one of the hottest topics of the information age, and an increasingly visible factor in the discourse surrounding cultural production. As the production, reproduction, and dissemination of culture is increasingly facilitated by digital technologies, cultural producers have become keenly aware that the management of their intellectual properties is crucial to their survival and prosperity. The supervision and control of these intellectual properties and the rights bestowed upon property holders by the law have become particular points of contention in debates surrounding digital culture and media. New technologies have facilitated not only the sanctioned reproduction and distribution of content, but also alternative methods of content acquisition that challenge the boundaries of the law and have the potential to greatly disturb traditional economic practices and conditions.

Whereas it is quickly becoming clear that intellectual property rights will play a role in shaping our culture, the impact of intellectual property rights on the development of theatre remains less clear. As the origins of contemporary theatre precede the digital era by millennia, the cultural place of theatre in America is attached to inherent characteristics and traditions that predate PCs, CDs, and Napster. The study of theatre has as a result become separated from the study of other media, and field of theatrical production is rarely a topic of consideration in debates regarding intellectual property rights. Nevertheless, the economic and legal issues surrounding intellectual property that cause such a stir in the realm of digital media continue to have significant repercussions on how theatre is produced.

While recognizing that theatre is being influenced by intellectual property is an important first step in understanding the contemporary state of theatre, the question remains: how do we study these trends if political and economic conditions continue to be of secondary concern in the field of theatre studies? As the field currently stands, the methodologies used in the study of theatre predominantly address the aesthetics of performance and the phenomenology of theatrical experience. As such, shifts in popular culture, competition with technological media, and the process by which theatre has ascended to the status of high art in the United States fall outside the boundaries of most theatrical discourse. But, the rapidly evolving nature of twenty-first century cultural production, has made it imperative that the field adopt additional, interdisciplinary methodologies, which can fully address the technological innovations, economic developments and social changes of the twentieth and twenty-first centuries. Specifically, the study of theatre must more seriously concern itself with the political and economic forces that drive cultural production, 
so that scholarship will be as prepared to address the impact of the world beyond the theatre doors as it is to analyze the goings on within the theatre itself.

One of the first steps towards a more complete understanding of theatre is considering theatre as a medium, akin to television, film, video games, and the Internet. Raymond Williams defined »medium « as a social practice that consists of the collaborative work of people involved in the production, dissemination, and consumption of culture (Williams: 161-164). This definition precisely describes theatrical production, which since its beginnings has been the result of the coming together of many individuals to create a cultural good through specific processes of production, dissemination, and reproduction. Thinking of theatre as a medium allows us to better understand theatre as a form of cultural production, as we can now juxtapose theatre alongside the dominant contemporary technological media and borrow homologous methodologies from the fields of communication and media studies. In order to better place their objects of study in cultural context, these fields have embraced political economic theory as a way of understanding productive and consumptive forces. As theatre functions in the same cultural marketplace, it only makes sense to investigate how those same forces impact theatrical production. This methodology of political economic analysis is also a particularly useful manner in which to approach the issue of how intellectual property rights are influencing the development of the field of theatrical production. Understanding how intellectual property rights are shaping contemporary theatrical production demands an interrogation of the cultural logic of capitalism as a system and the logic of corporate and individual behavior within that system. It requires a methodology that can engage with the apparatuses of authorship, ownership, distribution, and commoditization at both the conceptual and practical level and connect the impact of those apparatuses on the resulting theatrical productions. The political economic approach allows us to accomplish these goals by integrating the empirical details of the microinteractions of the producer-creator and distributor-consumer relationships with the macro-level legal and economic forces that provide the structure and logic of theatrical production.

\section{The Historical, Legal, and Cultural Ramifications of Intellectual Property Rights}

Over the course of the twentieth century, the tradition of ownership and authorship in American theatre has, aside from some work in the avant garde and experimental movements, remained relatively unchanged. Playscripts have been seen as the origin point for most theatrical work and the playwright has been given a privileged position as the primary author of the theatrical experience. At the same time the culture industries as a whole have evolved and changed significantly, especially as corporate mega firms have asserted their position in the theatrical field over the last quarter-century. Lastly, the recent digital boom brought with it new technologies such as the Internet, which have lowered the barrier of entry for creative work, begetting new products, new markets, new means of distribution, as well as new ways of perceiving authorship and ownership (Lessig: 126). As the marketplace has expanded and become more complex, the concept of intellectual property has become a significant factor in the elevation of the economic stakes of cultural production. Because of decreasing transaction costs in the production of digital culture, reproduction and distribution have become less expensive and the owner- 
ship and protection of strong intellectual properties has become a profitable strategy. In addition, the notoriously vague and complex legal architecture that defines intellectual property has further made the cultural marketplace more contentious and complicated. As a result, the deployment of copyright law plays a significant role in dictating conditions within the cultural marketplace, as copyright holders exert control over their properties and the legal repercussions of violating those copyrights burden cultural producers. Although copyright, patent and trademark laws (the legal foundations of intellectual property) have existed since the early eighteenth century and the Statute of Anne in England, the history of the term intellectual property is in fact a short one. The phrase was first used for the inaugural assembly of the United Nations' World Intellectual Property Organization in 1967 (Lemley: 895). During the subsequent forty years, intellectual property has come to be recognized as a valuable resource in the generation of revenue and the assertion of cultural power. Ronald Bettig argues that

»Since the early 1970s, an ascending fraction of the capitalist class, centered in the knowledge, culture, and high-technology sectors, has begun to organize the transition to a new phase of capitalism - post-Fordism or >technocapitalism $<$ - in which the ownership of intellectual property rights to information, knowledge, and cultural goods is central (Bettig: 49).

The development of intellectual property has therefore become an important factor in contemporary cultural production, as producers, investors, artists and artisans each try to lay claim to as much of the available intellectual property as possible.

Bettig notes that »since intellectual property rights are both economic and statutory in nature, claims to ownership of intellectual and artistic works must be recognized by law to be effective « (Bettig: 3 ). The challenge therefore is to develop a system that establishes parameters for intellectual property that are in the best interest of the public good. The system must simultaneously promote creative endeavors by providing protection from plagiarism and exploitation - without constricting creativity. To further complicate the matter, these laws must provide equal protection and control over intellectual property to the independent artist as they do to the corporation. Therefore, the questions of how much protection is too much protection and who benefits most from these laws are central to debates over intellectual property rights. Alex Kozinski, a judge sitting on the Ninth Circuit Court of Appeals, has elucidated the challenge of striking a balance in the protection of intellectual property

Overprotecting intellectual property is as harmful as underprotecting it. Culture is impossible without a rich public domain. Nothing today, likely nothing since we tamed fire, is genuinely new: Culture, like science and technology, grows by accretion, each new creator building on the works of those who came before. Overprotection stifles the very creative forces it's supposed to nurture (Bradford: 4).

Over the last quarter century intellectual property rights have evolved from a tool for the promotion of invention and cultural production in the name of the public good into a method by which developing conceptions of ownership could be codified into natural law. This transformation belies the intention of the crafters of early American intellectual property legislation. Section 8 of Article I of the Constitution states that one of the powers of Congress is »To promote the Progress of Science and useful Arts, by securing for limited Times to Authors and Inventors the exclusive Right to their respective Writings and Discoveries « (US Constitu- 
tion). This article was meant to provide authors and inventors with the protection necessary to ensure they would be able to generate revenue from their intellectual work, and not to establish a tool for profit-making and cultural control. But the application of copyright laws has shifted as they are now deployed to codify what can be defined as property, a definition they are neither designed for nor are particularly well suited to provide. Since every party with a vested interest in the definition and scope of intellectual property has a different opinion on how much protection is too much, intellectual property rights have become an increasingly heated topic of debate. On the one hand, media corporations, music producers, and film studios argue that if they are to continue to be creative and productive they must remain profitable, and maintaining control over these properties is the way they are able to do that. On the other hand, creative artists who sample music and remix culture in their own production of culture argue that less strict controls ultimately lead to more production and a more diverse and creative culture. Every time a claim of copyright infringement puts the creation of a new cultural good in jeopardy, creators become more cautious of the economic implications of any misstep. No matter how trivial and seemingly unjustifiable these claims seem to be, each case sees a little bit of control of the creative process eroded from artists and more ceded to corporations with the financial and legal resources to afford a court battle. Siva Vaidhyanathan has written that the role of intellectual property rights in our culture has changed, and that »copyright issues are now more about large corporations limiting access to and use of their products, and less about lonely songwriters snapping their pencil tips under the glare of bare bulbs « (Vaidhyanathan: 12). For Vaidhyanathan the evolution of intellectual property rights over the last hundred years has »really been about the rights of publishers first, authors second, and the public a distant third «(15). Finally, Bettig argues that the problematic state of intellectual property rights and in particular the role of media conglomerates in shaping legislation and setting precedents has resulted »in the unequal distribution of the rewards for human intellectual and artistic creativity, especially to the detriment of actual creators, and that it primarily benefits the capitalist class rather than society as a whole« (Bettig: 44).

\section{Assessing the Impact of Intellectual Property on Theatrical Production}

With this perspective on the state of intellectual property rights and having engaged a methodology with which to better study the impact of intellectual property on theatre, we must consider what political economic and cultural conditions most directly influence this aspect of the cultural marketplace. One reason the study of intellectual property tends to occur within fields that address film, television, publishing, and the Internet, is that copyright law is designed to address those media that can be copied. United States law protects »works of authorship fixed in any tangible medium of expression ... from which they can be perceived, reproduced, or otherwise communicated « (Circular 92: Copyright Law of the United States of America and Related Laws Contained in Title 17 of the United States Code, June 2003, $\S 101$ ). This particular definition of works of authorship is ill suited to address the particular ephemeral nature of theatrical production and the irreproducibility of many of its resulting commodities. While play scripts, music, lyrics, and choreography - all of which can be notated and reproduced - are protec- 
ted by copyright laws, the performance, direction, acting, and portions of the design are only ever protected if individual agreements are made between producers and artists or producers and unions. Despite the incongruity of copyright law with the practice of making theatre, there are very real and significant impacts on theatre, as artistic control, the freedom to create, and economic possibility are affected at a number of different levels.

The first level at which we see intellectual property rights playing a role in the development of theatrical production is the interaction between individual artists and producers. As the digital age has increased the exposure of these rights and notions of authorship have been challenged and redefined, the individual artists involved in the creation of theatre have likewise become more keenly aware of the income generating potential of their work. Many sectors of the theatrical community who already receive protection under copyright laws, such as playwrights, choreographers, and composers, have sought out further clarification as to the applicability of those laws on their work to ensure they will retain the same amount of protection. The Dramatists Guild, which represents the interests of American playwrights, has looked to maintain the position of privilege in the theatrical field that copyright affords playwrights. But other members of the theatrical community, such as Lynn Thomson, the dramaturg for RENT, and the Society for Stage Directors and Choreographers, the union for theatrical directors, which has supported a number of director's in copyright issues, have fought to change or expand the existing laws, so that their intellectual labor would receive equal protection under the law. This changing notion of who is the rauthor of theatre has important conceptual as well as economic implications, because as property rights take center stage, theatre's ontology is questioned. As the notion of separate ownership and the potential for income from royalties and licensing become points of contention, they may serve to undermine the collaborative structures that have acted as the framework for the development of individual works as well as the field as a whole.

Taking a step back from individual artists and producers, we see intellectual property rights impacting the development of theatre at the level of content selection and production trends, as media conglomerates such as Disney, Time Warner, and Viacom have entered the theatrical marketplace, increasing the corporate presence and changing the economic stakes. As these companies have realized the value in extending the life of their libraries of intellectual properties, they have looked to propagate these properties across a variety of media to generate new streams of revenue and increase cultural exposure. As a result of this increased corporate presence in theatre, the trend of plays and musical being turned into movies, which prevailed during the twentieth century, has been reversed, and stages across the country and on Broadway in particular are now filled with second or third generation manifestations of already established intellectual properties. These corporations, using their sizable capital resources to absorb the financial risks of producing theatre, have made musicals derived from older intellectual properties such as Hairspray, Mamma Mia!, The Lion King and plays such as The Graduate more common in American theatres. The confluence of this corporate assertion along with the increasing economic challenge of producing a new play or musical has quickly made this style of secondary or tertiary production the rule and no longer the exception on Broadway, as musicals for SHREK, LEGALLY BLONDE, and other Hollywood blockbusters are on the way. As Broadway and the New York theatre scene is the origin point for theatrical notoriety in the United States, and the plays and musicals that are licensed by a majority of other theatres in the country 
are based on this notoriety, it is likely that this trend will spread and these properties further propagated. While this is a good economic situation for the corporations, it is yet to be seen how it bodes for the generation of innovative, original works of theatre. It has always been difficult for a new work of theatre to overcome the many obstacles on the way to success and longevity, but now independent writers, producers, and composers must compete against the economic resources of media conglomerates, which are intent on concentrating and consolidating control of American culture.

Finally, in placing theatre within the larger field of cultural production, we can see how new digital technologies have made it easier to reproduce and distribute content. This technology has also made it easier for cultural producers to adapt their intellectual properties across a number of different media, extending the life and profitability of those properties. But, the success of this model is predicated on creating durable creative goods that can be easily reproduced, mass marketed, and cross-promoted via delivery media such as DVDs, CDs, or the Internet. The ephemeral and live nature of theatre makes it difficult for theatrical producers to profit greatly in this market as the primary commodity of theatrical production vanishes at the end of each live performance. The cost of copying and distributing music, books, or films pales in comparison to the costs of recreating a theatrical performance, which include actor and crew salaries, rent for space, costs of props and scenery, playwright royalties, etc. This difference in cost is made even more glaring by the audience limitations of live performance, which can reach at most thousands of viewers while other media can easily reach millions or even billions. The laws that outline copyright and other intellectual property rights further exacerbate this disparity. As these laws focus on works created in any »tangible medium of expression « a certain protection and preferential value is given to those types of works that can be recorded. The end result is that the ephemeral nature of theatre and the difficulty of capturing the complete experience on recordable media leave theatre at a distinct economic disadvantage in the contemporary capitalist system of American culture.

Looking at the contemporary theatrical field we see a Disneyfied Broadway, disagreements between playwrights and directors over who reaps the rewards for creating dramatic action, and THE BRADY BUNCH, LESTAT, and MAMMA MiA! on American stages. These developments are symptomatic of the condition of theatre in contemporary culture and reveal how theatrical producers are responding to the role of property rights as part of the cultural logic of capitalism in the twenty-first century. So, if we are to comprehensively monitor and predict how theatre as a medium will continue to develop in the contemporary cultural marketplace, it is imperative that we continue to interrogate the role of intellectual property rights in that development. 


\section{Literature}

Bettig, Ronald V. (1996): Copyrighting Culture: The Political Economy of Intellectual Property. Boulder, Colorado: Westview Press.

Bradford, Gigi (2005): »Why Would You Read This Book?« In: David Bollier/Gigi Bradford/Laurie Racine/Gigi B. Sohn (Eds.): So What ... About Copyright?: What Artists Need to Know About Copyright \& Trademarks. http://static.publicknowledge.org/pdf/so-what-about-copyright.pdf (06.10.2005).

Circular 92: Copyright Law of the United States of America and Related Laws Contained in Title 17 of the United States Code. (June 2003). Chapter 1 Subject Matter and Scope of Copyright.

Lemley, Mark (1977): »Book Review-Romantic Authorship and the Rhetoric of Property «. In: Texas Law Review, 873-906

Lessig, Lawrence (2001): The Future of Ideas: The Fate of the Commons in a Connected World. New York: Random House.

US Constitution. Art I, Sec 8.

Vaidhyanathan, Siva (2001): Copyrights and Copywrongs: The Rise of Intellectual Property and How It Threatens Creativity. New York: New York UP.

Williams, Raymond (1977): Marxism and Literature. Oxford: Oxford UP. 



\title{
TEIL 5
}

\author{
Vom Nutzen UND NACHTEIL DES \\ MEDIENBEGRIFFS FÜR DAS THEATER \\ UND DIE THEATERWISSENSCHAFT
}





\title{
Vom Nutzen und Nachteil des Medienbegriffs FÜR DAS THEATER UND DIE THEATERWISSENSCHAFT
}

\author{
PODIUMSDISKUSSION MIT CHRISTOPHER BALME, ULRIKE HASS, \\ ChIEl KatTenbelt, ANDREAS KotTE Und IRINA RAJEWSKY, \\ EINGELEITET UND MODERIERT VON KAY KIRCHMANN ${ }^{1}$
}

Kay Kirchmann: Mein erster Vorschlag ist, dass wir uns auf dem Podium erst einmal verständigen über die epistemologischen Grundlagen dieses Kongresses. Das Kongressthema hieß»Theater und Medien«, und die Leitfrage lautete: Ist Theater ein Medium oder nicht? Es fällt auf, dass sowohl Theater wie Medien durch diese Formulierungen zunächst als zwei unverbrüchliche Entitäten festgeschrieben werden. Es gibt das Theater, es gibt die Medien. In einem Fall bei der diesjährigen Preisfrage der Gesellschaft für Theaterwissenschaft wurde, wie ich gehört habe, mehrheitlich befunden, dass Theater irgendwie vielleicht schon ein Medium ist, aber die Preisfrage selbst suggeriert ja immerhin auch so etwas wie die Möglichkeit, dass Theater darunter fallen könnte oder eben auch nicht. »Theater und Medien « - in dieser Formulierung wiederum ist ja schon die Nicht-Identität beider Entitäten festgeschrieben. Das heißt beide Formulierungen sind relativ voraussetzungsreich, sie legen im Grunde genommen schon den Erkenntnisrahmen fest, innerhalb dessen wir uns zu bewegen hatten. Und diese epistemologischen Voraussetzungen, also diese Axiome, kann man natürlich befragen.

Das zweite Axiom, gerade in der Formulierung »Theater und Medien « lautet: Es gibt das Theater, offensichtlich ein monolithischer Block von erstaunlicher innerer Kohärenz und Geschlossenheit, denn es hieß ja nicht »die theatralen Formen«, sondern »das Theater « - Singular - und dem stehen dann eben »die Medien« gegenüber, also eine Pluralität, die eben einen Teil unserer alltäglichen Arbeitsprobleme darstellt. Die Frage ist dann natürlich: Was ist jetzt dieses vielgestaltige Andere, also diese Pluralität der Medien, die hier in ihrem respektive seinem Verhältnis zum Theater bedacht und befragt werden sollen? Und naturgemäß sollte man von der Medienwissenschaft erwarten, dass sie auf diese Frage Antworten formulieren kann, aber wir haben es schon häufiger gehört, die allermeisten wissen es inzwischen: Diese Antwort gibt es nicht.

Insofern lautet die 1. These: Es gibt keinen Medienbegriff, oder - in memoriam Robert Lembke - welchen Medienbegriff hätten's denn gerne? Innerhalb der Medienwissenschaft ist es eben so, dass wir langsam einräumen, dass wir auch alle miteinander nicht genau wissen, was ein Medium eigentlich ist. Wir können uns in den seltensten Fällen darüber verständigen, was denn eigentlich der Gegenstand unserer relativ jungen akademischen Disziplin ist. Positiv gewendet könnte man sagen:

1 Diese Podiumsdiskussion fand am 15. Oktober 2006 im Markgrafentheater Erlangen statt und resümierte den zu Ende gehenden VIII. internationalen Kongress der Gesellschaft für Theaterwissenschaft. 
Unsere Kompetenzen als Medienwissenschaftler/-innen liegen offensichtlich sehr viel eher darin begründet, permanent diesen Medienbegriff zu problematisieren, als darin, ihn zu klären. Negativ gewendet kann man sagen, das ist eines der wenigen akademischen Fächer, zumindest in der deutschsprachigen Landschaft, die ein dermaßen ungeklärtes Verhältnis zu ihrem eigentlichen Gegenstandsbereich haben. Das stiftet, wie wir alle wissen, extreme Kommunikationsprobleme. Es gibt zwar einen Kernbereich von Medien, auf die man sich relativ schnell einigen kann Film, Fernsehen, Radio, das sind Medien, da ist relativ schnell Einigkeit hergestellt, und vom Telefon an über die Frage »Ist die Zeitung ein Medium?«, »Ist Sprache ein Medium? «, von da an wird es eigentlich immer unübersichtlicher. Und dann - auch das ist alltägliches Leid von uns - wuchern halt sehr schnell die Subkategorien, die Subdifferenzierungen: »Verbreitungs-« oder »Kommunikationsmedien «, »personale « oder »apersonale «, »symbolisch generalisierte « oder »Handlungsmedien « usw. usw., da gibt es ja mittlerweile unendlich viele Kategorisierungsversuche. Hinzu kommt die »Intermedialität«, angetreten mit dem Anspruch, das Problem zu klären. Um gleich schon die Spitze in die Runde zu geben: Ich glaube, das hat die Sache nicht geklärt, sondern noch mal verkompliziert. Vielleicht auch nicht, können wir gleich drüber reden. Das Problem liegt also ganz offensichtlich darin: Es gibt keine heuristische Distinktionskraft in unseren Medienbegriffen, die uns jetzt erlauben würde, einen Bereich des Medialen von einem Nicht-Medialen trennscharf zu sondern, und so waltet, wie Lorenz Engell das mal formuliert hat, ein »Pan-Medialismus «. Man kann sehr wohlbegründet schlechterdings alles zum Medium erklären, damit aber degenerieren das Medium und der Begriff des Mediums das Mediale zur Universalkategorie mit entsprechend geringem Erklärungspotential. Rainer Leschke hat nach Auffassung vieler hier in Erlangen Lehrender die vielleicht konziseste Systematik von Medientheorien vorgelegt und dabei in der Problematisierung des Medienbegriffs folgendes Fazit gezogen, ich zitiere ihn: »Der Gegenstand der Medienwissenschaften selbst ist abhängig von dem jeweils vertretenen wissenschaftlichen Ansatz, sodass auch in dieser Hinsicht keineswegs Einigkeit besteht. Ob man Medien als technische Verbreitungsinstrumente oder Kanäle definiert, oder ob man sie als Ausweitungen des Körpers betrachtet, (also die berühmte McLuhan-These,) das macht gerade auch in Bezug auf den Gegenstandsbereich der Medienwissenschaften einen erheblichen Unterschied aus. Der Gegenstand der Medienwissenschaften hat sich historisch als recht flexibel erwiesen«. Sie merken schon, dass Leschke hier sogar im Plural spricht, es gibt also jetzt schon Medienwissenschaften, auch das ist eine Debatte, die in der Medienwissenschaft immer mal geführt wird: Gibt es die Medienwissenschaft oder gibt es gleich Medienwissenschaften, aber was das dann sein soll, weiß wahrscheinlich kein Mensch mehr. Fazit: wir haben es mit einer notorischen Unschärfe des Medienbegriffs zu tun. Jetzt könnte man sagen: »Exklusivproblem der Medienwissenschaft, sollen die sich mal ein bisschen mehr Mühe geben!« Aber es ist natürlich im Grunde genommen so, dass jede Debatte über Medien innerhalb wie außerhalb der akademischen Landschaft von genau dieser Unschärfe geprägt wird. Und auch unsere Themenstellung auf diesem Kongress kann davon nicht unberührt bleiben, diese Unschärfe trägt sich natürlich auch hier hinein.

Wenn man auf die Gegenstände zurückkommt, merkt man das im Grunde sehr schnell, die Frage ist: Wann haben wir einen Gegenstand vorliegen, bei dem man sagen kann: »Hier ist die Frage nach dem Verhältnis von Theater und Medien sinnstiftend und erkenntnisleitend zu stellen«, und wo ist eine Demarkationslinie, die 
uns differenzieren lässt: »Hier stellt sich die Frage noch nicht, aber bei diesem Beispiel jetzt zeigt sie sich $\ll$ ?

Ich habe ein paar Bilder vorbereitet von einer Bühnenkünstlerin, die wiederum mit meiner theaterwissenschaftlichen Teilvergangenheit zu tun hat: Pina Bausch. Ich zeige Ihnen verschiedene Bühnenfotografien aus ihren Inszenierungen und frage jeweils danach, ob hierbei die Frage nach dem Verhältnis von Theater und Medien relevant ist.

Wenn man hier jetzt verschiedene Definitionen von Medien zugrunde legt, erhält man auch sehr schnell unterschiedliche Antworten auf diese Frage. Müssen wir z.B. nach dem Verhältnis von Theater und Medien fragen, wenn auf einer Bühne, hier der des Wuppertaler Tanztheaters, Mode gezeigt wird? McLuhan würde sagen: »Ja. Mode ist ein Medium, Kleidung ist ein Medium«, und deswegen würde sich für ihn unsere Frage stellen. Stellt sich die Frage aber auch schon dann, wenn ein Performer, ein Actor, Lutz Förster in diesem Fall, mit einem Buch über die Bühne läuft? Mutmaßlich würden die allerwenigsten von uns spontan sagen, dass dies ein Motiv sei, anhand dessen diese Frage sich aufdrängt, aber legt man die gängigen Medientheorien zugrunde, müsste man diese Frage schon bei solchen Beispielen stellen.

Wie ist es eigentlich mit Musik? Ist Musik ein Medium, oder kann man die Frage nach der Medialität reduzieren auf die die Technologien, die Instrumente der Musik? Würden wir also bei dem Befund, dass jemand mit einem Bandoneon durch ein Nelkenfeld stapft, oder dass eine Wurlitzer-Orgel auf der Bühne steht, dies bereits als Medieneinsatz im Theater etikettieren? Oder erst dann, wenn ein Mikrophon auf der Bühne aufgestellt ist? Das alles ist, wie gesagt, abhängig von den Vorannahmen.

Weiteres Beispiel: Licht. McLuhan und viele technizistische Medientheoretiker neigen zu der Auffassung, Licht sei ein Medium. Müssten wir die Frage also auch hier stellen, dann gäbe es allerdings eigentlich keine Theateraufführung mehr, die nicht medial mitgeformt wäre. Man kann das Spiel sogar noch weiter treiben: Ist der Sand, der, wie hier auf dem Foto zu sehen, von der Bühnendecke fällt, das Medium des Lichtes, also das Medium im Medium?

Weiteres Beispiel: der Bühnenraum von Rolf Borzik zu KonTAKTHOF. Fangen wir schon an, anhand dieses Bühnenraumes die Frage nach dem Verhältnis von Theater und Medien zu stellen, nur weil an den Wänden Photographien von Boxern zu besichtigen sind? Oder würden wir dies einfach ganz normal subsumieren unter den Bestandteilen des Bühnenbildes? Oder, und das wäre die böse Unterstellung meinerseits, stellen wir solche Fragen nicht doch erst dann, wenn die jeweils neuesten oder scheinbar neuesten Medientechnologien im Spiel sind, hier [vgl. Ausführungen oben] aus den jüngeren Stücken von Pina Bausch Beispiele von Video- und Diaprojektionen? Dabei wäre wahrscheinlich die Frage viel schneller als gegenstandsadäquat anerkannt worden. Also worüber wir uns zu verständigen hätten, oder womit ich Sie bitten würde, in die Diskussion einzusteigen: Wie gehen wir mit der Tatsache um, dass wir keinen geklärten Medienbegriff haben, beziehungsweise viel zu viele Medienbegriffe haben, und im gleichen Atemzug natürlich in so einer Kongressformulierung »Theater und Medien « davon ausgehen, dass das Theater irgendwie das Andere der Medien ist?

Christopher Balme: Ich meine, Sie haben eigentlich sehr plausibel dargelegt, dass fast alles zum Medium erklärt werden kann. Man weiß nach der ersten Lektüre irgendeiner »Einführung in die Medienwissenschaft«, dass es x Definitionen gibt, und damit ist auch die Frage gleich beantwortet, muss ich ehrlich sagen. Bei 
dieser Vielfalt der Definitionsmöglichkeiten, ausgehend von McLuhan, gibt es kaum einen Grund, Theater nicht dazu zu rechnen, um auf die erste basale Frage zu antworten. Und wenn man dann dazu auch noch Ihre verschiedenen Beispiele hinzurechnet, etwa das Bühnenlicht, das wir normalerweise erst mal nicht dazu rechnen würden, stellt sich heraus - und das wäre meine eigene Position -, dass die Frage des Mediums oder der Medialität im Theater immer eine historische ist. Es ist ein sehr kontingentes Phänomen, was wir als Fremdkörper im Sinne der Intermedialität erkennen und was nicht. Das wäre meine Antwort auf die Frage: Theater ist ein Medium, es gibt kaum einen Grund, es nicht dazuzurechnen; vielleicht können wir darüber in Einzelfällen noch mal sprechen Aber die interessantere Frage ist: »Wann nehmen wir etwas als Fremdmedium wahr? «, und das ist meines Erachtens ein kontingentes, also dem historischen Wandel unterworfenes, Phänomen.

Ulrike Haß: Ich glaube, die Schwierigkeit entsteht immer dann, wenn man »Medium« im Singular zu einer manifesten Figur verdichtet. Wie schon im Titel, »Theater und Medien«, ist »Theater« ununterscheidbar Singular und Plural in einem. Das würde ich gern als eine Figur verwenden, um daran anzuknüpfen, dass es für Einzelvorkommnisse bis hin zum Menschen eigentlich gilt, dass er für sich genommen alleine gestellt überhaupt nicht erscheinen kann. Es gilt also grundsätzlich diese Form des Singular-Plural-Seins. Man kann nicht erscheinen, ohne schon immer Mit-zu-Sein. Wenn ich an einige Vorträge vom heutigen Vormittag denke, dann ist gerade diese Figur in etlichen Beiträgen immer wieder verwendet worden, als eine Figur, von der gesagt wird, wir gehen von der Theatersituation aus im Sinne eines - ich benutze jetzt einen Begriff, der heute gefallen ist - medialen Settings. Ich würde es nicht so nennen, aber was damit gemeint ist, stimmt: Es ist von vornherein eine plurale Anordnung, in der etwas geschieht, das uns als Wahrnehmende im Zusammenhang mit Darstellung hervorbringt. Und dieses wäre sozusagen die Medialität des Theaters, wenn ich ein paar Gedanken der Tagung zusammenfasse, die mir gerade noch sehr gut im Kopf sind. Und ich denke, dass wir hinter diesen erreichten Stand der Diskussion nicht zurückfallen sollten, indem wir jetzt immer wieder die Frage nach dem Medium im Singular aufstellen. Ob ein Buch ein Medium ist oder nicht: Die Frage ist abhängig von der Perspektive, unter der ich sie zu betrachten gedenke, sie kann für sich genommen so eigentlich gar nicht gestellt werden.

Irina Rajewsky: Ich würde zunächst gerne an die von Ihnen angeführte >Spitze< anknüpfen: Die Intermedialitätsforschung ist wissenschaftsgeschichtlich tatsächlich nicht angetreten, um zu klären, was ein Medium ist, sondern sie ist angetreten, aus verschiedenen Traditionslinien kommend, um bestimmte Aspekte in künstlerischen Praktiken beschreiben zu können. Das kommt einmal aus den Interart Studies, komparatistisch, und zum anderen aus einer Traditionslinie, die man schon medienwissenschaftlich nennen könnte - Higgins, intermedia, die amerikanische Tradition, Fluxusbewegung und so weiter. Es ging immer schon um Phänomene, bei denen man gesehen hat: Da sind Grenzphänomene, da passiert etwas, das sich zwischen verschiedenen Größen bewegt und wo herkömmliche Konzepte und Kategorien nicht mehr ausgereicht haben. Und da den Intermedialitätsbegriff anzusetzen, halte ich persönlich für besonders sinnvoll. Gleichzeitig setzt er aber voraus, dass man eben tatsächlich zwischen Einzelmedien differenzieren kann; es hat nur dann Sinn, von Intermedialität zu reden, wenn ich zwei Größen habe, zwischen denen sich dieses $>$ Inter-< bewegen kann, also wenn ich überhaupt ein >Dazwischen $<$ beschreiben kann. Hier setzt jetzt die Frage an »Wie mache ich das denn? «. Und hier greift nun erneut Ihr Kommentar: Es gibt anscheinend Phänomene, wo 
wir plötzlich etwas als >anders < wahrnehmen. Ich würde als Lösungsvorschlag vor diesem Hintergrund einen Aspekt stark machen, den Werner Wolf in die Diskussion gebracht hat, nämlich von »konventionell als distinkt wahrgenommenen Medien « zu sprechen, was natürlich dann immer historisch, je nach Beobachterstandpunkt, je nach Diskurstradition, je nach Theoriehorizont usw. abläuft, was aber unter anderem zumindest auch auf einigen tatsächlich überzeitlichen Differenzen gründet.

Kirchmann: Das methodische Problem liegt aber doch genau in der Formulierbarkeit dessen, was ein Einzelmedium ist. Da gibt es ja nun jede Menge - auch gegenläufige - Tendenzen in der Theorie, also die Medium-Form-Unterscheidung von Heider und Luhmann. Es ist seit McLuhan eben der Verdacht in der Welt, dass der Inhalt eines Mediums immer schon ein anderer ist etc., also schon auf dieser Ebene haben wir natürlich Probleme. Bleiben wir bei dem scheinbar selbstevidenten Beispiel Buch/Schrift: Hinter der Schrift scheint wieder die Sprache auf, und, wenn man den technologischen Aspekt miteinbezieht, der Buchdruck usw. Wir haben hier also schon auf genau dieser Ebene, die ja die unabdingbare Voraussetzung für die Formulierung von Intermedialität ist, wie Sie gerade zu Recht gesagt haben, unsere erheblichen Problemlagen, weil wir gar nicht genau formulieren können, was denn jetzt sozusagen dieses Basismedium ist. Man muss dafür auf ein konventionalisiertes Medienverständnis rekurrieren, was dann natürlich wissenschaftstheoretisch nicht so überzeugend ist. Die Problemlage bleibt, denke ich, in Kraft.

Chiel Kattenbelt: Ich glaube, so wie man heute in vielen Fällen fragt »Ist es ein Medium?«, gab es auch eine Zeit, da man sich fragte »Ist es ein Zeichen?« Was ich problematisch finde ist, dass der Begriff Medium oft verwendet wird, ohne dass man klar macht, auf welcher Ebene man eigentlich von Medien spricht: auf der Ebene von Zeichensystemen, Institutionen, Technologien? Es ist sehr problematisch, dass das nicht explizit gemacht wird. Es wird auch viel gesprochen von »Medialität «, und ich denke, dass der Begriff Medialität Medien voraussetzt. Es gibt keine Medialität ohne Medien.

Andreas Kotte: An dieser Stelle sehe ich zumindest eine graduelle Verbesserung gegenüber der Situation von vor zehn Jahren. Heute wird bei Vorträgen mehr Wert gelegt darauf, dass man sagt: »Ich verwende Medium oder Medien so und so«. Ich sehe dort eine Verbesserung in der Kommunikation zwischen den Medienwissenschaften und der Theaterwissenschaft und das macht es uns allen auch etwas leichter. Beide Wissenschaften kämpfen mit dem selben Definitionsproblem. Der Satz »Definierbar ist nur, was keine Geschichte hat « ist vielleicht ein ganz guter Lösungsansatz. Als Theaterhistoriker betrachte ich den Mediendiskurs unter dem Zweckaspekt »Wie kann er für die Theaterwissenschaft bedeutsam sein?«. Und dann sehe ich drei Ebenen: erstens die metaphorische Ebene - Wind, Wasser, Sonne und so weiter als Medien, dann sage ich: »Okay, das ist für Theaterwissenschaft weniger interessant, das sind die Endlosdiskurse, das könnte man unter freier Meinungsäußerung abhaken«. Daneben gibt es die sowohl historisch wie philosophisch abgestützten Diskursformen mit großer Anregungsbreite. Und drittens noch eine höchst problematische Popularisierungsebene, wenn ich da z.B. lese, es gibt 17 Medien und das 14. ist das Theater, oder wenn geschrieben steht: »In der archaischen Periode waren die wichtigsten Medien die Frau und das Opferritual «. Aus diesem Grunde würde ich lieber - wie es Herr Ruchatz heute in seinem Vortrag getan hat - den Begriff »Medien« auf der zweiten Ebene vergleichend benutzen. Auf eine Formel gebracht: Wenn man Vorträge hört, die häufig den Begriff 
Medium aufgreifen, und man kann überall einfach das Wort Medium herauskürzen, ohne dass der Vortrag an Qualität verliert, dann ist etwas falsch.

Kirchmann: Dann scheinen wir uns ja doch an einem bestimmten Punkt einig zu sein, nämlich dass sich langsam die Erkenntnis Bahn bricht, dass Medium eigentlich weniger eine vorgängige Größe unserer Bemühungen ist, sondern etwas, das wir in dem jeweiligen Diskurs immer erst herstellen. Und wenn das ausreichend flankiert und ausgewiesen ist als Erkenntnisvoraussetzung, als Rahmung des eigenen Nachdenkens über Theater oder Medien, dann könnte man im weitesten Sinne von wissenschaftlicher Redlichkeit sprechen - und sei es, um die von Herrn Kotte zitierten frei flottierenden siebzehngestaltigen Medienhybride auszuschließen.

Kattenbelt: Vielleicht darf ich noch etwas hinzufügen: Ich denke, dass der Begriff Medium relativ spät im deutschsprachigen Raum verwendet wird. Es ist vielleicht nicht nur ein geschichtlicher Begriff, aber es gibt auch verschiedene Sprachgeschichten, was die Verwendung dieses Begriffs betrifft. Ich habe bei den vielen Vorträgen bemerkt, dass auch viel schief geht in der Übersetzung von Begriffen, so wird »Remediation « als »Remediatisierung « übersetzt. Gibt es denn auf Deutsch nicht so etwas wie »Remediation«, könnte man das nicht sagen? Es gibt also auch viele Unklarheiten, die in der Übersetzung von Begriffen entstehen.

Kirchmann: Ich greife in meiner zweiten These zwei Stichworte auf: den Medienvergleich und das Plädoyer für eine Historisierung. Einen bösen Verdacht möchte ich trotzdem am Leben erhalten. Natürlich trifft der niemanden von uns hier oben, aber es mag ja Kolleginnen und Kollegen geben, die, indem sie über Theater und Medien reden, eigentlich immer noch diese Ontologisierungspraxis betreiben. Viele Diskurse, sicherlich auch einige, die hier auf der Tagung zu hören waren, haben dieses ontologische Gepäck immer noch dabei. Da wird stark diskursanalytisch angefangen, und hinterher ist man doch wieder bei der Formulierung einer Wesenshaftigkeit des Theaters unter gleichzeitiger Beschwörung von Geschichtlichkeit angelangt. Es wird dann doch immer wieder in der einzelnen Rede über »das Theater « und »die Medien« oder meinethalben »das Theater « und »das Einzelmedium Film« gesprochen, es schleichen sich immer wieder solche latenten Ontologisierungen ein. Also ist es bei aller erkenntnistheoretischen Aufgeklärtheit offensichtlich nicht ganz einfach, dieser Ontologisierungsfalle zu entgehen; vielleicht läuft man - auch wir hier oben - auch immer wieder mal hinein. Historisch gesehen ist natülich diese Option der Medienvergleiche sehr interessant. Jens Ruchatz hat heute in seinem sehr schönen Vortrag [vgl. Aufsatz von Jens Ruchatz in diesem Band] zugespitzt formuliert, dass eigentlich erst der Medienvergleich Medien herstellt. Damit ist dann die Frage nach dem Verhältnis von Medien zu einem je gegebenen historischen Zeitpunkt eigentlich auch eine diskursive Strategie, nämlich dahingehend, dass in der Begegnung mit einem als etwas »anderes «, als »Fremdkörper « Apostrophierten etwas Entscheidendes passiert. Das jeweils diese Rede führende Medium (oder dessen VertreterInnen) verschaffen sich auf diesem Umweg, über diese Ausladung, »du da bist das, was ich als das Andere meiner selbst anerkenne «, im Grunde genommen vor allem Klarheit über das je eigene Medium, die je eigene Kunstform, egal wie wir es jetzt nennen wollen. Das ist natürlich in vielerlei Hinsicht schon in der Geschichte der Medientheorien ganz gut nachzuweisen. Diese Medienvergleiche, Leschke nennt das dann "primäre Intermedialität «, also die Abgrenzungsbemühungen zwischen zwei verschiedenen Medien, tauchen historisch gesehen natürlich immer dann auf, wenn ein neues, bzw. ein als solches apostrophiertes, Medium auf der Tagesordnung erscheint, wenn das Gefüge zwischen den Kunstformen, zwischen den einzelnen Medien, und 
vor allem die Frage nach Zuständigkeitsbereichen, nach gesellschaftlicher Relevanz, nach Neuformulierung des Kulturbegriffes, wenn all das zur Disposition gestellt ist. Diese Medienvergleiche sind insofern natürlich immer auch intentional aufgeladen. Also wir vergleichen Äpfel mit Birnen, Theater mit Medien, oder was auch immer genau, um uns in diesem Vergleich wiederum Klarheit darüber zu verschaffen, was denn jetzt eigentlich das Theater ist, was die Medien sind. Über diesen Vergleich konturieren sich erst die Gegenstände.

Der klassische Paragone ist im Grunde genommen die Geburtsstunde einer solchen Praxis. Auch da geht es ganz klar um Hierarchien, es geht um Zuweisungen von Gültigkeits- und Zuständigkeitsbereichen, von Geltungssphären, und es geht immer mindestens latent um die Frage nach dem besseren, moderneren, moralisch integereren Medium.

Solche Debatten gibt es eben in der Moderne zwischen Photographie und Malerei, Literatur und Film bzw. Fernsehen, jetzt zwischen analogen und digitalen Medien. Dem schließt sich theoriehistorisch sehr schnell, wenn nicht schon im gleichen Atemzug, so etwas wie eine Re-Ontologisierung der Vergleichsmedien an. Dieser Medienvergleich führt dann dazu, dass man Wesenhaftigkeiten glaubt erkennen oder vielleicht reformulieren, sie auf jeden Fall wieder neu festschreiben zu können; so z.B. wenn man sagt: »Gerade der Vergleich mit den neuen Medien, den digitalen Medien zeigt doch noch mal, dass das Theater der Ort des Körpers ist, der Präsenz, der Aktualität, usw., denn alles andere ist virtuell«. Wenn man das im Hinterkopf behält, dass es also eigentlich nur eine Vergleichspraxis ist, die dazu dient, innerhalb der Theater- und Medienpraxis selbst wie auch innerhalb der begleitenden Diskurse - seien sie nun akademisch oder nicht - sich des Orts der eigenen Mediums zu versichern, so gewinnt man noch eine neue Perspektivierung des Themas hinzu. Man kann dann eben einfach historische Redekonstellationen beobachten und feststellen: »Aha, hier um 1900 ist das Theater dank des Aufkommens des Films in der Situation, sich neu befragen zu müssen «. Vielleicht sind wir jetzt auch wieder genau in einer solchen Situation, dass durch das Auftauchen oder auch die stärkere Integration digitaler Artefakte in die Bühnenpraxis wieder ein neuer Klärungsbedarf besteht. Das >Eigene< und das >Andere< wird wieder zu einer Differenzlinie, anhand dessen man glaubt, Dinge erkennen zu können. Die zu Recht oft inkriminierte Pluralbildung »die Medien « könnte natürlich ihrerseits auch wieder begriffen werden als ein Symptom für eine historische Redekonstellation, aus der heraus - warum auch immer - man sich bemüßigt fühlt, vollkommen heterogene Phänomene unter das Dach einer Begriffsbildung zu zwingen. Was wäre denn in erster Konsequenz das phänomenal Gemeinsame von Zeitung, Film, Radio, PowerPoint, Schrift usw.? Es ist ja im Grunde genommen doch absolut disparat, was da unter einem Plural zusammengefasst wird. Wenn man aber die historische Ebene einzieht, die Herr Balme angemahnt hat, könnte man dies einfach als Symptom einer historischen Diskursformation begreifen, innerhalb derer es offensichtlich gesellschaftliche, kulturelle, wie auch immer determinierte Gründe gibt, diese Pluralbildung vorzunehmen.

Im Hinblick auf unsere Fragestellung heißt das eben: Was ist die eigentliche diskursive Strategie dahinter? Bzw. würden Sie dem überhaupt zustimmen, dass das eine diskursive Strategie ist, die dazu dienen soll, die Positionen von Theater und diesem berühmten $>$ Anderen $<$ des Theaters neu zu bestimmen?

Balme: Ich fühle mich natürlich viel sicherer und viel wohler, eine diskursive Strategie zu beobachten, als selbst eine Ontologisierung vorzunehmen. Man ist sozusagen in einer Beobachterposition, und es gibt natürlich für diese These sehr 
viele schöne Beispiele. Die frühe Kinodebatte am Anfang des 20. Jahrhunderts läuft aber natürlich nicht unter der begrifflichen Ägide »Medium«, sondern unter »Kunstform«. Wo man das wirklich sehr schön beobachten kann, ist in den 1960er Jahren mit den berühmten Bestrebungen zu einem armen Theater, zu einem leeren Raum, zu der berühmten Formel von Bentley - das sind alles wirklich ganz klare diskursive Strategien, Theater als ein Medium im Vergleich, in Abgrenzung zu anderen Medien zu definieren. Und das ist, denke ich schon, eine sehr legitime, sehr sichere wissenschaftliche Vorgehensweise, bei der wir sagen, wir beobachten die Diskurse, aber wir versuchen nicht selbst, Theater als Medium wesenhaft zu definieren. Und es gibt sicherlich viele andere Beispiele für solche Operationen.

Kotte: Ich sehe das ganz genauso. Wir reden über solche diskursive Strategien, und bei dem Sprechen über diese Strategien sind es natürlich dann die Begrifflichkeiten, die fallen. Dass wir im Prinzip nicht so sehr über die Dinge selbst, sondern über ihre Verwendung und ihre Funktion sprechen in diesen Strategien, das ist unbestritten.

Kirchmann: Wenn man den Diskurs aber beobachtet, dann gibt es dort eben diese Reontologisierungsbemühungen.

Rajewsky: Ich stimme dem natürlich auch vollkommen zu. Wobei zu fragen wäre, was für ein Diskursbegriff hier nun eigentlich verwendet wird. Ich stimme völlig zu, wenn es um das Reden über unsere wissenschaftlichen Diskurse geht. Aber ich möchte gerne noch einmal die künstlerische Praxis stark machen und die Frage, wie in der künstlerischen Praxis mit Medien umgegangen wird. Um an einem Beispiel klarzumachen, worauf ich hinaus will: Es gibt bestimmte mediale Konstellationen, nennen wir's mal so, die gerade die Grenze zu anderen Medien thematisieren oder reflektieren, und zwar in einer Weise, in der sie zeigen, dass sie selbst nicht zu etwas anderem werden können, sondern immer nur die Illusion aufbauen können, die Effekte eines anderen Mediums hervorzurufen. Beispiel: Photorealismus. Da haben wir Malerei, die versucht, mit ihren eigenen Mitteln eine Illusion von Photographie hervorzurufen. Beispiel: Klaus Obermaiers D.A.V.E. Da wird mit den gegebenen Mitteln versucht, eine Illusion der Virtualisierung herzustellen. Oder Sasha Waltz' Tanztheater, diese wunderbare Szene in KöRPER, wo mit den Mitteln des Tanztheaters eine Illusion der Malerei aufgebaut wird. Und ich würde sagen, gerade an solchen Stellen wird deutlich, dass es in der künstlerischen Praxis anscheinend Phänomene und Prozesse gibt, die gerade mediale Grenzen reflektieren. Ich weiß jetzt nicht, welches Wort ich hier setzen soll, weil es dann immer gleich allzu ontologisch klingt, aber da ist ja >irgendwasく, man kann anscheinend eben doch mediale Spezifika ausmachen: Malerei kann eben nicht zu Photographie werden, da fehlen in diesem Fall die technischen Mittel. Das heißt, ich stimme tendenziell natürlich $\mathrm{zu}$, es ist immer historisch bedingt, es ist immer diskursiv bedingt, es ist immer abhängig vom Beobachterstandpunkt, und dennoch kann man durchaus berechtigterweise - wenn man historisch rekonstruiert, wenn man die Diskurse mit einbezieht, wenn man eben diese ganzen Faktoren mitreflektiert - trotzdem immer noch von medialen Differenzen und Spezifika sprechen. Sonst nämlich komme ich wieder an den Punkt, an dem es dann auch keinen Sinn mehr hat, über Intermedialität zu reden.

$\boldsymbol{H a \beta}$ : Ich kann anknüpfen an das Beispiel Klaus Obermaier, auf das Sie jetzt dankenswerterweise verwiesen haben. Es macht deutlich, dass mit der eigenen medialen Verfasstheit, zum Beispiel einer Bühnenanordnung, gespielt und diese in einigen bestimmten Aspekten reflektiert wird, nämlich in der Frage des Übergangs des Körpers in eine visualisierte Fläche. Demgegenüber wird die mediale Verfasst- 
heit in anderen Aspekten überhaupt nicht thematisiert. Zum Beispiel wird nicht die Raumanordnung als solche thematisiert. Ich finde es völlig richtig, in diesem Fall des Theaters von Illusionstheater zu sprechen, eigentlich im barocken Sinne. Das heißt an diesem konkreten Beispiel: Einige Aspekte werden thematisiert, andere werden nicht thematisiert, werden nicht ausgestellt, nicht bearbeitet, nicht erkannt und problematisiert, und insofern befriedigen mich solche Beispiele immer nur teilweise oder auch gar nicht.

An diesem Beispiel jetzt festgemacht: Das Theater ist sozusagen der wunderbare Pluralgegenstand, an dem wir uns die Zähne ausbeißen, weil er nicht als Ganzes ins Verhältnis gesetzt werden kann zu etwas draußen. Das heißt in Bezug auf das Buchbeispiel: Natürlich können wir uns unter einer medientheoretischen Perspektive die Frage stellen: »In welcher Beziehung steht ein Buch auf der Bühne zur medialen Verfasstheit des Ortes? «. Und dann kommen wir auf andere Fragen, zum Beispiel: »In welchem Verhältnis stehen Theater und Schrift zueinander? In welcher Schicht basiert das Theater auf Schrift, oder wo hat es mit Schrift zu tun, die es dann wieder zum Verschwinden bringt und von der es eigentlich gar nichts wissen will usw.? « Eine Fragestellung ist also immer derart zu entwickeln, dass sie nicht in die Ontologisierungsfalle tappt, sondern uns aufgrund der pluralen Verfasstheit des Theaters zur Konkretion zwingt.

Kattenbelt: Ich bemerke, dass es in Bezug auf die Diskussion über Medien eine gewisse Angst gibt, über Ontologie zu sprechen. Es gibt kaum noch jemanden, der sich darüber klar äußert. Die einzigen, die sich darum kümmern, sind die Politiker. Gerade sind in Brüssel neue Gesetze in Vorbereitung, die die Medien betreffen, für ganz Europa gültig. Und die Politiker stoßen dann auf die Frage, was denn eigentlich noch Fernsehen ist. Wenn wir diesen Begriff verwenden, und nicht mehr unbedingt verweisen auf das Broadcast-Modell, dann gibt es auch Fernsehen im Internet. Ich denke, die Angst vor Ontologisierung ist eigentlich auch eine diskursive Strategie.

Rajewsky: Ich glaube tatsächlich, die Frage des Kongresses wäre zu reformulieren. Weg von der Frage »Ist Theater ein Medium? «, da wollen wir mal das Ontologische weglassen, sondern hin zur Frage: »Lässt sich Theater sinnvoll als ein Medium beschreiben?« - als Medium, das natülich per se plurimedialer Natur wäre. Und hier vielleicht noch eine Anmerkung zu dem, was ich mit den »konventionell als distinkt wahrgenommenen Medien « meinte - ich versuche das jetzt wieder von der kulturellen Praxis und auch vom Rezipienten aus zu denken. Nehmen wir zum Beispiel Lars von Triers Film DogviLLE. Dort wird auf eine bestimmte Theaterästhetik und zugleich offenkundig auf die Medialität des Theaters abgehoben, und im Umgang Lars von Triers mit dieser theatralen Ästhetik und mit theatralen Elementen und Strukturen tritt auch hier wieder ganz deutlich eine mediale Differenz, eine Differenz zwischen Film und Theater, zutage. Insofern würde ich schon sagen: Es kann in künstlerischen Praktiken auf das theatrale Medium rekurriert werden, das funktioniert zumindest für den Rezipienten und anscheinend ebenso für den Produzenten. Und anscheinend gibt es bestimmte - natürlich je historisch zu bestimmende - medial gebundene Frames, so könnte man es kognitionstheoretisch nennen, die tatsächlich für die Bedeutungskonstitution von künstlerischen Praktiken abrufbar sind und auch vom Rezipienten realisiert werden. Natürlich - das ist wie in der Intertextualitätsdebatte - gibt es auch den Rezipienten, der eben diesen Frame nicht abrufen kann, der bestimmte Dinge nicht erfasst. Das war aber auch bei der Intertextualität schon so, das ist kein neues Prob- 
lem. Bestimmte Dinge können eben nur rezipiert werden, wenn ich eine bestimmte Kompetenz mitbringe.

Um es auf einen Punkt zu bringen: Gerade ausgehend von Konzepten der Intermedialität, die Intermedialität als eine Analysekategorie für künstlerische Praktiken begreifen, lässt sich Theater aus meiner Sicht ganz fraglos sinnvoller Weise als ein Medium beschreiben.

Balme: Zwei kurze Bemerkungen. Zum einen noch eine Bemerkung zu Brüssel, da geht es um Medienrecht. Wenn es um Medienrecht geht, ist es klar: Die Juristen müssen Ontologien vornehmen, die müssen definieren, aber dabei würde dann selbst die Gewissheit, dass Film ein Medium ist, wahrscheinlich rausfliegen. Ich glaube nicht, dass im Brüsseler Medienrecht Film überhaupt eine Rolle spielt. Vielleicht noch als Produkt, das über einen Broadcastchannel vermittelt wird, aber als Medium würde der Film in diesen Überlegungen wohl auch rausfliegen. Wenn man es so betrachtet, wären Theater und Film vermutlich im gleichen Boot.

Der zweite Punkt ist diese Wahrnehmung in DogVILLE. Es ist klar: Theater hat eine gewisse mediale Verfasstheit, die wahrgenommen und sofort erfasst werden kann. Nur eine kurze Anekdote: Ich saß zuhause und schaute mir - wie ich es immer machen muss - eine Theateraufzeichnung im Fernsehen an, als mein Sohn hereinkam. Es ging um eine HAMLET-Inszenierung aus Hannover und da stand einer auf der Bühne und hat nichts gesagt, und mein Sohn blieb fünf Sekunden lang neben mir stehen und sagte zu mir: »O dad, you're not watching theatre again!? «. Er hat fünf Sekunden gebraucht, um zu sehen, dass ich mir Theater im Fernsehen angeguckt habe, das hat gereicht.

Kotte: Theaterwissenschaft kennt verschiedene Zugangsweisen. Wenn Medienwissenschaftler über Theater reden, dann können sie einfach sagen: »Medien? Das ist wie ein Spitzdach«, man kann es ein bisschen verbreitern, und dann passt auch Theater darunter. Damit werden die Differenzen zwischen Theaterformen und Medienformen als weniger wichtig angesehen. Wenn man das Dach nicht erweitert, dann werden diese Differenzen als wichtig erachtet. Die Dachbildung erfolgt stets von der Medienwissenschaft aus, und deshalb gibt es überhaupt keinen Zwang, dass die Theaterwissenschaft das breitere Dach übernehmen muss. Das ist die eine Seite. Die andere Problematik: Theaterwissenschaftler verfolgen noch ganz andere Diskursstränge. Wir sind ja auch eine der Kunstwissenschaften, und wir müssen sehen, wie wir mit dem historischen Diskurs in der Musikwissenschaft und in der Kunstwissenschaft, wie wir dort - wo wir ja über 2000 Jahre fast ausgeklammert worden sind - umgehen. Das erfordert Offenheit, andere Zugangsweisen, weshalb sich Theaterwissenschaft nicht noch von selbst unter ein unpassendes Medien-Dach begeben sollte, über welchem letztendlich noch ein kommunikationstheoretisches Dach ausgebreitet wird. Diese Linie würde im Wissenschaftsdiskurs zu einer enormen Verarmung führen.

Kirchmann: Das mit dem Dach würde ich gerne aufgreifen und dann in einer kaum merklichen - Überleitung die dritte These mit ins Spiel bringen. Es gibt natürlich tatsächlich nicht nur die Dächer, die die Medienwissenschaft oder die die Wissenschaften allgemein bauen, es gibt ja auch die Dächer oder Zugehörigkeitsbestimmungen oder auch Nicht-Zugehörigkeitsbestimmungen, die die kulturelle Praxis selbst baut. Wenn ich zurückschaue in ein Segment, in dem ich mich immerhin halbwegs firm fühle, was Theaterfragen angeht, also die Epochenschwelle 1900, Eintritt in die Moderne, so tauchte doch dort vielleicht zum ersten Mal in dieser Vehemenz im Kontext der Kinodebatte, aber auch als Diskursfigur innerhalb des Theater selbst, die Frage nach dem Verhältnis Theater-Medien auf. Und da ist 
es interessant zu beobachten, dass die Photographie oder die Rotationspresse vergleichbare Debatten nicht in diesem Maße haben initiieren können. Der Film aber konnte das. Mit dem Film tritt etwas auf die historische Agenda, was offensichtlich das Theater in einem sehr viel höherem Maße motiviert und inspiriert, über sich selbst noch mal nachzudenken und sein Verhältnis zu diesem Neuen, was da kommt, zu definieren. Dafür gibt es sich sicherlich ganz viele verschiedene Gründe, Massenkultur ist eines der Schlagworte. Ganz offensichtlich verbirgt sich dahinter so etwas wie eine Problematisierung oder ein Als-problematisch-Empfinden dieses - wenn man so will - ungehindert demokratischen Zugangs zu den Medien Stichwort Reproduzierbarkeit - als den das Benjamin hinlänglich beschrieben hat.

Die Frage ist aber, ob man in dieser Debatte, die innerhalb der Filmtheorie wie innerhalb der Theatertheorie geführt wird, als der Film auf die historische Tagesordnung tritt, und die sich in kürzer werdenden Zyklen wiederholt, als das Fernsehen und die neuen Medien auftreten, ob man in dieser Debatte ein weiteres Mal analysieren sollte, was der eigentliche Hintergrund dieser jeweils rekurrierenden historischen Redekonstellationen ist, durch die sich das Theater in seinem Verhältnis zu dem jeweils Neuen befragt. Geht es da tatsächlich vordergründig um die Frage eines klassischen Paragone in Hinsicht auf Zuständigkeitsbereich usw., oder verbirgt sich in dieser Diskursfigur noch eine sehr viel weitergehende Frage, nämlich die Frage nach dem Verhältnis des Theaters zum jeweiligen Modernisierungsschub? Wenn man die Debatten um 1900 betrachtet, kann man eine konservative Linie beobachten, die eben das Theater festschreiben will als Bollwerk gegen die Zumutungen der Moderne, als Besitzstandswahrung eines bürgerlichen Kulturbegriffs gegen das proletarisch-schmuddelige Jahrmarktsmedium, das da mit fragwürdigen Stoffen die Menschheit überzieht. Vergleichbares scheint mir auch wieder aufzutauchen in den Debatten der 1950er Jahre um das Fernsehen, auch da wird wieder der kulturskeptizistische und medienkritische Impetus bemüht. Man hat sich mit dem Film jetzt arrangiert, der ist inzwischen ja auch erwachsen geworden, der kann auch irgendwie Kunst machen, aber jetzt kommt schon der nächste Bastard auf die Bühne, der nennt sich Fernsehen und damit ist der nächste $>$ Untergang des Abendlandes< eingeleitet, gegen den das Theater in Stellung gebracht wird. Daneben ist eine zweite Tendenz zu beobachten, die avantgardistische natürlich. In den Theateravantgarden geht es spätestens ab der Zäsur 1900, mit den Vorläuferjahren und -figuren, Wagner, Appia, Craig usw., natürlich immer genau um die gegenteilige Stoßrichtung. Da ist der Appell vorherrschend, dass sich das Theater dem Modernisierungsschub um 1900 anzuschließen hat, und gerade deswegen dieses Andere der Medien nicht als Entgegensetzungsfolie benutzen soll, sondern als Integrationsmechanismus. Bei Léger, bei Schlemmer usw. finden wir immer wieder den Appell, sich dem Tempo der Zeit, wie es so schön hieß, nicht zu verschließen und eben die neuen Möglichkeiten, die die sogenannten Massenmedien bieten, doch in den Kanon der theatralen Gestaltungsmöglichkeiten zu übernehmen. Das sind zwei gegenläufige Tendenzen, die man eigentlich bei jeder solcher Zäsuren beobachten kann. Also einmal das Theater als Bollwerk gegen Modernisierungstendenzen, als - ich werde jetzt sehr polemisch - Gralshüterin des Guten, Wahren, Schönen gegen die Verflüchtigungen der offensichtlich völlig wertvergessenen Medien. Auch Herr Kotte konnte sich in seinem Beitrag nicht ganz davon freisprechen, das Theater als das Andere von FORSTHAUS FALKENAU zu begreifen, was natürlich eine unzulässige Reduktion des Fernsehens ist, ohne das Fernsehen damit in irgendeiner Form verteidigen zu wollen. Die andere Linie ist wie gesagt die avantgardistische Praxis, die für Integration, für Gesamtkunstwerk, Polymodali- 
tät, Synästhesie usw. bürgt und dann die Medien immer schon als das zu Integrierende, zu Subsumierende begreift.

Was ist ihre Meinung: Gibt es diesen Hintergrund solcher Debatten, also die jeweilige Frage nach der Modernisierung? Wie stellt sich das nach wie vor sicherlich als zentrale Kunstpraxis unserer Kulturen anzusetzende Theater zu der jeweiligen Moderne, wie werden daraufhin wieder Wertkämpfe über Fragen wie »Was ist Kultur? Was ist Kunst? « etc. verhandelt? Und ist das Theater nicht ein sozusagen sehr prominentes, ich sage jetzt nicht »Medium«, sondern »Organ «, das in dieser Debatte generell bzw. stellvertretend den gesamtkulturellen Diskurs formuliert?

Kotte: Ihre historische Beschreibung stimmt. Es gab und gibt diese Ablehnungstendenzen, Ablehnung des Modernen, der Medien, wie wir überall nachlesen können, aber es handelt sich dabei stets um eine Ablehnung dieses Neuen auf der Diskursebene. Andererseits, wenn man es hinterfragt, dann sind das doch alles wunderschöne Schübe für die Befreiung von Theater in praxi. Theater wird befreit von den alten Funktionen, es muss nicht mehr alle erreichen, nicht mehr vordergründig bilden, es kann sich öfter störend einschalten. Sie haben Recht mit der Beschreibung, aber die Frage ist, ob dies nicht Befreiungsschritte gewesen sind.

Kirchmann: In the long run - natülich.

Balme: Zum einen ist einfach zu beobachten, dass sich im Zuge das 20. Jahrhunderts mit der Erfindung neuer Medien das Theater immer weiter ausdifferenziert hat. Es hat noch nie so viele verschiedene Theaterformen, Genres, Praktiken gegeben wie heute, das ist einfach so. Wenn man das Theaterleben Anfang des 21. Jahrhunderts mit dem am Ende des 19. Jahrhunderts vergleicht, dann haben wir eine viel reichhaltigere, vielfältiger Theaterkultur als damals. Das wird oft vergessen in diesen eher kulturpessimistischen Diskursen.

Das wäre der eine Punkt, der zweite Punkt ist: Wenn man das weiterdenkt, ist es eigentlich erstaunlich, wie hartnäckig sich das Theaterdispositiv - wenn man es überhaupt als Dispositiv bezeichnen kann - hält und benutzt wird von neuen Medien als Messinstrument. Ich habe heute den Vortrag von Julia Glesner gehört über Theater und Internet. Weil diese Arbeit bei mir entstanden ist, war sie mir relativ vertraut, aber es ist schon erstaunlich, dass - kaum ist dieses Medium Internet erfunden worden - schon versucht wird, Theater darin zu realisieren. Hat man nichts Besseres zu tun mit diesem Medium als Theater zu spielen? Das ist schon faszinierend. Und das sagt auch etwas aus über die Wirkungsmächtigkeit unseres Dispositivs, also jetzt eher in einem kulturoptimistischen Sinne gesprochen.

Haß: Ich möchte darauf hinaus, dass diese Schwellen - sagen wir mal 1900 und das Ende des 20. Jahrhunderts - sich wirklich sehr stark voneinander unterscheiden, und der erste analytische Schritt darin bestehen müsste, die Schwelle als solche auch zu charakterisieren. Es kommt mir so vor, dass das Auftreten der visuellen technischen Medien Anfang des 20. Jahrhunderts ein großes Feld der Reflexion und der reflexiven Durchdringung, also der visuellen optischen Verfasstheit von Gesellschaften im 20. Jahrhundert geleistet hat und das, was in diesem Bereich geleistet worden ist, angekommen ist. Sehr produktiv zum Beispiel im Theater der 1980er und 1990er Jahre, das angefangen hat, sich anhand von Videoprojektionen usw. nach der eigenen bildlichen Verfasstheit der Szene zu fragen. Das ist ein riesiger Komplex, in dem dann auffällt, wo Verwandtschaften bestehen zwischen dem Theaterraum, der räumlichen Anordnung, dem Kino usw. Ich denke - und das finde ich gerade vor dem Hintergrund, dass ich mich seit längerem auch mit der Entwicklung in den sogenannten Bildwissenschaften befasse -, dass die 1990er Jahre oder das, was auf der Grundlage der Digitalisierung eingeleitet worden ist, 
davon zu unterscheiden ist. Denn diese Schwellenzeit steht noch aus, sodass wir sie neu charakterisieren müssen, bzw. die ganze Debatte, die darüber im Gange ist, wo wir die klassische dichotomische Verfasstheit des Optischen verlassen, berücksichtigen müssen. Ich nenne als Beispiel die riesige Diskussion, die in der Bildwissenschaft anhebt und die auf der Feststellung eines Zusammenbruchs bestimmter klassischer Oppositionen beruht. Zum Beispiel kann heute niemand das Internet benutzen, ohne nicht zugleich auch Sender und Empfänger in einem zu sein - der Zusammenbruch dieser Relation ist ein solches Beispiel.

In den Diskussionen dazu bildet sich allmählich die Tendenz heraus zu unterscheiden zwischen Charakteristika der visuellen Kultur als solcher, in der alles, dessen man ansichtig werden kann, auch gegenstandswürdig ist, und eben dem Bild, durchaus in einem klassischen Dispositiv des Bildes. Anhand dieses Beispiels möchte ich nur darauf hinweisen, für wie wichtig ich es halte, die Schwellenzeit selbst zu charakterisieren und selbst als das eigentliche Problem anzusehen.

Kirchmann: Ich würde den Zusammenhang ein bisschen anders formulieren als Sie es getan haben. Mein Eindruck ist derjenige, dass das, was Sie als die klassischen Dichotomien beschrieben haben, dass diese Dichotomien eigentlich immer erst nach medientechnologischen Innovationen als Dichotomien sichtbar werden oder als solche in den Diskurs eintreten. Mir will es so scheinen, dass das Theater den Begriff des Körpers in der konzeptuellen Aufladung, den dieser Begriff in der Moderne erfahren hat, eigentlich erst als eigenen Diskursbestandteil integriert hat in dem Moment, in dem durch die sogenannten Medientechnologien etwas auftaucht, das als das Andere des Körpers begriffen wird. Genauso die Frage nach dem Bild. Erst in dem Moment, in dem die - wie wir alle wissen - extrem hypostasierte Referenzlosigkeit der digitalen Bildgenerierung als Matrix vorhanden ist, wird retrospektiv etwas konstruiert, nämlich »Bild «, das dann eben als das Andere gesetzt wird, das jetzt historisch bedroht ist. Und das wird dann auf einmal zum Leitbegriff und auch zu einer Selbstverständigungs- und Selbstbeschreibungsformel. Das kann man auch im Bereich der Filmwissenschaft sehr klar beobachten: In dem Moment, wo das Jenseits des photochemischen Bildes auftaucht, wird das Ganze überhaupt erst zu einer Wertkategorie. Vorher ist es sozusagen mehr oder weniger unhinterfragte Voraussetzung des Filmischen. Das heißt, dass genau in diesen Schwellen- und Umbruchsituationen überhaupt erst die Kategorien und die Begriffe entstehen, mit Hilfe derer sich retrospektiv einer Zugehörigkeit zu einer bestimmten historischen Linie versichert wird. Das Theater ist dann eben nicht mehr der Ort der Bildung, der Literatur etc., sondern es ist dann auf einmal der Ort des Körpers, der Film ist dann auf einmal der Ort des analogen Bildes. Das ist alles erst möglich an dem Punkt, an dem eine Intervention durch das jeweils Neue überhaupt droht, diese Kategorien obsolet werden zu lassen. Im Grunde sind das retrospektive Konstruktionen.

Rajewsky: Da würde ich vollkommen zustimmen, und das ist ja auch ein interessanter Punkt, an dem man ganz gut Entwicklungen sieht, wie dann solche Einzelmedien wahrgenommen werden. Der Film ist sicherlich ein wunderbares Beispiel. Jetzt wird das Digitale noch als das Andere wahrgenommen, aber wir befinden uns genau auf der angesprochenen Schwellensituation; in ein paar Jahren wird das Digitale sicherlich vollkommen selbstverständlich zum Film als >Einzelmedium< gehören. Genauso lassen sich Phänomene wie die Klangkunst anführen. Klangkunst wurde anfänglich von den Künstlern selbst ganz dezidiert als Kombination unterschiedlicher Medien gesetzt und eingefordert, gerade um die Konventionalität von medialen Grenzziehungen zu reflektieren; heute wird sie dagegen als 
eine eigenständige Mediengattung wahrgenommen. Und mit dem Theater ist es natürlich genau das Gleiche, das Theater ist per se plurimedial und kann diese Plurimedialität natürlich immer weiter ausbauen, immer wieder neue Elemente mit hereinnehmen.

Ich wollte noch eine andere Sache sagen, weil hier nun - obwohl wir uns ja eigentlich fast einig waren - weiterhin einerseits von >dem Theater< und andererseits von >den Medien< gesprochen wird. Ich möchte einfach noch mal ganz klar sagen: Ich finde es wichtig und würde stark machen wollen, dass jeder Kommunikation - oder auch jeder Aisthetisierung - Medialität unterliegt. Jedes Zeichen braucht ein Medium, ist medial bedingt. Ich glaube, dahinter kommen wir nicht zurück in der Debatte, auch wenn alles diskursiv bedingt sein mag. Und dementsprechend sind intermediale Phänomene beschaffen - schon eines der ersten sehr schönen Beispiele ist für mich Platons PHAIDROS mit der Debatte um Mündlichkeit/Schriftlichkeit; das ist eine intermediale Fragestellung. Oder dann kommt das neue Trägermedium des Buches dazu, das auf einer anderen Ebene, nämlich intermedial zwischen Buchdruck und Handschrift, angesiedelt ist. Usw. Es sind also durchaus ganz alte Phänomene, die wir hier verhandeln, wenn sich natürlich durch die elektronischen, digitalen Medien auch neue Fragestellungen ergeben und alles vielleicht ein bisschen komplexer wird.

$\boldsymbol{H a} \boldsymbol{\beta}$ : Ich denke nicht, dass man das in dieser Allgemeinheit so ausdrücken kann, dass das neu hinzutretende Phänomen überhaupt erst bewusst macht, was ich jetzt klassische Dichotomien genannt habe. Sie haben wieder ein Beispiel gebracht, diese Verwurzeltheit sowohl in der antiken Konstellation als auch in der europäischen Neuzeit, und dass sich das immer so begriffen hat, dass die ganze Entwicklung sozusagen im dichotomischen Denkstil ausgearbeitet wurde. Das, meine ich, ist ja nicht ein Effekt, der hinzutretend erzeugt wird, sondern es liegt so vor.

Und insofern ist tatsächlich für die Entwicklung ab den 1990er Jahren zu bedenken, inwiefern diese Entwicklung eben diese lange Tradition der dichotomischen Verfasstheit von Reflektionsprozessen und -artefakten und kulturellen Umgebungen angreift.

Kirchmann: Völlig d'accord, ich habe ja auch nicht gesagt, dass es nicht immer schon dichotomisch strukturiert gewesen ist. Worauf ich nur hinweisen wollte ist eben, dass die semantische Aufladung dessen, was als vordergründiger Wesenskern eines Mediums respektive Theaters begriffen wird, sich verändert unter der Intervention des jeweils Neuen. Und das, was als das scheinbar Andere oder radikal Andere begriffen wird, dann zur eigenen ontologischen Fundierung benutzt wird. Dies sind dann eben Begriffe wie Körper, Bild, Analogizität usw.

Kattenbelt: Ich denke, ein wichtiges Merkmal vieler zeitgenössischer Theateraufführungen - soweit sie neue Medientechnologien verwenden - ist, dass meistens in dieser Verwendung auch eine Darstellungsstrategie gewählt wird, die gar nicht übereinstimmt mit den Darstellungsstrategien, wie sie dominant sind in denjenigen Medien, aus denen das Theater sie entnommen hat. Und das bedeutet, dass das Theater in der Verwendung dieser neuen Medien eigentlich immer wieder entdeckt, dass seine Stärke auch darin liegt, auf der Bühne wirklich die neuen Technologien zu inszenieren. Die Bilder und die Töne dieser neuen Technologien werden also nicht nur vorgeführt, sondern gleichzeitig auch aufgeführt und damit reflexiv verwendet. Und ich denke, dass unser Blick auf die Geschichte des Theaters des 20. Jahrhunderts noch viel zu logozentrisch ist, dass die Bekümmernis um das Bild im Theater viel größer ist, als es in den Diskursen über das Theater anerkannt wurde. 
Kirchmann: Vielleicht nur ganz kurz dazu, weil es ja auch eine wiederkehrende Figur ist: die Festschreibung des Theaters als eines Ortes, der befähigt ist, jene Reflexionsleistung zu tätigen, die - das ist ja implizit enthalten - das jeweilige Referenzmedium selbst nicht zu leisten imstande sei. Dem steht natürlich eine ganz lange Tradition von Selbstreflexion in den jeweiligen Medien gegenüber. Wenn man sich heute eine durchschnittliche amerikanische TV-Serie anschaut, wird da in einem Maße Selbstreflexion und Medienreflexion betrieben, dass mancher Heros der Avantgarde der Jahrhundertschwelle vor Neid erblassen könnte.

Ich wehre mich einfach gegen diese Hypostasierung des Theaters als eines Ortes, der den Medien jetzt mal zeigt, was eigentlich Sache ist. Das machen die Medien schon auch selbst, das wäre in dem Sinne kein Privileg, das ich dem Theater einzuräumen bereit wäre. Es scheint ganz offensichtlich eine Funktion zu sein, die das Theater im Laufe des 20. Jahrhunderts hinzugewonnen hat, aber das ist natürlich eingebunden in die generelle Thematisierung von medialen Verhältnissen, die mit dem Anbruch der Moderne eben zum ästhetischen Programm überhaupt wird.

Balme: Das Theater hat sich schon immer Gedanken über sich selbst gemacht.

Kirchmann: Über sich selbst, aber nicht über die anderen.

Balme: Lesen Sie irgendeinen Prolog eines Stücks aus der frühen Neuzeit, in jedem Prolog kommt irgendeine Reflexion über die Grundsituation des Theaters vor. Das ist das beste Beispiel, dass Theater ein Medium ist. Anscheinend gehört es zu den Medien, zumindest zu den darstellenden, den fiktionalen, dazu, dass sie metareflexiv funktionieren oder zumindest eine Grundtendenz dazu haben.

Kirchmann: Aber das Argument von Herrn Kattenbelt war ja zu sagen, dass das Theater nicht der Ort ist, der nur über sich selbst reflektieren kann, sondern dass es ein privilegierter Ort ist, um über Medien zu reflektieren. Die gleiche Argumentationsfigur haben wir in der Medienkunst. Da heißt es ja auch immer: Diese Internetinstallationen sind der Ort, an dem der - offenbar immer als halb tumb, unterbewusst vorausgesetzte - Mediengebrauch des herkömmlichen Mediennutzers jetzt mal reflexiv aufgearbeitet wird. Das finde ich problematisch.

Kattenbelt: Das haben Internet und Theater miteinander gemeinsam, denke ich.

Kirchmann: Ja, aber das machen Film und Fernsehen ja auch schon endlos lange. Und es ist inzwischen selbst im Mainstream-Fernsehen angekommen, dies zu tun. Vielleicht können wir uns einfach dahingehend verständigen - und das wäre dann natürlich die klassische Überschneidung von Funktionssystem Kunst und von Funktionssystem Medien - dass also die Kunst der Ort ist, um genau diese Reflexionsleistung zu tätigen, und natürlich kann jedes Medium in diesem Sinne künstlerisch moderne Praxis werden, indem es seine eigenen Konstituenten reflektiert - oder die der scheinbar anderen.

Kattenbelt: Aber die Beispiele, die ich etwa von amerikanischem Fernsehen kenne, in denen das Fernsehen mit seinen eigenen Konventionen spielt, sind nur unter der Voraussetzung möglich, dass man völlig anerkennt, dass Television ein Bestandteil der Wirklichkeit geworden ist, und das, denke ich, hat nicht die selbe Reflexivität wie zum Beispiel die historischen Avantgarde.

Rajewsky: Ich möchte noch einmal zurückkommen auf das, was Sie vorher sagten, dass diese Diskurse immer dann hervortreten, wenn etwas Neues aufkommt. Dabei nimmt der Computer aus meiner Sicht eine ganz besondere Stellung ein, weil er die Materialität entzieht. Und mein Eindruck ist immer, dass das Nachdenken über Medialität ganz stark mit einem Nachdenken über die Materialität der Medien zusammenhängt. Zum Beispiel wird die Materialität der Schrift überhaupt 
erst wirklich diskutiert seit es den Computer gibt, vorher war das nicht so sehr ein Thema. Und der Computer ist hier interessant, indem er eben die Materialität auflöst, übrigens auch Grenzziehungen zwischen Medien auflöst. Beim Computer kann man im Grunde nur noch von virtueller Intermedialität sprechen, eben ohne die Ebene der Materialität, und darüber müsste die Intermedialitätsforschung eigentlich sehr viel genauer nachdenken, dieser Aspekt wird kaum reflektiert. Es wird immer gesagt, der Computer könne mediale Differenzen auflösen, aber gemeinhin ohne die Materialitäten mitzudenken, und was das eigentlich bedeutet, ist ein offenes Forschungsfeld. [...]

Die Herausgeber: Passend zum Verweis auf offene Forschungsfelder brach an dieser Stelle die Tonaufzeichnung ab, das »Letzte Band « war an sein Ende gekommen. An der konkreten »Materialität« der Medien scheitert damit der Abdruck des vierten und letzten Diskussionsthemas zu der Frage, wie sich das Verhältnis von Theater- und Medienwissenschaft institutionell entwickeln solle, welche Kooperationen, Integrationen, Usurpationen wünschenswert oder zu fürchten seien.

Dabei könnte es durchaus als konsequent erscheinen, dass 1.) ausgerechnet der institutionelle Aspekt der Podiumsdiskussion dem »Medien-Material« zum Opfer fiel, 2.) die Publikation damit auch an dieser Stelle in der wissenschaftstheoretischen Auseinandersetzung mit »Theater und Medien « verbleibt und die wissenschaftspolitischen Implikationen andernorts verhandelt werden müssen - und 3.) dass sich das »Live-Event « des Kongresses im Erlanger Markgrafentheater zumindest an seinem Ende als ebenso ephemer erweist wie das Theater selbst. 
ANHANG 



\section{REGISTER}

Das Register umfasst Namen und Titel, die in den Beiträgen im Fließtext, nicht jedoch als Literaturnachweise in Klammern oder Fußnoten, erwähnt werden. Die Einträge sind sortiert nach

1.) Gruppen/Bands/Companys,

2.) Personen (Künstler/-innen, Wissenschaftler/-innen etc.) und

3.) Titel von Büchern, Filmen, Inszenierungen etc., jeweils in der Form (Originaltitel oder deutsche Übersetzung), die von den Autor/-innen benutzt wurde.

\section{Gruppen}

400asa

Alliance Theatre Company

ArchitekTanz

Ars Electronica Futurelab

Atlas Group

Ballets Suédois

Blast Theory

Chameleons

Dumb type

Einstürzende Neubauten

Forsythe Company

Gob Squad

Hamnet Players

La Fura dels baus

La Pocha Nostra

Merlin Crew

Mixed Reality Lab

Performance Group

Plaintext Players

Re:Group

Rimini Protokoll 386, 439f, 445, 448ff

Rolling Stones

Showcase Beat Le Mot

TgSTAN

The Doors

The Finalists

The Rolling Stones

The Who

Trisha Brown Compagnie

395,396

320

303,305

397

486

395,397

397

347

Wooster Group

364, 375, 409ff,

417ff, 421f, 447

\section{Personen}

Abbas, Geoff

419

Abramović, Marina

$378 \mathrm{f}$

Adorno, Theodor W. 187, 251ff, 404

Aeschylus

205

Agamben, Giorgio

Ahlen, Leopold

95,405

Alberti, Leon Battista

Almereyda, Michael

46f, 80

Almodóvar, Pedro

212

$223 \mathrm{f}$

Ammer, Andreas

270

Andersen, Hans Christian $\quad 389$

Anger, Kenneth

189

Antoine, André

495

238

Antoniadis, Prodromos

371,555

Appia, Adolphe

426

Aragon, Louis

$305 \mathrm{f}$

Ardaí, Petra

205

Aristophanes

Aristoteles

45, 212, 288,

296, 446, 531

Arnheim, Rudolf

226, 265, 269

Arnold, Dorothea

$182 \mathrm{f}$

467

Aronov, Dimitri

260

Arsenijevic, Stefan

$371,373,377$

Artaud, Antonin

Assmann, Jan

Auslander, Philip

Axjonow, Iwan

303f, 306

148

Azari, Fedele

136

Bacon, Francis 


\begin{tabular}{|c|c|c|c|}
\hline Balanchine, George & 470 & Bougard, Julie & 364 \\
\hline Balitzki, Jürgen & 391 & Boulez, Pierre & 337 \\
\hline Balk, Claudia & $109 \mathrm{f}$ & Bourdieu, Pierre & 187 \\
\hline Balme, Christopher & $60,71,551$ & Boyle, Mark & 470 \\
\hline Bals, Mieke & 57 & Brandl, Peter & 469 \\
\hline Bardot, Brigitte & 403 & Brandstetter, Gabriele & 100 \\
\hline Bärfuß, Lukas & 193 & Brătan, Laurențiu & 256 \\
\hline Barkey, Grace Ellen & 447 & Braun, Alfred & 266 \\
\hline Barney, Matthew & $171 \mathrm{ff}$ & Brecher, Egon & 494 \\
\hline Barthes, Roland & $\begin{array}{r}49,91,94 \\
113,223,435\end{array}$ & \multirow[t]{3}{*}{ Brecht, Bertolt } & $\begin{array}{r}110,130,143,154, \\
179,264,266 \mathrm{ff}, 304\end{array}$ \\
\hline Baudrillard, Jean & $\begin{array}{r}192 \mathrm{f}, 375 \\
462,507\end{array}$ & & $\begin{array}{r}357 \mathrm{ff}, 367,369 \text {, } \\
371374,3104\end{array}$ \\
\hline Bauersima, Igor & 193 & & $446 f, 450$ \\
\hline Baumann, Catja & $195 \mathrm{f}$ & Bronnen, Arnolt & 266,268 \\
\hline Baumbauer, Frank & 401,405 & Brook, Peter & 303,319 \\
\hline Bausch, Pina & 547 & Brown, Gordon & 521 \\
\hline Baxter, Anne & 220 & Brown, James & 433 \\
\hline Bazin, André & 222,304 & Brunelleschi, Filippo & 46 \\
\hline Becker, Constanze & 238 & Bukowski, Oliver & 193 \\
\hline Beckett, Samuel & $161 \mathrm{ff}, 269$ & Bulgakow, Michail & 31 \\
\hline Beer-Hofmann, Richard & 299 & \multirow[t]{2}{*}{ Buñuel, Luis } & $53 f, 188,402$, \\
\hline Beethoven, Ludwig van & 351,354 & & $409,411 \mathrm{ff}$ \\
\hline Behrens, Constanze & 196 & Burckhardt, Barbara & 434 \\
\hline Belmont, Véra & 231 & Burkhard, Gedeon & 241 \\
\hline Belschner, Thorsten & 462 & Burns, Adam & 467 \\
\hline Belschner, Torsten & 460,462 & Burns, Elizabeth & 260 \\
\hline Beltrametti, Silvano & 37 & Burton, Richard & 418 \\
\hline Benayoun, Maurice & 460 & Busch, Paul Vincenz & 498 \\
\hline Benesch, Felix & 196 & Bush, George W. & 505 \\
\hline Benjamin, Walter & $146,226,274 f$ & Bußmann, Philip & 309,343 \\
\hline & $333,341,361$, & Butor, Michel & $167 f$ \\
\hline & $367,378,555$ & Byron, George Gordon & 266 \\
\hline Bentham, Jeremy & 233,384 & Cacoyannis, Michael & $211,214 f$ \\
\hline Bentley, Eric & 552 & Cage, John & 192 \\
\hline Bergson, Henri & 337 & Calderón de la Barca, & \\
\hline Berkeley, George & 165 & Don Pedro & $67,73,75 \mathrm{ff}$ \\
\hline Berlau, Ruth & 110 & Callas, Maria & 215 \\
\hline Berlioz, Louis Hector & 274 & Campe, Rüdiger & 295 \\
\hline Bernhard, Thomas & 86 & Canudo, Riciotto & 425 \\
\hline Bernhardt, Sarah & 495 & Carlson, Marvin & 57 \\
\hline Bidou, Henry & 496 & Caroll, Lewis & 426 \\
\hline Blair, Tony & 521 & Carrington, Leonora & 401f, 404f \\
\hline Blankenburg, Julia & 464 & Caspersen, Dana & 309 \\
\hline Boehm, Gottfried & $102 \mathrm{f}, 105$ & Cassavetes, John & $223 f$ \\
\hline Böhm, Arne & 462 & Casseri, Giulio & 285 \\
\hline Bolter, Jay & 122 & Cassiers, Guy & $130,304,425 \mathrm{ff}$ \\
\hline Bolter, Jay David & $128 \mathrm{f}$ & Castil-Blaze & 274 \\
\hline Booth, Susan & 504 & Castorf, Frank & $0,375 \mathrm{ff}, 383 \mathrm{f}$ \\
\hline Borzik, Rolf & 547 & $389 \mathrm{ff}, 3$ & $396 \mathrm{ff}, 431,447$ \\
\hline
\end{tabular}


Cézanne, Paul

Cherri, Ali

Chlebnikov, Viktor Vladimirovič

Christa Sommerer

Christie, Ian

Cicero, Marcus Tullius

Clair, René

Clémenti, Pierre

Cocteau, Jean

Cohen, Bruno

Coleman, Allan D.

Cortona, Pietro da

Craig, Edward Gordon

Crary, Jonathan

Crommelynck, Fernand

Cronenberg, David

Cukor, George

Czerwinski, Albert

Dafoe, Willem

Dalí, Salvador

Dankwart, Gesine

Darwin, Charles

Davis, Bette

de Man, Paul

de Mello, Simone

Dearing, Sir Ron

Debord, Guy

Debray, Régis

Deflorin, Elmar

Degas, Edgar

deLahunta, Scott

Delerue, George

Deleuze, Gilles

Delluc, Louis

Deneuve, Catherine

Depoorters, Kris

Derrida, Jacques

Descartes, René

Diamond, Liz

Diderot, Denis

Dixon, Steve

Döblin, Alfred

Dostoevskij, Fëdor

Michajlovič

Drumbl, Johann

Dubin, Véronique
105

452

143

$459 \mathrm{f}$

$215 \mathrm{f}$

295

188

412

461

463

109

285

304, 371,

531,555

69

149

$231 \mathrm{f}$

$220 \mathrm{ff}$

273

306, 412f, 421

402

193

34

220

88

474

521

192, 255, 442

$57,60 \mathrm{ff}$

37

495

469

401, $403 \mathrm{f}$

$176,255,375$

425,427

412

441

211, 333, 373,

448,454

165,288 ,

289, 290

410

35,384

472

264, 267

$364,384,389$
Duchamp, Marcel

Düffel, John van

Dulac, Germaine

162,188

439

$425 \mathrm{f}$

Dumitrescu, Florian

256

$110 \mathrm{f}$

153

Eck, Adam von

Eco, Umberto

Edgerton, Samuel

Edison, Thomas A.

89, 201, 307

Ehrenberg, Alain

Eisenstein, Sergej M.

Ekhof, Konrad

Elsner, Monika

Elßler, Fanny

Elzenheimer, Regine

Eminem

Endruweit, Astrid

Engel, Fritz

Engell, Lorenz

Epstein, Jean

Ernst, Max

Euripides

Eysler, Edmund

Féral, Josette

Fiebach, Joachim

Findlay, Iver

Finley, Karen

Fischer-Lichte, Erika

Flesch, Hans

Fliakos, Ari

Flusser, Vilém

Fohrmann, Jürgen

Ford, John

Foreman, Richard

Förster, Lutz

Forsythe, Billy

Forsythe, William

Fosse, Jon

Foucault, Michel

France, Anatole

Freud, Siegmund

Fuchs, Elinor

Fuery, Patrick
47

364

375

130, 216,

225, $391 \mathrm{f}$

290

201

275

343

435

364

268

546

146

$162,420 \mathrm{f}$

205, 214ff, 266,

409ff, 413, 415

497

304

255

419

$504 \mathrm{ff}$

$68,70,72$,

118, 233, 255,

260, 341, 378,

$487,531 \mathrm{f}$

265

413, $419 f$

89, 191

114

404

$410 \mathrm{f}$

547

421

89ff, 95f, 309ff,

315,317

193

46, 51, 95, 233,

$317,411,414$

495

414

304

172 


Furttenbach, Joseph
Furuhashi, Teiji
Gagarin, Juri
Gance, Abel
Garton, Andrew
Gautier, Théophile
Geerke, Hartmut
Gendera, Ottmar
George, Heinrich
Gert, Valeska
Ghezzo, Dinu
Gielgud, Sir John
Gilbert, John
Giotto di Bondone
Girard, René
Girardet, Christoph
Girshausen, Theo
Gleich, Michael
Glesner, Julia
Gluck, Christoph Willibald
$\quad$ Ritter von

Godard, Jean-Luc

Goebbels, Heiner 188, 403ff, 413 267,447

Goethe, Johann Wolfgang von

$34,38,213$,

371,446

Goetz, Rainald 192

Goffman, Erving 229 465

Gold, Michael 419

Gold, Sam Louise

Golonka, Wanda 320ff, 325, 364

Gómez-Peňa, Guillermo

Goodman, Nelson 505

109

Gorki, Maxim 269

Gosch, Jürgen

Grant, Michael

Grau, Oliver

38,48

233

461

Gray, Spalding 421

Greenaway, Peter

130,230

Greengrass, Paul

501

276

304

Groot Nibbelink, Liesbeth

Gropius, Walter

$382,384 \mathrm{f}$

Großmann-Vendrey, Susanne 263

Grotowski, Jerzy

$372 \mathrm{ff}, 377 \mathrm{f}$,

417, $419 \mathrm{ff}$

Gruchy, Mic

Gründgens, Gustaf 268 239, 266,

Guattari, Felix

Guitry, Lucien

Guitry, Sacha

Gumbrecht, Hans Ulrich

Haarmann, Anke

Habermas, Jürgen

Haffner, Nick

Hajdu, Georg

Halbwachs, Maurice

Haller, Hans-Peter

Händel, Georg Friedrich

Handke, Peter

Harding, Joanne

Harris, Stuart

Hartley, Joanne

$\mathrm{Ha}$, Ulrike

Hauptmann, Carl

Hauptmann, Gerhart

Haverkamp, Anselm

Hawke, Ethan

Hawks, Howard

Hay, Alex

Hebbel, Christian Friedrich

Heeg, Günther

Hegedüs, Agnes

Hegemann, Carl

Heidegger, Martin

Heider, Fritz

Heitkamp, Dieter

Hendrix, Jimi

Hentschläger, Kurt

Herrmann, Max

Hershey, Barbara

Hervé, Jean

Heyme, Hansgünther

Hickethier, Knut

Higgins, Dick

Hill, Aaron

Hilling, Anja

Hindemith, Paul

Hinterberger, Thilo

Hippokrates

Hitchcock, Alfred

Hochhuth, Rolf

Hoff, Peter

Hoffmann, Melchior

Hoffmann, Stefan

Hofmannsthal, Hugo von

Homer

$122,128 \mathrm{f}$

Hoogstraeten, Samuel van

Grusin, Richard

375

495

495

71,76

286

377

311

474

62

342

289

59,192

472

$480 \mathrm{f}$

472

264, 266

293

212

404

470

266

326

461, 464

193, 376, 383

$359,361,363$

470

411

404

450

195

464

296, 403 
Horkheimer, Max

Horsley, Jake

Howes, Libby

Hrvatin, Emil

Hübchen, Henry

Huber, Jörg

Hulfeld, Stefan

Huppert, Isabelle

Husserl, Edmund

Ibsen, Henrik

Imdahl, Max

Indiana, Gary

Ingres, Dominique

Irons, Jeremy

Jakobson, Roman

Jancsó, Miklós

Janin, Jules

Jannings, Jörg

Jans, Erwin

Jarmusch, Jim

Jelinek, Elfriede

Jessner, Leopold

Jung, Jean- François

Kaegi, Stefan

Kafka, Franz

Kahn, Oliver

Kaiser, Georg

Kaiser, Paul

Kandinsky, Wassily

Kane, Sarah

Kant, Immanuel

Kantor, Tadeusz

Kästner, Erich

Kater, Firtz

Kato, Hirokazu

Kattenbelt, Chiel

Kaufman, Michail

Kendall, Thomas

Kerkhoven, Marianne van

Kern, David

Kessel, Joseph

Kidman, Nicole

Kierkegaard, Søren

Kilian, Jens

Kimmig, Stefan

Kipphardt, Heinar

Kirby, Michael

Kittler, Friedrich

Klaus, Händl
404

183

421

$365 f$

390

347

531,533

48

337

$266,390,396 f$

$17,105 \mathrm{f}$

504

206

232

$142,147,212$

211f, 215

$273 \mathrm{ff}$

267

$304 \mathrm{f}$

257

52ff, 56, $401 \mathrm{f}$

266

364

$386,445,448$,

450,453

295, 299ff

37

266

312

129f, 188

320ff, 326

$86,166,453$

377

269

193

469

307, 559

156

313

307

317

414

180,230

$200 \mathrm{f}$

401

439

450

421

88

193
Kleist, Heinrich von

266

Klucis, Gustav

151,152

Kluge, Alexander

247ff, 353, 450

Knilli, Friedrich

263

Kogan, Raquel

466

Kolbe, Corina

432

$329 \mathrm{f}$

Kolesch, Doris

Kondek, Chris

$357,364 \mathrm{ff}$

Kongerød, Desireé

469

330f, $333 \mathrm{f}$

Kott, Jan

377

Kotte, Andreas

550,555

Krabiel, Klaus-Dieter

359,362

Krämer, Sybille

69f, 78,

$120,122 \mathrm{f}$

Kreuder, Friedemann

62

439

184

343

265, 270

Krug, Hans-Jürgen

Kühl, Christiane

Kurz-Bernardon, Joseph

Felix von

$364 \mathrm{f}$

35

La Cava, Gregory

219f, 224

LaBute, Neil

504

Lacan, Jacques

Landsberg, Alison

$157,166,378$

Lang, Franciscus

172

$286 \mathrm{ff}$

Lang, Fritz

$403 \mathrm{f}$

Langheinrich, Ulf $\quad 466$

Langhoff, Lukas $\quad 196$

Lauwers, Jan 130

Le Grice, Josephine $\quad 465$

LeCompte, Elisabeth $\quad$ 409ff, 417ff

Léger, Fernand

188,555

Lehmann, Hans-Thies 307, 531, 533

Leiris, Michel

Lenz, Jakob

Michael Reinhold

379

338

Leonhard, Joachim-Felix

264

Lepage, Robert

375

Leschke, Rainer

Lessing, Gotthold

Ephraim

546,550

101ff, 111,

113f, 531

Leyde, Emil

510,513

$361,364 f$

496

469 
Lindström, Inga

Lintermann, Bernd

Linz, Rainer

Littlewood, Joan

Loher, Dea

Lorca, Federico Garcia

Lösch, Volker

Louis XIV

Lubitsch, Ernst

Luhmann, Niklas

$89,114,120,252$,
$372,375,549$

Luhrmann, Baz

Lynch, David

Lyotard, Jean-François

Lysès, Charlotte

Machover, Tod

Maier, Tracy Kai

Mainka, Jörg

Maistre, François

Malevič, Kazimir S.

Mankiewicz, Joseph L.

Mann, Michael

Mann, Thomas

Mannoni, Maud

Marceau, Sophie

Marées, Hans von

Marey, Etienne-Jules

Marinetti, Filippo Tommaso

Marks, Laura

Marx, Peter

Masafret, Martin

Masi, Ines

Masnata, Pino

Matschoß, Thomas

Maxwell, Richard

Mayenburg, Marius von

McKinnon, Kenneth

McLuhan, Marshall

McManus, Thomas

Medek, Tilo

Mejerchold, Vsevolod

Mendelsohn, M. Felix

Mendelssohn, Moses

Merleau-Ponty, Maurice

Mersch, Dieter

Mesguich, Daniel

Meyer, Petra Maria

Meyerhold, Vsevolod E.
467

521

193

390

$179,181 \mathrm{ff}$

410

230

188

86,95

495

473

315

343,345

413

$142 \mathrm{f}$

220f, 224

191

439

454

231

$17,99,104 \mathrm{ff}$

312

$133 \mathrm{ff}$

172

62

37

134

135

196

383

193

215

68,187 ,

364f, 546ff

311

364

371

264

446

59f, 106

$85 f, 118,120$

454

59

35,148
Michalzik, Peter

435

Mignonneau, Laurent

$459 \mathrm{f}$

Millet, Jean-François

412

Minetti, Bernard

364

Mitulescu, Cătălin

256

Moholy-Nagy, Lászlo

188

Moissi, Alexander

293, 295, 299ff

Molderings, Herbert

Molière, Jean-Baptiste

Poquelin

Moll, Georgia

Monca, Georges

Monet, Claude

146

Monteverdi, Claudio

231, 297, 495

404

496

495

211,213

Morales, Victor

Moravia, Alberto

364,366

403

206

$223 \mathrm{f}$

Moreau, Yolande

397

396

$206 f$

Mounet-Sully, Jean

211,213

Amadeus

452

$322 \mathrm{f}$

Mueller, Anne

Mühl-Benninghaus, Wolfgang

494

Müller, Heiner

48, 95, 267, 364, 390, 394, 447

Müller, Jürgen E.

$329 \mathrm{f}$

Müller, Matthias

225

201

256, 260

Mungiu, Cristian

153

472

Murphy, Paul

34

483

474

Naugle, Lisa

248,252

Negt, Oskar

Nelson, Anne

504

Nestroy, Johann

35,497

$383 \mathrm{ff}$

401f

Neuwirth, Olga

31,40

$340 \mathrm{ff}$

Nono, Luigi

37,277

Novalis

469,552

ier, Klaus

472

504

Orchard, Rob

230 
Othello

Paech, Joachim

Paik, Nam June

Palance, Jack

Pam, Andrew

Panofsky, Erwin

Paracelsus

Pasolini, Pier Paolo

Pavis, Patrice

Peirce, Charles S.

Peisl, Nicole

Peri, Jacopo

Perloff, Carey

Petipa, Marius

Pfister, Manfred

Piano, Renzo

Piccoli, Michel

Pilcher, Rosamunde

Pilz, Dirk

Pinthus, Kurt

Piscator, Erwin

Pitt, Hermann

Plachetka, Karina

Platel, Alain

Platon

Plessner, Helmuth

Plewe, Daniela Alina

Pohl-Meiser, Viktoria

Pollesch, René

Ponton, Anita

Popova, Liubov

Porte, Gilles

Porter, Cole

Porumboiu, Corneliu

Poussin, Nicolas

Pozzo, Andrea

Praxmarer, Robert

Primavesi, Patrick

Prince, Charles

Proust, Marcel

Pucher, Stefan

Pudovkin, Vsevolod

Puhlmann, Albrecht

Puiu, Cristi

Pulvermacher, Carla

Purcell, Henry

Quincey, Thomas de

Quintilianus, Marcus Fabius 88, $295 f$

49, 234, 250

192

403

467

226, 382

60

207, 211, 215

371

$248,250,252 \mathrm{f}$

317

213

505

276

188

340

403

36

182

265,267

$375,382,385$,

494, 499

38

238

130

45,558

378,484

461

497

196, 383

472

$148 \mathrm{f}$

$223 \mathrm{f}$

153

256

51

48

469

314

$495 \mathrm{f}$

$167,425 \mathrm{ff}$

237, 364,

431f, 434ff

225

354

$256 \mathrm{f}$

470

121

379
Raabke, Tilman

401f, 405
Raad, Walid

Rabal, Francisco

445, 450f, 453

Racine, Jean

Raeney, Mark

Rajewsky, Irina

Rajewsky, Irina O.

Ray, Man

Raynal, Paul

Reaney, Mark

Rebentisch, Juliane

Reed, Wendy

Reich, Hermann

Renoir, Auguste

Renoir, Jean

Reuther, Carola

Ricci, Giulio

Riccoboni, Francesco

Richter, Falk

Richter, Hans

Rifkin, Jeremy

Rijnders, Gerardjan

Rimbaud, Arthur

Rinke, Moritz

Robbe-Grillet, Alain

Rodčenko, Aleksandr M.

Rodin, Auguste

Röggla, Kathrin

Rohmer, Èric

Rokem, Freddie

Roller, Jochen

Roloff, Volker

Roman, Christopher

Rostand, Edmond

Röttger, Kati

Rouse, Mikel

Rubens, Peter Paul

Ruchatz, Jens

Rußka, Ida

Ruttmann, Walter

Ryan, Joel

Saint-Saens, Camille

Sarrasani, siehe auch

$$
\text { Stosch-Sarrasani }
$$

Sarraute, Nathalie

Saul, John Ralston

Sawday, Jonathan

Schaudig, Michael

Schechner, Richard

Scheer, Alexander
412

231, 409ff

465

$129,181 \mathrm{f}$

251

188

266

465

313

472

34

495

495

181

135

531

$192 \mathrm{f}$

188

485

130

133

193

$161,343 \mathrm{f}$

150, 156

495

193

257

62

$439,442 \mathrm{f}$

260

316

495

59

195, 197, 200

$51 \mathrm{f}$

$549 \mathrm{f}$

497

188

309

495

497ff

161

201

290

264

410, 440

435 


\begin{tabular}{|c|c|c|c|}
\hline Schiller, Friedrich & $\begin{array}{r}193,268, \\
390,446\end{array}$ & $\begin{array}{l}\text { Stremler, Stephanie } \\
\text { Strzolka, Rainer }\end{array}$ & $\begin{array}{l}238 \\
265\end{array}$ \\
\hline \multicolumn{2}{|c|}{ Schimmelpfennig, Roland 193} & Stuart, Meg & 364 \\
\hline Schleef, Einar & $320,322,325$ & Studlar, Gaylyn & 414 \\
\hline Schlegel, Friedrich & 274 & Sugiera, Malgorzata & 307 \\
\hline Schleiermacher, Friedri & ich & Sutherland, Ivan & 458 \\
\hline Schlemmer, Oskar & 371,555 & Tabori, George & 267 \\
\hline Schlingensief, Christopl & h $33,35,457$ & Tafuri, Manfredo & 148 \\
\hline \multirow[t]{2}{*}{ Schmidt, Paul } & 409f, 413, & Taglioni, Marie & 274 \\
\hline & 415,421 & Tanguy, Yves & 102 \\
\hline Schödel, Helmut & 320 & Tannion, Robert & 469 \\
\hline Schumann, Albert & 498 & Tate, Nahum & 121 \\
\hline Schwarz, Samuel & 37 & Tautorat, Oliver & 96 \\
\hline Schwitzke, Ernst & 265 & Tholen, Georg Christor & $\mathrm{ph}$ \\
\hline Scorsese, Martin & 412 & Thomas, Kendall & 91 \\
\hline Scott, Ridley & 315 & Thomson, Lynn & 539 \\
\hline See, Sheena & $411,414,420$ & Till, Nicholas & 213 \\
\hline Seel, Martin & 85 & Tischendorf, Bert & 323 \\
\hline Seidel, Beate & 184 & Toller, Ernst & 266 \\
\hline Sermon, Paul & 471 & Tomaschewsky, Joachi & 390 \\
\hline \multirow[t]{3}{*}{ Shakespeare, William } & $48,211 \mathrm{f}, 214$ & Toporkow, Wassili & \\
\hline & $266,390,393$, & Ossipowitsch & 297 \\
\hline & $431 \mathrm{ff}, 466,480$ & Trier, Lars von & 179ff, 184, \\
\hline Shaw, Jeffrey & 462,464 & & $211 \mathrm{f}, 215 \mathrm{f}, 553$ \\
\hline Shepherd, Scott & $411,413,420$ & Truffaut, François & 224 \\
\hline Siegmund, Gerald & 62,324 & Tschaikowski, Peter & 330,333 \\
\hline Simanowski, Roberto & 128 & Turrini, Peter & $86 f f$ \\
\hline Simmons, Jean & 220 & Ulbricht, Walter & 394 \\
\hline Šklovskij, Viktor & 144 & Valk, Kate & 411f, 414, \\
\hline Smith, Anna Deavere & 504 & & $418 \mathrm{ff}, 422$ \\
\hline Sophocles & $205 \mathrm{ff}, 212$ & Valverde de Hamusco, & Juan $\quad 284 \mathrm{f}$ \\
\hline Sorel, Jean & 413 & Vawter, Ron & 421 \\
\hline Spiegel, Adriaan van de & 285 & Veiel, Andres & $193,238,240 f$ \\
\hline Spira, Katrin & $195 f$ & Verhaerens, Emile & 299 \\
\hline Staatsmann, Peter & 474 & Vermeer, Jan & 427 \\
\hline Stahnke, Manfred & 474 & Vertov, Dziga & $145 f, 155$, \\
\hline \multicolumn{2}{|l|}{ Stanislavskij, Konstantin } & & $157,225 f$ \\
\hline \multirow[t]{2}{*}{ Sergeevič } & 293, 295ff, & Vesalius, Andreas & $284 \mathrm{f}$ \\
\hline & 301,371 & Veth, Kurt & \\
\hline Starnberger, Gerhard & 111 & Vill, Susanne & 464 \\
\hline Staub, Peter & 37 & Virilio, Paul & $88,320,367$ \\
\hline Stelarc & 467 & Vogel, Jürgen & 241 \\
\hline Stemann, Nicolas & 56 & Völlm, Gesine & 401 \\
\hline Stenzl, Jürg & 343 & Vontobel, Roger & 192 \\
\hline Stepanova, Varvara & 156 & Vostell, Wolf & 375 \\
\hline Stephan, Domingo & 464 & Vuillermoz, Emile & 425 \\
\hline Sternberg, Joseph von & 414 & Wackernagel, Bettina & 47 \\
\hline Stockhausen, Karlheinz & 193,337 & Wagner, Karl Willy & 359 \\
\hline Stosch-Sarrasani, Hans & $497 \mathrm{ff}$ & Wagner, Richard & 129,458 , \\
\hline Strasberg, Lee & 297 & & 498,55 \\
\hline
\end{tabular}


Waldenfels, Bernhard

Waldvogel, Florian

Wall, Jeff

Wallen, Lawrence

Waltz, Sasha

Warburg, Aby

Weber, Samuel

Weichert, Stephan Alexander $\quad 501 \mathrm{f}$

Weill, Kurt

Weiss, Peter

Welsch, Wolfgang

Welz, Peter

Werfel, Franz

Westerheide, Bettina

Whitehouse, Charlotte

Wieler, Jossi

Wiesinger, Kai

Wildgans, Anton

Wiles, David

Wilhelm II.

Wille, Franz

Williams, Raymond

Wilson, Harold

Wilson, Robert

Winckelmann, Johann Joachim

Winkler, Gerhard

Wirth, Andrzej

Wittenbrink, Theresia

Wittgenstein, Ludwig

Wolff-Plottegg, Manfred

Wortmann, Sönke

Wowereit, Klaus

Yeats, William Butler

Zabala, Ander

Zadek, Peter

Zapp, Andrea

Zappa, Frank

Zawistowski, Roman

Zebington, Gary

Zech, Paul

Zehelein, Klaus

Zell, Thomas C.

Zenck, Martin

Ziegler, Christian

Ziehe, Thomas

Zimmermann, Bernd Alois

Žižek, Slavoj

Zuckmayer, Carl
106, $119 f$

354

113

462

121,552

62,225

50 359

450

512

310 , 317

266, 269

474

472

364,401 ,

403, 405

241

494

212

495

431

372

522

$48,130,364$

102

345,474

191

$264 \mathrm{ff}$

$341,343 f$

462

238, 241

38

324

$314 \mathrm{f}$

383

471

389

377

467

390

343

$183 \mathrm{f}$

343

468

513

$337 \mathrm{ff}$

378, 441f, 507

266

\section{Titel}

24

4.48 Psychosis

A bout de souffle

187f, 193

$320,321,323$

413

A la recherche du temps perdu

167,425

$220 \mathrm{ff}$

Actress, The

250

Aida

205

Ajax

$419 \mathrm{ff}$

Akpropolis

90,315

315

Alien

All About Eve

220ff, 224, 226

Alpenglühen

$85 \mathrm{f}, 88 \mathrm{f}$

andalusischer Hund, Ein

402

Angelus, The

412

Angriff der Gegenwart auf die übrige Zeit, Der

247

Antenna, L' 135

Antigone 205

Apocalypse live 270

Arbeit des Schauspielers an sich selbst, Die

296

Architectural Device for Forsythe Movement

Artisten in der Zirkuskuppel, Die

Aufstieg und Fall der Stadt Mahagony

Auftrag, Der 390

Auge und der Geist, Das $\quad 106$

Ausbildung des Redners 295

B. Ein Stück über Sport und Behinderung

Baa-Lamb's Holiday, The

Babel

53,56

Baby of Mâcon, The

Badener Lehrstück vom Einverständnis/Lehrstück

Bählamms Fest

361f, 367

Bau, Der

401, 403

390,394 ,

396, 399

Beautiful Vision $\quad 396$

Being Julia

Belle de Jour

409, 411f, 414

Bernarda Albas Haus

Big Brother

Body of Water, A

Bonanza 


\begin{tabular}{|c|c|c|c|}
\hline Bouncy Castle & 93,309 & \multicolumn{2}{|l|}{ Deutschland im Herbst } \\
\hline Brady Bunch, The & 540 & \multicolumn{2}{|l|}{ Devil is a Woman, The } \\
\hline Brain Opera & 473 & \multicolumn{2}{|l|}{ Dialektik der Aufklärung } \\
\hline Brainmusic / Braindance & 470 & \multicolumn{2}{|l|}{ Dido \& Aeneas } \\
\hline Breaking the Rules & 417 & \multicolumn{2}{|l|}{ Digitale Bauhaus, Das } \\
\hline Buddenbrooks & 439 & \multicolumn{2}{|l|}{ disprezzo, Il } \\
\hline Cain & 266 & \multicolumn{2}{|c|}{ Distribution of Empathy, The } \\
\hline Călătorie la oraş & 259 & \multirow[t]{2}{*}{ Dogville } & $40,179 \mathrm{ff}$, \\
\hline Calmettes, André & 206 & & $183 \mathrm{f}, 553 \mathrm{f}$ \\
\hline Camera Virtuosa & 463 & \multicolumn{2}{|l|}{ Drawing Restraint } \\
\hline Cargo Sofia-X. Eine & & \multicolumn{2}{|l|}{ Edipo $\mathrm{Re}$} \\
\hline europäische Last- & \multirow{3}{*}{$386,448 \mathrm{ff}$} & Egmont & 266 \\
\hline KraftWagen-Fahrt 380 & & \multirow{2}{*}{\multicolumn{2}{|c|}{$\begin{array}{l}\text { Einen Jux will er } \\
\text { sich machen }\end{array}$}} \\
\hline cartuş de Kent şi un pachet & & & 497 \\
\hline de cafea, Un & $257 f$ & El Lab & 505 \\
\hline Cassandra Project & $483 f$ & Electra & \\
\hline Castorf, Frank & 447 & Electra, My Love & $\begin{array}{r}205,211,213 \mathrm{ff} \\
211\end{array}$ \\
\hline Caveman & 383 & \multicolumn{2}{|l|}{ Electreia } \\
\hline Cet obscur objet du désir & 414 & \multicolumn{2}{|l|}{ emploi du temps, L' } \\
\hline Ceux de chez nous & 495 & empty space, The & 303,319 \\
\hline Chameleon 3. Net Congestion & 472 & Endless House & $90,93,313$ \\
\hline Chance 2000 - Wahlkampf- & & Endstation Amerika & $383,431,447$ \\
\hline zirkus '98 & 35 & \multicolumn{2}{|l|}{ Eraritjaritjaka. Das } \\
\hline Chien Andalou, Un & 53 & \multicolumn{2}{|l|}{ Museum der Sätze } \\
\hline chien andalu, Un & 402 & Eröffnungsfeierlichkeite & en der \\
\hline Chunking & 447 & Kriegausstellung, & Die \\
\hline City of Abstracts & 309 & Esther Kahn & $223 f$ \\
\hline Clavigo & 390 & Eugen Onegin & 330 \\
\hline Close Enough to Kiss & 383 & Euridice & 213 \\
\hline Close to Home & 189 & Europa in Flammen & 498 \\
\hline Clouds After Cranach & 90 & Exoskeleton & 467 \\
\hline conFIGURATING the CAVE & 464 & F@ust Version 3.0 & 459 \\
\hline Cremaster Cycle, The & 171,175 & Fatzer-Fragment & 367 \\
\hline Criminal Minds & $187 f$ & Faust & $38,239,266$ \\
\hline CSI & $87 f, 193$ & Faust I & 268 \\
\hline D.A.V.E. & 552 & Fest des Lamms, Das & $401 \mathrm{ff}$ \\
\hline Dämonen & 383 & Festung & 192 \\
\hline De Anima & 296 & Fidelio & 351,354 \\
\hline Dead Cat Bounce & 364 & Fidelio, 21. Jahrhundert & 349,350 , \\
\hline Dead Line & 440 & & $352 f$ \\
\hline Death of the Avantgarde, The & 417 & Fille de marbre, La & 276 \\
\hline Della pittura & 80 & Film & $161 f, 165 f$ \\
\hline Dennis Cleveland & $195 \mathrm{ff}$ & Forever Young & 447 \\
\hline Dernier Métro, Le & 224 & Forsthaus Falkenau & 36,555 \\
\hline Desert Rain & 462 & Friedrichstraße & $195 \mathrm{ff}, 199 \mathrm{ff}$ \\
\hline Desperate Housewives 187,1 & 189,193 & Future Music Blender & 473 \\
\hline Destricted & 176 & Germania 3 & 267 \\
\hline deutsche Drama aus zwei & & Gewehre der Frau & \\
\hline Jahrhunderten, Das & 265 & Carrar, Die & 269 \\
\hline Deutschland 2 & 440,448 & Gier & 320ff, $325 f$ \\
\hline
\end{tabular}


Gier nach Gold

431

Gilmore Girls

193

Giselle, ou Les Wilis

273,276

Gold Heart Trilogy

Graduate, The

Granular $\approx$ Synthesis

Großmütiger Hahnrei

Gute Zeiten, Schlechte Zeiten

Gutes Wedding - Schlechtes Wedding

Hairspray

Hamlet

$212,383,418$,

480,554

Hamnet

Hangmen also die

Hanneles Himmelfahrt

Heilige Johanna der

Schlachthöfe, Die

Heptameron

Hesperidentriptychon

345,474

17,99 ,

103,106

Hier ist der Apparat 357f, 364ff, 369

Hippolytus

205, 409,

411,413

Hoist

176

Höllensturz der Verdammten

Hollywoodelegien

404

Honky Tonk Woman

Human Writes

396

$85,89,91 \mathrm{ff}$,

309ff, 313, 315ff

I feel a great desire to meet the masses once again 445,451

Idiot, Der

$35,384,389$

Idomeneo

213

Interactive Plant Growing, The 459

Jakobowsky und der Oberst $\quad 269$

Jedermann

266

Kammer/Kammer

89,90

Kandidat, Der

247

Kinopravda

Kleine Haie

König Lear

Kontakthof

Körper

Krapp's last Tape/

Das letzte Band

Kreuzworträtsel Boxenstopp

Kunst und Gemüse

Landschaft mit Argonauten

Laokoon 166ff, 269

440

33, 457

364

145,155

390

547

552

94,102
$238,241 \mathrm{ff}$
Laokoon oder Über die

Grenzen der Malerei

und Poesie

101

Last Temptation of Christ, The 412

Laune des Verliebten, Die 266

Leben in dieser Zeit 269

leere Raum, Der

303,319

Legally Blonde

539

Legend of Oedipus, The

$206 \mathrm{ff}$

Légende d'Oedipe, La 206ff

Lestat $\quad 540$

Let It Bleed 395

Lieb' Vaterland 495

Lindberghflug/Ozeanflug 268,

$357 f, 361 f f$

Lindenstraße

36

Lion King, The 539

Lips of Thomas $\quad 378$

Little Red Rooster $\quad 397$

Lost 187

L-Word, The 189

Lysistrata 205

M. Butterfly 231ff

Macbeth 38, 48

Macht der Gefühle, Die $\quad 247,249$,

Mädchen und der Truthahn, Das 260

Mahagonny 130

Mamma Mia! 539f

Manderlay 179, 184

Manifesto of Futurist Cuisine 135

Mann im Fenster $\quad 50$

Mann mit der Kamera, Der $\quad 157$

Marineschauspiel im Schützengraben

Marquise

231,234

Me, The Monster

Medea

205, 211, $215 f$

Meine Schneekönigin

Meister und Margarita, Der $\quad 31,35$

Memory Theater VR 461

Mépris, Le 401, 403

Messingkauf 446

Miami Vice 191

Midsummer Night's Dream, A 266f

Miss Universal Happiness $\quad 410$

Mit kleinen Siegen zurück ins Leben

Moulin Rouge 
My neck is thinner than

a hair: engines

445,451

Nacht nach der

Abschlussfeier, Die

Nachtasyl

390

269

Napoleon

188

Nibelungen, Die

no point

Nora

Not I

390,396

161f, 168

Notes for an African Oresteia 215

Nouvelle revue

495

Novemberwind

Odyssee

299

$403 \mathrm{f}$

Oedipe-roi

206

Oedipus the King 205f, 208, 212

Oedipus Tyrannus 205f, 208, 212

On Murder Considered as

One of the Fine Arts

Opening Night

379

Oresteia

$223 \mathrm{f}$

Orfeo

205

213

Orphée

461

Orpheus Kristall

474

Othello

$390,393 \mathrm{ff}$,

431f, 435

Ozeanflug/

Lindberghflug 268, 357f, 361ff

Passion Christi

266

Pate, Der

189

Patriotin, Die

247

Peer Gynt

266

Pension Schmidt

196

Perform Performing

Phaidros

$439,442 \mathrm{f}$

558

Phèdre

Philemon und Baucis

409f, 415

267

467

Ping Body

$305 \mathrm{ff}$

Place where we belong, The

Play

225

Politeia

Poor Theatre

Prometeo. Tragödie des Hörens

Prometheus

Protection

Proust 1. The side of Swann

Proust 3. The side of Charlus

Proust 4. The side of Marcel

Psycho
Publikums-

beschimpfung $\quad 59,164,192$

Pygmalion

294

$161 \mathrm{f}$

Quadrat

23,226

Quartett

Queer as folk

48

189

$151 \mathrm{f}$

390

Räuber, Die

466

259

539

Rent

466

RESET

Retranslation / Final Unfinished Portrait

(Francis Bacon) 310, 317

Rigadin

496

289

Rinaldo

Romeo und Julia

88

499

Rumstick Road

$\mathrm{S} / \mathrm{N}$

411,414

459

Sabenation. Go home \& follow the news

439ff, 448

Scandinavia

scanned V

Scattered Crowd

Scharfe Schnitte Die Klinik-Soap

196

390

Schlacht, Die

299

141,143

324

Six Feet Under

Sommernachtstraum, Ein 266, 465

SonoMorphis

187,189

Spiel

$161 \mathrm{ff}, 167 \mathrm{f}$

Spiel ohne Worte

Spielwütigen, Die

238ff, 244

Stage Beauty

Stage Door

219f, $222 \mathrm{f}$

Stange Kent und ein

Päckchen Kaffee, Eine $\quad 257 f$
Stomach Sculpture 
Stranger than Paradise

Stukgoed - A beau mentir qui vient de loin

Sylphide

System I-IV

Tagesschau

Tartuffe

Telematic Dreaming

Theatre of the Skies, A

Third Hand

Three Atmospheric Studies

Three Places in Rhode Island

To Be Or Not To Be

To You, The Birdie!

$$
\text { (Phèdre) }
$$

Tod der Saphira, Der

409ff, 419, 447

Tod des Tizian, Der

Todo Sobre Mi Madre

Torpedo - los!

Torquato Tasso

Totentanz

trans

Troerinnen

Trommeln in der Nacht

Trotz Alledem!

trunkene Schiff, Das

Tum-Tum

Turkey Girl

Twin Peaks

Ultima Ratio

unbekannte Drama, Das

United 93

Untitled Event

U-S-A - Land of Opportunities

Verachtung, Die

419,447
51
266
223,226
498
266
362
464
266
390
499
390
135
260
188
461
267
501
192
179
403

Vermischte Nachrichten very long silence, A. 4.48 Psychosis

321,323

Viático cordero, El

72f, 77,79

View at Delft

vilaine femme brune, Une

495

Violetta and the Aeroplanes

135

Vita futurista

134

Volksfeind, Ein

390, 397, 399

Voyeur

343,345

Voyeur, Le

Wallensteins Lager

266, $268 \mathrm{f}$

Waltons

189

Warum geht's denn jetzt?

497

Web of Life

462

Welcome, Mrs. President

189

whenever on on on nohow on / airdrawing

White Bouncy Castle 309

White Trash

Wien im Krieg

Within the Quota

153

Wolokolamsker Chaussee

390

Woman who walked into doors, The

304

World Skin 460, 461

World Wide Web-Slums

196

Wunder von Mâcon, Das

230

You Got the Silver 395

You Made Me

a Monster 93, 309ff, 315ff

Zang Tumb Tumb

134

Zauberei auf dem Sender

265

Zen für Film

192

zerbrochene Krug, Der

266

Zeugen! Ein Strafkammerspiel 448 



\section{AUTORINNEN UND AUTOREN}

Balme, Prof. Dr. Christopher, Professor und Direktor am Institut für Theaterwissenschaft der Ludwig-Maximilians-Universität München.

Berghaus, Prof. Dr. Günter, Senior Research Fellow at the University of Bristol, UK.

Bläske, Stefan, Doktorand im Initiativkolleg »Sinne - Technik - Inszenierung « und Lehrbeauftragter am Institut für Theater-, Film- und Medienwissenschaft der Universität Wien.

Bormann, Dr. Hans-Friedrich, wissenschaftlicher Assistent am Institut für Theaterwissenschaft der Freien Universität Berlin, Mitarbeiter im DFG-Sonderforschungsbereich »Kulturen des Performativen« und im Zentrum für Bewegungsforschung.

Brandstetter, Prof. Dr. Gabriele, Professorin für Theaterwissenschaft und Tanzwissenschaft am Institut für Theaterwissenschaft der Freien Universität Berlin.

Brincken, Dr. Jörg von, wissenschaftlicher Angestellter am Institut für Theaterwissenschaft der Ludwig-Maximilians-Universität München.

Bühler-Dietrich, Dr. Annette, wissenschaftliche Mitarbeiterin am Institut für Literaturwissenschaft, Abteilung Neuere Deutsche Literatur, der Universität Stuttgart.

Callens, Prof. Dr. Johan, Professor of English within the Language and Literature Department at the Vrije Universiteit Brussel, Belgium.

Chapple, Freda, Director of Regional and External Activities for the Institute for Lifelong Learning, Programme Director BA Literature and Creative Media and BA English Studies and Performing Arts, University of Sheffield, UK.

Diekmann, PD Dr. Stefanie, Vertretungsprofessorin im Studiengang »Europäische Medienwissenschaften« an der Universität und FH Potsdam.

Dombois, Dr. Johanna, Musiktheater-Regisseurin und Autorin.

Ellrich, Prof. Dr. Lutz, Professor für Medienwissenschaft am Institut für Theater-, Film- und Fernsehwissenschaft an der Universität zu Köln.

Elzenheimer, Dr. Regine, Musiktheaterdramaturgin am Nationaltheater Mannheim und Lehrbeauftragte u.a. an der Universität Frankfurt/Hessische Theaterakademie. 
Englhart, PD Dr. Andreas, wissenschaftlicher Angestellter am Institut für Theaterwissenschaft der Ludwig-Maximilians-Universität München.

Erincin, Serap, performer, director and graduate student, Department of Performance at New York University's Tisch School of the Arts, USA.

Ernst, Dr. Christoph, wissenschaftlicher Mitarbeiter am DFG-Graduiertenkolleg »Kulturhermeneutik im Zeichen von Differenz und Transdifferenz « an der Friedrich-Alexander-Universität Erlangen-Nürnberg.

Ernst, Dr. Wolf-Dieter, akademischer Rat am Institut für Theaterwissenschaft der Ludwig-Maximilians-Universität München.

Ertel, Dr. Erhard, wissenschaftlicher Mitarbeiter am Institut für Theaterwissenschaft der Freien Universität Berlin.

Friedrich, Prof. Dr. Sabine, Professorin für Romanische Philologie an der FriedrichAlexander-Universität Erlangen-Nürnberg.

Glesner, Dr. Julia, Leiterin Referat Kommunikation und Pressesprecherin der Klassik Stiftung Weimar

Gombert, Dr. Ina, Lehrbeauftragte am Institut für Theater- und Medienwissenschaft an der Friedrich-Alexander-Universität Erlangen-Nürnberg.

Groot Nibbelink, Drs. Liesbeth, Junior teacher and researcher Theatre Studies at Utrecht University, Netherlands.

Gruber, Prof. Dr. Klemens, Ao. Professor am Institut für Theater-, Film- und Medienwissenschaft der Universität Wien.

Grüebler, Thomas, lic. sc. rel., Leiter diverser Projekte an der Schnittstelle von Theorie und Praxis und e-learning-Beauftragter am »Institute for the Performing Arts and Film« der Zürcher Hochschule der Künste.

Haß, Prof. Dr. Ulrike, Professorin für Theaterwissenschaft an der Ruhr-UniversitätBochum.

Hees, Dr. Edwin, Associate Professor (theatre and film history and analysis) at the Drama Department, University of Stellenbosch, South Africa.

Huschka, Dr. Sabine, Vertretungsprofessorin für Tanzwissenschaft sowie Mitarbeiterin im DFG-Forschungsprojekt »Tanz und Wissen. Eine kulturhistorische Studie zu den Episteme choreografierter Körper« am Institut für Theaterwissenschaft der Freien Universität Berlin.

Kattenbelt, Dr. Chiel, Universitair Hoofddocent am Department for Media and Culture Studies an der Universität Utrecht, Niederlande. 
Keramidas, Dr. Kimon, Ph.D. in Theatre (City University of New York) and Certificate in Interactive Technology and Pedagogy, USA.

Kirchmann, Prof. Dr. Kay, Professor für Medienwissenschaft am Institut für Theater- und Medienwissenschaft an der Friedrich-Alexander-Universität ErlangenNürnberg.

Klein, Dr. Thomas, wissenschaftlicher Mitarbeiter für Filmwissenschaft/Mediendramaturgie an der Johannes Gutenberg-Universität Mainz.

Klepacki, Dr. Leopold, Akademischer Rat am Institut für Pädagogik an der Friedrich-Alexander-Universität Erlangen-Nürnberg.

Klöck, Prof. Dr. Anja, Professorin für Schauspiel an der Hochschule für Musik und Theater Felix Mendelssohn Bartholdy in Leipzig.

Kotte, Prof. Dr. Andreas, Professor und Direktor am Institut für Theaterwissenschaft der Universität Bern.

Kramer, Dr. Kirsten, wissenschaftliche Mitarbeiterin am Institut für Romanistik der Friedrich-Alexander-Universität Erlangen-Nürnberg.

Krivanec, Eva, wissenschaftliche Mitarbeiterin am Institut für Theater-, Film- und Medienwissenschaft und Koordinatorin des Initiativkollegs »Sinne - Technik Inszenierung « der Universität Wien.

Kurzenberger, Prof. Dr. Hajo, Professor für Theaterwissenschaft/Theaterpraxis an der Universität Hildesheim.

Matzke, Dr. Annemarie, wissenschaftliche Mitarbeiterin mit Schwerpunkt Tanzwissenschaft am Institut für Theaterwissenschaft der Freien Universität Berlin.

Merx, Drs. Sigrid, Junior teacher/researcher at Utrecht University, Netherlands, Dept.of Media and Culture Studies.

Michaels, Dr. Bianca, wissenschaftliche Mitarbeiterin am Institut für Theaterwissenschaft der Ludwig-Maximilians-Universität München.

Michelakis, Dr. Pantelis, Senior Lecturer in Classics at the University of Bristol, UK.

Müller-Schöll, PD Dr. Nikolaus, wissenschaftlicher Assistent am Institut für Theaterwissenschaft der Ruhr-Universität Bochum.

Pewny, Dr. Katharina, Theaterwissenschaftlerin, Lektorin am Institut Schauspiel, Universität für Musik und darstellende Kunst Graz.

Primavesi, Prof. Dr. Patrick, Professor am Institut für Theaterwissenschaft der Universität Leipzig. 
Rajewsky, Dr. Irina, wissenschaftliche Mitarbeiterin am Kulturwissenschaftlichen Forschungskolleg »Medien und kulturelle Kommunikation « an der Universität zu Köln.

Rey, Prof. Anton, Dozent und Leiter des »Institute for the Performing Arts and Film« der Zürcher Hochschule der Künste.

Röttger, Prof. Dr. Kati, Professorin für Theaterwissenschaft und Leiterin Leerstoelgroep Theaterwetenschap an der Universiteit van Amsterdam, Niederlande.

Ruchatz, Dr. Jens, wissenschaftlicher Assistent am Institut für Theater- und Medienwissenschaft der Friedrich-Alexander-Universität Erlangen-Nürnberg.

Schoenmakers, Prof. em. Dr. Henri, bis 2007 Lehrstuhlinhaber für Theater- und Medienwissenschaft an der Friedrich-Alexander-Universität Erlangen-Nürnberg. Lehrt an der Roosevelt Academy, Niederlande.

Seibert, Prof. Dr. Peter, Professor im Fachbereich Sprach- und Literaturwissenschaften, Fachgebiet Literatur und Medien, an der Universität Kassel.

Sick, Prof. Dr. Franziska, Professorin für Romanische Literaturwissenschaft an der Universität Kassel.

Sollich, Robert, Stipendiat im Graduiertenkolleg »InterArt« der Freien Universität Berlin und freier Operndramaturg.

Sörgel, Dr. Sabine, Lecturer in Drama, Theatre and Performance, University of Aberystwyth, Wales, UK.

Thurner, Prof. Dr. Christina, Assistenzprofessorin am Institut für Theaterwissenschaft der Universität Bern.

Vill, Prof. Dr. Susanne, Professorin für Theaterwissenschaft an der Universität Bayreuth.

Vlad, Alexandra, wissenschaftliche Mitarbeiterin an der Babeş-Bolyai Universität Clui-Napoca/Klausenburg.

Wagner, Dr. Meike, wissenschaftliche Angestellte am Institut für Theaterwissenschaft der Ludwig-Maximilians-Universität München.

Warstat, PD Dr. Matthias, wissenschaftlicher Assistent am Institut für Theaterwissenchaft der Freien Universität Berlin. Ab WS 2008/09 Lehrstuhlinhaber Theater- und Medienwissenschaft an der Universität Erlangen-Nürnberg.

Wiesel, Dr. Jörg, Dozent für Performance an der Hochschule für Gestaltung und Kunst Basel und Gastprofessor am Institut für Theaterwissenschaft der Freien Universität Berlin.

Wortelkamp, Prof. Dr. Isa, Juniorprofessorin für Tanzwissenschaft am Institut für Theaterwissenschaft der Freien Universität Berlin. 


\section{Kultur- und Medientheorie}

Christian Kassung (Hg.) Die Unordnung der Dinge Eine Wissens- und Mediengeschichte des Unfalls Dezember 2008, ca. 400 Seiten, kart., zahlr. Abb., ca. 33,80 €, ISBN: 978-3-89942-721-9

\section{Sandra Poppe,}

Thorsten Schüller,

Sascha Seiler (Hg.)

9/11 als kulturelle Zäsur

Repräsentationen des

11. September 2001 in

kulturellen Diskursen,

Literatur und

visuellen Medien

Dezember 2008, ca. 294 Seiten, kart., ca. $28,80 €$,

ISBN: 978-3-8376-1016-1

Gerald Kapfhammer,

Friederike Wille (Hg.)

"Grenzgänger"

Mittelalterliche Jenseitsreisen

in Text und Bild

Dezember 2008, ca. 300 Seiten,

kart., zahlr. Abb., ca. 31,80 €,

ISBN: 978-3-89942-888-9

Margreth Lünenborg (Hg.)

Politik auf dem Boulevard?

Die Neuordnung der

Geschlechter in der Politik

der Mediengesellschaft

Dezember 2008, ca. 300 Seiten, kart., zahlr. Abb., ca. 29,80 €, ISBN: 978-3-89942-939-8
Erika Fischer-Lichte, Kristiane Hasselmann, Alma-Elisa Kittner (Hg.) Kampf der Künste! Kultur im Zeichen von Medienkonkurrenz und Eventstrategien

Dezember 2008, ca. 300 Seiten, kart., zahlr. Abb., ca. 28,80 €, ISBN: 978-3-89942-873-5

Kathrin Ackermann, Christopher F. Laferl (Hg.)

Transpositionen

des Televisiven

Fernsehen in Literatur und Film

Dezember 2008, ca. 200 Seiten, kart., zahlr. Abb., ca. 25,80€, ISBN: 978-3-89942-938-1

Susanne Regener Visuelle Gewalt Menschenbilder aus der Psychiatrie des 20. Jahrhunderts Dezember 2008, ca. 220 Seiten, kart., zahlr. Abb., ca. 25,80 €, ISBN: 978-3-89942-420-1

Christian Pundt Medien und Diskurs Zur Skandalisierung von Privatheit in der Geschichte des Fernsehens November 2008, ca. 400 Seiten, kart., ca. $36,80 €$, ISBN: 978-3-89942-994-7

Özkan Ezli, Dorothee Kimmich, Annette Werberger (Hg.) Wider den Kulturenzwang Migration, Kulturalisierung und Weltliteratur

November 2008, ca. 290 Seiten, kart., ca. $28,80 €$, ISBN: 978-3-89942-987-9

Leseproben und weitere Informationen finden Sie unter: www.transcript-verlag.de 


\section{Kultur- und Medientheorie}

Susanne von Falkenhausen KugelbauVisionen

Kulturgeschichte einer Bauform von der Französischen

Revolution bis zum

Medienzeitalter

Oktober 2008, 214 Seiten,

kart., zahlr. Abb., 24,80 €,

ISBN: 978-3-89942-945-9

Uwe Seifert, Jin Hyun Kim,

Anthony Moore (eds.)

Paradoxes of Interactivity

Perspectives for Media Theory,

Human-Computer Interaction,

and Artistic Investigations

Oktober 2008, 346 Seiten,

kart., ca. $35,80 €$,

ISBN: 978-3-89942-842-1

Ulrike Haß,

Nikolaus Müller-Schöll (Hg.)

Was ist eine Universität?

Schlaglichter auf

eine ruinierte Institution

Oktober 2008, ca. 160 Seiten,

kart., ca. $12,80 €$,

ISBN: 978-3-89942-907-7

Doris Kolesch, Vito Pinto,

Jenny Schrödl (Hg.)

Stimm-Welten

Philosophische,

medientheoretische und

ästhetische Perspektiven

Oktober 2008, ca. 216 Seiten,

kart., ca. $24,80 €$,

ISBN: 978-3-89942-904-6

Daniel Gethmann,

Susanne Hauser (Hg.)

Kulturtechnik Entwerfen

Praktiken, Konzepte

und Medien in Architektur

und Design Science

Oktober 2008, 300 Seiten,

kart., zahlr. Abb., ca. 29,80 €,

ISBN: 978-3-89942-901-5
Ines Kappert

Der Mann in der Krise

oder: Kapitalismuskritik in der Mainstreamkultur

Oktober 2008, 232 Seiten,

kart., $24,80 €$,

ISBN: 978-3-89942-897-1

Alma-Elisa Kittner

Visuelle Autobiographien

Sammeln als Selbstentwurf bei Hannah Höch, Sophie Calle und Annette Messager

Oktober 2008, ca. 300 Seiten, kart., zahlr. Abb., ca. 29,80 €, ISBN: 978-3-89942-872-8

Ramón Reichert

Amateure im Netz

Selbstmanagement und

Wissenstechnik im Web 2.o.

YouTube - MySpace -

Second Life

Oktober 2008, ca. 220 Seiten, kart., zahlr. Abb., ca. 23,80 €, ISBN: 978-3-89942-861-2

Kristiane Hasselmann

Die Rituale der Freimaurer

Zur Konstitution eines bürgerlichen Habitus im England des 18. Jahrhunderts

Oktober 2008, ca. 300 Seiten, kart., zahlr. Abb., ca. 29,80 €, ISBN: 978-3-89942-803-2

Dorothee Kimmich,

Wolfgang Matzat (Hg.)

Der gepflegte Umgang

Interkulturelle Aspekte

der Höflichkeit in Literatur

und Sprache

(unter Mitarbeit von Alfred

Stumm und Andreas Gehrlach)

Oktober 2008, 212 Seiten,

kart., ca. $19,80 €$,

ISBN: 978-3-89942-820-9

Leseproben und weitere Informationen finden Sie unter: www.transcript-verlag.de 


\section{Kultur- und Medientheorie}

Henri Schoenmakers,

Stefan Bläske, Kay Kirchmann,

Jens Ruchatz (Hg.)

Theater und Medien/

Theatre and the Media

Grundlagen - Analysen -

Perspektiven.

Eine Bestandsaufnahme

September 2008, 584 Seiten,

kart., zahlr. z.T. farb. Abb., 19,8o €,

ISBN: 978-3-8376-1064-2

Gunther Gebhard,

Oliver Geisler,

Steffen Schröter (Hg.)

StreitKulturen

Polemische und antagonistische

Konstellationen in Geschichte und Gegenwart

September 2008, 236 Seiten,

kart., $25,80 €$,

ISBN: 978-3-89942-919-o

Annette Bitsch

Diskrete Gespenster

Die Genealogie des

Unbewussten aus der

Medientheorie und Philosophie der Zeit

September 2008, 552 Seiten,

kart., ca. 42,80 €,

ISBN: 978-3-89942-958-9

York Kautt

Image

Zur Genealogie

eines Kommunikationscodes

der Massenmedien

September 2008, 370 Seiten,

kart., zahlr. Abb., ca. 30,80 €,

ISBN: 978-3-89942-826-1

Geert Lovink

Zero Comments

Elemente einer kritischen

Internetkultur

August 2008, 332 Seiten,

kart., $28,80 €$,

ISBN: 978-3-89942-804-9
Christa Sommerer,

Laurent Mignonneau,

Dorothée King (eds.)

Interface Cultures

Artistic Aspects of Interaction

August 2008, 348 Seiten,

kart., zahlr. Abb., 34,80 €,

ISBN: 978-3-89942-884-1

Michael Schetsche,

Martin Engelbrecht (Hg.)

Von Menschen und

Außerirdischen

Transterrestrische

Begegnungen im Spiegel

der Kulturwissenschaft

August 2008, 286 Seiten,

kart., $27,80 €$,

ISBN: $978-3-89942-855-1$

Simone Loleit

Wahrheit, Lüge, Fiktion:

Das Bad in der deutsch-

sprachigen Literatur

des 16. Jahrhunderts

Juli 2008, 390 Seiten,

kart., $41,80 €$,

ISBN: $978-3-89942-666-3$

Antonia Wunderlich

Der Philosoph im Museum

Die Ausstellung

"Les Immatériaux" von

Jean François Lyotard

Juli 2008, 264 Seiten,

kart., zahlr. Abb., 28,80€,

ISBN: 978-3-89942-937-4

Claudia Lillge,

Anne-Rose Meyer (Hg.)

Interkulturelle Mahlzeiten

Kulinarische Begegnungen und

Kommunikation in der Literatur

Juni 2008, 370 Seiten,

kart., $30,80 €$,

ISBN: 978-3-89942-881-0

Leseproben und weitere Informationen finden Sie unter: www.transcript-verlag.de 
